\title{
WestVirginiaUniversity
}

THE RESEARCH REPOSITORY @ WVU

Graduate Theses, Dissertations, and Problem Reports

2006

\section{Experimental and numerical investigation of seepage into longitudinal drains}

\author{
Ricardo Constantino Kiriakidis Longhi \\ West Virginia University
}

Follow this and additional works at: https://researchrepository.wvu.edu/etd

\section{Recommended Citation}

Kiriakidis Longhi, Ricardo Constantino, "Experimental and numerical investigation of seepage into longitudinal drains" (2006). Graduate Theses, Dissertations, and Problem Reports. 4241.

https://researchrepository.wvu.edu/etd/4241

This Dissertation is protected by copyright and/or related rights. It has been brought to you by the The Research Repository @ WVU with permission from the rights-holder(s). You are free to use this Dissertation in any way that is permitted by the copyright and related rights legislation that applies to your use. For other uses you must obtain permission from the rights-holder(s) directly, unless additional rights are indicated by a Creative Commons license in the record and/ or on the work itself. This Dissertation has been accepted for inclusion in WVU Graduate Theses, Dissertations, and Problem Reports collection by an authorized administrator of The Research Repository @ WVU.

For more information, please contact researchrepository@mail.wvu.edu. 
Experimental and Numerical Investigation of Seepage into Longitudinal Drains

Ricardo Constantino Kiriakidis Longhi

\author{
A DISSERTATION \\ Submitted to the \\ College of Engineering and Mineral Resources \\ at West Virginia University \\ in partial fulfillment of the requirements for \\ the degree of
}

Doctor of Philosophy

in

Civil and Environmental Engineering

Hema J. Siriwardane Ph.D., Chair

Udaya B. Halabe Ph.D.

Roger C. Viadero Ph.D.

Dr. H. Ilkin Bilgesu Ph.D.

Dr. Thomas H. Wilson Ph.D.

Department of Civil and Environmental Engineering

\author{
West Virginia University \\ Morgantown, West Virginia \\ 2006
}

Keywords: Longitudinal Drains, Trench Drains, Seepage, Modeling of Seepage 


\section{ABSTRACT \\ Experimental and Numerical Investigation of Seepage into Longitudinal Drains

\author{
Ricardo Constantino Kiriakidis Longhi
}

The effectiveness of longitudinal drains was investigated by using experimental and numerical methods. The main objective of the longitudinal drains was to extract and deflect the water flowing through the soil. The influence of water level, drain spacing, slope inclination and soil type was investigated. Results show that the longitudinal drains can reduce the amount of water flowing through the soil significantly.

Several soil types were used in order to cover a wide range of properties. Different soil types were obtained by mixing Ohio River sand and Kaolinite clay in different proportions depending on the desired hydraulic conductivity. In this research the clay content of soils ranged from 5\% to $35 \%$. The soils were labeled: A, B, C, D and E.

In order to study longitudinal drains in the laboratory, a versatile physical model was built. This model represents the space between drains. The bed of this model can be inclined to different slope angles so that the performance of longitudinal drains at different slope angles can be investigated. Four different slope angles were used in this study (horizontal, four to one, three to one and two to one). The width of model can also be modified to different values. In this study, three values were selected for the width; six inches, twelve inches, and eighteen inches.

To better understand the behavior of the longitudinal drains, two conditions were studied: transient state and steady state. Transient state is the condition in which the flow of water and piezometric levels are fluctuating within the soil over time. Steady state is the state at which flow and water levels do not show any significant change over time. The performance of longitudinal drains was investigated by performing both laboratory experiments and computational modeling work. The computer model was calibrated by comparing model calculations with experimental data. The computer model was used to predict the performance of field-scale longitudinal drains.

Results from this study show that the longitudinal drains are very effective in reducing seepage through soils. Longitudinal drains remove a significant portion of water that would otherwise flow through the soil. The transient time depends on the soil type used. 


\section{ACKNOWLEDGMENTS}

The author wishes to express special thanks the chair person, Dr. Hema Siriwardane for his guidance, constant supervision and for reviewing this dissertation, which made this research possible. Also special thanks to Dr. George Hall for his immeasurable help during this research. Gratitude is also expressed to Dr. Ilkin Bilgesu, Dr. Udaya Halabe, Dr. Thomas Wilson and Dr. Roger Viadero for serving on my examination committee and for taking time from their busy schedule to work with me in preparing this document.

The Financial support provided by West Virginia Department of Transportation, Division of Highways for this project through a research contract to West Virginia University is gratefully acknowledged.

Special thanks to my family, for their constant support and to my wife, Viviana, for her love and faith, for putting up with late nights. 


\section{TABLE OF CONTENTS}

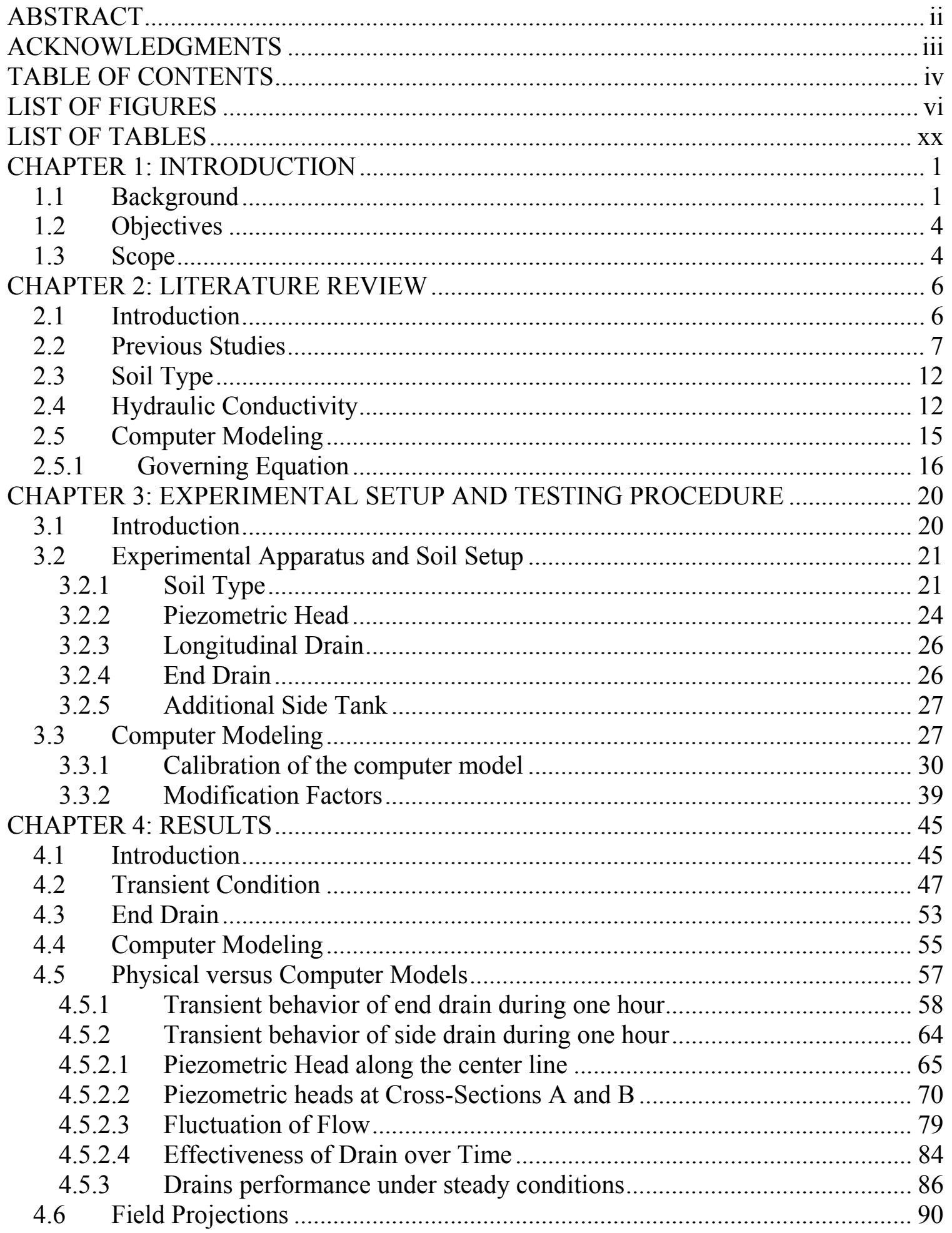


4.6.1 Transient Behavior of field drains ........................................................ 91

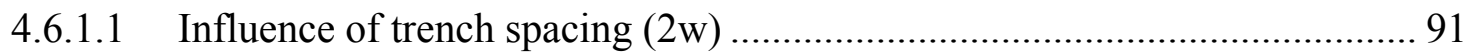

4.6.1.2 Influence of Drain Length..................................................................... 104

4.6.1.3 Influence of Drain Inclination.............................................................. 115

4.6.1.4 Influence of Soil Type .................................................................. 128

4.6.2 Performance of Longitudinal Drains under Steady State Conditions......... 136

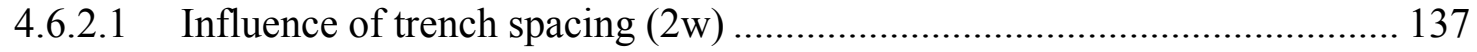

4.6.2.2 Influence of Drain Length................................................................... 140

4.6.2.3 Influence of Drain Inclination.............................................................. 144

4.6.2.4 Influence of Soil Type ........................................................................... 147

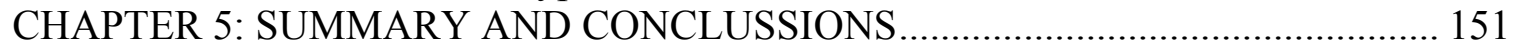

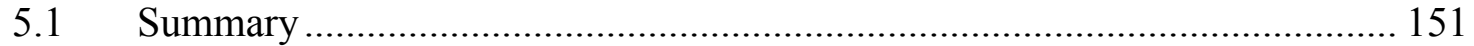

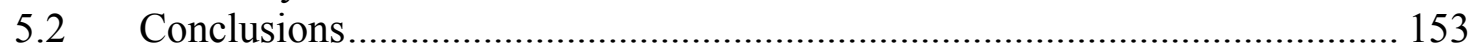

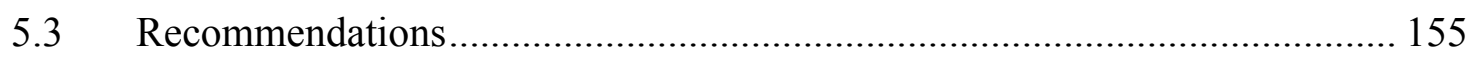

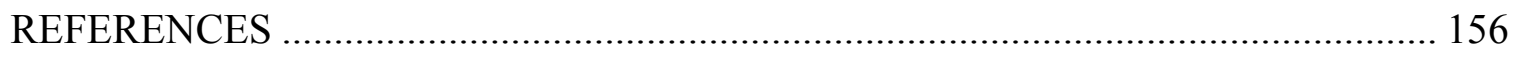

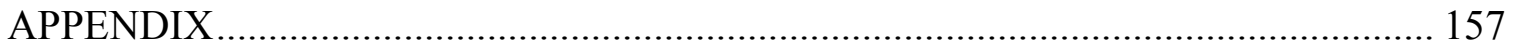

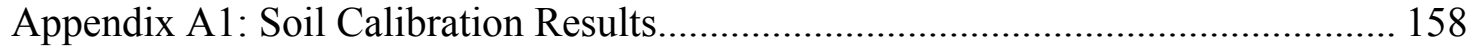

Appendix A2: Laboratory Vs Computer Model End Drain Cases ........................... 177

Appendix A3: Laboratory Vs Computer Model Side Drain Cases............................ 194

Appendix A4: Laboratory Vs Computer Model Piezometric Heads at

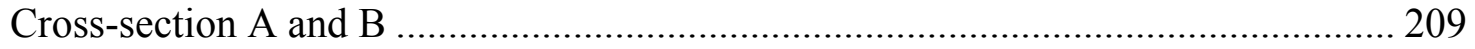

Appendix A5: Laboratory Vs Computer Model Flow Fluctuation at each drain ....... 238

Appendix A6: Laboratory Vs Computer Model Efficiency .................................. 253

Appendix A7: Soil A Field Model...................................................................... 258

Appendix A8: Results for Field Cases for Soils C and E ...................................... 287

Appendix A9: Grain size distribution and Liquid Limit curves .............................. 312 


\section{LIST OF FIGURES}

Figure 1.1: Schematic Figure of a Longitudinal Slope Drain ......................................... 2

Figure 1.2: Schematic Diagram of Longitudinal Drains on a Slope................................. 3

Figure 2.1: Flow pattern before and after installation of a longitudinal drain.................. 6

Figure 2.2: Theoretical flow through inclined infinite slopes......................................... 8

Figure 2.3: Flow through finite slope (experimental)............................................ 9

Figure 2.4: Constant Head Hydraulic Conductivity Apparatus...................................... 14

Figure 2.3: Schematic Diagram of flow through a Three-dimensional Block.................. 16

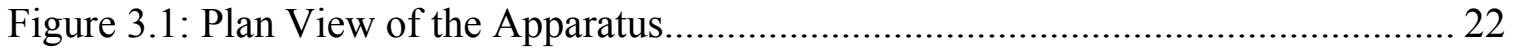

Figure 3.2: Experimental Change in Hydraulic Conductivity with Clay Content............ 23

Figure 3.3: Piezometric Terminals Locations ............................................................... 25

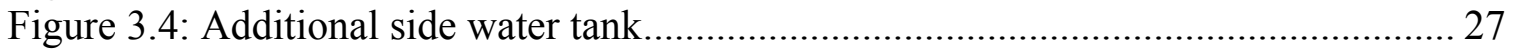

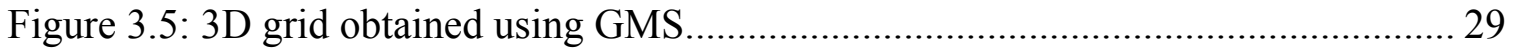

Figure 3.6: Cells defined as drains (Bottom, Centered and All) ..................................... 30

Figure 3.7: Cells defined as drains (End, Mid-Bottom and Bottom-end)....................... 31

Figure 3.8: Cumulative percent removed along the drain for all drain set-ups

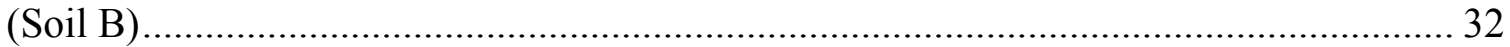

Figure 3.9: Cumulative percent removed along the drain for the three main

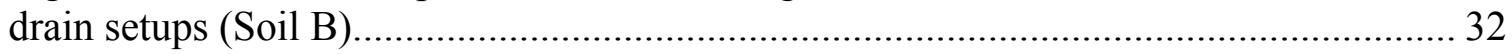

Figure 3.10: Volume removed at each drain for all drain set-ups (Soil B)...................... 33

Figure 3.11: Volume removed in each drain for the three main drain set-ups

(Soil B).

Figure 3.12: Volume removed along the drain for the three main drain set-ups

(Soil B)

Figure 3.13: Measured and Computed Cumulative percent removed along the

drain for Soil type B

Figure 3.14: Volume removed at each drain for a soil type B with modified

Hydraulic Conductivity....

Figure 3.15: Variation of Drainage Volume along the length for soil type B

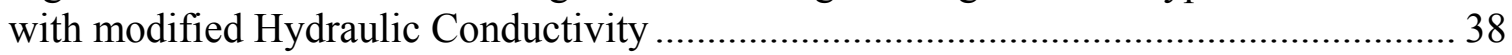

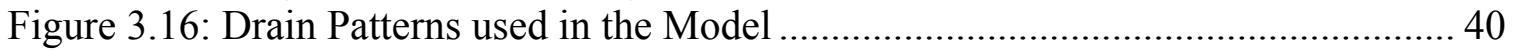

Figure 3.17: Relationship between the hydraulic conductivity ratio and clay content..... 41

Figure 3.17: Relationship between the hydraulic conductivity ratio and clay content.... 42

Figure 4.1: Flow Fluctuation at D1 for Soil Type C at Zero slope, 12" width ................ 48

Figure 4.2: Flow Fluctuation at D2 for Soil Type C at Zero slope, 12" width................ 48

Figure 4.3: Piezometric Head for Soil Type C at Zero slope, 12" width......................... 49

Figure 4.4: Cumulative percent removal for Soil Type C at Zero slope, 12" width........ 49

Figure 4.5: Flow Fluctuation at drain D'1 for Soil Type C at zero slope, 12" width ....... 51

Figure 4.6: Flow Fluctuation at drain D'2 for Soil Type C at zero slope, 12" width ....... 51

Figure 4.7: Piezometric variation along for Soil Type C at Zero slope, 12" width......... 52

Figure 4.8: Cumulative percent removed for Soil Type C at zero slope, 12" width ........ 52

Figure 4.9: Flow fluctuation at drain D7 for Soil Type $\mathrm{C}$ at zero slope with

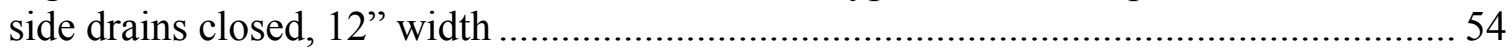


Figure 4.10: Piezometric level along center line for Soil Type $\mathrm{C}$ at Zero slope, 12 " width.

Figure 4.11: Computed piezometric variation along center line for Soil Type C at Zero slope, 12" width 56

Figure 4.12: Comparison of piezometric variation along center line for

Soil Type $C$ at zero slope after half hour 57

Figure 4.13: Piezometric variation along Center Line for Soil Type A

- Physical Model 59

Figure 4.14: Piezometric variation along Center Line for Soil Type A

- Computer Model. 59

Figure 4.15: Comparison in Flow Rate Fluctuation for Soil Type A 60

Figure 4.16: Piezometric Level along Center Line for Soil Type A after 1 minute ........ 61 Figure 4.17: Piezometric Level along Center Line for Soil Type A after 5 minutes....... 61

Figure 4.18: Piezometric Level along Center Line for Soil Type A after 15 minutes...... 62

Figure 4.19: Piezometric Level along Center Line for Soil Type A after 30 minutes...... 62

Figure 4.20: Piezometric Level along Center Line for Soil Type A after 60 minutes...... 63

Figure 4.21: Piezometric head along center line for soil type A - Computer Model........ 66

Figure 4.22: Piezometric head along center line for soil type A - Physical Model .......... 67

Figure 4.23: Piezometric head along center line for soil type A after 1 minute .................67

Figure 4.24: Piezometric head along center line for soil type A after 5 minutes ............. 68

Figure 4.25: Piezometric level along center line for soil type A after 15 minutes ........... 68

Figure 4.26: Piezometric head along center line for soil type A after 30 minutes .......... 69

Figure 4.27: Piezometric head along center line for soil type A after 60 minutes .......... 69

Figure 4.28: Piezometric head along cross-section A for soil type A

- Computer Model

Figure 4.29: Piezometric head along cross-section A for soil type A

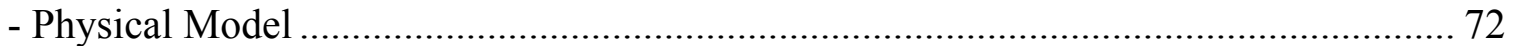

Figure 4.30: Piezometric head along cross-section A for soil type A after 1 minute....... 73

Figure 4.31: Piezometric head along cross-section A for soil type A after 5 minutes ..... 73

Figure 4.32: Piezometric head along cross-section A for soil type A after 15 minutes ... 74

Figure 4.33: Piezometric head along cross-section A for soil type A after 30 minutes ... 74

Figure 4.34: Piezometric head along cross-section A for soil type A after 60 minutes ... 75

Figure 4.35: Piezometric head along cross-section B for soil type A

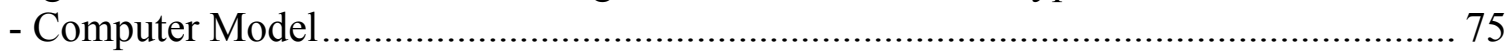

Figure 4.36: Piezometric head along cross-section B for soil type A

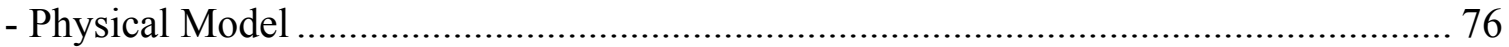

Figure 4.37: Piezometric head along cross-section B for soil type A after 1 minute ....... 76

Figure 4.38: Piezometric head along cross-section B for soil type A after 5 minutes...... 77

Figure 4.39: Piezometric head along cross-section B for soil type A after 15 minutes.... 77

Figure 4.40: Piezometric head along cross-section B for soil type A after 30 minutes.... 78

Figure 4.41: Piezometric head along cross-section B for soil type A after 60 minutes.... 78

Figure 4.42: Flow rate fluctuation for Soil Type A at drain D1 ................................. 79

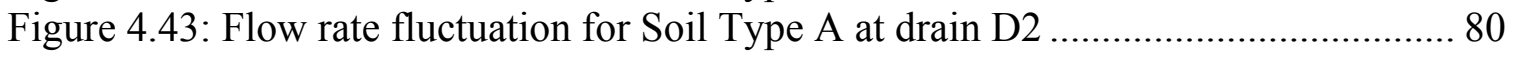

Figure 4.44: Flow rate fluctuation for Soil Type A at drain D3 .................................. 80

Figure 4.45: Flow rate fluctuation for Soil Type A at drain D4 ................................. 81

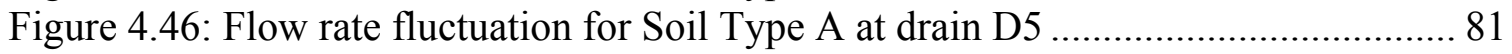




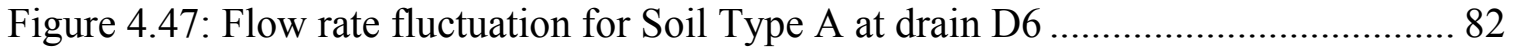

Figure 4.48: Flow rate fluctuation for Soil Type A at drain D7 .................................. 82

Figure 4.49: Cumulative Percent Removed along the Drain for Soil Type A

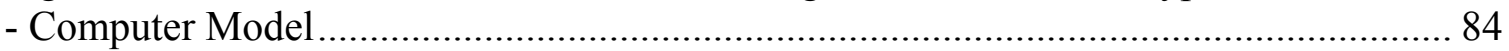

Figure 4.50: Cumulative Percent Removed along the Drain for Soil Type A

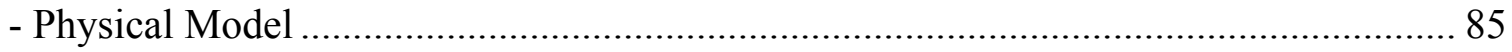

Figure 4.51: Cumulative percent removed for Soil Type A at zero slope, 12" width ...... 87

Figure 4.52: Volume removed at each drain for Soil Type A at zero slope, 12" width ... 87

Figure 4.53: Volume removed at each drain for Soil Type A at zero slope, 12" width ... 88

Figure 4.54: Piezometric head for Soil Type A at zero slope, 12" width ....................... 88

Figure 4.55: Piezometric head along cross-section A for Soil Type A at zero slope, 12"

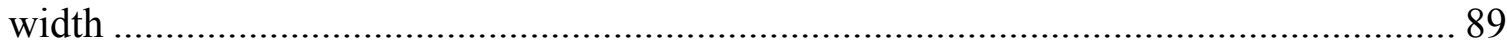

Figure 4.56: Piezometric head along cross-section B for Soil Type A at zero slope, 12"

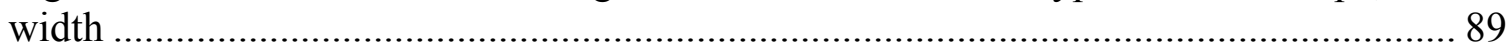

Figure 4.57: Piezometric head along the center line for case A-6-48-10 ...................... 92

Figure 4.58: Piezometric head along the center line for case A-12-48-10 .................... 93

Figure 4.59: Piezometric head along the center line for case A-18-48-10 .................... 93

Figure 4.60: Piezometric head along the center line for case A-24-48-10 ..................... 94

Figure 4.61: Piezometric head along the center line for case A-48-48-10 ..................... 94

Figure 4.62: Piezometric head along the cross-section A for case A-6-48-10 ............... 95

Figure 4.63: Piezometric head along the cross-section A for case A-12-48-10 ............. 96

Figure 4.64: Piezometric head along the cross-section A for case A-18-48-10 ............. 96

Figure 4.65: Piezometric head along the cross-section A for case A-24-48-10 .............. 97

Figure 4.66: Piezometric head along the cross-section A for case A-48-48-10 ............. 97

Figure 4.67: Piezometric head along the cross-section B for case A-6-48-10................ 98

Figure 4.68: Piezometric head along the cross-section B for case A-12-48-10 .............. 98

Figure 4.69: Piezometric head along the cross-section B for case A-18-48-10 .............. 99

Figure 4.70: Piezometric head along the cross-section B for case A-24-48-10.............. 99

Figure 4.71: Piezometric head along the cross-section B for case A-48-48-10 ............ 100

Figure 4.72: Cumulative Percent Removal for case A-6-48-10 ................................. 101

Figure 4.73: Cumulative Percent Removal for case A-12-48-10 .................................. 102

Figure 4.74: Cumulative Percent Removal for case A-18-48-10 ................................. 102

Figure 4.75: Cumulative Percent Removal for case A-24-48-10 ................................ 103

Figure 4.76: Cumulative Percent Removal for case A-48-48-10 ................................. 103

Figure 4.77: Effect of Width on Transient Time ......................................................... 104

Figure 4.78: Piezometric head along the center line for case A-12-48-10 ................... 105

Figure 4.79: Piezometric head along the center line for case A-12-96-10 ................... 105

Figure 4.80: Piezometric head along the center line for case A-12-144-10 ................. 106

Figure 4.81: Piezometric head along the center line for case A-12-192-10 ................. 106

Figure 4.82: Piezometric head along the cross-section A for case A-12-48-10 ............ 107

Figure 4.83: Piezometric head along the cross-section A for case A-12-96-10 ............ 108

Figure 4.84: Piezometric head along the cross-section A for case A-12-144-10 .......... 108

Figure 4.85: Piezometric head along the cross-section A for case A-12-192-10 .......... 109

Figure 4.86: Piezometric head along the cross-section B for case A-12-48-10............ 109

Figure 4.87: Piezometric head along the cross-section B for case A-12-96-10............ 110

Figure 4.88: Piezometric head along the cross-section B for case A-12-144-10.......... 110 
Figure 4.89: Piezometric head along the cross-section B for case A-12-192-10.......... 111

Figure 4.90: Cumulative Percent Removal for case A-12-48-10 ................................. 112

Figure 4.91: Cumulative Percent Removal for case A-12-96-10 .................................. 112

Figure 4.92: Cumulative Percent Removal for case A-12-144-10 ................................ 113

Figure 4.93: Cumulative Percent Removal for case A-12-192-10 ............................... 113

Figure 4.94: Effect of Drain Length on Transient Time .......................................... 114

Figure 4.95: Piezometric head along the center line for case A-12-48-0 .................... 115

Figure 4.96: Piezometric head along the center line for case A-12-48-10 .................. 116

Figure 4.97: Piezometric head along the center line for case A-12-48-20 .................... 116

Figure 4.98: Piezometric head along the center line for case A-12-48-30 ................... 117

Figure 4.99: Piezometric head along the center line for case A-12-48-40 .................. 117

Figure 4.100: Piezometric head along the cross-section A for case A-12-48-0 ............ 118

Figure 4.101: Piezometric head along the cross-section A for case A-12-48-10 .......... 119

Figure 4.102: Piezometric head along the cross-section A for case A-12-48-20 .......... 119

Figure 4.103: Piezometric head along the cross-section A for case A-12-48-30 .......... 120

Figure 4.104: Piezometric head along the cross-section A for case A-12-48-40 .......... 120

Figure 4.105: Piezometric head along the cross-section B for case A-12-48-0 ............ 121

Figure 4.106: Piezometric head along the cross-section B for case A-12-48-10.......... 121

Figure 4.107: Piezometric head along the cross-section B for case A-12-48-20........... 122

Figure 4.108: Piezometric head along the cross-section B for case A-12-48-30.......... 122

Figure 4.109: Piezometric head along the cross-section B for case A-12-48-40.......... 123

Figure 4.110: Cumulative Percent Removal for case A-12-48-0 ................................. 124

Figure 4.111: Cumulative Percent Removal for case A-12-48-10. .............................. 125

Figure 4.112: Cumulative Percent Removal for case A-12-48-20 ............................... 125

Figure 4.113: Cumulative Percent Removal for case A-12-48-30 .............................. 126

Figure 4.114: Cumulative Percent Removal for case A-12-48-40 ............................... 126

Figure 4.115: Influence of slope inclination on transient time ................................... 127

Figure 4.116: Piezometric head along the center line for case A-12-48-30 ................. 129

Figure 4.117: Piezometric head along the center line for case C-12-48-30.................. 129

Figure 4.118: Piezometric head along the center line for case E-12-48-30 .................. 130

Figure 4.119: Piezometric head along the cross-section A for case A-12-48-30 .......... 131

Figure 4.120: Piezometric head along the cross-section A for case C-12-48-30........... 131

Figure 4.121: Piezometric head along the cross-section A for case E-12-48-30 ........... 132

Figure 4.122: Piezometric head along the cross-section B for case A-12-48-30........... 132

Figure 4.123: Piezometric head along the cross-section B for case C-12-48-30........... 133

Figure 4.124: Piezometric head along the cross-section B for case E-12-48-30 .......... 133

Figure 4.125: Cumulative Percent Removal for case A-12-48-30 .............................. 134

Figure 4.126: Cumulative Percent Removal for case C-12-48-30............................... 135

Figure 4.127: Cumulative Percent Removal for case E-12-48-30 .............................. 135

Figure 4.128: Influence of soil type on the transient time ......................................... 136

Figure 4.129: Piezometric head along the center line for different drain spacing .......... 137

Figure 4.130: Piezometric head along cross-section A for different trench spacing ...... 138

Figure 4.131: Piezometric head along cross-section B for different trench spacing ...... 139

Figure 4.132: Influence of drain spacing on Cumulative Percent Removal .................. 140

Figure 4.133: Piezometric head along the center line for different drain lengths........... 141

Figure 4.134: Piezometric head along cross-section A for different drain lengths ........ 141 
Figure 4.135: Piezometric head along cross-section B for different drain lengths......... 142

Figure 4.136: Influence of drain length on Cumulative Percent Removal .................... 143

Figure 4.137: Piezometric head along the center line for different slope angles............ 144

Figure 4.138: Piezometric head along cross-section A for different slope angles.......... 145

Figure 4.139: Piezometric head along cross-section B for different slope angles......... 146

Figure 4.140: Influence of slope angle on Cumulative Percent Removal ..................... 147

Figure 4.141: Piezometric head along the center line for different soil types ............... 149

Figure 4.142: Piezometric head along cross-section A for different soil types ............. 149

Figure 4.143: Piezometric head along cross-section B for different soil types .............. 150

Figure 4.144: Influence of soil type on Cumulative Percent Removal.......................... 150

Figure A1.1: Cumulative percent removed along the drain for all drain set-ups

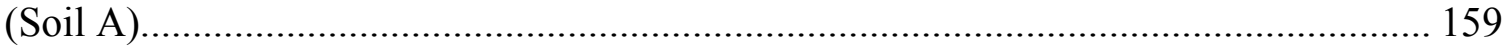

Figure A1.2: Cumulative percent removed along the drain for the three main

drain set-ups (Soil A) ....................................................................................... 159

Figure A1.3: Volume removed at each drain for all drain set-ups (Soil A)................... 160

Figure A1.4: Volume removed in each drain for the three main drain set-ups

(Soil A).

Figure A1.5: Volume removed along the drain for the three main drain set-ups

(Soil A).

Figure A1.6: Cumulative percent removed along the drain for all drain set-ups

(Soil C)

Figure A1.7: Cumulative percent removed along the drain for the three main

drain set-ups (Soil C)

Figure A1.8: Volume removed at each drain for all drain set-ups (Soil C) .................... 162

Figure A1.9: Close-up of volume removed at each drain for all drain set-ups

(Soil C)

Figure A1.10: Close-up of volume removed in each drain for the three main

drain set-ups (Soil C)

Figure A1.11: Volume removed along the drain for the three main drain set-ups

(Soil C).....

Figure A1.12: Cumulative percent removed along the drain for all drain set-ups

(Soil D).

Figure A1.13: Cumulative percent removed along the drain for the three main

drain set-ups (Soil D)

Figure A1.14: Volume removed at each drain for all drain set-ups (Soil D).

Figure A1.15: Close-up of volume removed at each drain for all drain set-ups

(Soil D)

Figure A1.16: Close-up of volume removed in each drain for the three main

drain set-ups (Soil D)

Figure A1.17: Volume removed along the drain for the three main drain set-ups

(Soil D).

Figure A1.18: Cumulative percent removed along the drain for all drain set-ups

(Soil E)

Figure A1.19: Cumulative percent removed along the drain for the three main

drain set-ups (Soil E)

Figure A1.20: Volume removed at each drain for all drain set-ups (Soil E) 168 
Figure A1.21: Close-up of volume removed at each drain for all drain set-ups (Soil E)

Figure A1.22: Close-up of volume removed in each drain for the three main drain set-ups (Soil E)

Figure A1.23: Volume removed along the drain for the three main drain set-ups

(Soil E)

Figure A1.24: Measured and Computed Cumulative percent removed along the drain for Soil A with modified Hydraulic Conductivity

Figure A1.25: Volume removed at each drain for a soil type A with modified

Hydraulic Conductivity....

Figure A1.26: Variation of Drainage Volume along the length for soil type A with modified Hydraulic Conductivity

Figure A1.27: Measured and Computed Cumulative percent removed along the drain for Soil $\mathrm{C}$ with modified Hydraulic Conductivity ....

Figure A1.28: Volume removed at each drain for a soil type $\mathrm{C}$ with modified

Hydraulic Conductivity....

Figure A1.29: Variation of Drainage Volume along the length for soil type C with modified Hydraulic Conductivity

Figure A1.30: Measured and Computed Cumulative percent removed along the

drain for Soil D with modified Hydraulic Conductivity

Figure A1.31: Volume removed at each drain for a soil type D with modified

Hydraulic Conductivity....

Figure A1.32: Variation of Drainage Volume along the length for soil type D

with modified Hydraulic Conductivity

Figure A1.33: Measured and Computed Cumulative percent removed along the

drain for Soil E with modified Hydraulic Conductivity

Figure A1.34: Volume removed at each drain for a soil type E with modified

Hydraulic Conductivity....

Figure A1.35: Variation of Drainage Volume along the length for soil type E

with modified Hydraulic Conductivity

Figure A2.1: Piezometric variation along Center Line for Soil Type B

-Physical Model 178

Figure A2.2: Piezometric variation along center line for Soil Type B

- Computer Model 178

Figure A2.3: Comparison in Flow Rate Fluctuation for Soil Type B

Figure A2.4: Piezometric Level along center line for Soil Type B after 1 minute.

Figure A2.5: Piezometric Level along center line for Soil Type B after 5 minutes ....... 180

Figure A2.6: Piezometric Level along center line for Soil Type B after 15 minutes .... 180

Figure A2.7: Piezometric Level along center line for Soil Type B after 30 minutes ..... 181

Figure A2.8: Piezometric Level along center line for Soil Type B after 60 minutes ..... 181

Figure A2.9: Piezometric variation along Center Line for Soil Type C

-Physical Model.

Figure A2.10: Piezometric variation along center line for Soil Type C

- Computer Model

Figure A2.11: Comparison in Flow Rate Fluctuation for Soil Type C.

Figure A2.12: Piezometric Level along center line for Soil Type C after 1 minute 183 
Figure A2.13: Piezometric Level along center line for Soil Type C after 5 minute....... 184

Figure A2.14: Piezometric Level along center line for Soil Type C after 15 minute..... 184

Figure A2.15: Piezometric Level along center line for Soil Type $\mathrm{C}$ after 30 minute.... 185

Figure A2.16: Piezometric Level along center line for Soil Type C after 60 minute..... 185

Figure A2.17: Piezometric variation along Center Line for Soil Type D

-Physical Model

Figure A2.18: Piezometric variation along center line for Soil Type D

- Computer Model

Figure A2.19: Comparison in Flow Rate Fluctuation for Soil Type D

Figure A2.20: Piezometric Level along center line for Soil Type D after 1 minute....... 187

Figure A2.21: Piezometric Level along center line for Soil Type D after 30 minutes ... 188

Figure A2.22: Piezometric Level along center line for Soil Type D after 60 minutes ... 188

Figure A2.23: Piezometric Level along center line for Soil Type D after 1 Day ........... 189

Figure A2.24: Piezometric Level along center line for Soil Type D after 2 Days ......... 189

Figure A2.25: Piezometric variation along Center Line for Soil Type B

-Physical Model.

Figure A2.26: Piezometric variation along center line for Soil Type E

- Computer Model

Figure A2.27: Comparison in Flow Rate Fluctuation for Soil Type E

Figure A2.28: Piezometric Level along center line for Soil Type E after 1 minute ....... 191

Figure A2.29: Piezometric Level along center line for Soil Type E after 60 minutes ... 192

Figure A2.30: Piezometric Level along center line for Soil Type E after 1 Day

Figure A3.1: Piezometric head along Center Line Soil Type B - Computer Model 195

Figure A3.2: Piezometric head along Center Line Soil Type B - Physical Model........ 195

Figure A3.3: Piezometric head along Center Line Soil Type B, after 1 minute............. 196

Figure A3.4: Piezometric head along Center Line Soil Type B, after 5 minutes ........... 196

Figure A3.5: Piezometric head along Center Line Soil Type B, after 15 minutes ......... 197

Figure A3.6: Piezometric head along Center Line Soil Type B, after 30 minutes ......... 197

Figure A3.7: Piezometric head along Center Line Soil Type B, after 60 minutes ......... 198

Figure A3.8: Piezometric head along Center Line Soil Type C, Computer Model........ 198

Figure A3.9: Piezometric head along Center Line Soil Type C, physical Model .......... 199

Figure A3.10: Piezometric head along Center Line Soil Type C, after 1 minute........... 199

Figure A3.11: Piezometric head along Center Line Soil Type C, after 5 minutes ......... 200

Figure A3.12: Piezometric head along Center Line Soil Type C, after 15 minutes ....... 200

Figure A3.13: Piezometric head along Center Line Soil Type C, after 30 minutes ....... 201

Figure A3.14: Piezometric head along Center Line Soil Type C, after 60 minutes ....... 201

Figure A3.15: Piezometric head along Center Line Soil Type D, Computer Model..... 202

Figure A3.16: Piezometric head along Center Line Soil Type D, physical Model ........ 202

Figure A3.17: Piezometric head along Center Line Soil Type D, after 1 minute........... 203

Figure A3.18: Piezometric head along Center Line Soil Type D, after 5 minutes ......... 203

Figure A3.19: Piezometric head along Center Line Soil Type D, after 15 minutes ...... 204

Figure A3.20: Piezometric head along Center Line Soil Type D, after 30 minutes ...... 204

Figure A3.21: Piezometric head along Center Line Soil Type D, after 60 minutes ....... 205

Figure A3.22: Piezometric head along Center Line Soil Type E, Computer Model ...... 205

Figure A3.23: Piezometric head along Center Line Soil Type E, Physical Model ....... 206

Figure A3.24: Piezometric head along Center Line Soil Type E, after 1 minute ........... 206 
Figure A3.25: Piezometric head along Center Line Soil Type E, after 15 minutes ....... 207

Figure A3.26: Piezometric head along Center Line Soil Type E, after 60 minutes ....... 207

Figure A3.27: Piezometric head along Center Line Soil Type E, after 240 minutes ..... 208

Figure A3.28: Piezometric head along Center Line Soil Type E, after 360 minutes ..... 208

Figure A4.1: Piezometric head along cross-section A for soil type B

- Computer Model

Figure A4.2: Piezometric head along cross-section A for soil type B

- Physical Model

Figure A4.3: Piezometric head along Cross-Section A for soil type B

after 1 minute

Figure A4.4: Piezometric head along Cross-Section A for soil type B

after 5 minutes.

Figure A4.5: Piezometric head along Cross-Section A for soil type B

after 15 minutes.

Figure A4.6: Piezometric head along Cross-Section A for soil type B

after 30 minutes

Figure A4.7: Piezometric head along Cross-Section A for soil type B

after 60 minutes

Figure A4.8: Piezometric head along cross-section B for soil type B

- Computer Model

Figure A4.9: Piezometric head along cross-section B for soil type B

- Physical Model

Figure A4.10: Piezometric head along Cross-Section B for soil type B

after 1 minute

Figure A4.11: Piezometric head along Cross-Section B for soil type B

after 5 minutes.

Figure A4.12: Piezometric head along Cross-Section B for soil type B

after 15 minutes.

Figure A4.13: Piezometric head along Cross-Section B for soil type B

after 30 minutes.

Figure A4.14: Piezometric head along Cross-Section B for soil type B

after 60 minutes

Figure A4.15.: Piezometric head along cross-section A for soil type C

- Computer Model

Figure A4.16: Piezometric head along cross-section A for soil type C

- Physical Model

Figure A4.17: Piezometric head along Cross-Section A for soil type C

after 1 minute

Figure A4.18: Piezometric head along Cross-Section A for soil type C

after 5 minutes.

Figure A4.19: Piezometric head along Cross-Section A for soil type C

after 15 minutes.

Figure A4.20: Piezometric head along Cross-Section A for soil type C

after 30 minutes.

Figure A4.21: Piezometric head along Cross-Section A for soil type C

after 60 minutes. 
Figure A4.22: Piezometric head along cross-section B for soil type C

- Computer Model.

Figure A4.23: Piezometric head along cross-section B for soil type C

- Physical Model

Figure A4.24: Piezometric head along Cross-Section B for soil type C

after 1 minute

Figure A4.25: Piezometric head along Cross-Section B for soil type C after 5 minutes

Figure A4.26: Piezometric head along Cross-Section B for soil type C

after 15 minutes

Figure A4.27: Piezometric head along Cross-Section B for soil type C

after 30 minutes

Figure A4.28: Piezometric head along Cross-Section B for soil type C

after 60 minutes.

Figure A4.29: Piezometric head along cross-section A for soil type D

- Computer Model

Figure A4.30: Piezometric head along cross-section A for soil type D

- Physical Model

Figure A4.31: Piezometric head along Cross-Section A for soil type D

after 1 minute

Figure A4.32: Piezometric head along Cross-Section A for soil type D

after 5 minutes

Figure A4.33: Piezometric head along Cross-Section A for soil type D

after 15 minutes.

Figure A4.34: Piezometric head along Cross-Section A for soil type D

after 30 minutes.

Figure A4.35: Piezometric head along Cross-Section A for soil type D

after 60 minutes.

Figure A4.36: Piezometric head along cross-section B for soil type D

- Computer Model

Figure A4.37: Piezometric head along cross-section B for soil type D

- Physical Model 228

Figure A4.38: Piezometric head along Cross-Section B for soil type D

after 1 minute 228

Figure A4.39: Piezometric head along Cross-Section B for soil type D after 5 minutes

Figure A4.40: Piezometric head along Cross-Section B for soil type D

after 15 minutes.

Figure A4.41: Piezometric head along Cross-Section B for soil type D

after 30 minutes

Figure A4.42: Piezometric head along Cross-Section B for soil type D after 60 minutes.

Figure A4.43: Piezometric head along cross-section A for soil type E

- Computer Model

Figure A4.44: Piezometric head along cross-section A for soil type E

- Physical Model 
Figure A4.45: Piezometric head along Cross-Section A for soil type E after 1 minute

Figure A4.46: Piezometric head along Cross-Section A for soil type E after 5 minutes.

Figure A4.47: Piezometric head along Cross-Section A for soil type E

after 15 minutes.

Figure A4.48: Piezometric head along Cross-Section A for soil type E after 30 minutes. 233

Figure A4.49: Piezometric head along Cross-Section A for soil type E

after 60 minutes. 234

Figure A4.50: Piezometric head along cross-section B for soil type E

- Computer Model 234

Figure A4.51: Piezometric head along cross-section B for soil type E

- Physical Model 235

Figure A4.52: Piezometric head along Cross-Section B for soil type E after 1 minute 235

Figure A4.53: Piezometric head along Cross-Section B for soil type E after 5 minutes 236

Figure A4.54: Piezometric head along Cross-Section B for soil type E

after 15 minutes. 236

Figure A4-55: Piezometric head along Cross-Section B for soil type E after 30 minutes. 237

Figure A4-56: Piezometric head along Cross-Section B for soil type E after 60 minutes. 237

Figure A5.1: Flow rate fluctuation for Soil Type B at drain D1 239

Figure A5.2: Flow rate fluctuation for Soil Type B at drain D2. 239

Figure A5.3: Flow rate fluctuation for Soil Type B at drain D3..... 240

Figure A5.4: Flow rate fluctuation for Soil Type B at drain D4.................................... 240

Figure A5.5: Flow rate fluctuation for Soil Type B at drain D5.................................... 241

Figure A5.6: Flow rate fluctuation for Soil Type B at drain D6.................................... 241

Figure A5.7: Flow rate fluctuation for Soil Type B at drain D7 ................................... 242

Figure A5.8: Flow rate fluctuation for Soil Type $C$ at drain D1.................................. 242

Figure A5.9: Flow rate fluctuation for Soil Type C at drain D2 ................................. 243

Figure A5.10: Flow rate fluctuation for Soil Type C at drain D3 ................................ 243

Figure A5.11: Flow rate fluctuation for Soil Type C at drain D4 ................................ 244

Figure A5.12: Flow rate fluctuation for Soil Type C at drain D5 .................................. 244

Figure A5.13: Flow rate fluctuation for Soil Type C at drain D6................................. 245

Figure A5.14: Flow rate fluctuation for Soil Type C at drain D7 ................................. 245

Figure A5.15: Flow rate fluctuation for Soil Type D at drain D1 .............................. 246

Figure A5.16: Flow rate fluctuation for Soil Type D at drain D2 ............................... 246

Figure A5.17: Flow rate fluctuation for Soil Type D at drain D3 ……….................... 247

Figure A5.18: Flow rate fluctuation for Soil Type D at drain D4 ……........................ 247

Figure A5.19: Flow rate fluctuation for Soil Type D at drain D5 ................................ 248

Figure A5.20: Flow rate fluctuation for Soil Type D at drain D6 ................................ 248

Figure A5.21: Flow rate fluctuation for Soil Type D at drain D7 ................................ 249

Figure A5.22: Flow rate fluctuation for Soil Type E at drain D ................................... 249 
Figure A5.23: Flow rate fluctuation for Soil Type D at drain D2 .............................. 250

Figure A5.24: Flow rate fluctuation for Soil Type D at drain D3 .............................. 250

Figure A5.25: Flow rate fluctuation for Soil Type D at drain D4 ............................... 251

Figure A5.26: Flow rate fluctuation for Soil Type D at drain D5 ............................... 251

Figure A5.27: Flow rate fluctuation for Soil Type D at drain D6 .............................. 252

Figure A5.28: Flow rate fluctuation for Soil Type D at drain D7 .............................. 252

Figure A6.1: Cumulative Percent Removed along the Drain for Soil Type B

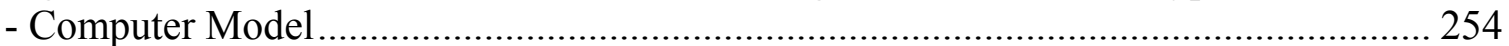

Figure A6.2: Cumulative Percent Removed along the Drain for Soil Type B

- Physical Model .................................................................................................... 254

Figure A6.3: Cumulative Percent Removed along the Drain for Soil Type C

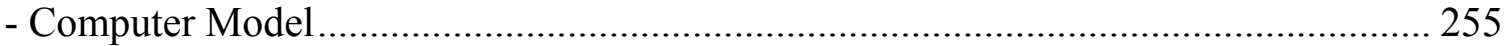

Figure A6.4: Cumulative Percent Removed along the Drain for Soil Type C

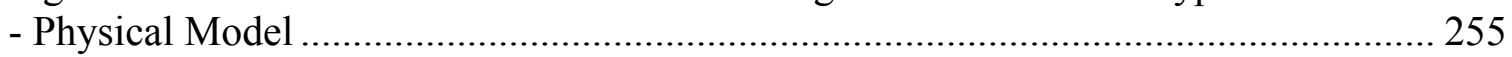

Figure A6.5: Cumulative Percent Removed along the Drain for Soil Type D

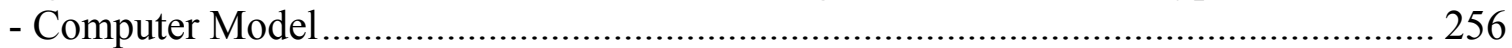

Figure A6.6: Cumulative Percent Removed along the Drain for Soil Type D

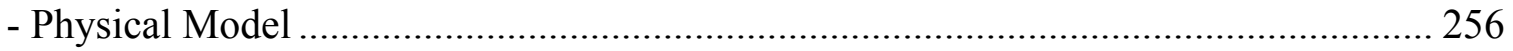

Figure A6.7: Cumulative Percent Removed along the Drain for Soil Type E

- Computer Model ..................................................................................................... 257

Figure A6.8: Cumulative Percent Removed along the Drain for Soil Type E

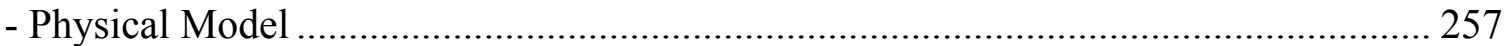

Figure A7.1: Cumulative Percent Removal for case A-6-96-10.................................. 259

Figure A7.2: Piezometric head along center line for case A-6-96-10 ......................... 259

Figure A7.3: Piezometric head along cross-Section X for case A-6-96-10.................. 260

Figure A7.4: Piezometric head along cross-Section Y for case A-6-96-10................... 260

Figure A7.5: Cumulative Percent Removal for case A-6-144-10................................ 261

Figure A7.6: Piezometric head along center line for case A-6-144-10 ......................... 261

Figure A7.7: Piezometric head along cross-Section X for case A-6-144-10 ................ 262

Figure A7.8: Piezometric head along cross-Section Y for case A-6-144-10 ................. 262

Figure A7.9: Cumulative Percent Removal for case A-6-144-10................................. 263

Figure A7.10: Piezometric head along center line for case A-6-144-10 ...................... 263

Figure A7.11: Piezometric head along cross-Section X for case A-6-144-10............... 264

Figure A7.12: Piezometric head along cross-Section Y for case A-6-144-10............... 264

Figure A7.13: Cumulative Percent Removal for case A-6-192-10............................... 265

Figure A7.14: Piezometric head along center line for case A-6-192-10 ..................... 265

Figure A7.15: Piezometric head along cross-Section X for case A-6-192-10.............. 266

Figure A7.16: Piezometric head along cross-Section Y for case A-6-192-10 .............. 266

Figure A7.17: Cumulative Percent Removal for case A-18-96-10 ............................. 267

Figure A7.18: Piezometric head along center line for case A-18-96-10 ....................... 267

Figure A7.19: Piezometric head along cross-Section X for case A-18-96-10.............. 268

Figure A7.20: Piezometric head along cross-Section Y for case A-18-96-10.............. 268

Figure A7.21: Cumulative Percent Removal for case A-18-144-10........................... 269

Figure A7.22: Piezometric head along center line for case A-18-144-10 .................... 269

Figure A7.23: Piezometric head along cross-Section X for case A-18-144-10............ 270

Figure A7.24: Piezometric head along cross-Section Y for case A-18-144-10............ 270 
Figure A7.25: Cumulative Percent Removal for case A-18-192-10........................... 271

Figure A7.26: Piezometric head along center line for case A-18-192-10 .................... 271

Figure A7.27: Piezometric head along cross-Section X for case A-18-192-10 ............. 272

Figure A7.28: Piezometric head along cross-Section Y for case A-18-192-10............. 272

Figure A7.29: Cumulative Percent Removal for case A-24-96-10............................. 273

Figure A7.30: Piezometric head along center line for case A-24-96-10 ..................... 273

Figure A7.31: Piezometric head along cross-Section X for case A-24-96-10 .............. 274

Figure A7.32: Piezometric head along cross-Section Y for case A-24-96-10 ............... 274

Figure A7.33: Cumulative Percent Removal for case A-24-144-10............................ 275

Figure A7.34: Piezometric head along center line for case A-24-144-10 .................... 275

Figure A7.35: Piezometric head along cross-Section X for case A-24-144-10 ............. 276

Figure A7.36: Piezometric head along cross-Section Y for case A-24-144-10............ 276

Figure A7.37: Cumulative Percent Removal for case A-24-192-10........................... 277

Figure A7.38: Piezometric head along center line for case A-24-192-10 ..................... 277

Figure A7.39: Piezometric head along cross-Section X for case A-24-192-10............ 278

Figure A7.40: Piezometric head along cross-Section Y for case A-24-192-10............ 278

Figure A7.41: Cumulative Percent Removal for case A-48-48-10 ............................. 279

Figure A7.42: Piezometric head along center line for case A-48-48-10 ..................... 279

Figure A7.43: Piezometric head along cross-Section X for case A-48-48-10 .............. 280

Figure A7.44: Piezometric head along cross-Section Y for case A-48-48-10.............. 280

Figure A7.45: Cumulative Percent Removal for case A-48-96-10 ............................... 281

Figure A7.46: Piezometric head along center line for case A-48-96-10 ...................... 281

Figure A7.47: Piezometric head along cross-Section X for case A-48-96-10.............. 282

Figure A7.48: Piezometric head along cross-Section Y for case A-48-96-10.............. 282

Figure A7.49: Cumulative Percent Removal for case A-48-144-10 ............................ 283

Figure A7.50: Piezometric head along center line for case A-48-144-10 .................... 283

Figure A7.51: Piezometric head along cross-Section X for case A-48-144-10 ............. 284

Figure A7.52: Piezometric head along cross-Section Y for case A-48-144-10............ 284

Figure A7.53: Cumulative Percent Removal for case A-48-192-10........................... 285

Figure A7.54: Piezometric head along center line for case A-48-192-10 .................... 285

Figure A7.55: Piezometric head along cross-Section X for case A-48-192-10 ............ 286

Figure A7.56: Piezometric head along cross-Section Y for case A-48-192-10............ 286

Figure A8.1: Fluctuation of Flow at D1 for Case C-12-48-20. ................................... 288

Figure A8.2: Fluctuation of Flow at D2 for Case C-12-48-20 .................................... 288

Figure A8.3: Fluctuation of Flow at D3 for Case C-12-48-20 .................................... 289

Figure A8.4: Fluctuation of Flow at D4 for Case C-12-48-20 ................................... 289

Figure A8.5: Fluctuation of Flow at D5 for Case C-12-48-20 ................................... 290

Figure A8.6: Fluctuation of Flow at D6 for Case C-12-48-20 ..................................... 290

Figure A8.7: Fluctuation of Flow at D7 for Case C-12-48-20 .................................... 291

Figure A8.8: Cumulative Percent Removed Along the Drain for Case C12-48-20 ....... 291

Figure A8.9: Variation of Piezometric Head Along the Center Line for case C-12-48-20

Figure A8.10: Variation of Piezometric Head Along cross-Section A for case

C-12-48-20 292

Figure A8.11: Variation of Piezometric Head Along cross-Section B for case C-12-48-20. 293 
Figure A8.12: Fluctuation of Flow at D1 for Case C-12-48-30 .................................. 294

Figure A8.13: Fluctuation of Flow at D2 for Case C-12-48-30 ................................... 294

Figure A8.14: Fluctuation of Flow at D3 for Case C-12-48-30 ................................... 295

Figure A8.15: Fluctuation of Flow at D4 for Case C-12-48-30 .................................. 295

Figure A8.16: Fluctuation of Flow at D5 for Case C-12-48-30 .................................. 296

Figure A8.17: Fluctuation of Flow at D6 for Case C-12-48-30 .................................. 296

Figure A8.18: Fluctuation of Flow at D7 for Case C-12-48-30 ................................. 297

Figure A8.19: Cumulative Percent Removed Along the Drain for Case C12-48-30 .... 297

Figure A8.20: Variation of Piezometric Head Along the Center Line for case

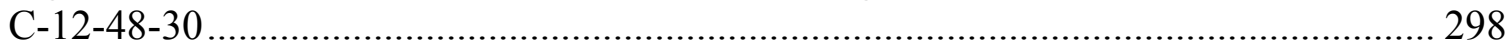

Figure A8.21: Variation of Piezometric Head Along Cross-Section A for case

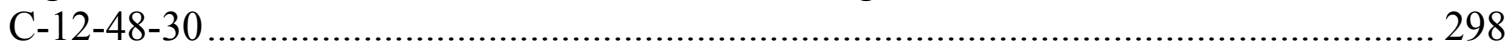

Figure A8.22: Variation of Piezometric Head Along Cross-Section B for case

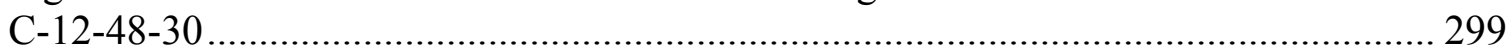

Figure A8.23: Fluctuation of Flow at D1 for Case E-12-48-20 ................................. 300

Figure A8.24: Fluctuation of Flow at D2 for Case E-12-48-20 ................................... 300

Figure A8.25: Fluctuation of Flow at D3 for Case E-12-48-20 .................................. 301

Figure A8.26: Fluctuation of Flow at D4 for Case E-12-48-20 .................................. 301

Figure A8.27: Fluctuation of Flow at D5 for Case E-12-48-20 .................................. 302

Figure A8.28: Fluctuation of Flow at D6 for Case E-12-48-20 ................................... 302

Figure A8.29: Fluctuation of Flow at D7 for Case E-12-48-20 ................................... 303

Figure A8.30: Cumulative Percent Removed Along the Drain for Case E-12-48-20 .... 303

Figure A8.31: Variation of Piezometric Head Along the Center Line for case

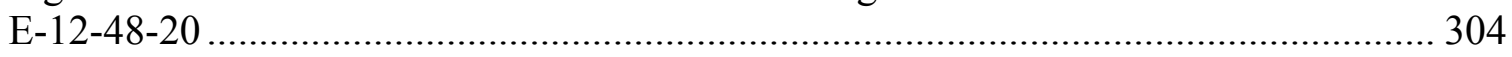

Figure A8.32: Variation of Piezometric Head Along cross-Section A for case

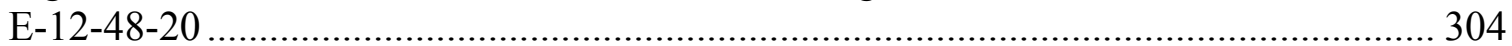

Figure A8.33: Variation of Piezometric Head Along cross-Section B for case

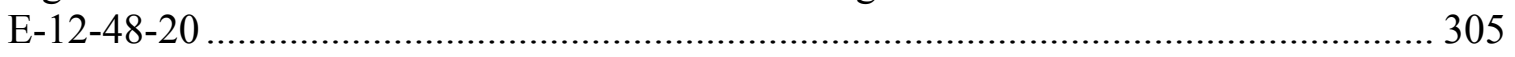

Figure A8.34: Fluctuation of Flow at D1 for Case E-12-48-30 .................................. 306

Figure A8.35: Fluctuation of Flow at D2 for Case E-12-48-30 .................................. 306

Figure A8.36: Fluctuation of Flow at D3 for Case E-12-48-30 .................................... 307

Figure A8.37: Fluctuation of Flow at D4 for Case E-12-48-30 .................................. 307

Figure A8.38: Fluctuation of Flow at D5 for Case E-12-48-30 .................................. 308

Figure A8.39: Fluctuation of Flow at D6 for Case E-12-48-30 ................................... 308

Figure A8.40: Fluctuation of Flow at D7 for Case E-12-48-30 .................................. 309

Figure A8.41: Cumulative Percent Removed Along the Drain for Case E-12-48-30 .... 309

Figure A8.42: Variation of Piezometric Head Along the Center Line for case

E-12-48-30 ................................................................................................... 310

Figure A8.43: Variation of Piezometric Head Along Cross-Section A for case

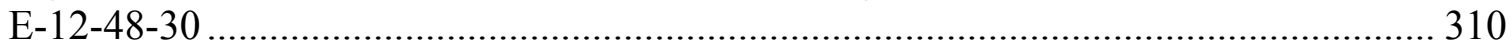

Figure A8.44: Variation of Piezometric Head Along Cross-Section B for case

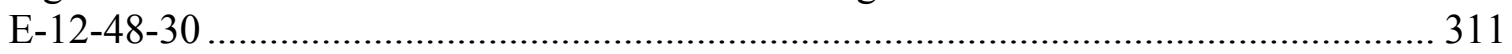

Figure A9.1: Grain Size Distribution curves for All Soil Types ............................... 313

Figure A9.2: Grain Size Distribution curve for Soil Type A.................................. 315

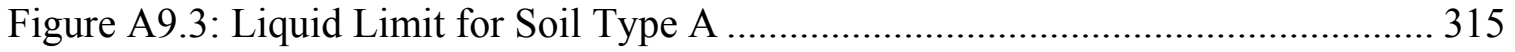

Figure A9.4: Grain Size Distribution curve for Soil Type B .................................... 316 


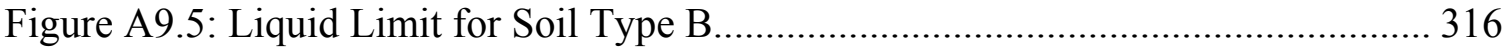

Figure A9.6: Grain Size Distribution curve for Soil Type C ..................................... 317

Figure A9.7: Liquid Limit for Soil Type C................................................................... 317

Figure A9.8: Grain Size Distribution curve for Soil Type D...................................... 318

Figure A9.9: Liquid Limit for Soil Type D ............................................................. 318

Figure A9.10: Grain Size Distribution curve for Soil Type E .................................... 319

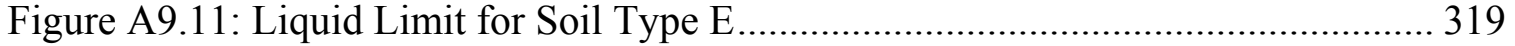

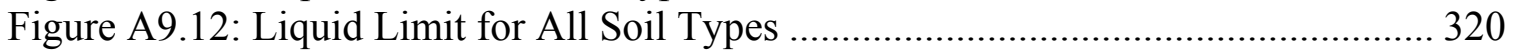




\section{LIST OF TABLES}

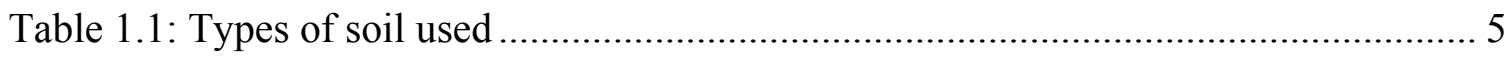

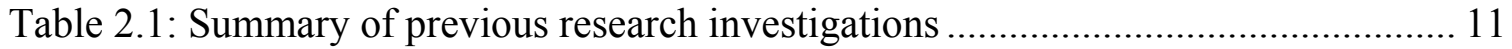

Table 2.2: Typical values for hydraulic conductivities (Das, 1993) .............................. 13

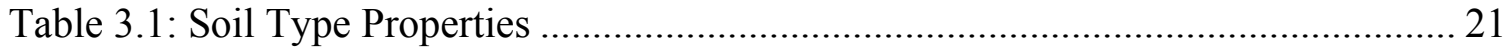

Table 3.2: Hydraulic Conductivities used in different Computer Models ......................... 38

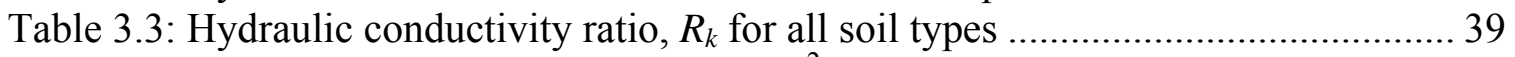

Table 3.4: Modification Factor Equations and $\mathrm{R}^{2}$ values $(\mathrm{X}=$ Clay content $)$.................. 43

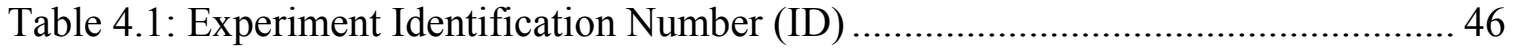

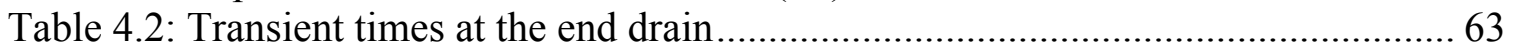

Table 4.3: Transient time along the center line.............................................................. 70

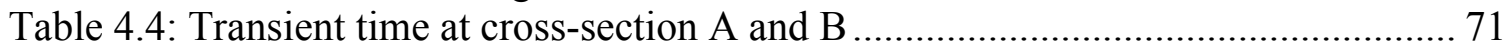

Table 4.5: Observed time for flow to reach Steady State conditions at each drain .......... 83

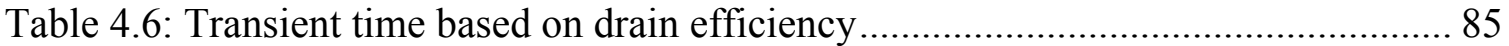

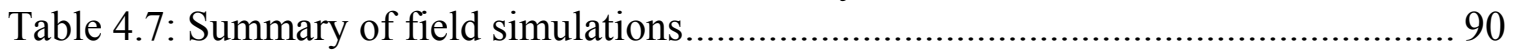

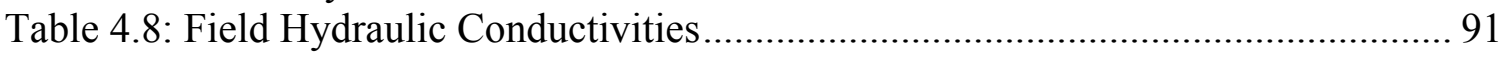

Table A9.1: Atterberg Limits for soils used in the study .......................................... 314 


\section{CHAPTER 1: INTRODUCTION}

\subsection{Background}

The stability of hilly ground terrain and the potential for failure, or landslide, is a concern where movements of existing or planned slopes would have an effect on the safety of people and property or the usability and value of the area (McCarthy 2002). Seepage of water through slopes has a significant influence on slope failures. As such, removal or reduction of seepage from earth slopes will improve the stability of slopes. Usually, the seepage is removed by using different types of drains.

Longitudinal drains are drains placed parallel to the slope itself, as shown in Figure 1.1 and Figure 1.2. The name originated because the drain is located along the longitudinal length of the slope. The space between drains is called trench width. Because of symmetry, only half the trench needs to be investigated in experimental or computer modeling studies.

In a previous study (Kiriakidis, 2002), the performance of longitudinal drains for different soil types under different conditions, such as slope inclination, water level and trench width was investigated under steady state conditions. In this study, the effectiveness of longitudinal drain placed along the slope was investigated under steady state and transient conditions for a number of soil types. Data was collected to study the

transient behavior of longitudinal drains for different soil types under laboratory conditions. In addition to laboratory experiments, a transient analysis was conducted using a computer modeling technique. The experimental results were compared with 


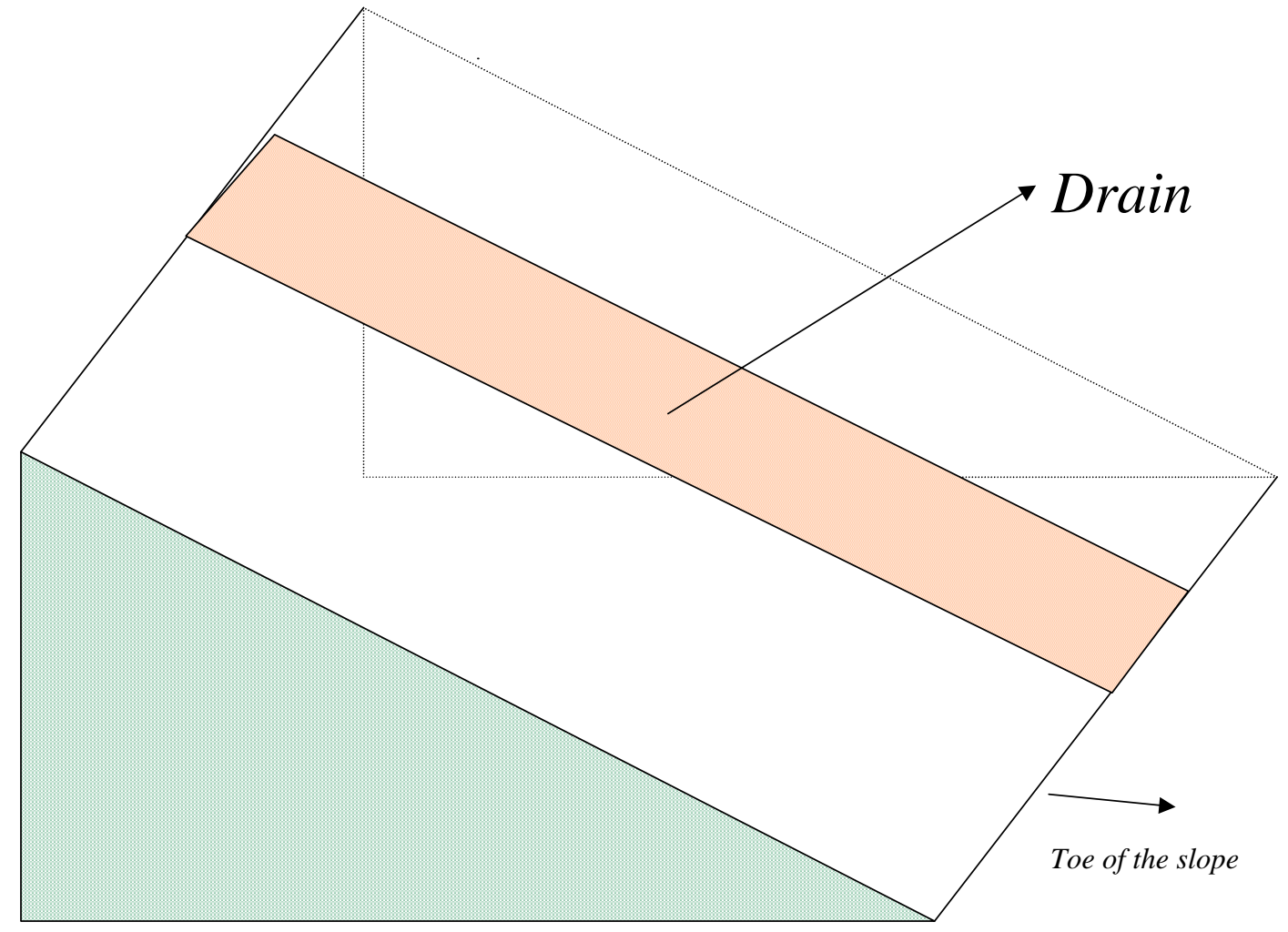

Figure 1.1: Schematic Figure of a Longitudinal Slope Drain 


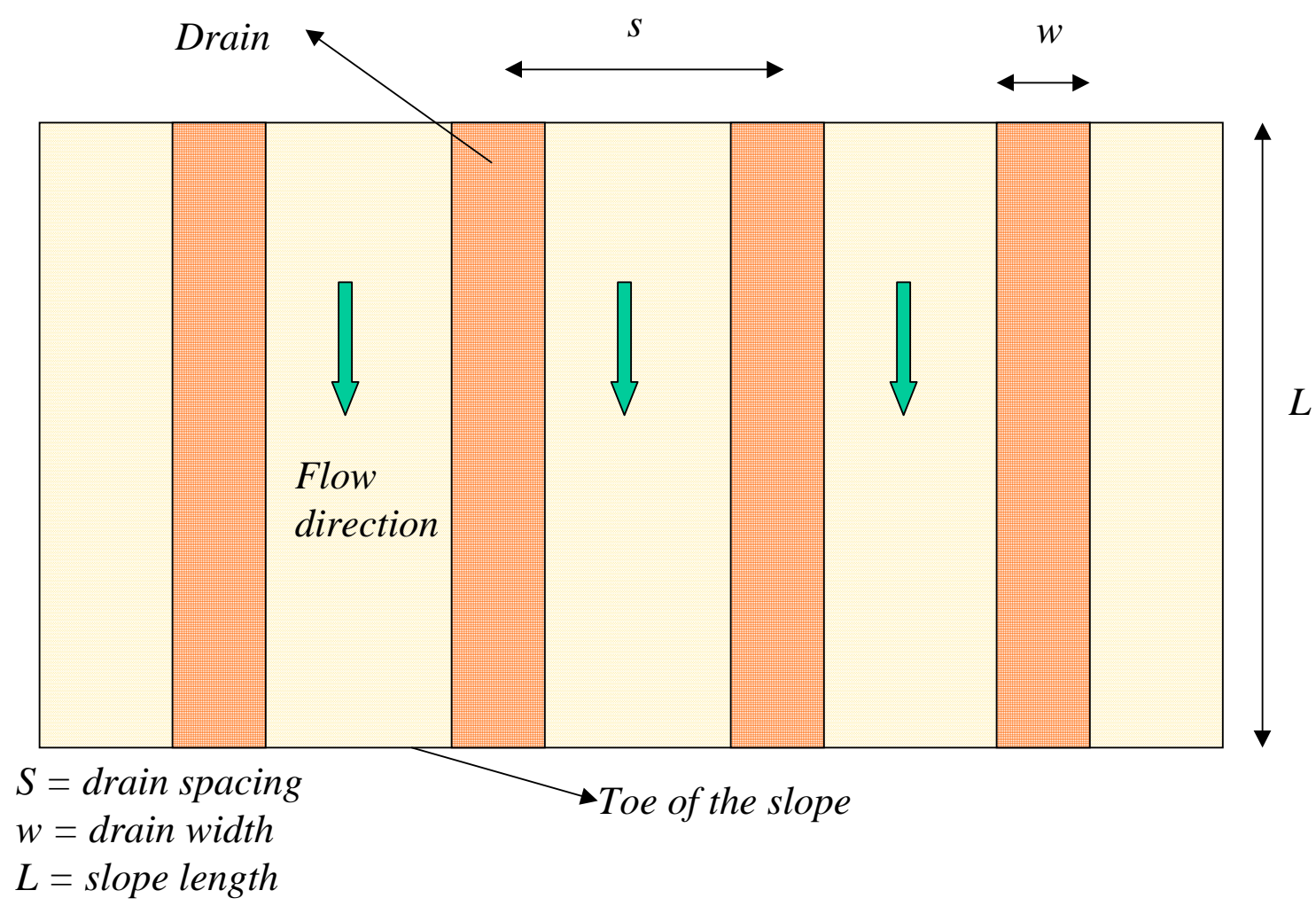

Figure 1.2: Schematic Diagram of Longitudinal Drains on a Slope 
results from computer models. The boundary conditions were imposed to simulate laboratory tests in the computer model. Results from the laboratory and computer modeling studies show that the longitudinal drains proved to be an excellent method for reducing the amount of water within the soil. Although the study was successful, it was limited by the size of the soil type used. The drains did prove to be very effective under laboratory conditions.

\subsection{Objectives}

The primary objective of this research was to compare the experimental results with the computer modeling results for the performance of longitudinal drains. Both experimental and computer models have the same boundary conditions. The computer model was calibrated by comparing the experimental data with numerical results. Certain material properties of the soil can be back-calculated from this comparison.

The second objective of this study was to use computer modeling technique to predict the performance of longitudinal drains under field conditions.

\subsection{Scope}

The scope of this work was limited to five soil types. Their properties are presented below in Table 1.1. Details of the study are presented in the following chapters of this report. 
Table 1.1: Types of soil used

\begin{tabular}{|c|c|c|c|}
\hline Soil Type & Mix & $\begin{array}{c}\text { Hydraulic Conductivity } \\
\mathrm{k}(\mathrm{cm} / \mathrm{s})\end{array}$ & $\begin{array}{c}\text { Hydraulic Conductivity } \\
\mathrm{k}(\mathrm{in} / \mathrm{min})\end{array}$ \\
\hline A & $95 \%$ Sand and 05\% Clay & $2.00 \mathrm{E}-02$ & $4.72 \mathrm{E}-01$ \\
\hline B & $85 \%$ Sand and 15\% Clay & $1.43 \mathrm{E}-03$ & $3.38 \mathrm{E}-02$ \\
\hline C & $75 \%$ Sand and 25\% Clay & $2.83 \mathrm{E}-04$ & $6.69 \mathrm{E}-03$ \\
\hline D & $70 \%$ Sand and 30\% Clay & $6.21 \mathrm{E}-05$ & $1.47 \mathrm{E}-03$ \\
\hline E & $65 \%$ Sand and 35\% Clay & $7.20 \mathrm{E}-06$ & $1.70 \mathrm{E}-04$ \\
\hline
\end{tabular}




\section{CHAPTER 2: LITERATURE REVIEW}

\subsection{Introduction}

To better understand the basic principles involved with longitudinal drains it is important to first understand the main factors such as soil type, hydraulic conductivity and slope angle that affect the performance of longitudinal drains. The longitudinal drains deflect the flow of water, reducing the seepage forces inside the soil. Figure 2.1 shows the influence of a longitudinal drain.
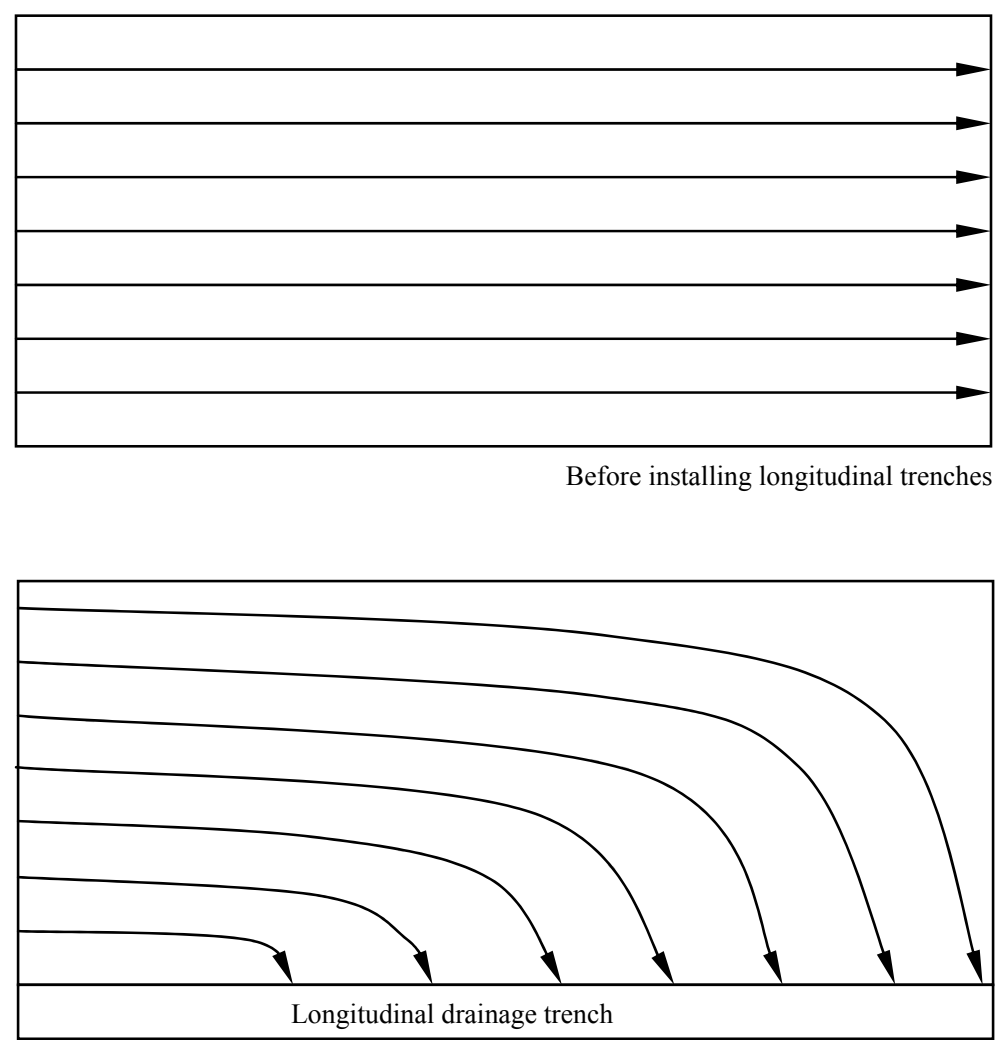

After installing longitudinal trenches

Figure 2.1: Flow pattern before and after installation of a longitudinal drain. 


\subsection{Previous Studies}

A paper that describes the influence of drainage trenches on slope stability was published in 1984 (Stanic, 1984). Subsequently, two experimental research investigations were conducted (Staud, 2000; Kiriakidis, 2002) to study seepage through longitudinal drains in earth slopes. These papers are the only ones related to the scope of this project. This dissertation is an extension of research work presented by Staud (2000), Kiriakidis (2002) and Kakarla (2004).

Stanic (1984) studied the behavior of water flow in slopes, by analyzing the piezometric level along an infinite slope, as shown in Figure 2.2. He used finite element analysis to study the effect of longitudinal drain systems on the factor of safety against sliding. Stanic (1984) made five major assumptions. First, the slope was assumed to be infinite in all directions with an inclination of $\beta$ with the horizontal. Second, the potential failure surface was assumed to be impermeable and at a constant depth below the surface. Third, the direction of seepage in the slope before the installation of drains was assumed to be parallel to the slope face and steady with respect to time. Fourth, the soil in the slope was assumed to be homogeneous and isotropic with respect to hydraulic conductivity. Fifth, the drains were assumed to be parallel to each other in the direction of maximal slope inclination and were assumed to extend to the failure surface.

The model was tested at different drain spacing (w), slope angles $(\beta)$ and soil type. To determine the piezometric surface, the data collected in the finite element analysis was normalized, by dividing the piezometric level by the water level (h) before the drain installment. The data was processed to obtain the maximum level in the slope for different angles and drain spacing. According to Stanic (1984), as the ratio of drain 
spacing to depth, w/h, becomes smaller, the average and maximum piezometric level decreases. Using the results of the finite element analysis, Stanic concluded that based on the reduction in piezometric levels an increase in the factor of safety is obtained for different combinations of normalized drain spacing and slope angles.

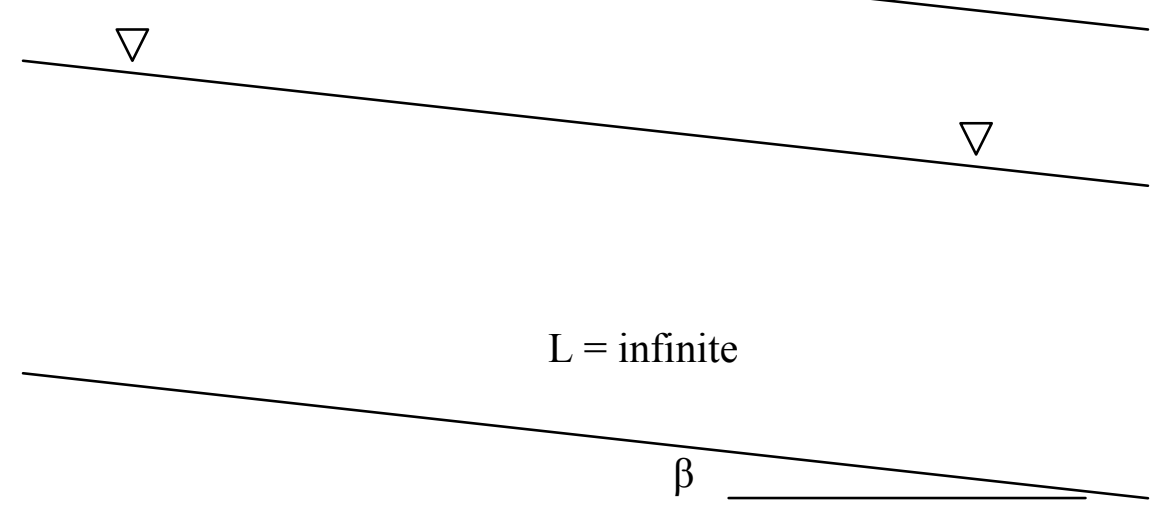

Figure 2.2: Theoretical flow through inclined infinite slopes.

The objective of Staud's study was to determine how the longitudinal drain system works under laboratory conditions in a finite slope (Figure 2.3). A model was constructed to assess the flow patterns caused by a trench drain in a slope. The experimental variables include the trench spacing $(W=2 w)$, seepage depth $(h)$, slope angle $(\theta)$ and the soil type which was controlled by the hydraulic conductivity (k). In the experimental setup, four values of slope angle were used; horizontal, 4 to $1\left(14.04^{\circ}\right), 3$ to $1\left(18.44^{\circ}\right)$ and 2 to $1\left(26.6^{\circ}\right)$. Three values of trench spacing were used; six inches, twelve inches and eighteen inches. Three values of seepage depth were considered; four inches, six inches and eight inches. One soil type was used; Soil A. The soil type for the experimental setup was selected on the basis of hydraulic conductivity $\left(\mathrm{k}=2 \times 10^{-2} \mathrm{~cm} / \mathrm{s}\right)$. 
The soil was placed in the experimental cell under dry conditions and the water was introduced at predetermined levels at the upstream end to maintain a constant head. Measurements of seepage volume were taken along the longitudinal direction of the trench after reaching steady state seepage conditions. The piezometric pressures at selected locations in the soil slope were measured.

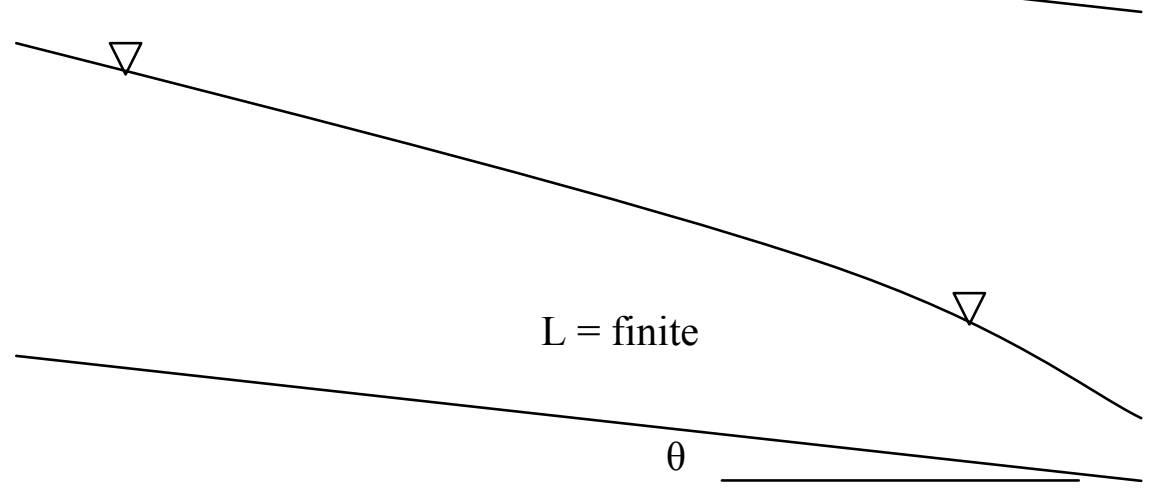

Figure 2.3: Flow through finite slope (experimental).

A continuation of Staud's work was presented by Kiriakidis in 2002 in which two extra soils (B and C) were studied. Limited experiments were conducted to study transient conditions for all three soils. The results showed that a longitudinal trench drain system with appropriate drain spacing can be used to remove a significant portion of seepage from soil slope. This report (Kiriakidis, 2002) contains laboratory data that provide quantitative information on the influence of different experimental parameters on the removal rate of seepage water.

In 2005 Kakarla used a computer modeling program to simulate the results obtained by Staud and Kiriakidis (Staud, 2000; Kiriakidis, 2002). His result proved that 
the computer modeling program was able to simulate the conditions used in laboratory setup and it was later used to extrapolate for larger sizes.

In Staud's study, seepage along the longitudinal drain was studied under the steady state conditions for soils A, B and C. The effects of width, length, angle and water level were studied. Later Kiriakidis, complemented this study by performing a study of the transient behavior of flow through the soil into the longitudinal drain. In this study the effects of width, length, angle and soil type were investigated for steady state and transient conditions. Kakarla (2005) used a computer modeling program GMS to generate three dimensional models similar to those used by Staud and Kiriakidis in their researches. In his study, Kakarla compared his results to those previously obtained in the laboratory. Kakarla used soil types A, B and C and his models were defined by fixing the water head along the drain.

In the present study the experimental data collected by Staud and Kiriakidis were complemented by introducing two new soil types (D and E). Also in this study, seepage through the end drain was studied in detail. The transient behavior of this drain was not investigated experimentally in any of the previous studies. For the modeling section in this study, several three dimensional models were defined similar to those presented by Kakarla (2005). However, in the present study the dimensions of the models and the method for simulation of drains are different than those used previously. In the present study the longitudinal drain was defined by selecting the desired cells in the model and defining them as actual drains, as opposed to Kakarla's method of fixing the fluid head at those cells. A summary of previous studies and the unique features of the present study are presented in Table 2.1. 
Table 2.1: Summary of previous research investigations

\begin{tabular}{|l|l|}
\hline Research by & Scope \\
\hline Staud (2000) & $\begin{array}{l}\text { Study of seepage through earth slopes } \\
\text { under steady state conditions for soil types } \\
\text { A, B and C. }\end{array}$ \\
\hline Kiriakidis (2002) & $\begin{array}{l}\text { Study of seepage through earth slopes } \\
\text { under Transient conditions for soil types A, } \\
\text { B and C. }\end{array}$ \\
\hline Kakarla (2005) & $\begin{array}{l}\text { Numerical model for soils A, B and C } \\
\text { Kiriakidis (2006) }\end{array}$ \\
$\begin{array}{l}\text { under steady state and transient conditions } \\
\text { for both longitudinal drains and end drain } \\
\text { for soil types A, B, C, D and E. Numerical } \\
\text { models for soils A, B, C, D and E }\end{array}$ \\
\hline
\end{tabular}

As seen latter in this report, different ways of defining the drains were studied. Results from these studies show that fixing the heads along the drains was not as effective as having the cell defined as drains. Later in this report, the different ways in which drain cells can be defined are shown for both before and after calibrating the model's hydraulic conductivity.

Also in this study a comprehensive method for calculating and selecting the hydraulic conductivity was developed (see section 3.3.2 on the calibration). In previous study by Kakarla (2005), hydraulic conductivity was randomly selected to match 
laboratory measurements. The method developed in the present study was utilized to convert the experimental value of hydraulic conductivity to the value to be used in the modeling software. By using the experimental value of hydraulic conductivity in the conversion equation, it is possible to obtain the corresponding value to be used in the computer program.

\subsection{Soil Type}

The soil type is a very important factor affecting both the drainage behavior and the slope itself. The geotechnical properties of a soil, such as grain size distribution, Atterberg Limits, soil composition and hydraulic conductivity are important parameters of this work. Detailed information on soil classification methods can be found in the textbook (Das, 1993). The hydraulic conductivity of sandy soils is relatively high and therefore water can be drained rapidly. Silty and clayey soils have very low hydraulic conductivity and as such it is more difficult to drain water. Drainage trenches are usually made up of gravel in view of their high hydraulic conductivity.

\section{$2.4 \quad$ Hydraulic Conductivity}

Soil being a particulate material, has many pore and voids between solid grains because of the irregular shape of the individual particles (McCarthy, 2002). The void spaces or pores between soil grains allow water to flow through. The amount of flow rate

depends on the soil type and its hydraulic conductivity. The hydraulic conductivity of soils depends on several factors: fluid viscosity, grain size distribution, void ratio, 
roughness of mineral particles, and degree of soil saturation. The value of hydraulic conductivity (k) varies widely for different soils. Some typical values for saturated soils are show in Table 2.1 (Das, 1993).

Table 2.2: Typical values for hydraulic conductivities (Das, 1993)

\begin{tabular}{|l|c|c|}
\hline \multicolumn{1}{|c|}{ Soil Type } & k (cm/sec) & k (ft/min) \\
\hline Clean gravel & $100-1.0$ & $200-2.00$ \\
\hline Coarse sand & $1.0-0.01$ & $2.0-0.02$ \\
\hline Fine sand & $0.01-0.001$ & $0.02-0.002$ \\
\hline Silty clay & $0.001-0.00001$ & $0.002-0.00002$ \\
\hline Clay & $<0.000001$ & $<0.000002$ \\
\hline
\end{tabular}

There are two standard laboratory tests, constant head test and falling head test, to determine hydraulic conductivity of a soil in the laboratory. In this research, hydraulic conductivity of soils was determined by using a constant head test in accordance to ASTM standard, designation D 2434-68. A schematic diagram of a constant head hydraulic conductivity apparatus is shown in Figure 2.4. Several units of such an apparatus was built and used in this research project. 


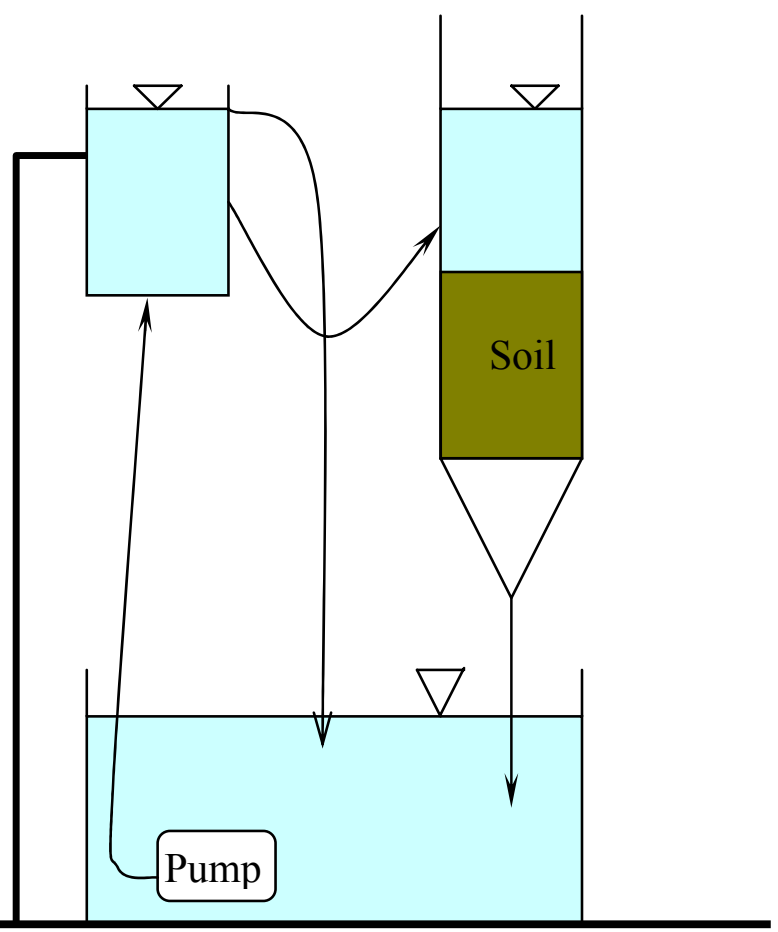

Figure 2.4: Constant Head Hydraulic Conductivity Apparatus.

The primary law governing flow through porous media is the Darcy's law (Cedergren, 1977). The flow volume can be expressed as:

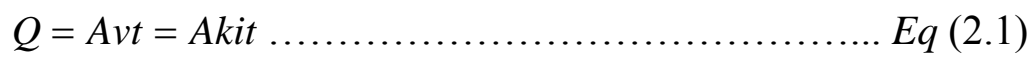

Where,

$$
i=\frac{h}{L}
$$

The hydraulic conductivity, $\mathrm{k}$, can be expressed as:

$$
k=\frac{Q L}{A h t}
$$

Where:

$$
\mathrm{Q}=\quad \text { Volume of water collected }\left(\mathrm{cm}^{3}\right) \text {. }
$$




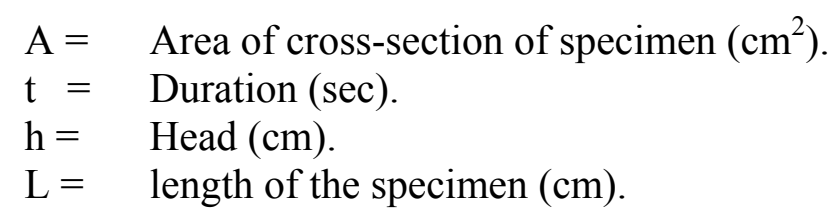

\subsection{Computer Modeling}

The advancements in computer modeling techniques have extended the boundaries of engineering studies. Calculation that used to take days may now take a few seconds. In the case of this investigation, experiments that normally take one to three weeks may be modeled in a matter of hours. Computer models work under ideal conditions, which not always apply to physical models. The computer models have to be calibrated by using the physical model.

The computer program used for the modeling part of this research is called GMS which stands for Groundwater Modeling System (GMS, 2002). GMS is a sophisticated and comprehensive groundwater modeling software package. Used by many researchers in government agencies, private firms, and in many countries, it has been proven to be a powerful groundwater modeling system (GMS, 2002). GMS provides tools for every phase of a groundwater simulation including site characterization, model development, calibration, post-processing, and visualization. GMS supports both two dimensional (2D) and three-dimensional (3D) finite-difference based models.

GMS has powerful graphical tools for visualization of results. Models can be built using digital maps and elevation models for reference and source data. A groundwater model can be displayed in plan view or 3D view. Cross-sections may be cut arbitrarily anywhere in the model. 


\subsubsection{Governing Equation}

The mechanics of flow through a three dimensional cubic block is shown in

Figure 2.3 below. If we define the dimensions of the cube sides as $\Delta x, \Delta y$, and $\Delta z$ then the total volume of the cube would be $\Delta V=\Delta x \cdot \Delta y \cdot \Delta z$.

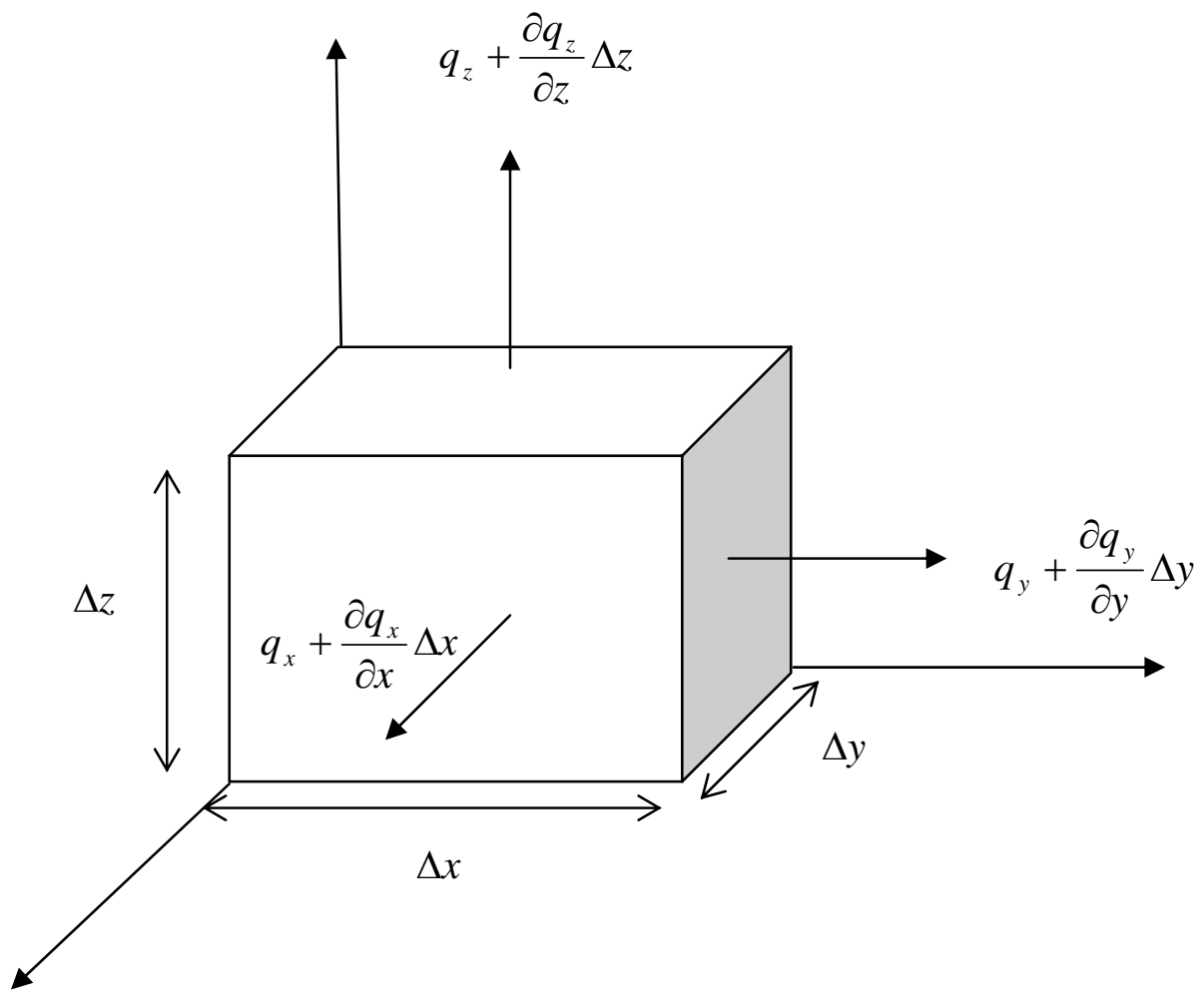

Figure 2.3: Schematic Diagram of flow through a Three-dimensional Block. 
The flow rate in each direction can be defined as:

$$
\begin{aligned}
& q_{x}+\frac{\partial q_{x}}{\partial x} \Delta x \text { in the } \mathrm{x} \text {-axis } \\
& q_{y}+\frac{\partial q_{y}}{\partial y} \Delta y \text { in the } \mathrm{x} \text {-axis } \\
& q_{z}+\frac{\partial q_{z}}{\partial z} \Delta z \text { in the z-axis }
\end{aligned}
$$

Where:

$q$ is the inflow

$$
\frac{\partial q_{x}}{\partial x}=\text { Change in flow within the object in x-axis. }
$$

The discharge is the flow rate times the cross-sectional area through which the flow occurs. The change in discharge in every direction can be found as (Freeze and Cherry, 1979):

$$
\begin{aligned}
& \frac{\partial q_{x}}{\partial x} \Delta x \cdot(\Delta y \cdot \Delta z) \text { in the } x \text {-axis; This quantity is equal to: } \\
& \frac{\partial q_{x}}{\partial x} \Delta V \text { in the x-direction. }
\end{aligned}
$$

Similarly, the change in discharge in $\mathrm{y}$ - and z-directions can be expressed as:

$$
\begin{aligned}
& \frac{\partial q_{y}}{\partial y} \Delta V \text { in the y-axis, and } \\
& \frac{\partial q_{z}}{\partial z} \Delta V \text { in the z-axis. }
\end{aligned}
$$


The Continuity equation for flow can be written as:

$$
Q_{\text {in }}-Q_{\text {out }} \pm(\text { generation_or_Decay })=0
$$

If we assume that there in no generation or decay in our volume, and that the water is incompressible, then the equation becomes:

$$
Q_{\text {in }}=Q_{\text {out }}
$$

Hence, the continuity equation can be written as:

$$
\left(\frac{\partial q_{x}}{\partial x}\right) \Delta V+\left(\frac{\partial q_{y}}{\partial y}\right) \Delta V+\left(\frac{\partial q_{z}}{\partial z}\right) \Delta V=0 \ldots \ldots \ldots \ldots \ldots \ldots \ldots \ldots q(2.6)
$$

Dividing the equation by $\Delta V$,

$$
\left(\frac{\partial q_{x}}{\partial x}\right)+\left(\frac{\partial q_{y}}{\partial y}\right)+\left(\frac{\partial q_{z}}{\partial z}\right)=0
$$

The above equation is called the continuity equation for the steady state flow.

Following Darcy's law,

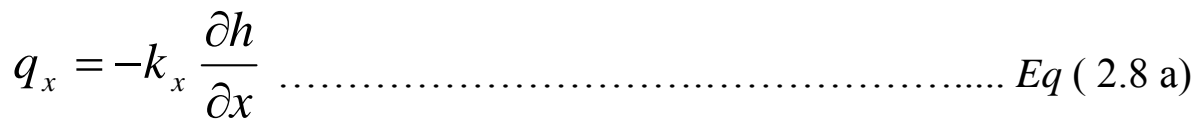

$$
\begin{aligned}
& q_{y}=-k_{y} \frac{\partial h}{\partial y} \\
& \text { and } \quad q_{z}=-k_{z} \frac{\partial h}{\partial z}
\end{aligned}
$$

By substituting the Darcy's law into the continuity equation, the following equation can be obtained: 


$$
\frac{\partial}{\partial x}\left(k_{x x} \frac{\partial h}{\partial x}\right)+\frac{\partial}{\partial y}\left(k_{y y} \frac{\partial h}{\partial y}\right)+\frac{\partial}{\partial z}\left(k_{z z} \frac{\partial h}{\partial z}\right)=0
$$

Considering the presence of any sources or sinks, and assuming $\mathrm{W}$ to be volumetric flux per unit volume the above equation can be written as (Freeze and Cherry, 1979):

$$
\frac{\partial}{\partial x}\left(k_{x x} \frac{\partial h}{\partial x}\right)+\frac{\partial}{\partial y}\left(k_{y y} \frac{\partial h}{\partial y}\right)+\frac{\partial}{\partial z}\left(k_{z z} \frac{\partial h}{\partial z}\right)-W=0
$$

If $\mathrm{S}_{\mathrm{s}}$ is the specific storage of the medium, the elemental volume retains a portion of flow in itself which is equal to $S_{s} \frac{\partial h}{\partial t}$. The above equation thus becomes,

$$
\frac{\partial}{\partial x}\left(k_{x x} \frac{\partial h}{\partial x}\right)+\frac{\partial}{\partial y}\left(k_{y y} \frac{\partial h}{\partial y}\right)+\frac{\partial}{\partial z}\left(k_{z z} \frac{\partial h}{\partial z}\right)-W=S_{s} \frac{\partial h}{\partial t}
$$

This is the equation that is solved in the computer model over a given region with boundary and initial conditions. The details of the solution procedures can be found elsewhere (GMS, 2002). 


\section{CHAPTER 3: EXPERIMENTAL SETUP AND TESTING PROCEDURE}

\subsection{Introduction}

Previous studies (Staud, 2000; Kiriakidis, 2002) have shown that the trench spacing (width), inclination, water level and soil type have a significant influence on the seepage in earth slopes with drainage trenches. One unresolved issue was the influence of the method of sample saturation on the experimental results. Usual saturation method used in all of the previous studies was to saturate the soil sample using longitudinal flow (seepage) through the soil samples. In a number of cases in previous studies, it was observed that some surface cracks appeared during the saturation of low permeability soils. It was unknown whether these cracks were the result of the saturation method. In order to resolve this issue, an experimental study was conducted with its focus on horizontal cases with a water level of eight inches and a width of twelve inches. In these tests, samples were saturated by allowing seepage to occur in the transverse direction. A series of samples were saturated using a side water tank, which was constructed out of plexi-glass material.

Based on the results, it was evident that the transverse saturation method was not satisfactory. Therefore, a different saturation approach was investigated. In the new approach, soil was saturated by using the main tank for longitudinal seepage, but the side drains were kept closed. This method allowed us to visually see the water level on both sides of the sample. It also allowed us to study the transient behavior of the end drain under longitudinal seepage. 


\subsection{Experimental Apparatus and Soil Setup}

A schematic diagram of the traditional experimental apparatus is shown in Figure 3.1. The apparatus was modified and a side tank was constructed to study influence of transverse (side) saturation.

\subsubsection{Soil Type}

Because the hydraulic conductivity of natural slopes can vary over a wide range of values, this study was conducted to investigate the behavior of soils with different hydraulic conductivities. As mentioned before, the scope of this research was limited to five soil types A, B, C, D and E (see Table 3.1).

Table 3.1: Soil Type Properties

\begin{tabular}{|c|c|c|}
\hline Soil Type & $\begin{array}{c}\text { Hydraulic Conductivity } \\
\mathrm{k}(\mathrm{cm} / \mathrm{s})\end{array}$ & $\begin{array}{c}\text { Hydraulic Conductivity } \\
\mathrm{k}(\mathrm{in} / \mathrm{min})\end{array}$ \\
\hline A & $2.00 \mathrm{E}-02$ & $4.72 \mathrm{E}-01$ \\
\hline B & $1.43 \mathrm{E}-03$ & $3.38 \mathrm{E}-02$ \\
\hline C & $2.83 \mathrm{E}-04$ & $6.69 \mathrm{E}-03$ \\
\hline D & $6.21 \mathrm{E}-05$ & $1.47 \mathrm{E}-03$ \\
\hline E & $7.20 \mathrm{E}-06$ & $1.70 \mathrm{E}-04$ \\
\hline
\end{tabular}

Based on the results, a relationship was found between the clay content and the hydraulic conductivity of the soil. Once a trend line was found, it was utilized to predict the hydraulic conductivity of soil D. The prediction compared well with the measurements for soil D. This relationship can be utilized to interpolate the permeability for different soil types. Details of the relationship between the clay content and permeability are given below. 


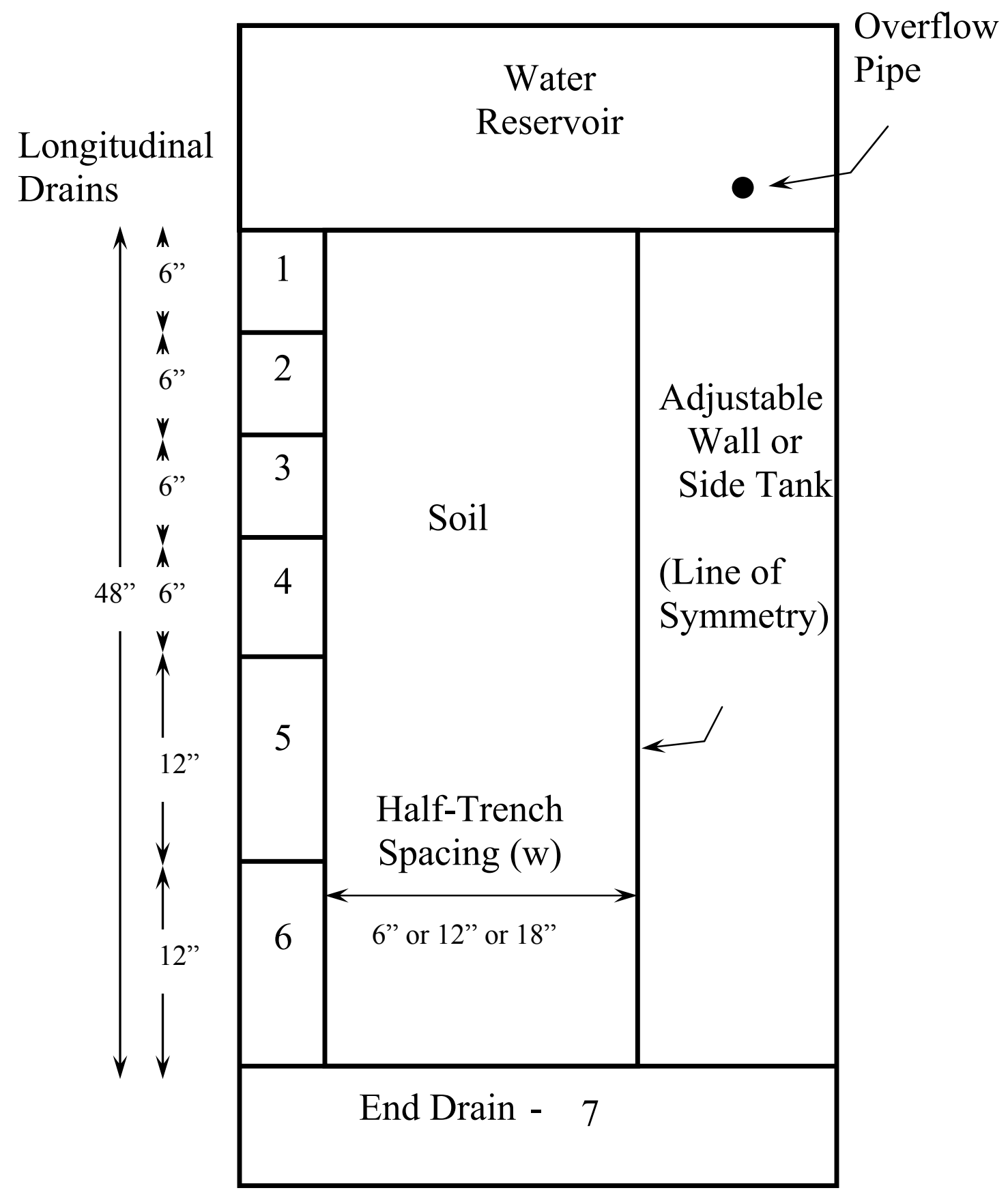

Figure 3.1: Plan View of the Apparatus. 
Different soil mixes were prepared with variable clay content $(5 \%, 10 \%, 15 \%$, $20 \%, 25 \%, 30 \%$ and $35 \%$ clay content) by mixing dry sand and kaolin clay. Figure 3.2 shows the relationship between hydraulic conductivity and clay content. This figure shows an exponential relationship between the clay content and permeability. The trend line on log-normal scale is linear with an $\mathrm{R}^{2}$ value of 0.977 . The equation for this trend line can be used to determine the permeability for different soils with known clay contents in the laboratory. The grain size distributions and index properties of the soils used in this study are given in Appendix A9.

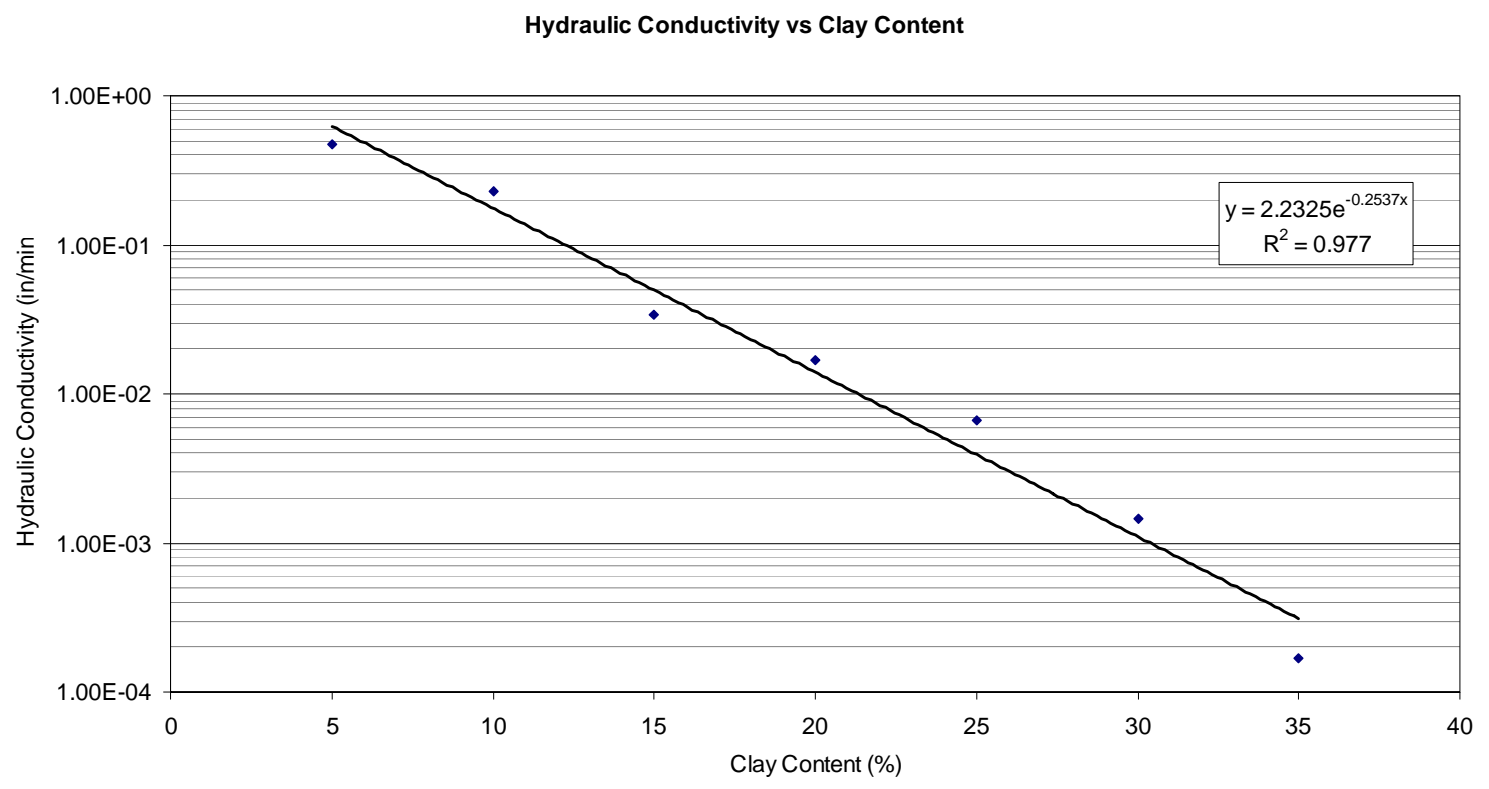

Figure 3.2: Experimental Change in Hydraulic Conductivity with Clay Content 
The following equation represents the relationship between clay content and the hydraulic conductivity

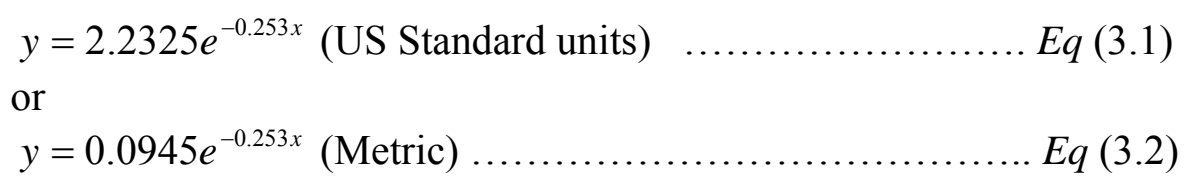

Where,

$\mathrm{y}=$ Hydraulic Conductivity (in/min for US standard units or $\mathrm{cm} / \mathrm{s}$ for metric).

$\mathrm{x}=$ Clay (Kaolinite) content as a percentage $(\%)$.

\subsubsection{Piezometric Head}

Piezometric head is the pressure of a liquid at any point. In this research, the liquid used was water. The water flows freely through the soil in the model without any external pressure. Because no pressures were introduced in the system the water level at a particular point can be determined by a simply reading the piezometric head.

The experimental setup contains a series of piezometric terminals arranged in such a way that allows the measurement of a water profile in the longitudinal direction along the centerline. Figure 3.3 shows the locations of piezometers for each of the selected widths. The apparatus has different sets of piezometric terminals that allow the piezometric tubes to be connected according to the selected width. Because of the symmetry assumption made earlier in this chapter, the centerline coincides with the position of the adjustable wall. In this set of experiments, the width of the apparatus was maintained at 12 inches. 


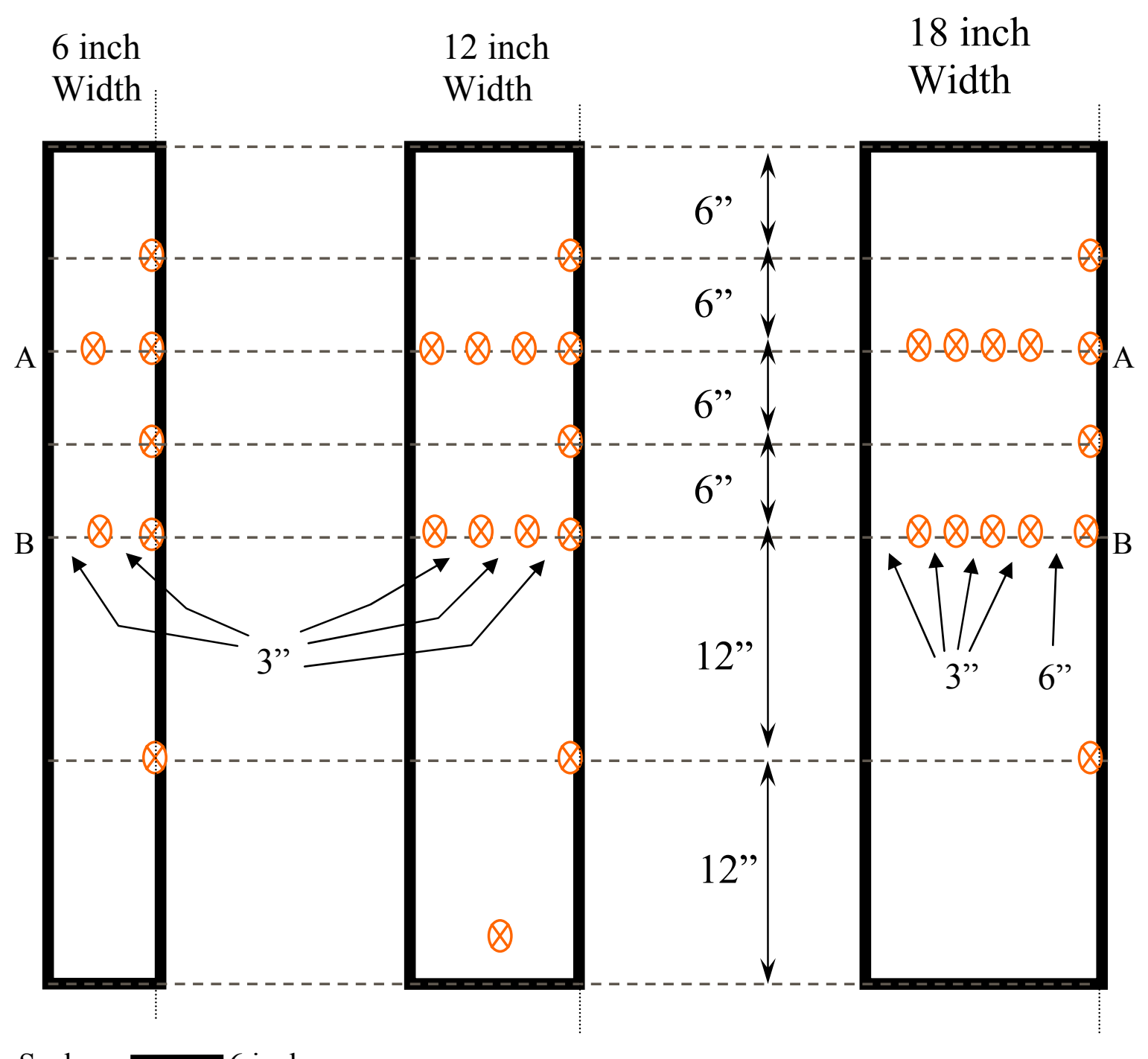

Scale $=6$ inches

Note: Section $\mathrm{X}$ is located at 12 inches from the top Section Y is located at 24 inches from the top

Figure 3.3: Piezometric Terminals Locations 


\subsubsection{Longitudinal Drain}

The longitudinal drain runs along one of the long edges of the soil zone as shown in Figure 3.1. It is divided into six independent sections, using $1 / 4$ inch $(0.64 \mathrm{~cm})$ thick plexi-glass walls (Figure 3.1). Each of the first four sections is 6 inches $(15 \mathrm{~cm})$ long, and the remaining two are 12 inches $(30 \mathrm{~cm})$ long. The reason for having independent sections of the drains is to determine the effectivenes of the drain with respect to the length of the soil zone.

To prevent any soil from entering the drain, a geotextile fabric was placed between the soil and the drain wall. Instead of using one continuous section, the fabric used was divided to each drain size, because the geotextile has in-plane conductivity. A gap of approximately $1 / 4$ inch $(0.64 \mathrm{~cm})$ was left between the sections and then sealed using silicone glue to prevent water from one section entering another. The drains were labeled one through seven (Figure 3.1) starting from the one closest to the main reservoir. Each drain has a $\frac{5}{8}$ inch $(1.59 \mathrm{~cm})$ flexible tubing that connects the drain to a PCV pipe, which feeds the secondary reservoir.

\subsubsection{End Drain}

A perforated wall of plexi-glass similar to the one in the face of the main water tank (reservoir) formed the end drain of the soil zone. Just like the longitudinal drains, the perforated wall of the end drain was covered with a section of the same fabric. The width of the fabric used was equal to the width of the soil zone. 


\subsubsection{Additional Side Tank}

In order to evaluate the influence of transverse saturation method on the results, a side tank big enough to fit within the apparatus was constructed to replace the removable wall. A schematic of the tank is shown in Figure 3.4. This additional side tank was also constructed from transparent plexi-glass. This tank was constructed so that the soil specimen can be saturated in the transverse direction.

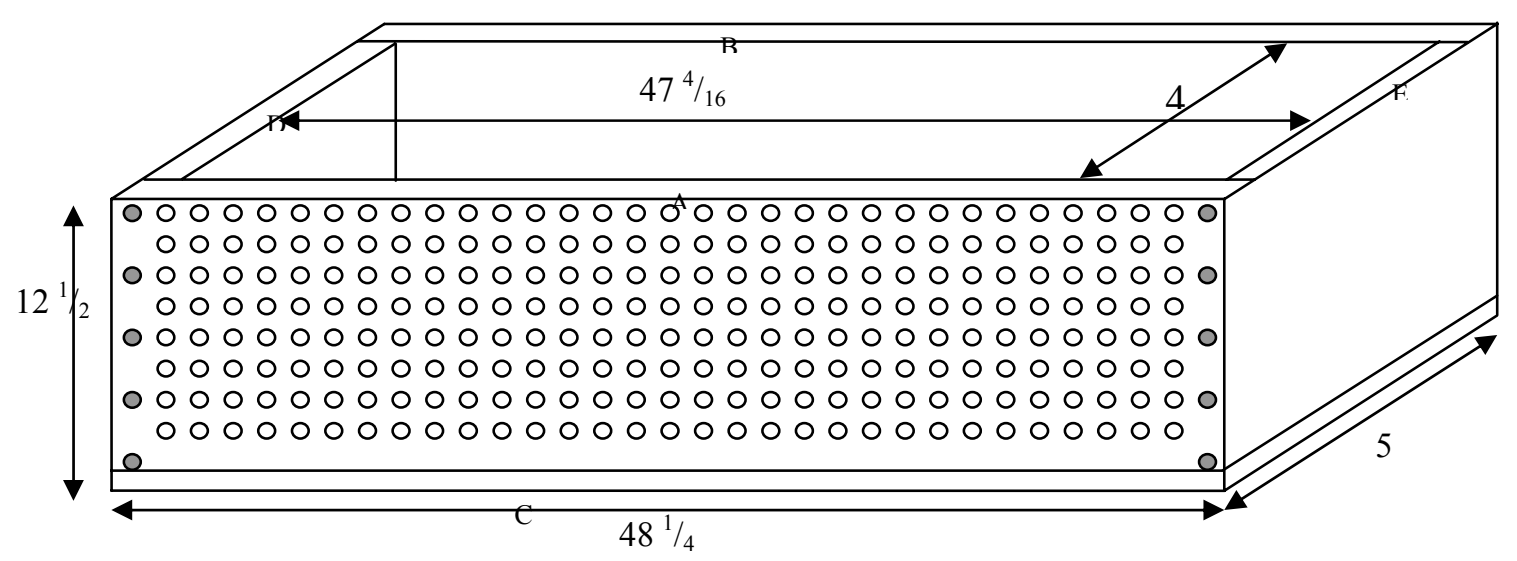

Figure 3.4: Additional side water tank

\subsection{Computer Modeling}

In this study, each laboratory experiment was simulated by using a computer model. Computer modeling not only allows the engineer to save time but it gives the ability to modify parameters which are difficult under laboratory conditions. The computer model used in this study is based on MODFLOW computer code (McDonald and Harbaugh, 1988) that was implemented in the GMS software package (GMS, 2002). MODFLOW simulates the groundwater flow within an aquifer by using the block- 
centered finite difference method (McDonald and Harbaugh, 1988). Finite difference method is a numerical method for solving partial differential equations.

Computer models were created to simulate the tests that were already performed. The computer models were created with the same dimensions as that of the physical model in order to obtain comparable results. Because of symmetry only half the total trench spacing was considered.

A 3D grid was created to simulate the experimental set-up. This grid was two units longer than the physical apparatus in the longitudinal dimension (for all set-ups it was set to 50 inches) and one unit larger in the transverse direction (i.e. seven cells for six inches wide set-ups, thirteen cells for twelve inches wide set-ups, and nineteen cells for eighteen inches wide set-ups). The height of the computer model was set to be two units larger than the experimental set-up and was divided in layers of two units (i.e. an experimental set-up with a water head of four inches was modeled with a height of six and three layers, an experimental set-up with a water head of six inches was modeled with a height of eight and four layers, and an experimental set-up with a water head of eight inches was modeled with a height of ten and five layers). The extra sets of cells in the transverse direction were defined as drains, thus, leaving the number of normal cells in the transverse direction (the width) equal to the experimental width. The two extra sets of cells in the longitudinal direction were defined as follows: one set was defined as the main water tank where a head equivalent to the head of the experiment was set to that entire group; the group of cells at the opposite end were defined as drain cells (representing the end drain), which left only forty eight cells in the longitudinal direction, making the length of the 3D grid same as the length of soil sample in the experimental 
set-up. Figure 3.5 shows a representation of an experimental set-up (six inches wide and with a water head of six inches) using GMS. This figure shows the cells defined as drains and the cells defined as main water tank.

The model generated using GMS can be used to used to obtain results for both steady state and transient state conditions. This program allows the user to specify how to run the simulation. GMS allows viewing the change in head with time. GMS can also visually show the transient behavior with its powerful animation tools.
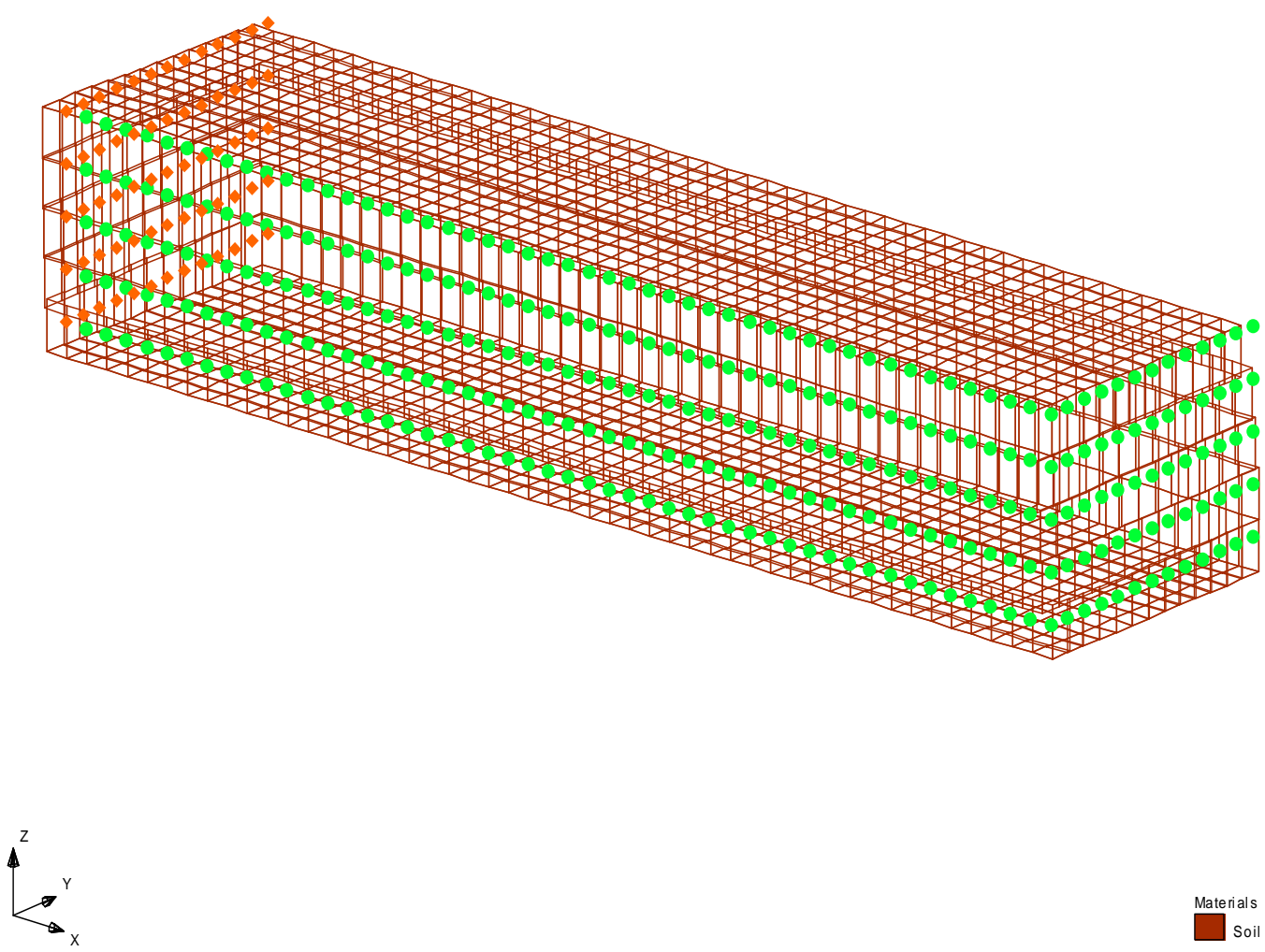

Figure 3.5: 3D grid obtained using GMS 


\subsubsection{Calibration of the computer model}

It was previously mentioned that a group of extra cells in the transverse direction were defined as drains. Because GMS allows the user to define each cell, it is possible to study the influence of drain geometry on the results. Three cases of drains were studied for all soils. In the first case, only the bottom cells were set as drains. In the second case, cells that coincide with the middle of the experimental drains were set as drains in the model. In the third case, all of the cells on the drain face were set as drains. Figure 3.6 and Figure 3.7 show all three types of setups.
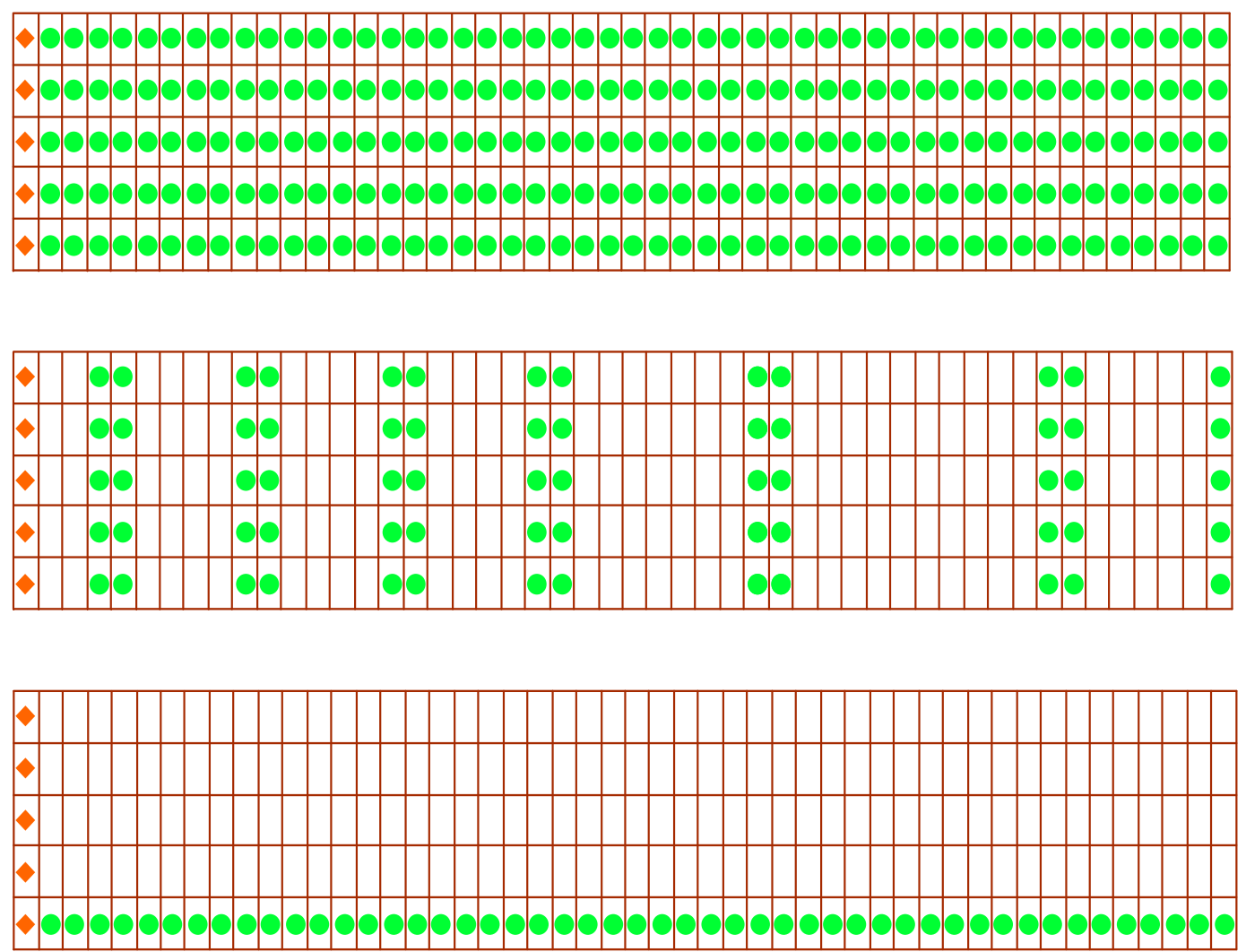

Figure 3.6: Cells defined as drains (Bottom, Centered and All) 

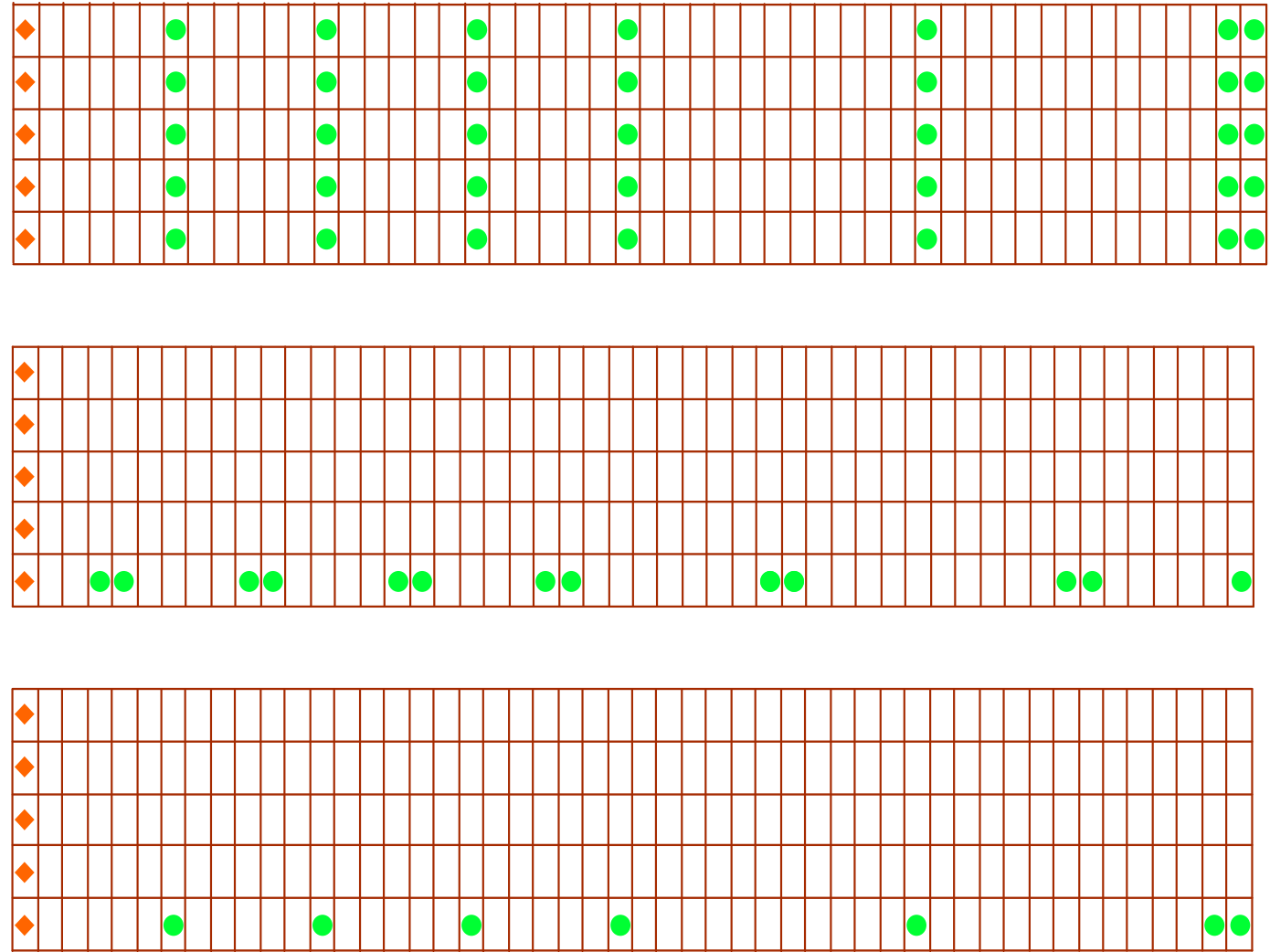

Figure 3.7: Cells defined as drains (End, Mid-Bottom and Bottom-end)

Results from each of these computer models were compared to its experimental counterpart. The models were compared using the cumulative percent removed and seepage removed at each drain. This comparison was performed for all soil types. Figures 3.8 thought 3.12 show the cumulative percent removed and the volumes collected in each drain for soil type B. 


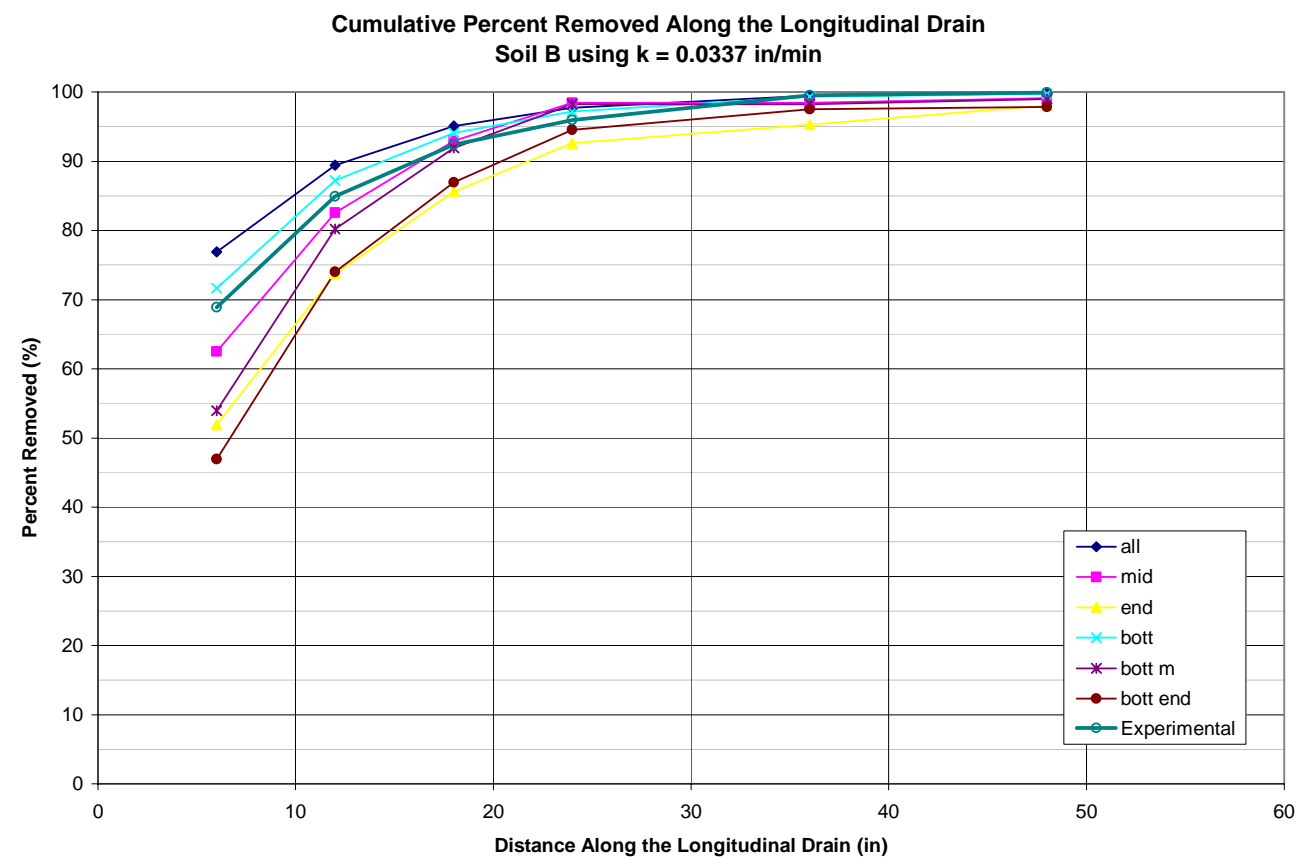

Figure 3.8: Cumulative percent removed along the drain for all drain set-ups (Soil B)

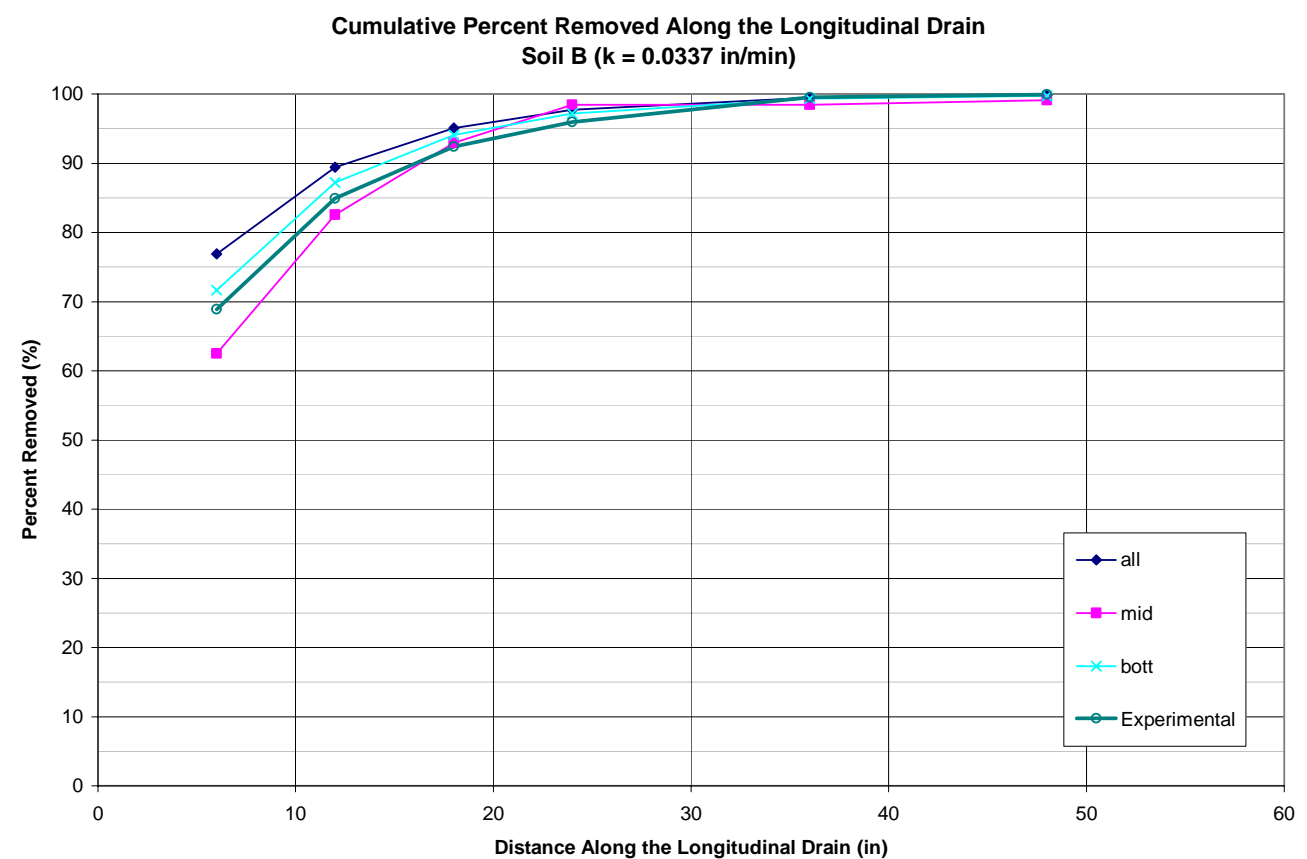

Figure 3.9: Cumulative percent removed along the drain for the three main drain setups (Soil B) 
The above figure shows a similar pattern for all types of drain set-up, and the percentages are very close to one another. It can be seen that defining all cells as drains and defining the bottom cells as drains are the two best options for soil B. The computed seepage volumes were also compared with measured data at each drain.

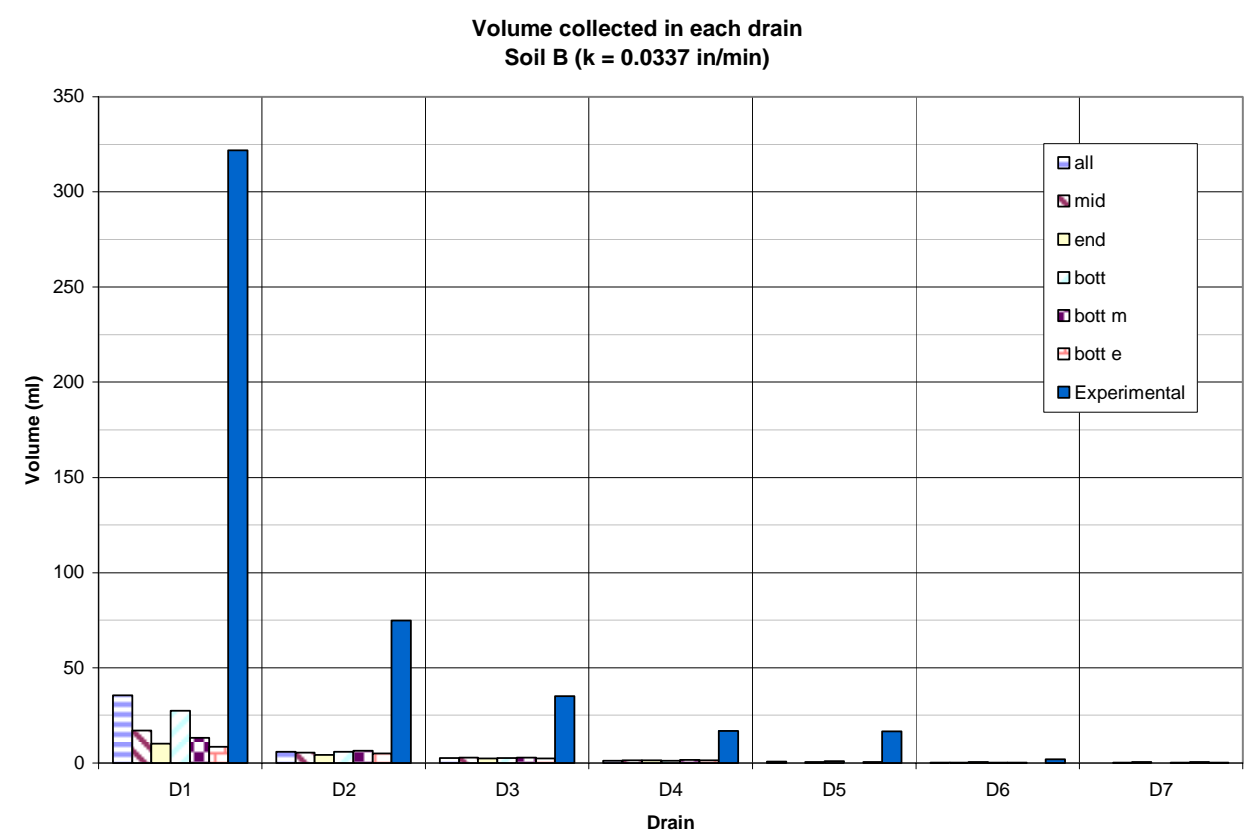

Figure 3.10: Volume removed at each drain for all drain set-ups (Soil B) 


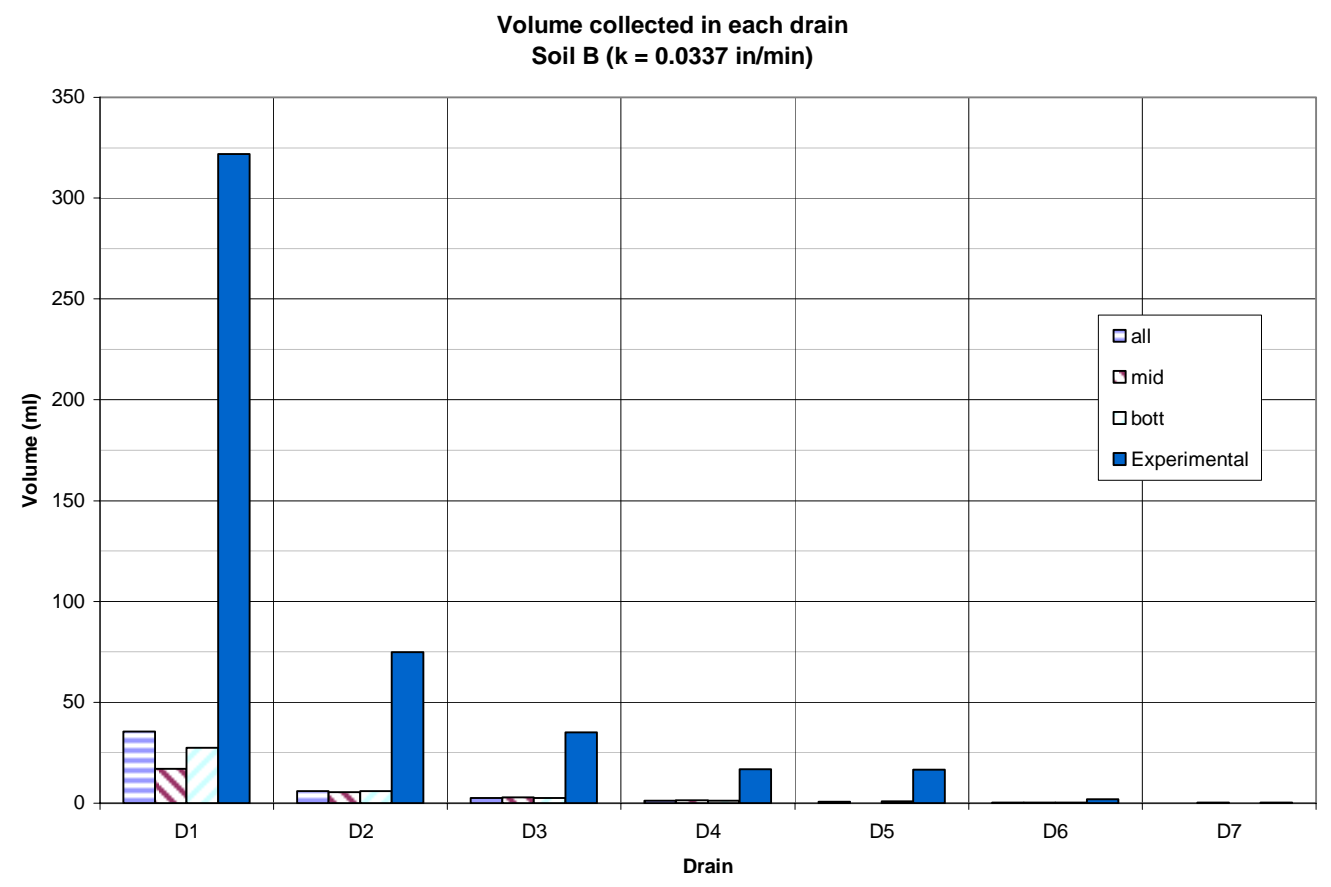

Figure 3.11: Volume removed in each drain for the three main drain set-ups (Soil B)

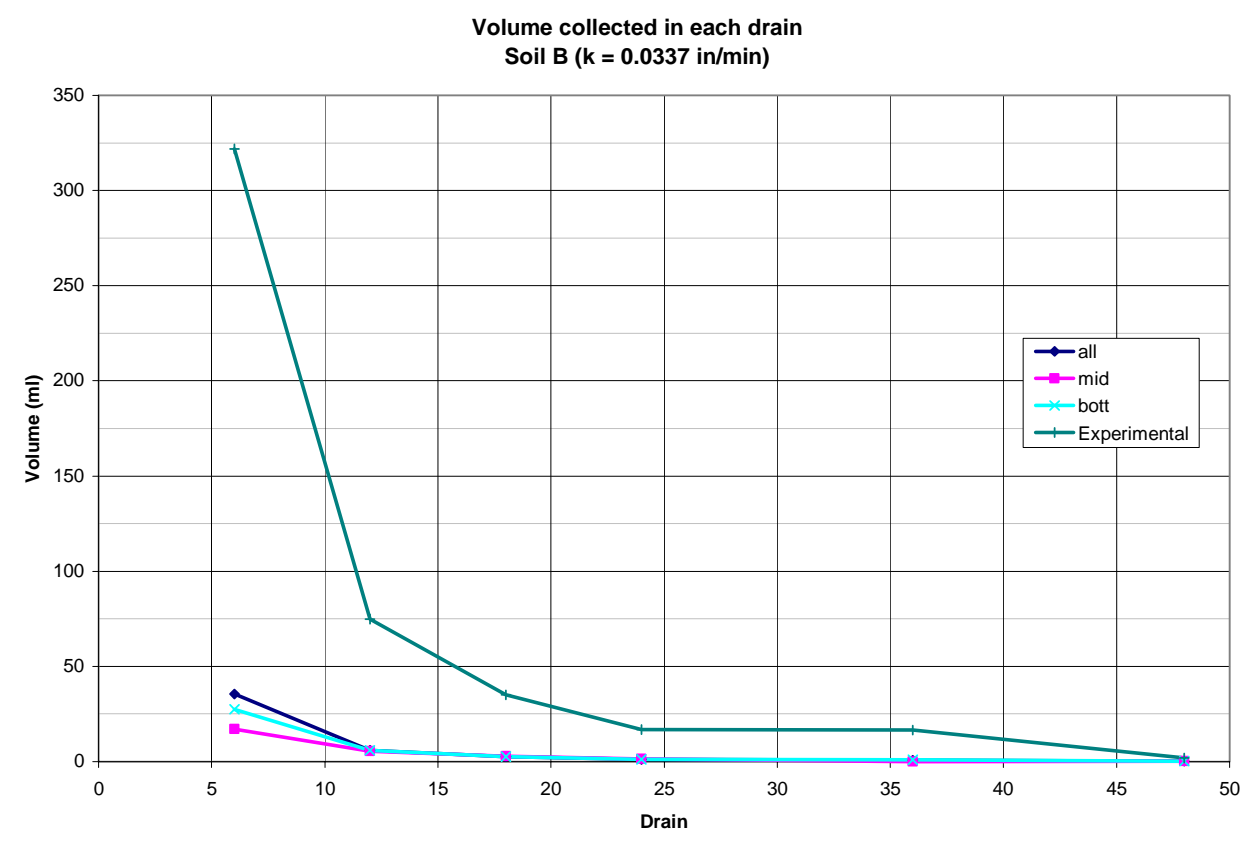

Figure 3.12: Volume removed along the drain for the three main drain set-ups (Soil B) 
Figures 3.11 and 3.12 show the actual amount of seepage being removed in each drain. The predicted volumes using the computer model are much smaller than those obtained using the physical model. Both the computer model and the physical model show the same trend (most of the water is being removed in the first drain). These same trends can be seen for soils A, C, D and E (see Figures A1.1 through A1.23 in the appendix).

Piezometric charts are shown in the next chapter. Because the piezometric head is not affected by the hydraulic conductivity, the variable taken into account is the amount of water removed, or seepage. While the computed pattern is satisfactory, the computer model data do not compare well with the measured volumes. Figure 3.11 shows the volume removed in each drain. This figure clearly shows that the physical model removes more water than that predicted by the computer model. Therefore, it is necessary to calibrate the hydraulic conductivity of the computer model.

Figures 3.8 and 3.9 are very important because they show that both the experimental model and the computer model have a very similar percent removal over the length of the slope. Both the laboratory and computer models show the same trend. To find the relationship between the laboratory and computer models, the hydraulic conductivity of the computer model was modified by trial and error until the amount of water removed at the first drain was within a 5 percent of that of the physical model. As mentioned before, the drain one is the drain at which most of the seepage was removed. This trial and error procedure was performed for all soil types (A, B, C, D, and E). 
There are two computer model set-ups that best simulated the physical model: the one in which all cells in the drain face were set as drains and the one in which only the bottom cells along the drain face were set as drains. These two computer model cases were studied for each soil type. The hydraulic conductivity value was modified independently for each case until the volumes collected at the first drain matched with the volume collected in the physical model. Figure 3.13 show the cumulative percent removed along the drain for soil type B and the computer model values for the two cases mentioned above. Note that the hydraulic conductivity value corresponding to each of the computer model cases was different. This Figure shows that the experimental curve and two models are still very close. Figure 3.9 and Figure 3.13 show identical results. This is because the hydraulic conductivity does not have a mayor influence on the effectiveness of the drain.

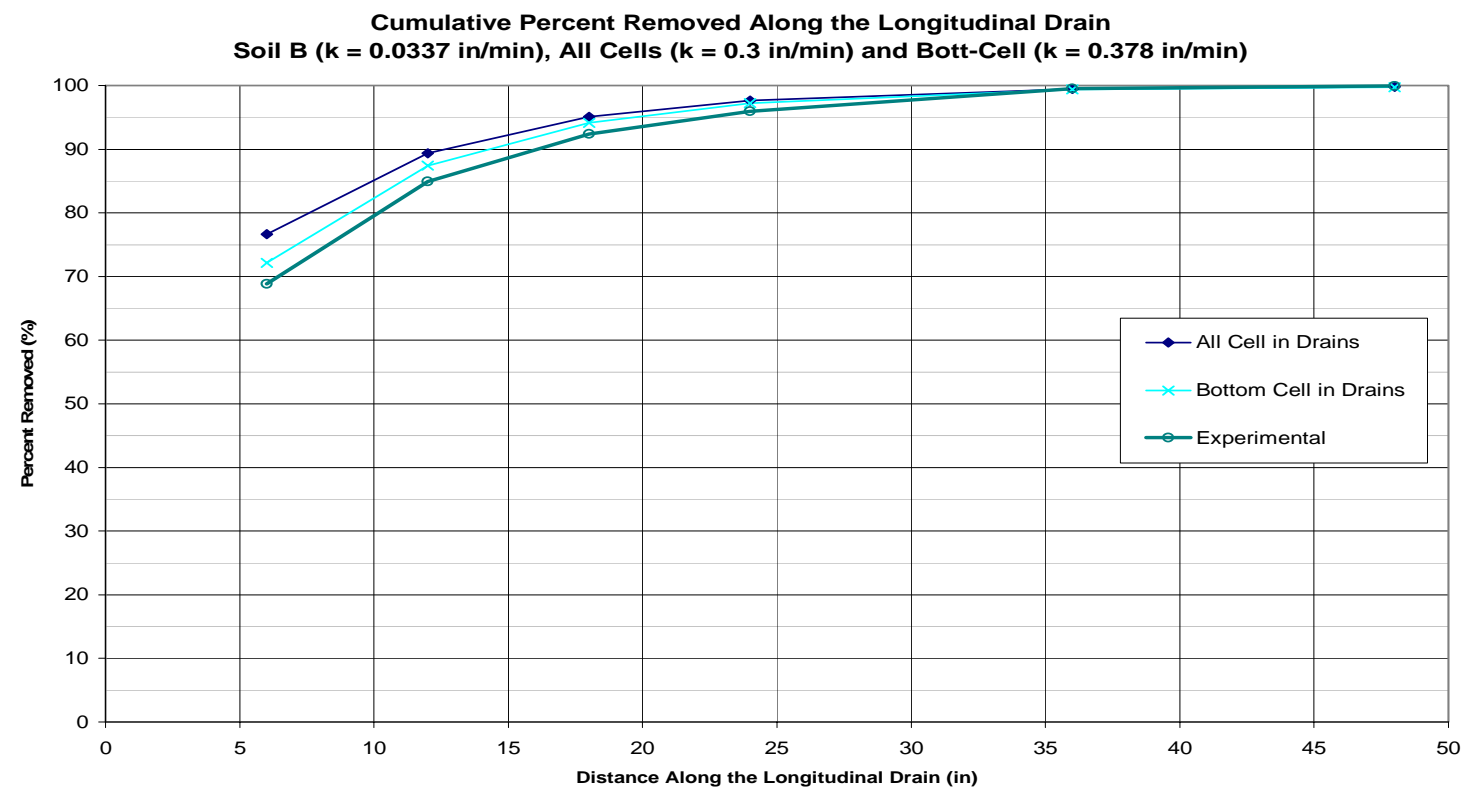

Figure 3.13: Measured and Computed Cumulative percent removed along the drain for Soil type B 
As opposed to the effectiveness of the drain (total cumulative percent seepage removed), the amount of water collected at each drain is directly proportional to the hydraulic conductivity. As shown in Figures 3.14 and 3.15, the volumes collected at the first drain after changing the hydraulic conductivities in the computer model are identical to those collected in the physical model. Even though there is no change in the percent removed with the modified hydraulic conductivity, the actual seepage volume going through each drain changes significantly. The effect of the hydraulic conductivity is further analyzed in the following sections.

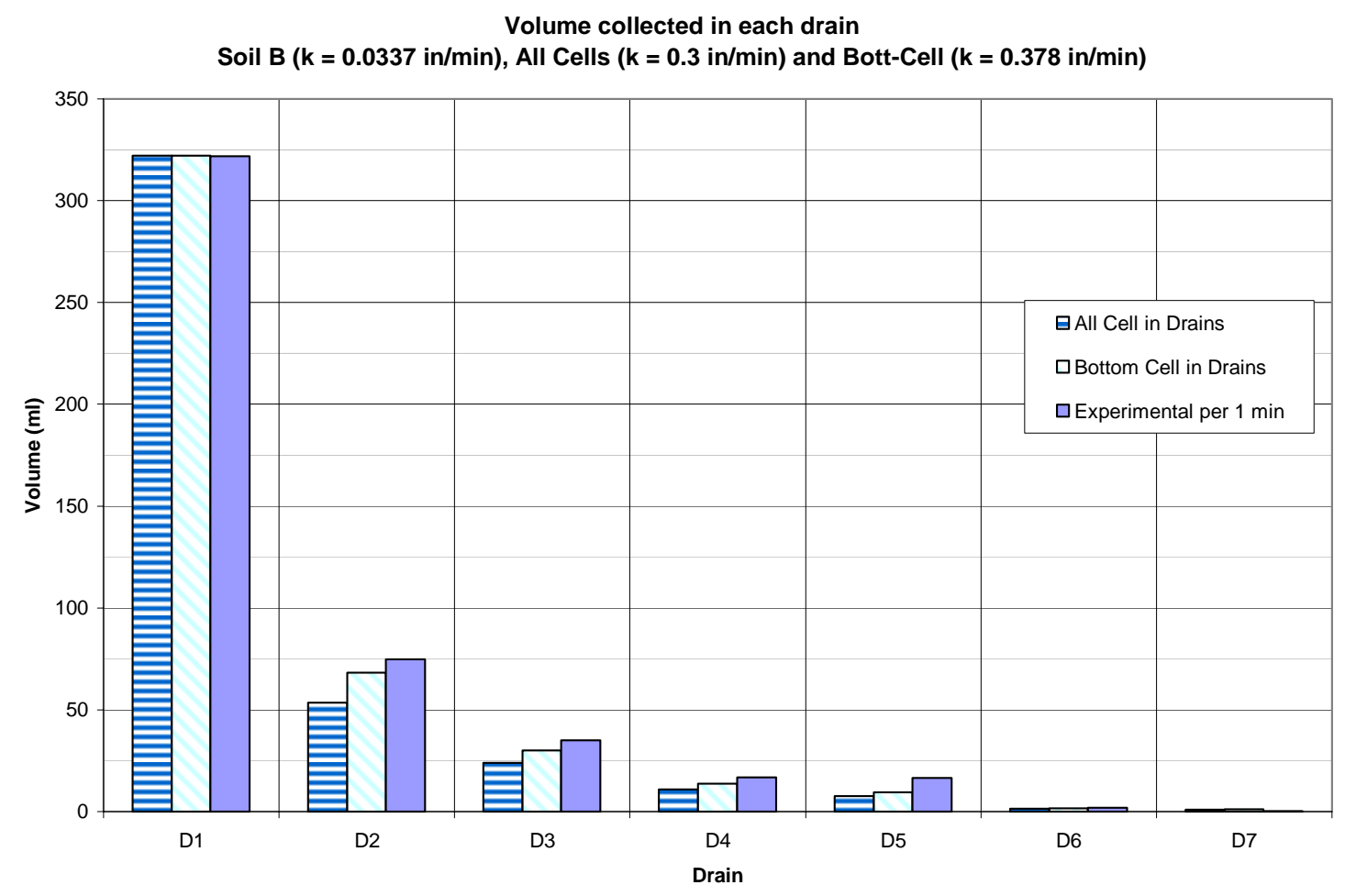

Figure 3.14: Volume removed at each drain for a soil type B with modified Hydraulic Conductivity 


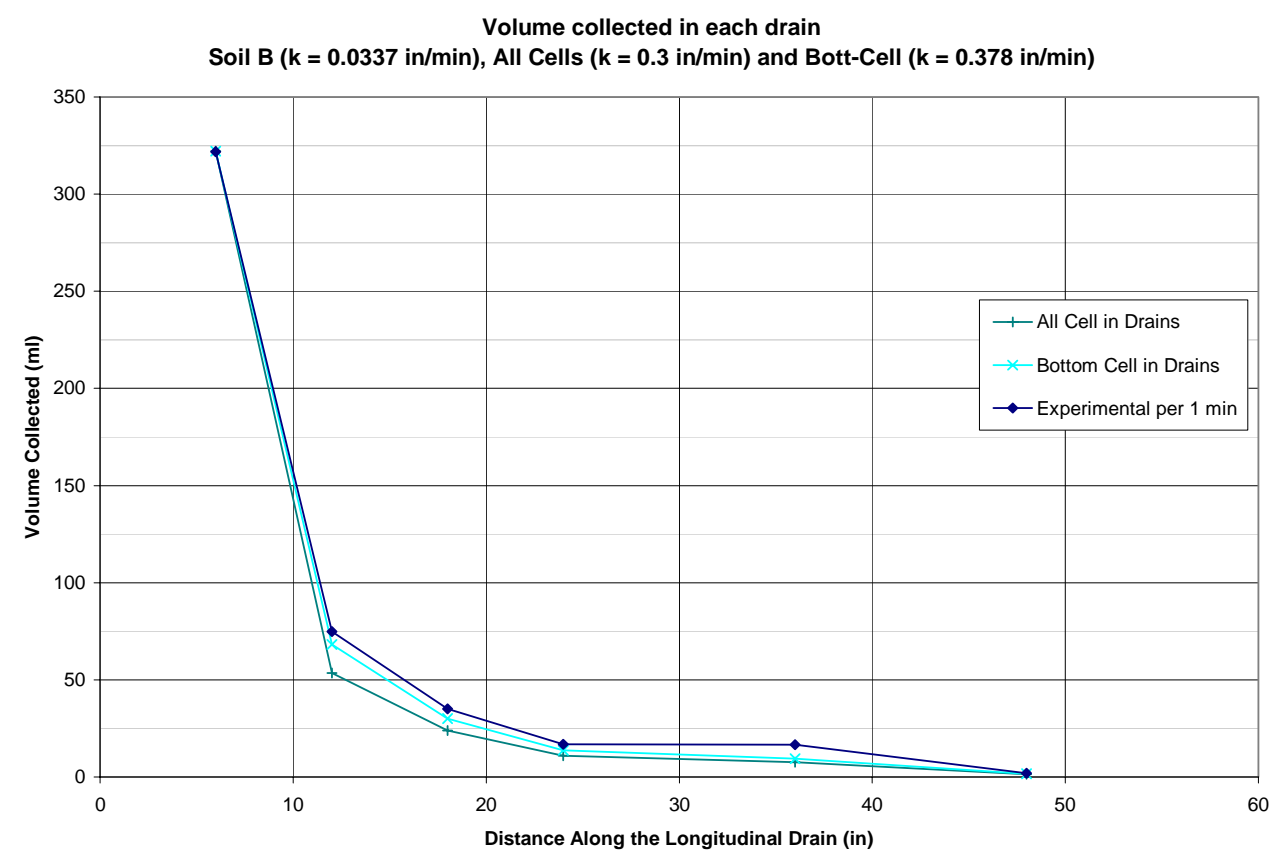

Figure 3.15: Variation of Drainage Volume along the length for soil type B with modified Hydraulic Conductivity

A similar procedure was followed to adjust the hydraulic conductivity of soils A, $\mathrm{C}, \mathrm{D}$ and $\mathrm{E}$, and the corresponding results are shown in Figures A1.24 through A1.36 in the appendix. The following table shows the values for hydraulic conductivities used for the physical models and for the computer models for both cases of drain set-ups.

Table 3.2: Hydraulic Conductivities used in different Computer Models

\begin{tabular}{|c|c|c|c|c|c|}
\hline & $\begin{array}{c}\text { Soil A } \\
\text { (in/min) }\end{array}$ & $\begin{array}{c}\text { Soil B } \\
\text { (in/min) }\end{array}$ & $\begin{array}{c}\text { Soil C } \\
\text { (in/min) }\end{array}$ & $\begin{array}{c}\text { Soil D } \\
\text { (in/min) }\end{array}$ & $\begin{array}{c}\text { Soil E } \\
\text { (in/min) }\end{array}$ \\
\hline $\begin{array}{c}\text { All Cells as } \\
\text { Drains }\end{array}$ & 0.406 & 0.3 & 0.2222 & 0.0661 & 0.0104 \\
\hline $\begin{array}{c}\text { Bottom Cells } \\
\text { as Drains }\end{array}$ & 0.512 & 0.378 & 0.2796 & 0.08323 & 0.0131 \\
\hline Experimental & 0.4727 & 0.0337 & 0.006685 & 0.00147 & 0.0001700 \\
\hline
\end{tabular}




\subsubsection{Modification Factors}

The relationship between the measured hydraulic conductivity in the physical model and the modified hydraulic conductivity used in the computer model was investigated. The results from the two main computational set-ups (all-Cells and bottom Cells as shown in Figure 3.16) were compared with measured data from the physical. The ratio $\left(\mathrm{R}_{\mathrm{k}}\right)$ between the hydraulic conductivity value used in the computer model and the physical model was calculated for all soil types as shown in Table 3.3. This ratio is defined as:

$$
R_{k}=\frac{k_{\text {model }}}{k_{\text {experimental }}}
$$

Table 3.3: Hydraulic conductivity ratio, $R_{k}$ for all soil types

\begin{tabular}{|l|c|c|c|c|c|}
\hline & $\begin{array}{c}\text { Soil A } \\
\text { (in/min) }\end{array}$ & $\begin{array}{c}\text { Soil B } \\
\text { (in/min) }\end{array}$ & $\begin{array}{c}\text { Soil C } \\
\text { (in/min) }\end{array}$ & $\begin{array}{c}\text { Soil D } \\
\text { (in/min) }\end{array}$ & $\begin{array}{c}\text { Soil E } \\
\text { (in/min) }\end{array}$ \\
\hline $\begin{array}{l}\text { All Cell in } \\
\text { Drains }\end{array}$ & 0.86 & 8.90 & 33.24 & 45.06 & 61.18 \\
\hline $\begin{array}{l}\text { Bottom Cell in } \\
\text { Drains }\end{array}$ & 1.08 & 11.216617 & 41.82 & 56.73 & 77.06 \\
\hline
\end{tabular}

There seems to be an exponential relationship between the value of $R_{k}$ and the clay content. Figure 3.17 shows the graphical representation between the hydraulic conductivity ratios and clay content. Using a powerful tool in the Microsoft Excel, a trend line was fitted to the data points to see if there is a relationship between the clay content 


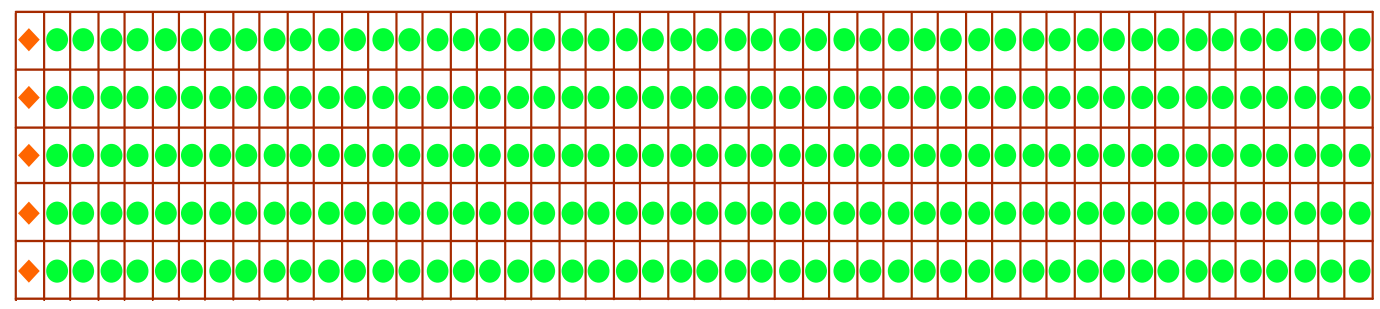

Case (a): Drains on the entire Drain Face

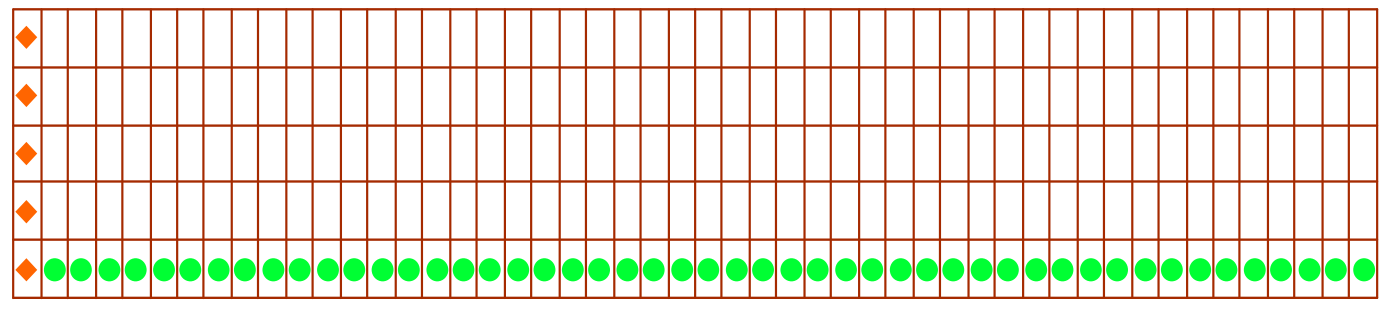

Case (b): Drains on the bottom of drain face

Figure 3.16: Drain Patterns used in the Model 
and the modification factor, $\mathrm{R}_{\mathrm{k}}$. The correlation coefficient (sum of the square distances between the trend line and the actual data points) known as the $\mathrm{R}^{2}$ value indicates that there is a strong correlation between the medication factor, $\mathrm{R}_{\mathrm{k}}$, and the clay content as shown in Figure 3.17.

Modification Factors for Drain Type vs Clay Content

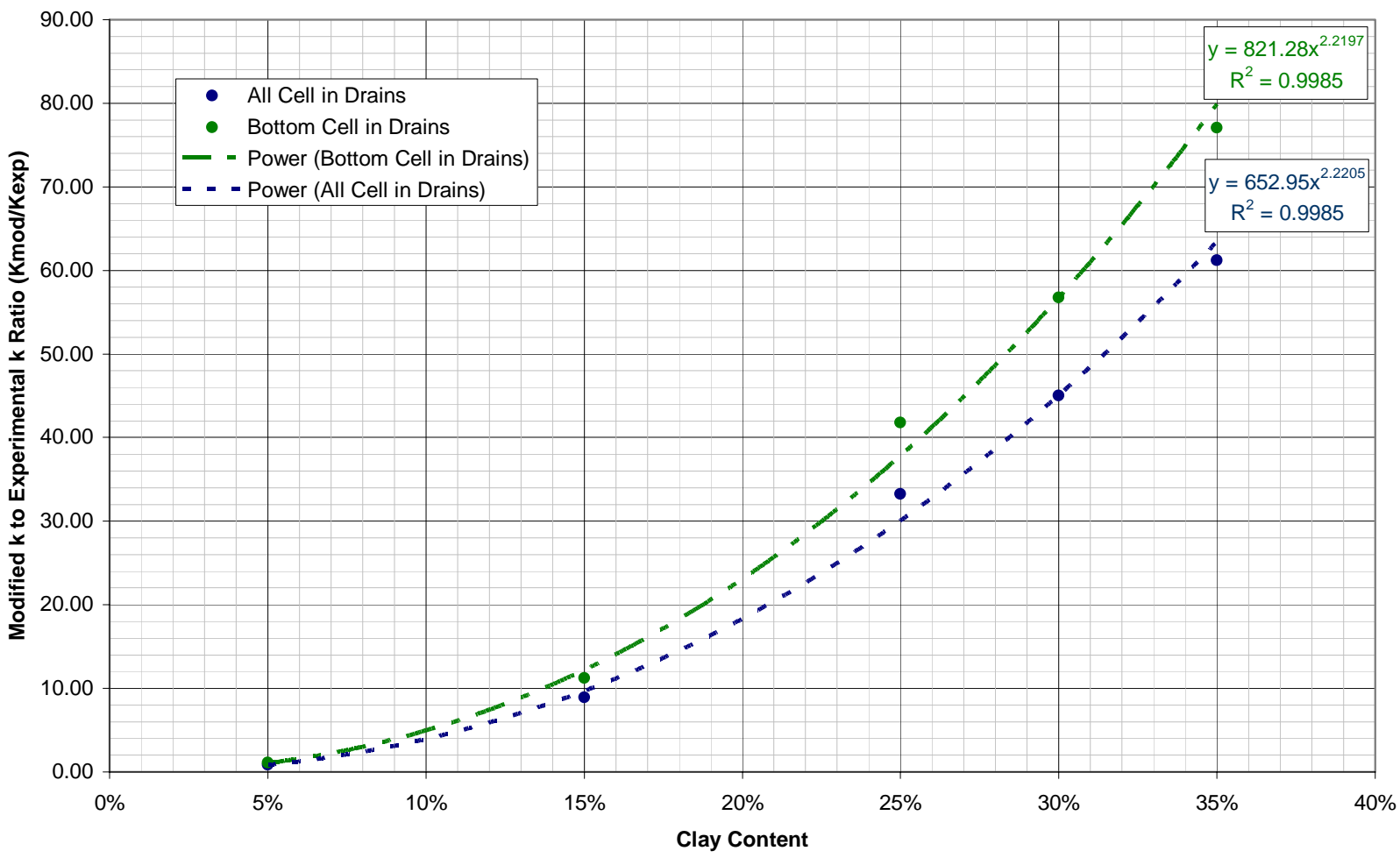

Figure 3.17: Relationship between the hydraulic conductivity ratio and clay content

As can be seen from Figure 3.17 , the $\mathrm{R}^{2}$ value for both the curves is very close to 1 , which means that there is a very good fit between the parameters. The equations for these trend lines and the $\mathrm{R}^{2}$ for each curve are shown in Table 3.4. The modification factors for measured permeability are shown in this table. These equations will allow the 
user to determine the values of hydraulic conductivity for use in the computer model for the different soils. Figure 3.17 shows these relationships when both the axes were changed to log scales.

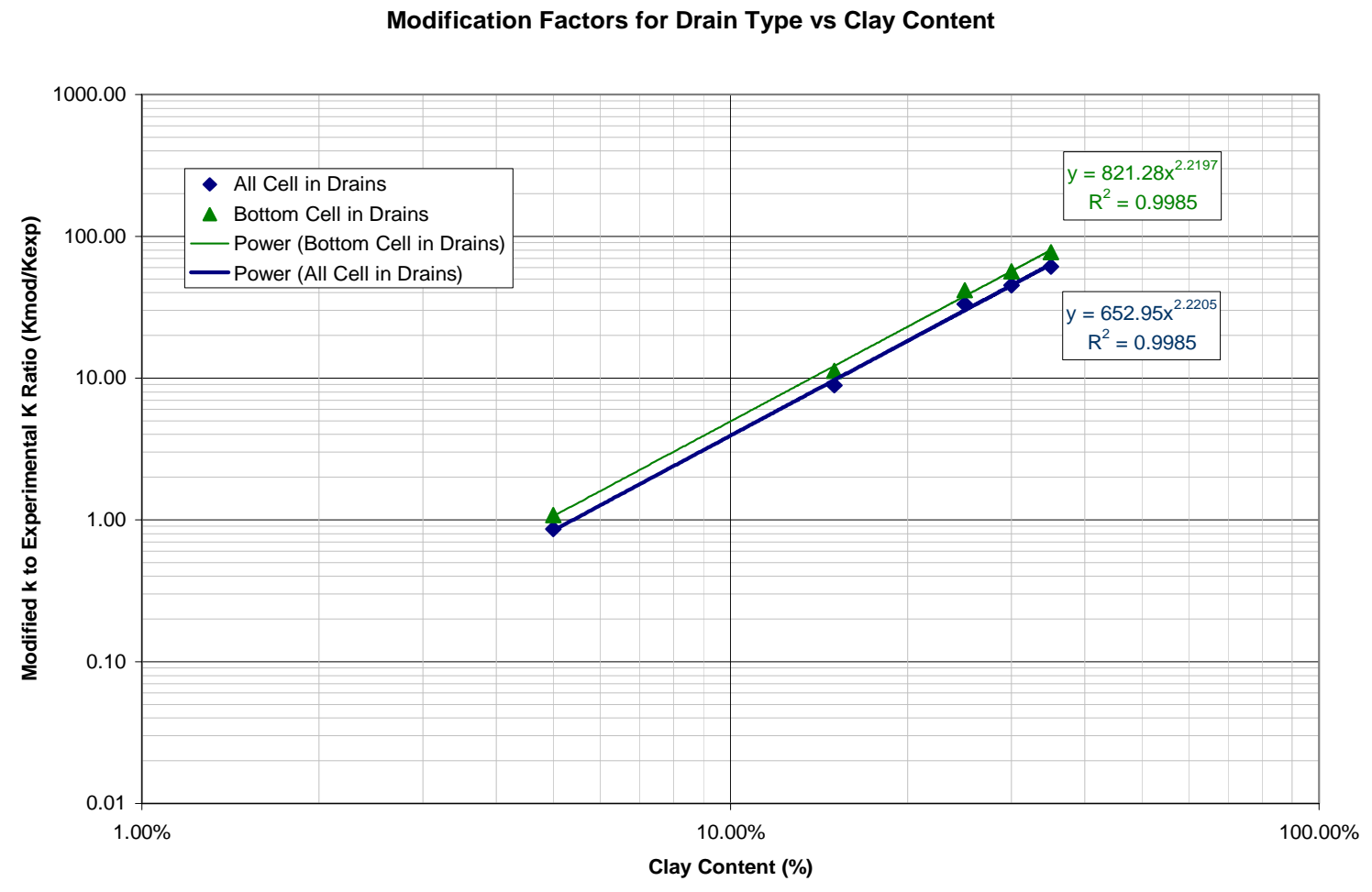

Figure 3.17: Relationship between the hydraulic conductivity ratio and clay content

Soil type D (seventy percent sand and thirty percent clay) was prepared after the calibration was determined to check whether the modification factor equation worked for a different soil type. Results for this soil was first compared with that of the physical model (see Appendix figures A1.12 through A1.17). Then, using the modification factor 
equation (see Table 3.5), the modified hydraulic conductivity was calculated and used in the program. The comparison of results was very good, which indicates that the developed equation is suitable for other soil types (see Appendix figures A1.30 through A1.32).

Table 3.4: Modification Factor Equations and $\mathrm{R}^{2}$ values $(\mathrm{X}=$ Clay content $)$.

\begin{tabular}{|l|c|c|}
\hline & Modification Factor Equations & $\mathrm{R}^{2}$ \\
\hline All Cells in Drains & $\mathrm{MF}=652.98(\mathrm{X})^{2.2206}$ & 0.9985 \\
\hline Bottom Cells in Drains & $\mathrm{MF}=821.29(\mathrm{X})^{2.2197}$ & 0.9985 \\
\hline
\end{tabular}

\subsubsection{Specific Storage}

Different soil parameters such as the hydraulic conductivity and specific storage appear in the governing differential equation that describes the seepage problem (see Equation 2.11). As can be seen from this equation, the specific storage appears only in the transient analysis of seepage. The values of hydraulic conductivity and specific storage are input parameters to the analysis using MODFLOW computer code. In the previous section, information on the modification of permeability was given on the basis of laboratory measurements under steady state conditions. Specific storage is an important aquifer property that influences the transient behavior (Cedergren, 1977; Freeze and Cherry, 1979; Said et al., 2004). Specific storage has a value between 0 and 1. In this study, the specific storage of the soil sample was determined by a trial-and-error procedure in which computed transient behavior was compared with measured data in the 
laboratory. The value of specific storage was changed until the amount of water flow and transient time matched with the values obtained in the physical model. Based on a number of trials, the value of specific storage, $S_{\mathrm{s}}$, was chosen as 0.36 for all of the soil types used in this study. The same value was used in the modeling of transient behavior of field scale longitudinal drains presented in this report. 


\section{CHAPTER 4: RESULTS}

\subsection{Introduction}

By using the model described in the previous chapter, an abundance of data on the performance of longitudinal drains was collected. Several graphs were prepared to facilitate and provide visual understanding of what is actually happening along the slope. The effectiveness of the drain and the influence of different factors affecting the flow are shown throughout the chapter.

Graduated cylinders were used to accurately collect water from each drain. The amount of water seeping though the slope would be the sum of the volumes of water collected by all seven drains. Water was collected in each drain for ten minutes when the readings were taken. The piezometric data was recorded at the beginning of each interval. For the transient study, readings were cumulatively taken at time zero (as soon as the drains were opened), $1 \mathrm{~min}, 2 \mathrm{~min}, 3 \mathrm{~min}, 4 \mathrm{~min}, 5 \min , 6 \mathrm{~min}, 7 \mathrm{~min}, 8 \mathrm{~min}, 9 \mathrm{~min}, 10$ min, $15 \mathrm{~min}, 20 \mathrm{~min}, 25 \mathrm{~min}, 35 \mathrm{~min}, 40 \mathrm{~min}, 50 \mathrm{~min}, 1 \mathrm{hr}, 2 \mathrm{hr}, 6 \mathrm{hr}, 12 \mathrm{hr}$, 24, hr and 48 hrs. After that, readings were taken every $24 \mathrm{hrs}$ until the steady state condition was reached. In addition to the data collected using the model, representative samples of the soil were taken and tested for hydraulic conductivity, specific gravity, and grain size distribution.

One of the important aspects of this study is that each test was performed at lest twice. All data regarding the composition and type of soil is given in this chapter. The apparatus was described in the previous chapter. The proportions of sand and clay for each soil mix are presented in this chapter. The reproducibility of the experimental data is 
very important. In this study, each experiment was repeated at least once to make sure that the data is reproducible. The following Table shows the experimental data collected up to date.

Table 4.1: Experiment Identification Number (ID)

\begin{tabular}{|c|c|c|c|c|c|c|c|c|c|c|c|c|c|c|c|}
\hline & \multicolumn{5}{|c|}{ Steady } & \multicolumn{5}{|c|}{ Transient } & \multicolumn{5}{|c|}{ End Drain Transient } \\
\hline "Half & \multicolumn{5}{|c|}{ Clay Content } & \multicolumn{5}{|c|}{ Clay Content } & \multicolumn{5}{|c|}{ Clay Content } \\
\hline Spacing & $5 \%$ & $15 \%$ & $25 \%$ & $30 \%$ & $35 \%$ & $5 \%$ & $15 \%$ & $25 \%$ & $30 \%$ & $35 \%$ & $5 \%$ & $15 \%$ & $25 \%$ & $30 \%$ & $35 \%$ \\
\hline
\end{tabular}

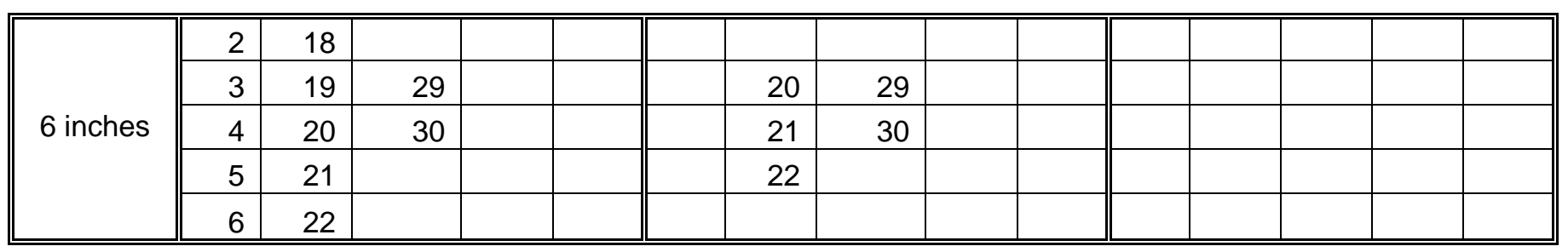

\begin{tabular}{|c|c|c|c|c|c|c|c|c|c|c|c|c|c|c|c|}
\hline \multirow{7}{*}{12 inches } & 7 & 16 & 27 & & & $\# 48$ & & 27 & & & $\# 48$ & 45 & 41 & & \\
\hline & 8 & 17 & 28 & & & $\# 49$ & 25 & 28 & & & $\# 49$ & 46 & 42 & & \\
\hline & 9 & 25 & $\$ \# 36$ & & & & 26 & $\$ \# 36$ & & & & 47 & 43 & & \\
\hline & $\# 48$ & 26 & $\$ \# 37$ & $\# 53$ & $\# 51$ & & $\# 50$ & $\$ \# 37$ & $\# 53$ & $\# 51$ & & $\# 50$ & 44 & $\# 53$ & $\# 51$ \\
\hline & $\# 49$ & $\# 50$ & $\$ \# * 38$ & $\# 54$ & $\# 52$ & & & $\$ \# * 38$ & $\# 54$ & $\# 52$ & & & & $\# 54$ & $\# 52$ \\
\hline & & & $\$ \# * 39$ & & & & & $\$ \# * 39$ & & & & & & & \\
\hline & & & $\$ \# 40$ & & & & & $\$ \# 40$ & & & & & & & \\
\hline
\end{tabular}

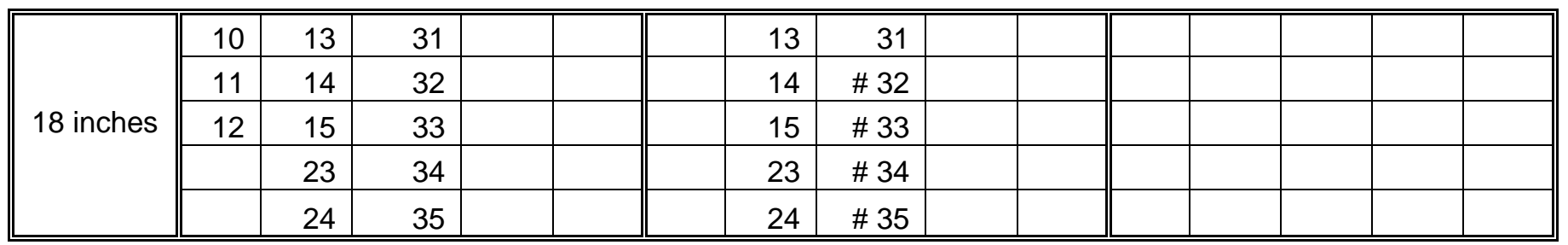

Sample was compacted

Continuous reading taken for the first hour

Saturated using side tank 


\subsection{Transient Condition}

The length of the drain has a great influence on its effectiveness. The drains closer to the water reservoir remove more water and show a greater fluctuation in the outflow. Although the first two drains are the ones showing the biggest changes, these changes are in the order of five percent. A small change such as this may seem insignificant, but depending on the total volume of water, a five percent fluctuation should be examined closely. The most critical transient behavior of flow happens during the first hour. Figures 4.1 and 4.2 show the changes during the first hour for drains 1 and 2 (which are the drains in which a greater water flow was noted). These figures show that the flow rate (flow volume per minute) fluctuates greatly during the first few minutes; these fluctuations begin to dampen as time passes. By the time the test reaches the half hour mark the fluctuation has almost disappeared. The Piezometric data is shown in Figure 4.3. This figure also shows the same phenomenon; the water level within the sample drops continuously, but after a few minutes the level drop becomes smaller. Figure 4.4 shows the cumulative percent of water removed along the longitudinal length of the drain. This figure shows the effectiveness of the drain and how it changes. This figure shows that the biggest changes occur in the first drains, and again the changes are more prominent in the first few minutes. 
Fluctuation in Flow Rate at D1

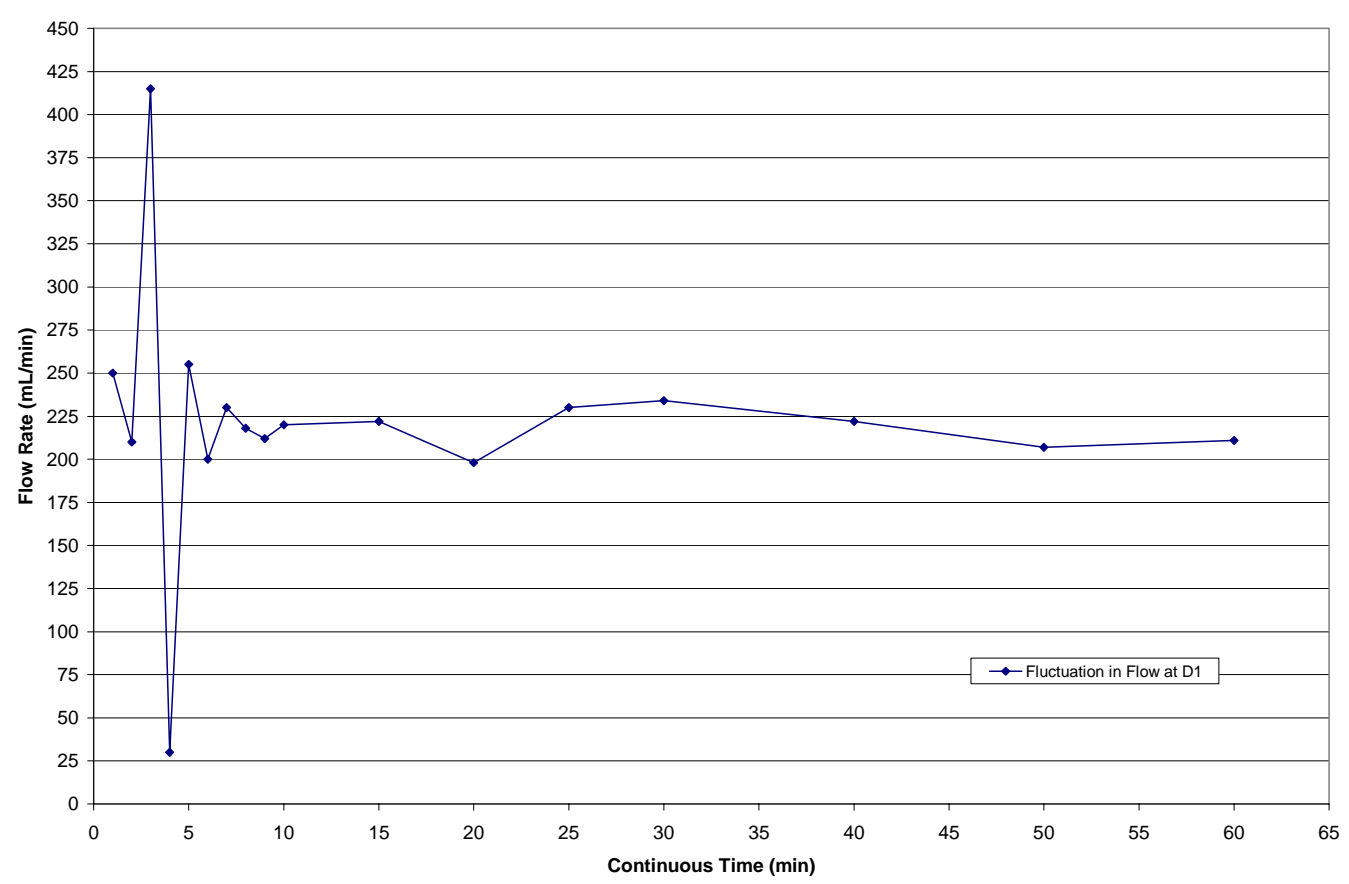

Figure 4.1: Flow Fluctuation at D1 for Soil Type C at Zero slope, 12" width Fluctuation in Flow Rate at D2

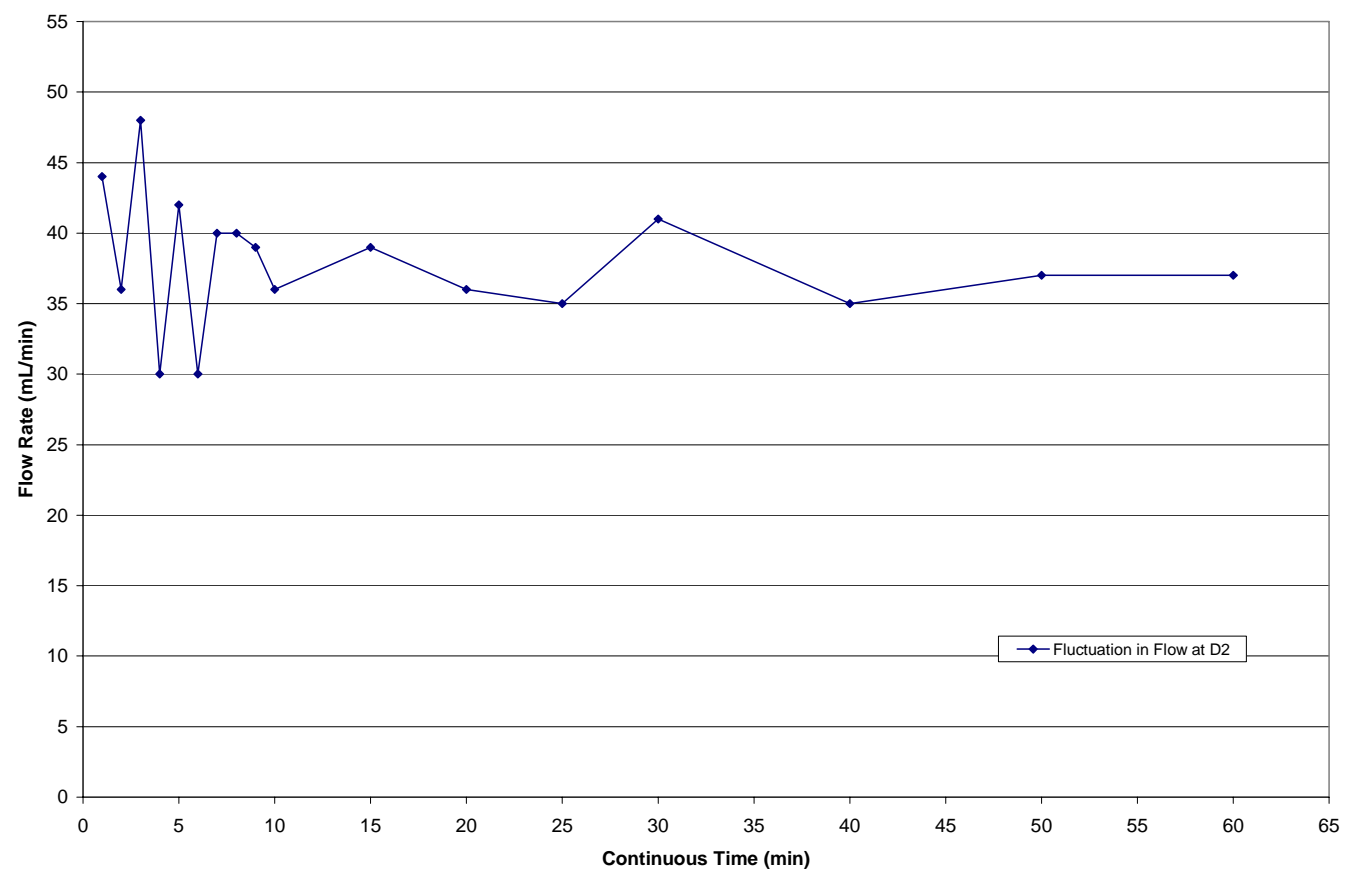

Figure 4.2: Flow Fluctuation at D2 for Soil Type C at Zero slope, 12" width 


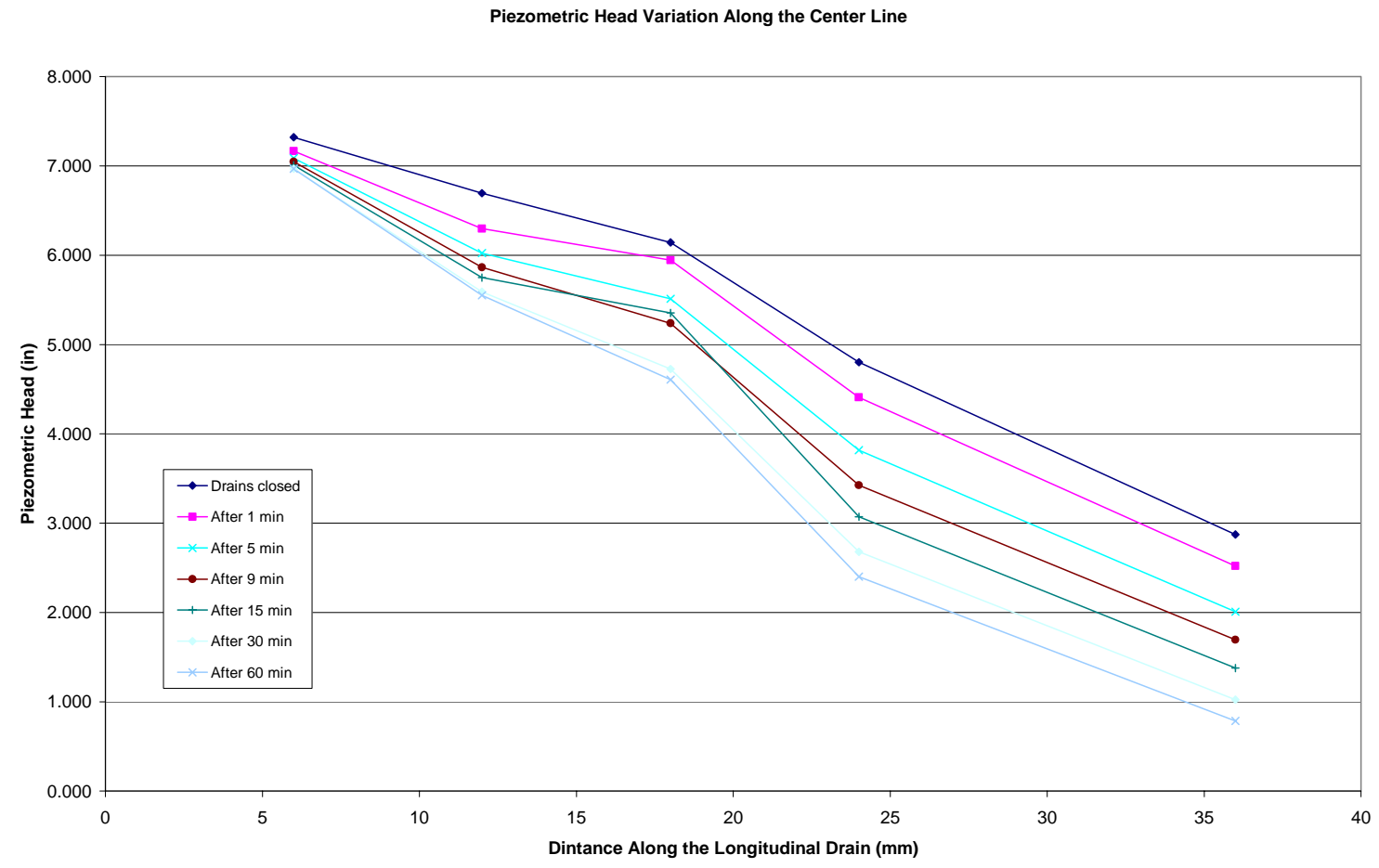

Figure 4.3: Piezometric Head for Soil Type C at Zero slope, 12" width

Cumulative Percent of Water Removed Along the Drain

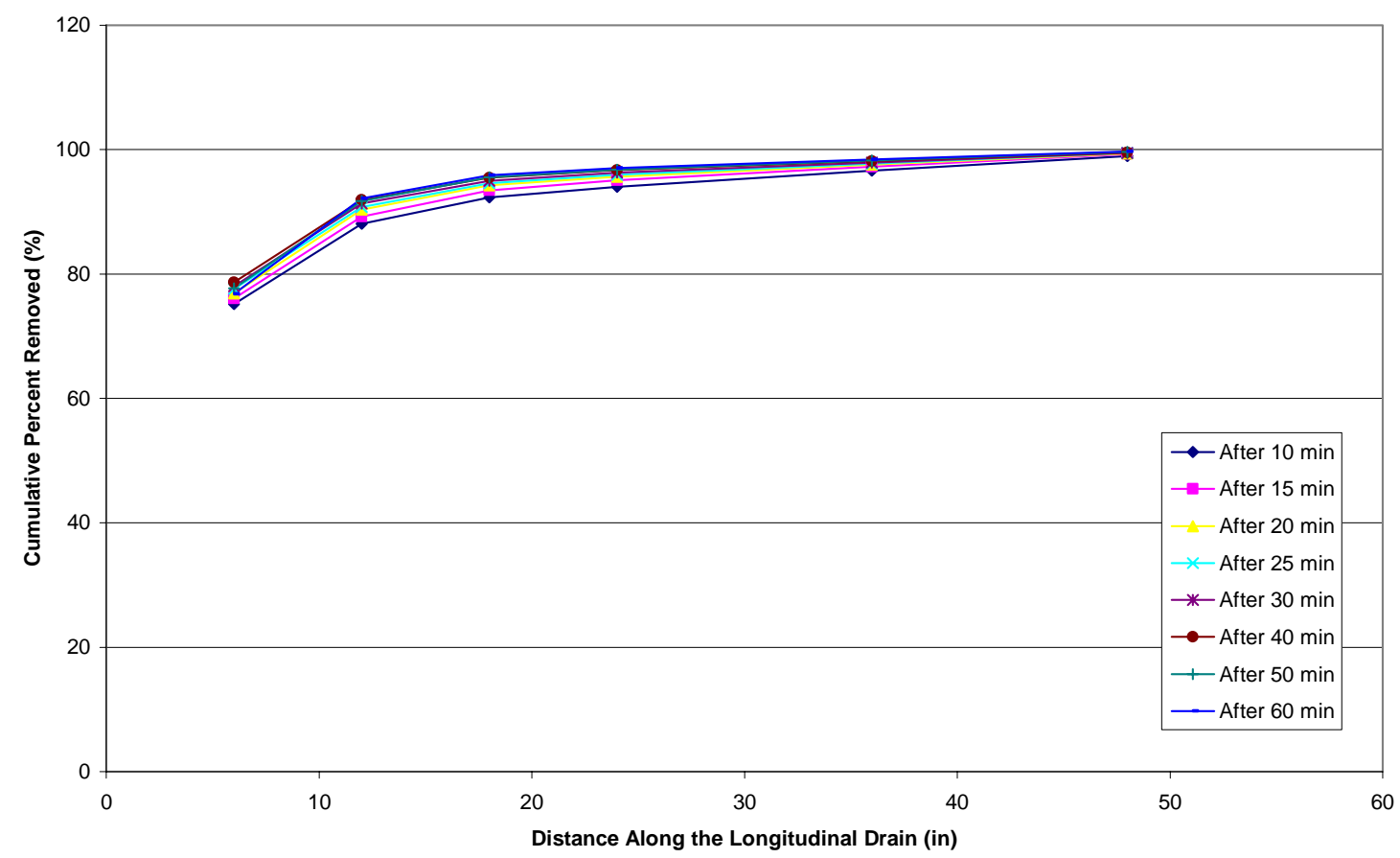

Figure 4.4: Cumulative percent removal for Soil Type C at Zero slope, 12” width 
After having obtained these results, it was necessary to check and see if drain one (D1) was affected because of its proximity to the main tank. An experiment was performed in which drain one remained closed so that the first drain in operation was D2 (D'1). Figures 4.5 and 4.6 show the results for the fluctuation in flow at D2 (D'1) and D3 (D'2). Figure 4.7 shows the piezometric data and Figure 4.8 shows the cumulative percent removal of water.

This set of graphs shows that the pattern is similar to the previous case. All major flow fluctuations occurred within the first few minutes of the test for both D'1 and D'2, just as it happened for D1 and D2. The piezometric head change was also similar to the previous case. The effectiveness of the drains is shown in terms of the cumulative percent of water removed in Figure 4.8. This plot also showed an increase in the drain effectiveness within the first few minutes. By the time the fluctuations in flow reduced, the effectiveness of the drains reached its maximum (same as previous case). These figures show that the closing of the first drain (D1) has no major effects on the results. Therefore, it was concluded that the proximity of D1 to the main tank has no significant influence on the seepage pattern. All other tests were performed with drain one (D1) active. 


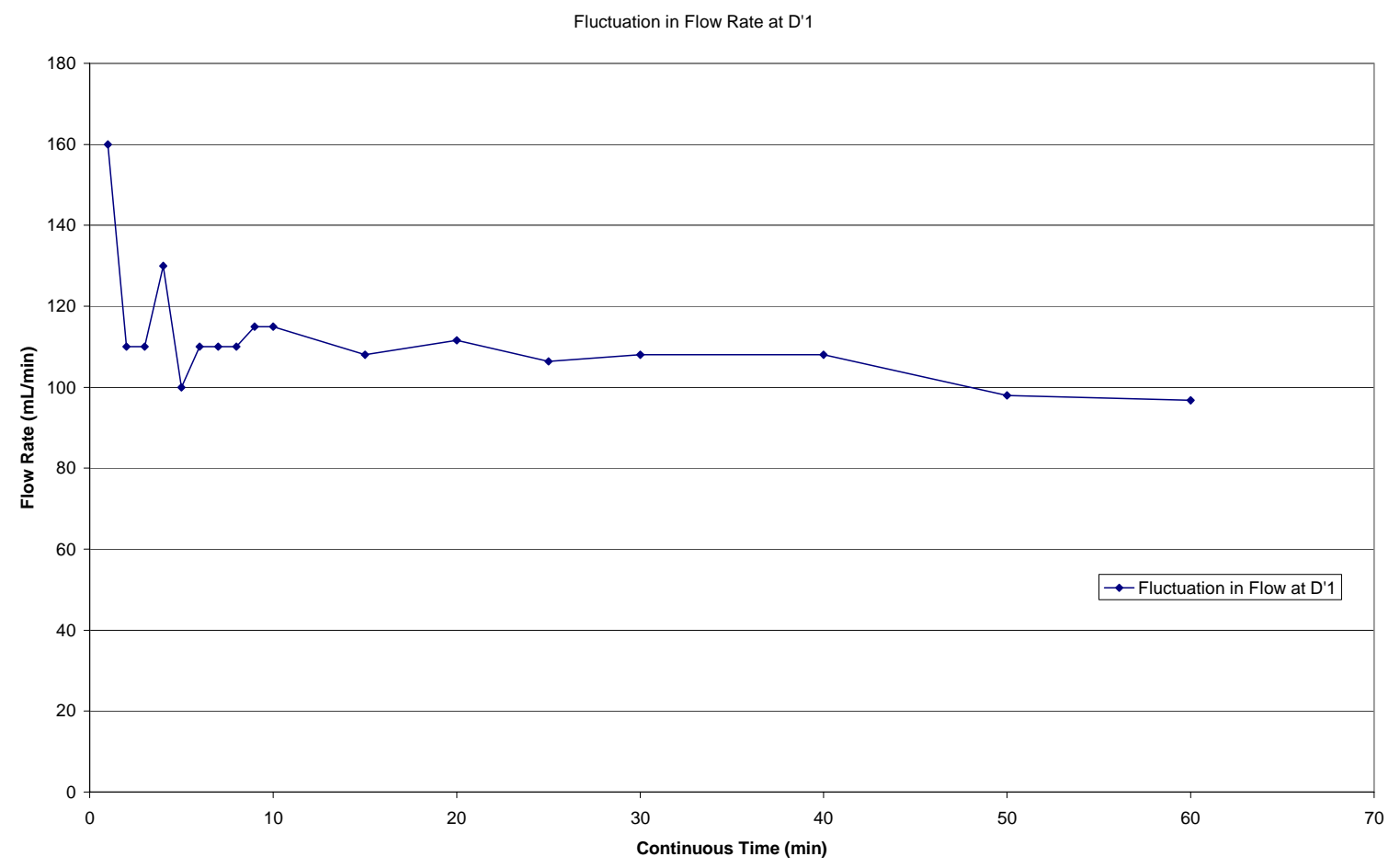

Figure 4.5: Flow Fluctuation at drain D'1 for Soil Type C at zero slope, 12" width

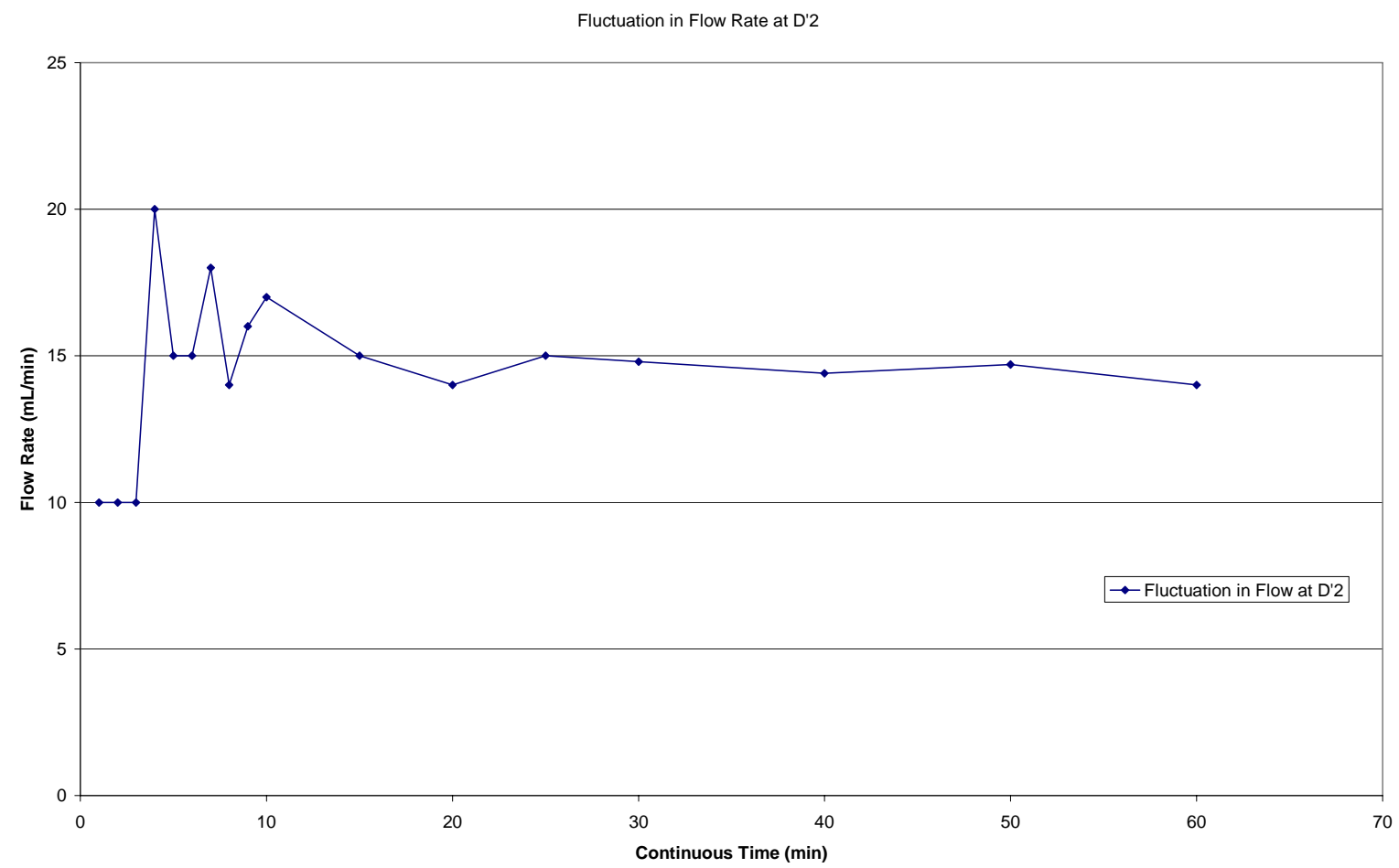

Figure 4.6: Flow Fluctuation at drain D'2 for Soil Type C at zero slope, 12" width 


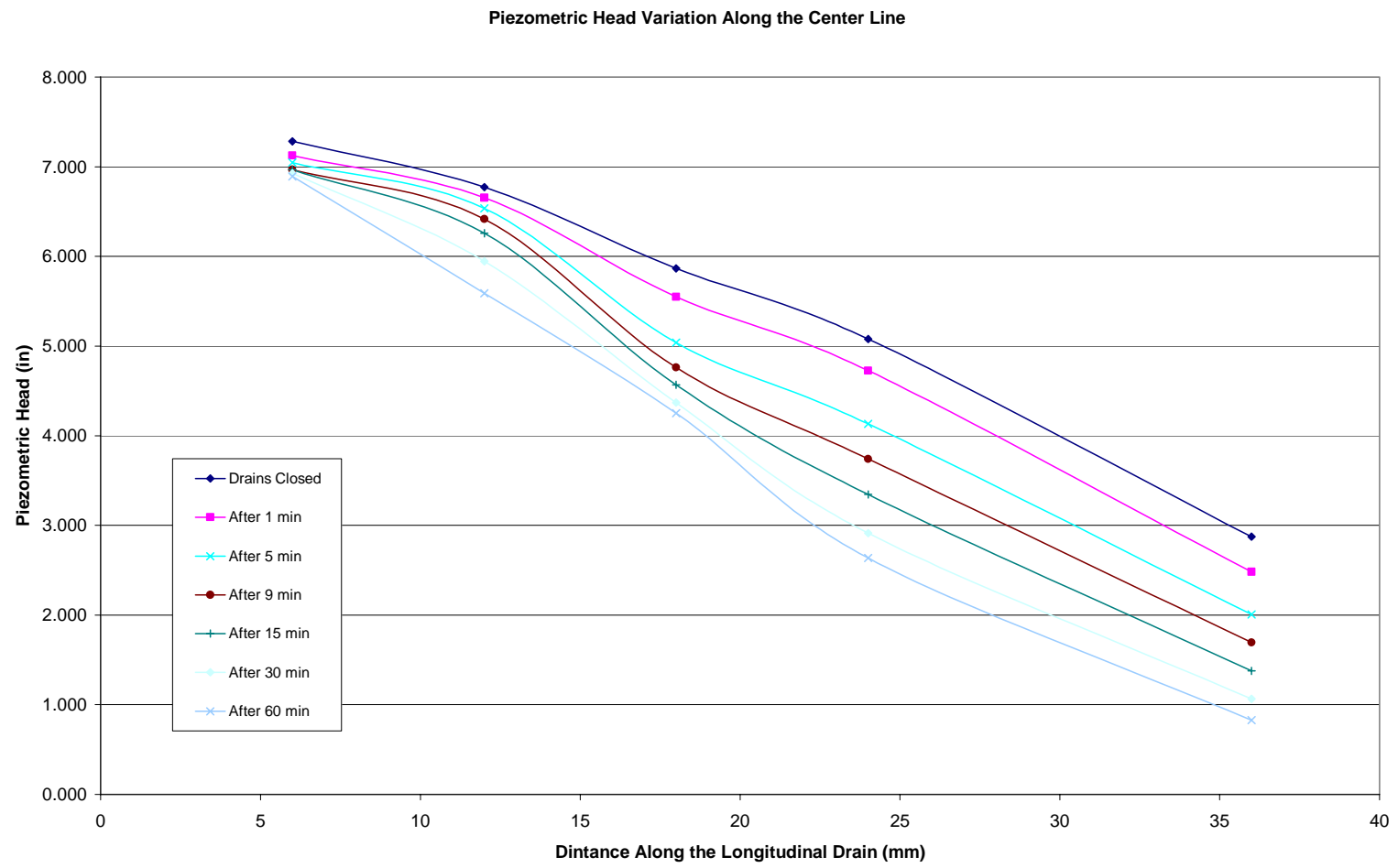

Figure 4.7: Piezometric variation along for Soil Type C at Zero slope, 12" width

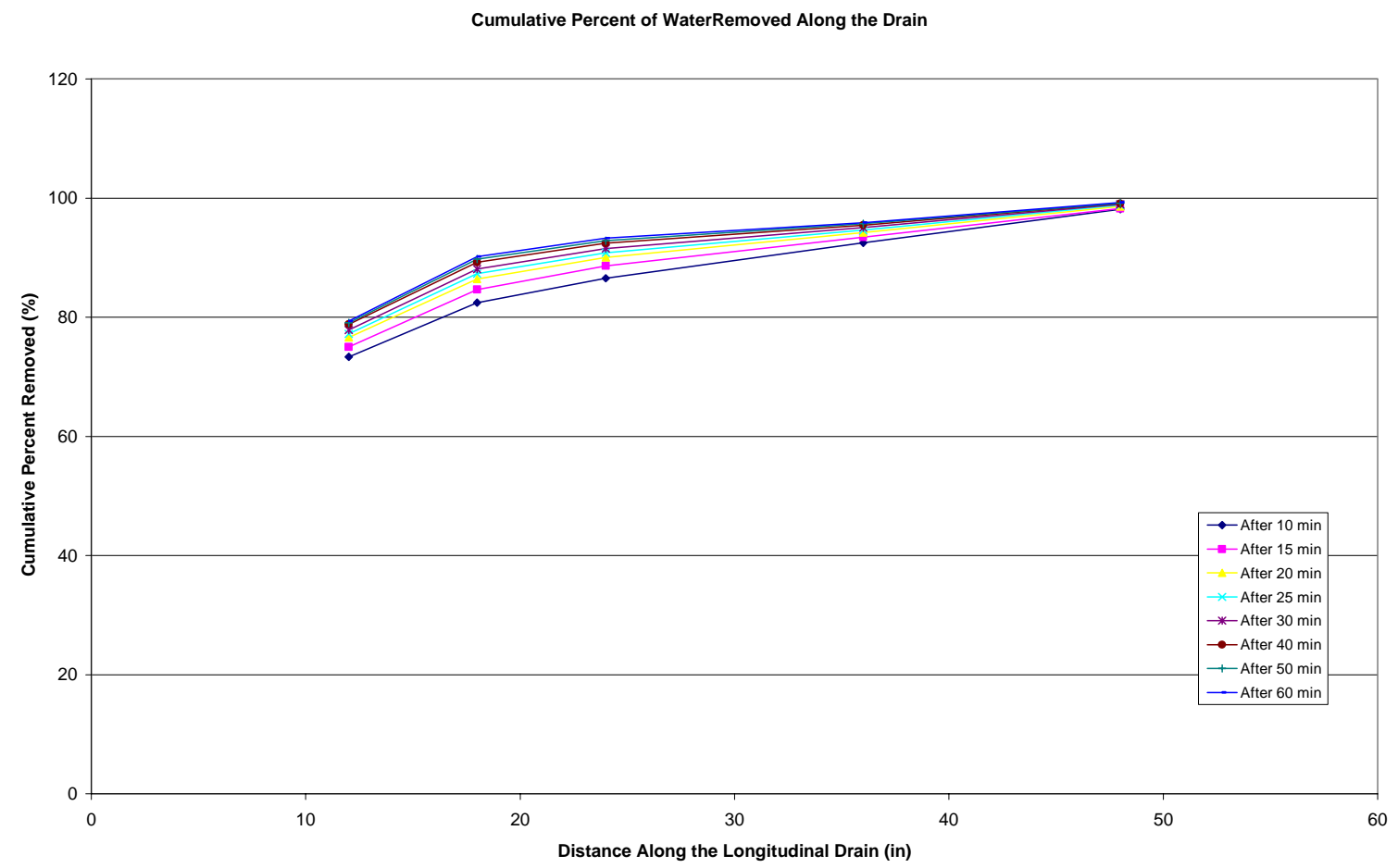

Figure 4.8: Cumulative percent removed for Soil Type C at zero slope, 12” width 


\subsection{End Drain}

After completing the analysis on the effect of the proximity of D1, several experiments were performed to study the variation of piezometric head starting from a constant value throughout the sample. Experiments were also performed to study the flow behavior of the end drain when all other drains (longitudinal drains) were closed. To accomplish this task, all drains were closed including the end drain. The end drain was closed by inserting a solid plexi-glass wall to seal the perforated end wall. Once all drains were disabled, water was introduced into the sample through the water reservoir. The level in the reservoir was increased in increments of one inch every six hours for low permeable samples to prevent surface cracking. Once the water level in the reservoir reached eight inches the piezometers were monitored until their readings stop moving. When all piezometers read the same level the sample had reached the desired saturation.

Once the sample was fully saturated, only the end drain was opened by removing the wall sealing. Piezometric readings were taken and flow rate was recorded for a continuous one hour. Figure 4.9 shows the flow rate fluctuation at the end drain (D7). Figure 4.10 shows the change in the piezometric head along the center line starting from a constant level. As can be seen from this figure, the water level dropped along the sample length when only the end drain was open. 


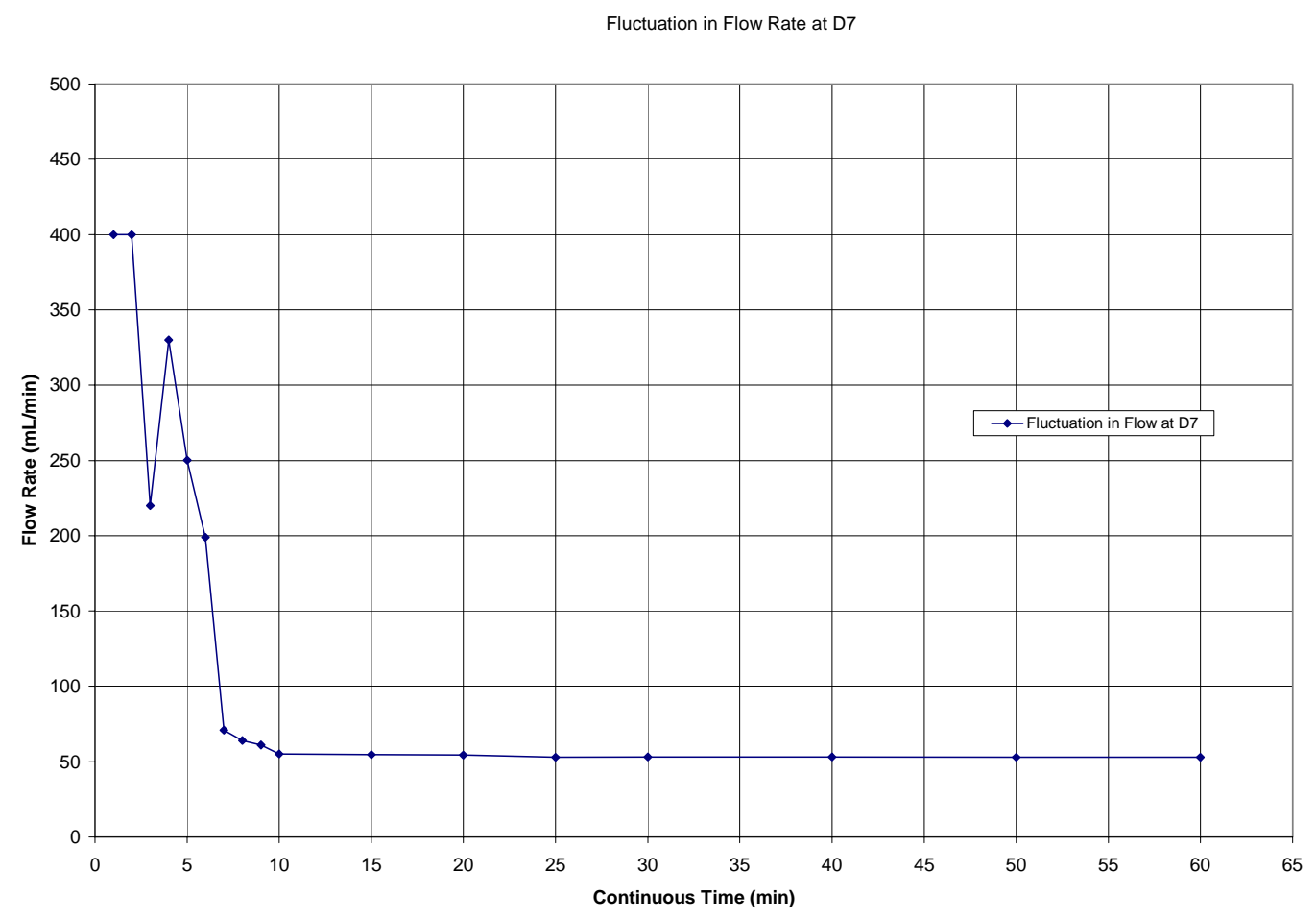

Figure 4.9: Flow fluctuation at drain D7 for Soil Type C at zero slope with side drains closed, 12" width 


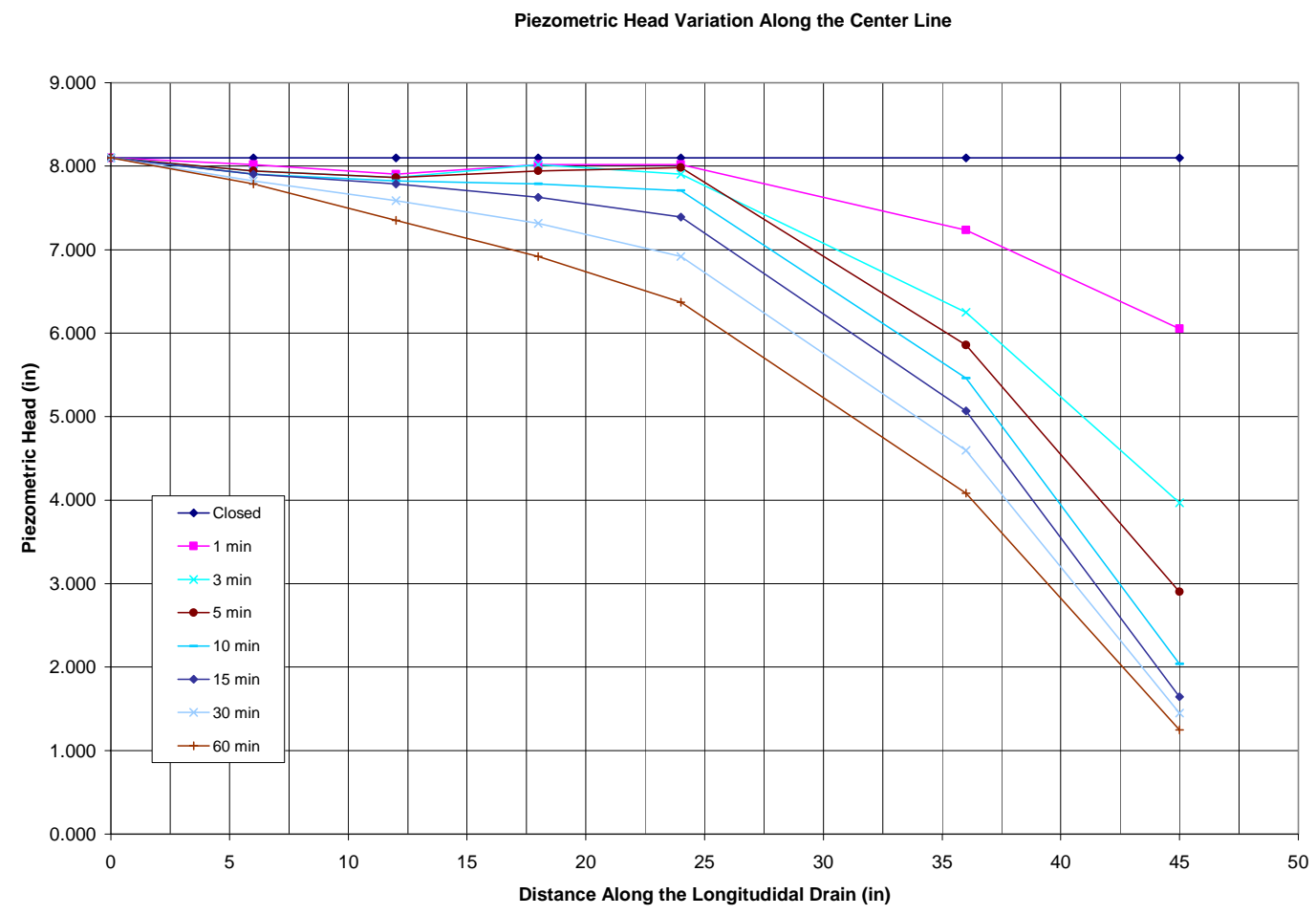

Figure 4.10: Piezometric level along center line for Soil Type C at Zero slope, 12" width

\subsection{Computer Modeling}

As described in the previous section, experiments were conducted to study the rate of seepage through the soil sample with only the end drain open. This experiment was simulated by using a computer model with the same boundary conditions as those in the experimental model. Figure 4.11 shows the computed variation in water level along the center line for soil Type $\mathrm{C}(\mathrm{k}=0.006 \mathrm{in} / \mathrm{min})$ for a half-trench spacing of twelve inches and a piezometric head of eight inches (which simulates the water level at the water reservoir) when the side drains were closed. This figure shows a similar trend as that of the experimental data. The water level drops significantly in the first few minutes. 


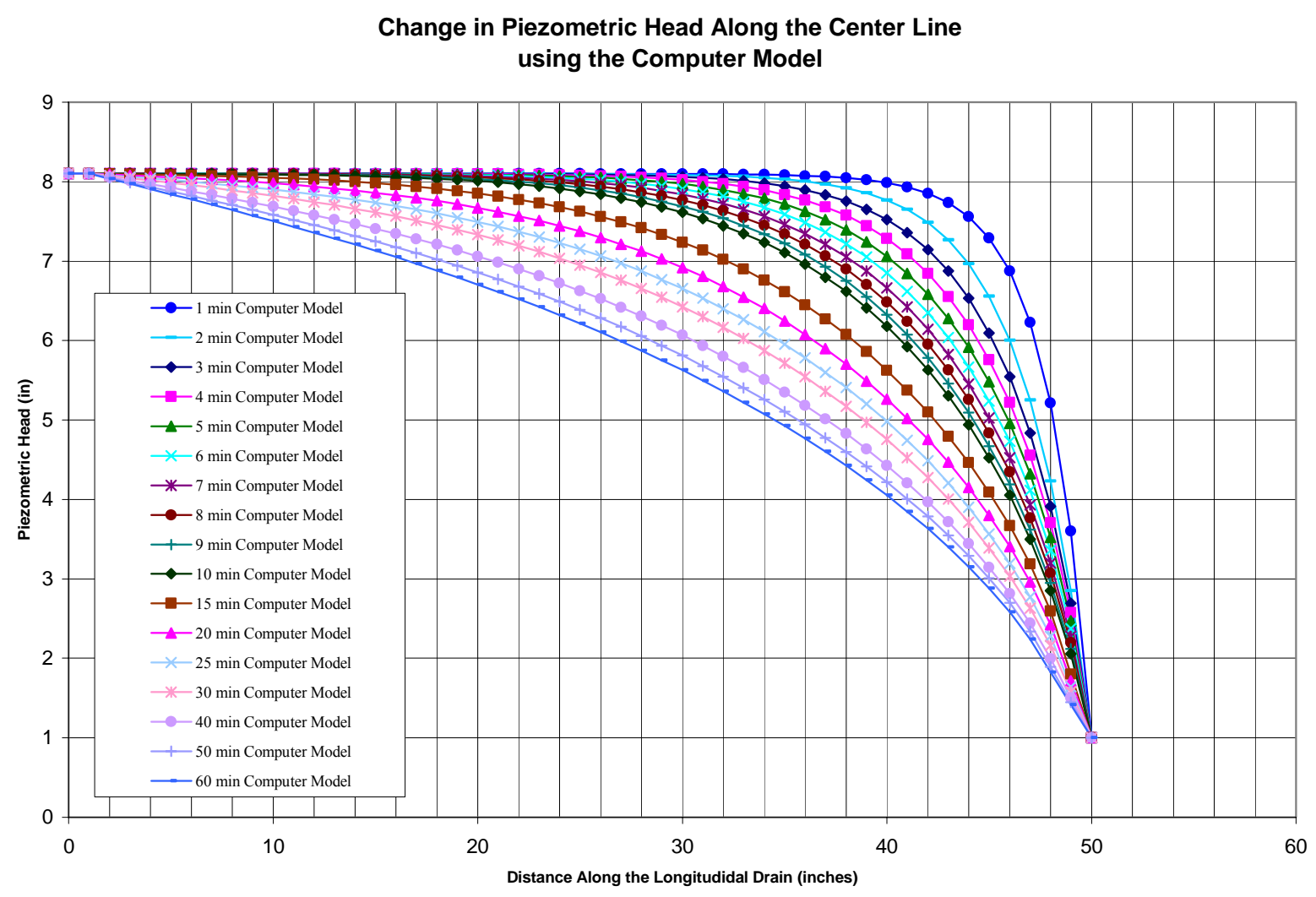

Figure 4.11: Computed piezometric variation along center line for Soil Type $\mathrm{C}$ at Zero slope, 12 " width

As can be seen from this figure, the difference in the water level after eight days is very close to that after one hour. It looks like the steady state conditions were reached in the model in about 8 hours. These results were compared with those obtained by using the physical model in Figure 4.12, which shows a comparison of the water level along the center line after half hour. The figure shows a nice fit between the two models. The model divides the sample in smaller sections, which allows a continuous trend in the flow, while the experimental set up is limited by the number of drains and their size. The difference in results between the computer model and the physical model is small. 


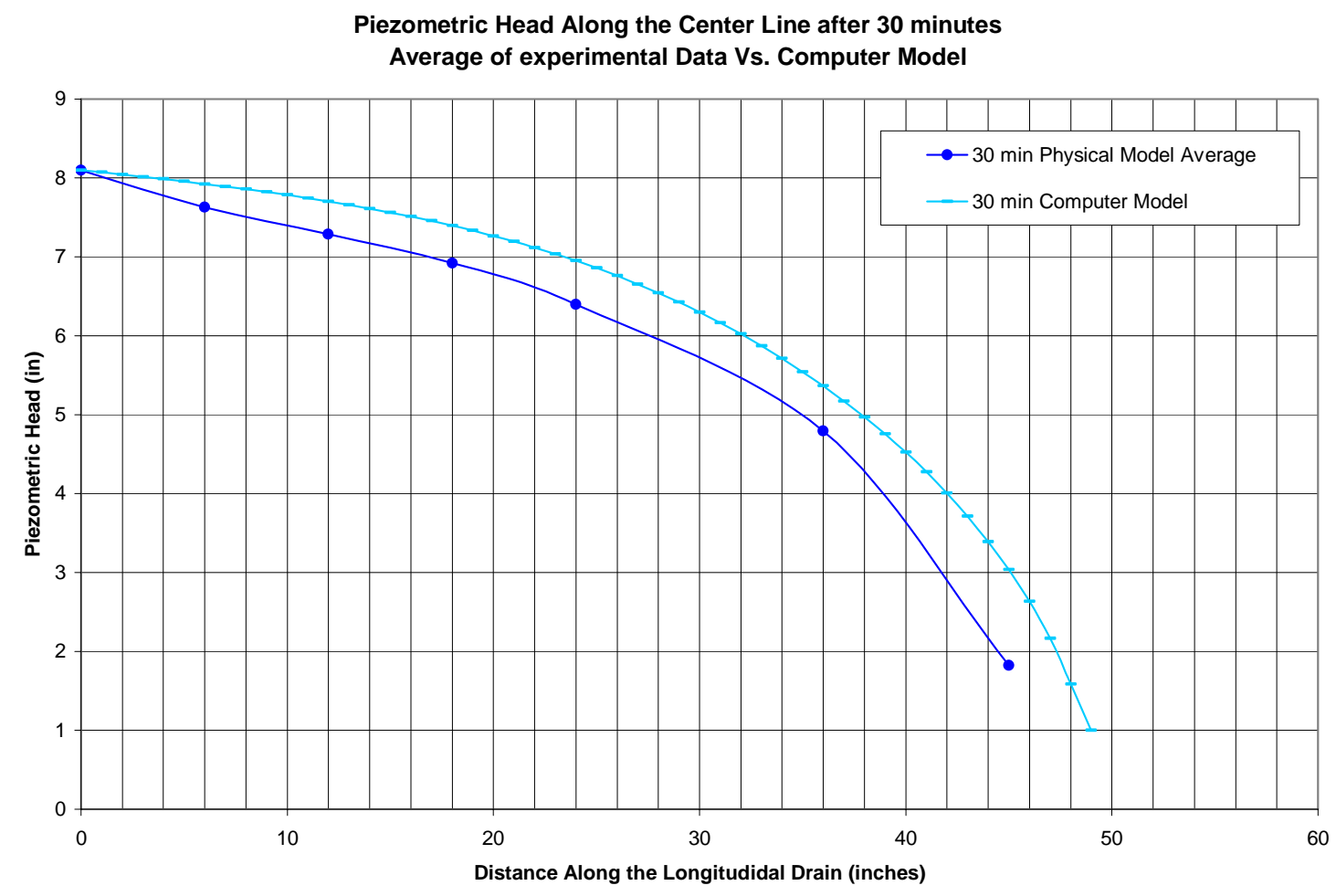

Figure 4.12: Comparison of piezometric variation along center line for Soil Type C at zero slope after half hour

\subsection{Physical versus Computer Models}

The behavior of seepage through a longitudinal drain was presented in the previous sections of this chapter for one soil type. A detailed investigation of transient behavior for different soils types and drainage conditions is presented in this section. Results from the computer model are compared with the data from the physical model. In this section, only the cases with half-trench spacing of 12 inches are presented. It should be noted that more tests were performed for this spacing than for any other. 
In the computer model used from this point onwards, the drains were simulated by using all cells in the wall as drains (see case (a) in Figure 3.16). This drain configuration tends to give values that are closer to the observed data than the ones obtained using the other setup.

\subsubsection{Transient behavior of end drain during one hour}

In this section, the change in flow rate is presented for both physical and computer models during the first hour after activation of the drain. All set-ups in this section have a half-trench width of twelve inches, an upstream head of eight inches and a horizontal slope. Figure 4.13 and Figure 4.14 show the one hour transient behavior of the

piezometric heads for soil A along the center line for the physical model and the computer model, respectively. These two figures show the drop in the water table during the first hour after activation of the end drain. 
Piezometric Head Along the Center Line Average of experimental Data

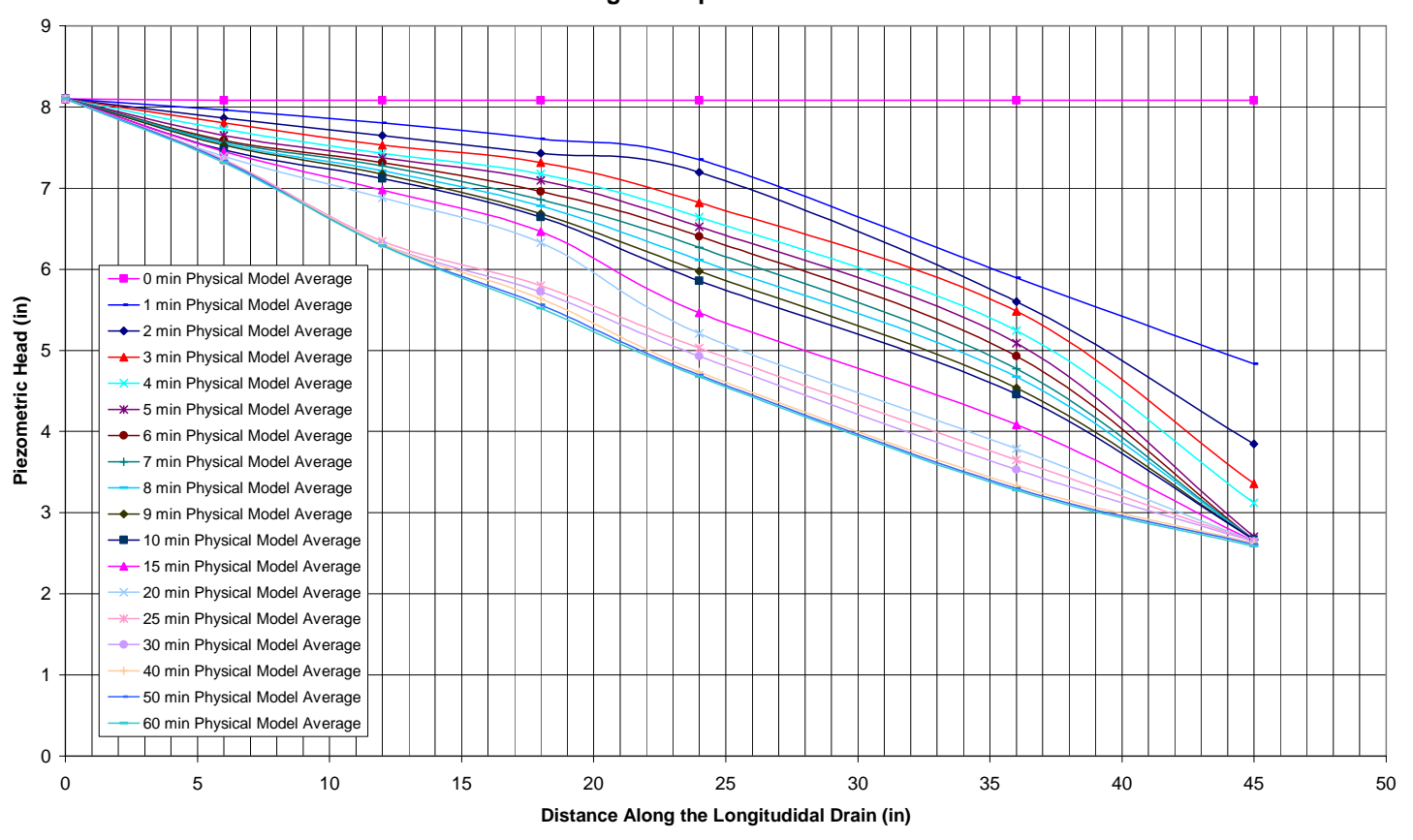

Figure 4.13: Piezometric variation along Center Line for Soil Type A - Physical Model

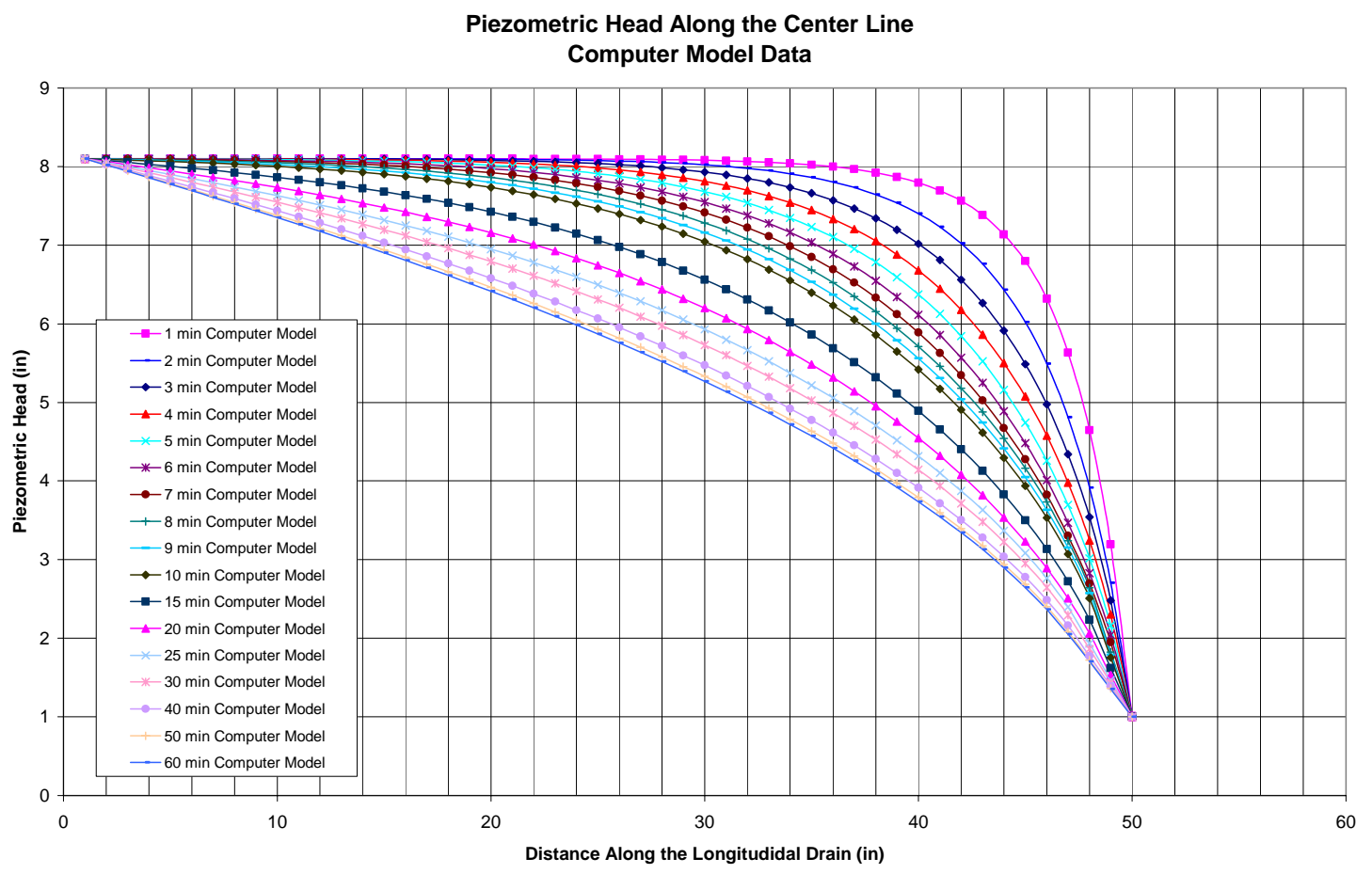

Figure 4.14: Piezometric variation along Center Line for Soil Type A - Computer Model 
As seen from these figures, the piezometric head inside the soil sample decreases very rapidly for the first ten minutes after activation of the end drain. After that, the drop in the piezometric head occurs at a much slower rate. This same phenomenon can be seen in Figure 4.15, which shows the change in flow rate at the end drain during the first hour after activation. As can be seen from this figure, both physical and computer models show that the flow rate stabilizes after approximately ten minutes. It should be noted that soil type A has the highest hydraulic conductivity value.

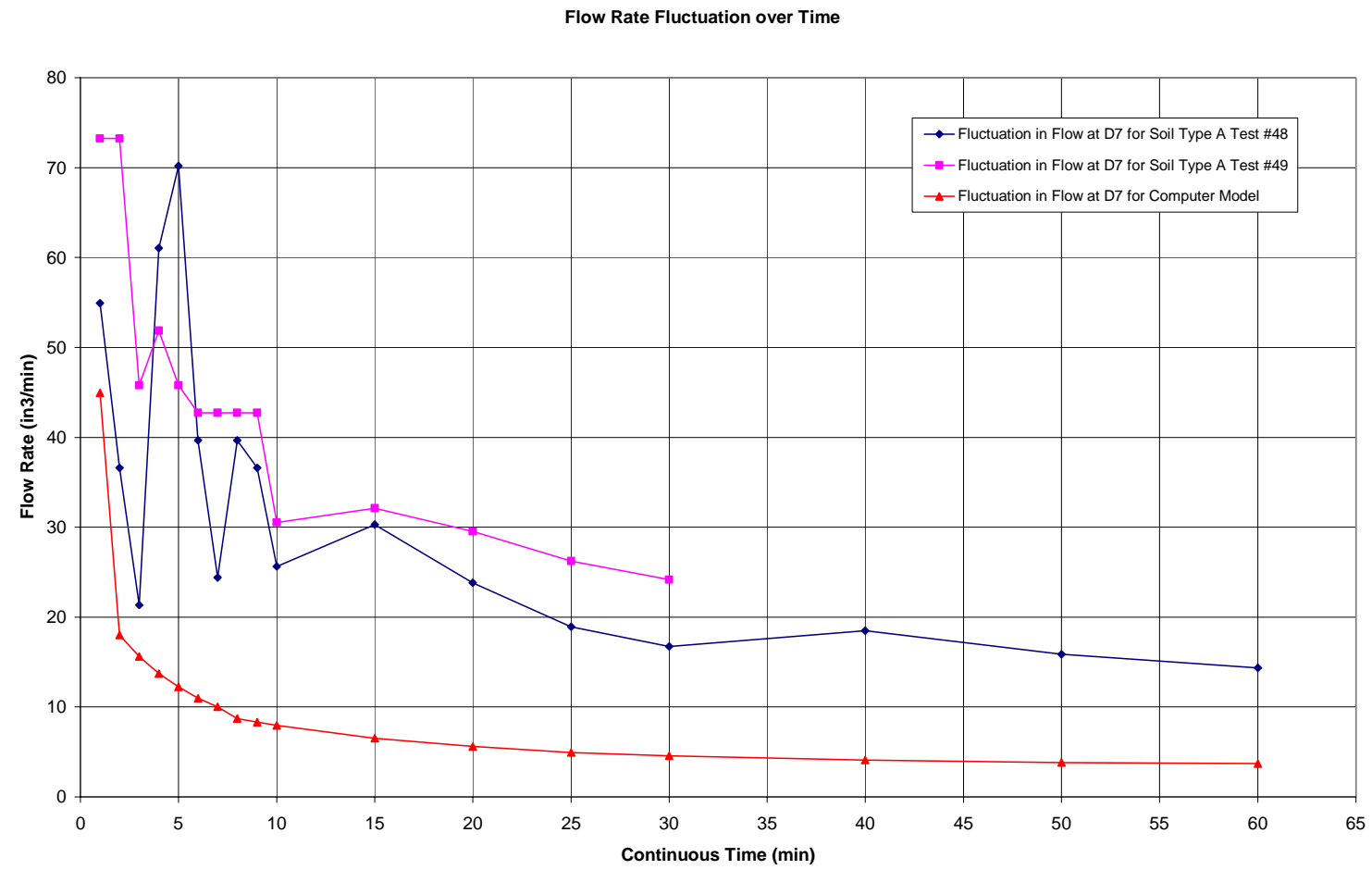

Figure 4.15: Comparison in Flow Rate Fluctuation for Soil Type A

Figures 4.16 to 4.20 show comparisons of piezometric heads from the computer model with the measured data in the physical model at different time periods ( 1 minute, 5 minutes, 15 minutes, 30 minutes, and 60 minutes). It can be seen that the computed values compare well with the data from the physical model. 
Piezometric Head Along the Center Line after 1 min Average of experimental Data Vs. Computer Model

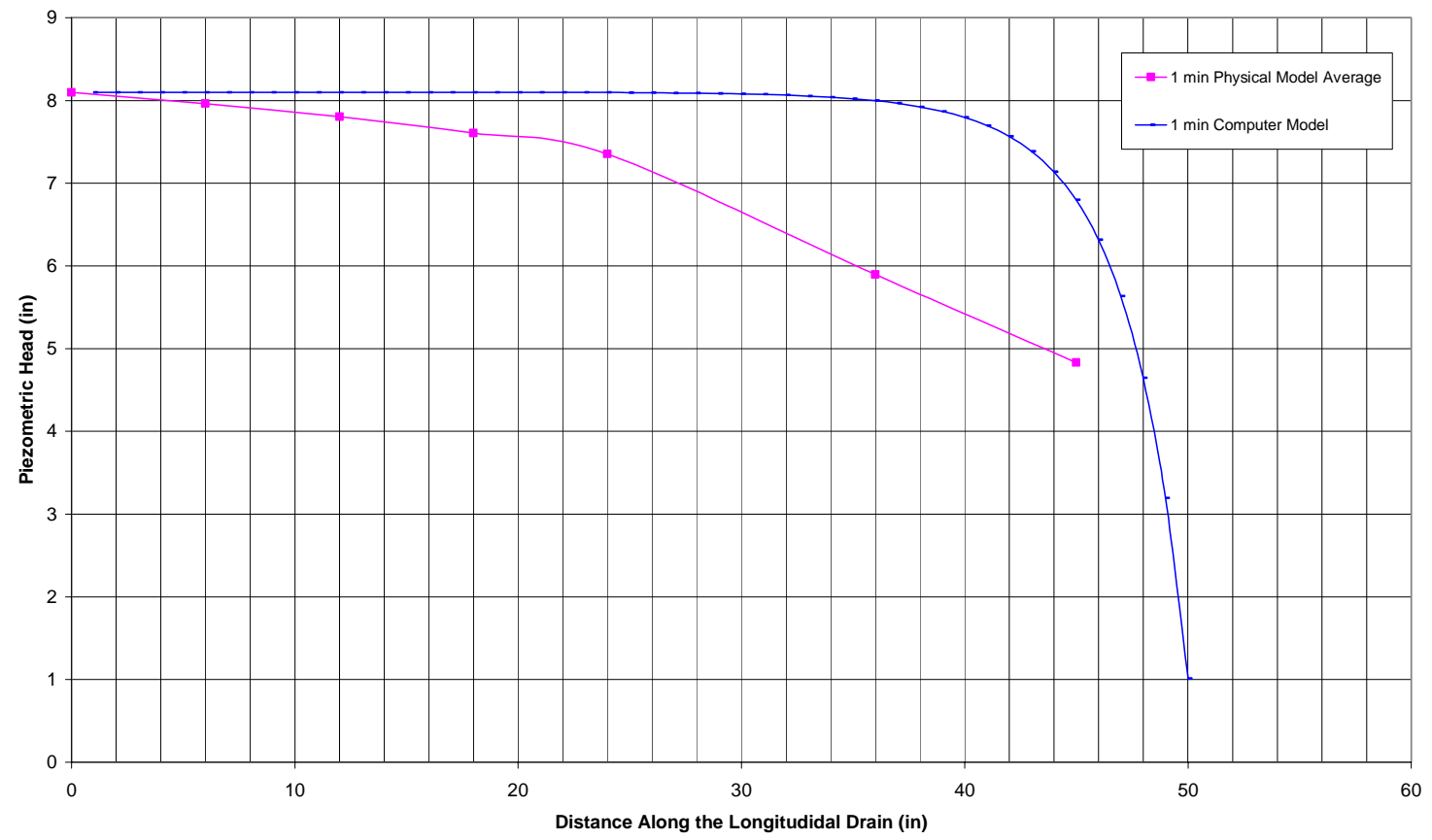

Figure 4.16: Piezometric Level along Center Line for Soil Type A after 1 minute

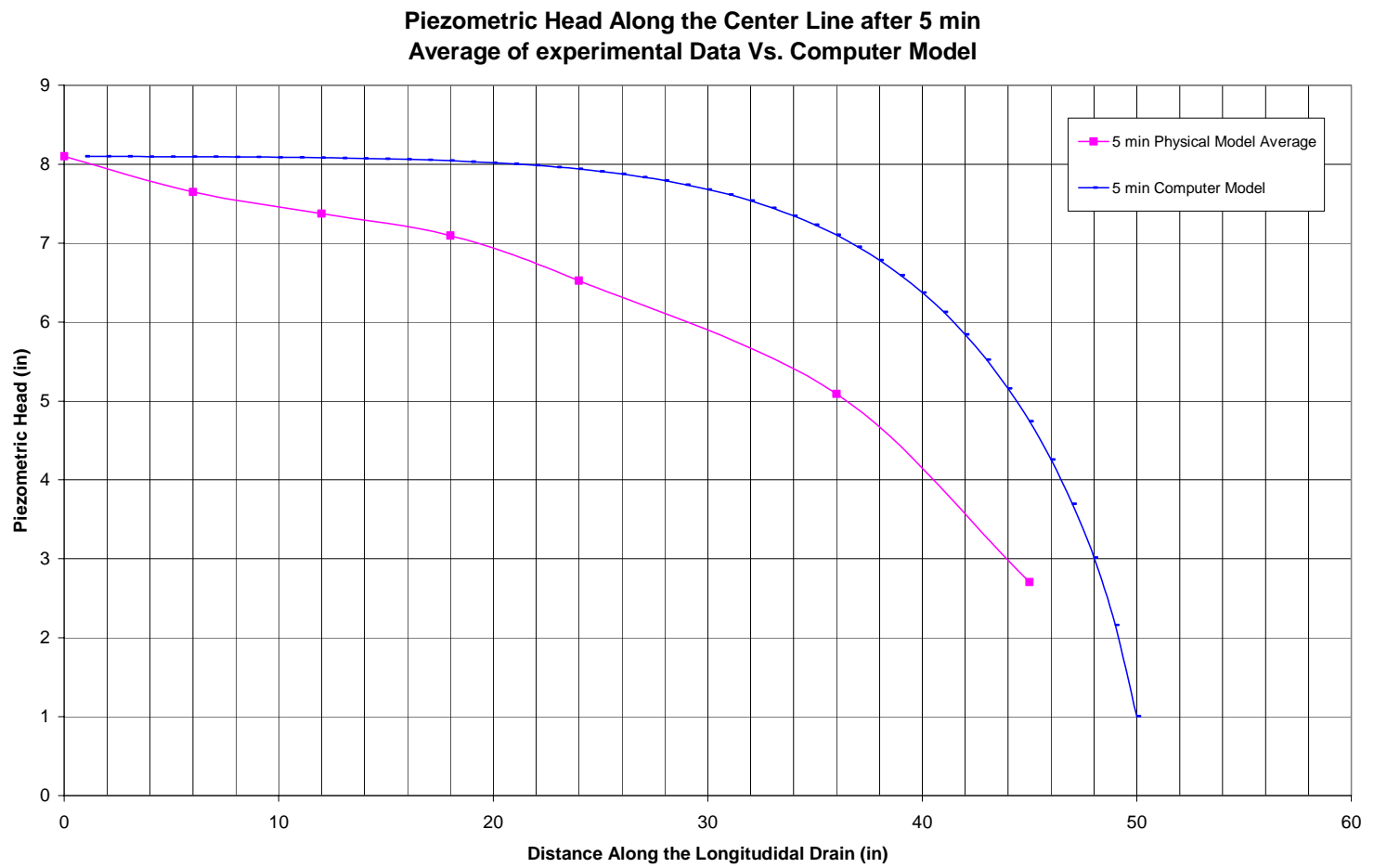

Figure 4.17: Piezometric Level along Center Line for Soil Type A after 5 minutes 


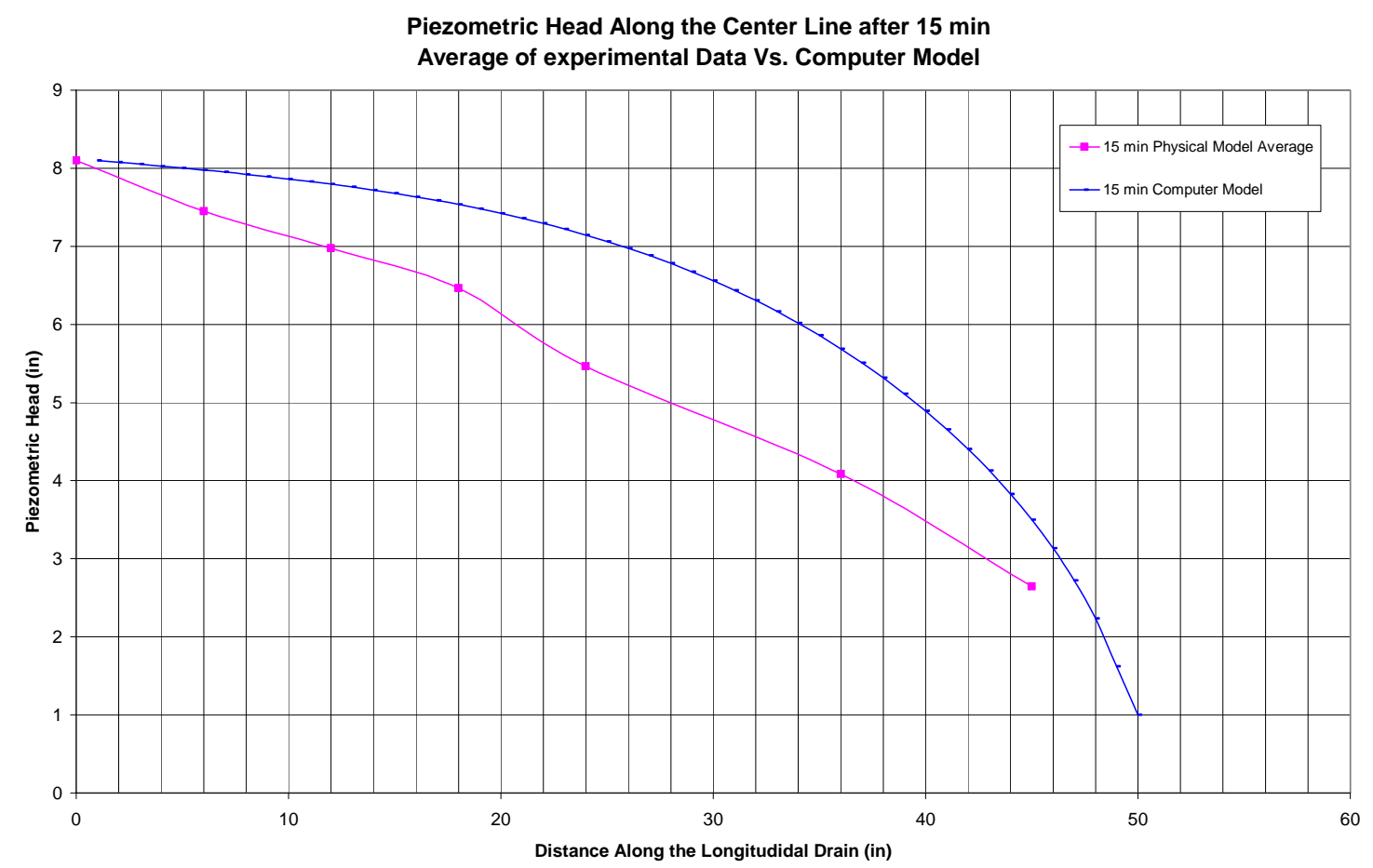

Figure 4.18: Piezometric Level along Center Line for Soil Type A after 15 minutes

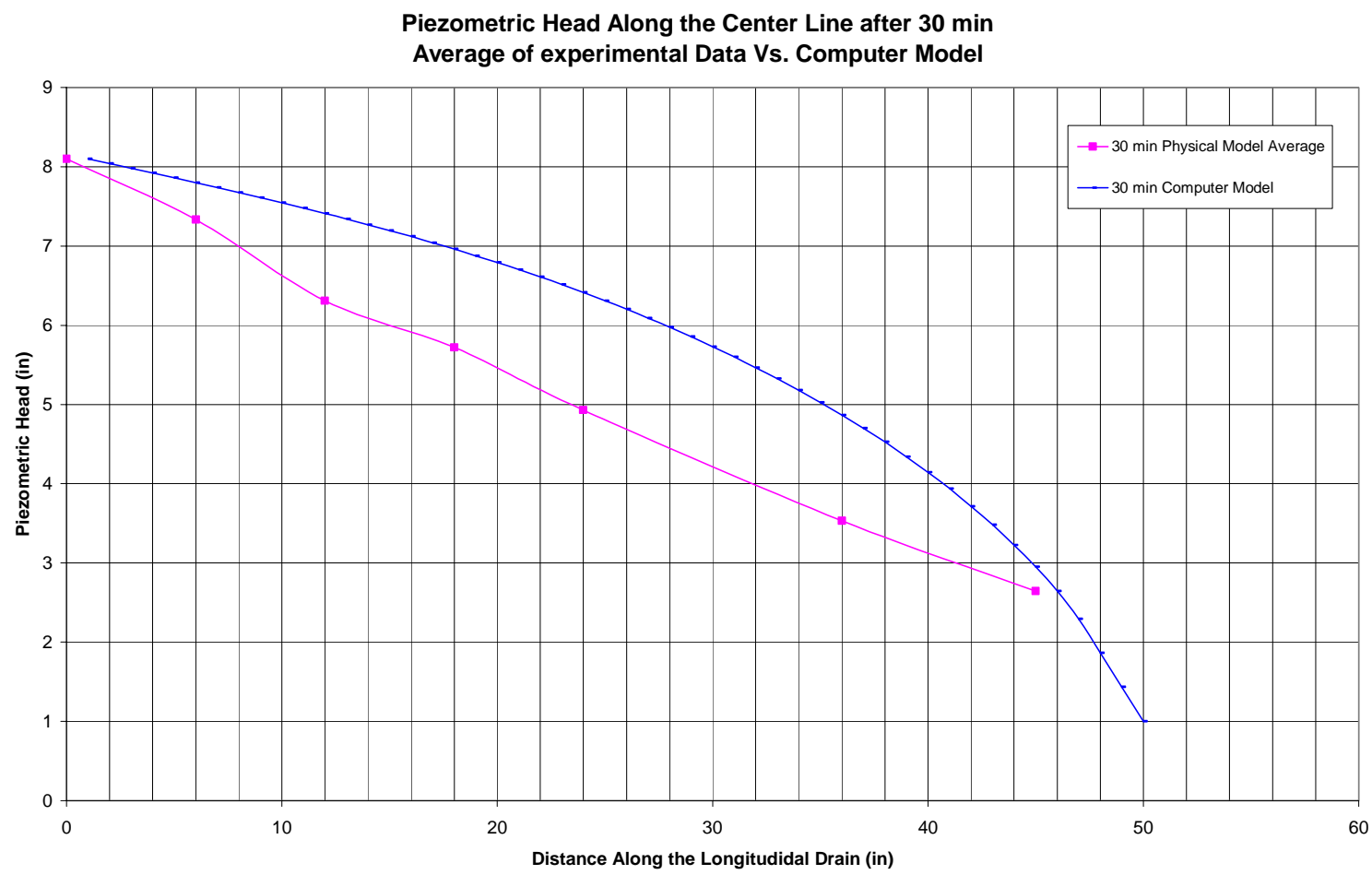

Figure 4.19: Piezometric Level along Center Line for Soil Type A after 30 minutes 


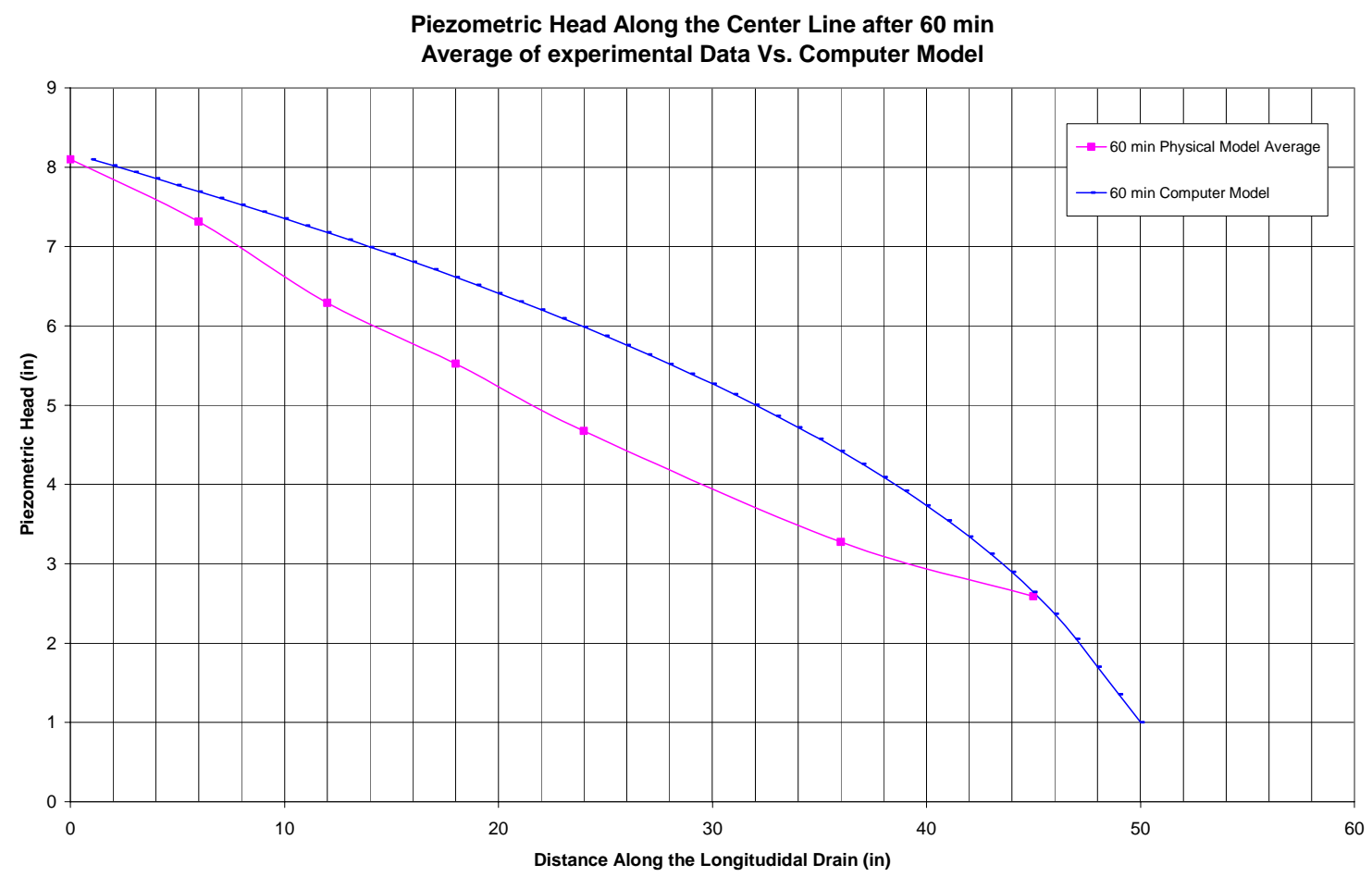

Figure 4.20: Piezometric Level along Center Line for Soil Type A after 60 minutes

These figures show that the values from the physical model and the computer model get closer to each other with time. The same type of analyses and comparisons were performed for soils B, C, D and E as can be seen in Appendix A2. The following table shows the transient times for these soils.

Table 4.2: Transient times at the end drain

\begin{tabular}{|l|l|l|l|l|l|}
\hline Soil Type & A & B & C & D & E \\
\hline Transient Time & $20 \mathrm{~min}$ & $30 \mathrm{~min}$ & $40 \mathrm{~min}$ & 4 hour & 1 day \\
\hline
\end{tabular}


As can be seen from the change in piezometric level over time for the different soils, the hydraulic conductivity is affecting the transient behavior. It can be noted that for soil A, most of the water level drop occurred during the first twenty minutes. For soil B the change occurred during the first half hour. For soil C most of the change in the water table occurred during the first forty minutes. For soil D, the majority of the change occurred during the first 4 hours. For soil E, most of the changes occurred during the first day. As shown in Table 4.2, the larger the clay content the longer it takes for the drains to be fully operational (steady state).

Another interesting feature that can be noted in the above figures is that the values obtained using the physical model and those obtained using the computer model get closer to each other as time progresses. The reason for that phenomenon could be that the piezometers in the physical model do not give instantaneous values, while the computer model provides instantaneous values. Moreover, there are only five piezometers along the center line of the physical model, while in the computer model there are forty eight piezometers.

\subsubsection{Transient behavior of side drain during one hour}

In the previous sections of this report, the seepage of water along the slope was investigated under transient and steady state conditions. When seepage forces exceed the capacity of the soil, the natural equilibrium of the slope is disturbed causing slope failures. The objective of this study was to investigate the effectiveness of longitudinal drains along the slope for removing seepage volume through the slope. 
It is unreasonable to assume that a longitudinal drain will become fully functional immediately after installation. For this reason, it is necessary to understand the time it will take for a longitudinal drain to be fully functional after installation. In other words, it is important to understand the duration of initial transient behavior of both the water table and the water flow to reach steady state conditions of effectiveness. The initial fluctuations of seepage determine the transient behavior of the drain.

In this section of the report, the transient behavior of the side drain (longitudinal drain) is presented. More than sixteen physical models were assembled and tested to collect data on the transient behavior of longitudinal drains. The majority of the models were twelve inches in width, had a constant water head of eight inches at the main tank, and were horizontal (zero slope). Computer models were prepared to mach the characteristics of these physical models in order to generate data for comparisons between physical and computer models.

\subsubsection{Piezometric Head along the center line}

The piezometric level along the center line drops at different rates for different soils. This means that the hydraulic conductivity plays a major role in the transition time. Figure 4.21 and Figure 4.22 show the change in piezometric head for the computer model and the physical model, respectively. Figure 4.23 through Figure 4.27 show comparisons of piezometric head for both models at different times. It is important to note that the similar plots were generated for all soil types. Results for soil A are shown below and results for soils B, C, D and E are shown in Appendix A3. 


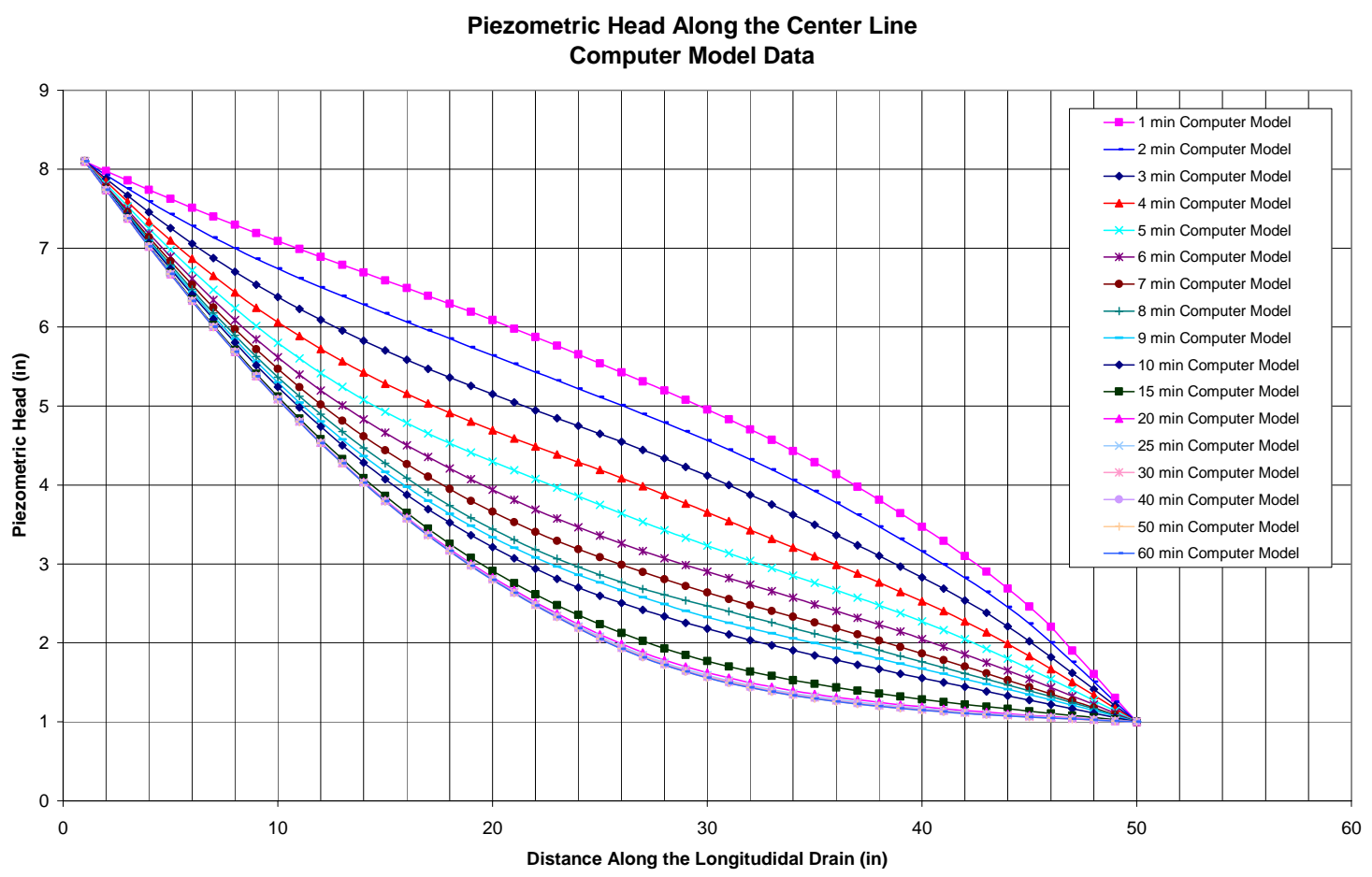

Figure 4.21: Piezometric head along center line for soil type A - Computer Model 


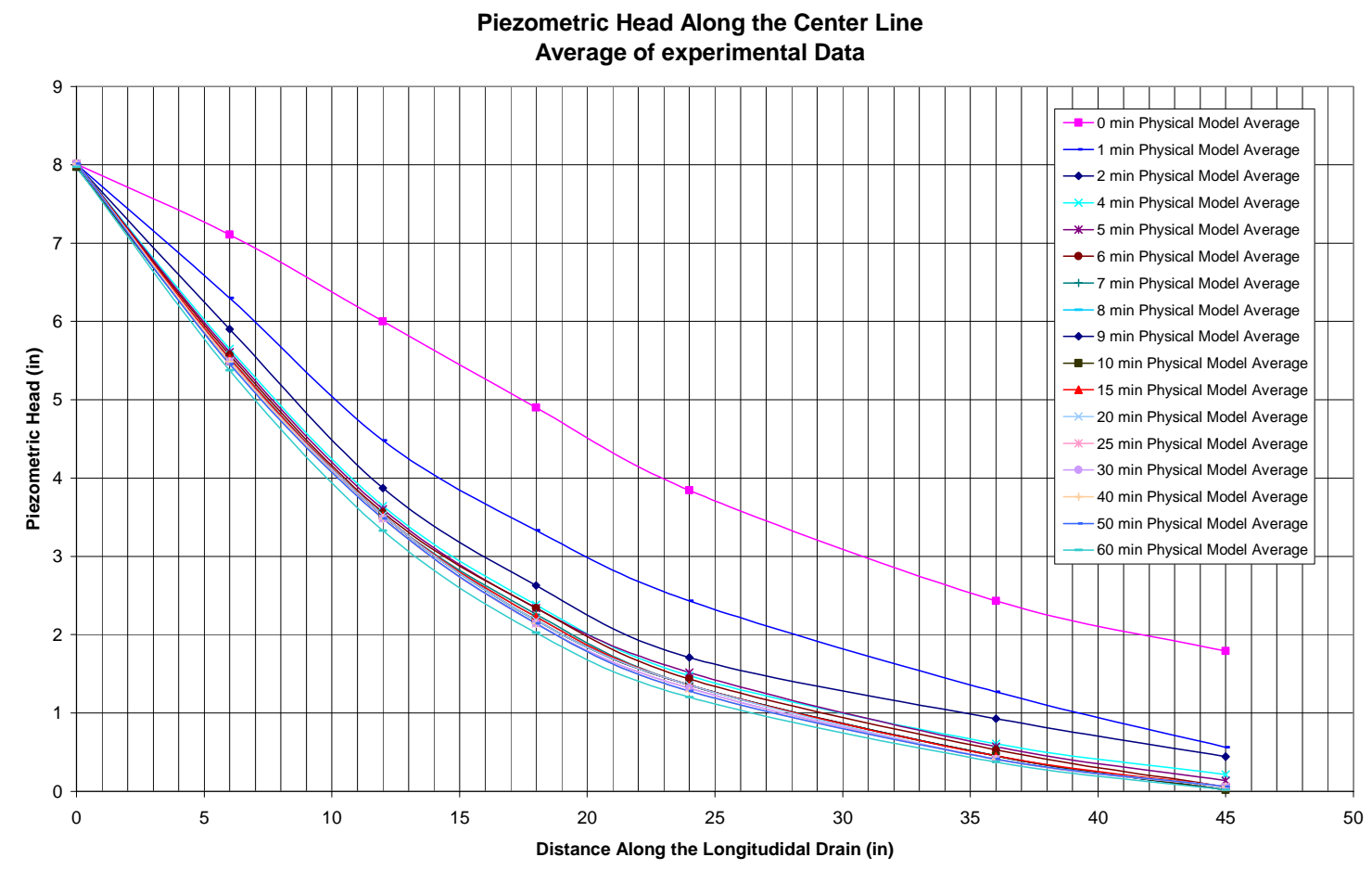

Figure 4.22: Piezometric head along center line for soil type A - Physical Model

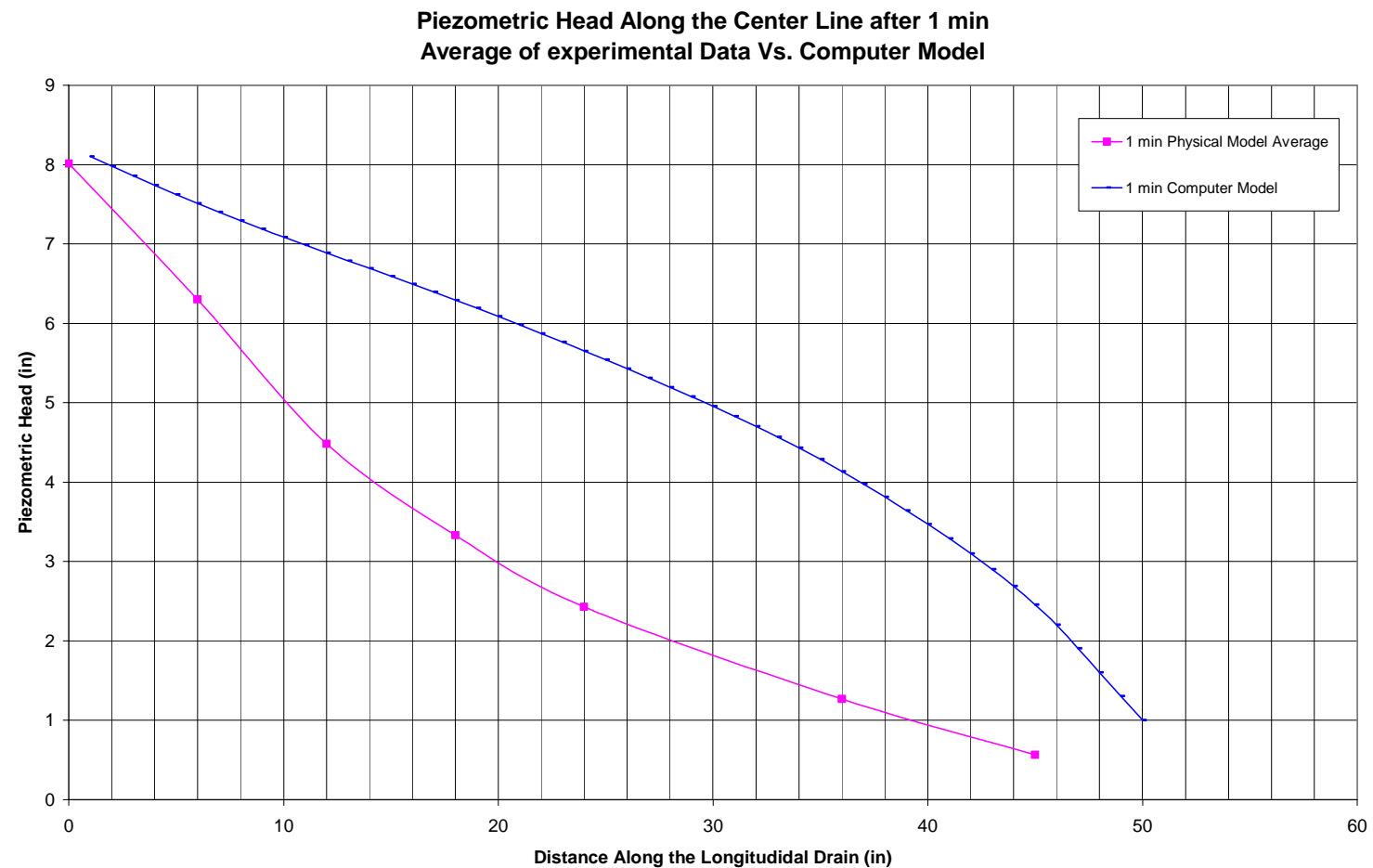

Figure 4.23: Piezometric head along center line for soil type A after 1 minute 


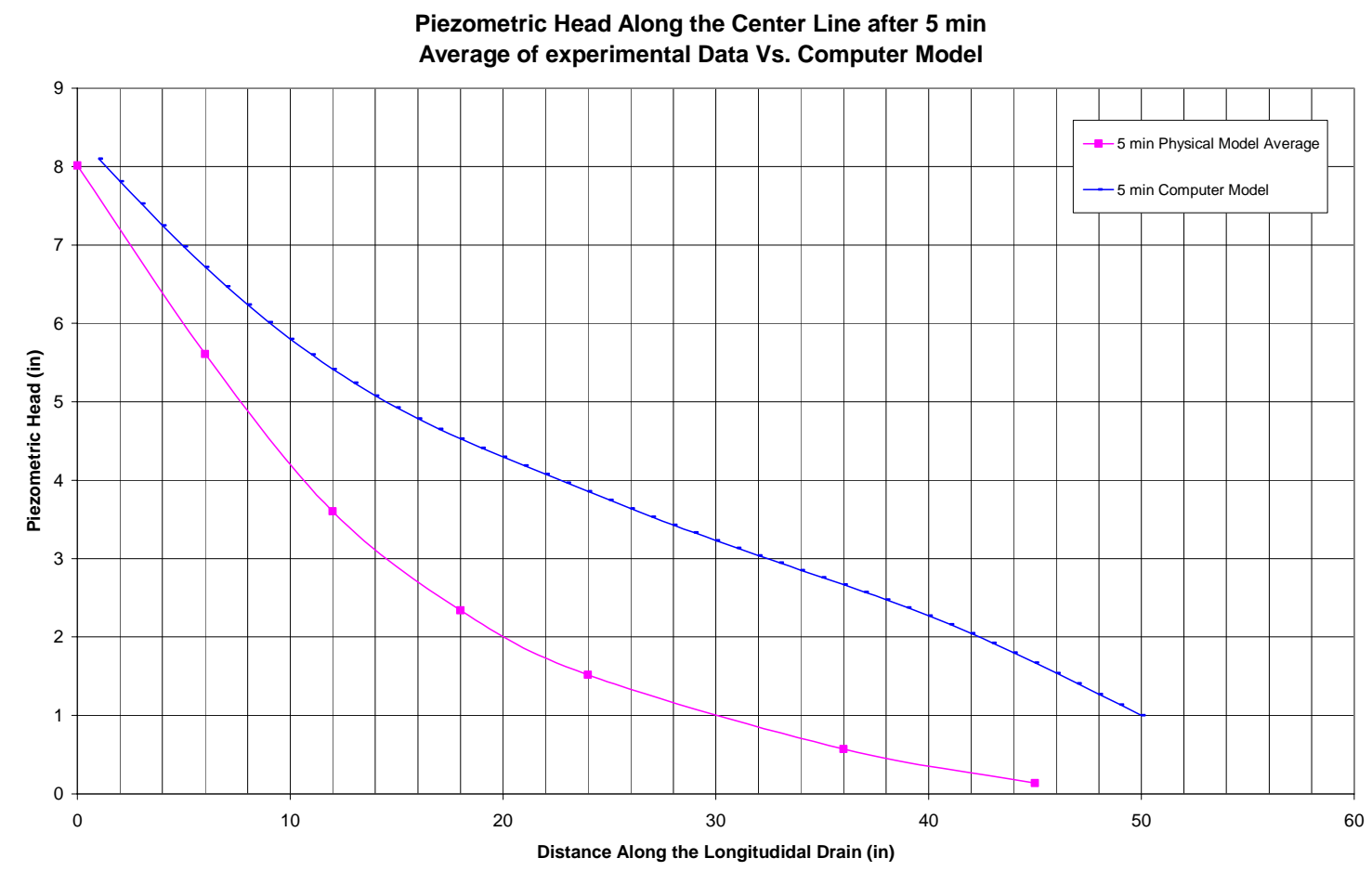

Figure 4.24: Piezometric head along center line for soil type A after 5 minutes

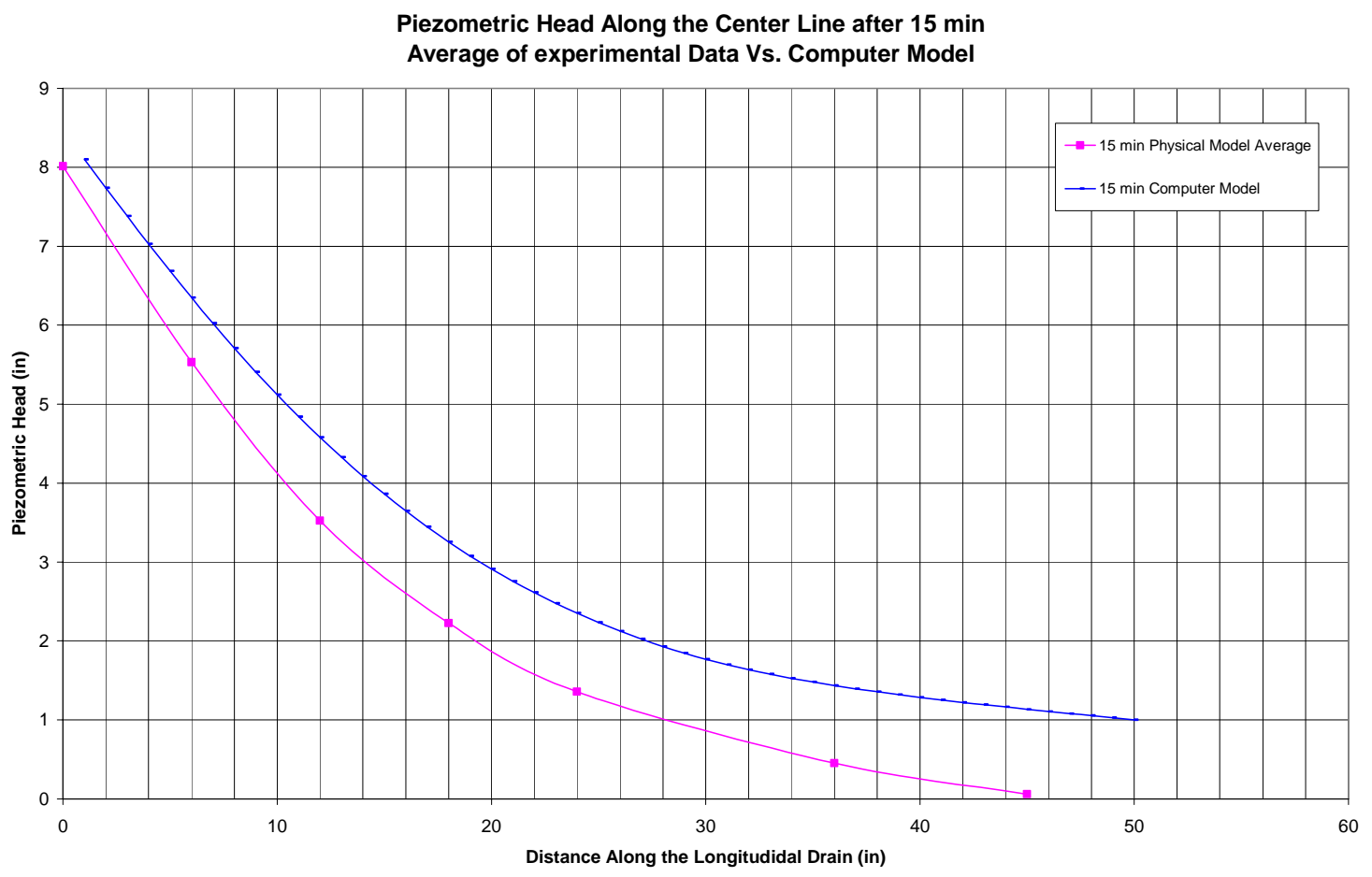

Figure 4.25: Piezometric level along center line for soil type A after 15 minutes 
Piezometric Head Along the Center Line after $\mathbf{3 0}$ min Average of experimental Data Vs. Computer Model

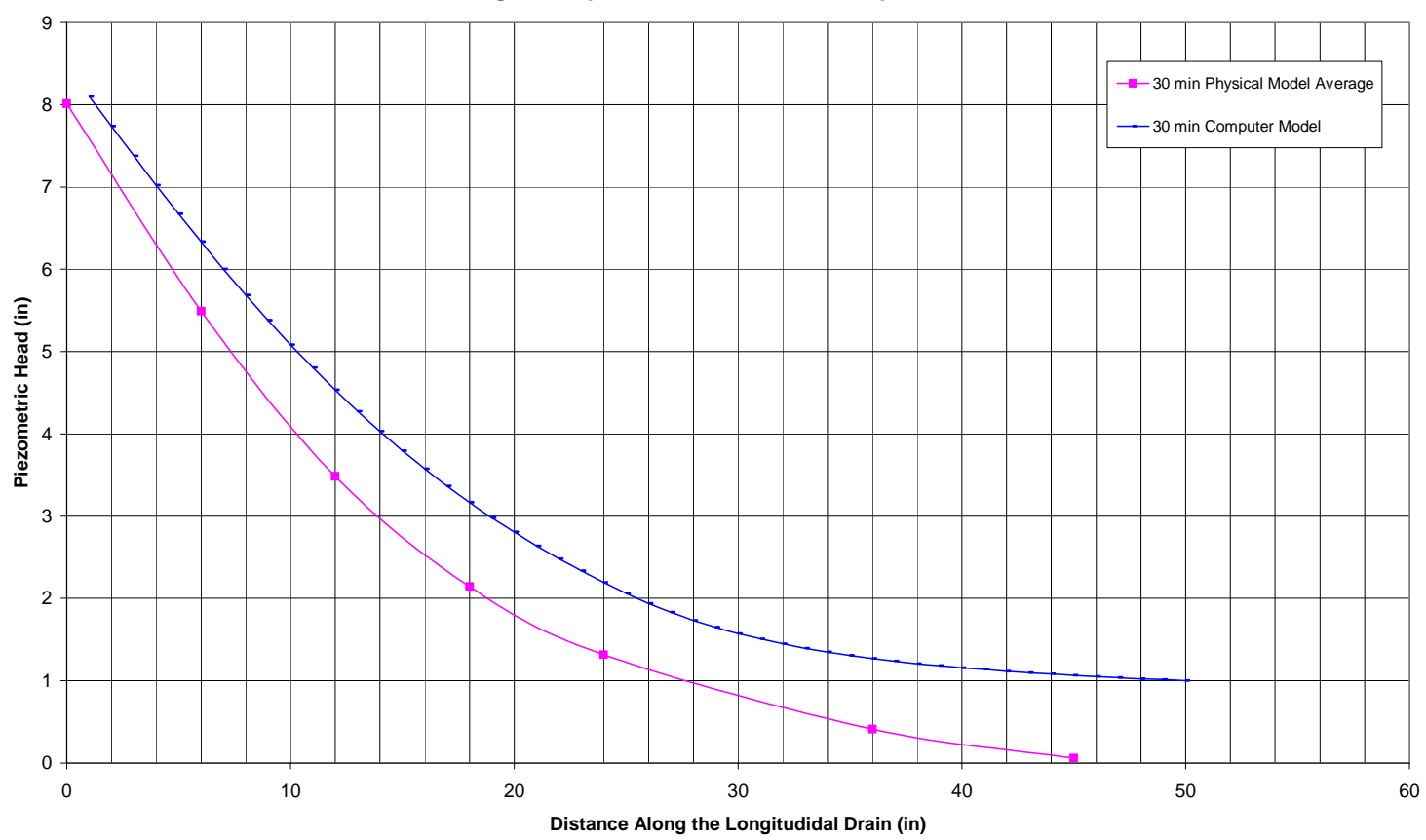

Figure 4.26: Piezometric head along center line for soil type A after 30 minutes

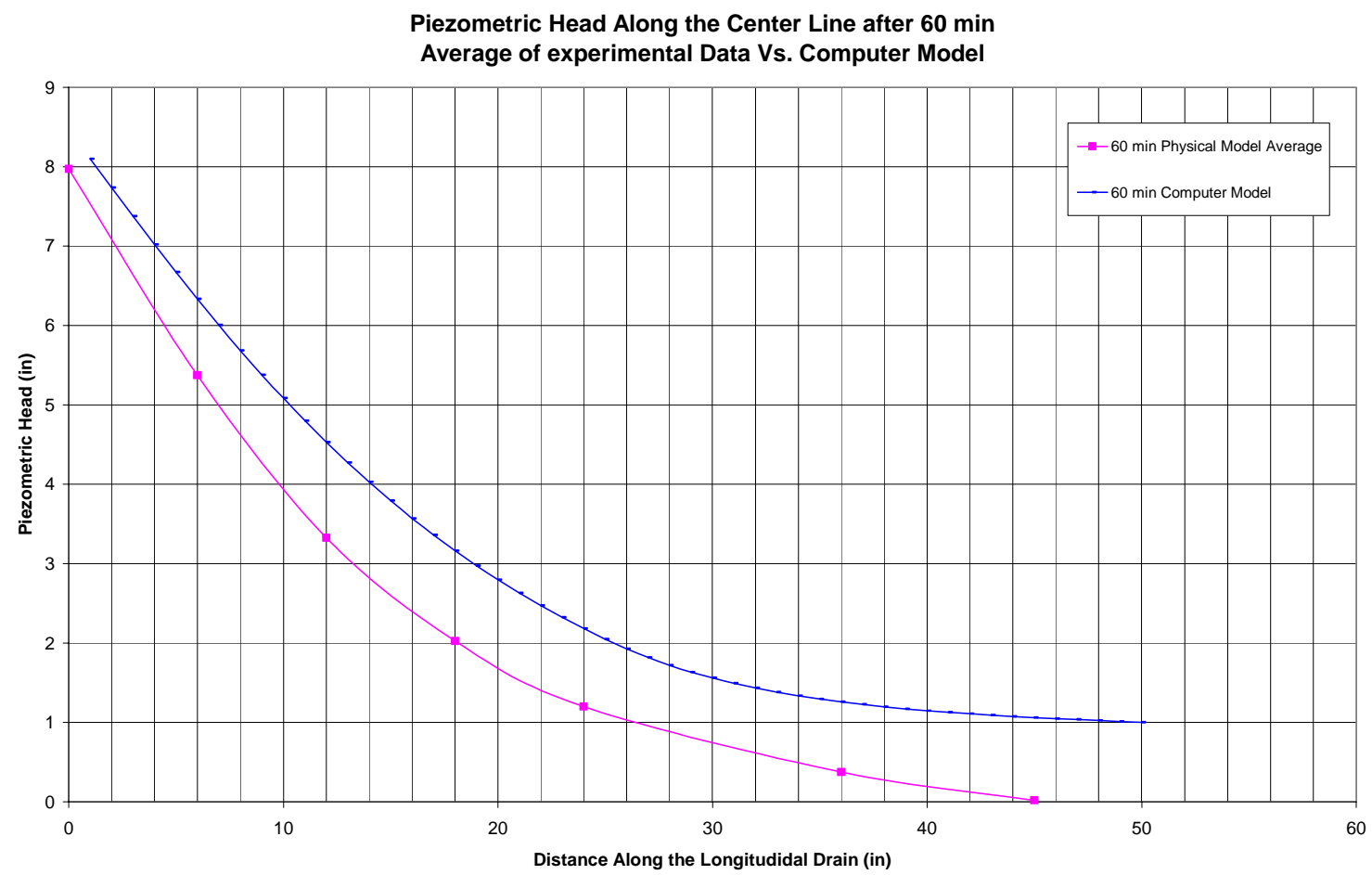

Figure 4.27: Piezometric head along center line for soil type A after 60 minutes 
The time period between the opening of the side drains and the reaching the steady state piezometric head along the center line was defined as the transient time. Table 4.3 shows transient time for different soils. The computed transient time compares well with the measured data for most of the soils tested in this study.

Table 4.3: Transient time along the center line

\begin{tabular}{|l|l|l|l|l|l|}
\hline & A & B & C & D & E \\
\hline Physical Model & $2 \mathrm{~min}$ & $10 \mathrm{~min}$ & $30 \mathrm{~min}$ & $40 \mathrm{~min}$ & $7 \mathrm{hr}$ \\
\hline Computer Model & $15 \mathrm{~min}$ & $20 \mathrm{~min}$ & $30 \mathrm{~min}$ & $50 \mathrm{~min}$ & $8 \mathrm{hr}$ \\
\hline
\end{tabular}

\subsubsection{Piezometric heads at Cross-Sections A and B}

In the previous sections, the variation of piezometric head along a longitudinal section was presented. The seepage occurred in the longitudinal direction only when the end drain was open. However, when the longitudinal and end drains are open, water flows in both longitudinal and transverse directions. The transverse flow has an influence on the shape of the water table. The longitudinal drain reduces the water head inside the soil not only along the longitudinal direction, but also along the transverse direction. Piezometric data was collected along two transverse cross-sections to study the influence of longitudinal drains on the water head along cross-sections A and B (see Figure 3.3). The cross-section A is located at a distance of 12 inches from the reservoir tank, while crosssection B is located at a distance of 24 inches from the reservoir tank as shown in Figure 3.3. Results for soil A are presented below. Results for soils B, C, D and E can be seen in Appendix A4. Figure 4.28 shows the variation of piezometric head based on the computer model along the cross-section A. Figure 4.29 shows the measured data on 
piezometric head along the cross-section A. Both models show the drop in piezometric head with time. Figures 4.30 through 4.34 show a comparison of computer model results with laboratory measurements along the cross-section A at different times for soil A. The reason for differences between these two figures could be that the piezometers in the physical model do not give instantaneous values, while the computer model provides instantaneous values.

Figure 4.35 shows the variation of piezometric head based on the computer model along the cross-section B. Figure 4.36 shows the measured data on piezometric head along the cross-section B. Both models show the drop in piezometric head with time. Figures 4.37 through 4.41 show a comparison of computer model results with laboratory measurements along the cross-section B at different times for soil A. The reason for differences between these two figures could be that the piezometers in the physical model do not give instantaneous values, while the computer model provides instantaneous values.

Based on the computer modeling data presented above and in Appendix A4, transient times for different soils were computed. Table 4.4 below shows the time required to reach steady state conditions along cross-sections A and B.

Table 4.4: Transient time at cross-section A and B

\begin{tabular}{|l|l|l|l|l|l|}
\hline & $\mathrm{A}$ & $\mathrm{B}$ & $\mathrm{C}$ & $\mathrm{D}$ & $\mathrm{E}$ \\
\hline $\begin{array}{l}\text { Cross-Section X, } \\
\text { Computer Model }\end{array}$ & $10 \mathrm{~min}$ & $20 \mathrm{~min}$ & $30 \mathrm{~min}$ & $60 \mathrm{~min}$ & $60 \mathrm{~min}$ \\
\hline $\begin{array}{l}\text { Cross-Section X, } \\
\text { Physical Model }\end{array}$ & $5 \mathrm{~min}$ & $5 \mathrm{~min}$ & $30 \mathrm{~min}$ & $50 \mathrm{~min}$ & $60 \mathrm{~min}$ \\
\hline $\begin{array}{l}\text { Cross-Section Y, } \\
\text { Computer Model }\end{array}$ & $15 \mathrm{~min}$ & $30 \mathrm{~min}$ & $30 \mathrm{~min}$ & $60 \mathrm{~min}$ & $60 \mathrm{~min}$ \\
\hline $\begin{array}{l}\text { Cross-Section Y, } \\
\text { Physical Model }\end{array}$ & $15 \mathrm{~min}$ & $20 \mathrm{~min}$ & $30 \mathrm{~min}$ & $50 \mathrm{~min}$ & $60 \mathrm{~min}$ \\
\hline
\end{tabular}




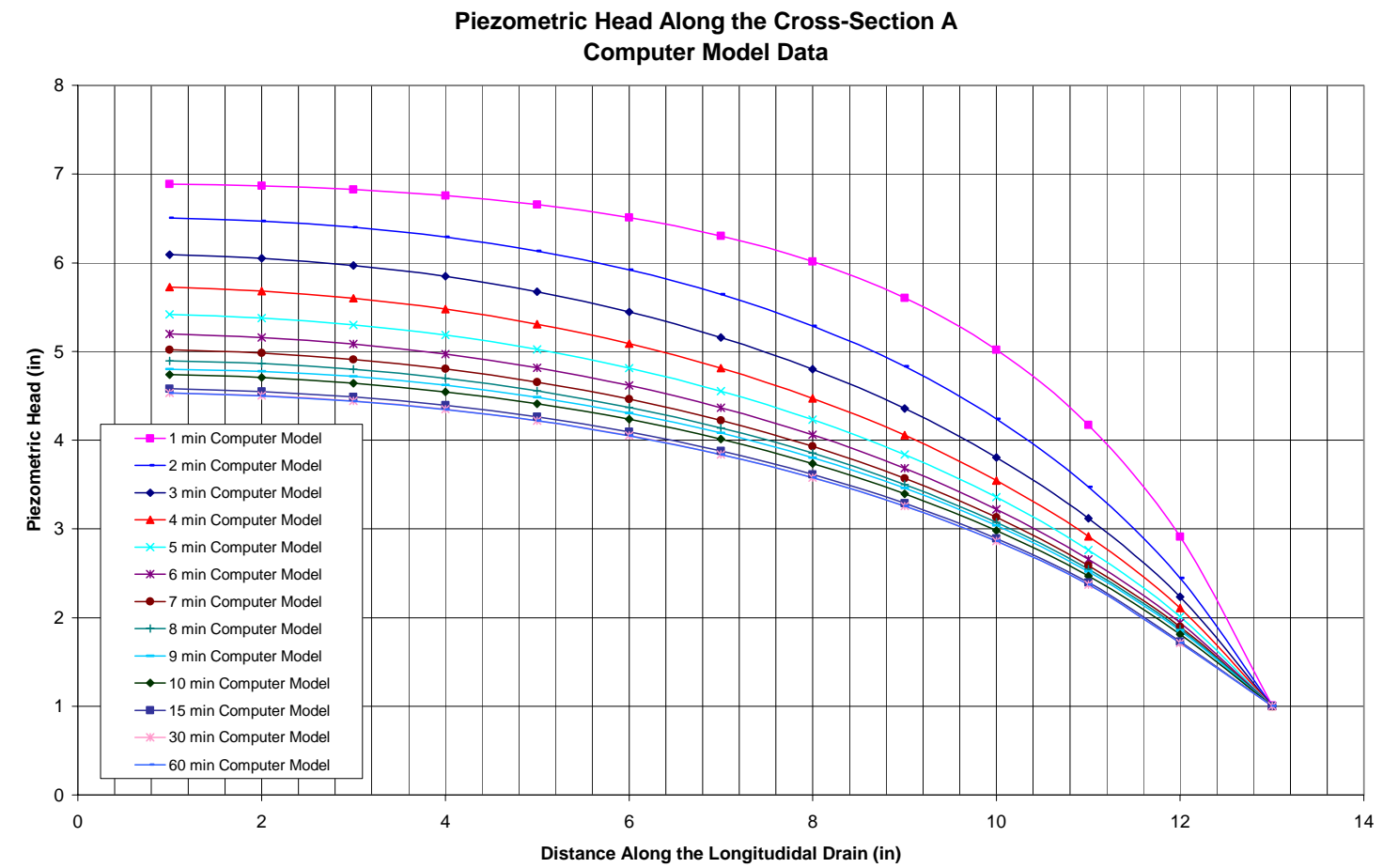

Figure 4.28: Piezometric head along cross-section A for soil type A - Computer Model

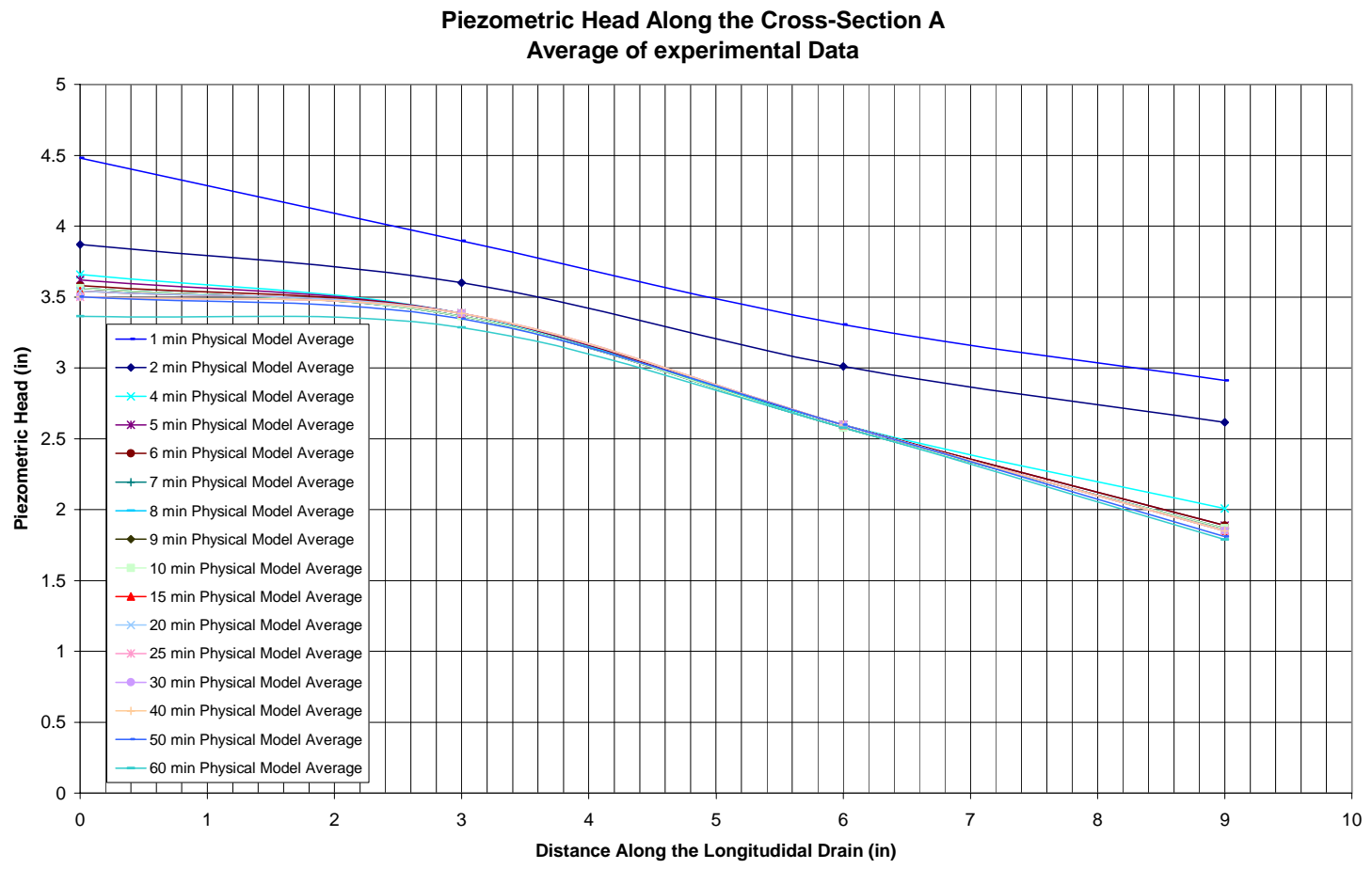

Figure 4.29: Piezometric head along cross-section A for soil type A - Physical Model 


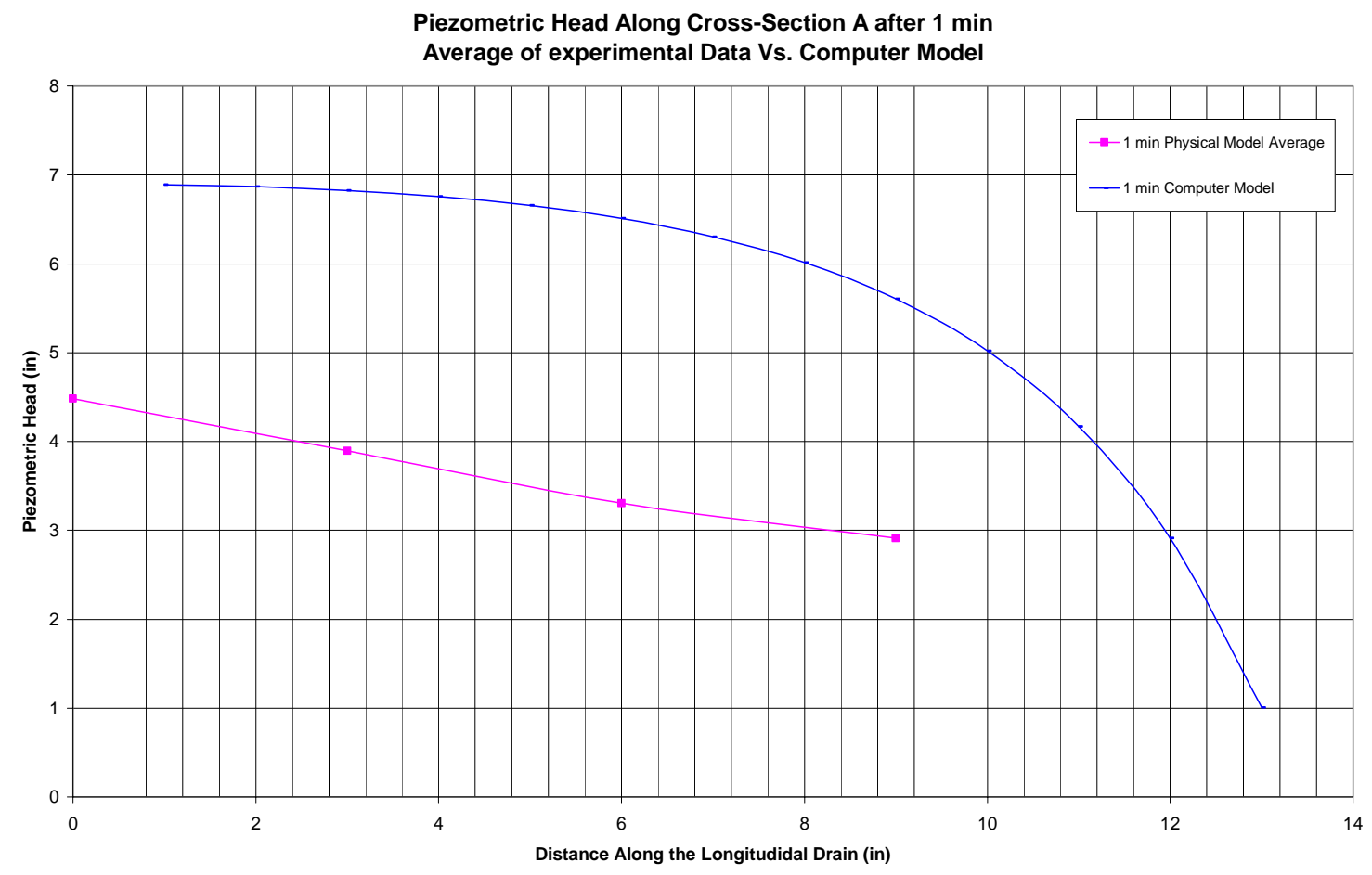

Figure 4.30: Piezometric head along cross-section A for soil type A after 1 minute

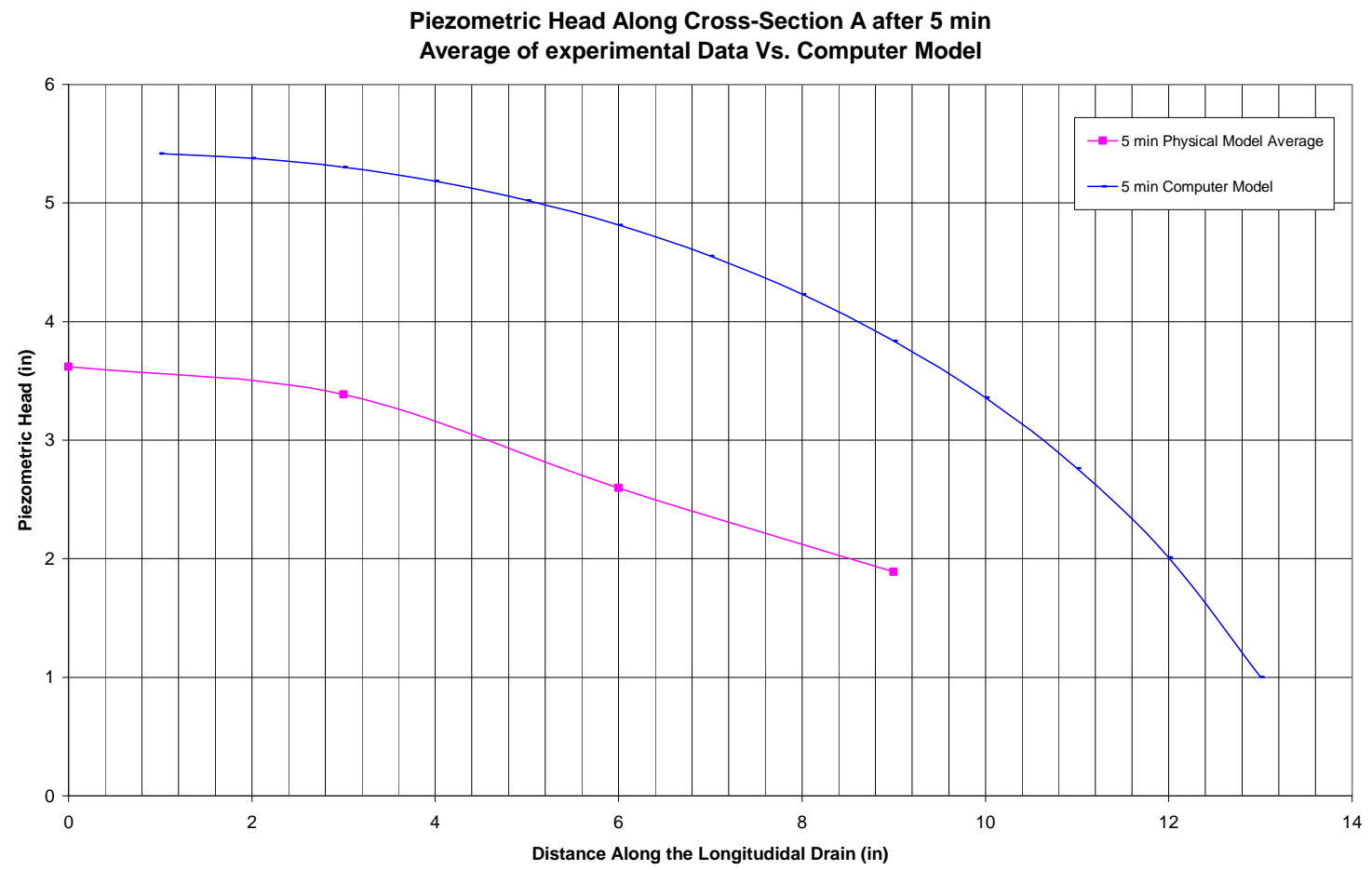

Figure 4.31: Piezometric head along cross-section A for soil type A after 5 minutes 


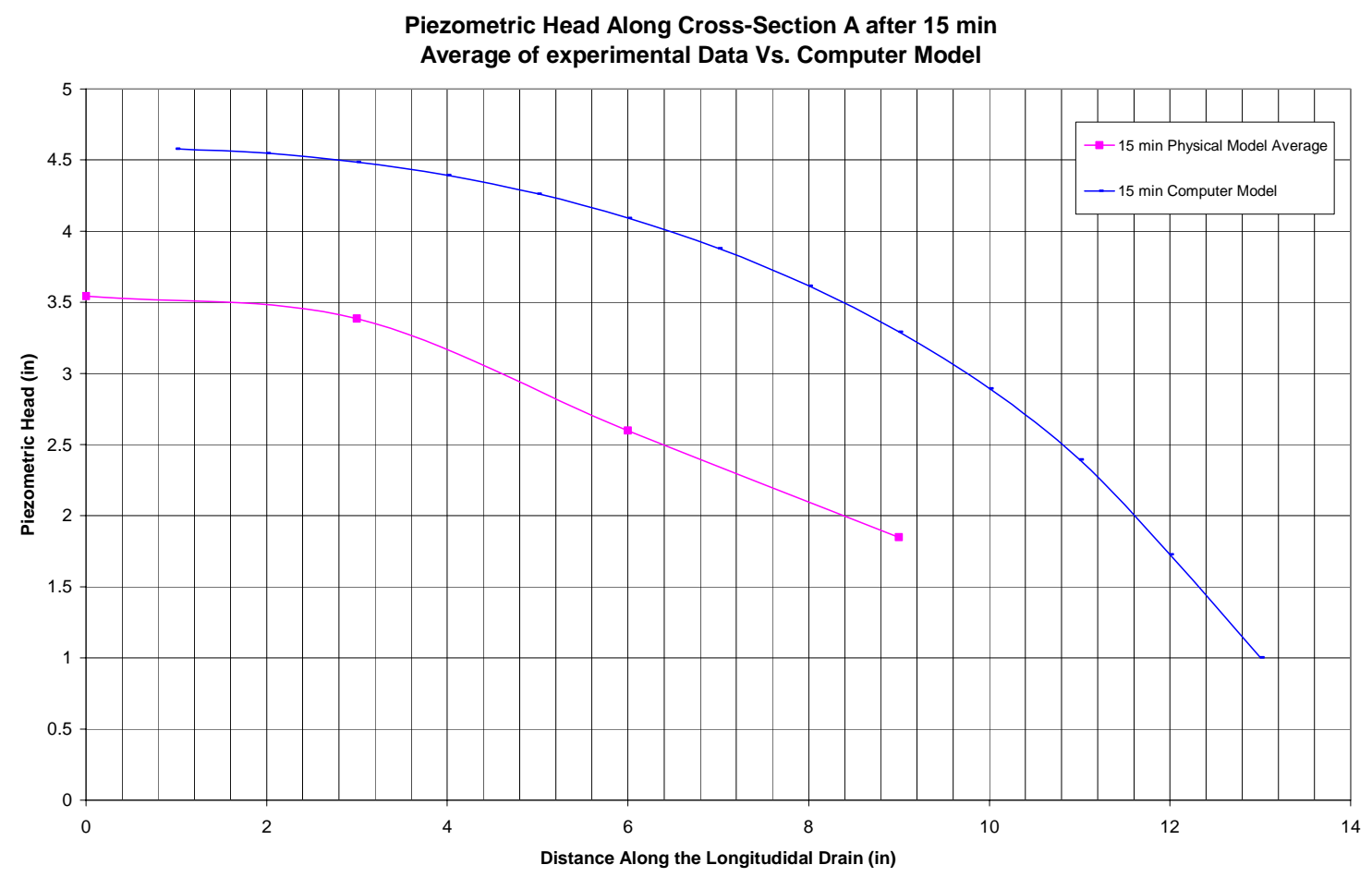

Figure 4.32: Piezometric head along cross-section A for soil type A after 15 minutes

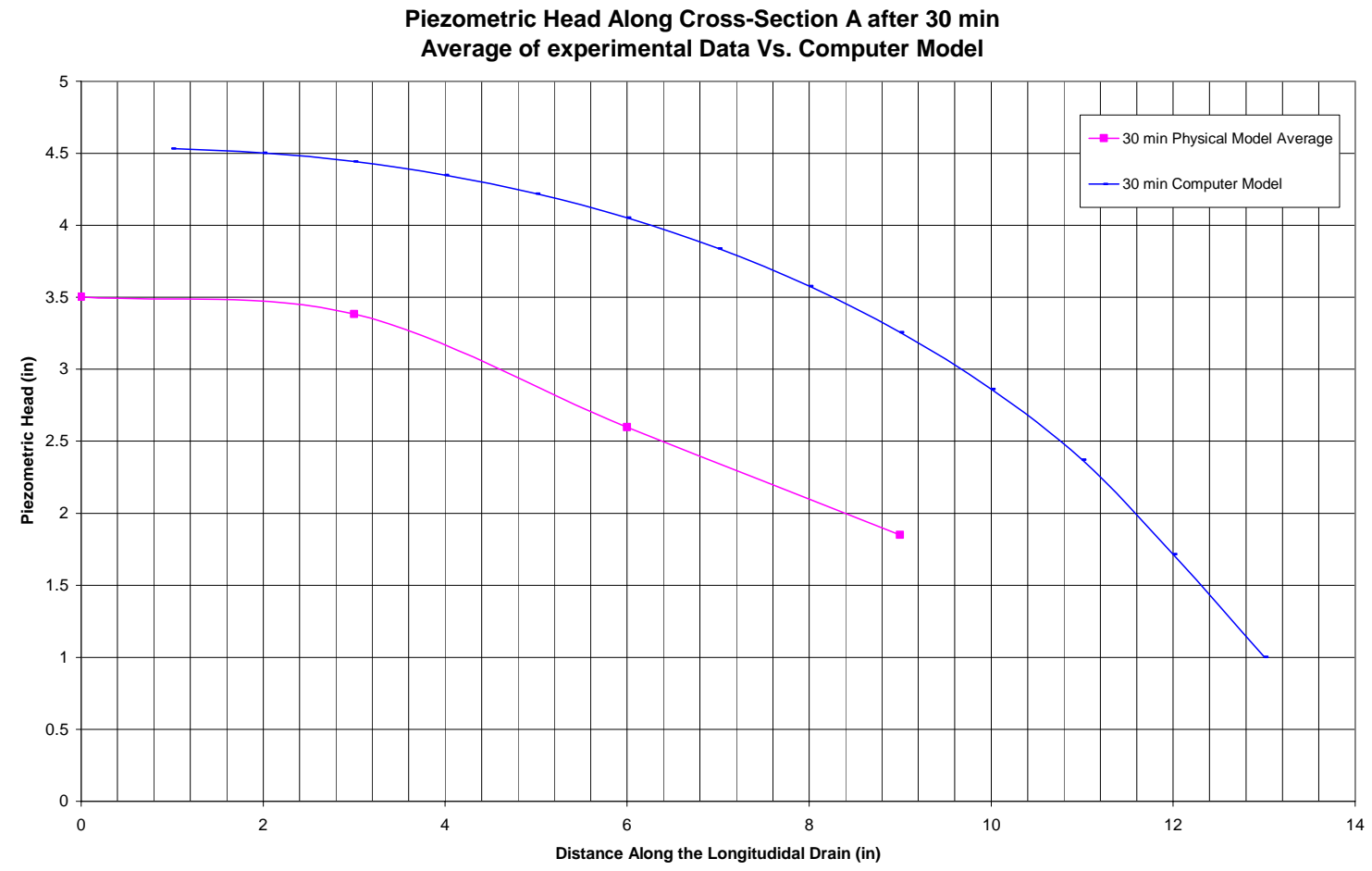

Figure 4.33: Piezometric head along cross-section A for soil type A after 30 minutes 


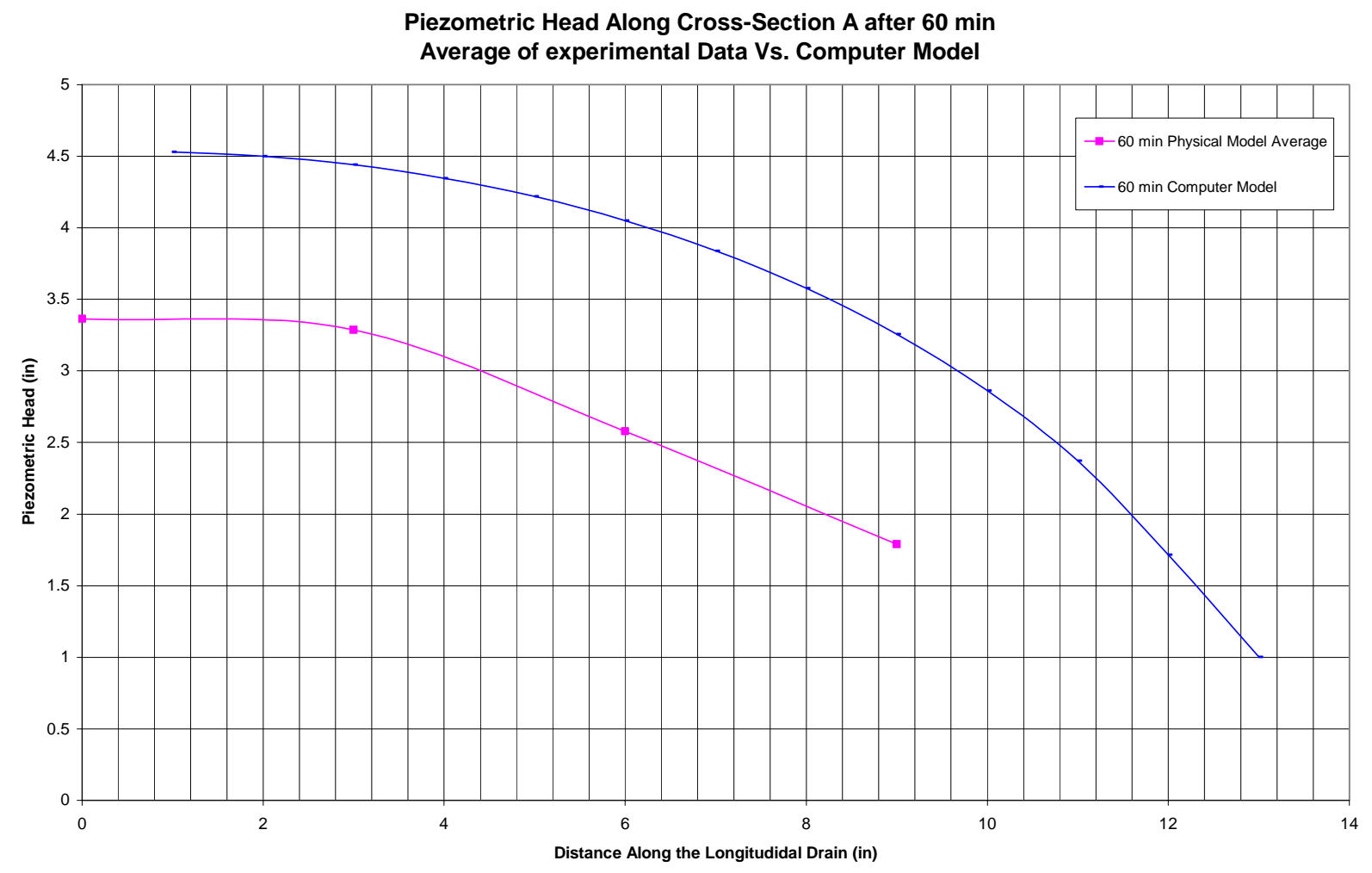

Figure 4.34: Piezometric head along cross-section A for soil type A after 60 minutes

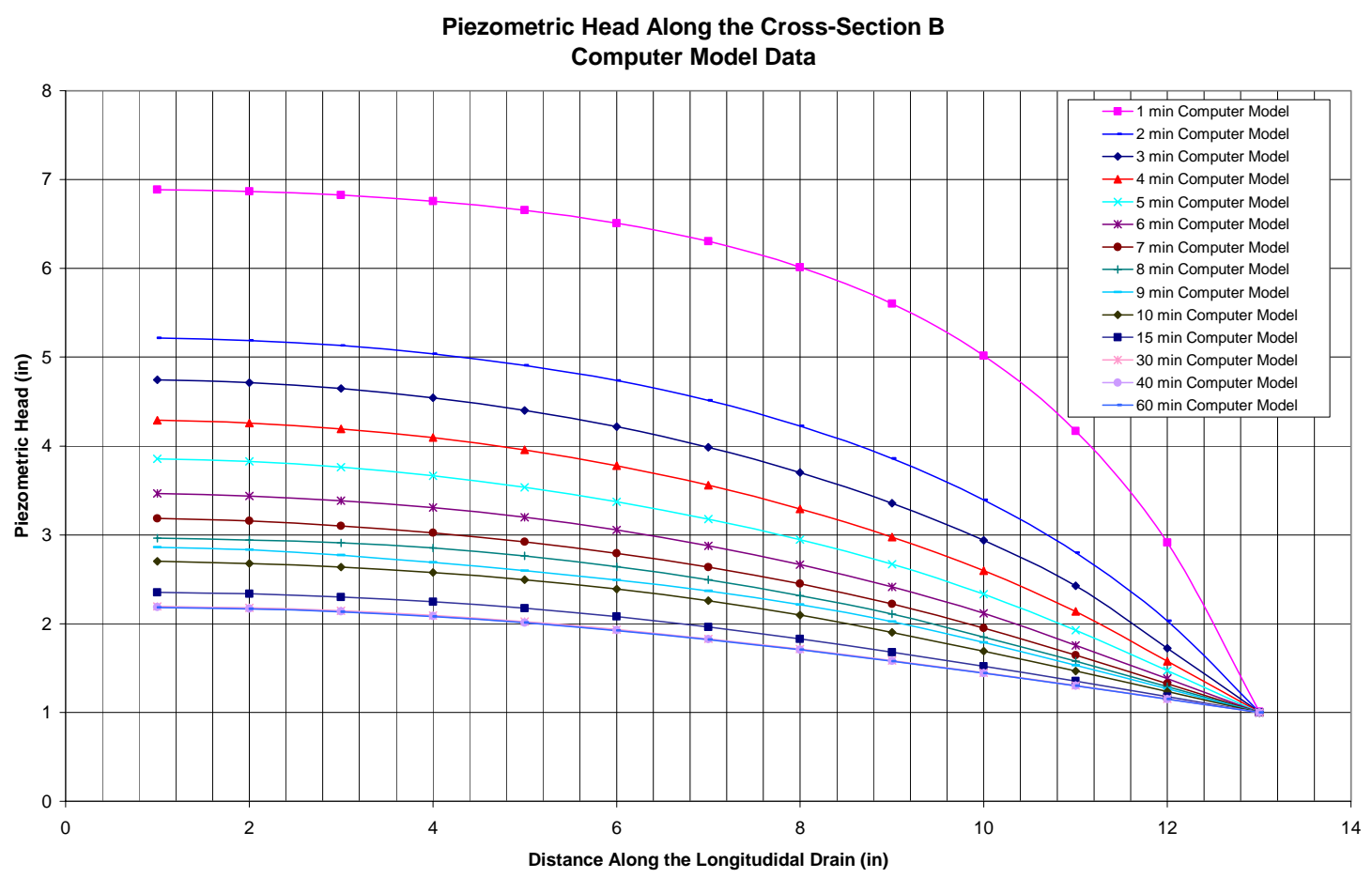

Figure 4.35: Piezometric head along cross-section B for soil type A - Computer Model 


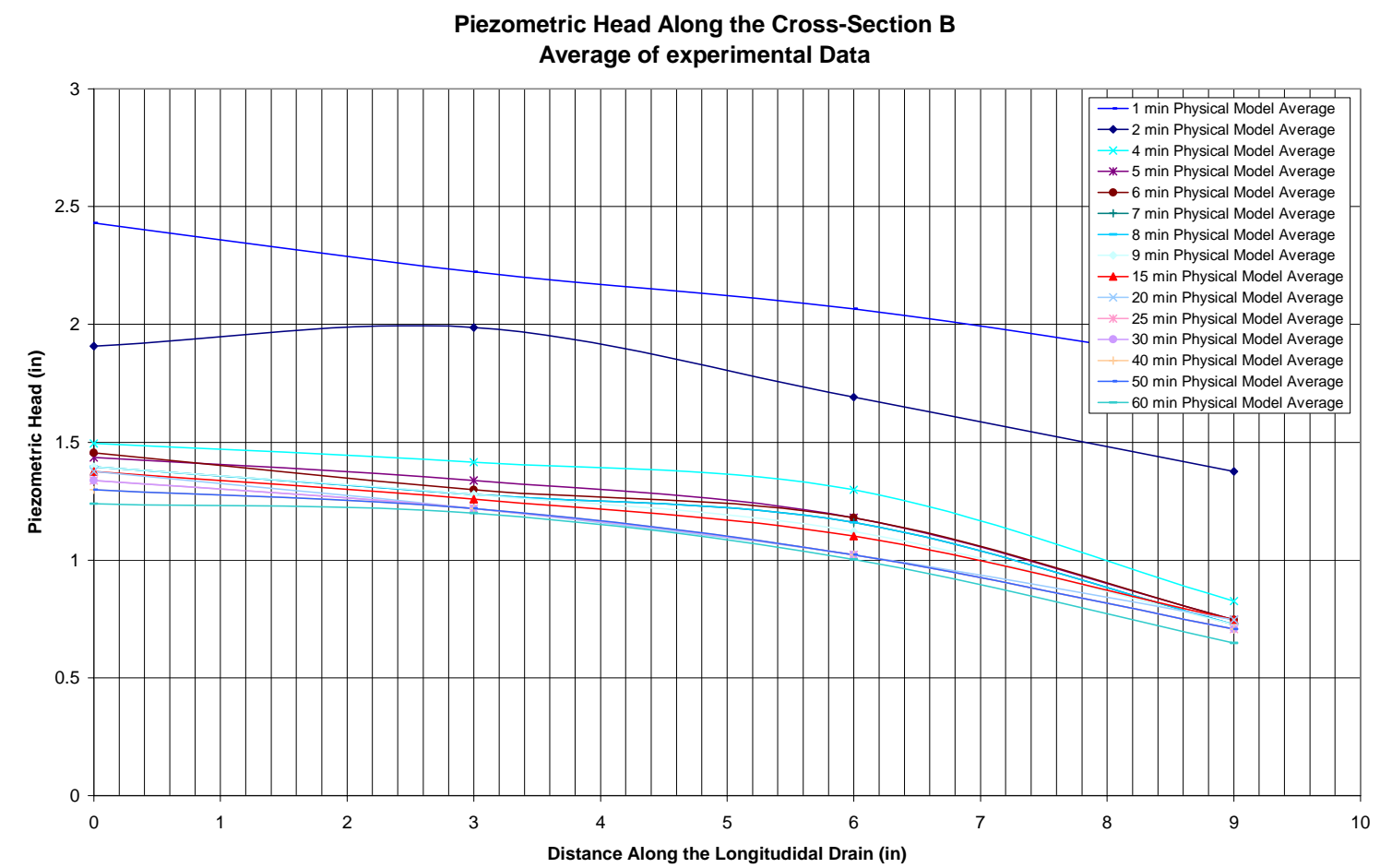

Figure 4.36: Piezometric head along cross-section B for soil type A - Physical Model

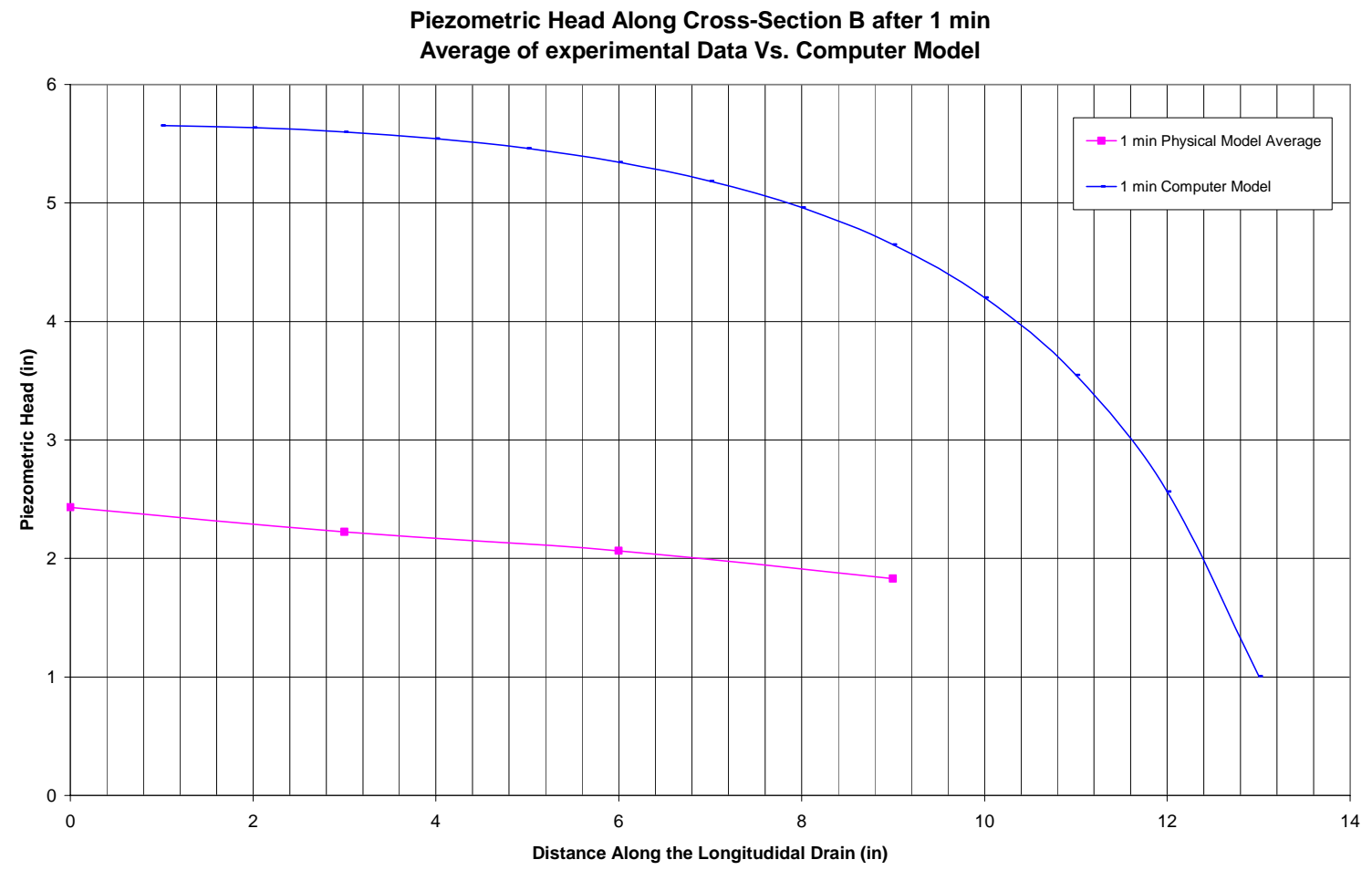

Figure 4.37: Piezometric head along cross-section B for soil type A after 1 minute 


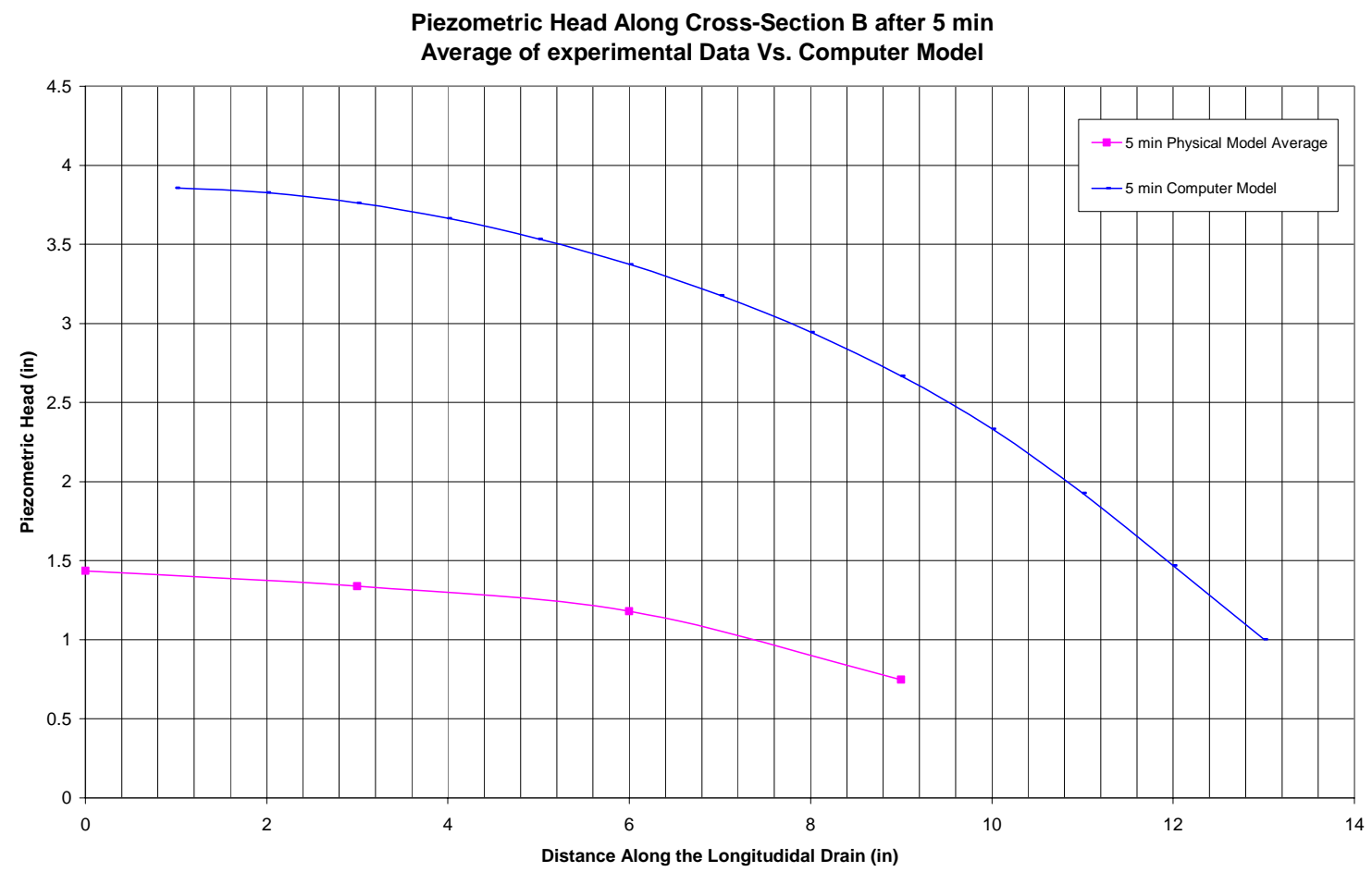

Figure 4.38: Piezometric head along cross-section B for soil type A after 5 minutes

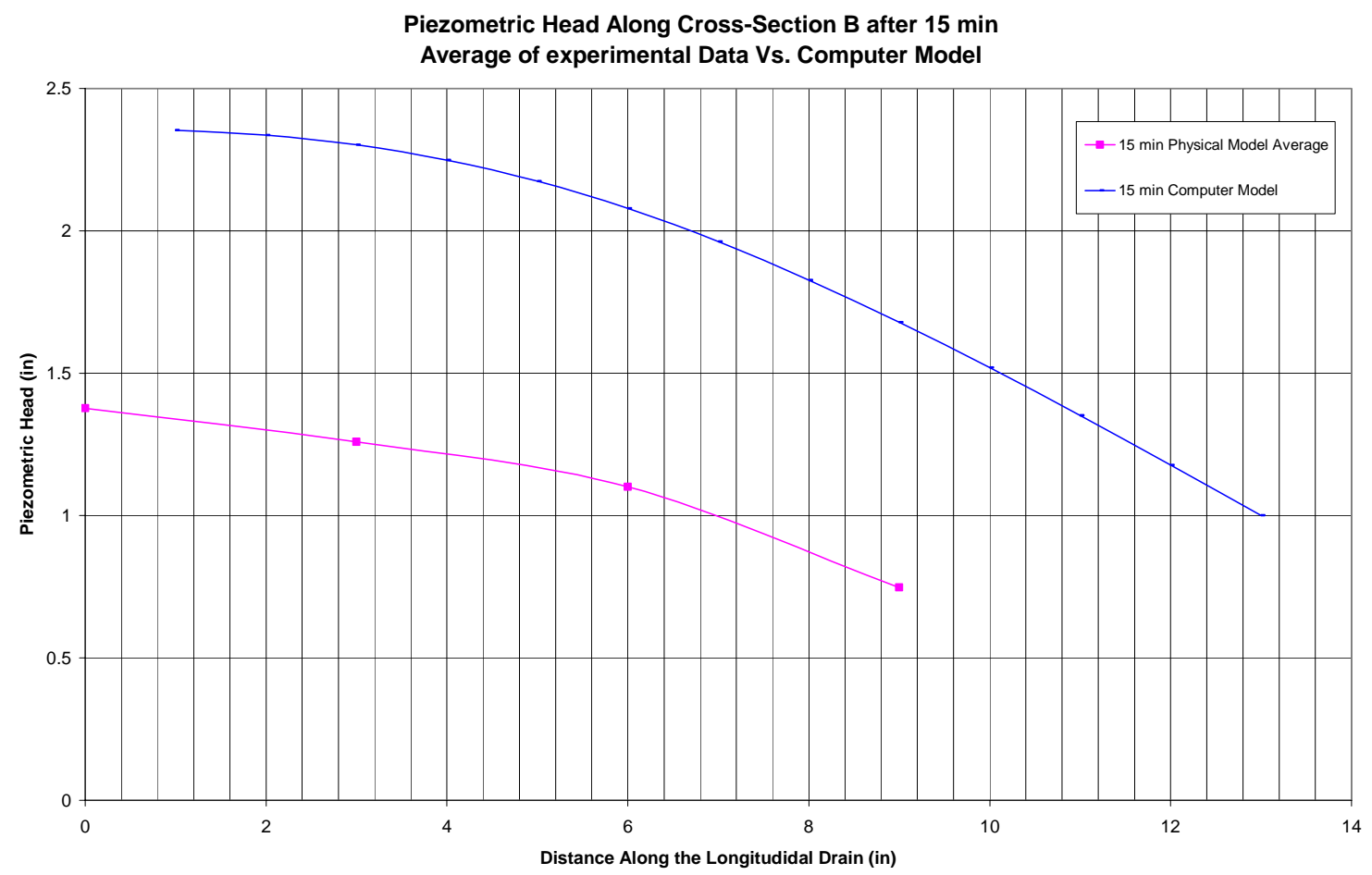

Figure 4.39: Piezometric head along cross-section B for soil type A after 15 minutes 


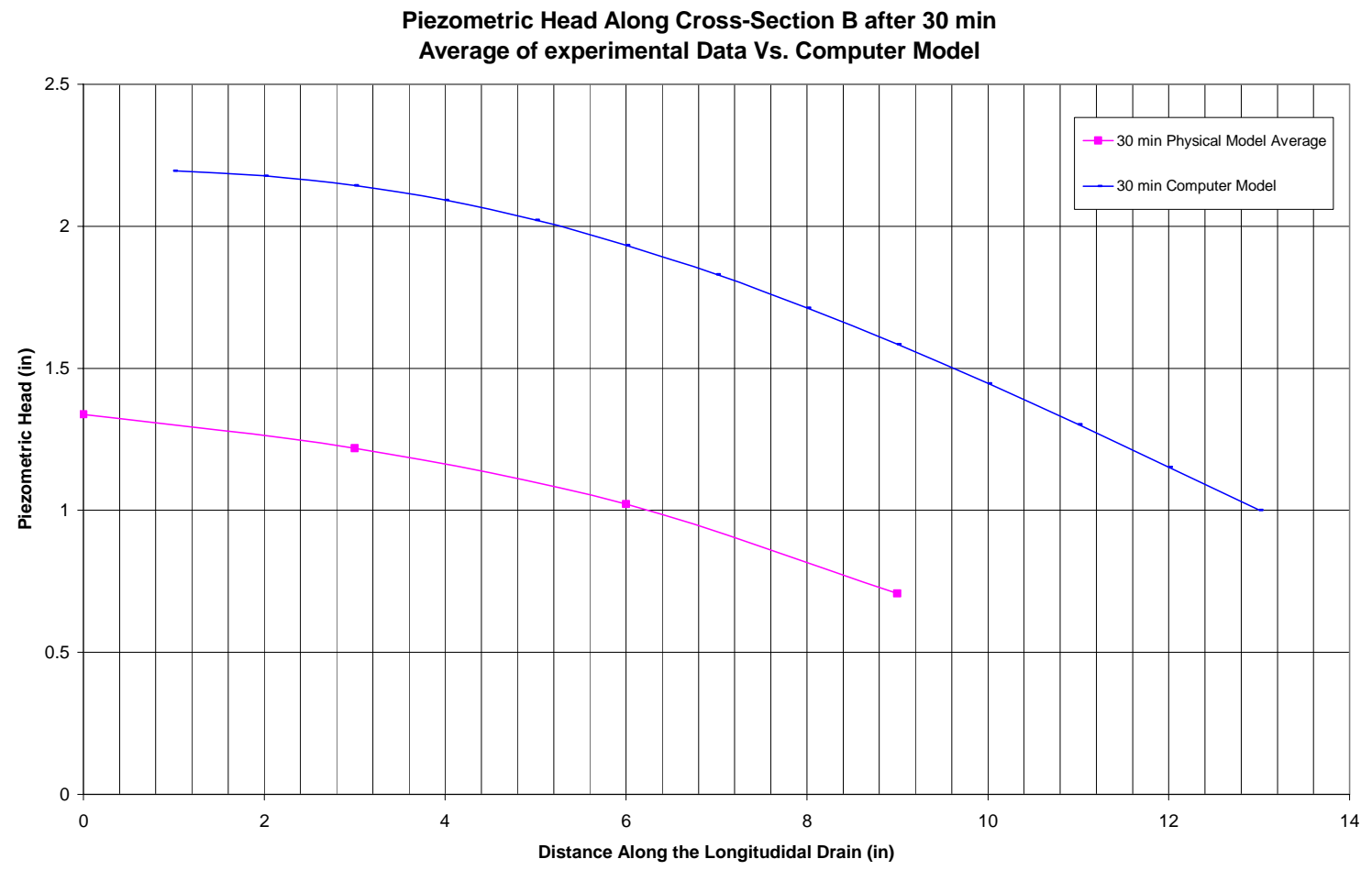

Figure 4.40: Piezometric head along cross-section B for soil type A after 30 minutes

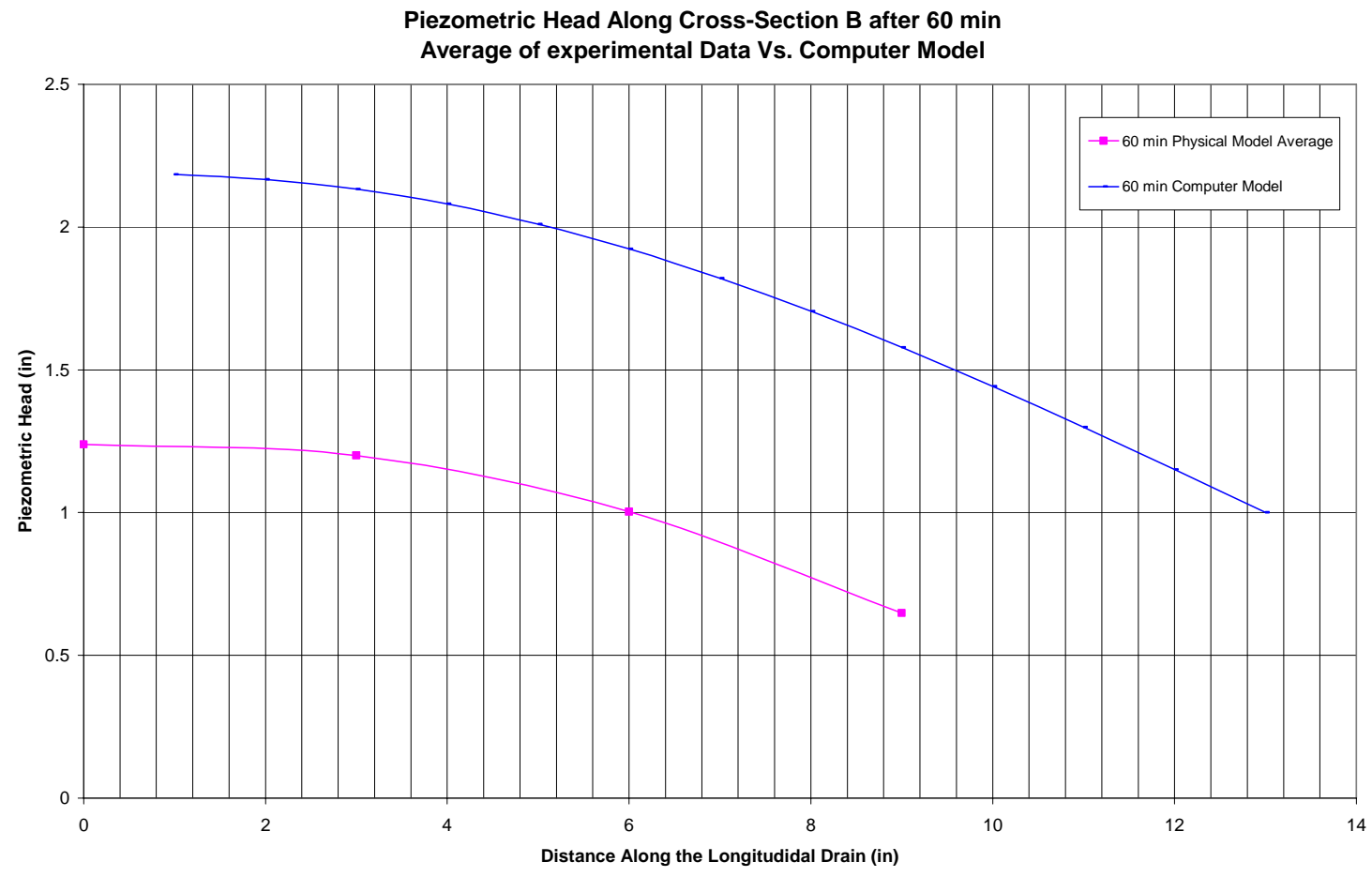

Figure 4.41: Piezometric head along cross-section B for soil type A after 60 minutes 


\subsubsection{Fluctuation of Flow}

The experimental data shows that the flow in each drain fluctuates during the transition time. In this section the changes in flow rate over time are shown for all drains and for all soil types. The experimental observations are compared with computer model results as shown in Figures 4.42 through 4.48 for soil type A. Results for soils B, C, D and E can be presented in Appendix A5. The following figures show three curves, two physical tests and the computer model. These figures show how the flow rate changes rapidly at first and how over time it reaches a steady state condition. The computer model does not show any fluctuations like in experimental data, but the computed flow rates gradually reached steady state conditions.

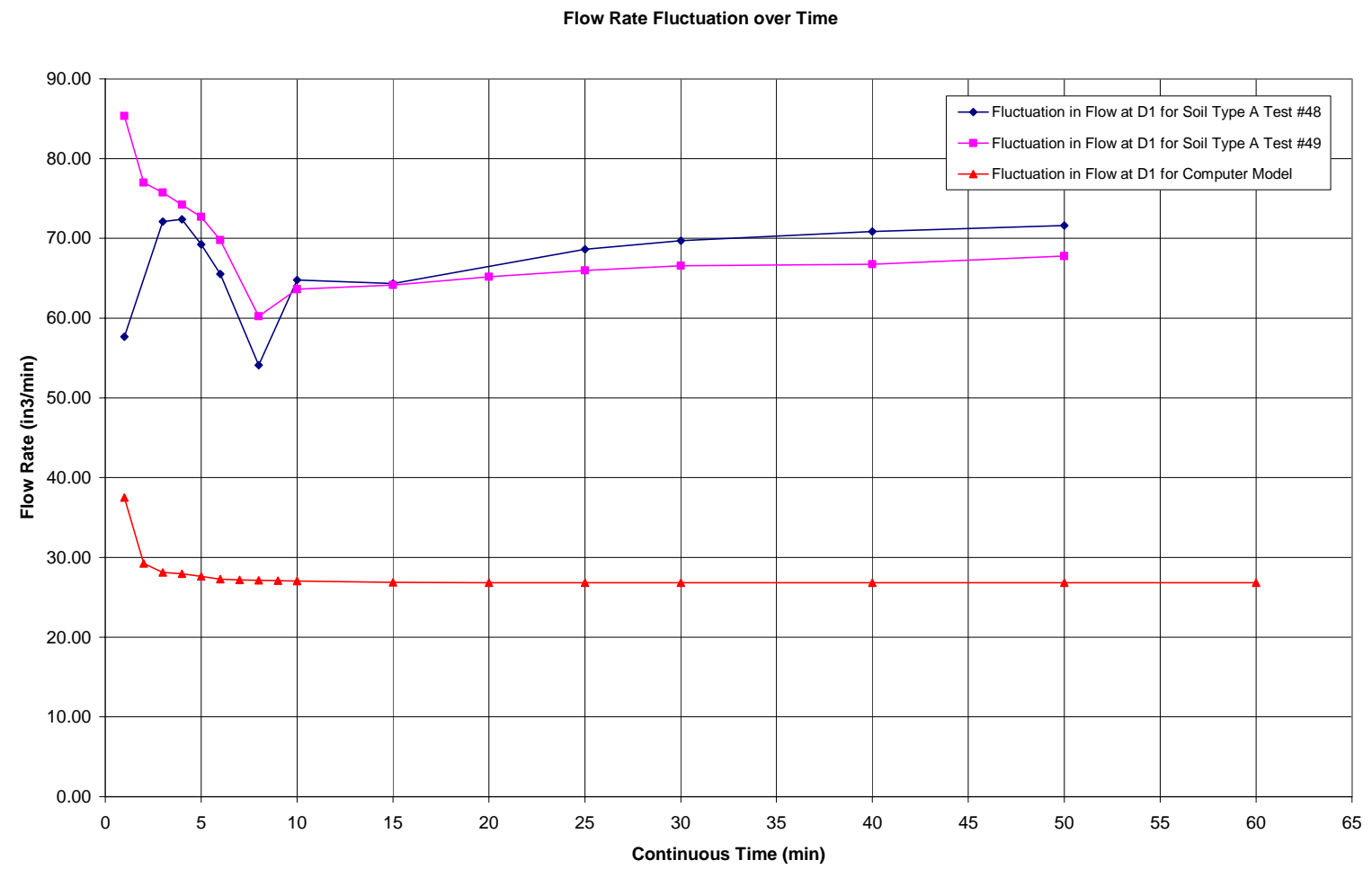

Figure 4.42: Flow rate fluctuation for Soil Type A at drain D1 
Flow Rate Fluctuation over Time

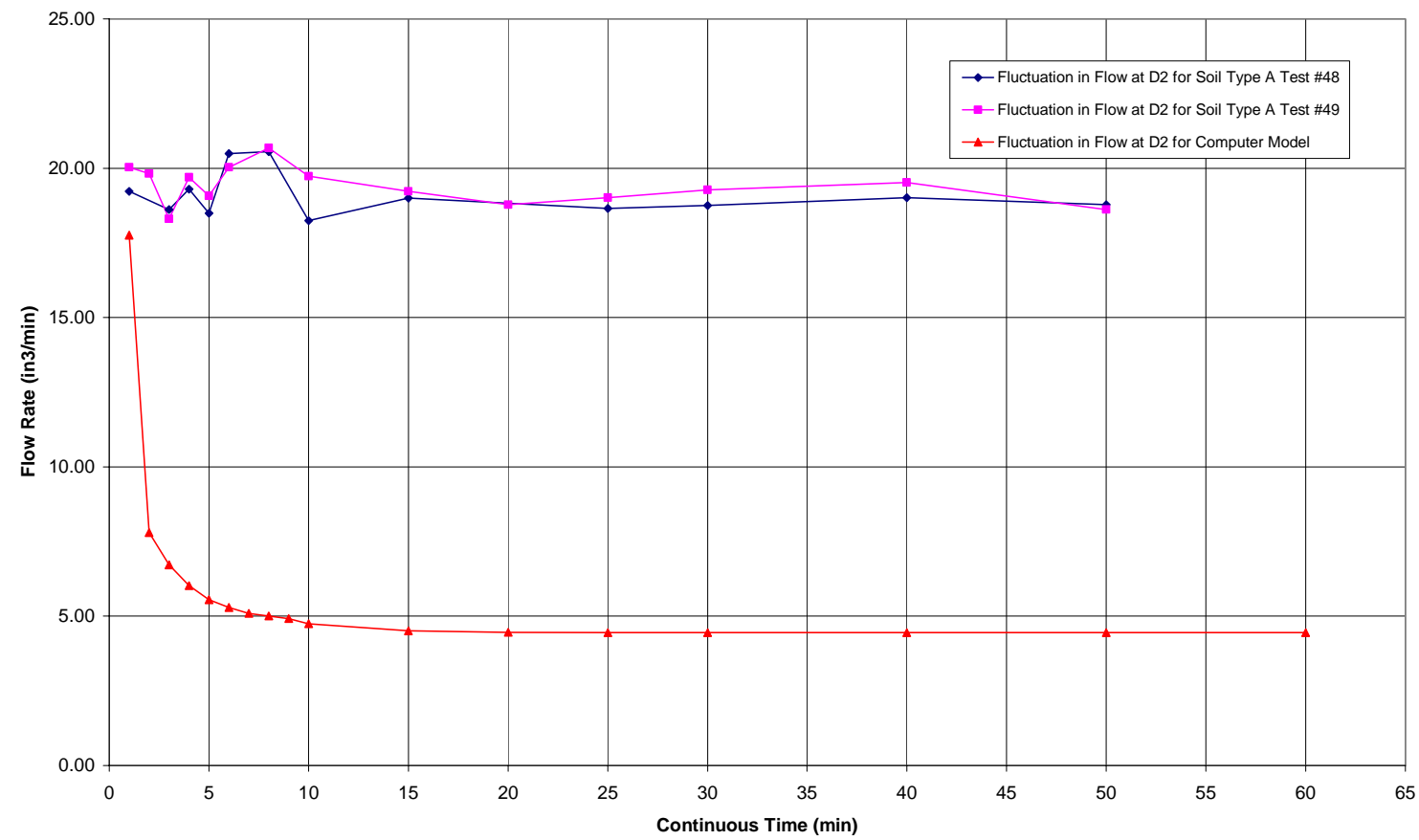

Figure 4.43: Flow rate fluctuation for Soil Type A at drain D2

Flow Rate Fluctuation over Time

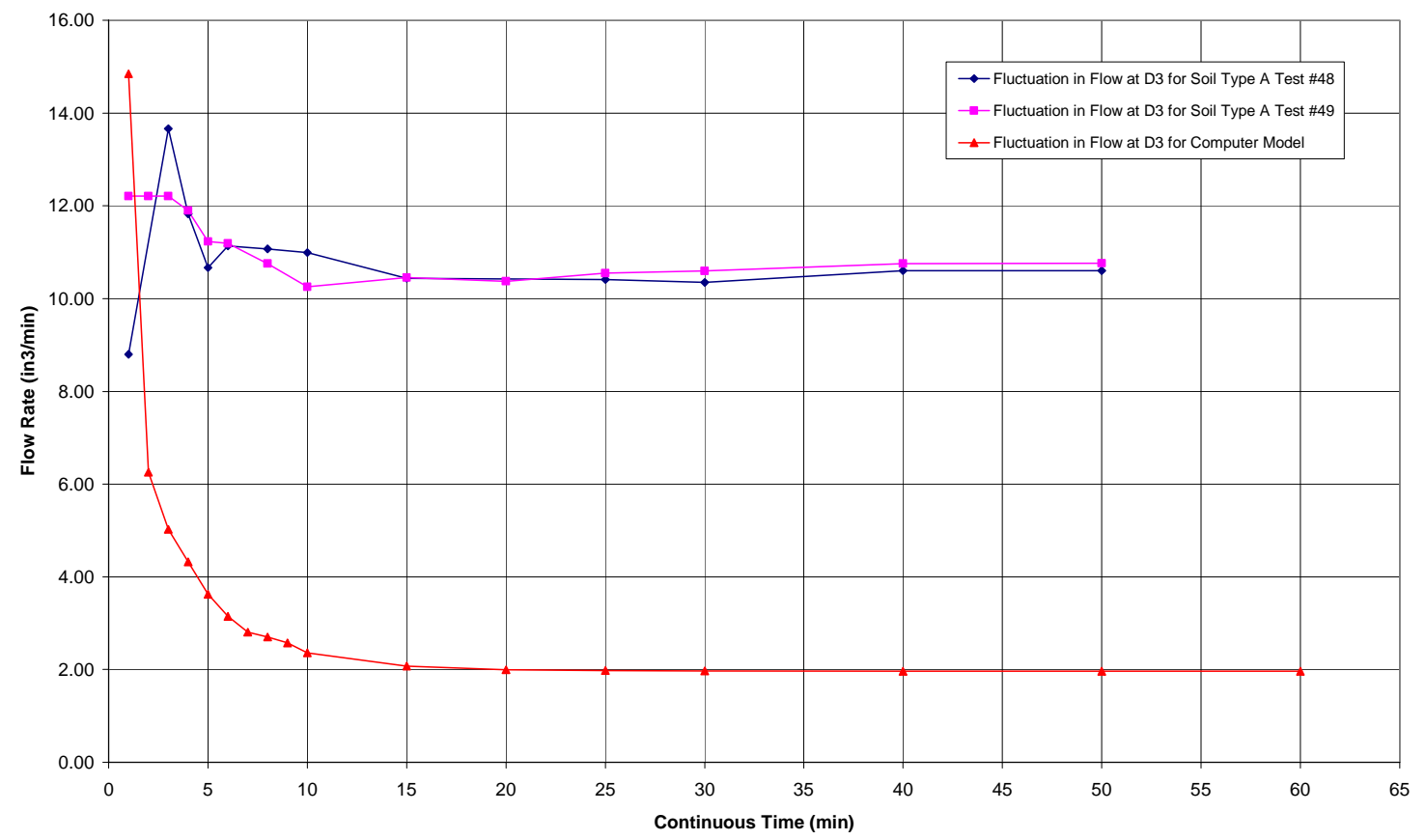

Figure 4.44: Flow rate fluctuation for Soil Type A at drain D3 
Flow Rate Fluctuation over Time

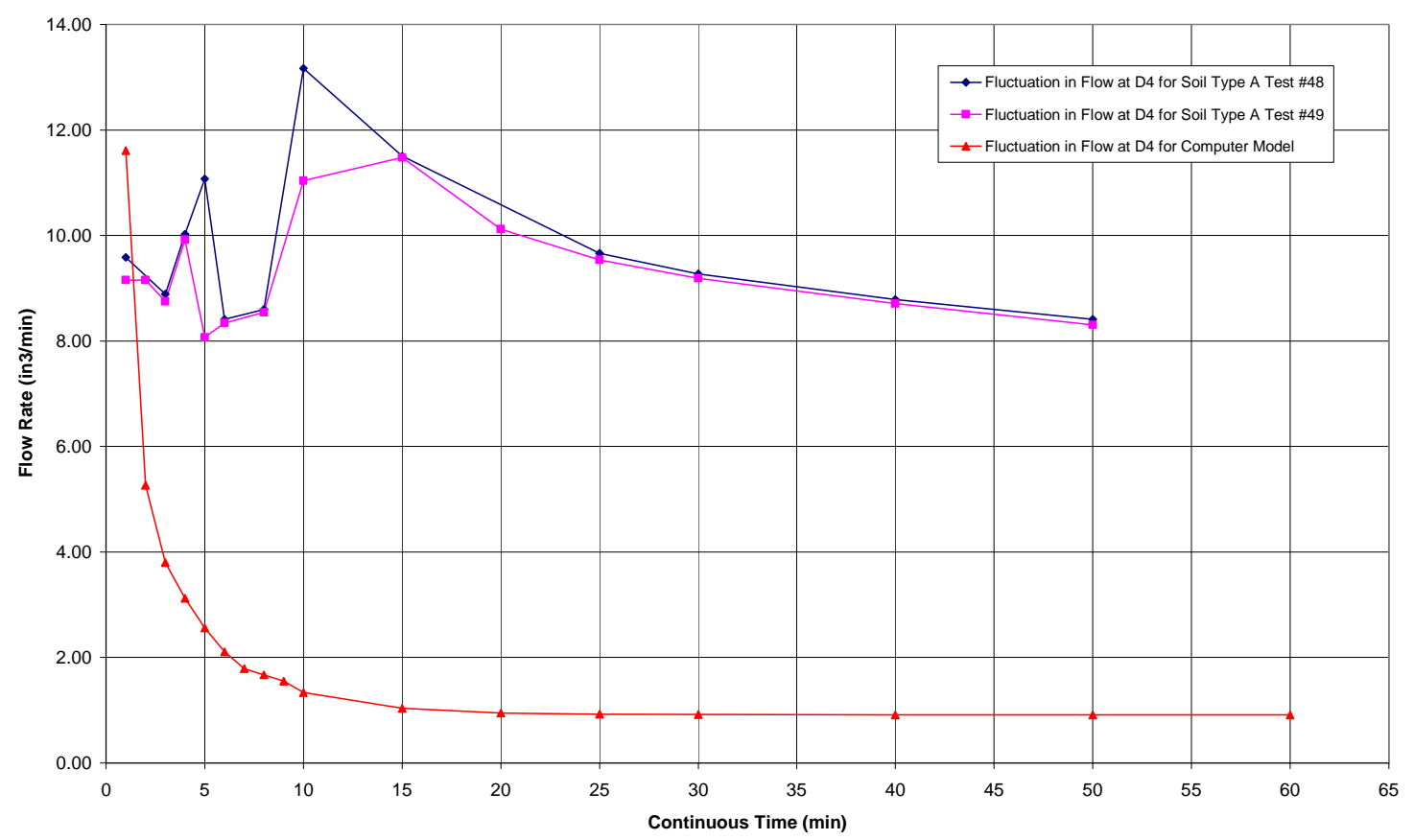

Figure 4.45: Flow rate fluctuation for Soil Type A at drain D4

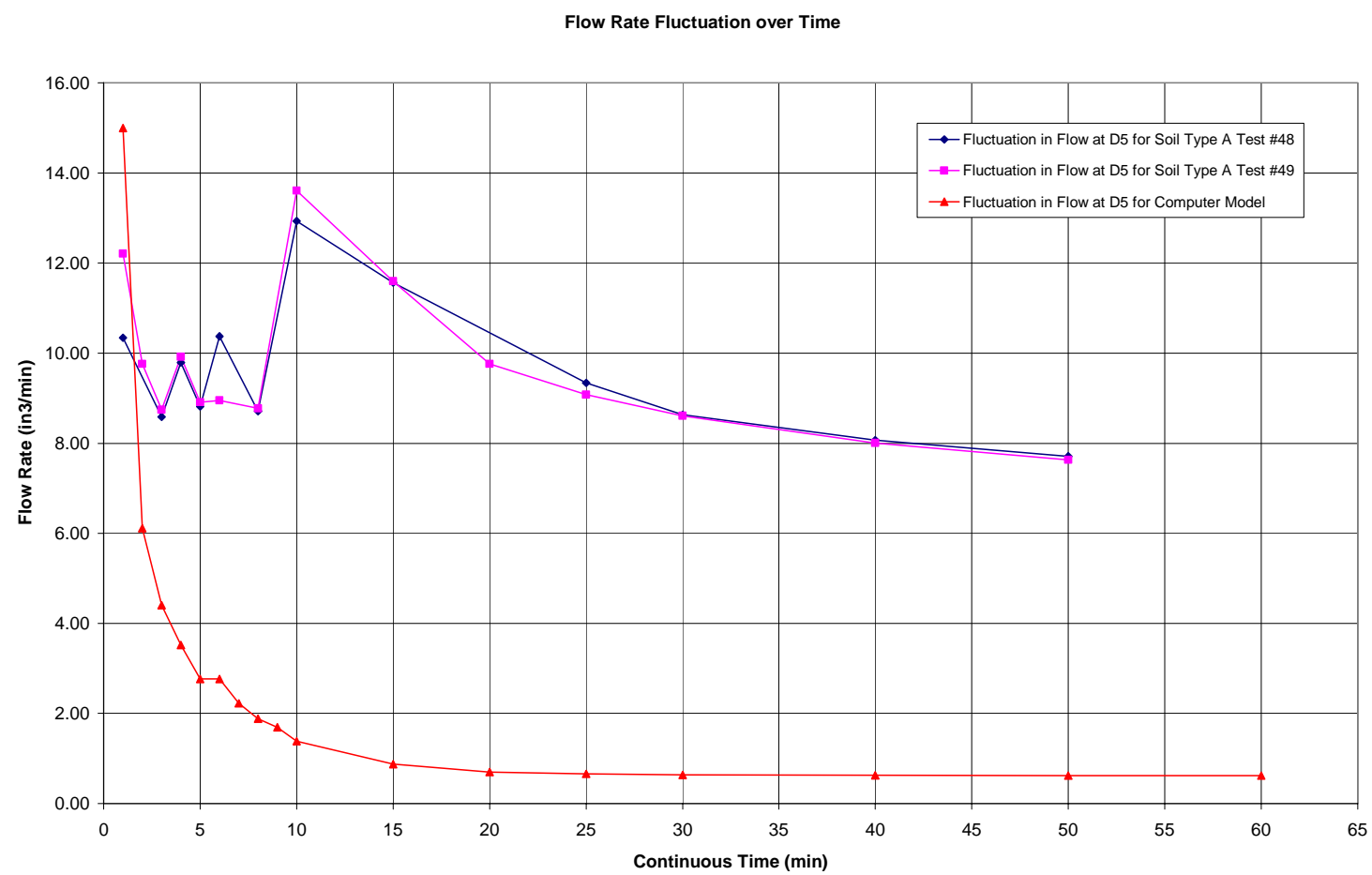

Figure 4.46: Flow rate fluctuation for Soil Type A at drain D5 
Flow Rate Fluctuation over Time

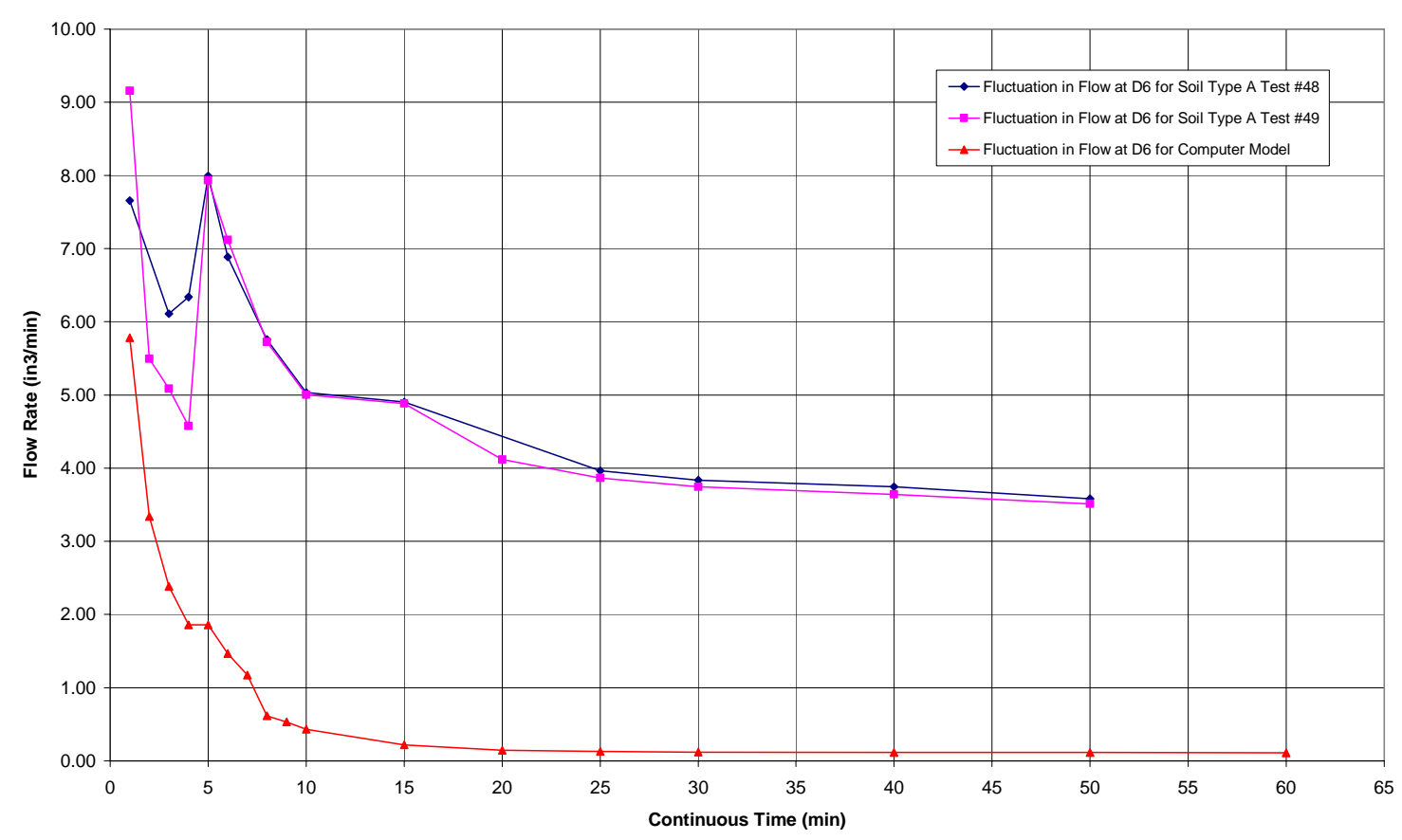

Figure 4.47: Flow rate fluctuation for Soil Type A at drain D6

Flow Rate Fluctuation over Time

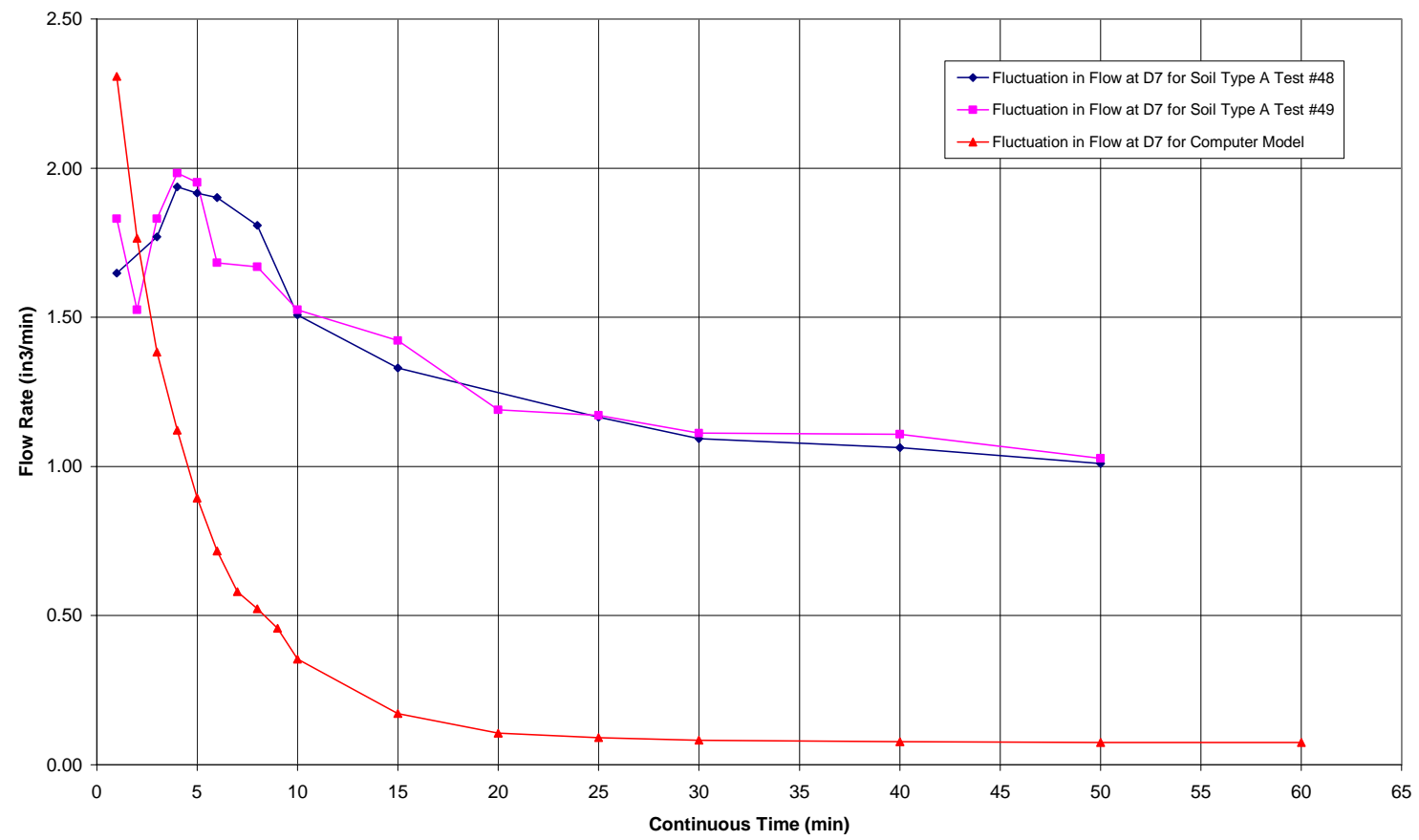

Figure 4.48: Flow rate fluctuation for Soil Type A at drain D7 
Table 4.4 shows the time required for the flow, at each drain, to become stable. In this table the time for both physical and computer model are summarized. In the determination of transient time, the actual flow volumes in drains were not considered. The primary factor that was investigated in this section was the time it takes to reach steady state conditions. The Actual volumes are important for other considerations such as pipe size. Overall, the computed values compare well with laboratory measurements.

Table 4.5: Observed time for flow to reach Steady State conditions at each drain

\begin{tabular}{|l|c|c|c|c|c|}
\hline & \multicolumn{4}{|c|}{ Soil Type } \\
\hline Drain ID & A & B & C & D & E \\
\hline $\begin{array}{l}\text { D1 } \\
\text { Computer Model }\end{array}$ & $10 \mathrm{~min}$ & $10 \mathrm{~min}$ & $15 \mathrm{~min}$ & $40 \mathrm{~min}$ & $50 \mathrm{~min}$ \\
\hline $\begin{array}{l}\text { D1 } \\
\text { Physical Model }\end{array}$ & $5 \mathrm{~min}$ & $10 \mathrm{~min}$ & $15 \mathrm{~min}$ & $40 \mathrm{~min}$ & $50 \mathrm{~min}$ \\
\hline $\begin{array}{l}\text { D2 } \\
\text { Computer Model }\end{array}$ & $10 \mathrm{~min}$ & $15 \mathrm{~min}$ & $30 \mathrm{~min}$ & $40 \mathrm{~min}$ & $50 \mathrm{~min}$ \\
\hline $\begin{array}{l}\text { D2 } \\
\text { Physical Model }\end{array}$ & $15 \mathrm{~min}$ & $15 \mathrm{~min}$ & $30 \mathrm{~min}$ & $40 \mathrm{~min}$ & $50 \mathrm{~min}$ \\
\hline $\begin{array}{l}\text { D3 } \\
\text { Computer Model }\end{array}$ & $10 \mathrm{~min}$ & $15 \mathrm{~min}$ & $30 \mathrm{~min}$ & $40 \mathrm{~min}$ & $50 \mathrm{~min}$ \\
\hline $\begin{array}{l}\text { D3 } \\
\text { Physical Model }\end{array}$ & $15 \mathrm{~min}$ & $15 \mathrm{~min}$ & $30 \mathrm{~min}$ & $40 \mathrm{~min}$ & $50 \mathrm{~min}$ \\
\hline $\begin{array}{l}\text { D4 } \\
\text { Computer Model }\end{array}$ & $10 \mathrm{~min}$ & $15 \mathrm{~min}$ & $30 \mathrm{~min}$ & $40 \mathrm{~min}$ & $50 \mathrm{~min}$ \\
\hline $\begin{array}{l}\text { D4 } \\
\text { Physical Model }\end{array}$ & $15 \mathrm{~min}$ & $15 \mathrm{~min}$ & $30 \mathrm{~min}$ & $40 \mathrm{~min}$ & $50 \mathrm{~min}$ \\
\hline $\begin{array}{l}\text { D5 } \\
\text { Computer Model }\end{array}$ & $10 \mathrm{~min}$ & $15 \mathrm{~min}$ & $30 \mathrm{~min}$ & $40 \mathrm{~min}$ & $50 \mathrm{~min}$ \\
\hline $\begin{array}{l}\text { D5 } \\
\text { Physical Model }\end{array}$ & $15 \mathrm{~min}$ & $15 \mathrm{~min}$ & $30 \mathrm{~min}$ & $40 \mathrm{~min}$ & $50 \mathrm{~min}$ \\
\hline $\begin{array}{l}\text { D6 } \\
\text { Computer Model }\end{array}$ & $10 \mathrm{~min}$ & $15 \mathrm{~min}$ & $30 \mathrm{~min}$ & $40 \mathrm{~min}$ & $50 \mathrm{~min}$ \\
\hline $\begin{array}{l}\text { D6 } \\
\text { Physical Model }\end{array}$ & $15 \mathrm{~min}$ & $15 \mathrm{~min}$ & $30 \mathrm{~min}$ & $40 \mathrm{~min}$ & $50 \mathrm{~min}$ \\
\hline $\begin{array}{l}\text { D7 } \\
\text { Computer Model }\end{array}$ & $15 \mathrm{~min}$ & $30 \mathrm{~min}$ & $40 \mathrm{~min}$ & $50 \mathrm{~min}$ \\
\hline $\begin{array}{l}\text { D7 } \\
\text { Physical Model }\end{array}$ & $15 \mathrm{~min}$ & $30 \mathrm{~min}$ & $40 \mathrm{~min}$ & $50 \mathrm{~min}$ \\
\hline
\end{tabular}




\subsubsection{Effectiveness of Drain over Time}

Results on the effectiveness of the longitudinal are presented in this section. The effectiveness of the drain is defined as the cumulative percentage of seepage water removed along the length of the drain. Several figures were generated to understand the amount of seepage removed along the drain as a percentage of the total amount of water flowing through the soil. Results for soil A are presented below. Results for soils B. C, D and E can be seen in Appendix A6. Figure 4.49 shows the percentage of seepage removal as a function of the drain length on the basis of the computer model described earlier.

Figure 4.50 shows the percentage seepage removed on the basis of measured experimental data. Experimental data compares well with the values computed in the computer model. As can be seen from these figures, the drain efficiency reaches steady-

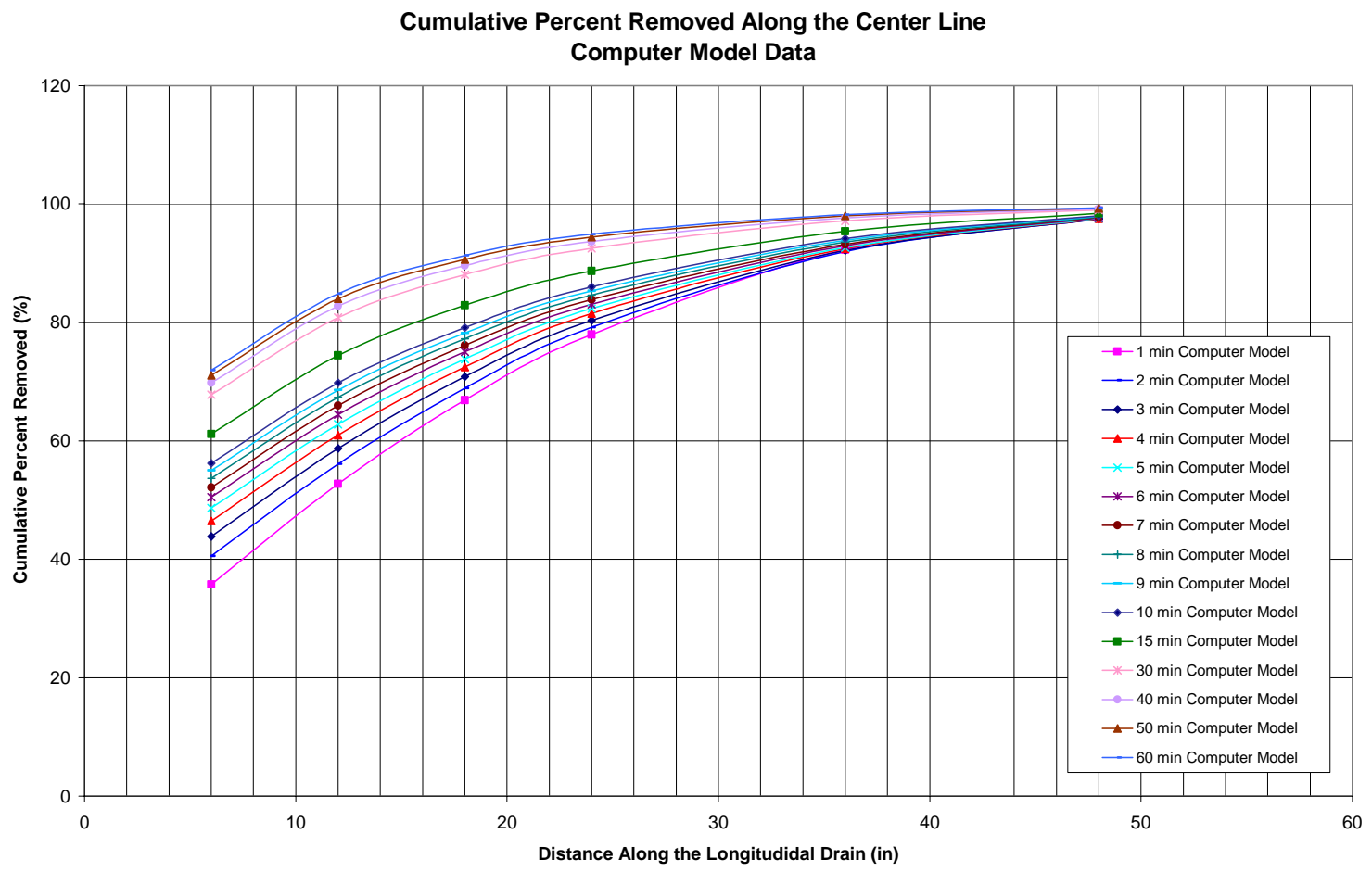

Figure 4.49: Cumulative Percent Removed along the Drain for Soil Type A - Computer Model 


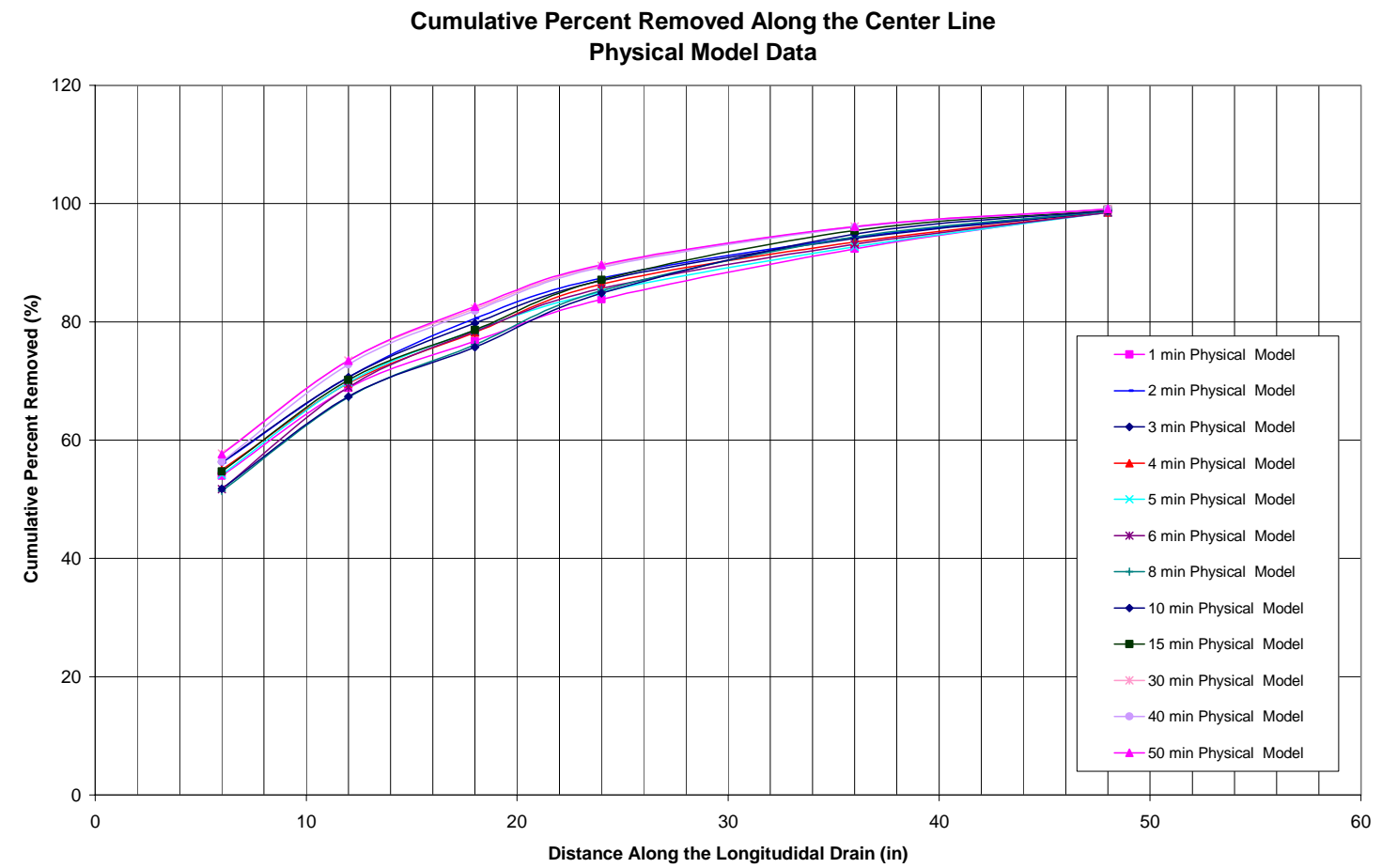

Figure 4.50: Cumulative Percent Removed along the Drain for Soil Type A - Physical Model

state values after some time. Transient times computed on the basis of drain efficiency are shown below in Table 4.5. The laboratory experiments show that the drains become fully functional in less than eight hours even for soil type E, which has a fairly low permeability value. These results show that the soil type has a significant influence on the transient time of longitudinal drains.

Table 4.6: Transient time based on drain efficiency

\begin{tabular}{|l|l|l|l|l|l|}
\hline Soils & A & B & C & D & E \\
\hline Computer Model & $15 \mathrm{~min}$ & $20 \mathrm{~min}$ & $30 \mathrm{~min}$ & $50 \mathrm{~min}$ & $8 \mathrm{hr}$ \\
\hline Physical Model & $5 \mathrm{~min}$ & $10 \mathrm{~min}$ & $30 \mathrm{~min}$ & $40 \mathrm{~min}$ & $7 \mathrm{hr}$ \\
\hline
\end{tabular}




\subsubsection{Drains performance under steady conditions}

Drains reach their full functionality after reaching the steady state conditions. Therefore, the capacity of a longitudinal drain is the total volume of seepage water removed by the drain under steady state conditions. The capacity of a drain depends on many factors such as the drain spacing, slope, permeability, and the drain length. The effectiveness (or efficiency) of a longitudinal drain is the percentage of seepage volume removed by the drain. In this section, results pertinent to the drain effectiveness under steady state conditions are presented for soil type A. Figure 4.51 shows the cumulative percent removed as a function of drain length for soil type A at zero slope (horizontal). This figure shows that longitudinal drains can remove a large percentage $(>80 \%)$ of seepage volume over a short drain length. Figure 4.52 and Figure 4.53 show the percentage of seepage volume removed in each of the longitudinal drain compartments in the laboratory apparatus. As can be seen from this figure, most of the seepage is removed by the first three compartments (D1, D2 and D3) of the longitudinal drain. Figure 4.54 shows the variation of piezometric head along the drain length for soil A. Figure 4.55 and Figure 4.56 show the variation of piezometric head along transverse cross-sections A and $\mathrm{B}$, respectively. The results from the computer model show similar trends as in the physical model, the computed values of piezometric head seem to be higher than the laboratory data. Results for soils B, C, D and E can be presented in Appendix A1. Overall, the results show that the longitudinal drains remove a significant portion of seepage volume. 


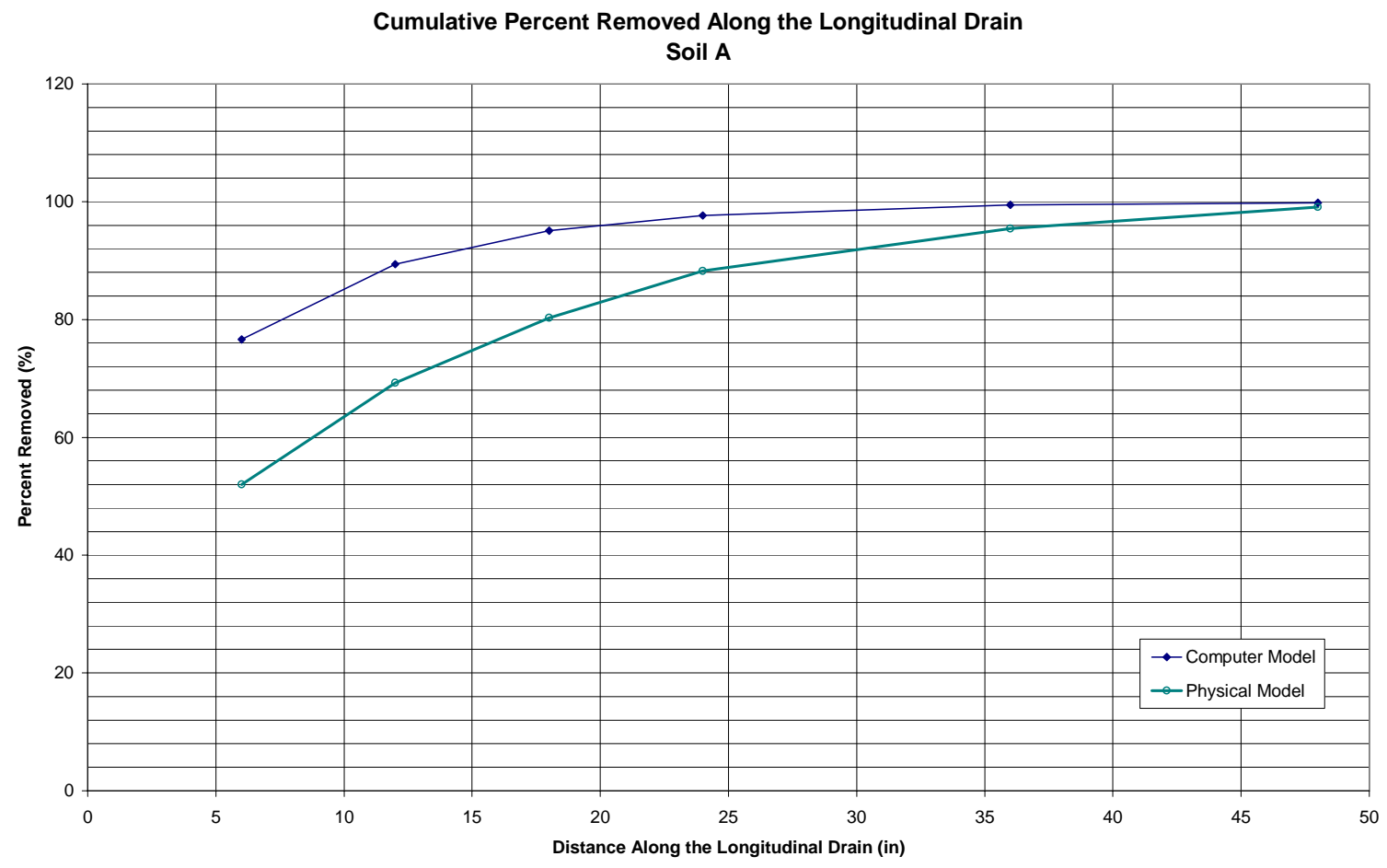

Figure 4.51: Cumulative percent removed for Soil Type A at zero slope, 12” width

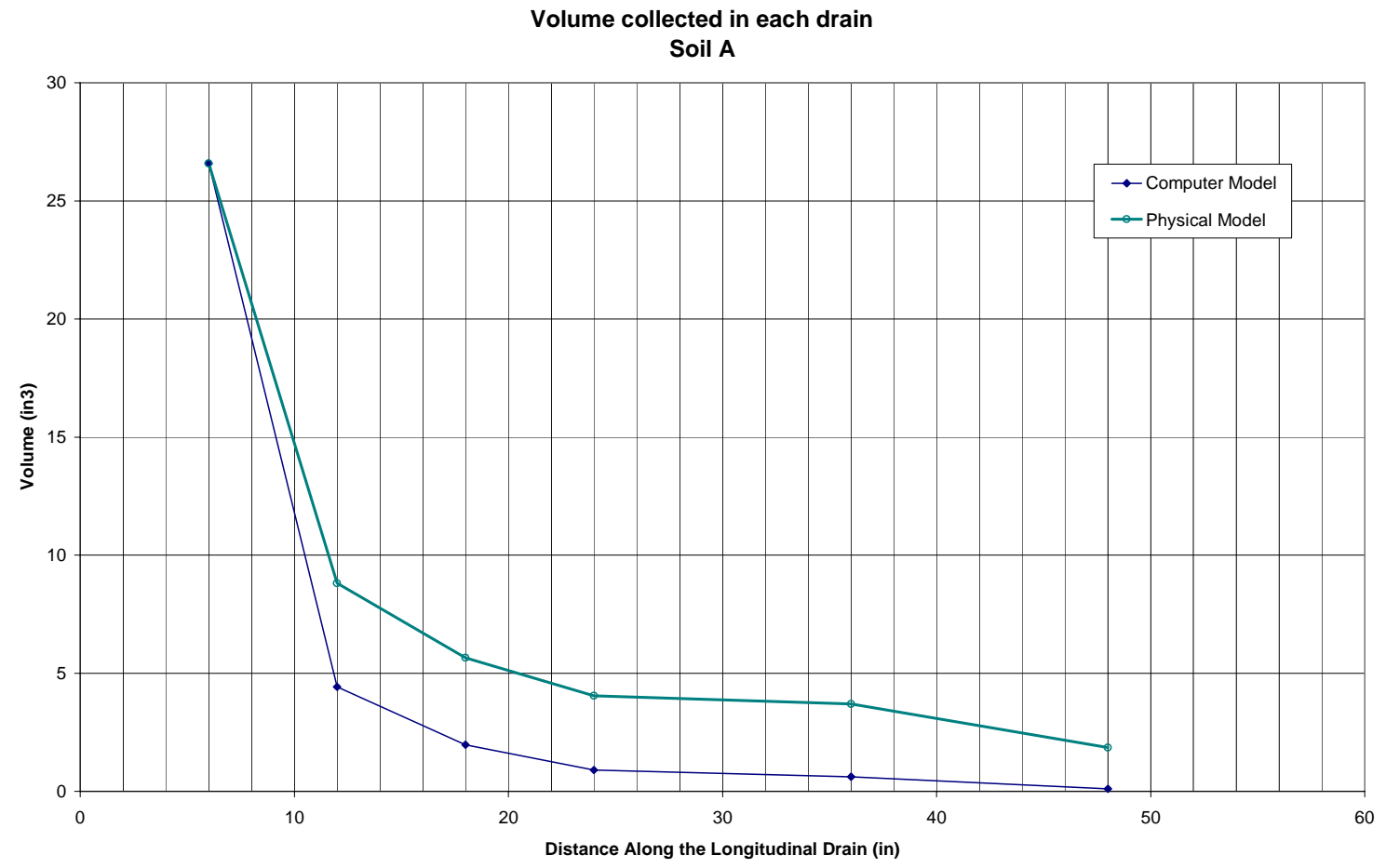

Figure 4.52: Volume removed at each drain for Soil Type A at zero slope, 12" width 


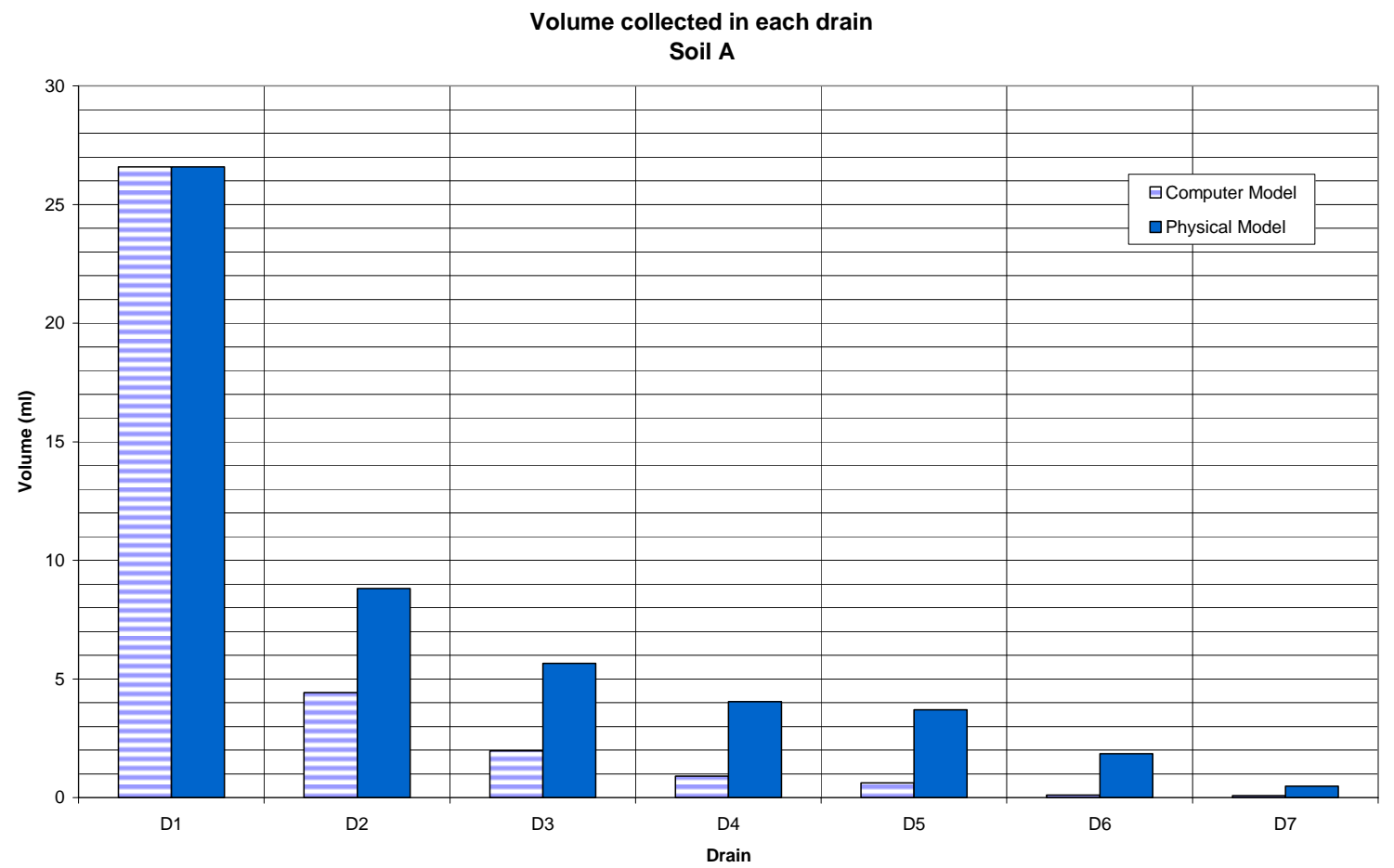

Figure 4.53: Volume removed at each drain for Soil Type A at zero slope, 12" width

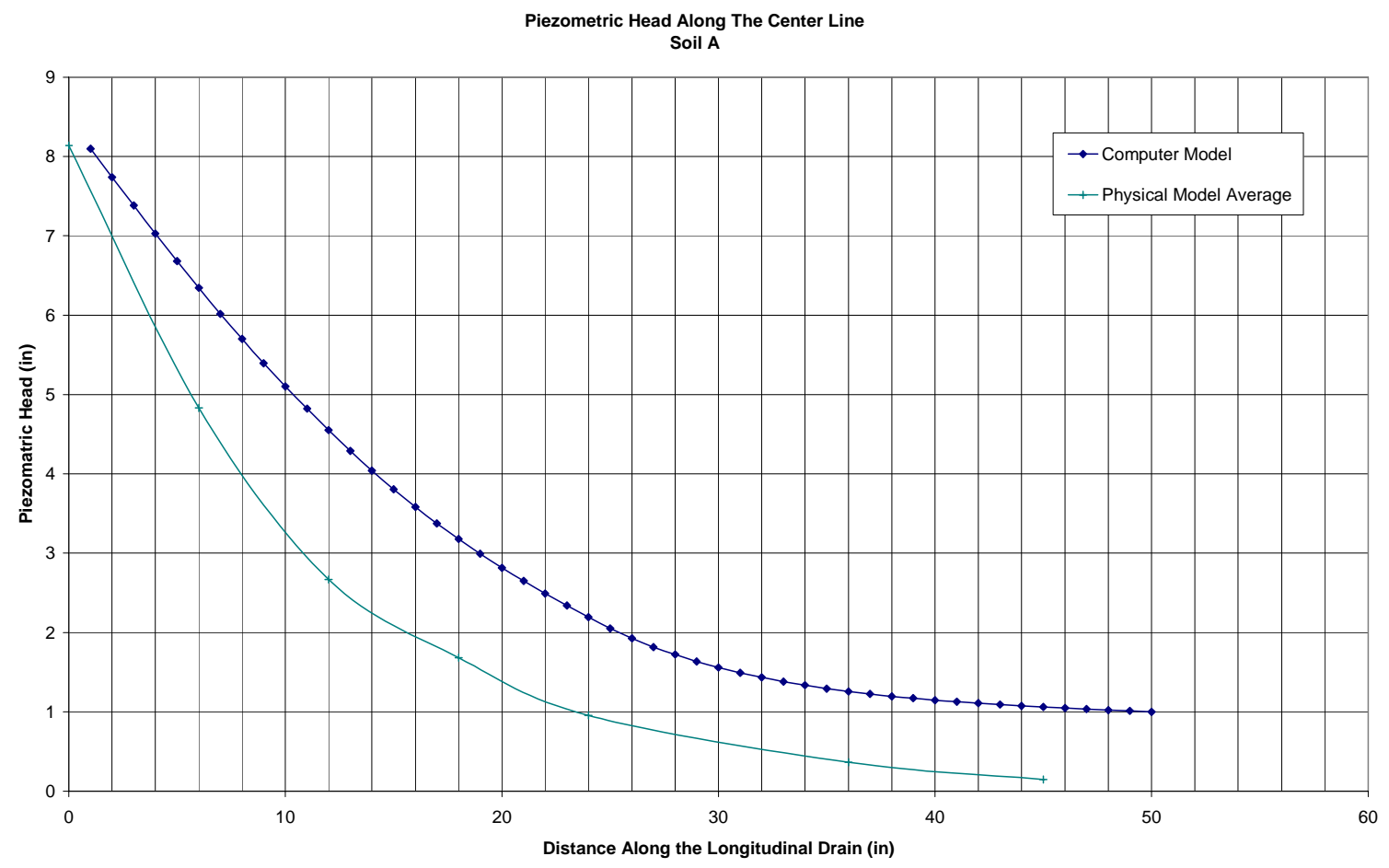

Figure 4.54: Piezometric head for Soil Type A at zero slope, 12” width 


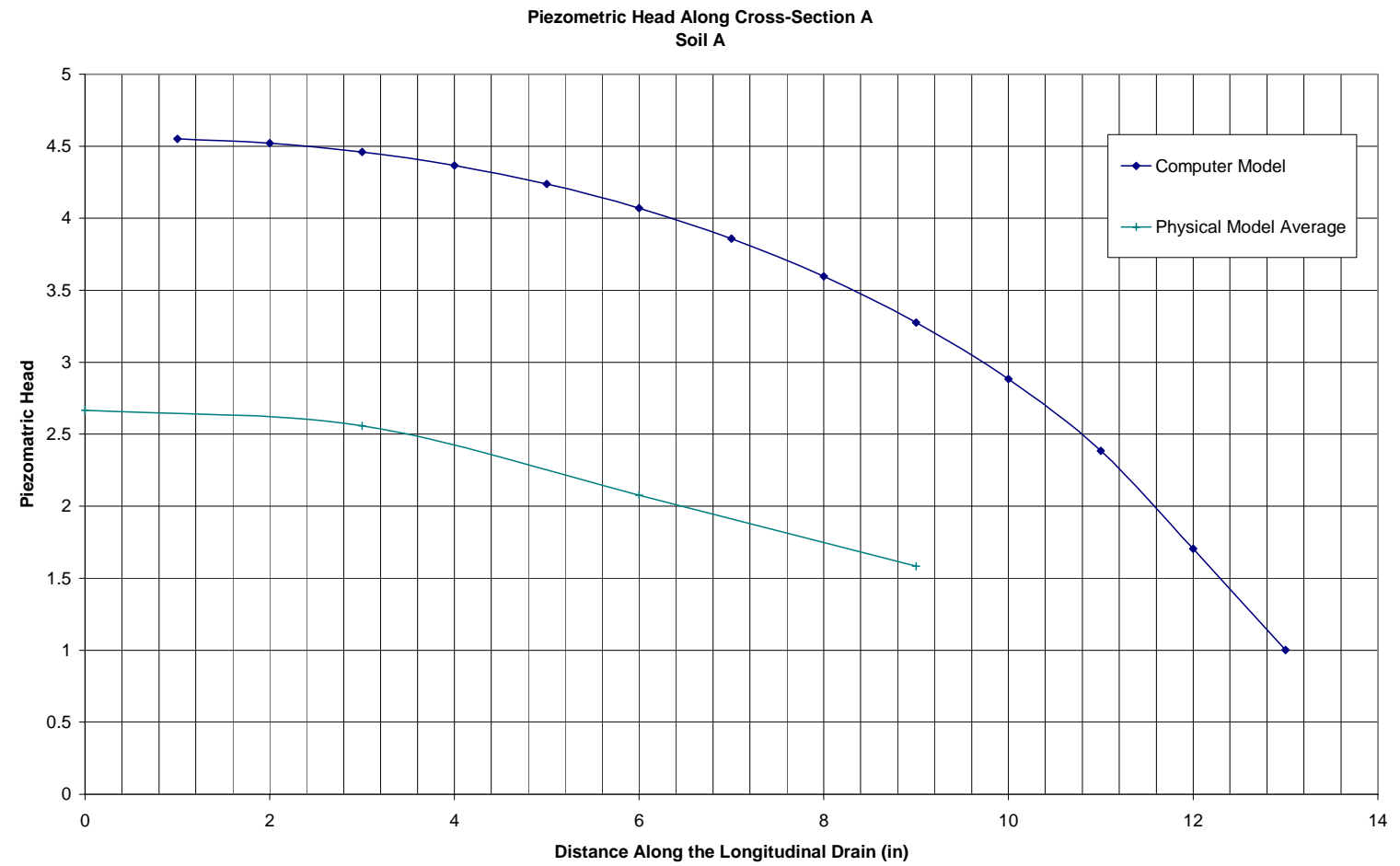

Figure 4.55: Piezometric head along cross-section A for Soil Type A at zero slope, 12” width

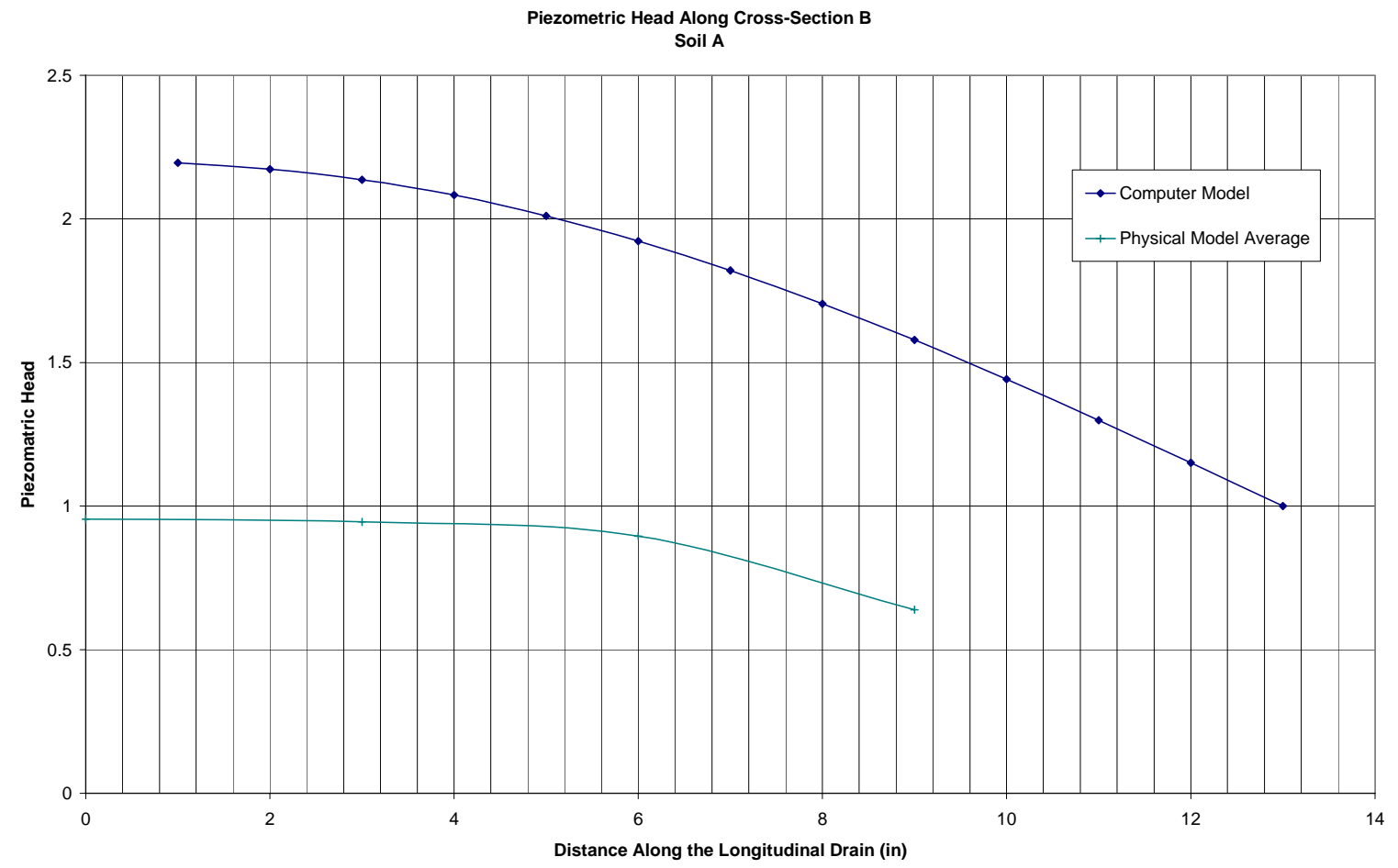

Figure 4.56: Piezometric head along cross-section B for Soil Type A at zero slope, 12” width 


\subsection{Field Projections}

The performance of longitudinal drains under field conditions is discussed in this section. Since there were no experiments under field conditions, the computer model was used to project field performance of several hypothetical longitudinal drains. Table 4.6 shows a summary of all the field simulations that were performed using the computer model. Each field case was assigned an identification (ID) number. The first number in the ID represents the half-trench width (w) (ft), the second number represents the length $(\ell)$ of the drain $(\mathrm{ft})$ and the third number represents the slope angle $(\theta)$. For example, the test number 18-144-10 represents a longitudinal drain with a half-trench spacing of $18 \mathrm{ft}$ (width), a length of $144 \mathrm{ft}$ and an inclination of 10 degrees.

Table 4.7: Summary of field simulations

$\begin{array}{llllllllll}\# & \text { ID } & \# & \text { ID } & \# & \text { ID } & \# & \text { ID } & \# & \text { ID } \\ 1 & 6-48-0 & 19 & 12-48-0 & 39 & 18-48-0 & 59 & 24-48-0 & 79 & 48-48-0 \\ 2 & 6-48-10 & 20 & 12-48-10 & 40 & 18-48-10 & 60 & 24-48-10 & 80 & 48-48-10 \\ 3 & 6-48-20 & 21 & 12-48-20 & 41 & 18-48-20 & 61 & 24-48-20 & 81 & 48-48-20 \\ 4 & 6-48-30 & 22 & 12-48-30 & 42 & 18-48-30 & 62 & 24-48-30 & 82 & 48-48-30 \\ 5 & 6-48-40 & 23 & 12-48-40 & 43 & 18-48-40 & 63 & 24-48-40 & 83 & 48-48-40 \\ 6 & 6-96-0 & 24 & 12-96-0 & 44 & 18-96-0 & 64 & 24-96-0 & 84 & 48-96-0 \\ 7 & 6-96-10 & 25 & 12-96-10 & 45 & 18-96-10 & 65 & 24-96-10 & 85 & 48-96-10 \\ 8 & 6-96-20 & 26 & 12-96-20 & 46 & 18-96-20 & 66 & 24-96-20 & 86 & 48-96-20 \\ 8 & 6-96-30 & 27 & 12-96-30 & 47 & 18-96-30 & 67 & 24-96-30 & 87 & 48-96-30 \\ 9 & 6-96-40 & 28 & 12-96-40 & 48 & 18-96-40 & 68 & 24-96-40 & 88 & 48-96-40 \\ 10 & 6-144-0 & 29 & 12-144-0 & 49 & 18-144-0 & 69 & 24-144-0 & 89 & 48-144-0 \\ 11 & 6-144-10 & 30 & 12-144-10 & 50 & 18-144-10 & 70 & 24-144-4 & 90 & 48-144-4 \\ 12 & 6-144-20 & 31 & 12-144-20 & 51 & 18-144-20 & 71 & 24-144-3 & 91 & 48-144-3 \\ 12 & 6-144-30 & 32 & 12-144-30 & 52 & 18-144-30 & 72 & 24-144-2 & 92 & 48-144-2 \\ 13 & 6-144-40 & 33 & 12-144-40 & 53 & 18-144-40 & 73 & 24-144-40 & 93 & 48-144-40 \\ 14 & 6-192-0 & 34 & 12-192-0 & 54 & 18-192-0 & 74 & 24-192-0 & 94 & 48-192-0 \\ 15 & 6-192-10 & 35 & 12-192-10 & 55 & 18-192-10 & 75 & 24-192-10 & 95 & 48-192-10 \\ 16 & 6-192-20 & 36 & 12-192-20 & 56 & 18-192-20 & 76 & 24-192-20 & 96 & 48-192-20 \\ 17 & 6-192-30 & 37 & 12-192-30 & 57 & 18-192-30 & 77 & 24-192-30 & 97 & 48-192-30 \\ 18 & 6-192-40 & 38 & 12-192-40 & 58 & 18-192-40 & 78 & 24-192-40 & 98 & 48-192-40\end{array}$


The modeling study was comprehensive. The study included more than two hundred models for each soil. Most of the modeling work was done with soil type A. These models were divided as follows: one hundred and ninety four models for side drain analysis; half of these cases were under steady state conditions and the other half was under transient conditions. One hundred and ninety four models for end drain studies; half of these cases were under steady state conditions and the other half was under transient conditions. For the field conditions, only three soil types were selected: soil type A, soil type C and soil type E. Since the dimensions for field sections are much larger than the ones used for laboratory set-up, larger units were used in the analysis. Time was measured in days as opposed to minutes, and the length was measured in feet. The following hydraulic conductivities were used in the field study (see Table 4.7). Appendix A7 show the models for soil A.

Table 4.8: Field Hydraulic Conductivities

\begin{tabular}{|l|c|c|c|}
\hline Soil Type & A & C & E \\
\hline Hydraulic Conductivity (ft/d) & 48.72 & 26.66 & 1.25 \\
\hline
\end{tabular}

\subsubsection{Transient Behavior of field drains}

\subsubsection{Influence of trench spacing (2w)}

In this section, results from the computer modeling study are presented. Transient time is the time for the drains to become fully functional. Drain effectiveness (or drain efficiency) is the percentage removal of seepage. In field installations, the transient time can be a critical issue. Hence, it is important to know in advance the time required for 
longitudinal drains to become fully functional and their behavior during the transient period. The influence of trench spacing $(2 w)$ on drain effectiveness and transient time is presented below. Because the dimensions are much larger than those used in the lab, it is logical to assume that the time will also increase. The parameters (inclination, width and length for all soil types) used in the study are variable as shown in Table 4.6. In a previous study completed in 2002 (Kiriakidis, 2002) it was determined that the boundary parameters did have an effect on the seepage behavior by using a physical model under laboratory conditions.

Figure 4.57 through Figure 4.61 show the change in piezometric head along the center line for the five different widths considered in this study. The samples shown in these figures correspond to soil type A, a constant length of forty eight feet and a ten degree slope.

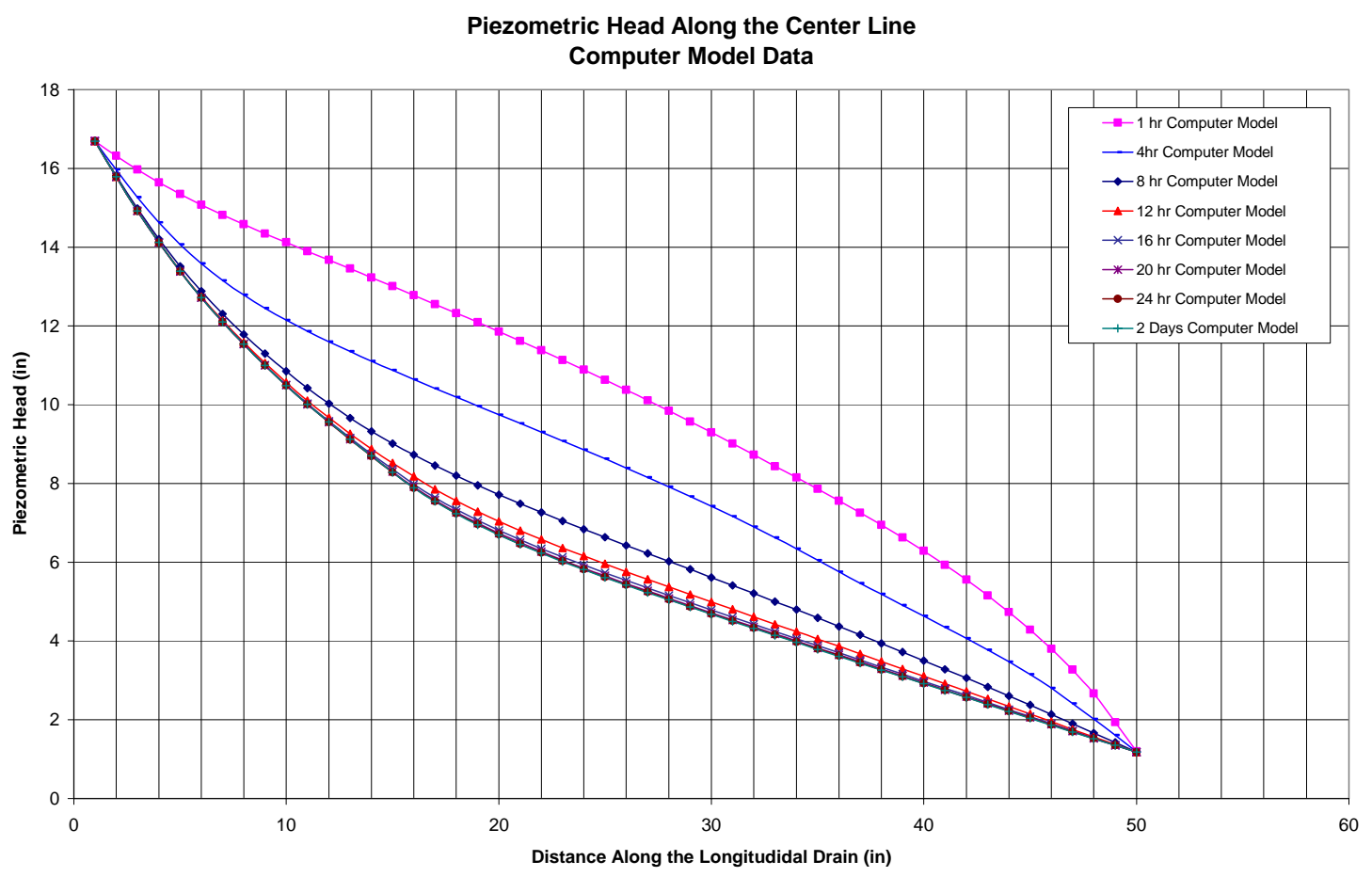

Figure 4.57: Piezometric head along the center line for case A-6-48-10 


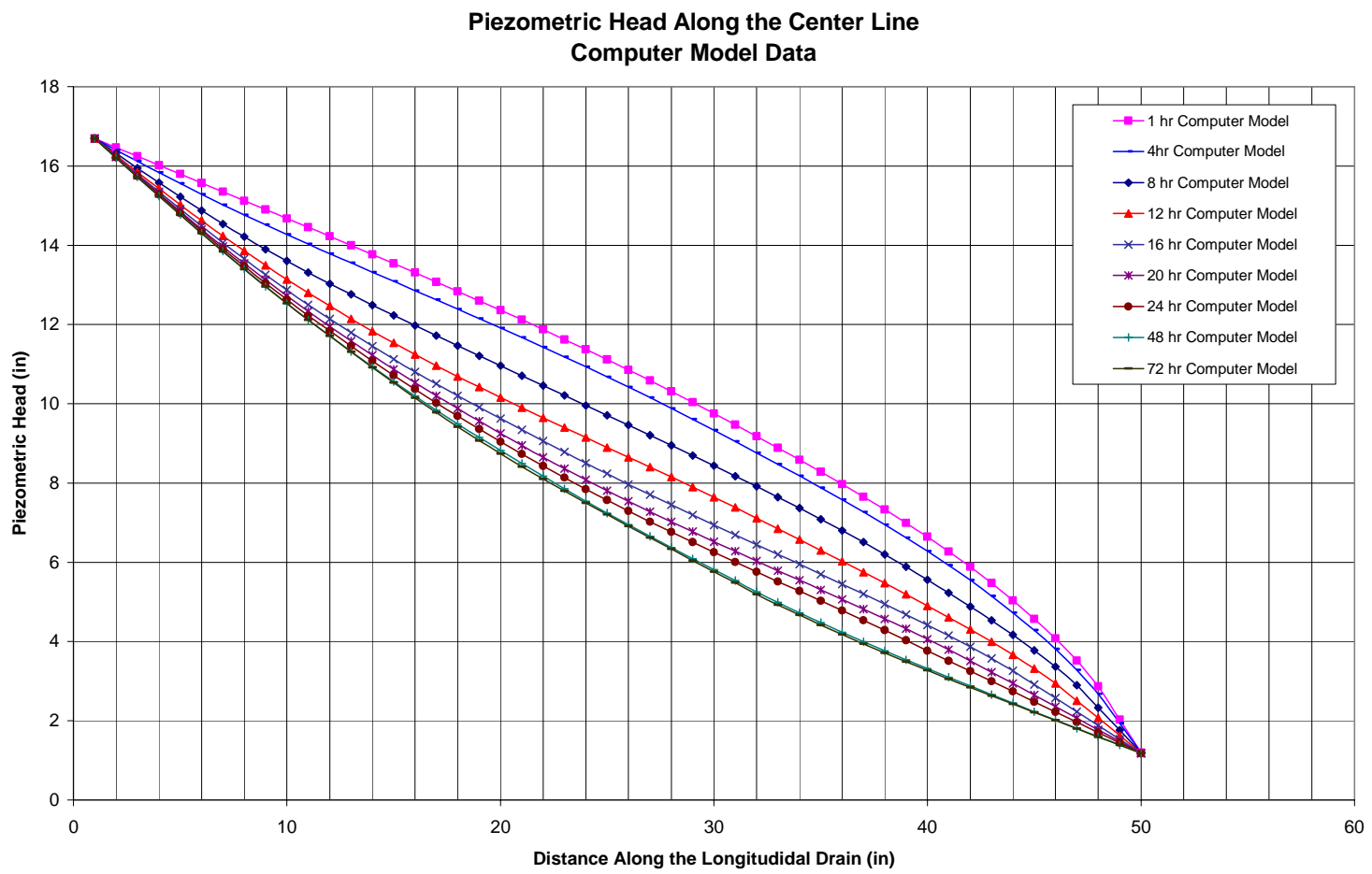

Figure 4.58: Piezometric head along the center line for case A-12-48-10

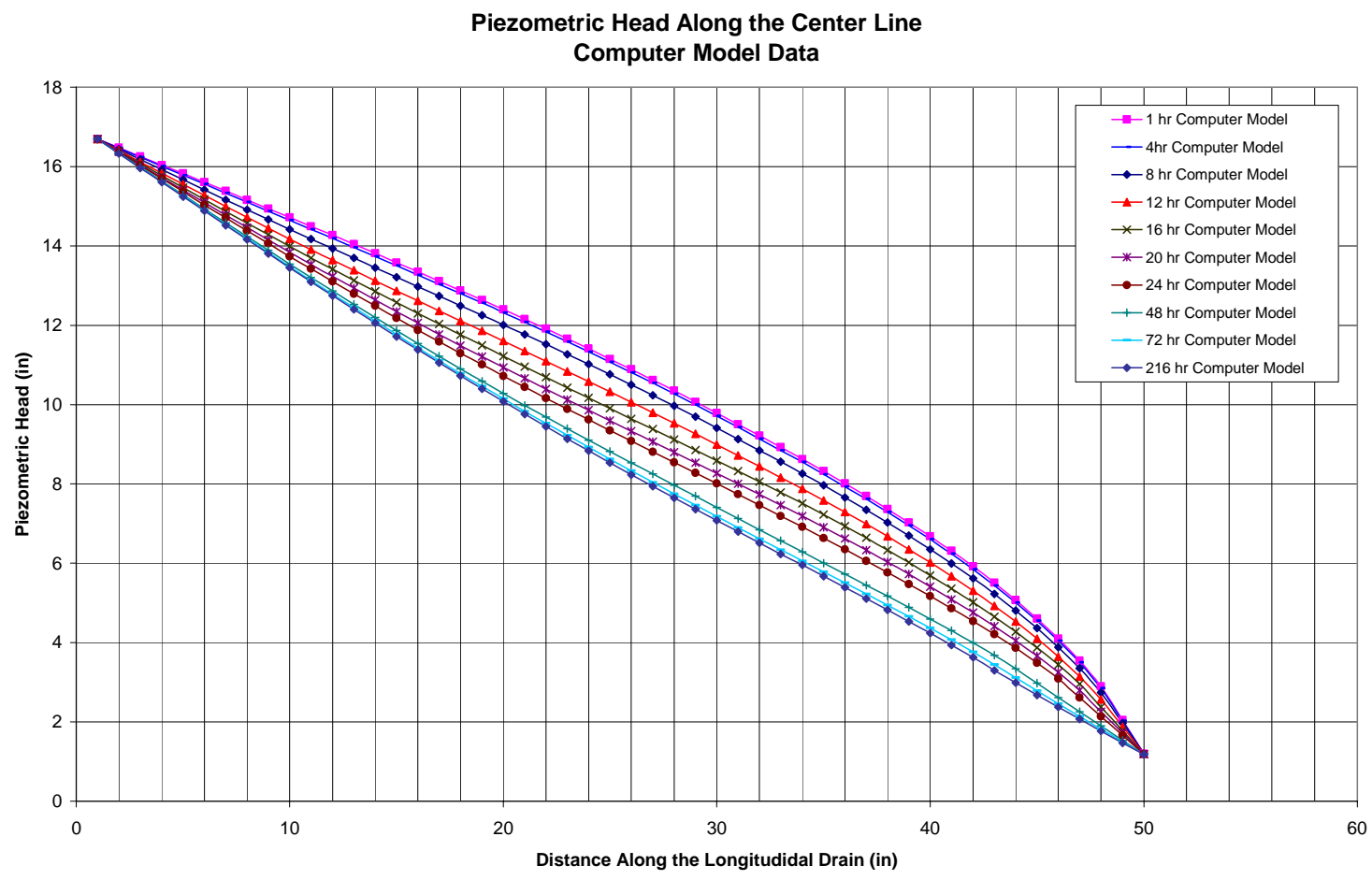

Figure 4.59: Piezometric head along the center line for case A-18-48-10 
Piezometric Head Along the Center Line Computer Model Data

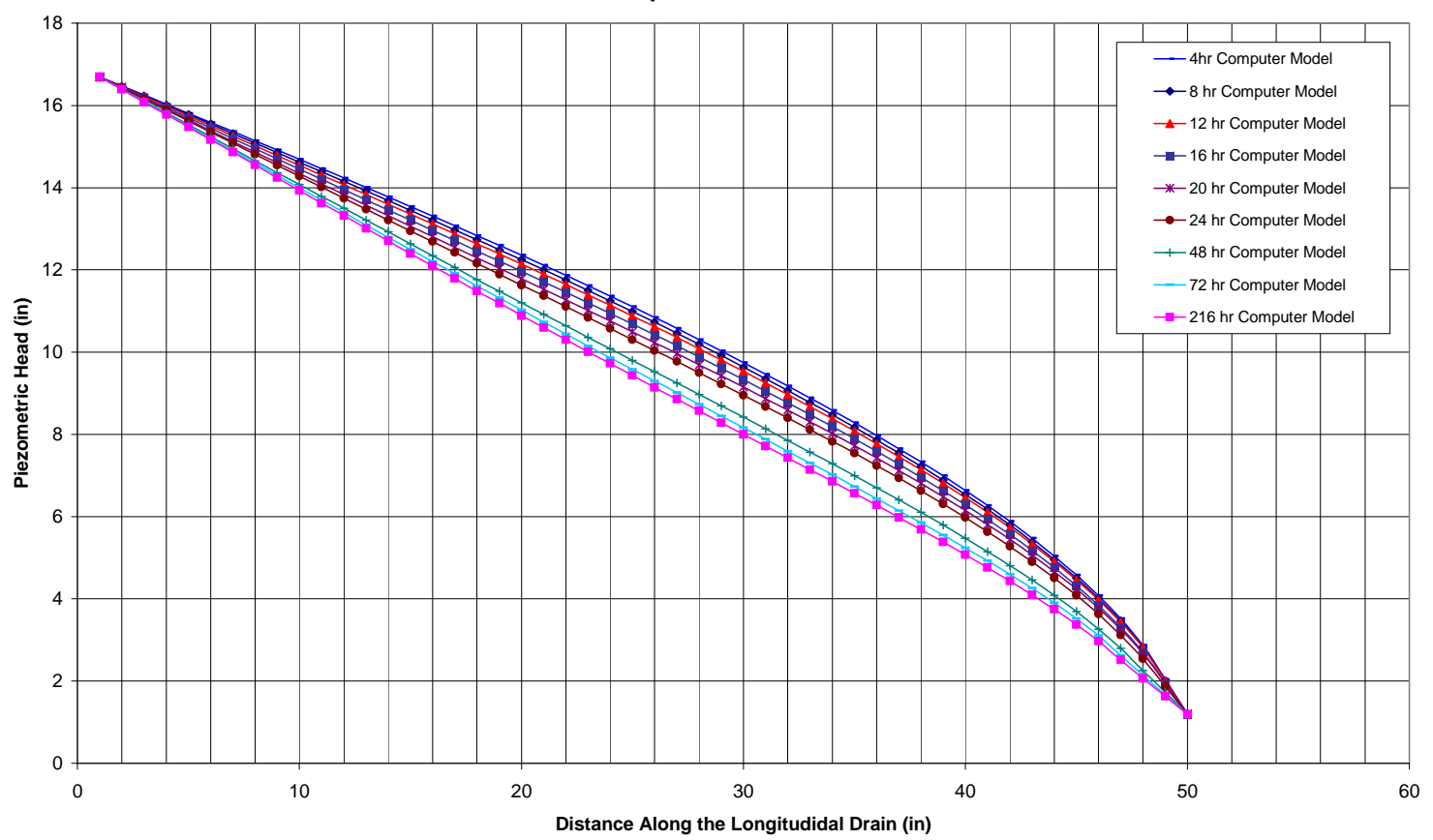

Figure 4.60: Piezometric head along the center line for case A-24-48-10

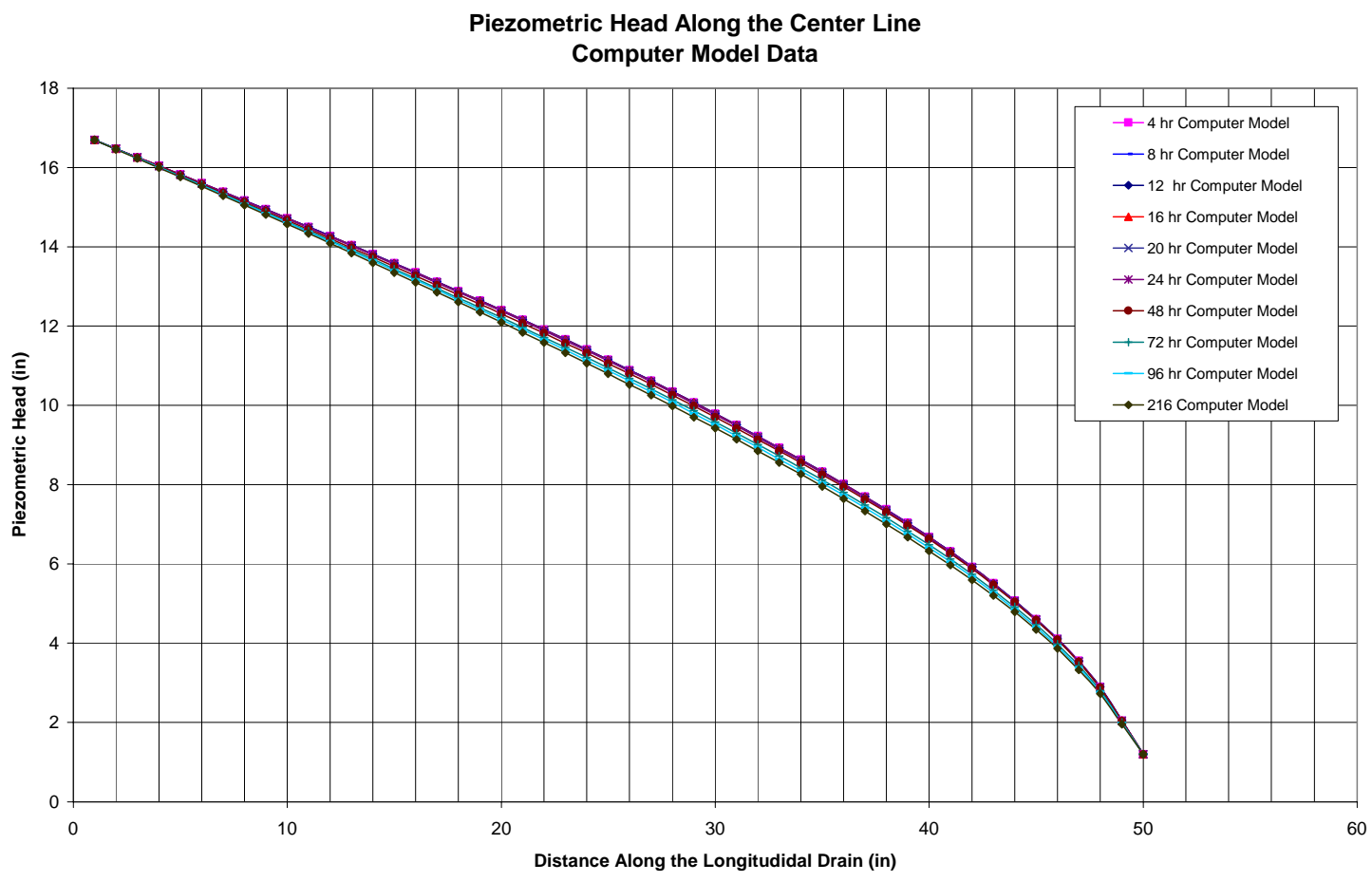

Figure 4.61: Piezometric head along the center line for case A-48-48-10 
As expected the width of the trench has a major effect in the piezometric head variation. These figures show that as the width increases the drop in the piezometric head between time periods is smaller. In the first case, a six-foot trench spacing, the piezometric head decreased by about half of the initial level after four hours, while for a forty-eight foot trench spacing the initial water level does not change much. Seepage forces are the result of the water head inside the soil. These figures show that as the trench becomes wider, the total drop in head over time decreases. For the same conditions as above, Figures 4.62 through Figure 4.71 show how the piezometric head changes along the cross-sections $\mathrm{A}$ and $\mathrm{B}$.

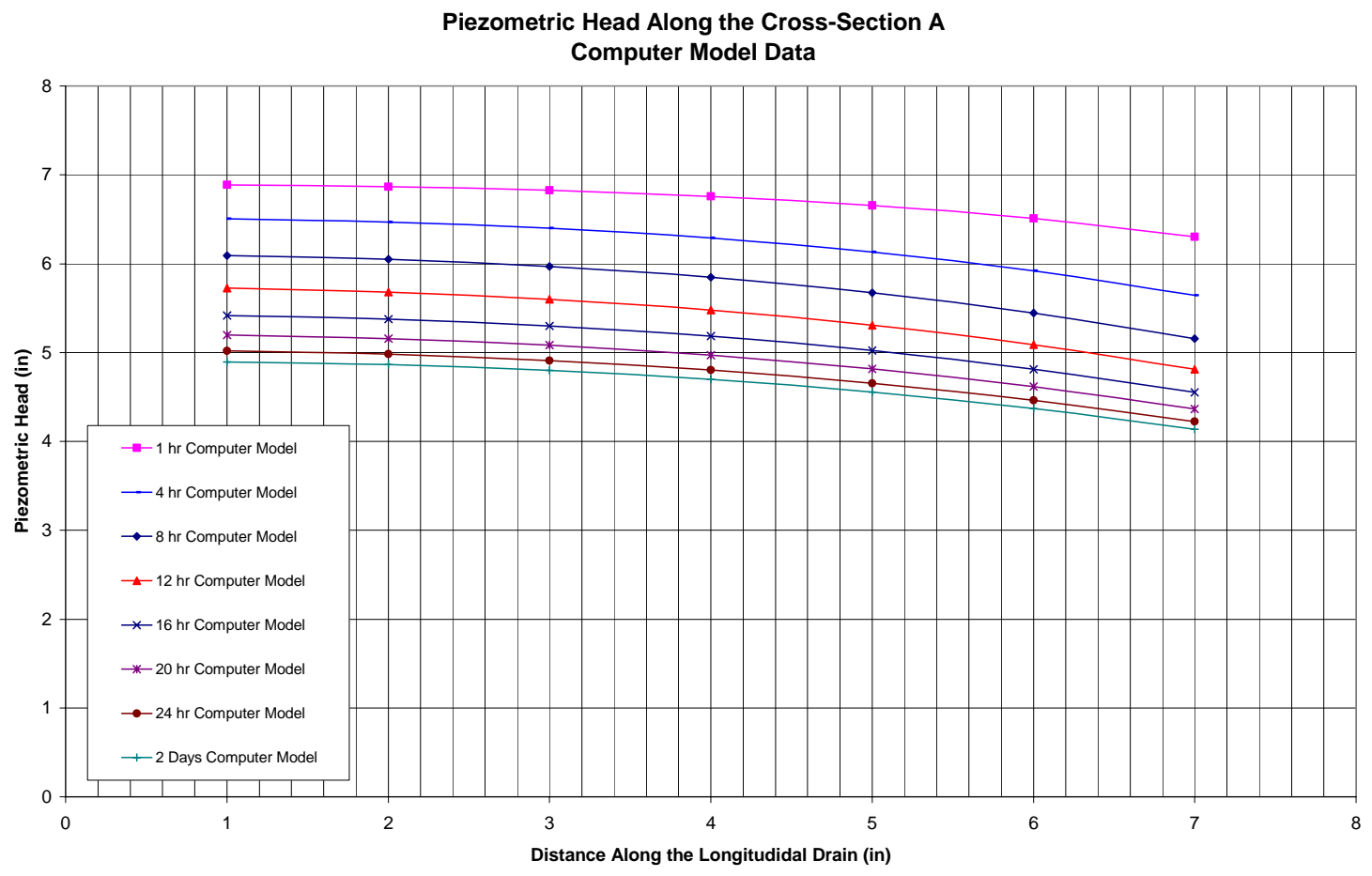

Figure 4.62: Piezometric head along the cross-section A for case A-6-48-10 
Piezometric Head Along the Cross-Section A Computer Model Data

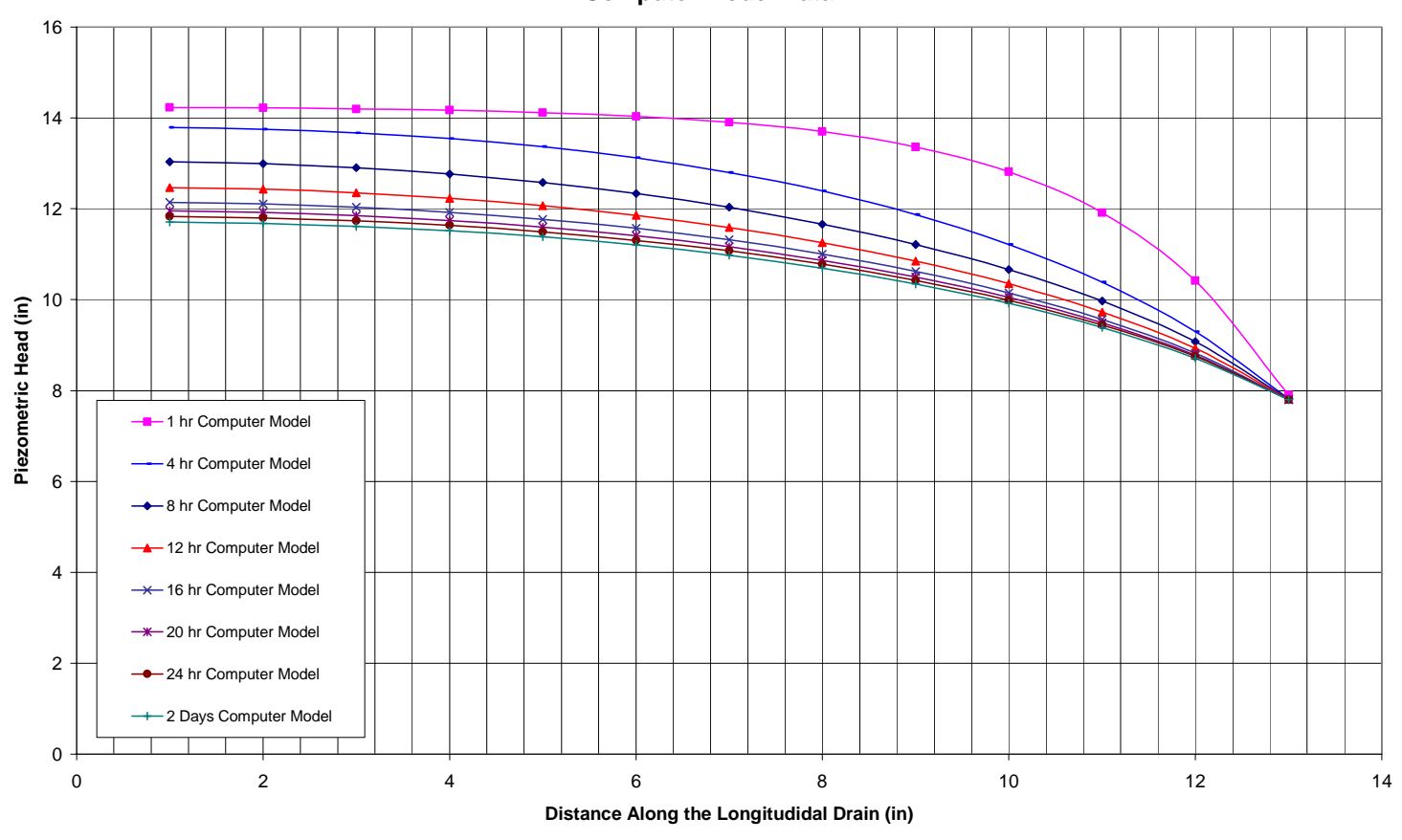

Figure 4.63: Piezometric head along the cross-section A for case A-12-48-10

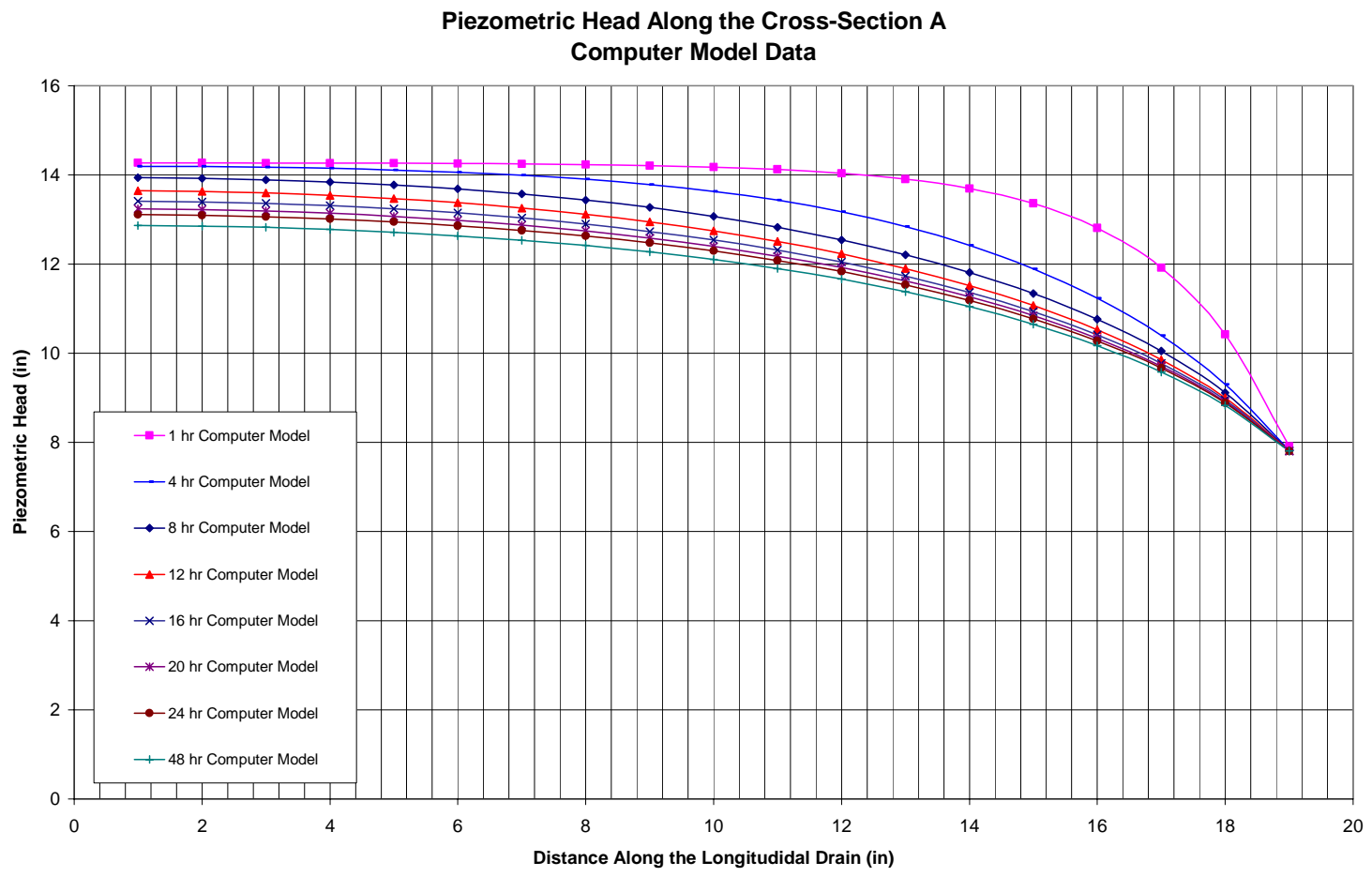

Figure 4.64: Piezometric head along the cross-section A for case A-18-48-10 
Piezometric Head Along the Cross-Section A Computer Model Data

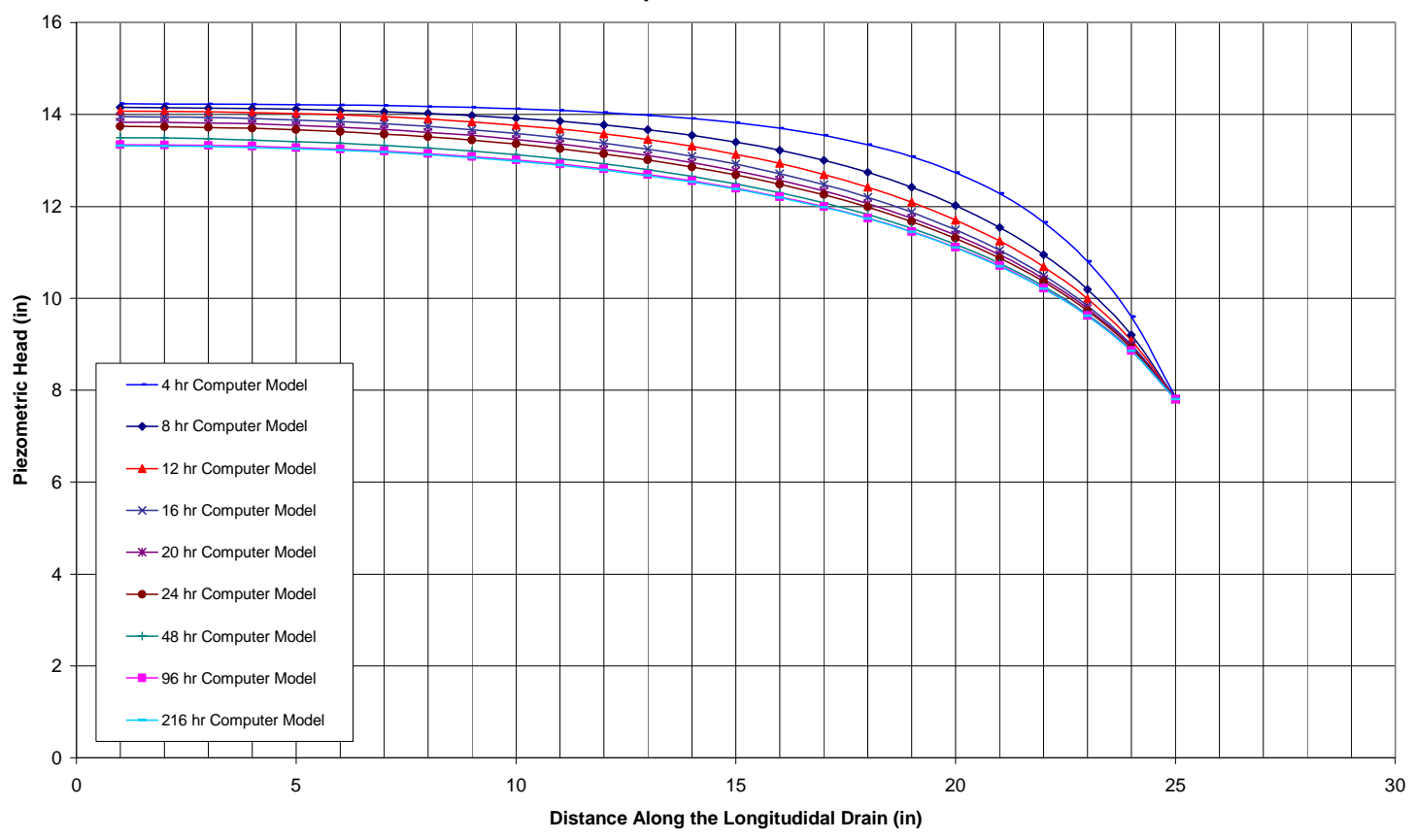

Figure 4.65: Piezometric head along the cross-section A for case A-24-48-10

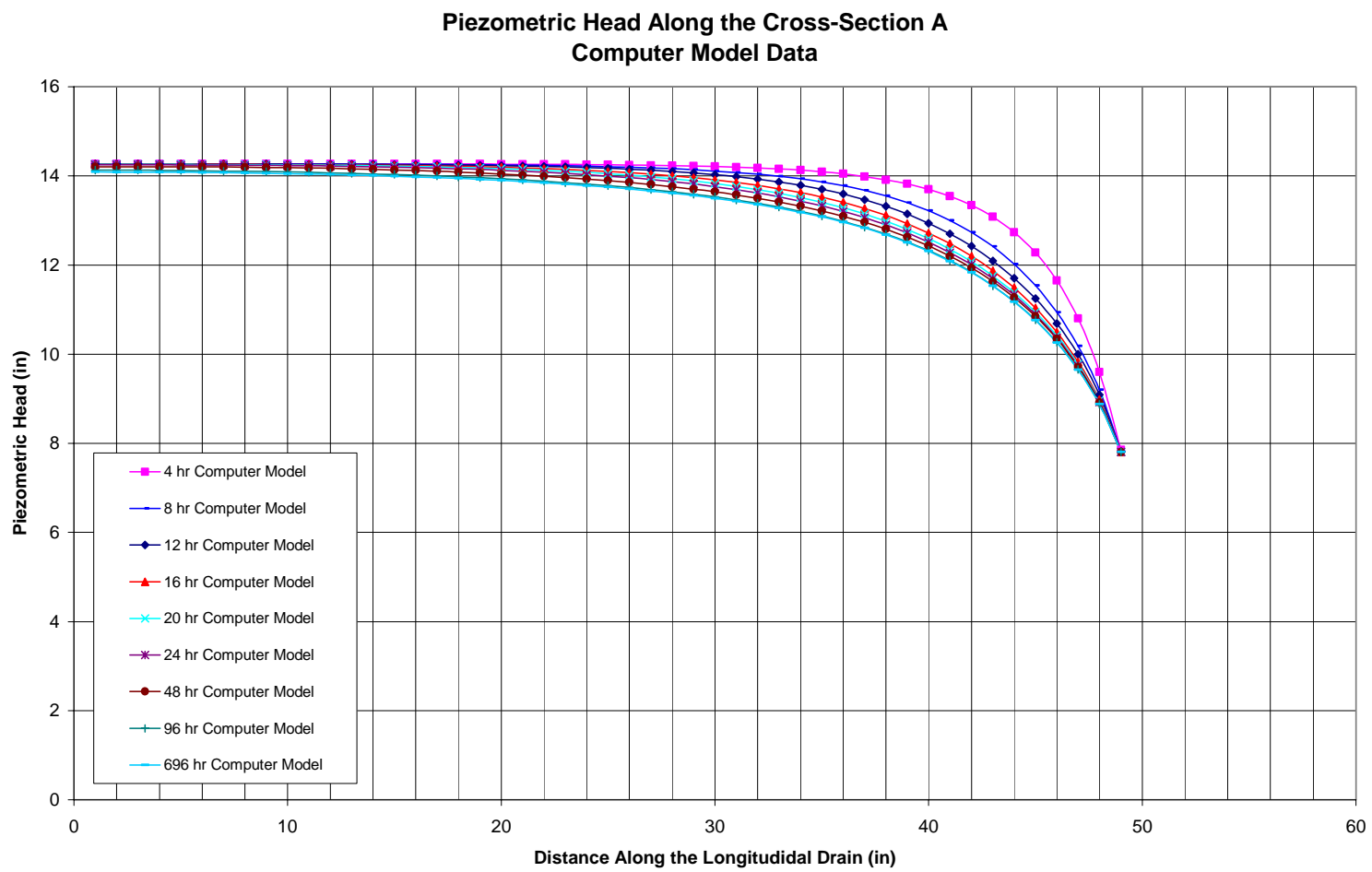

Figure 4.66: Piezometric head along the cross-section A for case A-48-48-10 


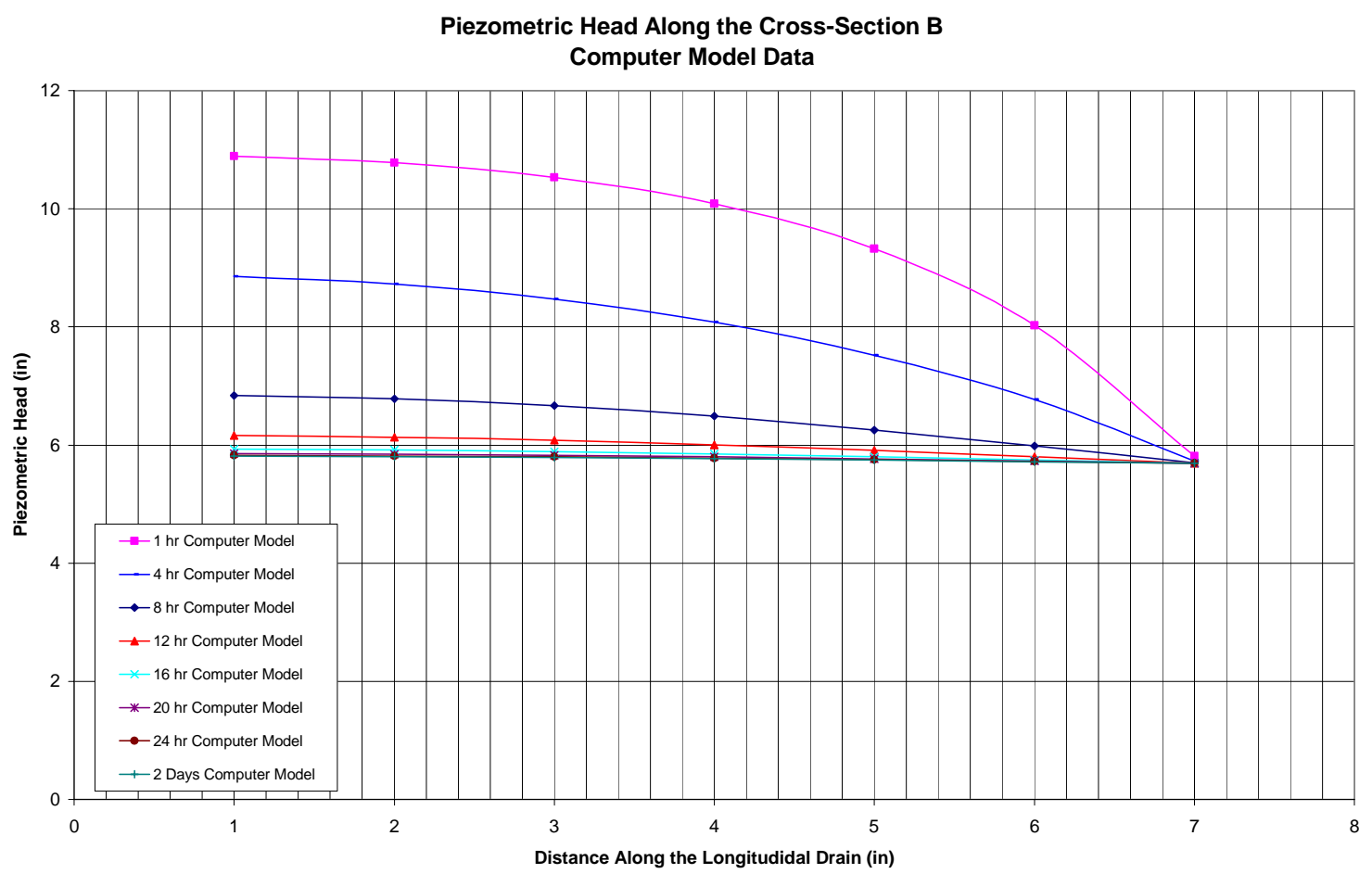

Figure 4.67: Piezometric head along the cross-section B for case A-6-48-10

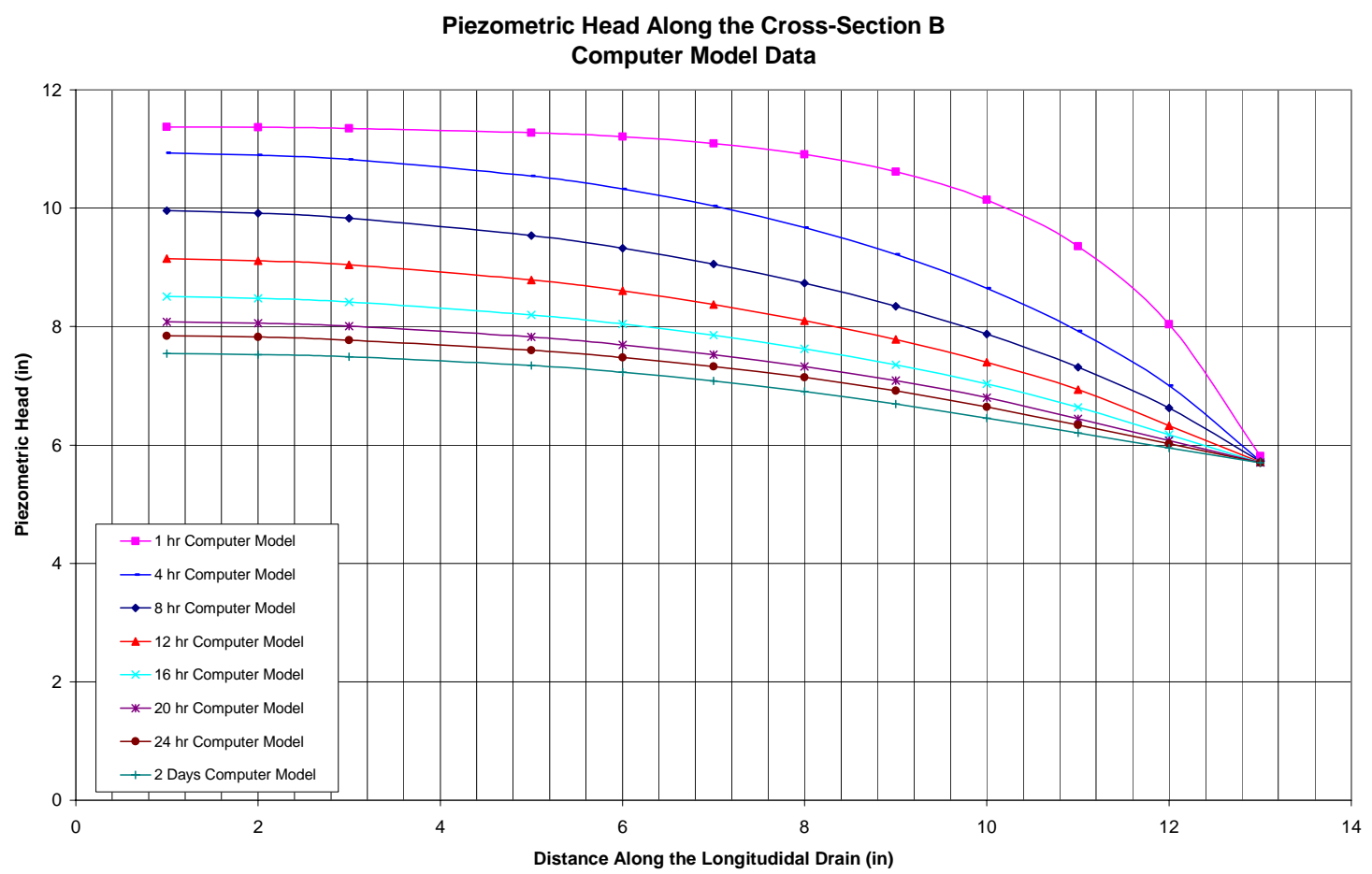

Figure 4.68: Piezometric head along the cross-section B for case A-12-48-10 


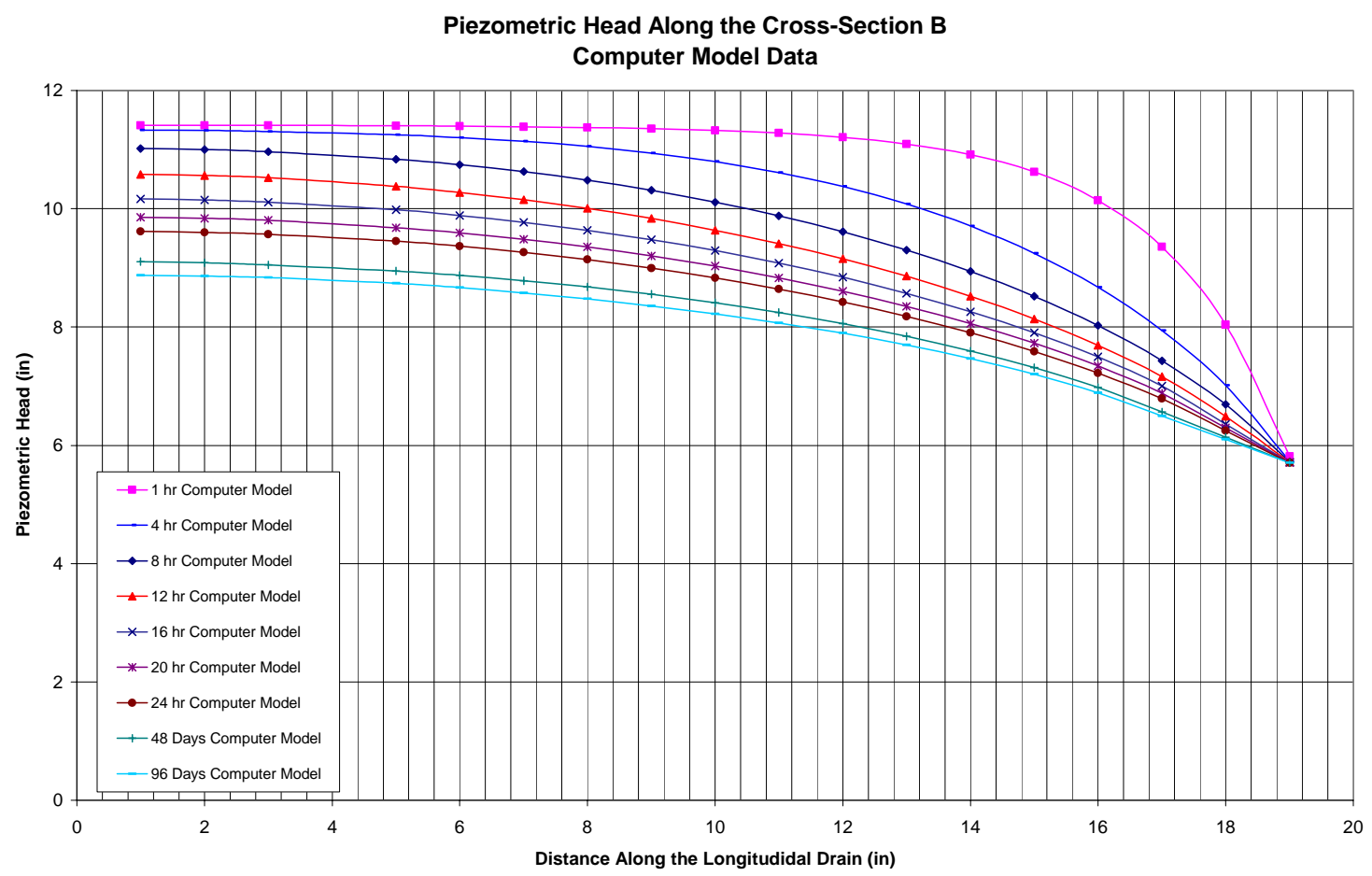

Figure 4.69: Piezometric head along the cross-section B for case A-18-48-10

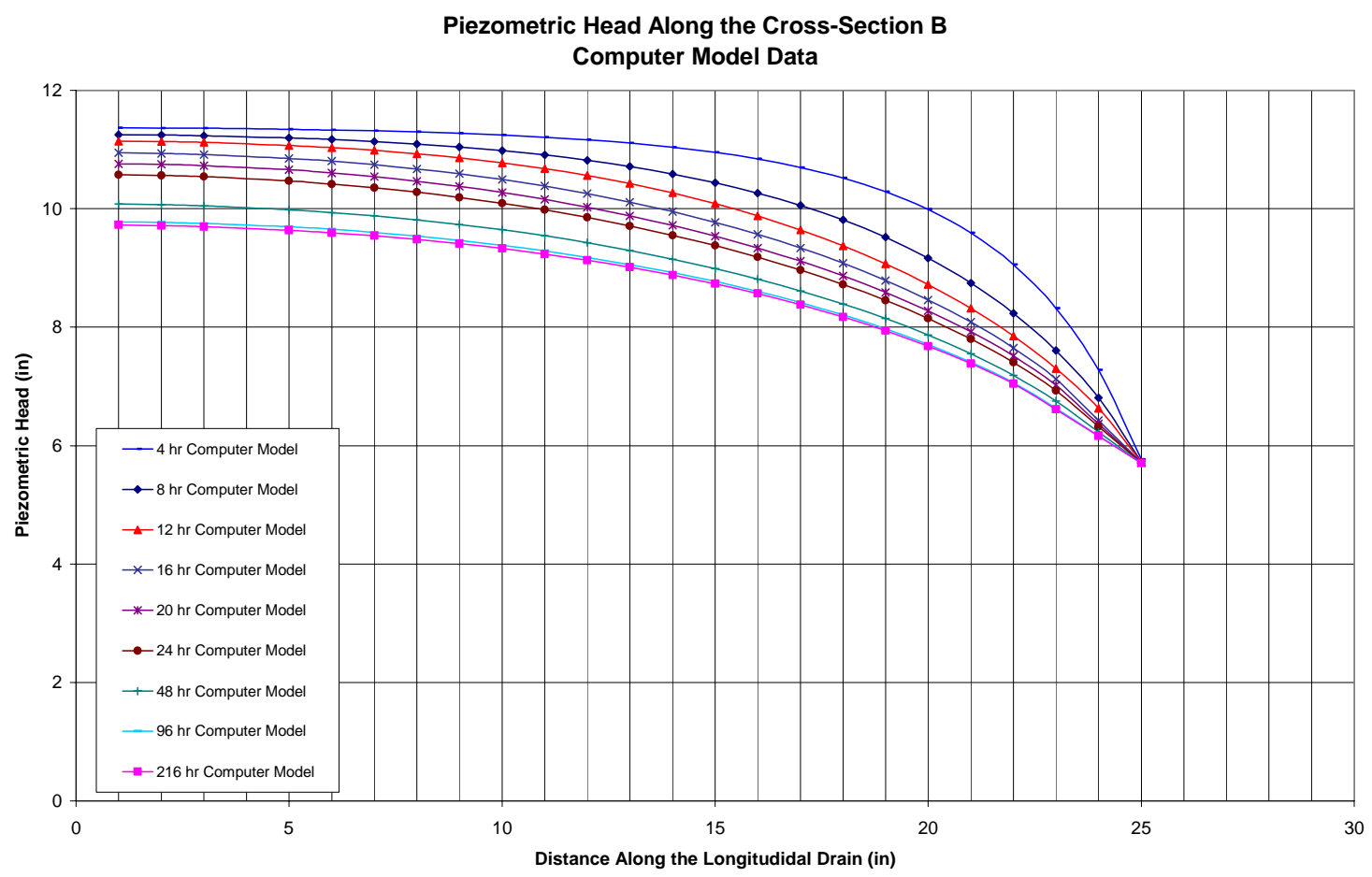

Figure 4.70: Piezometric head along the cross-section B for case A-24-48-10 


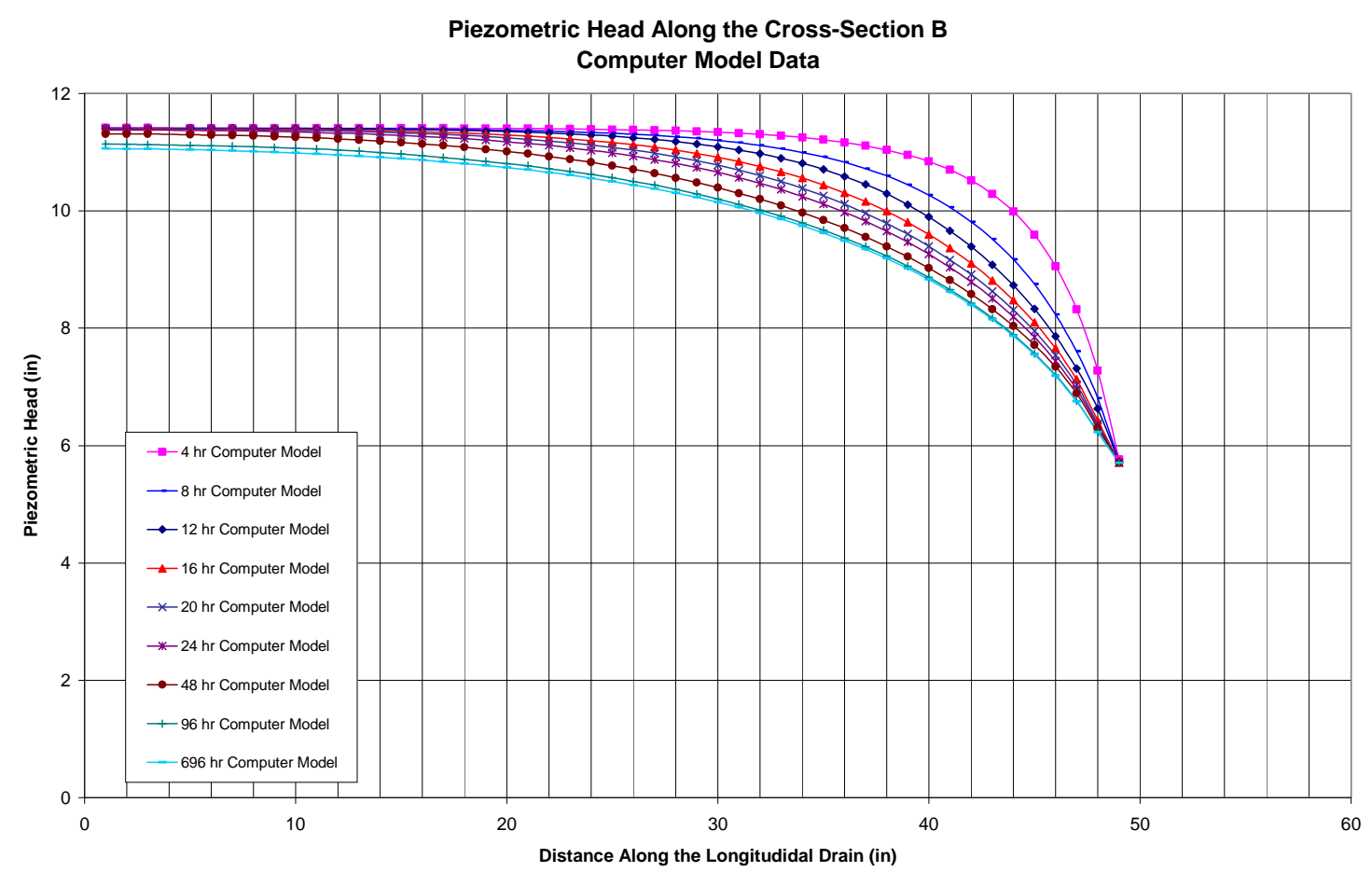

Figure 4.71: Piezometric head along the cross-section B for case A-48-48-10

Just as it happened with the piezometric heads along the center line, the variations of piezometric head along the cross-sections A and B are directly influenced by the trench width. These set of figures show that for a smaller width (trench spacing) the drop in total piezometric head (from initial time to steady state conditions), along the crosssections $\mathrm{A}$ and $\mathrm{B}$ is more noticeable. The drop in piezometric level for the case with smaller trench spacing (six-foot spacing), is much more than the drop seen in the case with a forty-foot trench spacing. A drop in the water level inside the soil will reduce seepage forces and improve stability.

In this section, results are presented to show how the effectiveness of the drains is affected by the trench spacing $(2 \mathrm{w})$. Figure 4.72 through Figure 4.76 show the influence 
of trench spacing on the drain effectiveness, which is expressed as a percentage of seepage removal by the drain. The drain effectiveness (drain efficiency) drops as the trench spacing is increased. The drain efficiency is about $95 \%$ for 6 -foot spacing, while the drain efficiency is about $75 \%$ for 48 -foot spacing. Clearly, it is advantages to have smaller trench spacing, but the cost will be higher. As the trench spacing becomes larger the transient time becomes larger as shown in Figure 4.77.

Cumulative Percent Removed Along the Longitudinal Drain

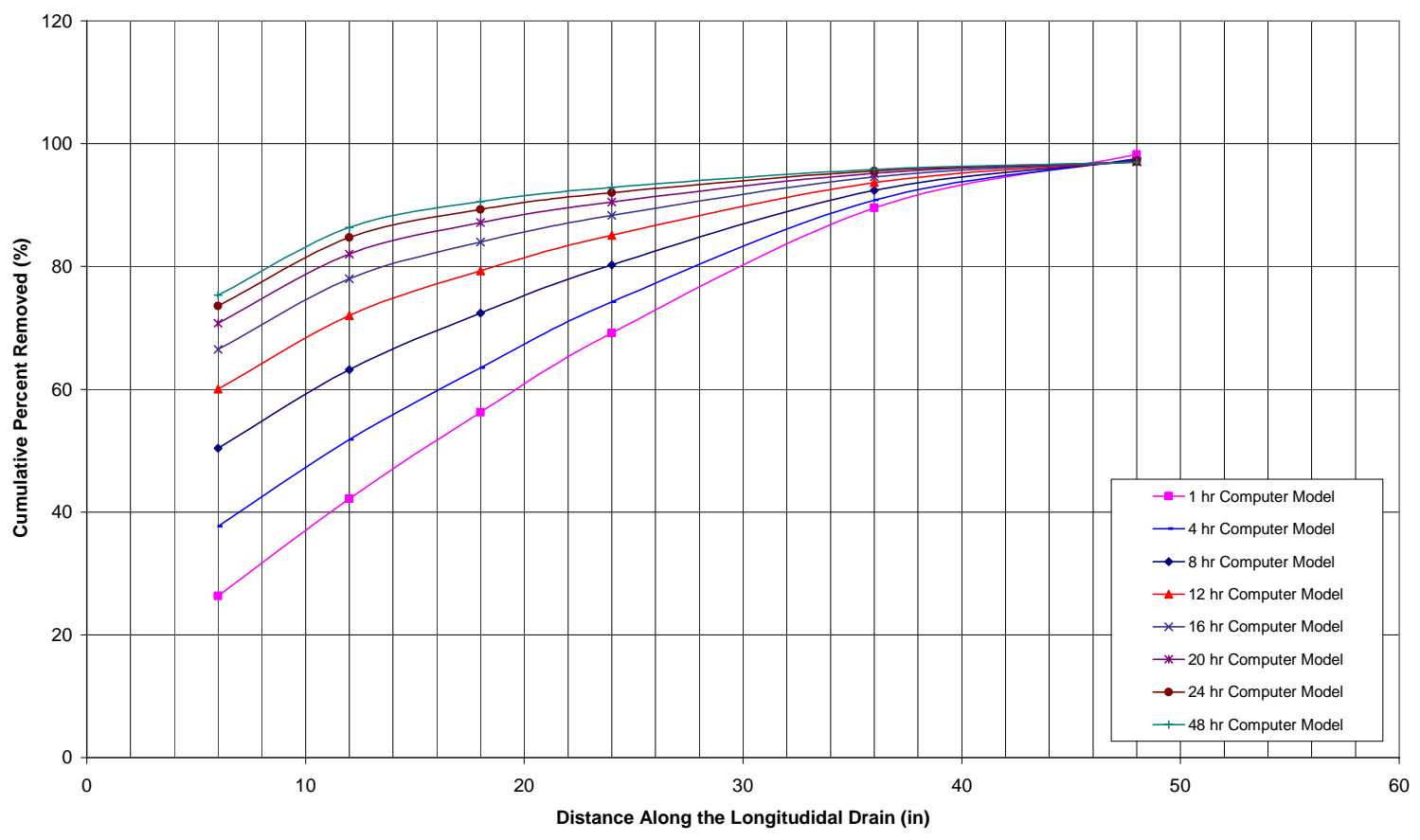

Figure 4.72: Cumulative Percent Removal for case A-6-48-10 
Cumulative Percent Removed Along the Longitudinal Drain

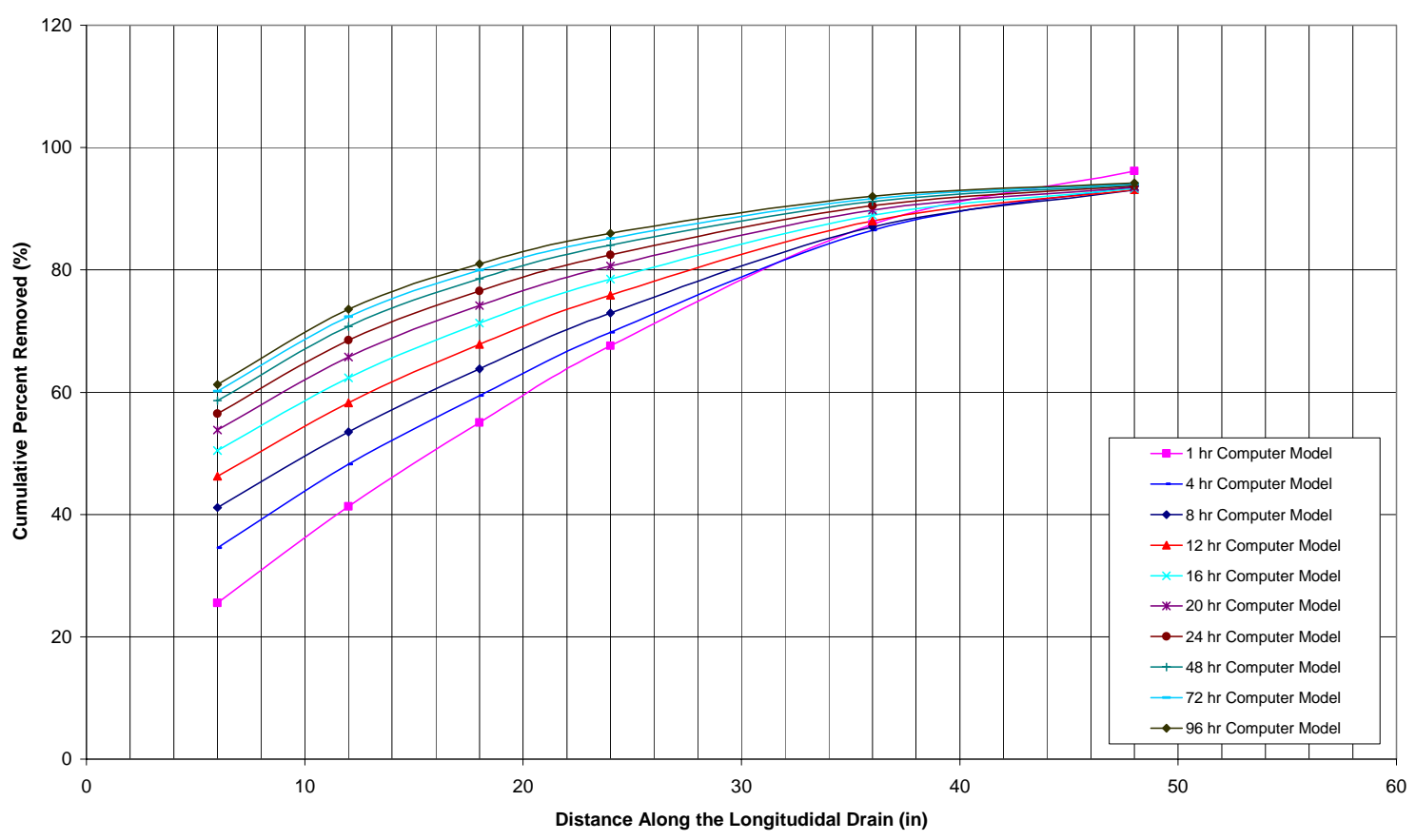

Figure 4.73: Cumulative Percent Removal for case A-12-48-10

Cumulative Percent Removed Along the Longitudinal Drain

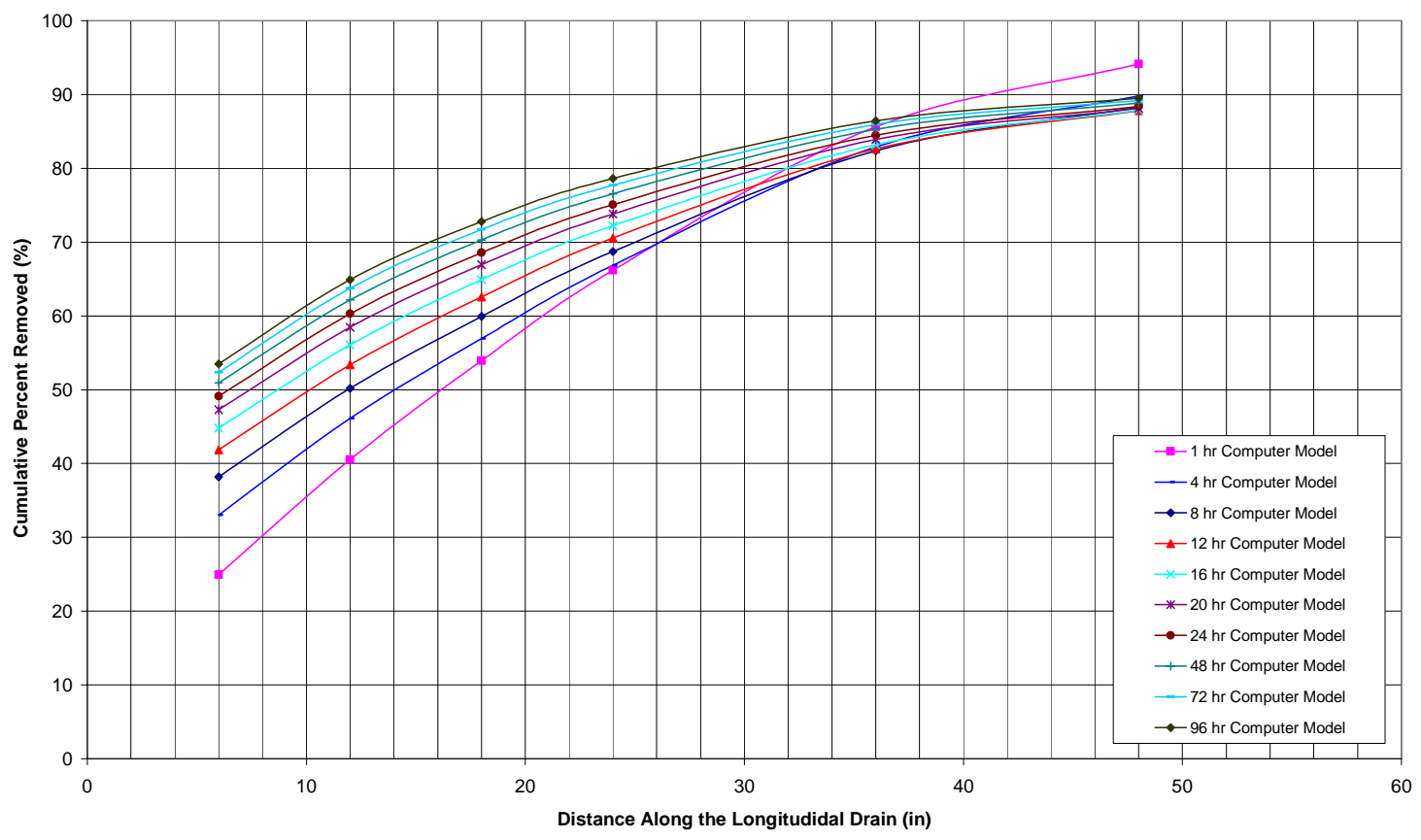

Figure 4.74: Cumulative Percent Removal for case A-18-48-10 
Cumulative Percent Removed Along the Longitudinal Drain

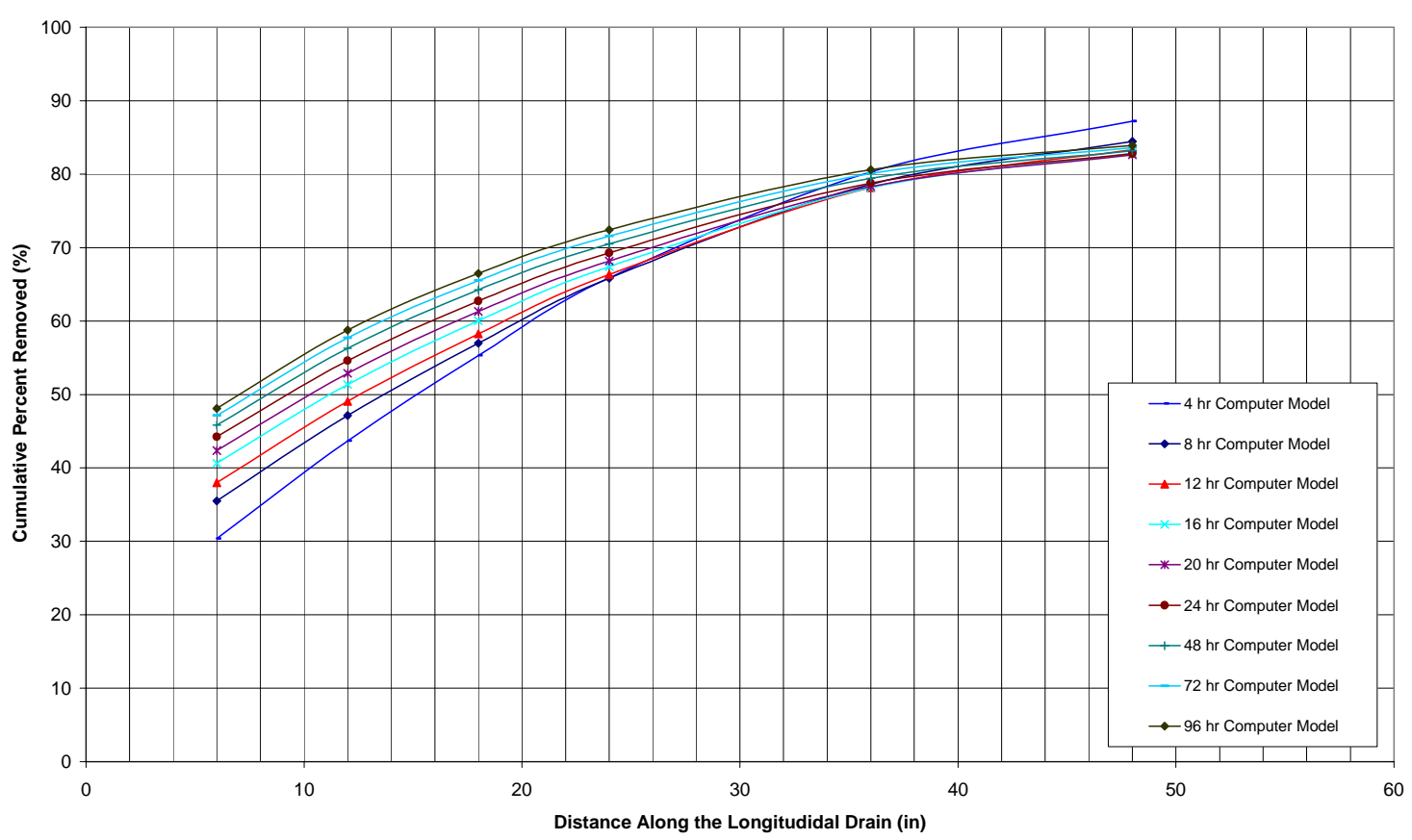

Figure 4.75: Cumulative Percent Removal for case A-24-48-10

Cumulative Percent Removed Along the Longitudinal Drain

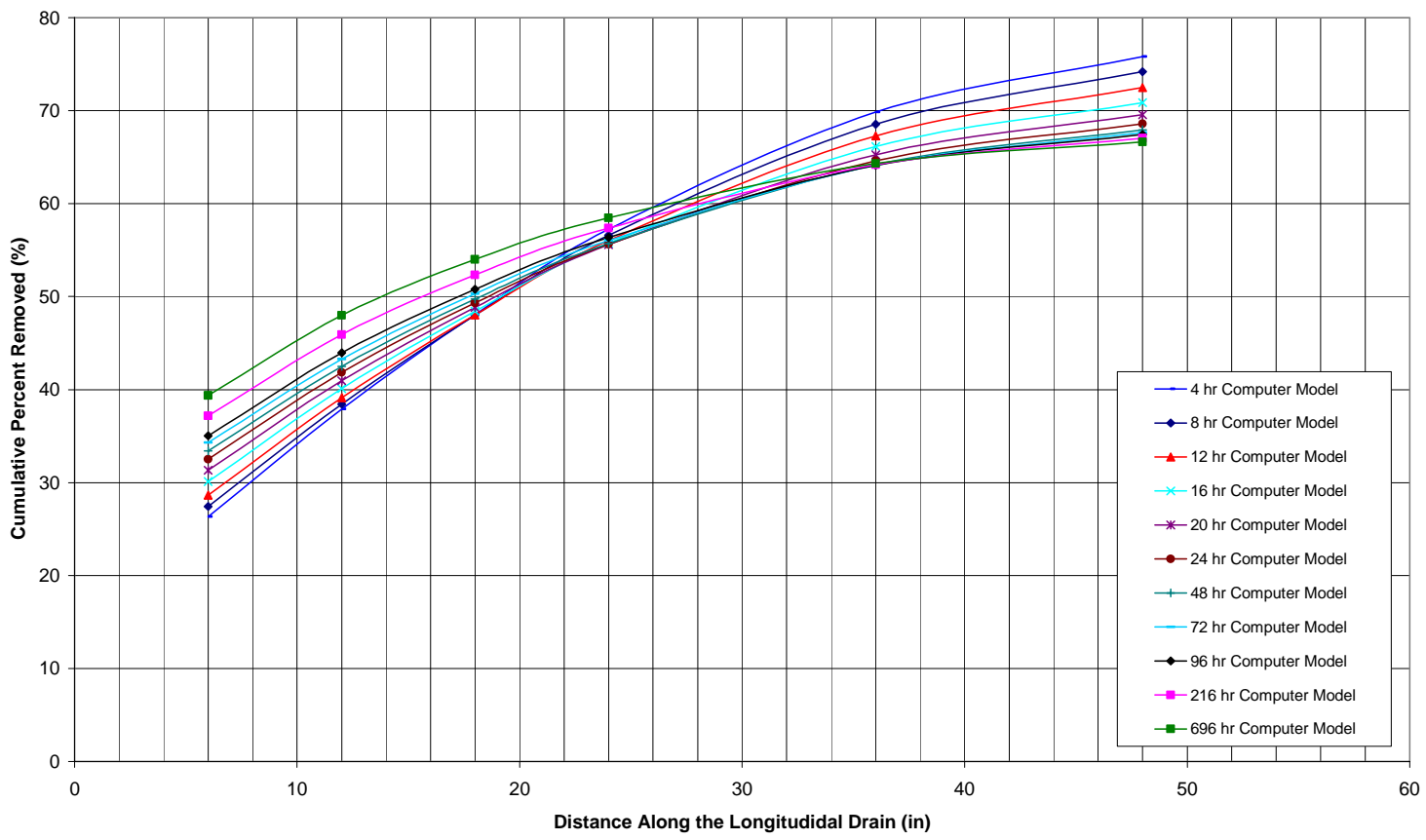

Figure 4.76: Cumulative Percent Removal for case A-48-48-10 


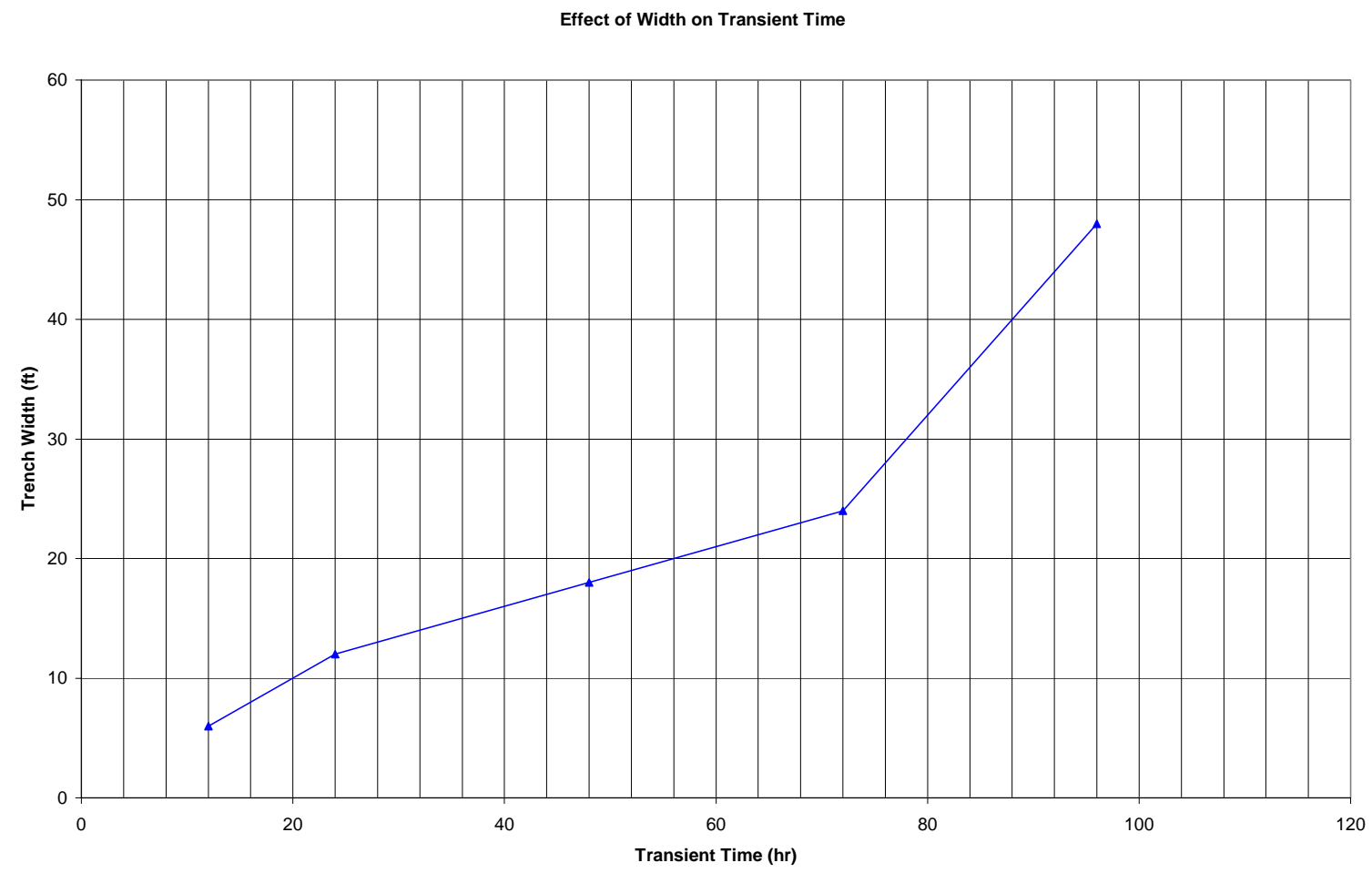

Figure 4.77: Effect of Width on Transient Time

\subsubsection{Influence of Drain Length}

The influence of drain length on the transient behavior of the drain is presented in this section. The drain length was varied while keeping all other geometric parameters at constant values. Results for the soil Type A is presented below. The length of the drain was varied while keeping a constant width of twelve feet and an inclination of ten degrees. The influence of drain length on piezometric heads, and drain effectiveness is presented below. Figures 4.78 through Figure 4.81 show the piezometric heads along the centerline. 


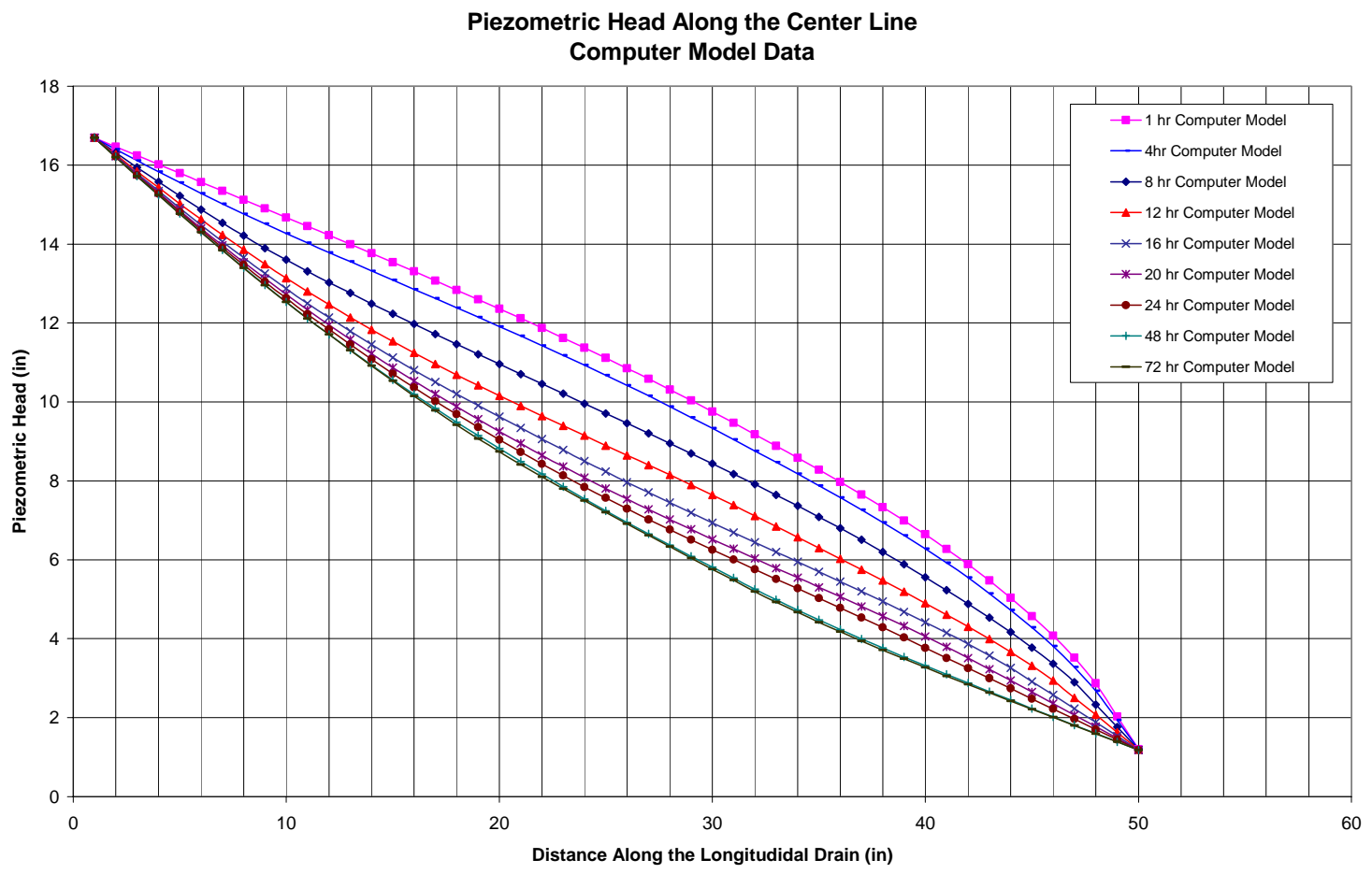

Figure 4.78: Piezometric head along the center line for case A-12-48-10

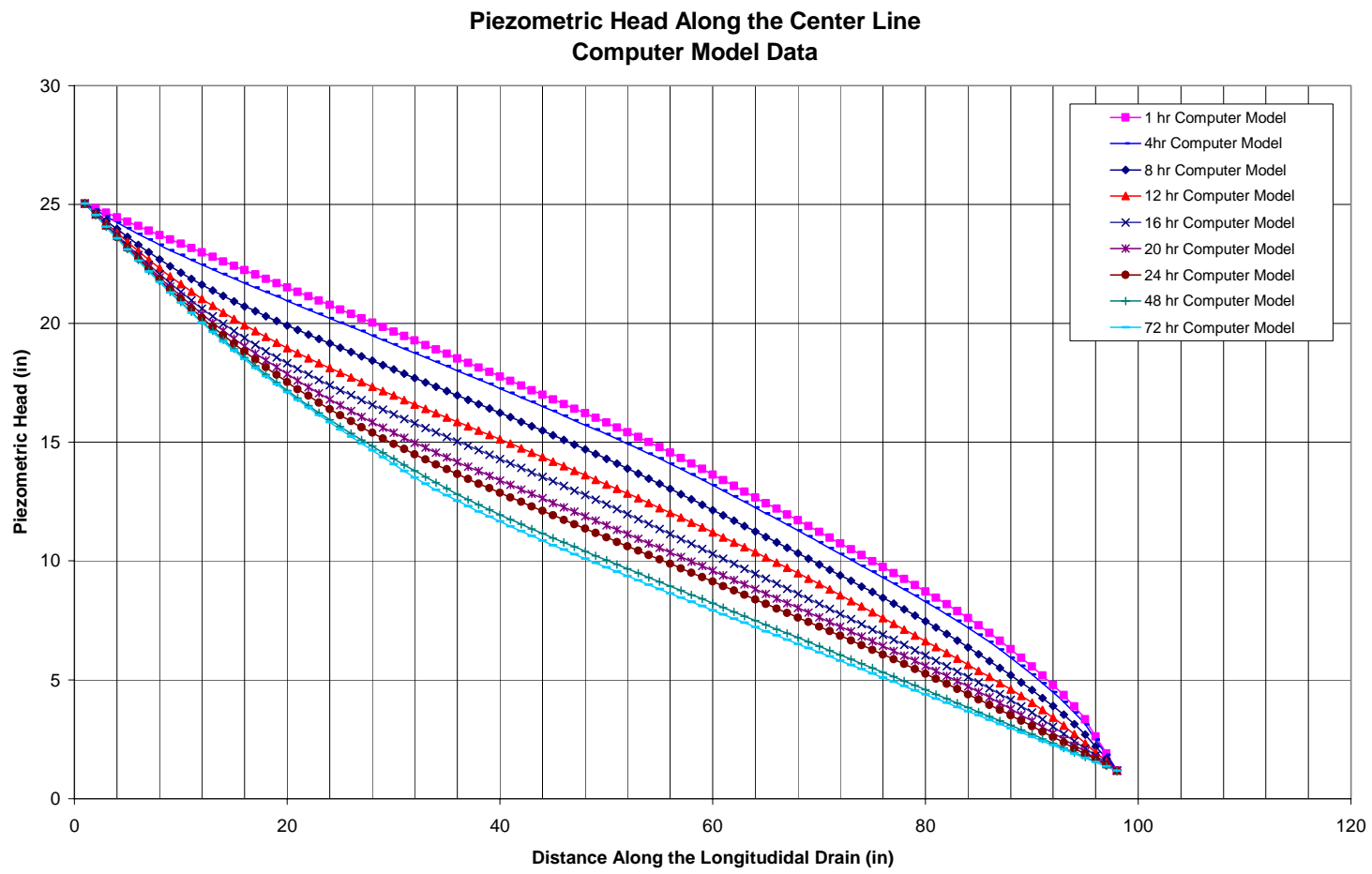

Figure 4.79: Piezometric head along the center line for case A-12-96-10 


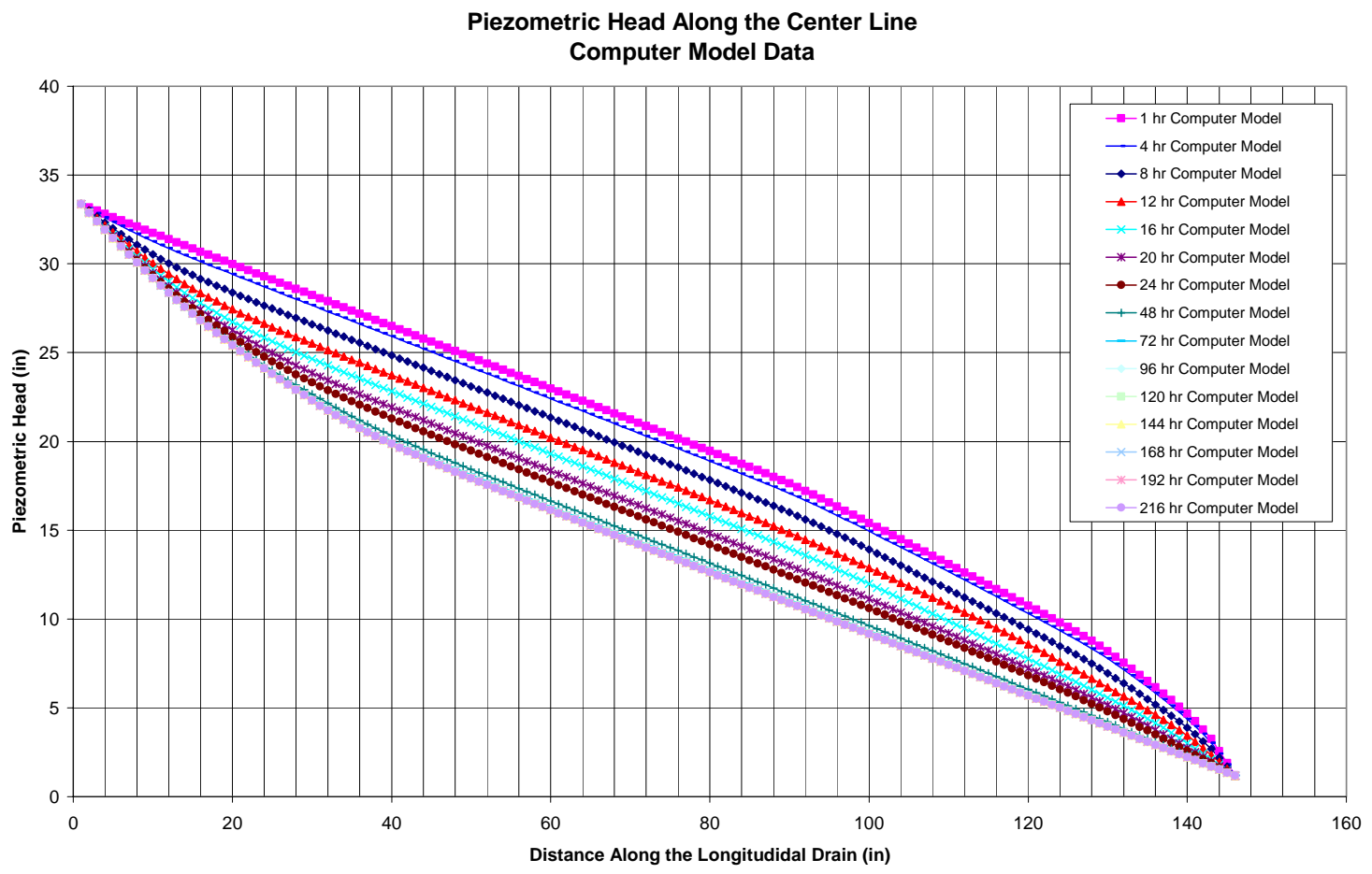

Figure 4.80: Piezometric head along the center line for case A-12-144-10

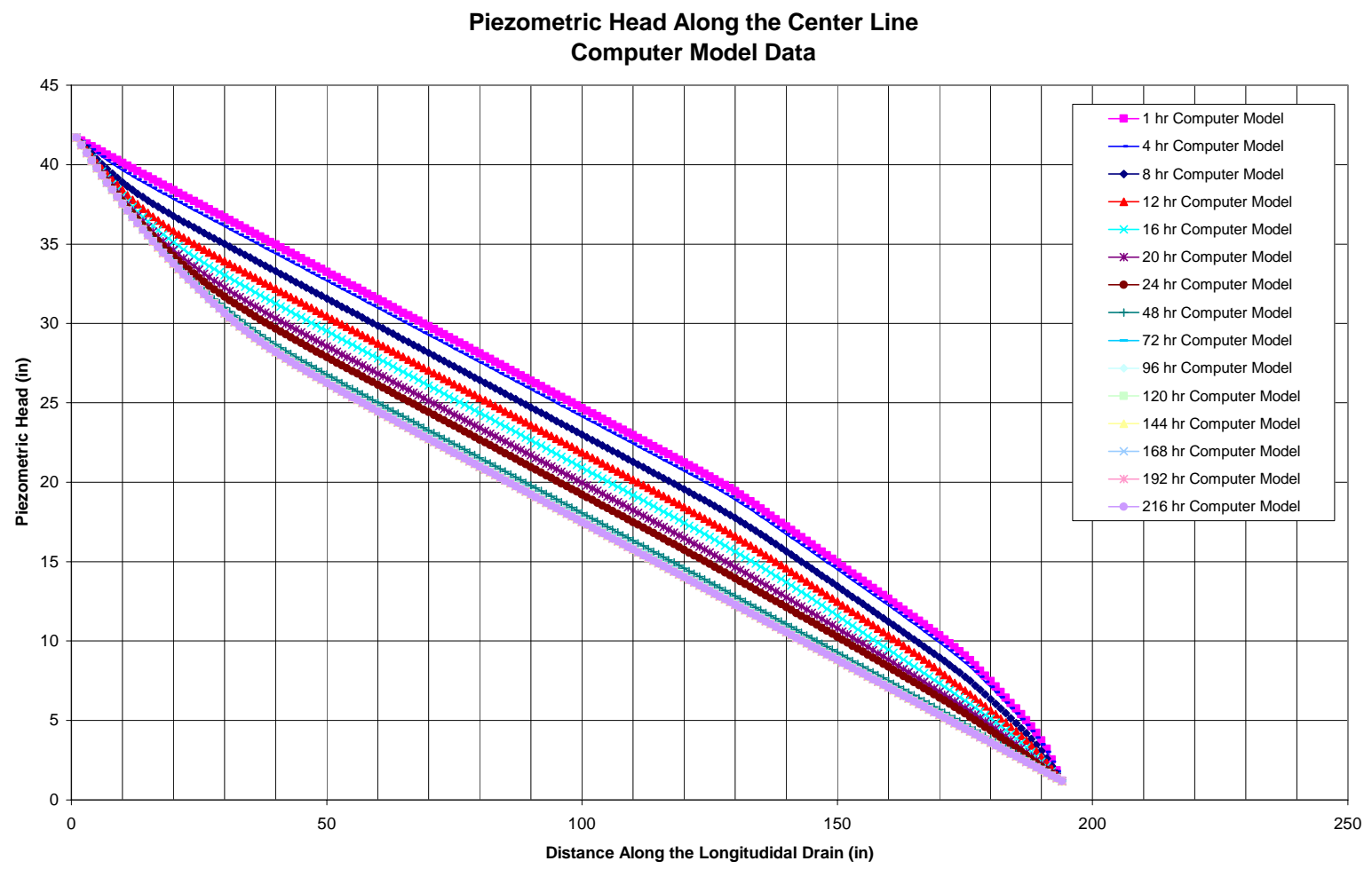

Figure 4.81: Piezometric head along the center line for case A-12-192-10 
The length of the slope does not seem to have any major effect in the total transient time. The time that takes the soil, for all the different lengths, to reach a steady state condition is about the same for all cases (forty eight hours). However, it is interesting to note that the piezometric level drops are more noticeable for the shorter length than for the larger length. As the drain length increases, the water level seems to drop more gradually than for the shorter lengths.

The influence of drain length on the piezometric head along the cross-sections A and B is presented below. The cross-section A is always at one fourth of the drain length and cross-section B is at half of the drain length. Therefore, the cross-section will be at proportional distances regardless of the length of the slope. Figure 4.82 through Figure 4.89 show the piezometric level along cross-sections A and B for the different lengths.

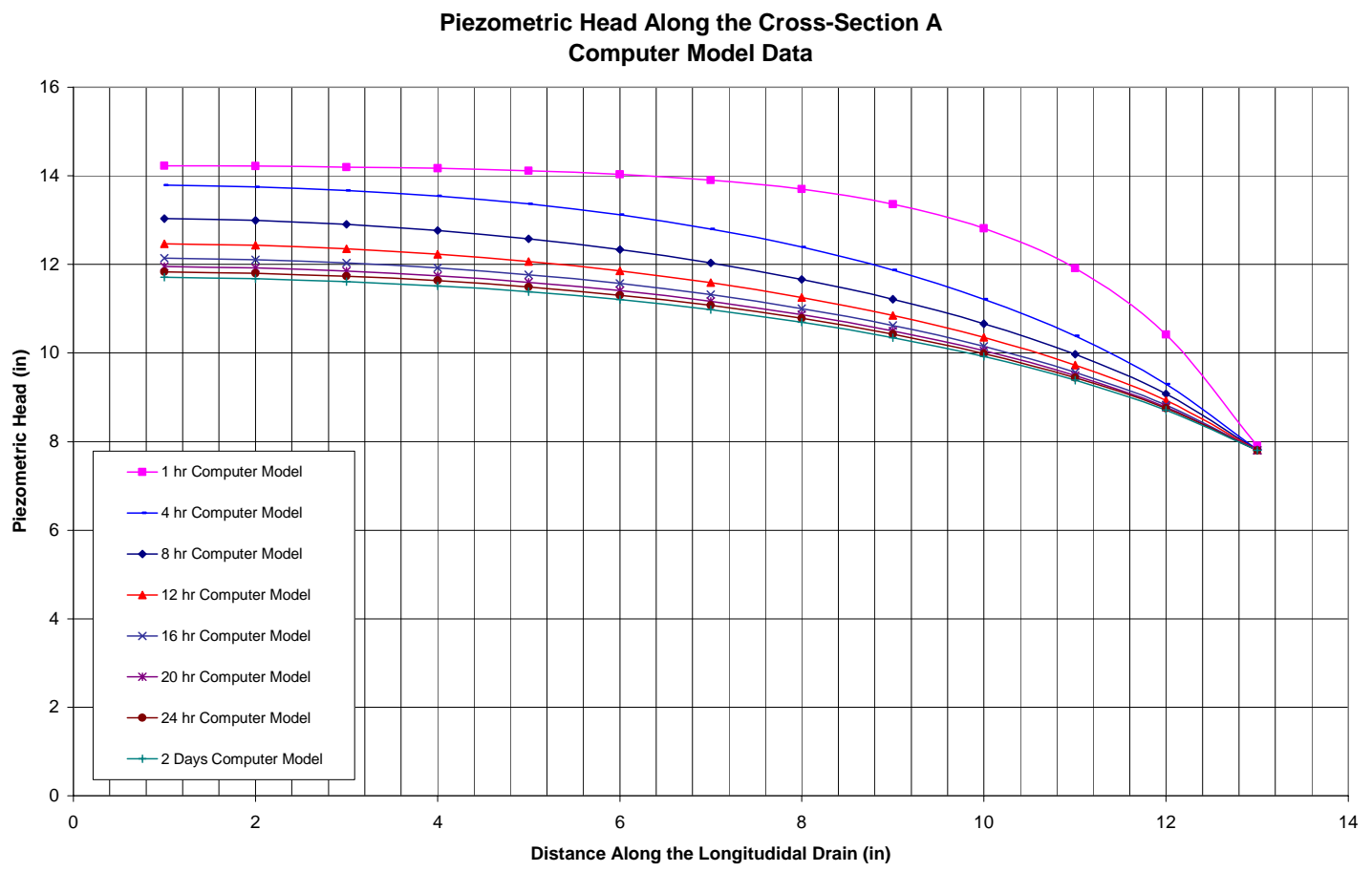

Figure 4.82: Piezometric head along the cross-section A for case A-12-48-10 


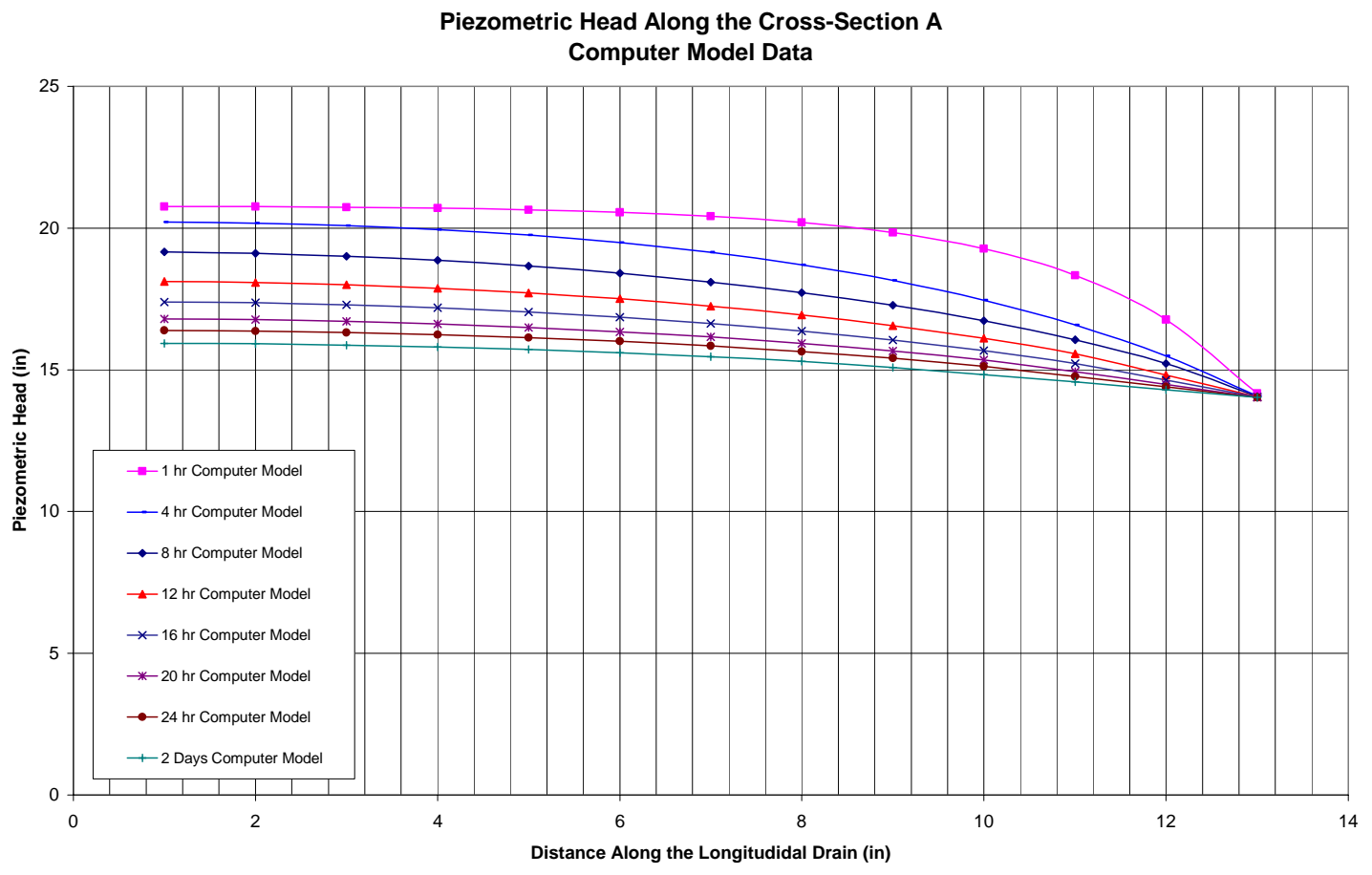

Figure 4.83: Piezometric head along the cross-section A for case A-12-96-10

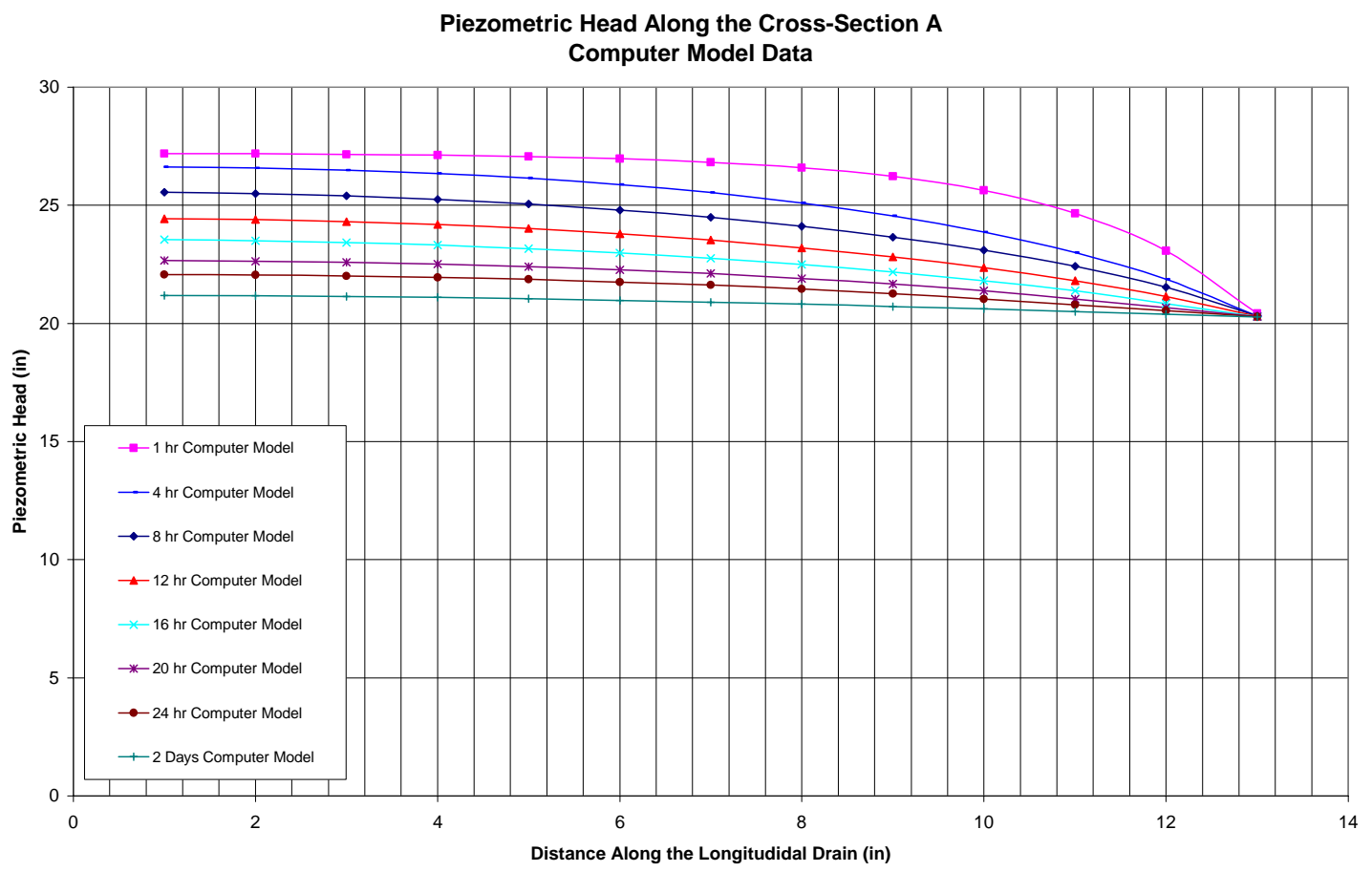

Figure 4.84: Piezometric head along the cross-section A for case A-12-144-10 


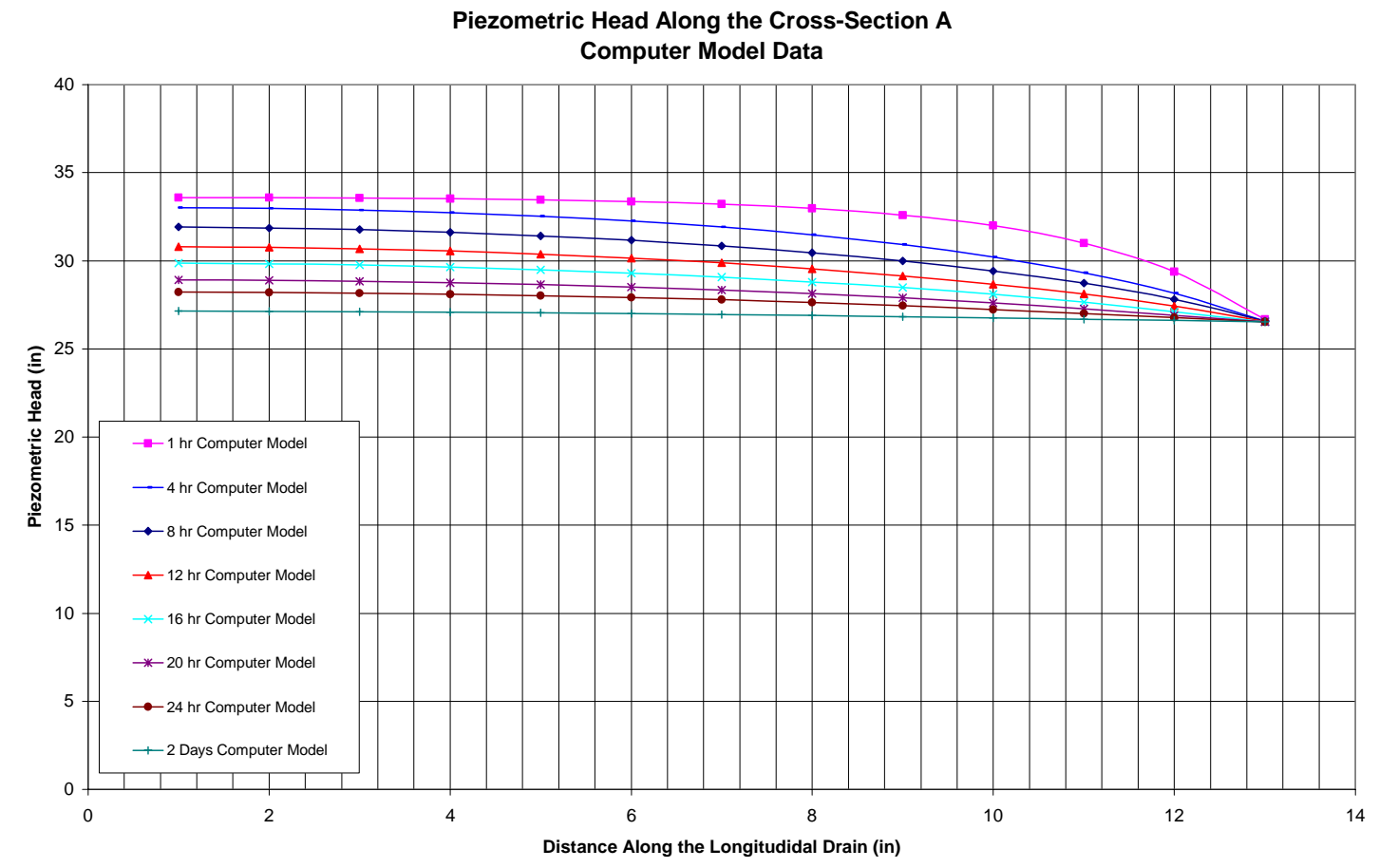

Figure 4.85: Piezometric head along the cross-section A for case A-12-192-10

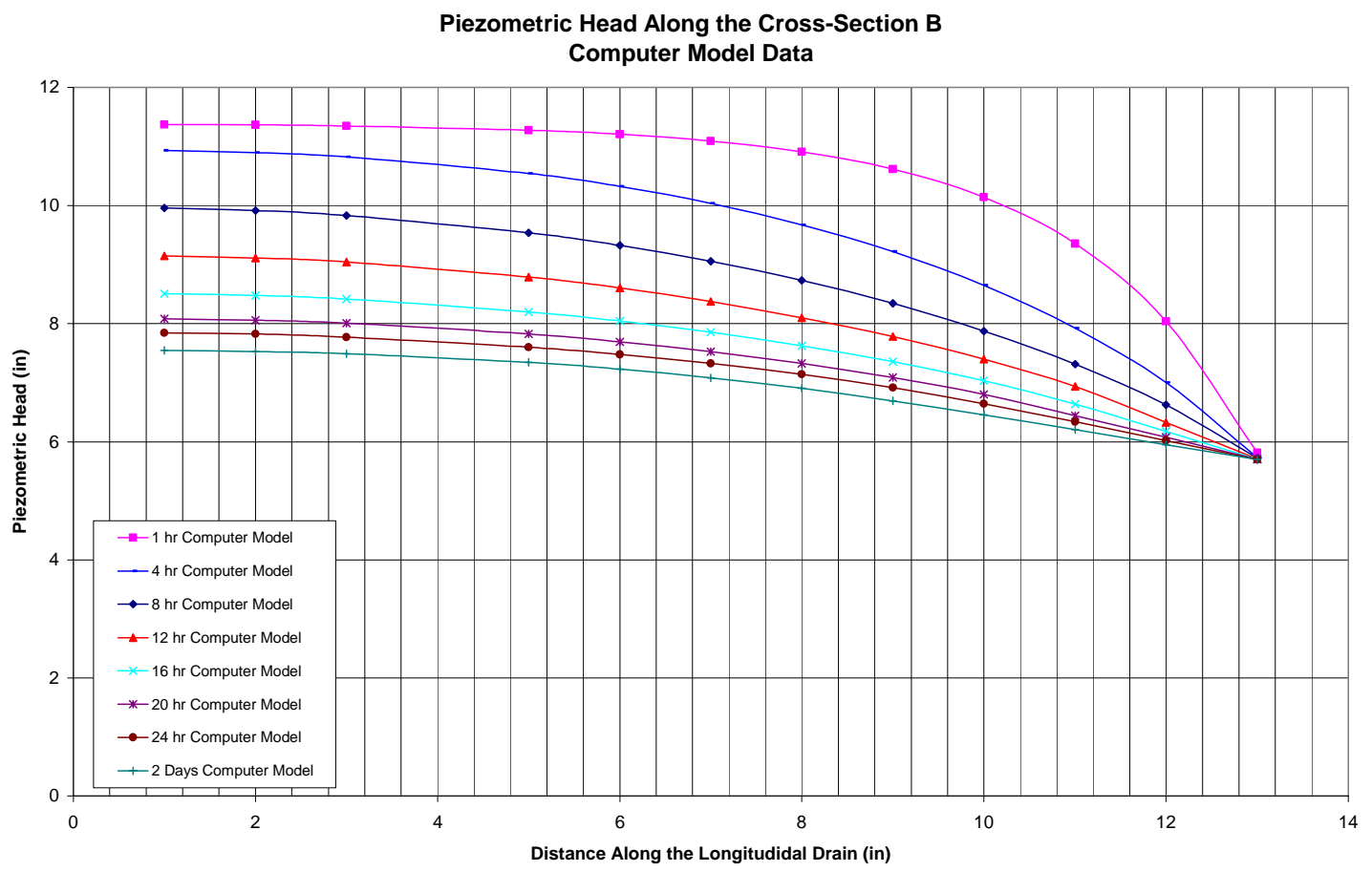

Figure 4.86: Piezometric head along the cross-section B for case A-12-48-10 


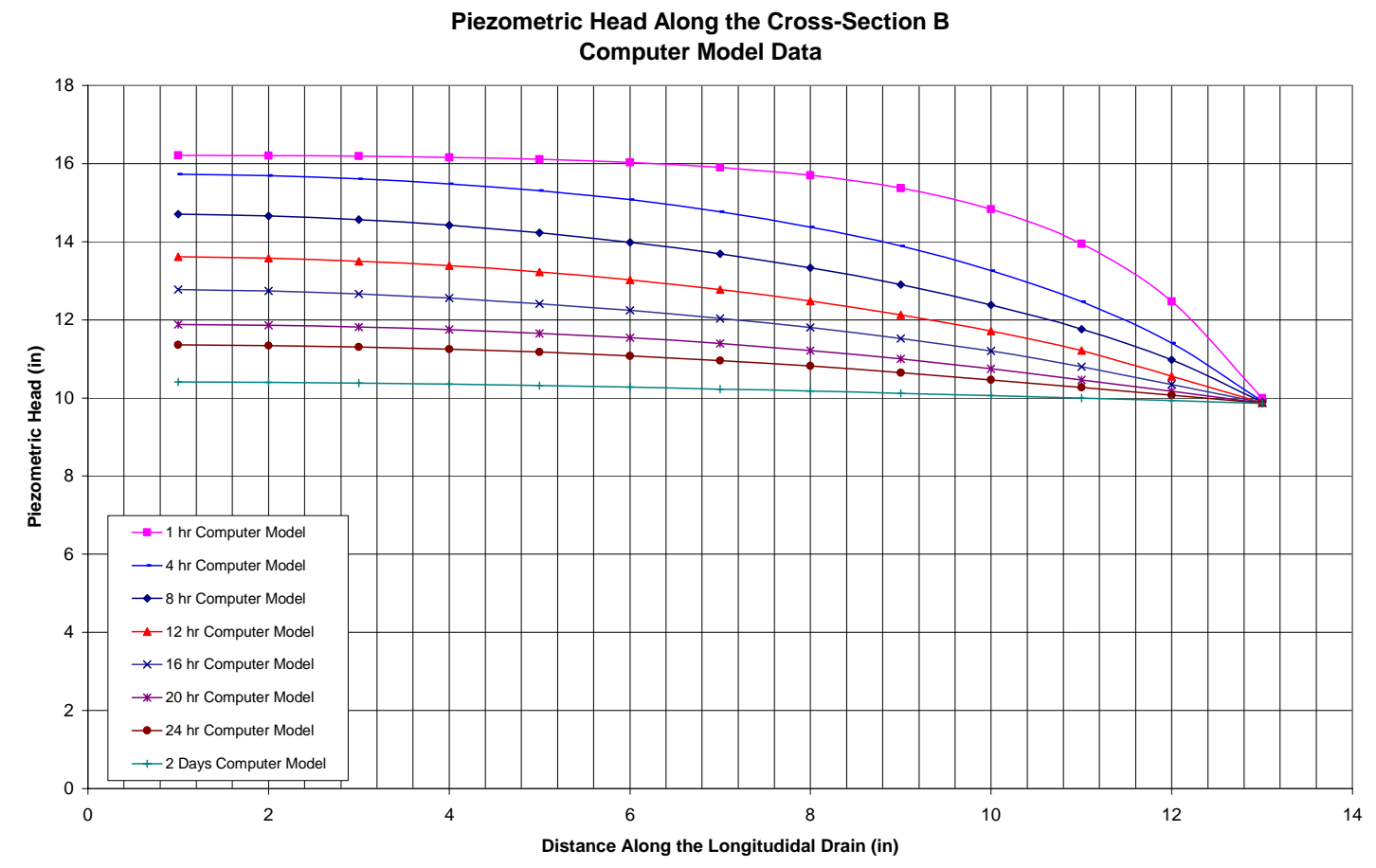

Figure 4.87: Piezometric head along the cross-section B for case A-12-96-10

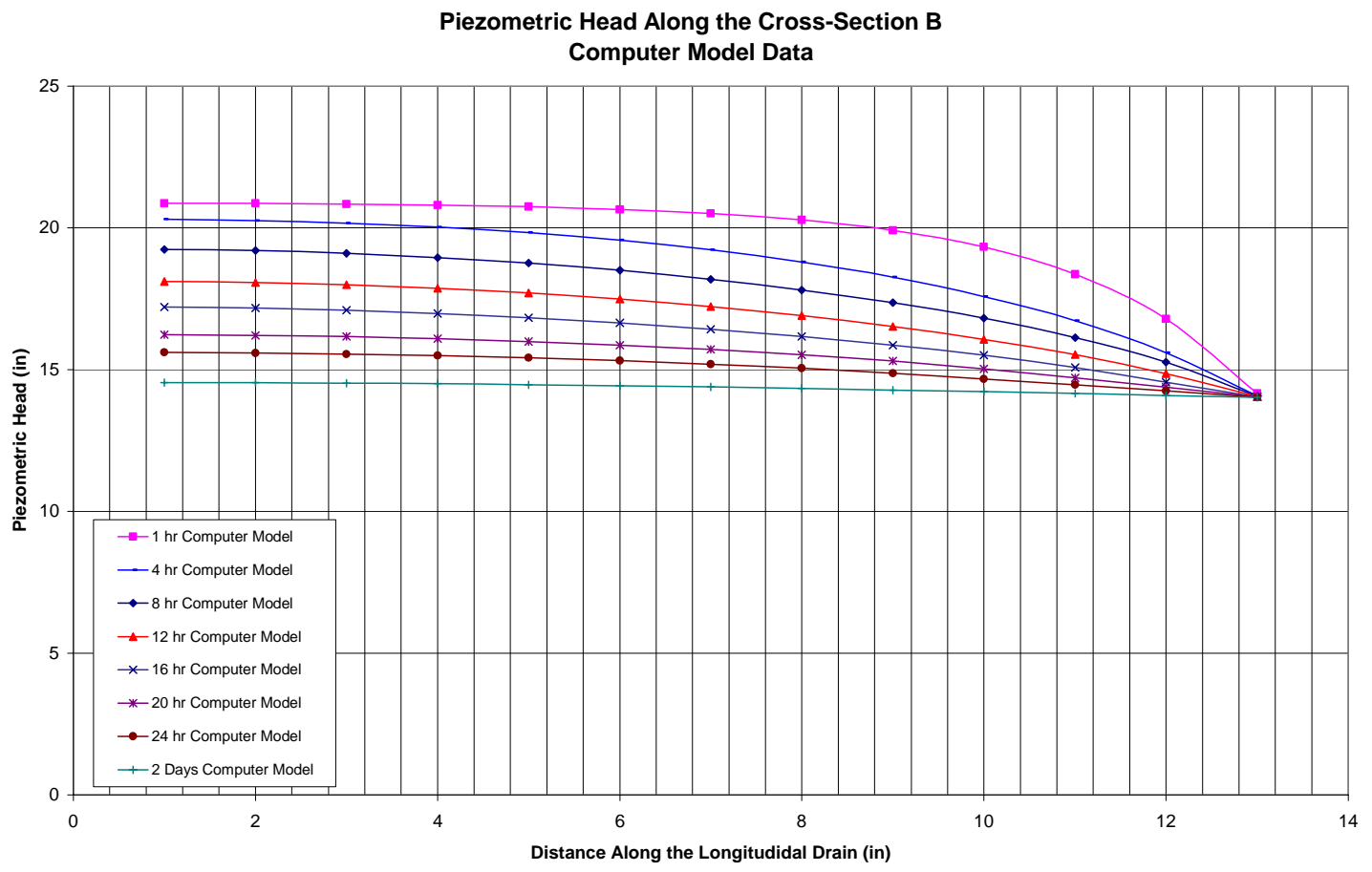

Figure 4.88: Piezometric head along the cross-section B for case A-12-144-10 


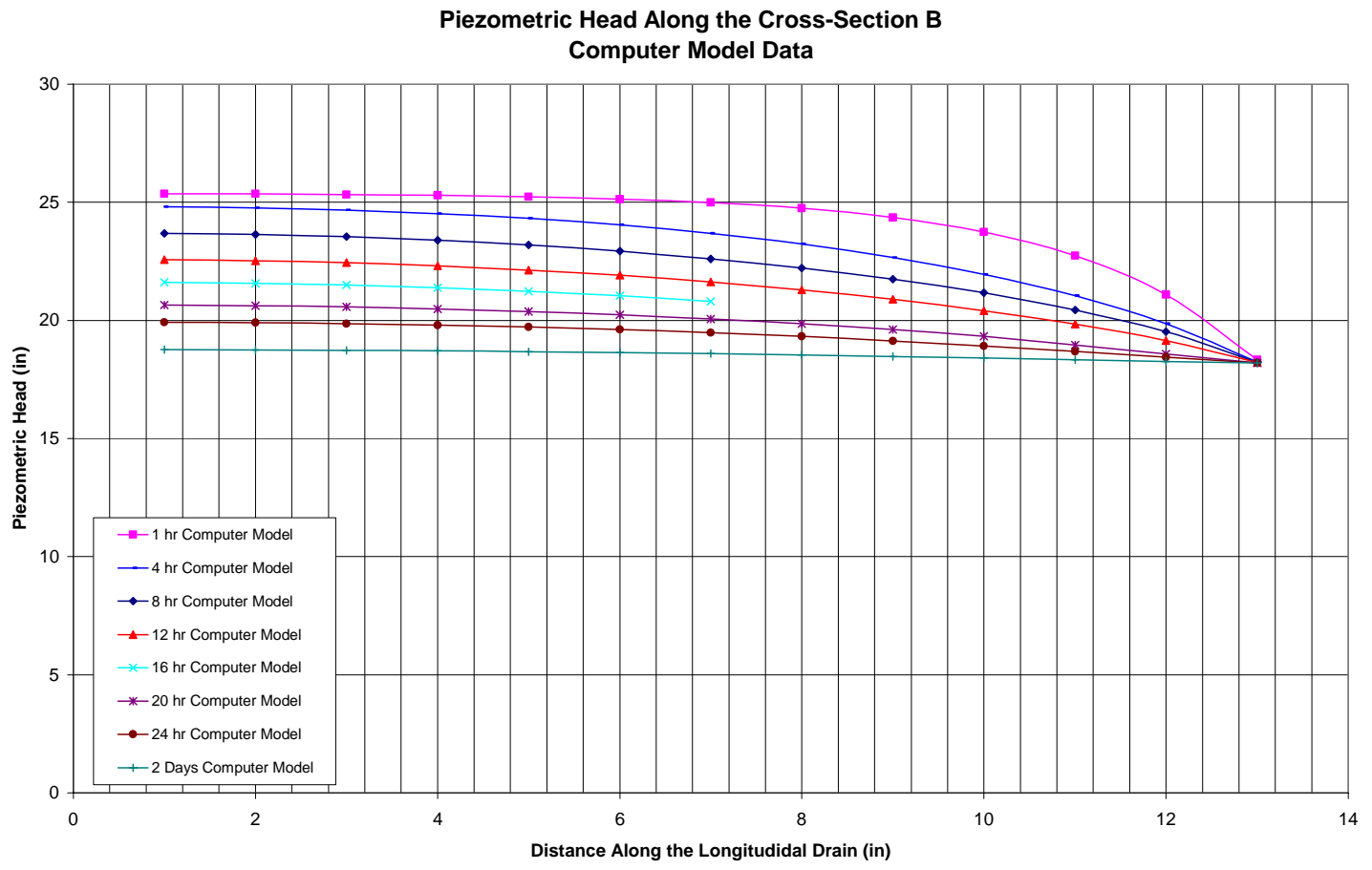

Figure 4.89: Piezometric head along the cross-section B for case A-12-192-10

As seen from these figures, the drainage length has no important effect on the transient behavior of the piezometric level at cross-sections A and B. Although the drain length is changing, there in no change in the distance between the center line and the drain. Since the actual cross-sectional dimension remains the same for all cases, there should be no change in the transverse piezometric head, and the results do support this fact.

The influence of the drain length on the effectiveness of the drain is presented below. Figure 4.90 through Figure 4.93 show the change in the efficiency of the drain with time. 
Cumulative Percent Removed Along the Longitudinal Drain

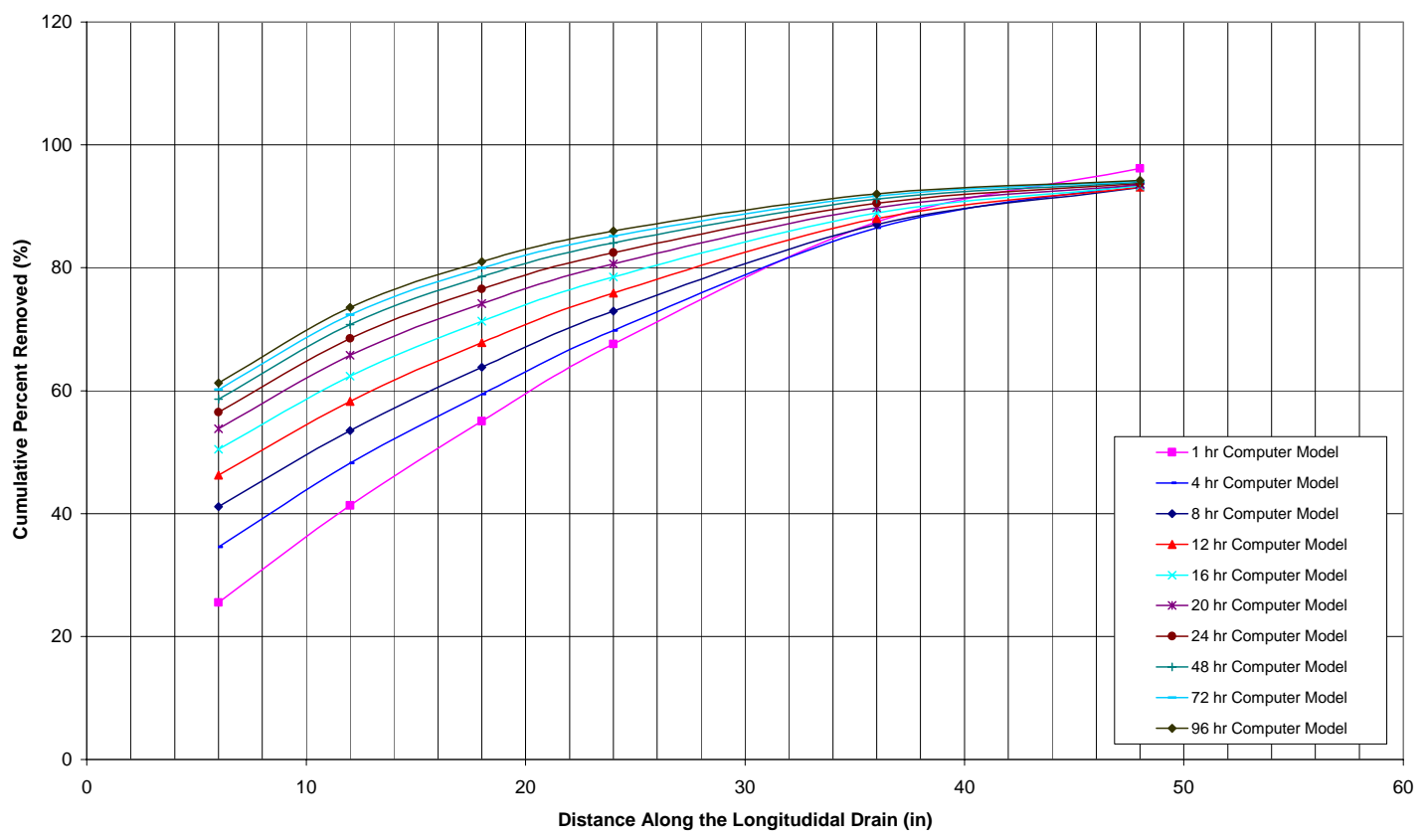

Figure 4.90: Cumulative Percent Removal for case A-12-48-10

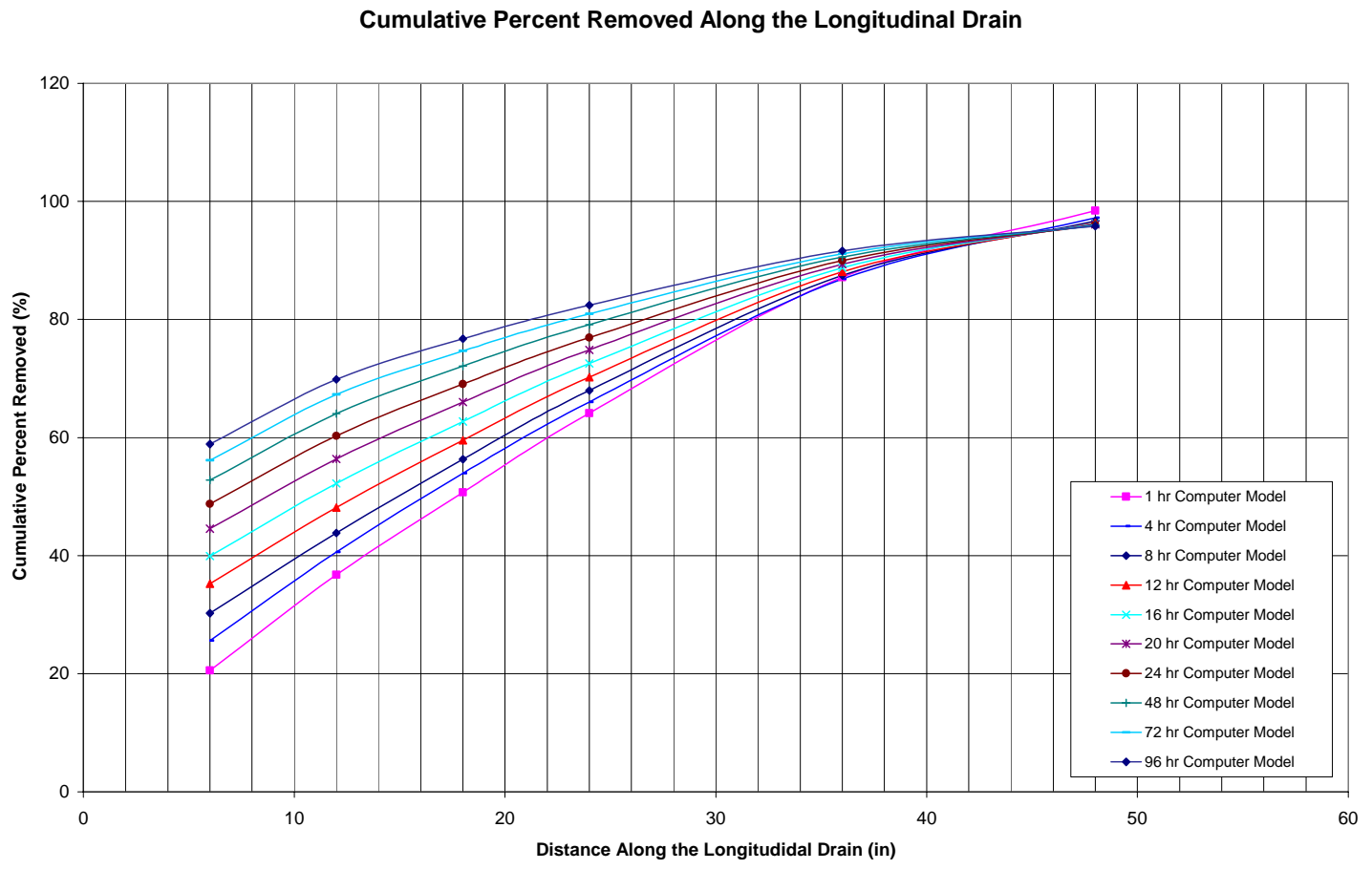

Figure 4.91: Cumulative Percent Removal for case A-12-96-10 
Cumulative Percent Removed Along the Longitudinal Drain

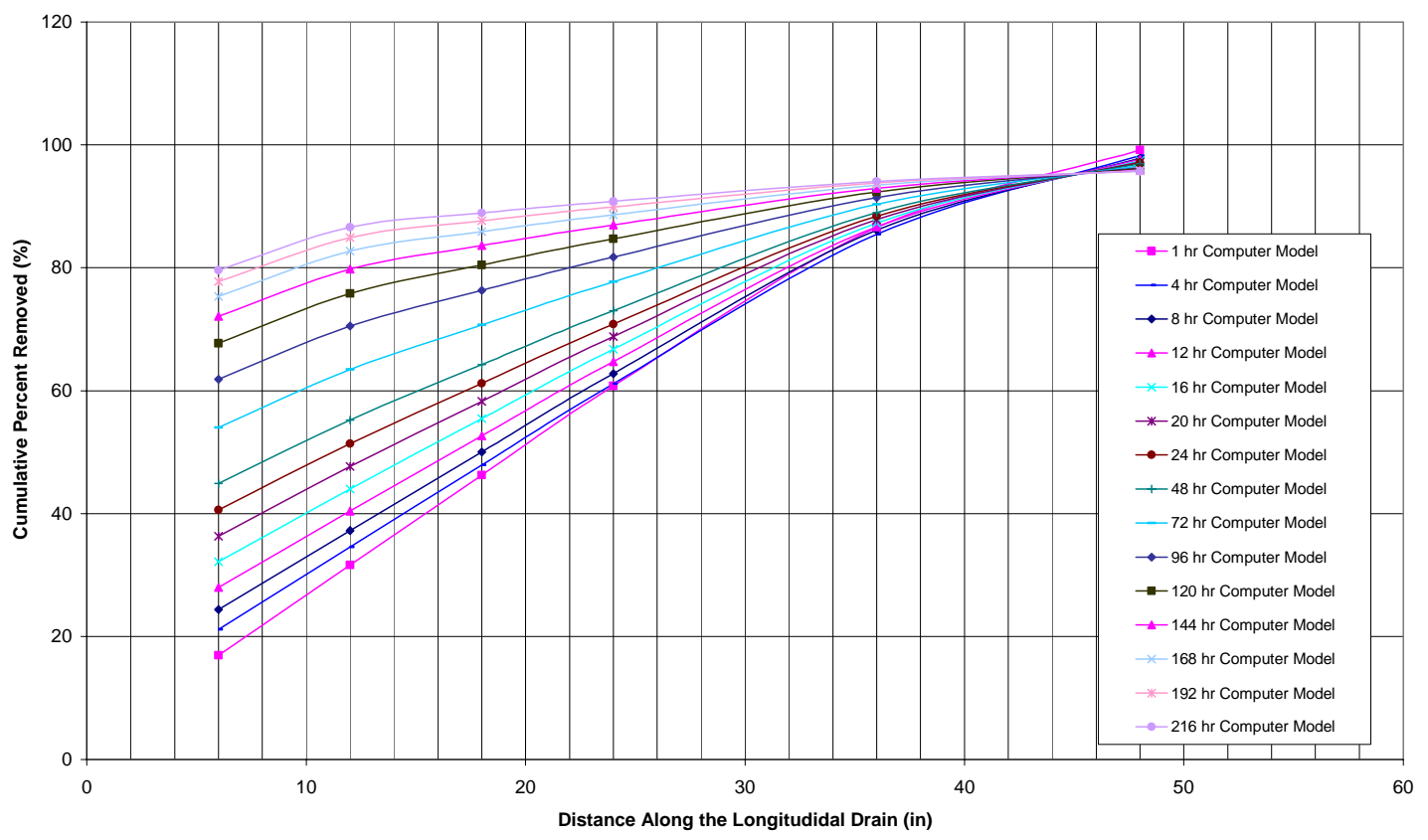

Figure 4.92: Cumulative Percent Removal for case A-12-144-10

Cumulative Percent Removed Along the Longitudinal Drain

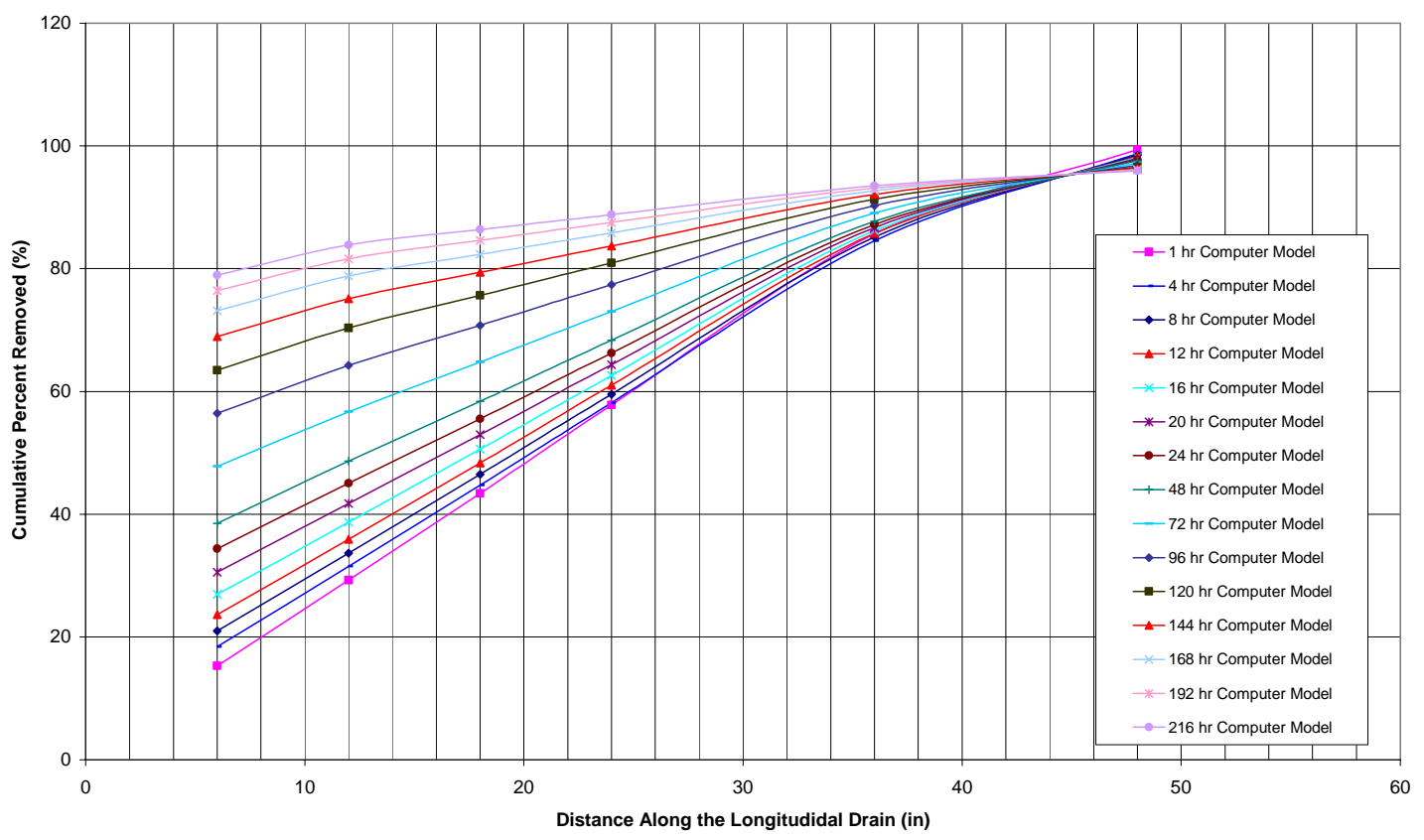

Figure 4.93: Cumulative Percent Removal for case A-12-192-10 
The length of the drain does affect the efficiency of the drain, but it has no major effect on piezometric level. Figure 4.94 shows how the length affects the transient time for the piezometric level.

It is interesting note that the drain effectiveness increases for the first few drains as the length increases. The drains were setup so that they cover the same ratio of length. For the case with a length of forty eight feet, the small drains are six feet long, which is one eighth of the length, while the larger drains are twelve feet long, which is one fourth of the drain length. This means that for the drain length of one hundred and ninety two feet, first four drains are twenty four feet long and the next two drains are forty eight feet long. This way the drains are equivalent in each case, thus permitting us to compare them.

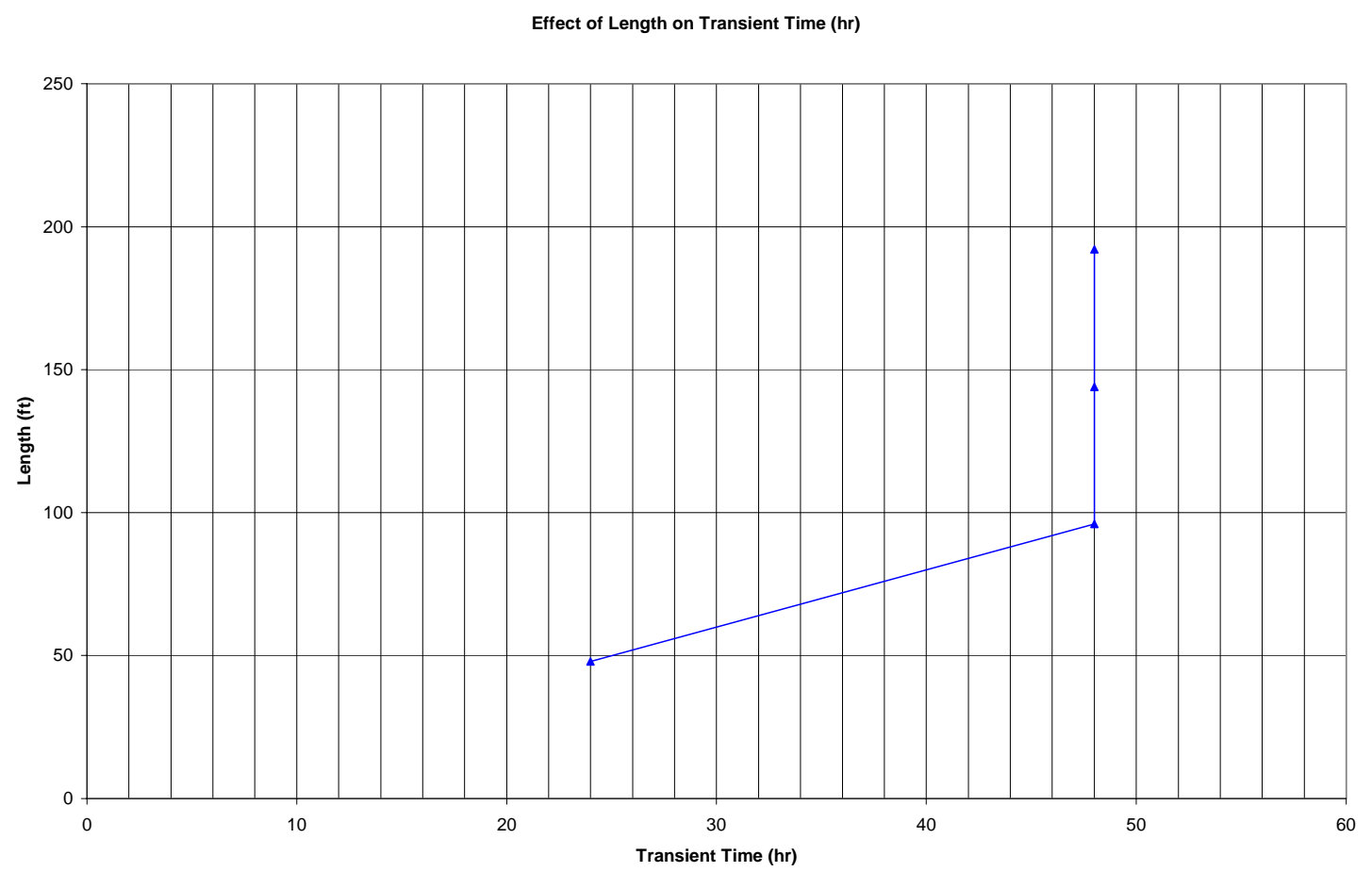

Figure 4.94: Effect of Drain Length on Transient Time 


\subsubsection{Influence of Drain Inclination}

Since one of the objectives of longitudinal drains is to improve slope stability, it is useful to investigate the influence of slope inclination on the seepage behavior through out the soil. In this section, a slope consisting of soil type A was considered. The drain length was assumed as forty eight feet and the drain spacing (w) was assumed as twelve feet. Figure 4.95 through Figure 4.99 show the change in piezometric level along the center line for the five different inclination angles considered in this study. Additional data for soil types $\mathrm{C}$ and $\mathrm{E}$ are given in Appendix A8.

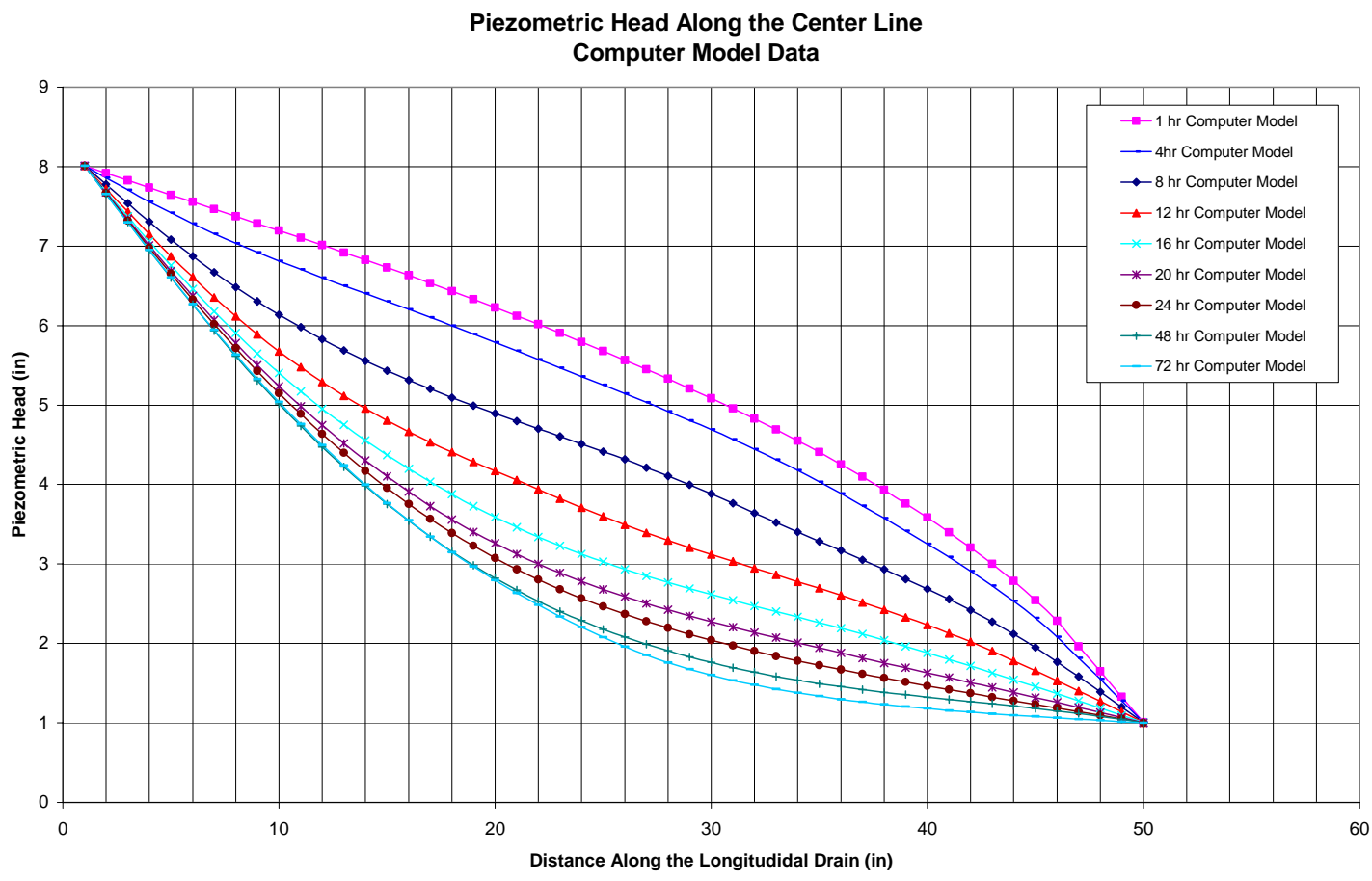

Figure 4.95: Piezometric head along the center line for case A-12-48-0 


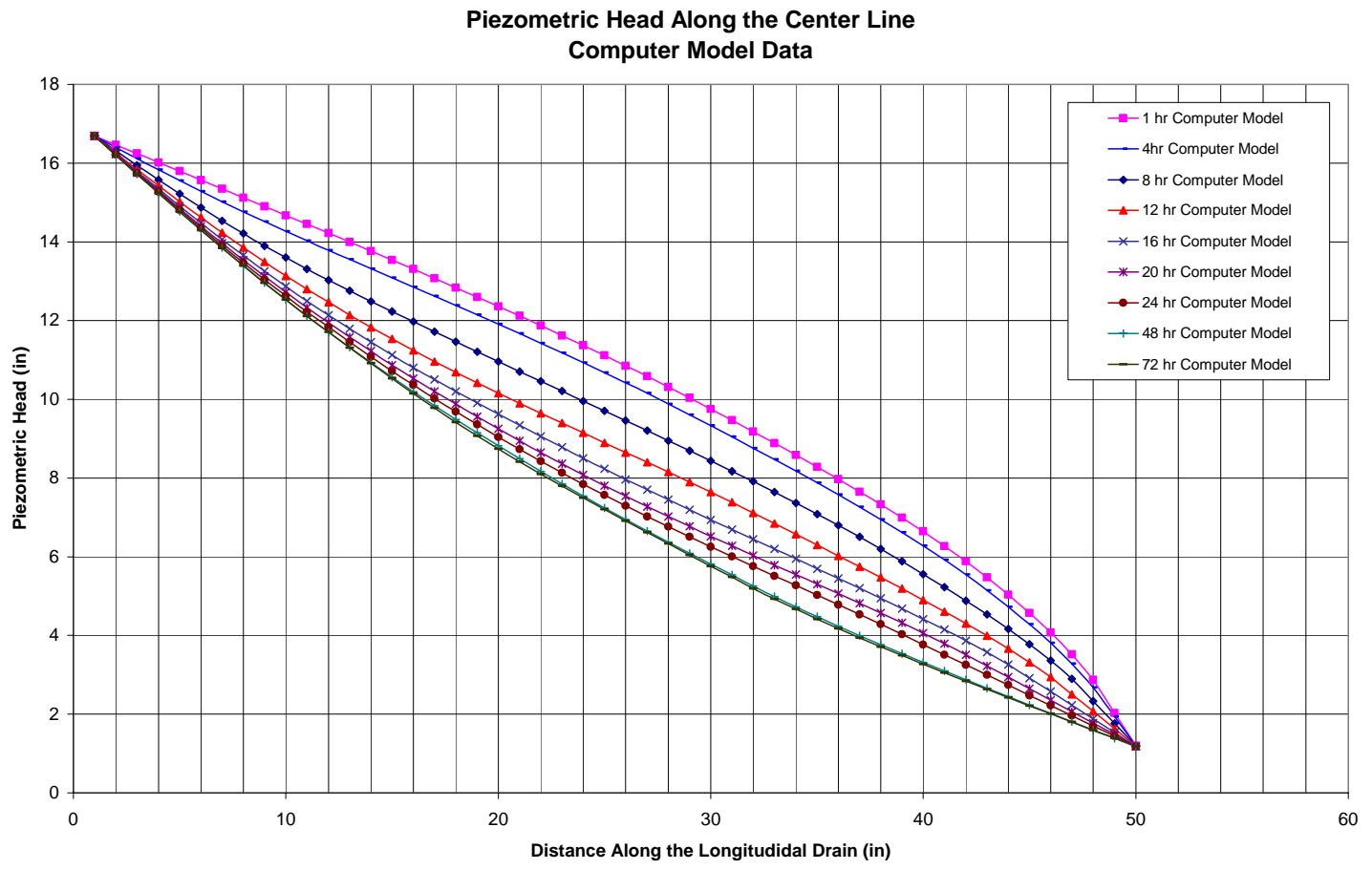

Figure 4.96: Piezometric head along the center line for case A-12-48-10

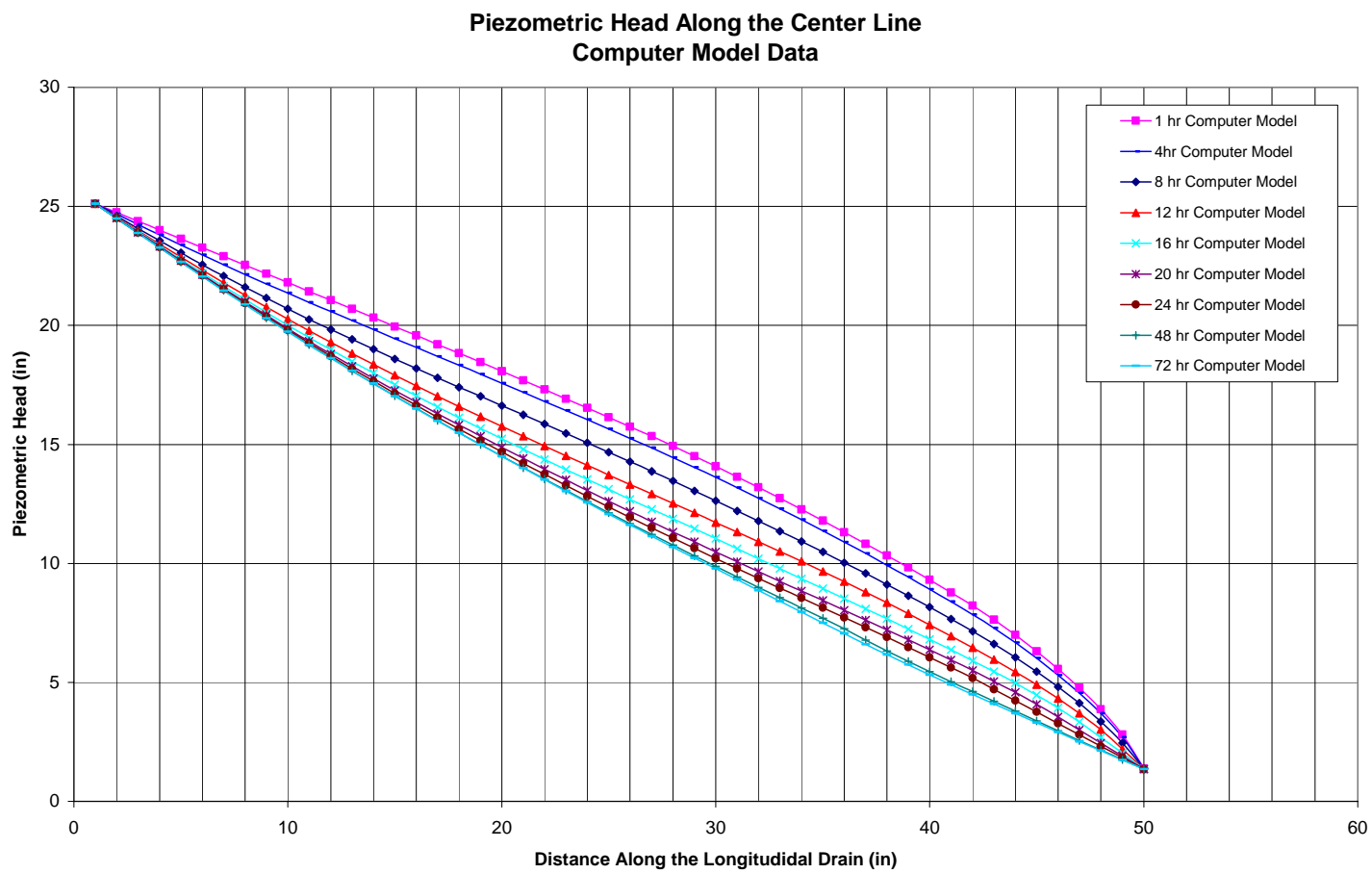

Figure 4.97: Piezometric head along the center line for case A-12-48-20 


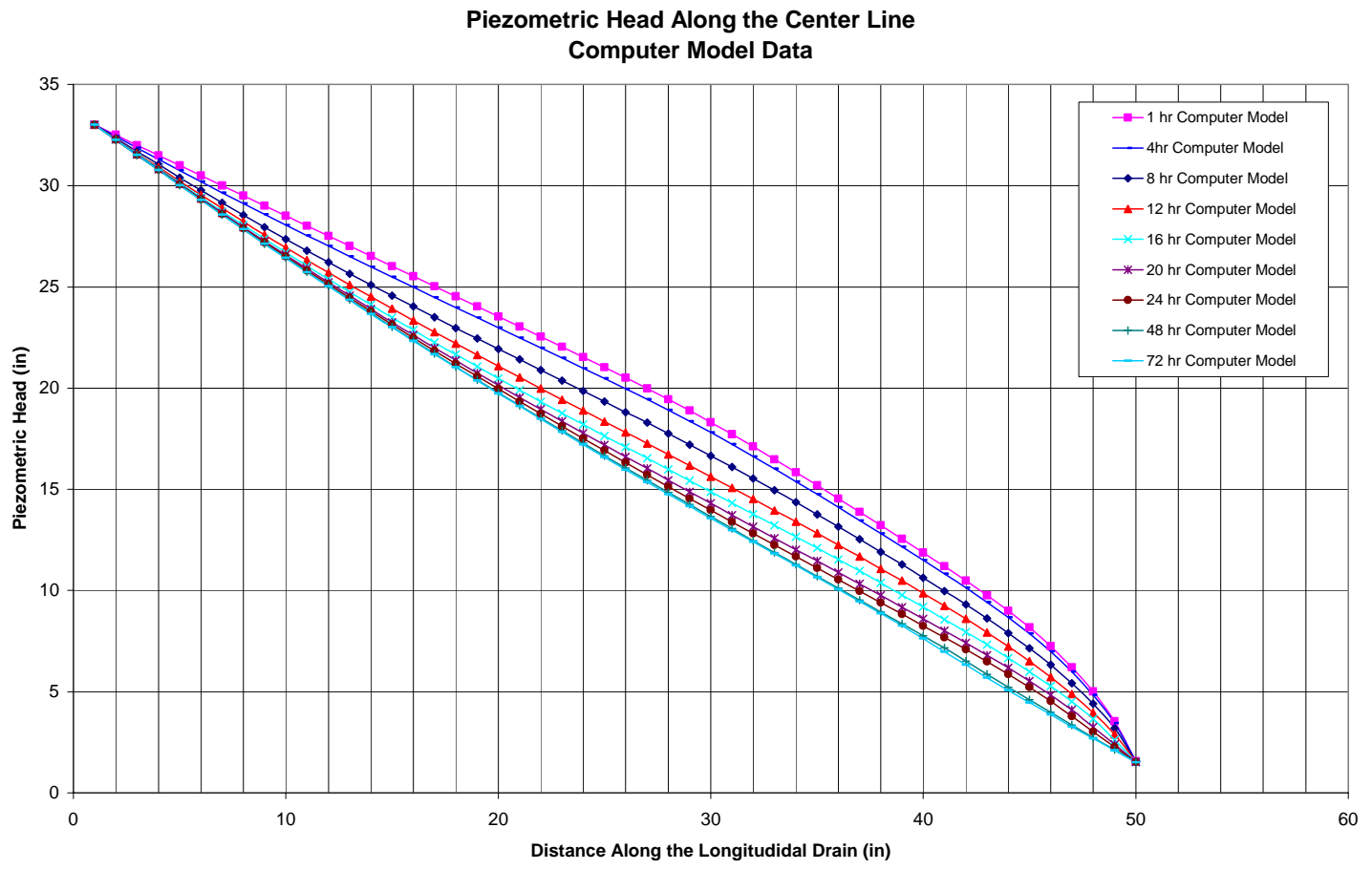

Figure 4.98: Piezometric head along the center line for case A-12-48-30

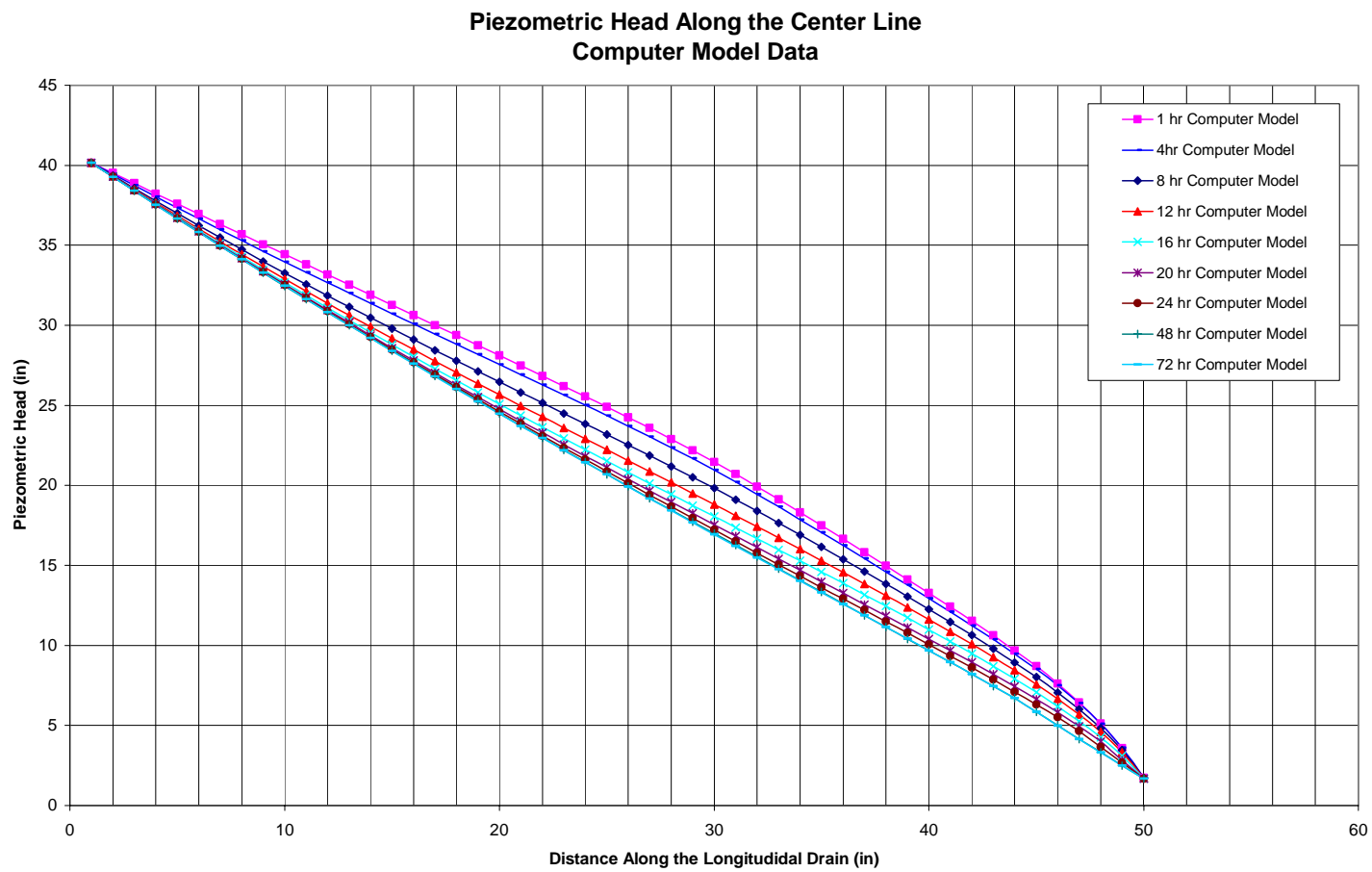

Figure 4.99: Piezometric head along the center line for case A-12-48-40 
We can be seen from these figures, the slope angle has a significant influence on the variation of the piezometric level over time. For the horizontal case, a significant drop in the piezometric level can be easily seen (Figure 4.95). For the steeper case with a slope of forty degrees, the drop in piezometric head is very small (Figure 4.99). The main observation that can be noted is the fact that as the slope becomes more and more steep, the drop in piezometric level is less noticeable with time. Another observation is the fact that for the horizontal case, the piezometric level stopped dropping after a period of half a day, while for the steeper case with a slope of forty degrees, it took more than one day to stop changing.

The influence of slope angle on the piezometric head along transverse crosssections A and B is presented below. Figure 4.100 through Figure 4.109 show the transverse variation of piezometric head for different slope angles.

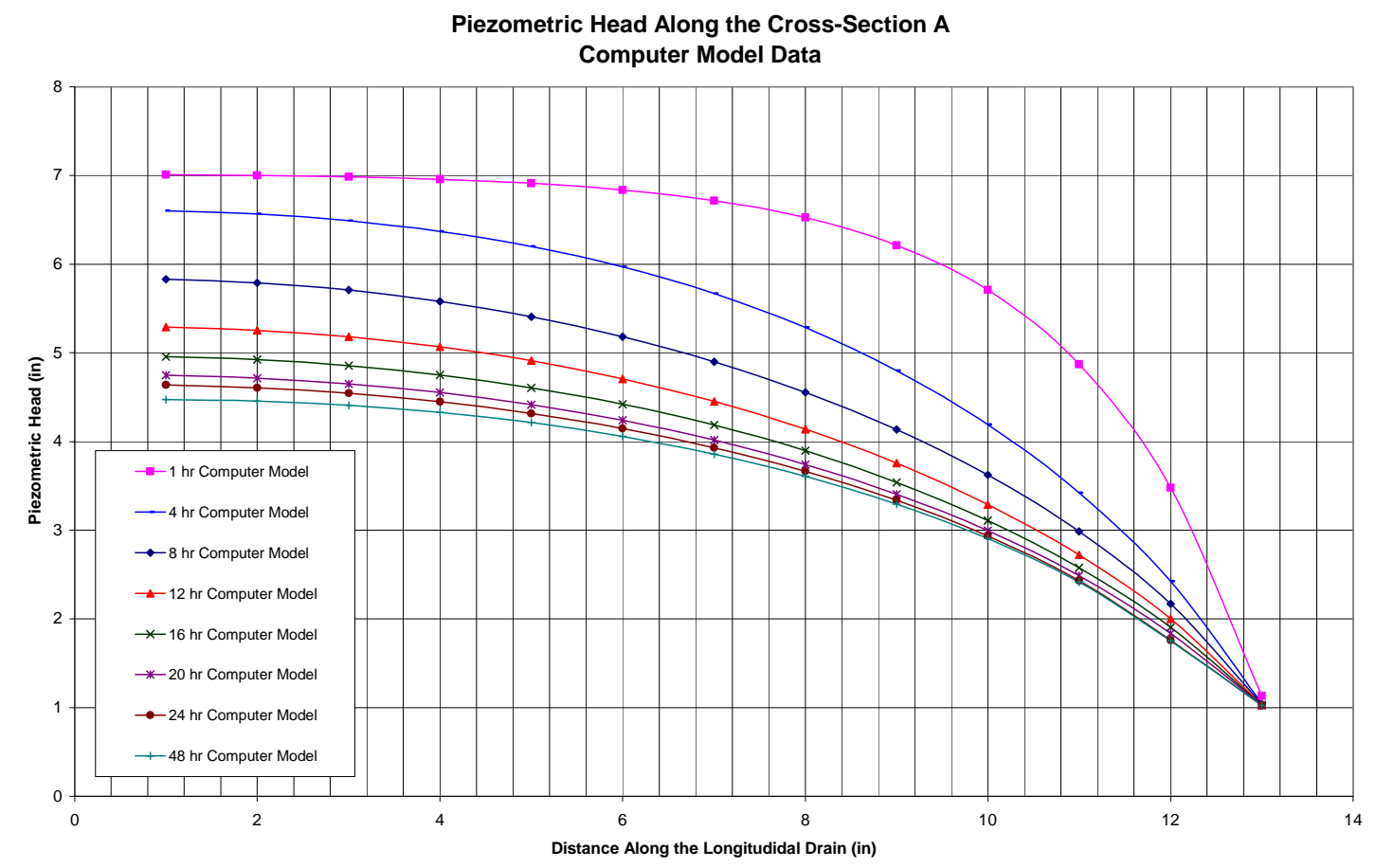

Figure 4.100: Piezometric head along the cross-section A for case A-12-48-0 


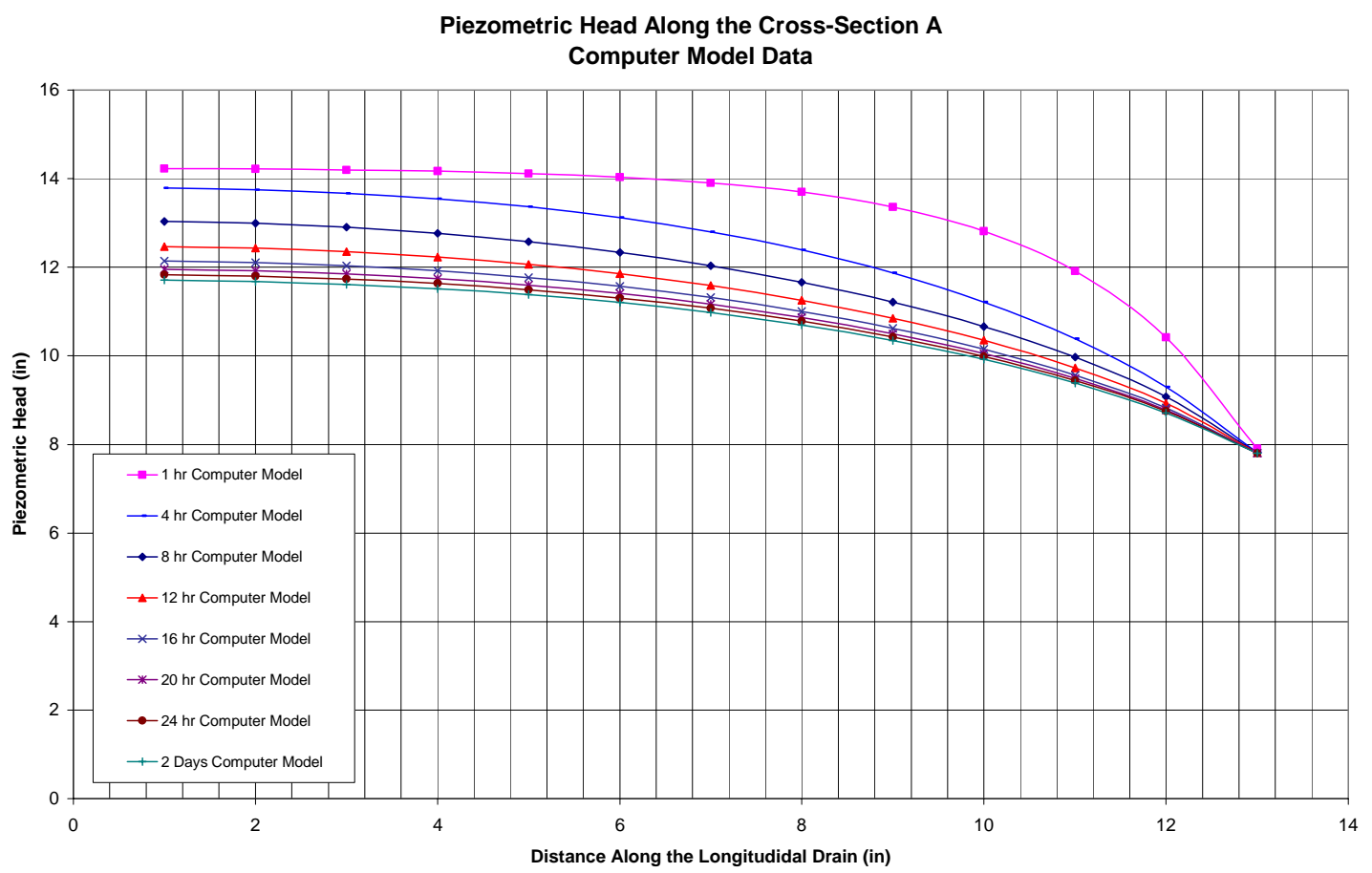

Figure 4.101: Piezometric head along the cross-section A for case A-12-48-10

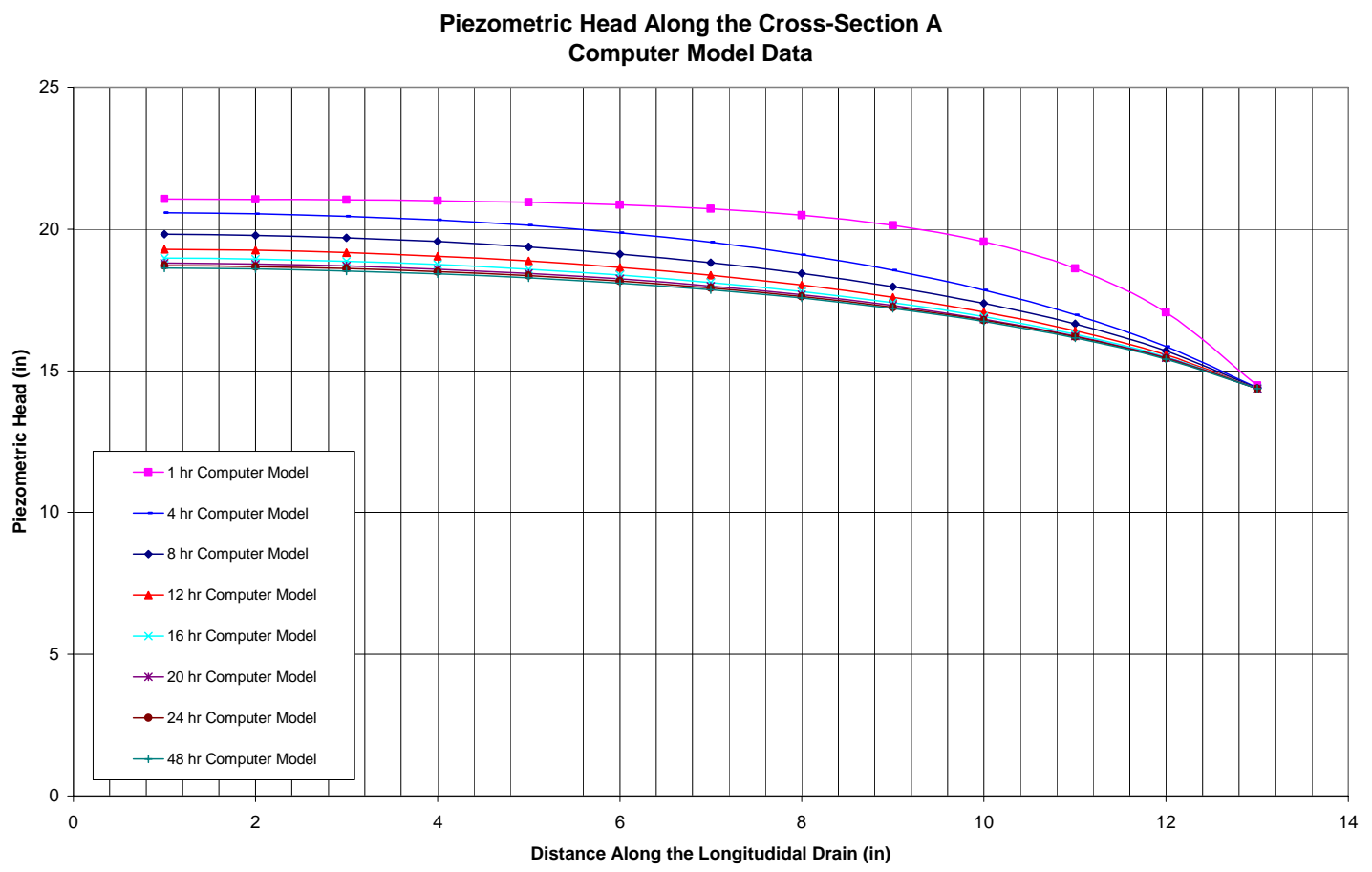

Figure 4.102: Piezometric head along the cross-section A for case A-12-48-20 


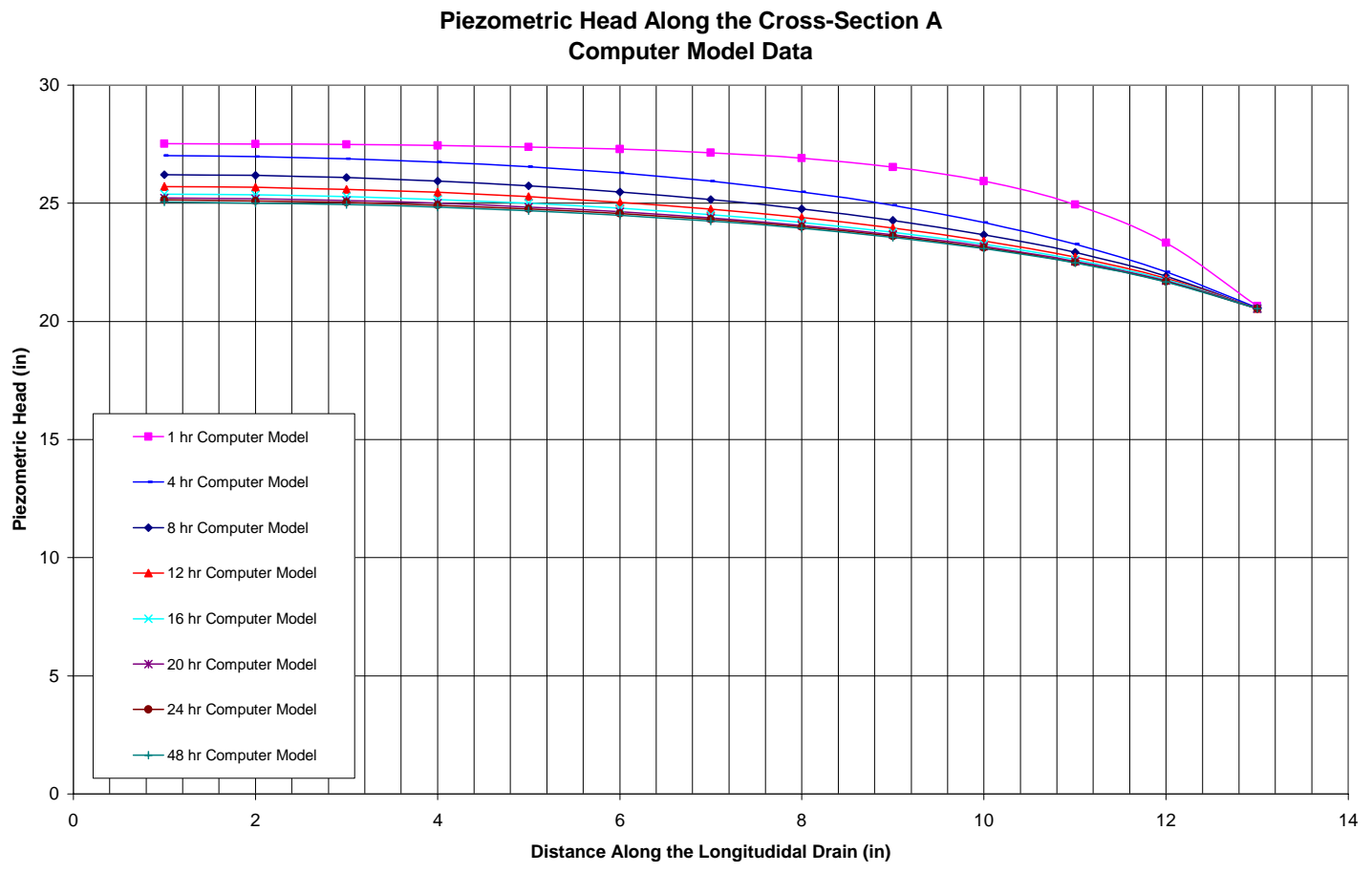

Figure 4.103: Piezometric head along the cross-section A for case A-12-48-30

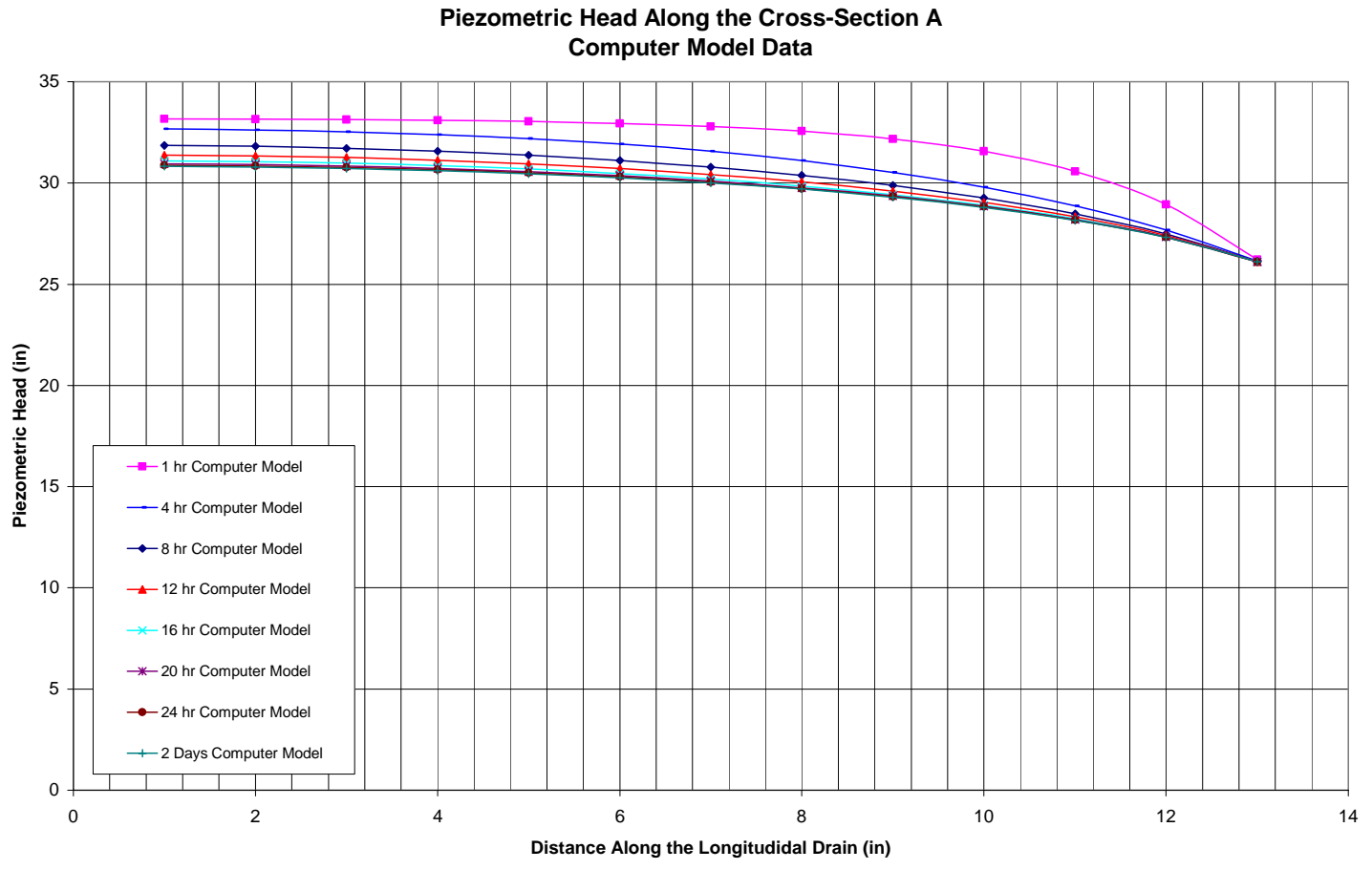

Figure 4.104: Piezometric head along the cross-section A for case A-12-48-40 


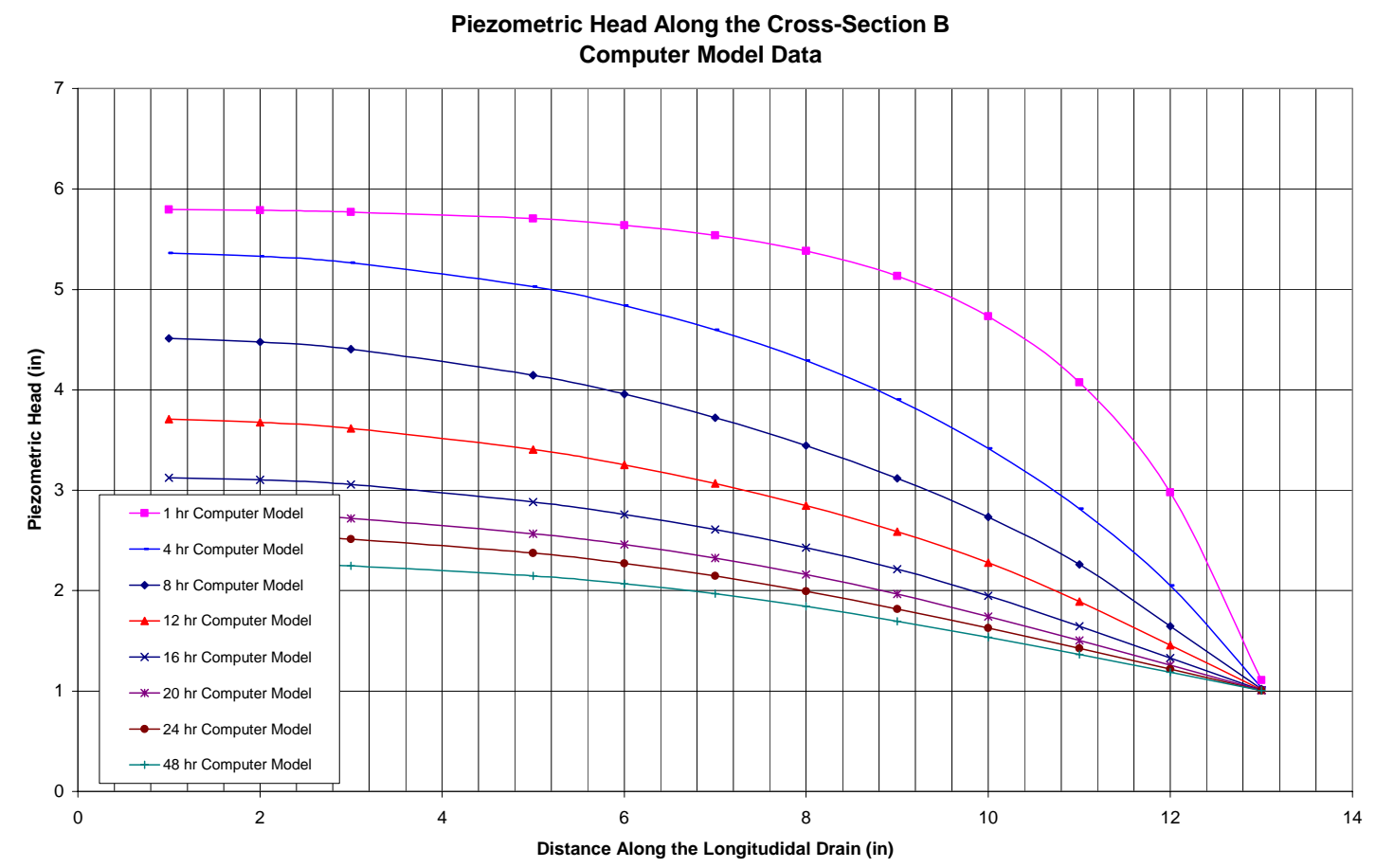

Figure 4.105: Piezometric head along the cross-section B for case A-12-48-0

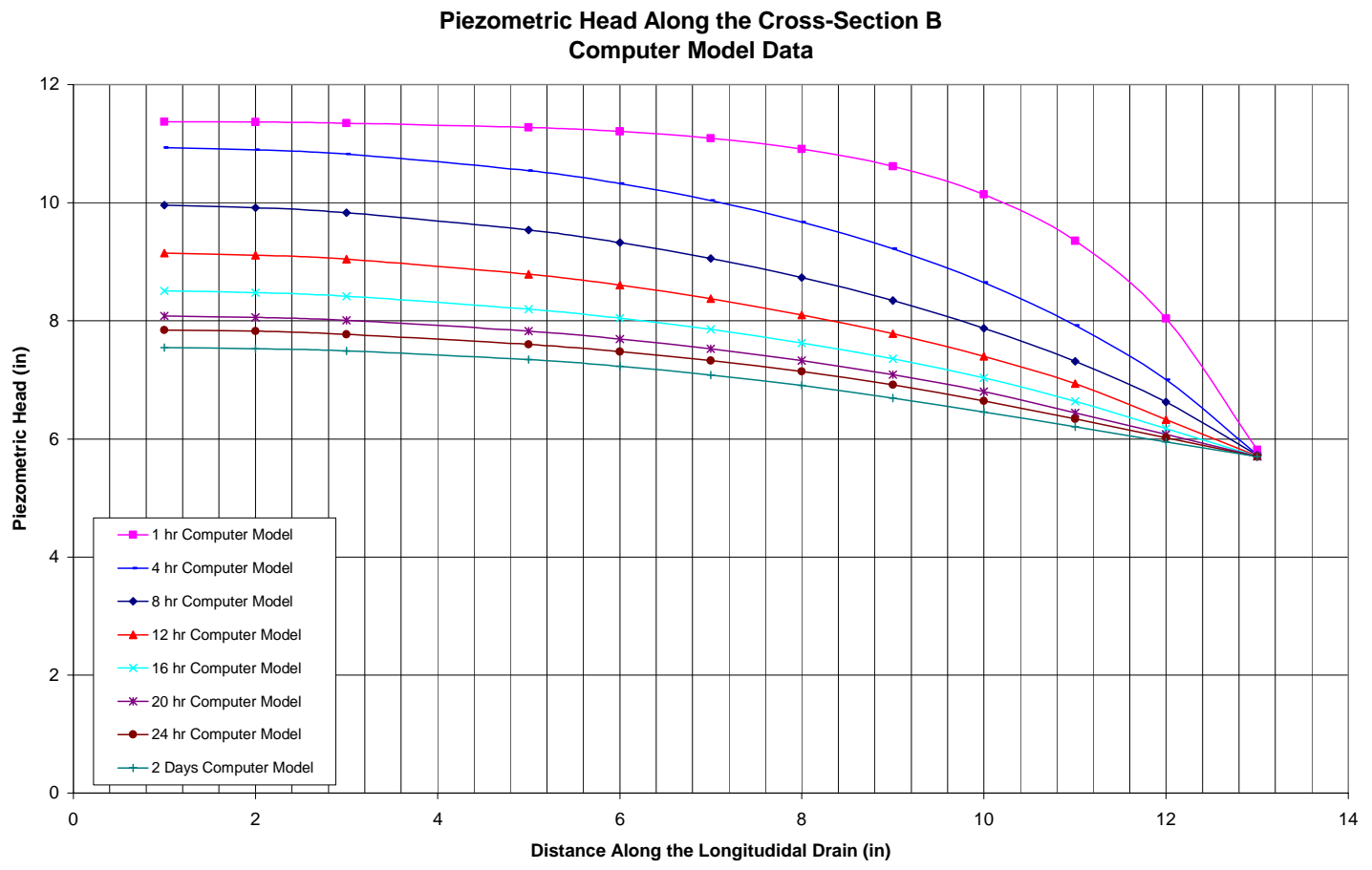

Figure 4.106: Piezometric head along the cross-section B for case A-12-48-10 


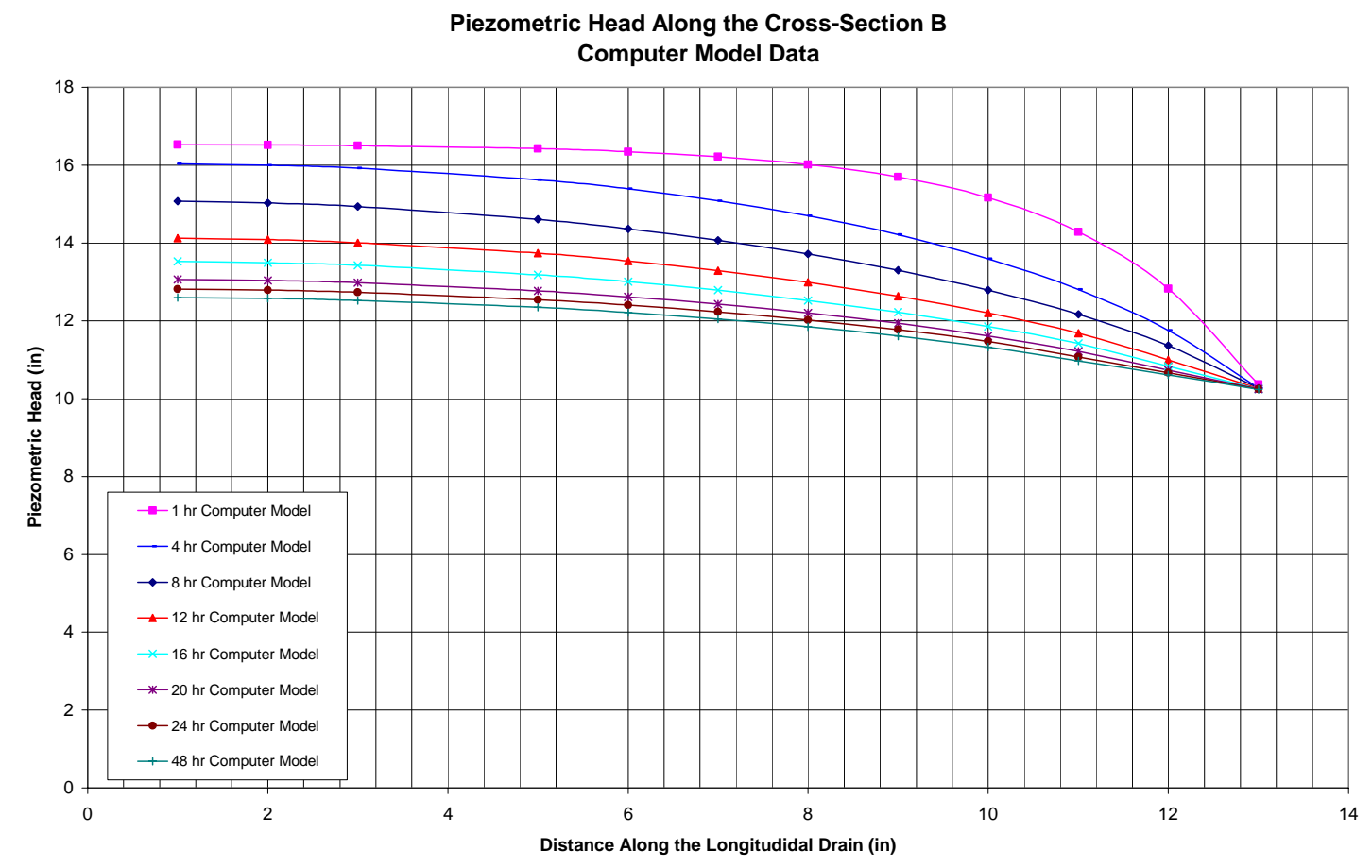

Figure 4.107: Piezometric head along the cross-section B for case A-12-48-20

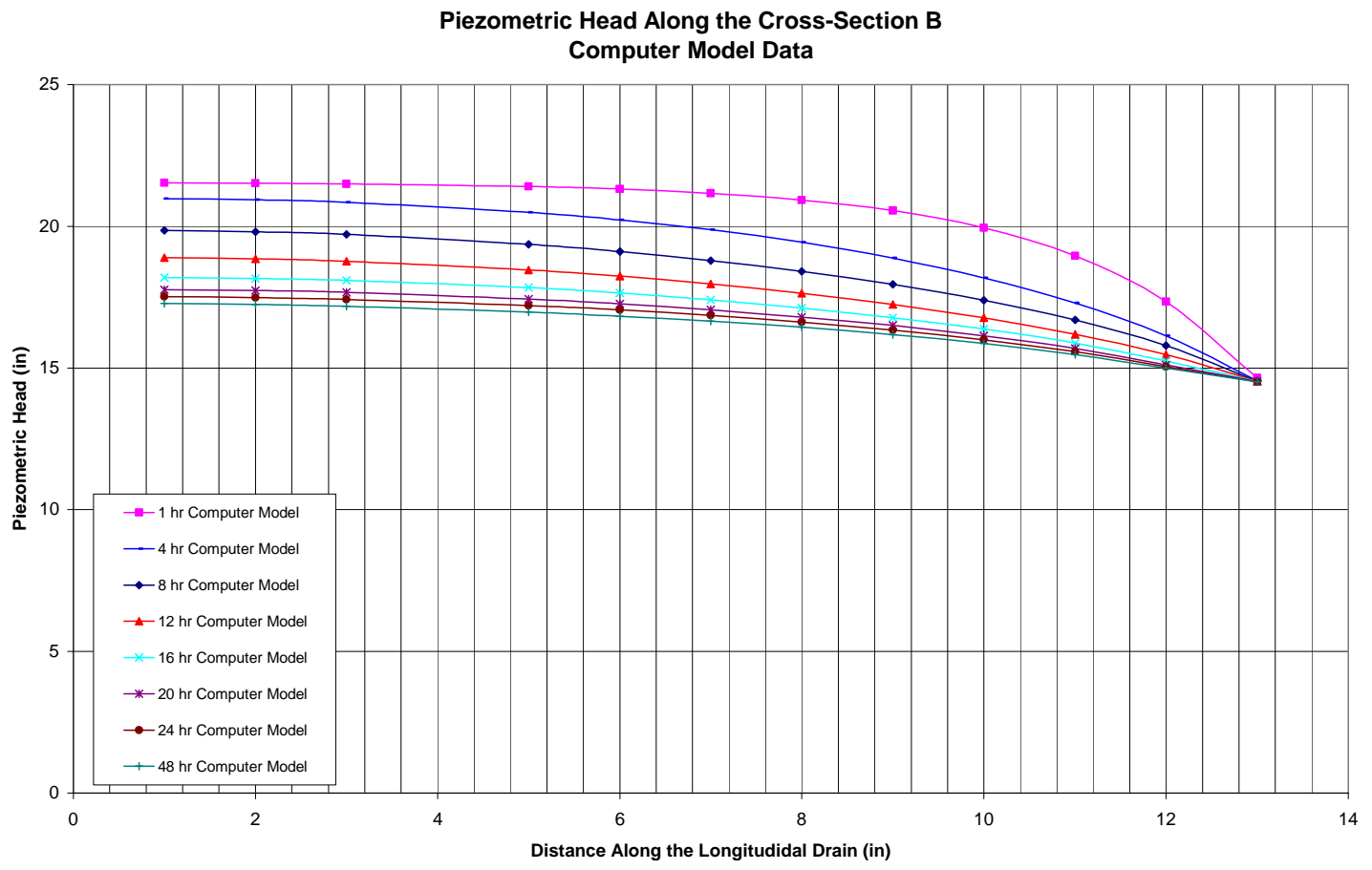

Figure 4.108: Piezometric head along the cross-section B for case A-12-48-30 


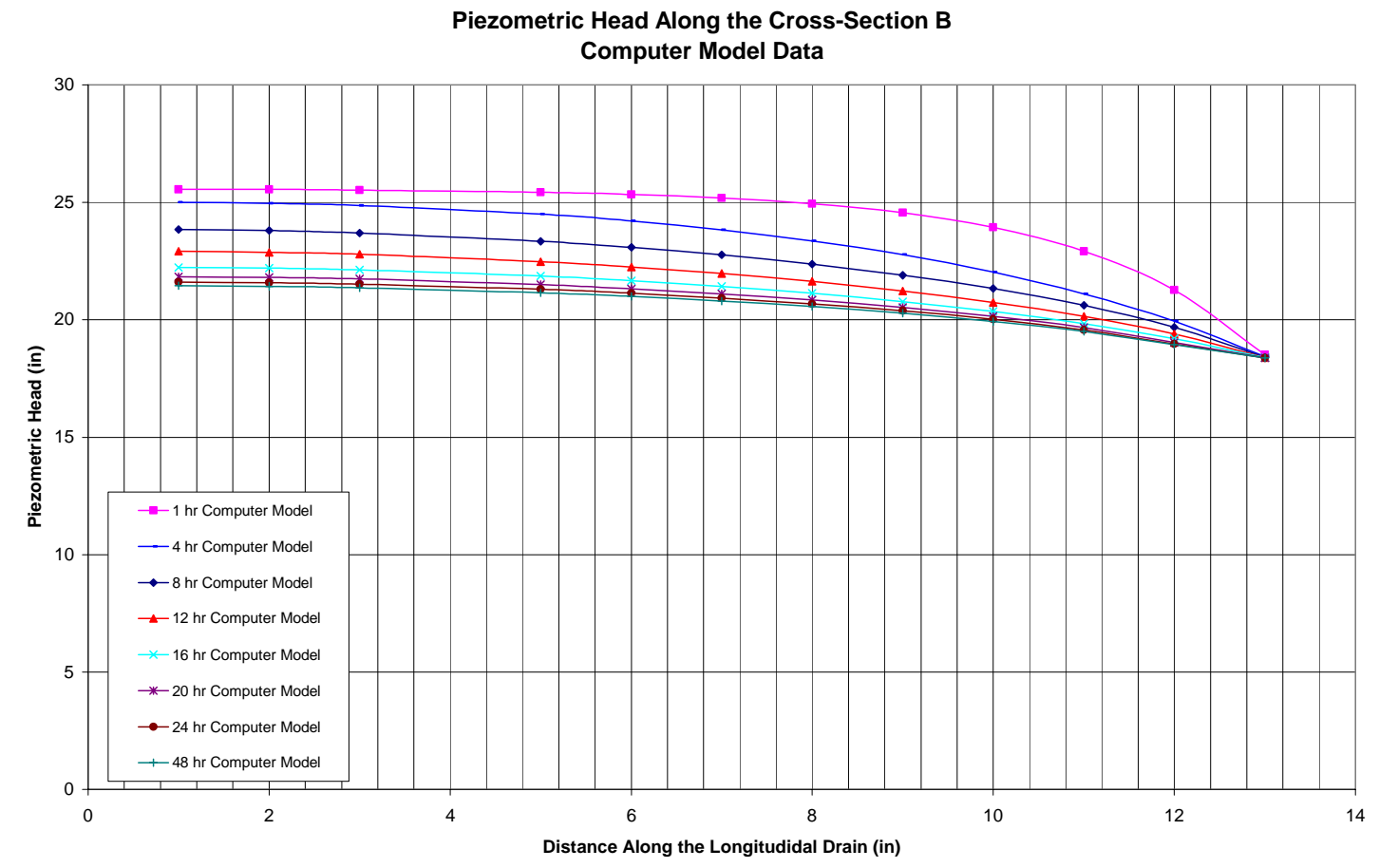

Figure 4.109: Piezometric head along the cross-section B for case A-12-48-40

As can be seen from these figures, the slope angle has an influence on the transient behavior of piezometric heads along transverse cross sections. This influence is similar to that of the piezometric head along the center line. The slope inclination is affecting the time required to stop changes to piezometric head. The piezometric data along transverse cross-sections also show that the transient time is about half a day for the the horizontal case, while the changes continue for at least a full day for the steeper case with a slope of forty degrees. Similar to what happened with the piezometric levels along the center line, the piezometric heads along both cross-sections show a big drop in level for the horizontal case, while the drop observed for the steeper case is less noticeable. 
The influence of slope angle on the drain effectiveness is shown below in Figure 4.110 through 4.114.

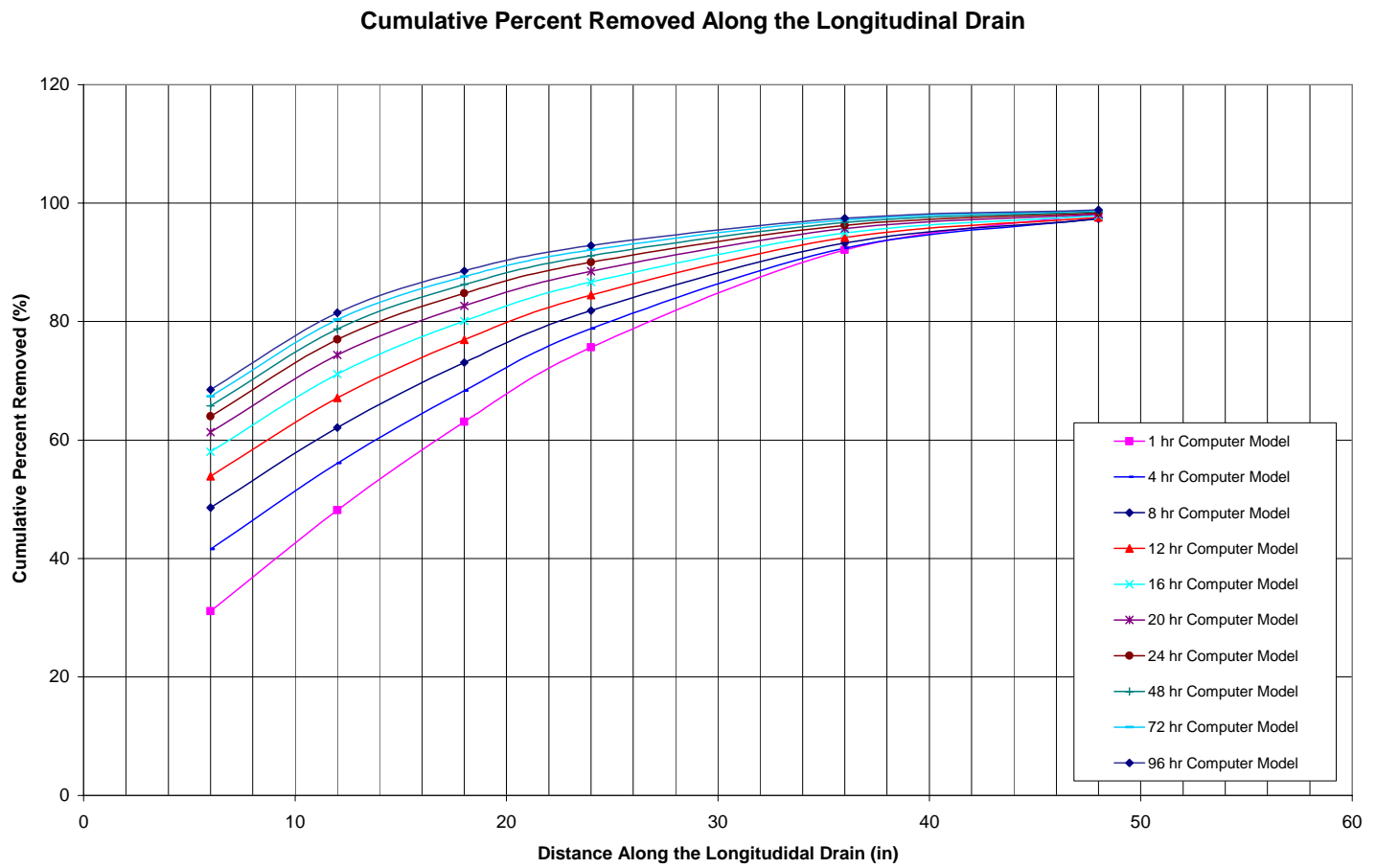

Figure 4.110: Cumulative Percent Removal for case A-12-48-0 
Cumulative Percent Removed Along the Longitudinal Drain

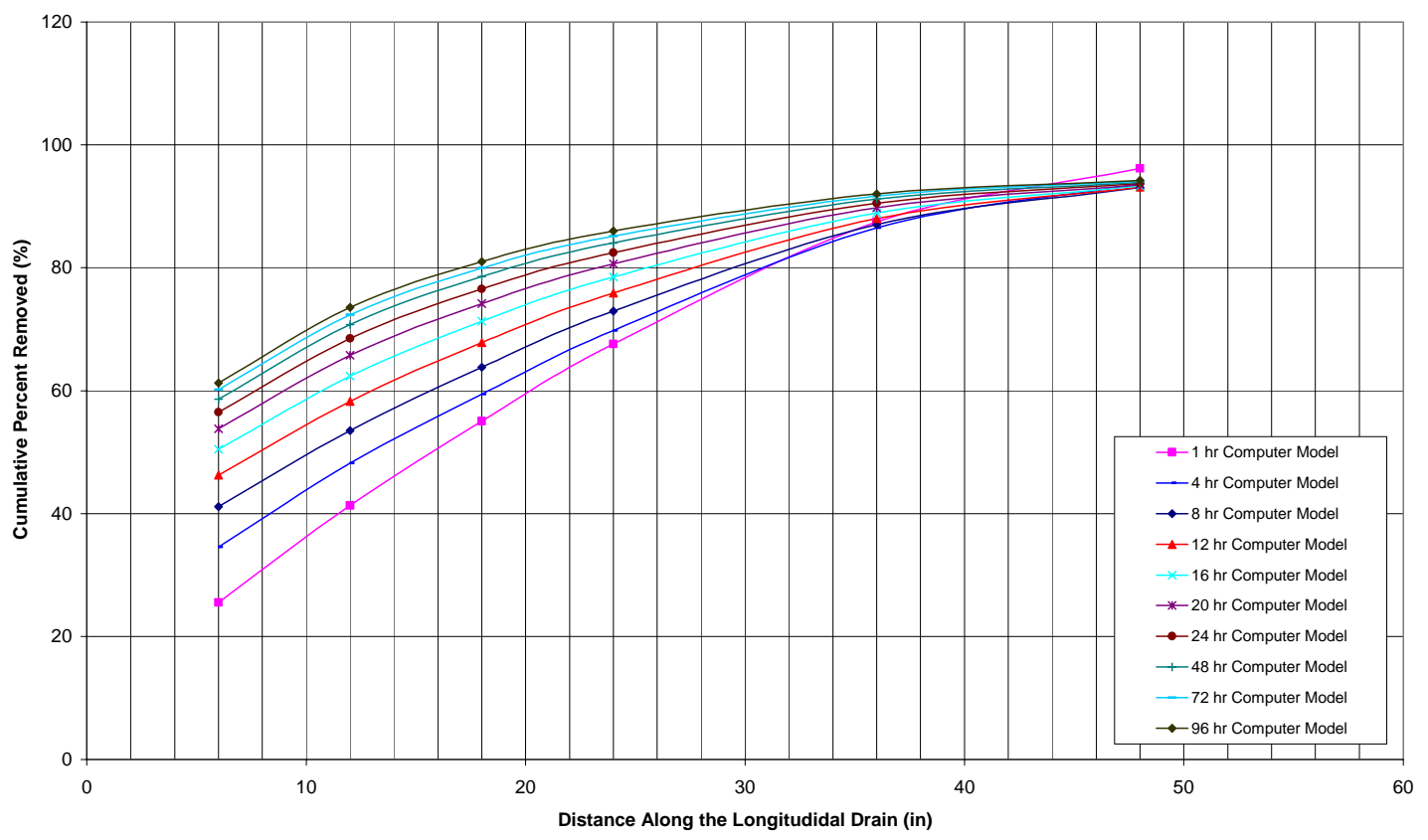

Figure 4.111: Cumulative Percent Removal for case A-12-48-10.

Cumulative Percent Removed Along the Longitudinal Drain

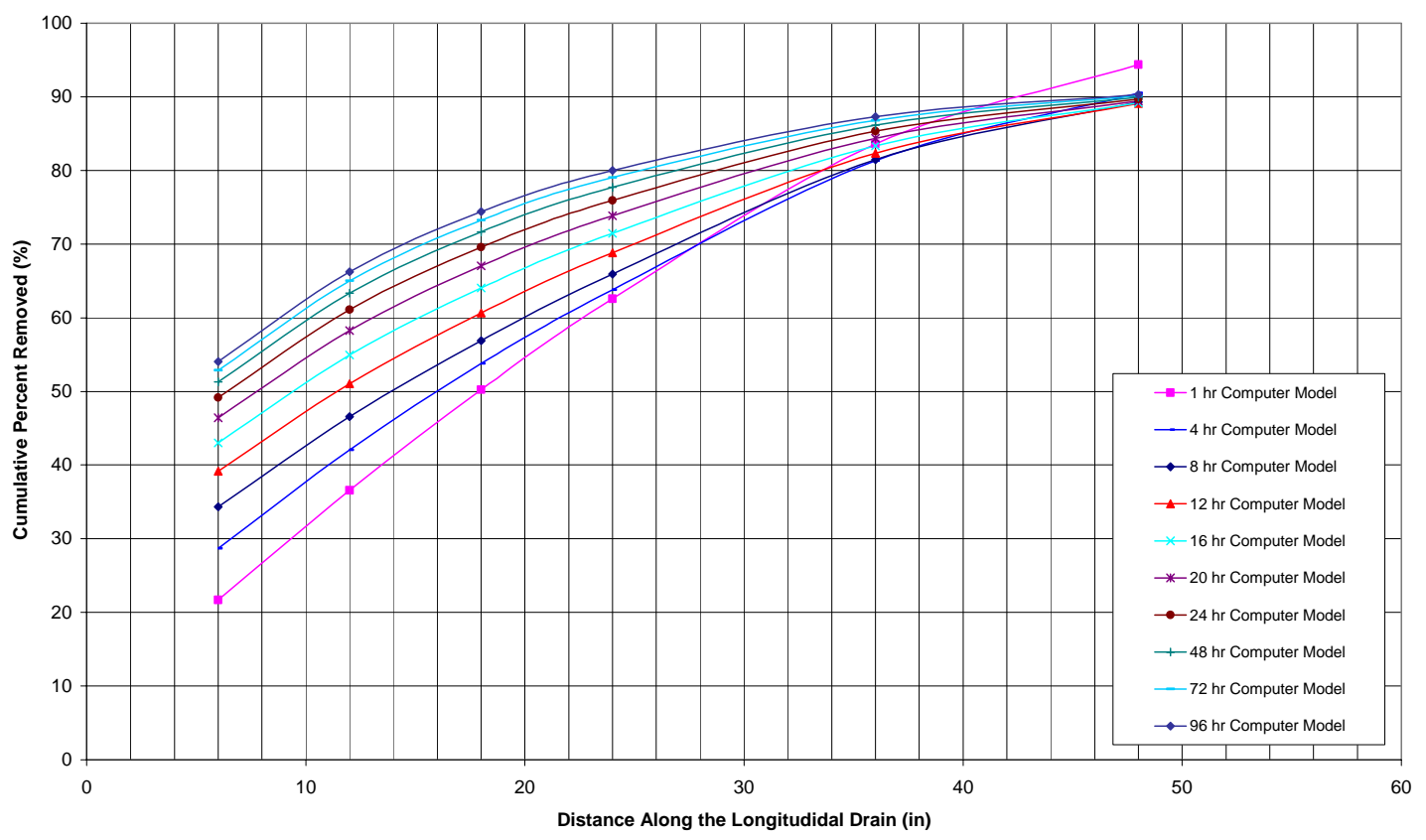

Figure 4.112: Cumulative Percent Removal for case A-12-48-20 
Cumulative Percent Removed Along the Longitudinal Drain

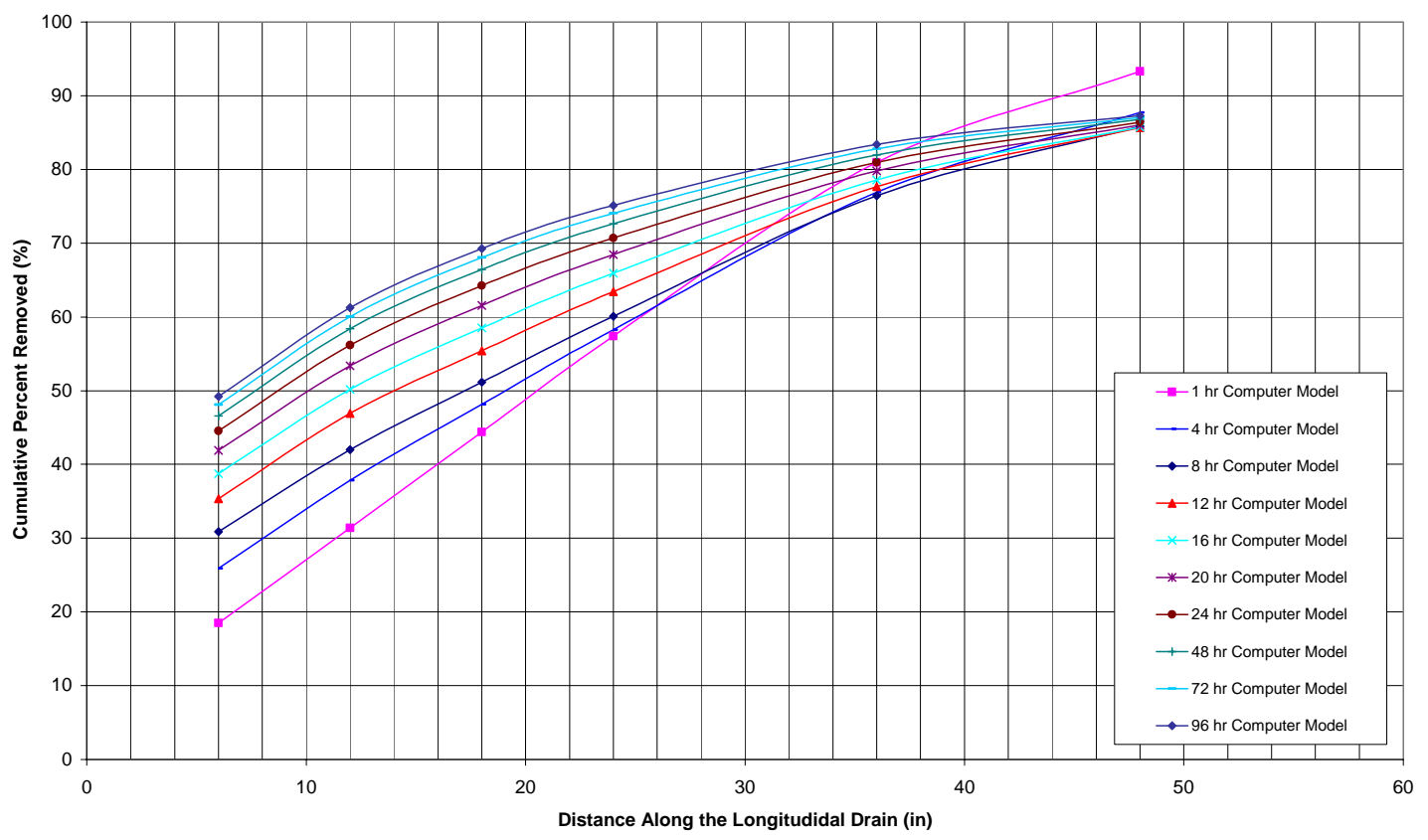

Figure 4.113: Cumulative Percent Removal for case A-12-48-30

Cumulative Percent Removed Along the Longitudinal Drain

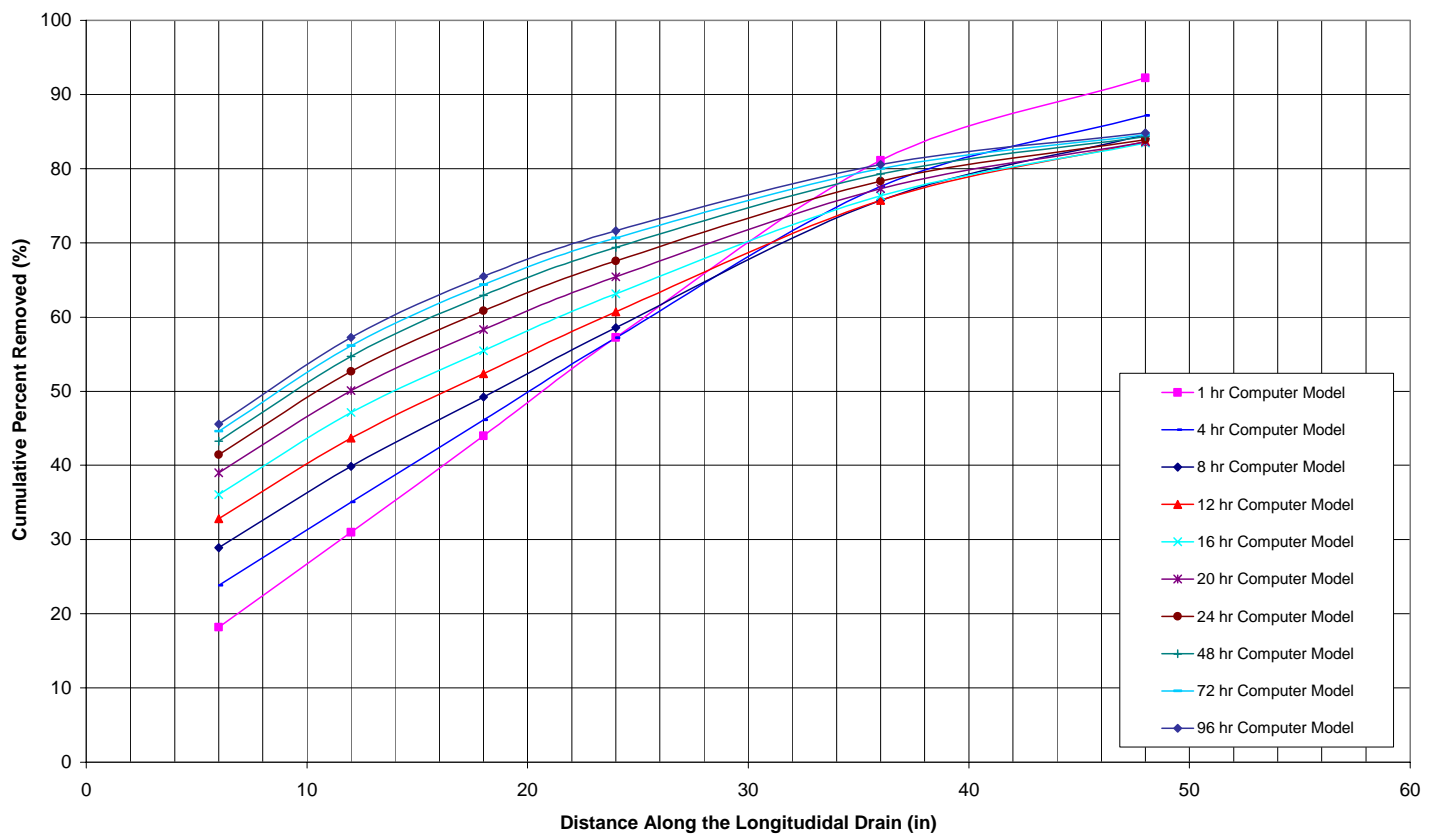

Figure 4.114: Cumulative Percent Removal for case A-12-48-40 
The results shown in Figure 4.110 through Figure 4.114 indicate that the gravity is forcing water towards the end thus reducing the effectiveness of the longitudinal drain. This issue will be further discussed in the section on steady state conditions. For all cases shown so far, it appears that the majority of the changes occurred within a period of two days. Figure 4.115 shows the effect of inclination on the transient time.

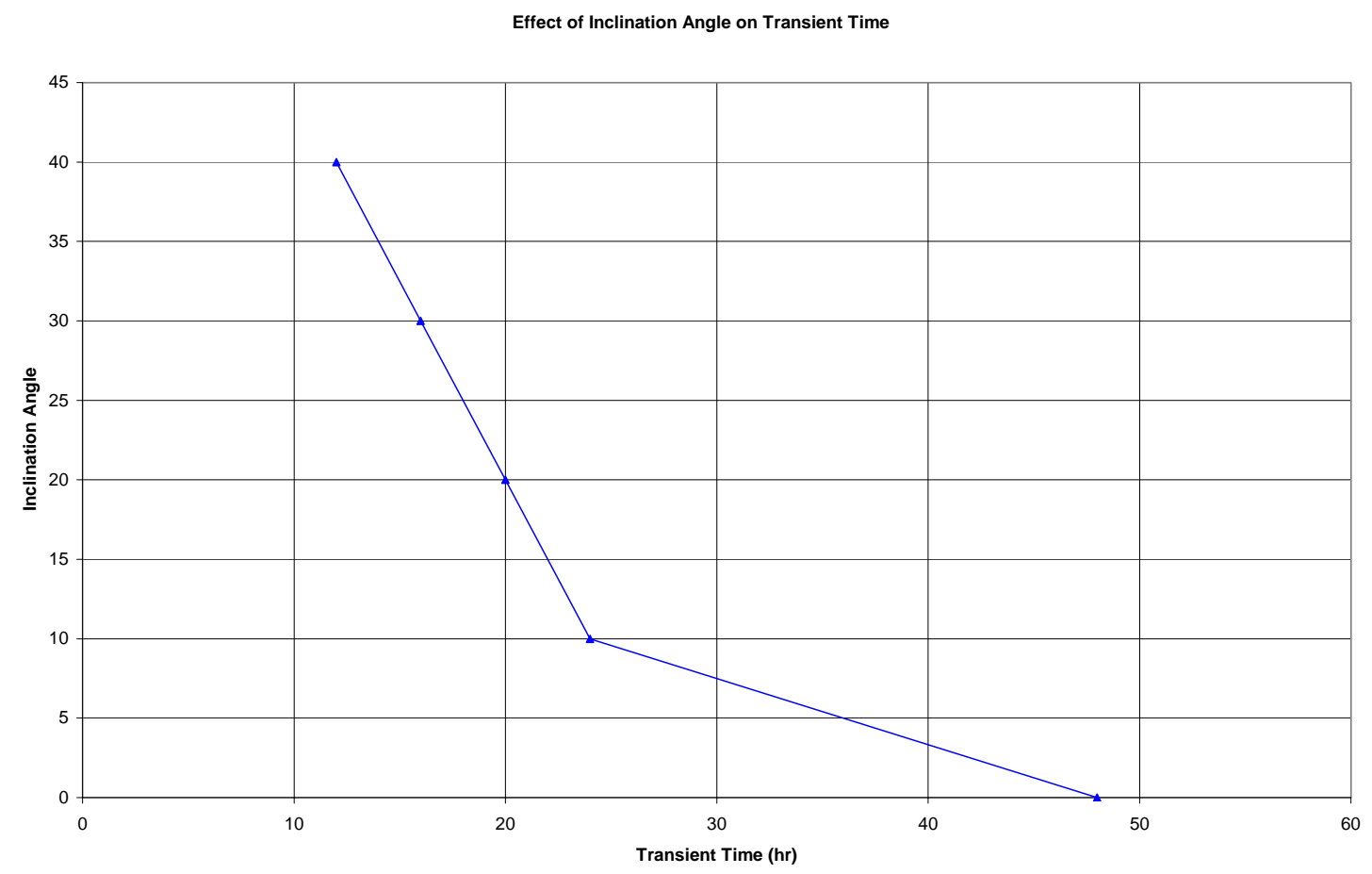

Figure 4.115: Influence of slope inclination on transient time 


\subsubsection{Influence of Soil Type}

Influence of drain length $(\ell)$, spacing $(2 \mathrm{w})$, and slope angle $(\theta)$ were presented in previous sections by considering the soil type A. In section, the influence of soil type is presented. The soil type controls the hydraulic conductivity and the hydraulic conductivity has an influence on seepage. The influence of soil type on the performance of longitudinal drains was investigated by considering three soil types: soil type A, soil type $\mathrm{C}$ and soil type $\mathrm{E}$. These three soils cover a broad range of hydraulic conductivities to provide sufficient information on the influence the hydraulic conductivity on the transient behavior of longitudinal drains under field conditions. The length of the drain was assumed as 48 feet, half-spacing as twelve feet, and the slope angle as thirty degrees. Figure 4.116 through Figure 4.118 show piezometric heads along the center line for soils $\mathrm{A}, \mathrm{C}$ and $\mathrm{E}$. The piezometric head along the cross-sections A and B are shown in Figure 4.119 through 4.124. Additional data for soil types C and E are given in Appendix A-8.

As can be seen from these figures, the soil type has a significant influence on the transient behavior of piezometric head along the center line. For the soil type A, it took close to twenty four hours to reach steady state conditions. Soil Type C took close to seventy two hours to reach the steady state conditions while the soil type E took about fourteen hundred hours. This is a clear indication that the hydraulic conductivity (hence the soil type) has a significant influence on the transient behavior of longitudinal drains. It is important to remember that seepage force can cause stability problems. Therefore, the purpose of a longitudinal drain is not only removing and dropping the water level in the slope, but also to do it quickly. Since the hydraulic conductivity has a significant influence on the transient behavior of a longitudinal drain, other geometric parameters 


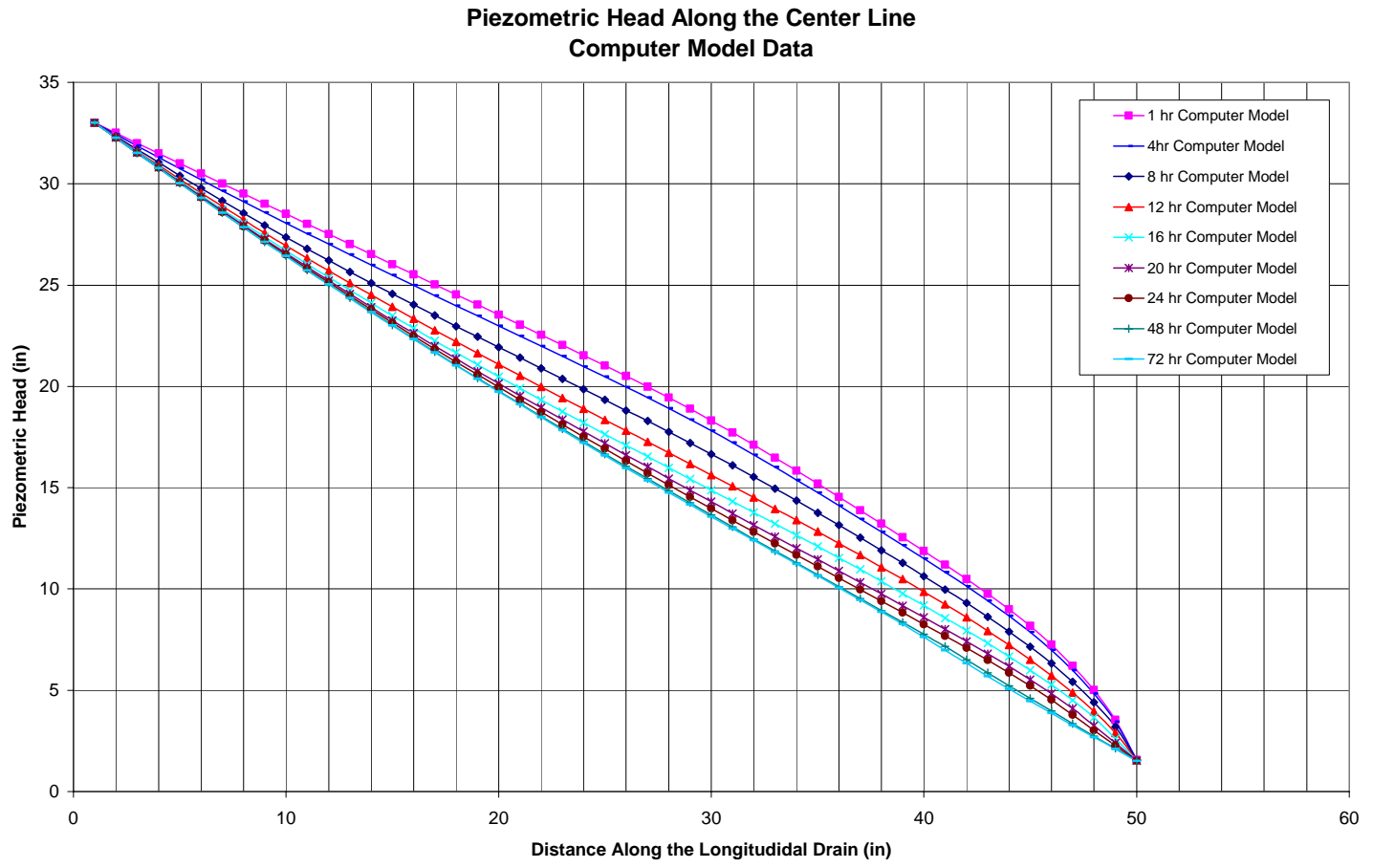

Figure 4.116: Piezometric head along the center line for case A-12-48-30

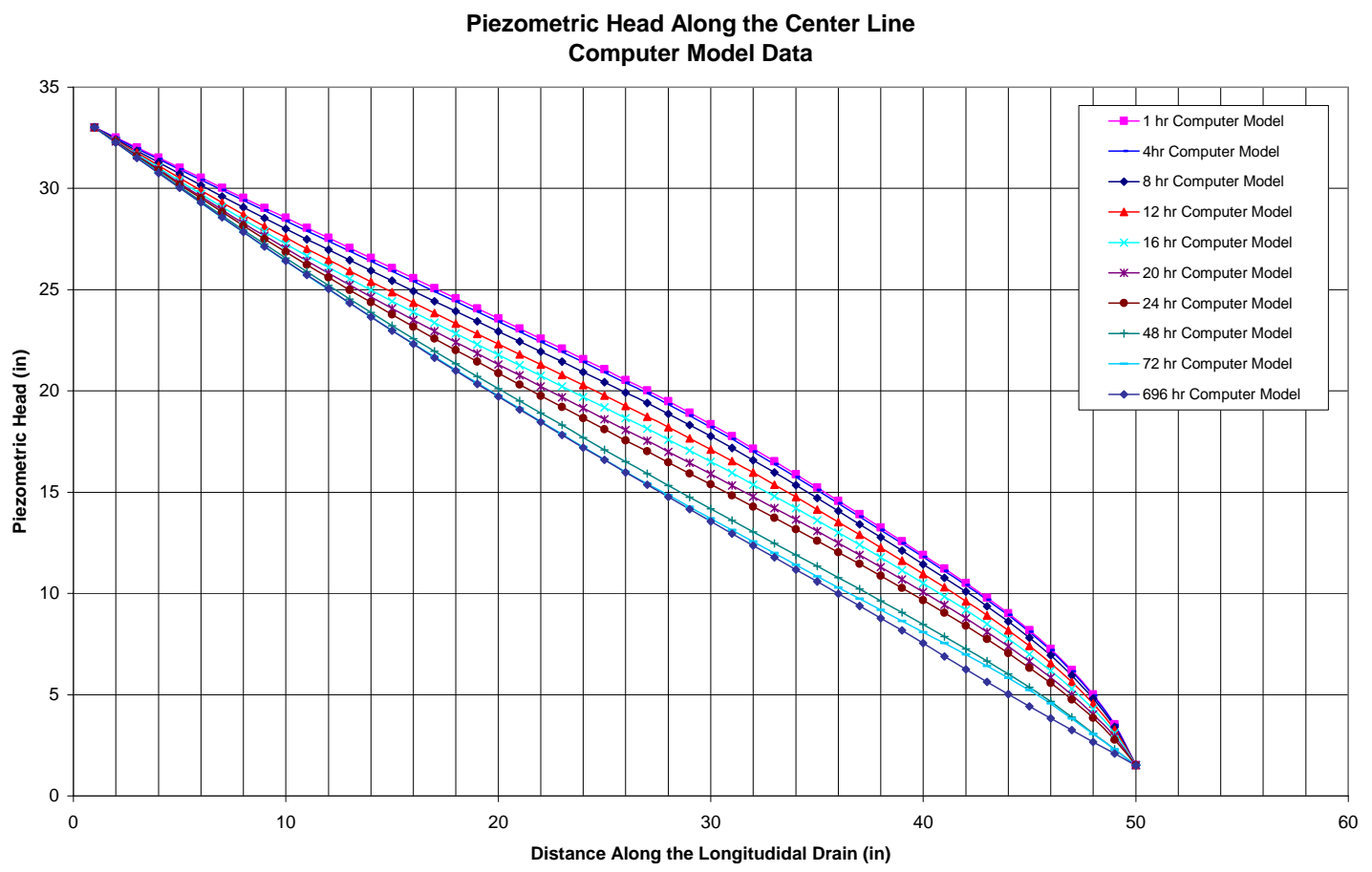

Figure 4.117: Piezometric head along the center line for case C-12-48-30 


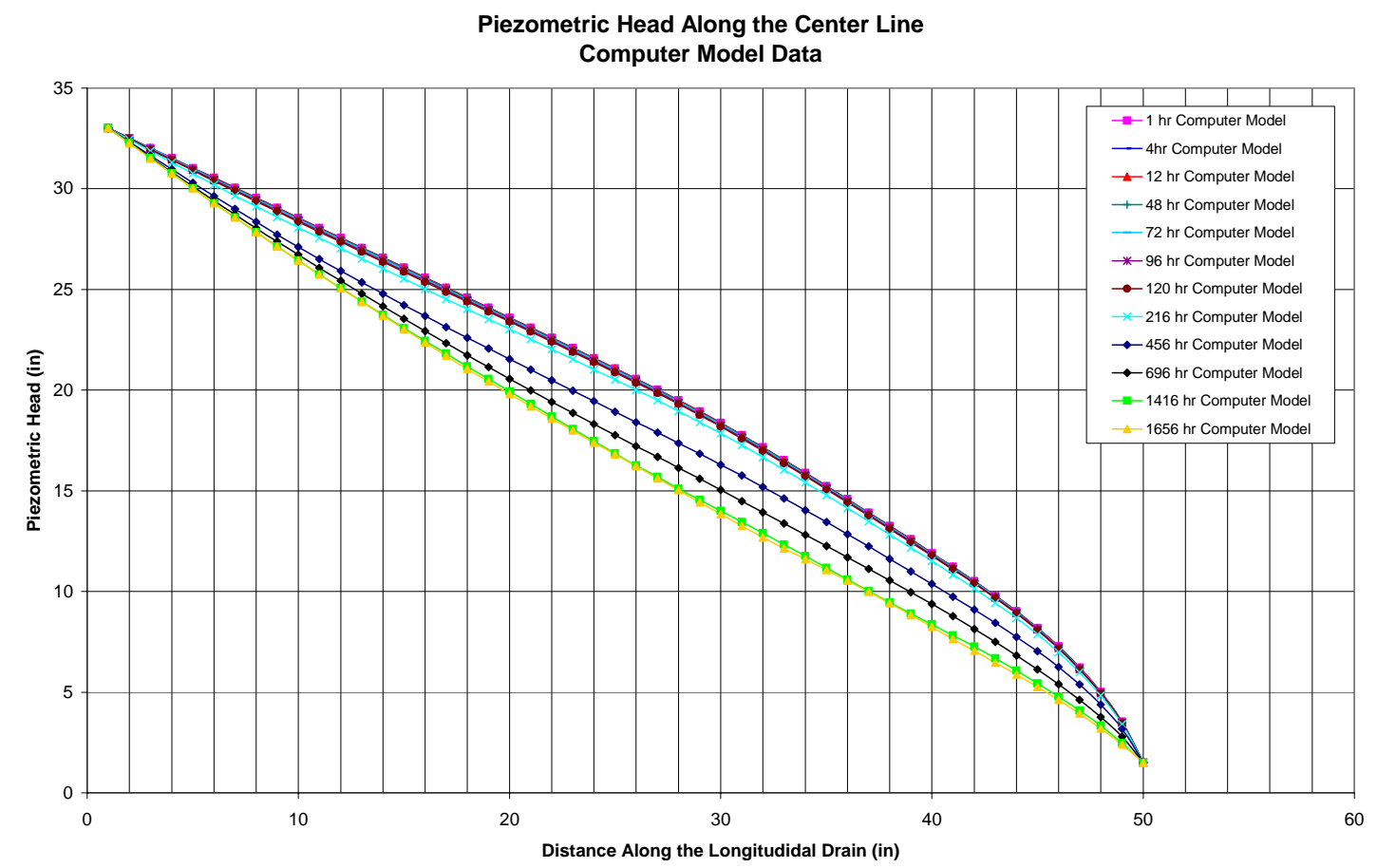

Figure 4.118: Piezometric head along the center line for case E-12-48-30

such as the drain spacing may have to be adjusted when dealing with low permeability soils. Figures 4.119 through 4.124 show the piezometric variation at A and B for the three soils used. Once again, the transient behavior of the piezometric head along the crosssections A and B is similar to that seen along the center line. Soil type A reached steady state conditions after twenty four hours. Soil type-C took more than forty eight hours to reach steady state conditions, while the soil type E took about fourteen hundred hours. These figures also show that the soil type has a significant influence on the transient time of longitudinal drains. 


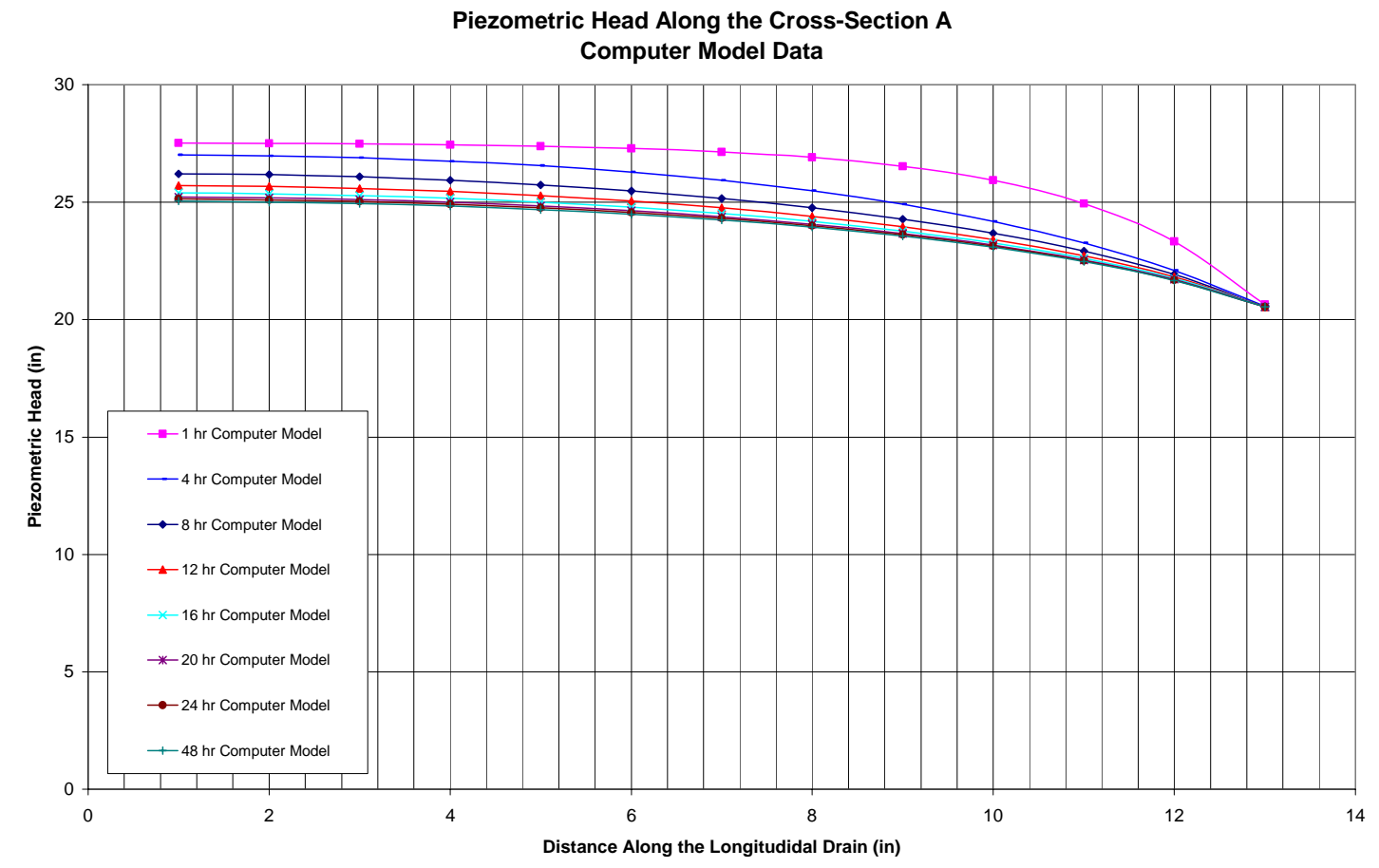

Figure 4.119: Piezometric head along the cross-section A for case A-12-48-30

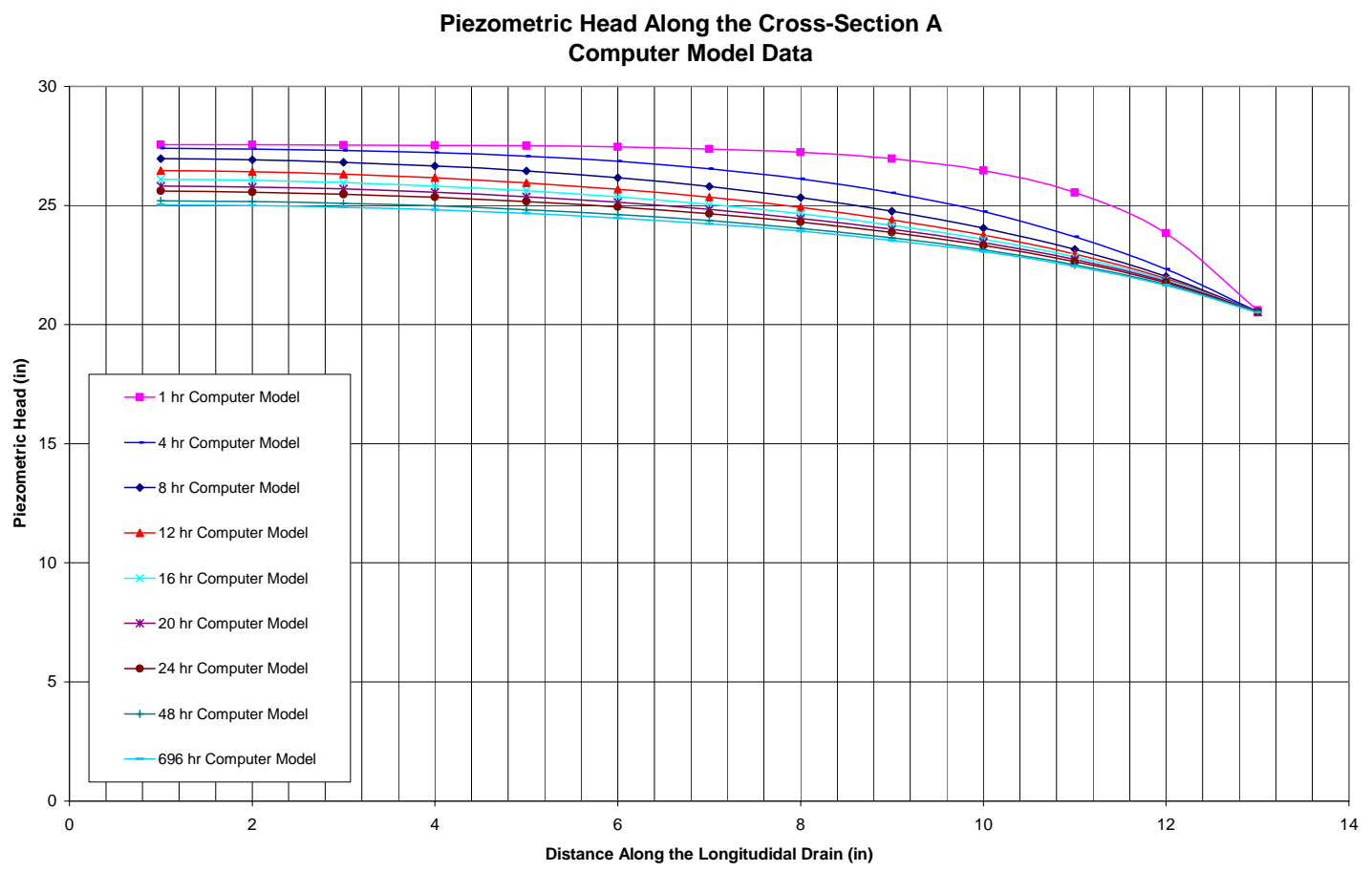

Figure 4.120: Piezometric head along the cross-section A for case C-12-48-30 


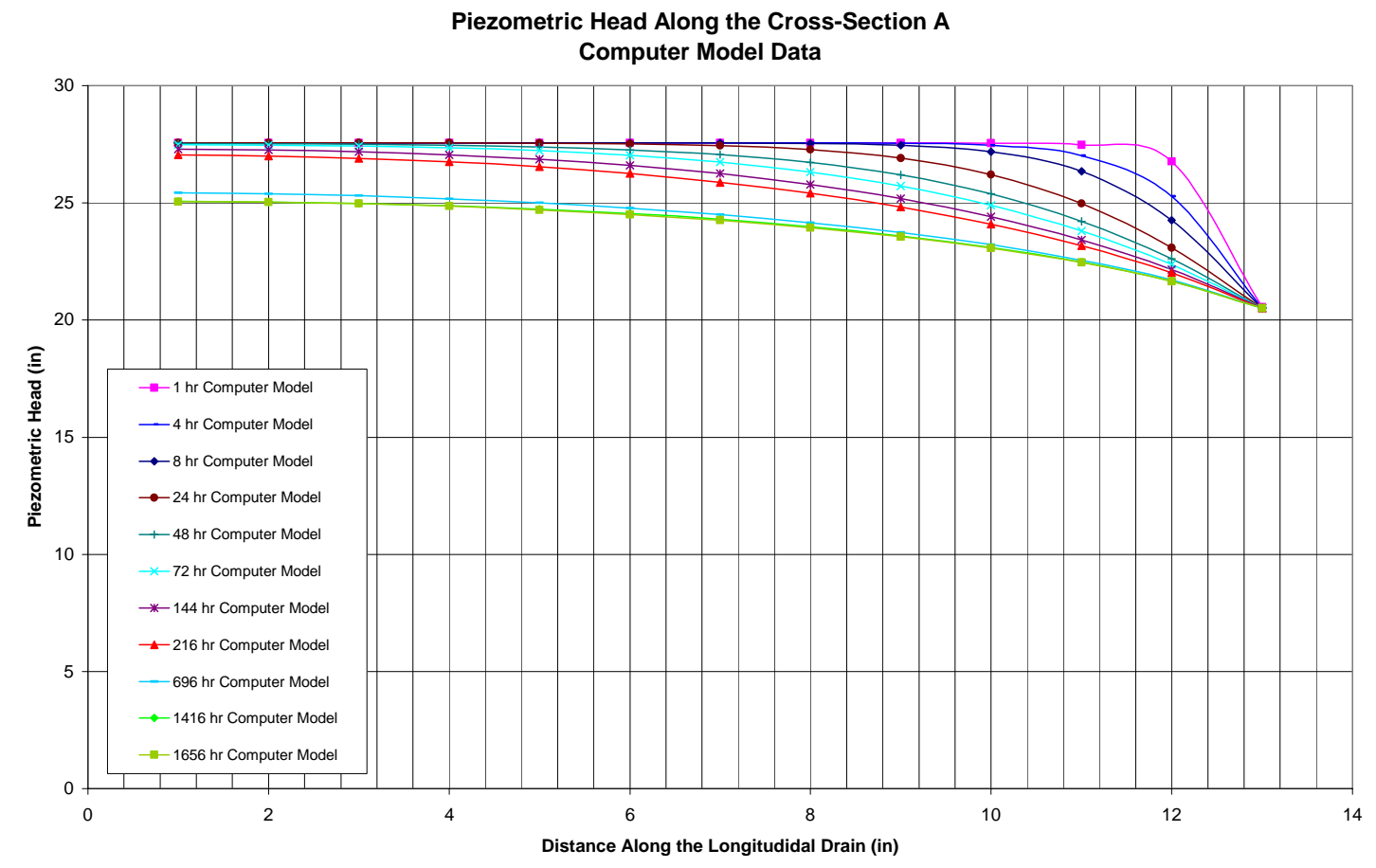

Figure 4.121: Piezometric head along the cross-section A for case E-12-48-30

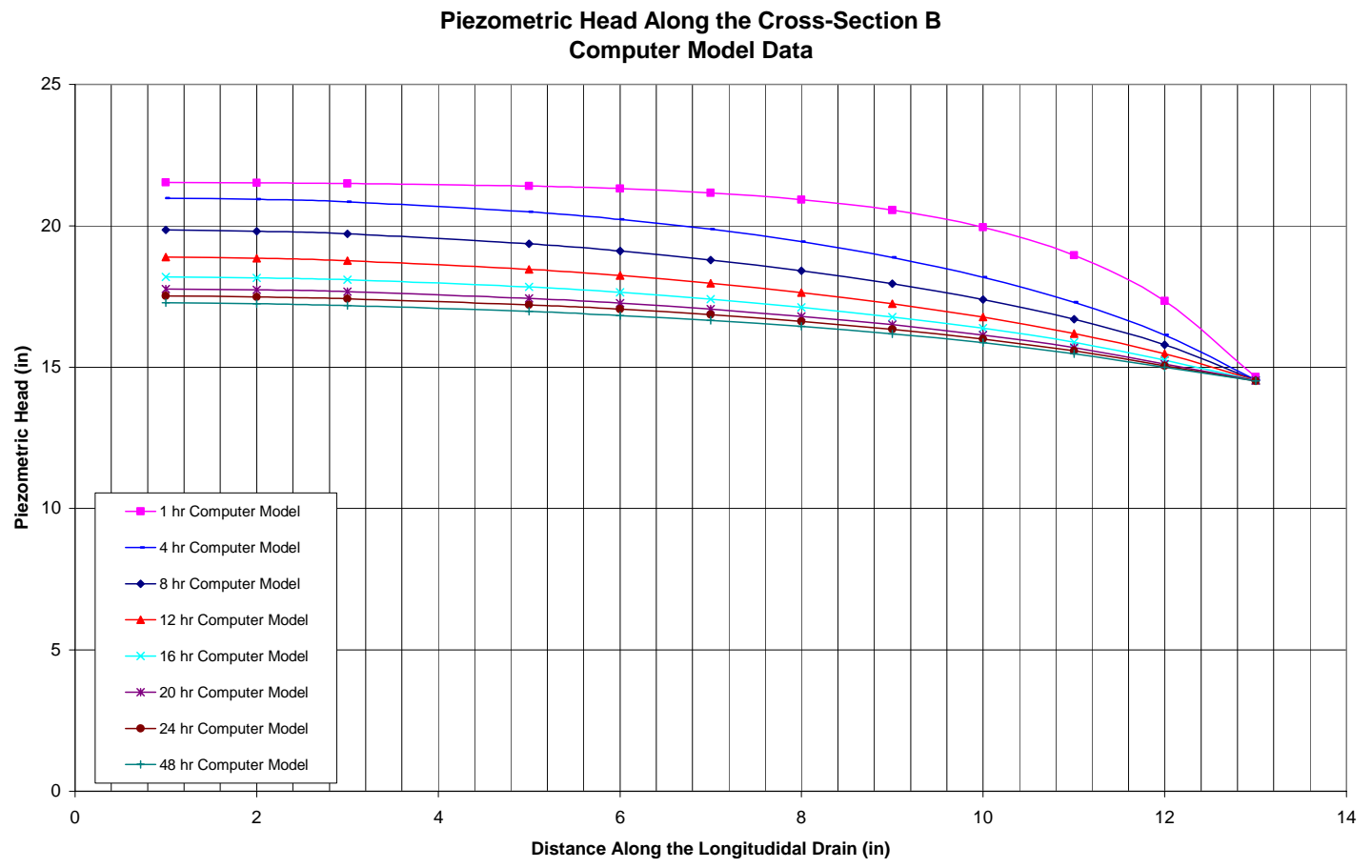

Figure 4.122: Piezometric head along the cross-section B for case A-12-48-30 


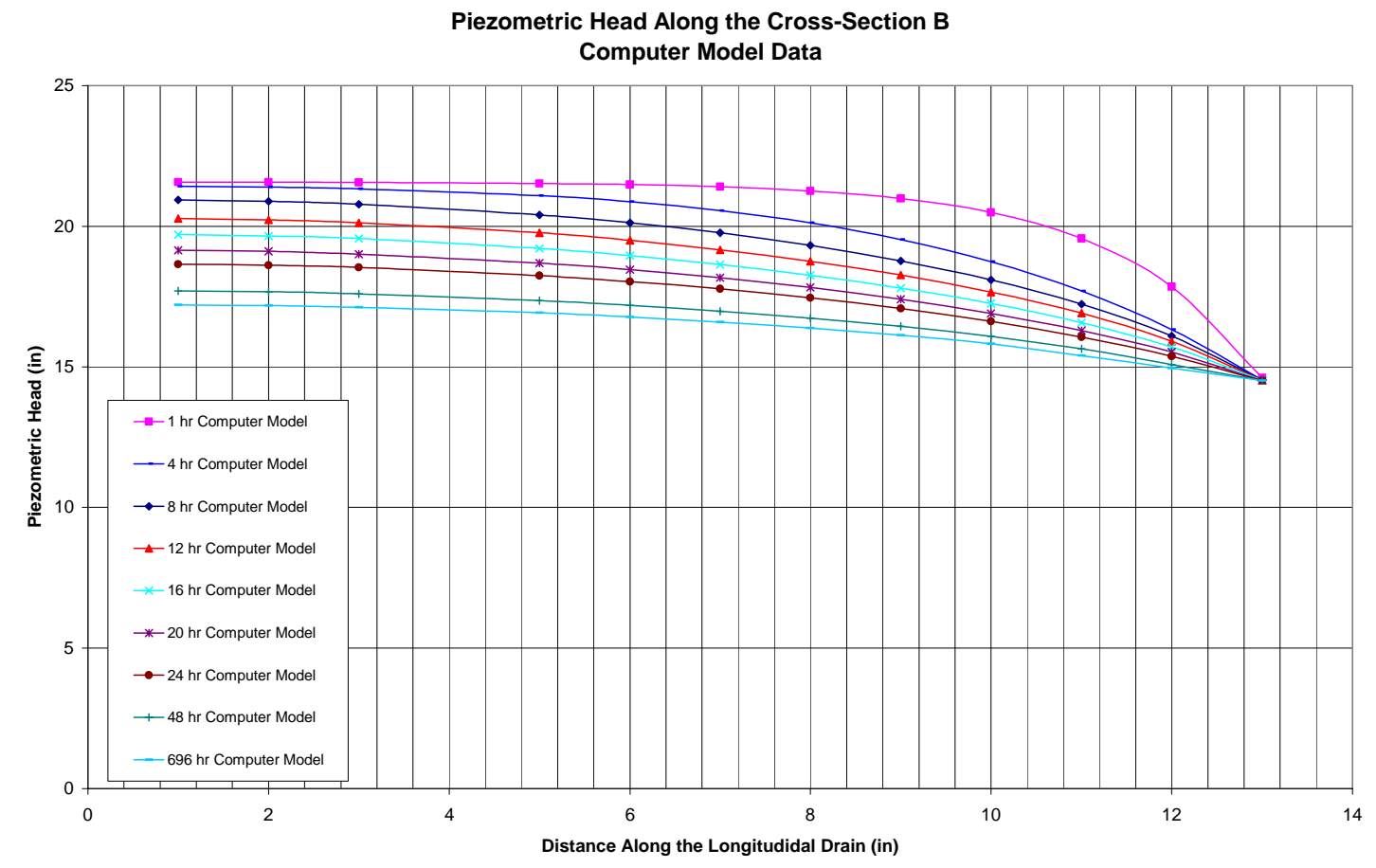

Figure 4.123: Piezometric head along the cross-section B for case C-12-48-30

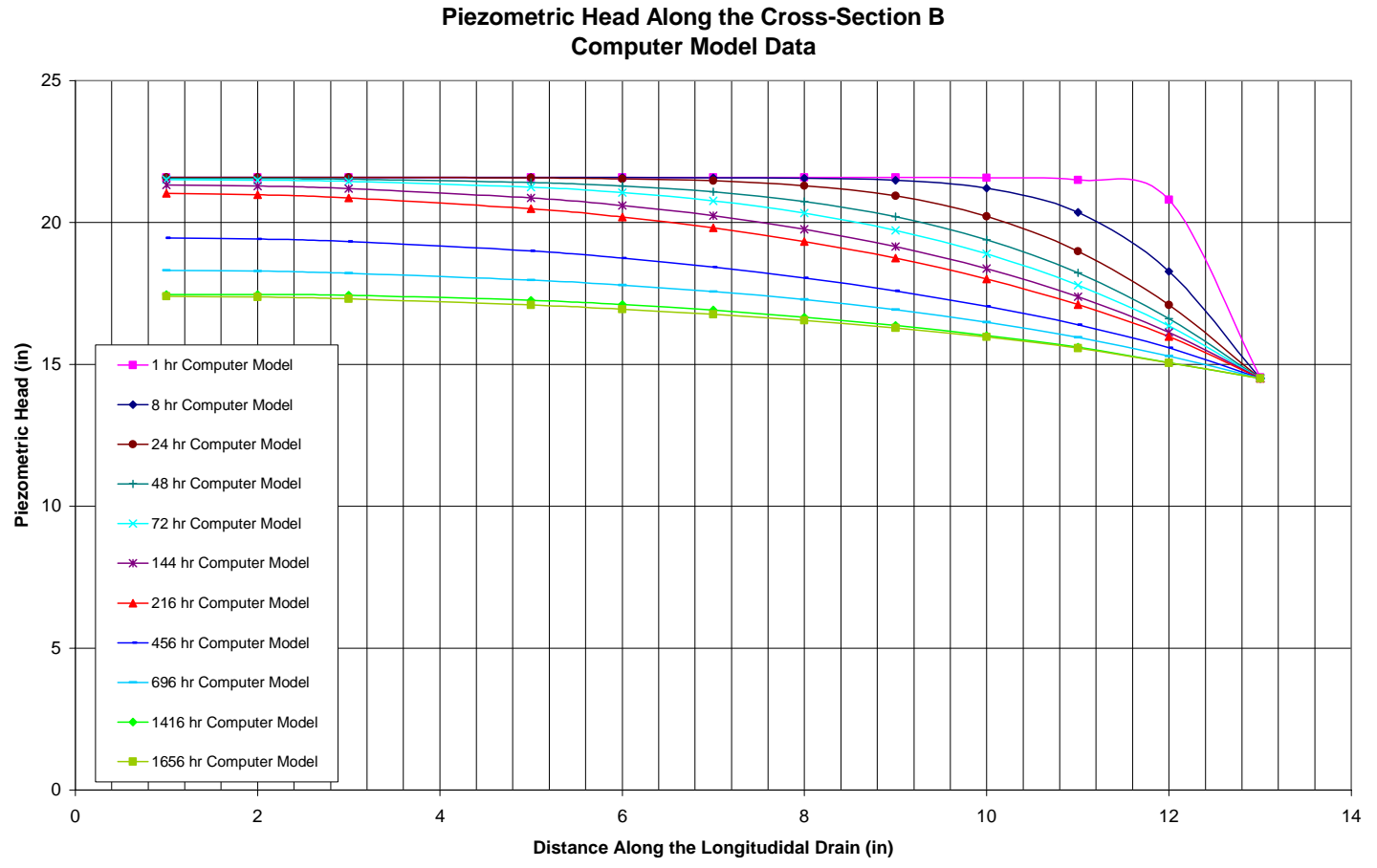

Figure 4.124: Piezometric head along the cross-section B for case E-12-48-30 
The influence of soil type on the drain effectiveness is presented below. Figure 4.125 through Figure 4.127 show the change in drain efficiency over time for the three soil types used. The soil type has two major effects on the drain performance. The soil type has an influence on the transient time. The soil type also has an influence on the percentage of seepage removal (i.e., drain efficiency). Figure 4.125 through Figure 4.127 show that the drain efficiency at a given time decreased when the hydraulic conductivity of the soil was reduced.

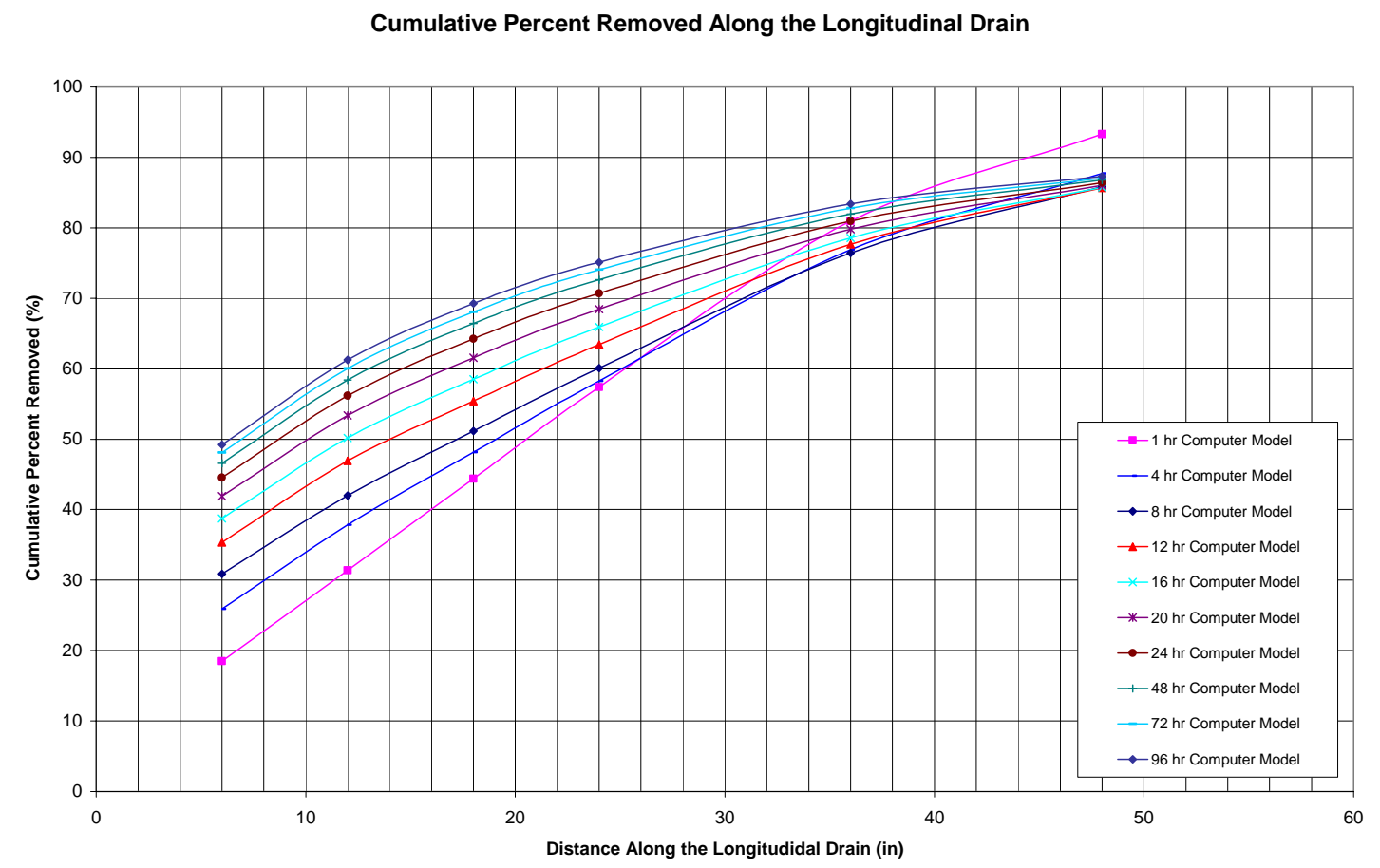

Figure 4.125: Cumulative Percent Removal for case A-12-48-30 
Cumulative Percent Removed Along the Longitudinal Drain

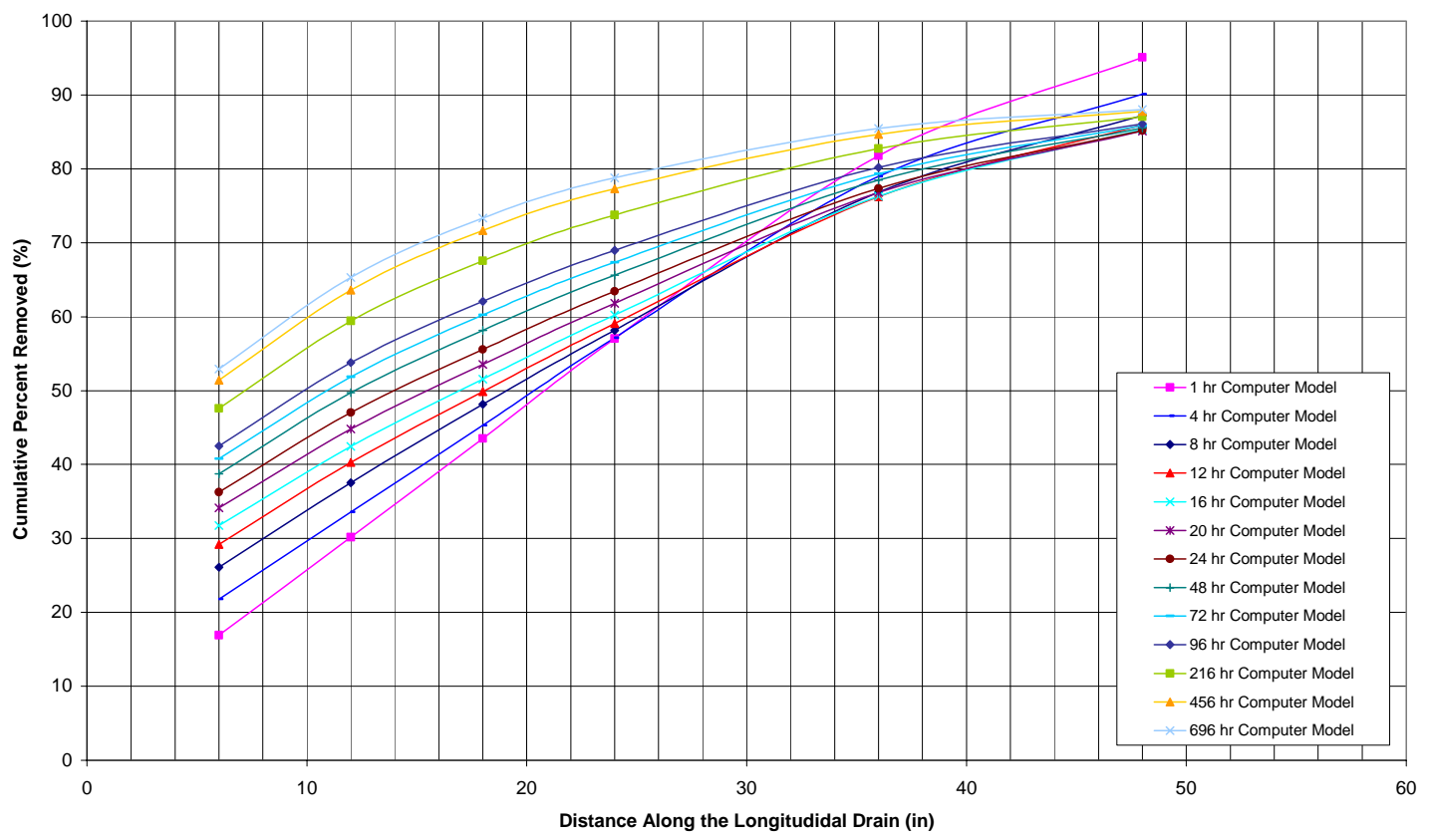

Figure 4.126: Cumulative Percent Removal for case C-12-48-30

Cumulative Percent Removed Along the Longitudinal Drain

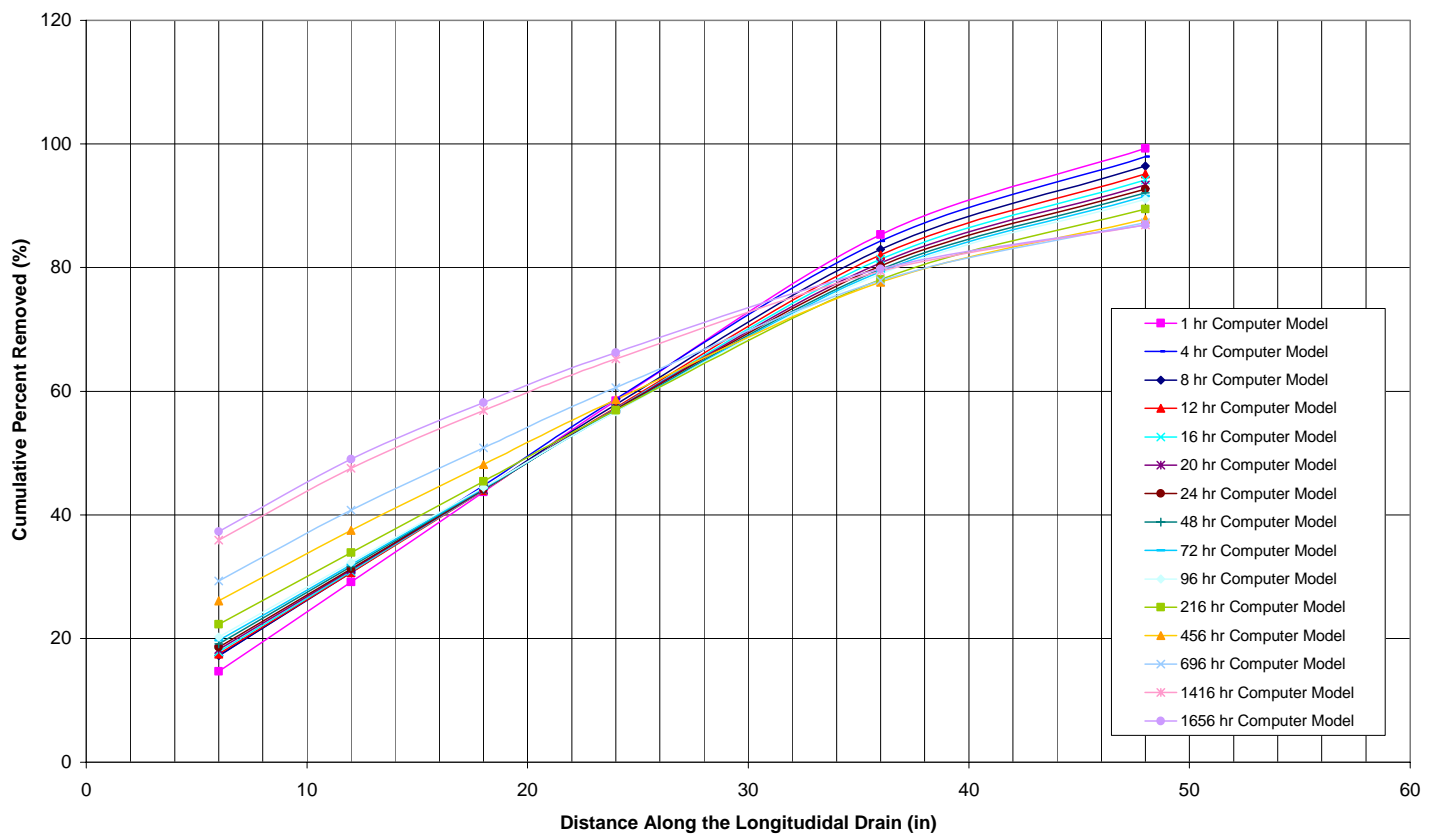

Figure 4.127: Cumulative Percent Removal for case E-12-48-30 
Figure 4.128 shows the influence of soil type on the transient time; in this graph soil type D was added to obtain a better curve. Clearly, the soil type has a significant influence on the transient time of a longitudinal drain.

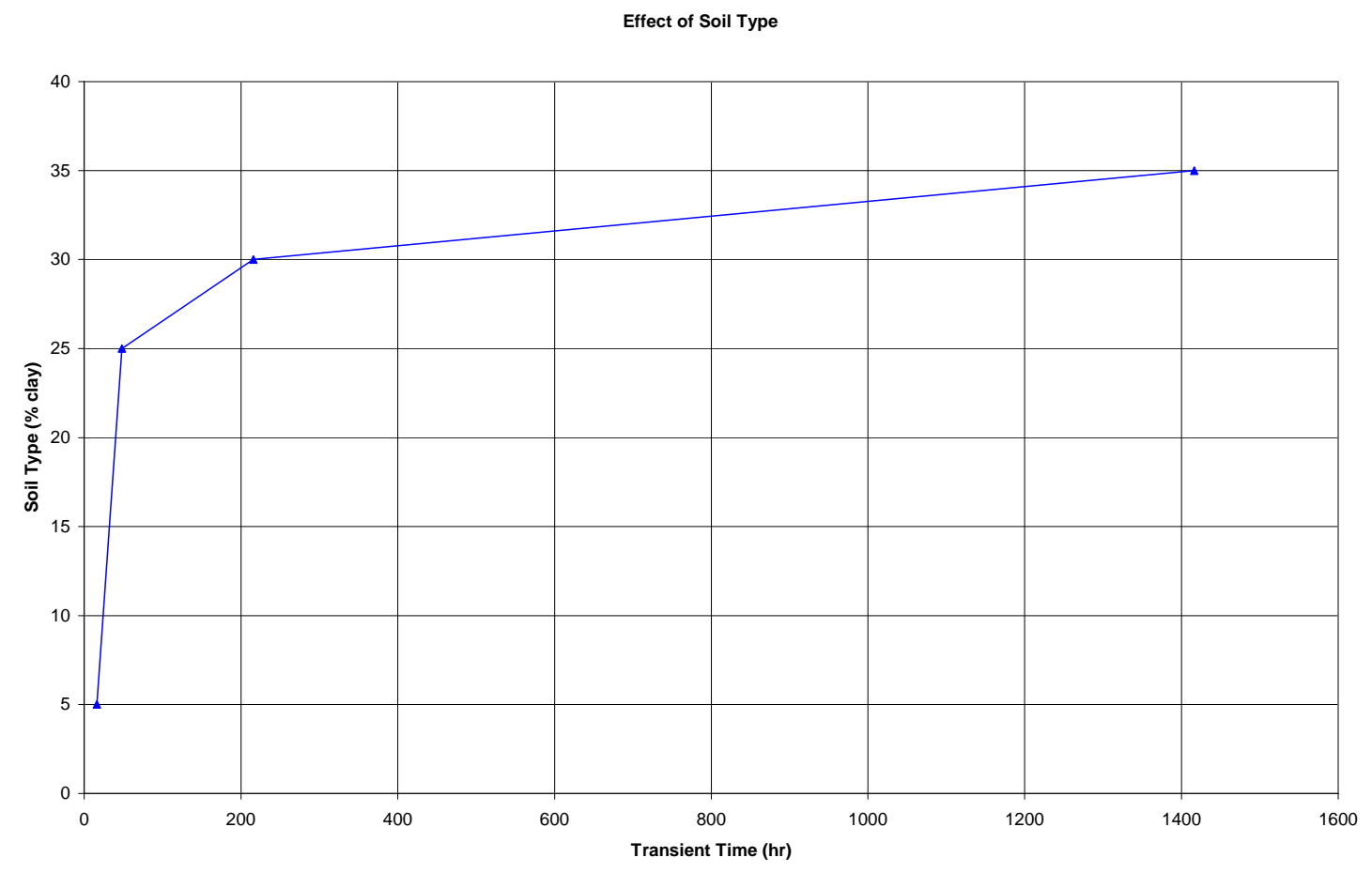

Figure 4.128: Influence of soil type on the transient time

\subsubsection{Performance of Longitudinal Drains under Steady State Conditions}

In this section, the field performance of longitudinal drains under steady state conditions is investigated by using the same computer model that was used in the transient study. The results of the computer modeling study on the influence of drain spacing, drain length, slope angle, and soil type are presented below. 


\subsubsection{Influence of trench spacing ( $2 w)$}

The influence of trench spacing on drain performance under steady state conditions was investigated by using soil A, drain with a length of forty eight feet and a slope of 10 degrees. The spacing was varied in the computer model. Let's analyze soil A, for a length of forty eight feet, and ten degrees. Figure 4.129 shows the influence of drain spacing on the piezometric head along the center line. The piezometric head is higher for larger values of drain spacing. This means that the piezometric levels can be reduced to desired levels by using smaller trench spacing. However, smaller trench spacing means higher cost. The computer model presented in this report can be used to determine an optimum range of geometric parameters by considering the effectiveness and cost.

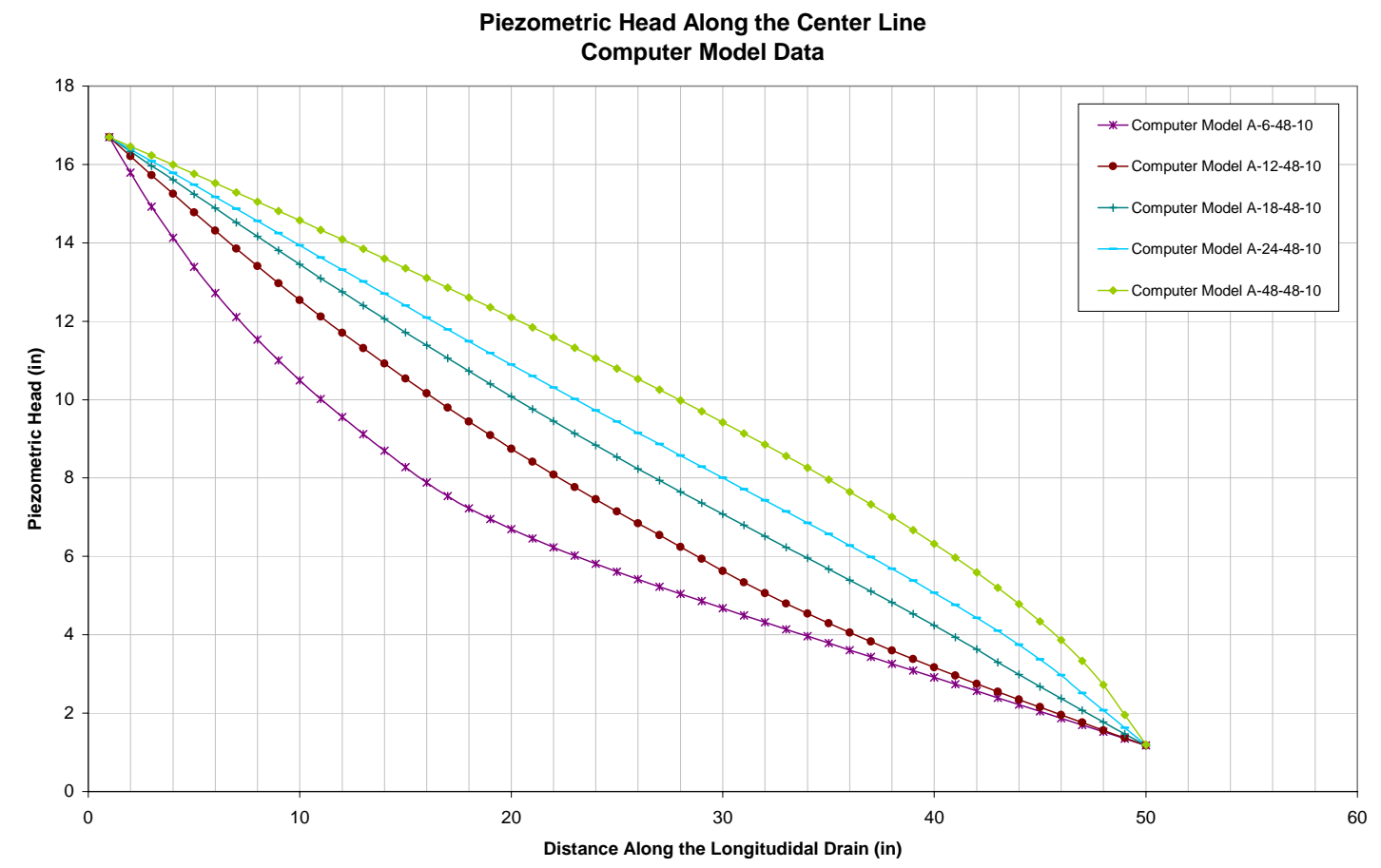

Figure 4.129: Piezometric head along the center line for different drain spacing 
Piezometric head along the cross-sections A and B are shown in Figure 4.130 and Figure 4.131. The piezometric levels are much higher for larger values of trench spacing. Therefore, the piezometric levels can be reduced to desired levels by using smaller trench spacing.

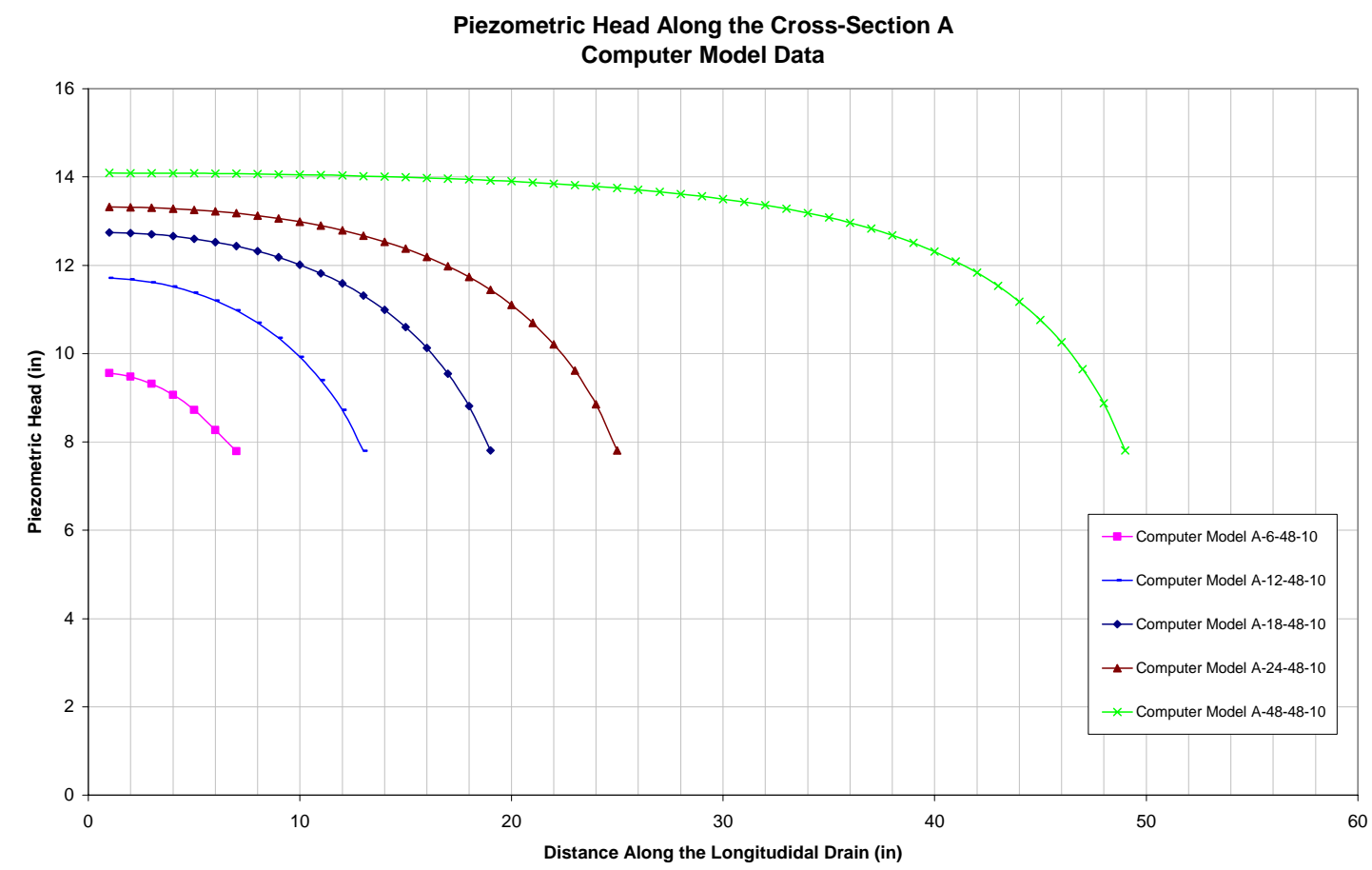

Figure 4.130: Piezometric head along cross-section A for different trench spacing 


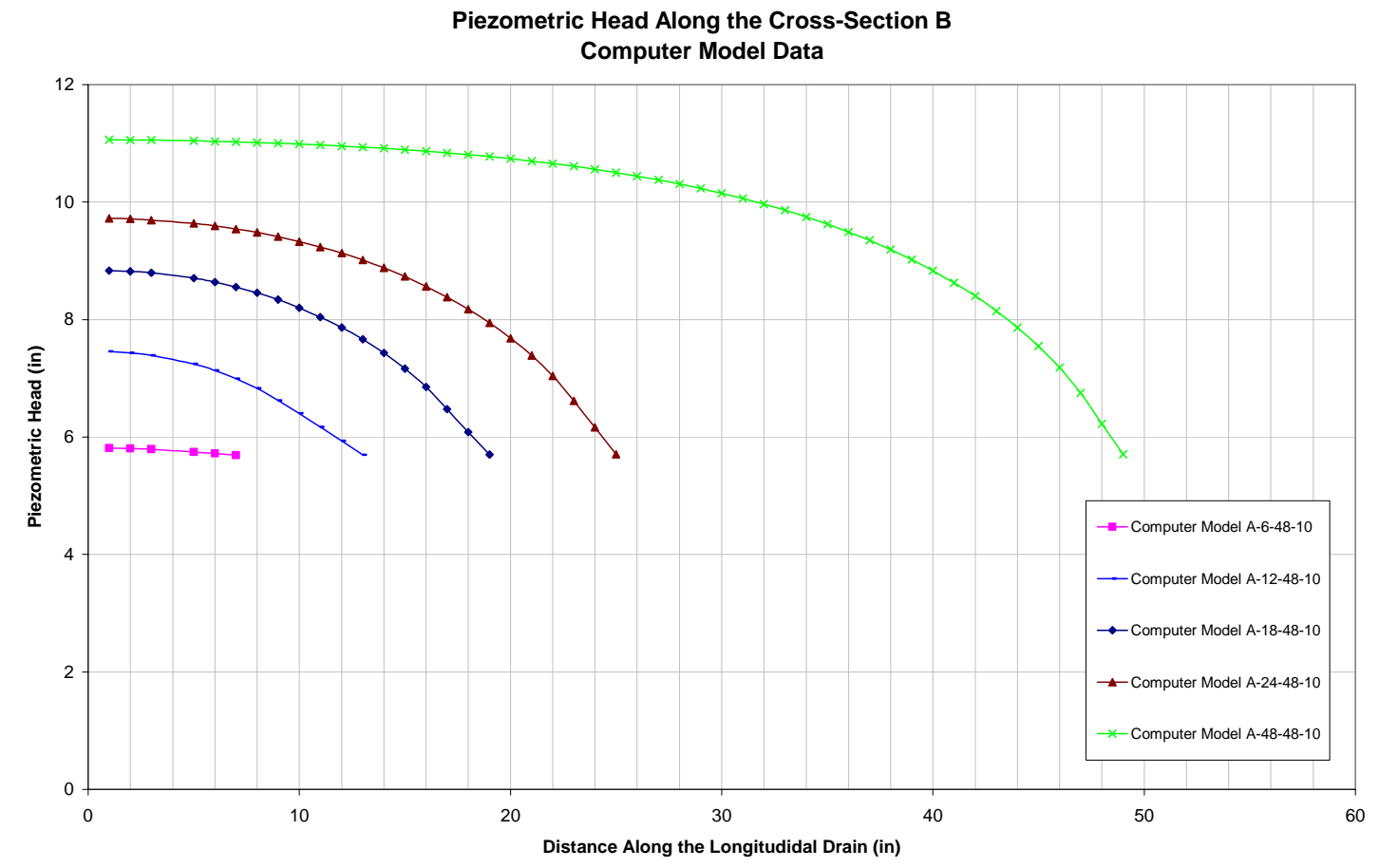

Figure 4.131: Piezometric head along cross-section B for different trench spacing

Influence of trench spacing on drain effectiveness is shown in Figure 4.132. This figure clearly shows the influence of drain spacing on the effectiveness of the drain. The drain comes less effective as the drain spacing is increased. If the space between drains (trench width) is too big, water will not notice the presence of the drain. The water particles which are farther away from the drain would probably flow as if no drain was in place. The computer model presented in this report can be used to determine the required minimum drain spacing for a desired amount of seepage removal. As can be seen from this figure, the drain effectiveness for soil type A can drop by as much as $35 \%$ when the trench spacing is increased from 12 feet to 48 feet. 
Cumulative Percent Removed Along the Longitudinal Drain

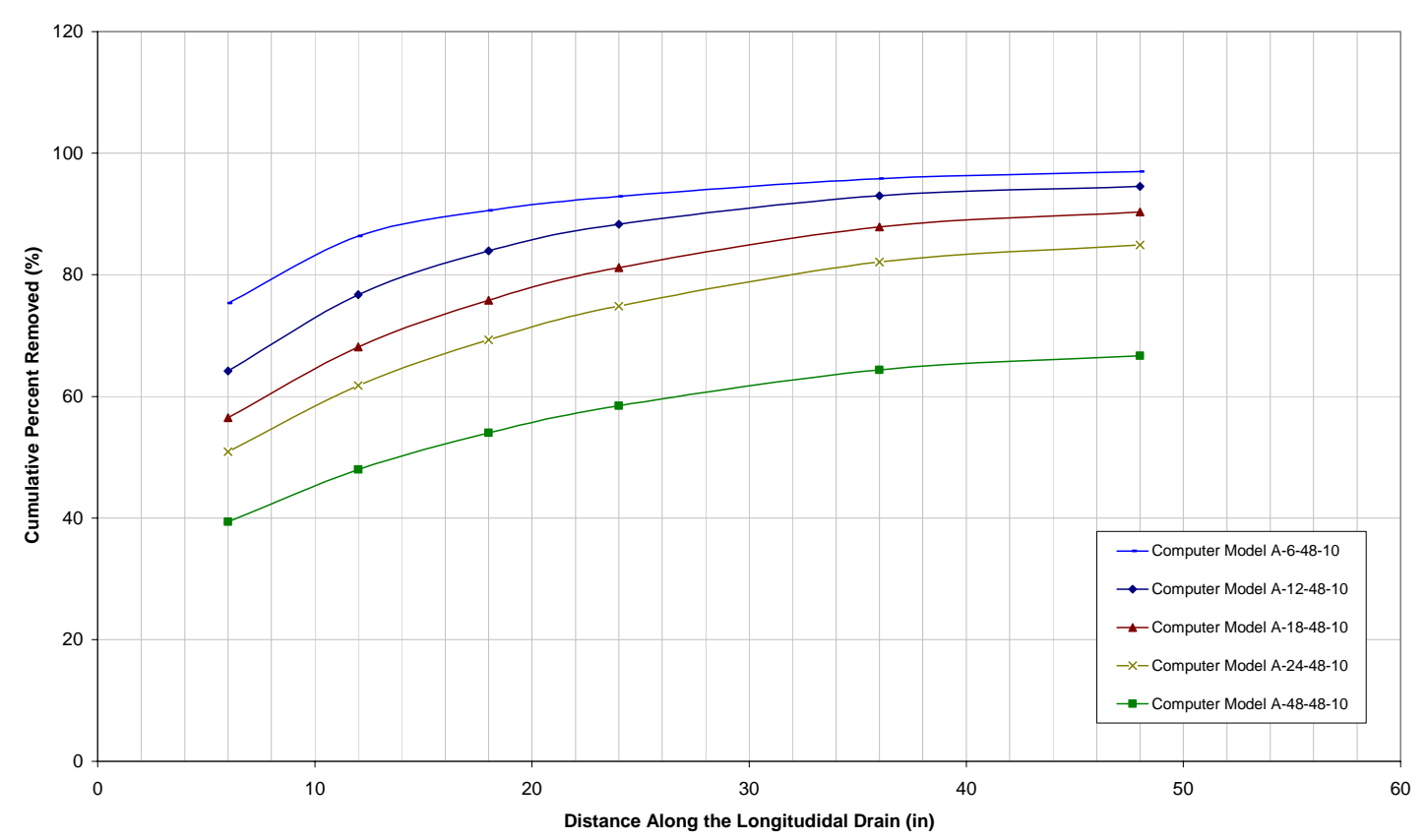

Figure 4.132: Influence of drain spacing on Cumulative Percent Removal

\subsubsection{Influence of Drain Length}

The influence of drain length on the steady state performance of the drain is presented in this section. The drain length was varied while keeping all other geometric parameters at constant values. Results for the soil Type A is presented below. The drain spacing was kept constant at twelve feet. The slope inclination was assumed as ten degrees. The influence of drain length on piezometric heads, and drain effectiveness is presented below. Figures 4.133 through Figure 4.135 show the piezometric heads along the centerline and cross-sections. 


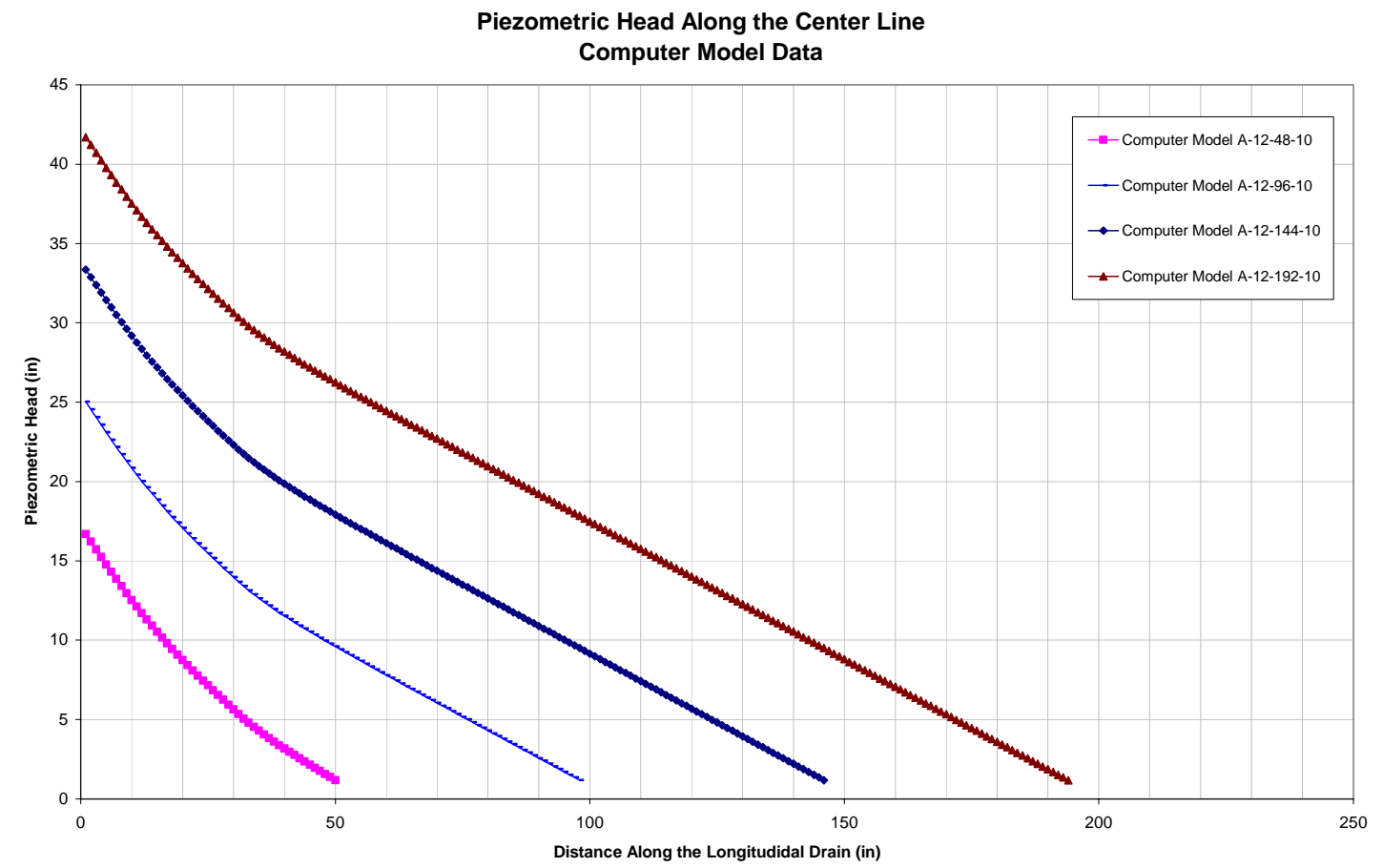

Figure 4.133: Piezometric head along the center line for different drain lengths

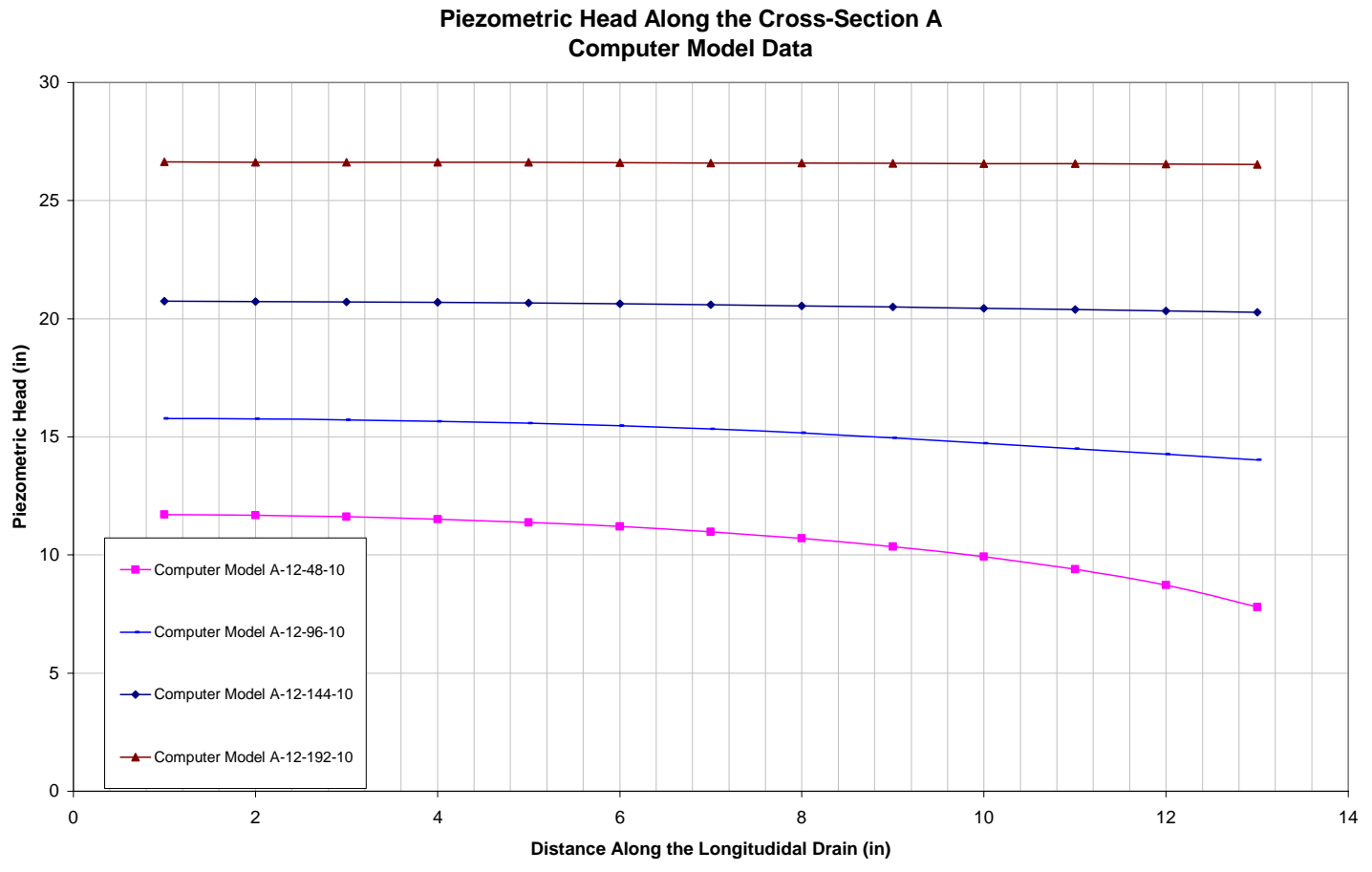

Figure 4.134: Piezometric head along cross-section A for different drain lengths 
As can be seen from these figures, the drain length does not have a significant influence on the piezometric head along the center line under steady state conditions. All piezometric curves along the center line seem to be almost parallel. From the data shown in Figures 4.134 and 4.135 for piezometric head along cross-sections $\mathrm{A}$ and $\mathrm{B}$, it can also be concluded that the drain length does not have a significant influence on the piezometric head under steady state conditions.

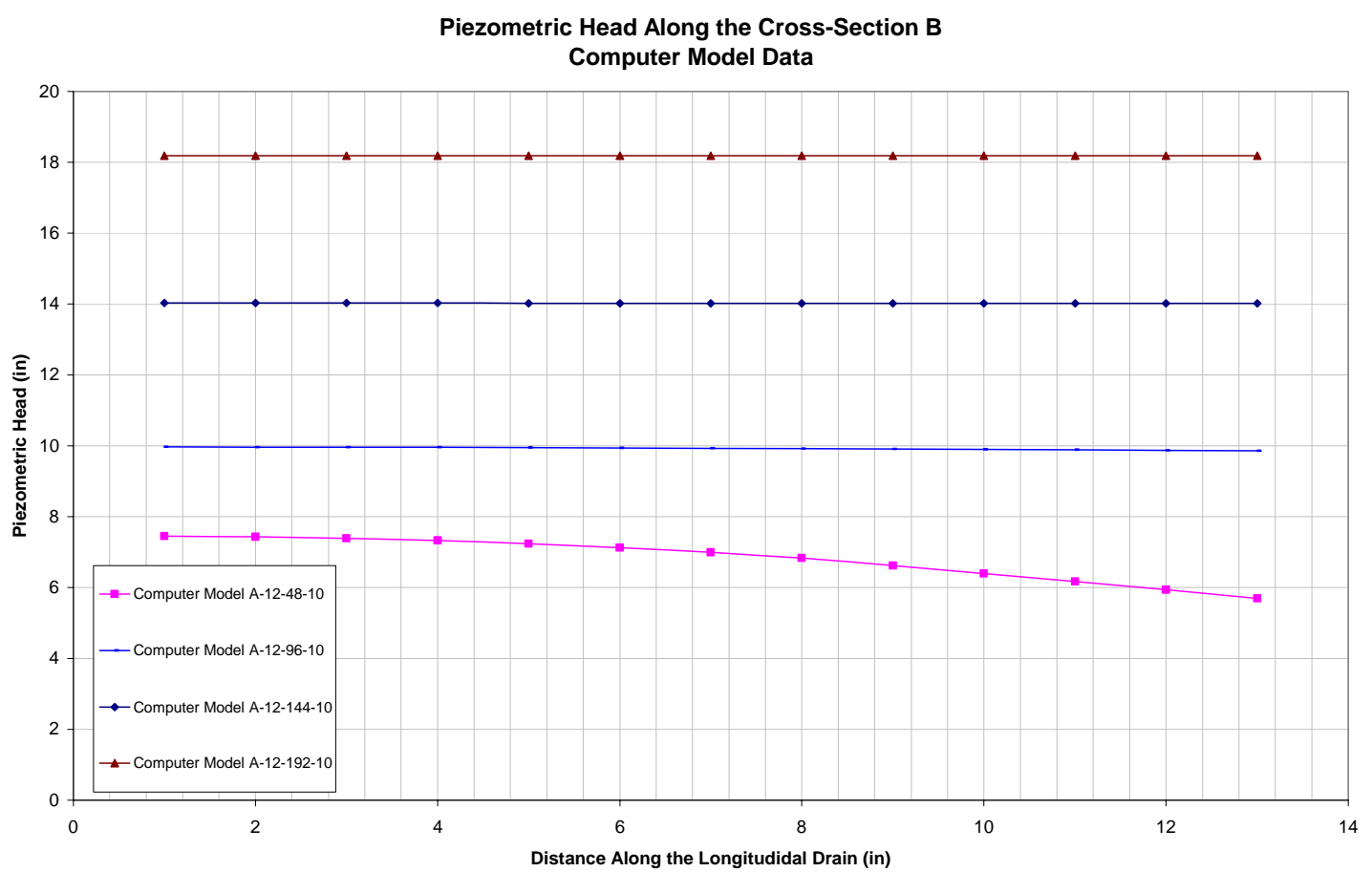

Figure 4.135: Piezometric head along cross-section B for different drain lengths 
Influence of trench spacing on drain effectiveness is shown in Figure 4.136. This figure shows that the drain length up to a value of 96 feet has no influence on the effectiveness of the drain. For drain lengths greater than 96 feet, there appears to be a slight increase in drain effectiveness near the upstream end of the drain. However, this increase is relatively small. In general, the drain length does not have a significant influence on the drain effectiveness under steady state conditions.

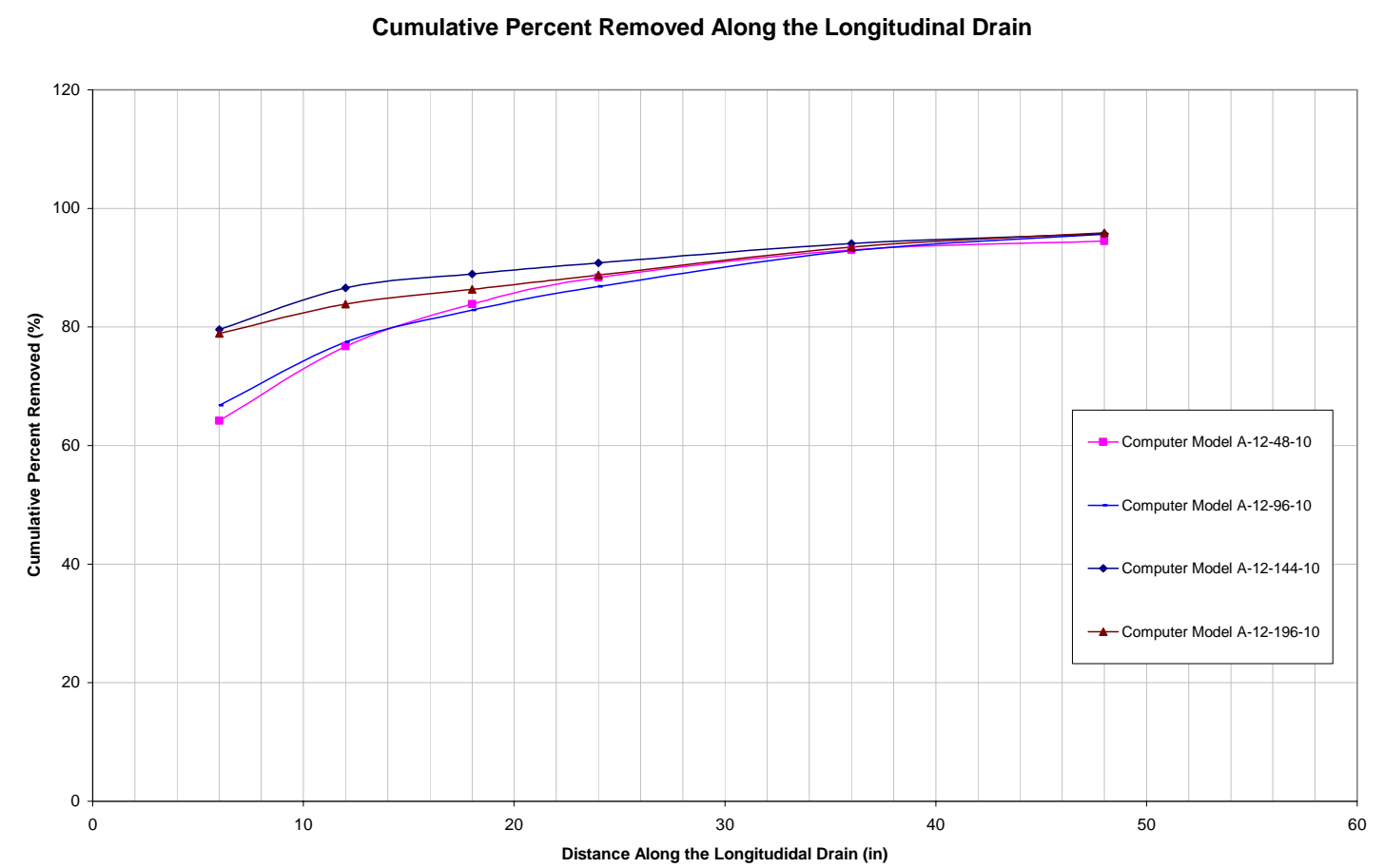

Figure 4.136: Influence of drain length on Cumulative Percent Removal 


\subsubsection{Influence of Drain Inclination}

In this section, a slope consisting of soil type A was considered. The drain length was assumed as forty eight feet and the drain spacing (w) was assumed as twelve feet. Figure 4.137 through Figure 4.139 show the piezometric head along longitudinal and transverse sections for five different inclination angles considered in this study. The vertical distances in the model change when the slope changes. This would cause changes in the piezometric head in the longitudinal direction. Piezometric head varies linearly with distance for slopes steeper than 10 degrees. For shallow slopes $\left(\theta<10^{0}\right)$, the piezometric head varies in a non-linear manner in the longitudinal direction as shown in Figure 4.137. Piezometric head along transverse cross-sections do not seem to be

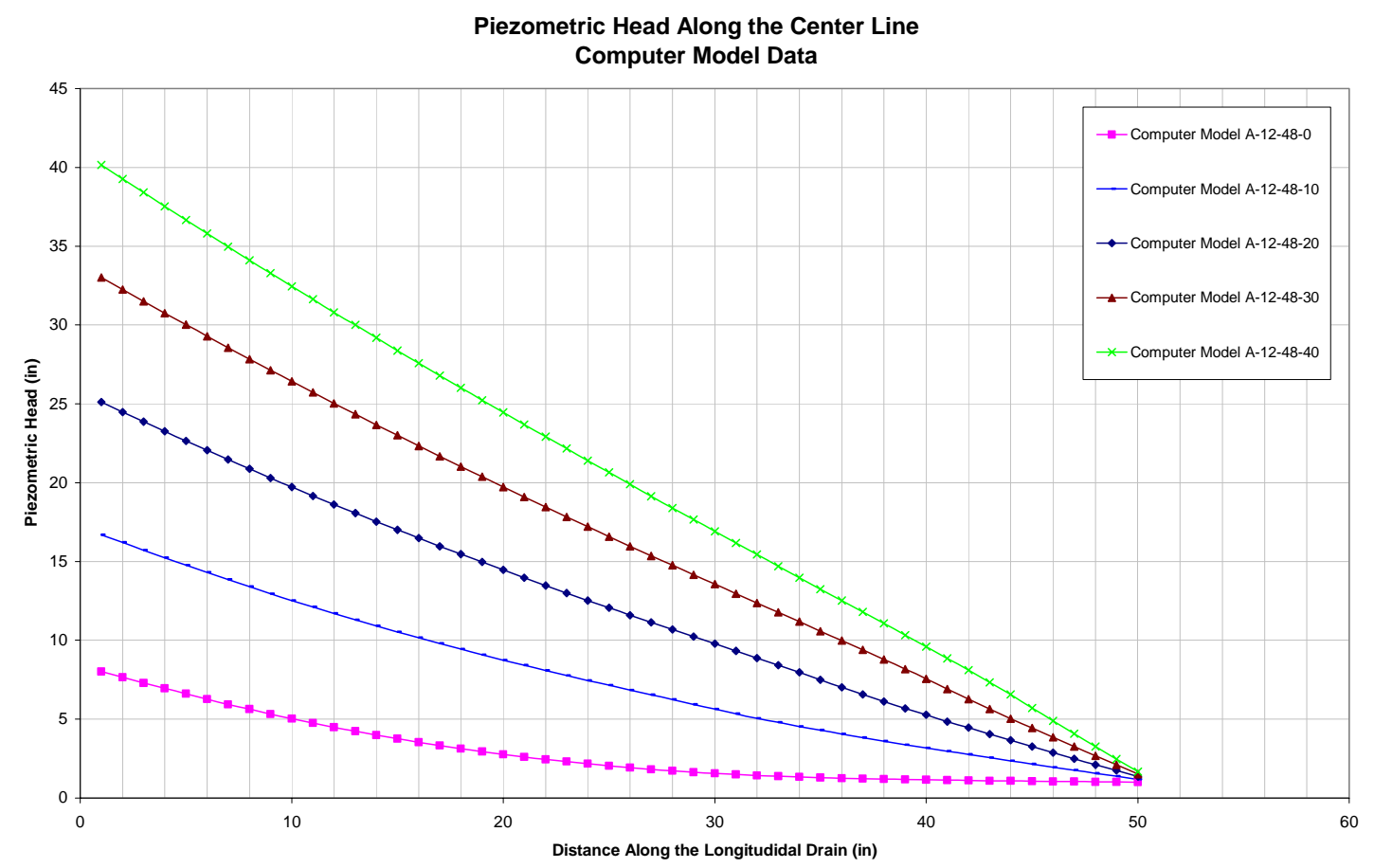

Figure 4.137: Piezometric head along the center line for different slope angles 
affected by the slope angle except for the fact that starting head is different due to changes geometry. For cross-sections A and B, the piezometric curves seem to be parallel. While the piezometric head along the center line follow the slope of the bed downward, the piezometric head at cross-sections A and B follow the bed, which has no inclination.

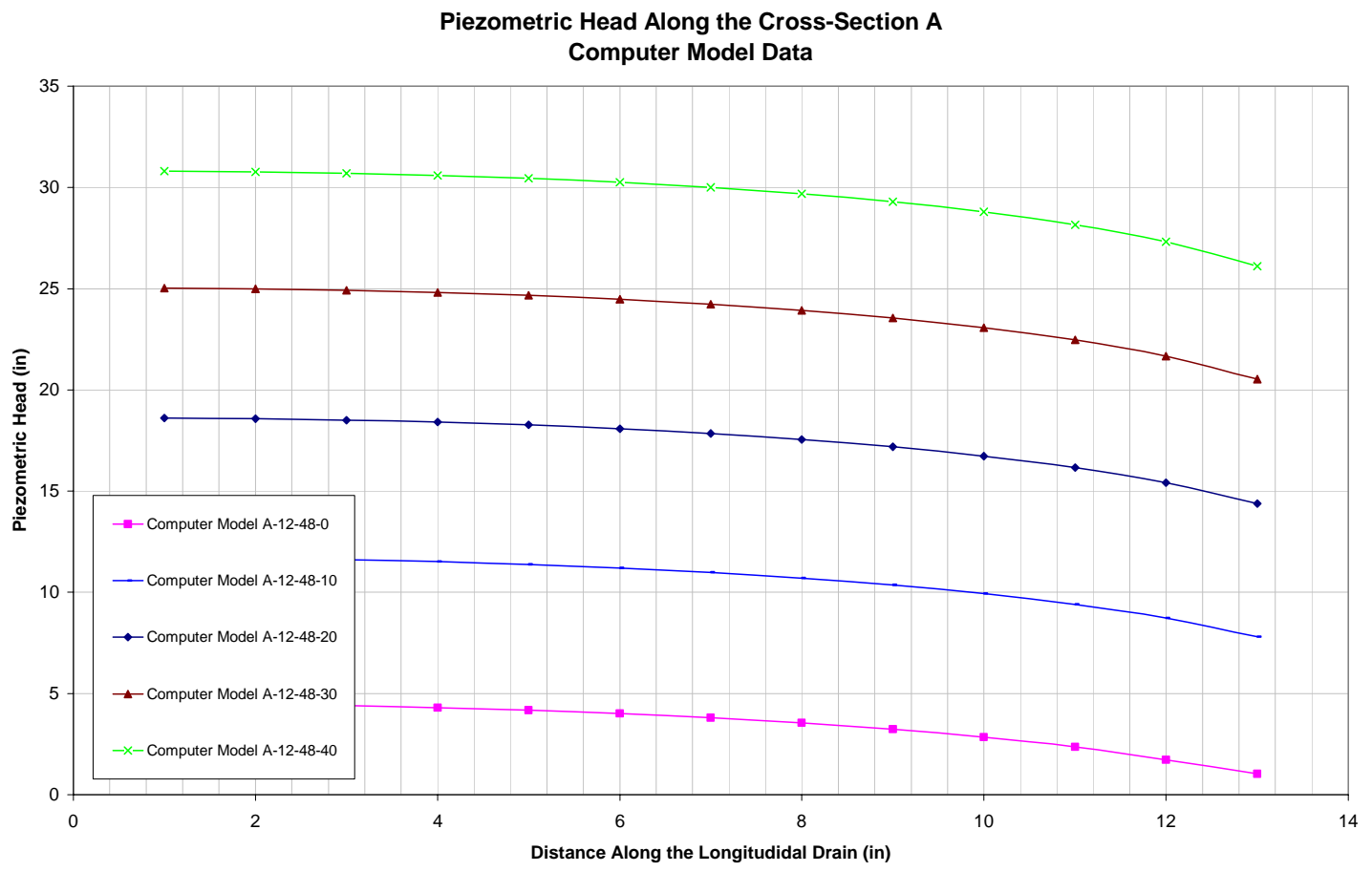

Figure 4.138: Piezometric head along cross-section A for different slope angles 


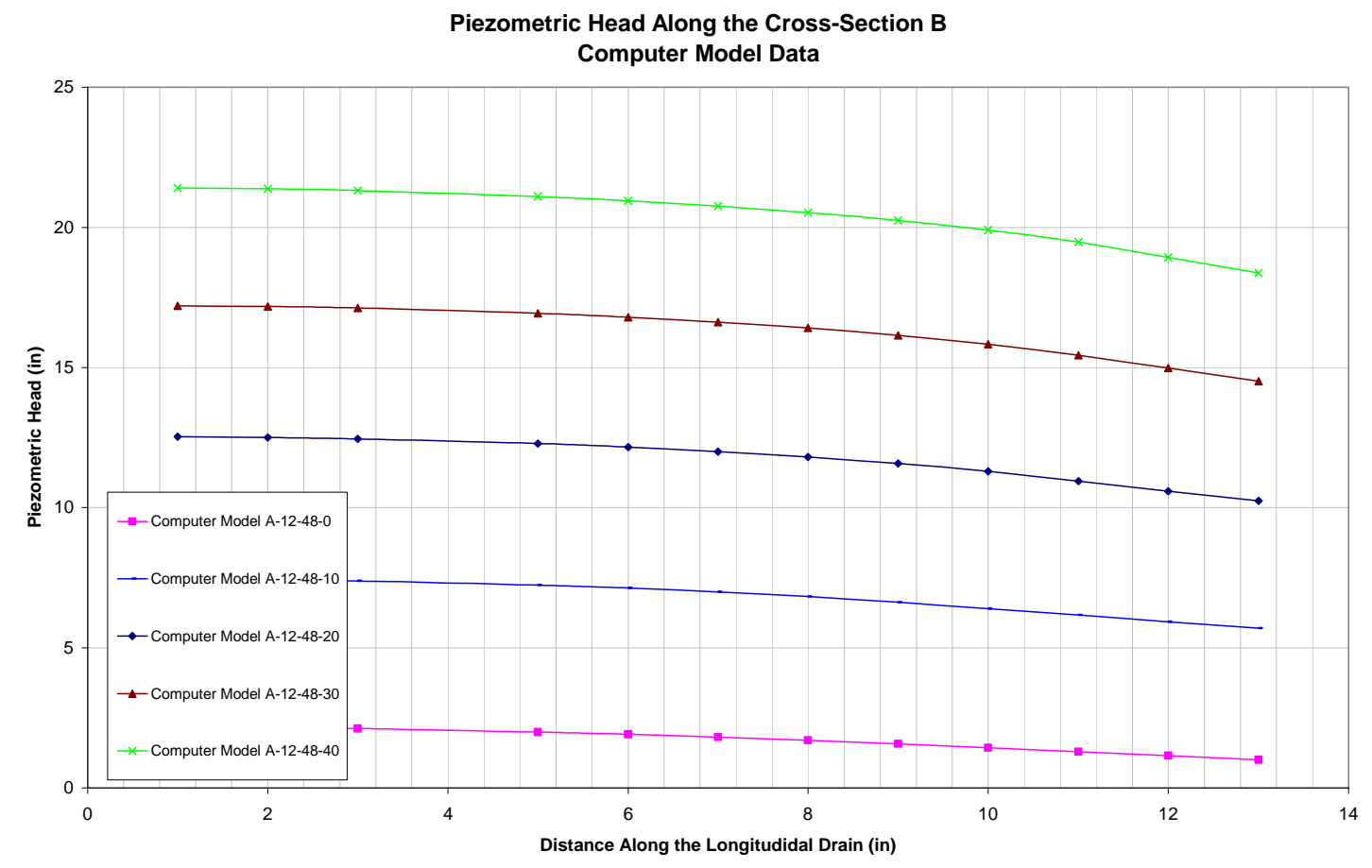

Figure 4.139: Piezometric head along cross-section B for different slope angles

The influence of slope inclination on the drain effectiveness is shown in Figure 4.140. This figure shows that inclination has a negative effect on the drain effectiveness to remove seepage water. The effectiveness of the drains dropped when the slope angle was increased. The effectiveness of the drain was almost $100 \%$ for the horizontal case, while the effectiveness dropped to about $90 \%$ for the steeper case $\left(\theta=40^{0}\right)$. 
Cumulative Percent Removed Along the Longitudinal Drain

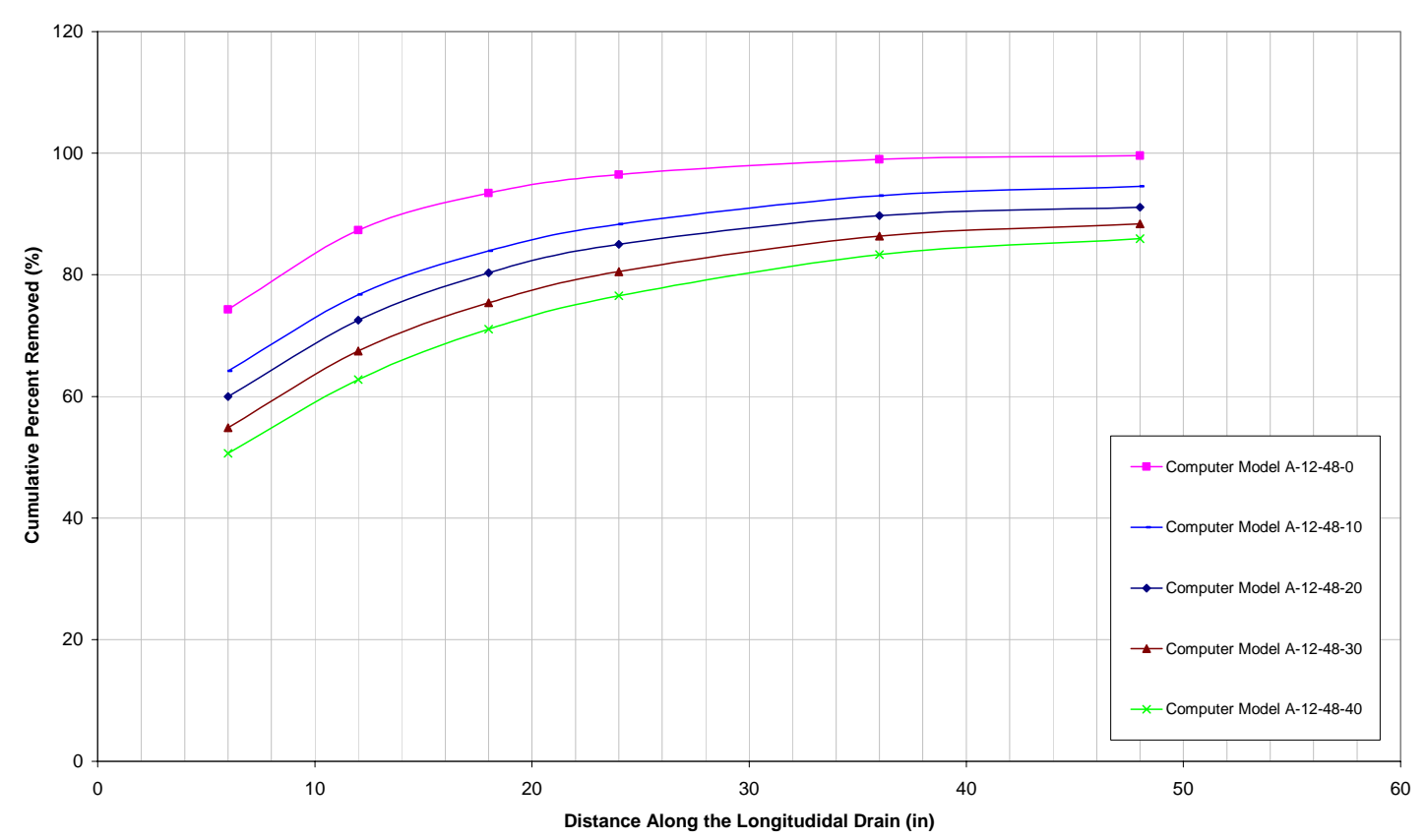

Figure 4.140: Influence of slope angle on Cumulative Percent Removal

\subsubsection{Influence of Soil Type}

Influence of drain length $(\ell)$, spacing $(2 \mathrm{w})$, and slope angle $(\theta)$ were presented in previous sections by considering the soil type A under steady state conditions. In section, the influence of soil type is presented. The influence of soil type on the performance of longitudinal drains was investigated by considering three soil types: soil type A, soil type $\mathrm{C}$ and soil type E. These three soils cover a broad range of hydraulic conductivities to provide sufficient information on the influence the hydraulic conductivity on the behavior of longitudinal drains under field conditions. The length of the drain was assumed as 48 feet, half-spacing as twelve feet, and the slope angle as thirty degrees. 
Figure 4.141 through Figure 4.143 show piezometric head along the longitudinal and transverse cross-sections sections for soils A, C and E. The hydraulic conductivity does not seem to affect the steady state piezometric heads. It can be seen that the piezometric head along the center line for the three different soil types overlap as can be seen in Figure 4.141. This means that the piezometric head under steady state conditions remain the same regardless of the hydraulic conductivity. A similar observation can be made on the piezometric head along both cross-sections A and B.

The influence of soil type on the drain effectiveness under steady state conditions is shown in Figure 1.144. The drains become less effective as the hydraulic conductivity decreases. 


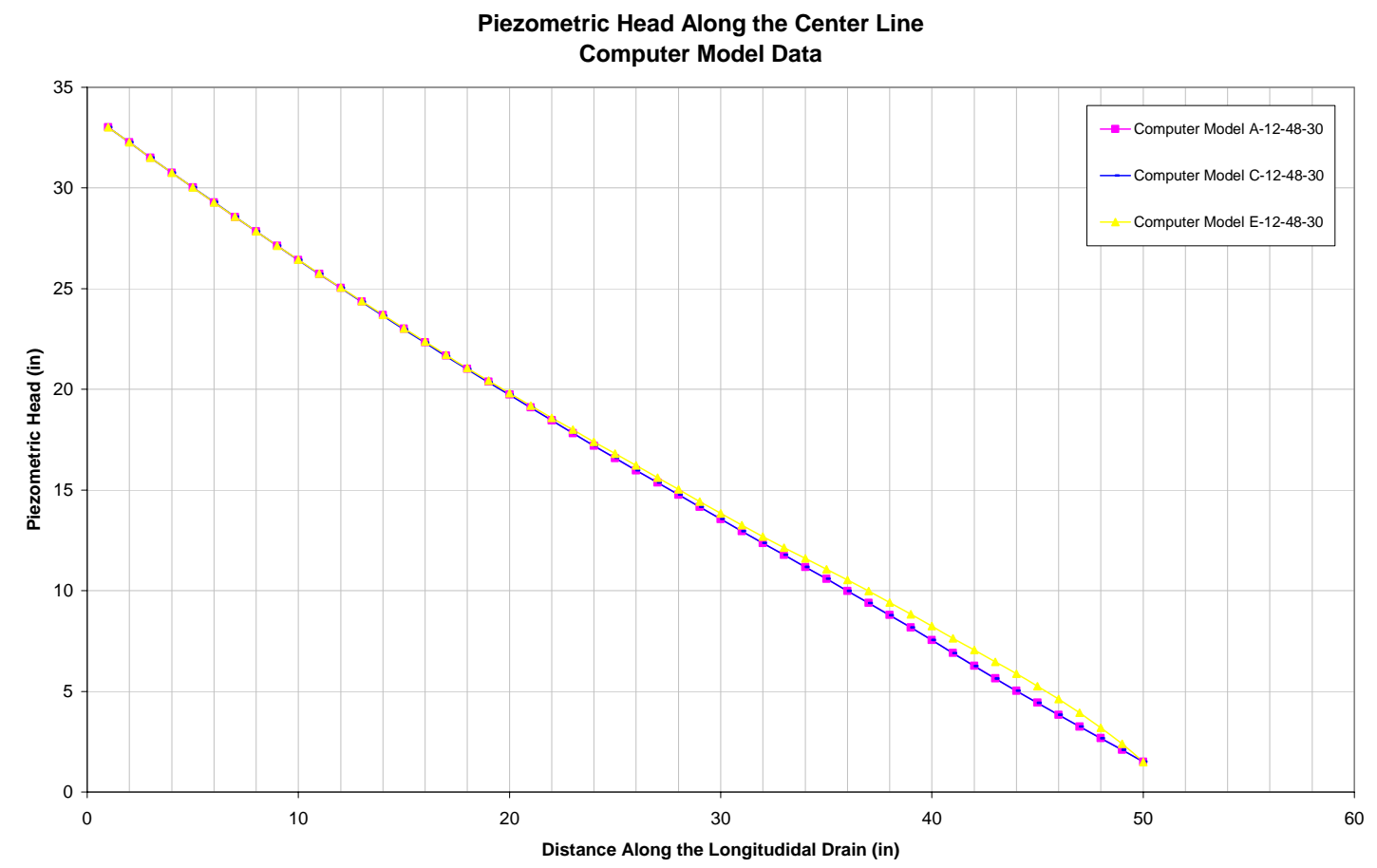

Figure 4.141: Piezometric head along the center line for different soil types

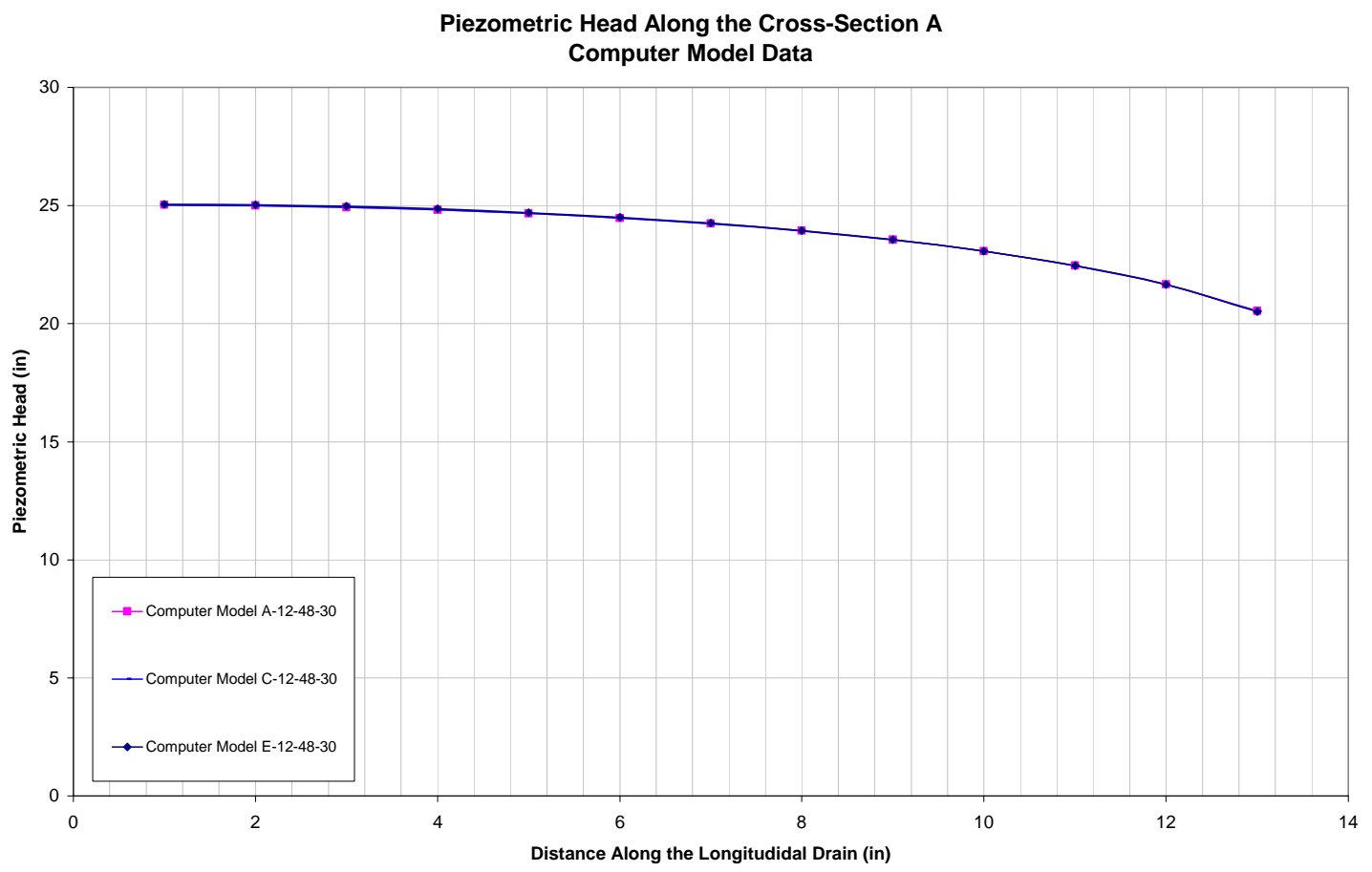

Figure 4.142: Piezometric head along cross-section A for different soil types 


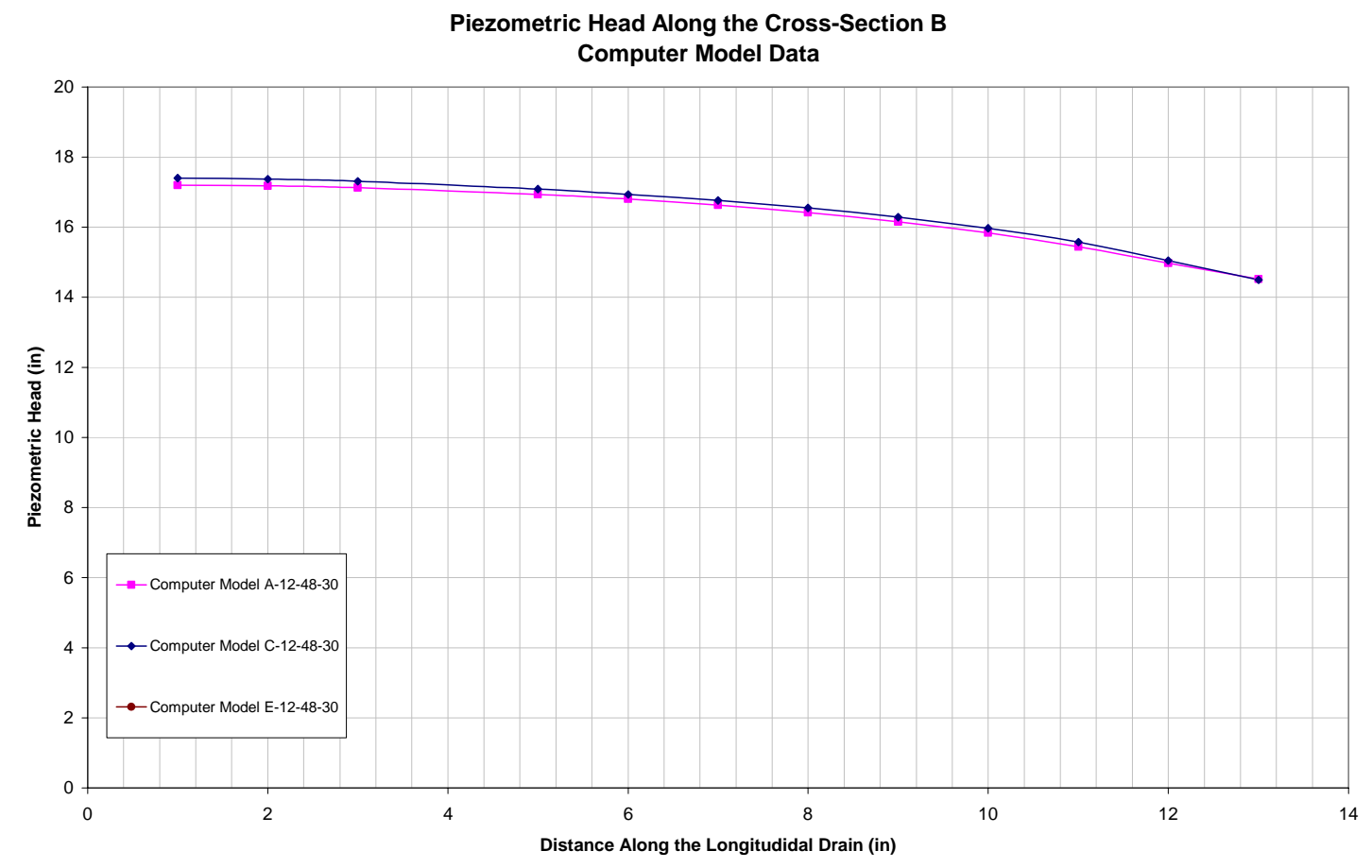

Figure 4.143: Piezometric head along cross-section B for different soil types

Cumulative Percent Removed Along the Longitudinal Drain

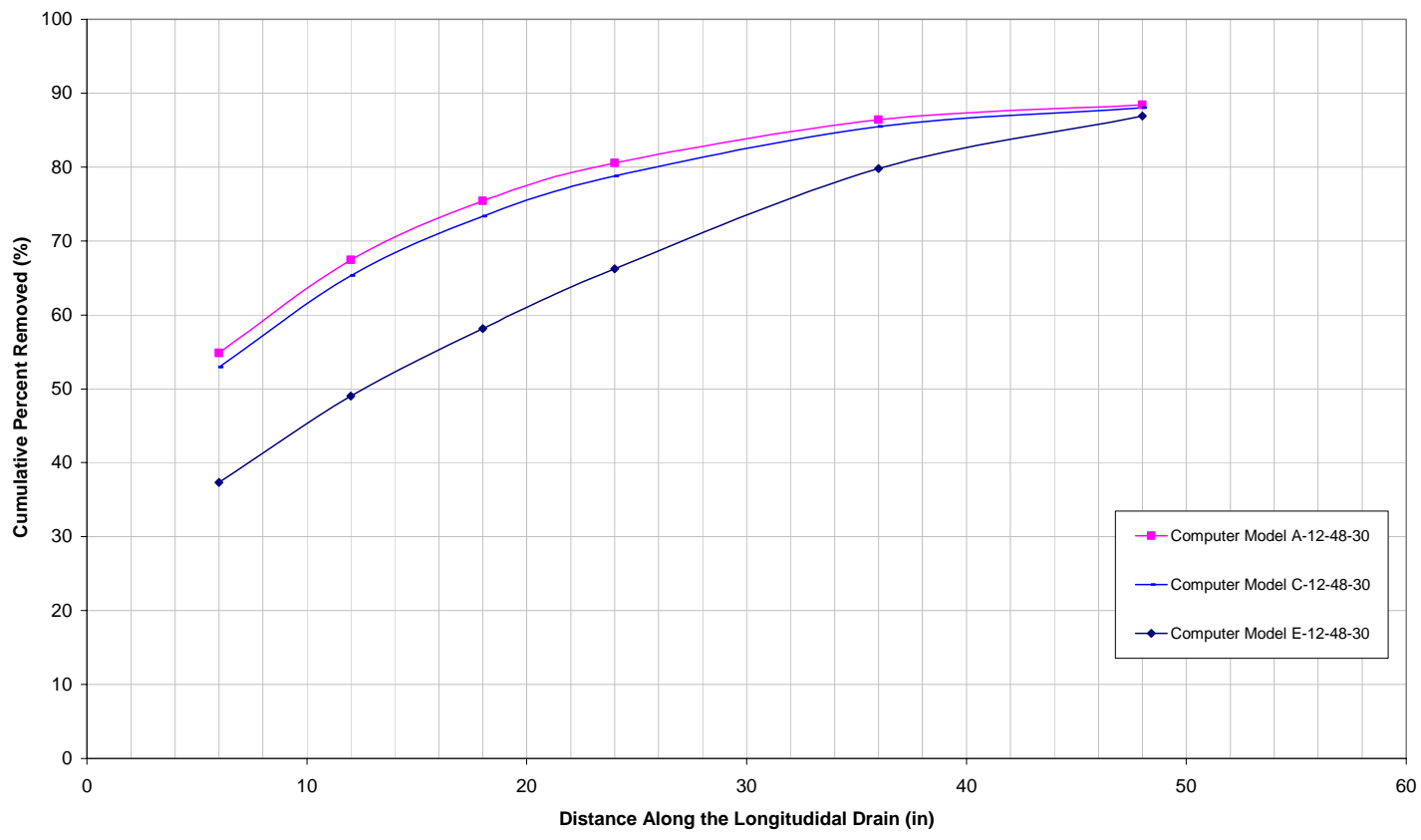

Figure 4.144: Influence of soil type on Cumulative Percent Removal 


\section{CHAPTER 5: SUMMARY AND CONCLUSSIONS}

\subsection{Summary}

Longitudinal drains appear to be a non-expensive way to decrease landslide problems by reducing the seepage forces. Longitudinal drains are drains placed parallel to the slope itself. However, very little information is available on the performance of longitudinal drains. The primary objective of this research was to compare the experimental results with the computer modeling results for the performance of longitudinal drains. Both experimental and computer models have the same dimensions and boundary conditions. The computer model was calibrated by comparing the experimental data with numerical results. The center-to-center spacing between two longitudinal drains is called the drain spacing. Because of symmetry, only half the trench geometry needs to be investigated in experimental or computer modeling studies. Certain material properties of the soil can be back-calculated from this comparison. The second objective of this study was to use the computer modeling technique to predict the performance of longitudinal drains under field conditions. Larger physical dimensions were used to simulated field conditions.

To better evaluate the performance of longitudinal drains it is important to first understand the influence of main factors such as hydraulic conductivity $(\boldsymbol{k})$, drain spacing $(2 \mathrm{w})$, drain length $(\ell)$ and slope angle $(\theta)$ on the performance of longitudinal drains. The longitudinal drains deflect the flow of water, reducing the seepage forces inside the soil.

Experimental data on the performance of longitudinal drains were collected using a laboratory model for five soil types. The length of the soil sample was kept constant at 
48 inches. Both the drain spacing and slope inclination were varied. The laboratory experiments were simulated by using a numerical model. The computer program used for the modeling part of this research is called GMS, which stands for Groundwater Modeling System (GMS, 2002). GMS is a sophisticated and comprehensive groundwater modeling software package. GMS is based on the finite difference method.

Experimental and computer modeling results on the performance of longitudinal drains were presented in this report. Drain performance under steady state and transient conditions was investigated. The computer model was calibrated by comparing numerical predictions with laboratory observations. The model was then used to study the performance of longitudinal drains under field conditions by using larger dimensions. The effectiveness of the drain is defined as the cumulative percentage of seepage water removed along the length of the drain. Transient time is the time for the drains to become fully functional. In field installations, the transient time can be a critical issue. Hence, it is important to know in advance the time required for longitudinal drains to become fully functional and their behavior during the transient period. The influence of soil permeability, drain spacing, drain length, and slope angle on the transient time and drain effectiveness was investigated. Transient behavior was investigated by considering both piezometric data and the percentage seepage removal. 


\subsection{Conclusions}

The majority of the fluctuations in flow recede after the first half-hour in the experimental set-up. Piezometric fluctuations continue for about three days after the flow seems to stabilize. It was shown that the Drain D1 is affected very little by the proximity of the main water tank. Results show that the longitudinal drains can effectively reduce seepage flow in soils. The differences observed between the physical and the computational models are considered as insignificant. The computer model (GMS) is an appropriate tool that can be applied to the study of longitudinal drains. Like any computational model, GMS needs to be calibrated by using experimental data.

Experimental results show that longitudinal drains could reduce the seepage by as much as ninety percent. The longitudinal drain becomes fully functional within two-days under laboratory conditions. The transient time appears to be very small. In view of the limited data collected at the beginning of the transient condition, part of the transient condition may have been missed in the experiments.

The drain spacing (2w) plays a major role in the piezometric head variation along the center line. As the trench spacing increases the variation of piezometric head from one time period to the next becomes less noticeable. Smaller trench spacing is better than the larger ones in reducing the piezometric head. Just as it happened with the piezometric head along the center line, the variation of head along cross-sections A and B shows a similar influence. Also, the effectiveness of the drains in removing the total amount of seepage flowing through the sample decreases as the drain spacing increases.

The length of the slope does not seem to have any major effect in the total transient time. The modeling results showed that the time it took for the soil to reach 
steady state conditions is about the same for all cases of length investigated. Length has no direct effect on the transient behavior of the piezometric level at cross-sections A and B. The time required for the efficiency of the drain to stop fluctuating is affected by the length. The length of the drain does affect the efficiency of the drain, but it has no major effect on piezometric level.

The slope angle has an influence on the variation of the piezometric level over time. As the slope becomes steeper, the drop in piezometric level with time is less noticeable. For the horizontal case, a drop in the piezometric level can be easily seen over time. While for a slope of forty degrees the drop in piezometric head over time is very small. The transient time is affected by inclination. In terms of drain efficiency, the transient time seems to increase with the decrease in slope angle (Figure 4.115). For all cases shown so far, it appears that the majority of the changes occurred within a period of two days under laboratory conditions. Another observation is that for the horizontal case, the piezometric level stopped dropping after a period of half a day, while for the steeper case with a slope of forty degrees, it took more than one day to stop changing.

Soil type affects the transient behavior of the piezometric heads along the center line. The transient time is inversely proportional to the hydraulic conductivity. As the hydraulic conductivity of soils decreases, the transient time increases. Similar behavior was seen along the cross-sections A and B. The soil type has two major effects: transient time and drain effectiveness. As the hydraulic conductivity of a soil decreases the transient time increases and the effectiveness decreases. 
The hydraulic conductivity does not seem to affect the steady state piezometric heads. The same phenomenon is noted on both cross-sections A and B. The effectiveness of the drain increases as the hydraulic conductivity increases.

\subsection{Recommendations}

In future studies, more statistical analysis should be performed using the data collected from this study. Tests should be performed in which only the first two drains along the slope are activated. Result from such a study should be compared to the ones obtained in this research to see whether shorted drain length can accomplish the objective of seepage removal. The cost of longitudinal drains would be lower, if the drain length can be reduced. Computer modeling study should be continued by using different layer properties (i.e., multi-layer system). 


\section{REFERENCES}

1. Ahmed Said A., Nachabe M., Ross M., and Vomacka J. "Methodology for Estimating Specific Yield in Shallow Water Environment Using Continuous Soil Moisture Data" ASCE pp. 1-13 (10.1061/40737(2004)218).

2. Cedergren, Harry R. (1977) "Seepage, Drainage, and Flow Nets." Wiley, New York..

3. Das, B.M. (1985) "Foundation Engineering." PWS Publishing Company, fourth edition, Boston.

4. $\quad$ Das, B.M. (1985) "Principles of Geotechnical Engineering." PWS Publishing Company, fourth edition, Boston.

5. Freeze, A. R. and Cherry, J. A. (1979) "Groundwater," Prentice Hall, Inc., Englewood Cliffs, NJ.

6. GMS (2002) Groundwater Modeling Systems, Reference Manual for version 4.0, Environmental Modeling Systems, Inc., Utah.

7. Kakarla, K. (2004) "Numerical Analysis of Seepage in Earth Slopes." M.S.Thesis, Department of Civil and Environmental Engineering, West Virginia University.

8. Kiriakidis, R., (2002) "Seepage in earth slopes with longitudinal drainage trenches". M.S.Thesis, Department of Civil and Environmental Engineering, West Virginia University.

9. McCarthy D., (2002) "Essentials of Soil Mechanics and Foundations." Prentice Hall, sixth edition, New Jersey.

10. McDonald, Michael G., and Arlen W. Harbaugh "A Modular three-dimensional finite-difference Ground-water flow Model”, Open-File Report 83-875, book 6, U. S. Geological Survey, 1988.

11. Stanic, B. (1984) "Influence of Drainage Trenches on Slope Stability." Journal of Geotechnical Engineering, ASCE, Vol 110(11), 1624-1636.

12. Staud, B.T. (2000) "Seepage through longitudinal drainage trenches." M.S. Thesis, Department of Civil and Environmental Engineering, West Virginia University. 


\section{APPENDIX}


Appendix A1: Soil Calibration Results 


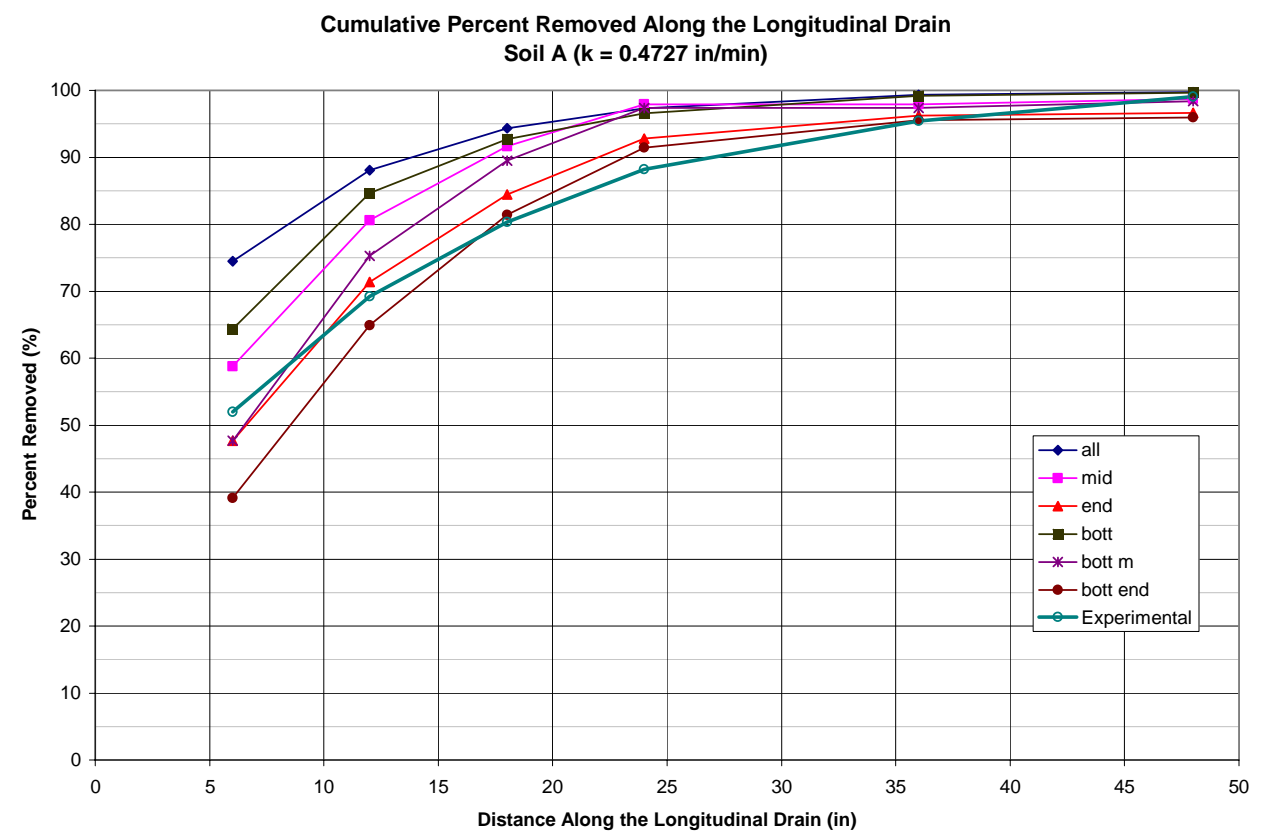

Figure A1.1: Cumulative percent removed along the drain for all drain set-ups (Soil A)

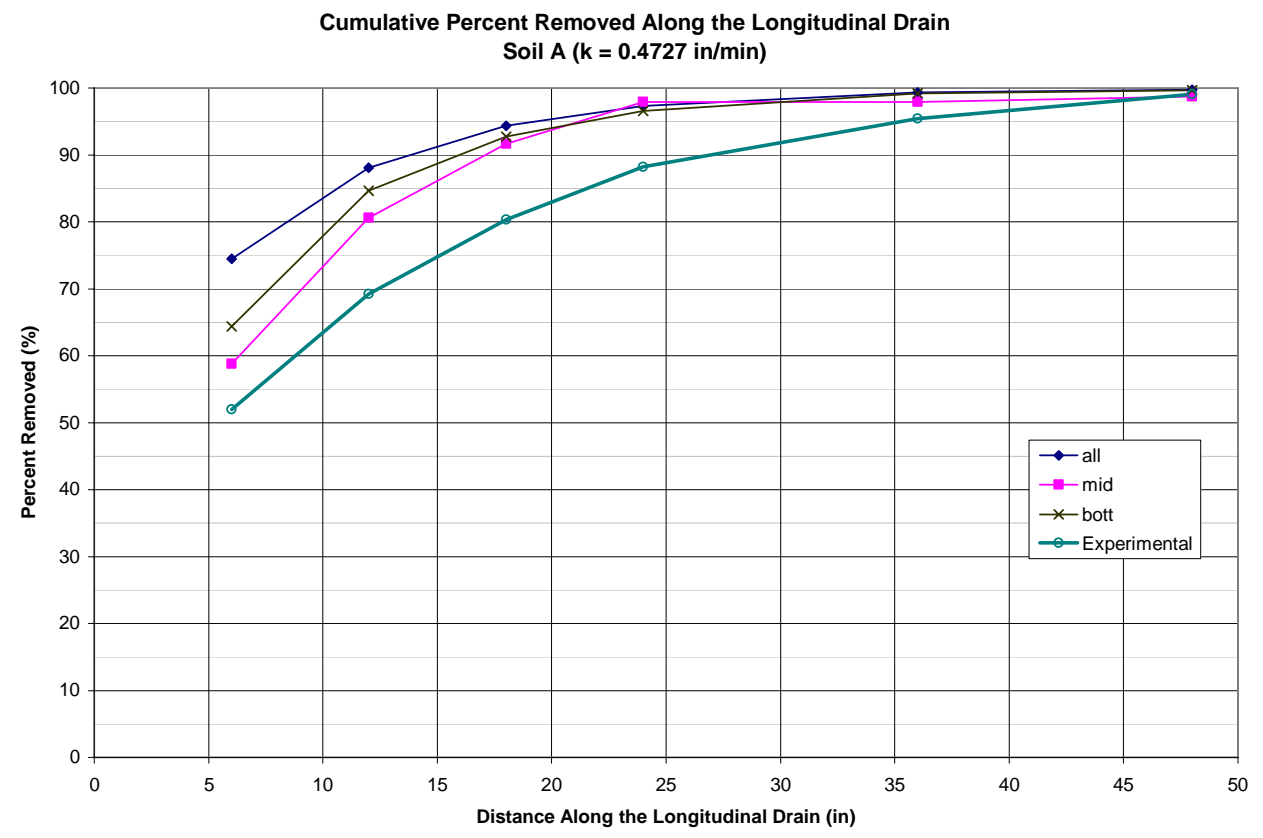

Figure A1.2: Cumulative percent removed along the drain for the three main drain set-ups (Soil A) 


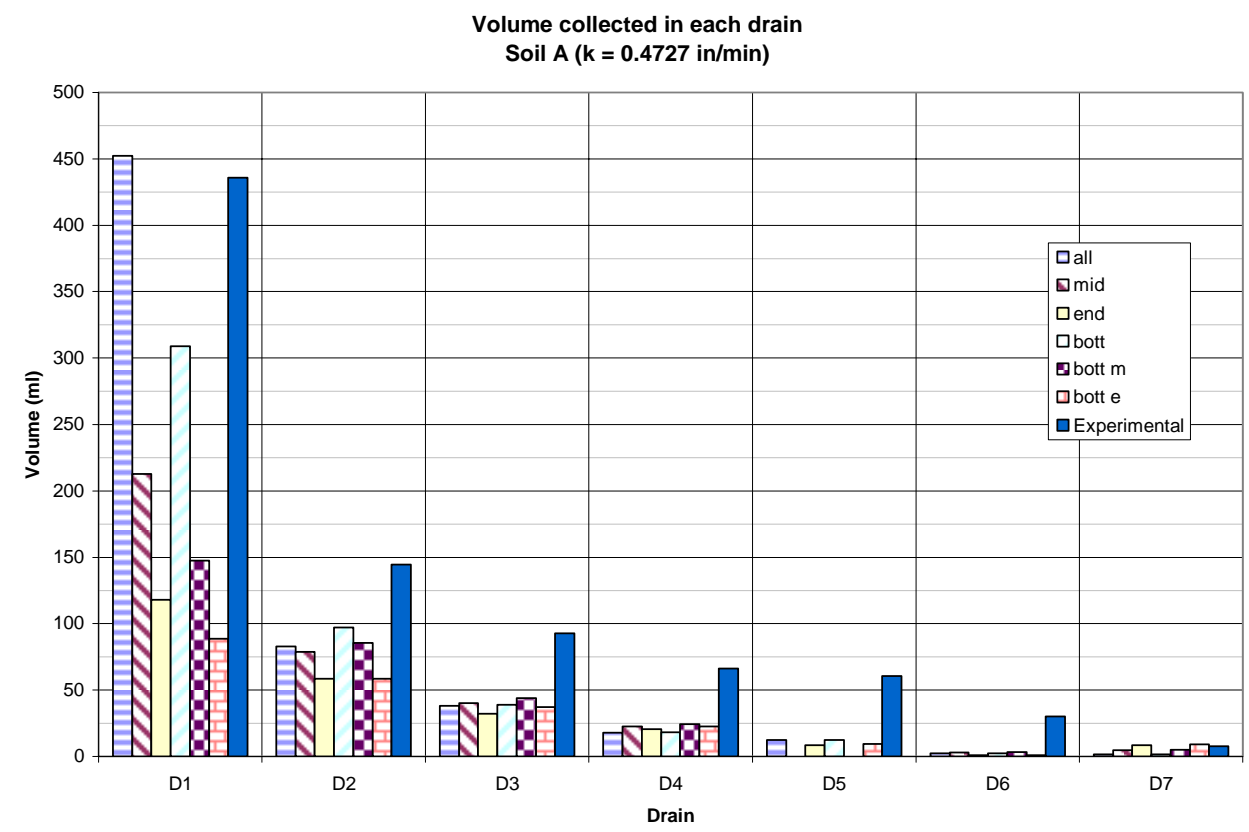

Figure A1.3: Volume removed at each drain for all drain set-ups (Soil A)

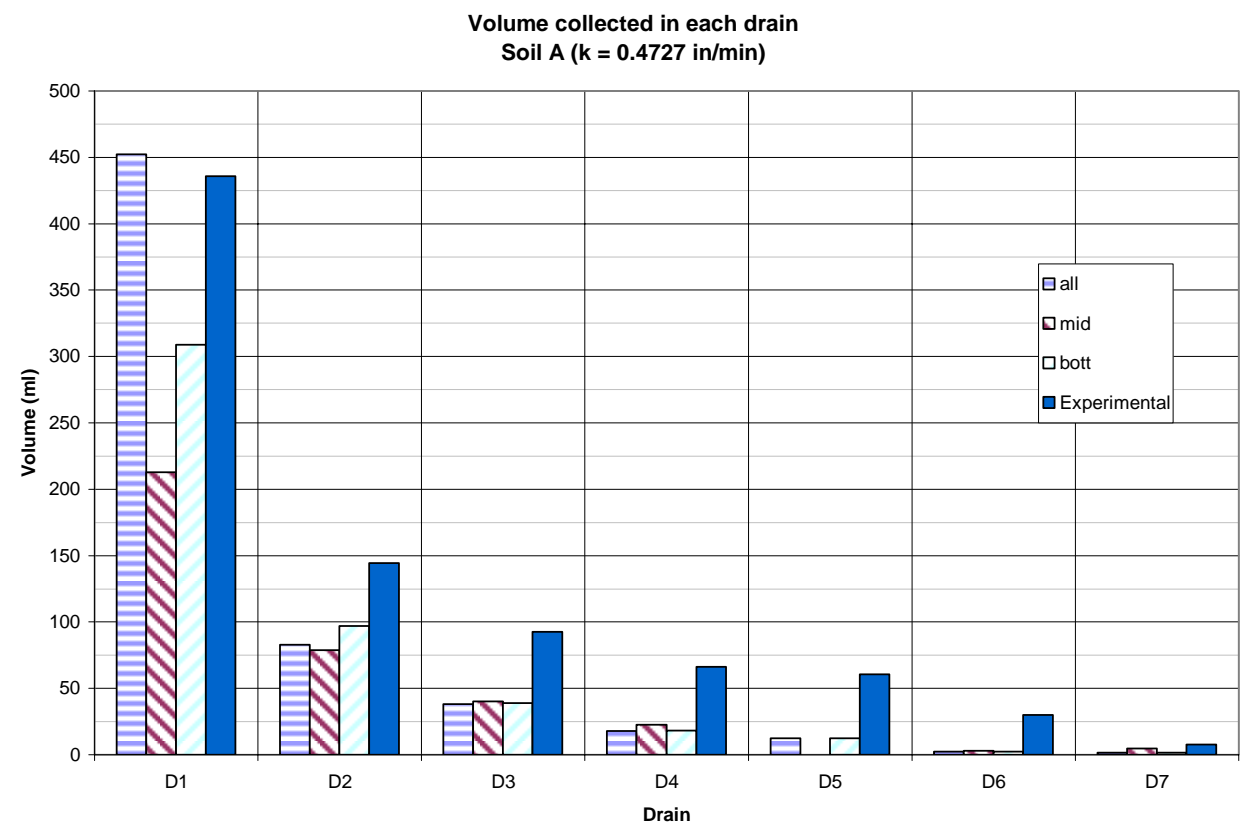

Figure A1.4: Volume removed in each drain for the three main drain set-ups (Soil A) 


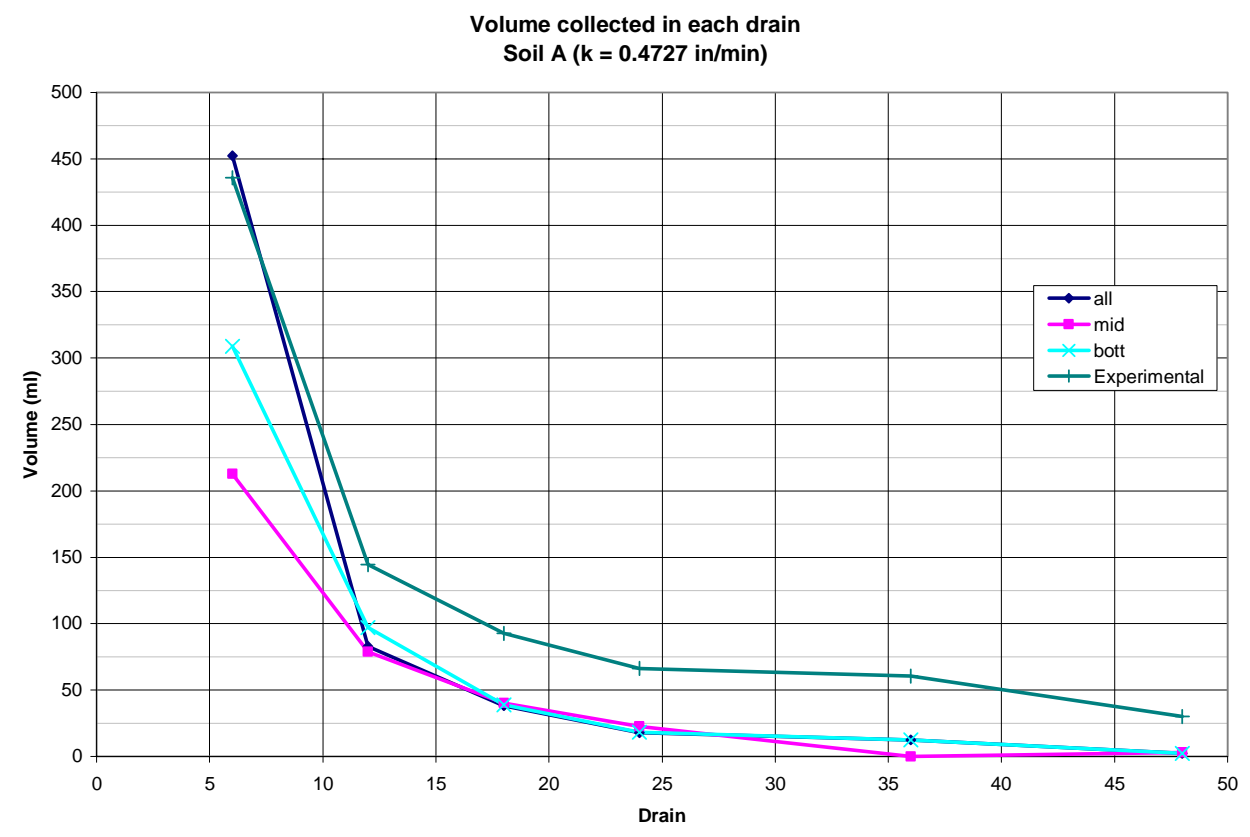

Figure A1.5: Volume removed along the drain for the three main drain set-ups (Soil A)

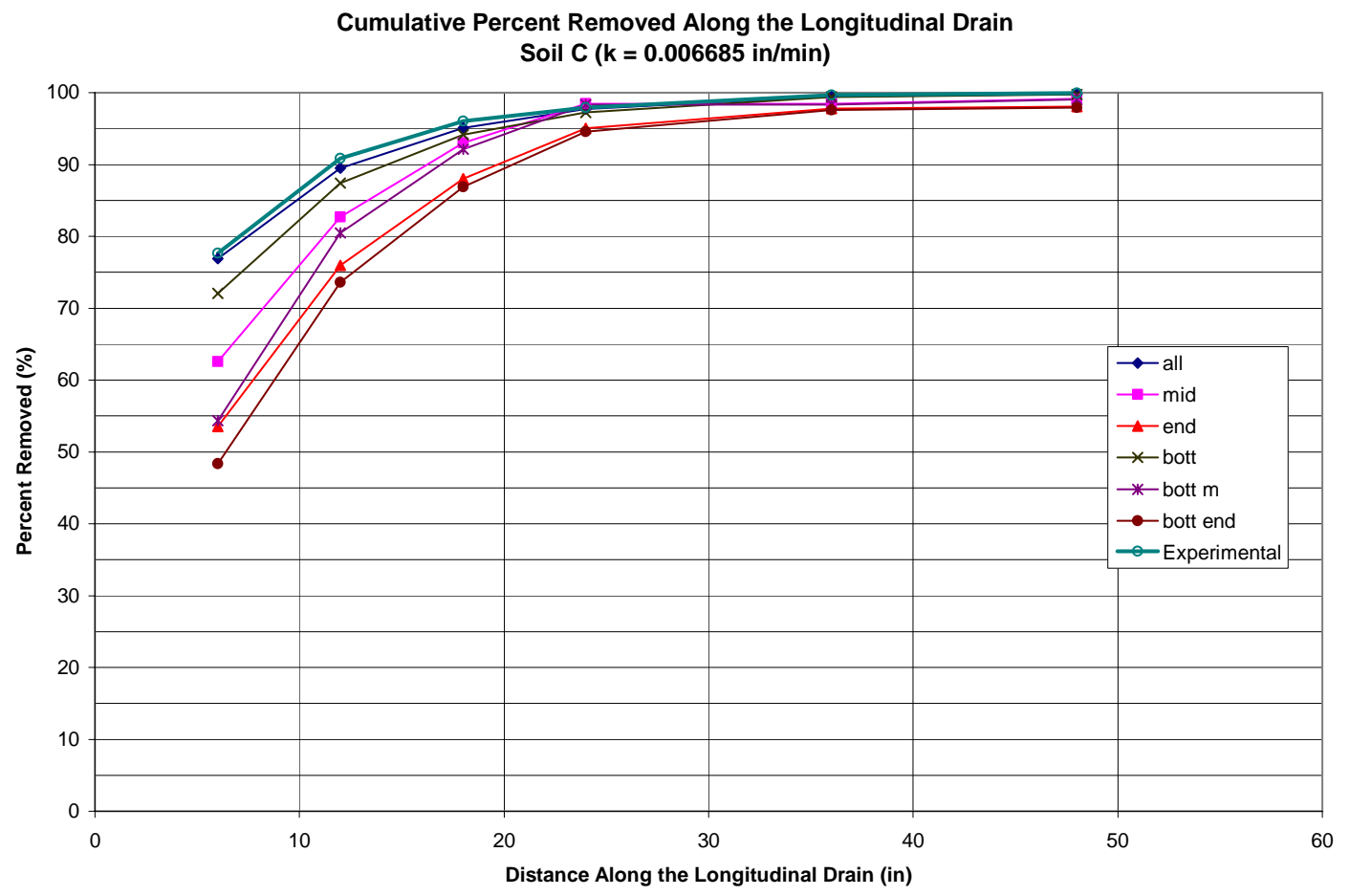

Figure A1.6: Cumulative percent removed along the drain for all drain set-ups (Soil C) 


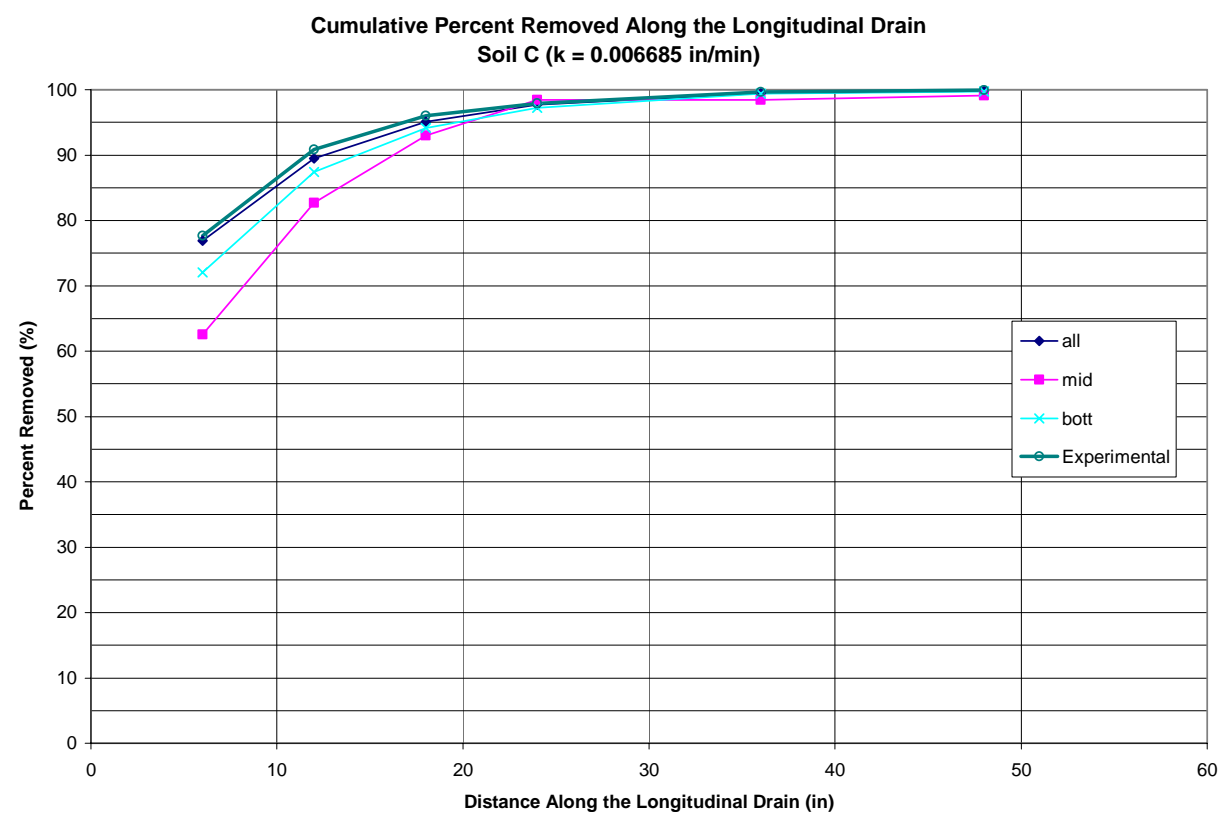

Figure A1.7: Cumulative percent removed along the drain for the three main drain set-ups (Soil C)

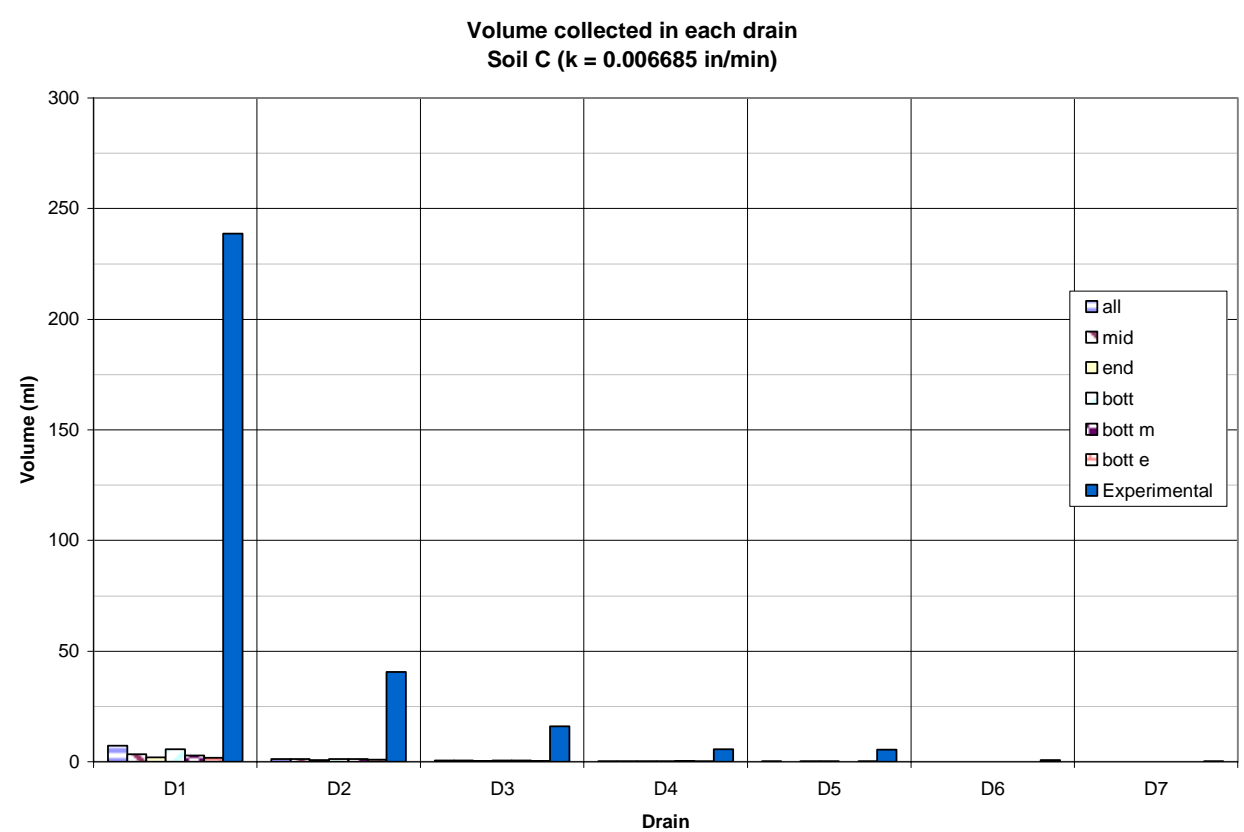

Figure A1.8: Volume removed at each drain for all drain set-ups (Soil C) 


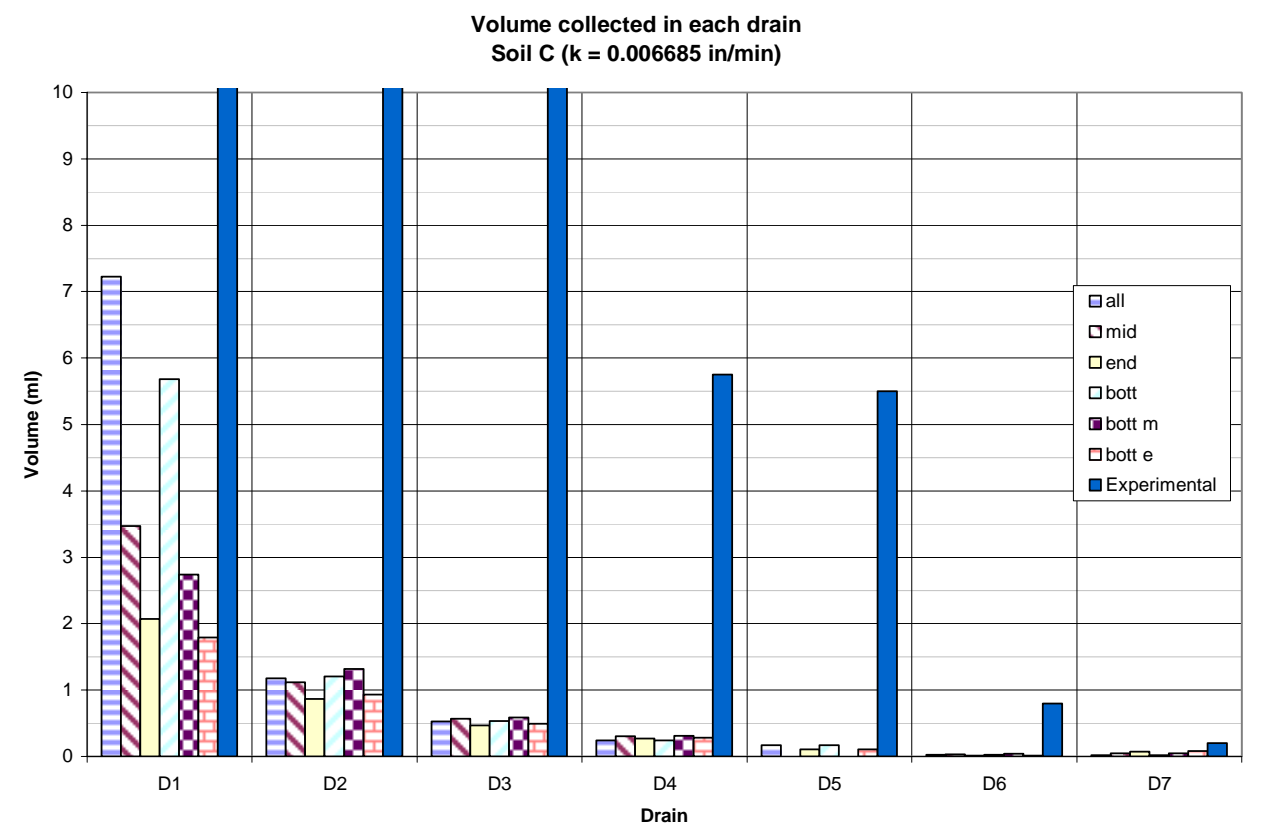

Figure A1.9: Close-up of volume removed at each drain for all drain set-ups (Soil C)

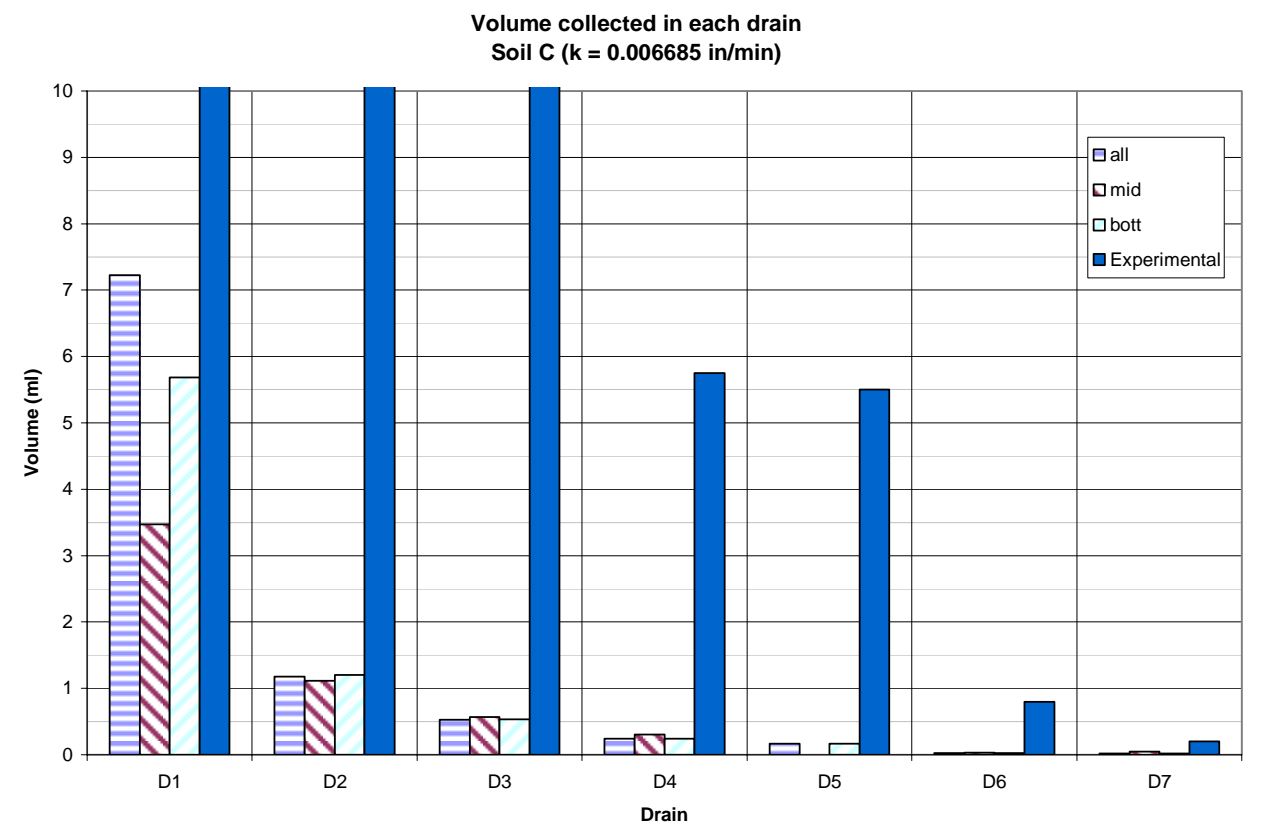

Figure A1.10: Close-up of volume removed in each drain for the three main drain set-ups (Soil C) 


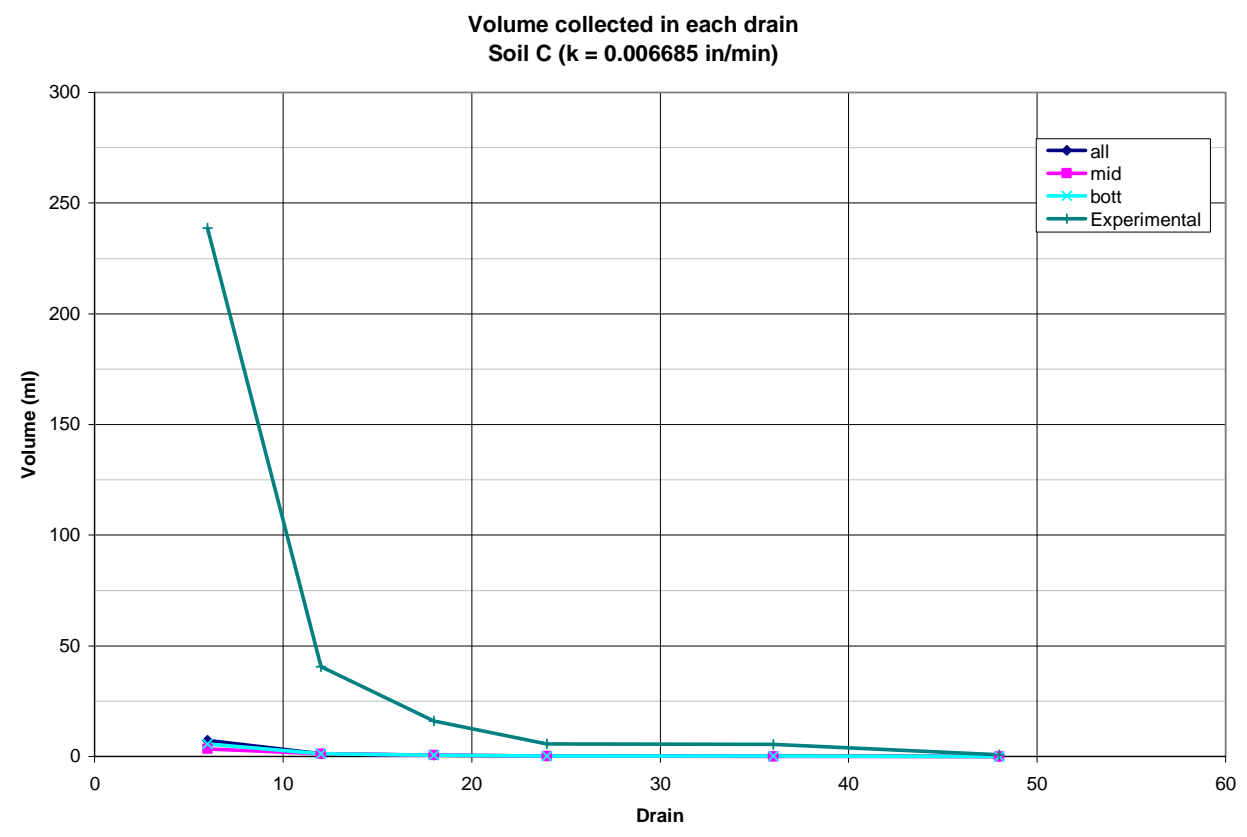

Figure A1.11: Volume removed along the drain for the three main drain set-ups (Soil C)

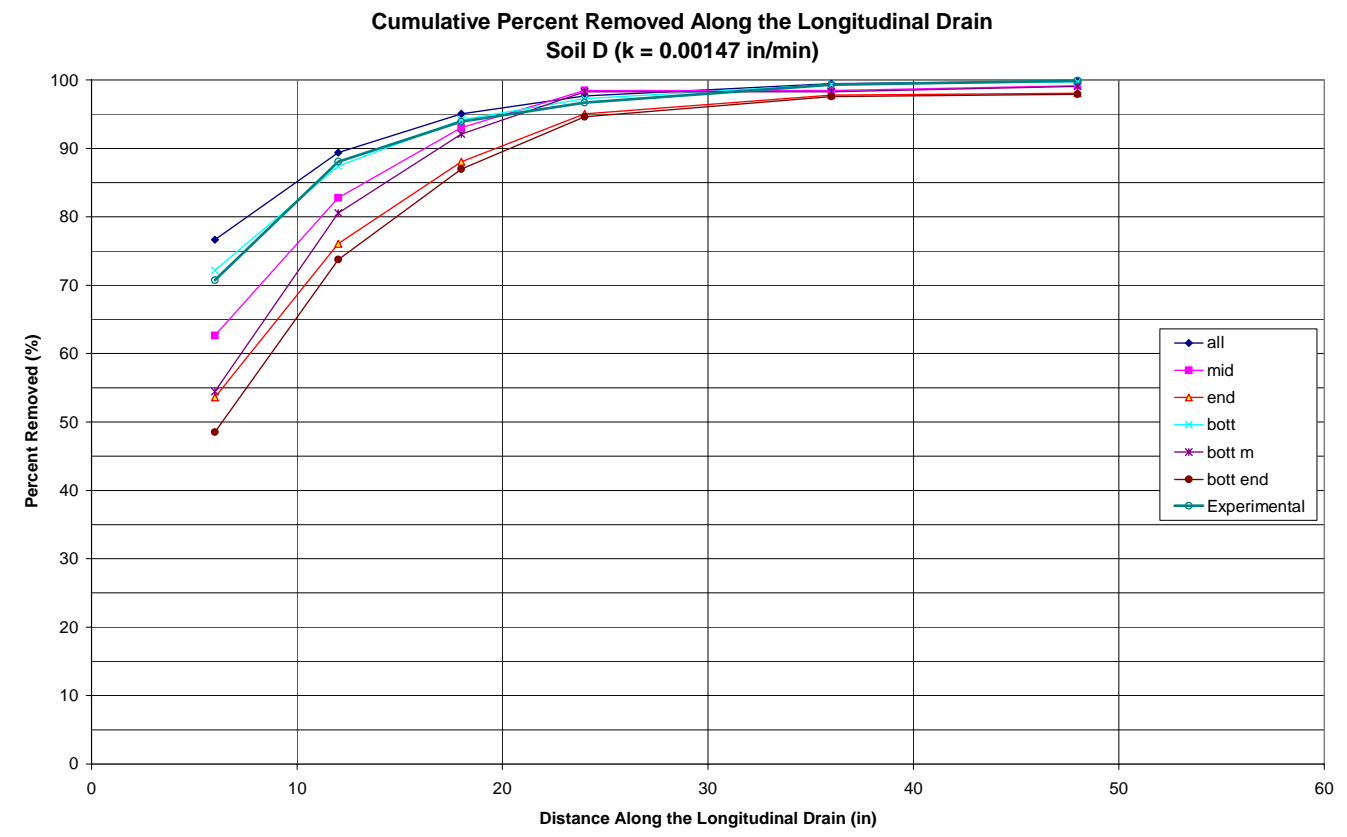

Figure A1.12: Cumulative percent removed along the drain for all drain set-ups (Soil D) 


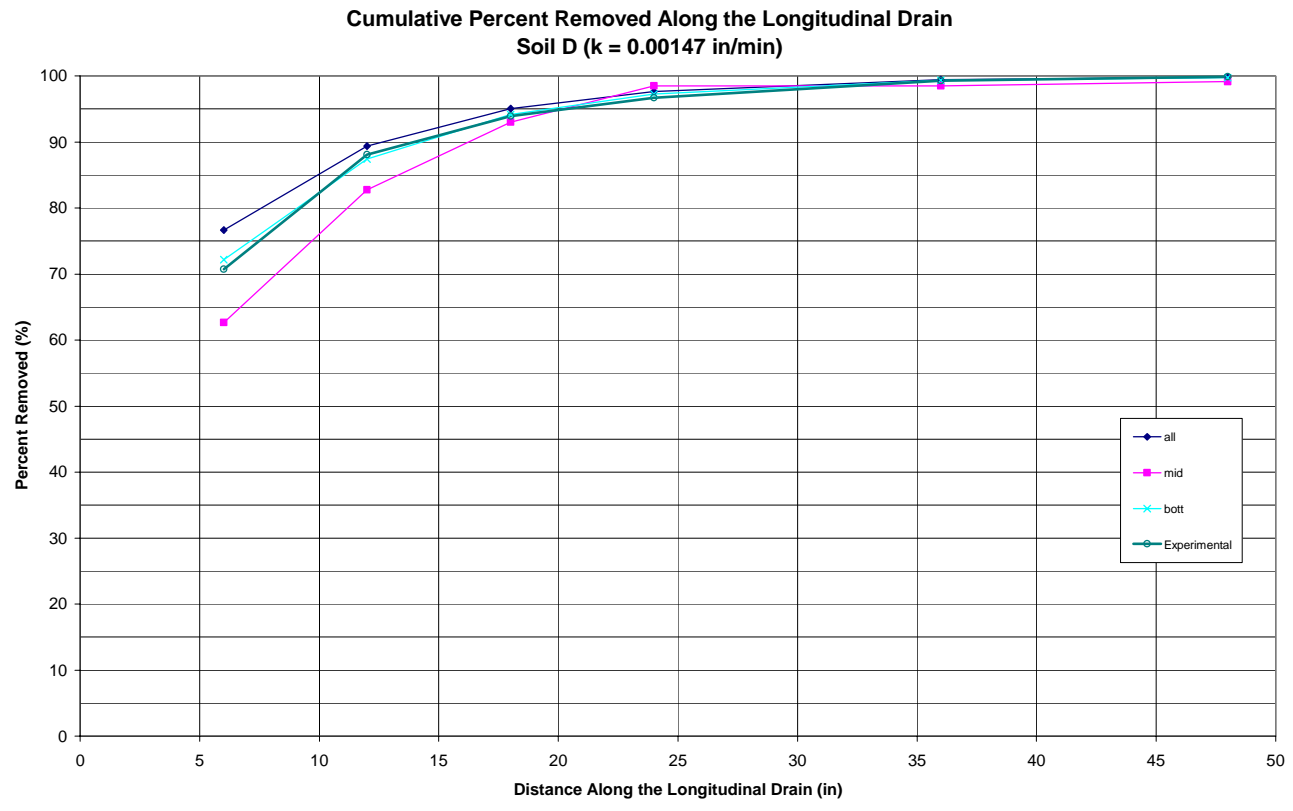

Figure A1.13: Cumulative percent removed along the drain for the three main drain setups (Soil D)

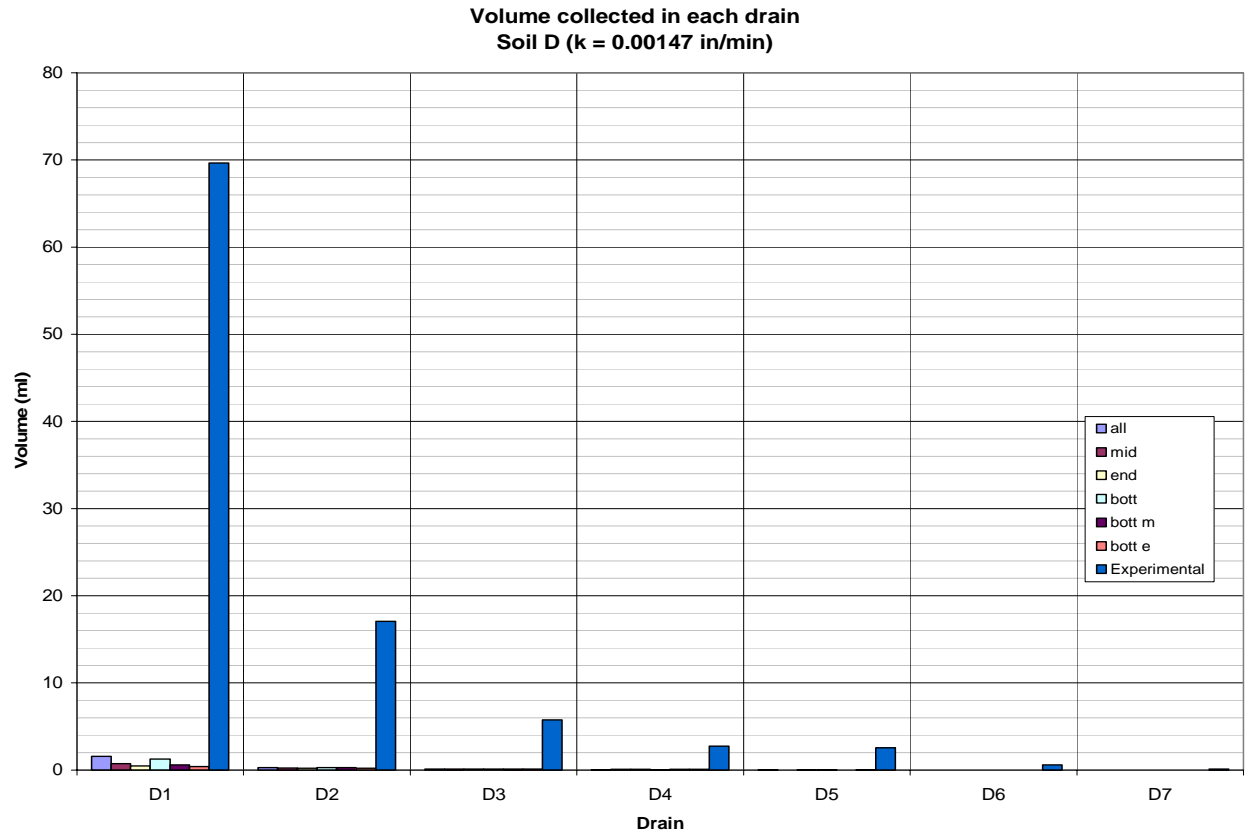

Figure A1.14: Volume removed at each drain for all drain set-ups (Soil D) 


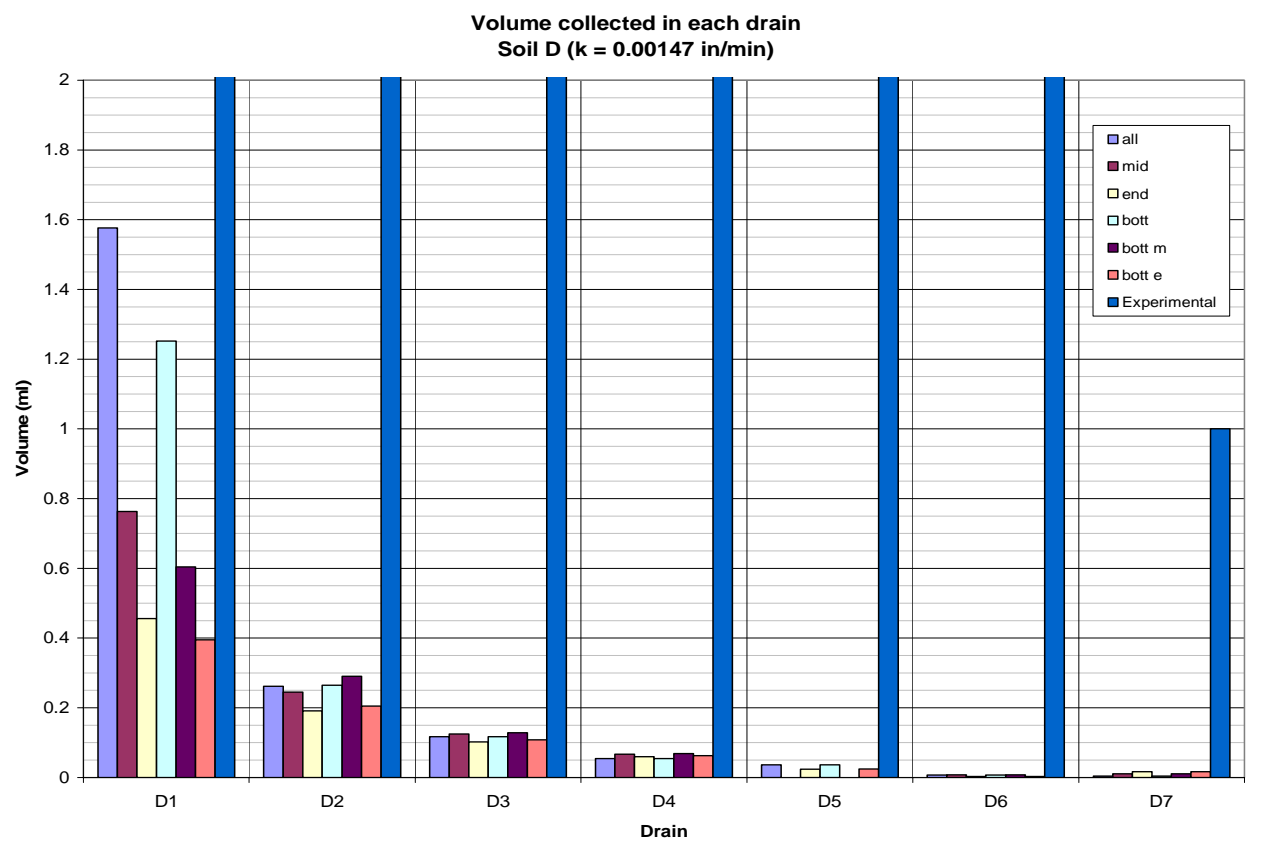

Figure A1.15: Close-up of volume removed at each drain for all drain set-ups (Soil D)

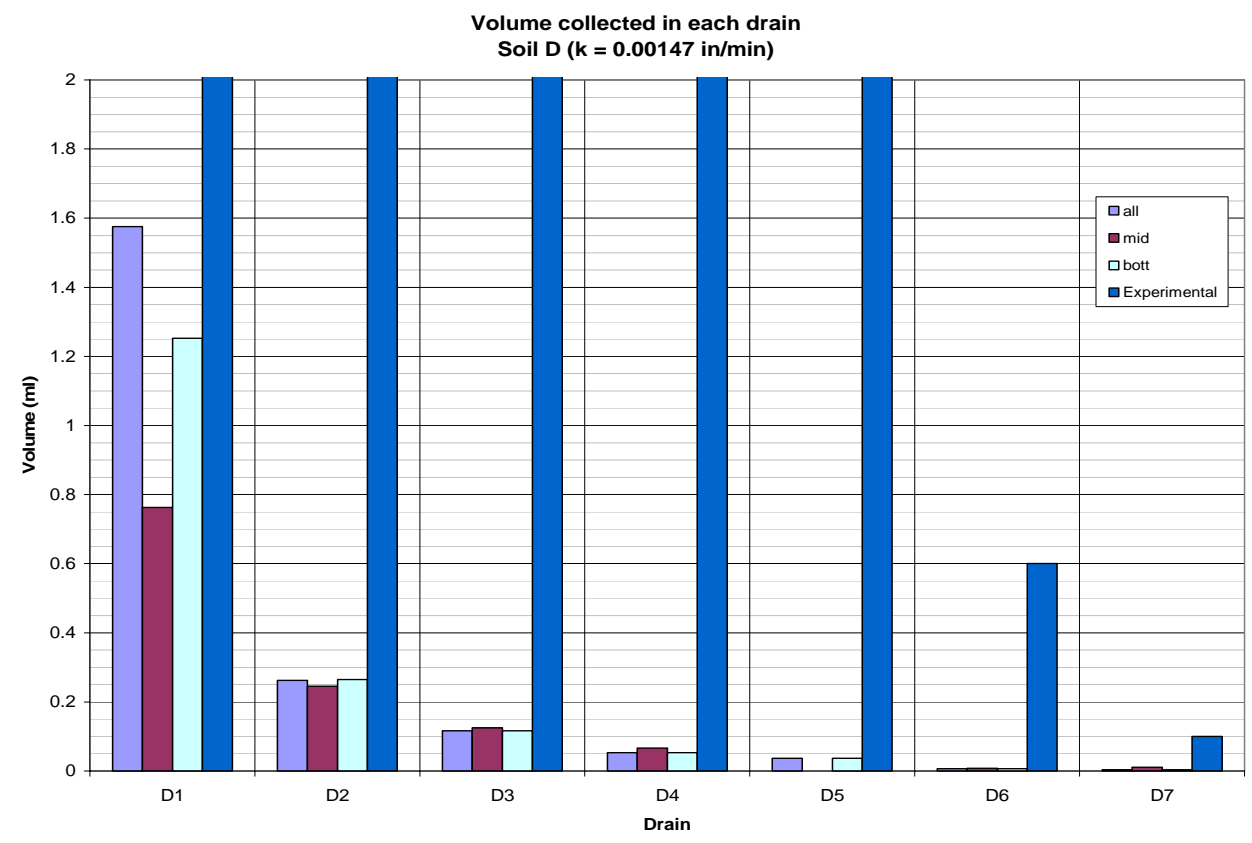

Figure A1.16: Close-up of volume removed in each drain for the three main drain set-ups (Soil D) 


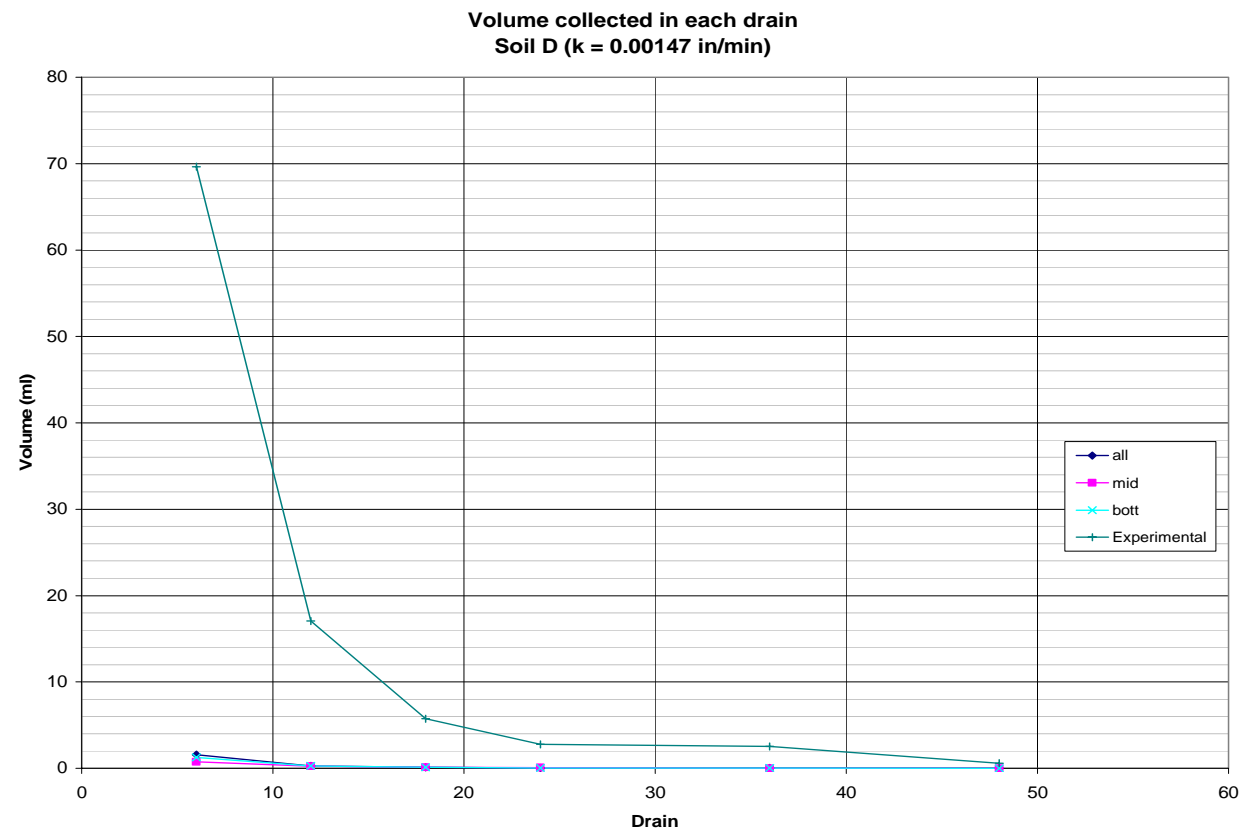

Figure A1.17: Volume removed along the drain for the three main drain set-ups (Soil D)

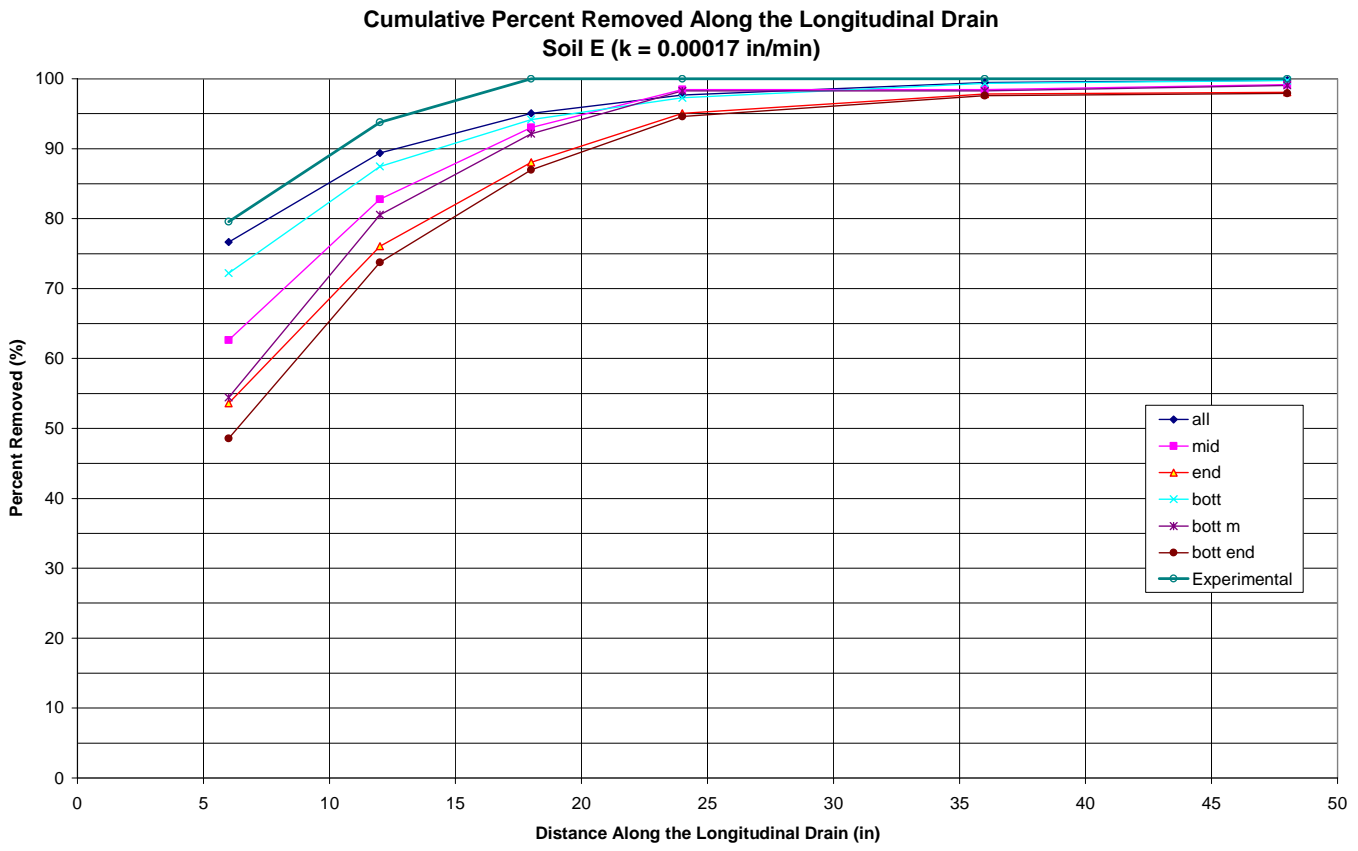

Figure A1.18: Cumulative percent removed along the drain for all drain set-ups (Soil E) 


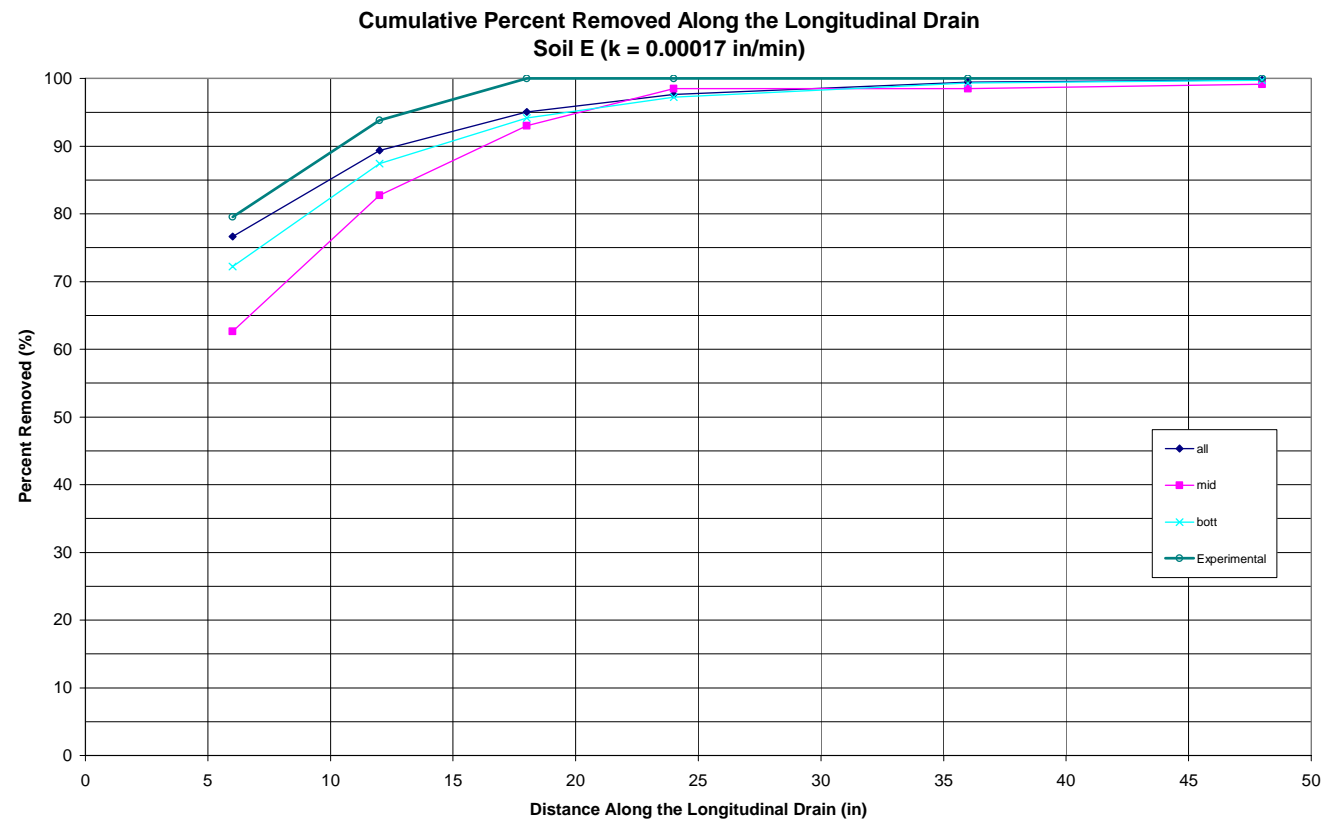

Figure A1.19: Cumulative percent removed along the drain for the three main drain setups (Soil E)

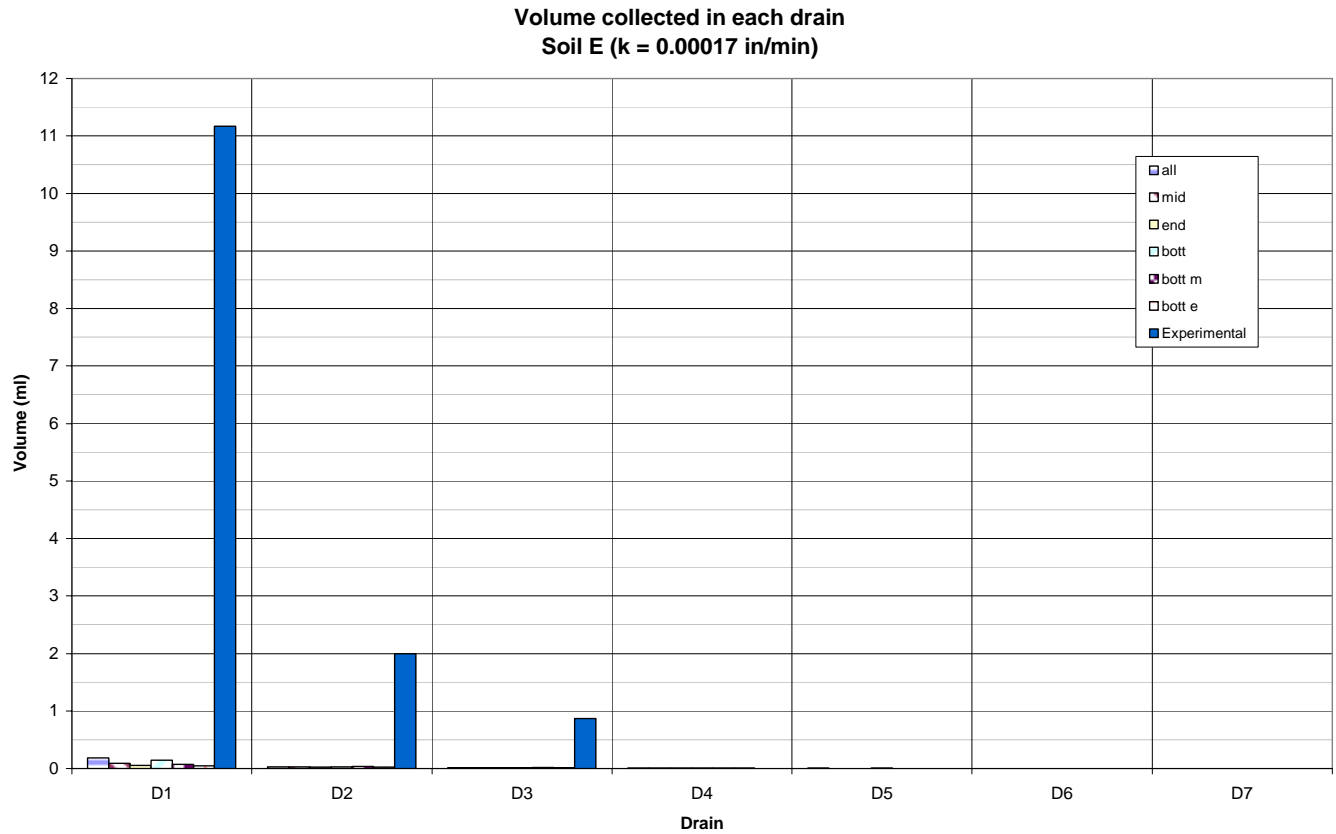

Figure A1.20: Volume removed at each drain for all drain set-ups (Soil E) 


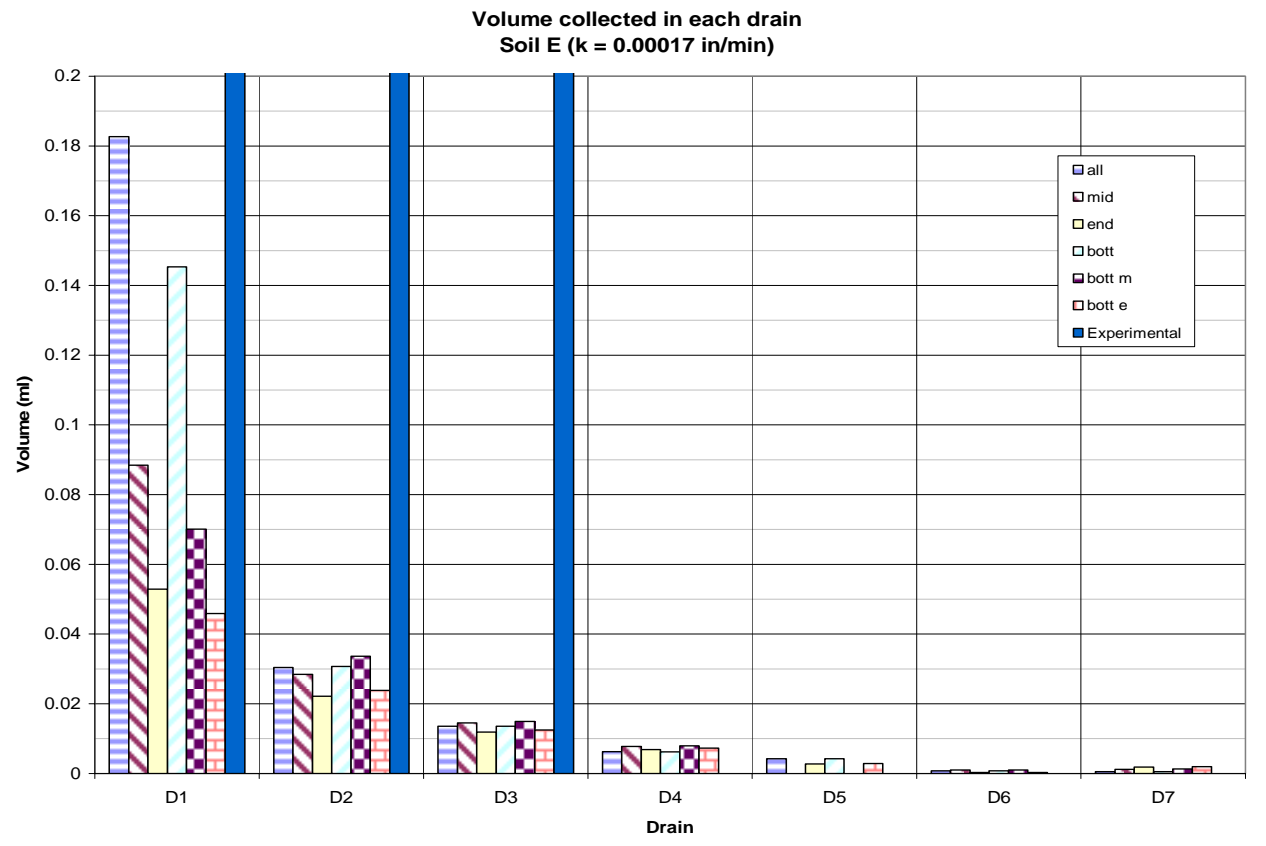

Figure A1.21: Close-up of volume removed at each drain for all drain set-ups (Soil E)

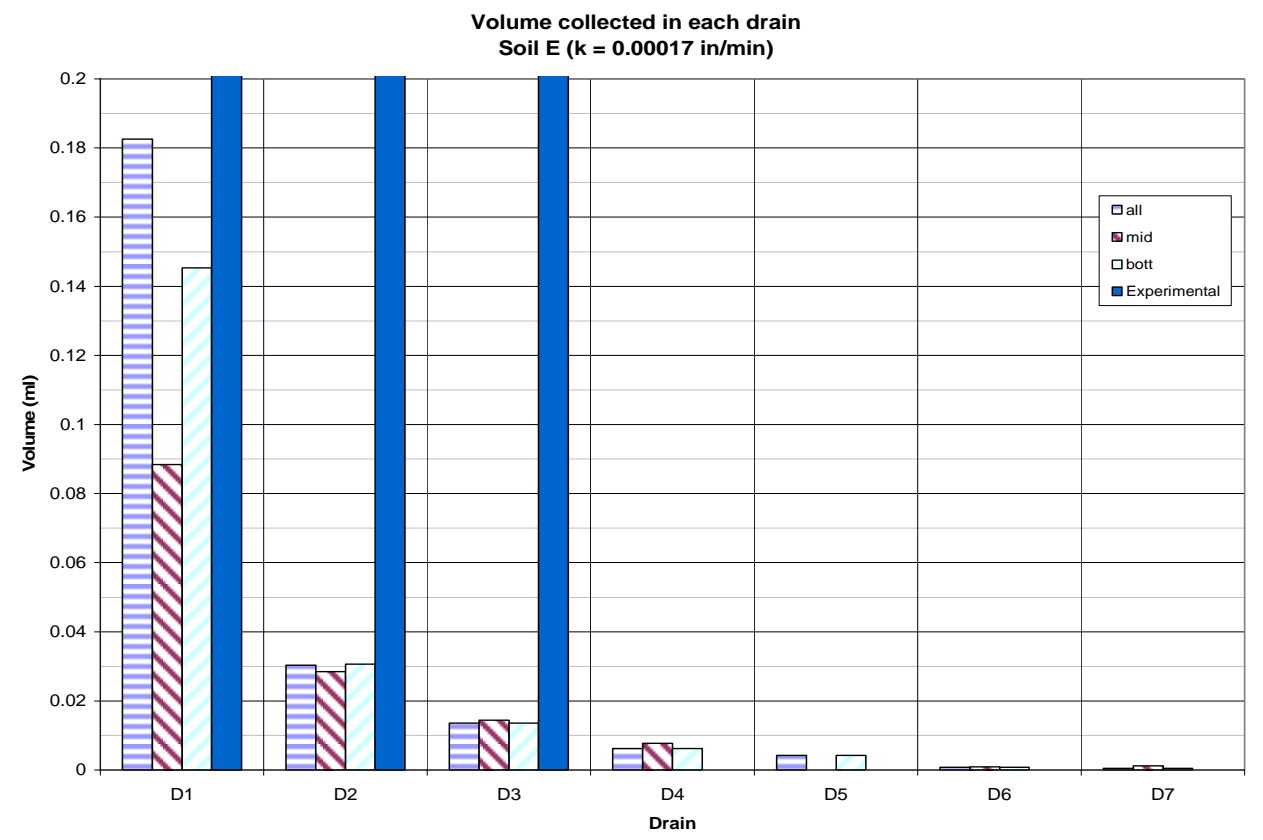

Figure A1.22: Close-up of volume removed in each drain for the three main drain set-ups (Soil E) 


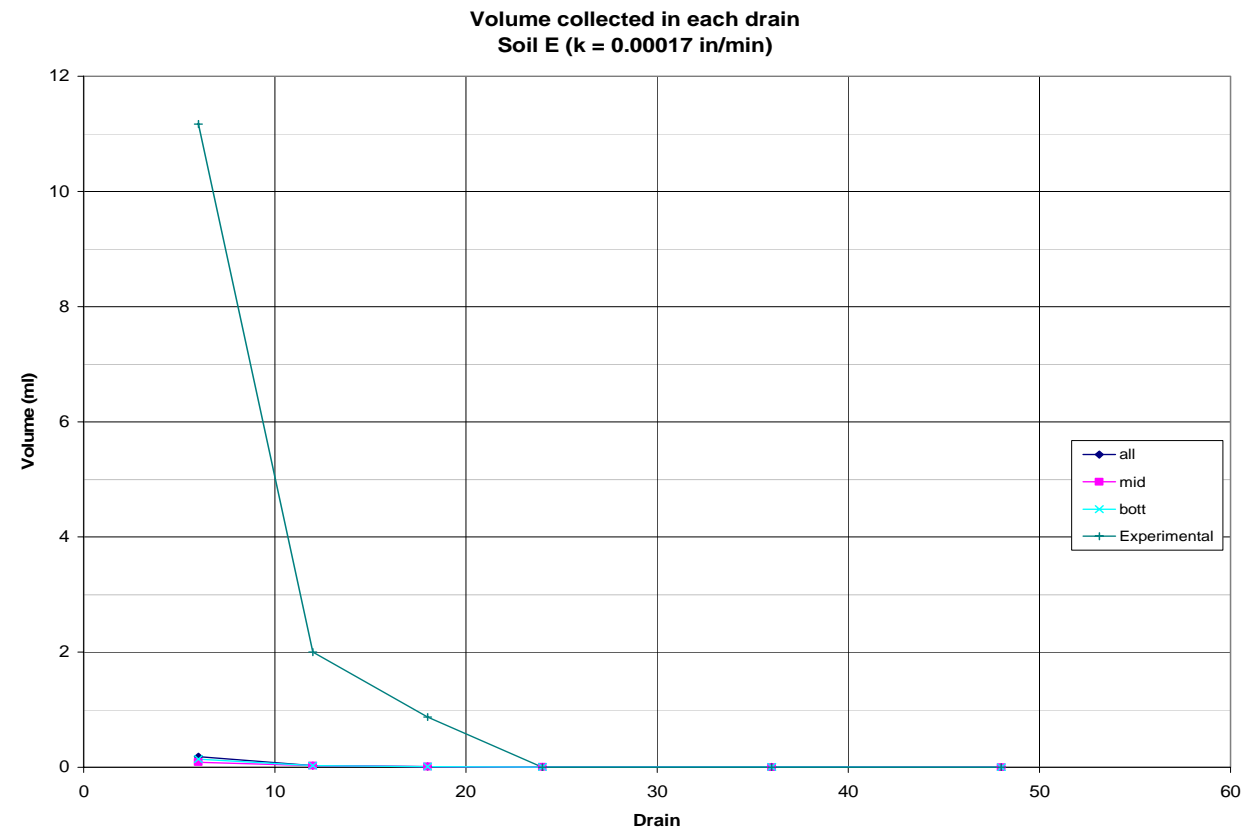

Figure A1.23: Volume removed along the drain for the three main drain set-ups (Soil E) 


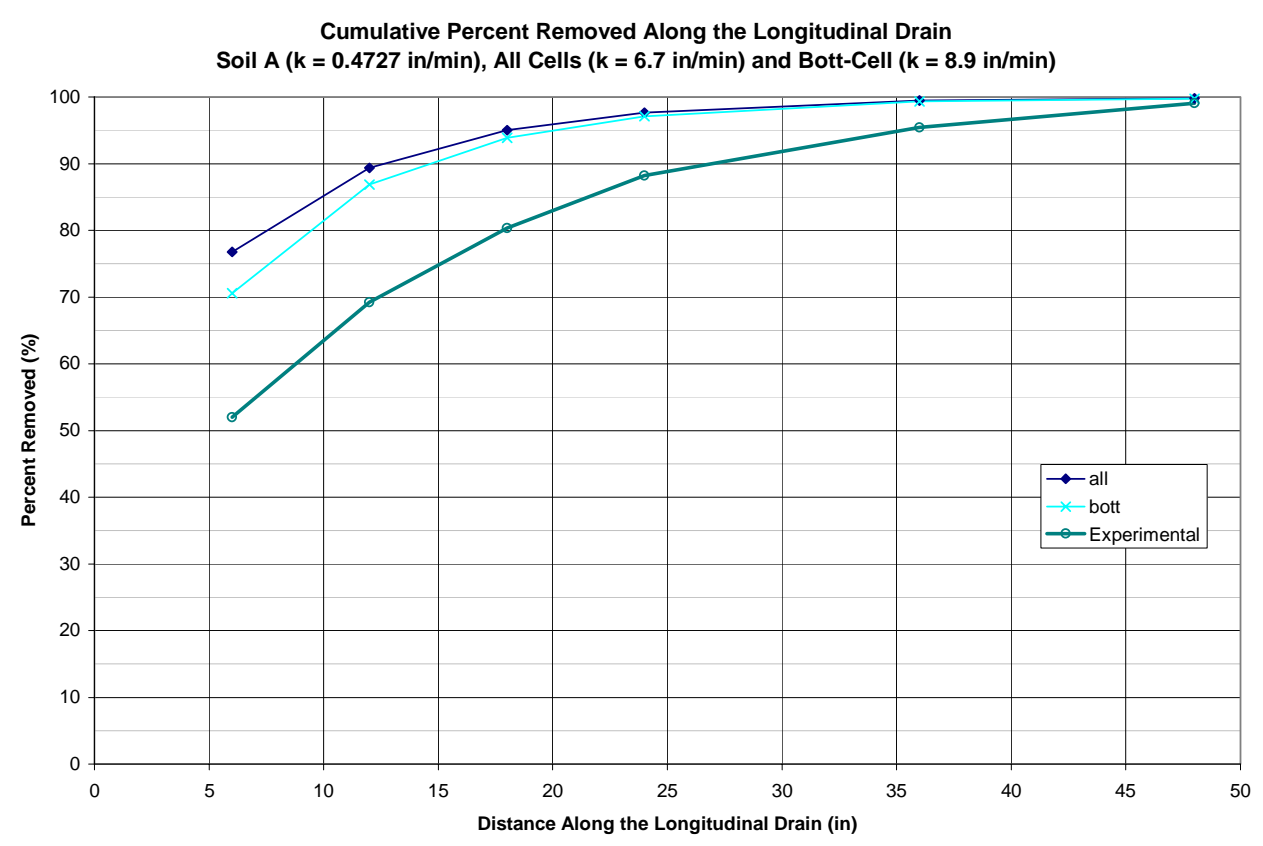

Figure A1.24: Measured and Computed Cumulative percent removed along the drain for Soil A with modified Hydraulic Conductivity

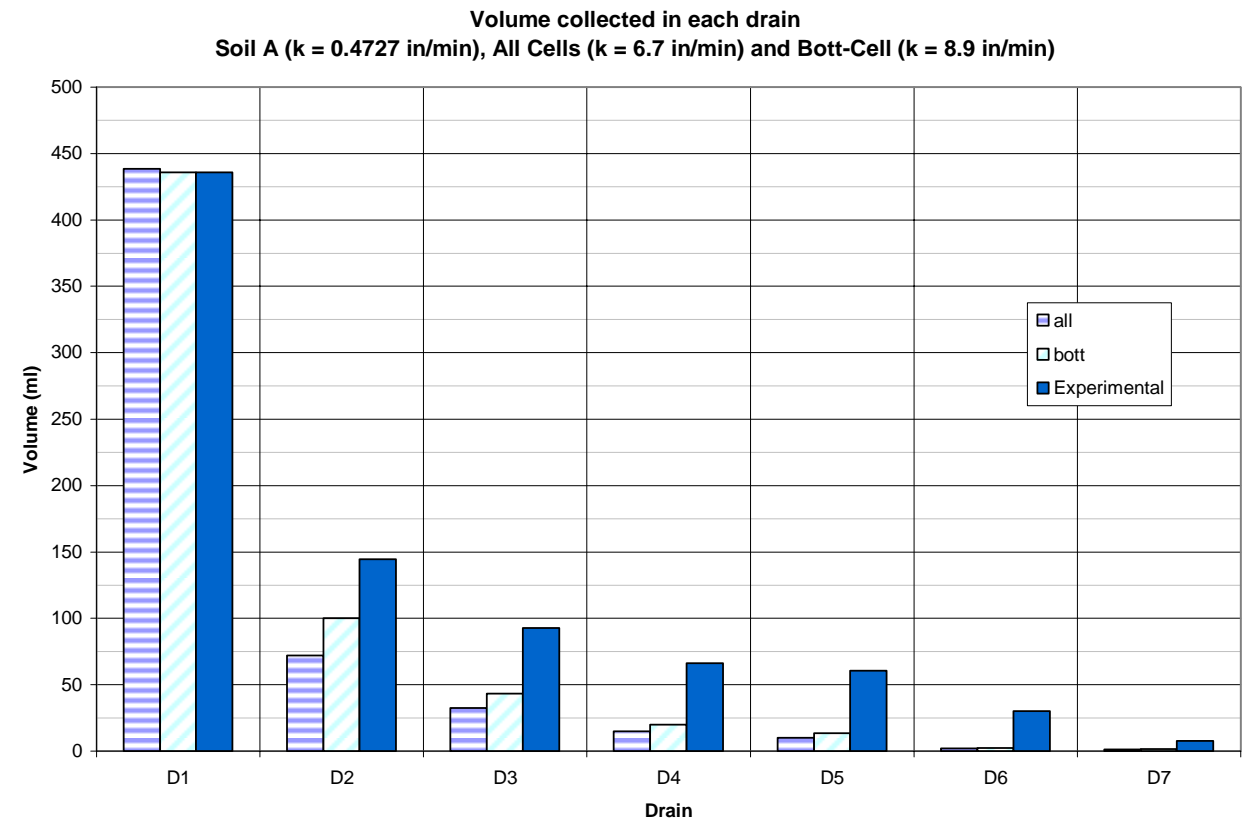

Figure A1.25: Volume removed at each drain for a soil type A with modified Hydraulic Conductivity 


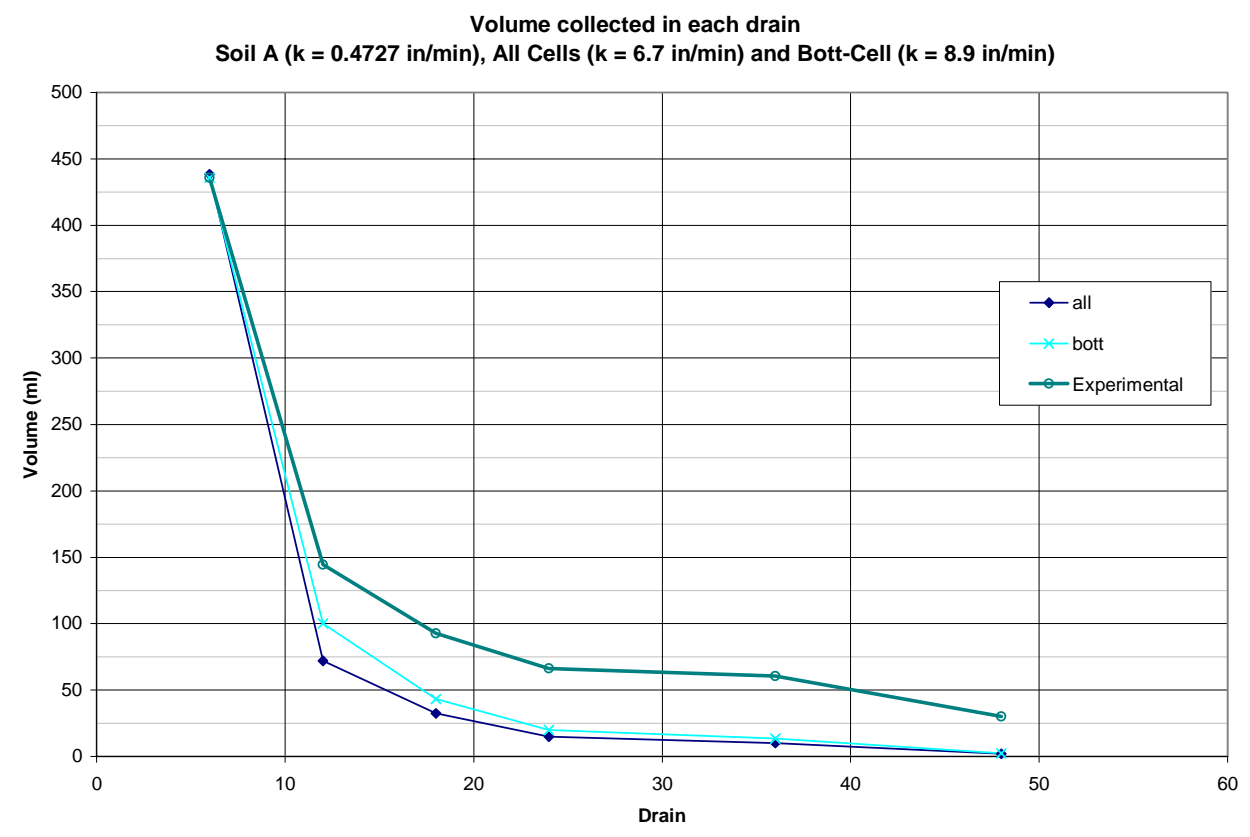

Figure A1.26: Variation of Drainage Volume along the length for soil type A with modified Hydraulic Conductivity

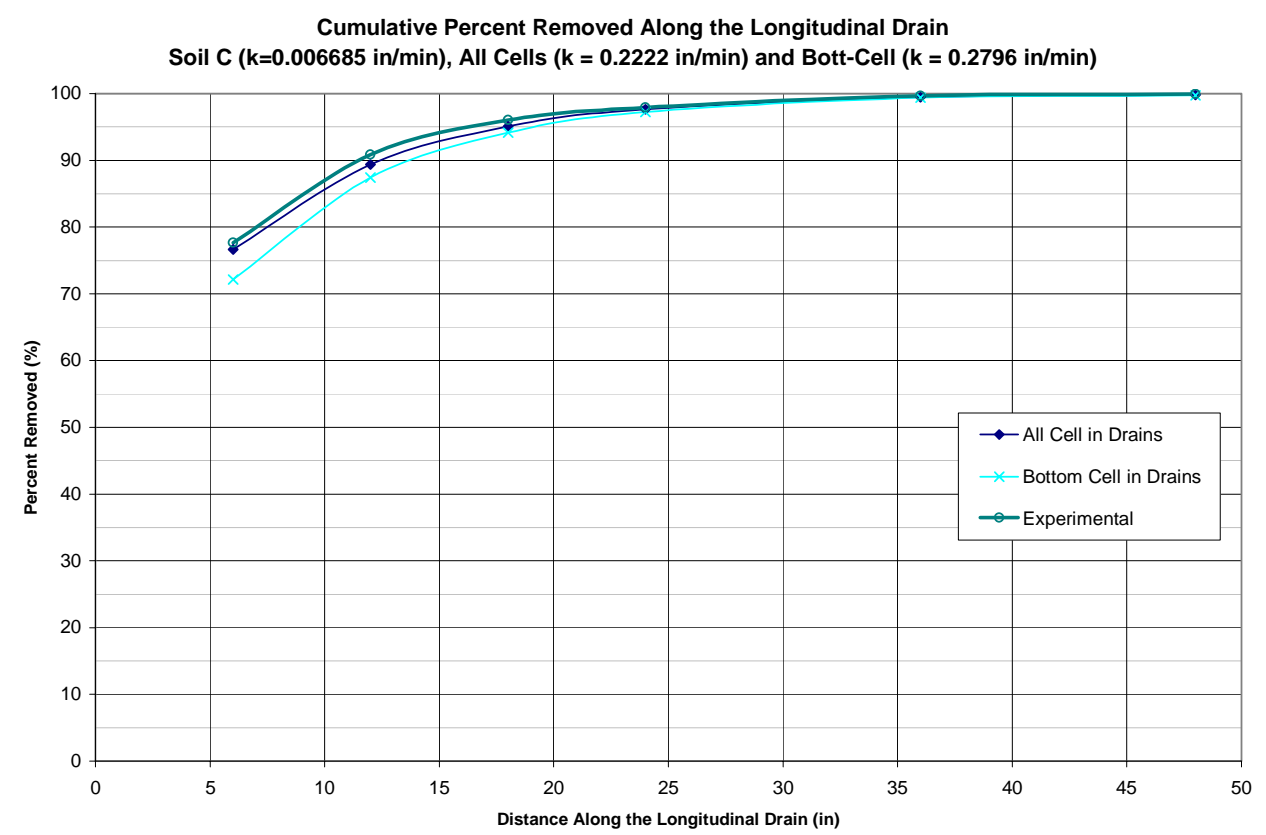

Figure A1.27: Measured and Computed Cumulative percent removed along the drain for Soil C with modified Hydraulic Conductivity 


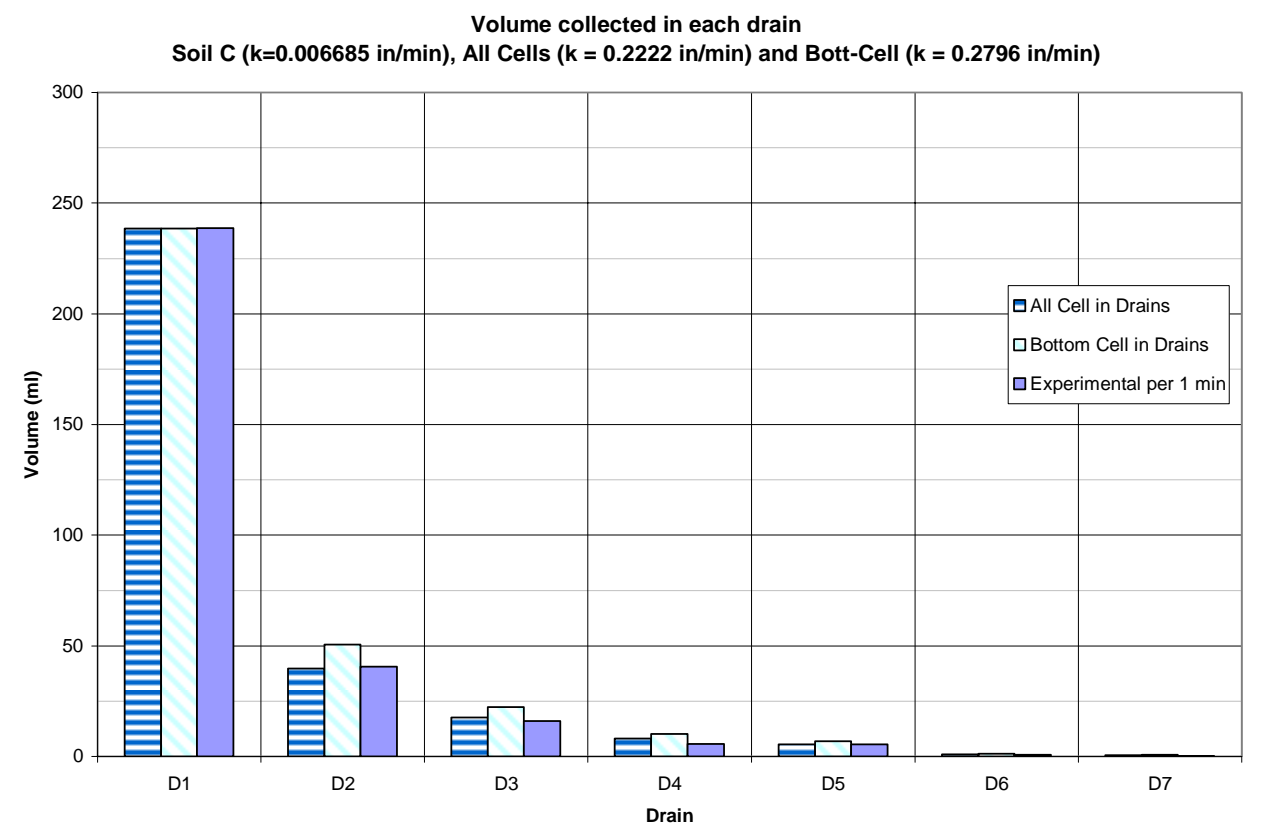

Figure A1.28: Volume removed at each drain for a soil type C with modified Hydraulic Conductivity

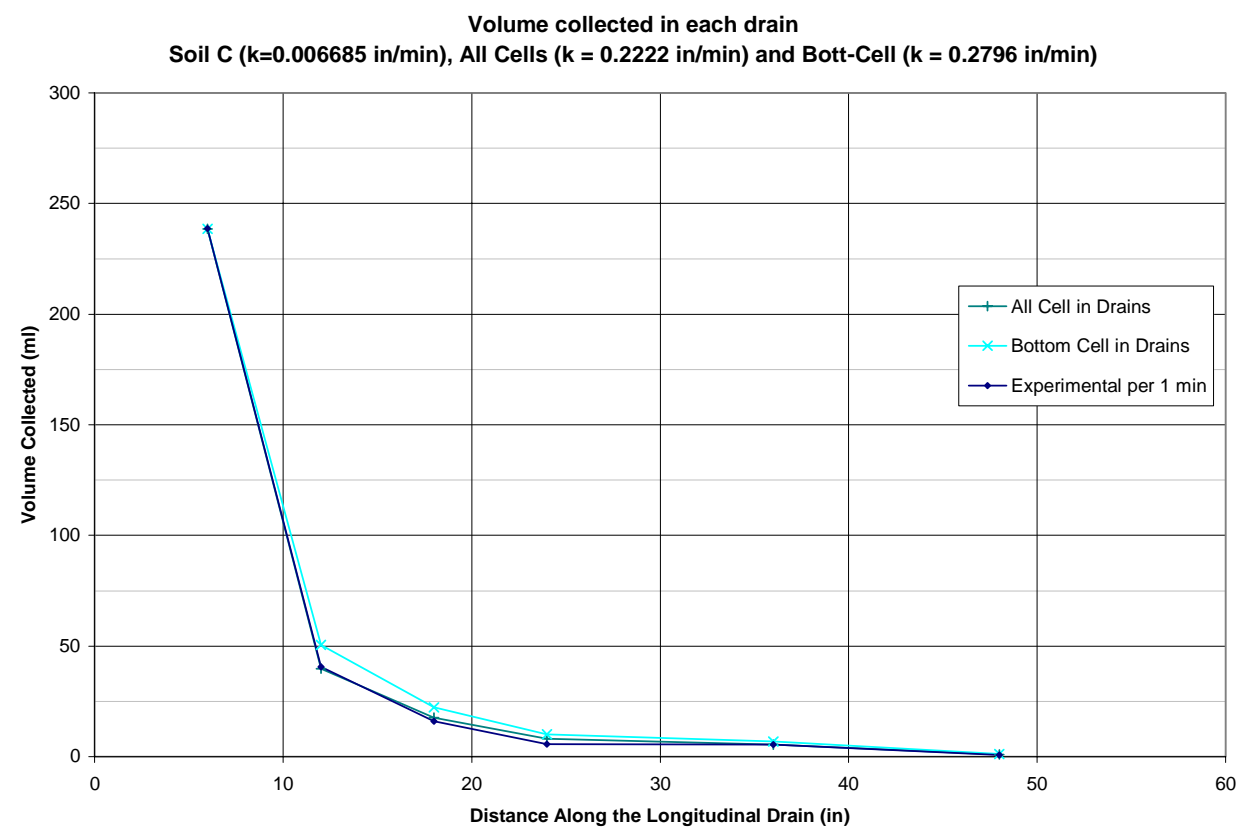

Figure A1.29: Variation of Drainage Volume along the length for soil type C with modified Hydraulic Conductivity 


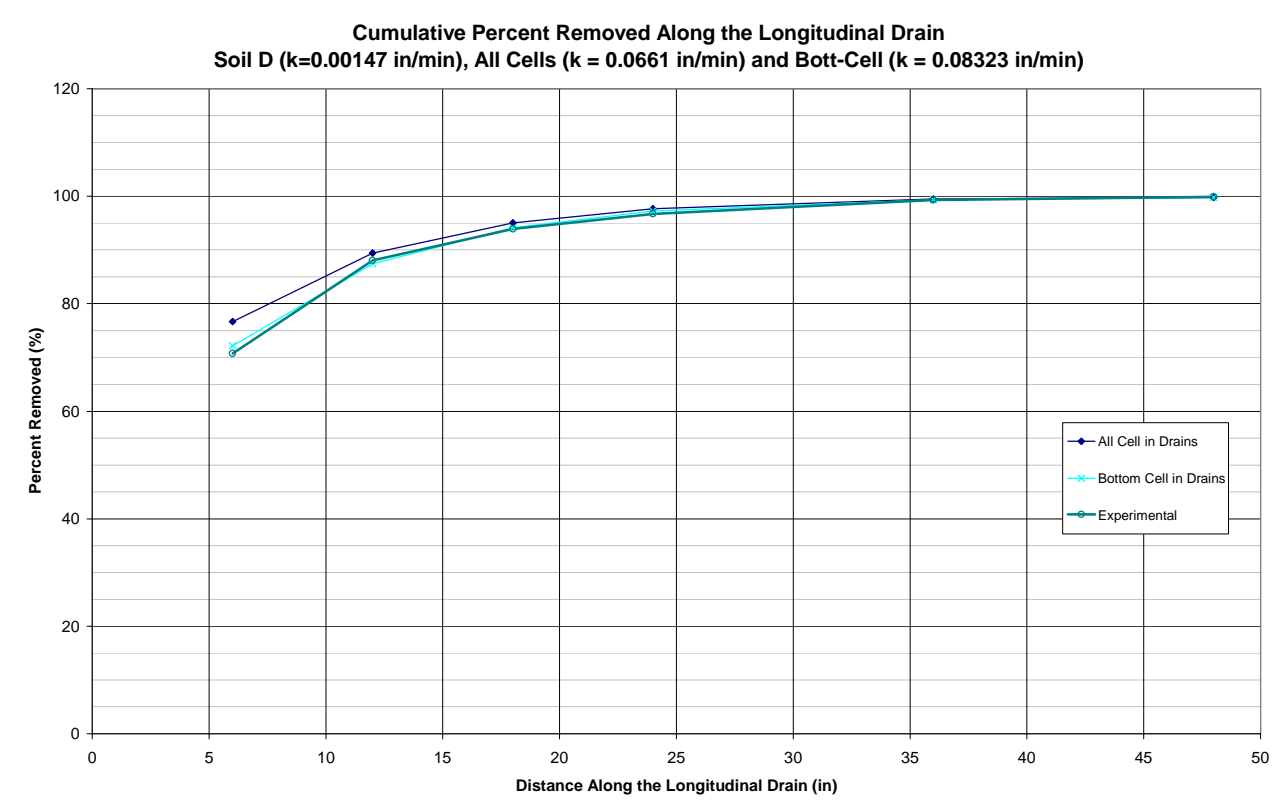

Figure A1.30: Measured and Computed Cumulative percent removed along the drain for Soil D with modified Hydraulic Conductivity

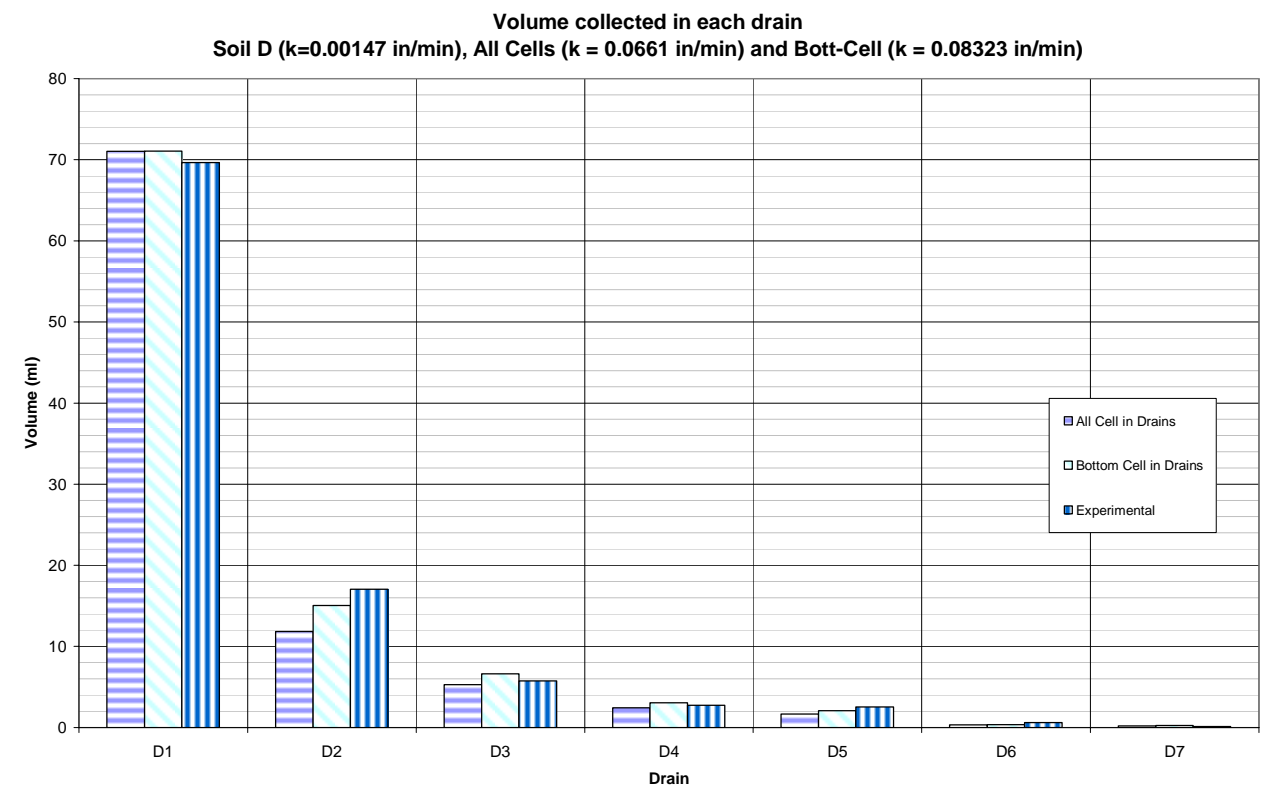

Figure A1.31: Volume removed at each drain for a soil type D with modified Hydraulic Conductivity 
Volume Collected in each drain

Soil D (k=0.00147 in $/ \mathrm{min})$, All Cells $(k=0.0661 \mathrm{in} / \mathrm{min})$ and Bott-Cell $(k=0.08323 \mathrm{in} / \mathrm{min})$

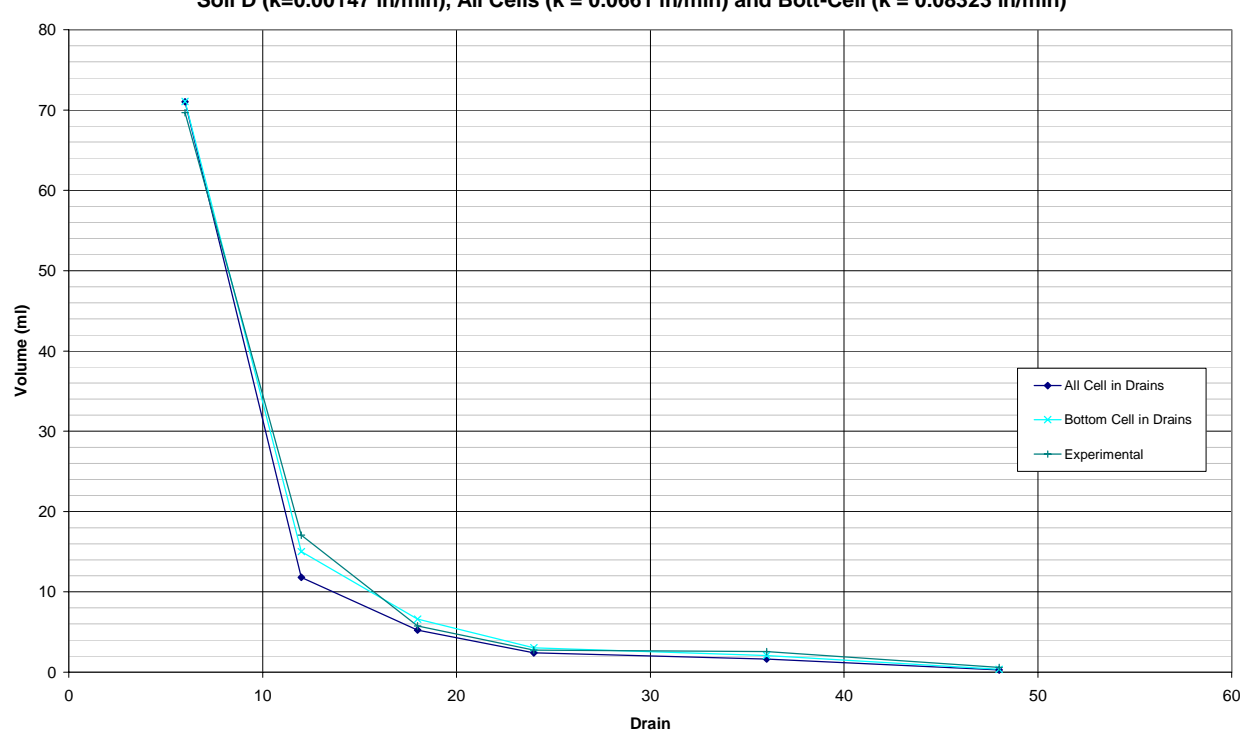

Figure A1.32: Variation of Drainage Volume along the length for soil type D with modified Hydraulic Conductivity

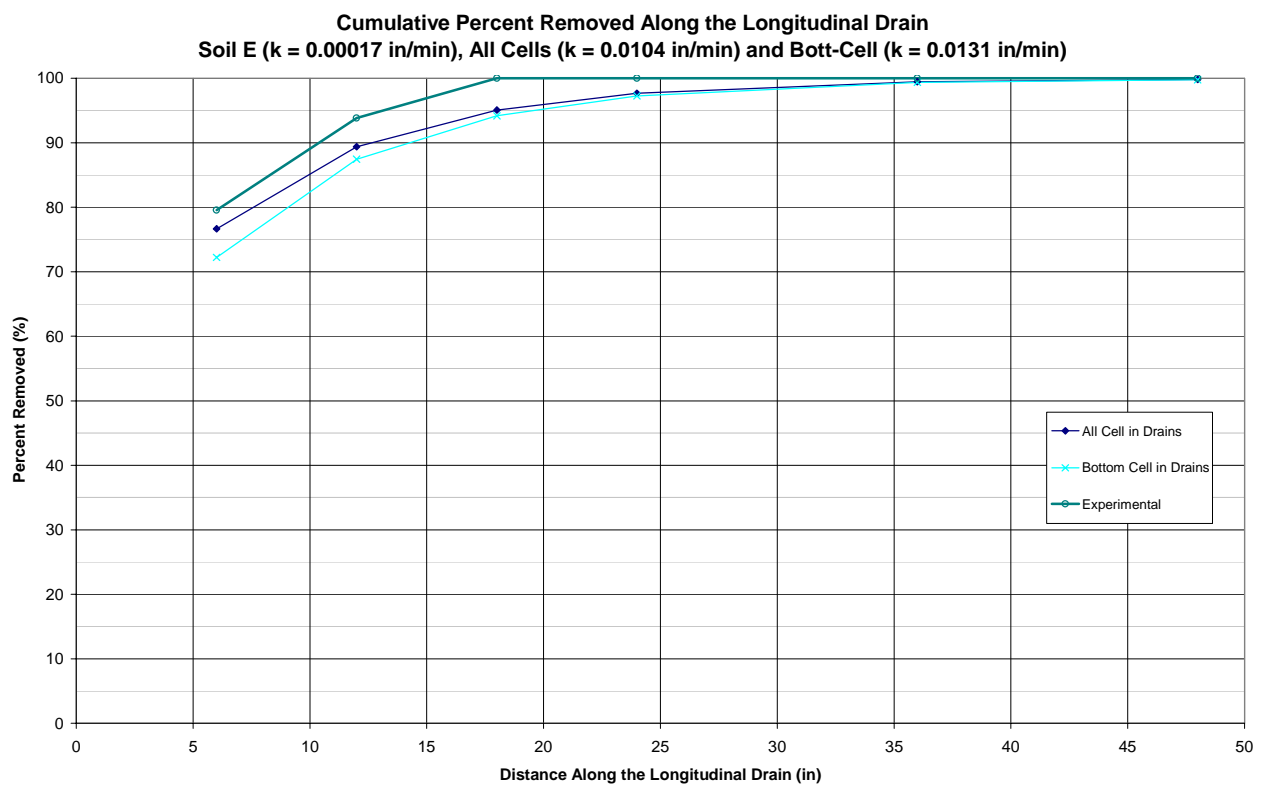

Figure A1.33: Measured and Computed Cumulative percent removed along the drain for Soil E with modified Hydraulic Conductivity 


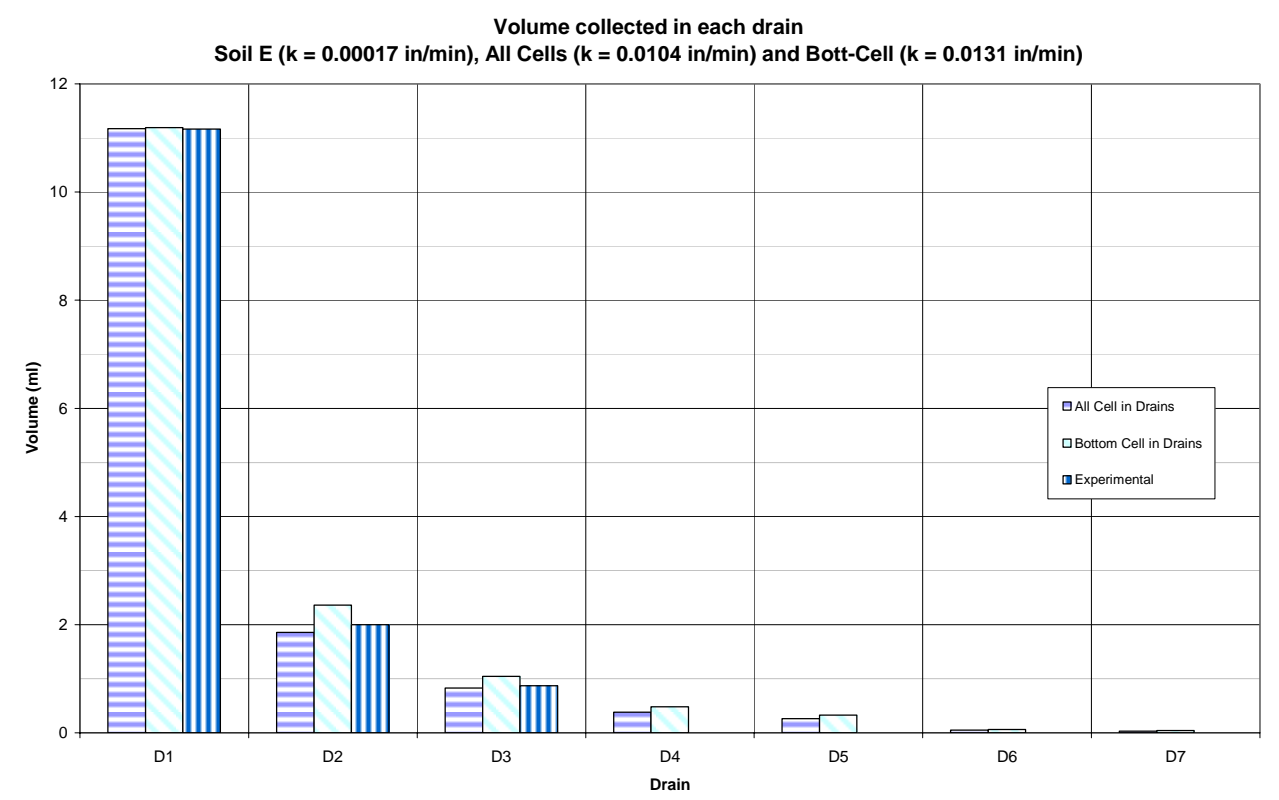

Figure A1.34: Volume removed at each drain for a soil type E with modified Hydraulic Conductivity

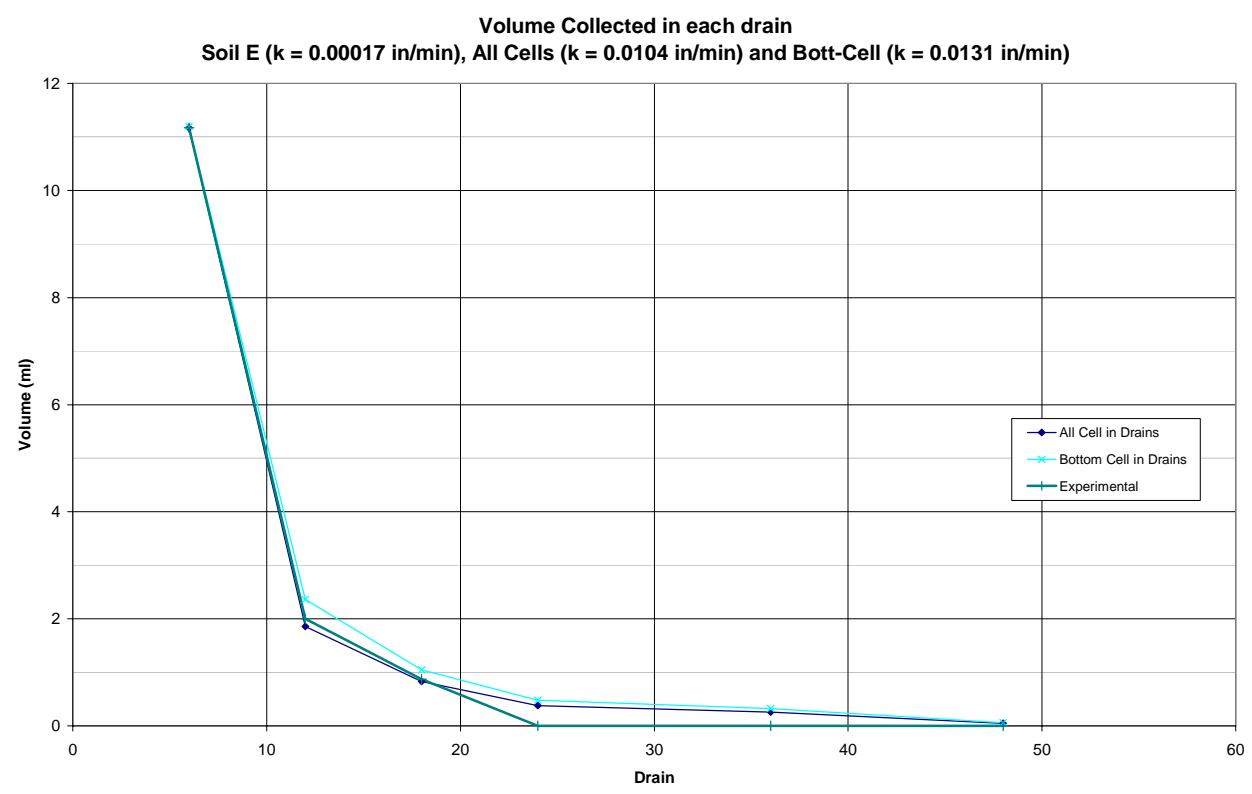

Figure A1.35: Variation of Drainage Volume along the length for soil type E with modified Hydraulic Conductivity 
Appendix A2: Laboratory Vs Computer Model End Drain Cases

$$
\begin{aligned}
& \mathrm{W}=12 \text { inches } \\
& l=48 \text { inches } \\
& \theta=0^{0}
\end{aligned}
$$




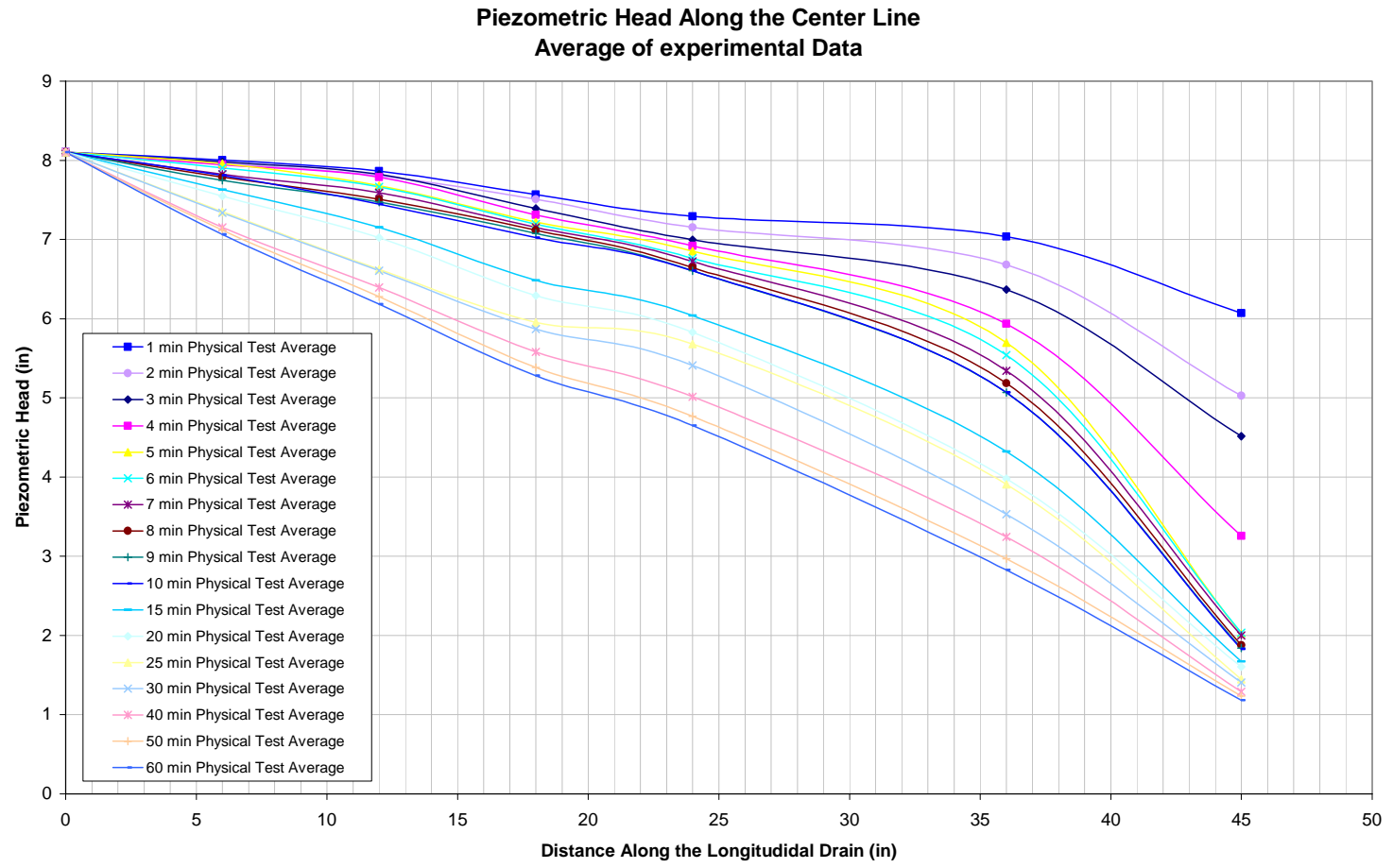

Figure A2.1: Piezometric variation along Center Line for Soil Type B -Physical Model

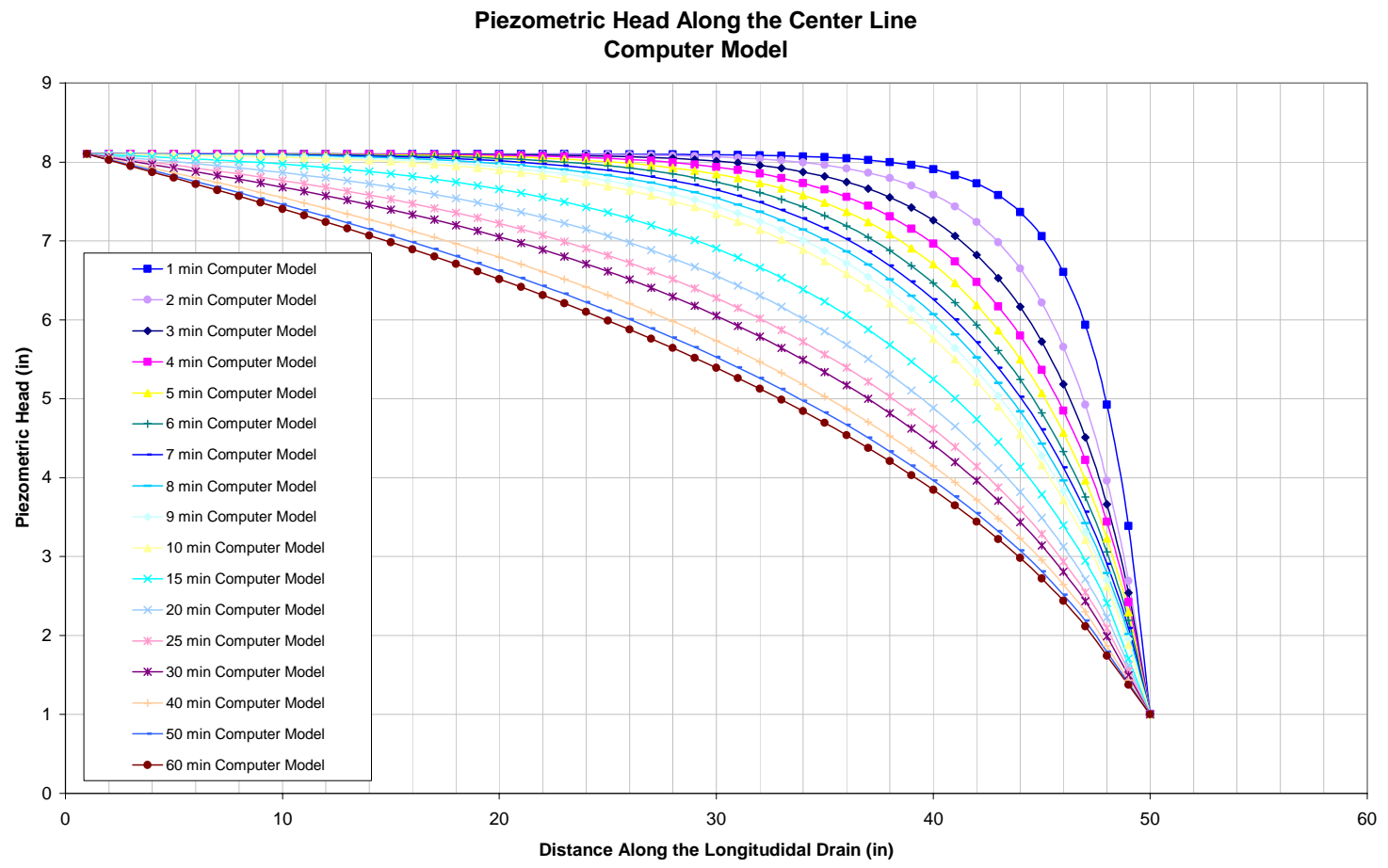

Figure A2.2: Piezometric variation along center line for Soil Type B - Computer Model 
Flow Rate Fluctuation over Time

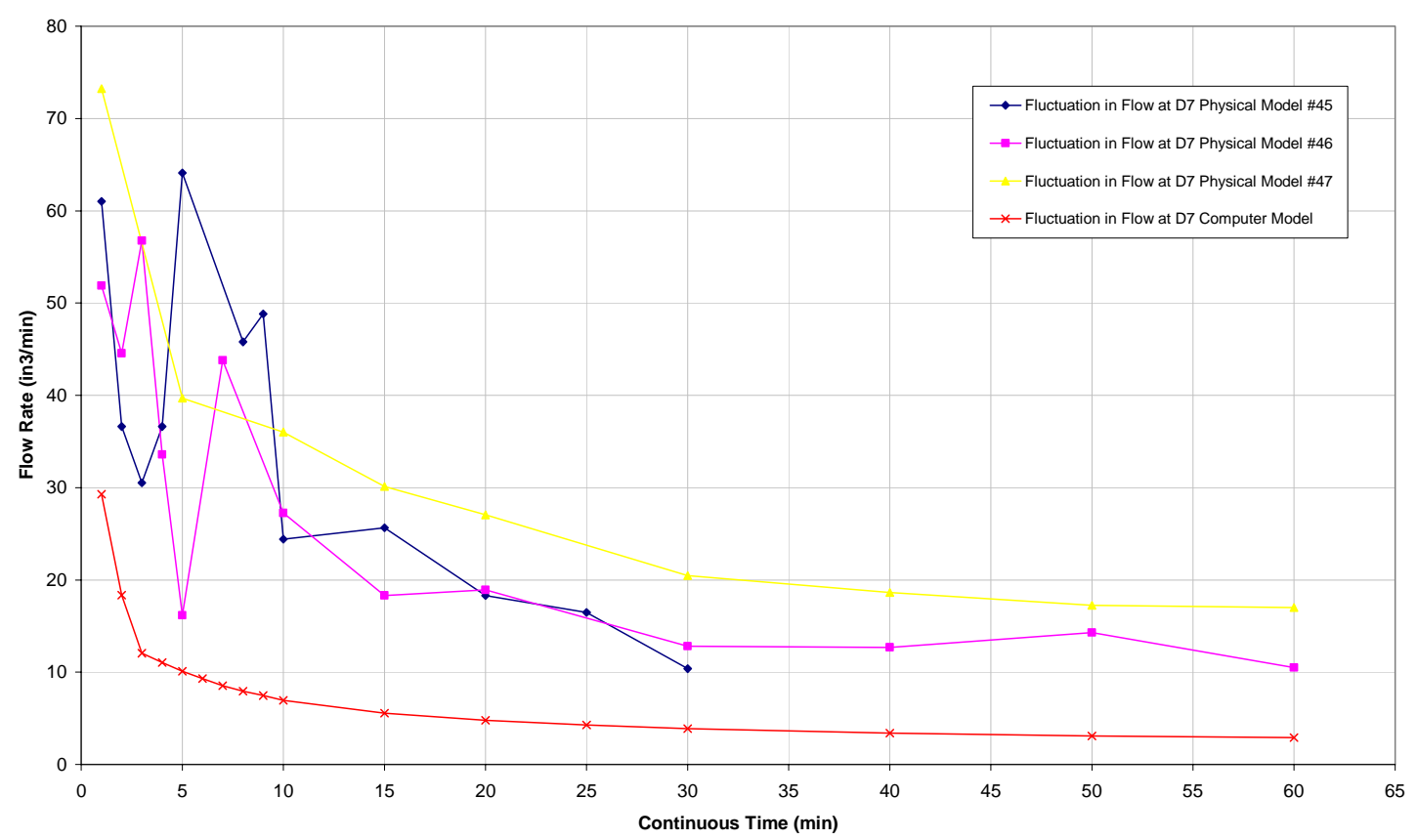

Figure A2.3: Comparison in Flow Rate Fluctuation for Soil Type B

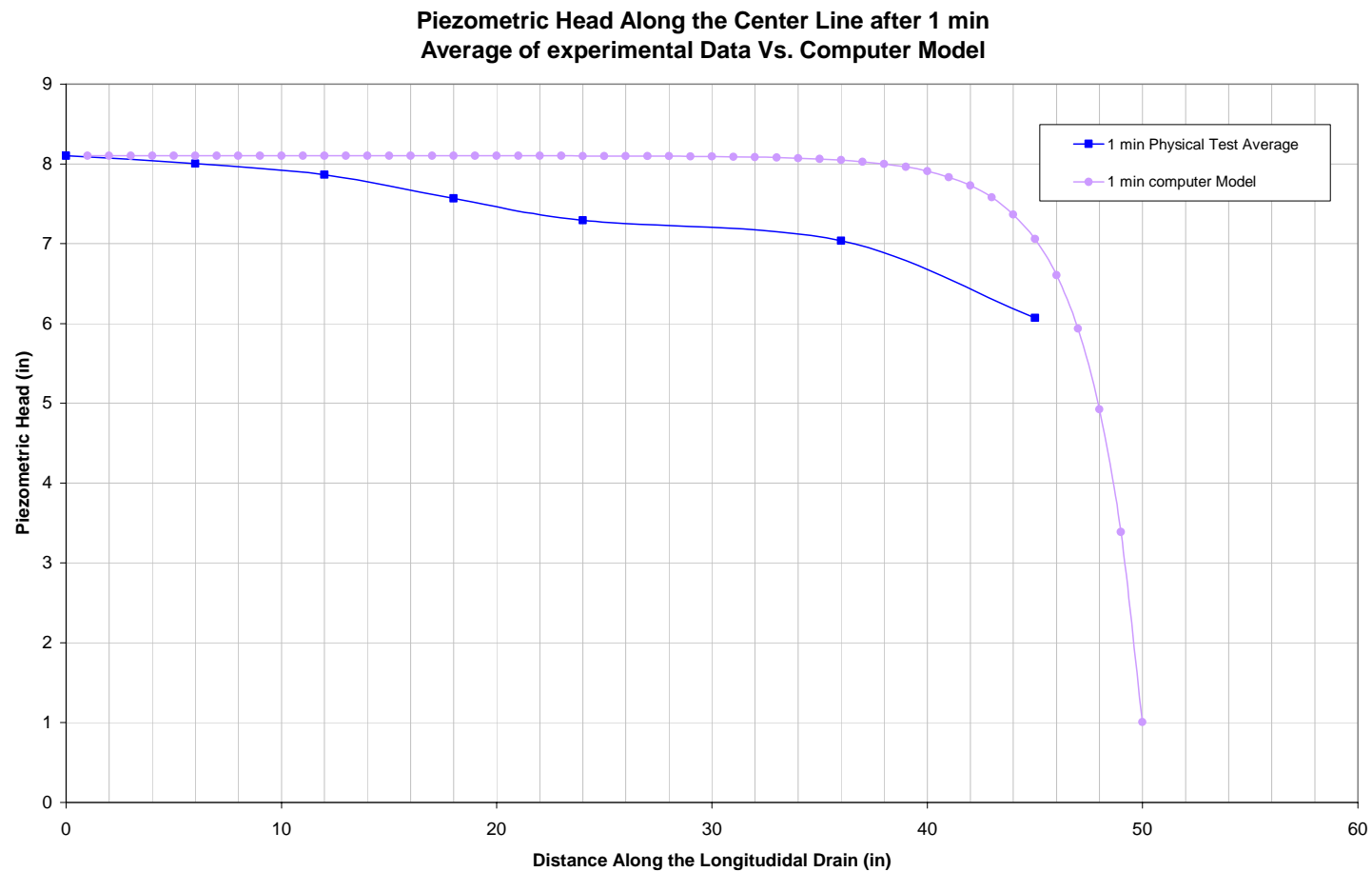

Figure A2.4: Piezometric Level along center line for Soil Type B after 1 minute 


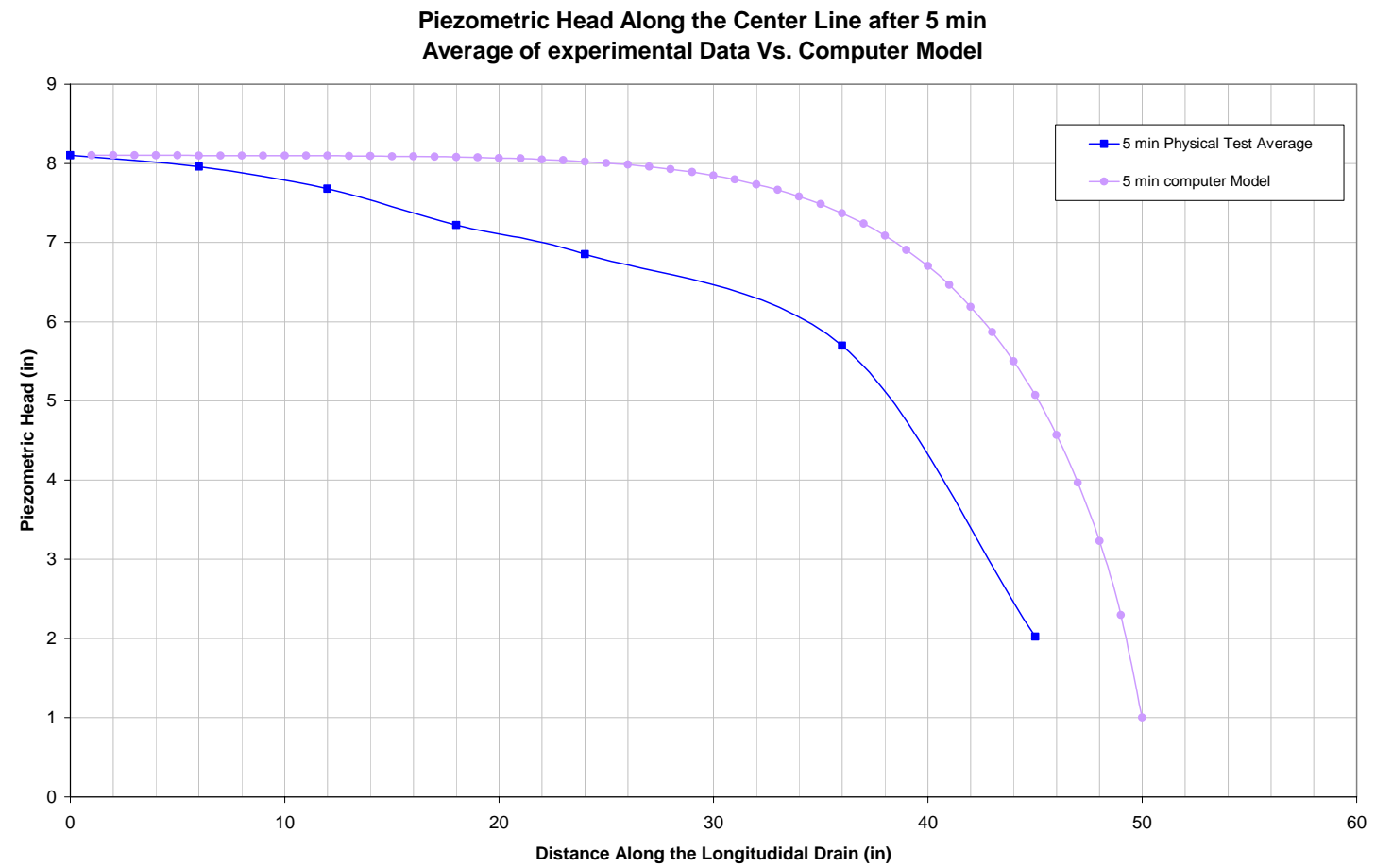

Figure A2.5: Piezometric Level along center line for Soil Type B after 5 minutes

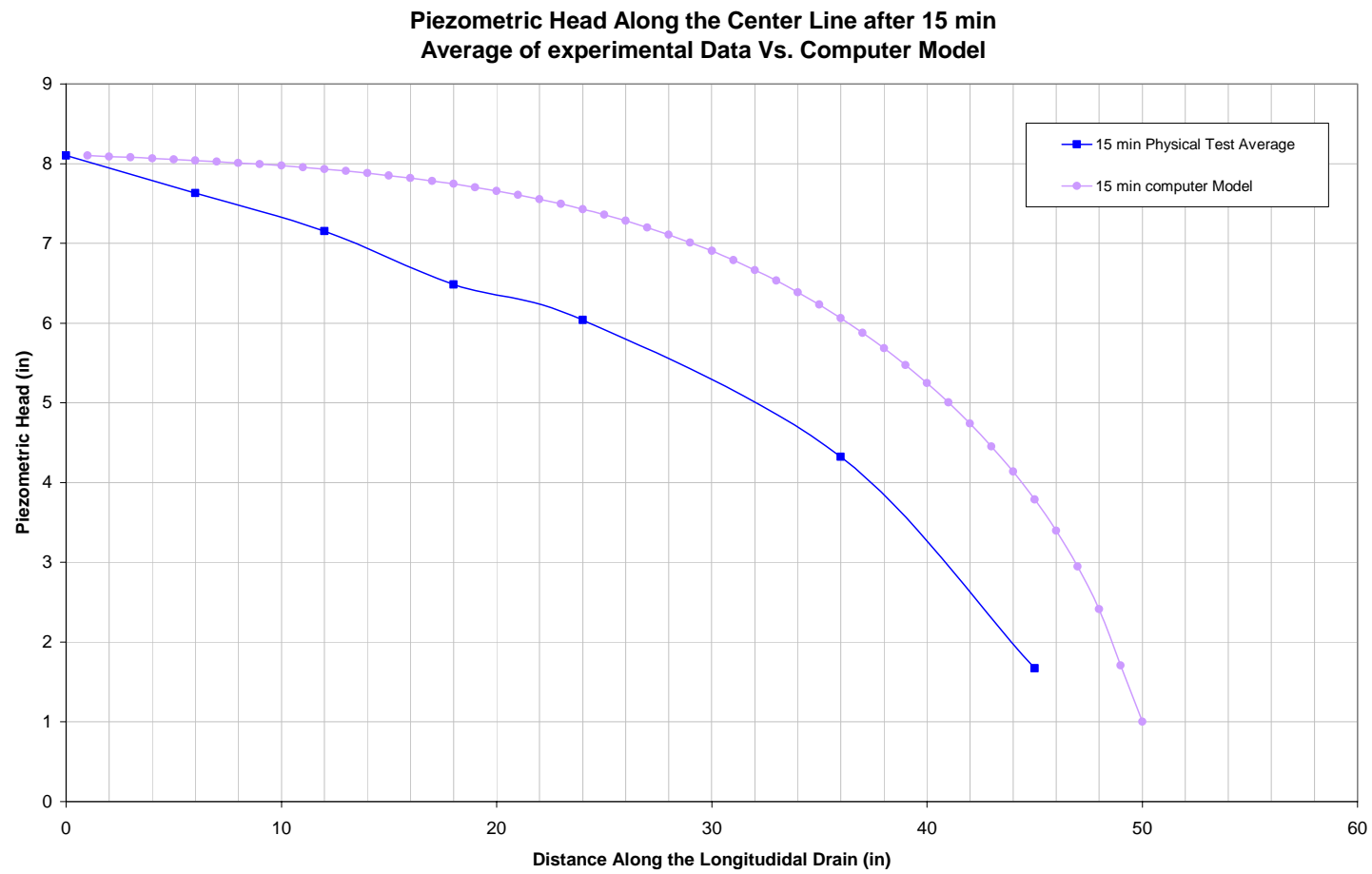

Figure A2.6: Piezometric Level along center line for Soil Type B after 15 minutes 


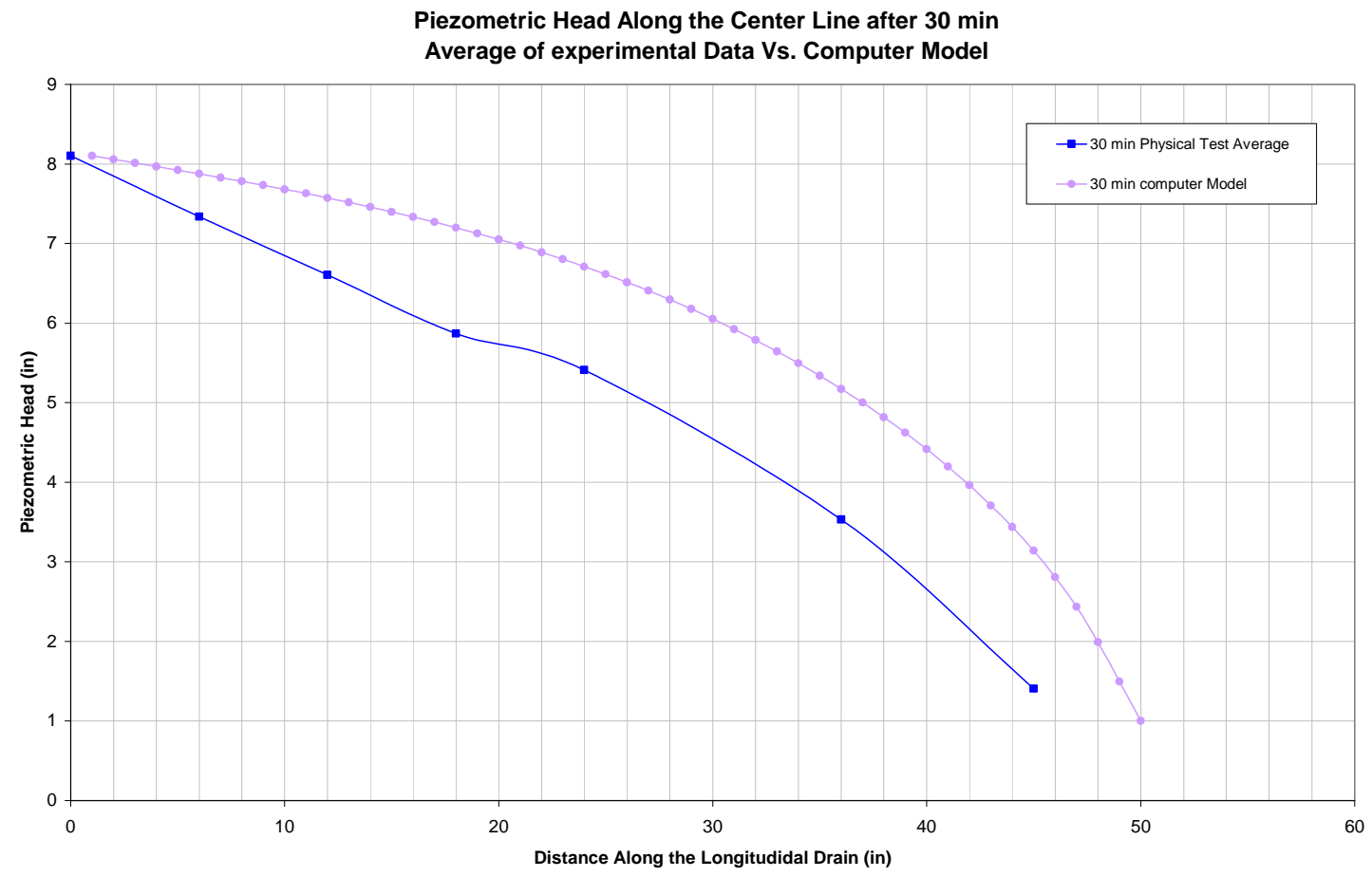

Figure A2.7: Piezometric Level along center line for Soil Type B after 30 minutes

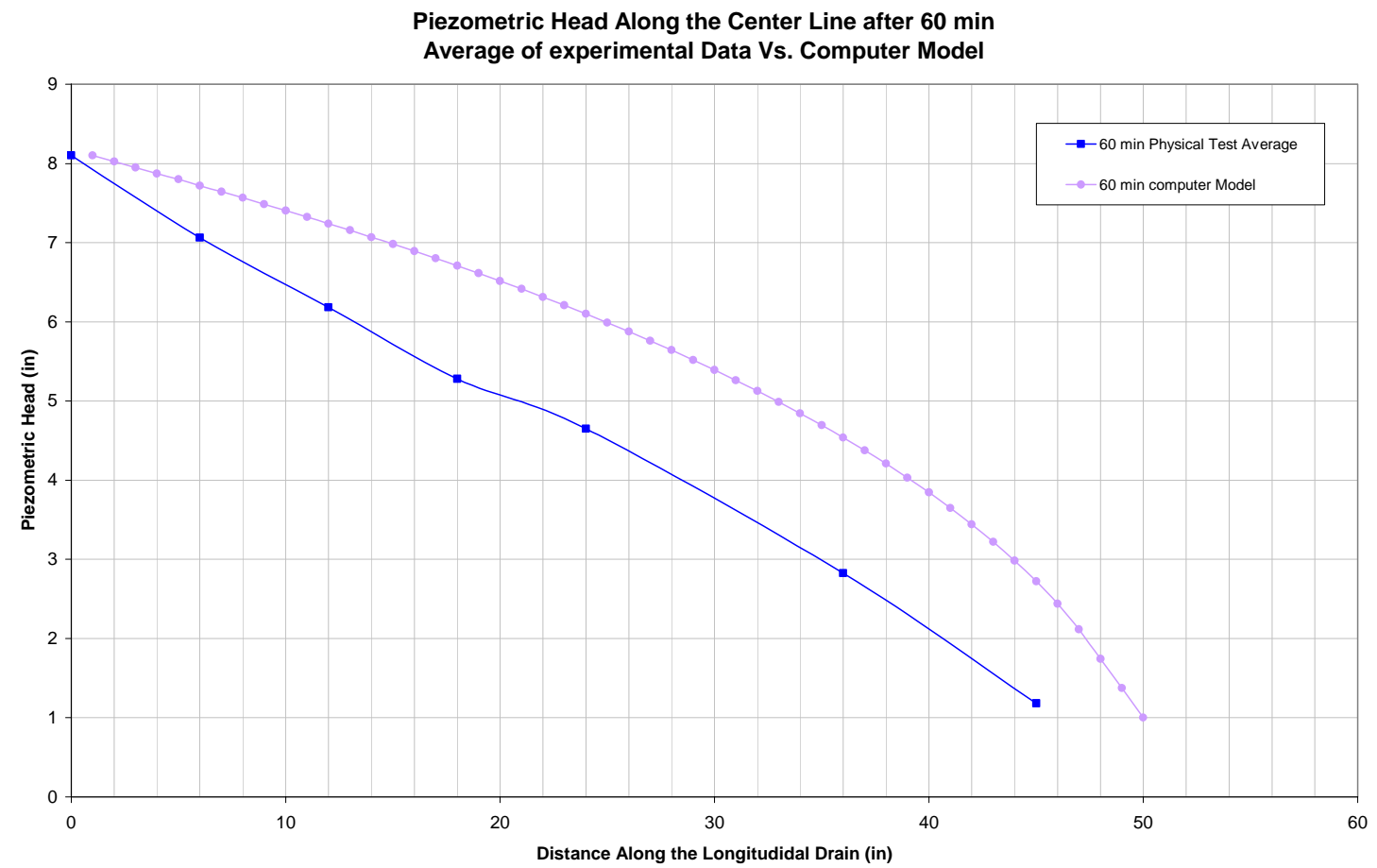

Figure A2.8: Piezometric Level along center line for Soil Type B after 60 minutes 


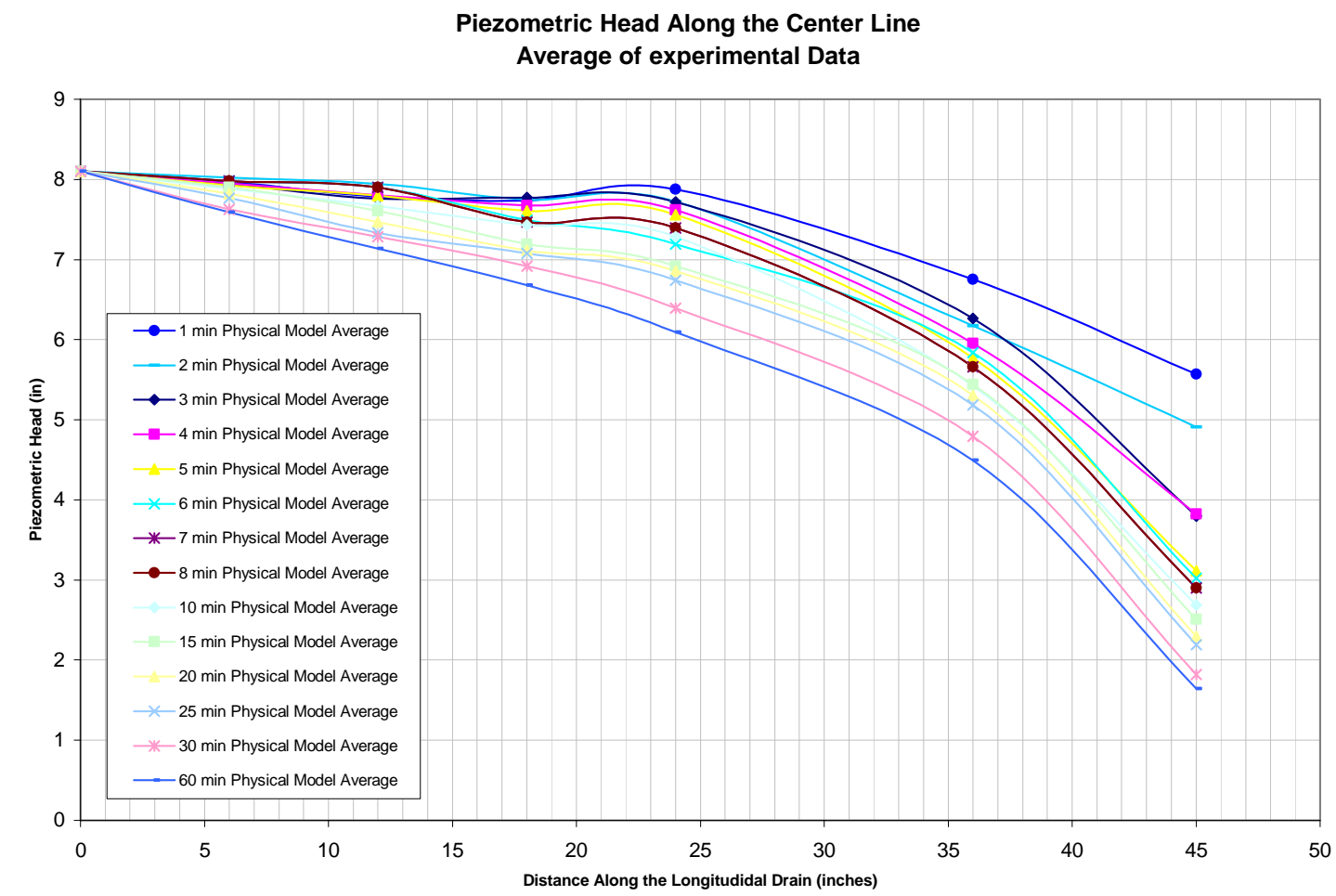

Figure A2.9: Piezometric variation along Center Line for Soil Type C -Physical Model

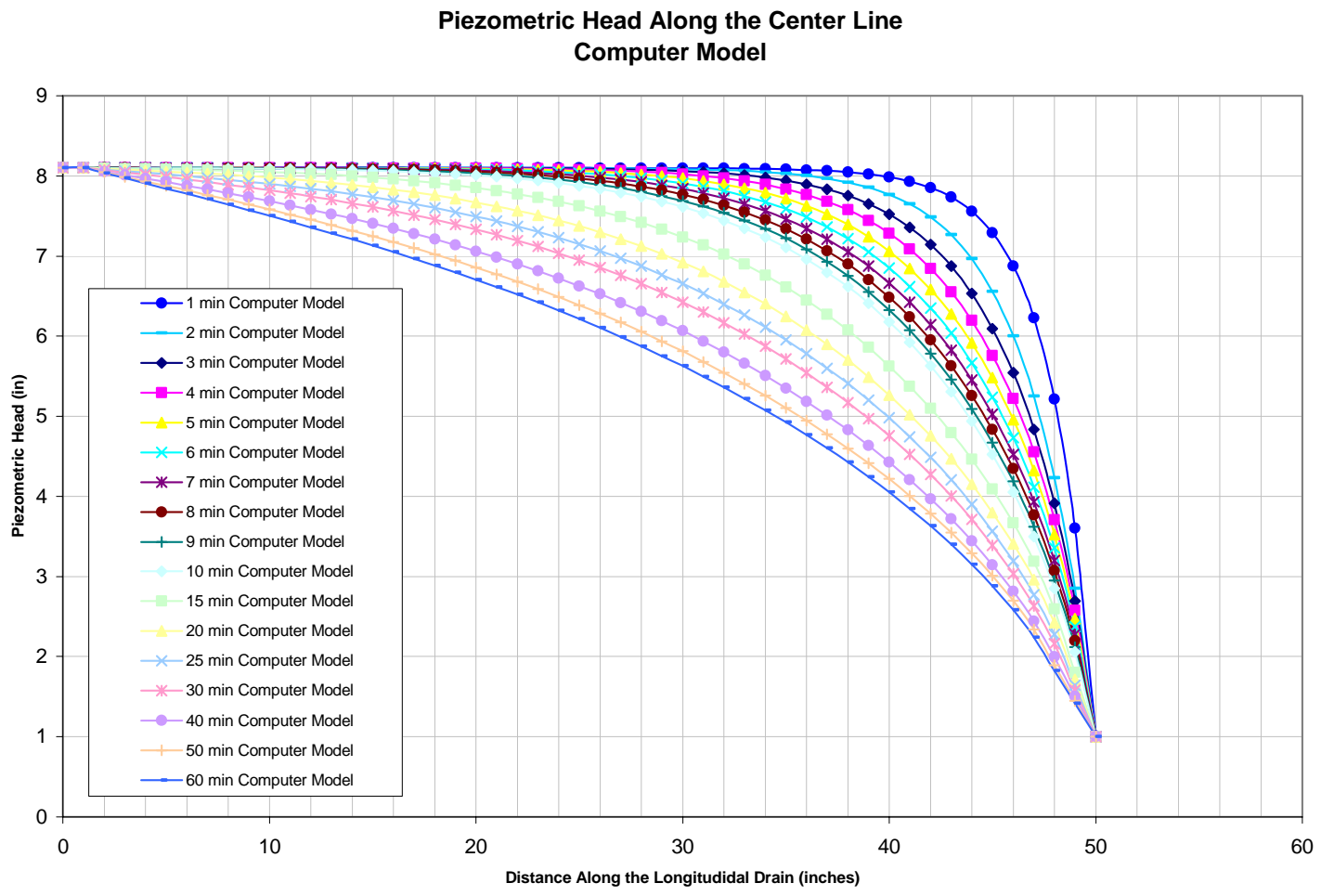

Figure A2.10: Piezometric variation along center line for Soil Type C - Computer Model 


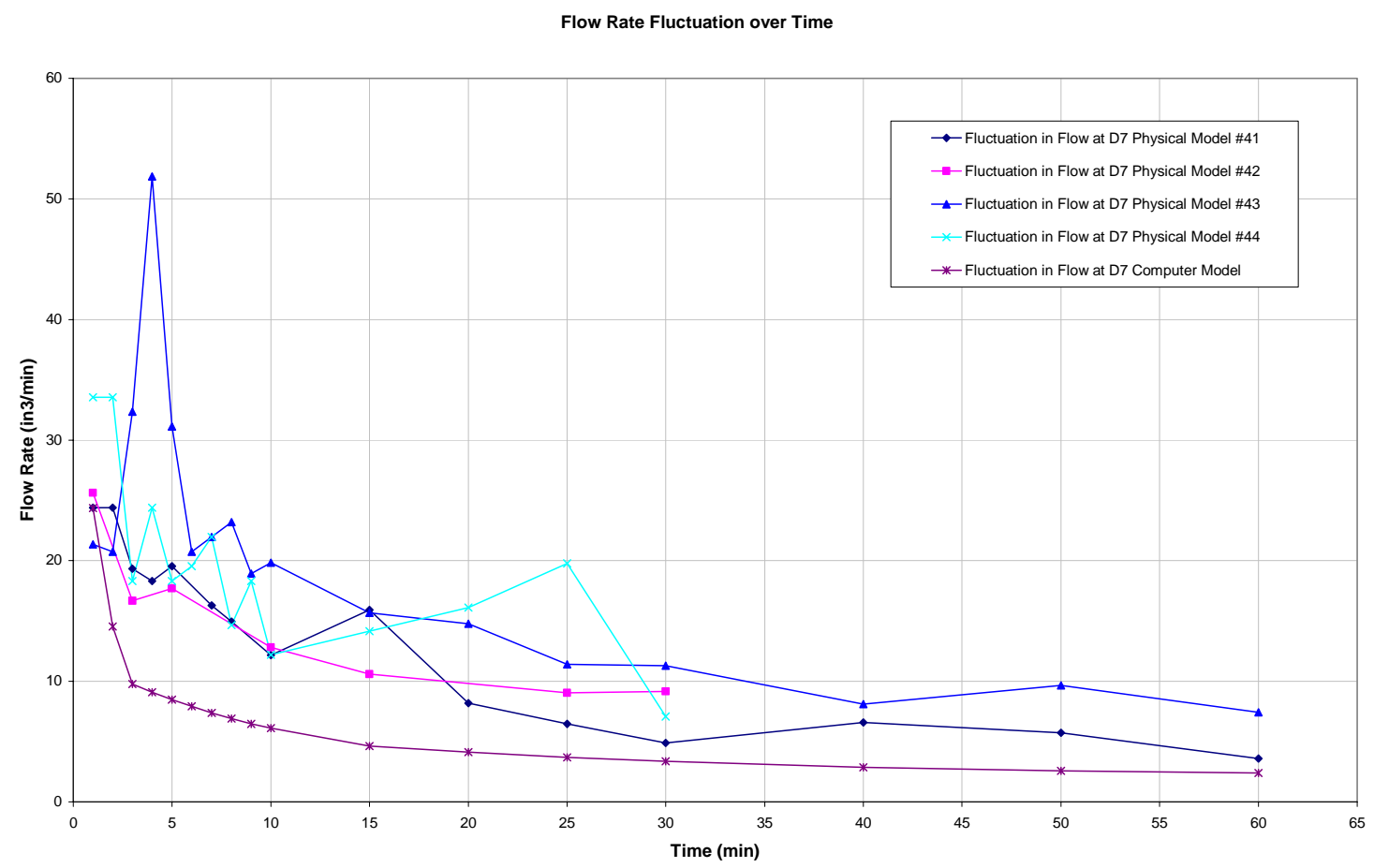

Figure A2.11: Comparison in Flow Rate Fluctuation for Soil Type C

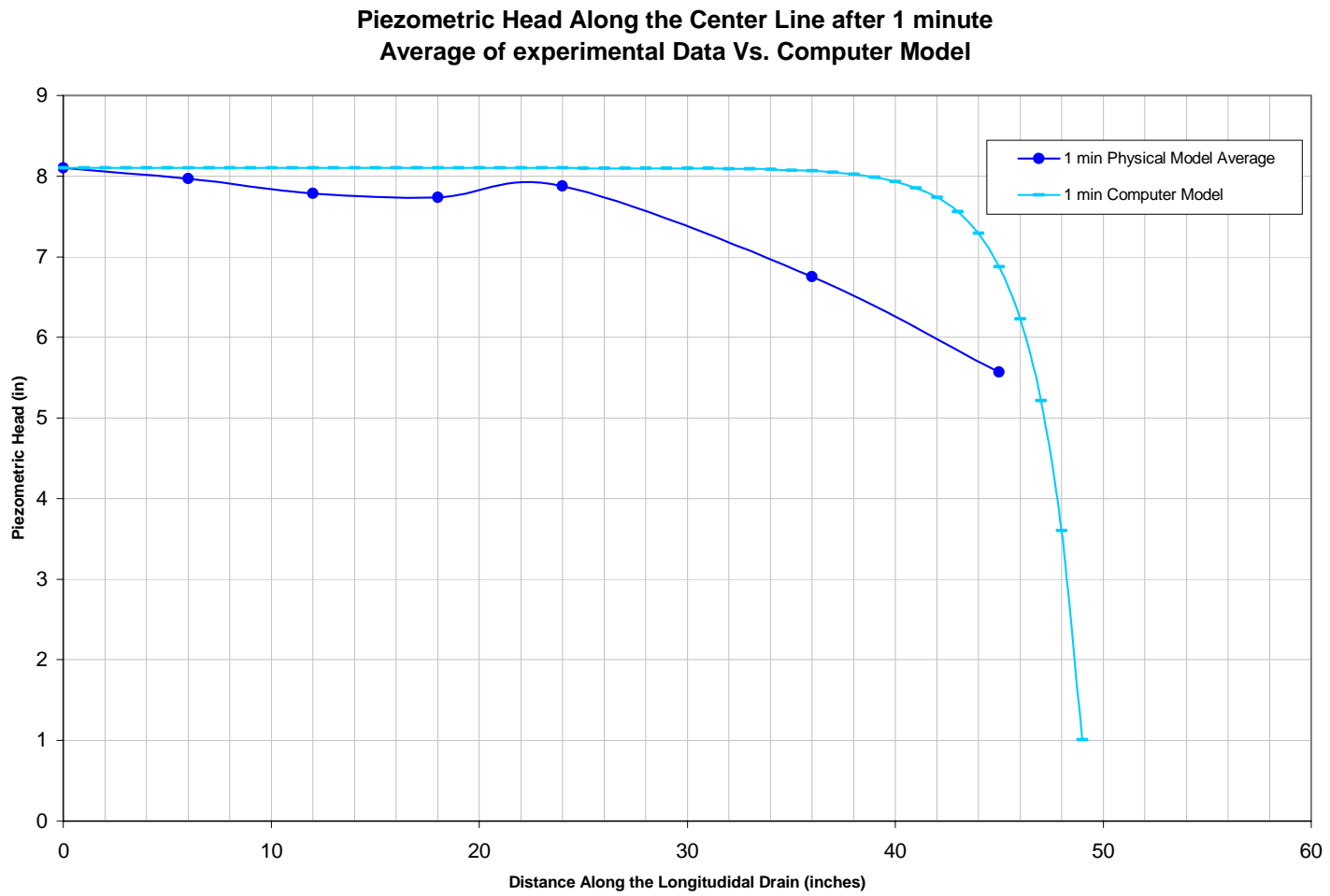

Figure A2.12: Piezometric Level along center line for Soil Type C after 1 minute 


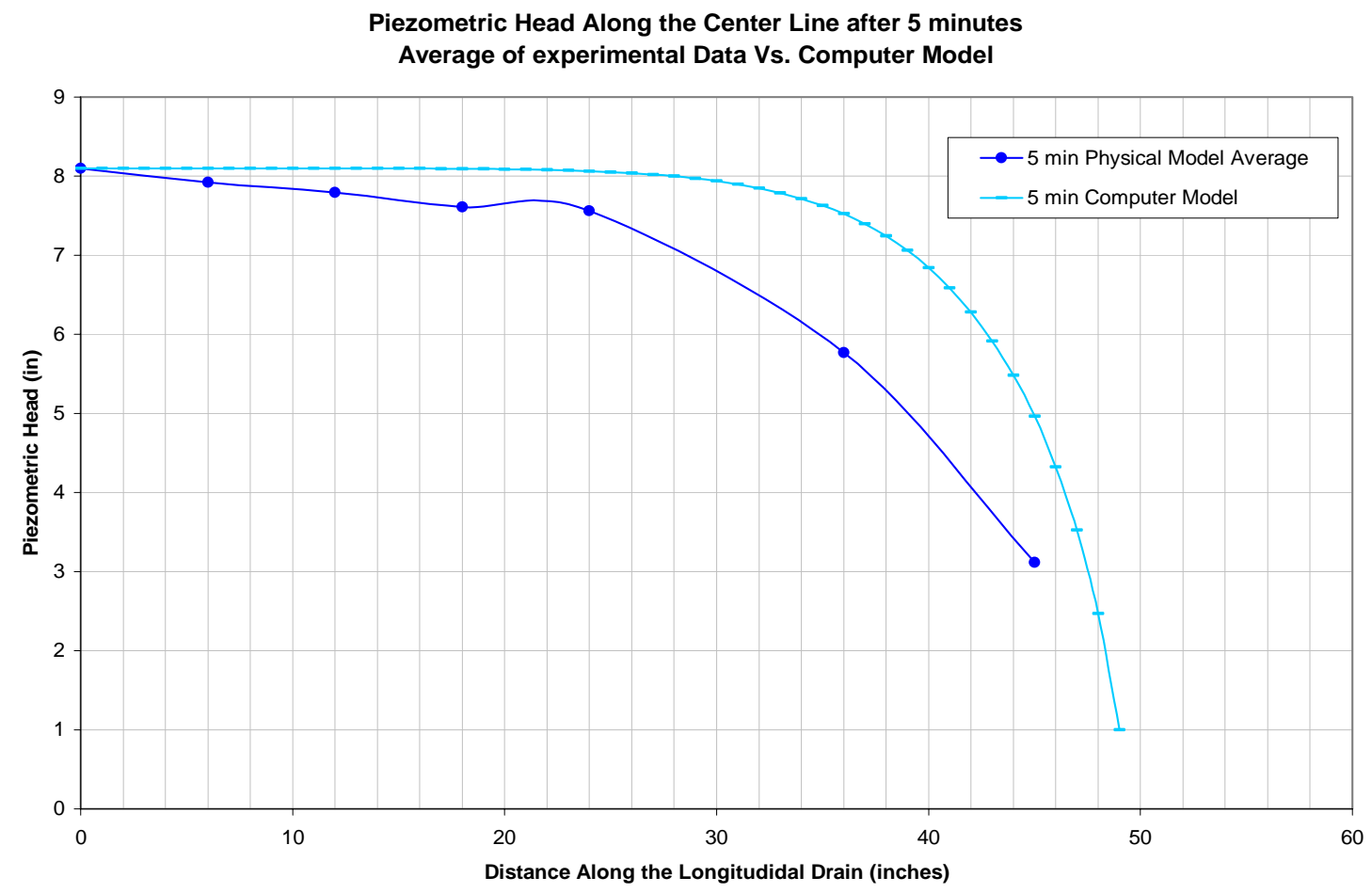

Figure A2.13: Piezometric Level along center line for Soil Type C after 5 minute

Piezometric Head Along the Center Line after 15 minutes

Average of experimental Data Vs. Computer Model

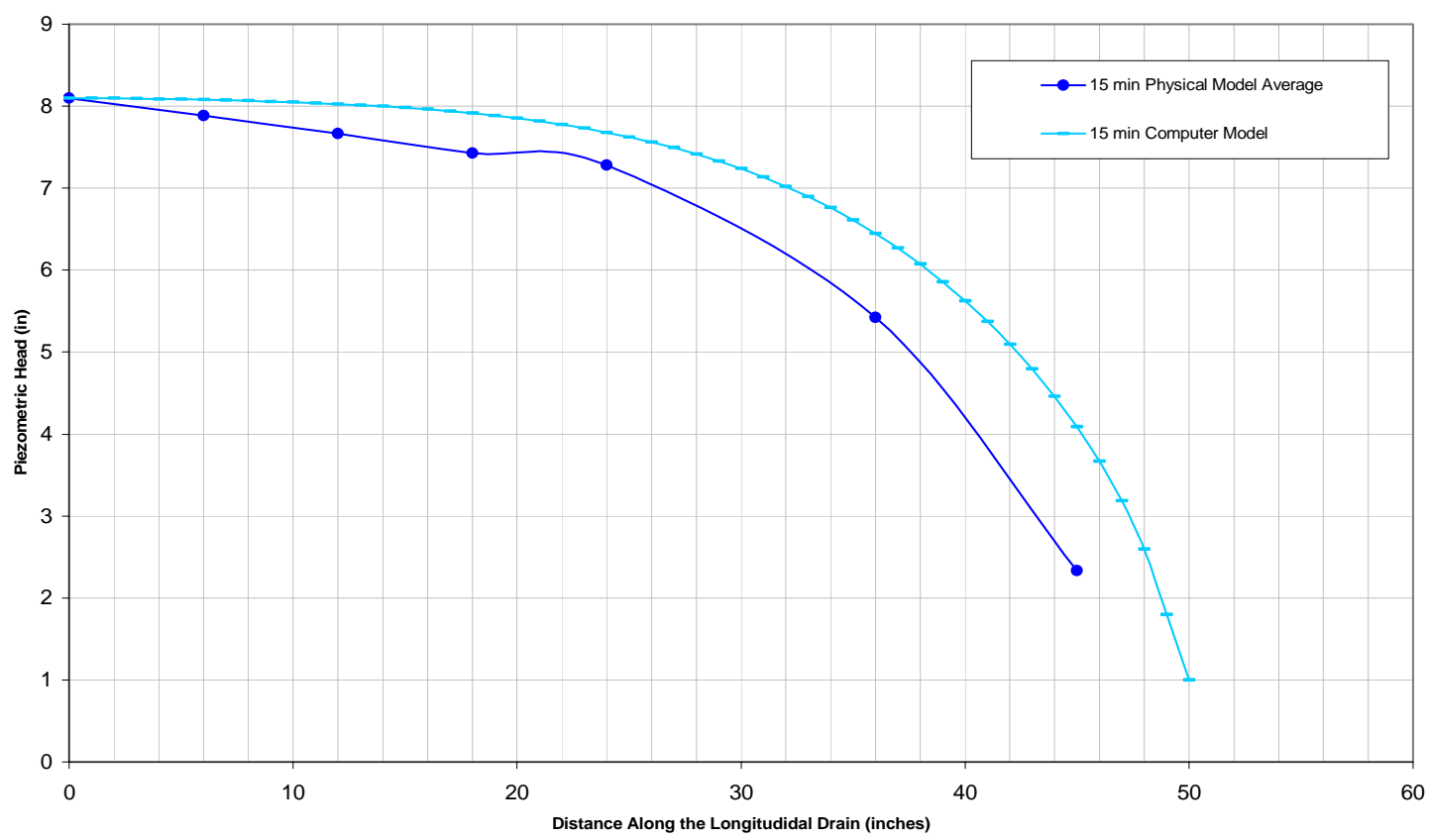

Figure A2.14: Piezometric Level along center line for Soil Type C after 15 minute 


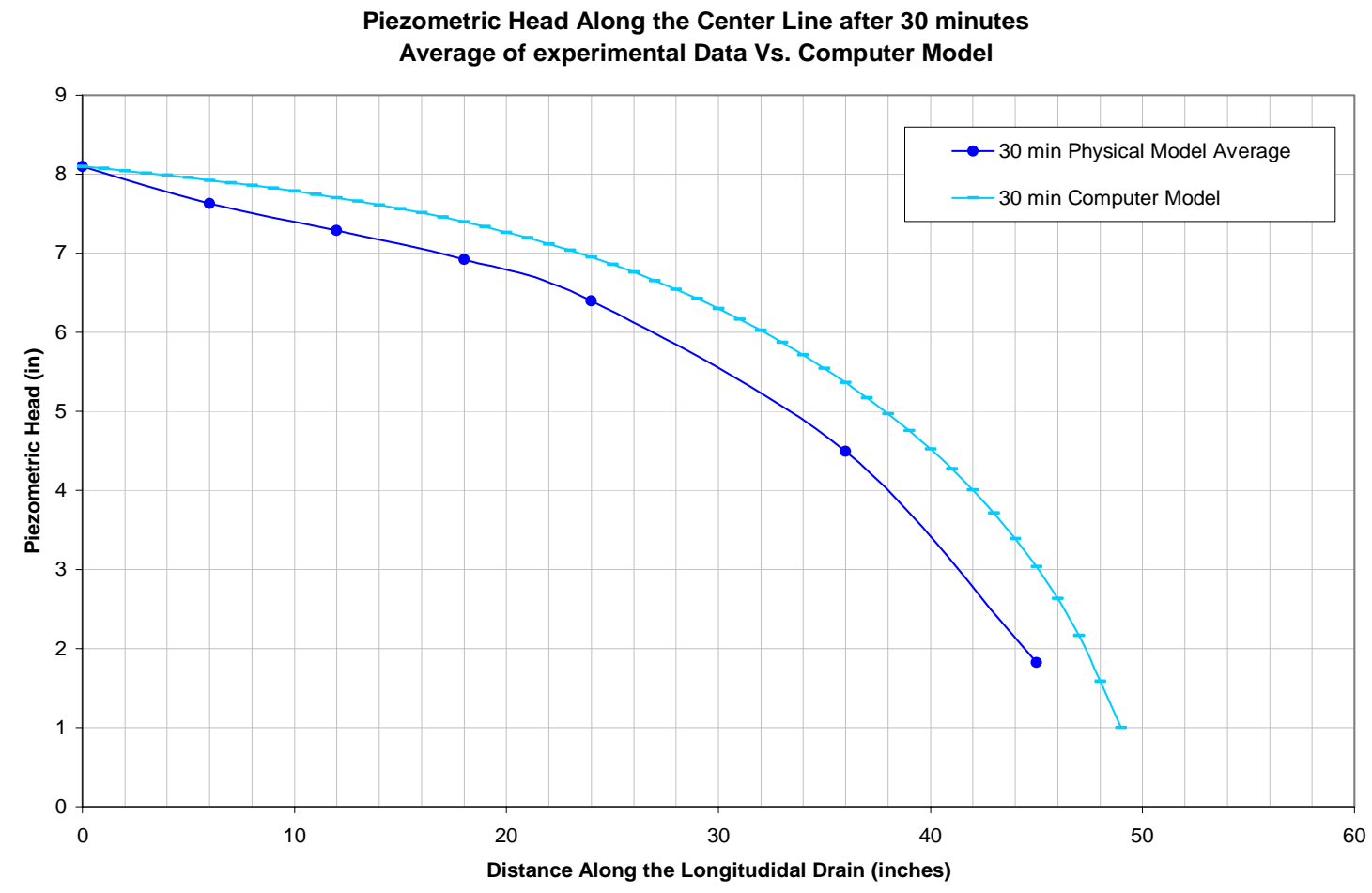

Figure A2.15: Piezometric Level along center line for Soil Type C after 30 minute

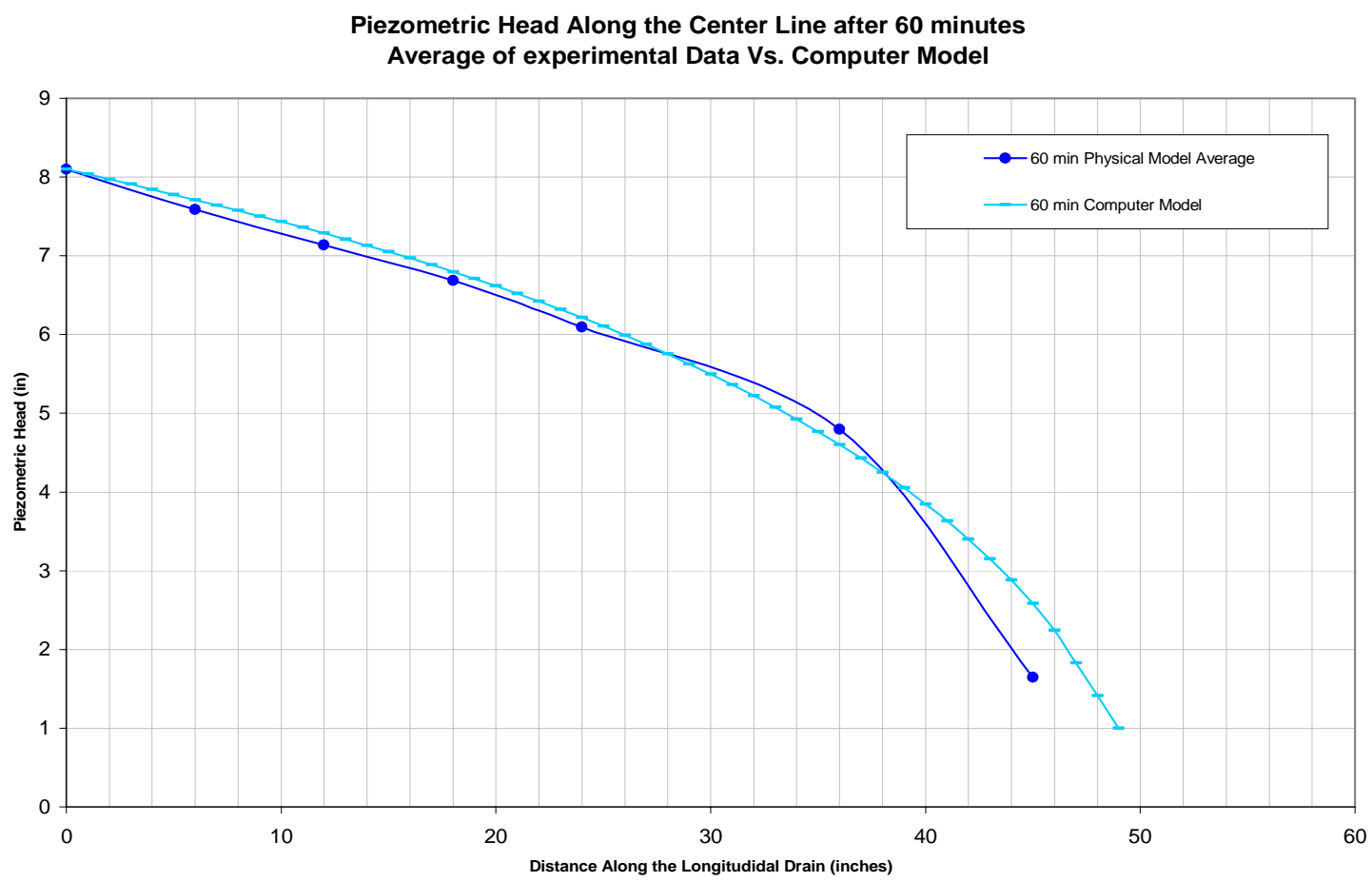

Figure A2.16: Piezometric Level along center line for Soil Type C after 60 minute 


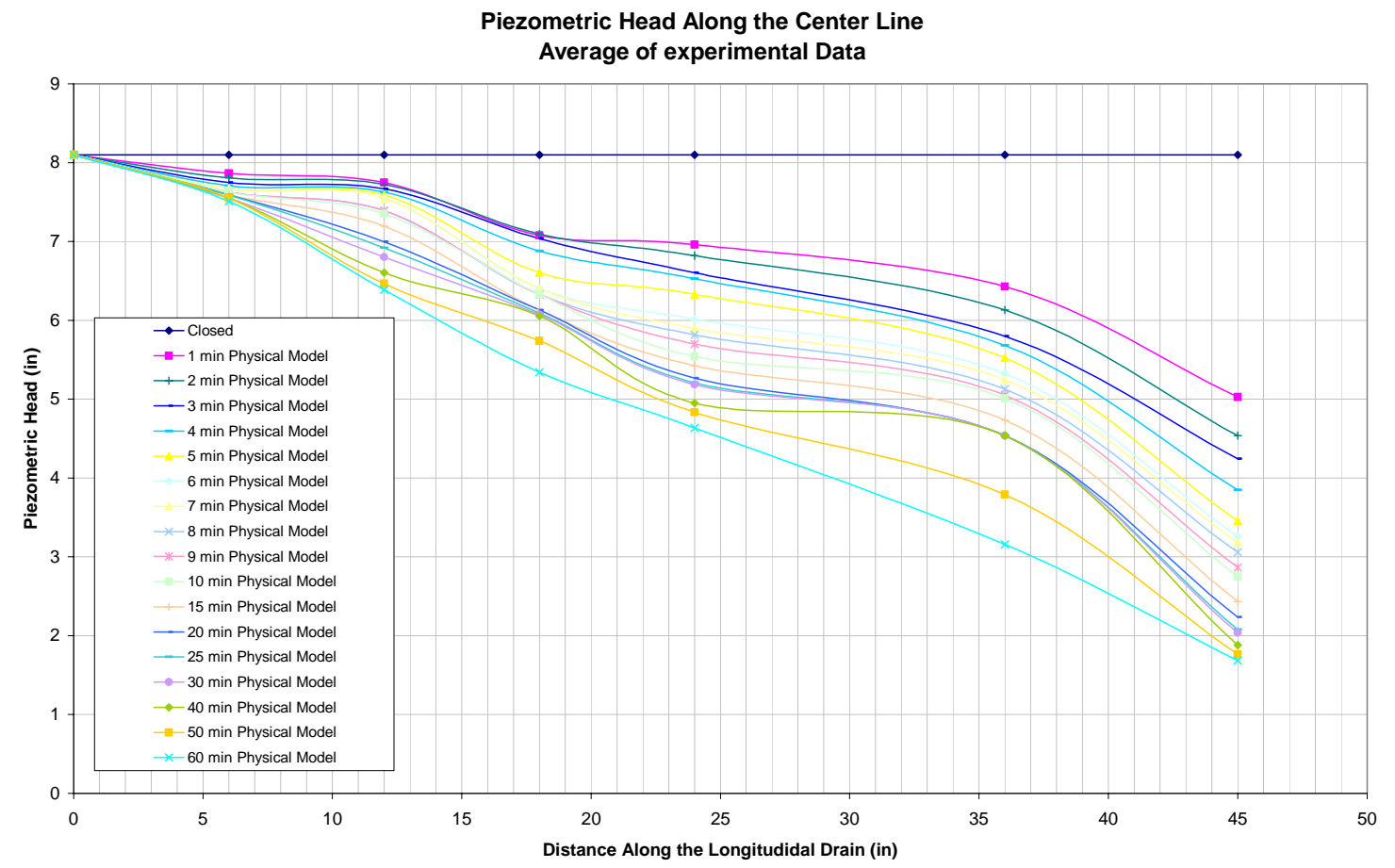

Figure A2.17: Piezometric variation along Center Line for Soil Type D -Physical Model

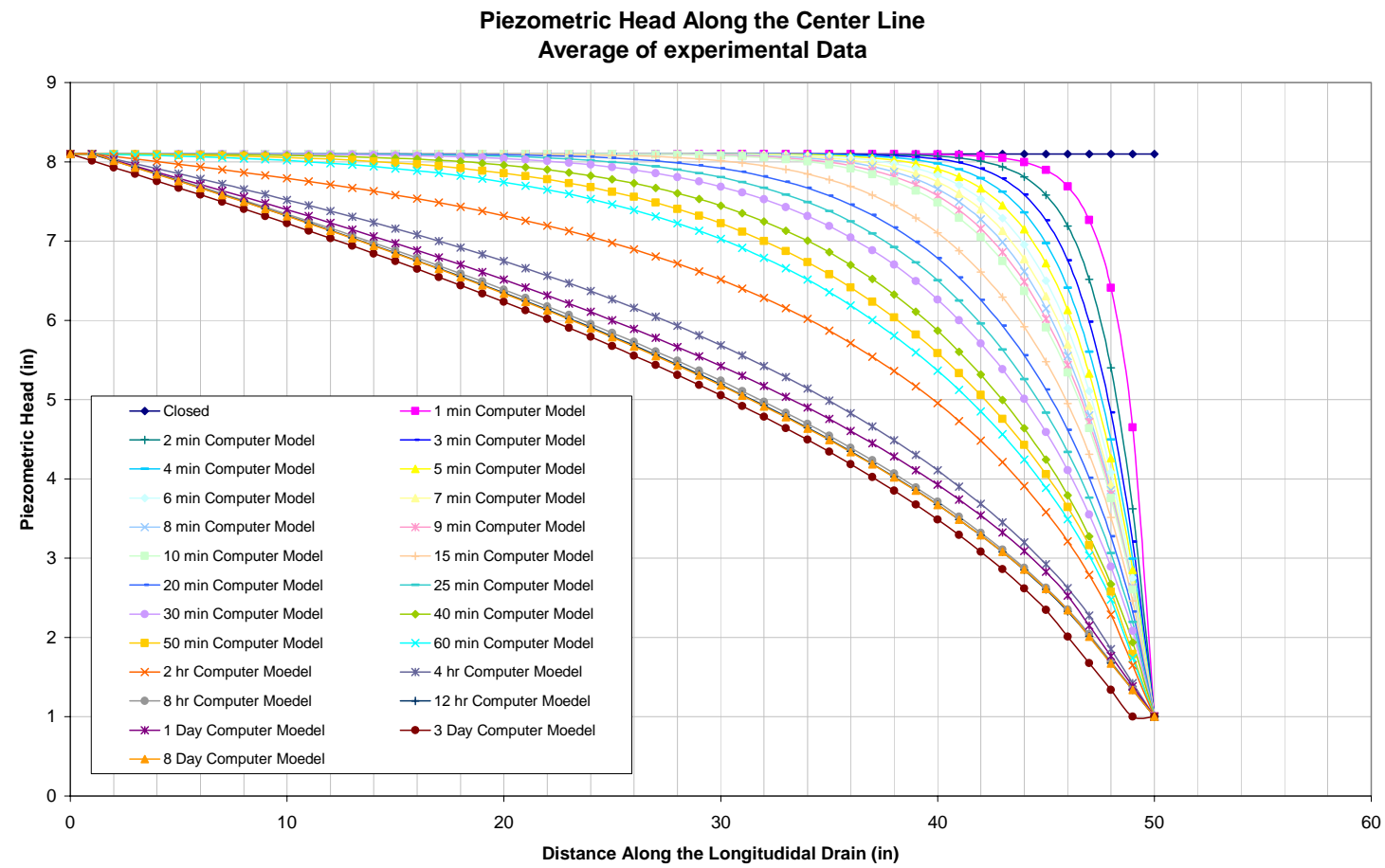

Figure A2.18: Piezometric variation along center line for Soil Type D - Computer Model 
Flow Rate Fluctuation over Time

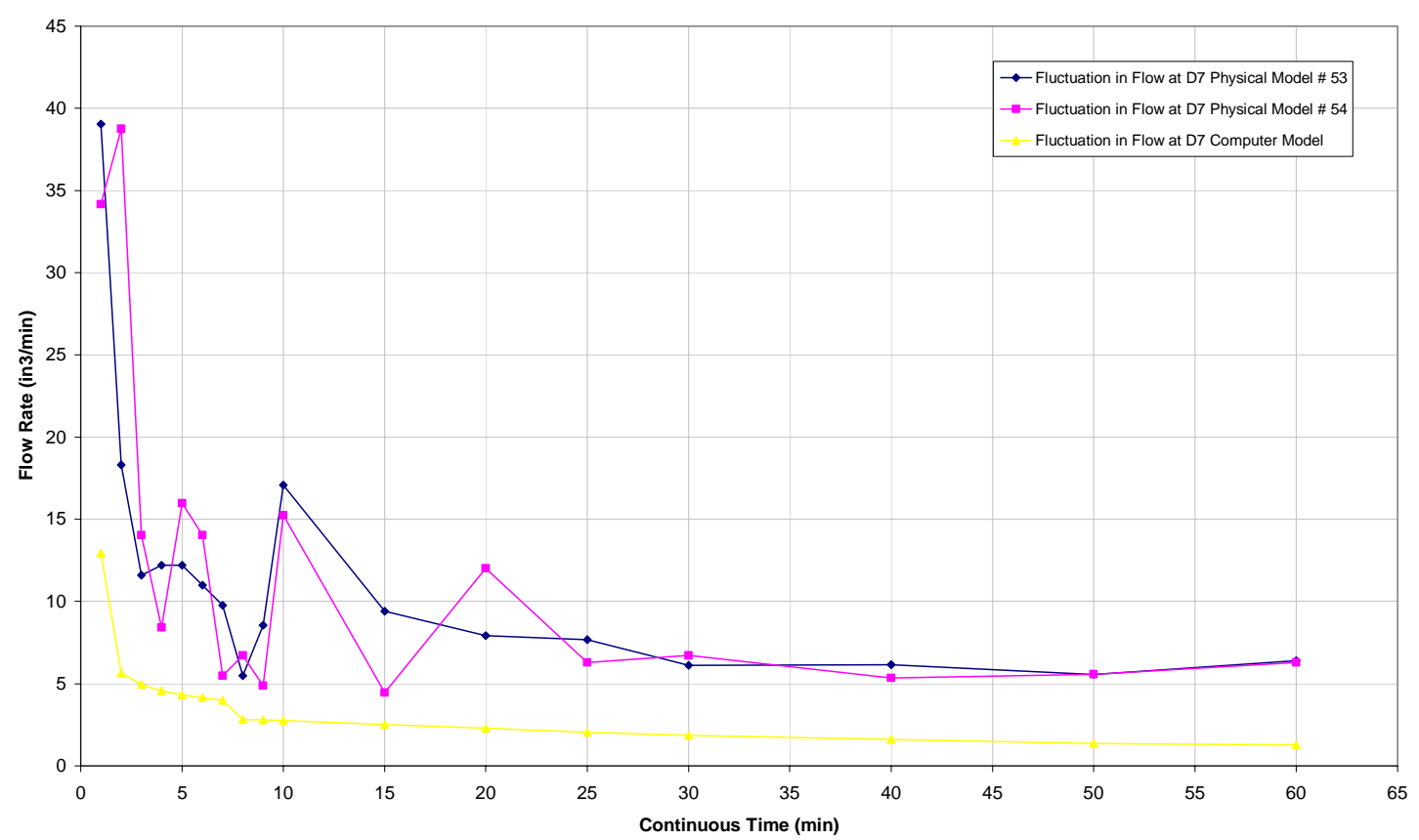

Figure A2.19: Comparison in Flow Rate Fluctuation for Soil Type D

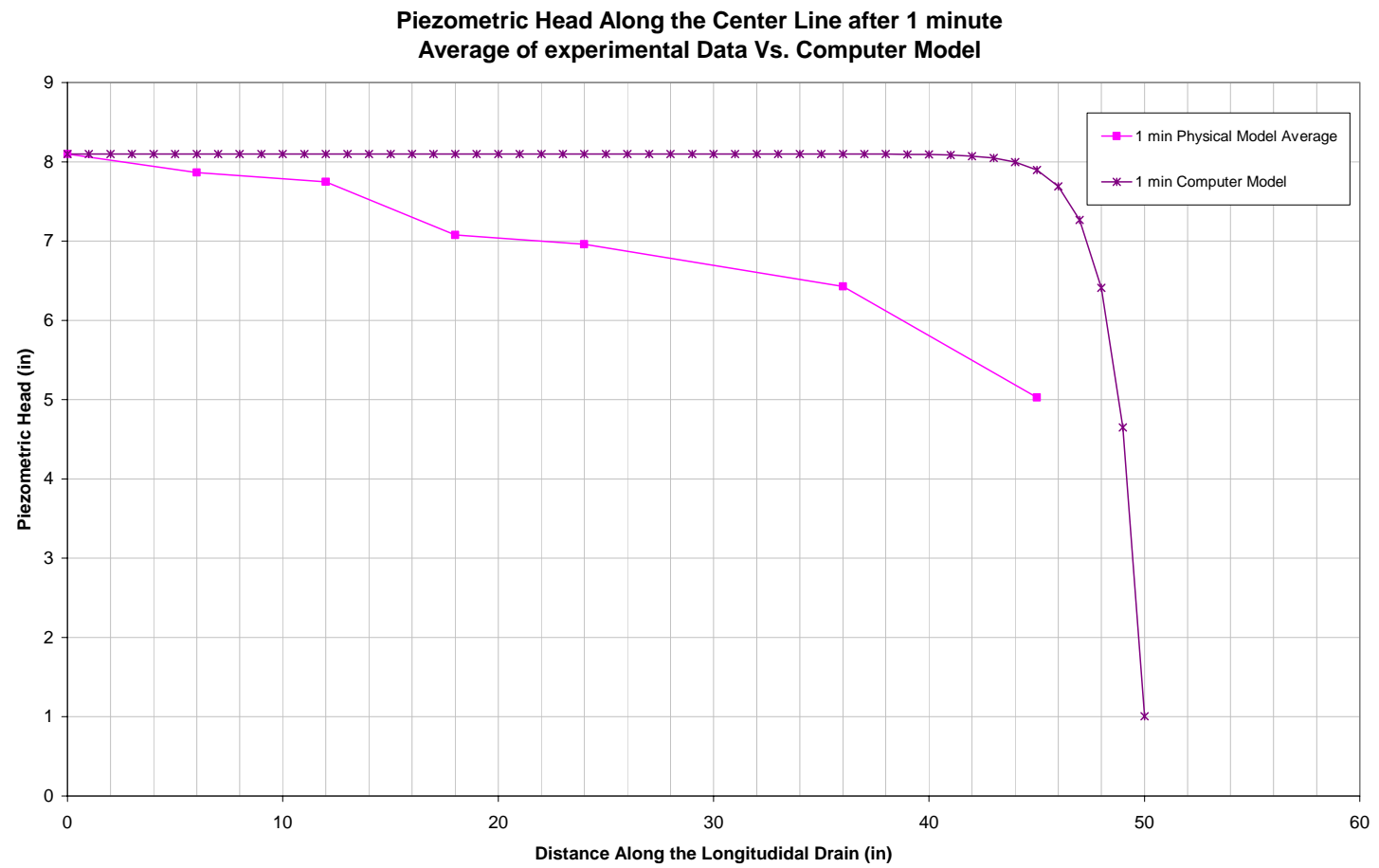

Figure A2.20: Piezometric Level along center line for Soil Type D after 1 minute 


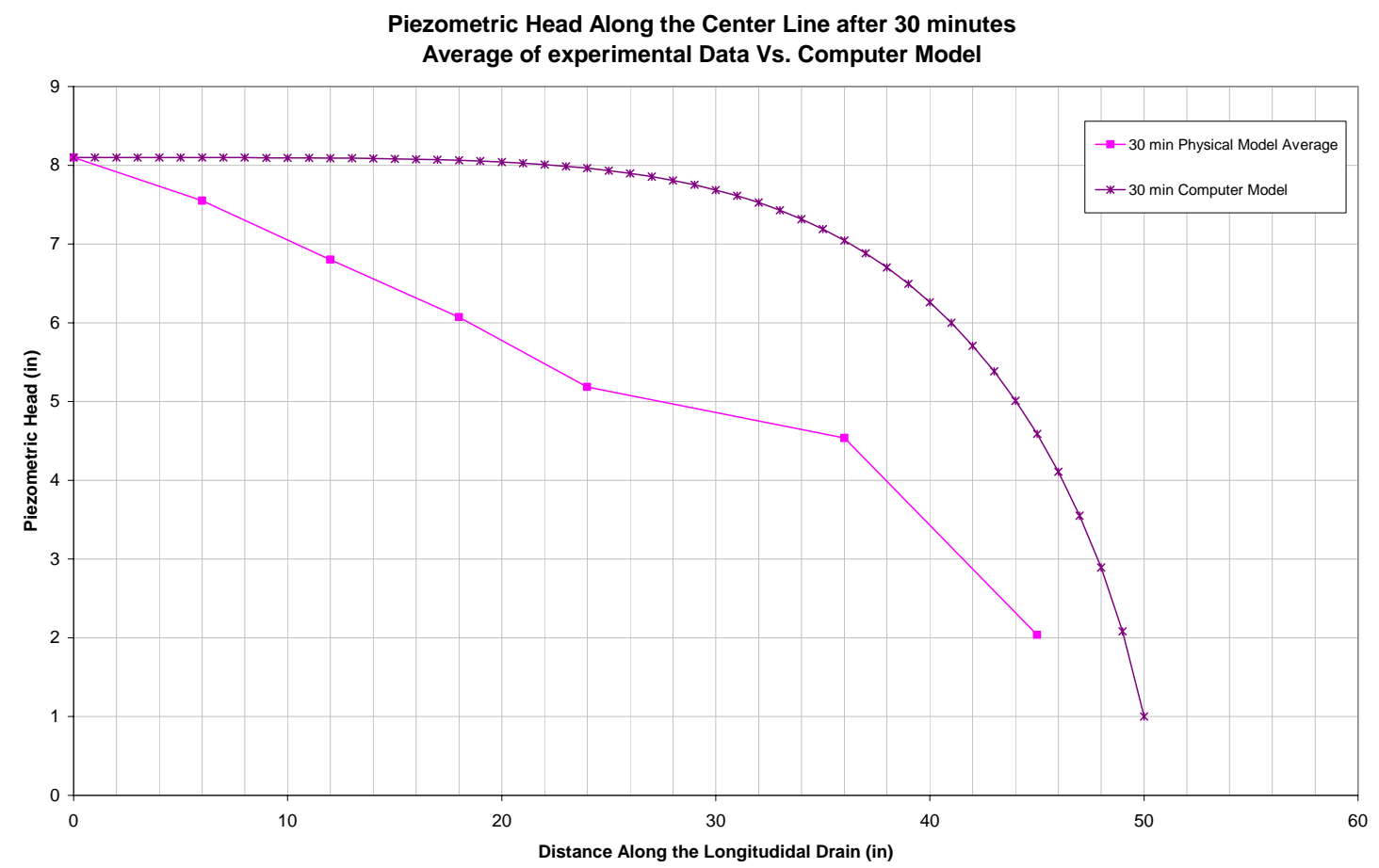

Figure A2.21: Piezometric Level along center line for Soil Type D after 30 minutes

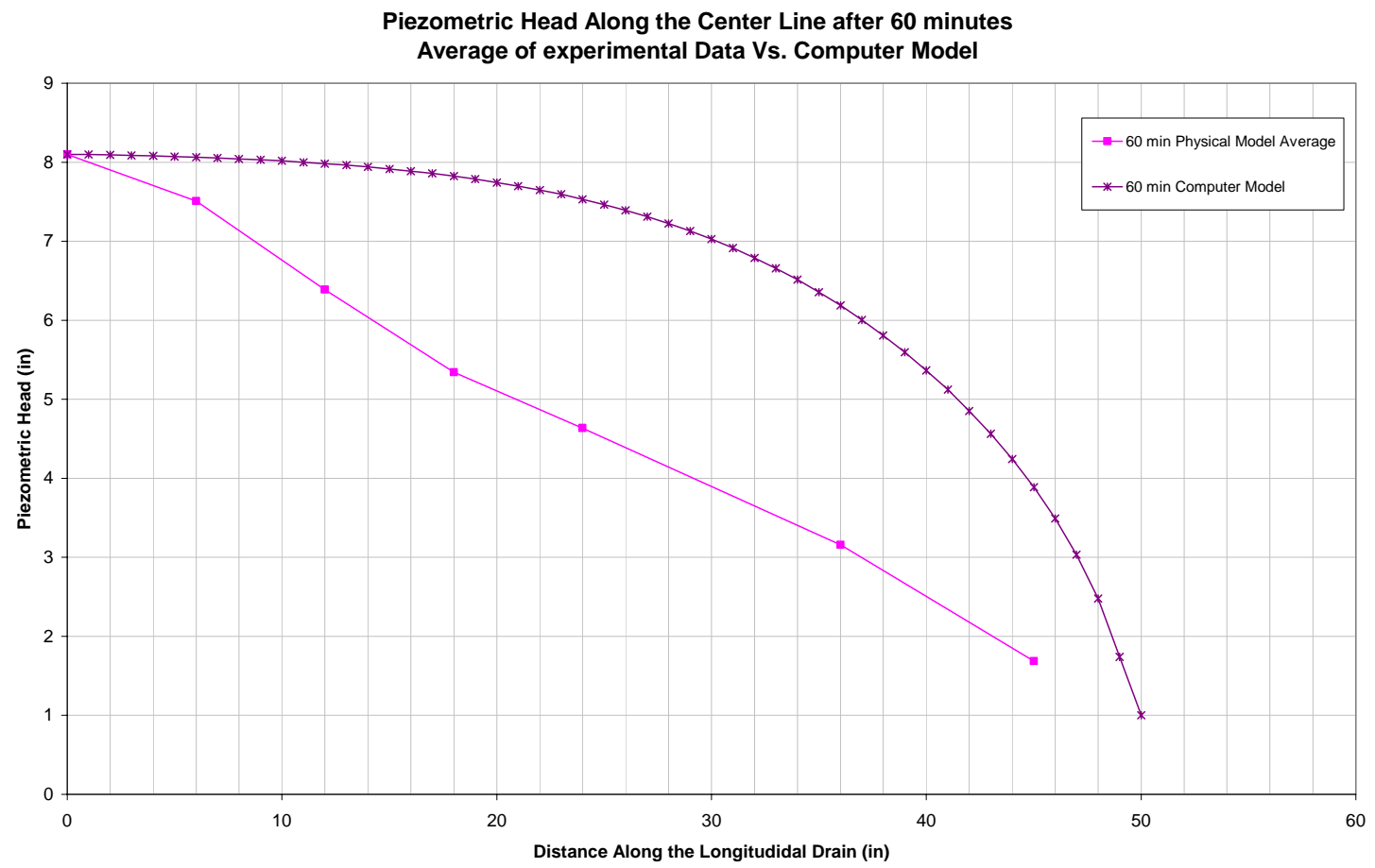

Figure A2.22: Piezometric Level along center line for Soil Type D after 60 minutes 


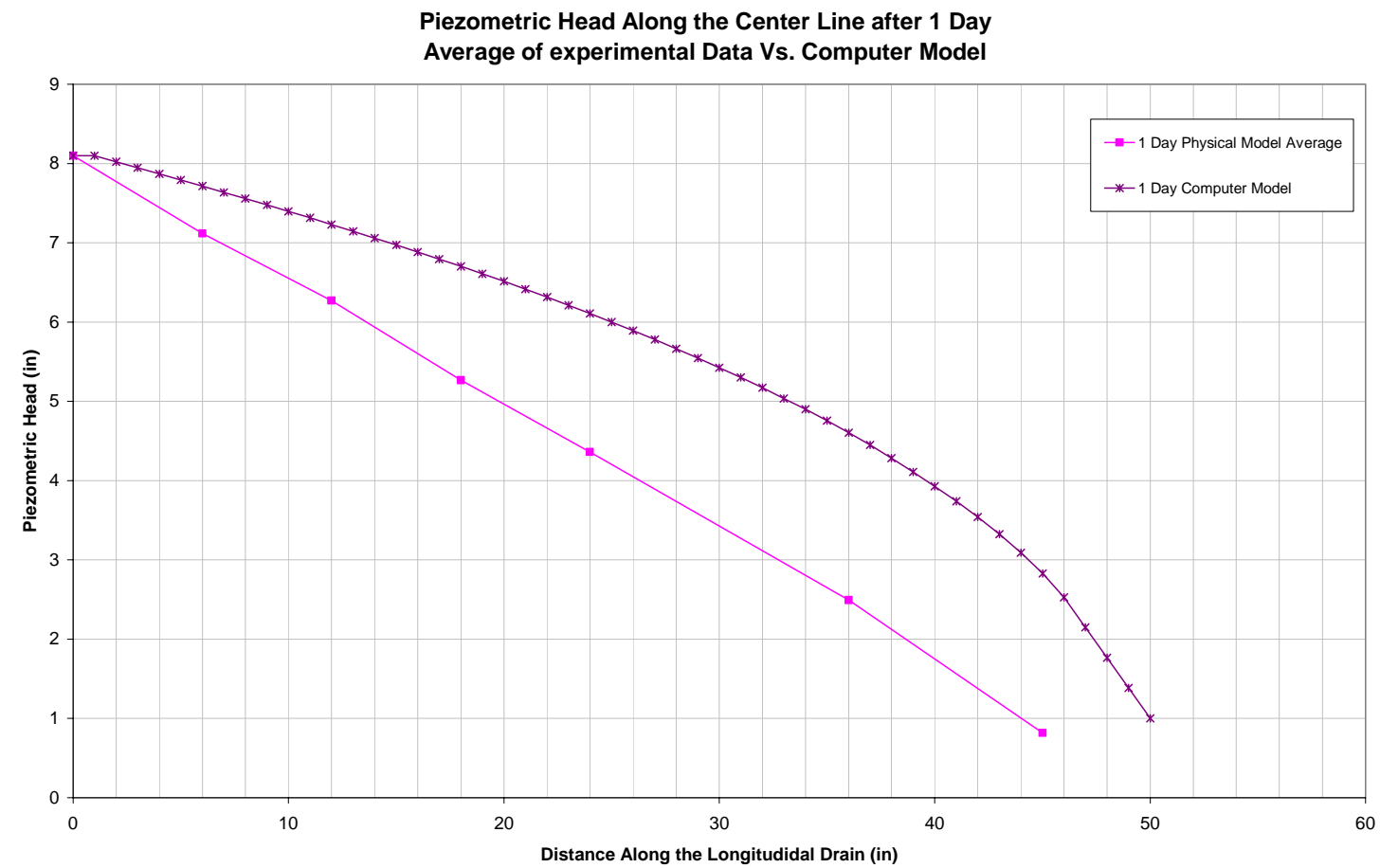

Figure A2.23: Piezometric Level along center line for Soil Type D after 1 Day

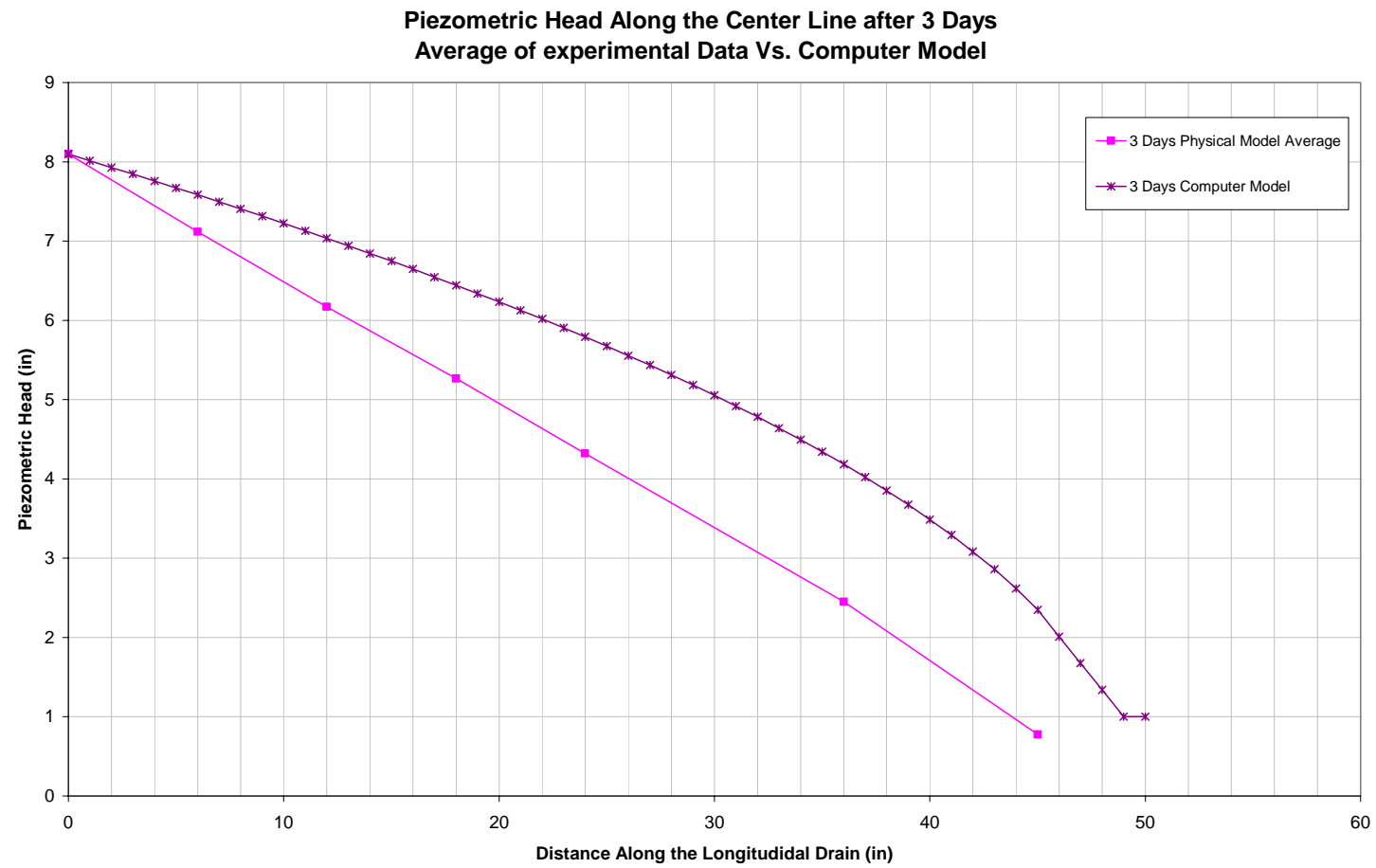

Figure A2.24: Piezometric Level along center line for Soil Type D after 2 Days 


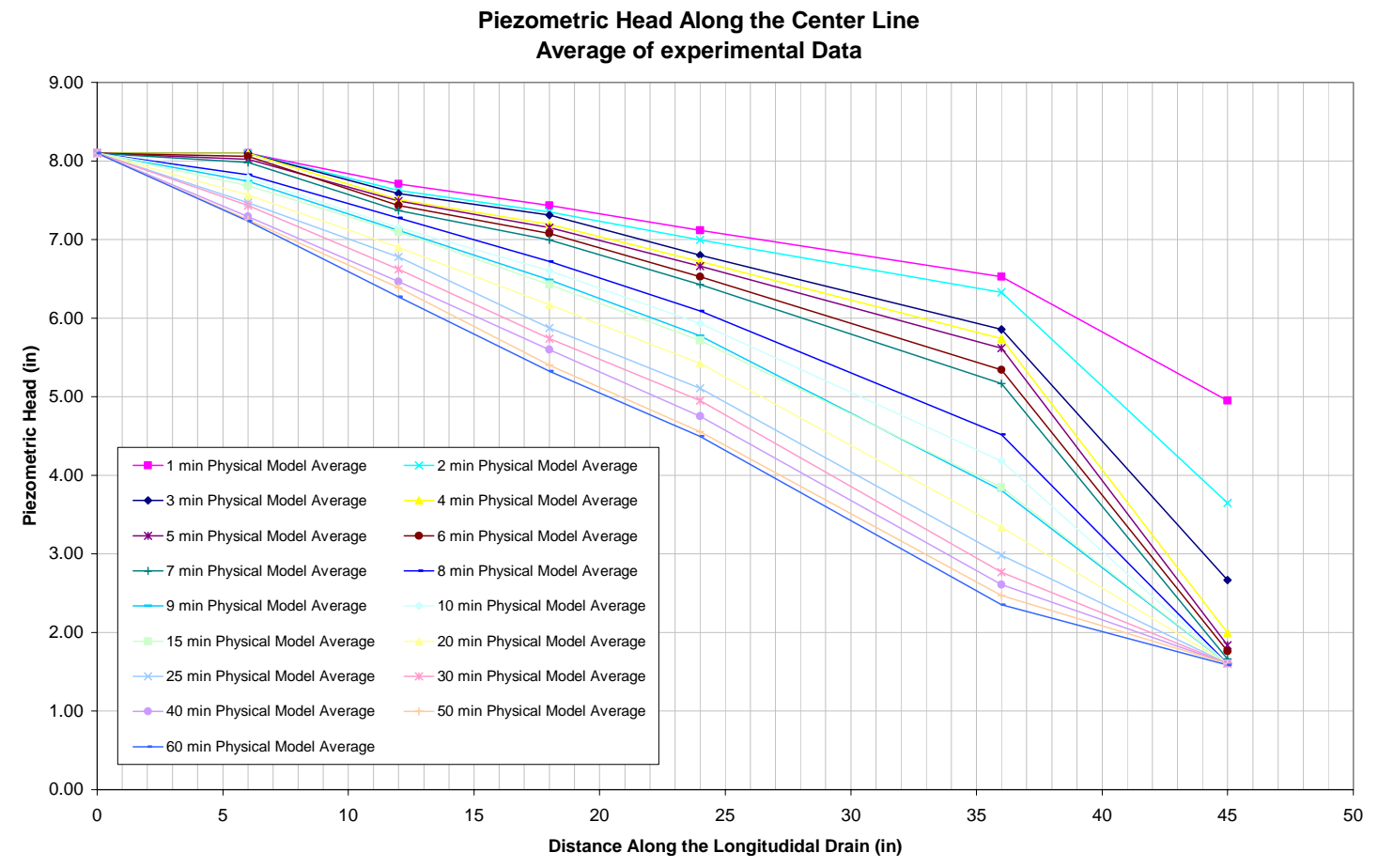

Figure A2.25: Piezometric variation along Center Line for Soil Type B -Physical Model

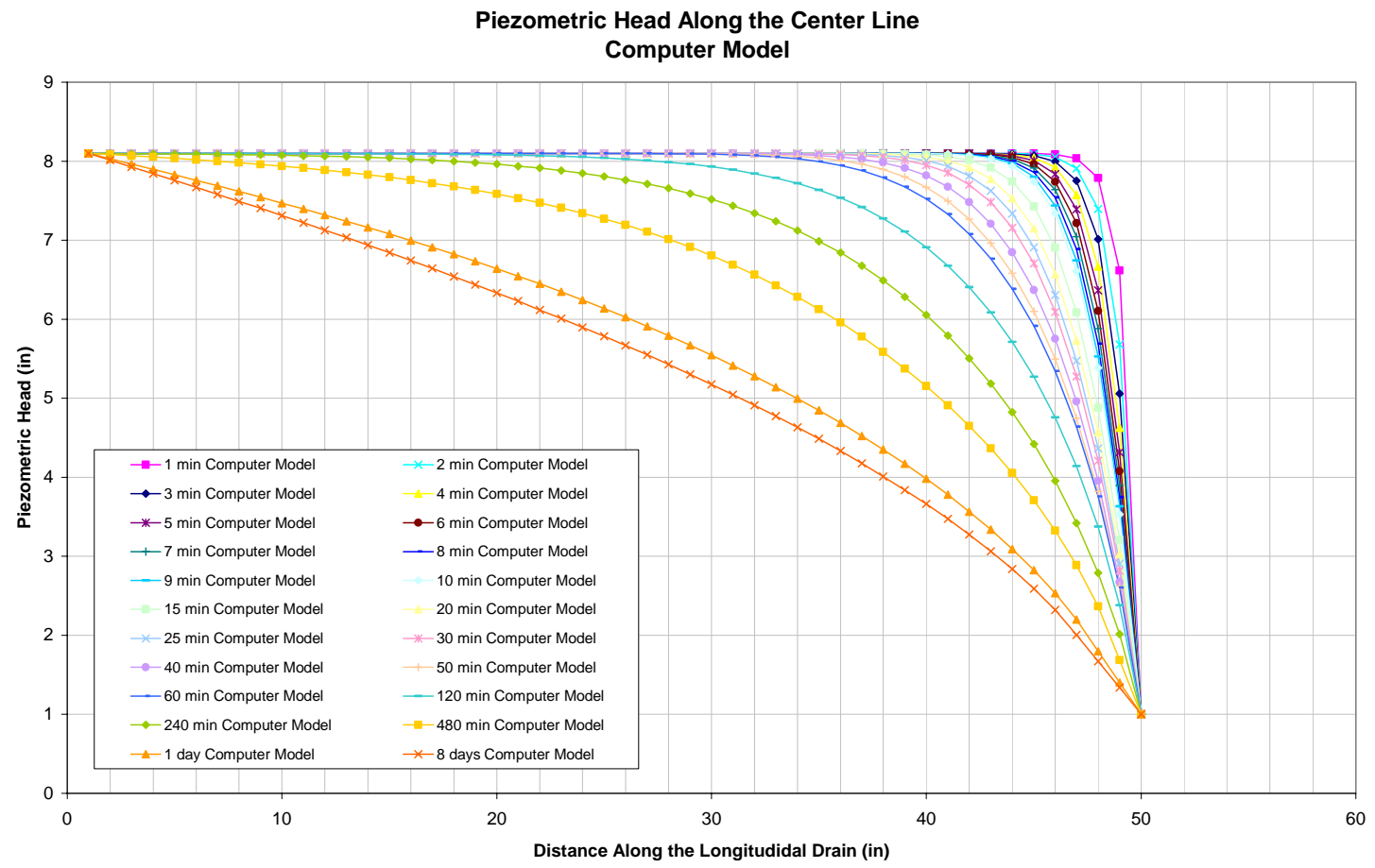

Figure A2.26: Piezometric variation along center line for Soil Type E - Computer Model 
Flow Rate Fluctuation over Time

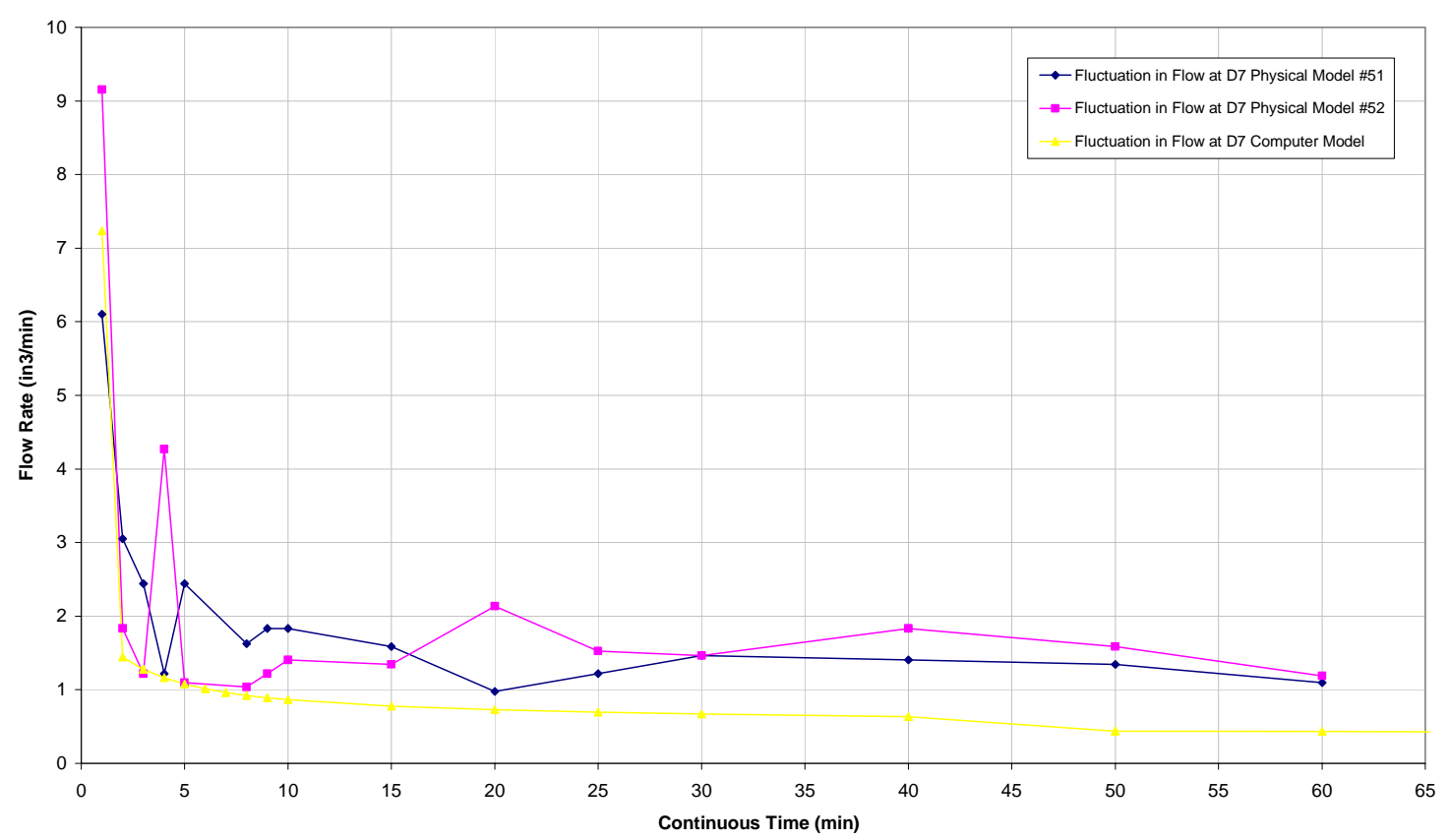

Figure A2.27: Comparison in Flow Rate Fluctuation for Soil Type E

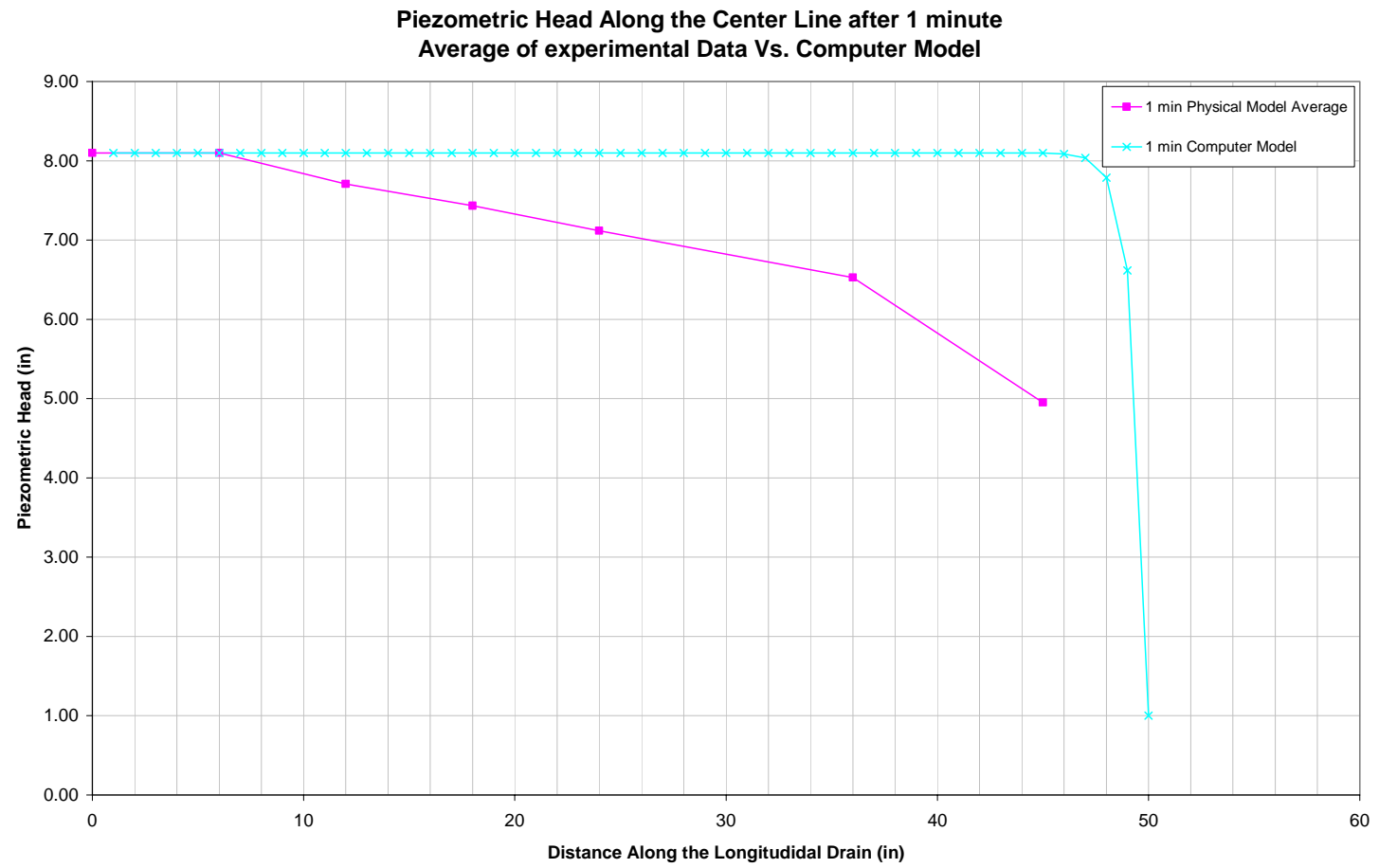

Figure A2.28: Piezometric Level along center line for Soil Type E after 1 minute 


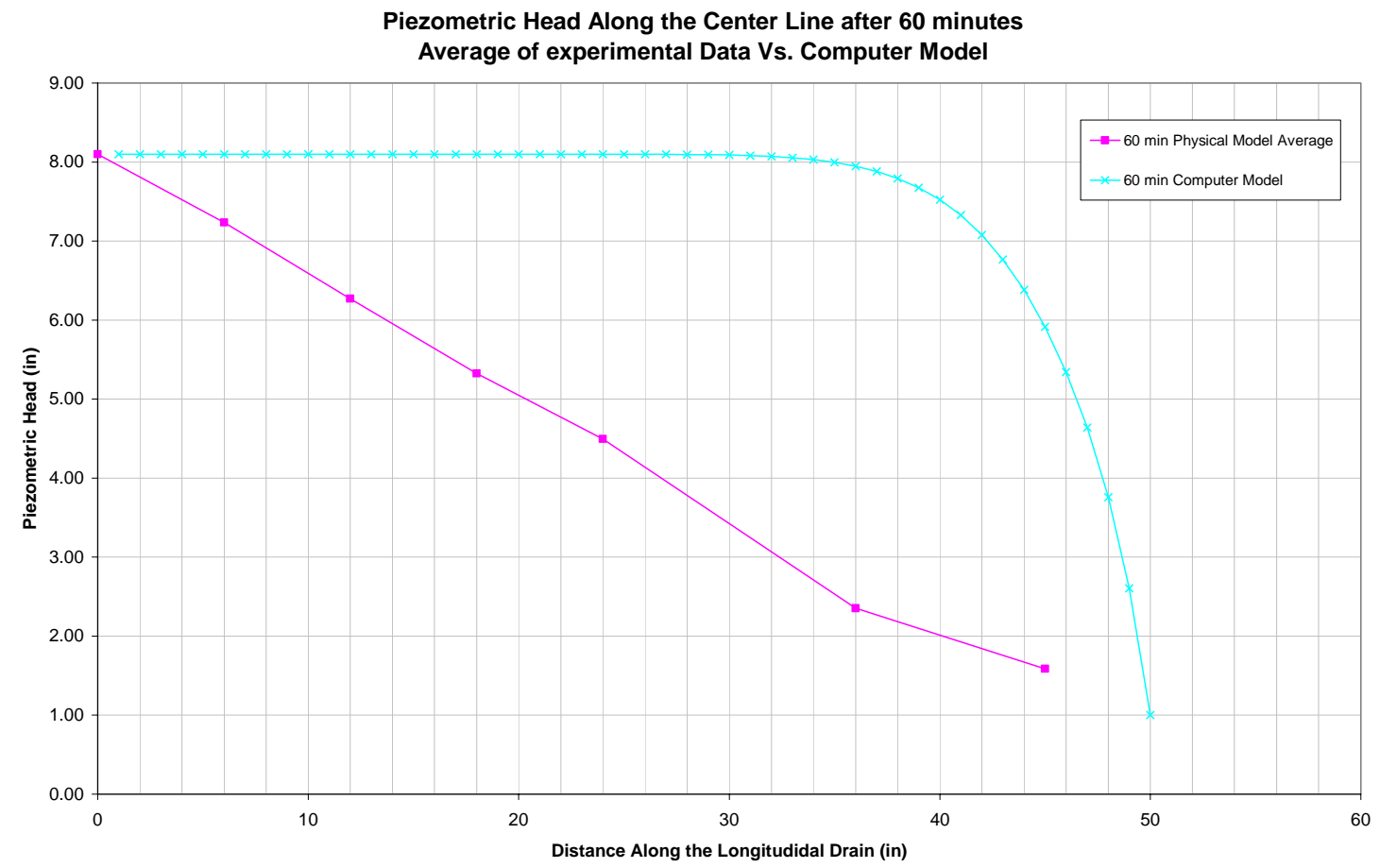

Figure A2.29: Piezometric Level along center line for Soil Type E after 60 minutes

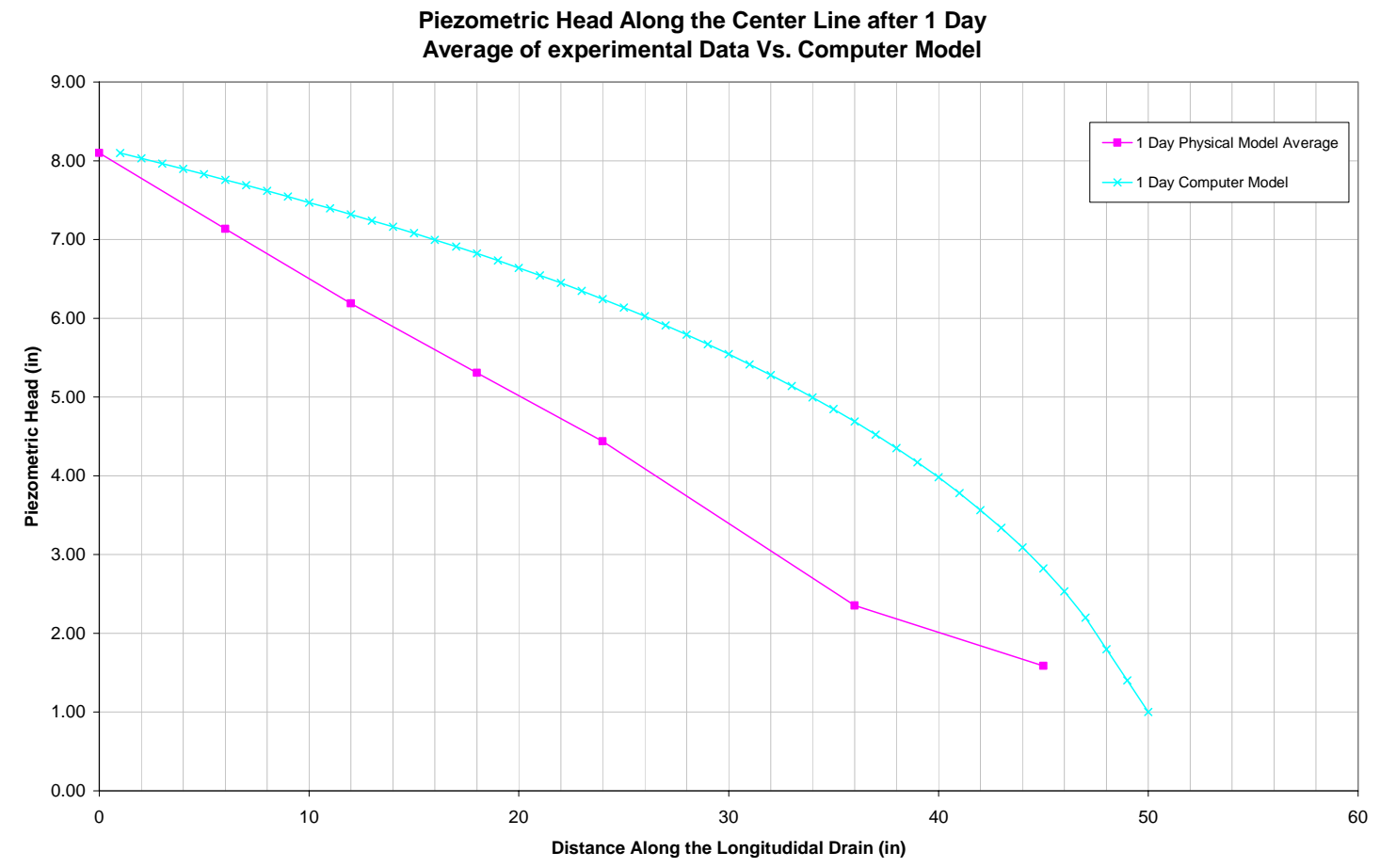

Figure A2.30: Piezometric Level along center line for Soil Type E after 1 Day 


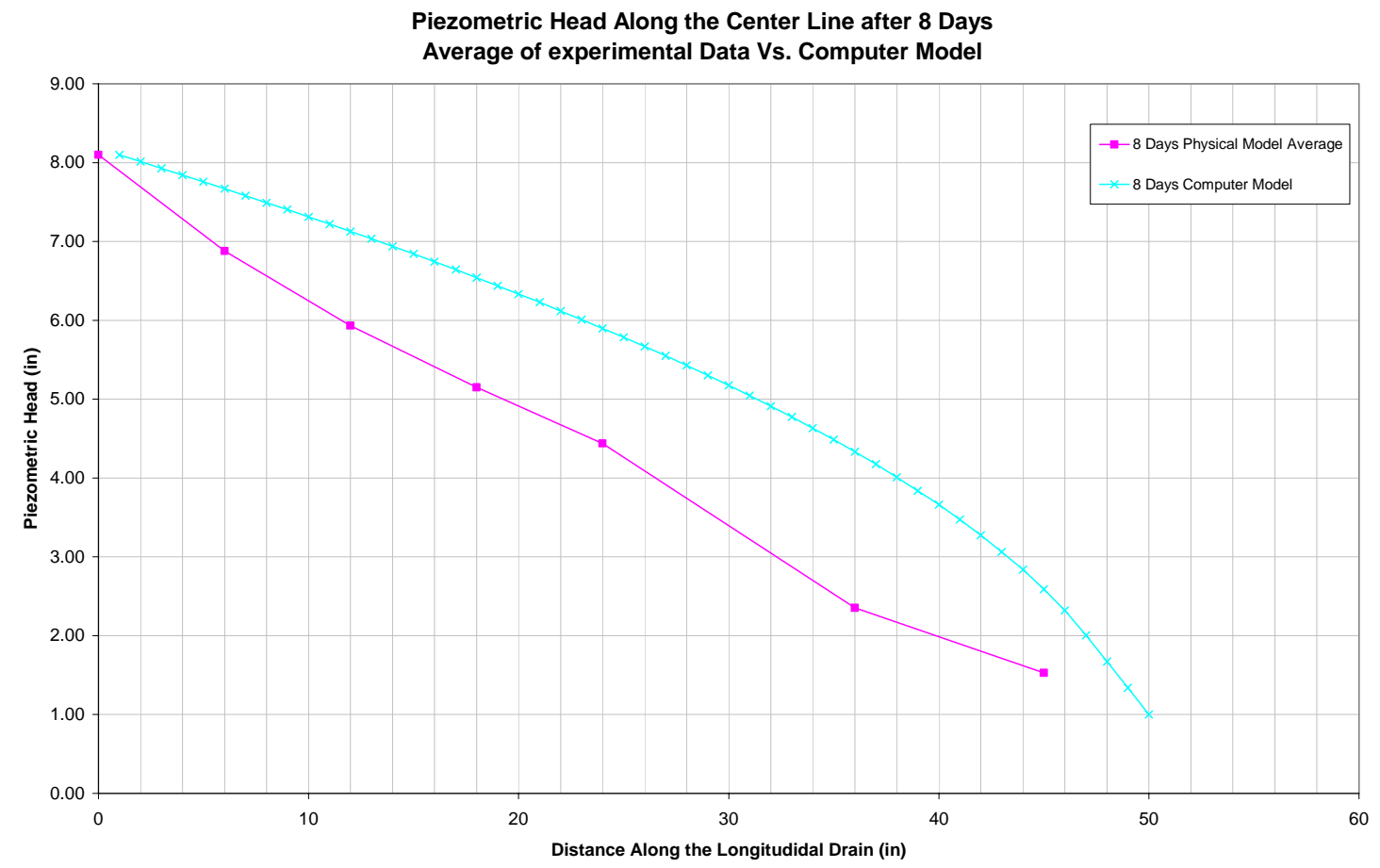

Figure A2.31: Piezometric Level along center line for Soil Type E after 8 Days 
Appendix A3: Laboratory Vs Computer Model Side Drain Cases

$$
\begin{aligned}
& \mathrm{W}=12 \text { inches } \\
& 1=48 \text { inches } \\
& \theta=0^{0}
\end{aligned}
$$




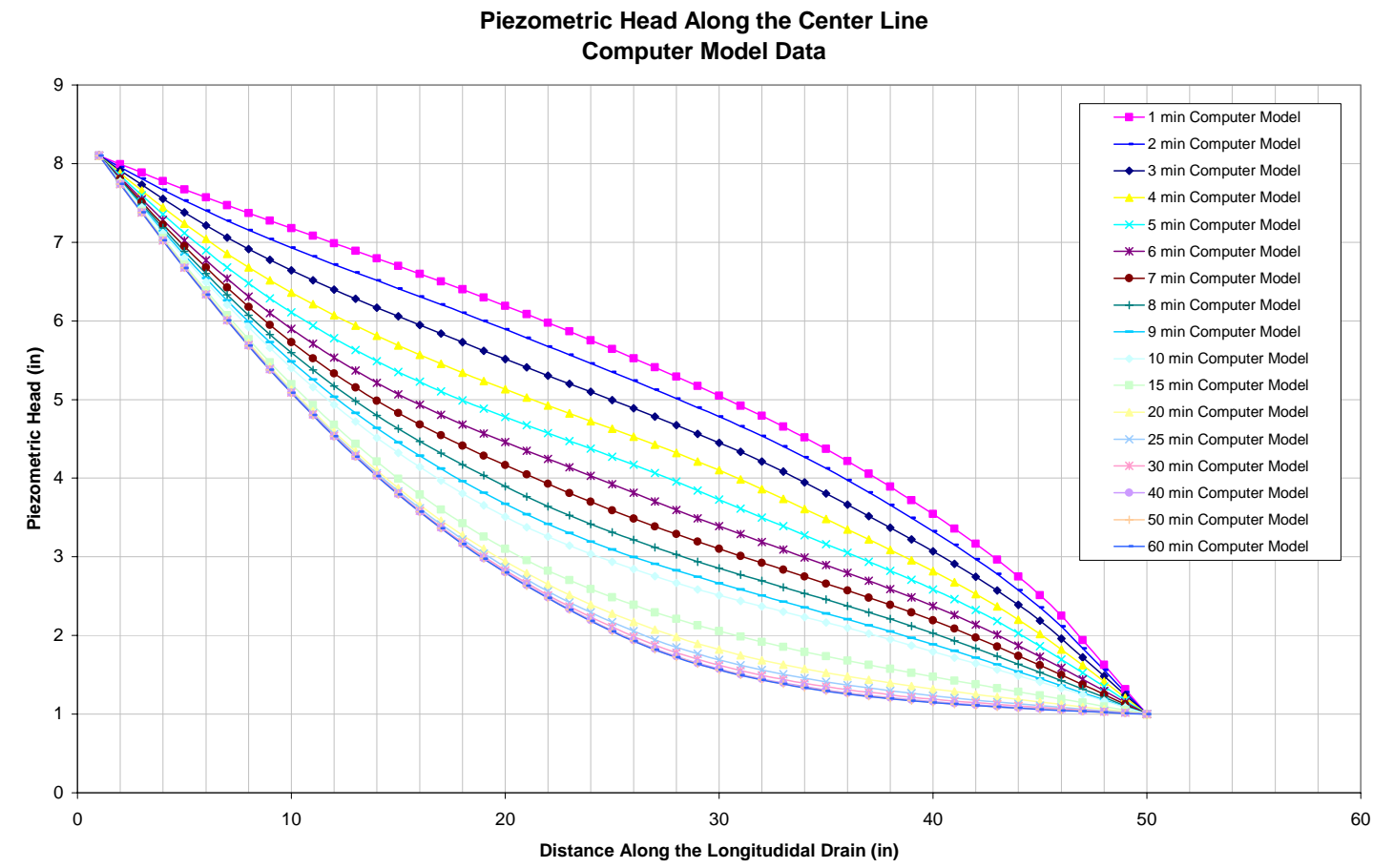

Figure A3.1: Piezometric head along Center Line Soil Type B - Computer Model

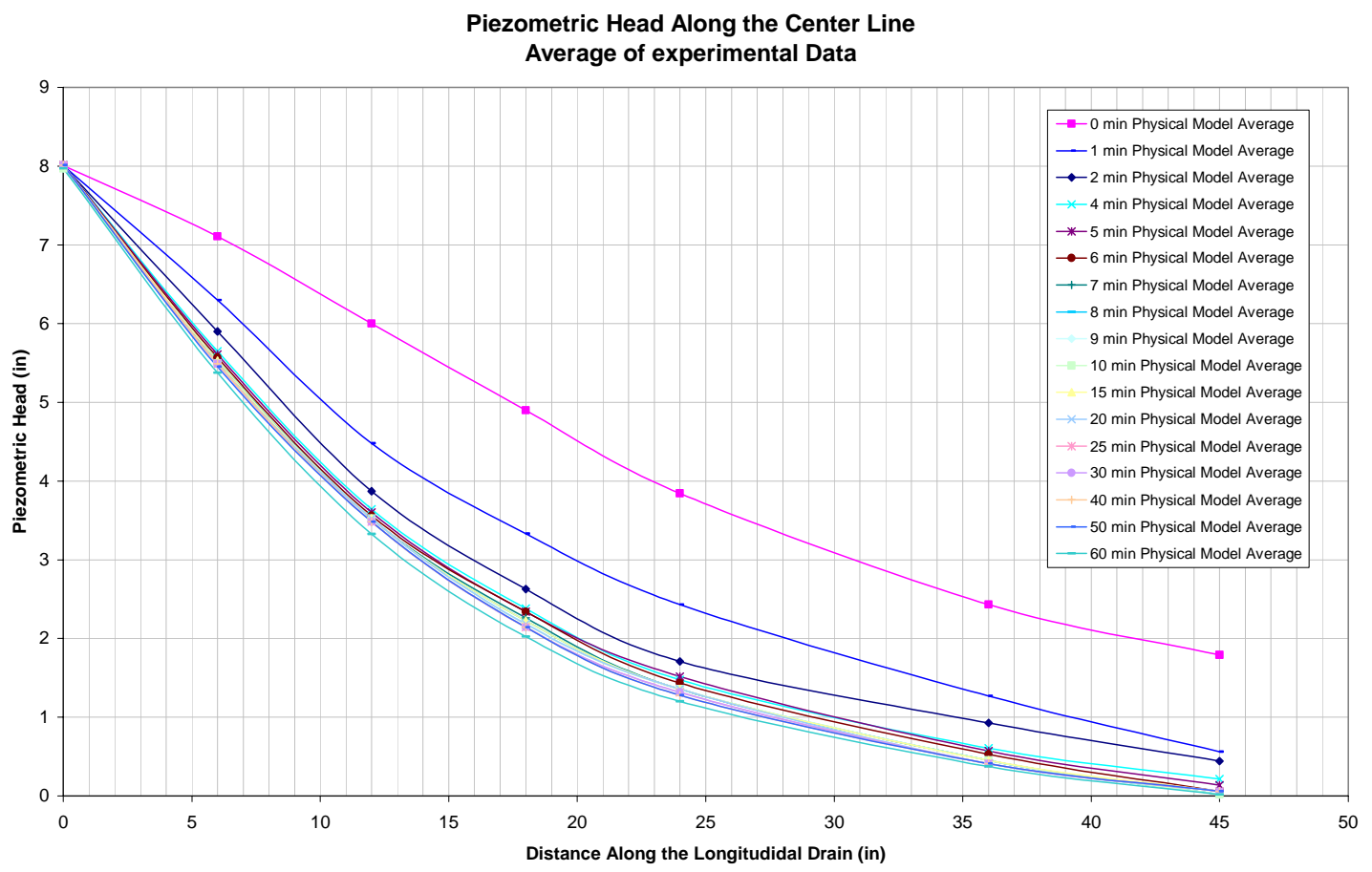

Figure A3.2: Piezometric head along Center Line Soil Type B - Physical Model 


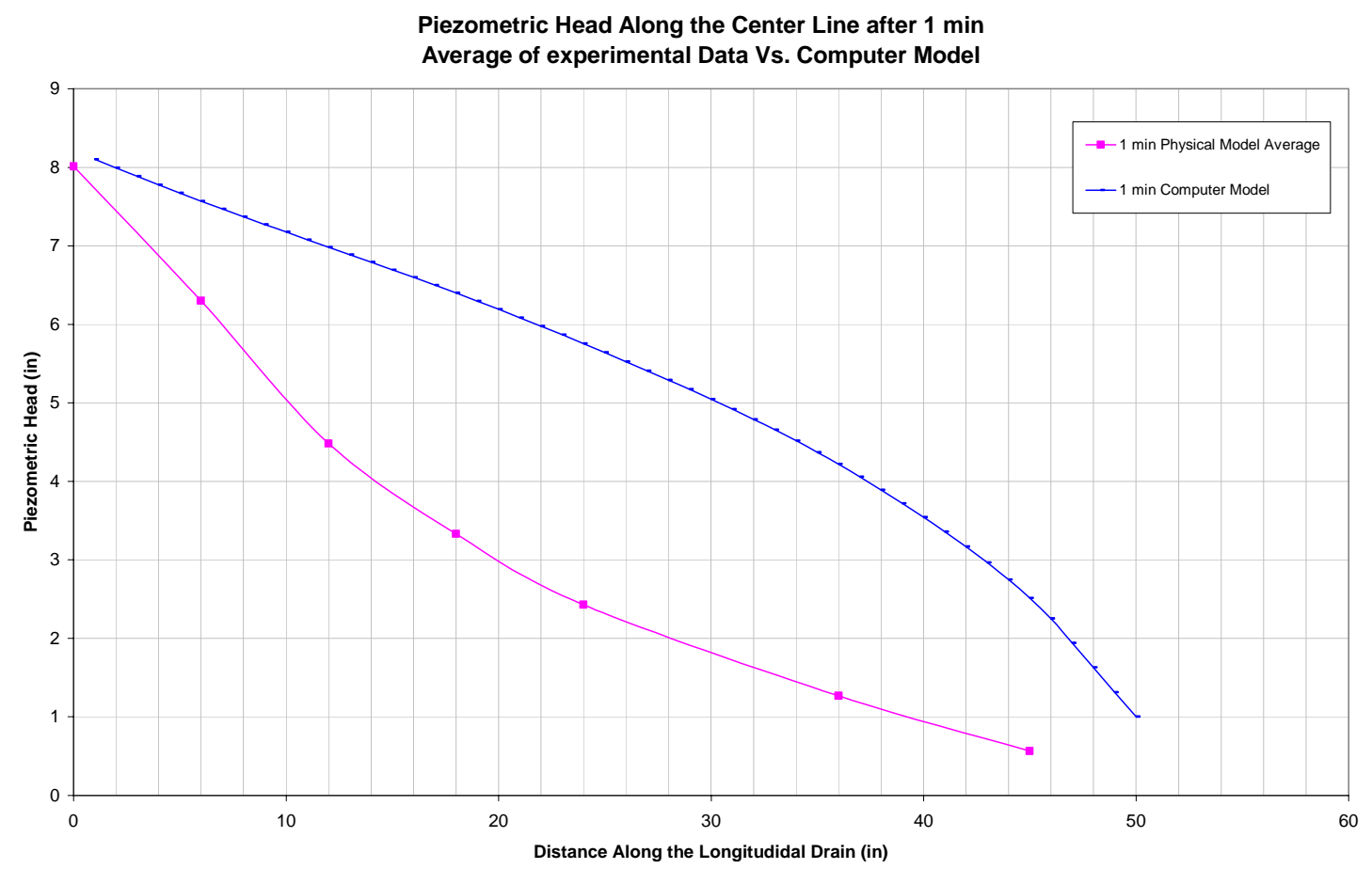

Figure A3.3: Piezometric head along Center Line Soil Type B, after 1 minute

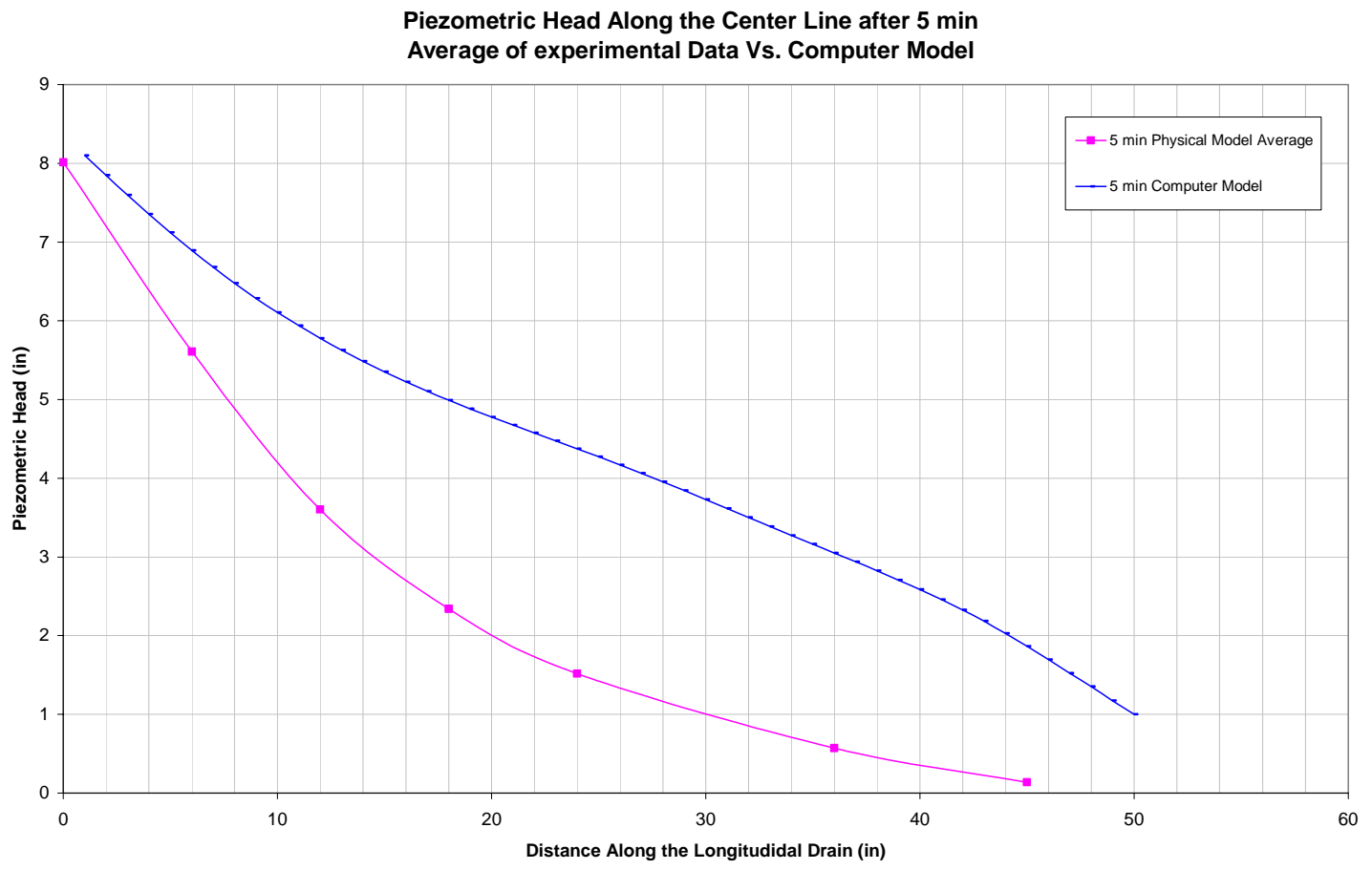

Figure A3.4: Piezometric head along Center Line Soil Type B, after 5 minutes 


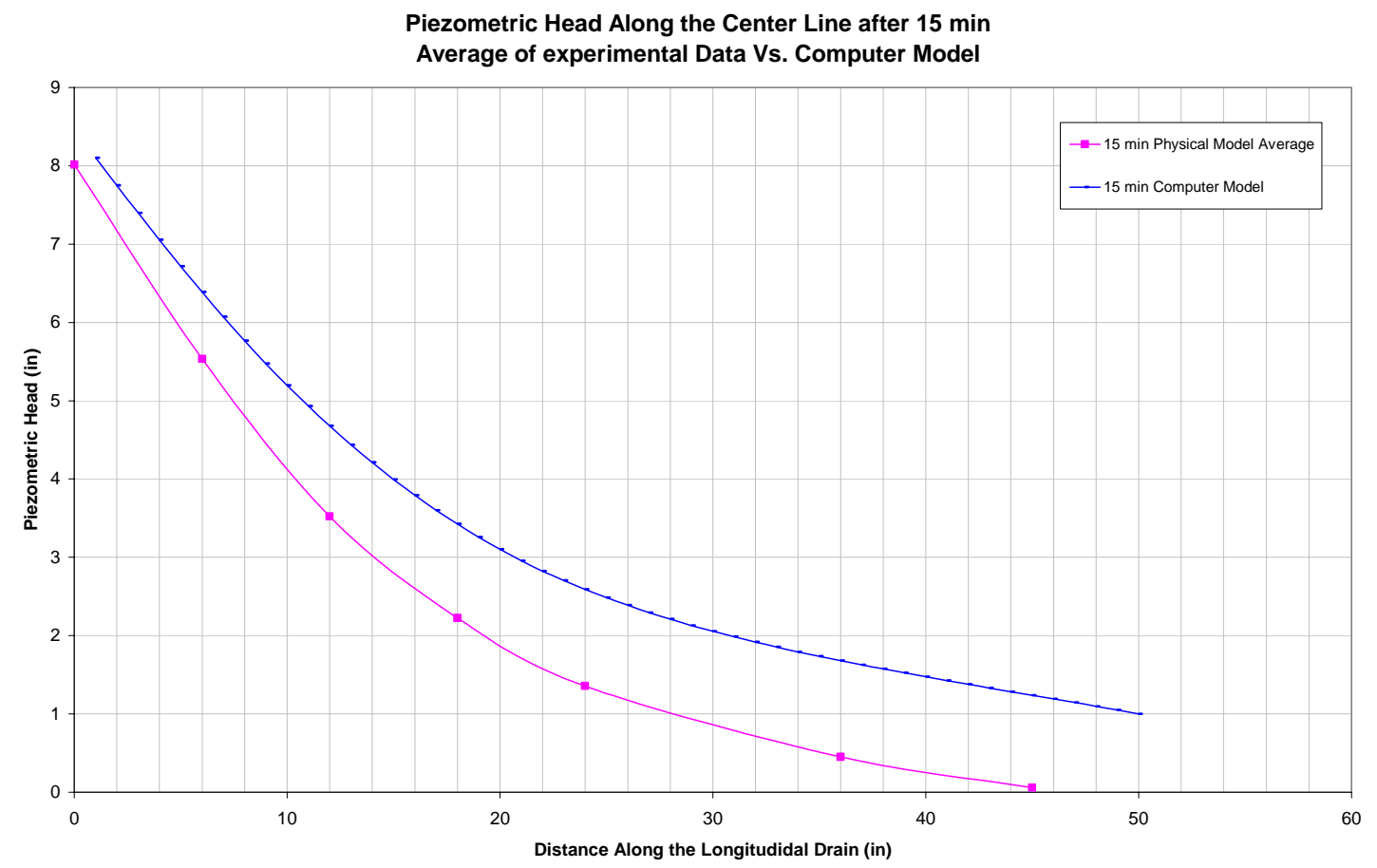

Figure A3.5: Piezometric head along Center Line Soil Type B, after 15 minutes

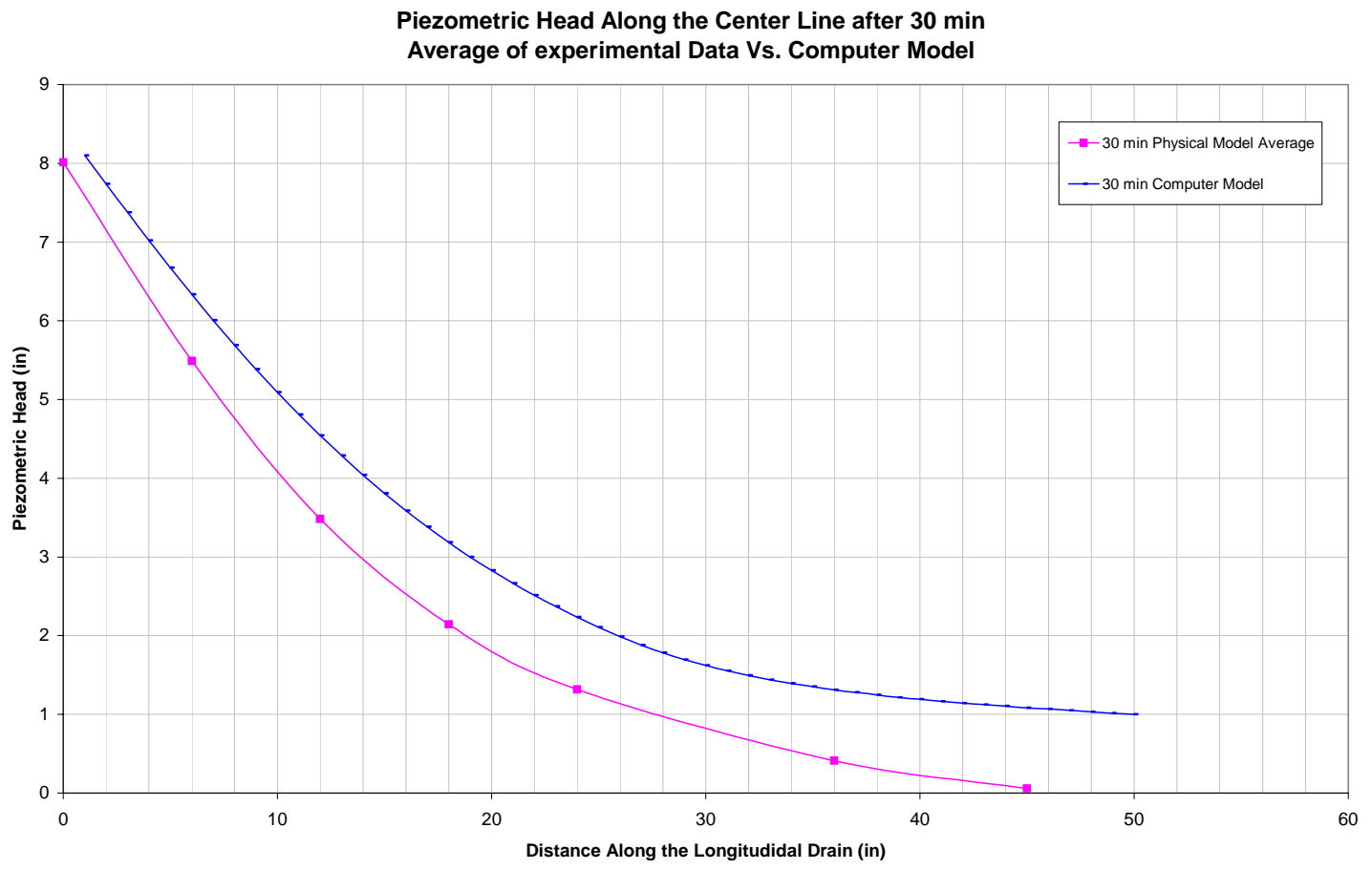

Figure A3.6: Piezometric head along Center Line Soil Type B, after 30 minutes 


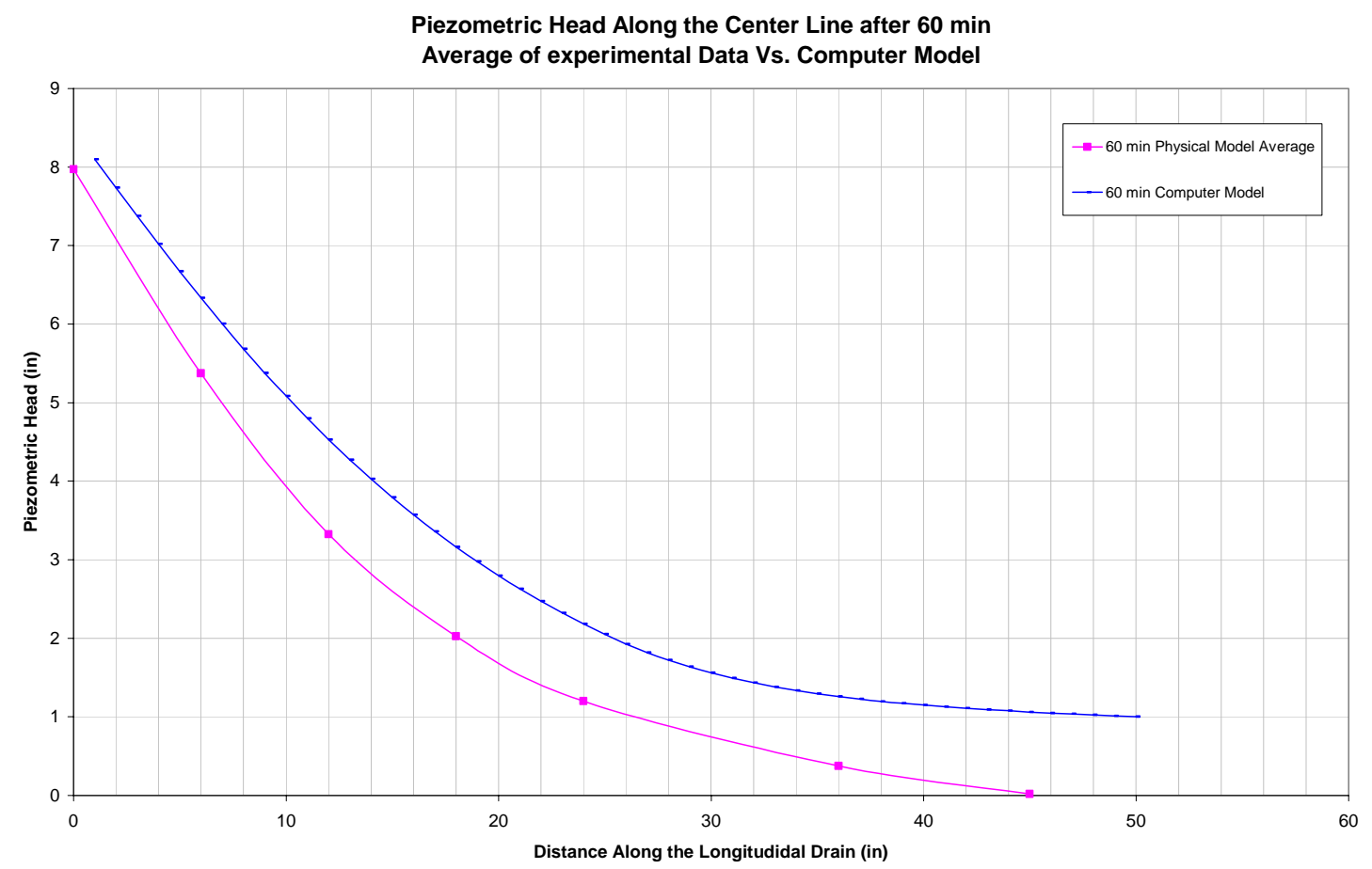

Figure A3.7: Piezometric head along Center Line Soil Type B, after 60 minutes

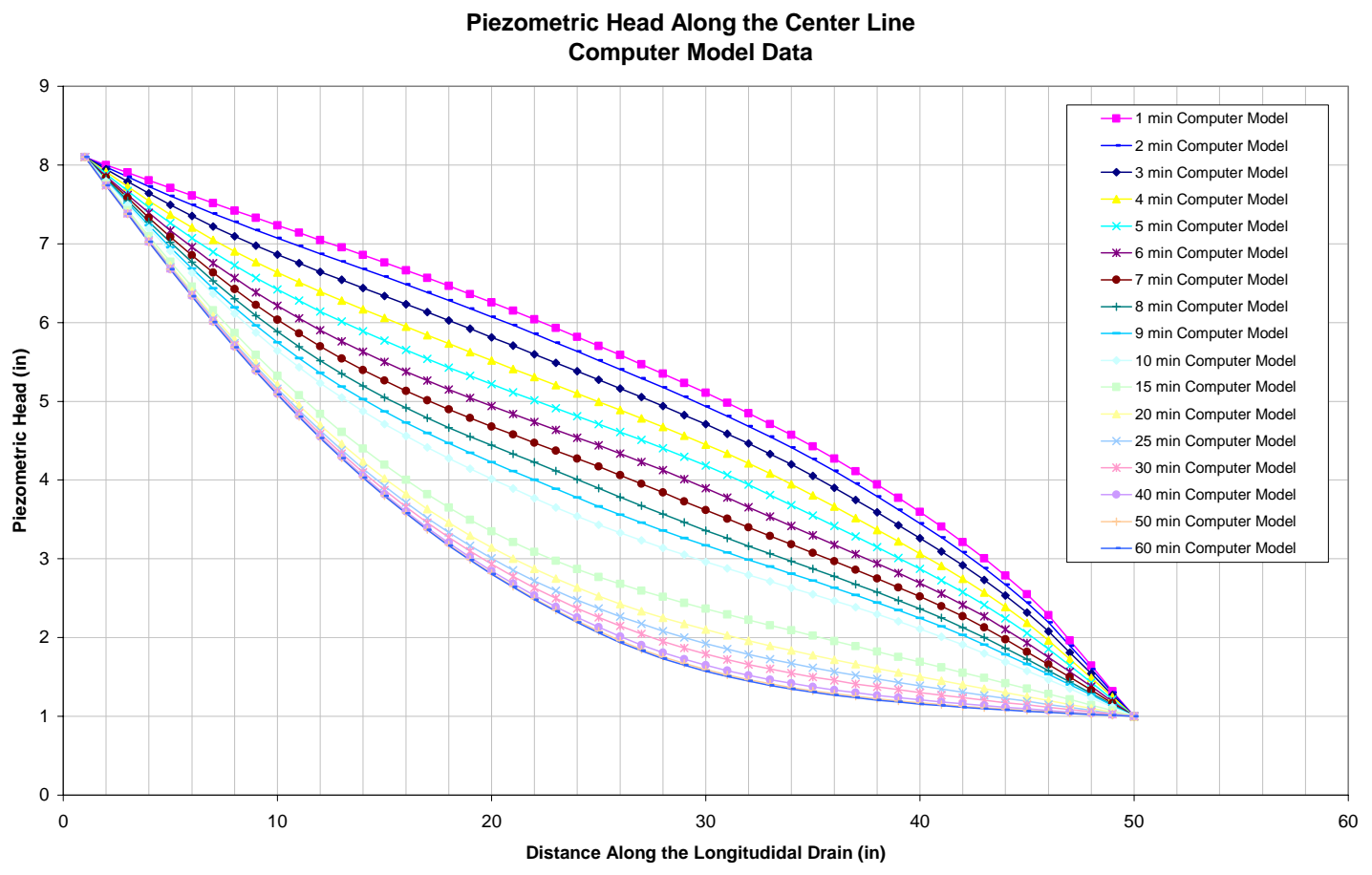

Figure A3.8: Piezometric head along Center Line Soil Type C, Computer Model 


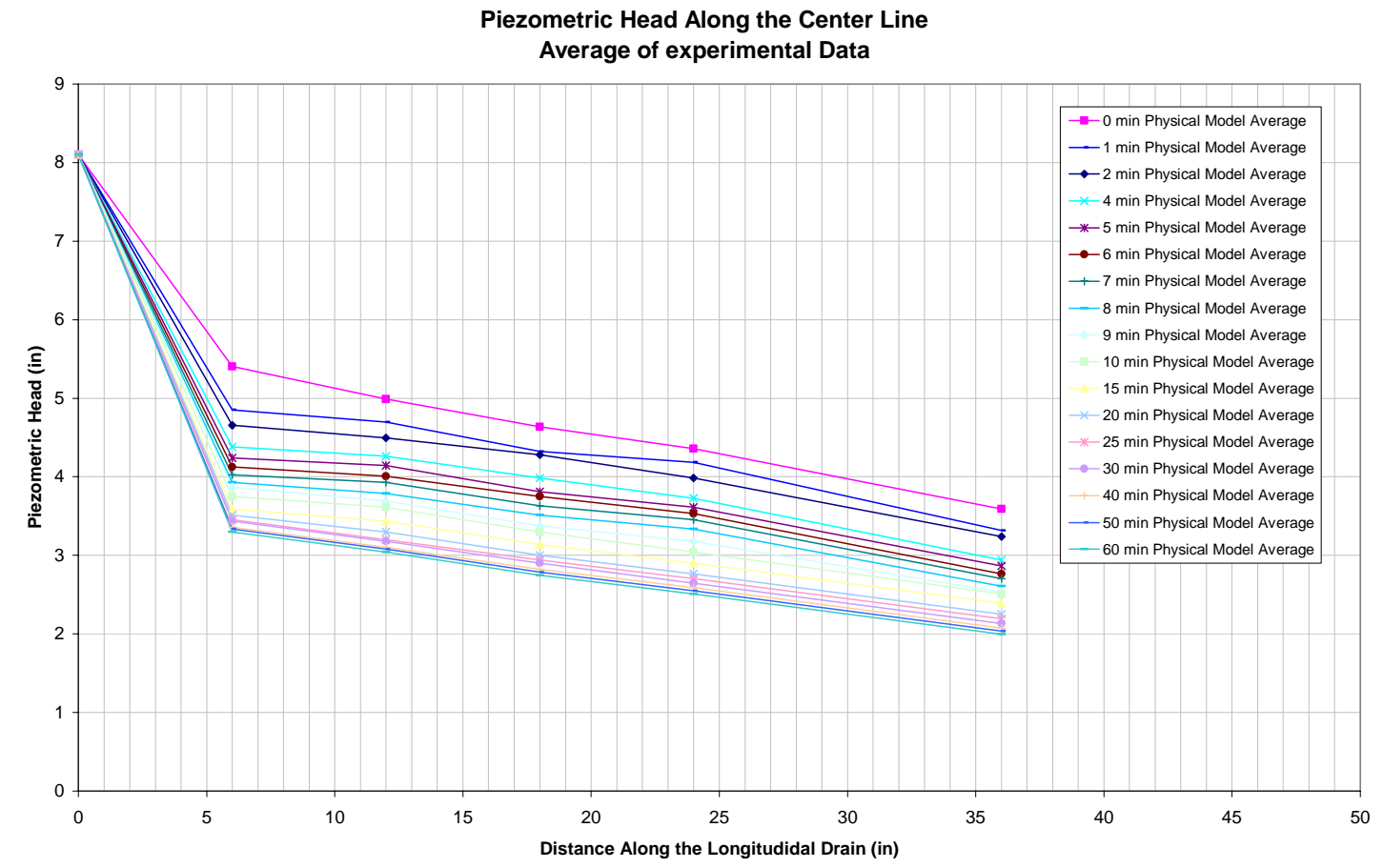

Figure A3.9: Piezometric head along Center Line Soil Type C, physical Model

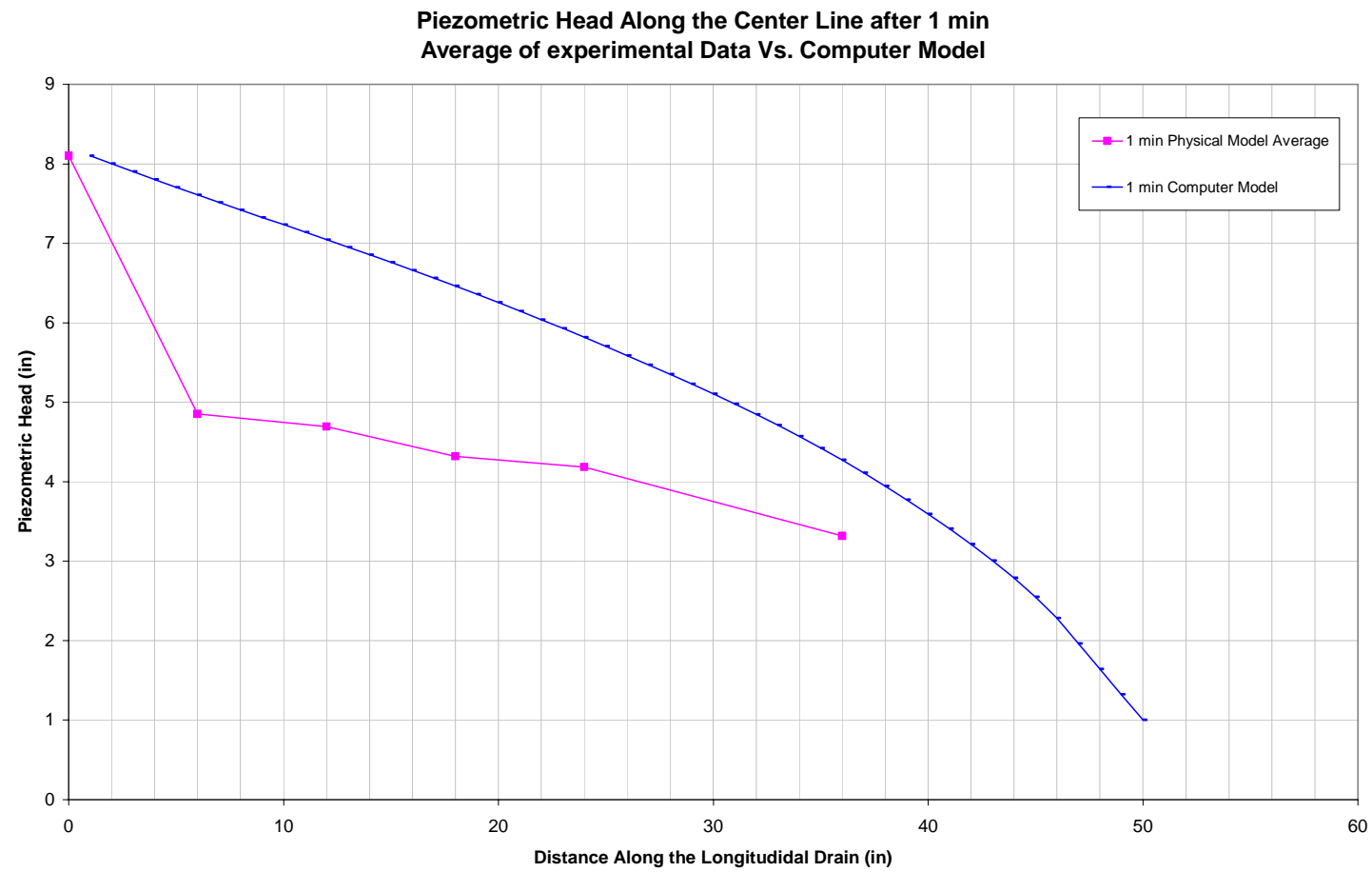

Figure A3.10: Piezometric head along Center Line Soil Type C, after 1 minute 


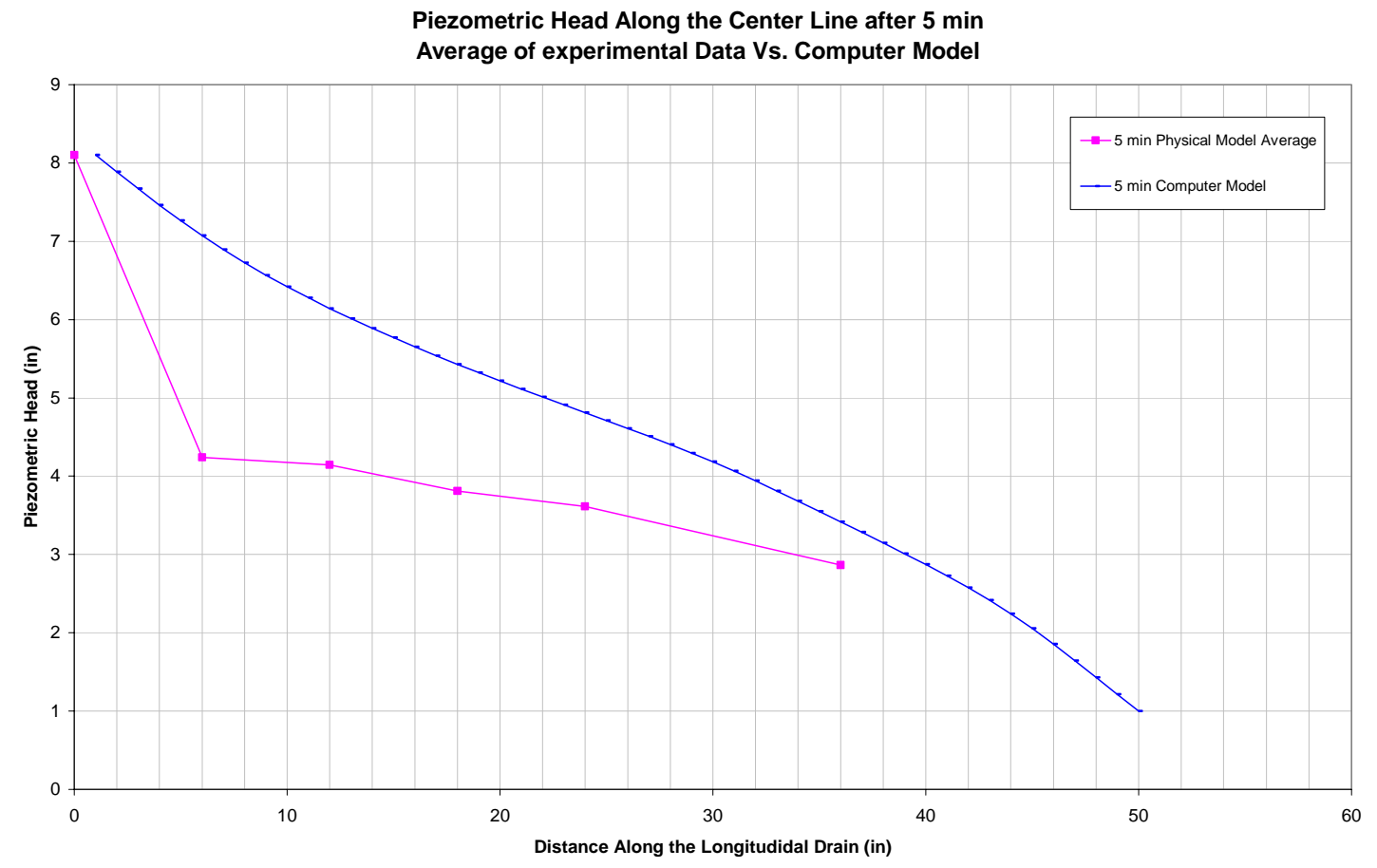

Figure A3.11: Piezometric head along Center Line Soil Type C, after 5 minutes

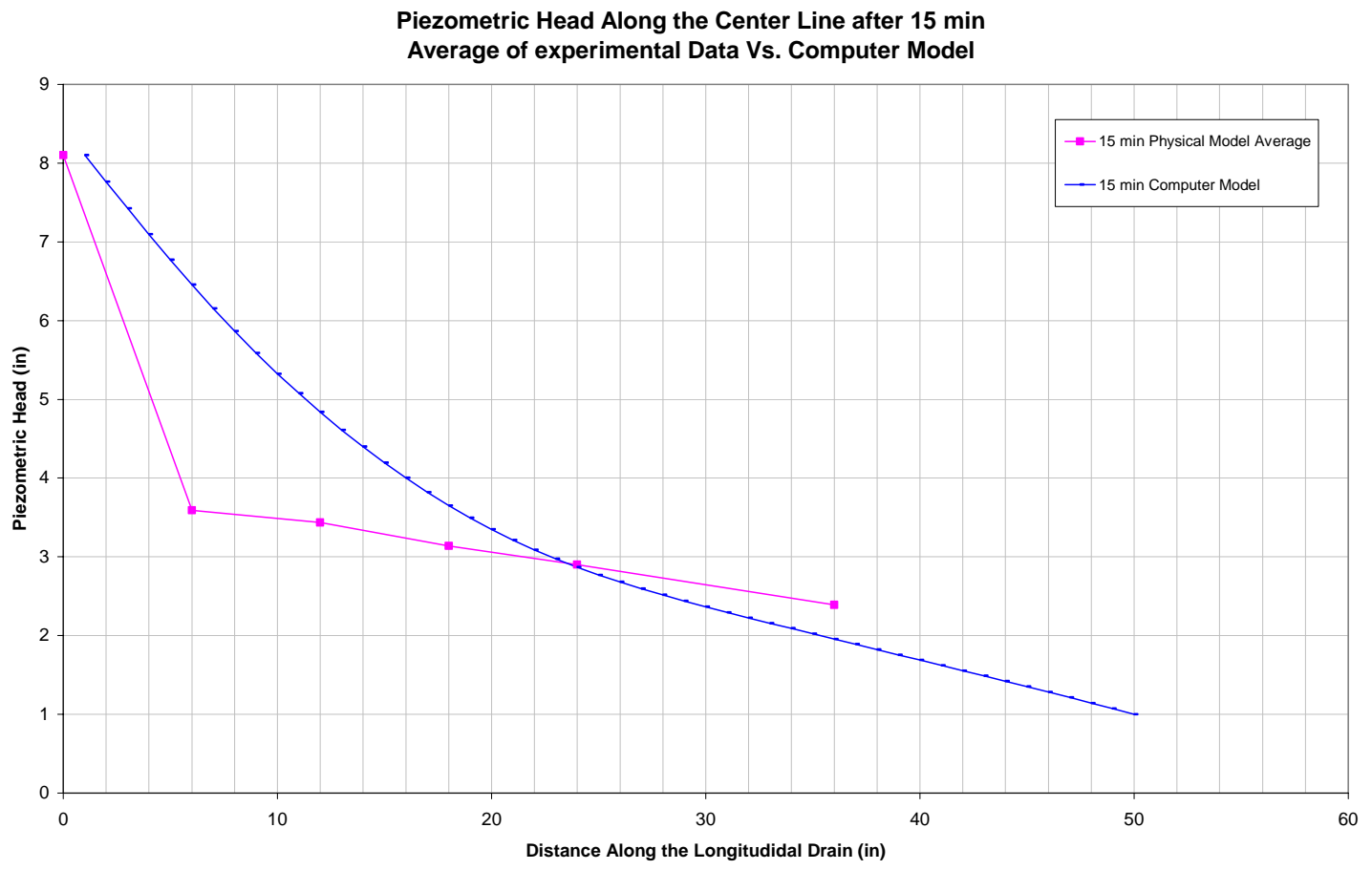

Figure A3.12: Piezometric head along Center Line Soil Type C, after 15 minutes 


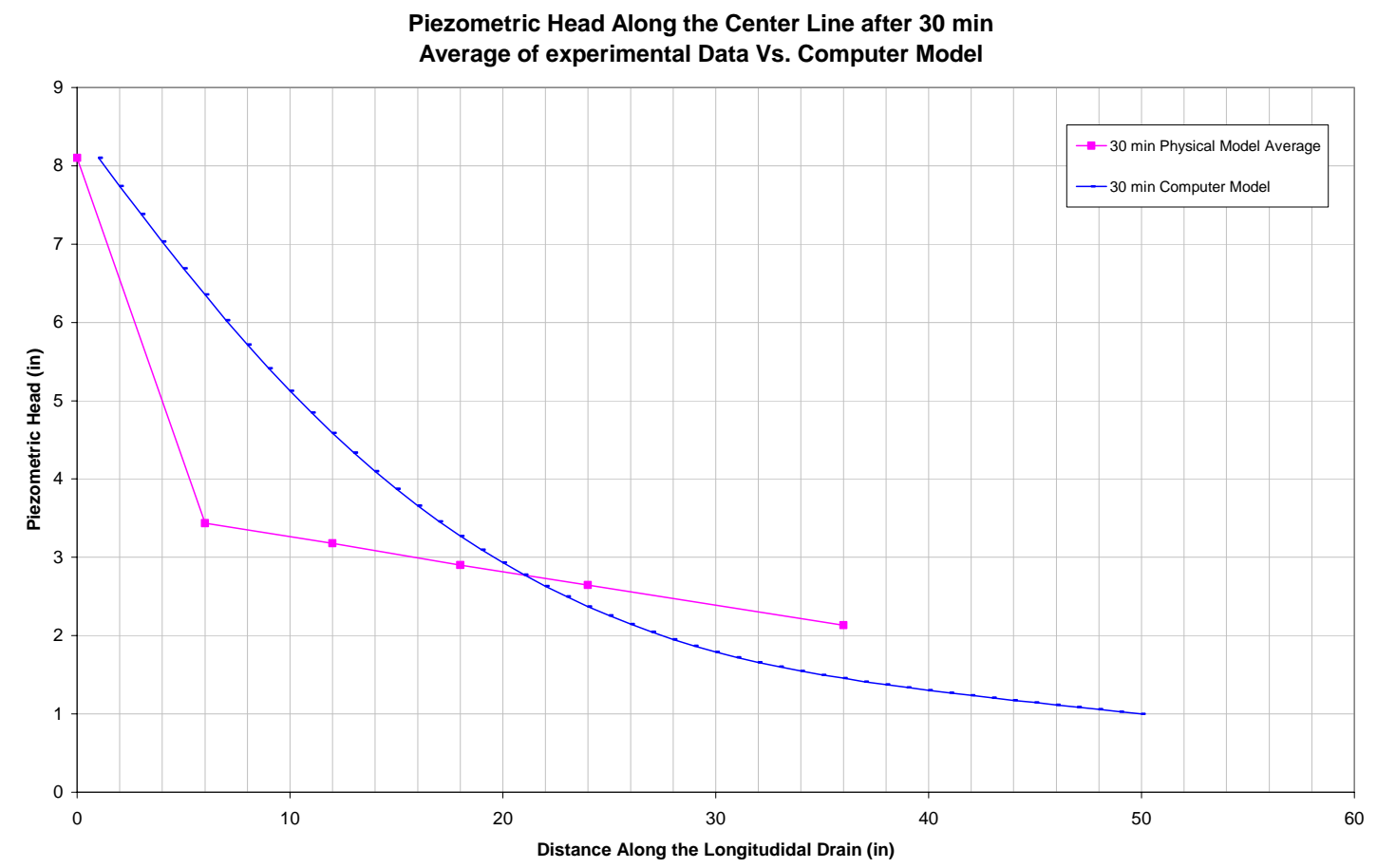

Figure A3.13: Piezometric head along Center Line Soil Type C, after 30 minutes

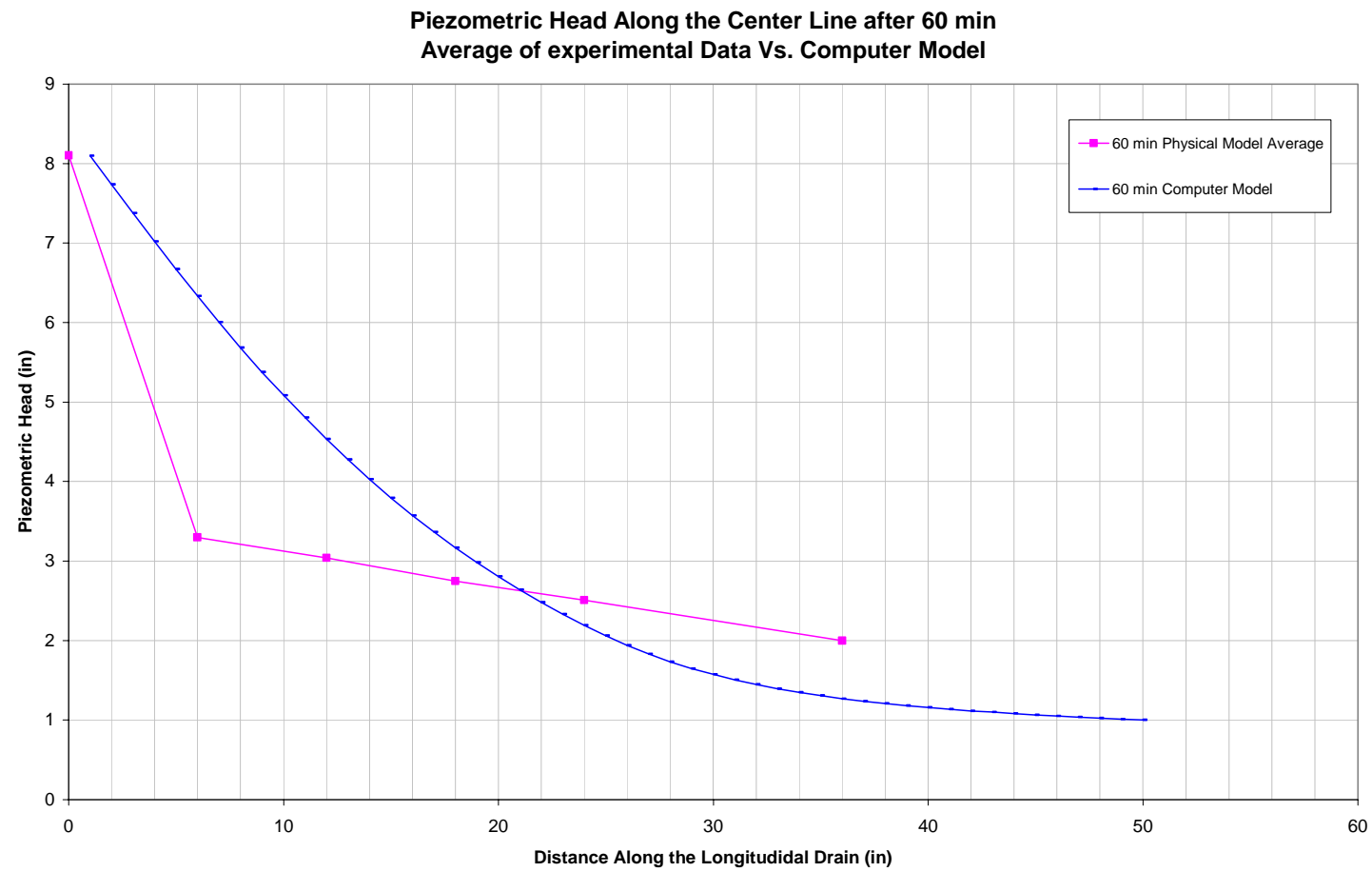

Figure A3.14: Piezometric head along Center Line Soil Type C, after 60 minutes 


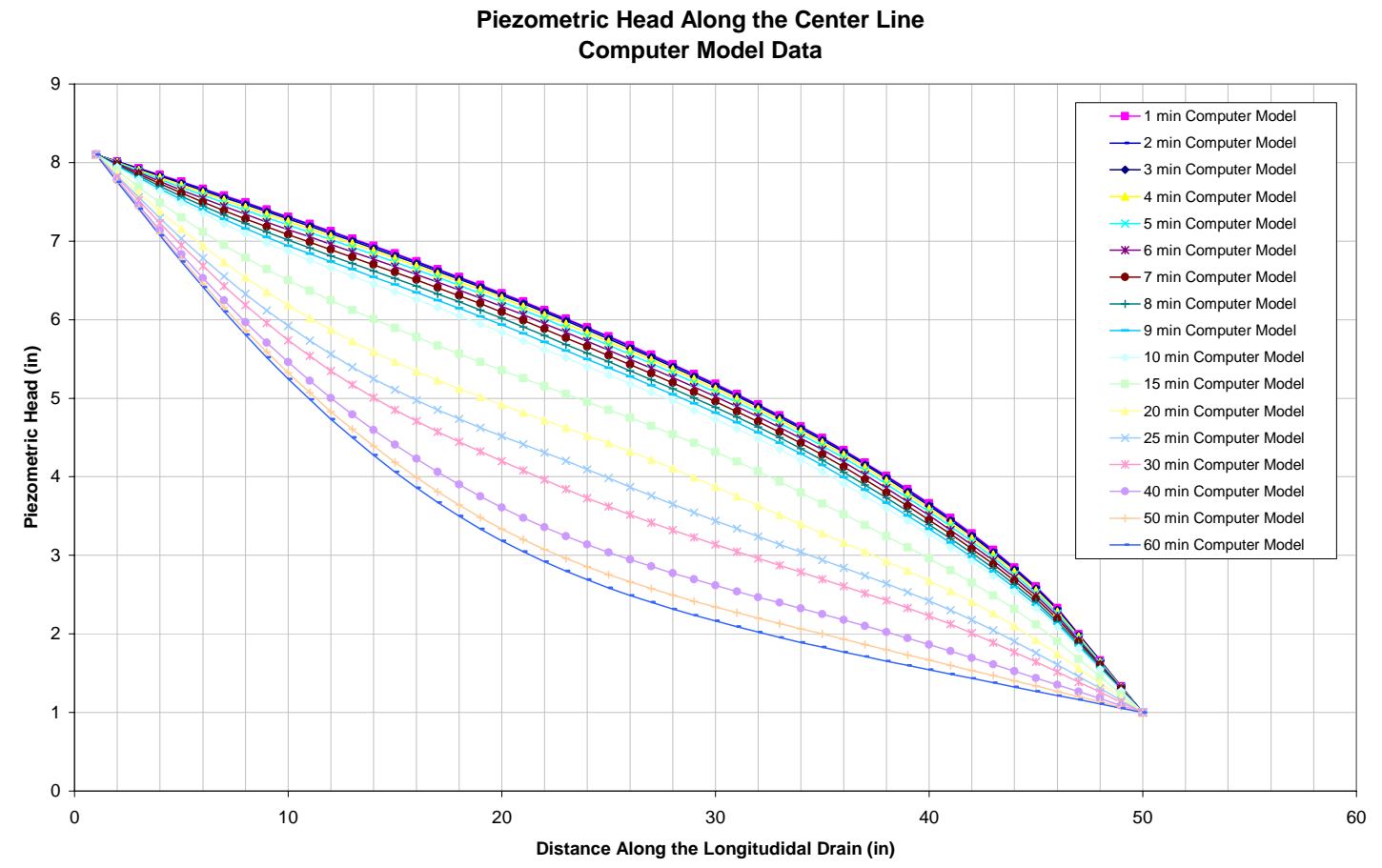

Figure A3.15: Piezometric head along Center Line Soil Type D, Computer Model

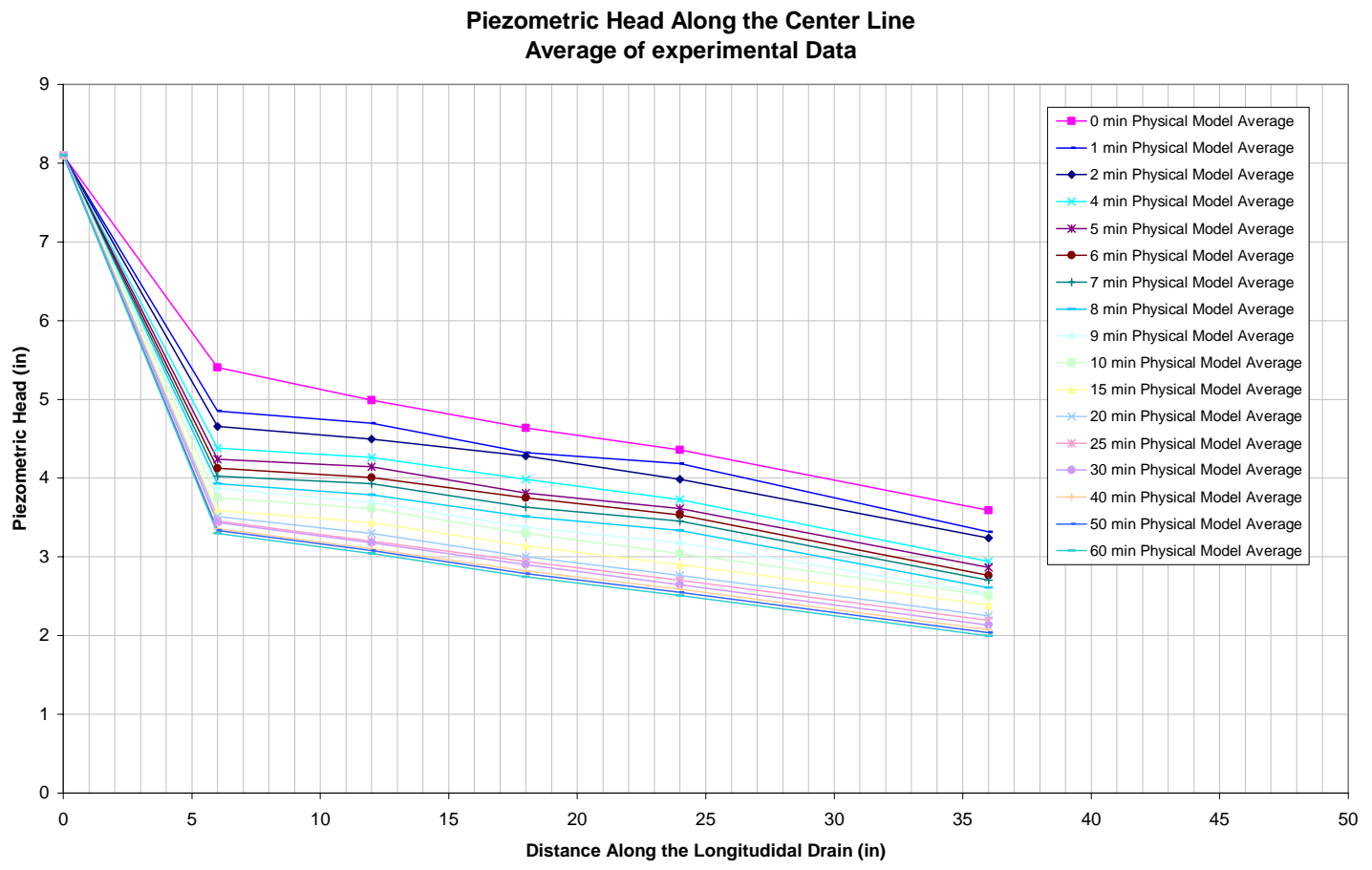

Figure A3.16: Piezometric head along Center Line Soil Type D, physical Model 


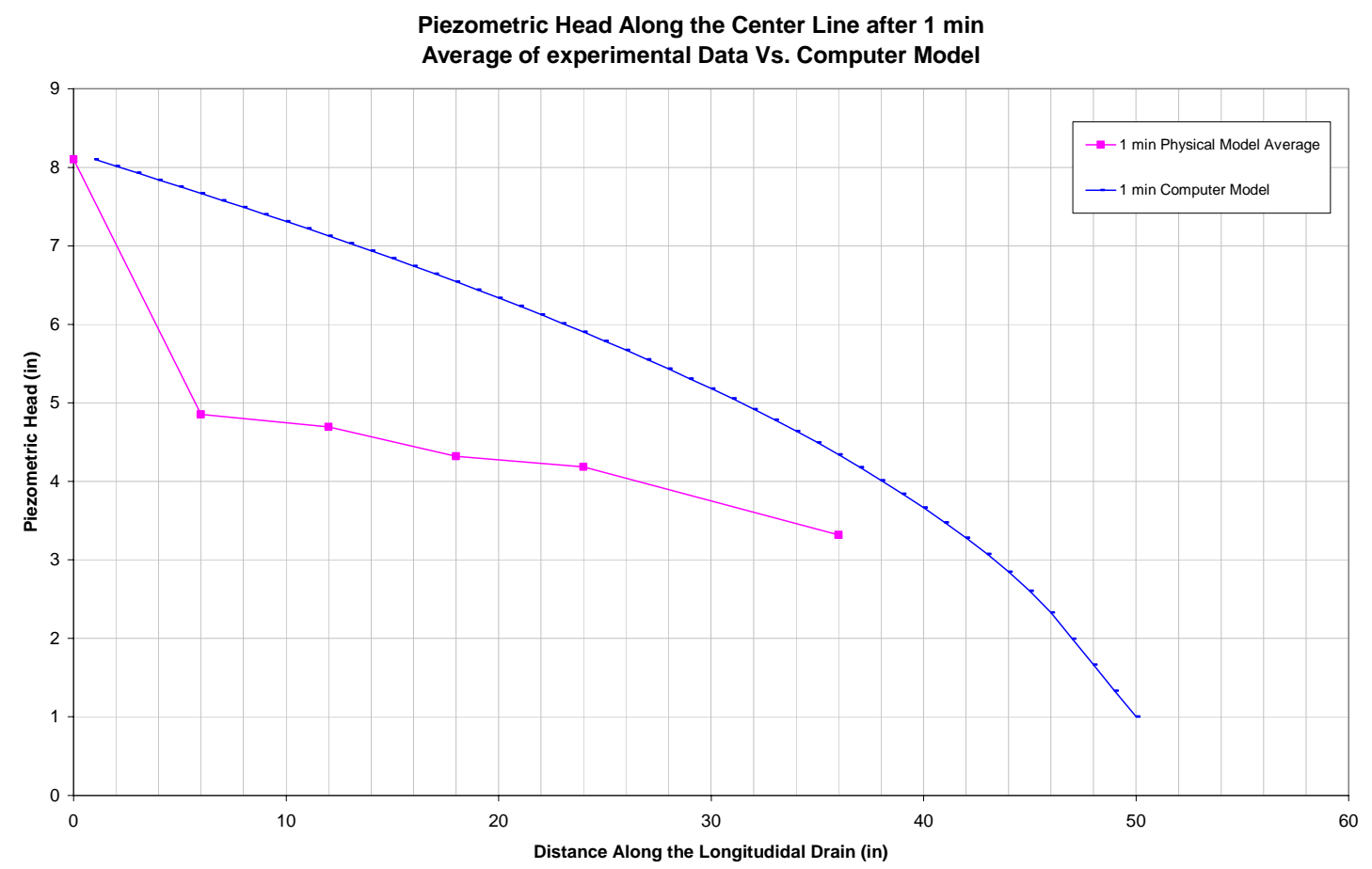

Figure A3.17: Piezometric head along Center Line Soil Type D, after 1 minute

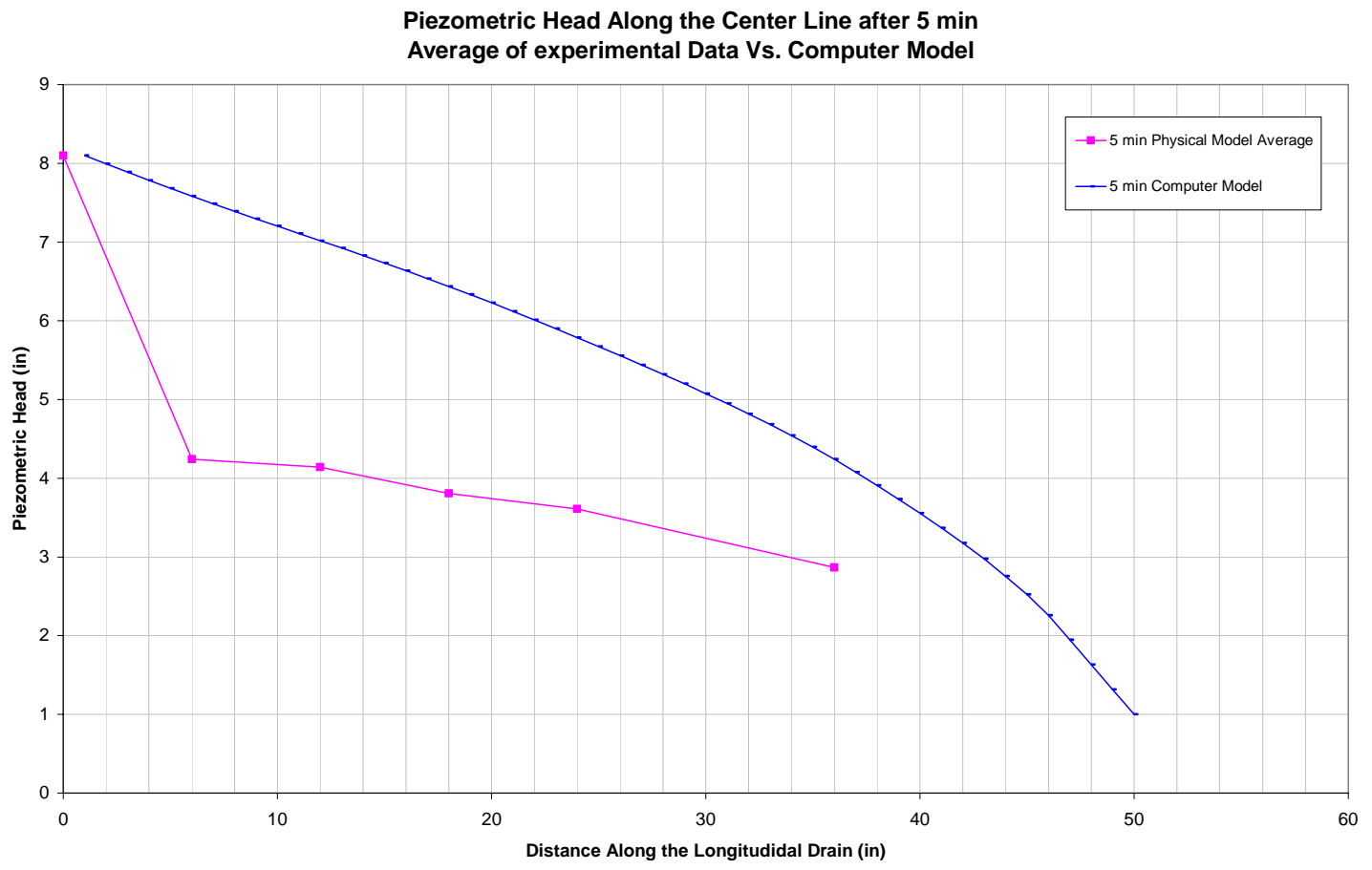

Figure A3.18: Piezometric head along Center Line Soil Type D, after 5 minutes 


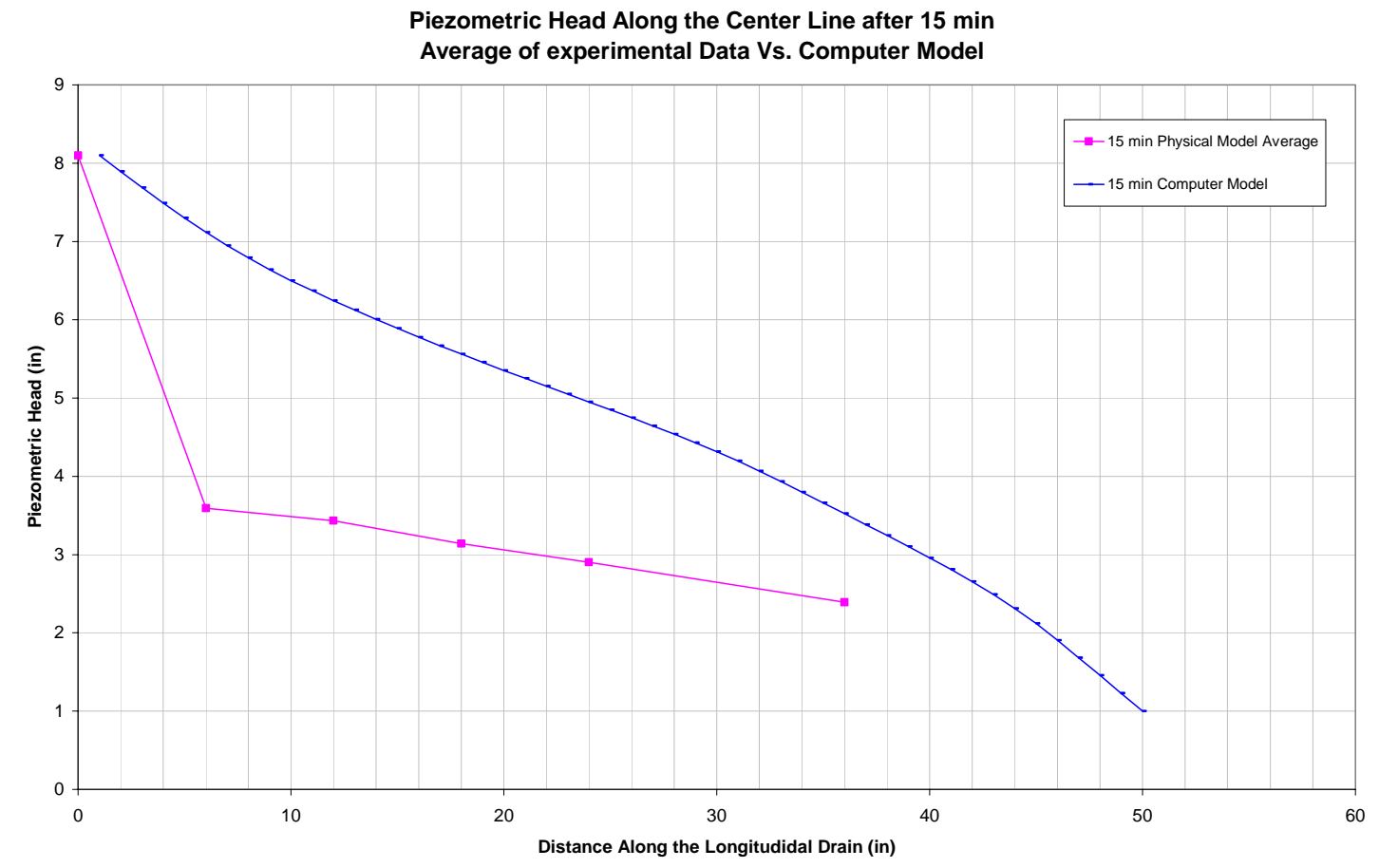

Figure A3.19: Piezometric head along Center Line Soil Type D, after 15 minutes

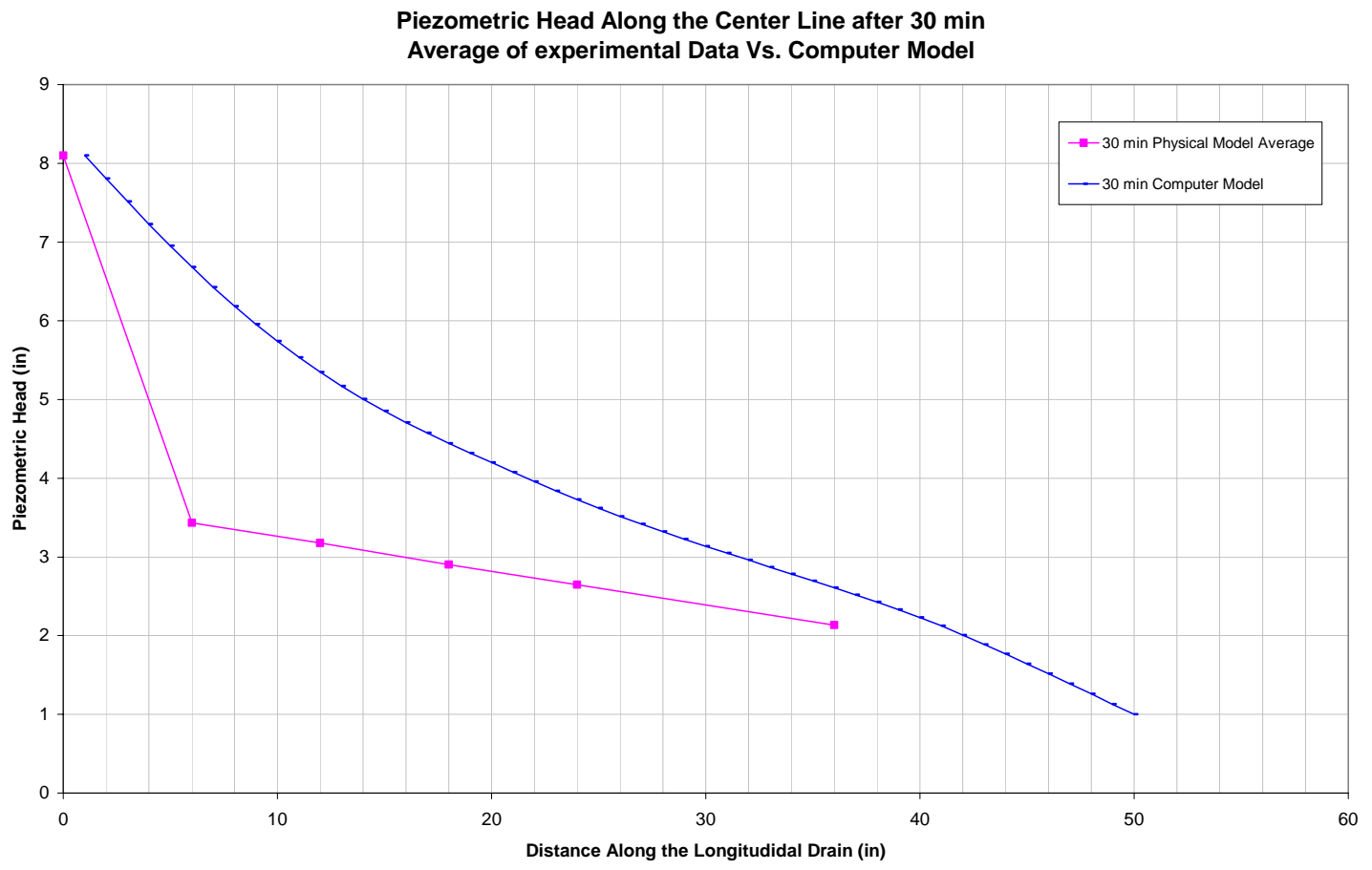

Figure A3.20: Piezometric head along Center Line Soil Type D, after 30 minutes 


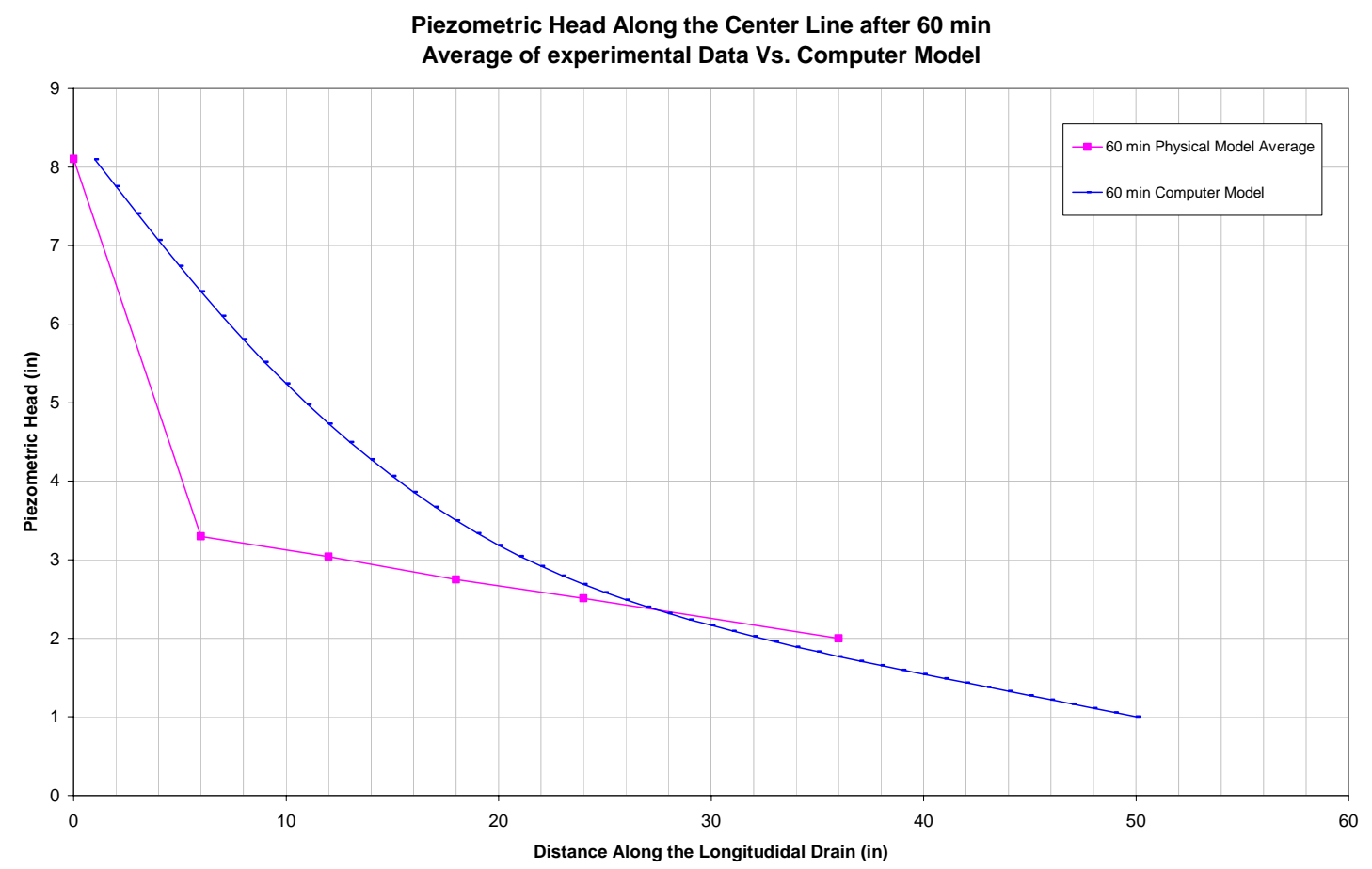

Figure A3.21: Piezometric head along Center Line Soil Type D, after 60 minutes

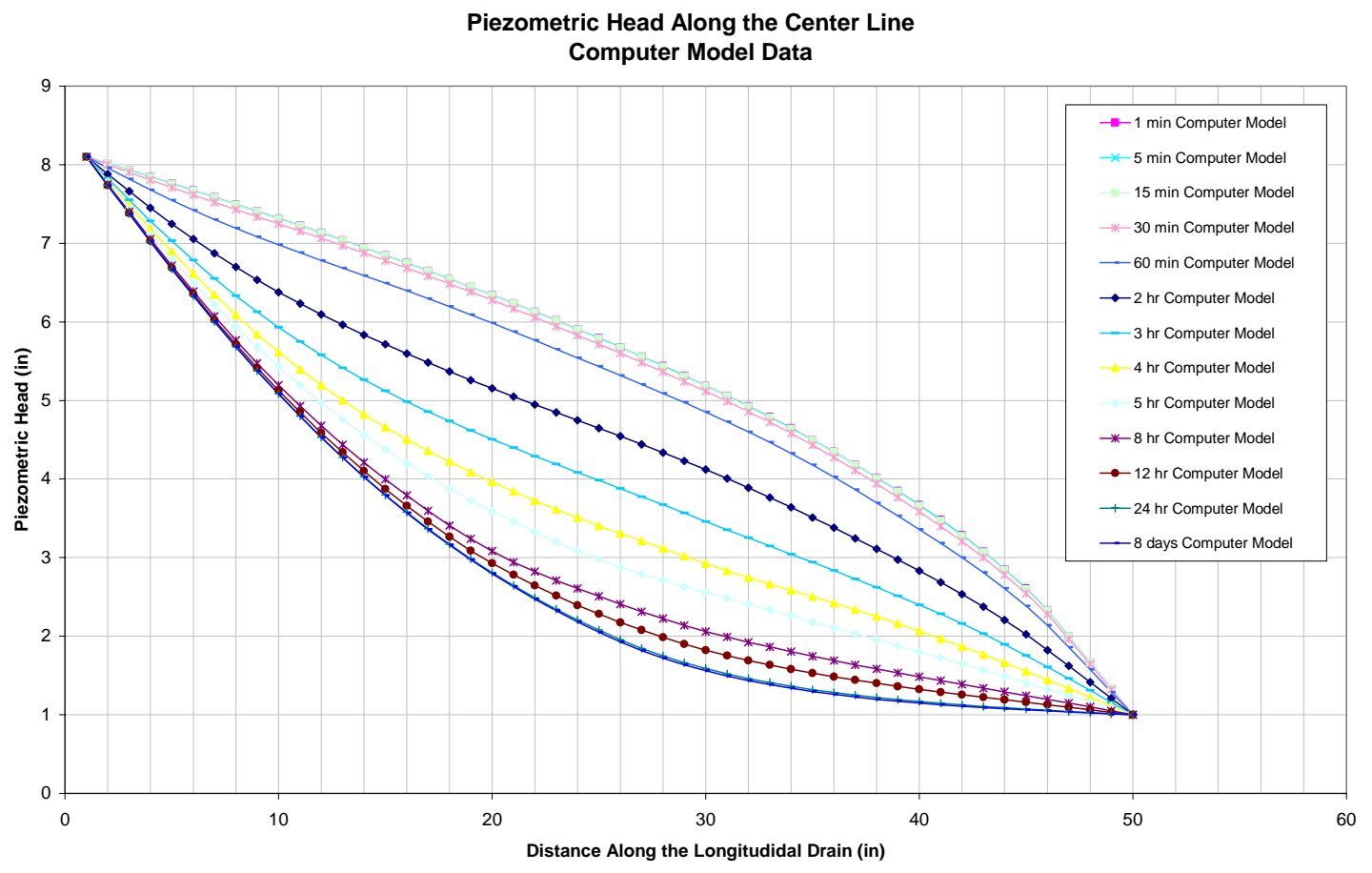

Figure A3.22: Piezometric head along Center Line Soil Type E, Computer Model 


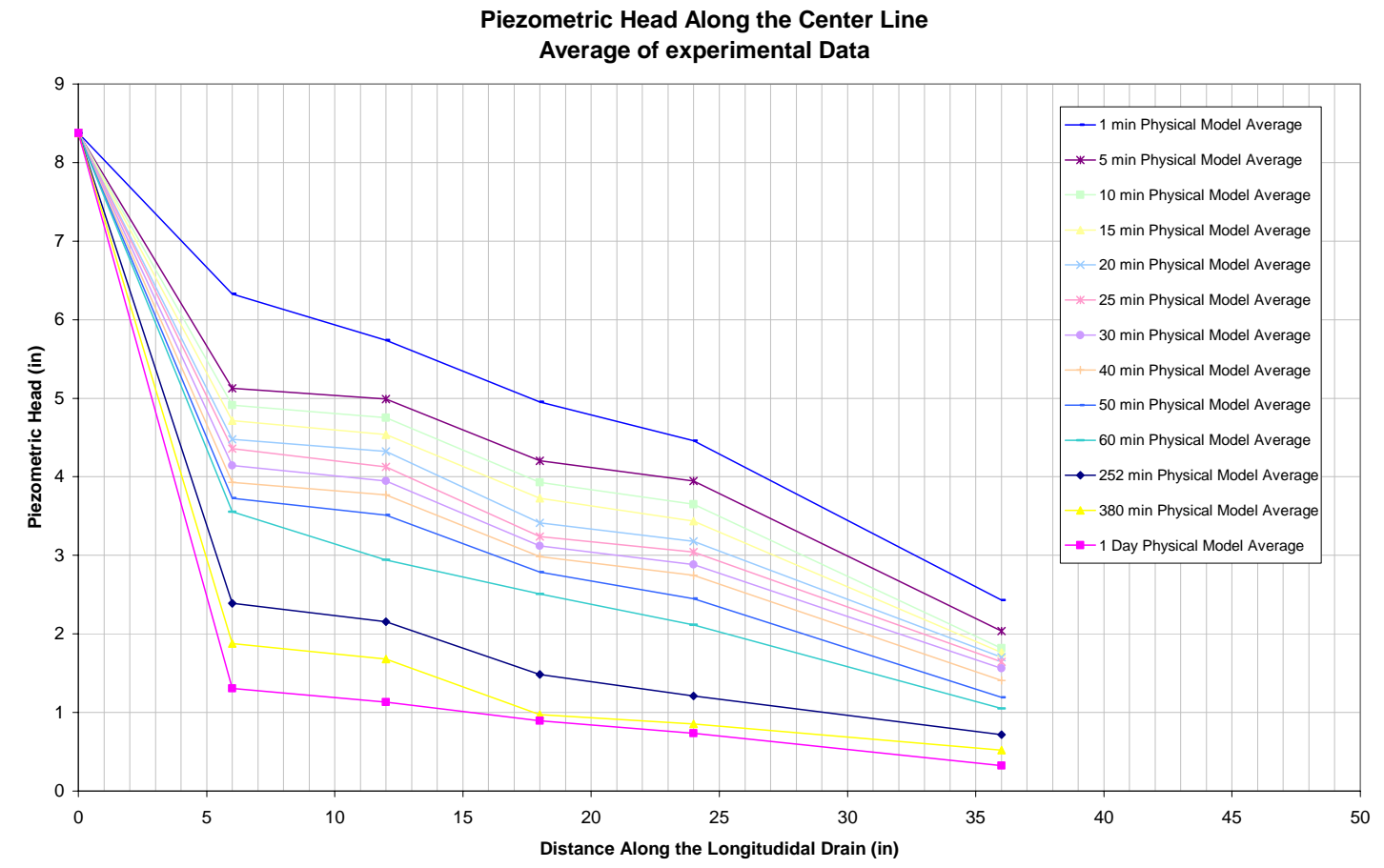

Figure A3.23: Piezometric head along Center Line Soil Type E, Physical Model

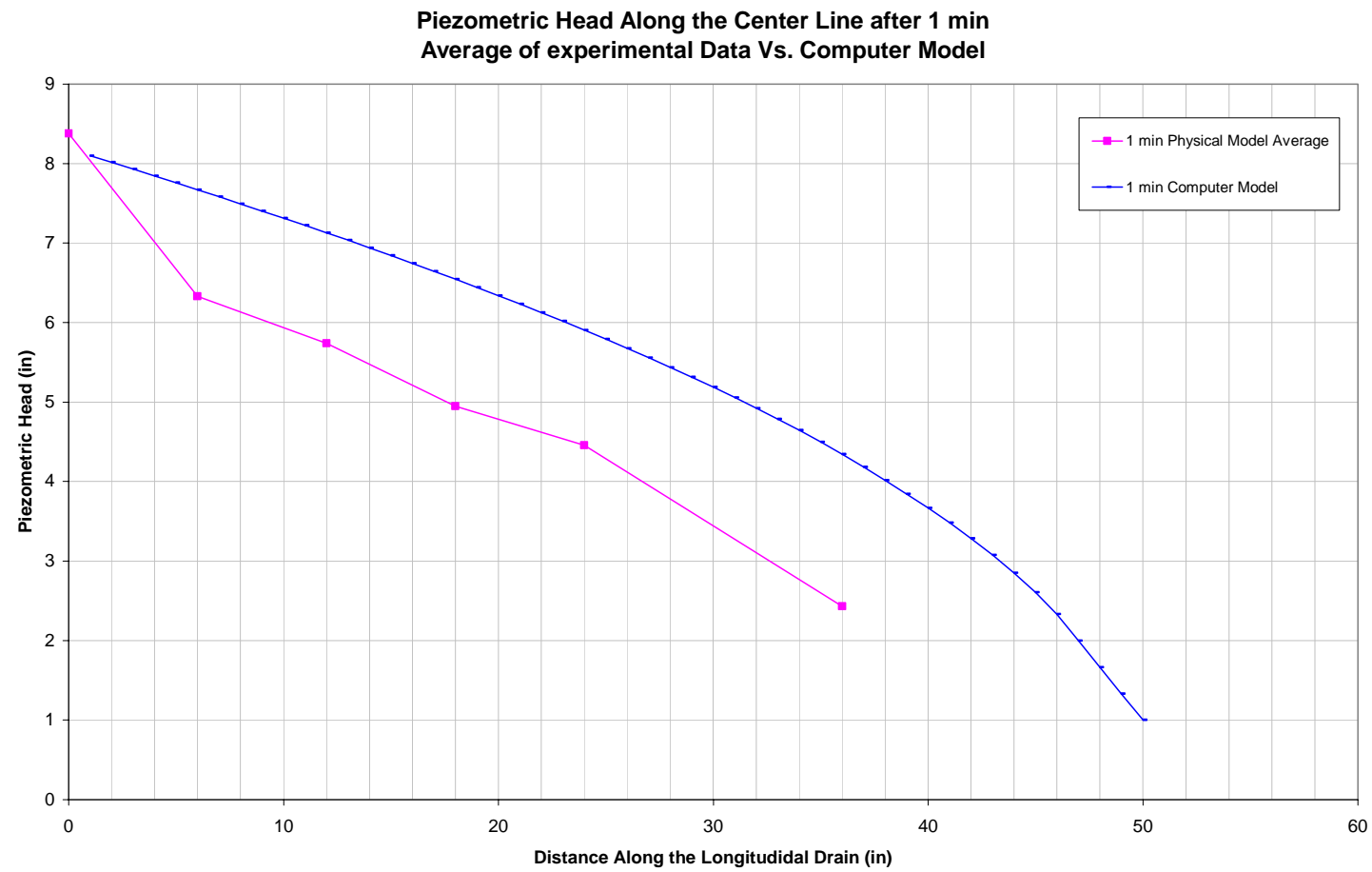

Figure A3.24: Piezometric head along Center Line Soil Type E, after 1 minute 


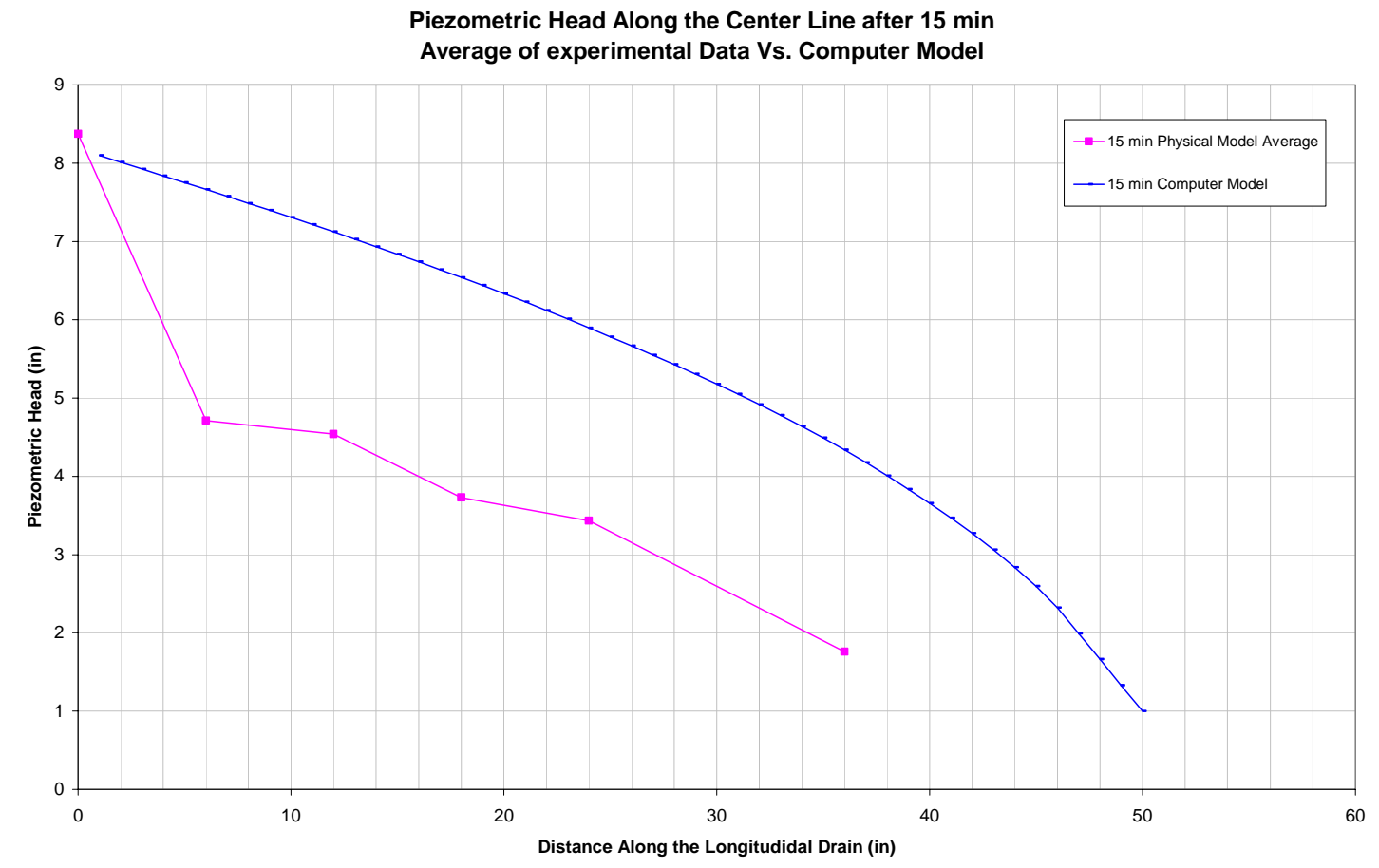

Figure A3.25: Piezometric head along Center Line Soil Type E, after 15 minutes

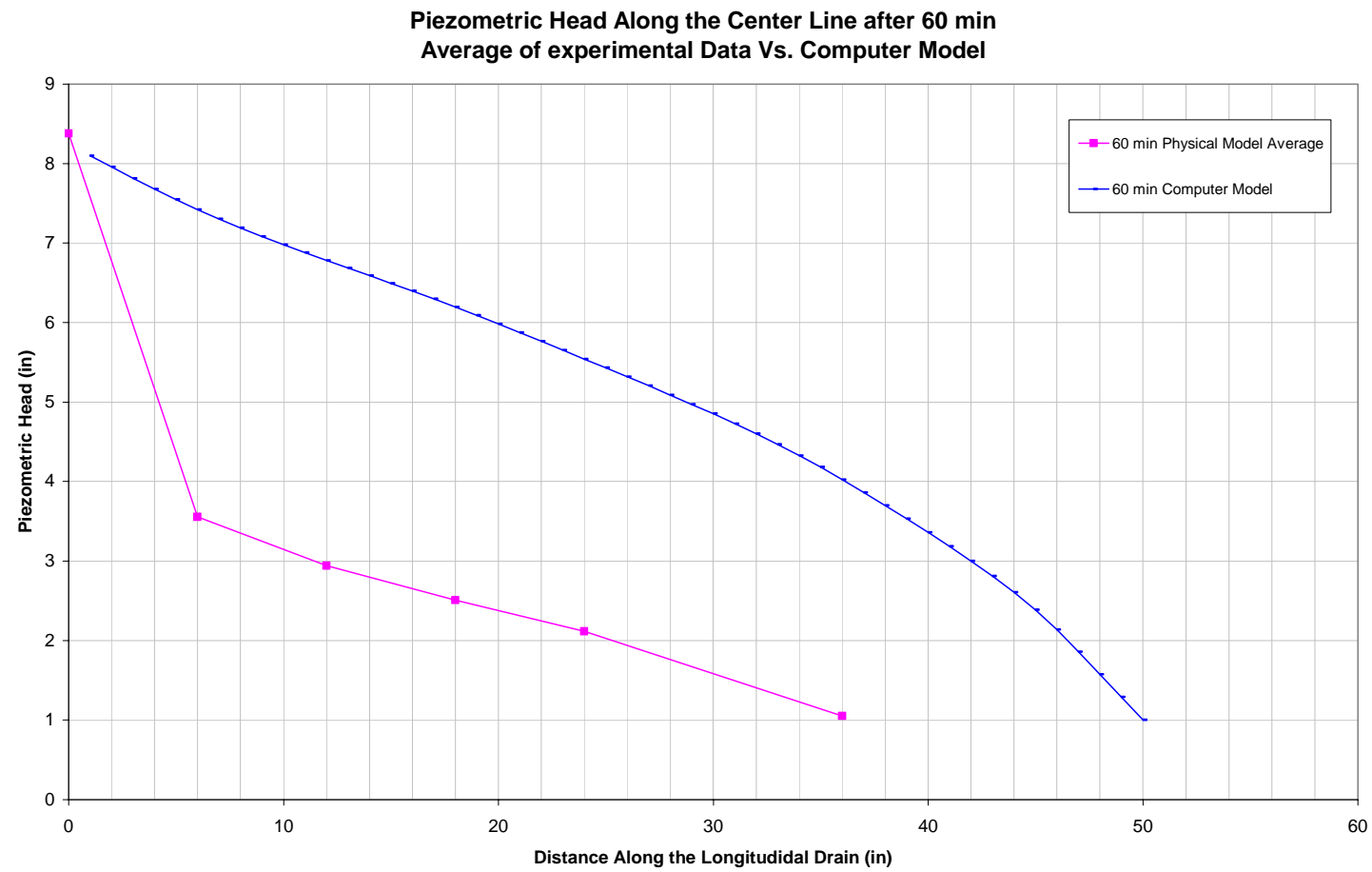

Figure A3.26: Piezometric head along Center Line Soil Type E, after 60 minutes 


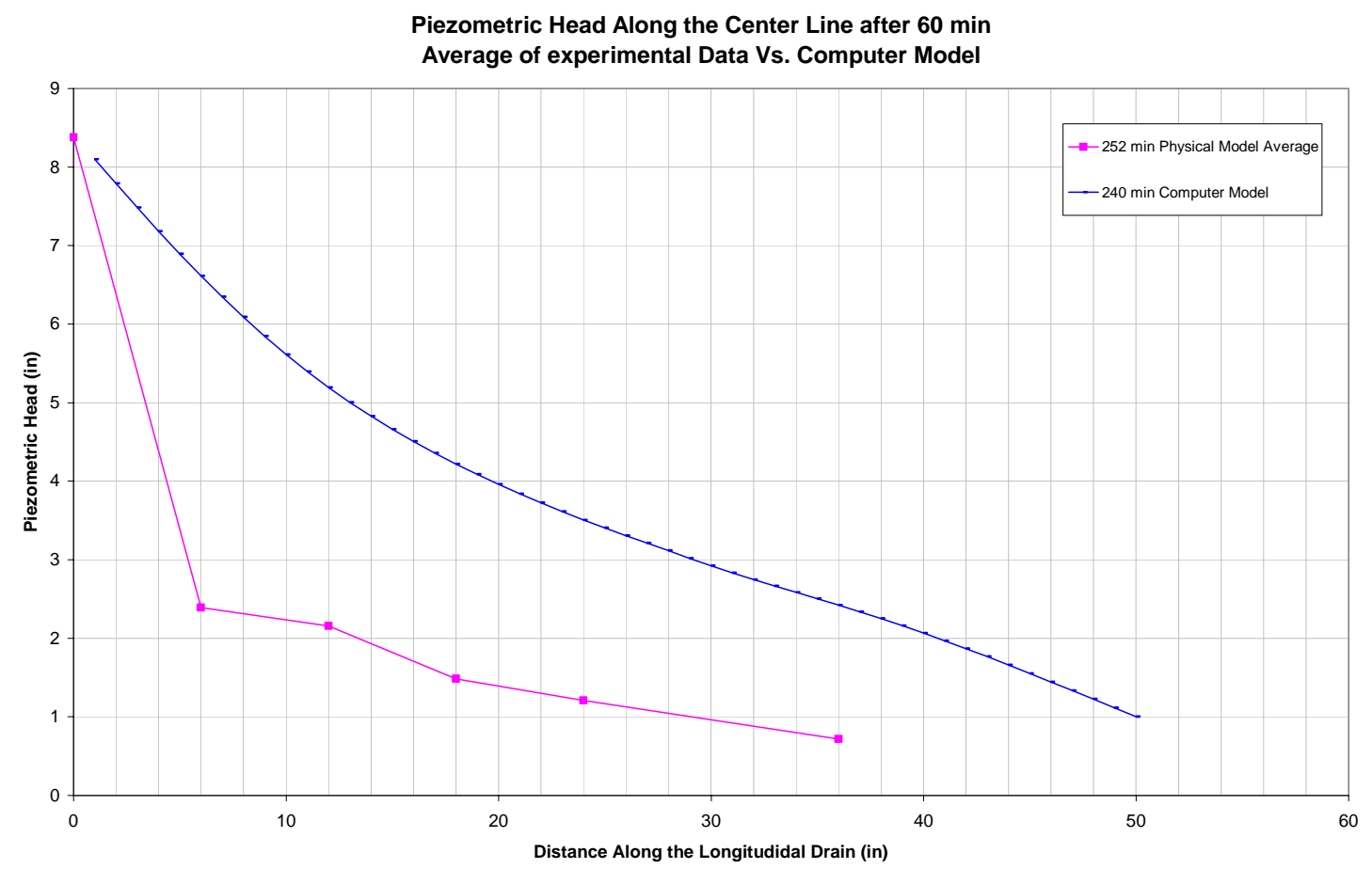

Figure A3.27: Piezometric head along Center Line Soil Type E, after 240 minutes

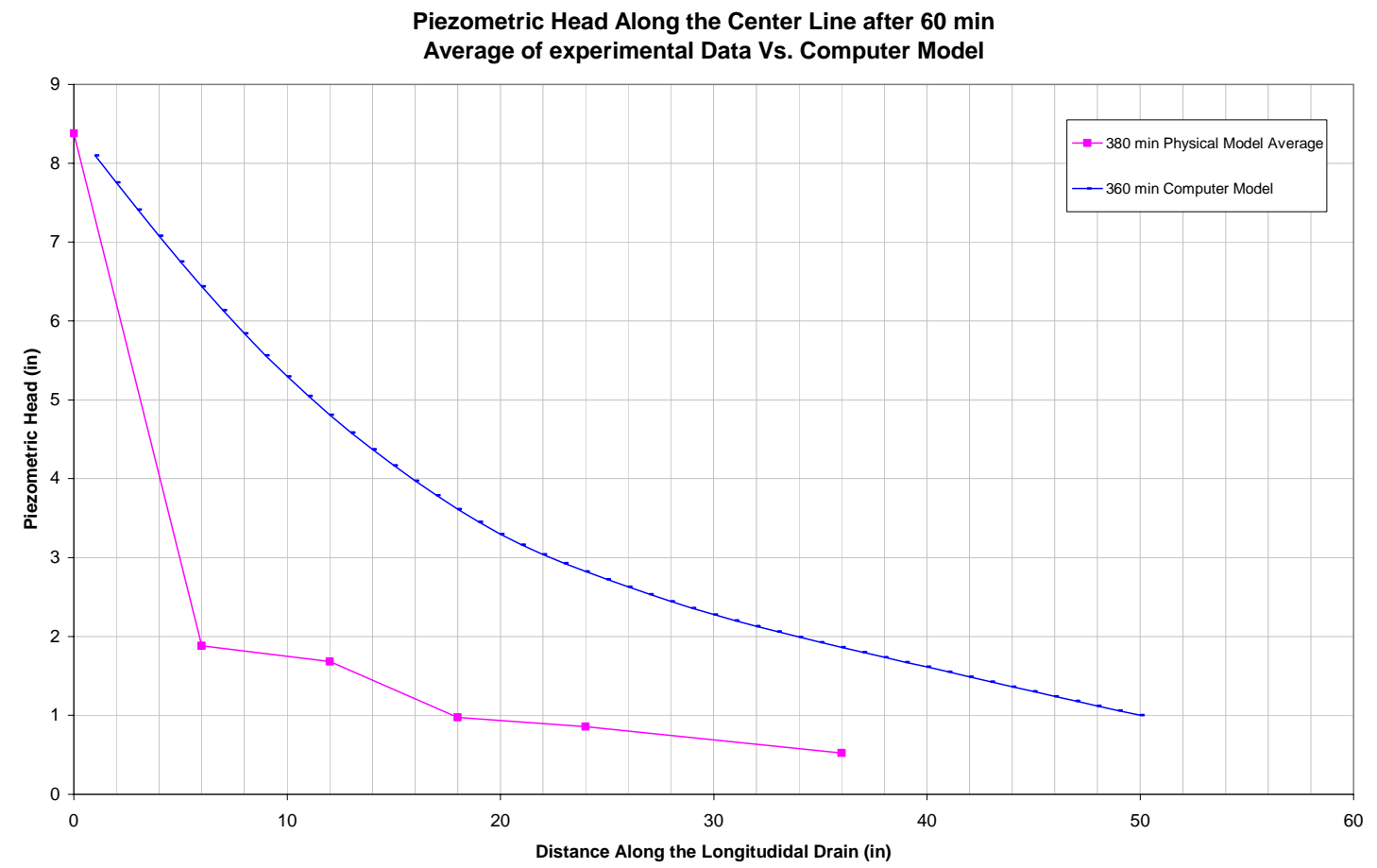

Figure A3.28: Piezometric head along Center Line Soil Type E, after 360 minutes 
Appendix A4: Laboratory Vs Computer Model Piezometric Heads at Cross-section $A$ and $B$

$$
\begin{aligned}
& W=12 \text { inches } \\
& I=48 \text { inches } \\
& \theta=0^{0}
\end{aligned}
$$




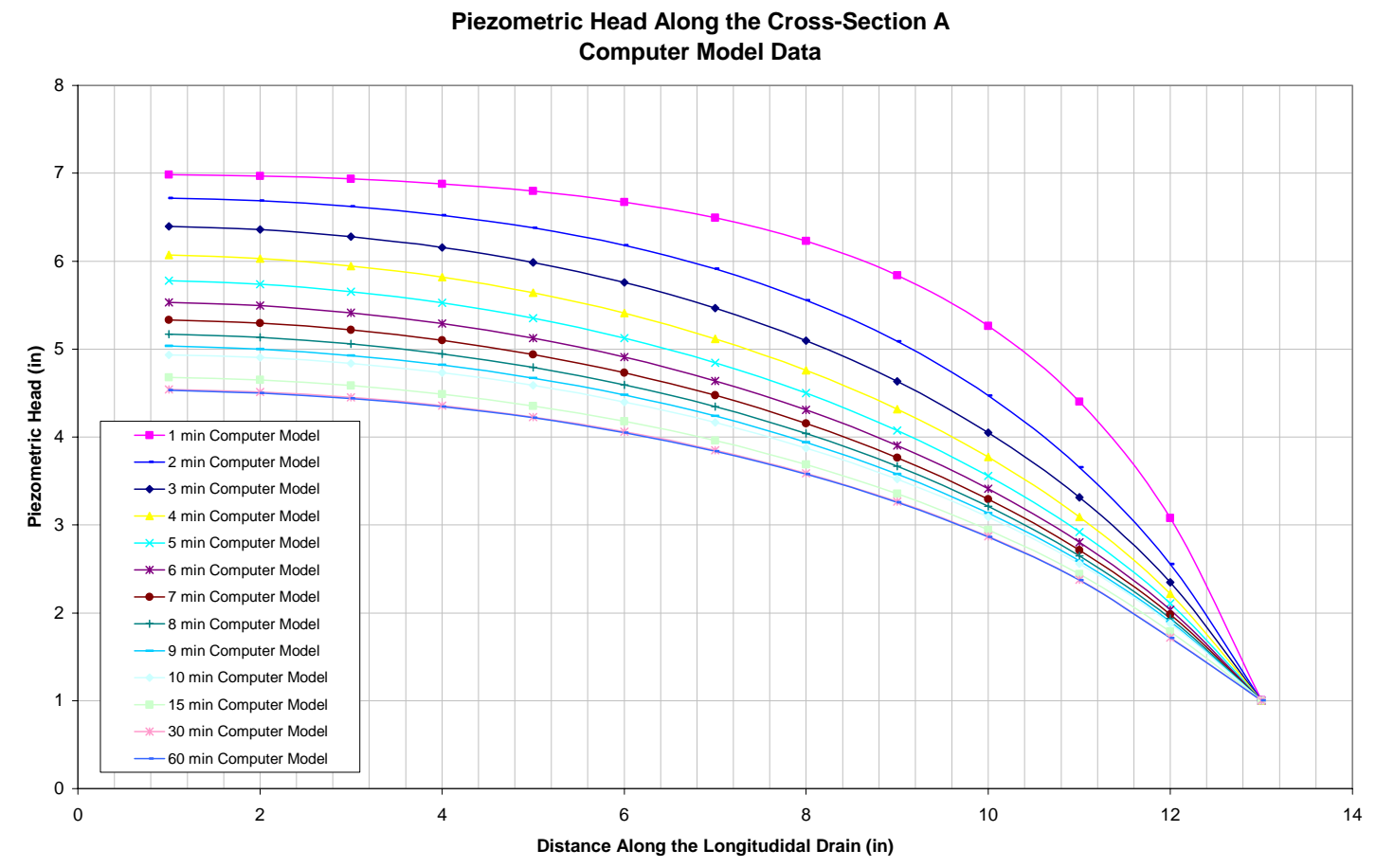

Figure A4.1: Piezometric head along cross-section A for soil type B - Computer Model

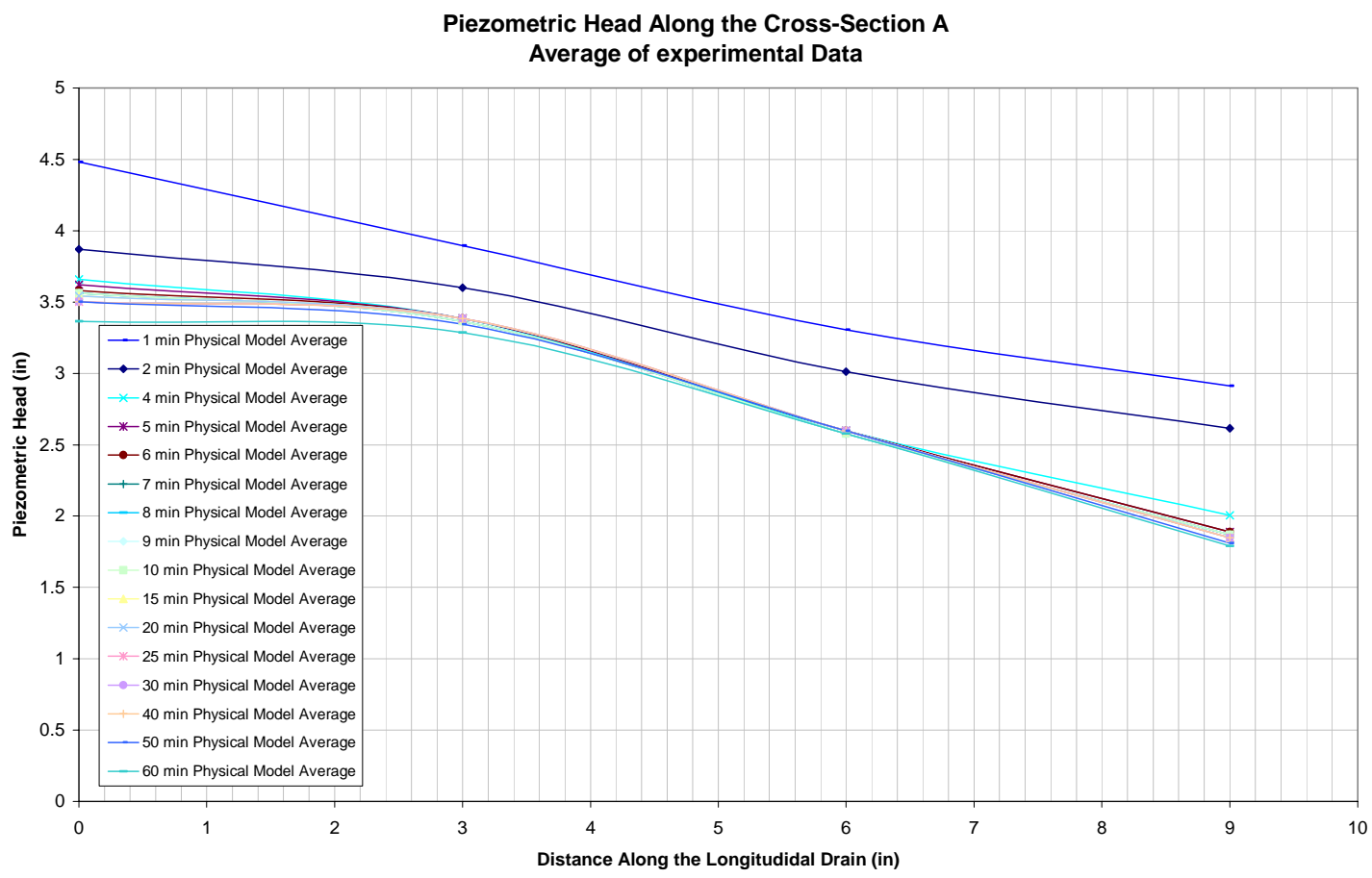

Figure A4.2: Piezometric head along cross-section A for soil type B - Physical Model 


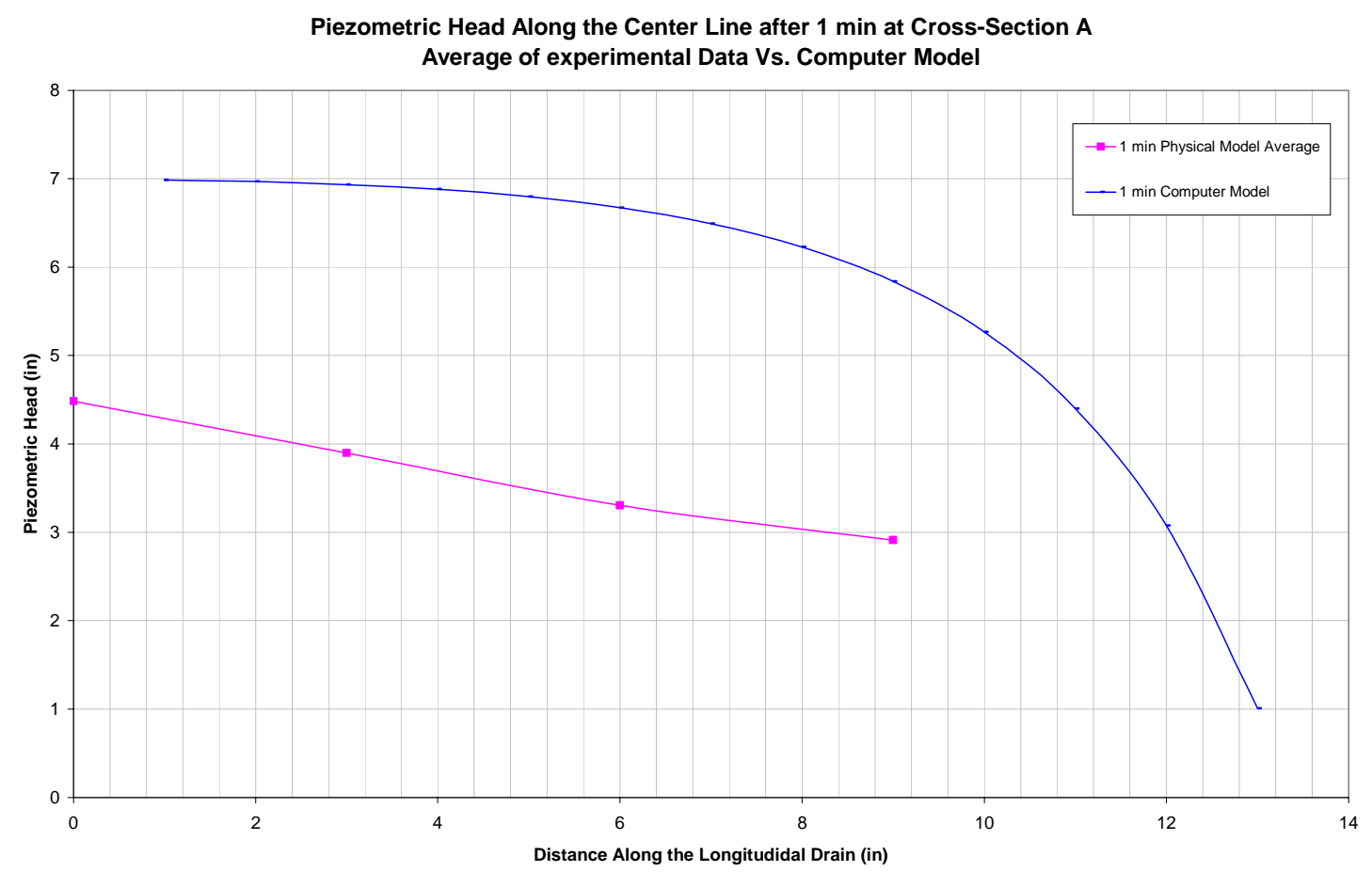

Figure A4.3: Piezometric head along Cross-Section A for soil type B after 1 minute

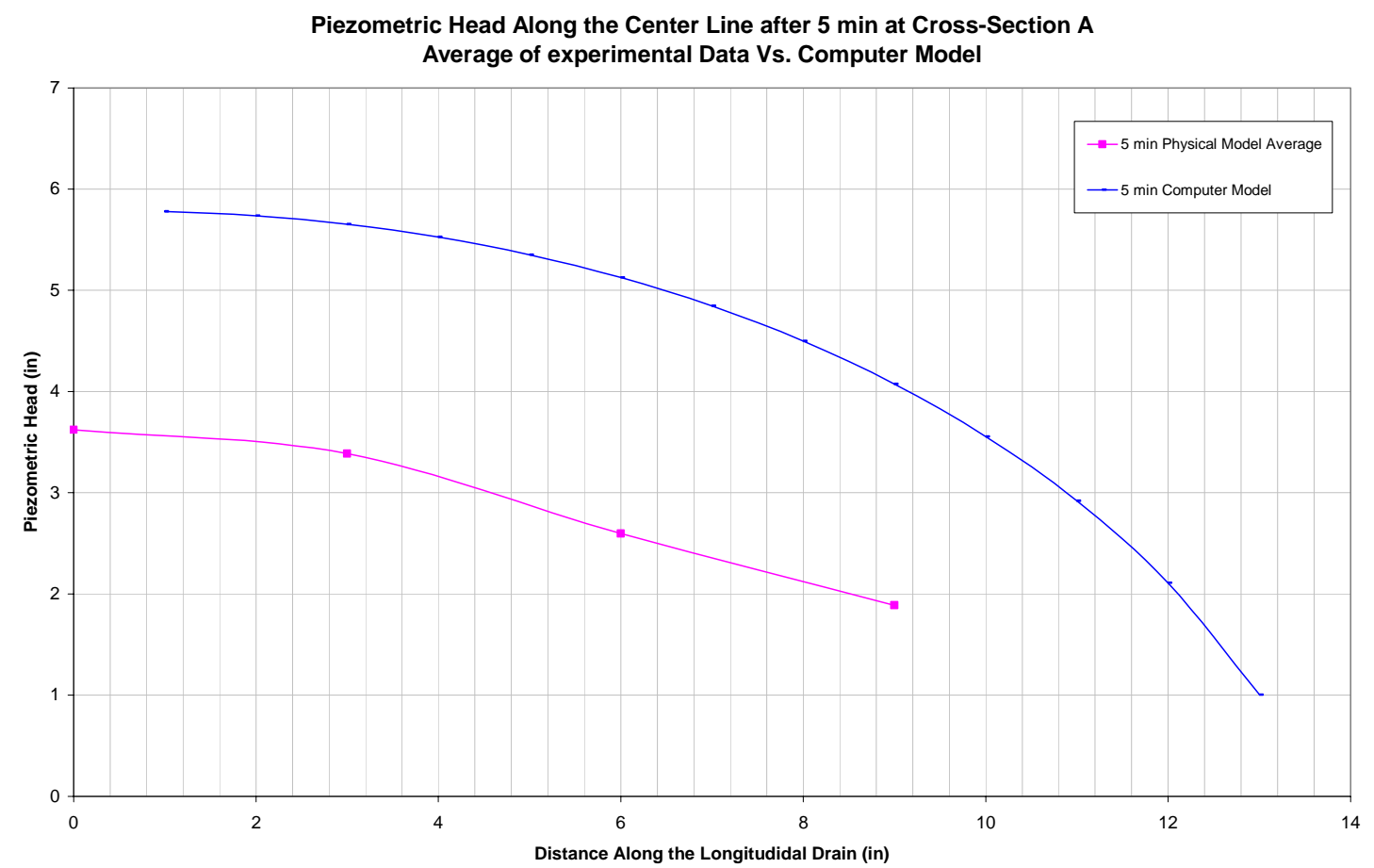

Figure A4.4: Piezometric head along Cross-Section A for soil type B after 5 minutes 


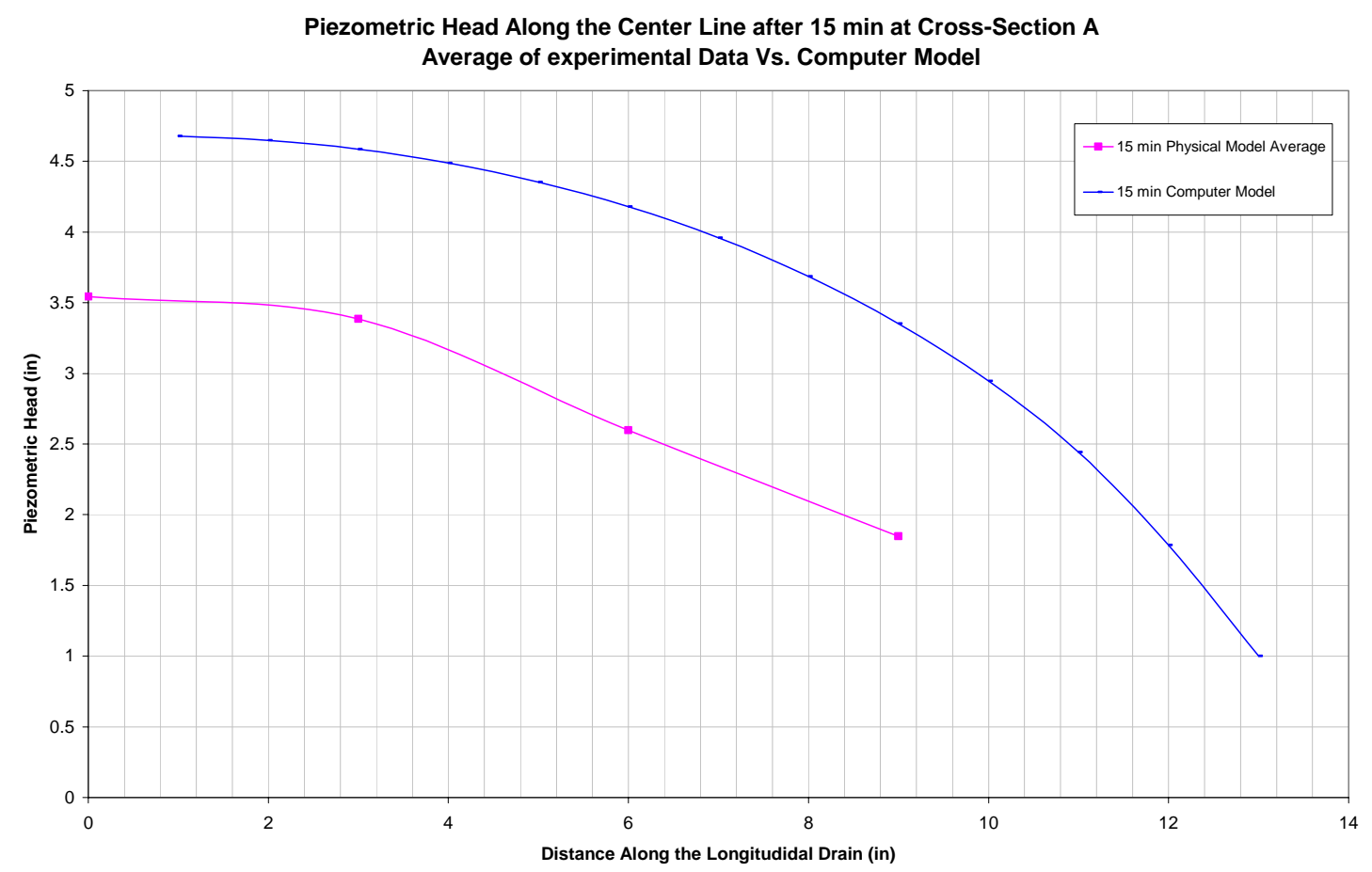

Figure A4.5: Piezometric head along Cross-Section A for soil type B after 15 minutes

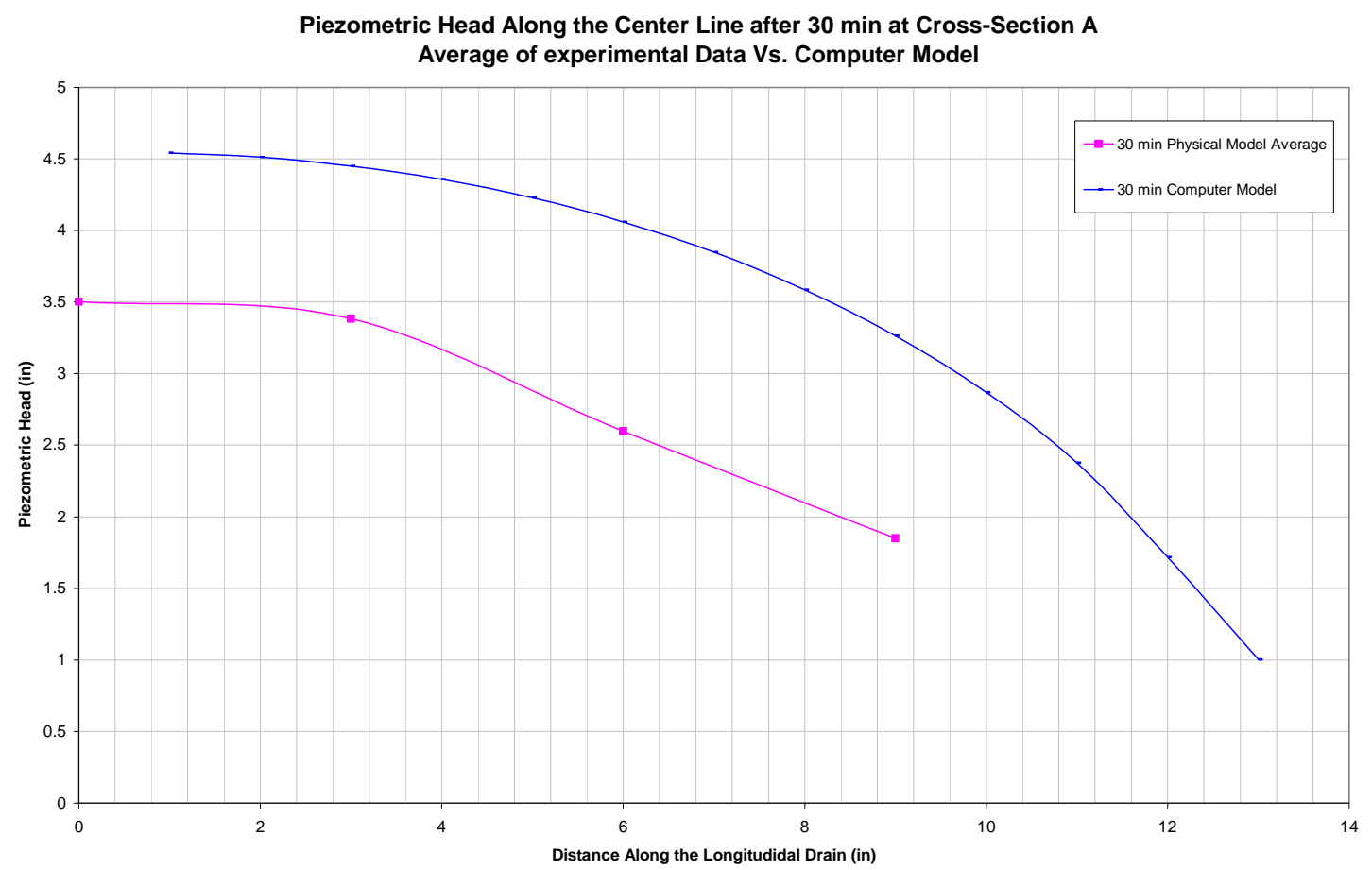

Figure A4.6: Piezometric head along Cross-Section A for soil type B after 30 minutes 


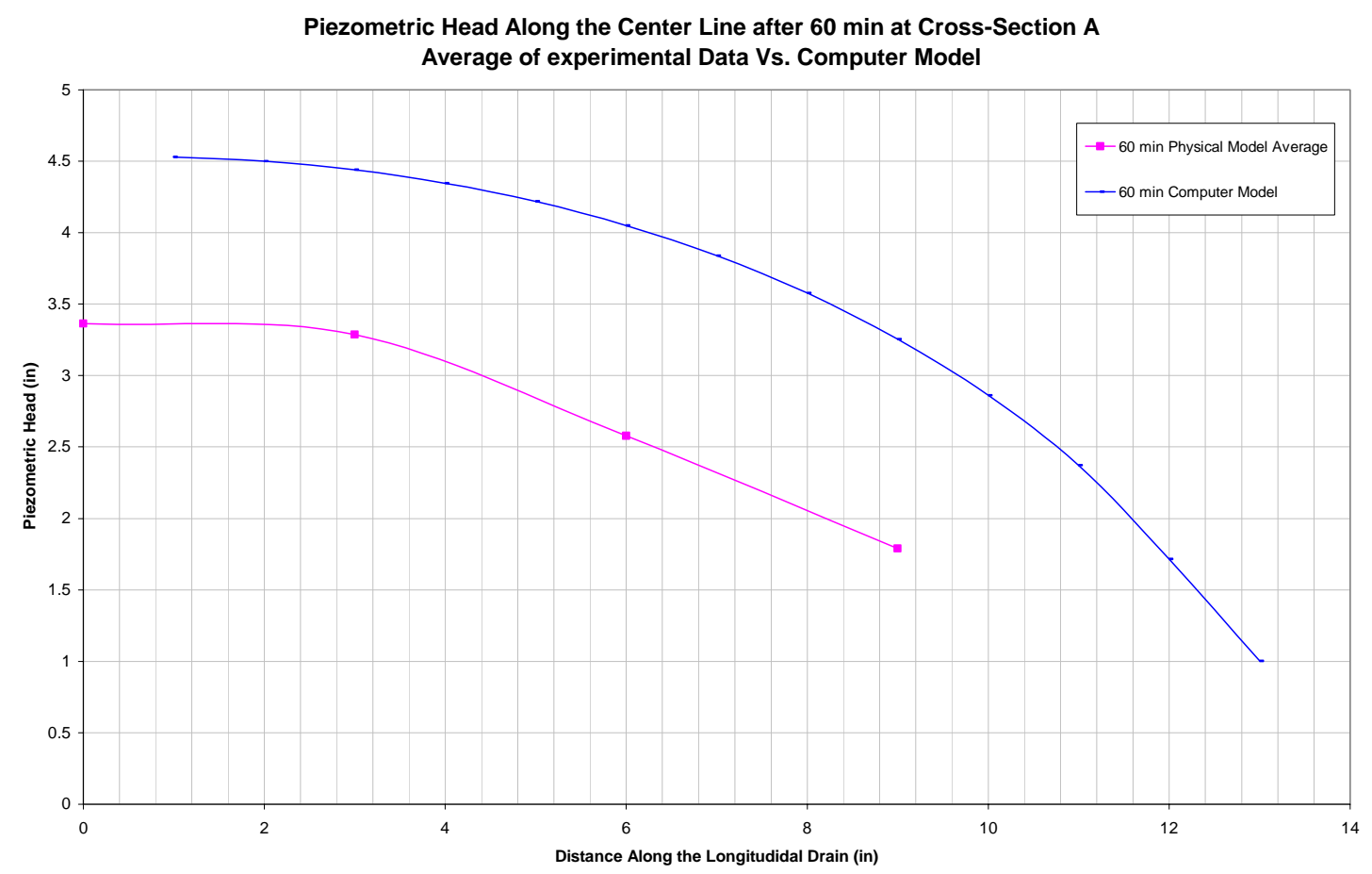

Figure A4.7: Piezometric head along Cross-Section A for soil type B after 60 minutes

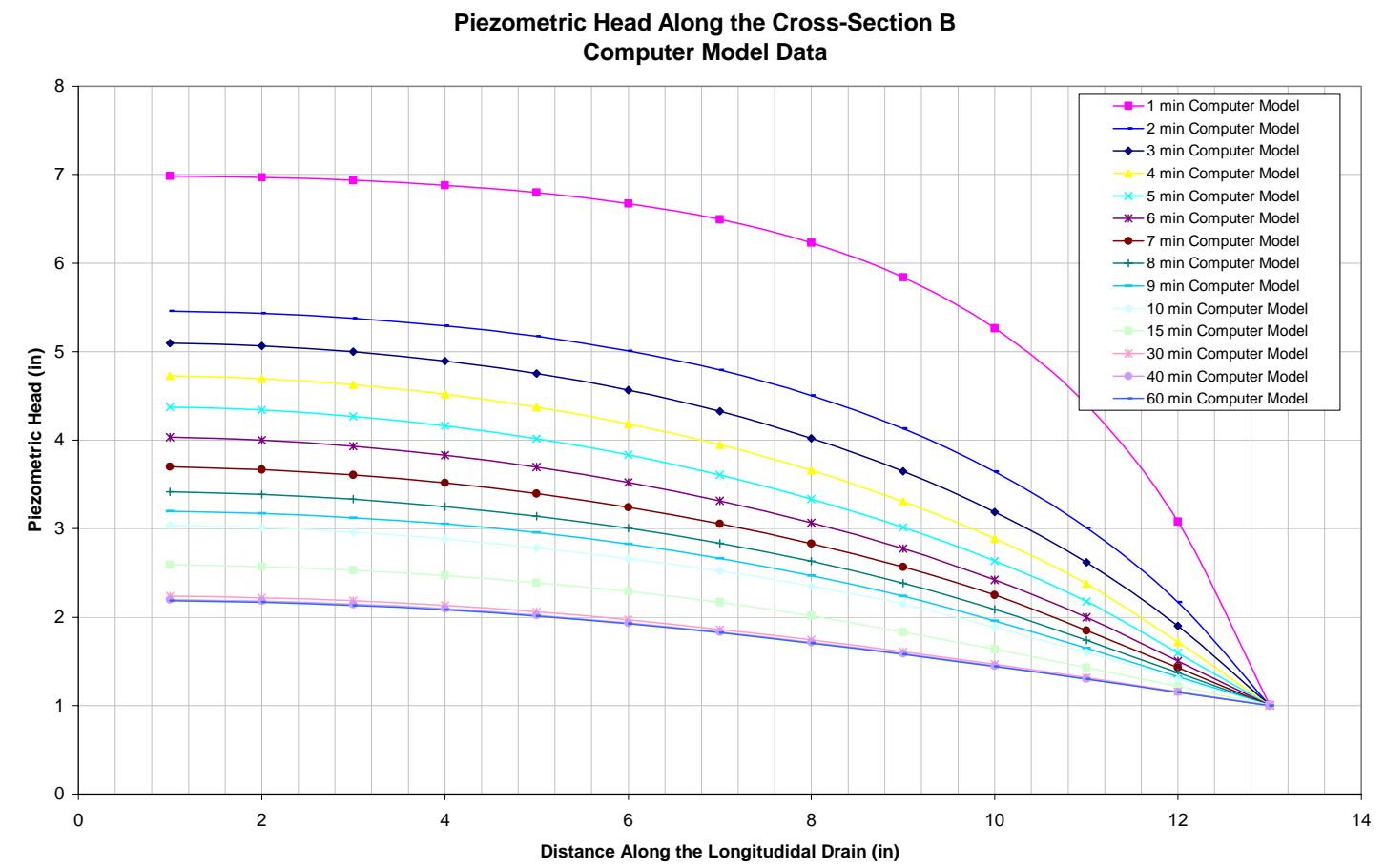

Figure A4.8: Piezometric head along cross-section B for soil type B - Computer Model 


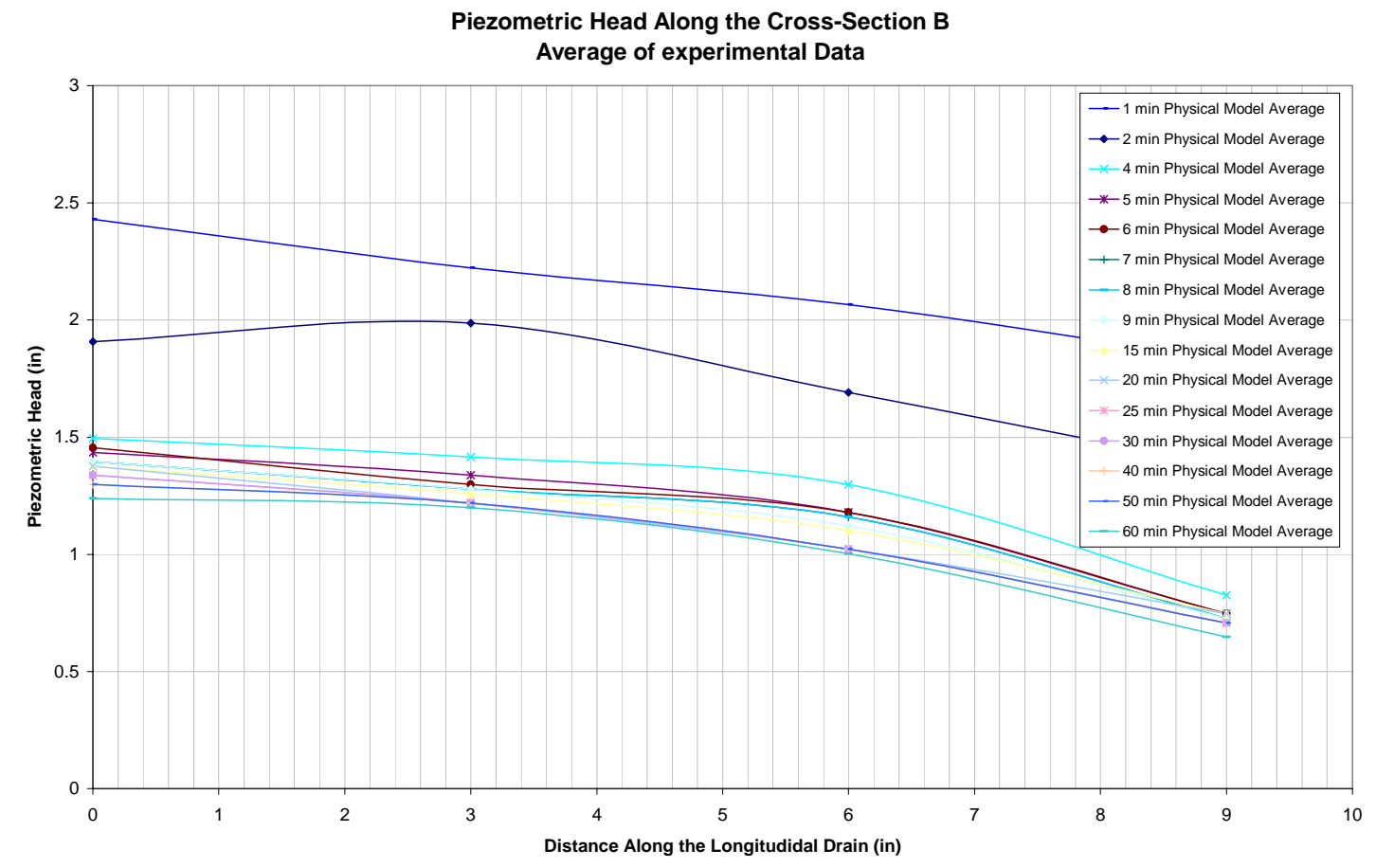

Figure A4.9: Piezometric head along cross-section B for soil type B - Physical Model

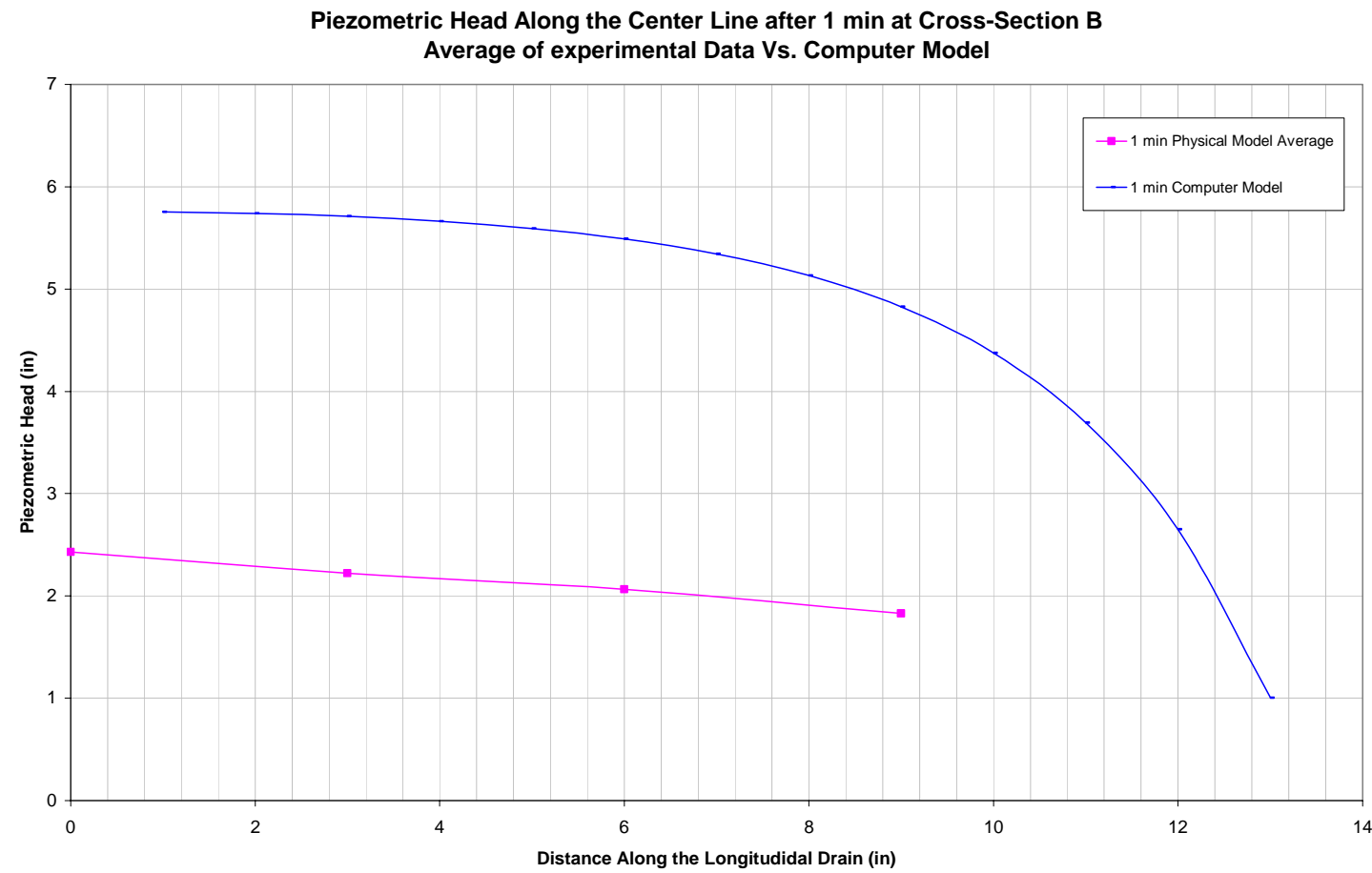

Figure A4.10: Piezometric head along Cross-Section B for soil type B after 1 minute 


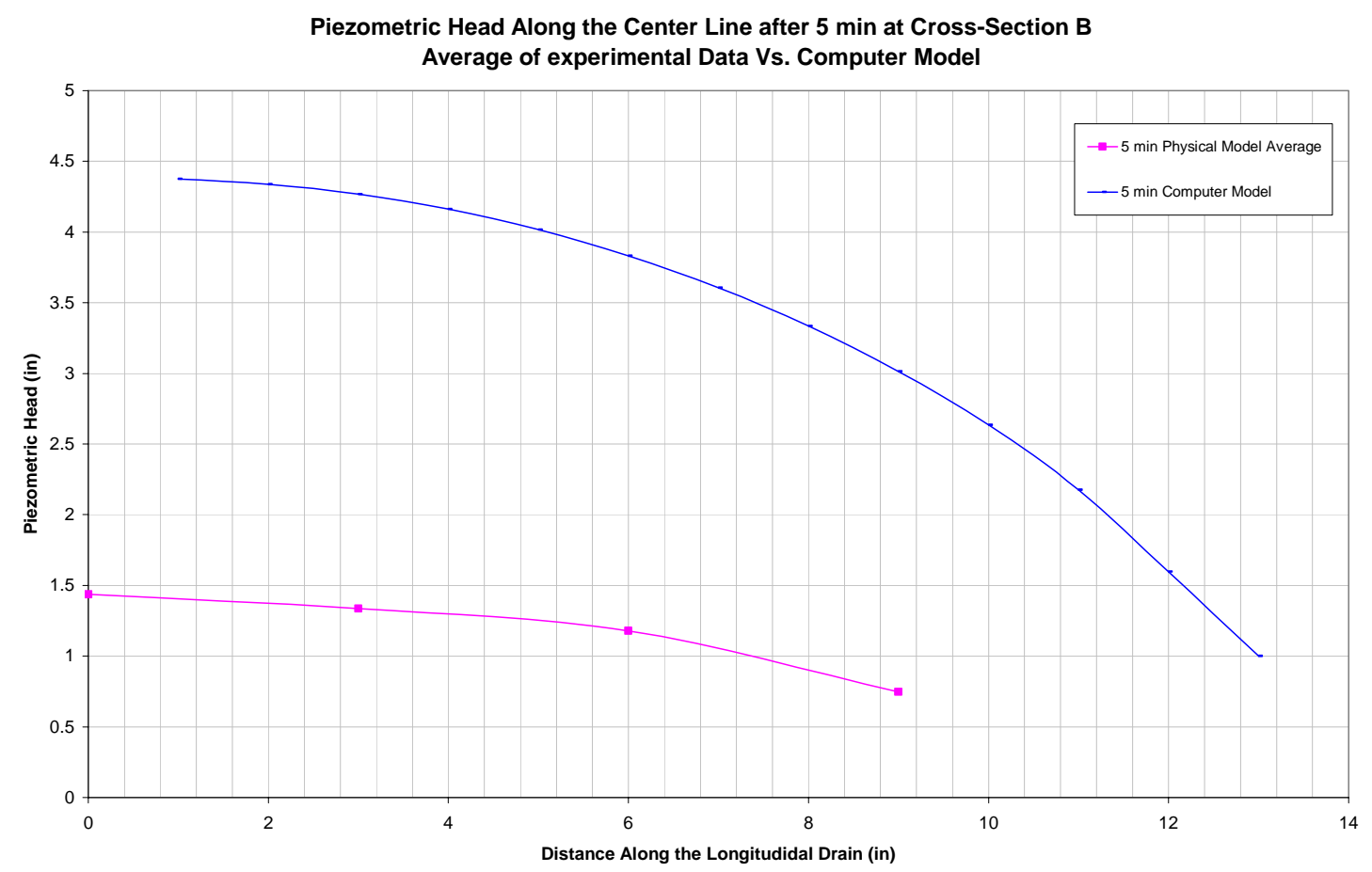

Figure A4.11: Piezometric head along Cross-Section B for soil type B after 5 minutes

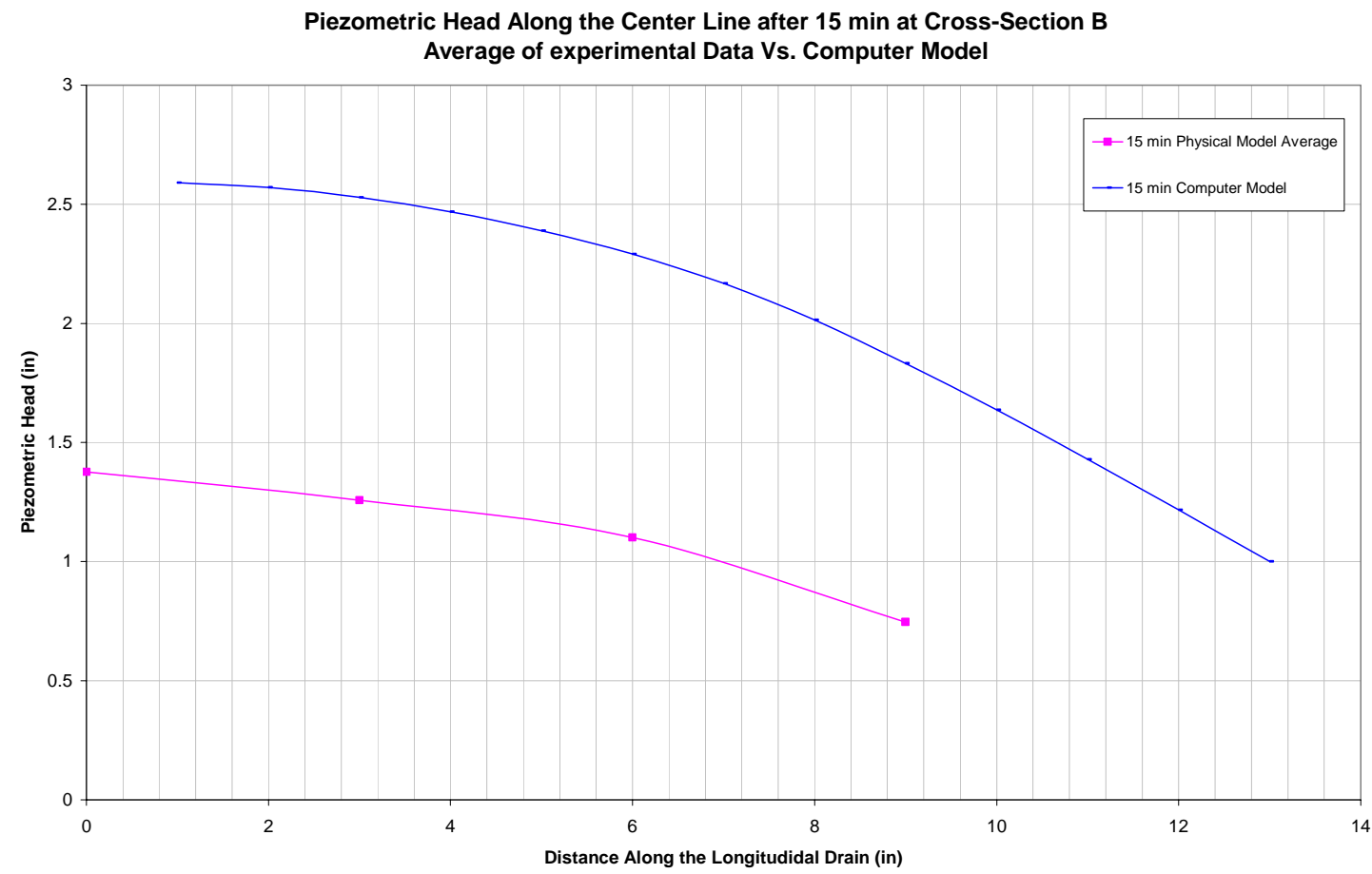

Figure A4.12: Piezometric head along Cross-Section B for soil type B after 15 minutes 


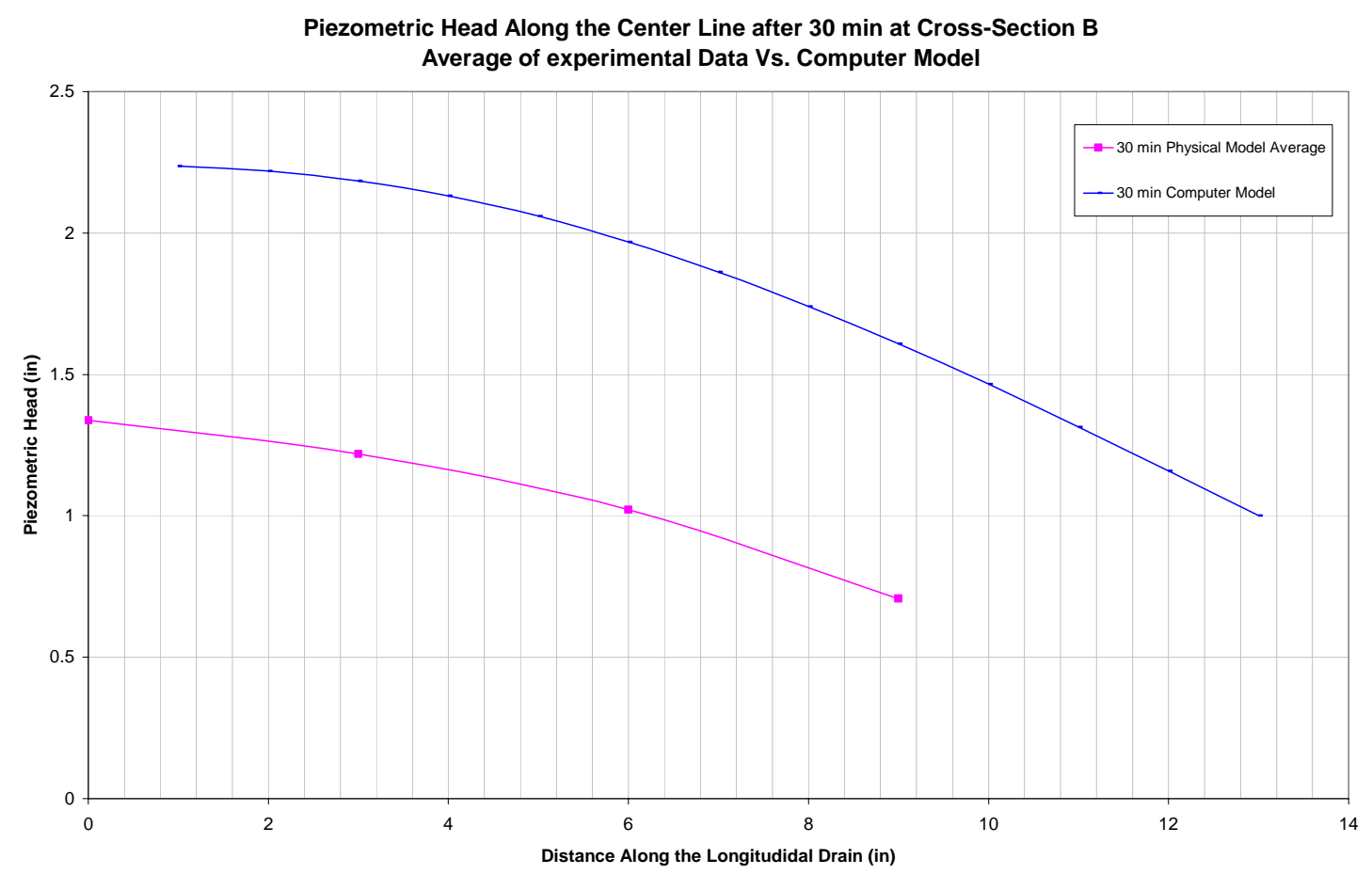

Figure A4.13: Piezometric head along Cross-Section B for soil type B after 30 minutes

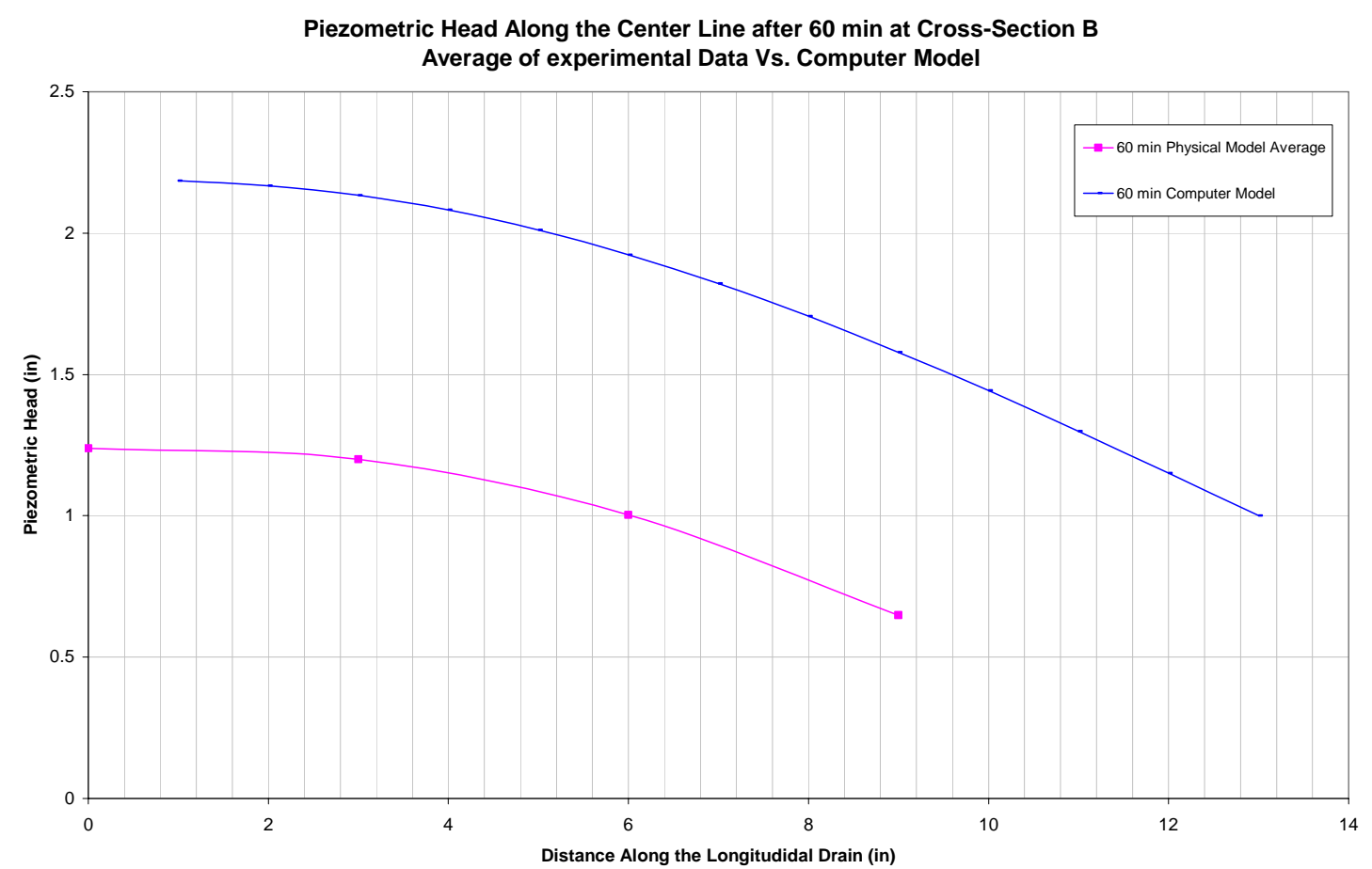

Figure A4.14: Piezometric head along Cross-Section B for soil type B after 60 minutes 


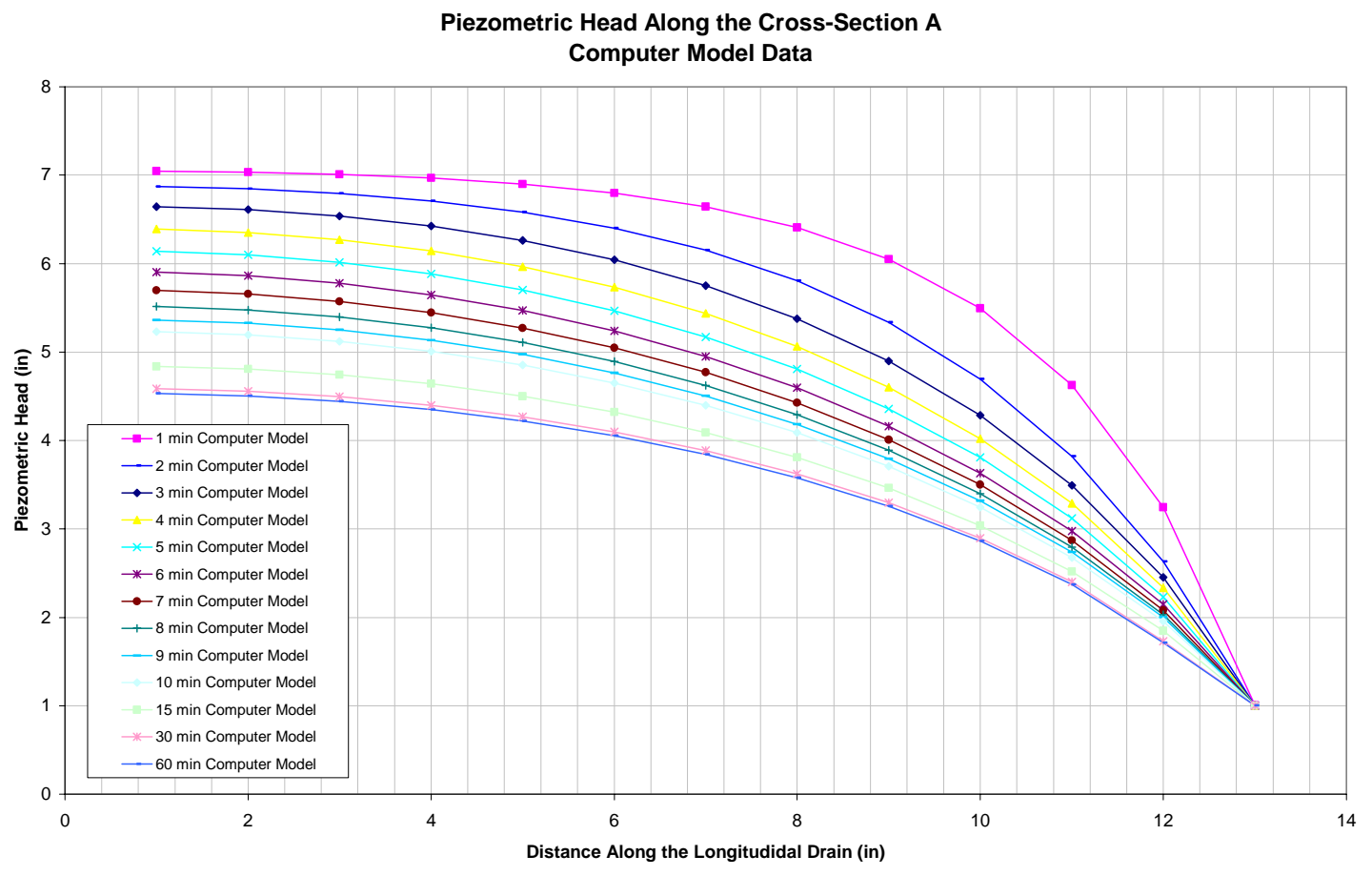

Figure A4.15.: Piezometric head along cross-section A for soil type C - Computer Model

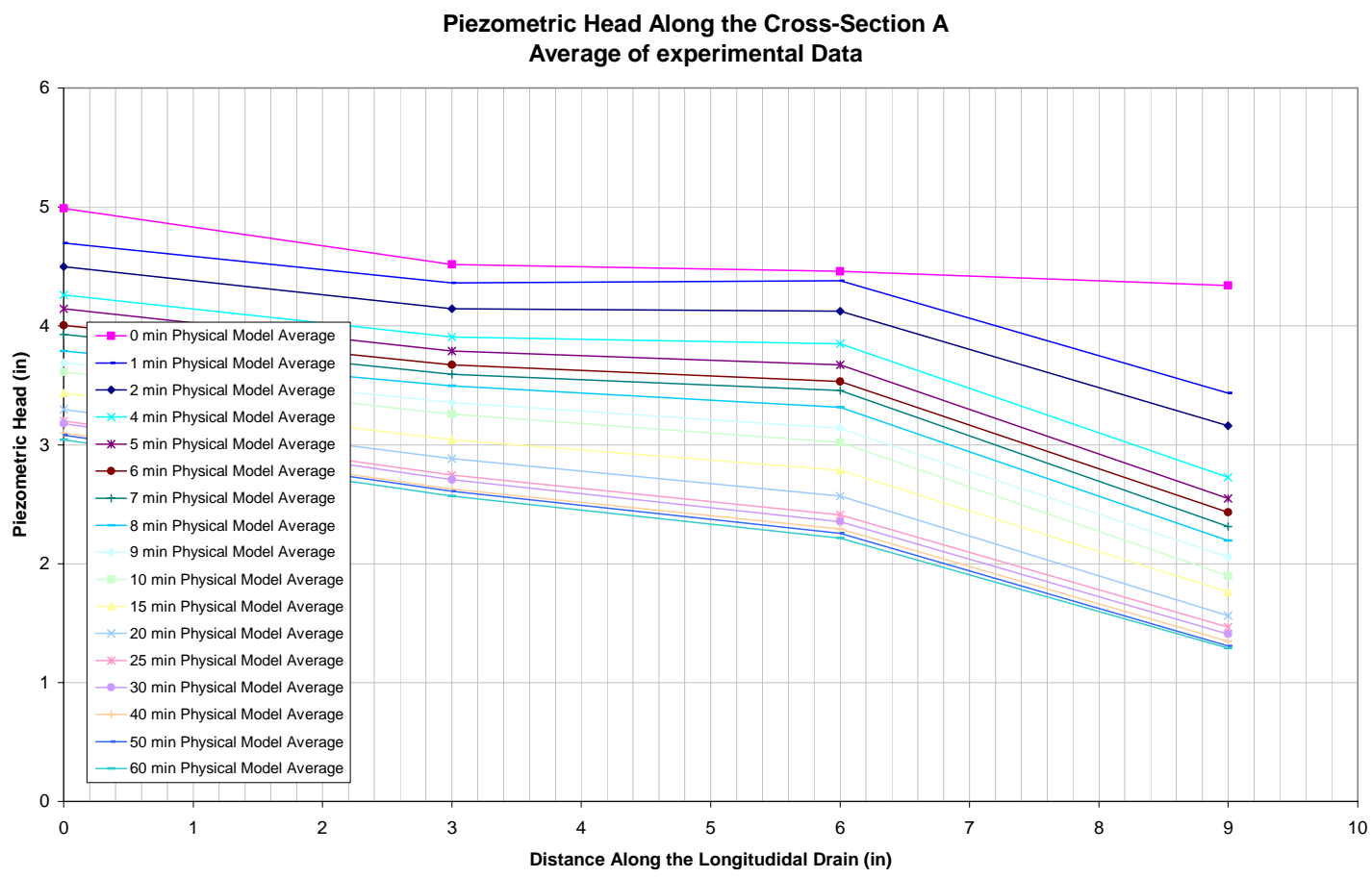

Figure A4.16: Piezometric head along cross-section A for soil type C - Physical Model 


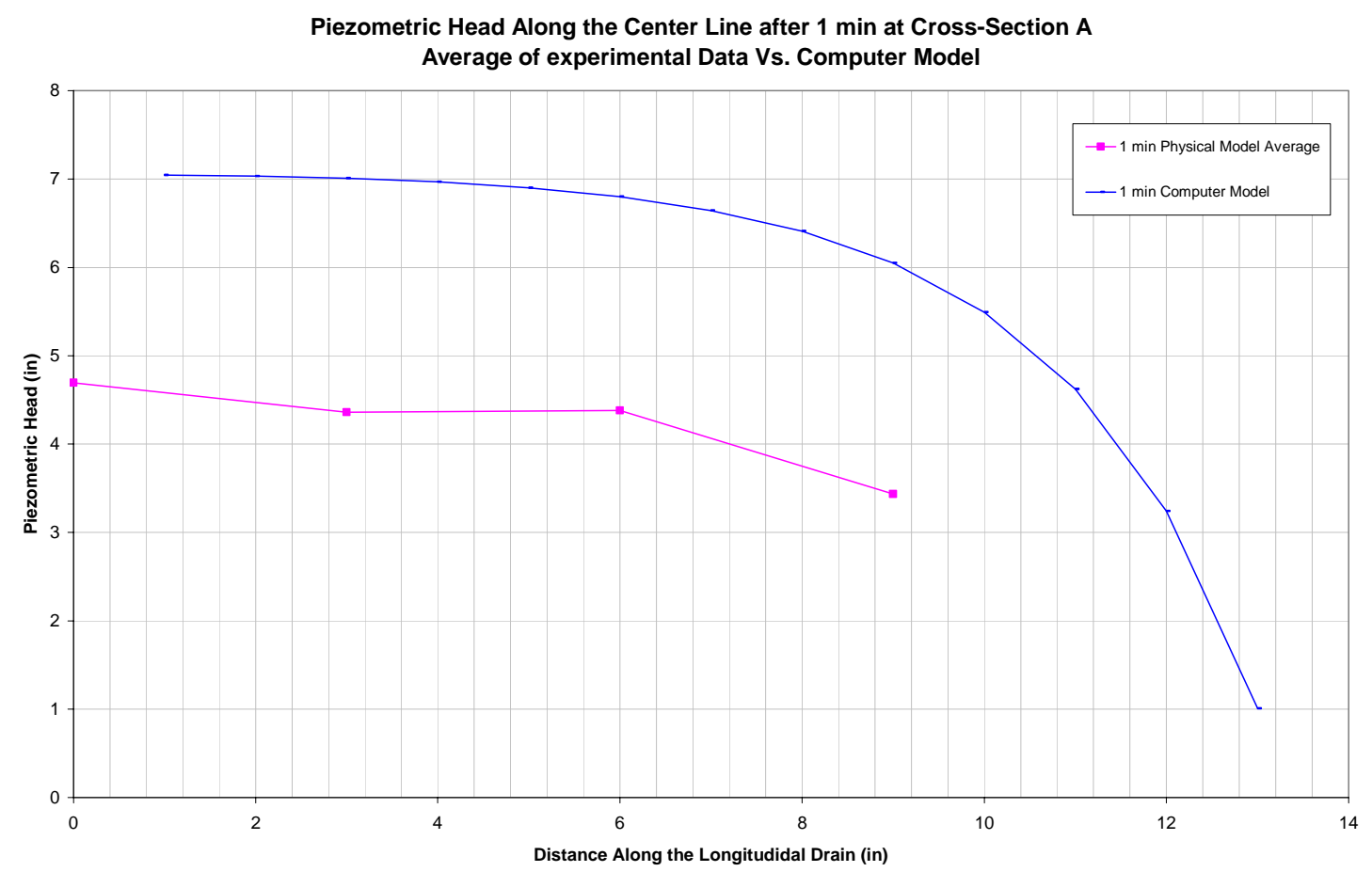

Figure A4.17: Piezometric head along Cross-Section A for soil type C after 1 minute

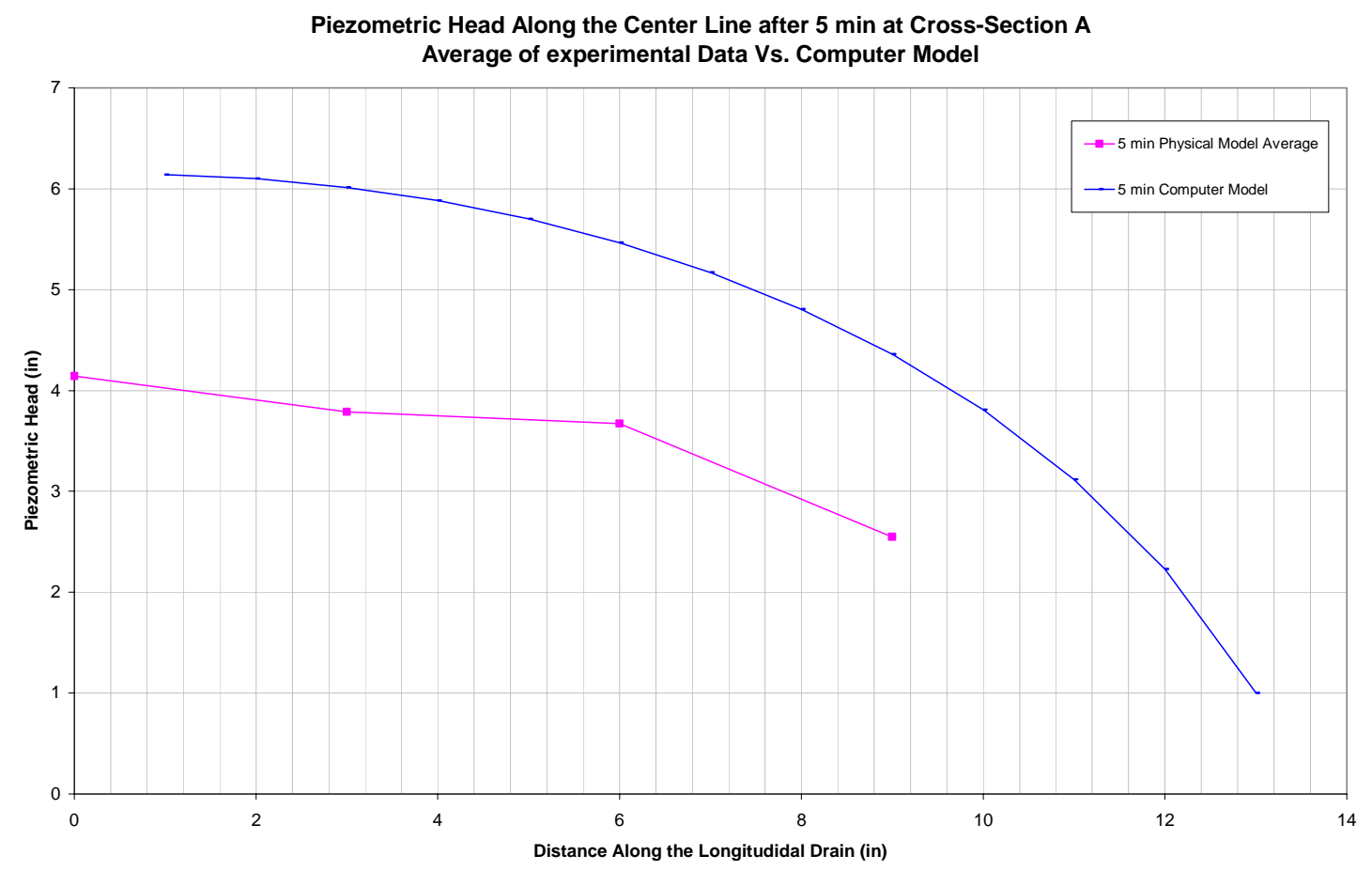

Figure A4.18: Piezometric head along Cross-Section A for soil type C after 5 minutes 


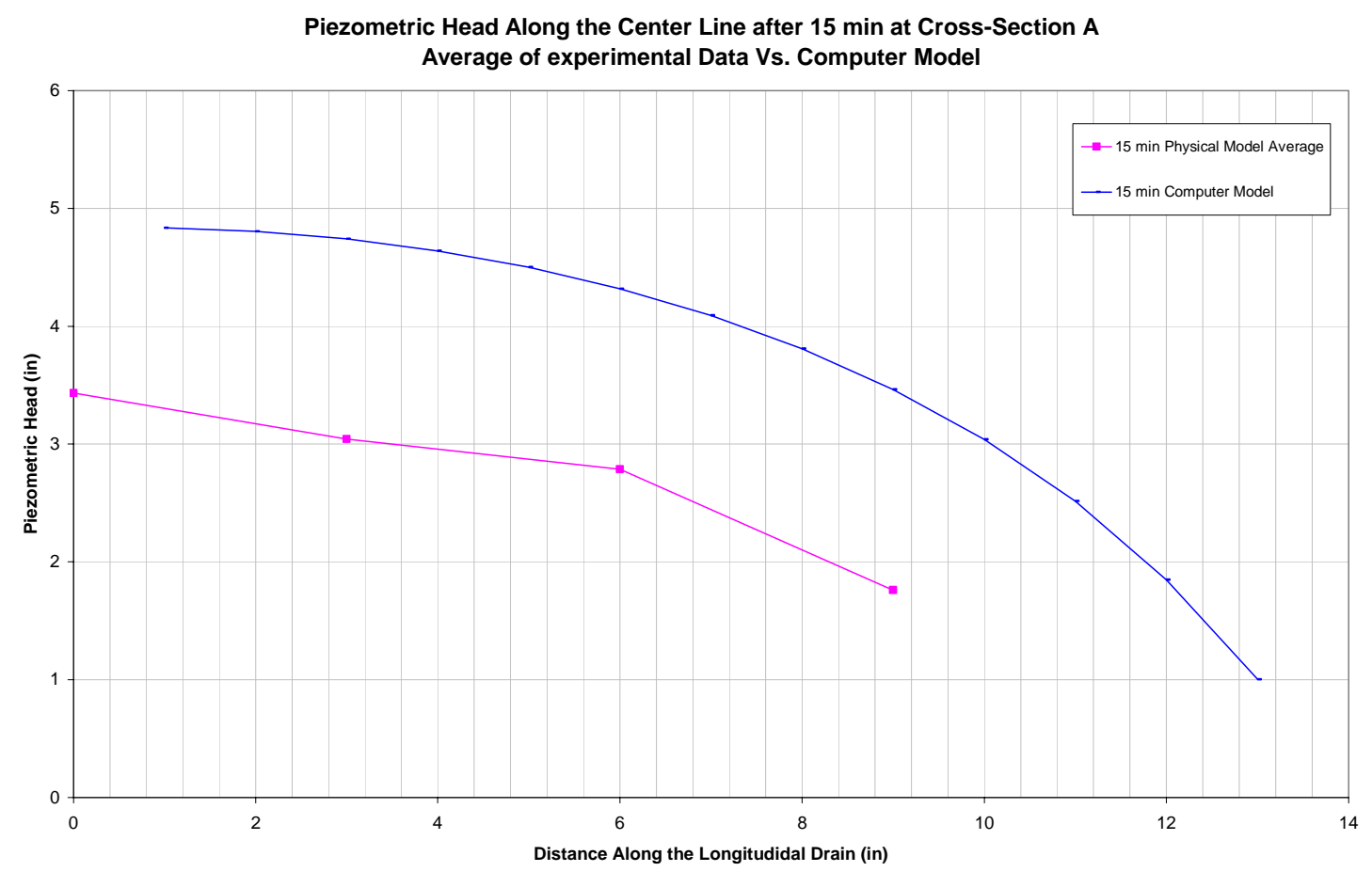

Figure A4.19: Piezometric head along Cross-Section A for soil type C after 15 minutes

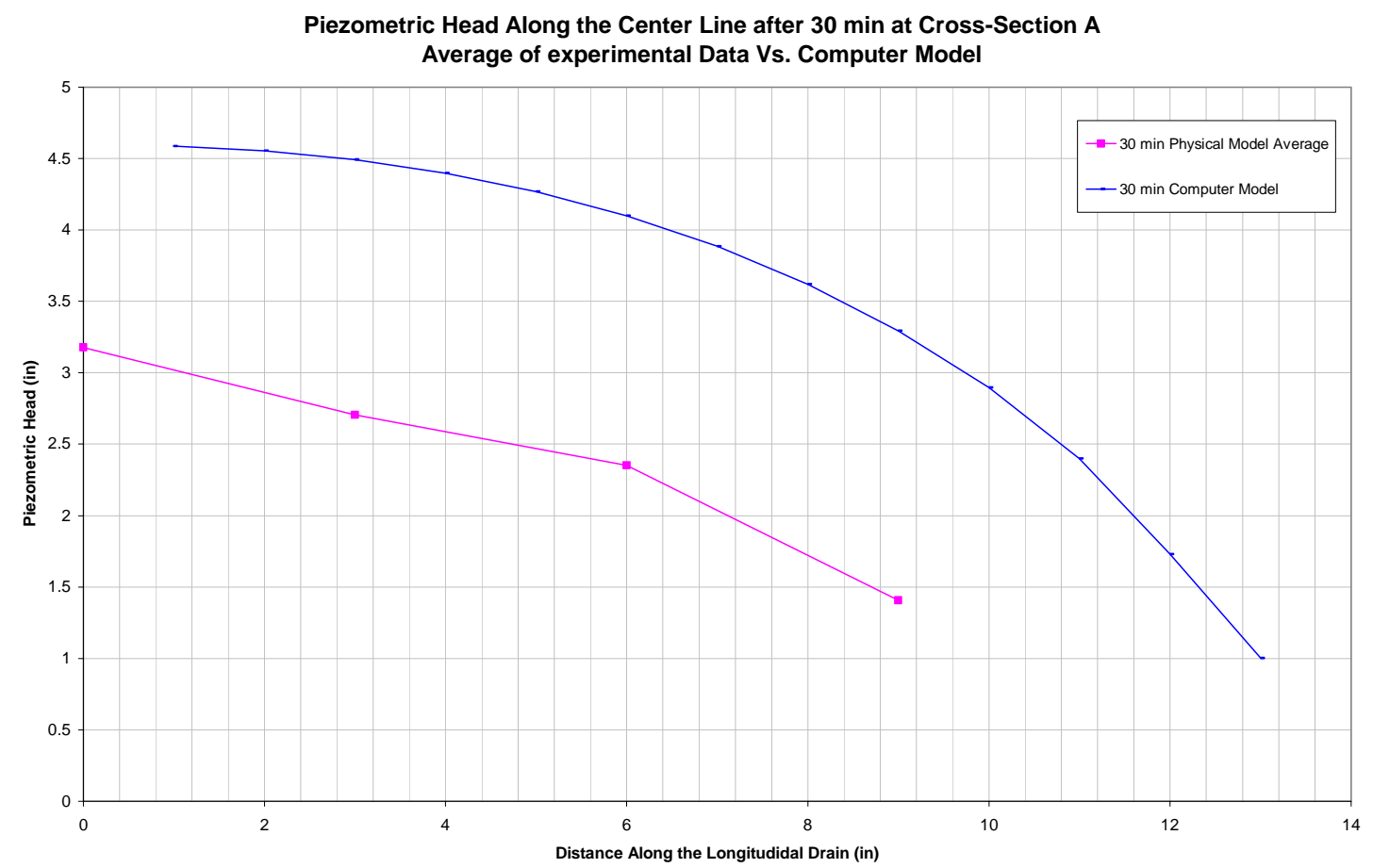

Figure A4.20: Piezometric head along Cross-Section A for soil type C after 30 minutes 


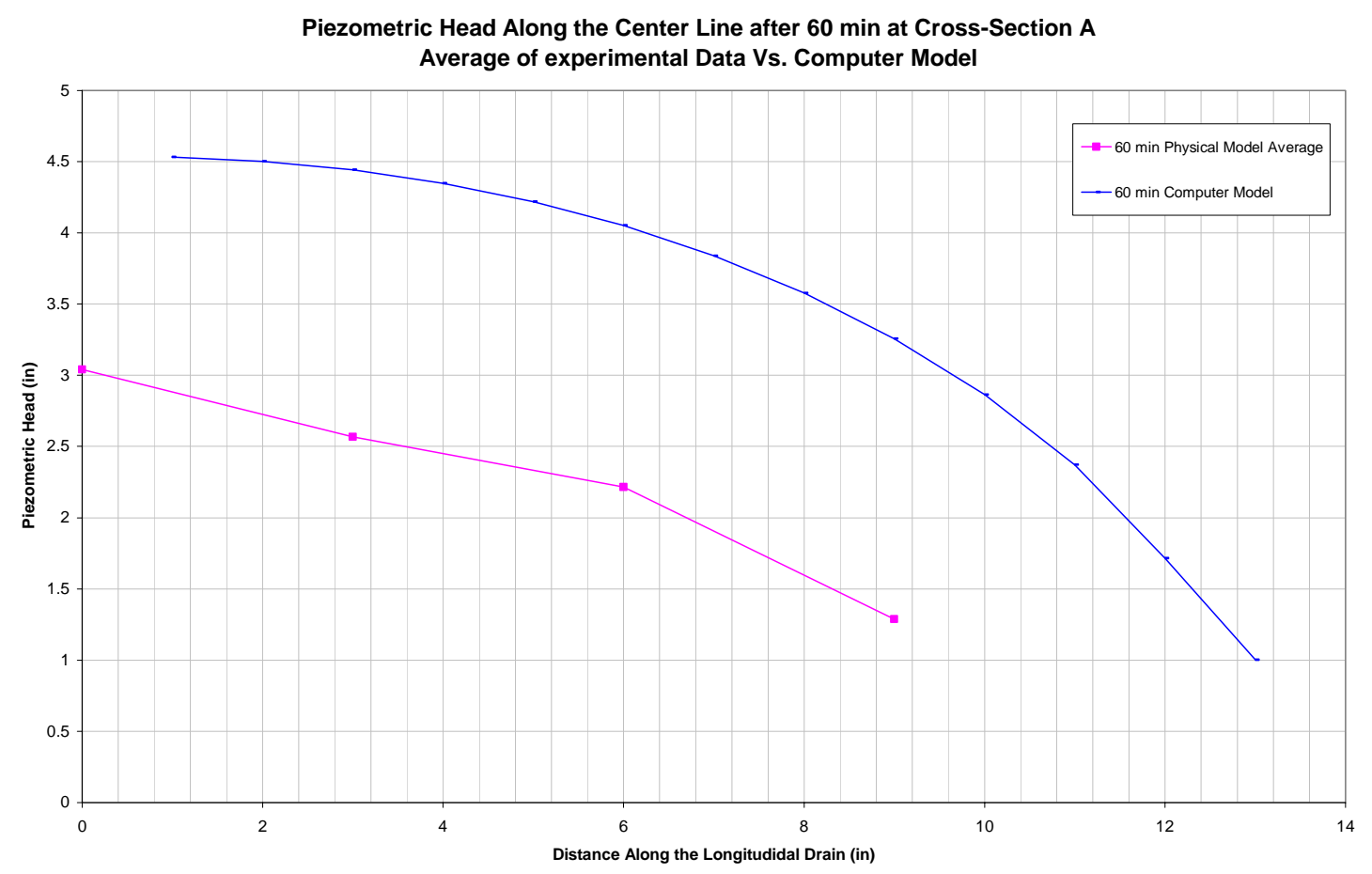

Figure A4.21: Piezometric head along Cross-Section A for soil type C after 60 minutes

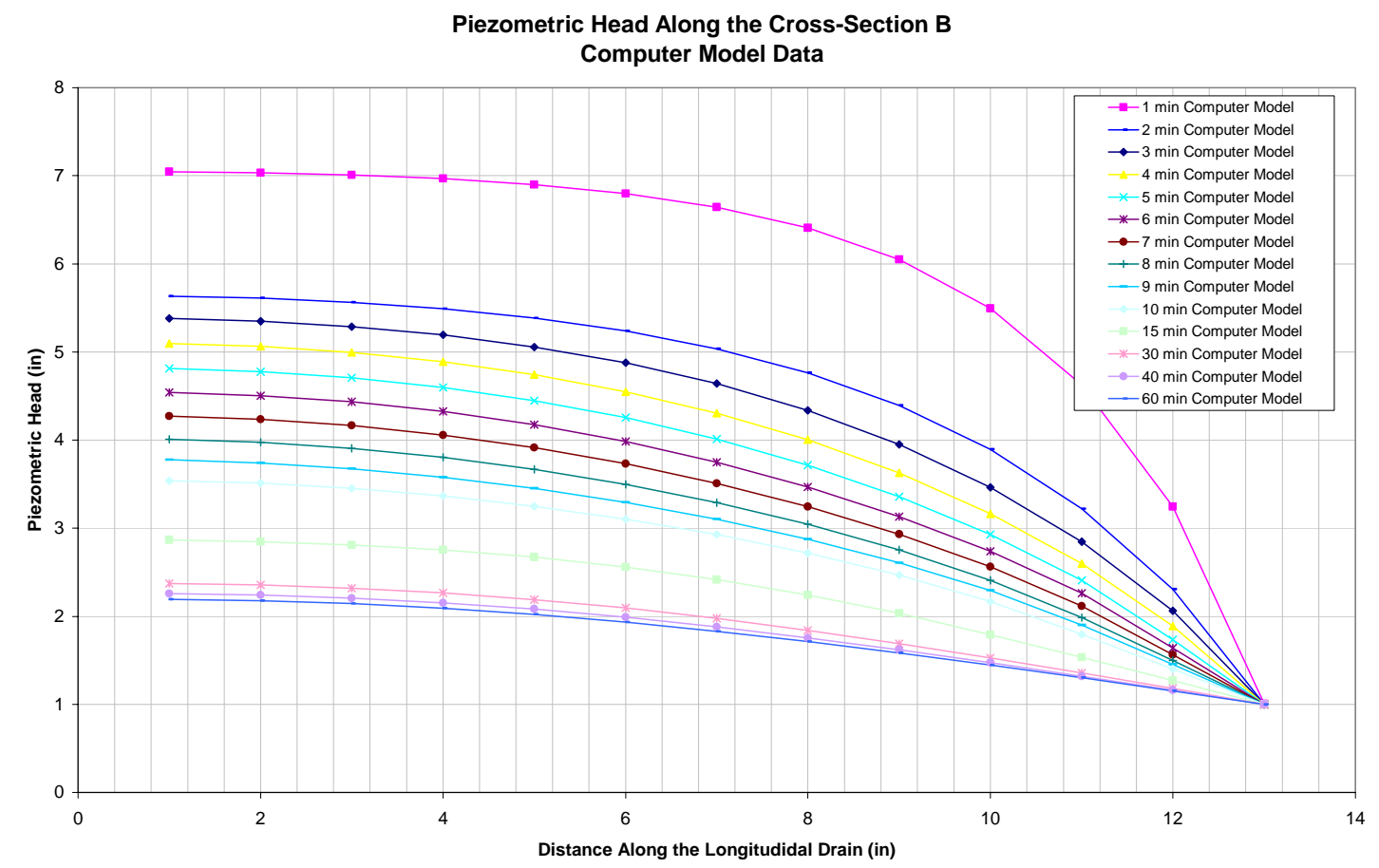

Figure A4.22: Piezometric head along cross-section B for soil type C - Computer Model 


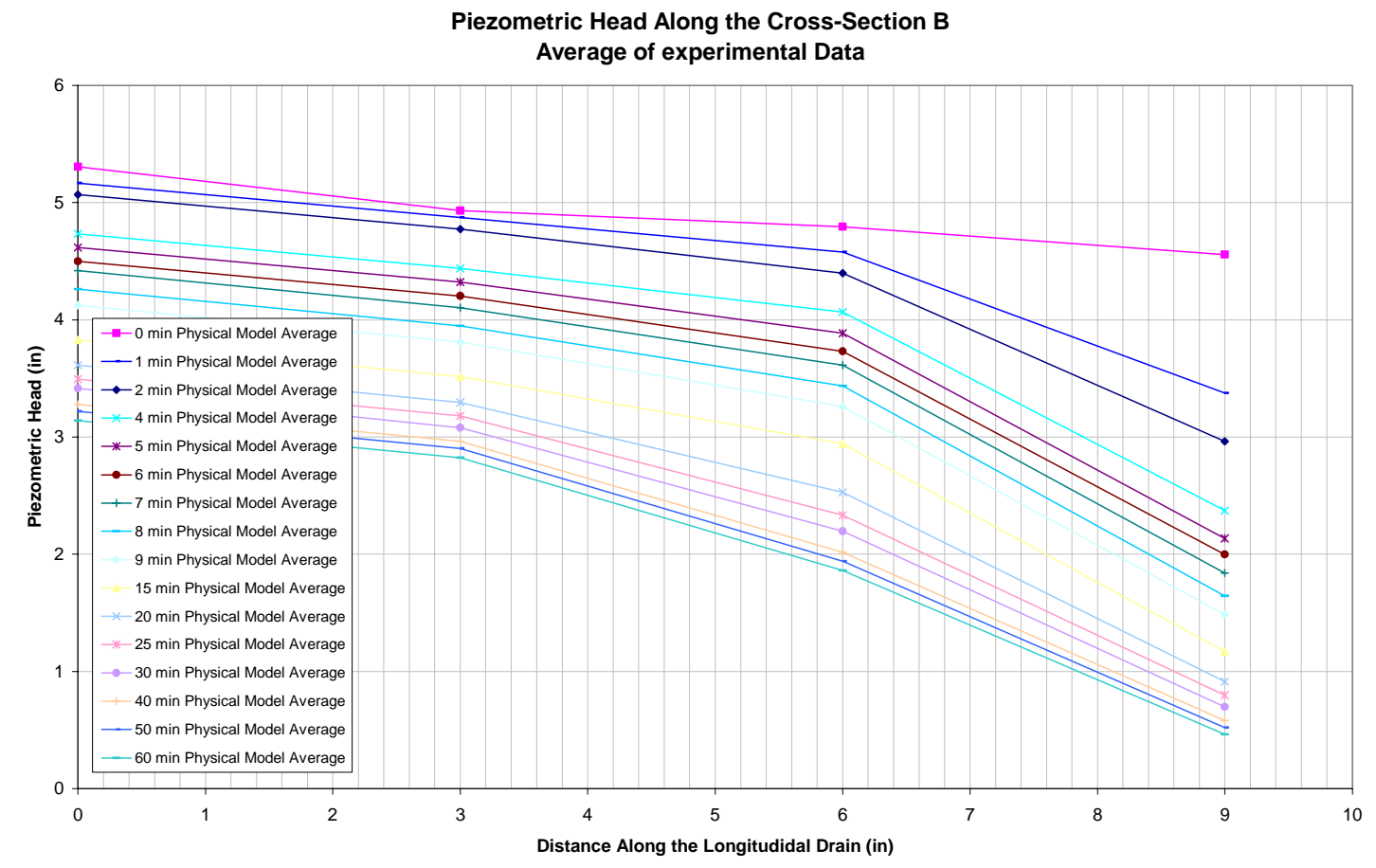

Figure A4.23: Piezometric head along cross-section B for soil type C - Physical Model

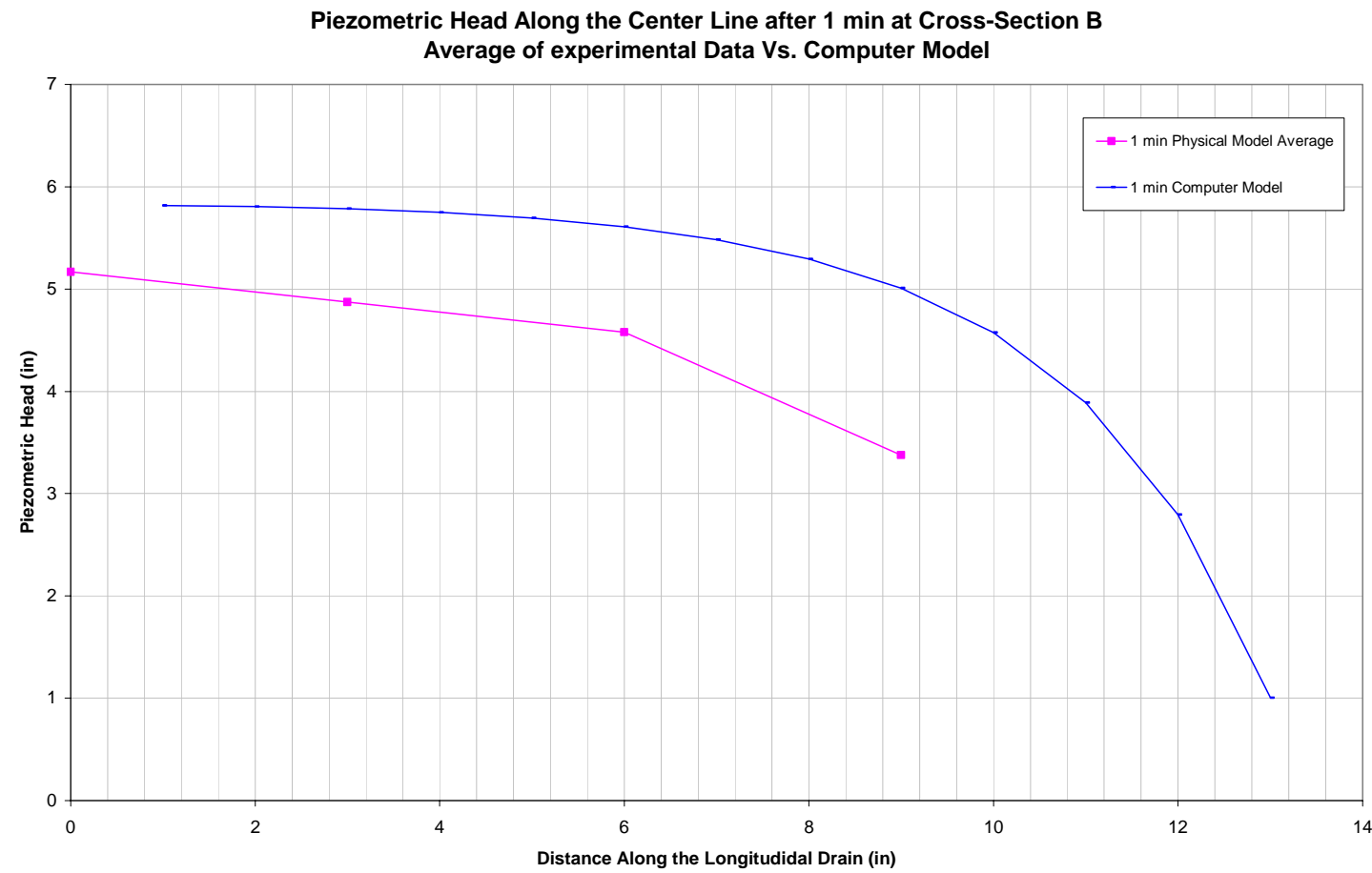

Figure A4.24: Piezometric head along Cross-Section B for soil type C after 1 minute 


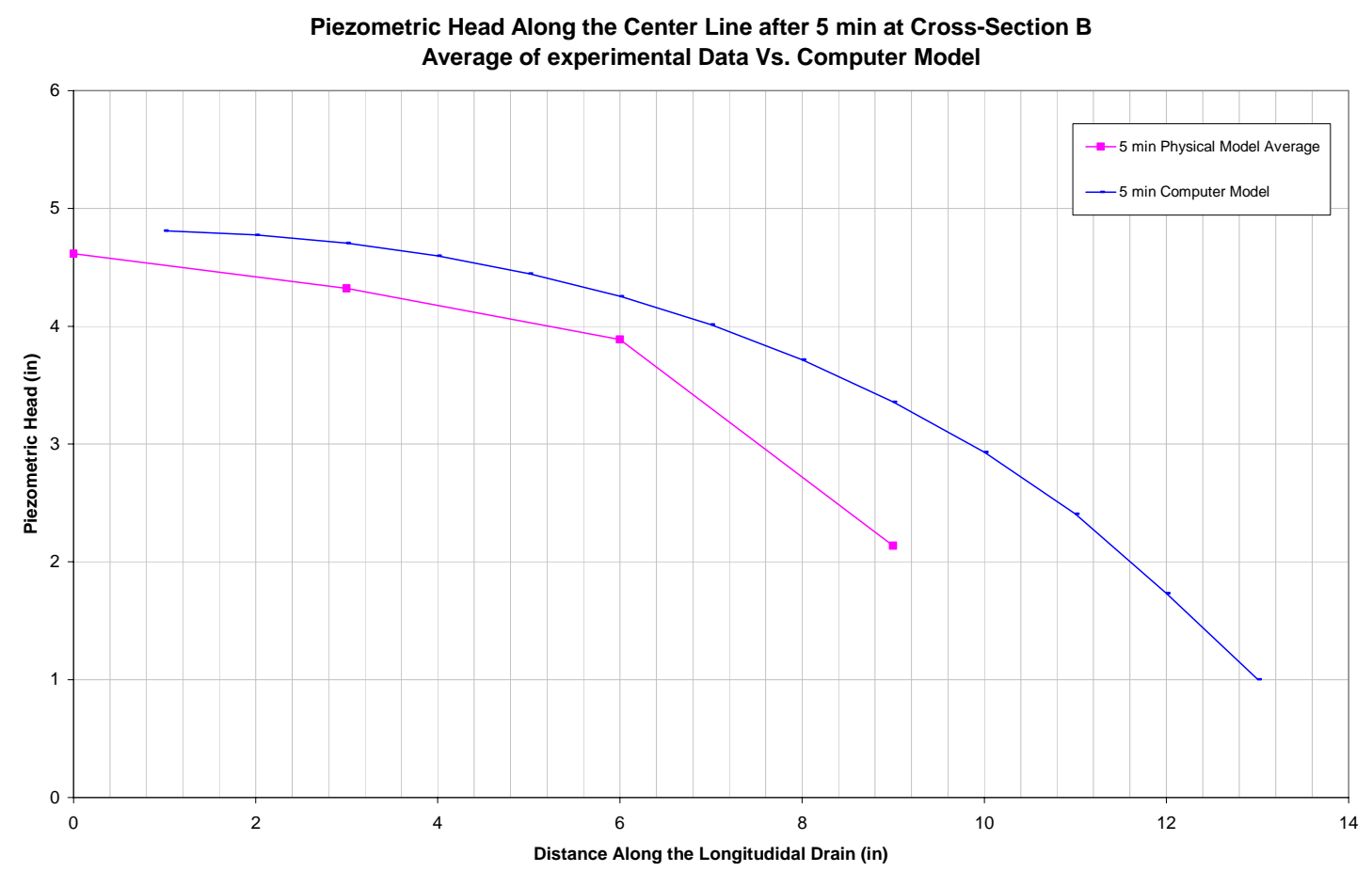

Figure A4.25: Piezometric head along Cross-Section B for soil type C after 5 minutes

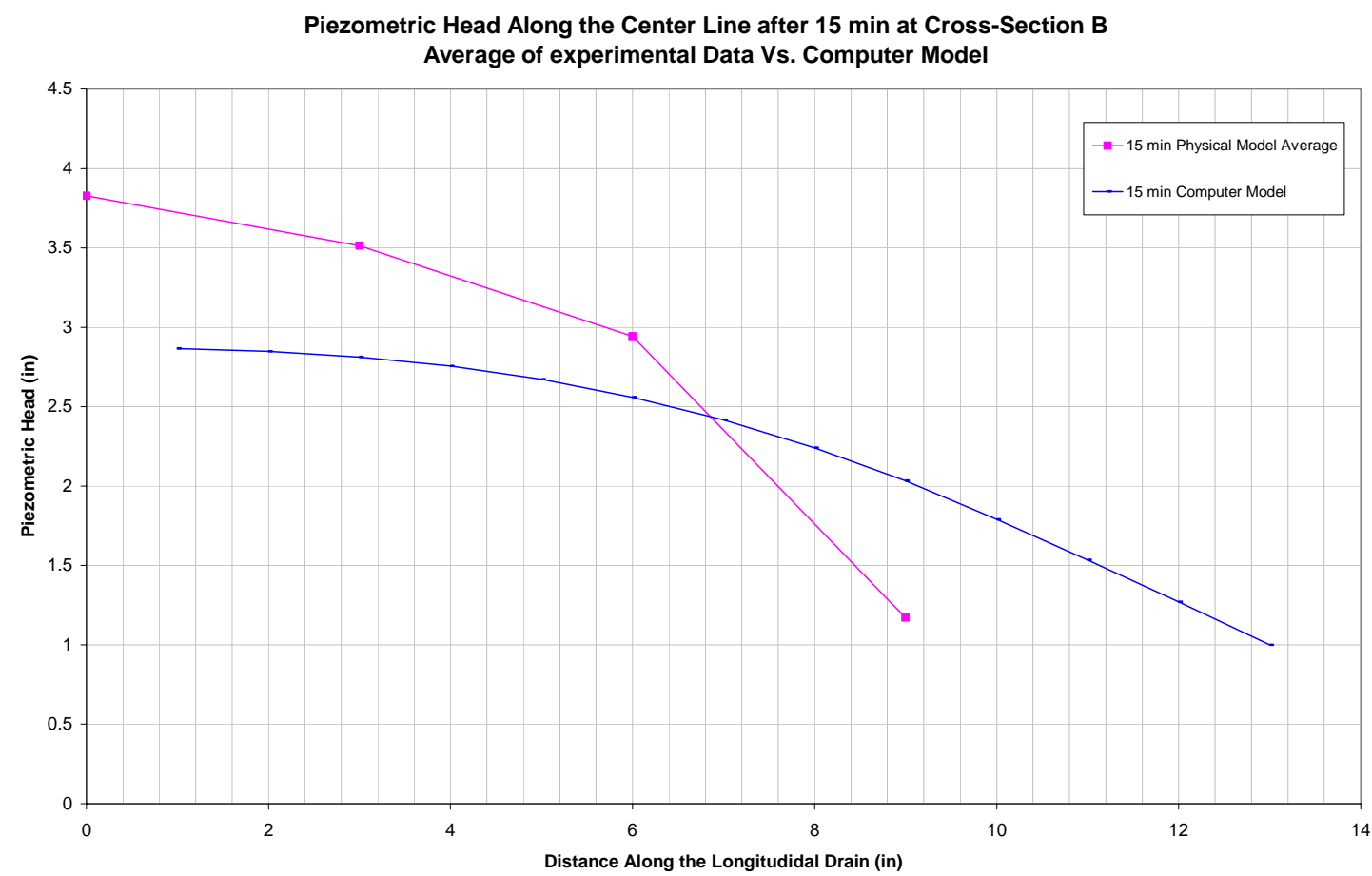

Figure A4.26: Piezometric head along Cross-Section B for soil type C after 15 minutes 


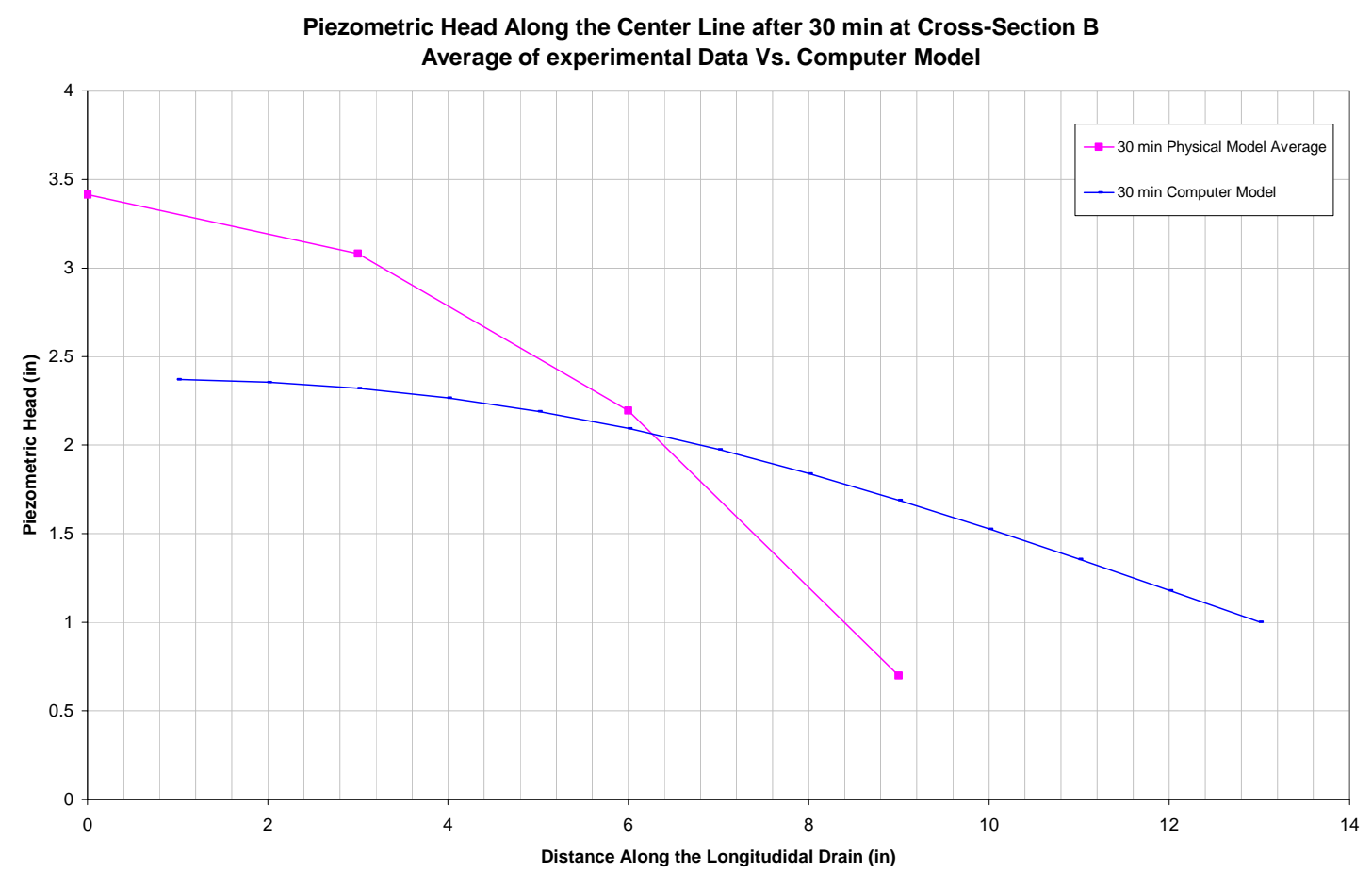

Figure A4.27: Piezometric head along Cross-Section B for soil type C after 30 minutes

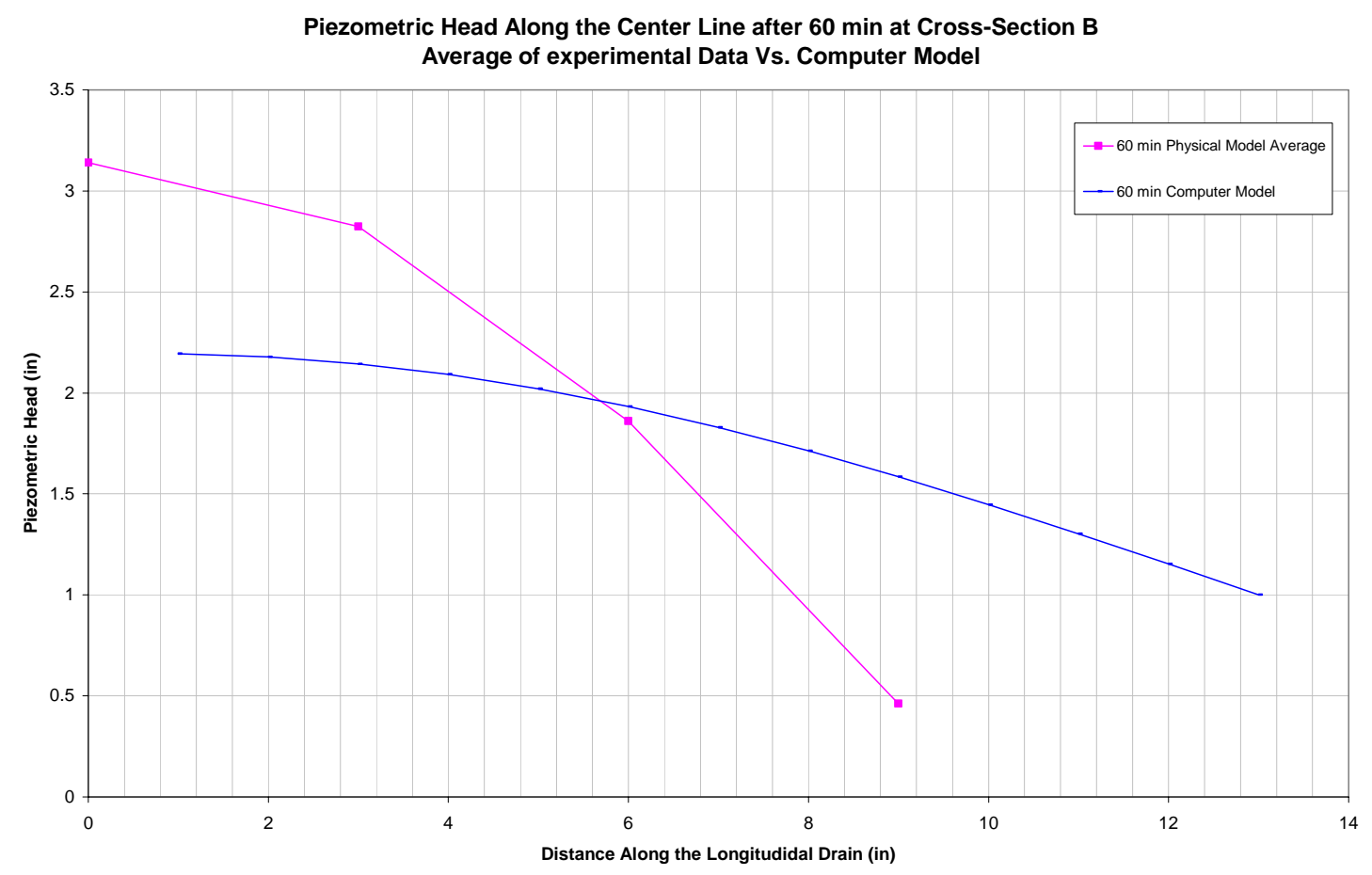

Figure A4.28: Piezometric head along Cross-Section B for soil type C after 60 minutes 


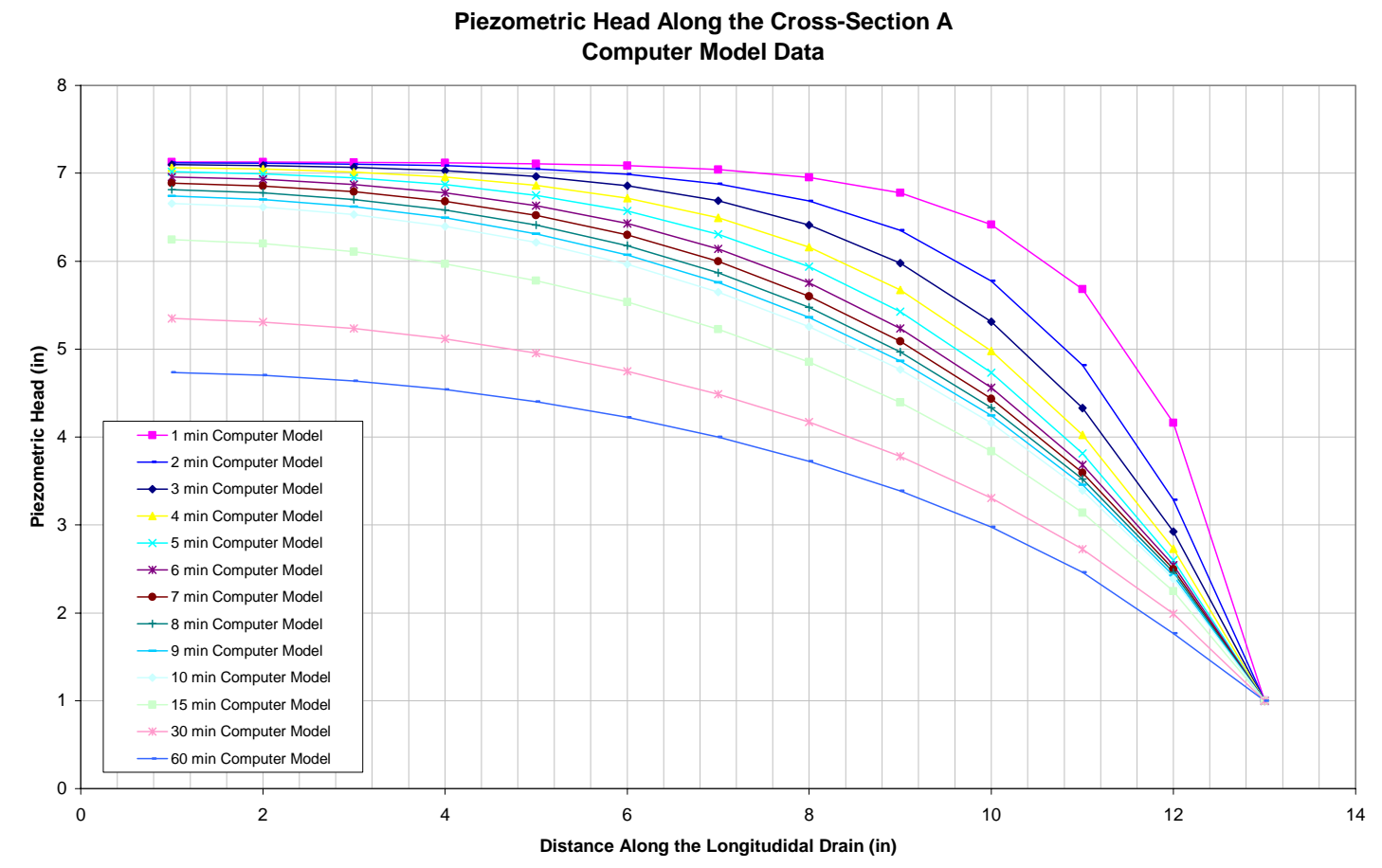

Figure A4.29: Piezometric head along cross-section A for soil type D - Computer Model

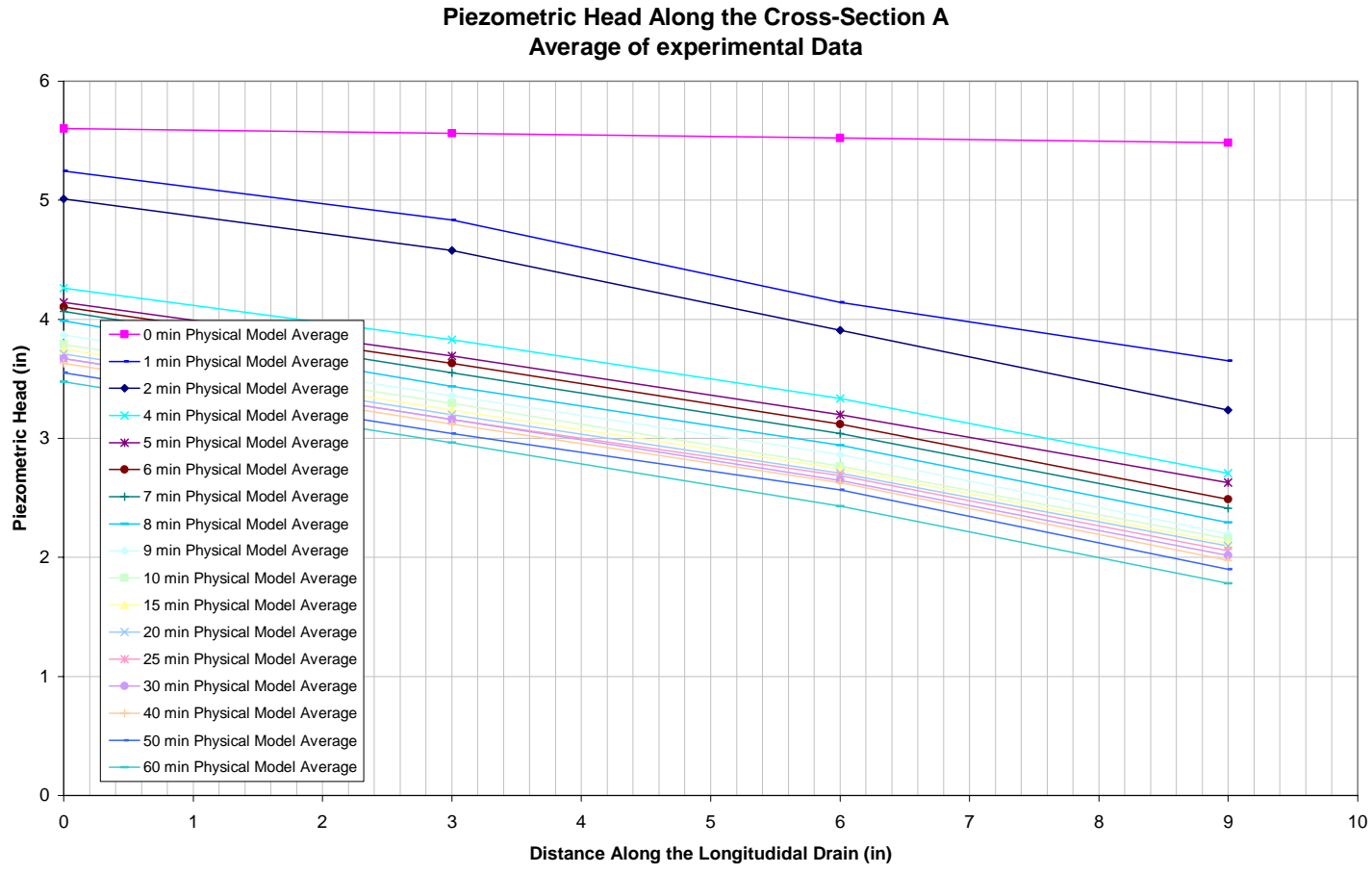

Figure A4.30: Piezometric head along cross-section A for soil type D - Physical Model 


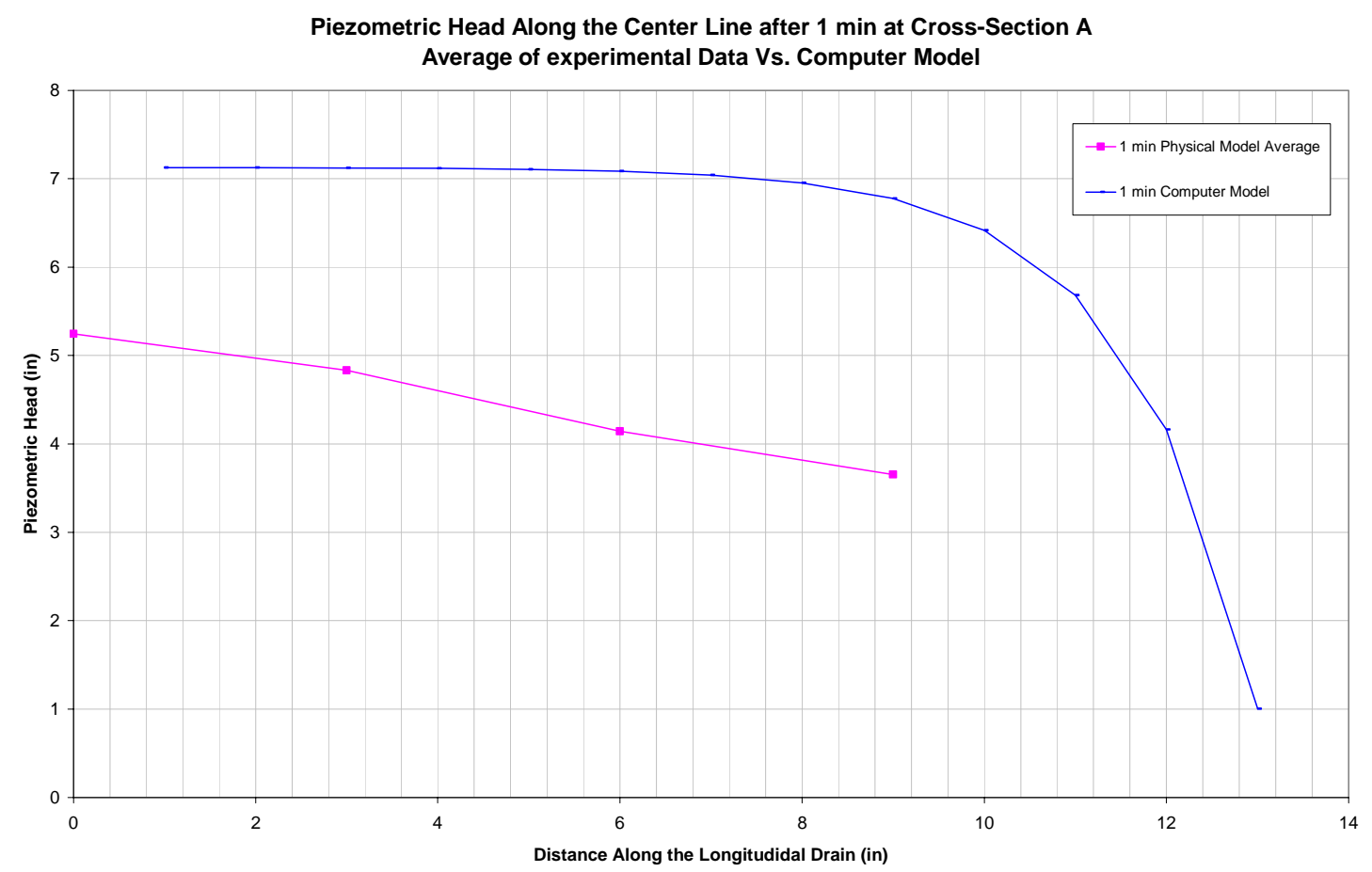

Figure A4.31: Piezometric head along Cross-Section A for soil type D after 1 minute

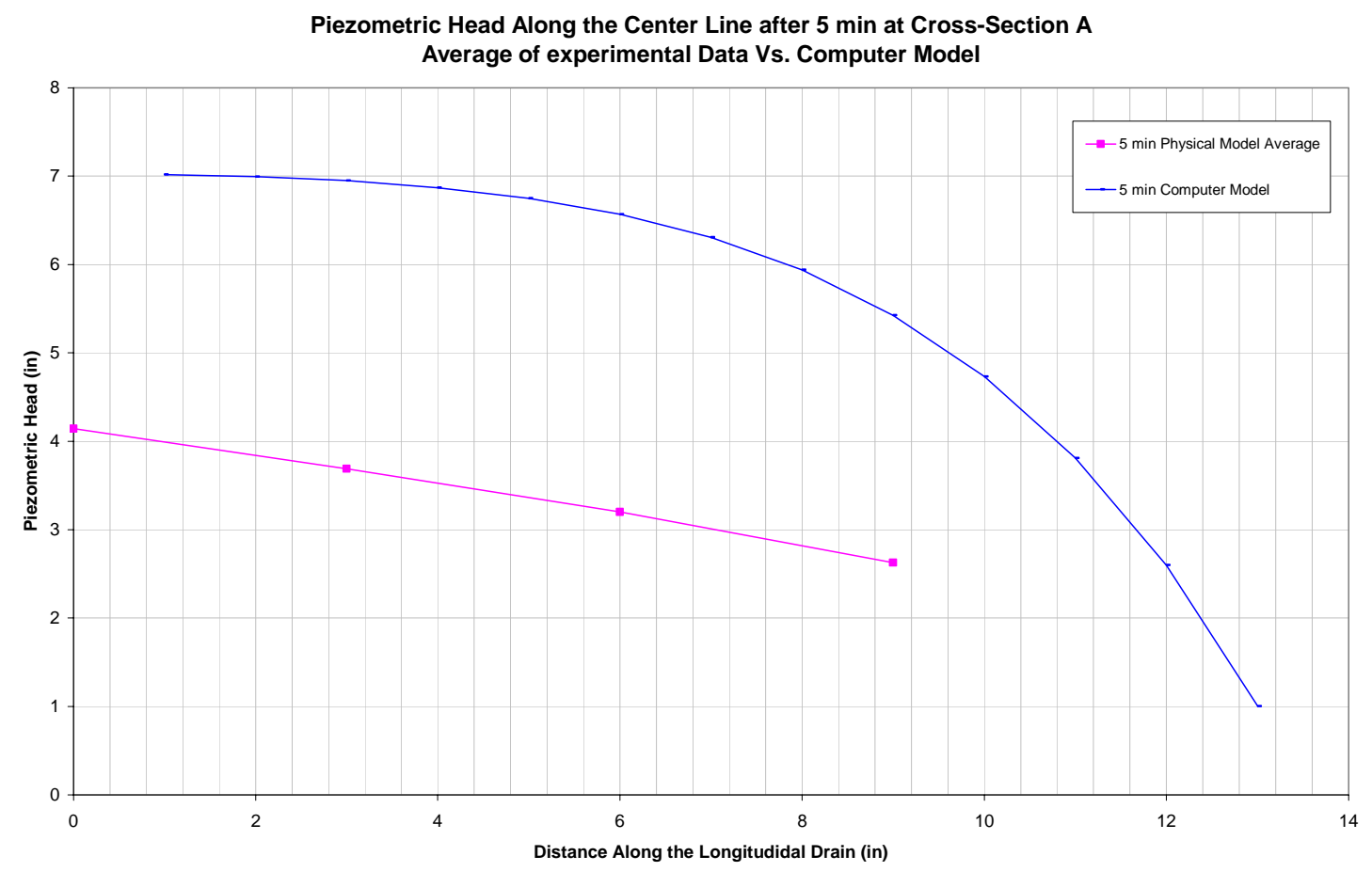

Figure A4.32: Piezometric head along Cross-Section A for soil type D after 5 minutes 


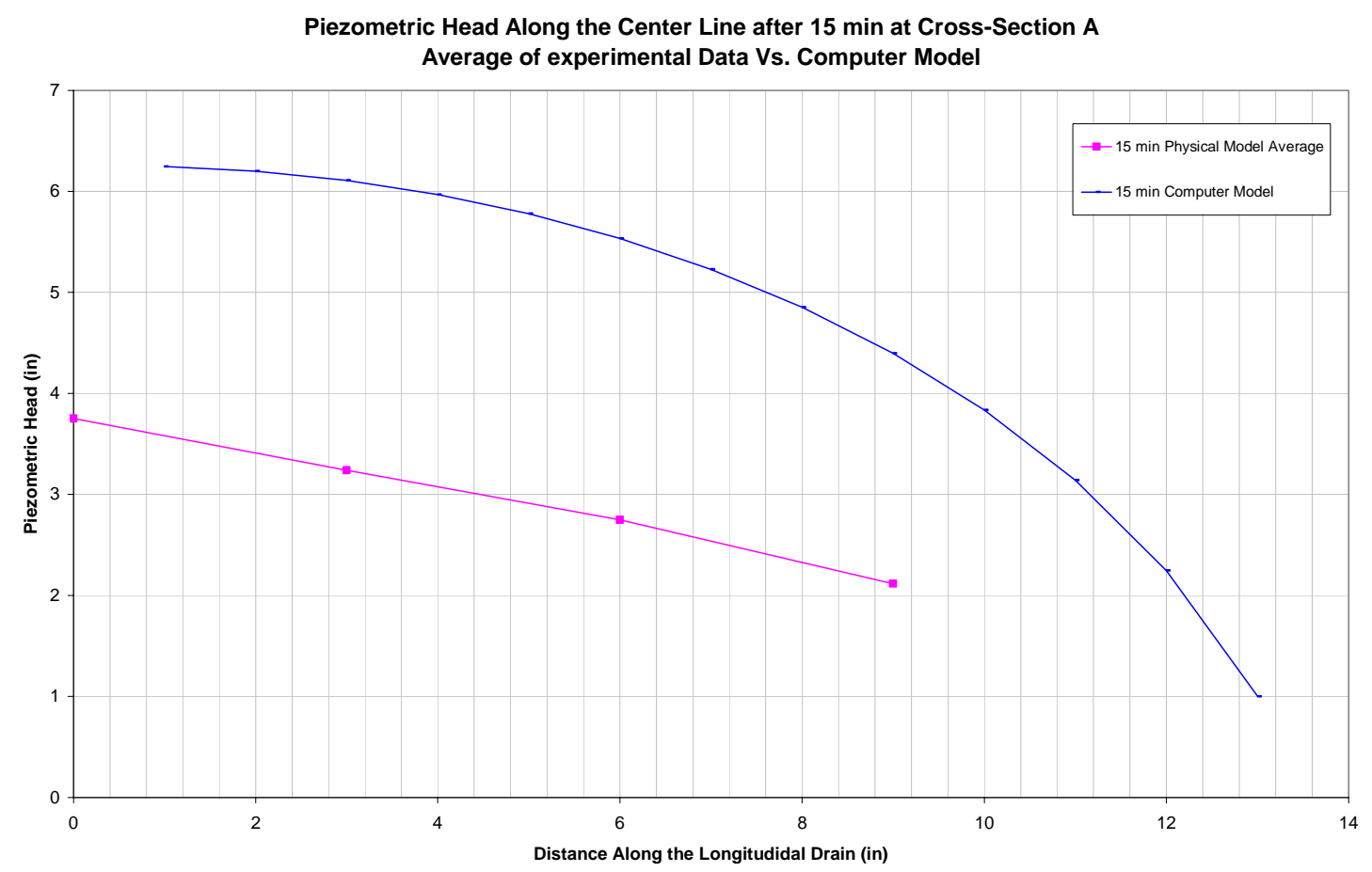

Figure A4.33: Piezometric head along Cross-Section A for soil type D after 15 minutes

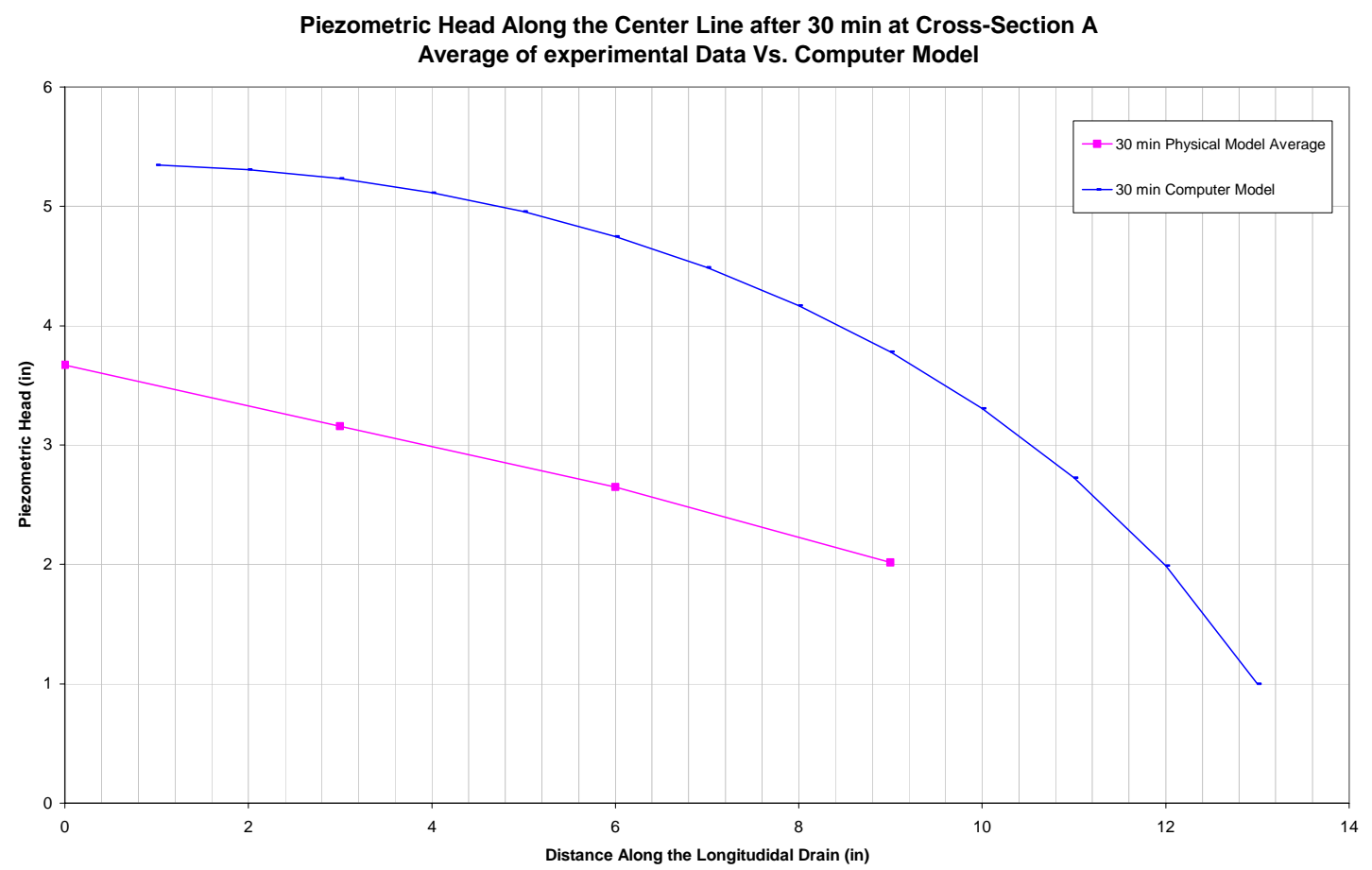

Figure A4.34: Piezometric head along Cross-Section A for soil type D after 30 minutes 


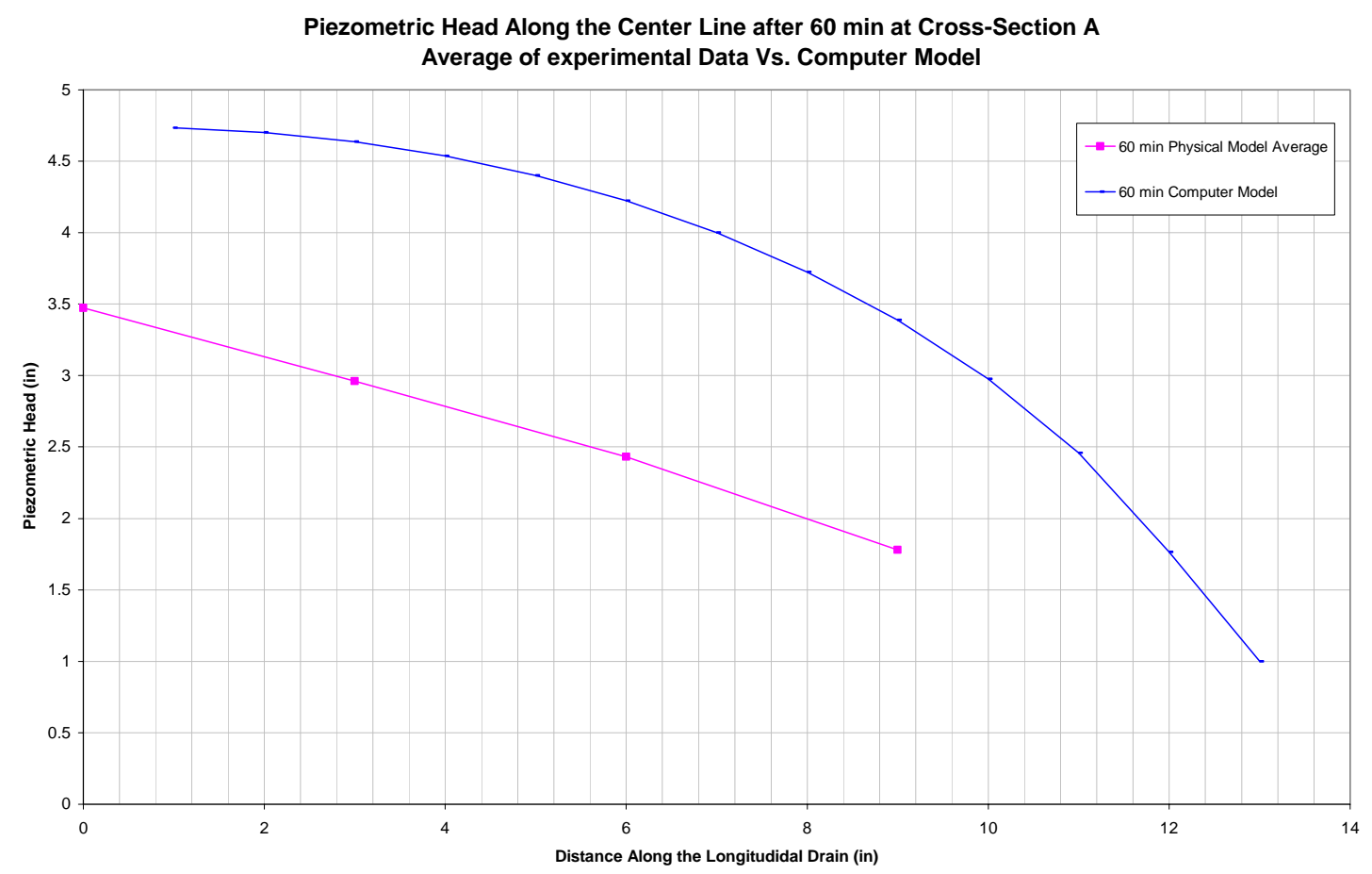

Figure A4.35: Piezometric head along Cross-Section A for soil type D after 60 minutes

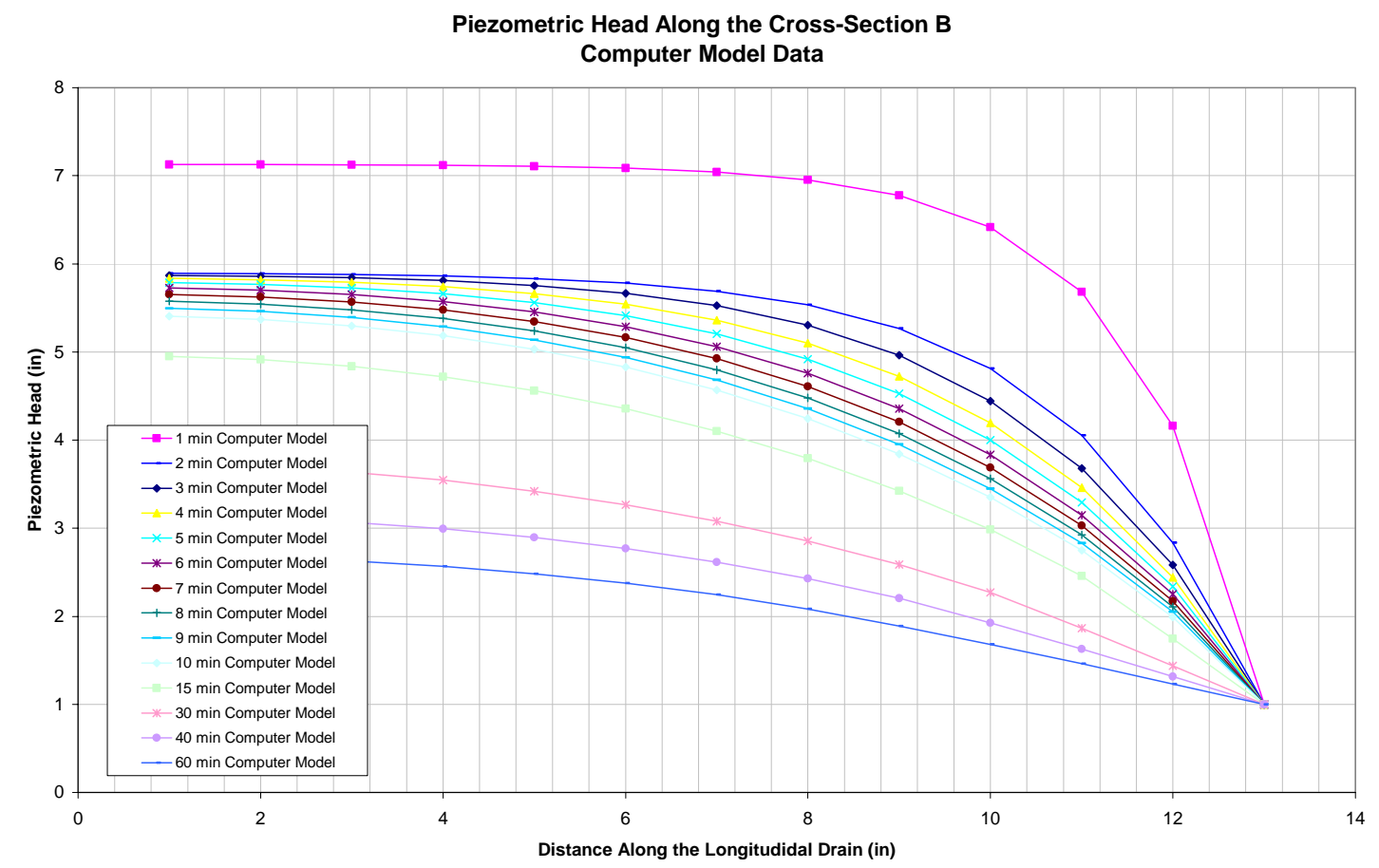

Figure A4.36: Piezometric head along cross-section B for soil type D - Computer Model 


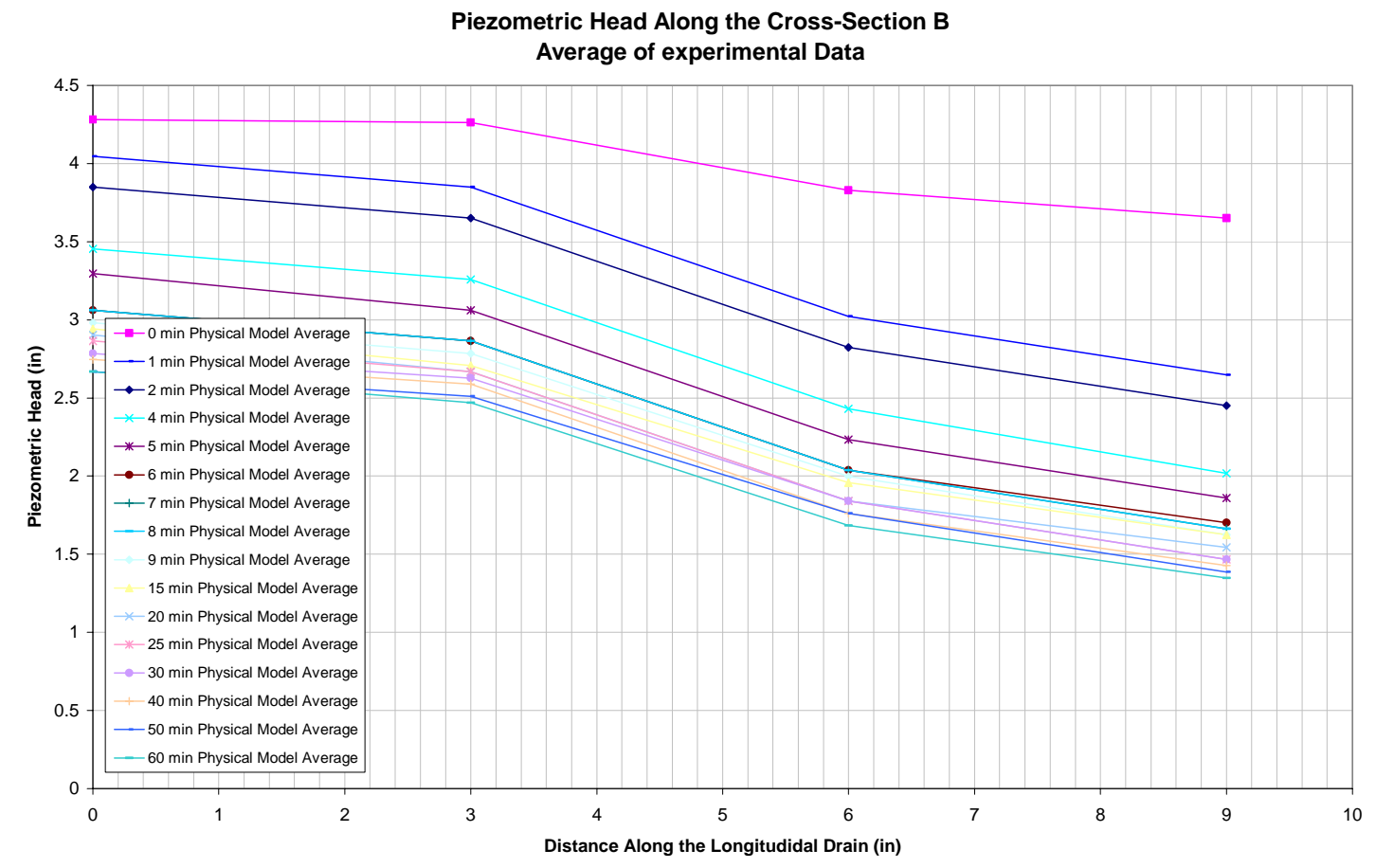

Figure A4.37: Piezometric head along cross-section B for soil type D - Physical Model

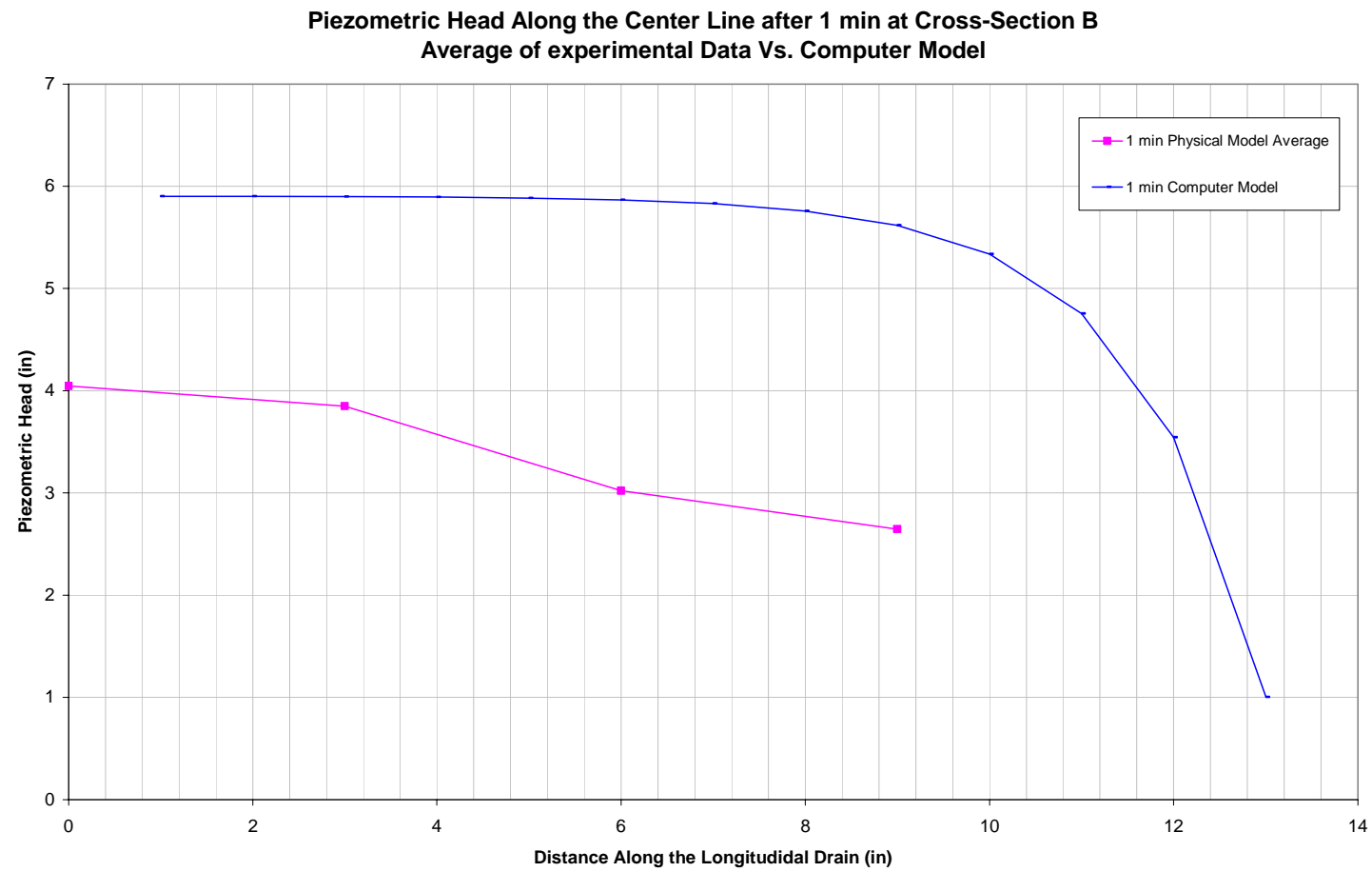

Figure A4.38: Piezometric head along Cross-Section B for soil type D after 1 minute 


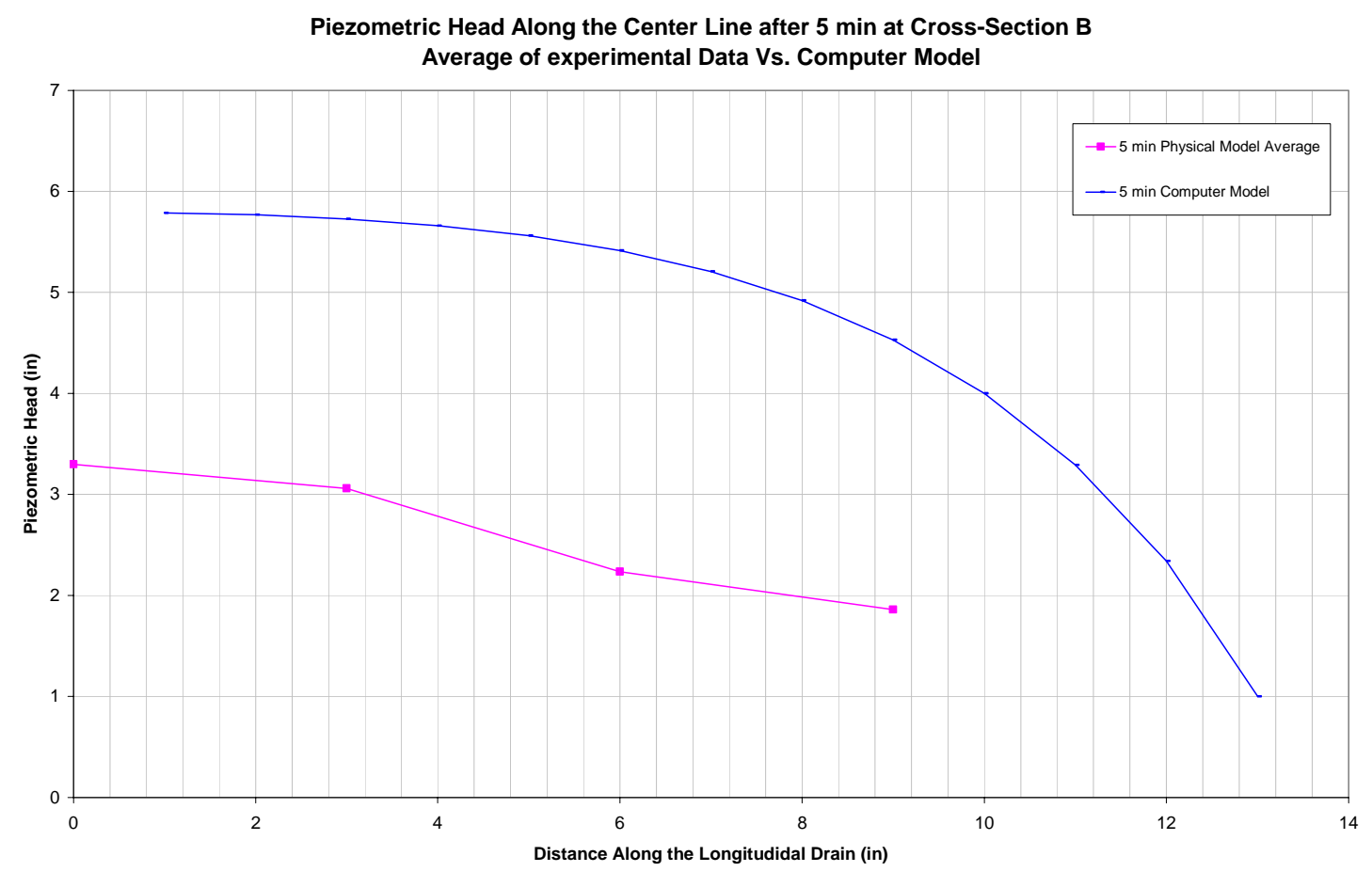

Figure A4.39: Piezometric head along Cross-Section B for soil type D after 5 minutes

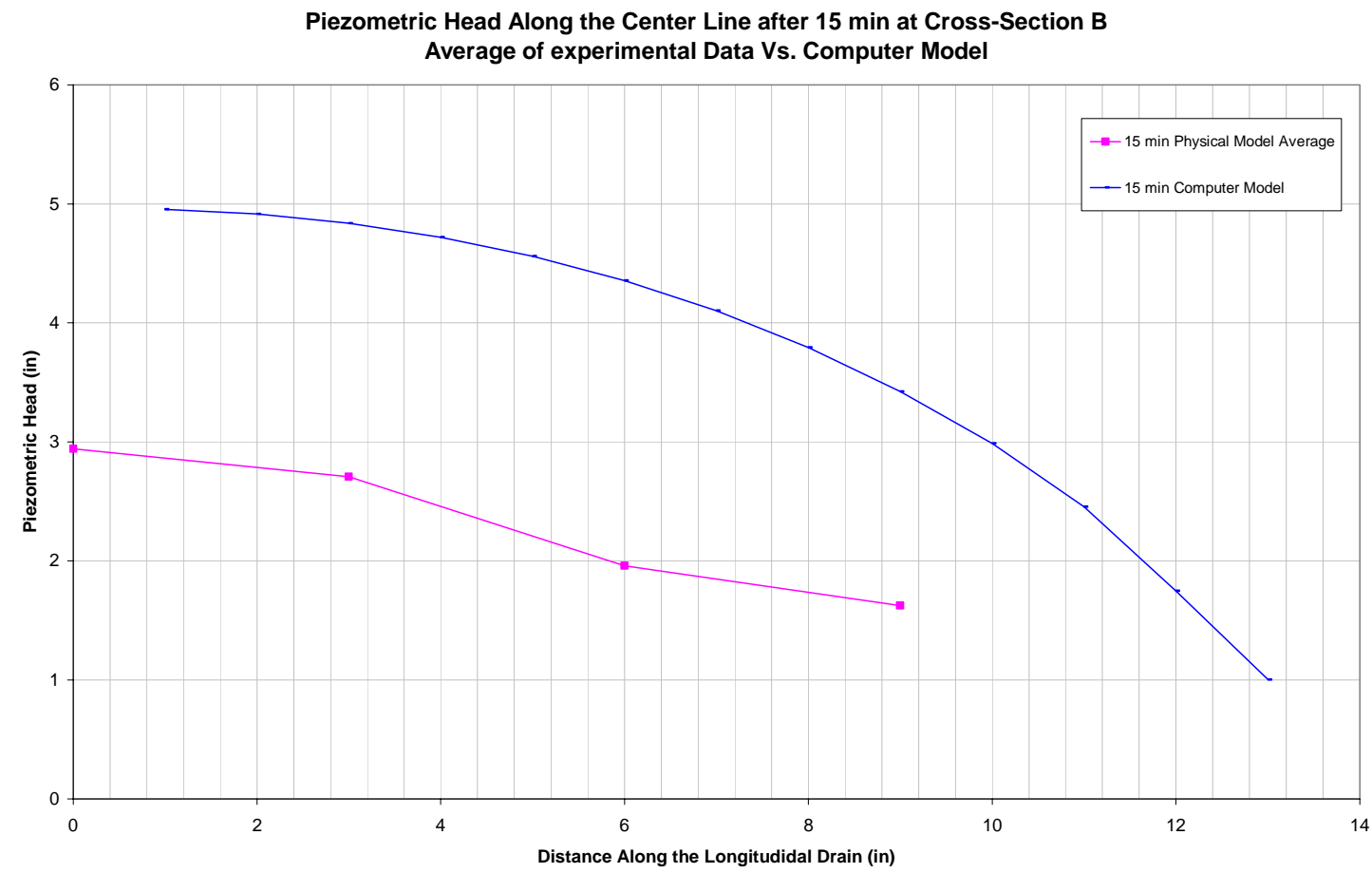

Figure A4.40: Piezometric head along Cross-Section B for soil type D after 15 minutes 


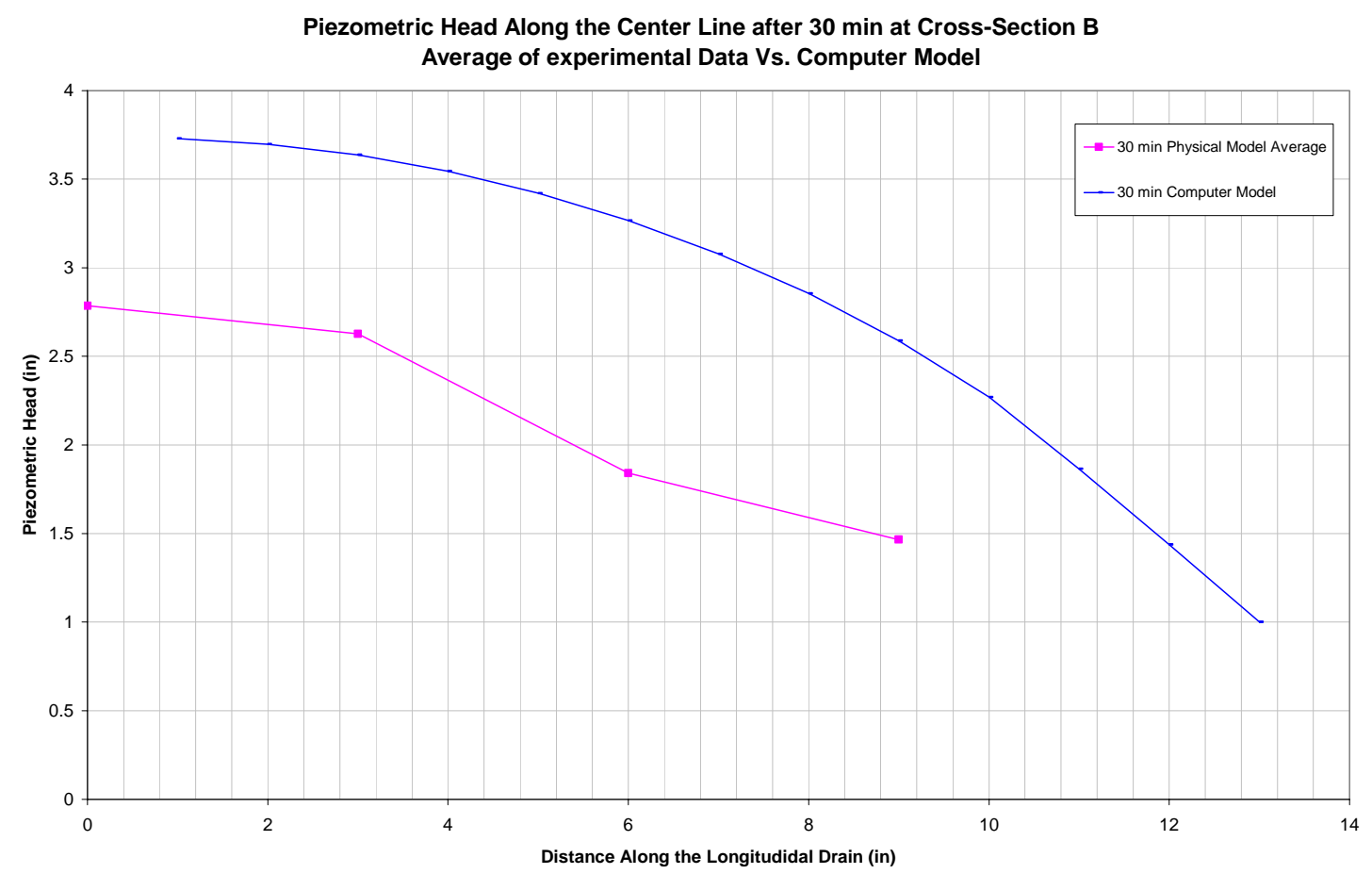

Figure A4.41: Piezometric head along Cross-Section B for soil type D after 30 minutes

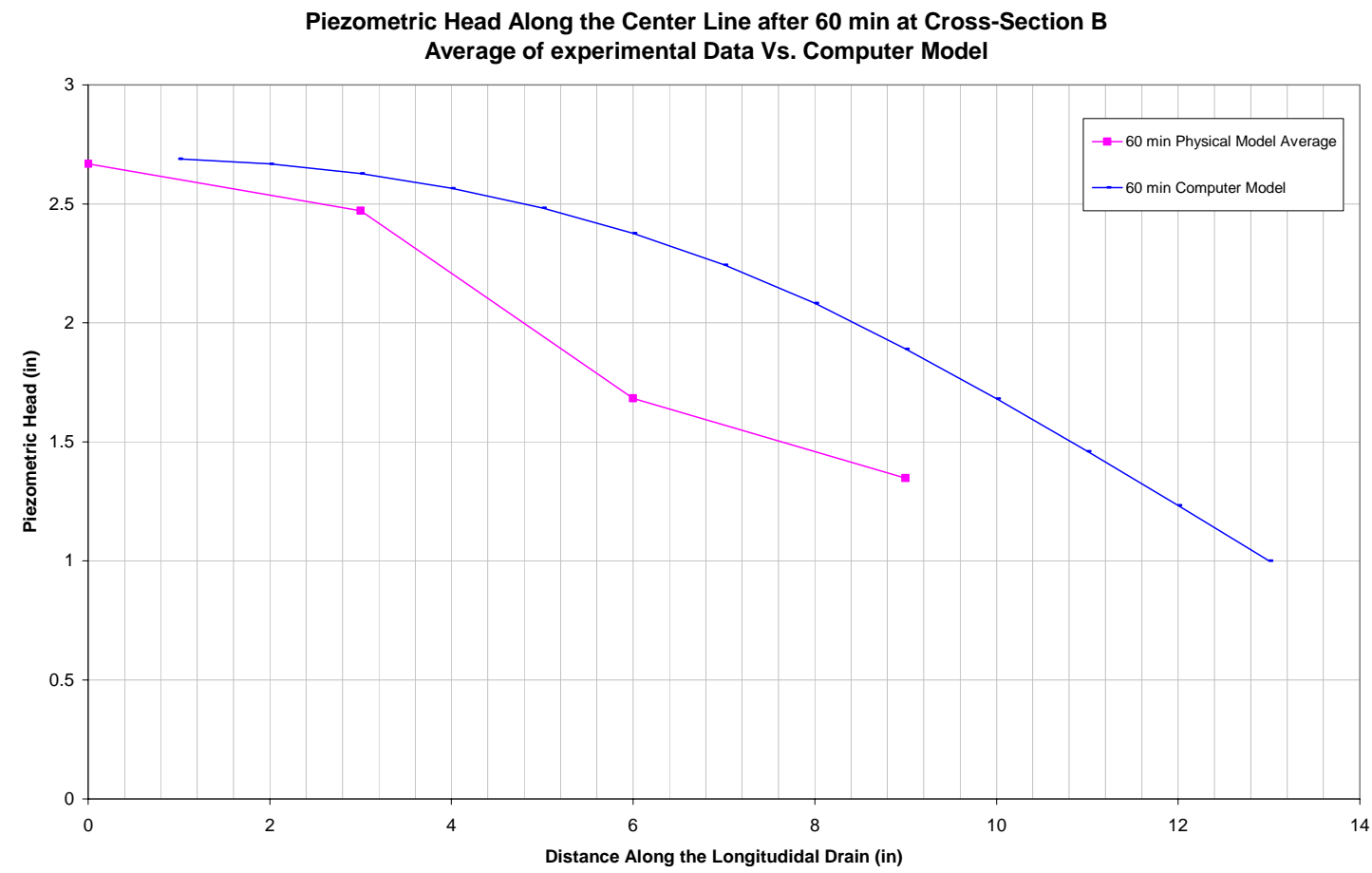

Figure A4.42: Piezometric head along Cross-Section B for soil type D after 60 minutes 


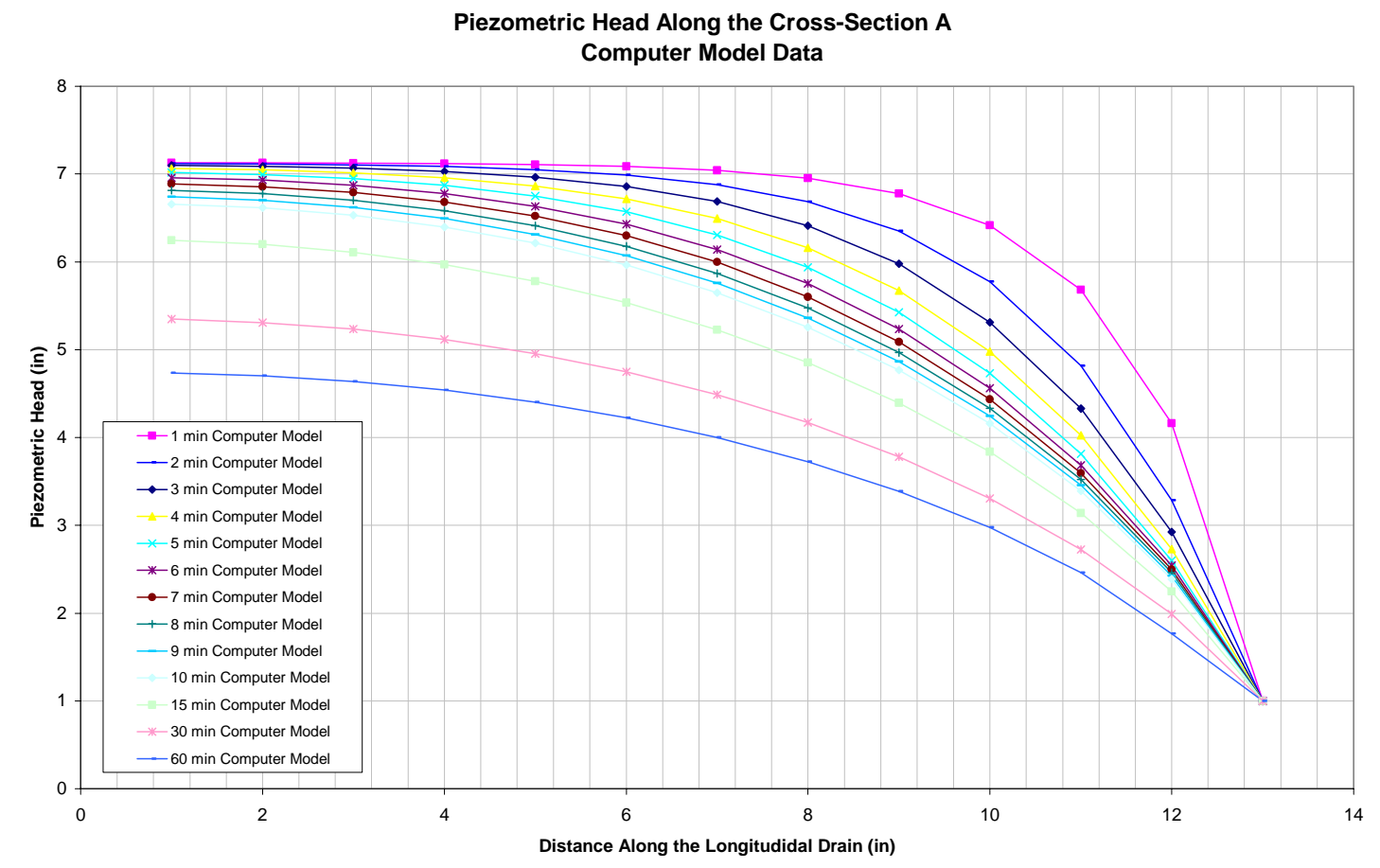

Figure A4.43: Piezometric head along cross-section A for soil type E - Computer Model

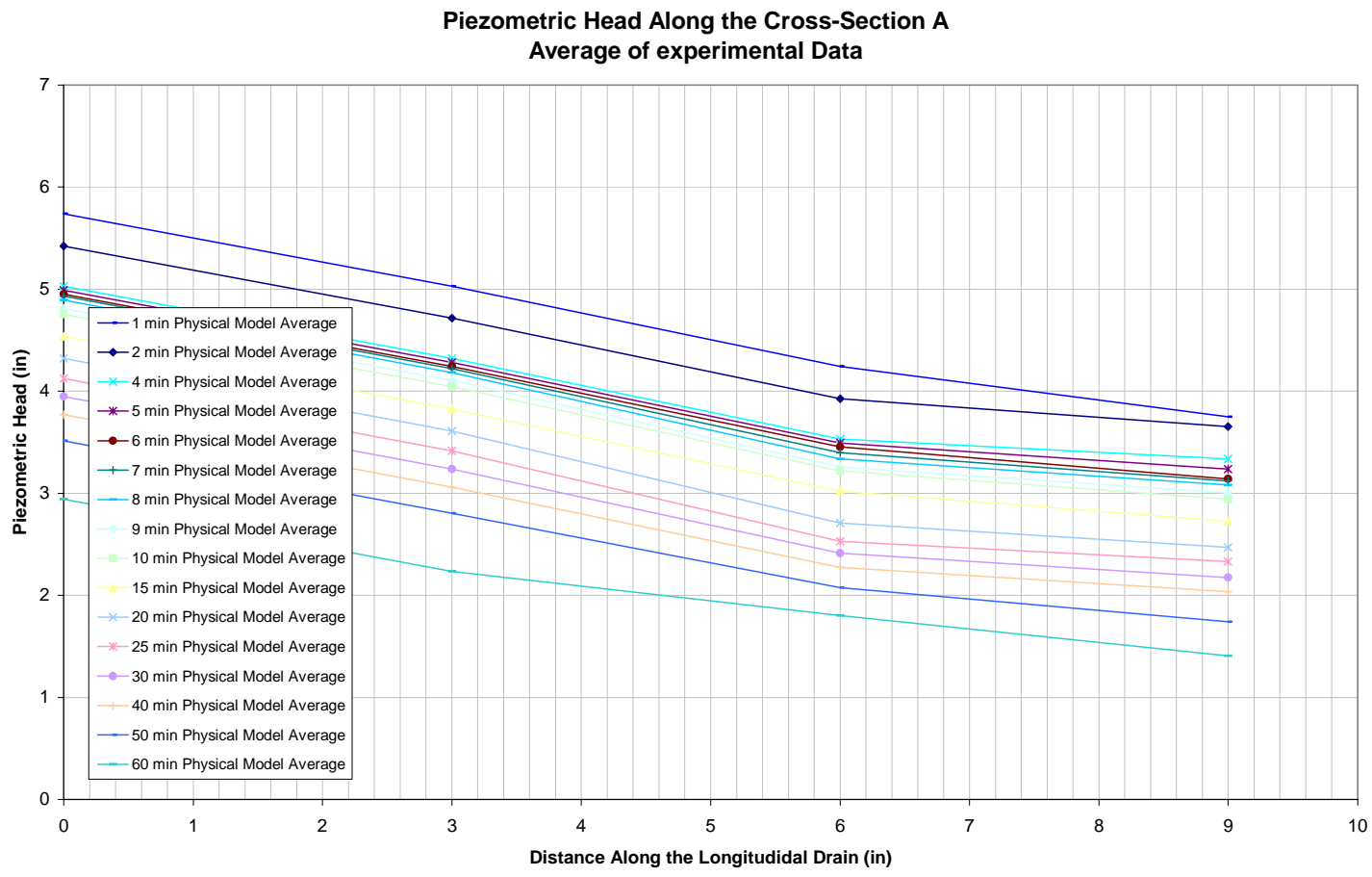

Figure A4.44: Piezometric head along cross-section A for soil type E - Physical Model 


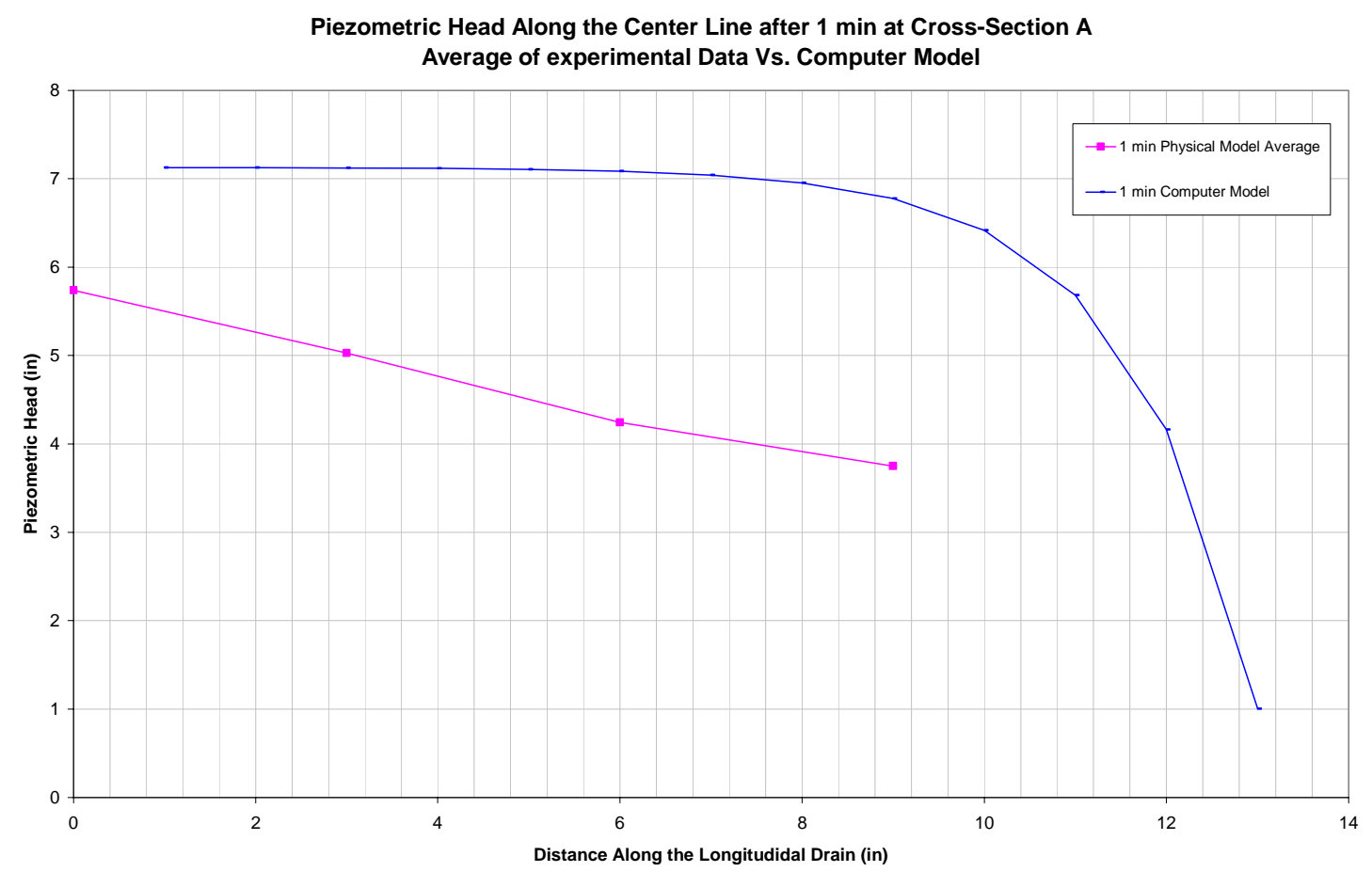

Figure A4.45: Piezometric head along Cross-Section A for soil type E after 1 minute

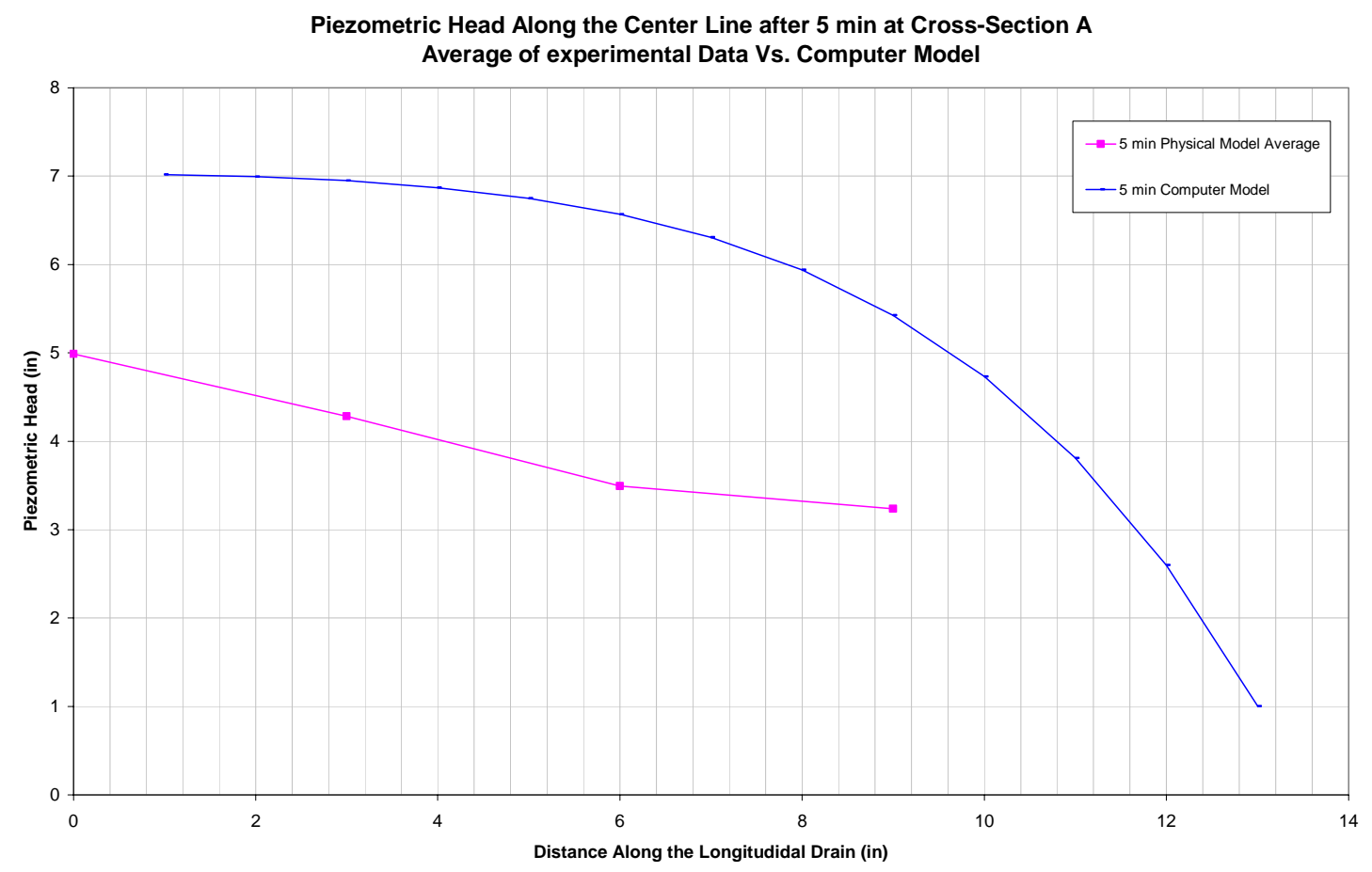

Figure A4.46: Piezometric head along Cross-Section A for soil type E after 5 minutes 


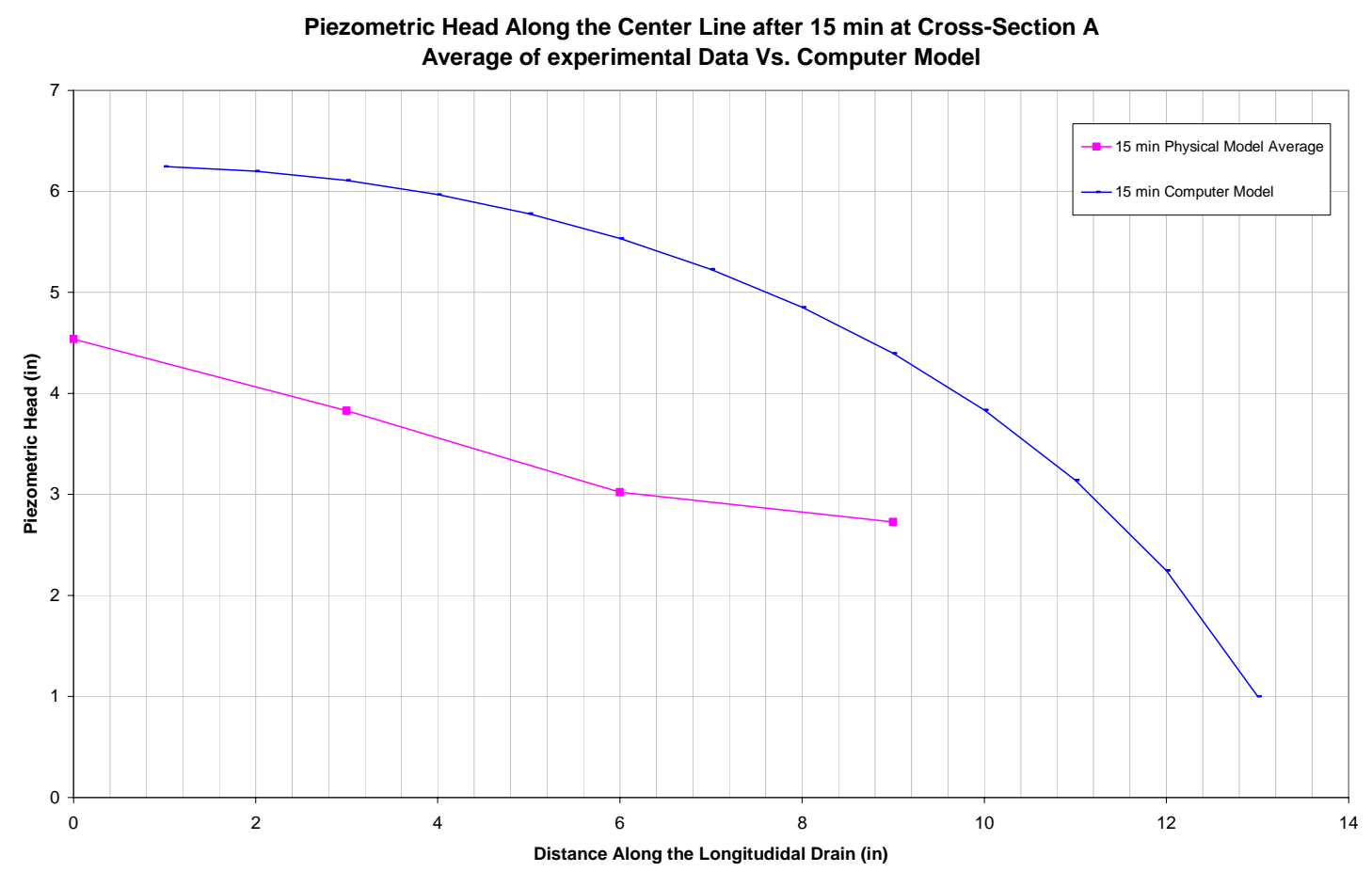

Figure A4.47: Piezometric head along Cross-Section A for soil type E after 15 minutes

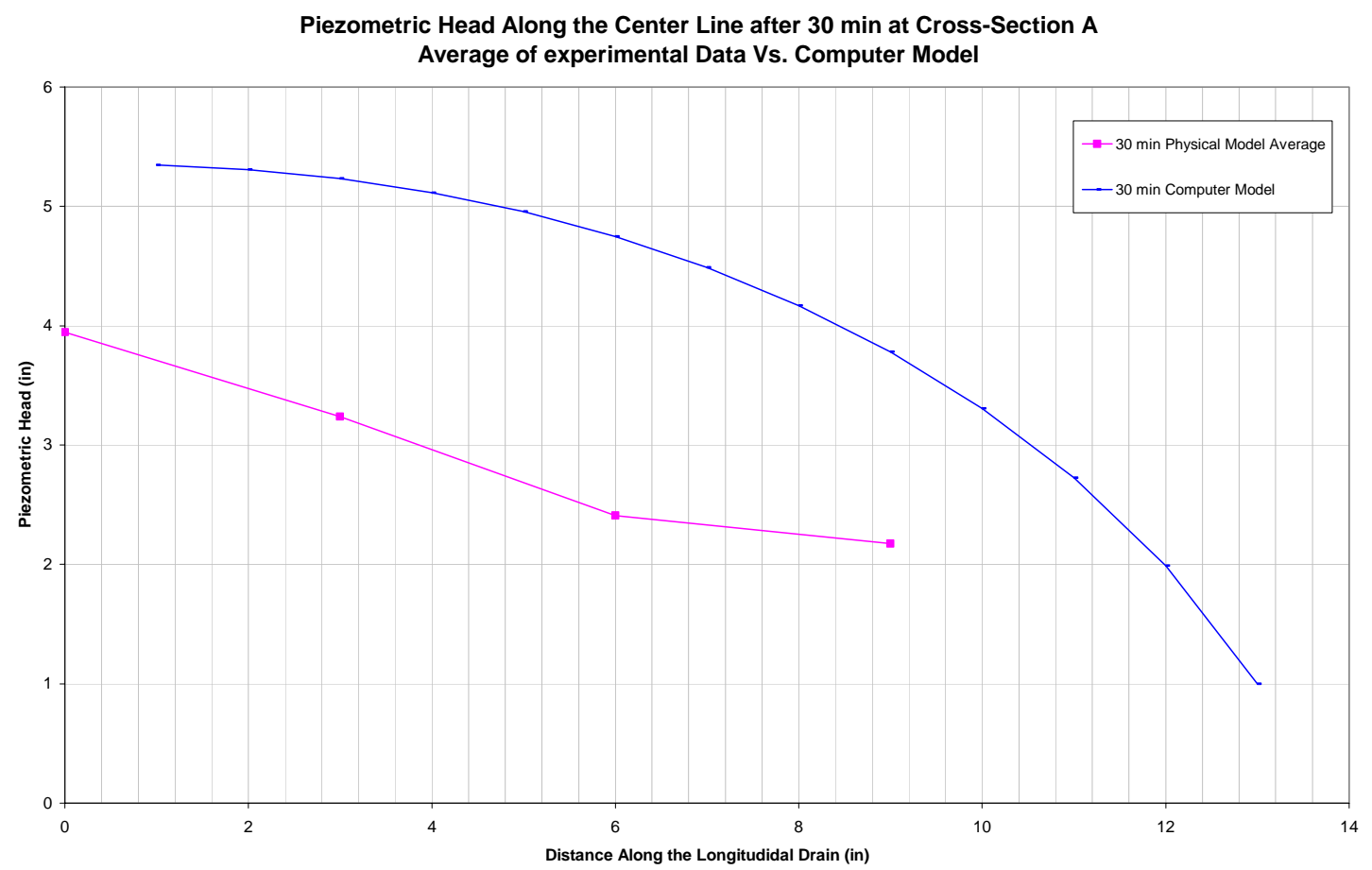

Figure A4.48: Piezometric head along Cross-Section A for soil type E after 30 minutes 


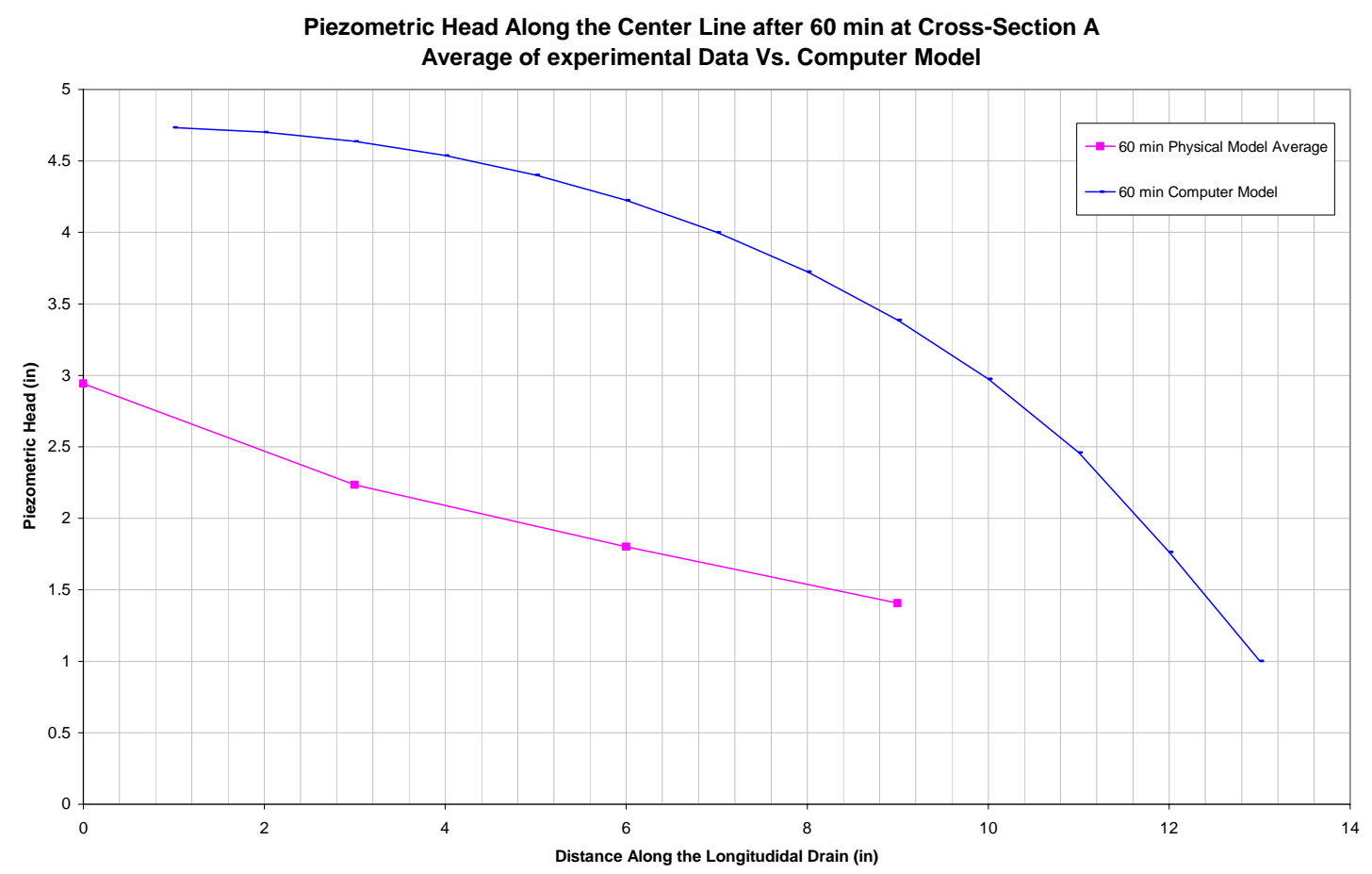

Figure A4.49: Piezometric head along Cross-Section A for soil type E after 60 minutes

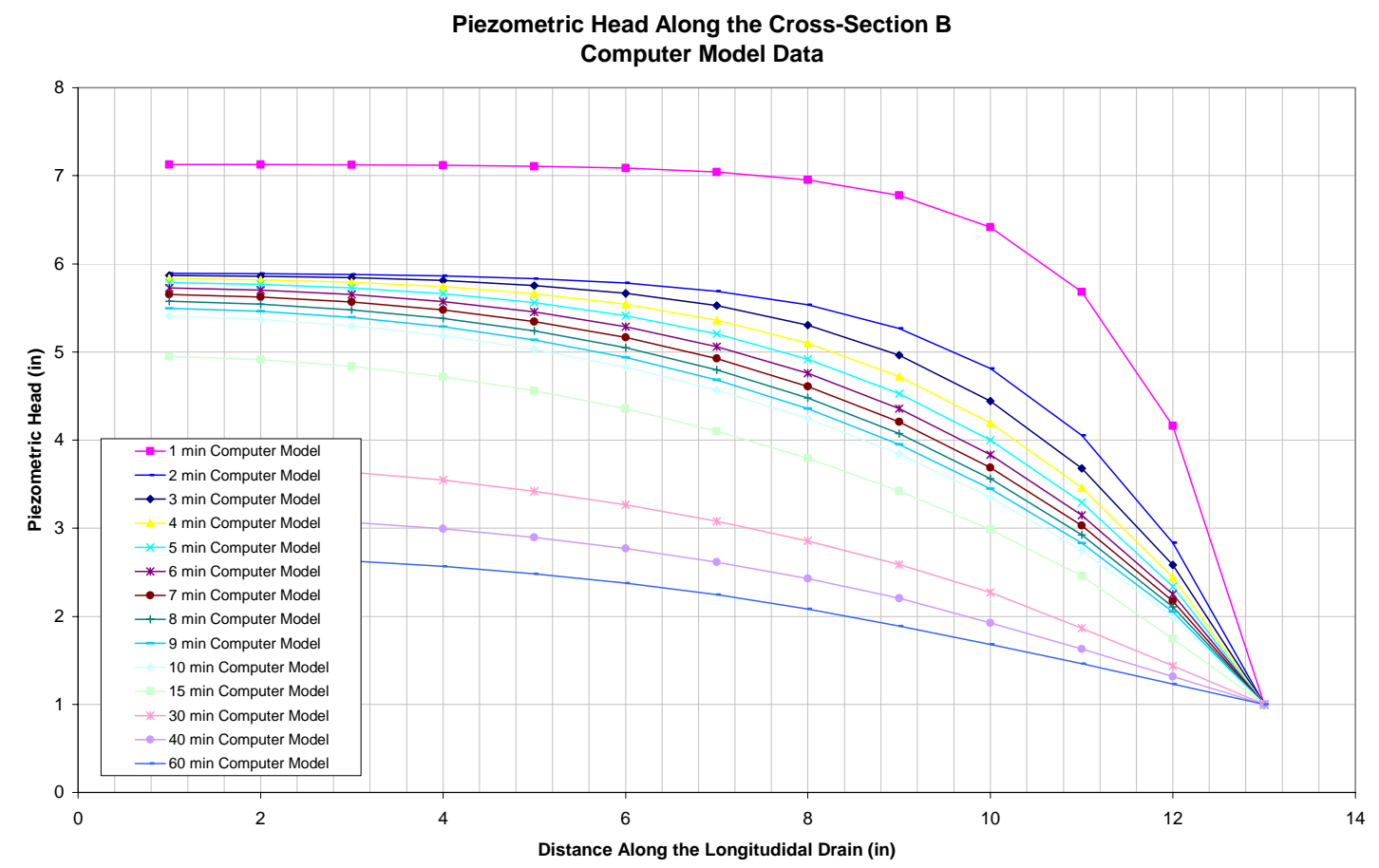

Figure A4.50: Piezometric head along cross-section B for soil type E - Computer Model 


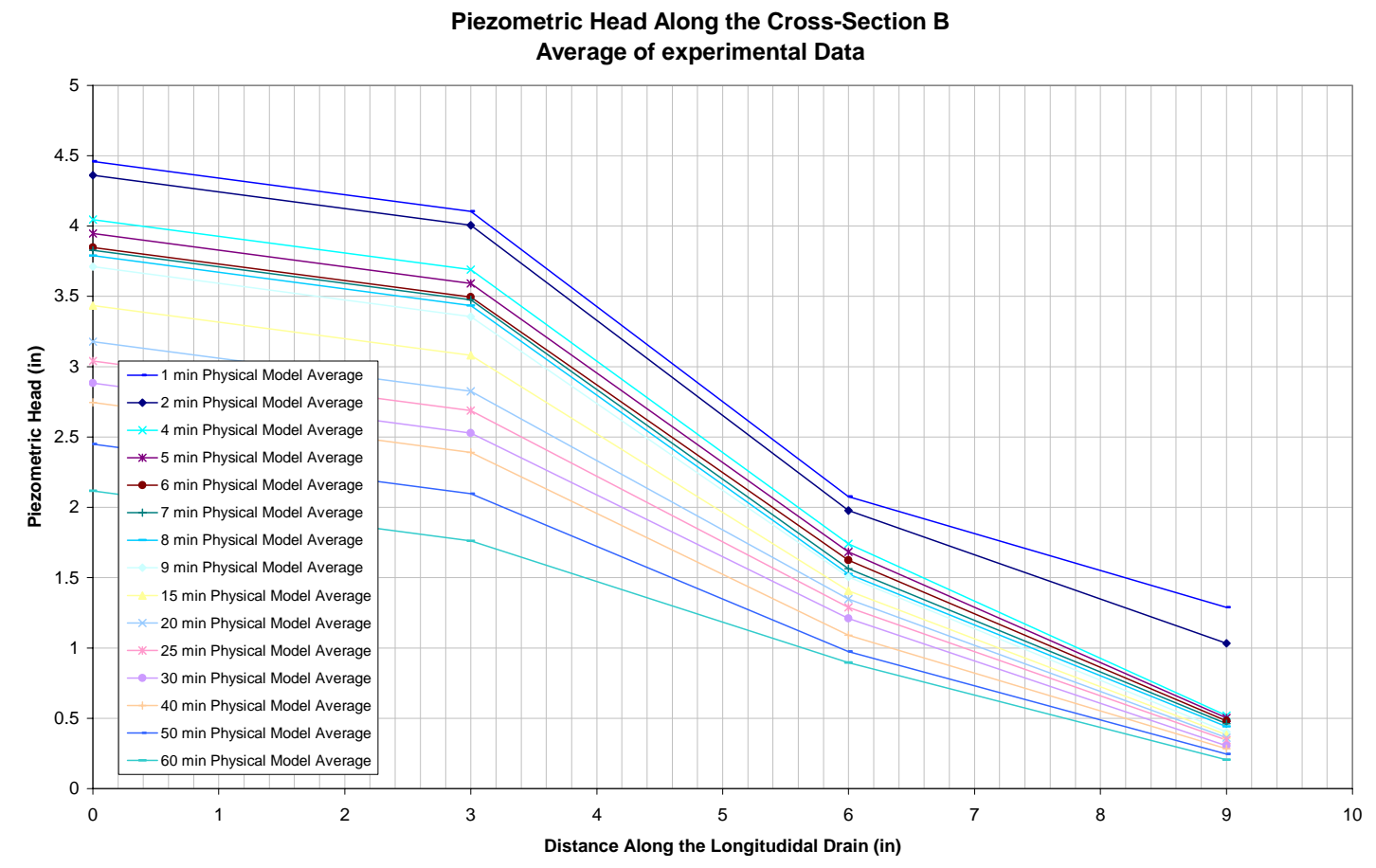

Figure A4.51: Piezometric head along cross-section B for soil type E - Physical Model

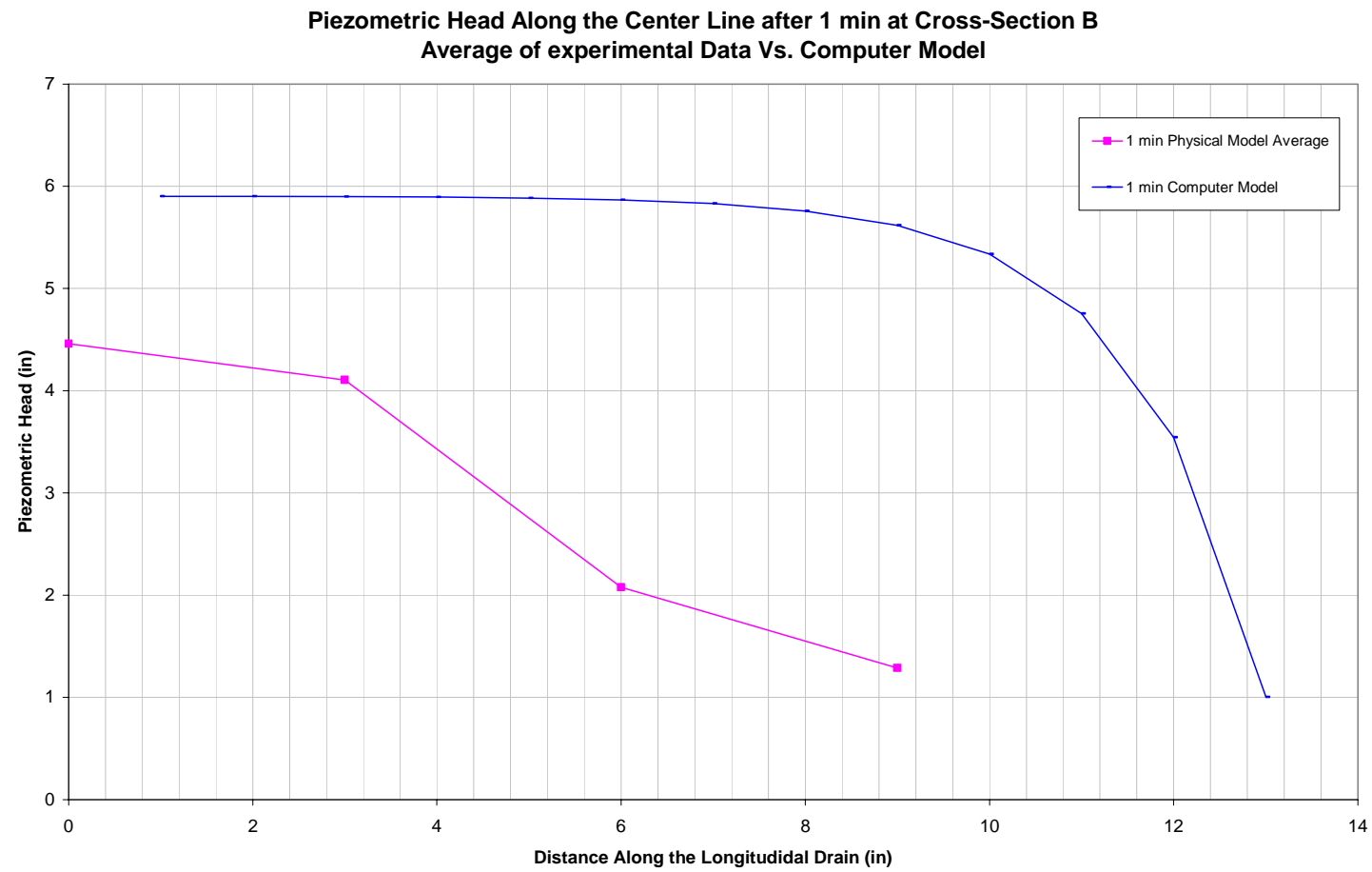

Figure A4.52: Piezometric head along Cross-Section B for soil type E after 1 minute 


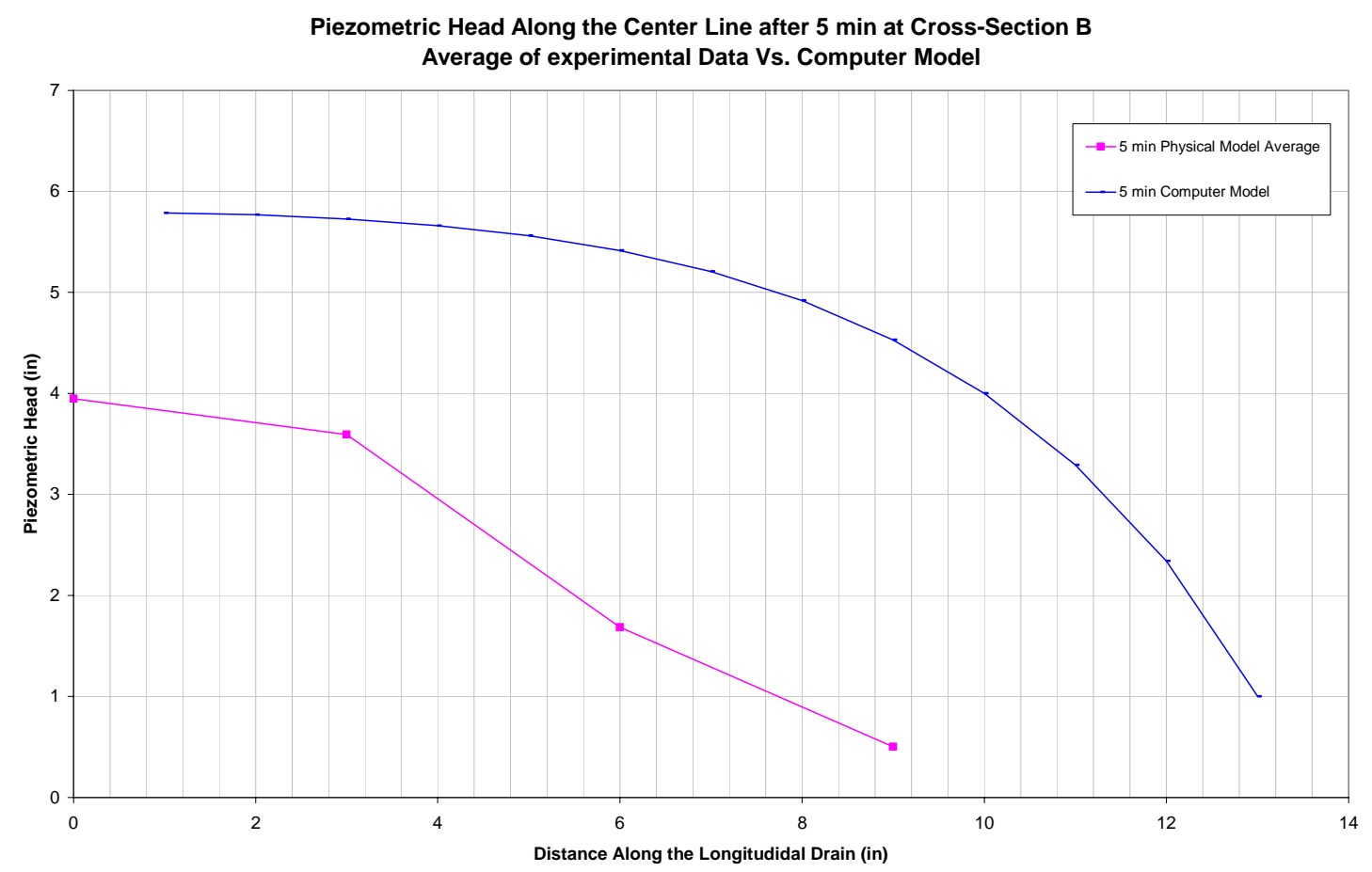

Figure A4.53: Piezometric head along Cross-Section B for soil type E after 5 minutes

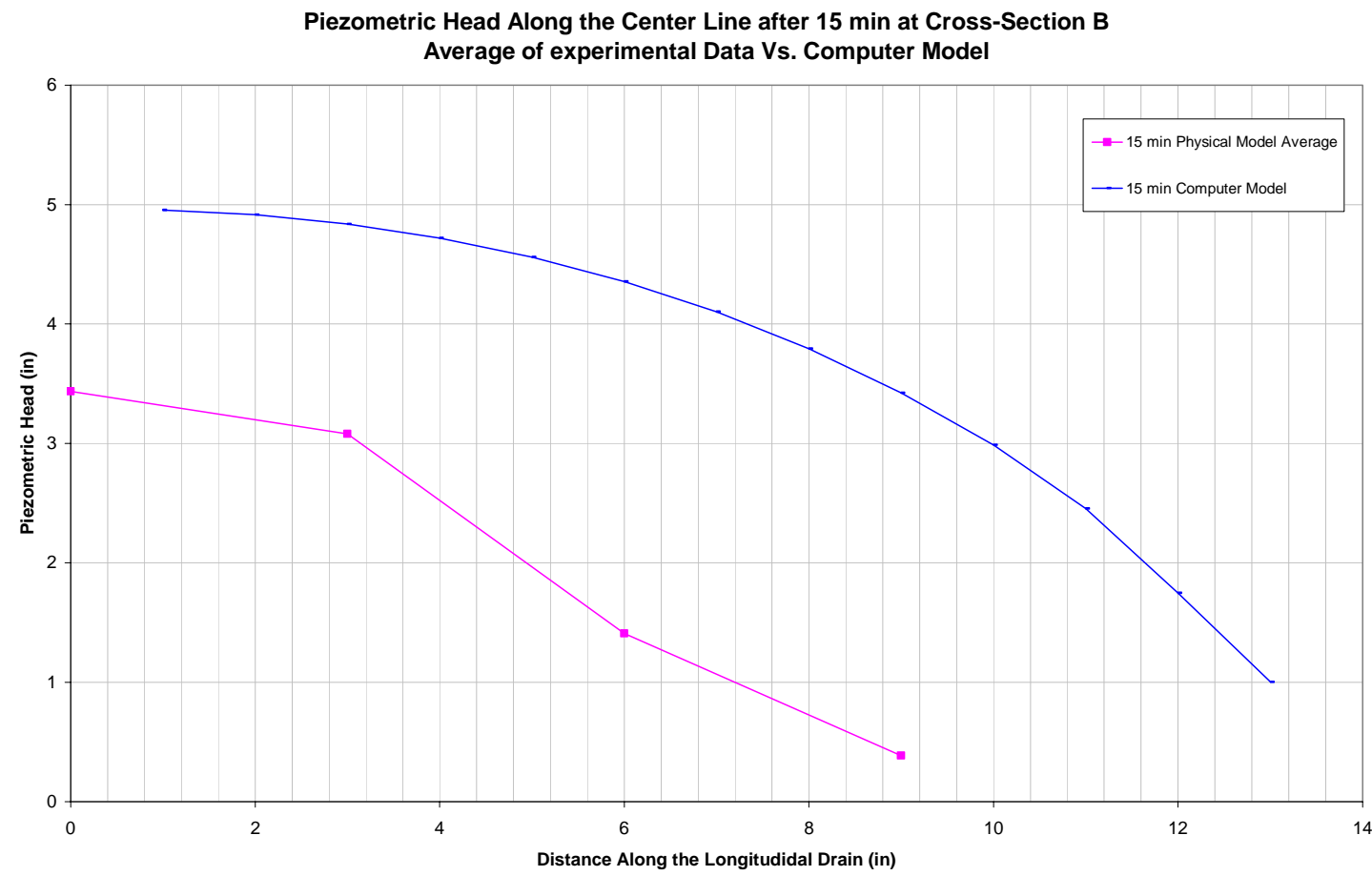

Figure A4.54: Piezometric head along Cross-Section B for soil type E after 15 minutes 


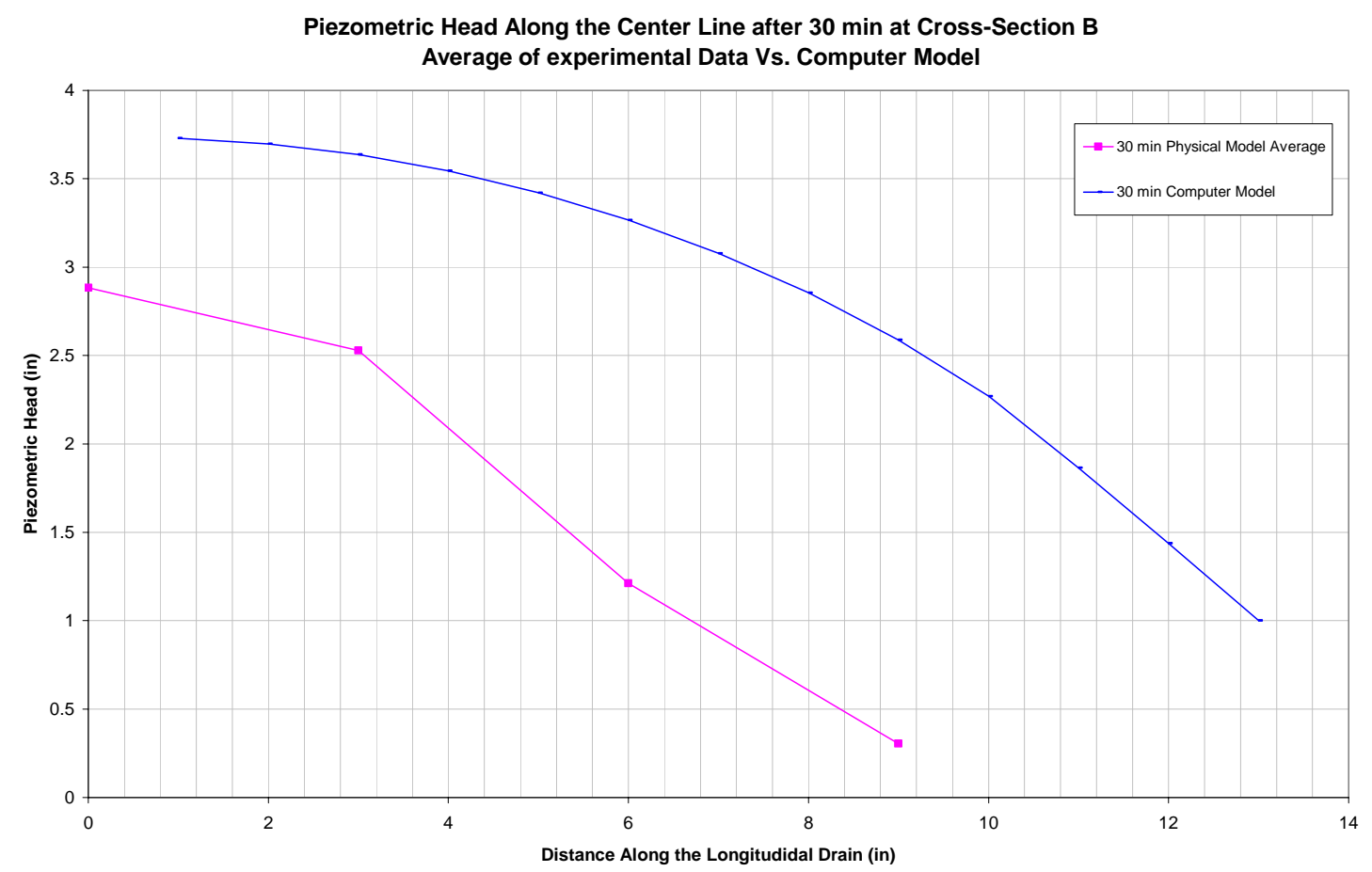

Figure A4-55: Piezometric head along Cross-Section B for soil type E after 30 minutes

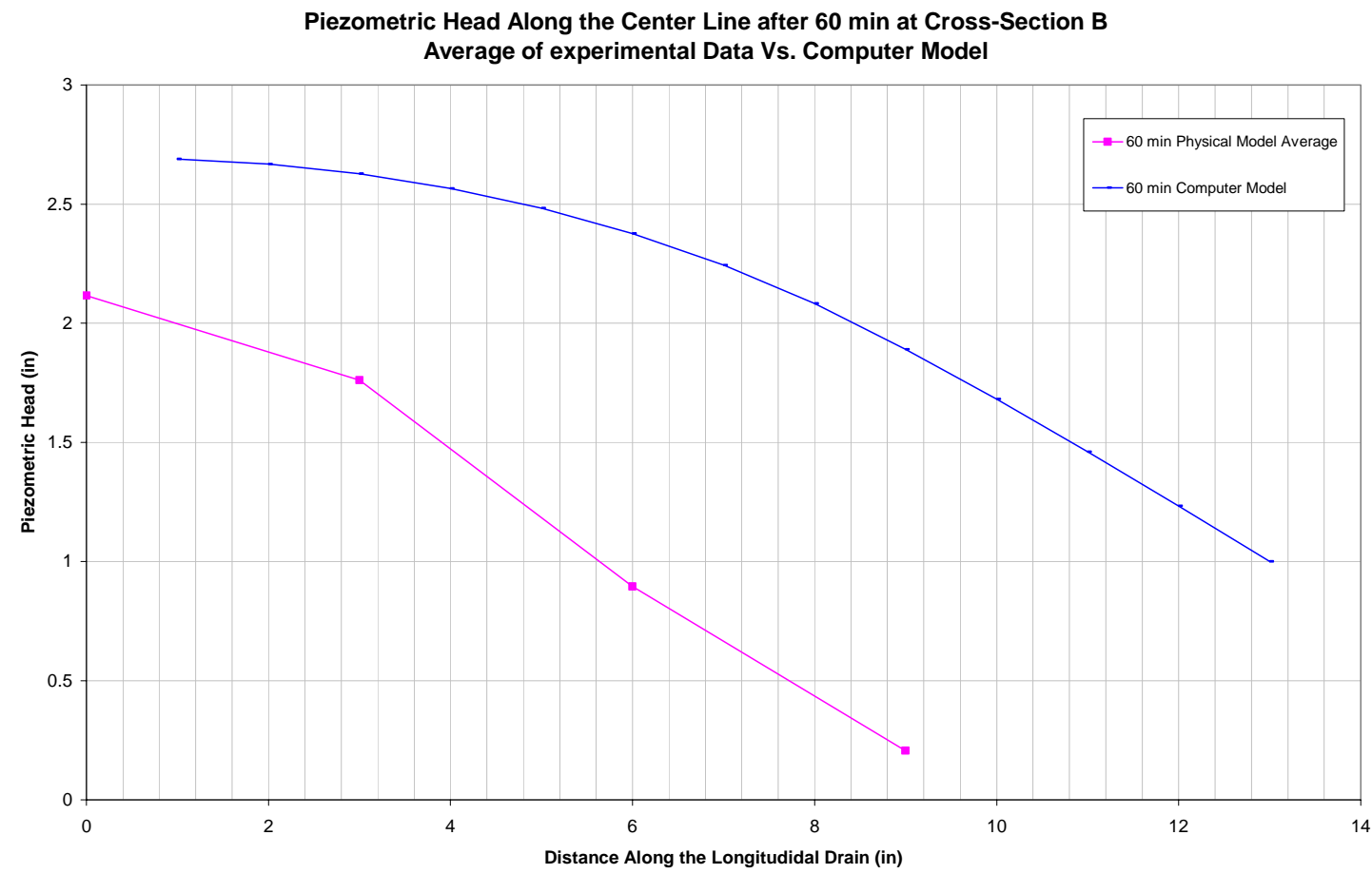

Figure A4-56: Piezometric head along Cross-Section B for soil type E after 60 minutes 
Appendix A5: Laboratory Vs Computer Model Flow Fluctuation at each drain

$$
\begin{aligned}
& W=12 \text { inches } \\
& I=48 \text { inches } \\
& \theta=0^{0}
\end{aligned}
$$




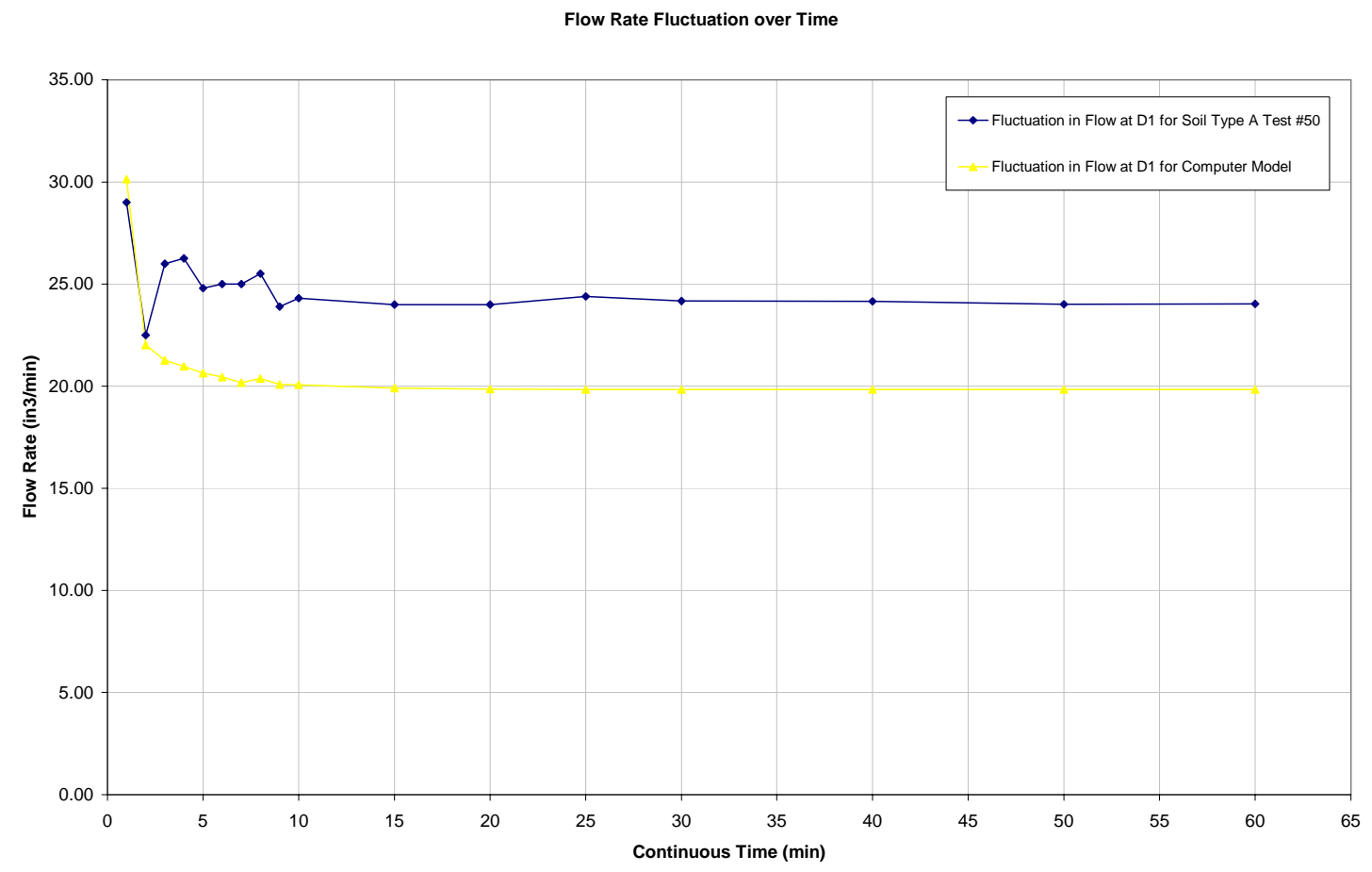

Figure A5.1: Flow rate fluctuation for Soil Type B at drain D1

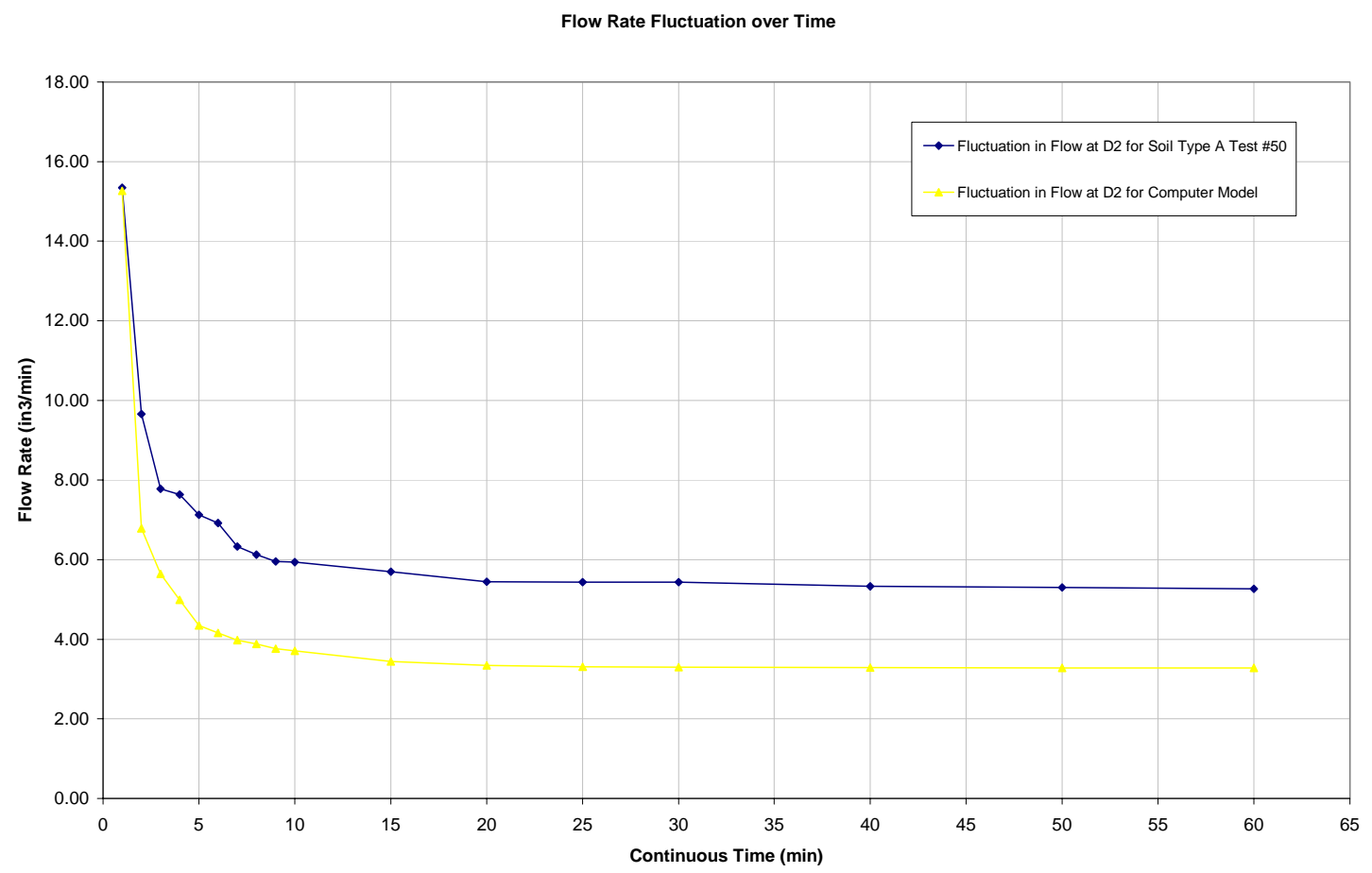

Figure A5.2: Flow rate fluctuation for Soil Type B at drain D2 
Flow Rate Fluctuation over Time

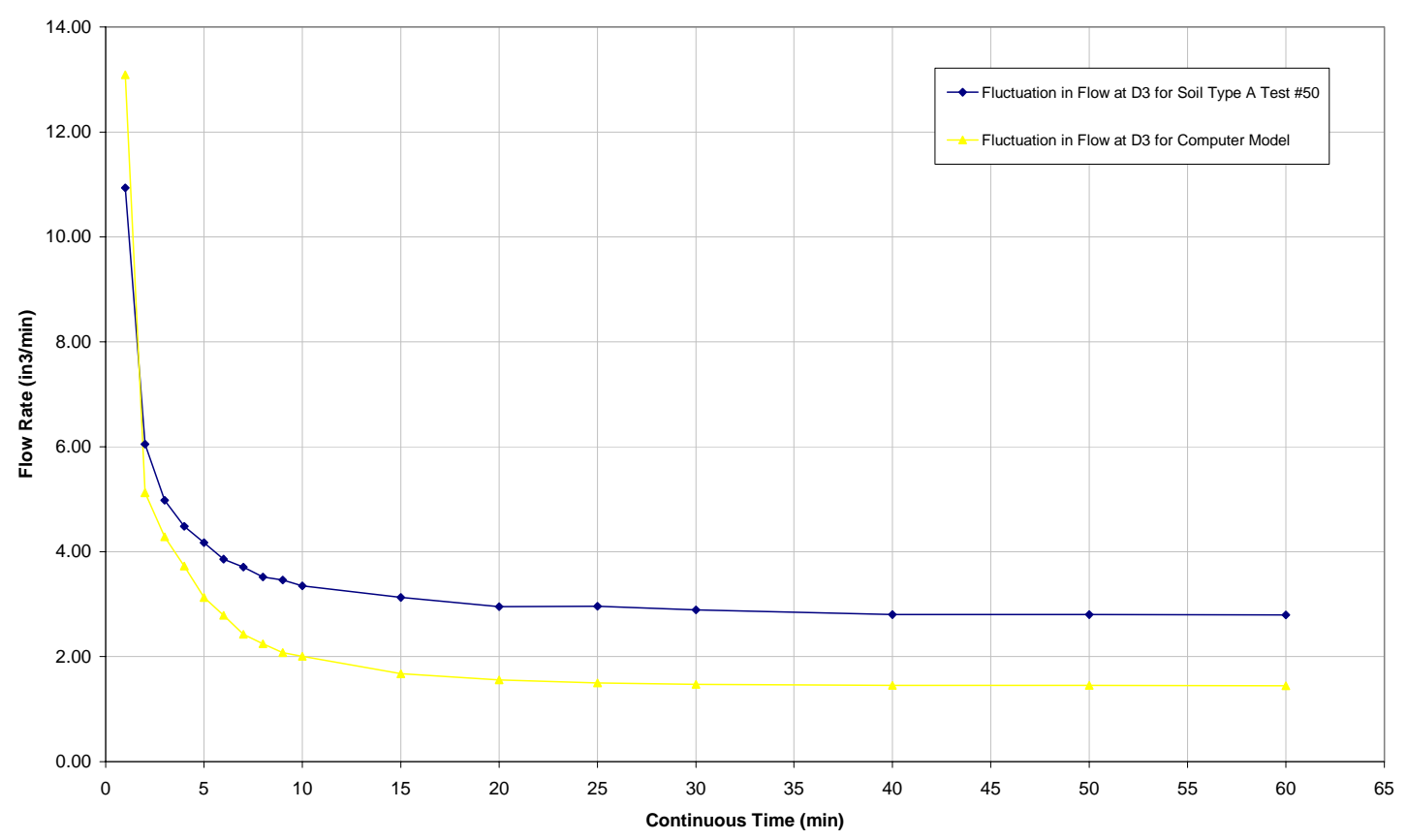

Figure A5.3: Flow rate fluctuation for Soil Type B at drain D3

Flow Rate Fluctuation over Time

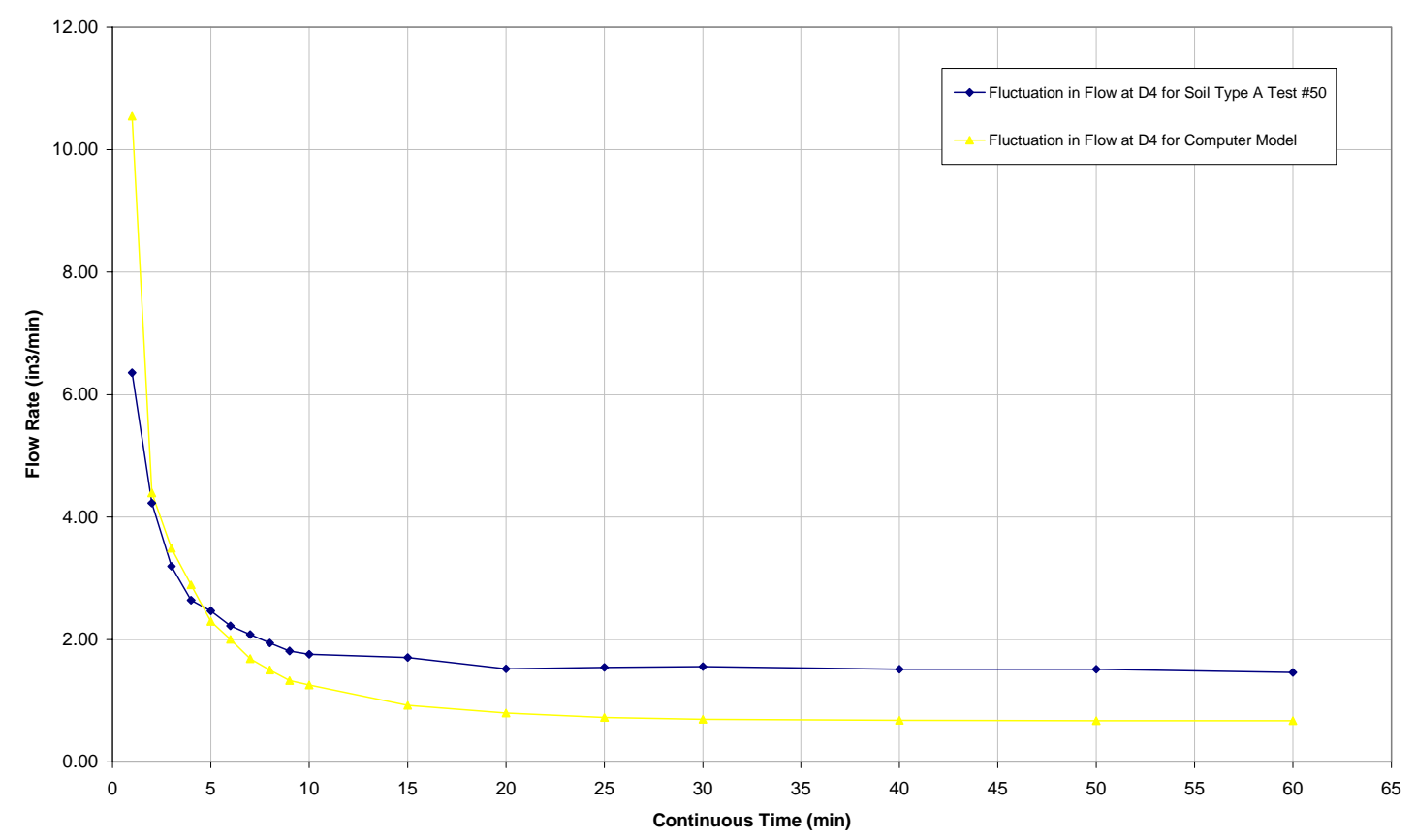

Figure A5.4: Flow rate fluctuation for Soil Type B at drain D4 
Flow Rate Fluctuation over Time

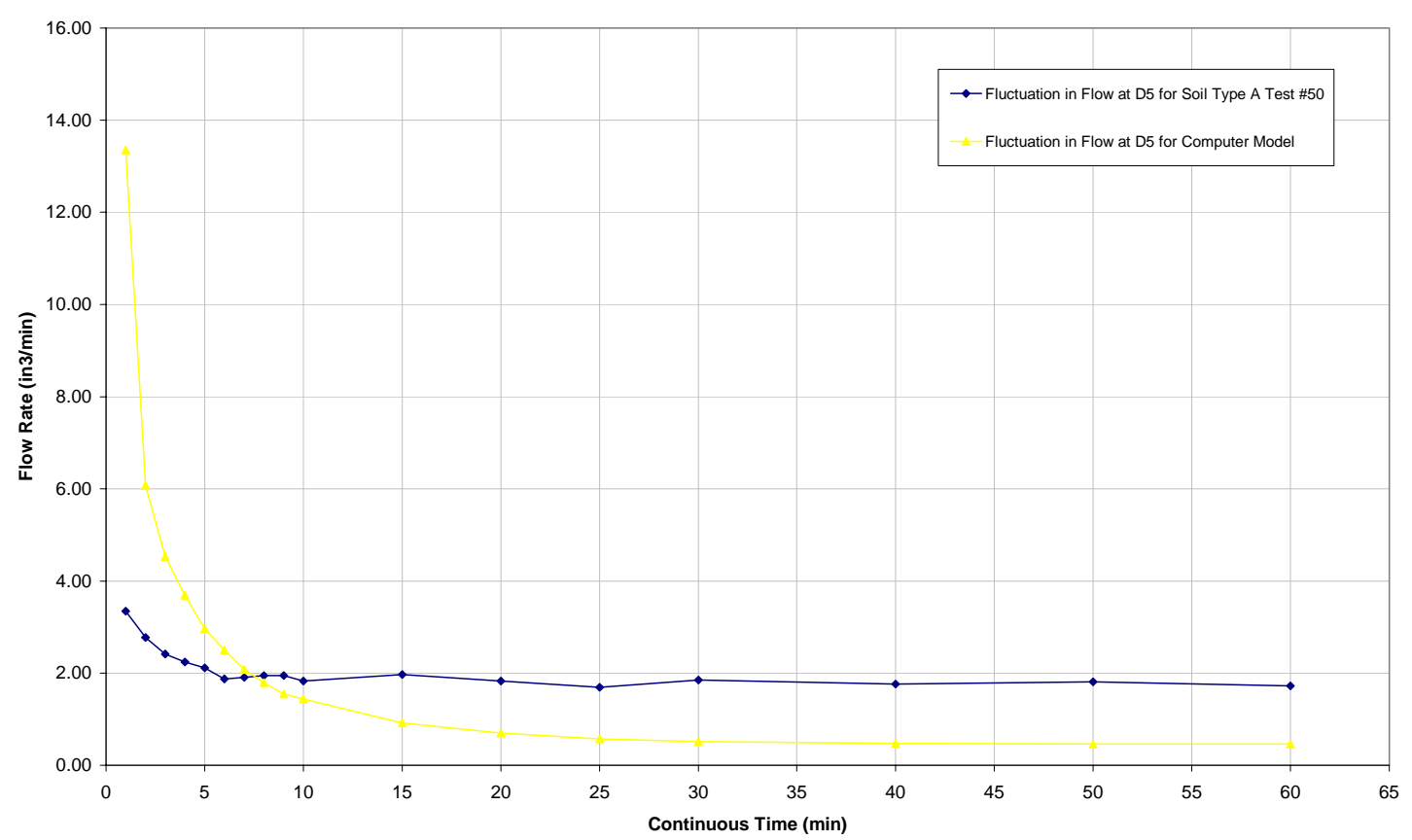

Figure A5.5: Flow rate fluctuation for Soil Type B at drain D5

Flow Rate Fluctuation over Time

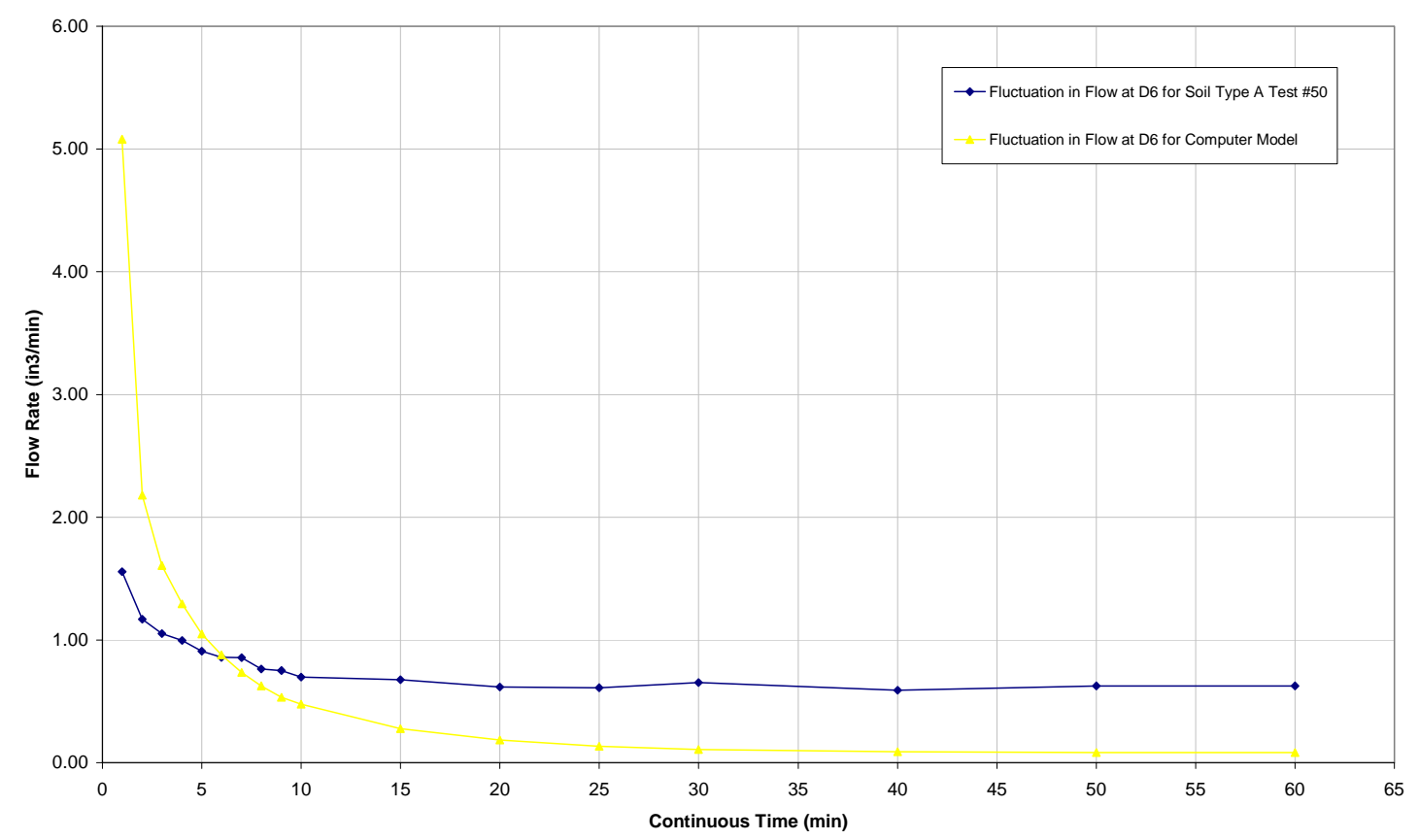

Figure A5.6: Flow rate fluctuation for Soil Type B at drain D6 
Flow Rate Fluctuation over Time

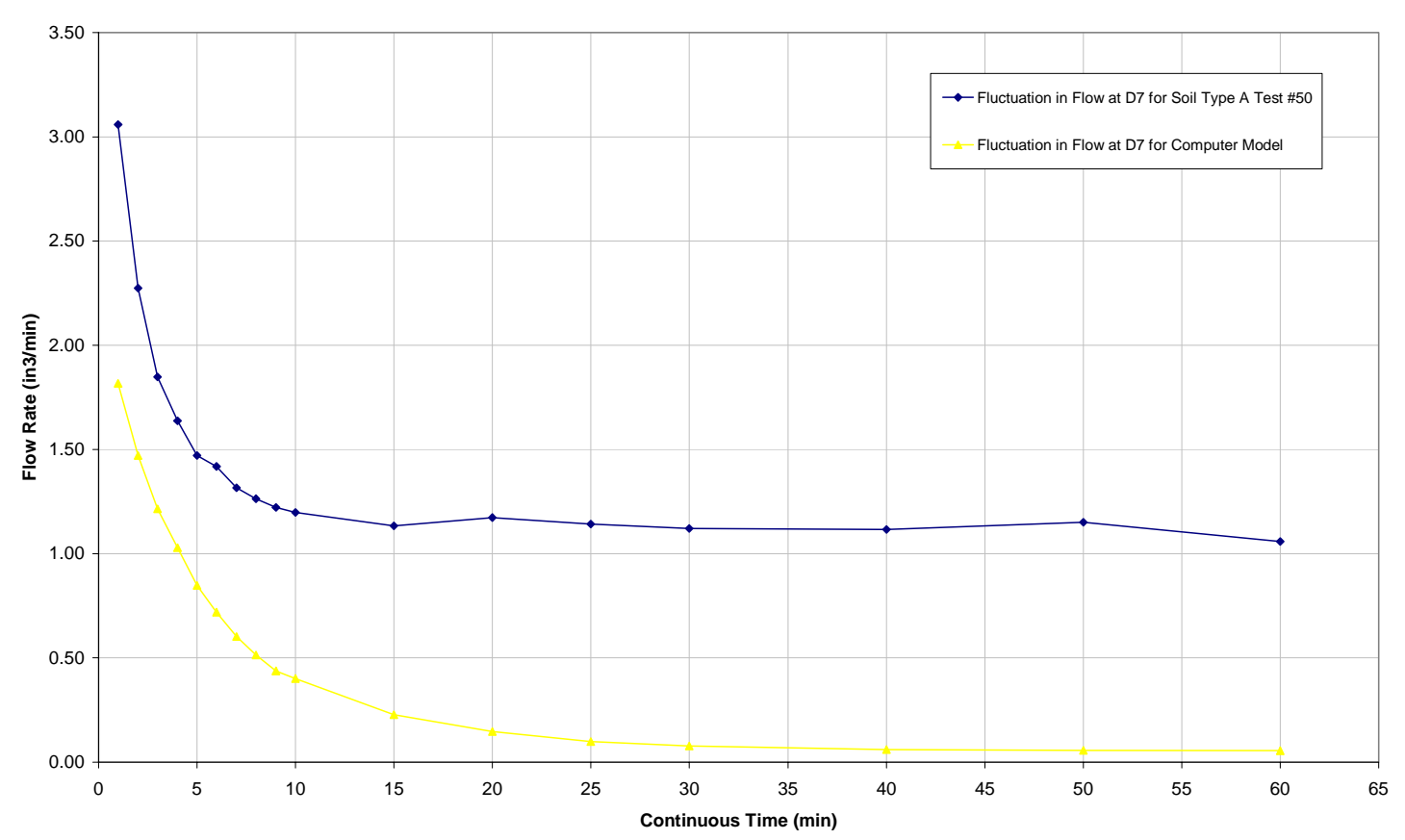

Figure A5.7: Flow rate fluctuation for Soil Type B at drain D7

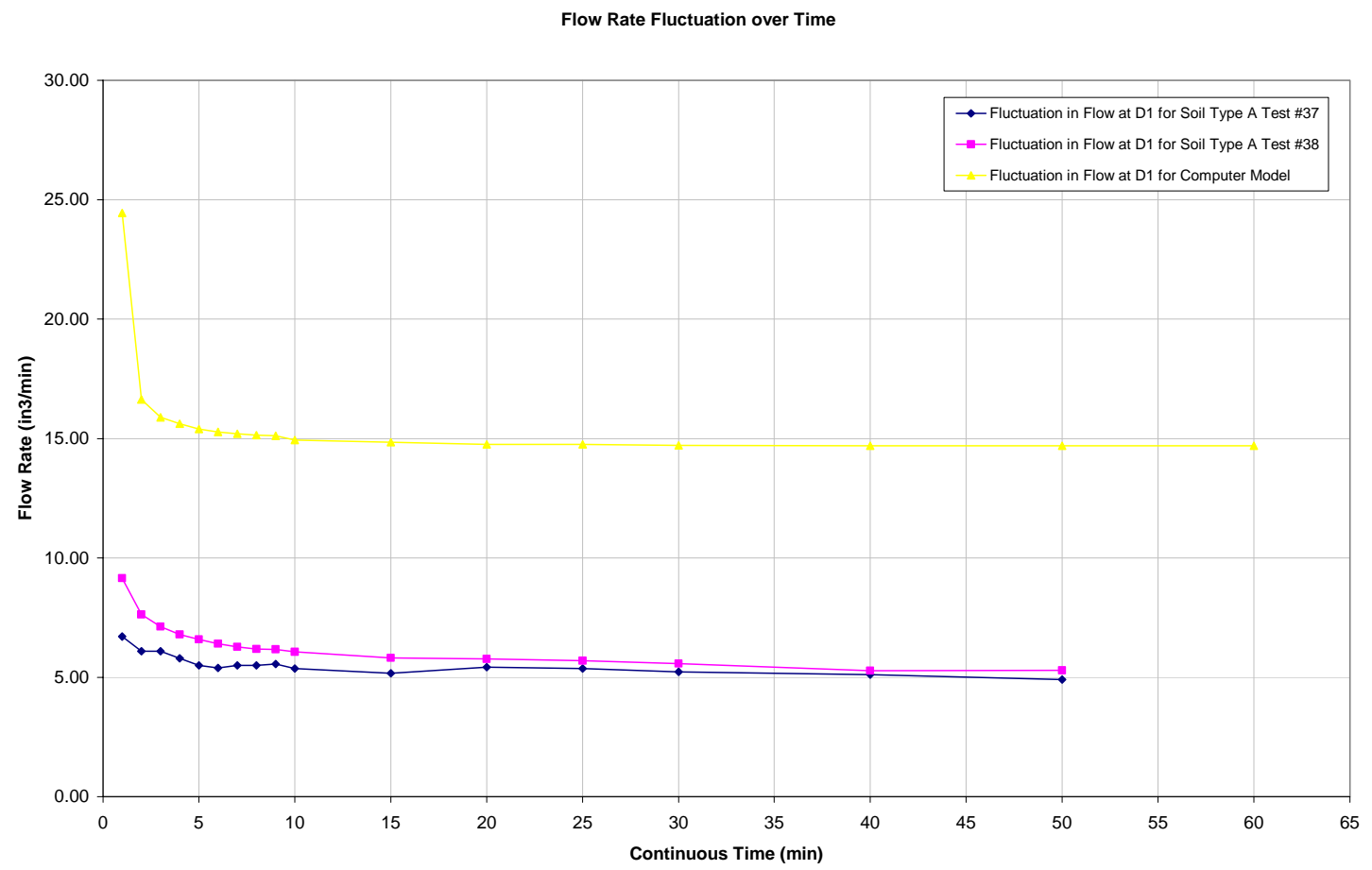

Figure A5.8: Flow rate fluctuation for Soil Type C at drain D1 
Flow Rate Fluctuation over Time

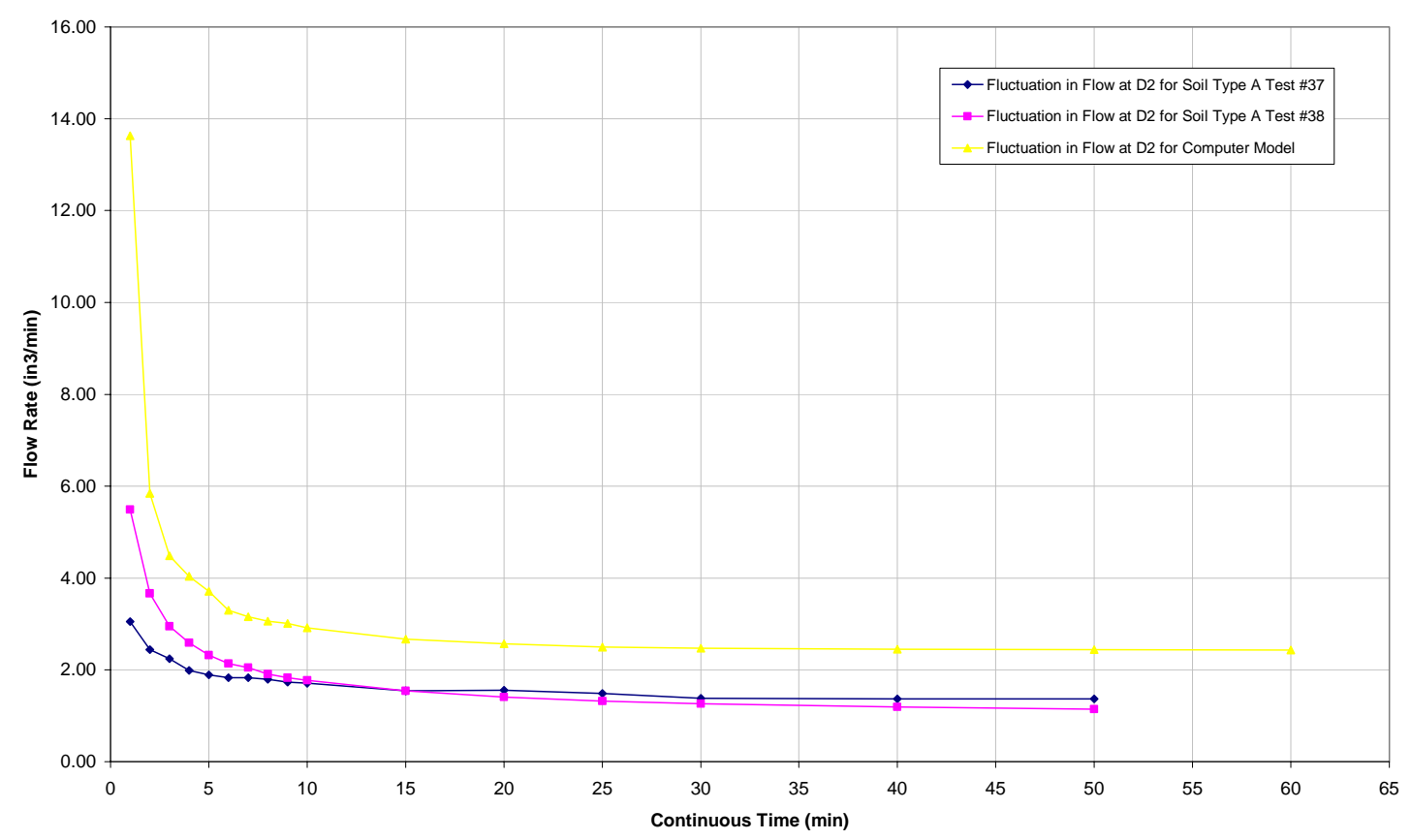

Figure A5.9: Flow rate fluctuation for Soil Type C at drain D2

Flow Rate Fluctuation over Time

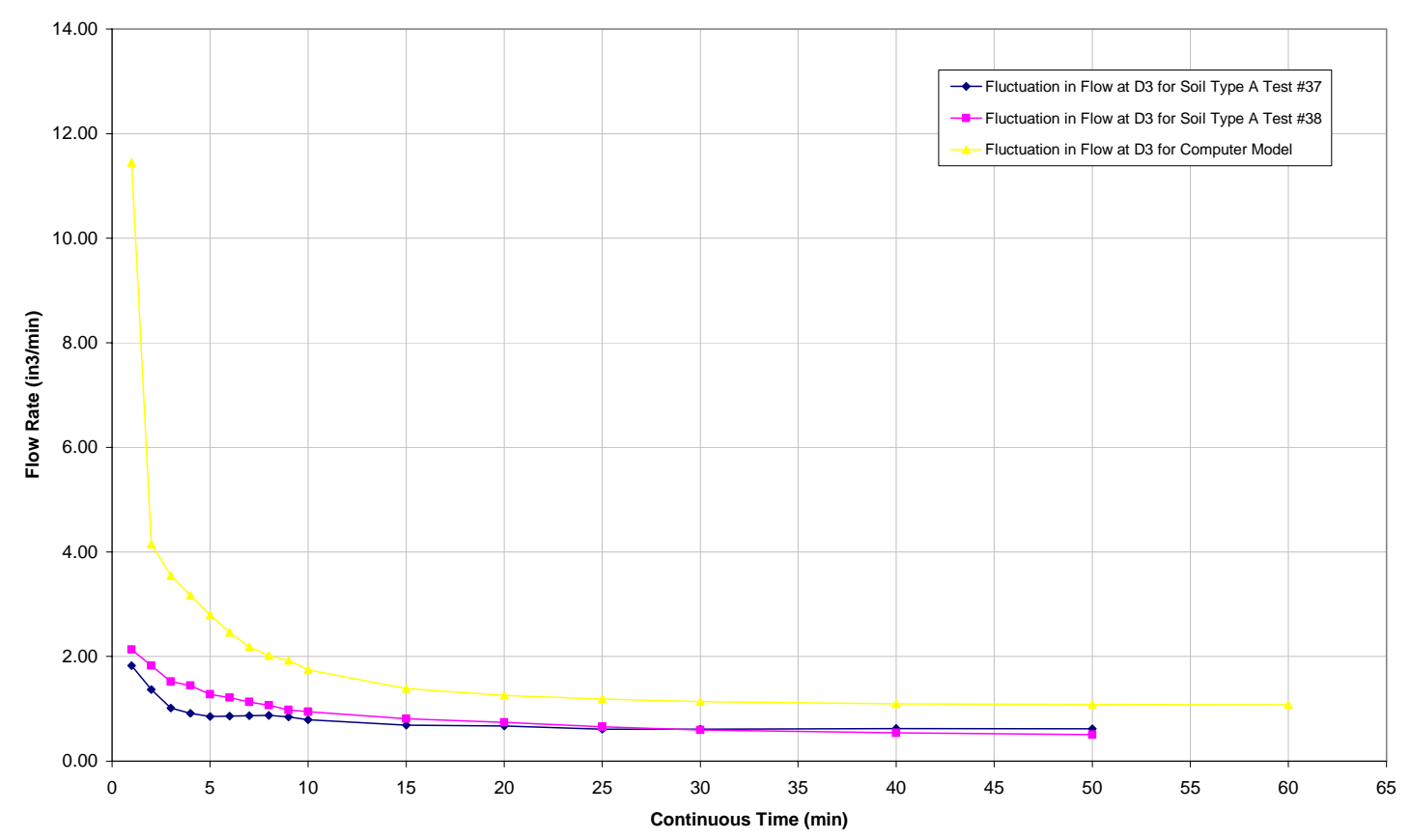

Figure A5.10: Flow rate fluctuation for Soil Type C at drain D3 
Flow Rate Fluctuation over Time

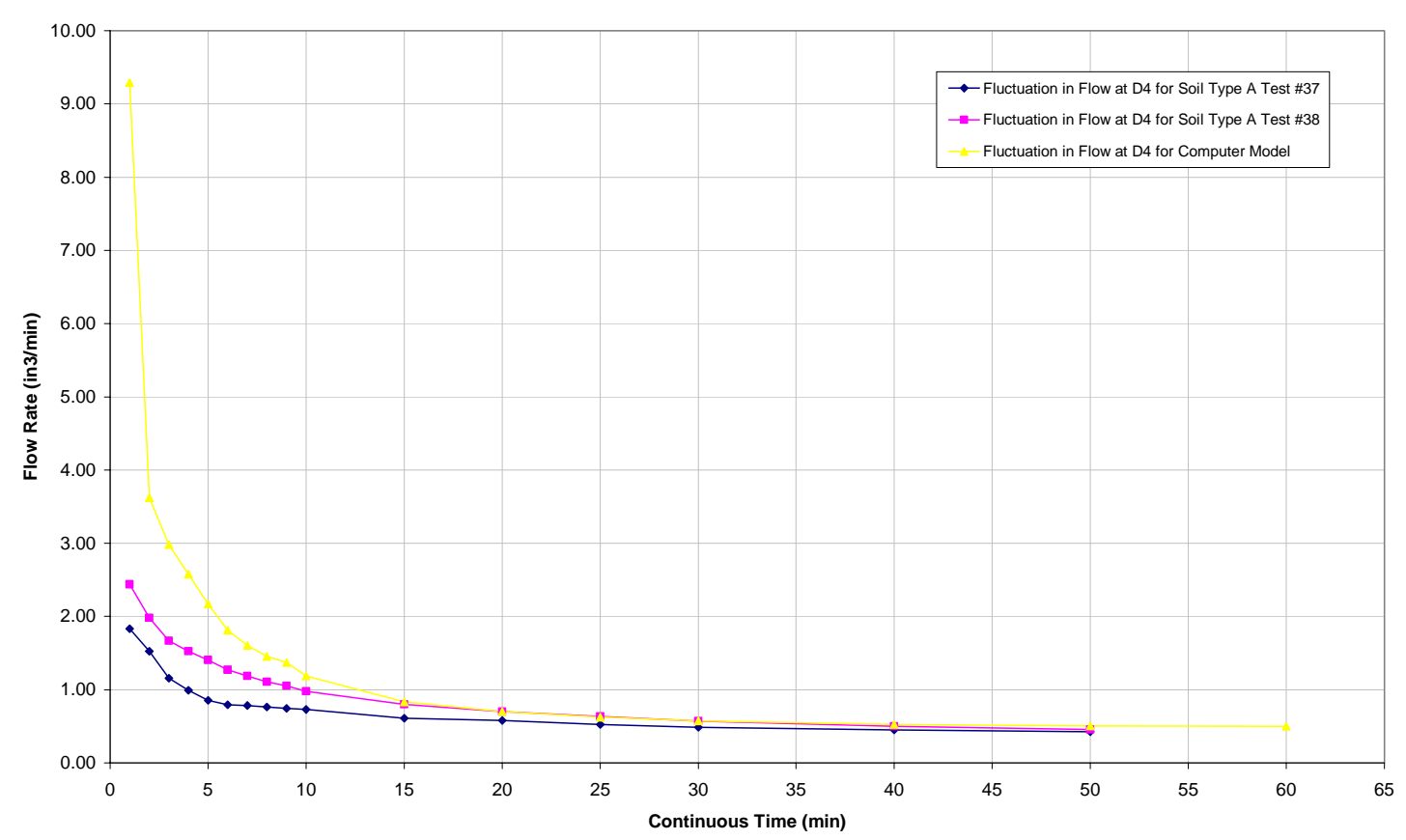

Figure A5.11: Flow rate fluctuation for Soil Type C at drain D4

Flow Rate Fluctuation over Time

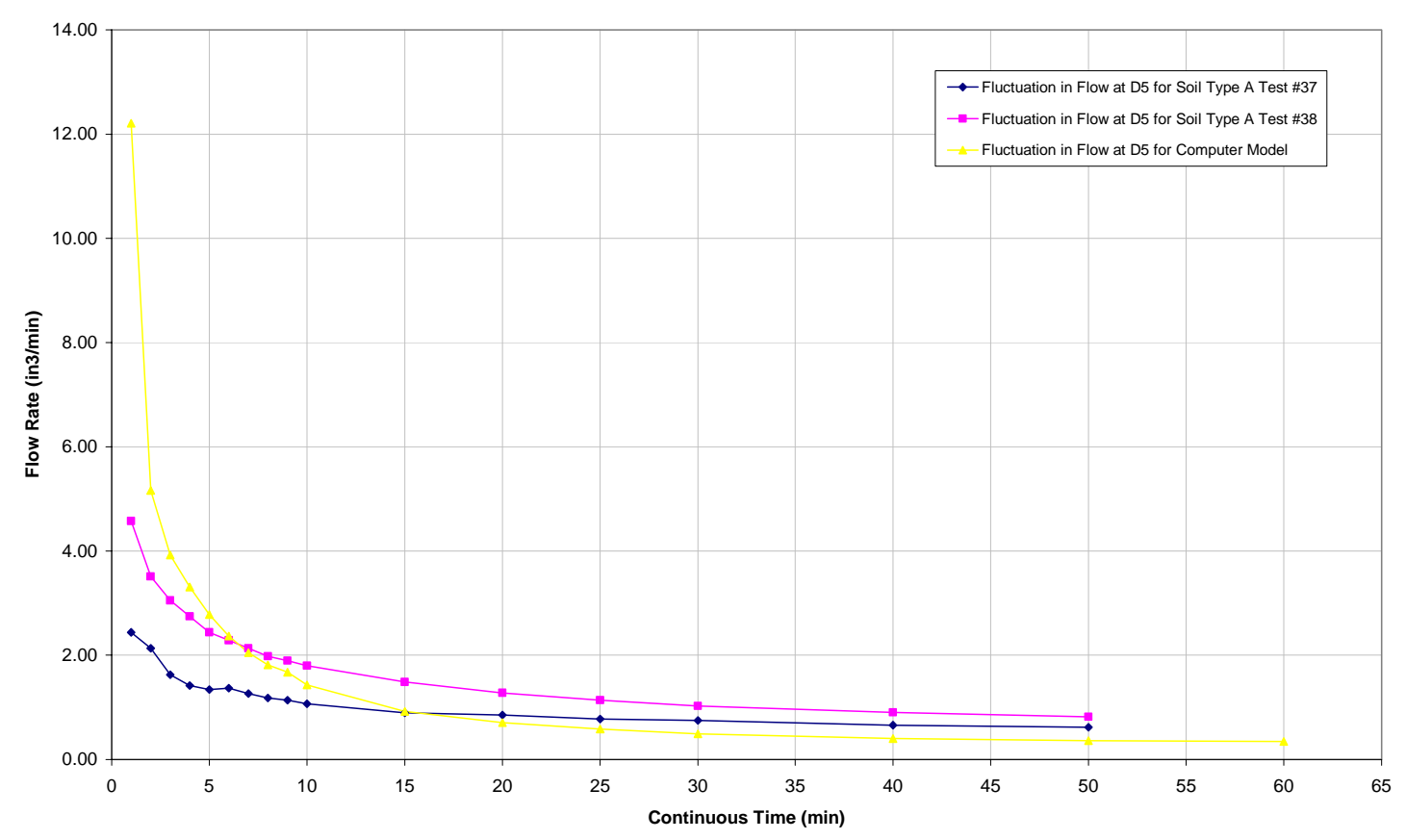

Figure A5.12: Flow rate fluctuation for Soil Type C at drain D5 
Flow Rate Fluctuation over Time

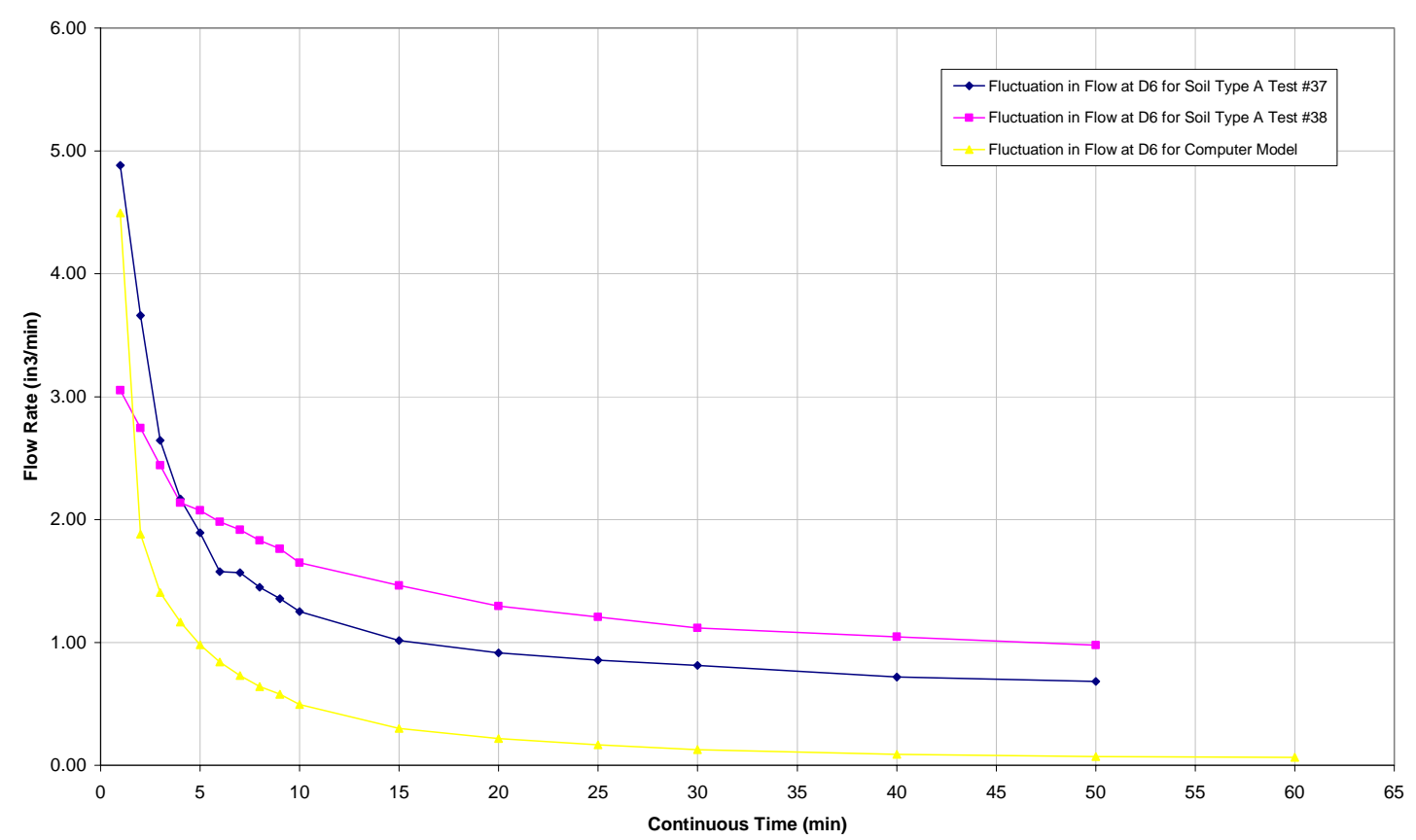

Figure A5.13: Flow rate fluctuation for Soil Type C at drain D6

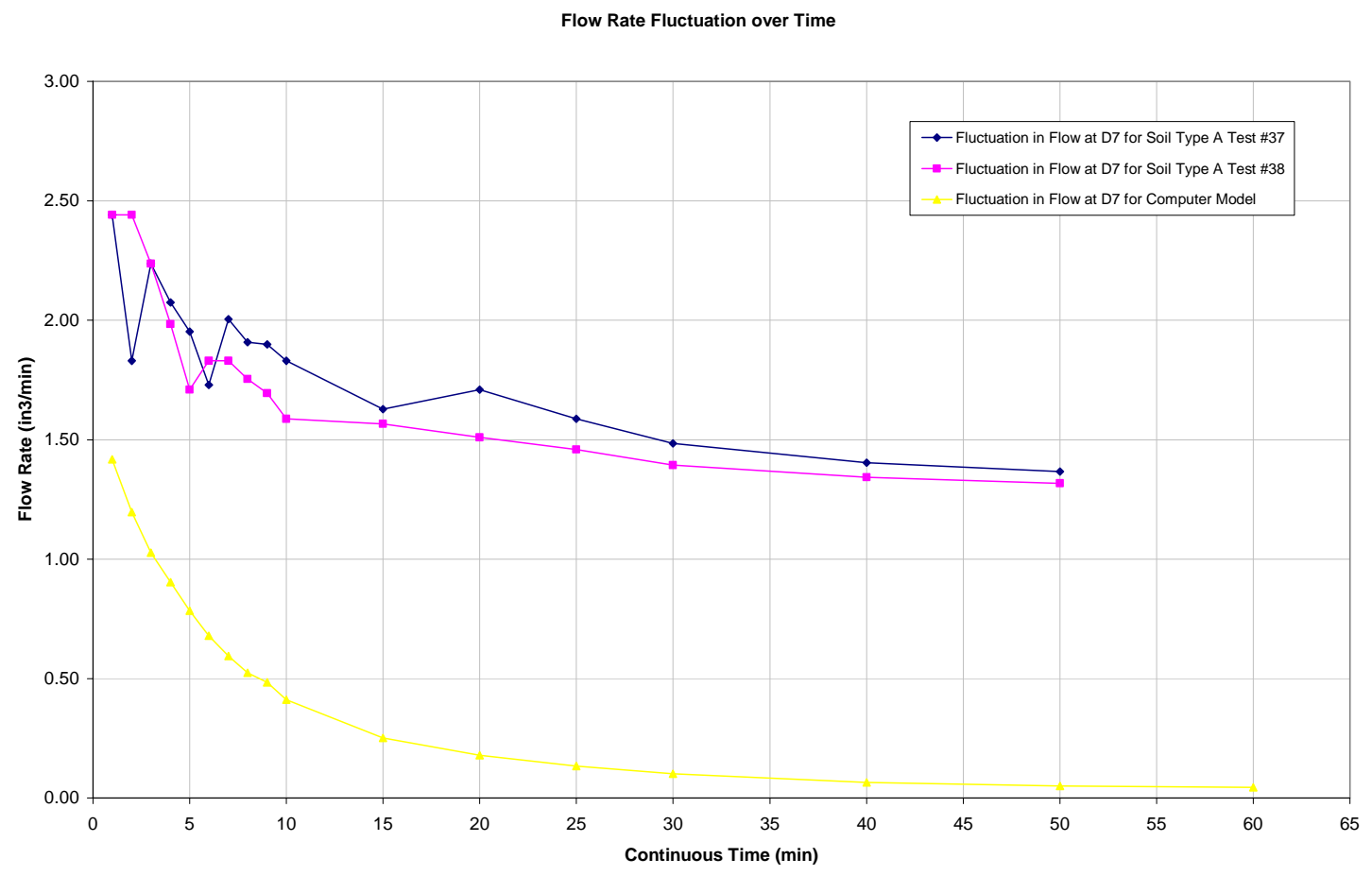

Figure A5.14: Flow rate fluctuation for Soil Type C at drain D7 
Flow Rate Fluctuation over Time

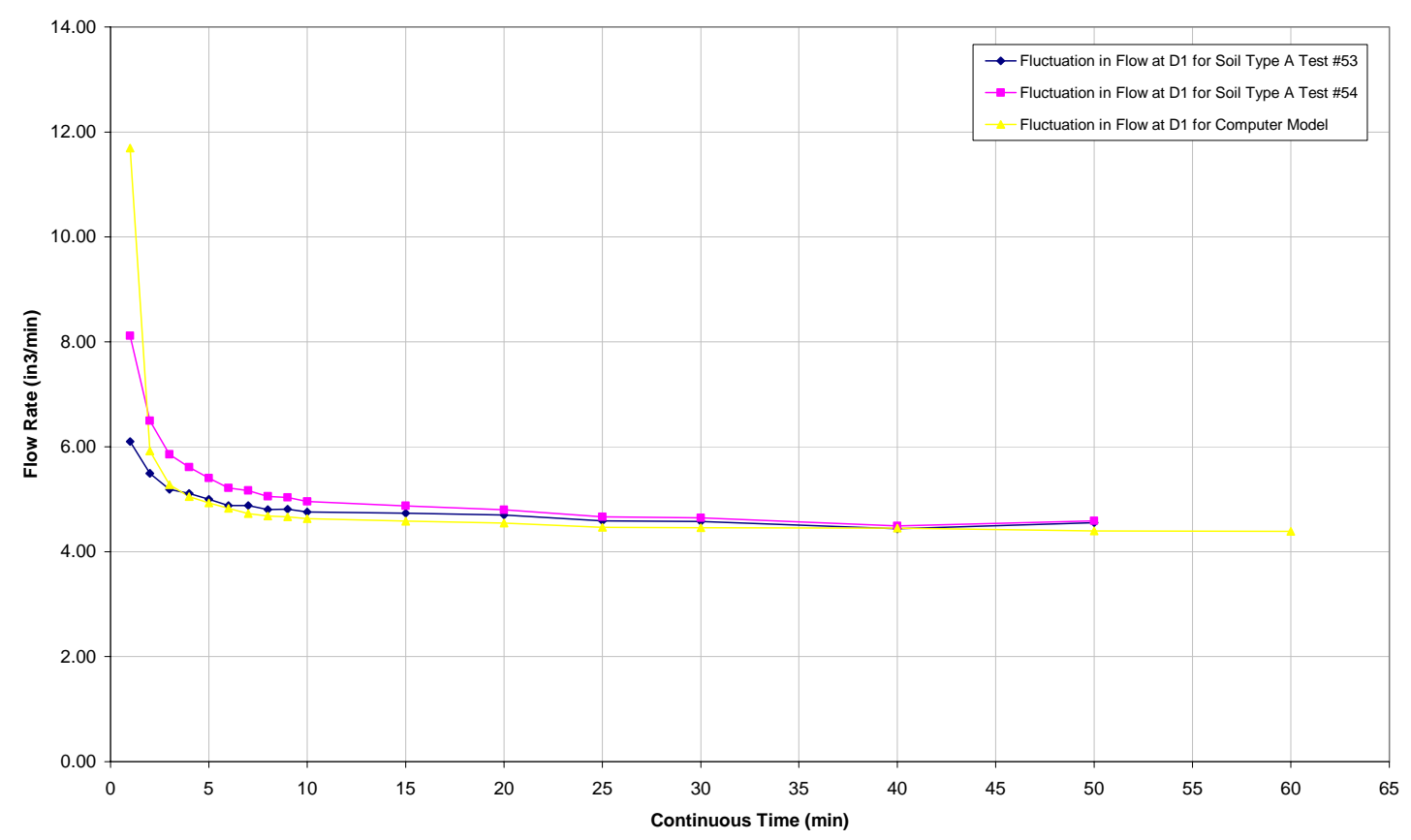

Figure A5.15: Flow rate fluctuation for Soil Type D at drain D1

Flow Rate Fluctuation over Time

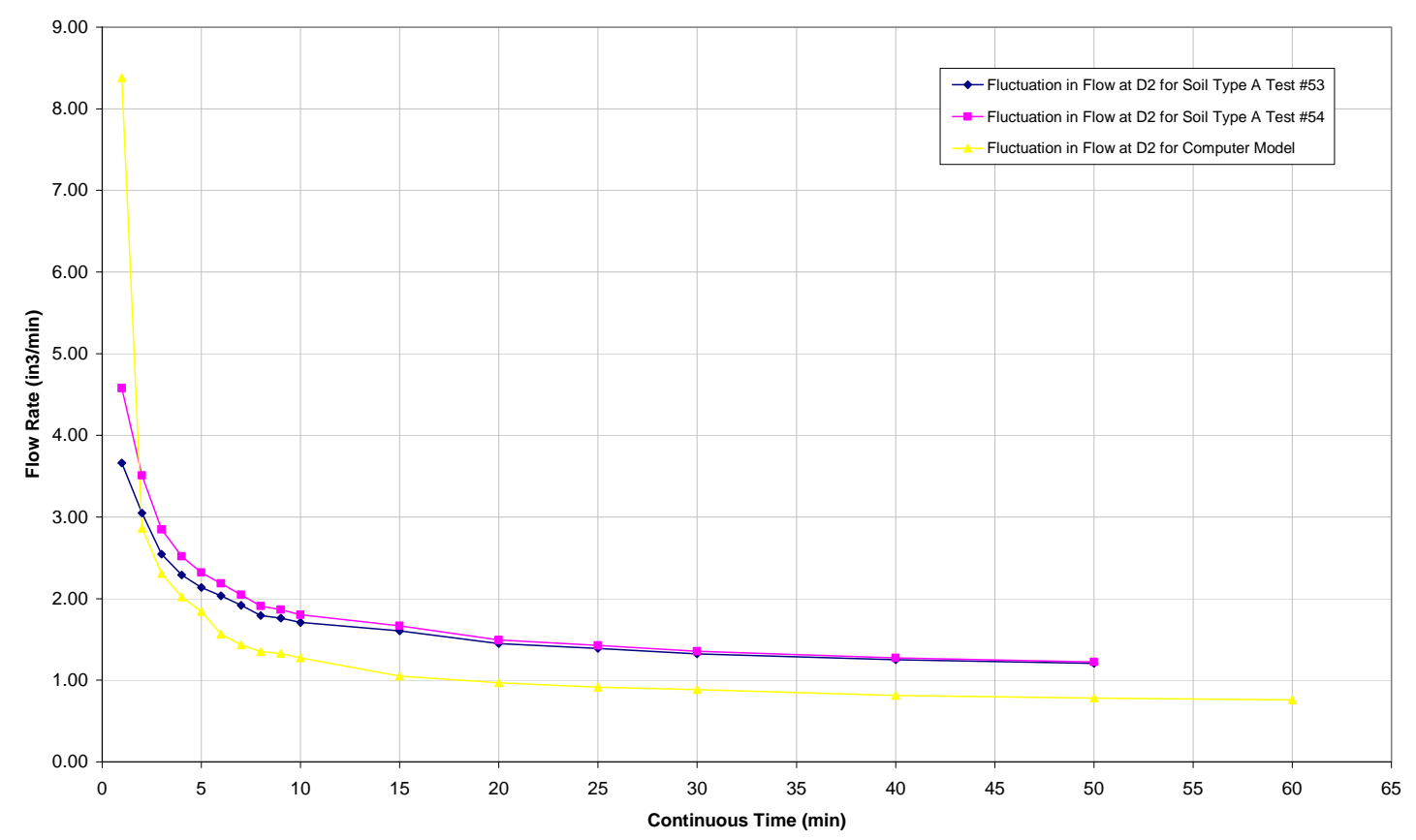

Figure A5.16: Flow rate fluctuation for Soil Type D at drain D2 
Flow Rate Fluctuation over Time

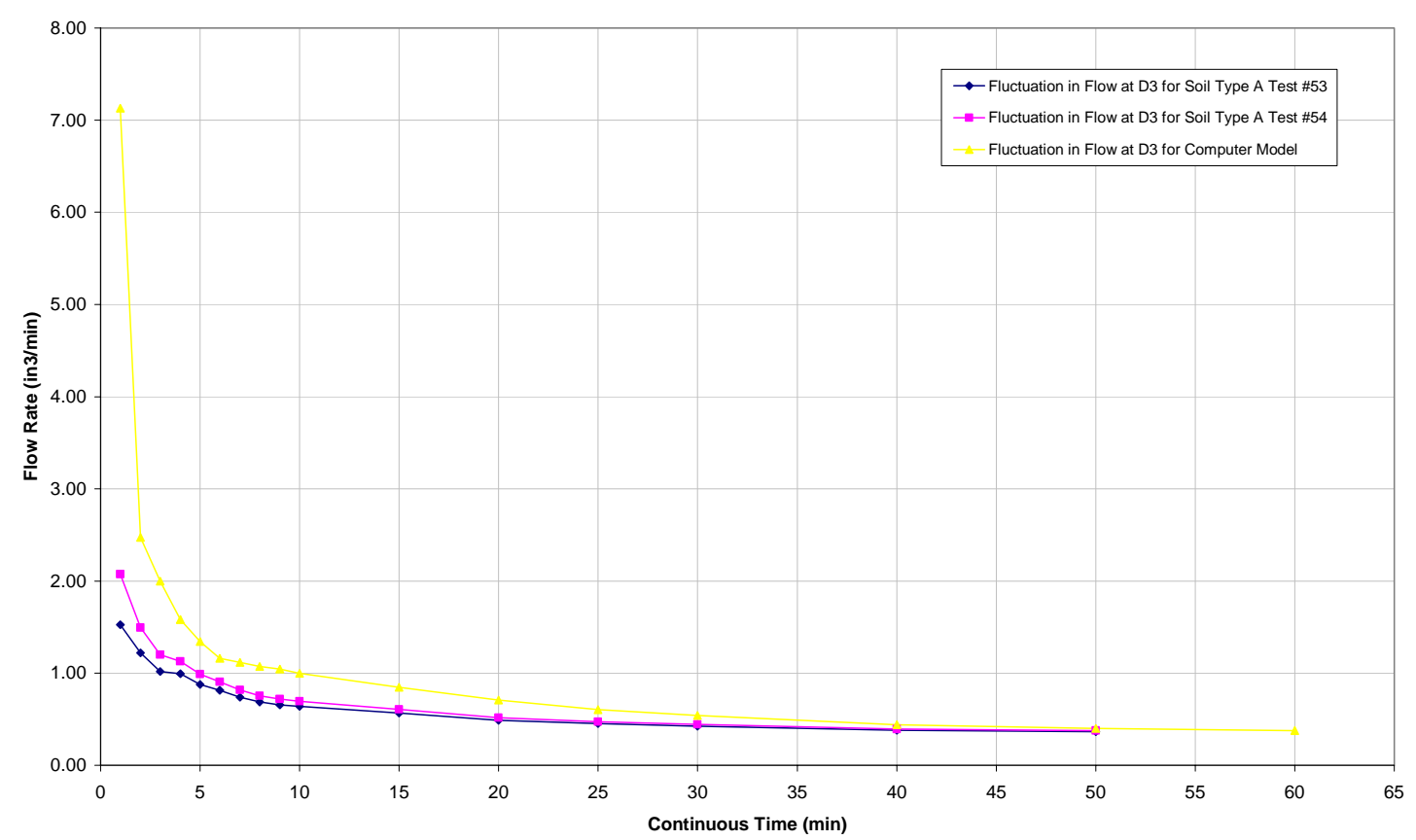

Figure A5.17: Flow rate fluctuation for Soil Type D at drain D3

Flow Rate Fluctuation over Time

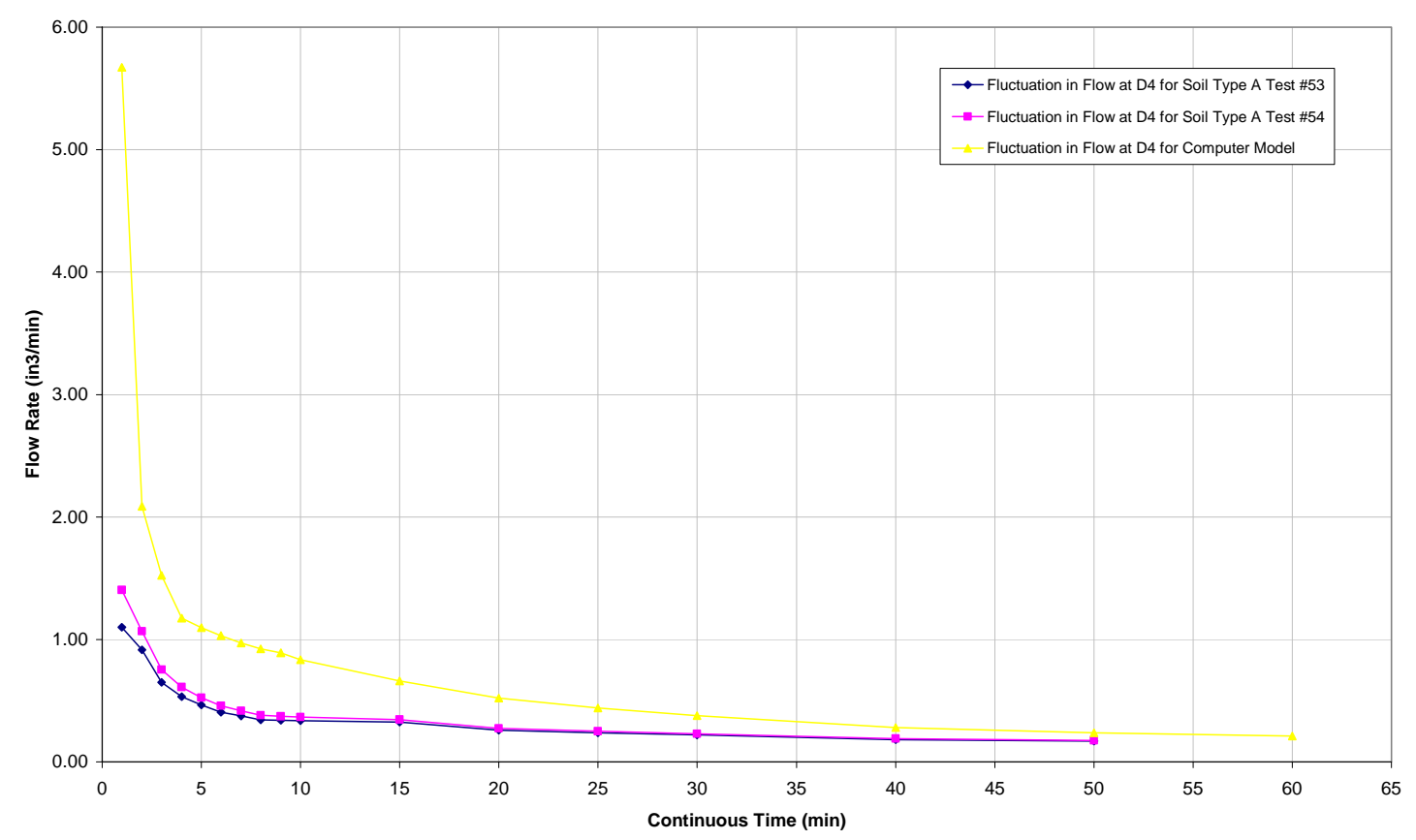

Figure A5.18: Flow rate fluctuation for Soil Type D at drain D4 
Flow Rate Fluctuation over Time

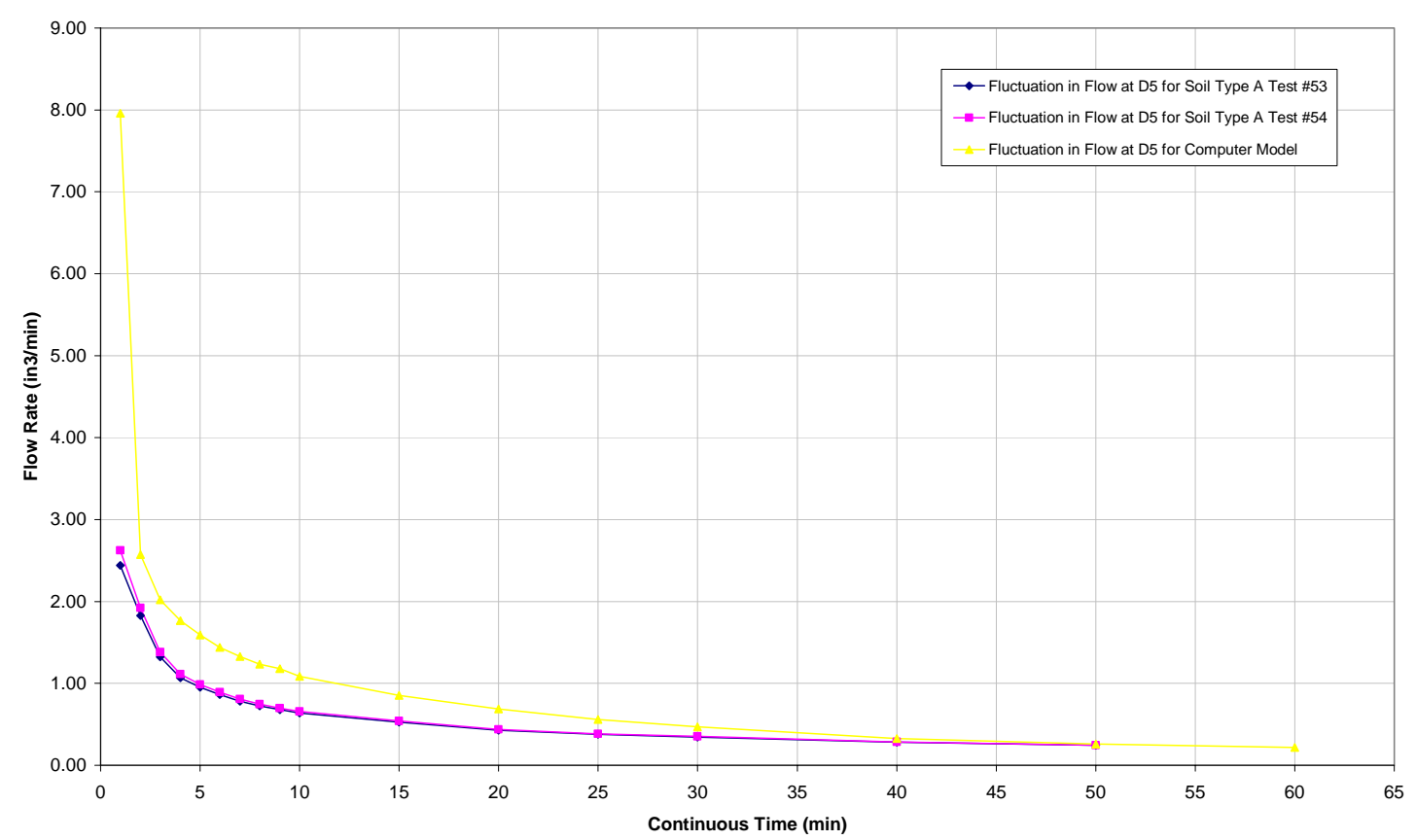

Figure A5.19: Flow rate fluctuation for Soil Type D at drain D5

Flow Rate Fluctuation over Time

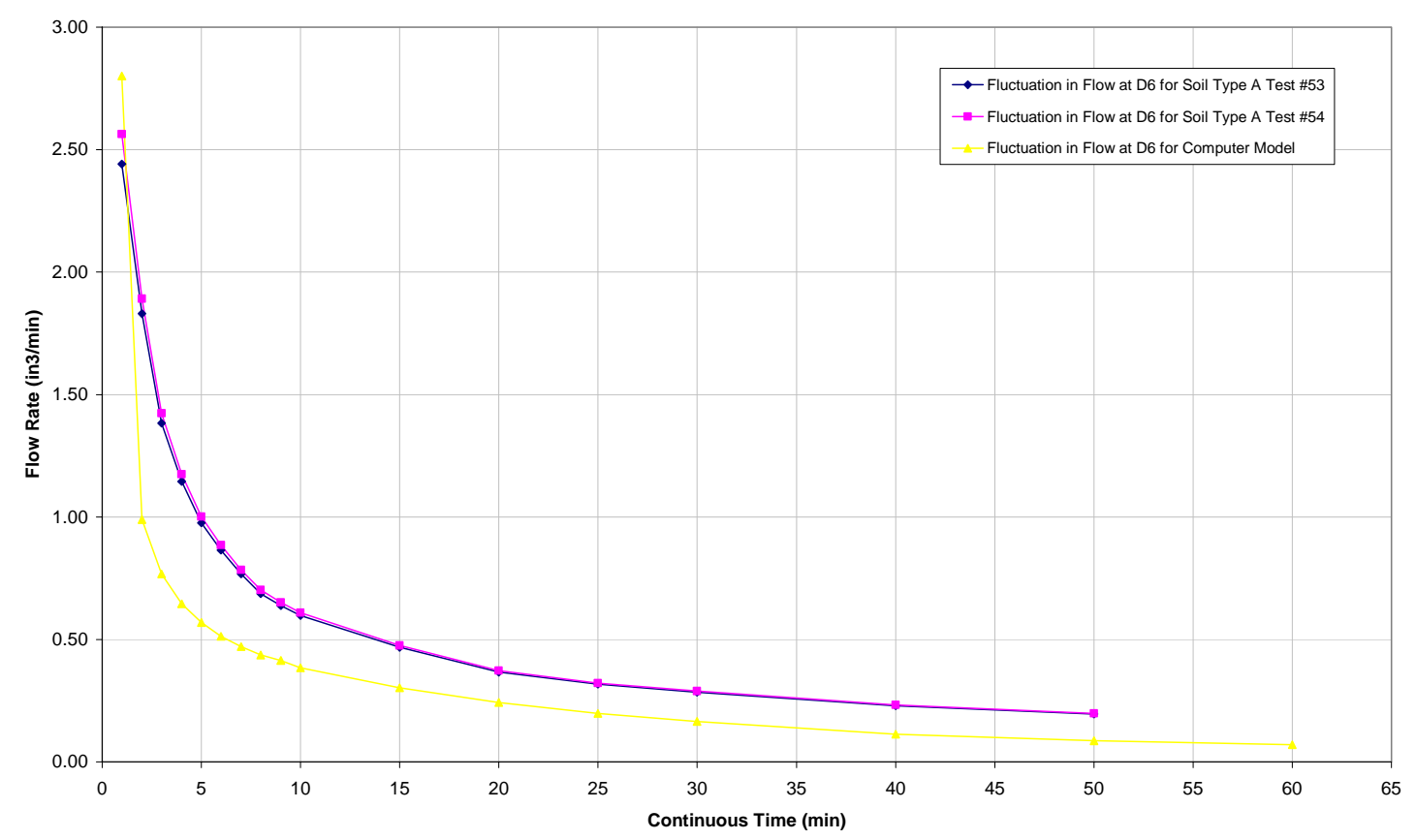

Figure A5.20: Flow rate fluctuation for Soil Type D at drain D6 
Flow Rate Fluctuation over Time

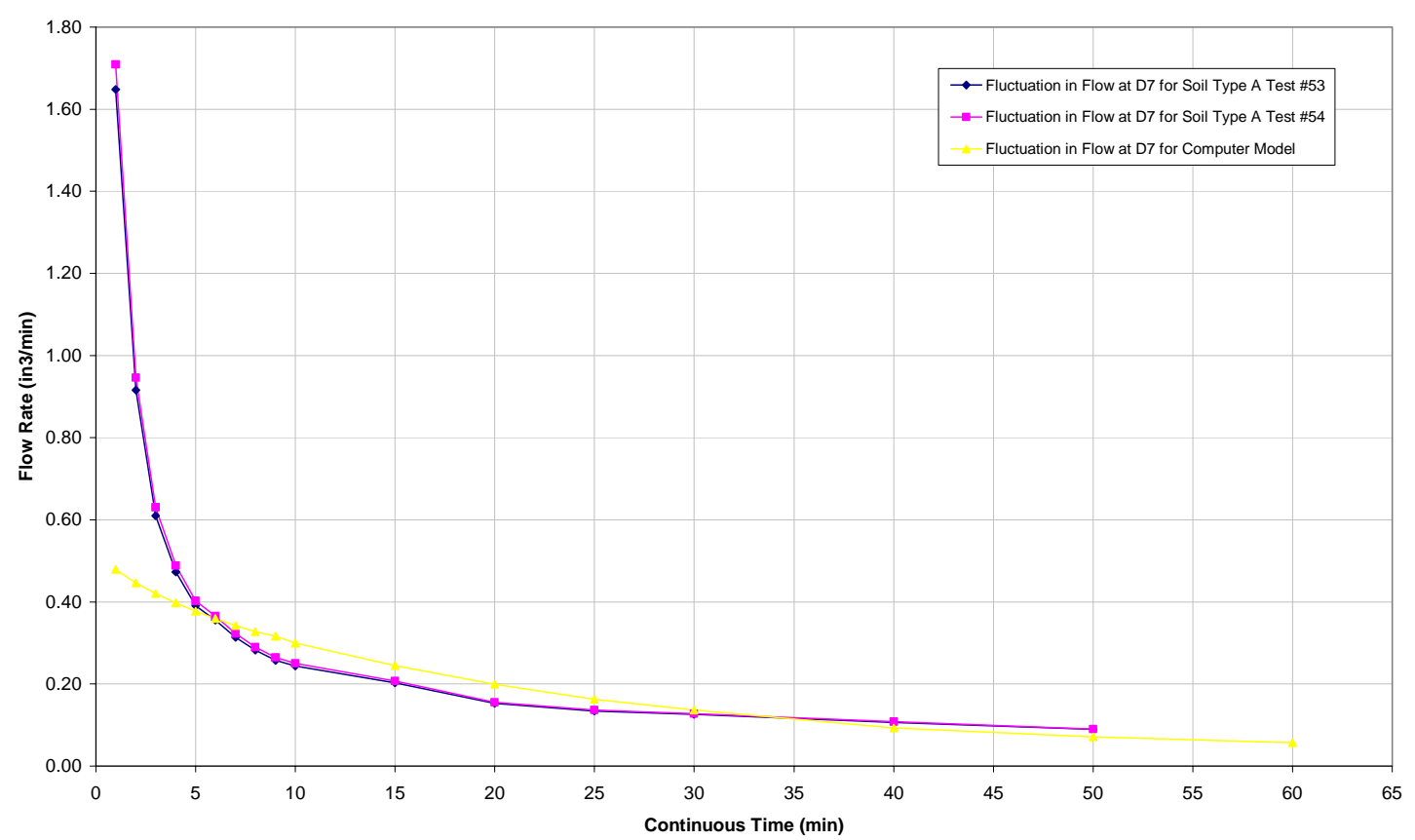

Figure A5.21: Flow rate fluctuation for Soil Type D at drain D7

Flow Rate Fluctuation over Time

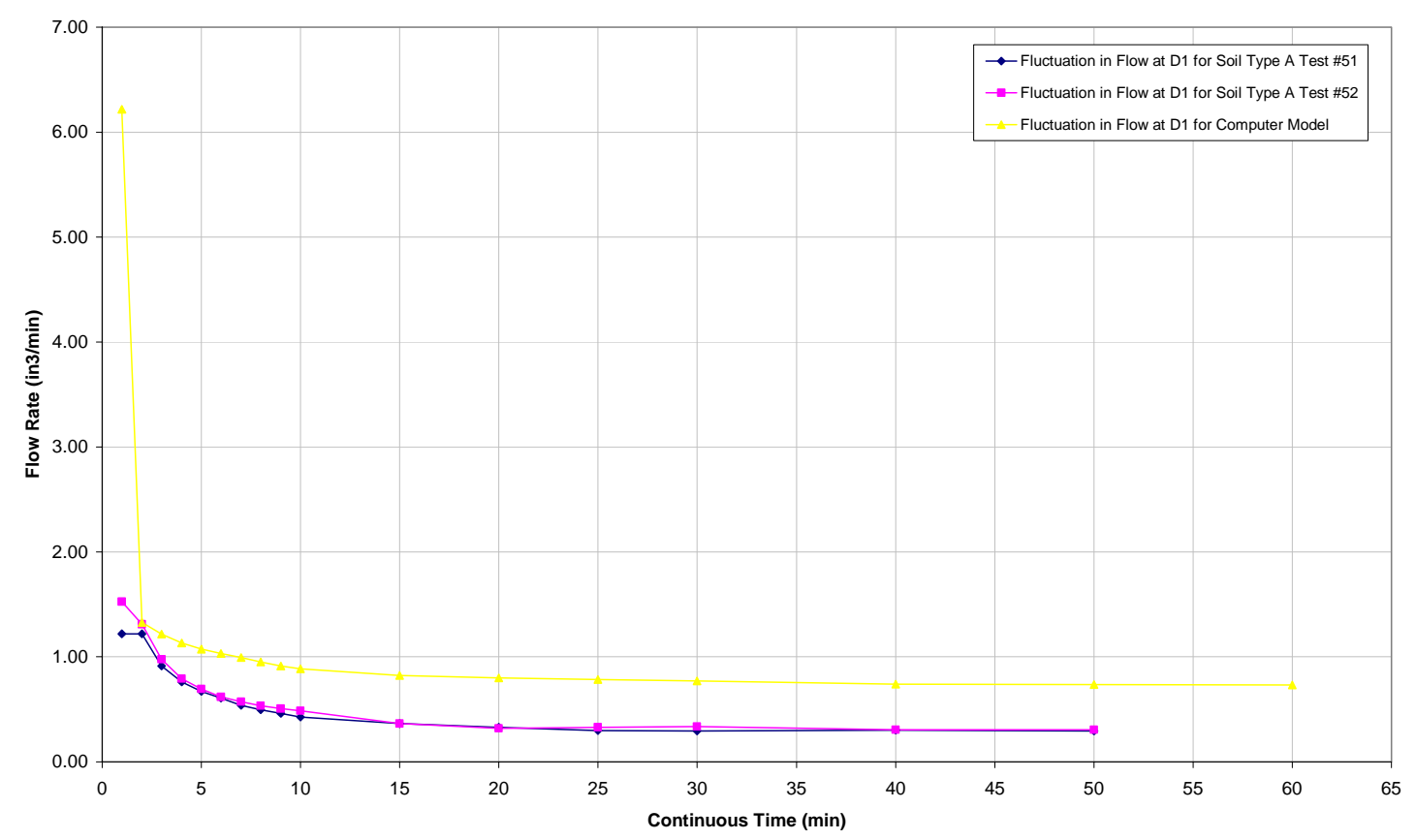

Figure A5.22: Flow rate fluctuation for Soil Type E at drain D 
Flow Rate Fluctuation over Time

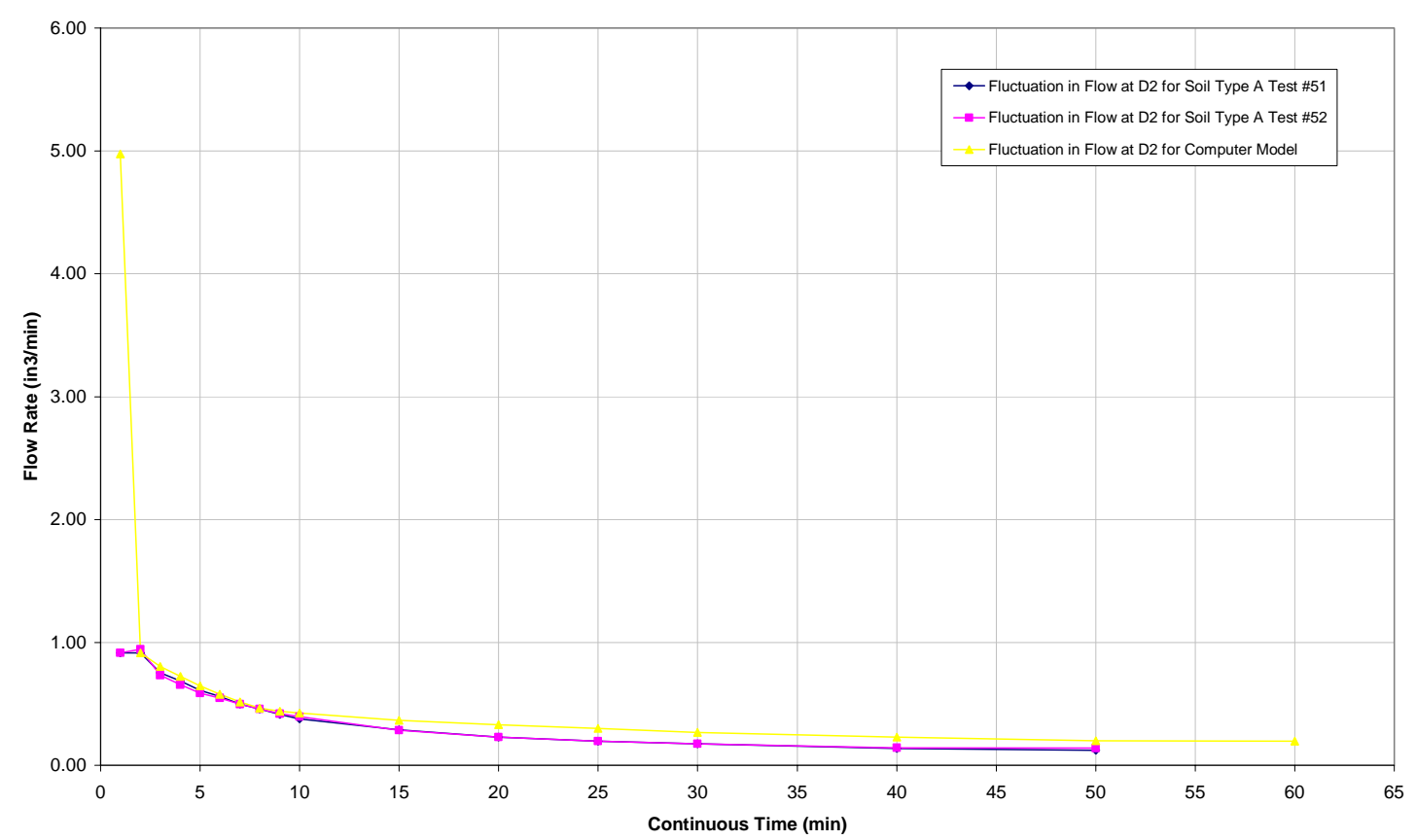

Figure A5.23: Flow rate fluctuation for Soil Type D at drain D2

Flow Rate Fluctuation over Time

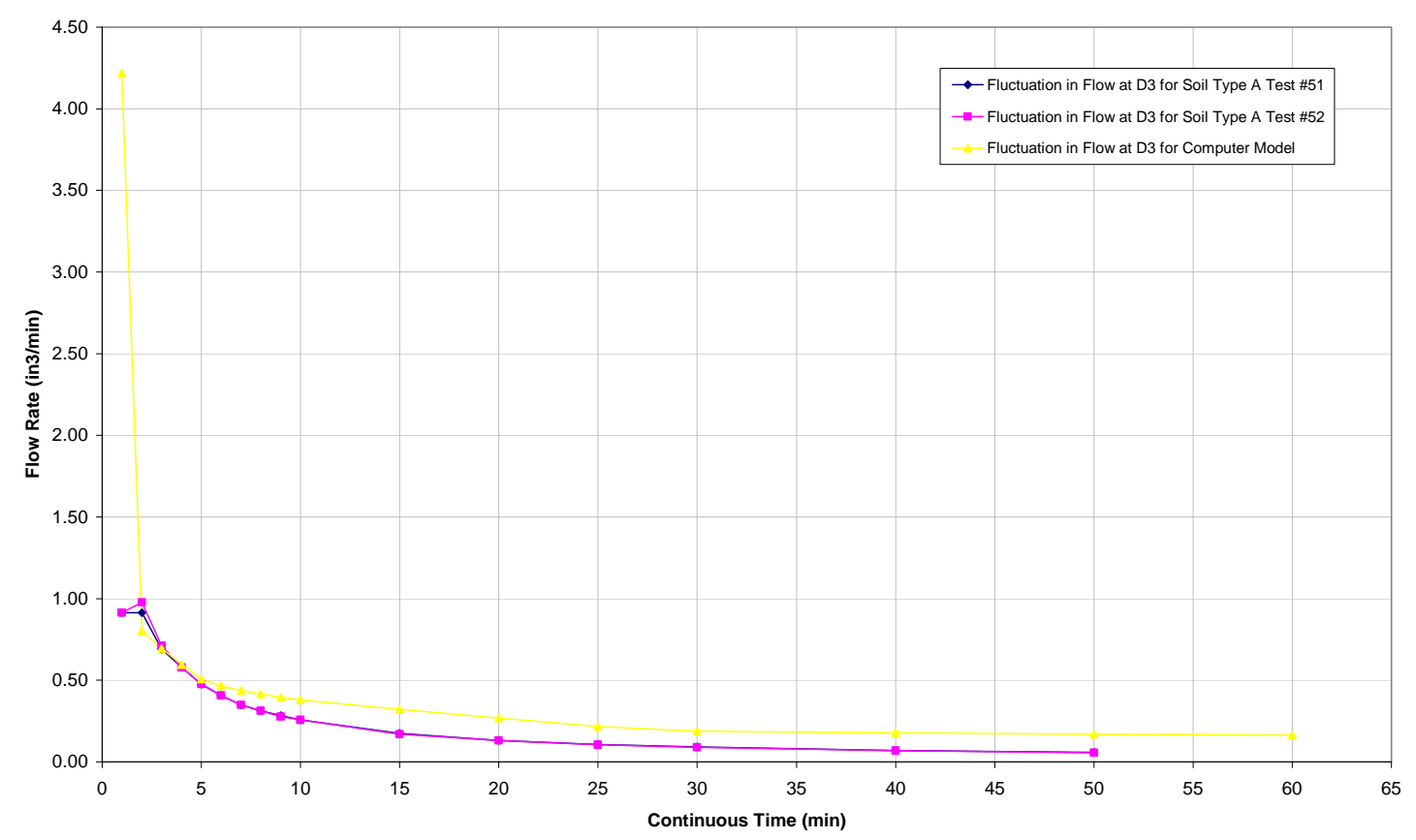

Figure A5.24: Flow rate fluctuation for Soil Type D at drain D3 
Flow Rate Fluctuation over Time

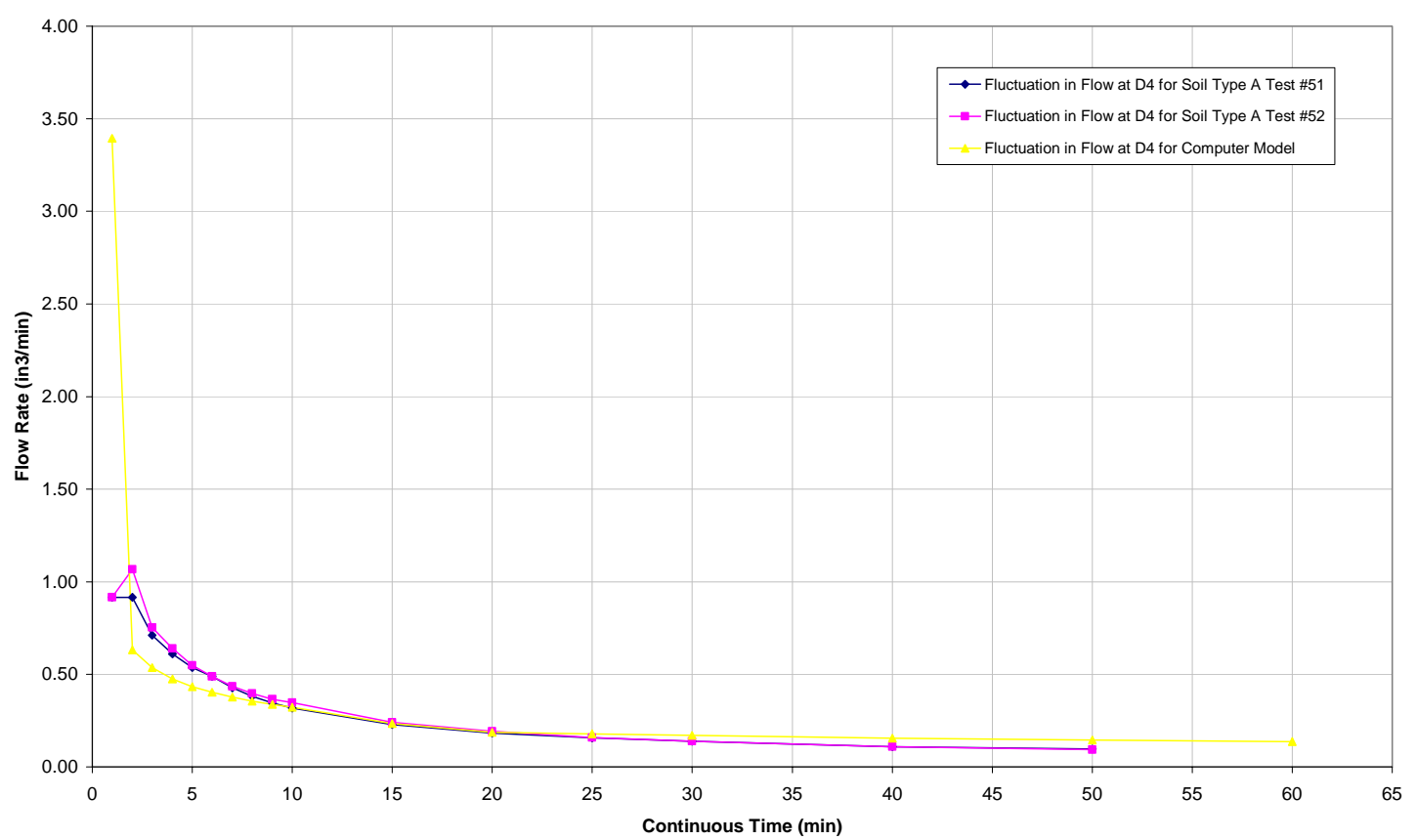

Figure A5.25: Flow rate fluctuation for Soil Type D at drain D4

Flow Rate Fluctuation over Time

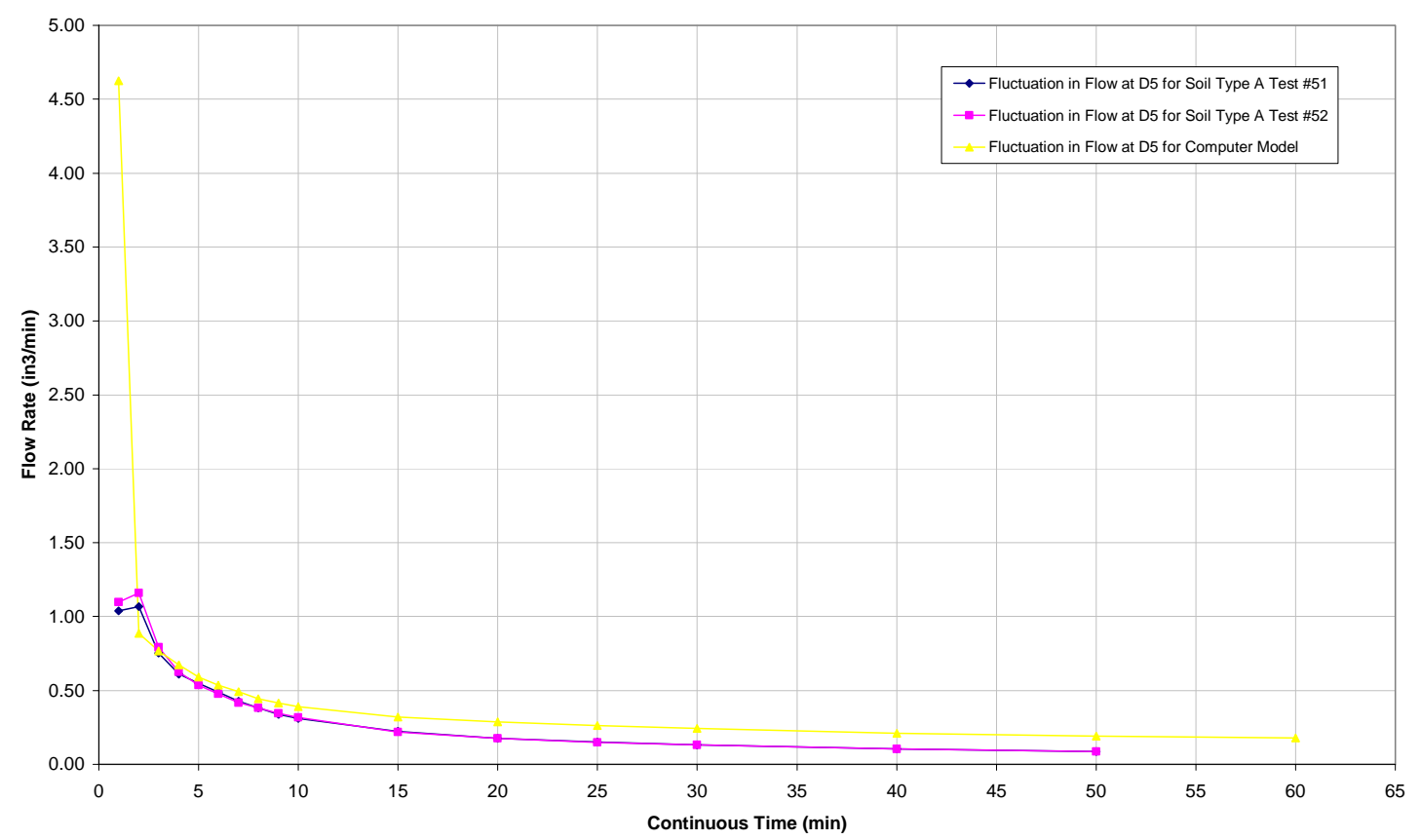

Figure A5.26: Flow rate fluctuation for Soil Type D at drain D5 
Flow Rate Fluctuation over Time

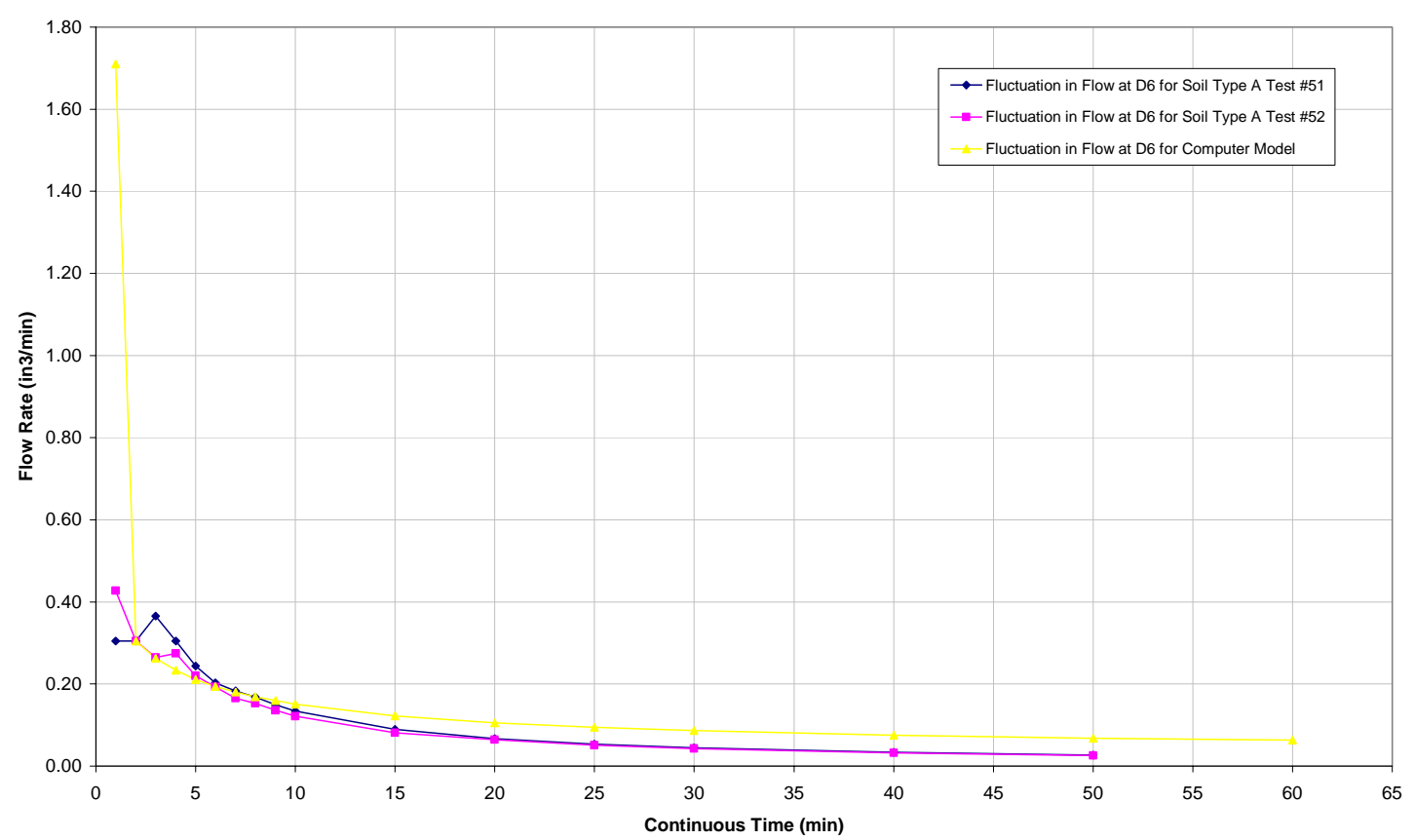

Figure A5.27: Flow rate fluctuation for Soil Type D at drain D6

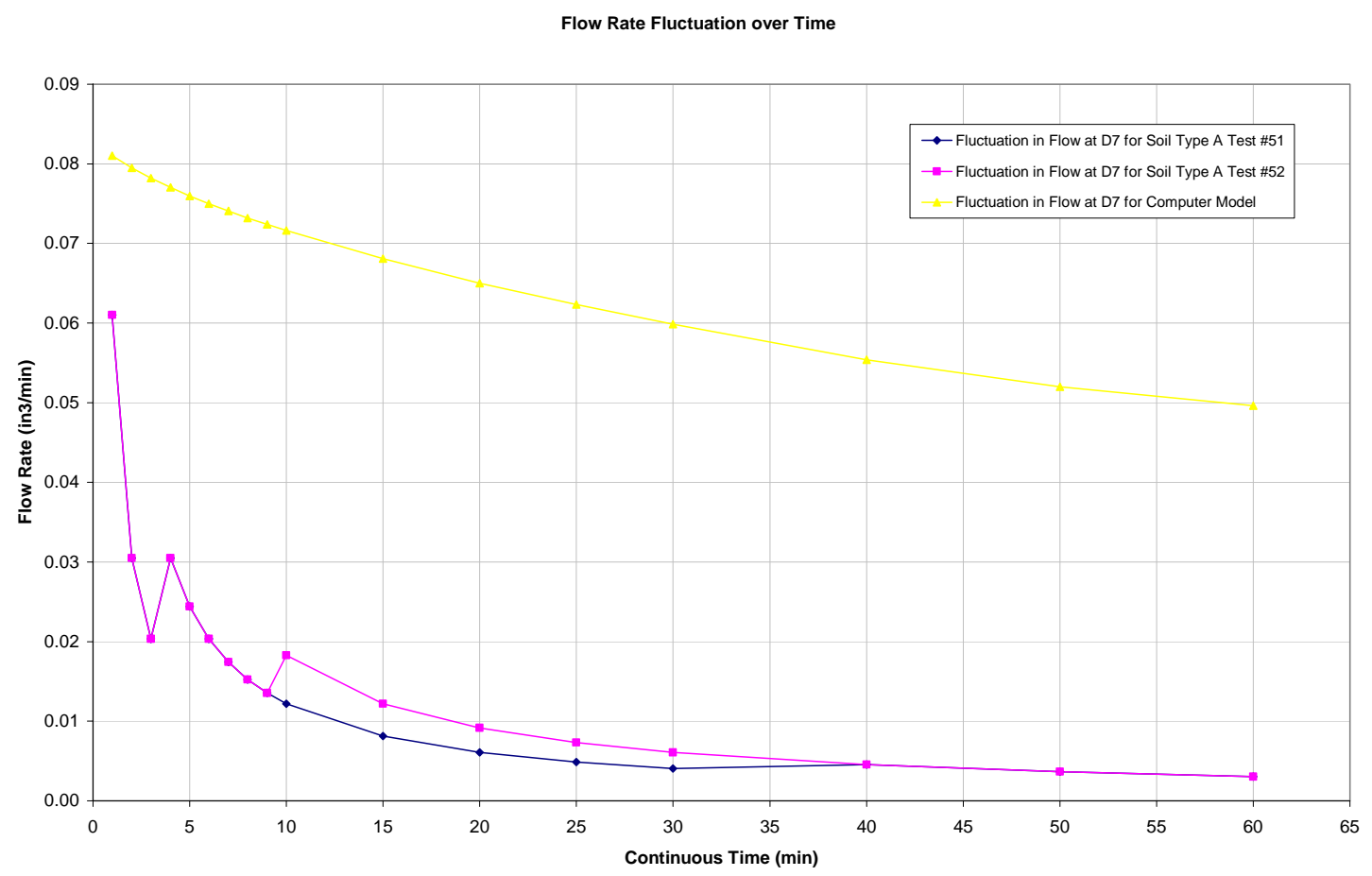

Figure A5.28: Flow rate fluctuation for Soil Type D at drain D7 
Appendix A6: Laboratory Vs Computer Model Efficiency

$$
\begin{aligned}
& W=12 \text { inches } \\
& I=48 \text { inches } \\
& \theta=0^{0}
\end{aligned}
$$


Cumulative Percent Removed Along the Center Line Computer Model Data

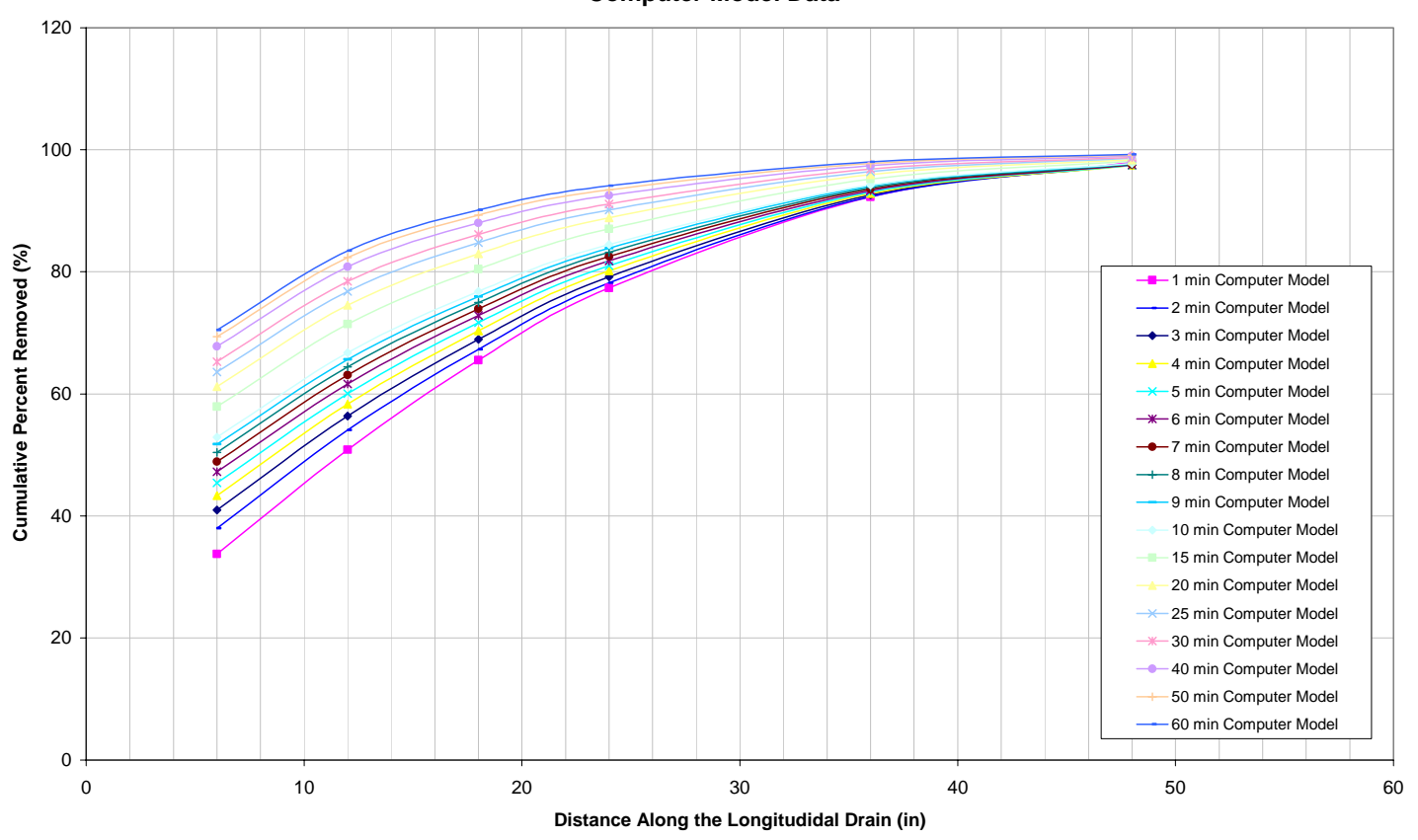

Figure A6.1: Cumulative Percent Removed along the Drain for Soil Type B - Computer Model

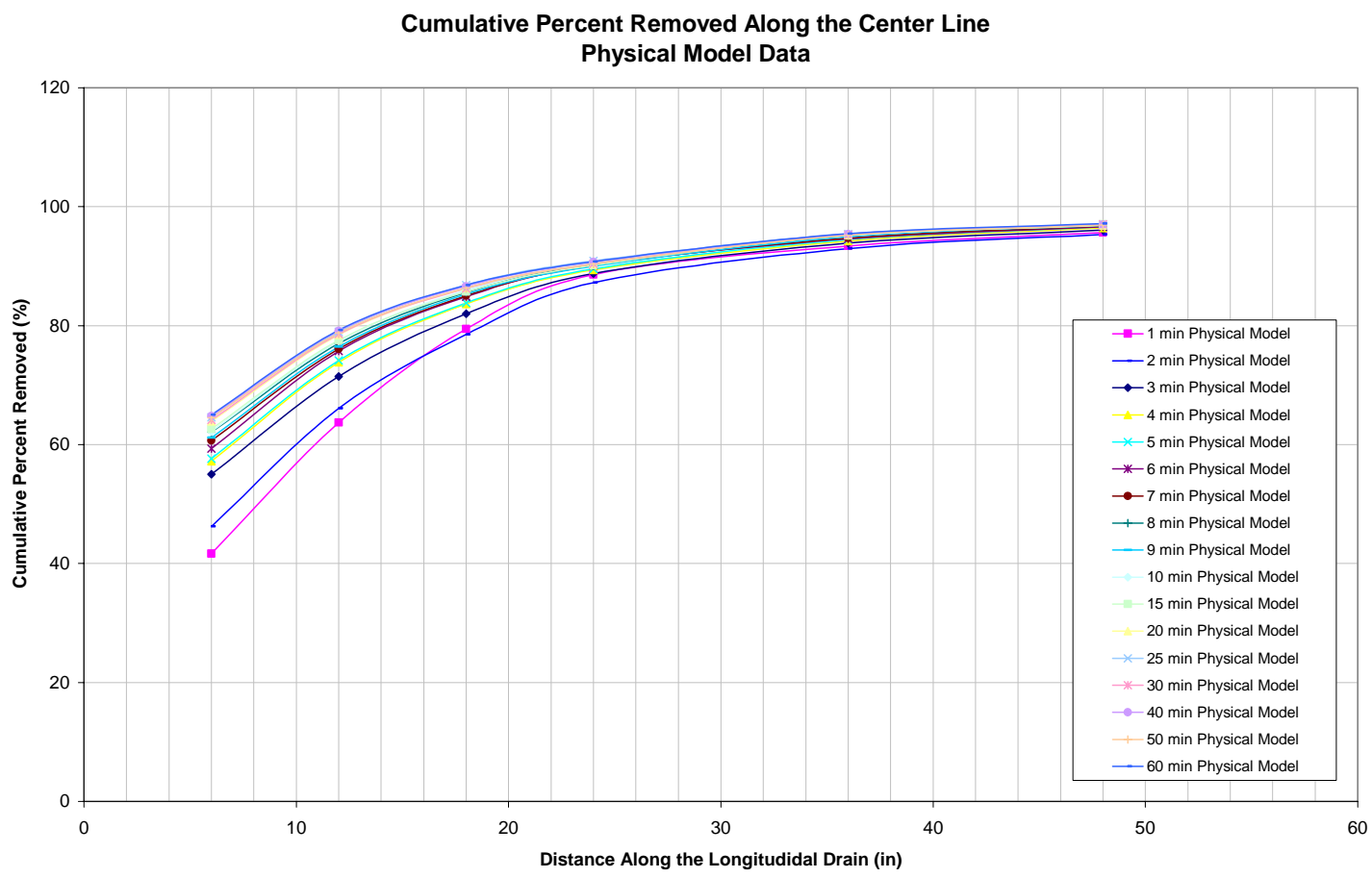

Figure A6.2: Cumulative Percent Removed along the Drain for Soil Type B - Physical Model 


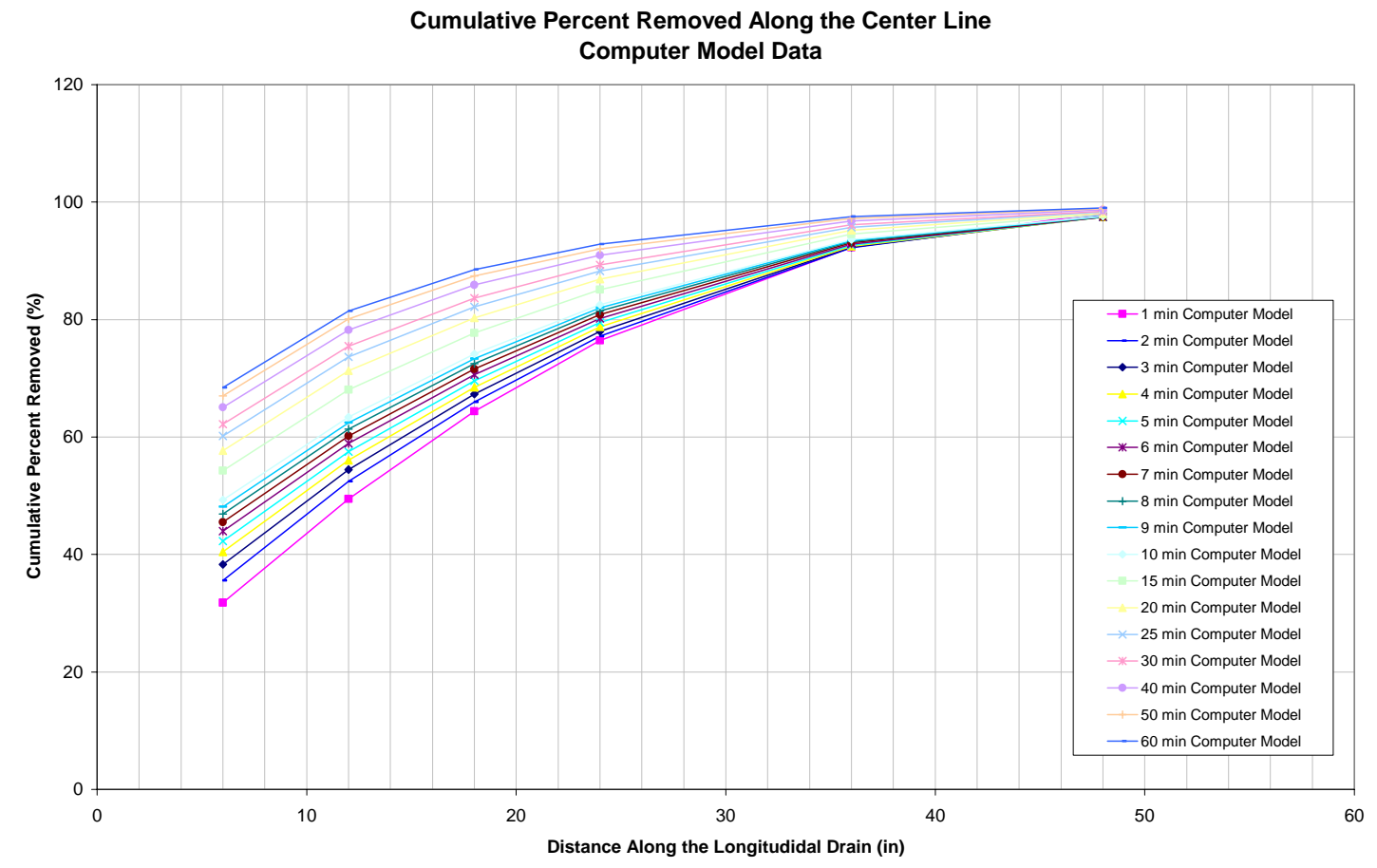

Figure A6.3: Cumulative Percent Removed along the Drain for Soil Type C - Computer Model

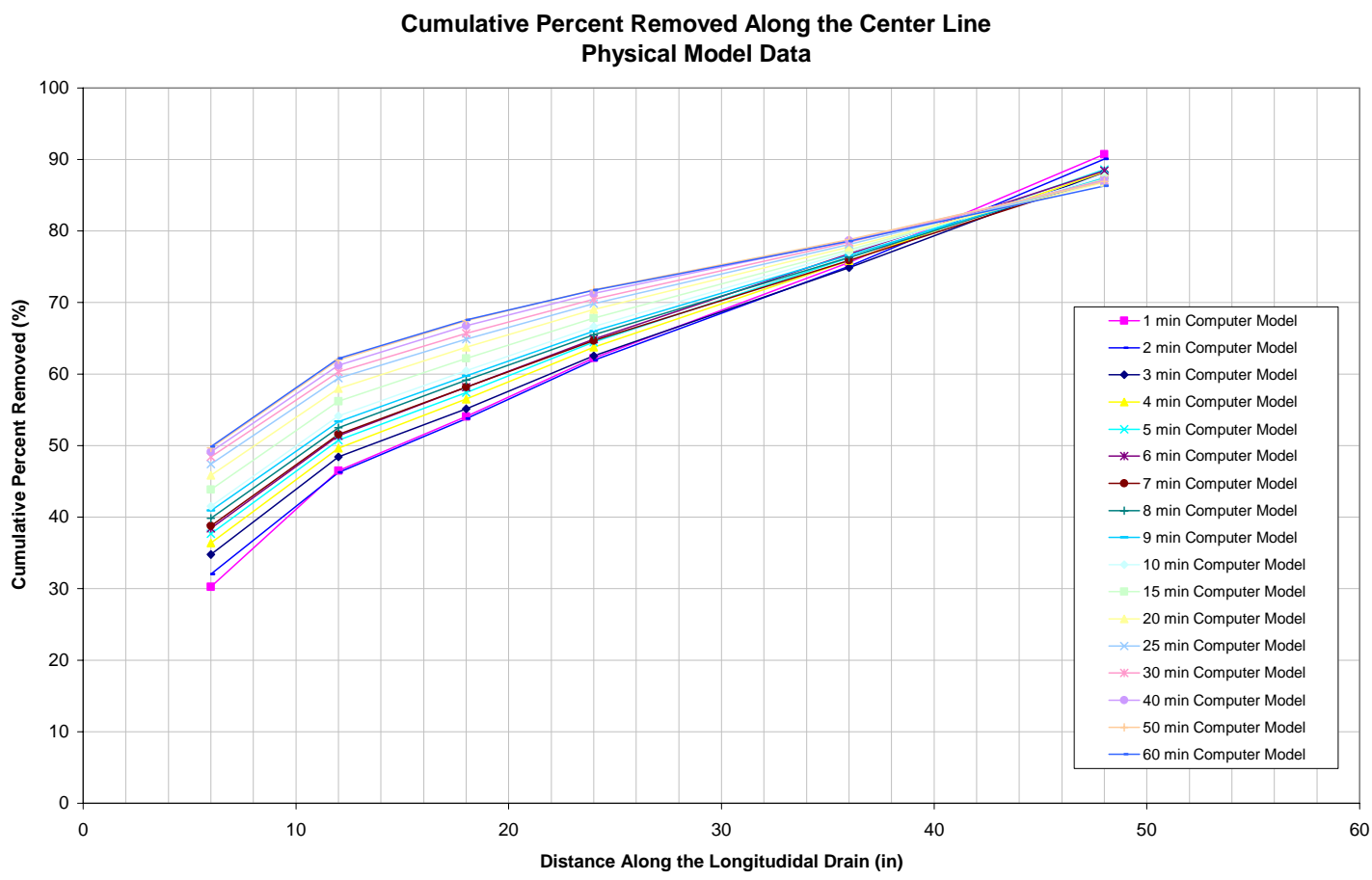

Figure A6.4: Cumulative Percent Removed along the Drain for Soil Type C - Physical Model 


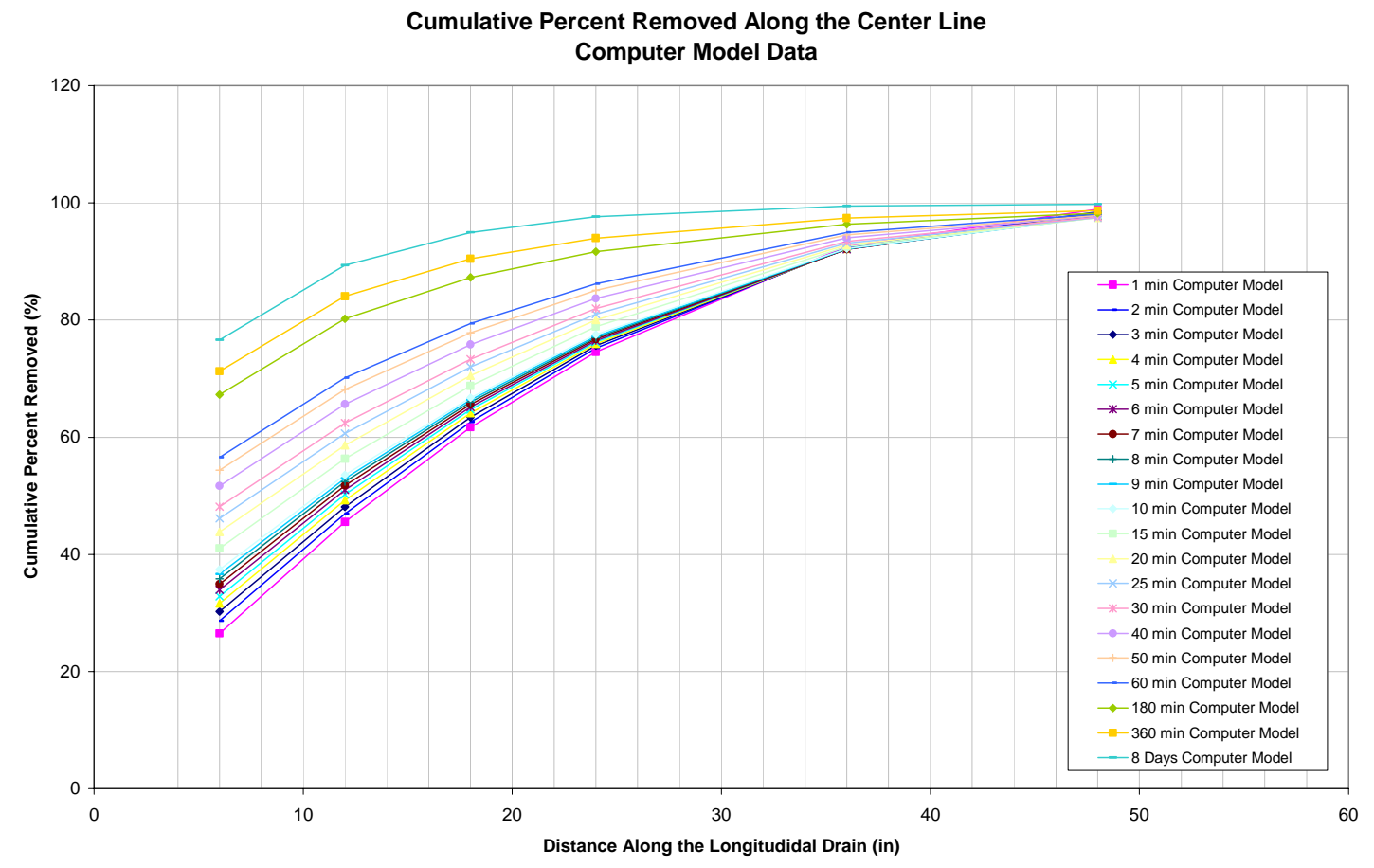

Figure A6.5: Cumulative Percent Removed along the Drain for Soil Type D - Computer Model

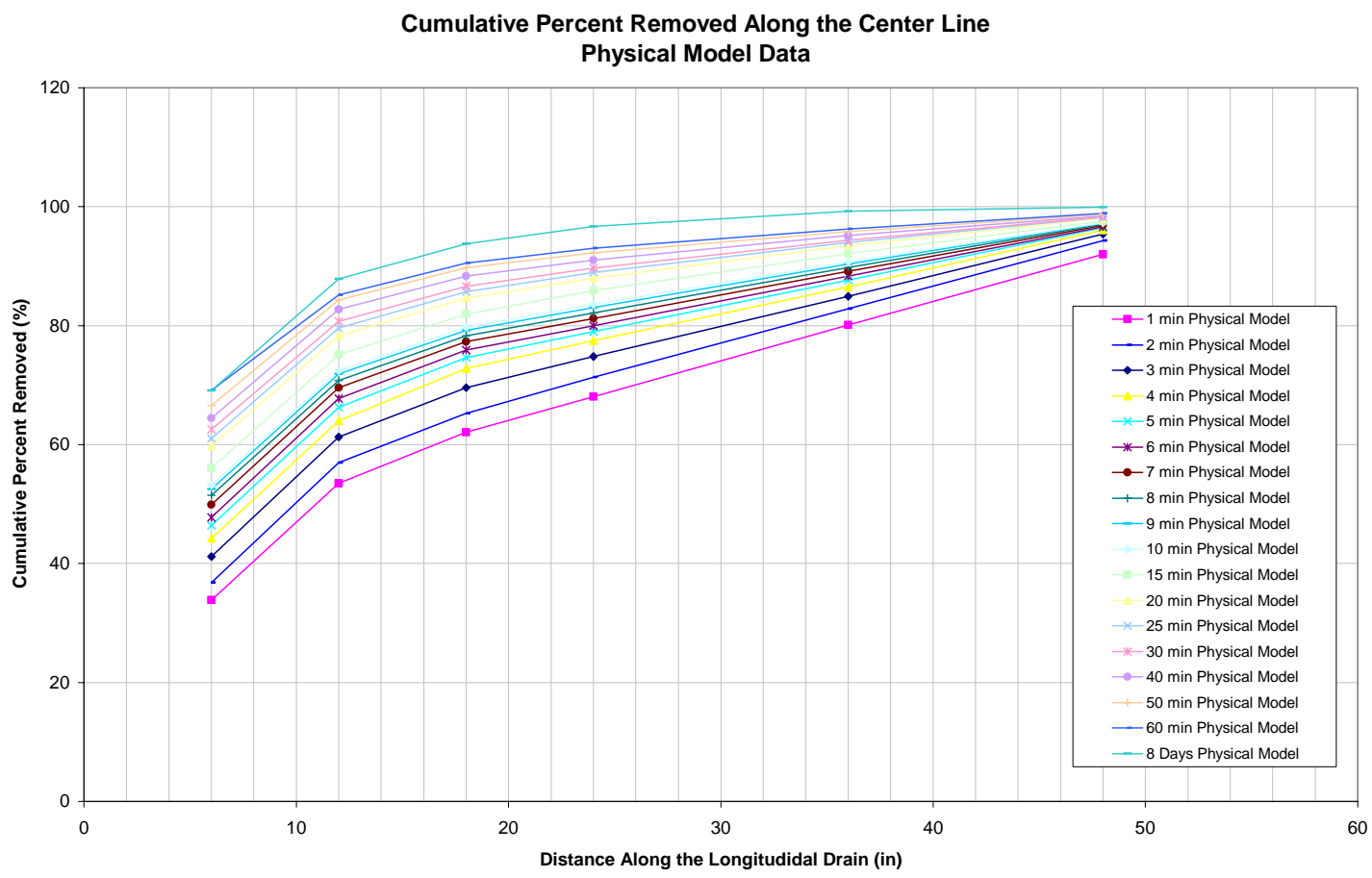

Figure A6.6: Cumulative Percent Removed along the Drain for Soil Type D - Physical Model 


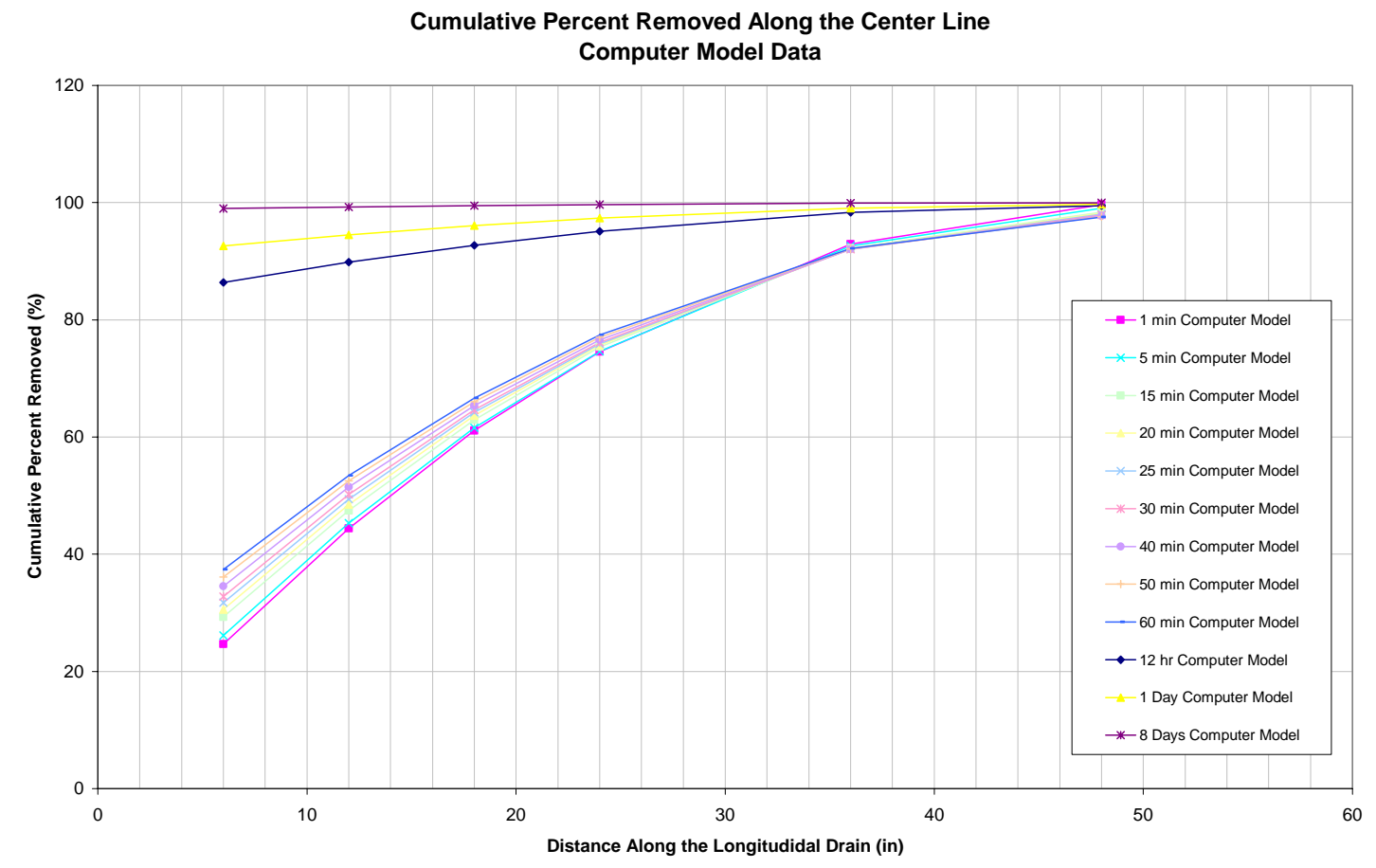

Figure A6.7: Cumulative Percent Removed along the Drain for Soil Type E - Computer Model

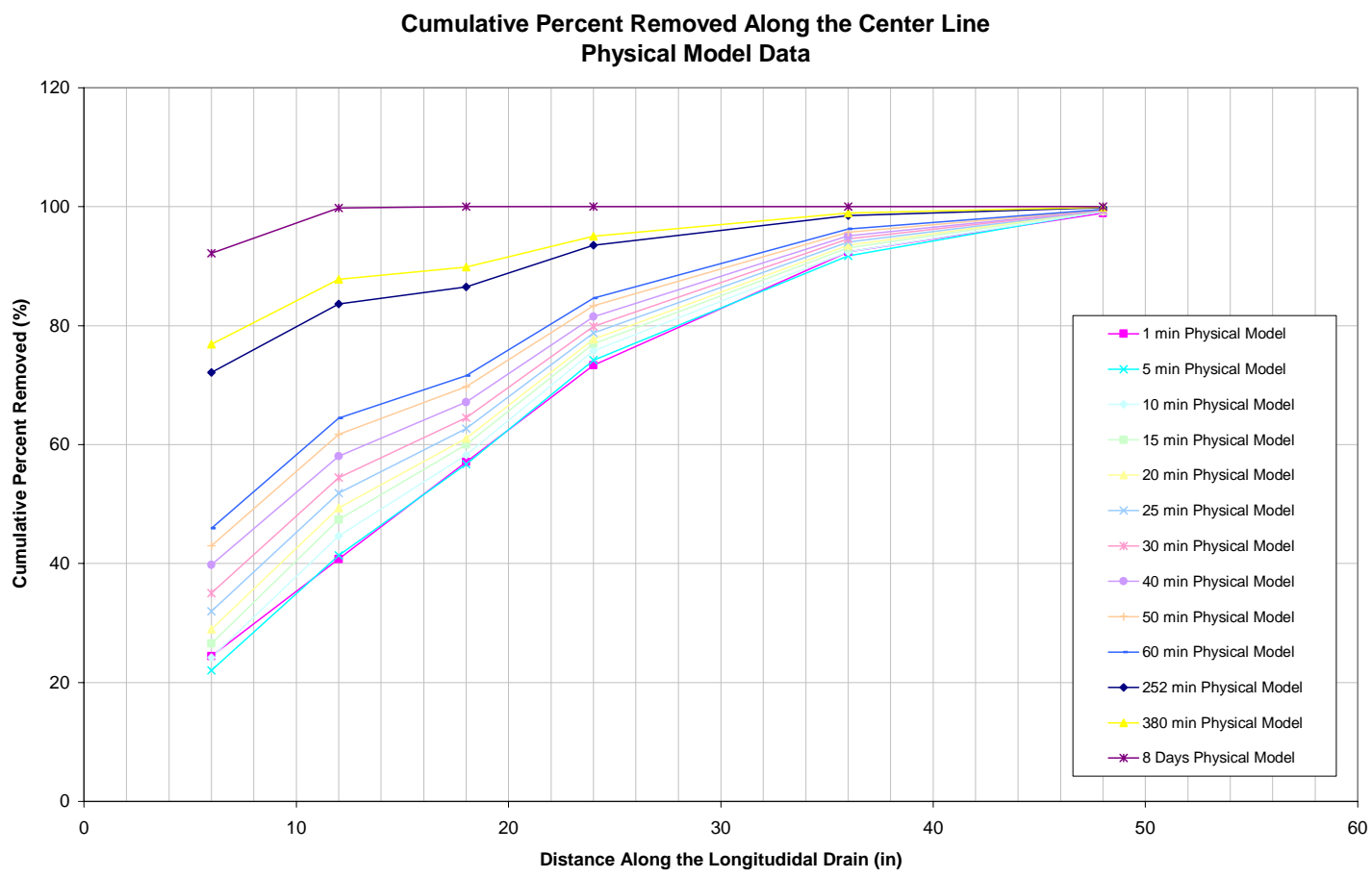

Figure A6.8: Cumulative Percent Removed along the Drain for Soil Type E - Physical Model 


\section{Appendix A7: Soil A Field Model}


Cumulative Percent Removed Along the Longitudinal Drain

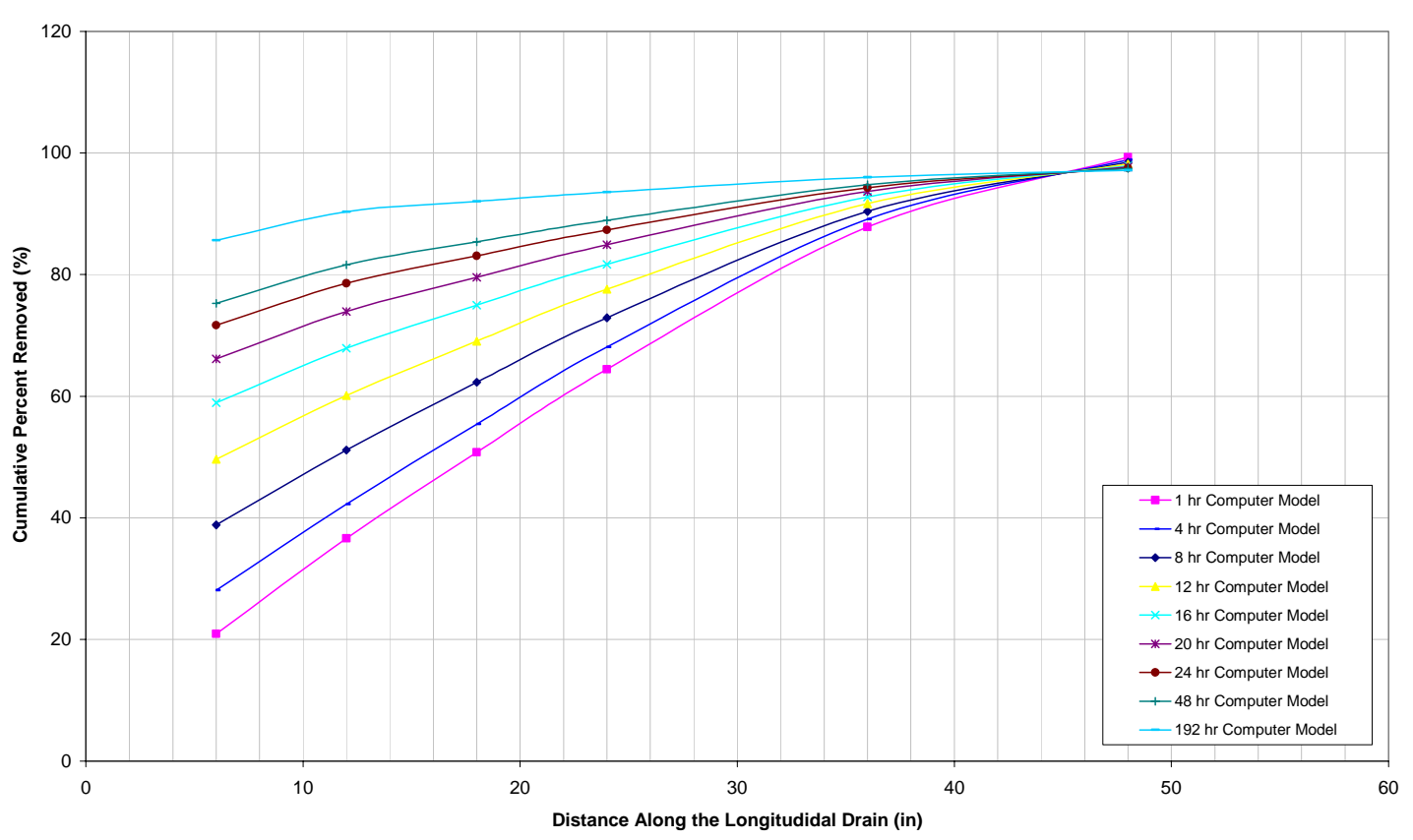

Figure A7.1: Cumulative Percent Removal for case A-6-96-10

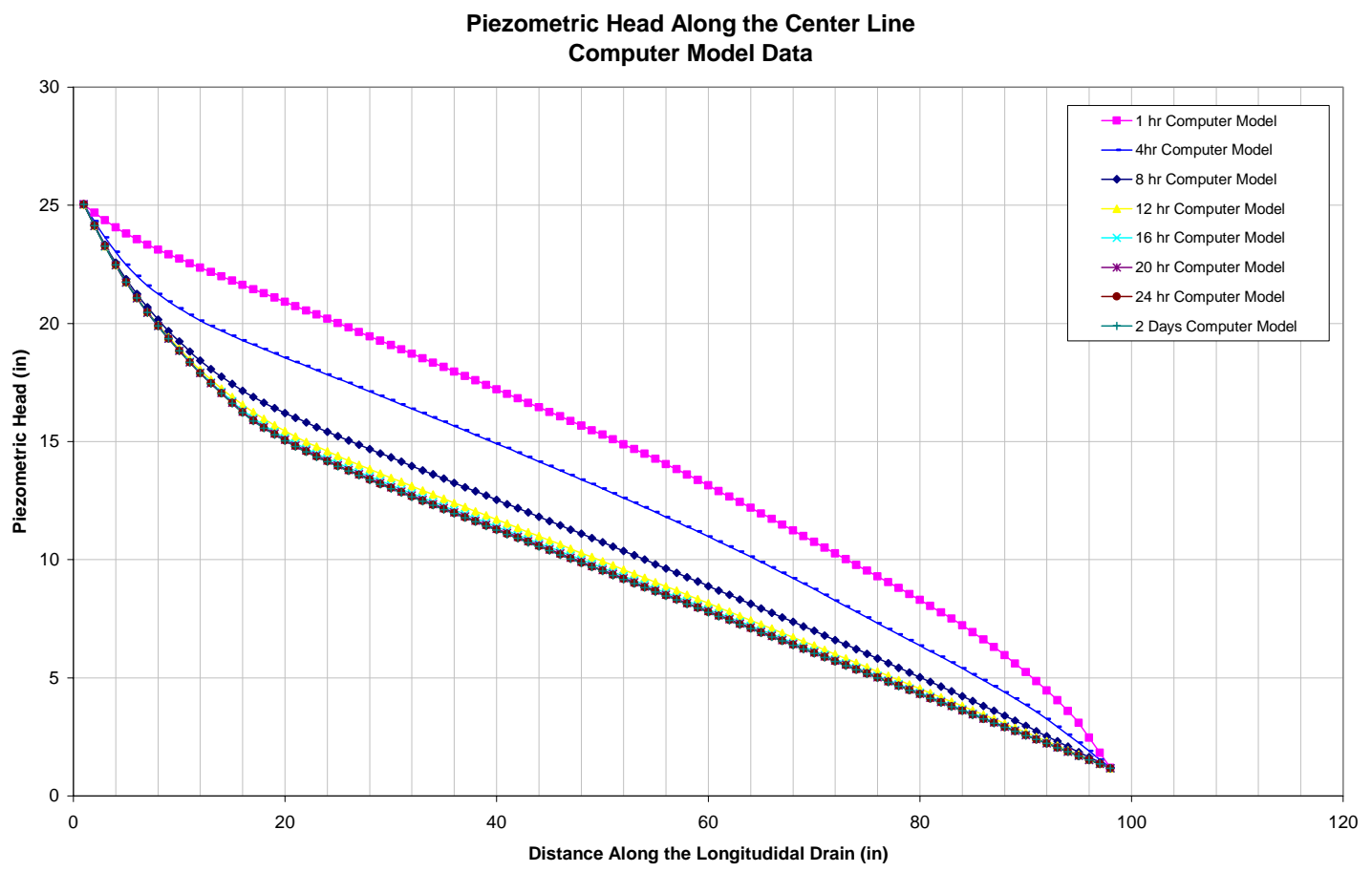

Figure A7.2: Piezometric head along center line for case A-6-96-10 


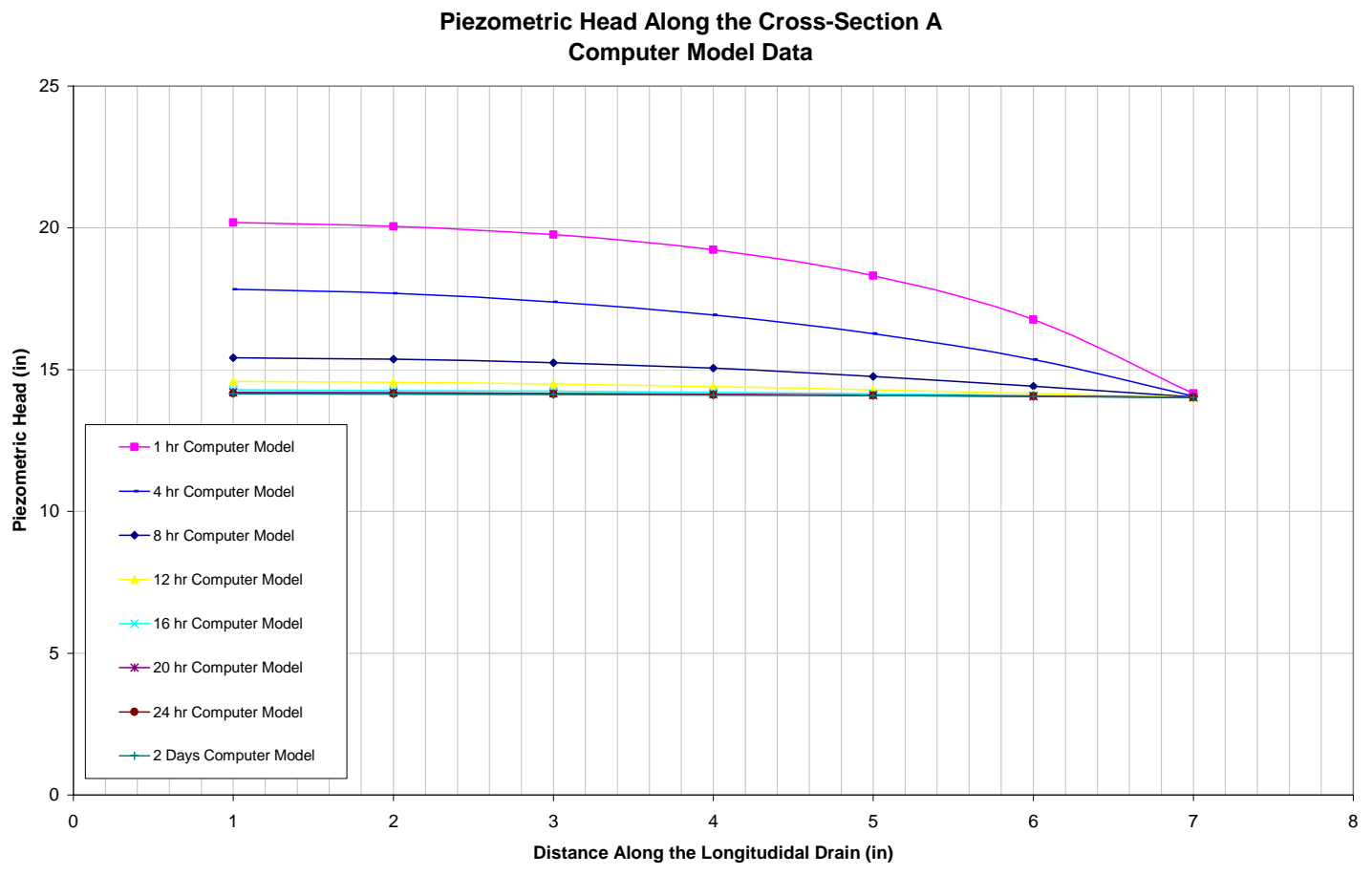

Figure A7.3: Piezometric head along cross-Section X for case A-6-96-10

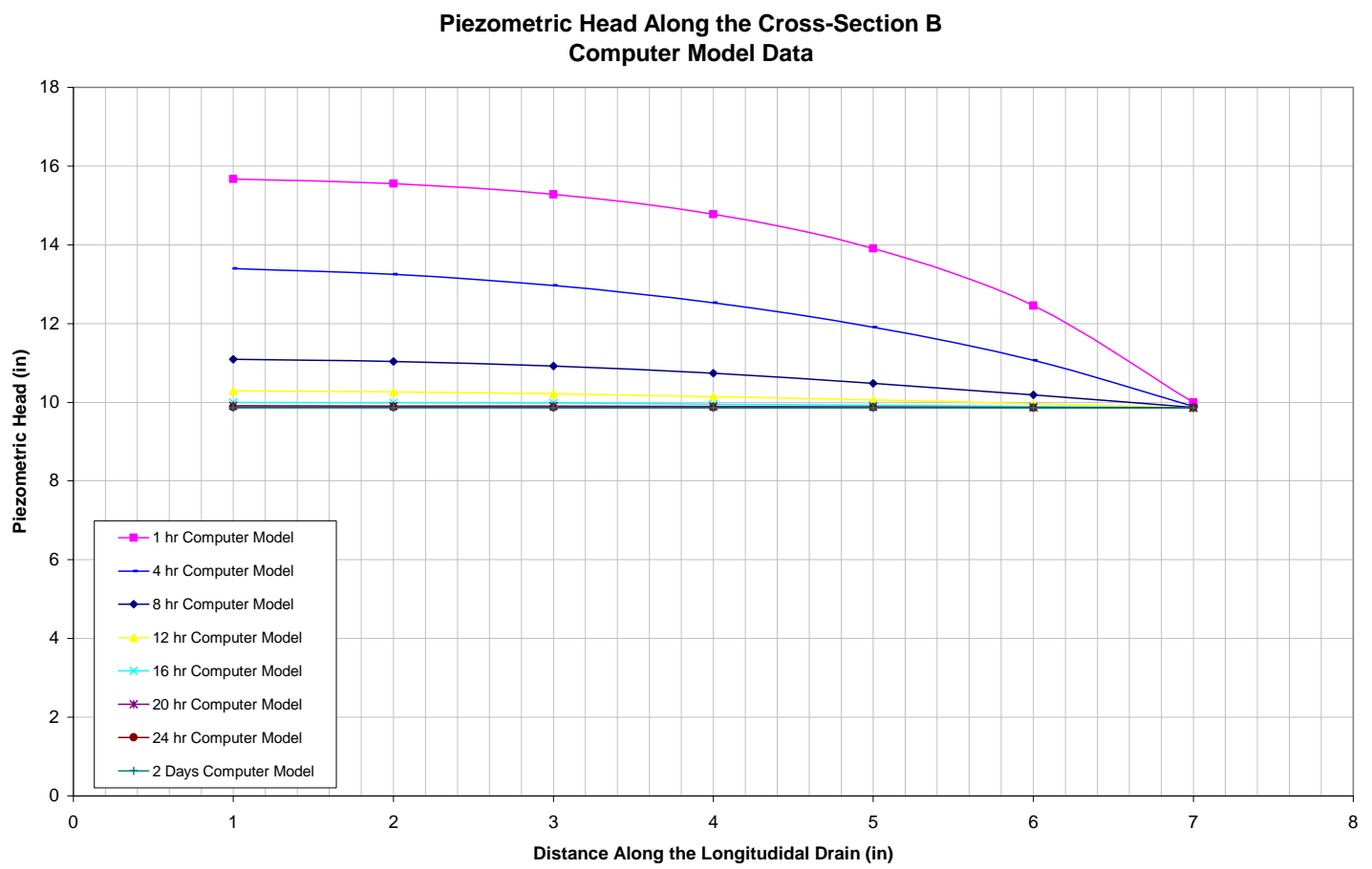

Figure A7.4: Piezometric head along cross-Section Y for case A-6-96-10 
Cumulative Percent Removed Along the Longitudinal Drain

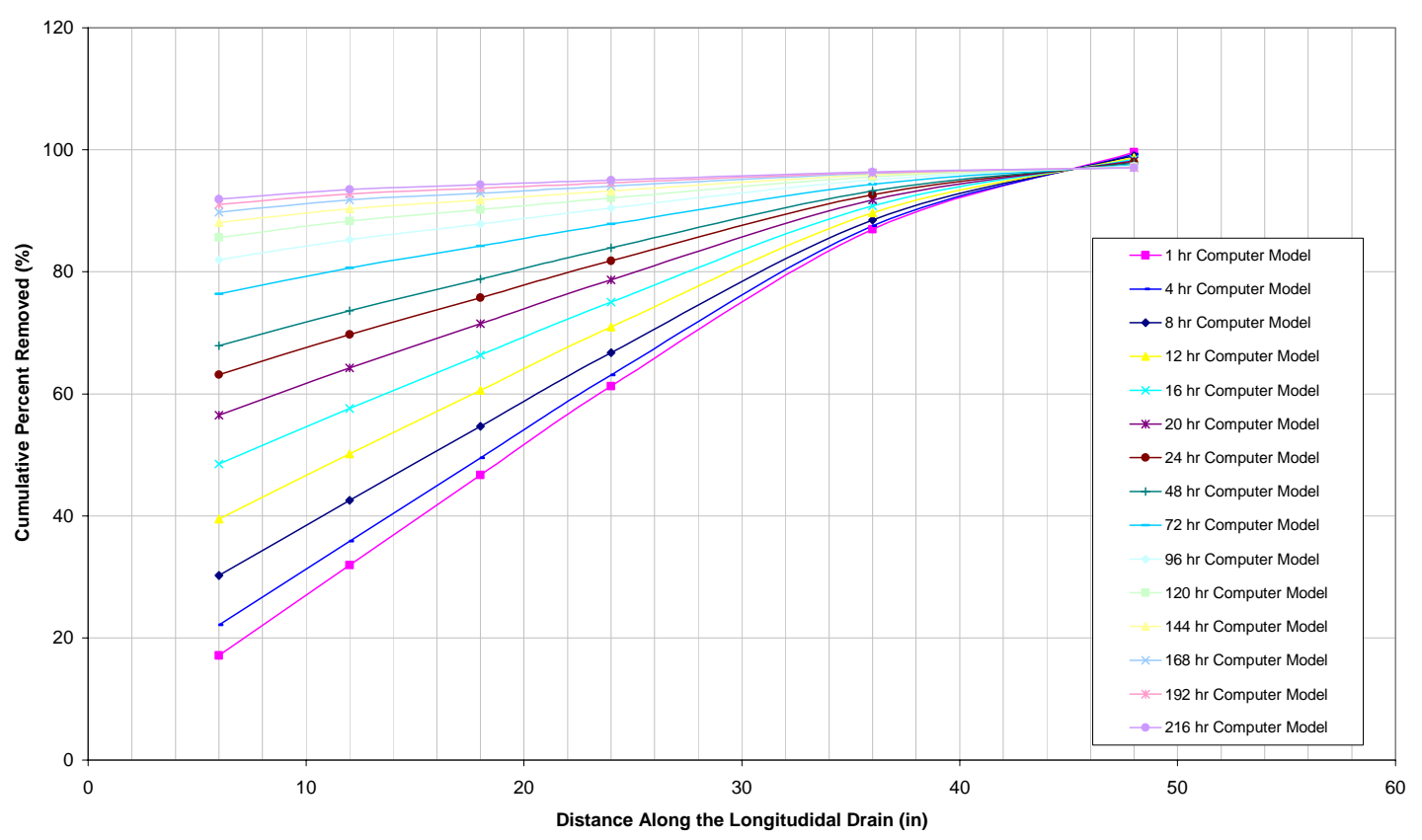

Figure A7.5: Cumulative Percent Removal for case A-6-144-10

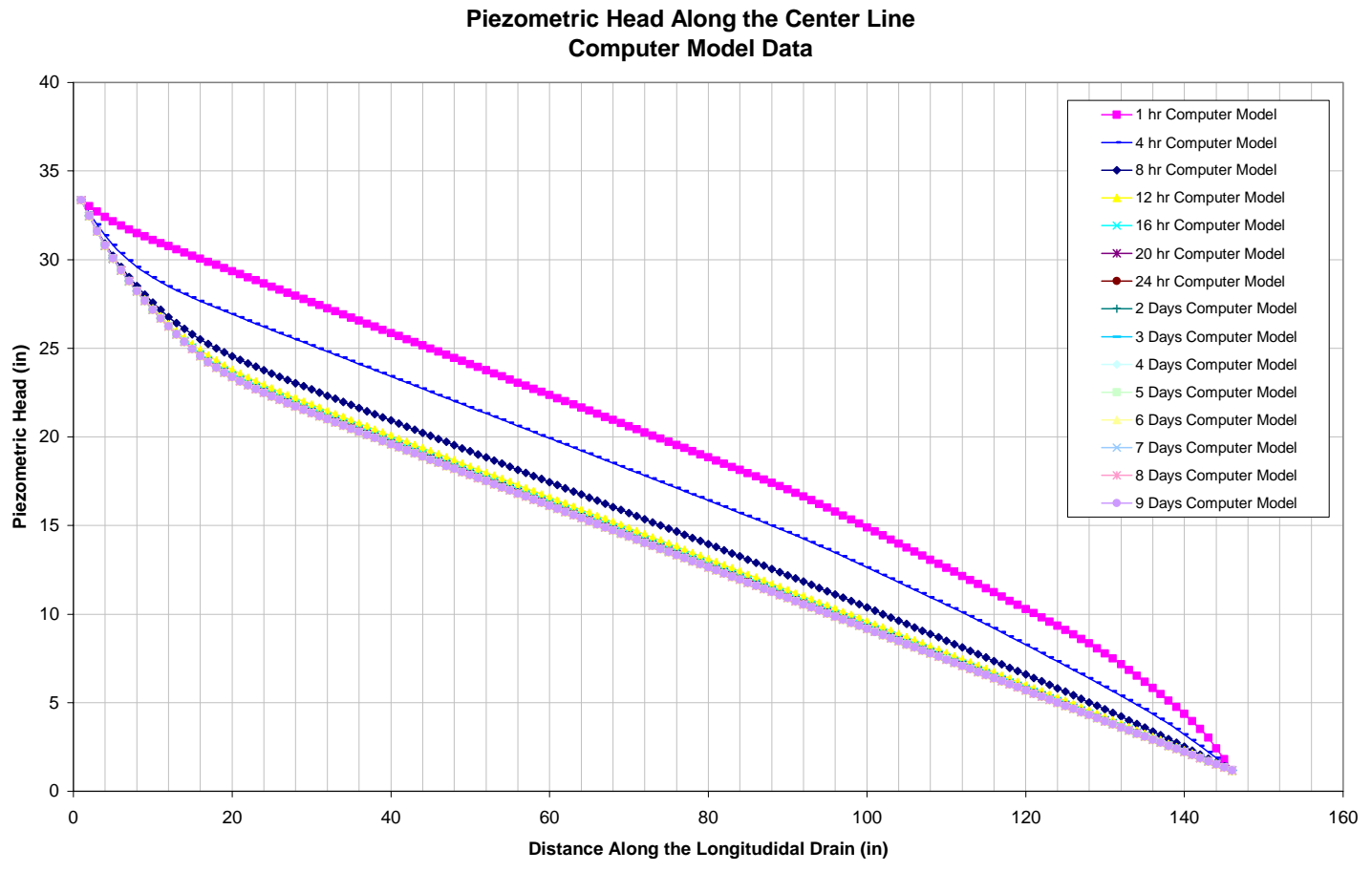

Figure A7.6: Piezometric head along center line for case A-6-144-10 


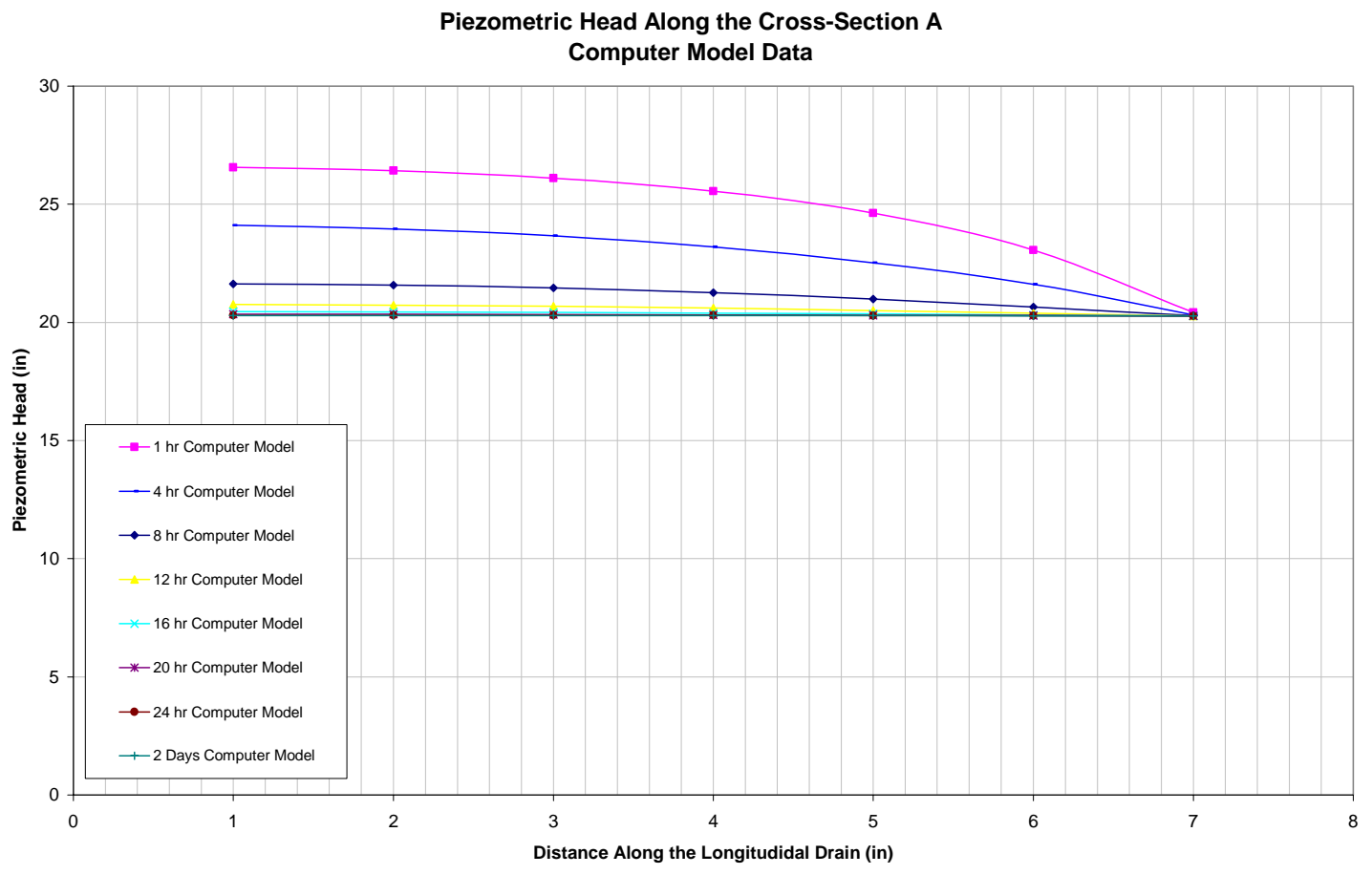

Figure A7.7: Piezometric head along cross-Section X for case A-6-144-10

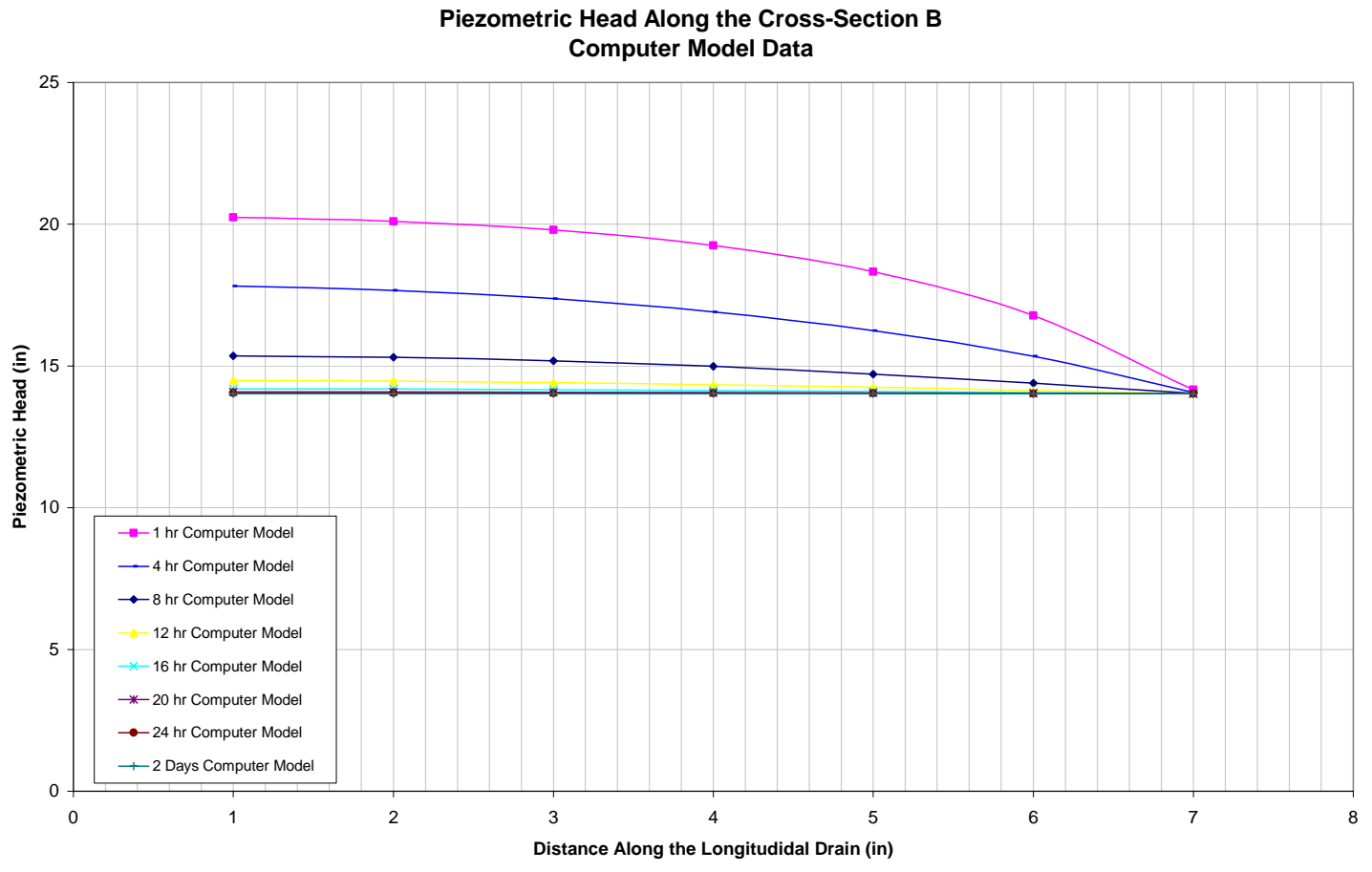

Figure A7.8: Piezometric head along cross-Section Y for case A-6-144-10 
Cumulative Percent Removed Along the Longitudinal Drain

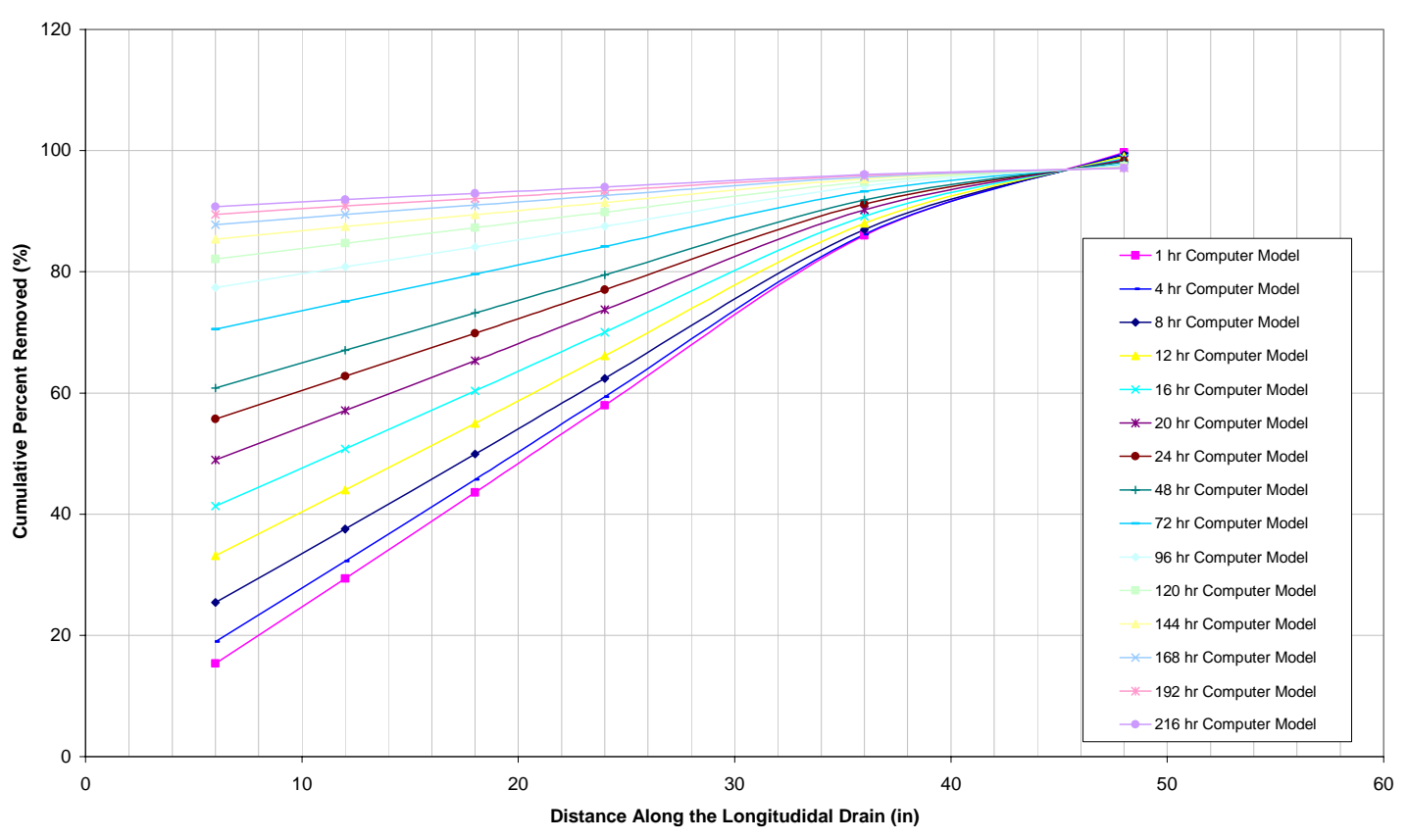

Figure A7.9: Cumulative Percent Removal for case A-6-144-10

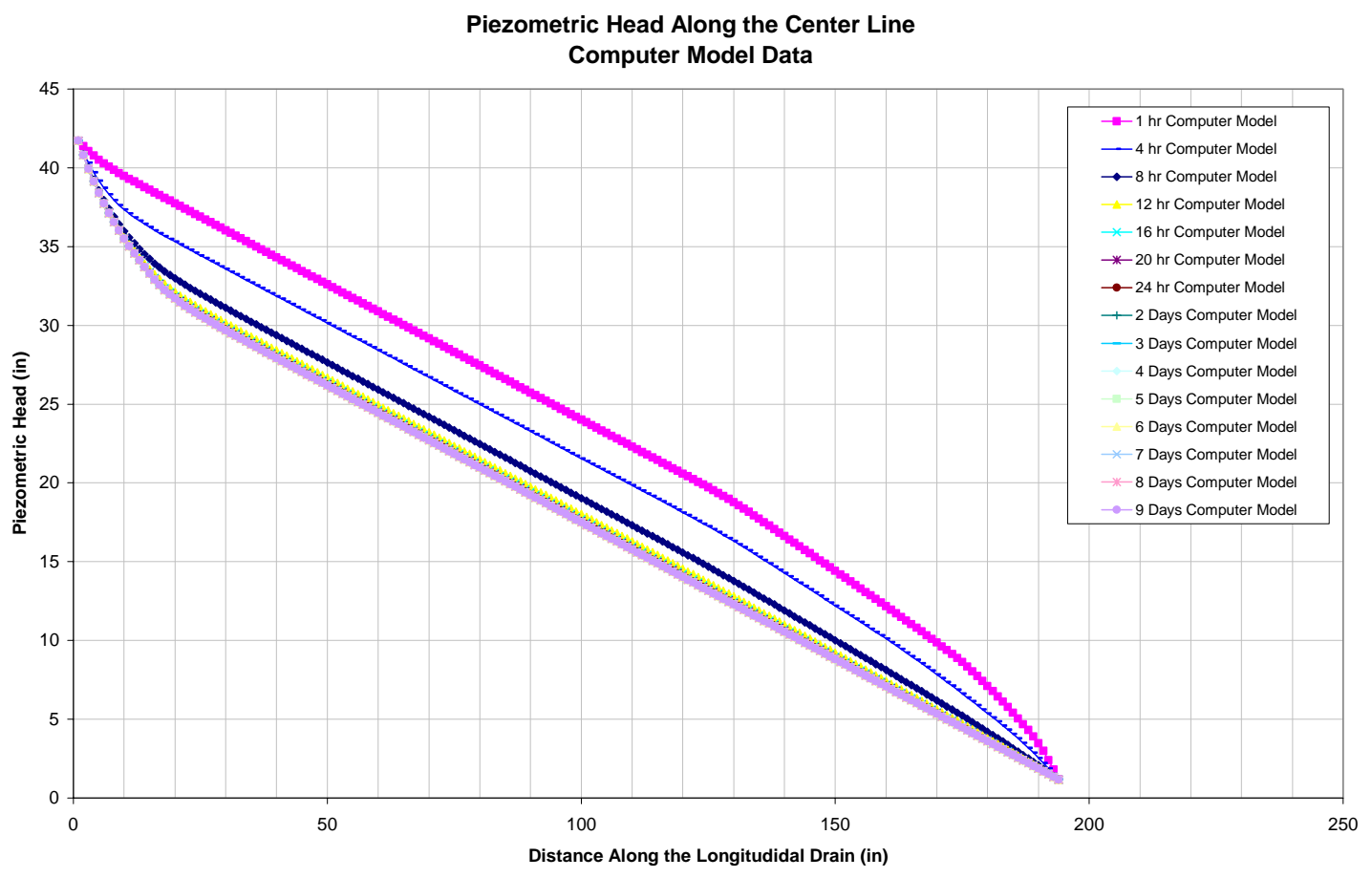

Figure A7.10: Piezometric head along center line for case A-6-144-10 


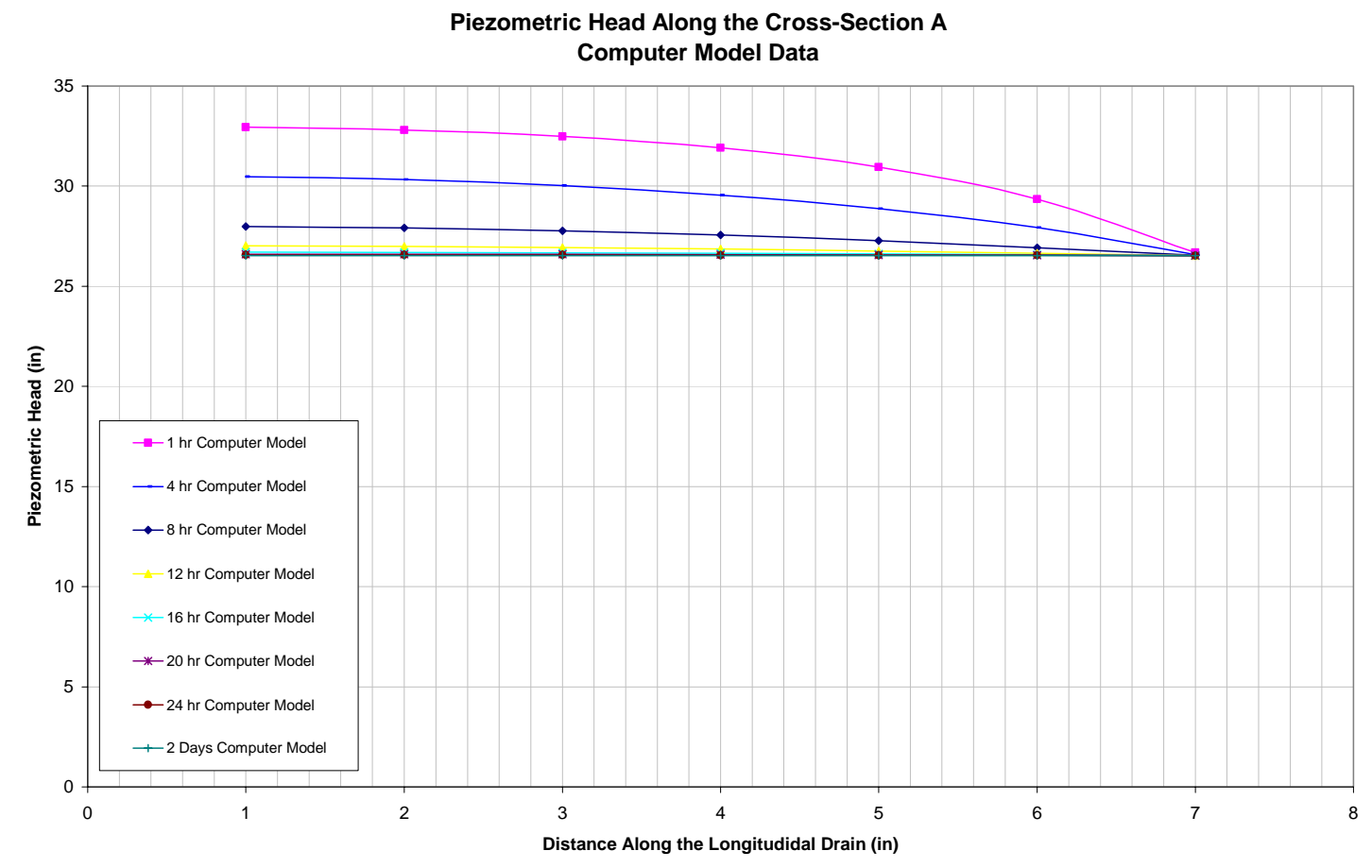

Figure A7.11: Piezometric head along cross-Section X for case A-6-144-10

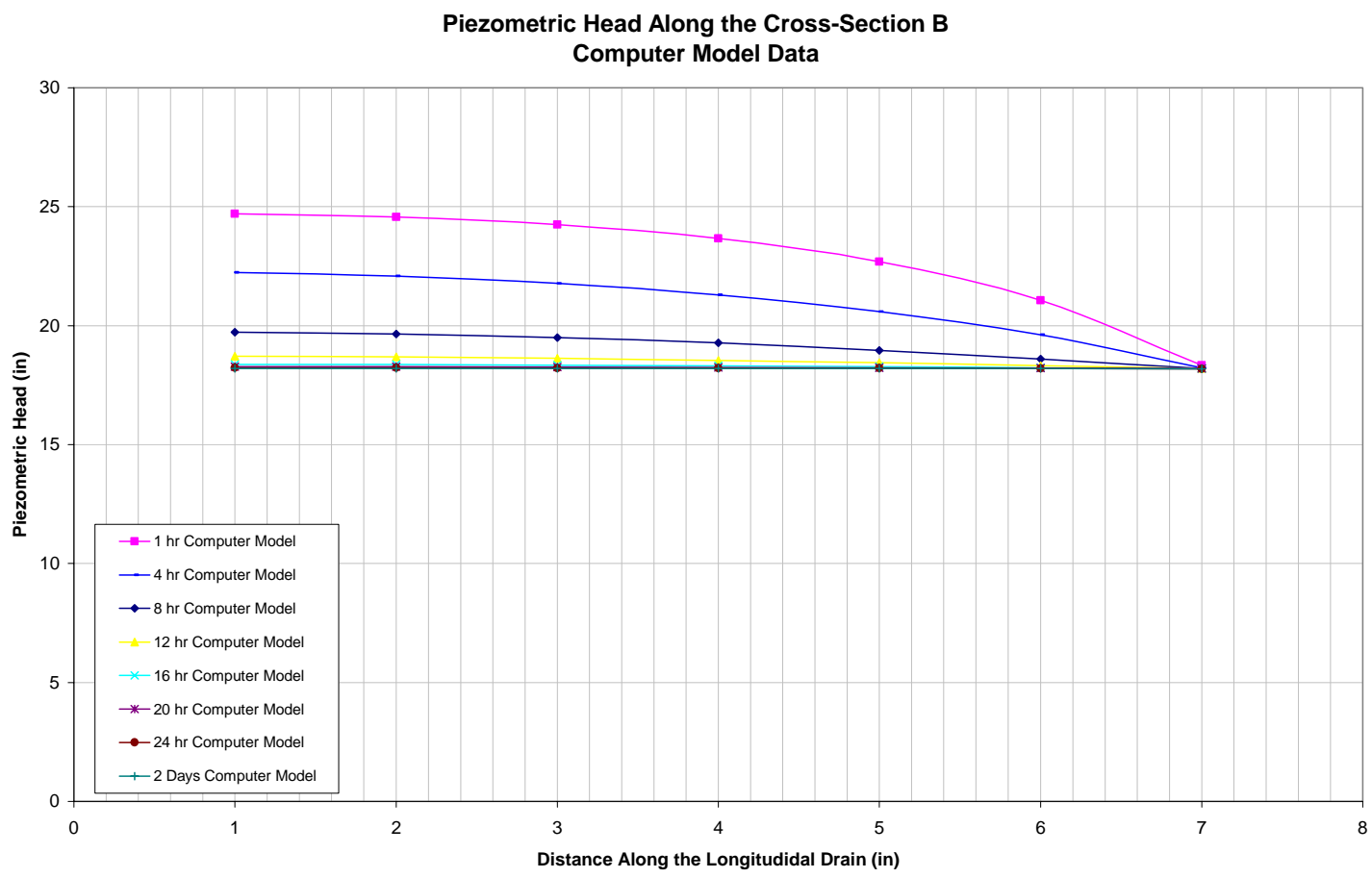

Figure A7.12: Piezometric head along cross-Section Y for case A-6-144-10 
Cumulative Percent Removed Along the Longitudinal Drain

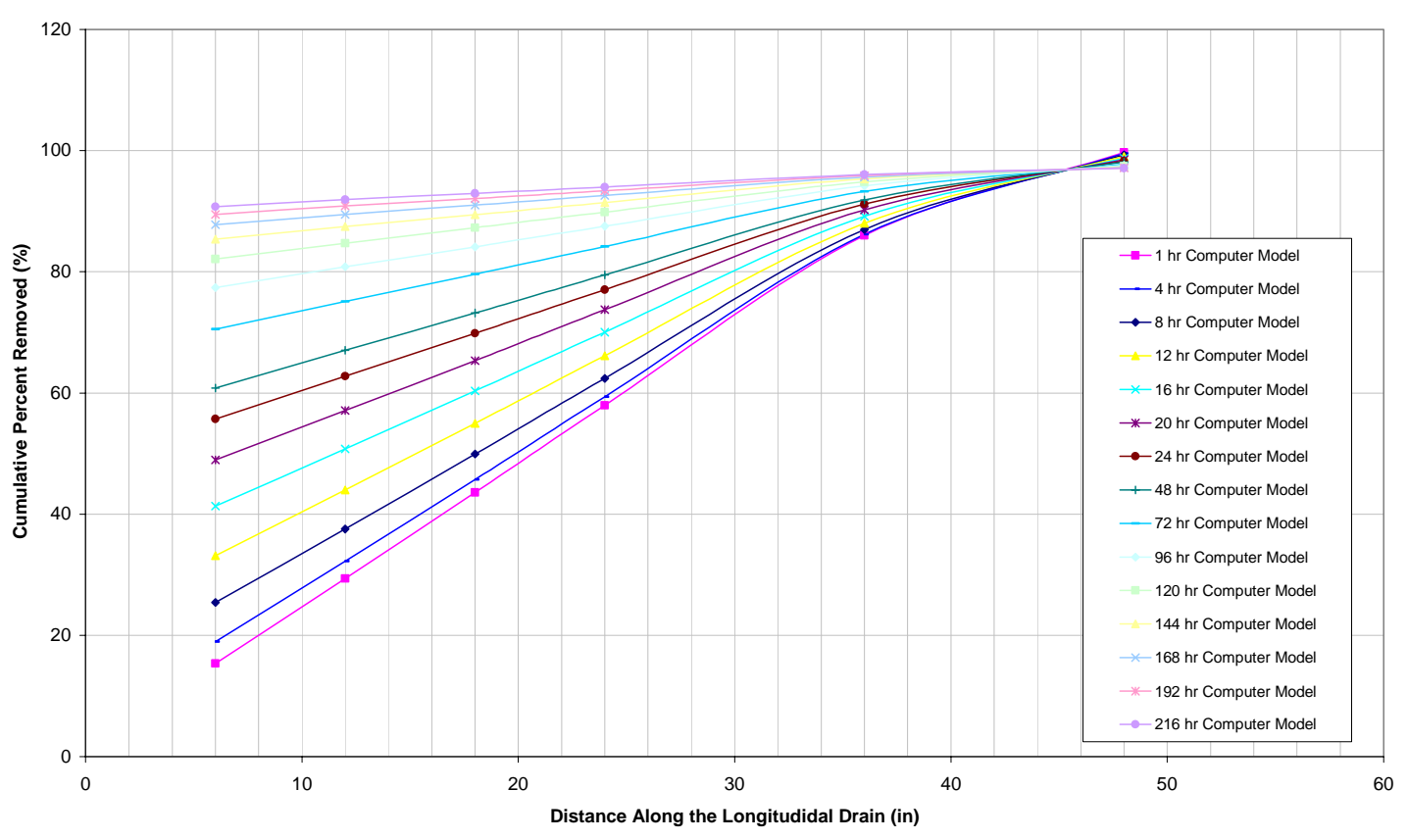

Figure A7.13: Cumulative Percent Removal for case A-6-192-10

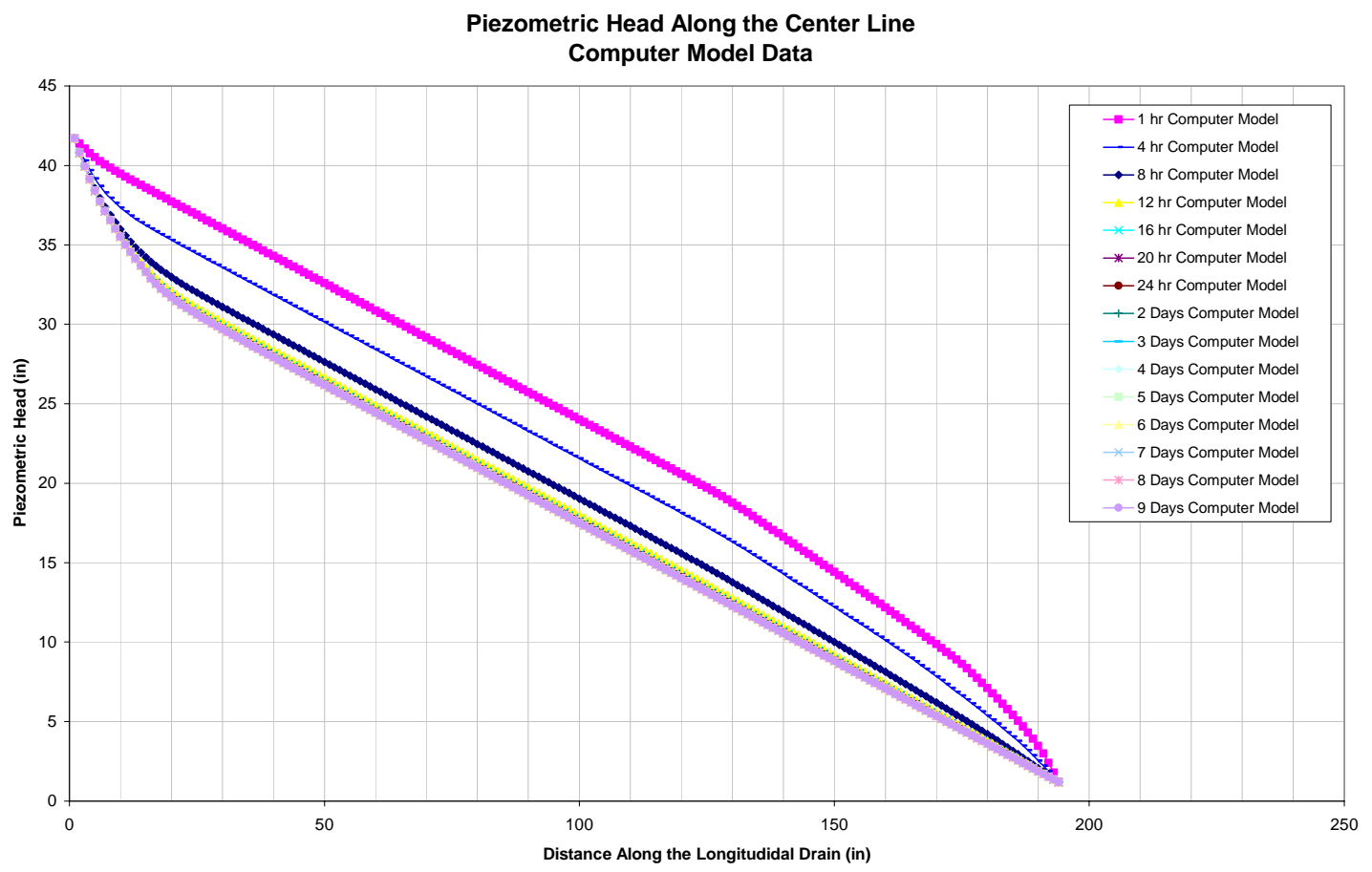

Figure A7.14: Piezometric head along center line for case A-6-192-10 


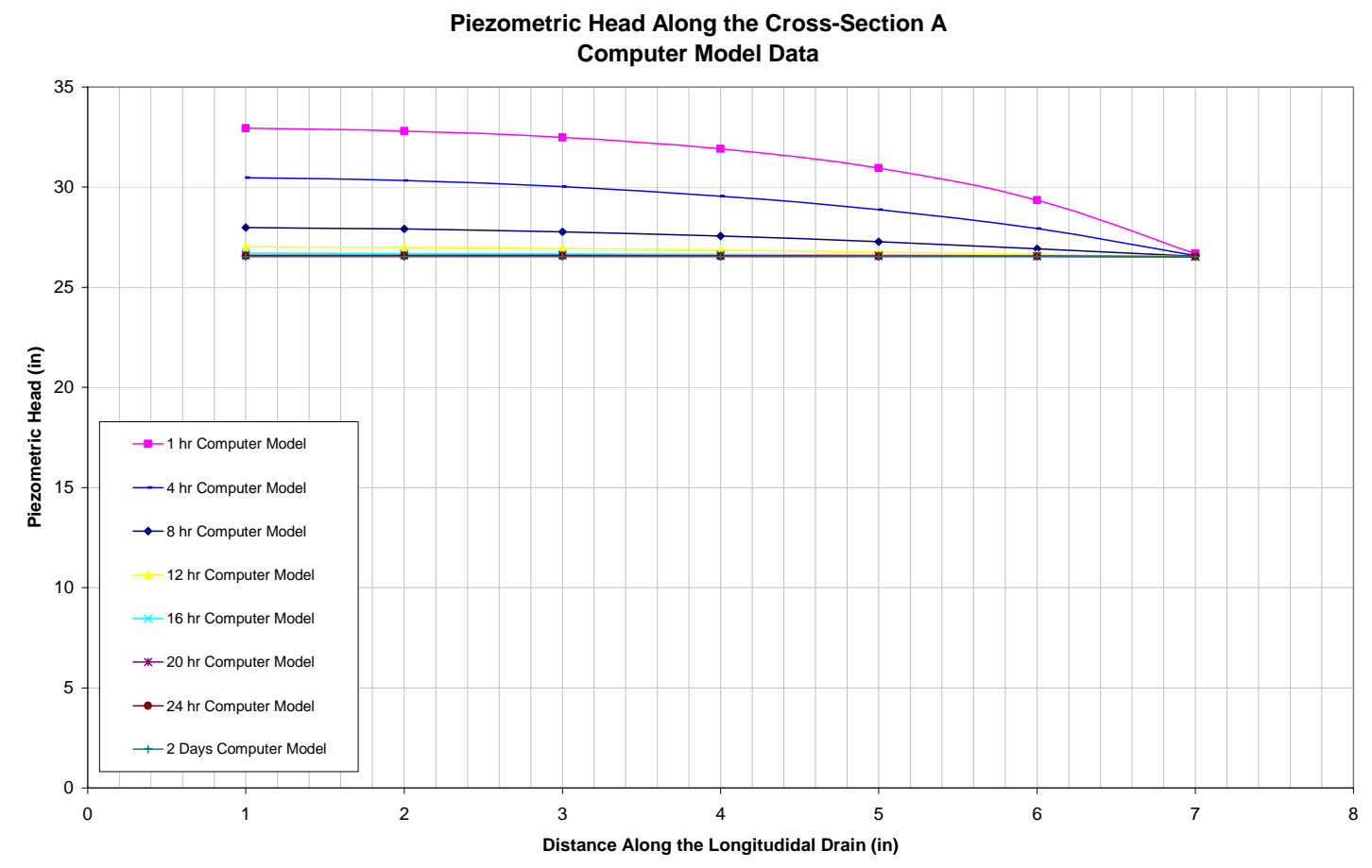

Figure A7.15: Piezometric head along cross-Section X for case A-6-192-10

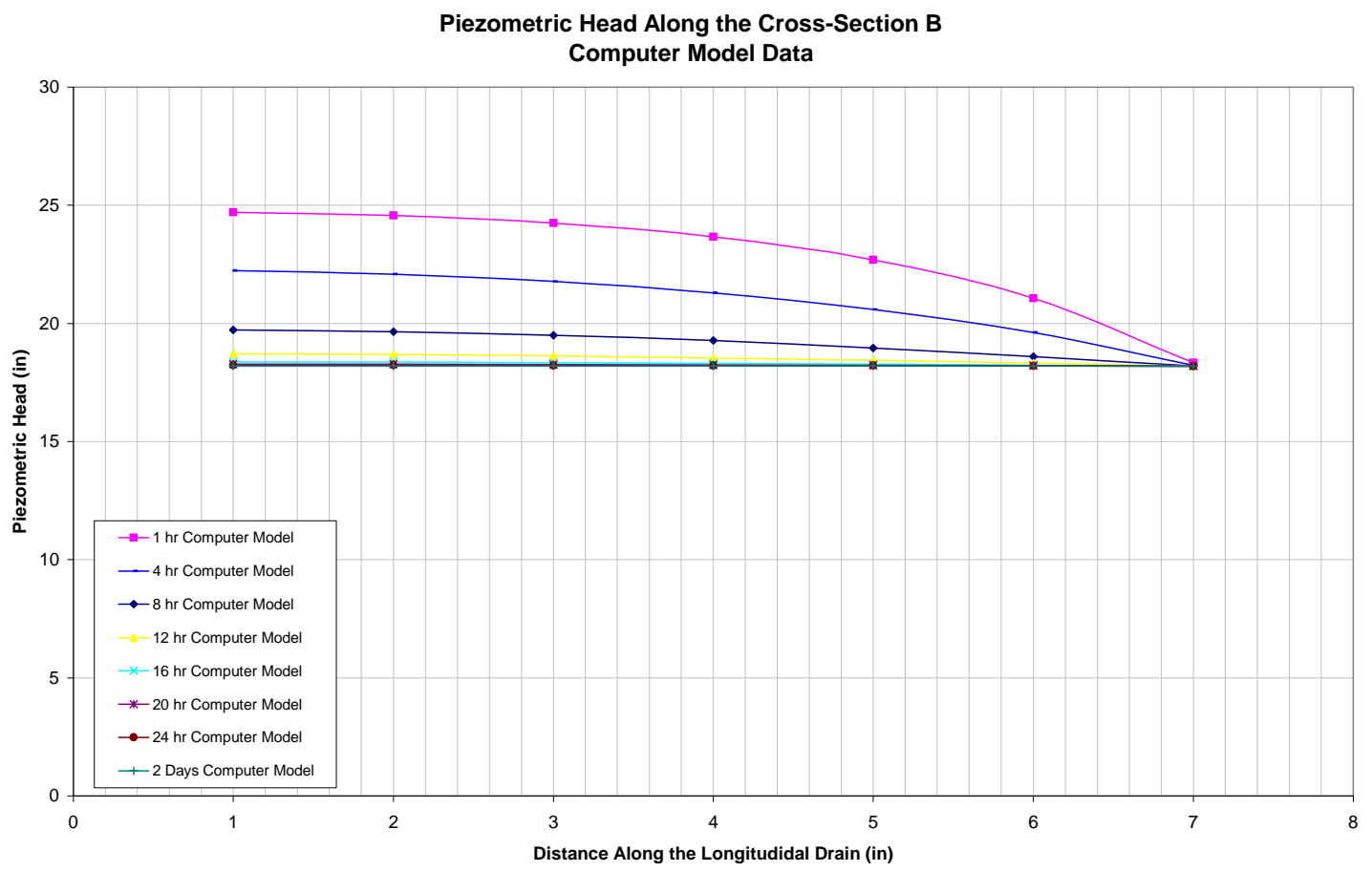

Figure A7.16: Piezometric head along cross-Section Y for case A-6-192-10 
Cumulative Percent Removed Along the Longitudinal Drain

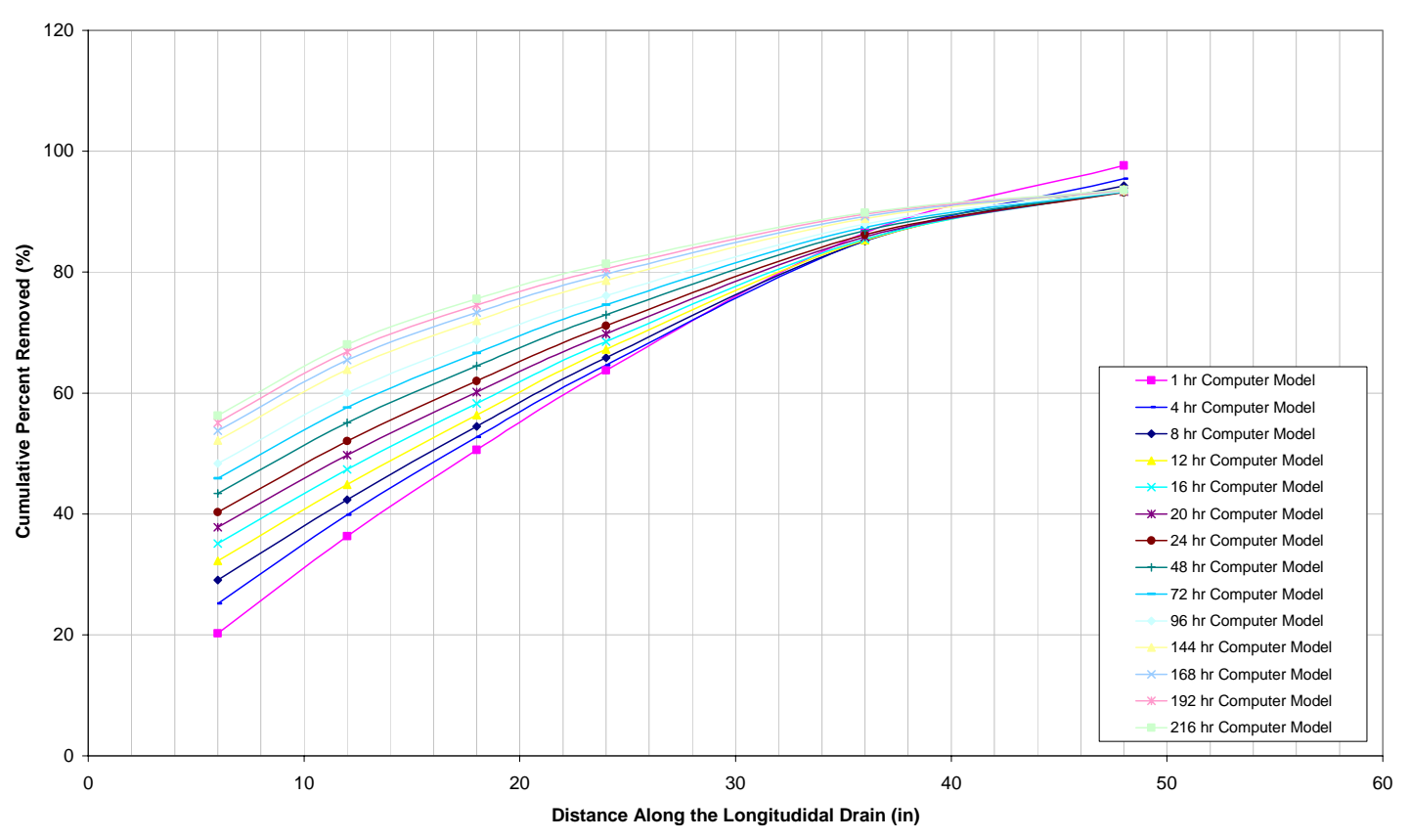

Figure A7.17: Cumulative Percent Removal for case A-18-96-10

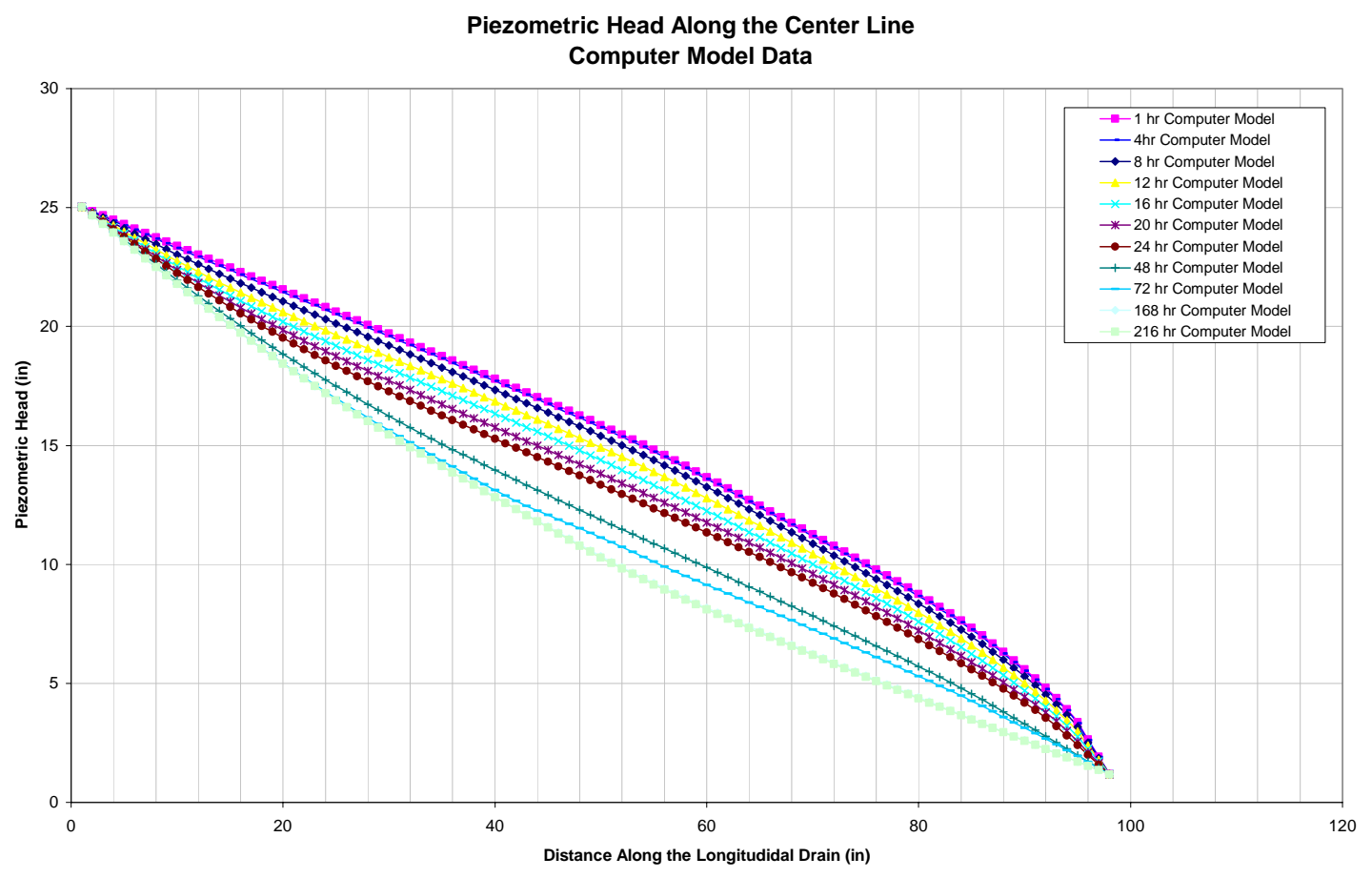

Figure A7.18: Piezometric head along center line for case A-18-96-10 


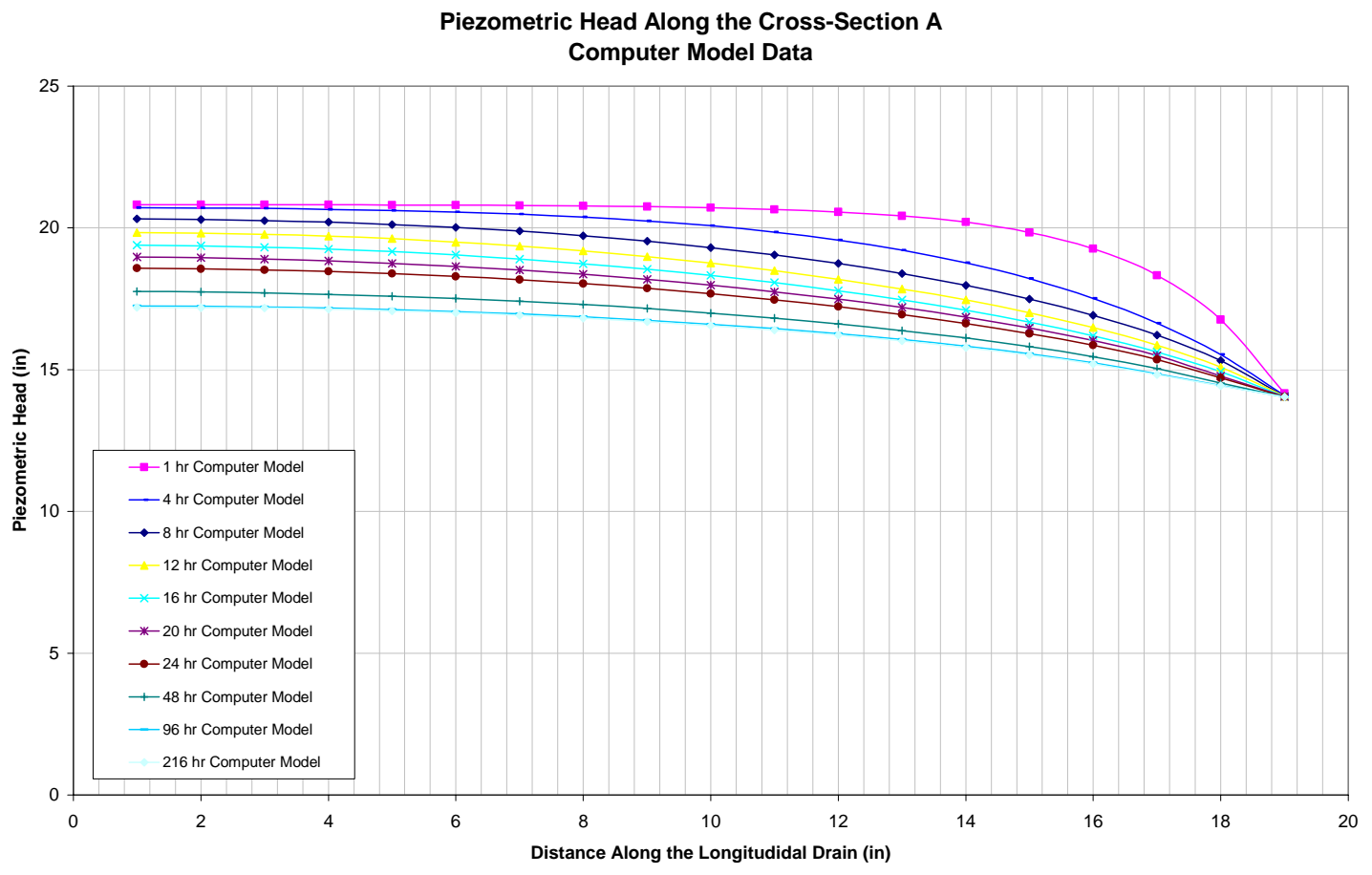

Figure A7.19: Piezometric head along cross-Section X for case A-18-96-10

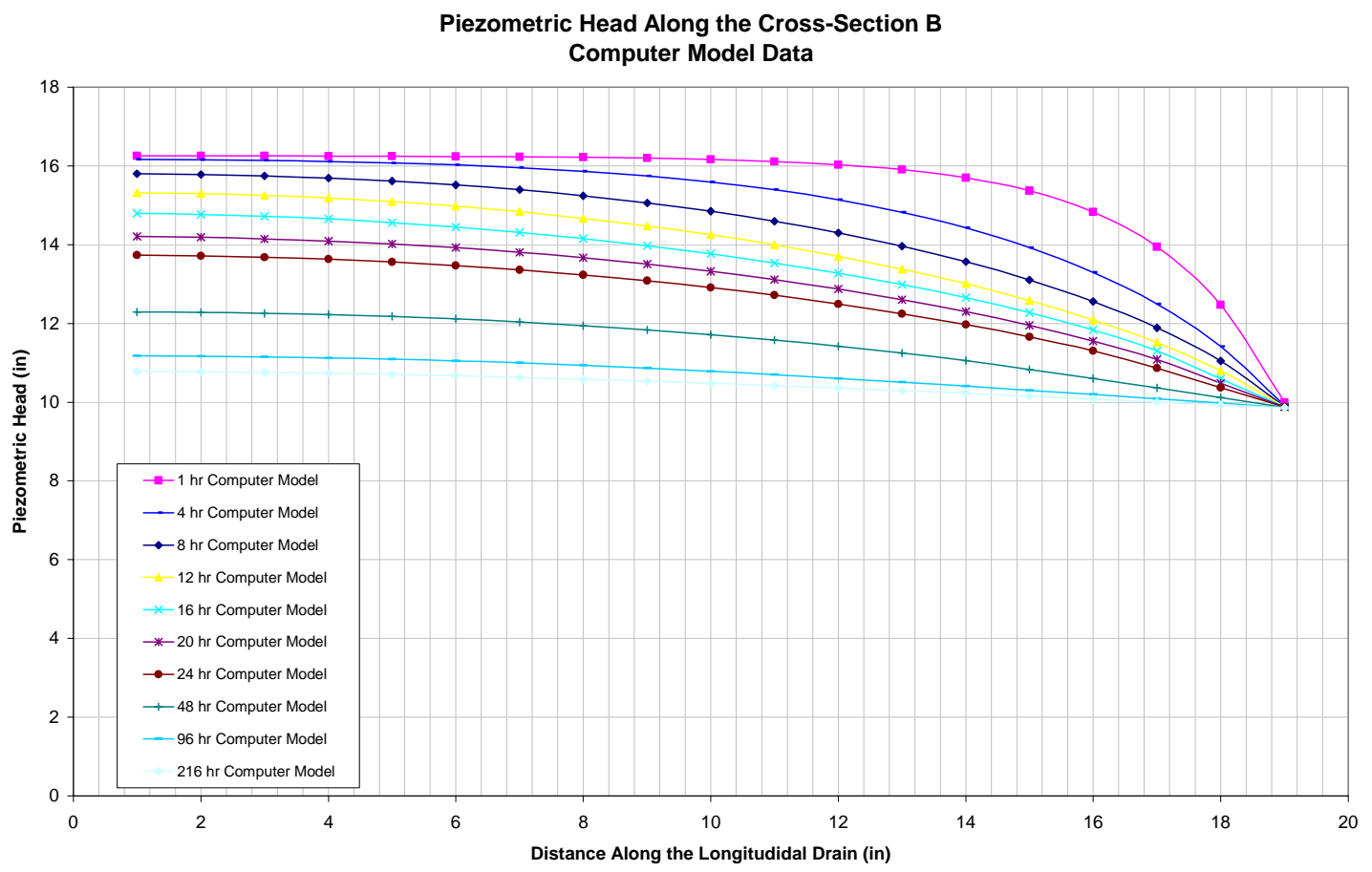

Figure A7.20: Piezometric head along cross-Section Y for case A-18-96-10 
Cumulative Percent Removed Along the Longitudinal Drain

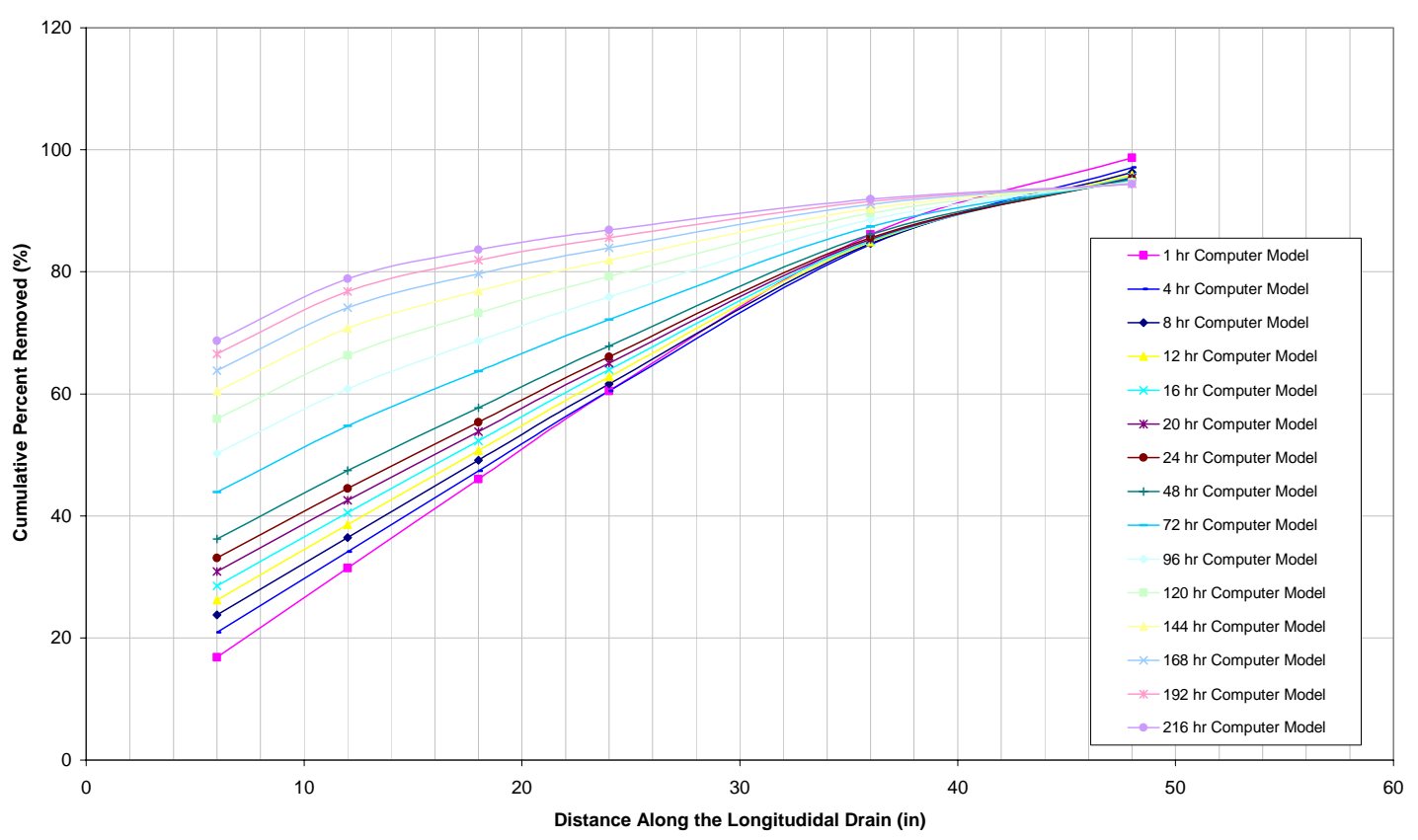

Figure A7.21: Cumulative Percent Removal for case A-18-144-10

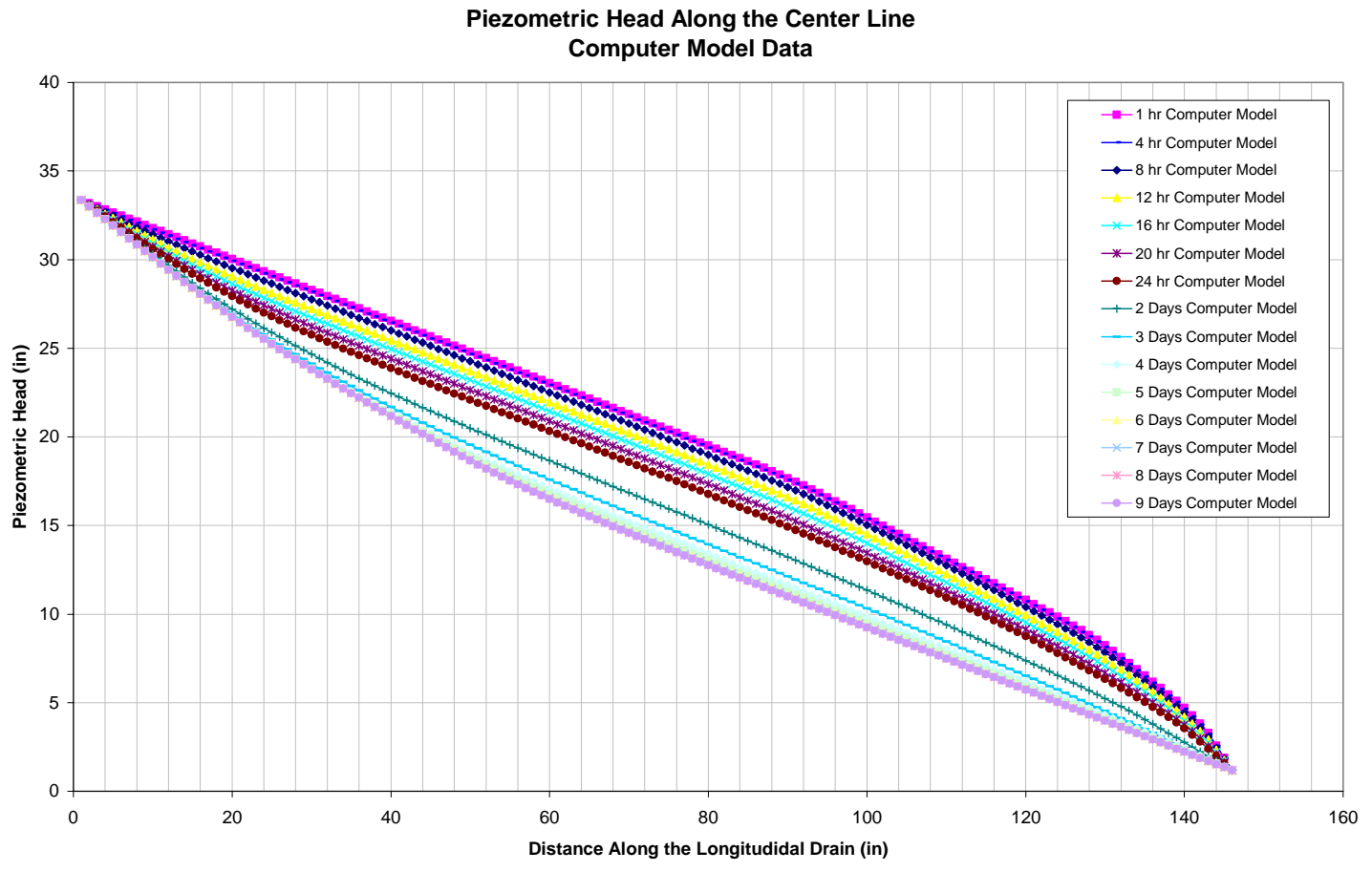

Figure A7.22: Piezometric head along center line for case A-18-144-10 


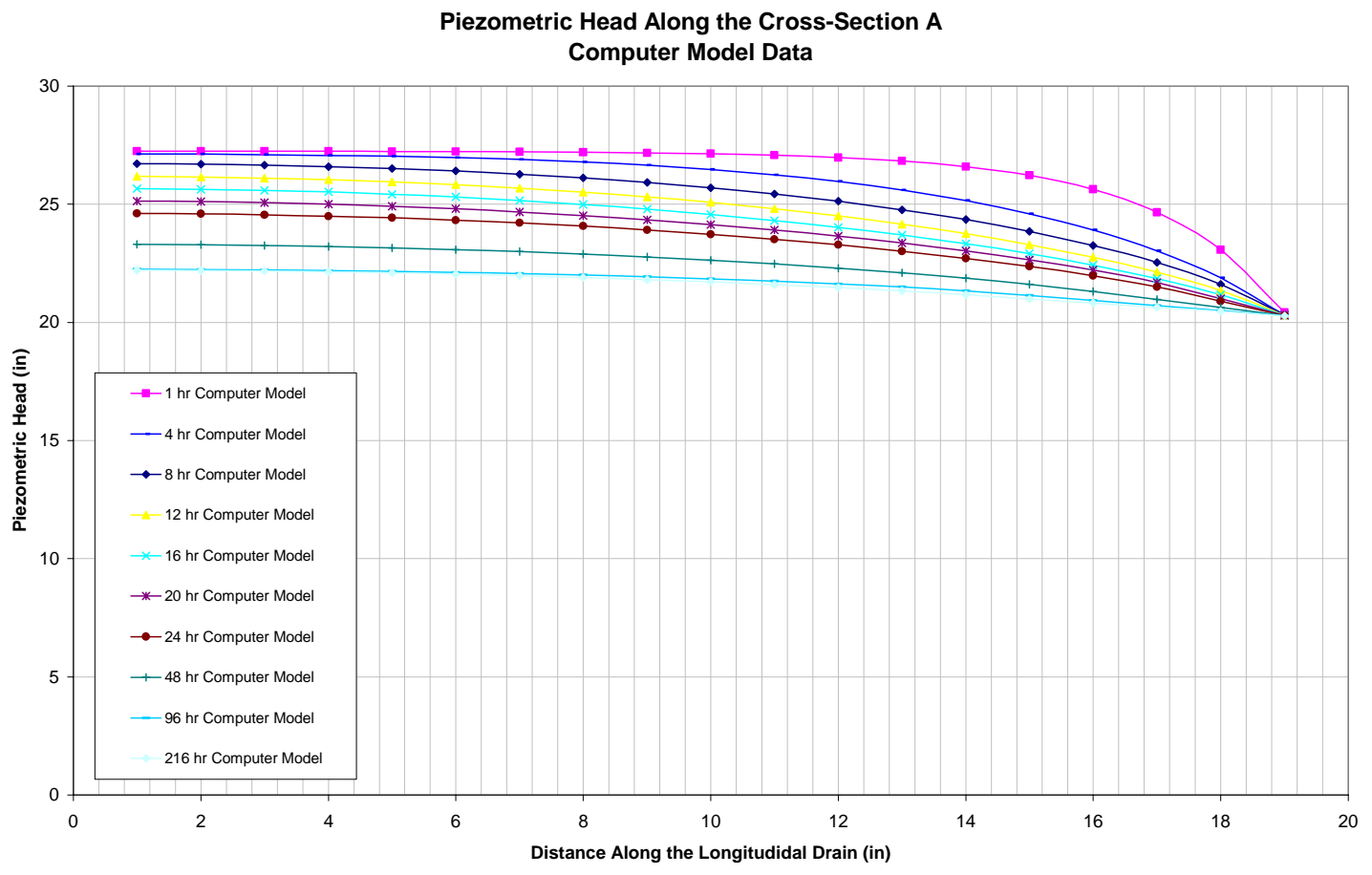

Figure A7.23: Piezometric head along cross-Section X for case A-18-144-10

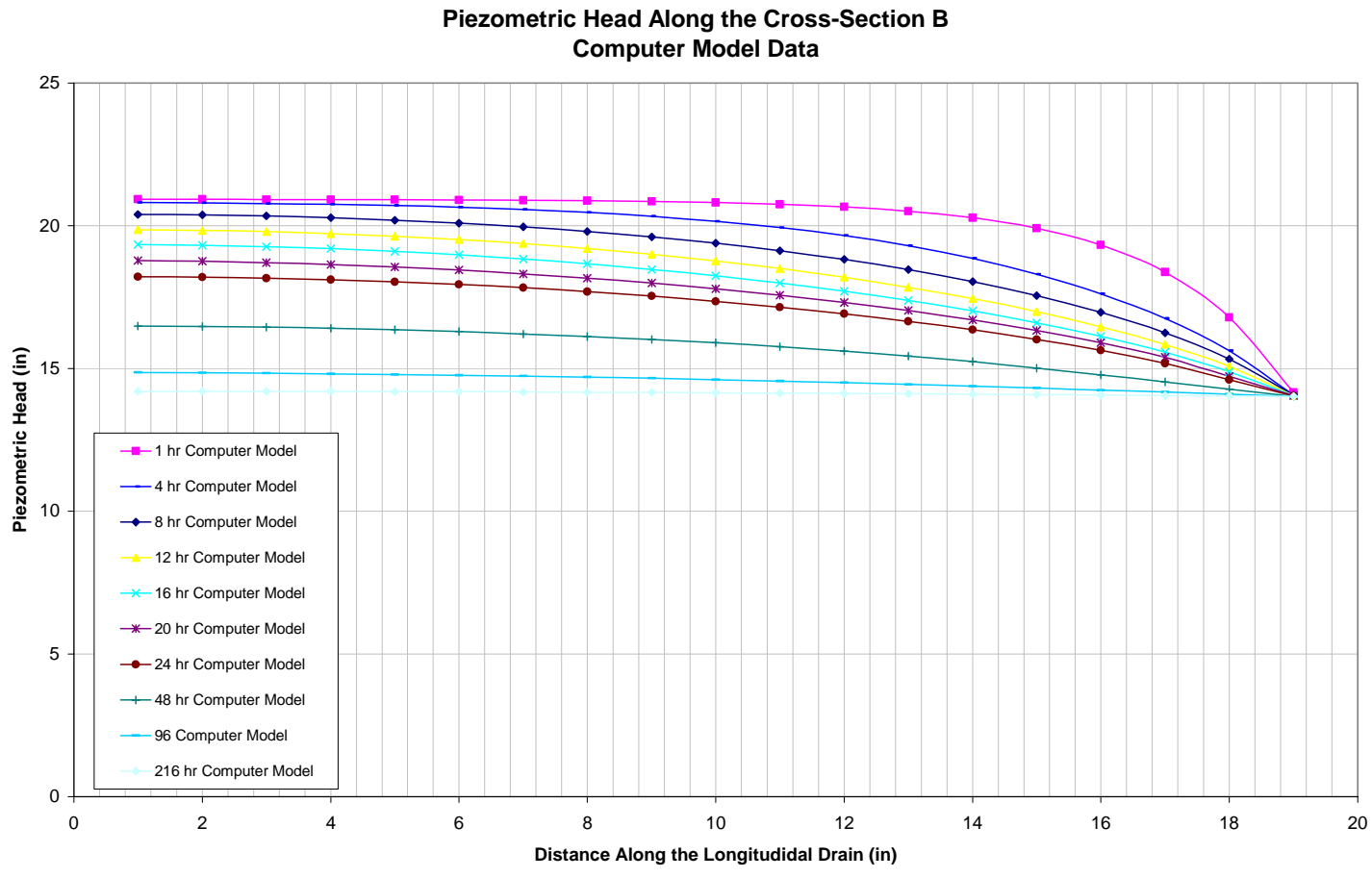

Figure A7.24: Piezometric head along cross-Section Y for case A-18-144-10 
Cumulative Percent Removed Along the Longitudinal Drain

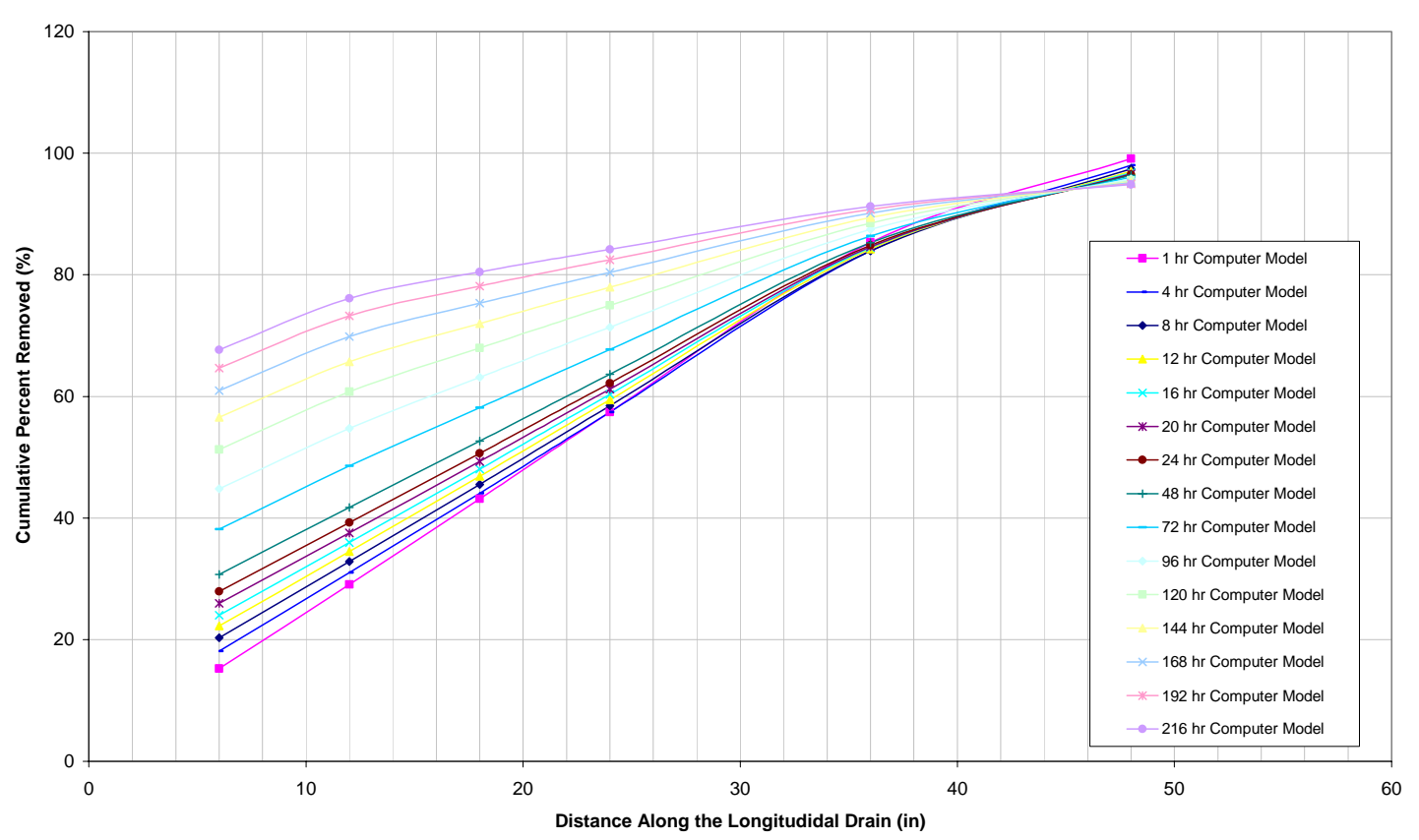

Figure A7.25: Cumulative Percent Removal for case A-18-192-10

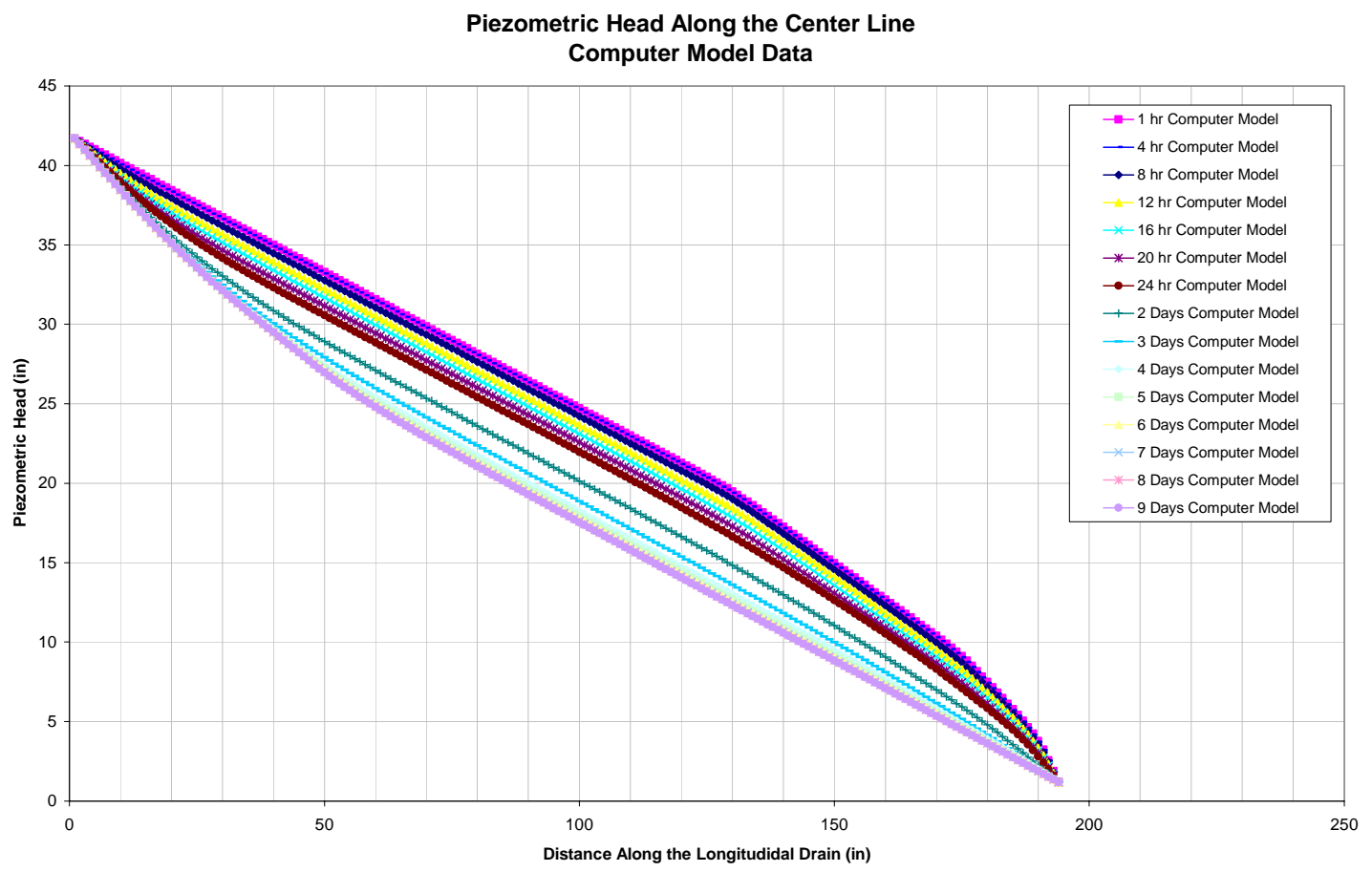

Figure A7.26: Piezometric head along center line for case A-18-192-10 


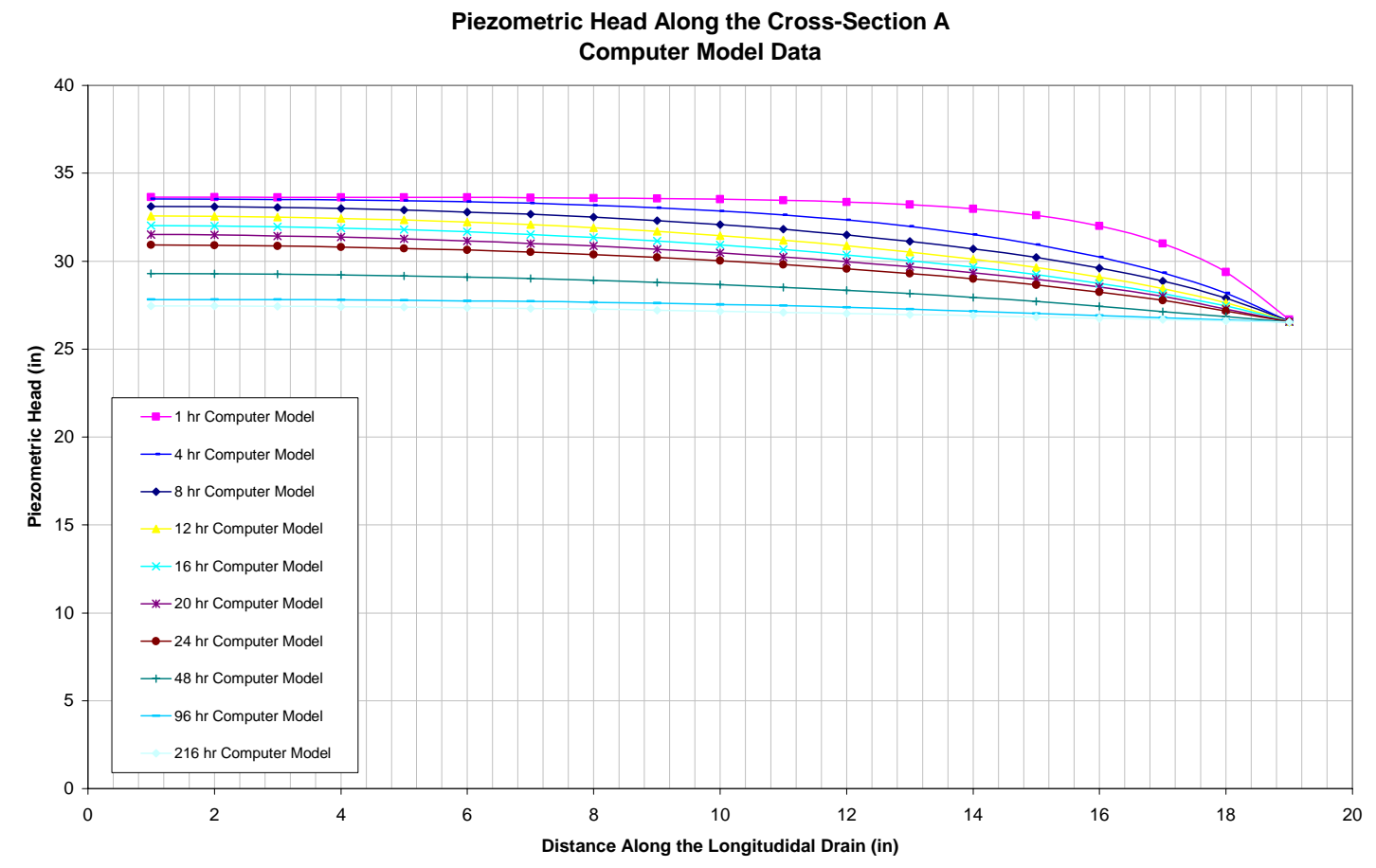

Figure A7.27: Piezometric head along cross-Section X for case A-18-192-10

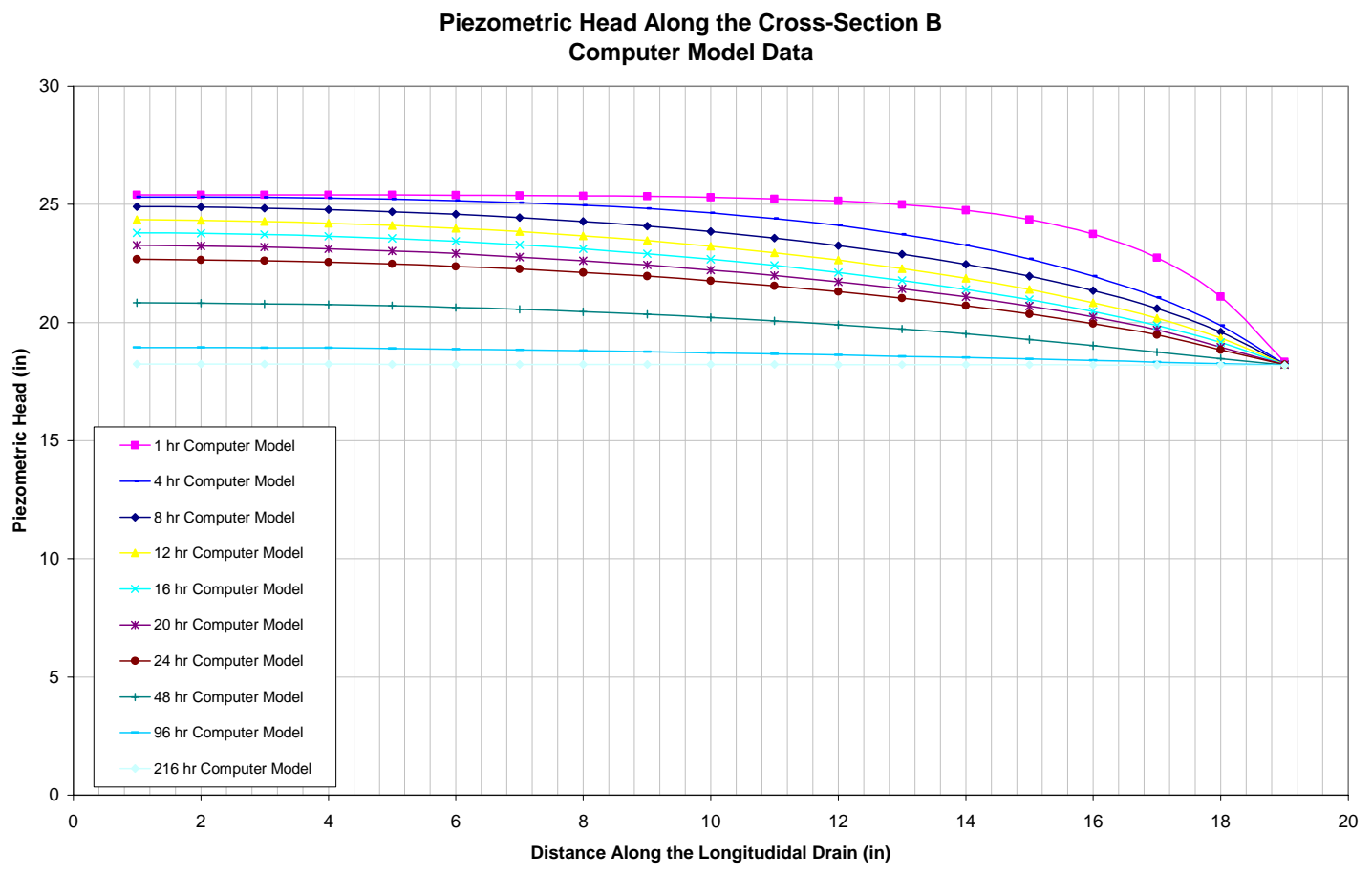

Figure A7.28: Piezometric head along cross-Section Y for case A-18-192-10 
Cumulative Percent Removed Along the Longitudinal Drain

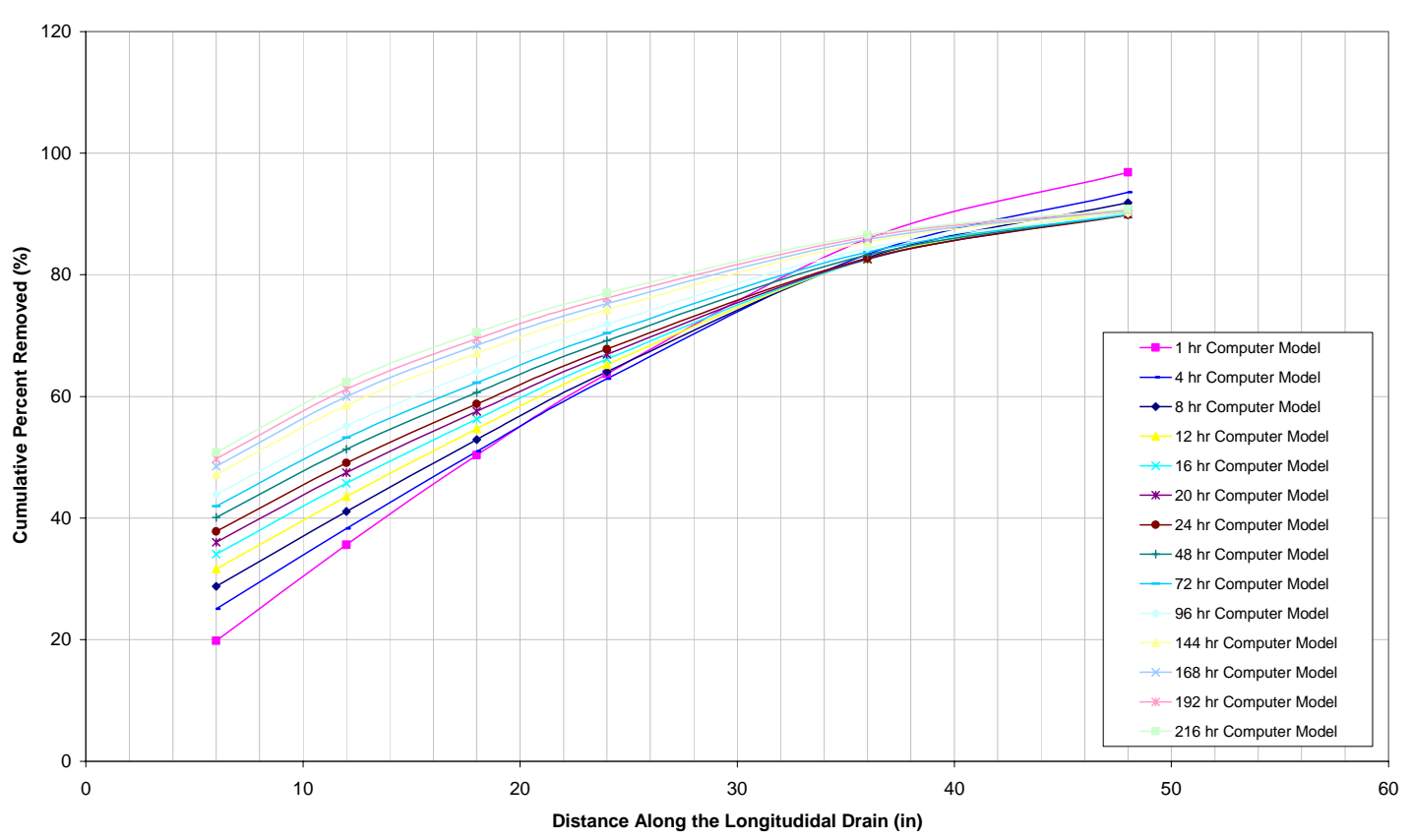

Figure A7.29: Cumulative Percent Removal for case A-24-96-10

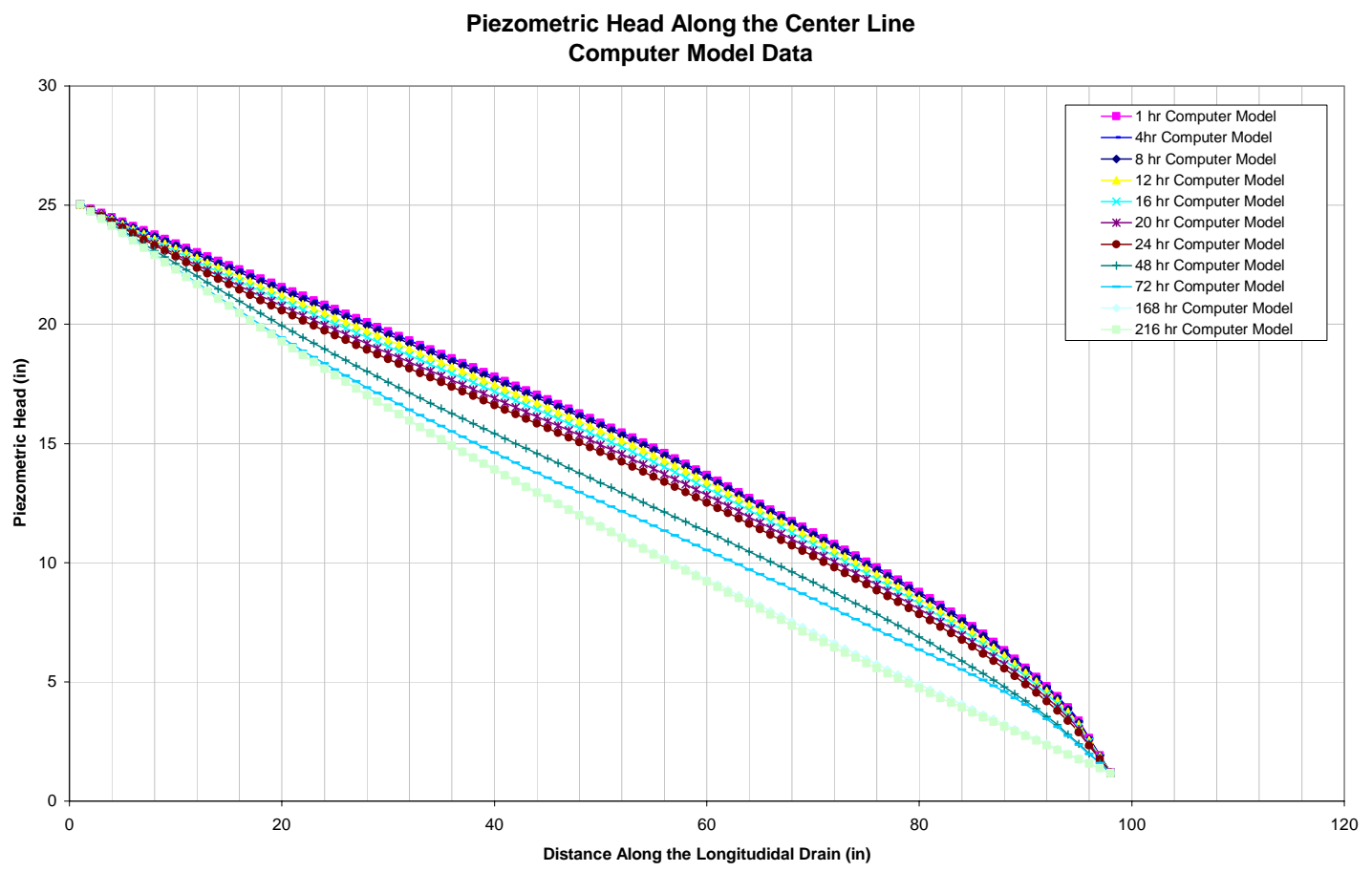

Figure A7.30: Piezometric head along center line for case A-24-96-10 


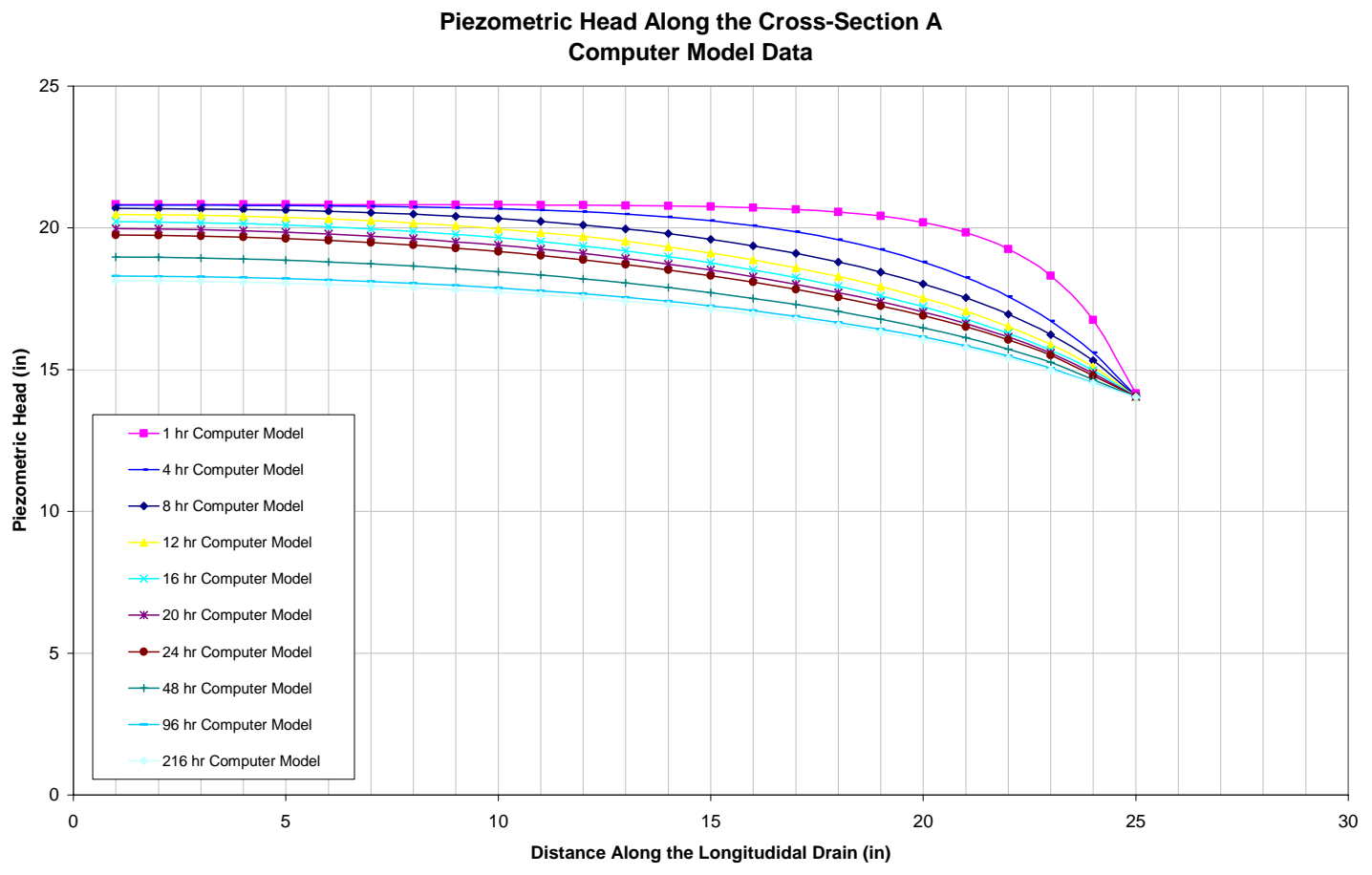

Figure A7.31: Piezometric head along cross-Section X for case A-24-96-10

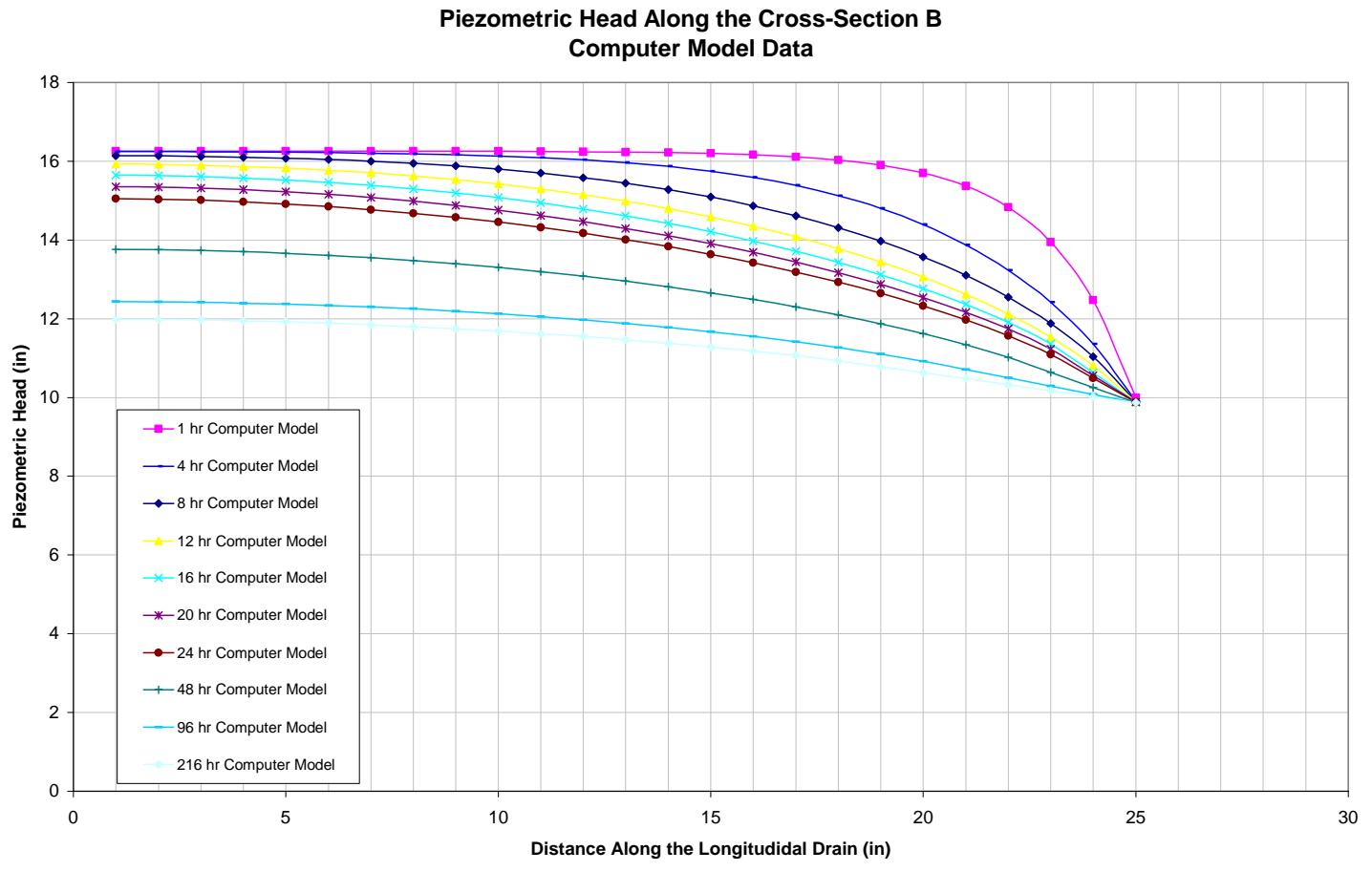

Figure A7.32: Piezometric head along cross-Section Y for case A-24-96-10 
Cumulative Percent Removed Along the Longitudinal Drain

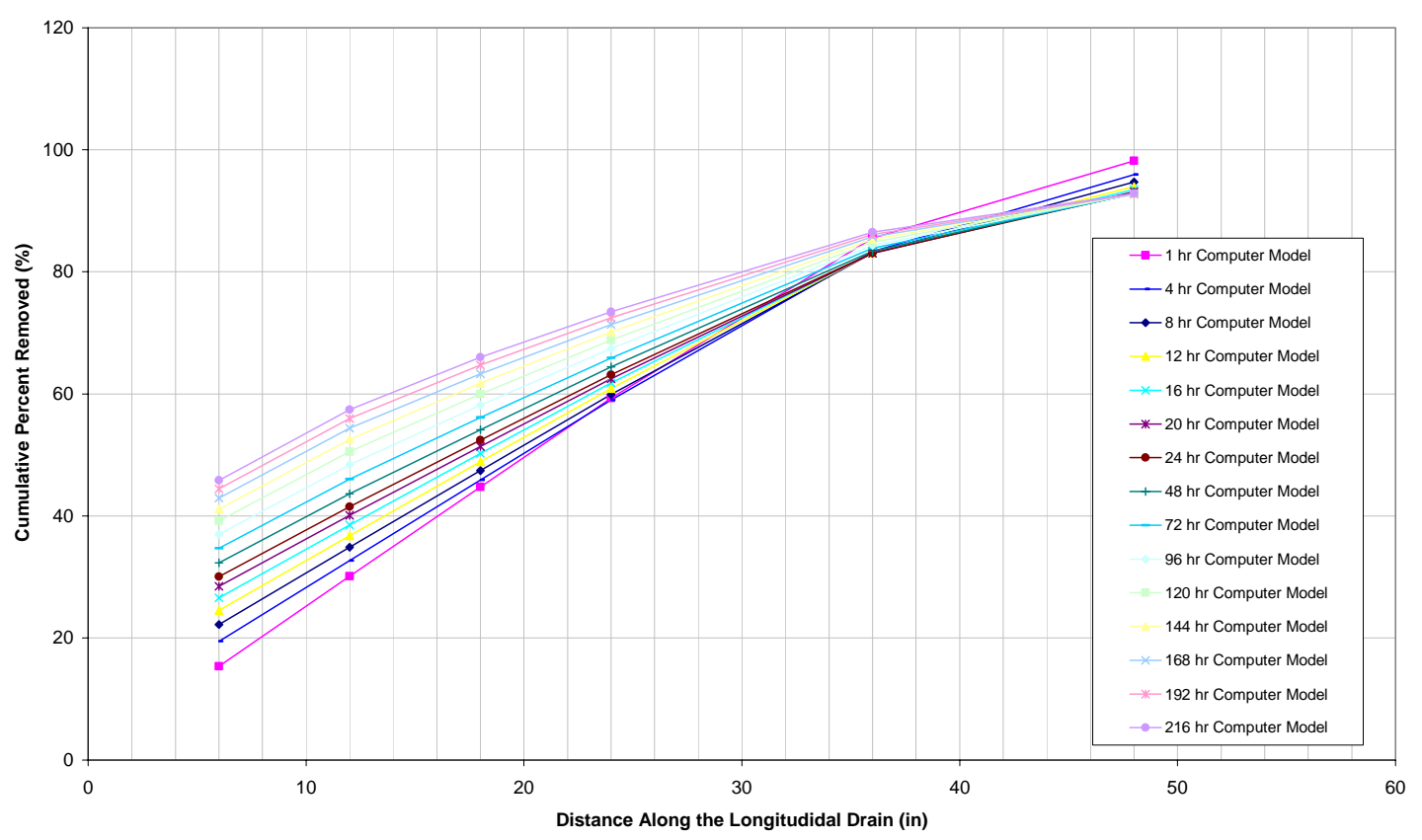

Figure A7.33: Cumulative Percent Removal for case A-24-144-10

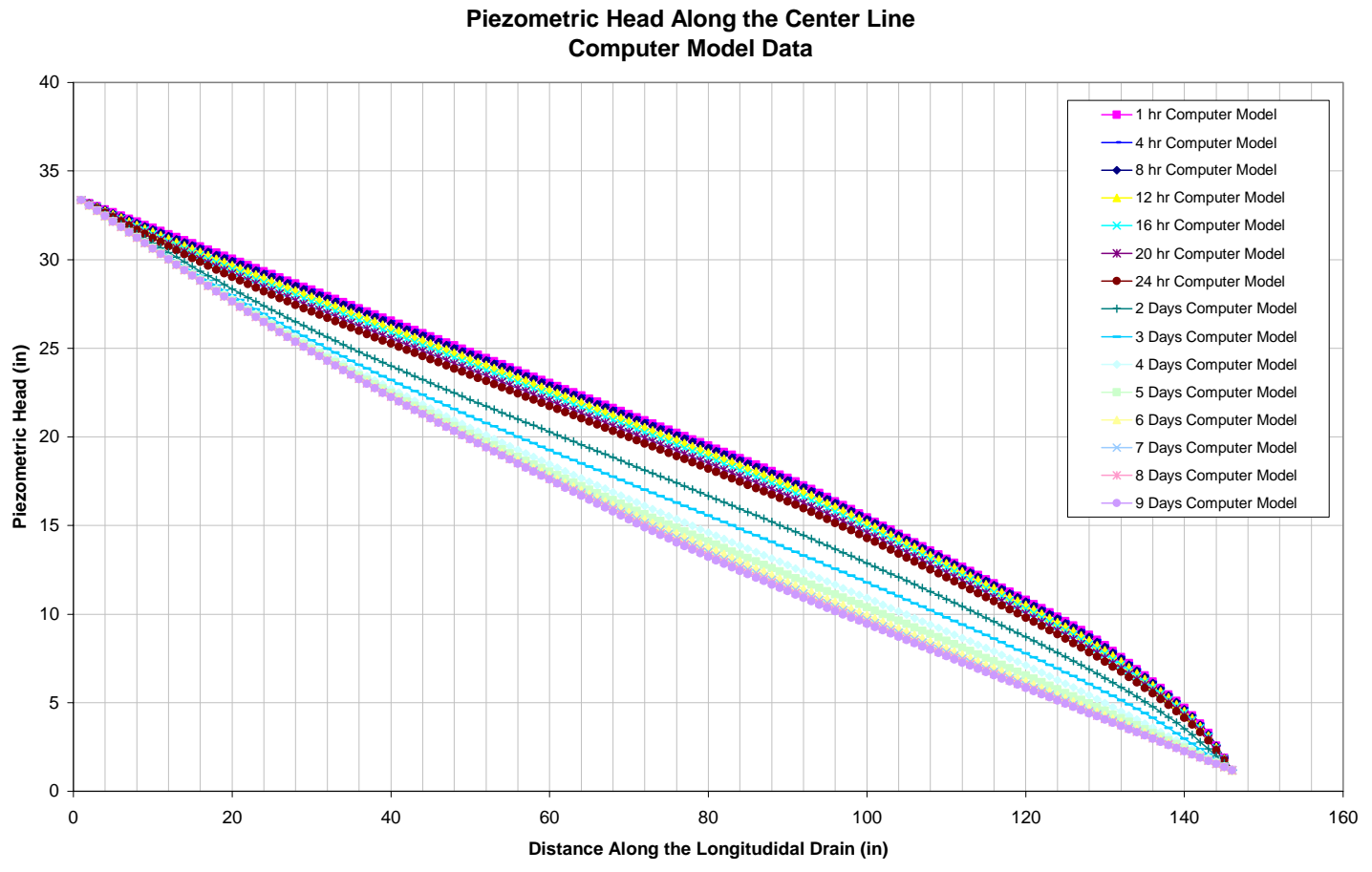

Figure A7.34: Piezometric head along center line for case A-24-144-10 


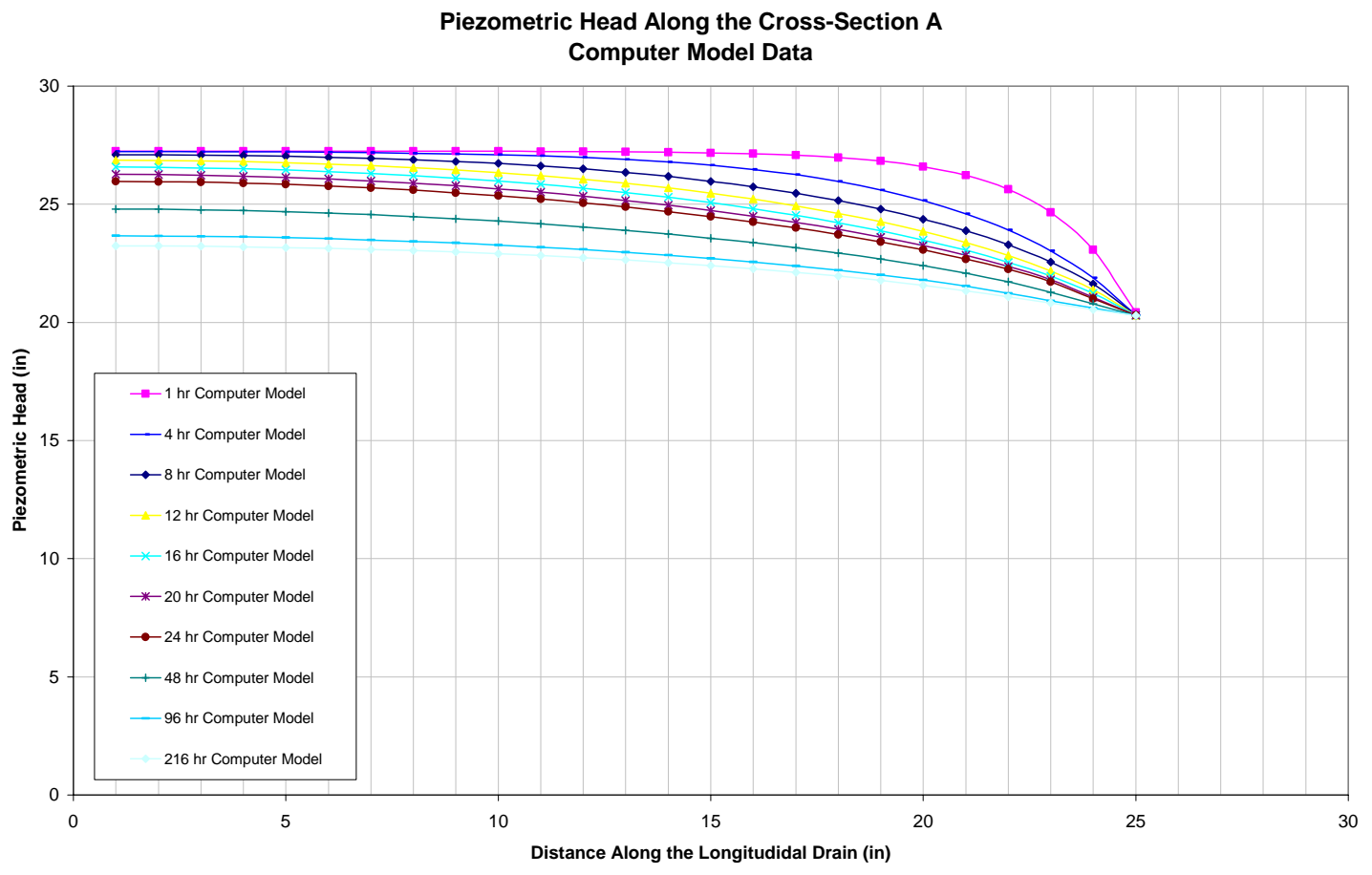

Figure A7.35: Piezometric head along cross-Section X for case A-24-144-10

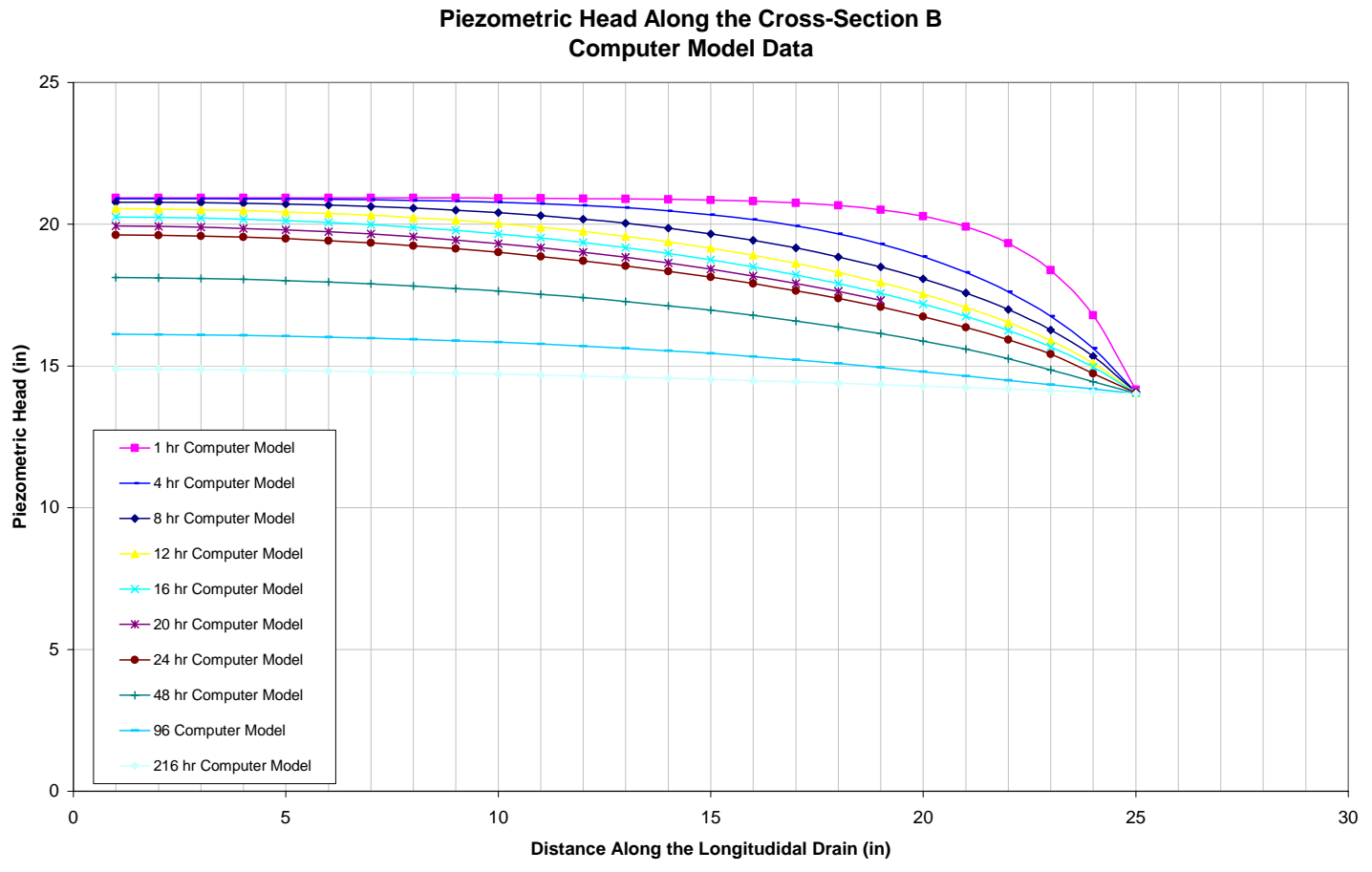

Figure A7.36: Piezometric head along cross-Section Y for case A-24-144-10 
Cumulative Percent Removed Along the Longitudinal Drain

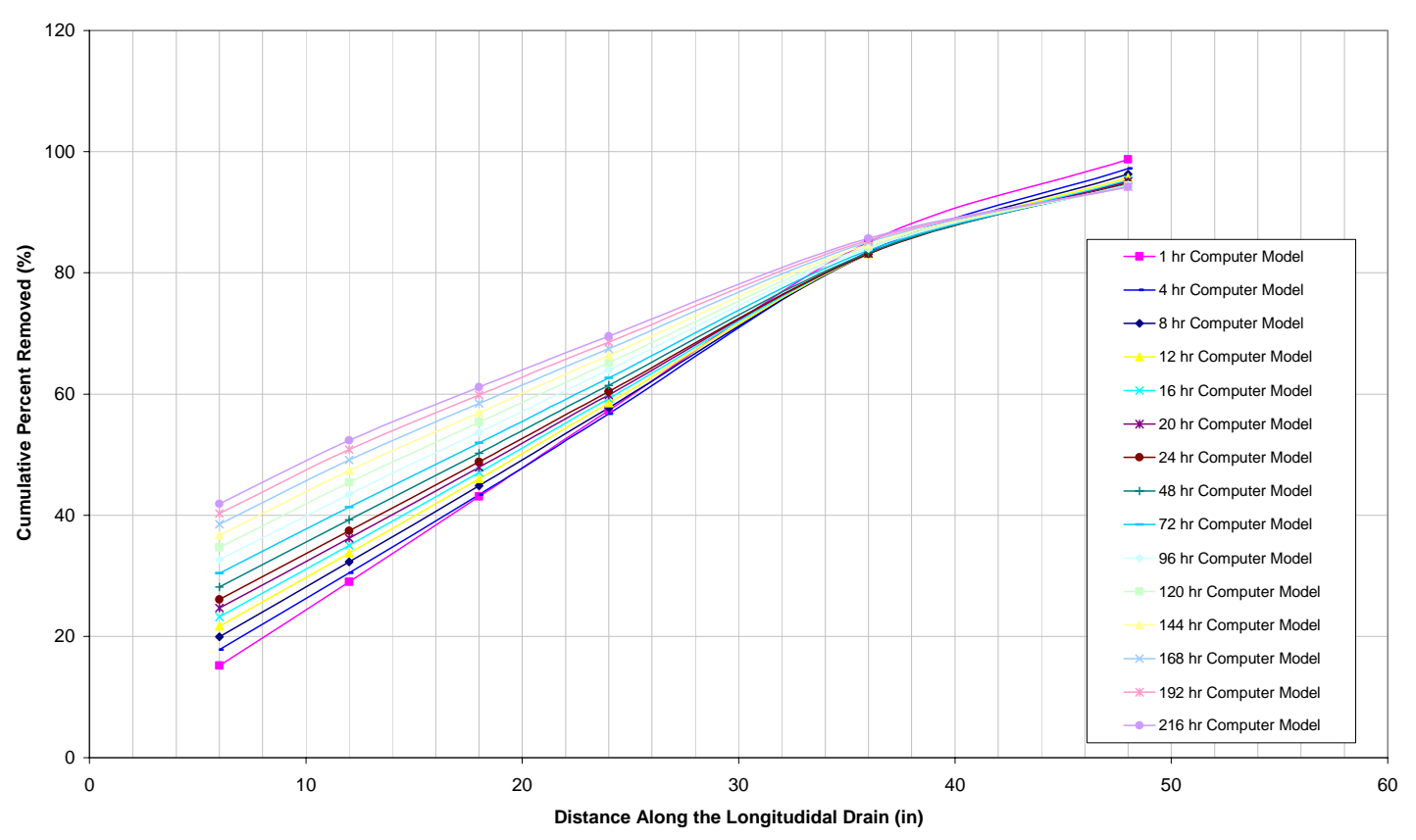

Figure A7.37: Cumulative Percent Removal for case A-24-192-10

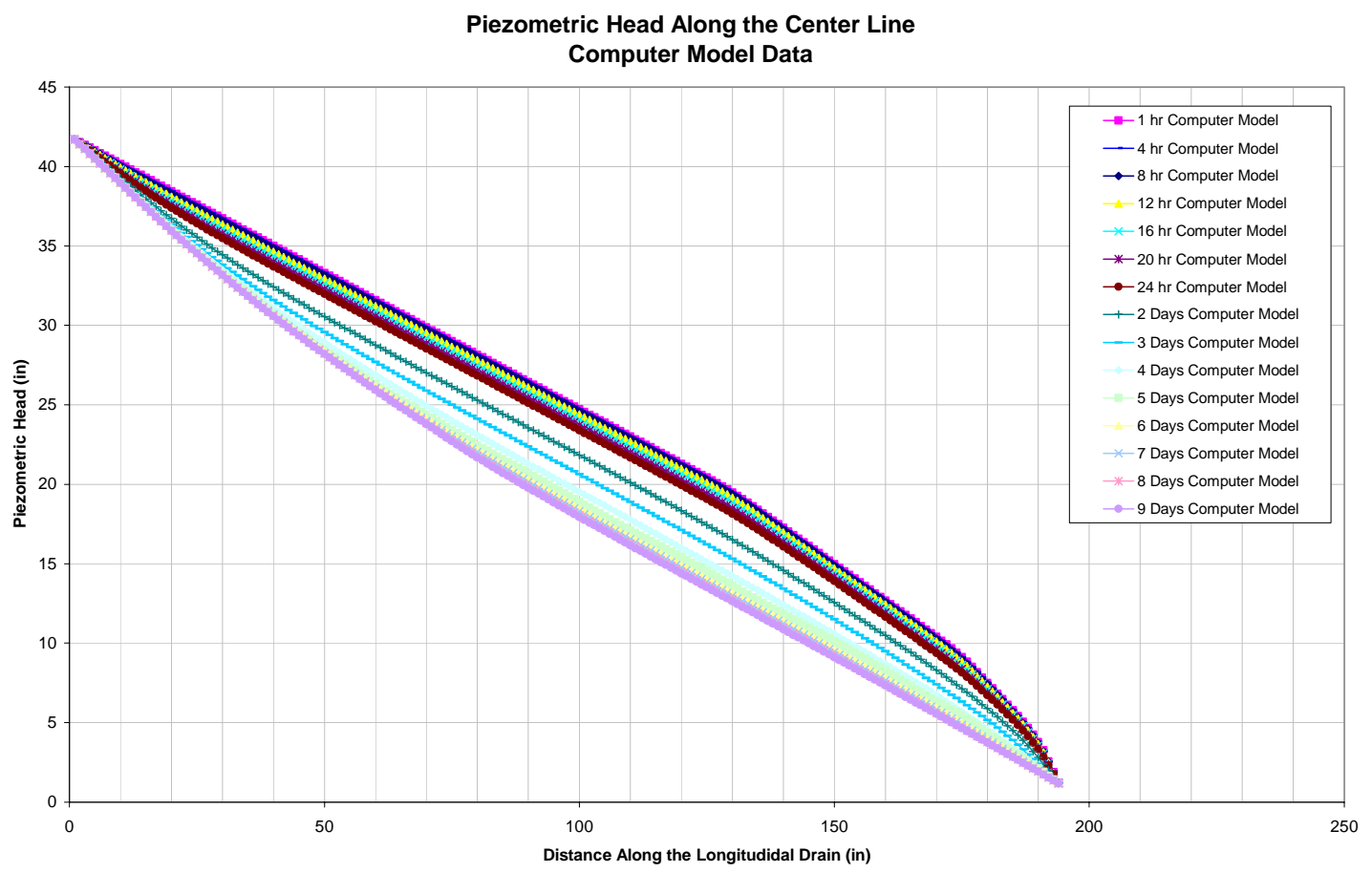

Figure A7.38: Piezometric head along center line for case A-24-192-10 


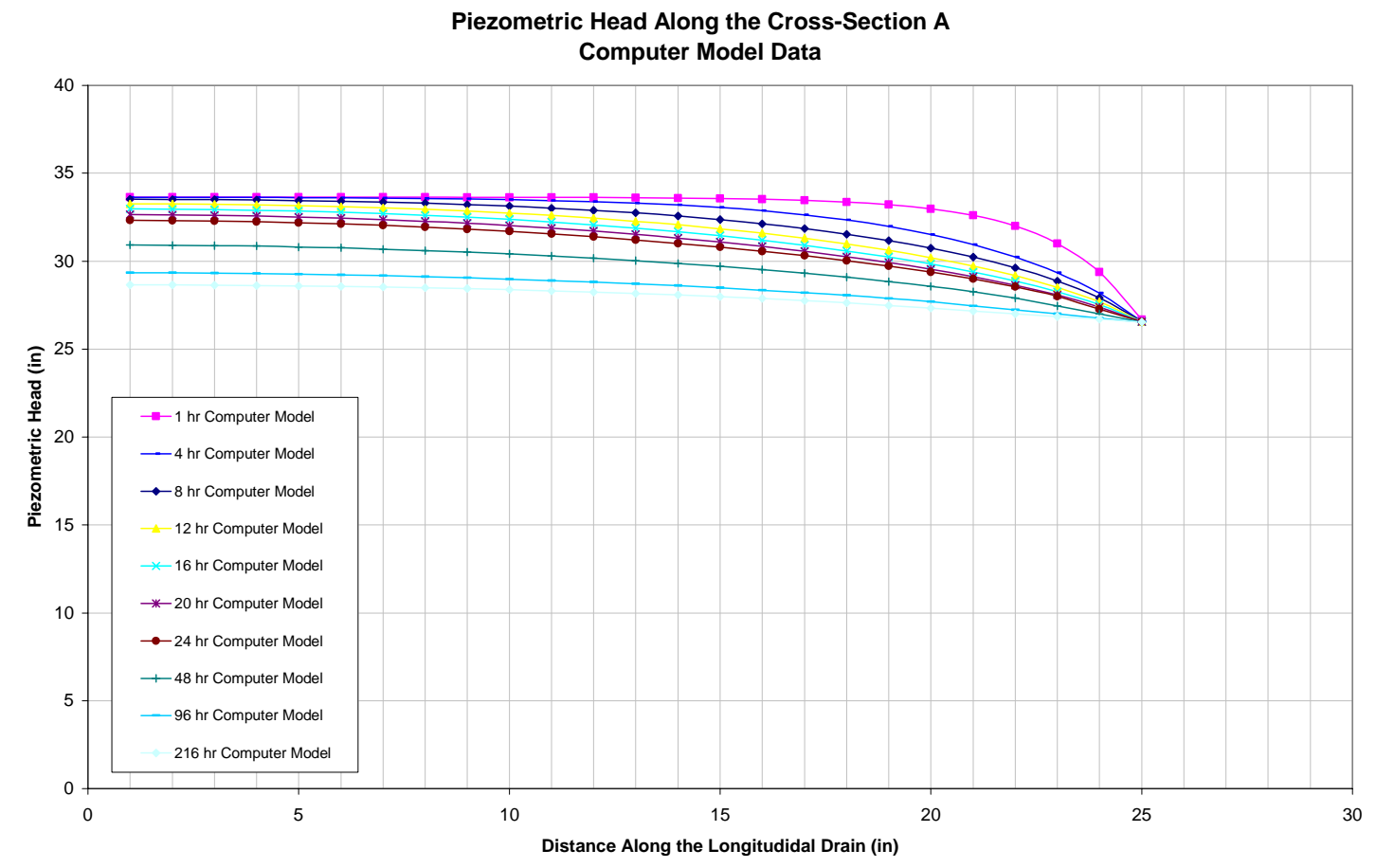

Figure A7.39: Piezometric head along cross-Section X for case A-24-192-10

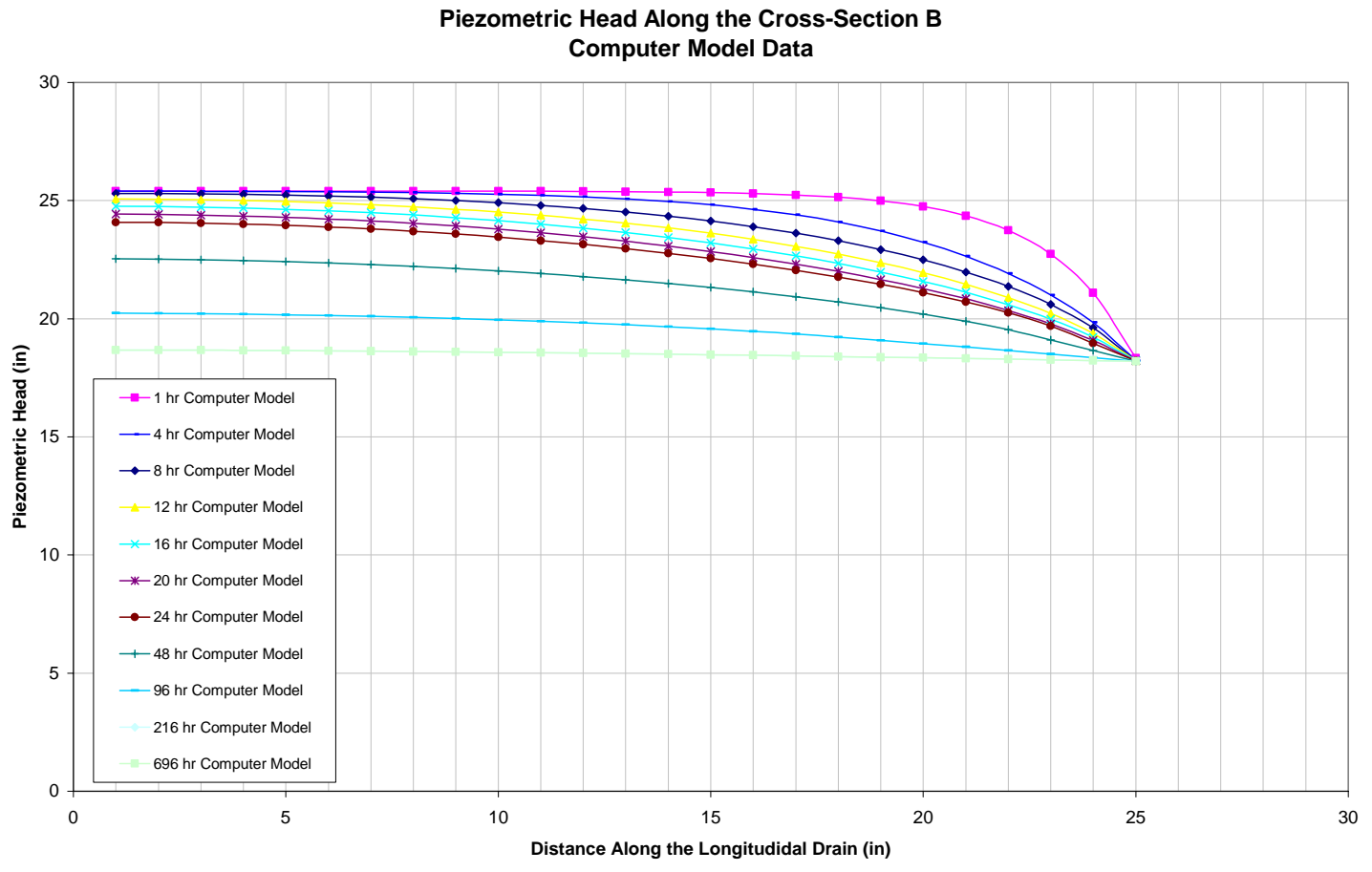

Figure A7.40: Piezometric head along cross-Section Y for case A-24-192-10 
Cumulative Percent Removed Along the Longitudinal Drain

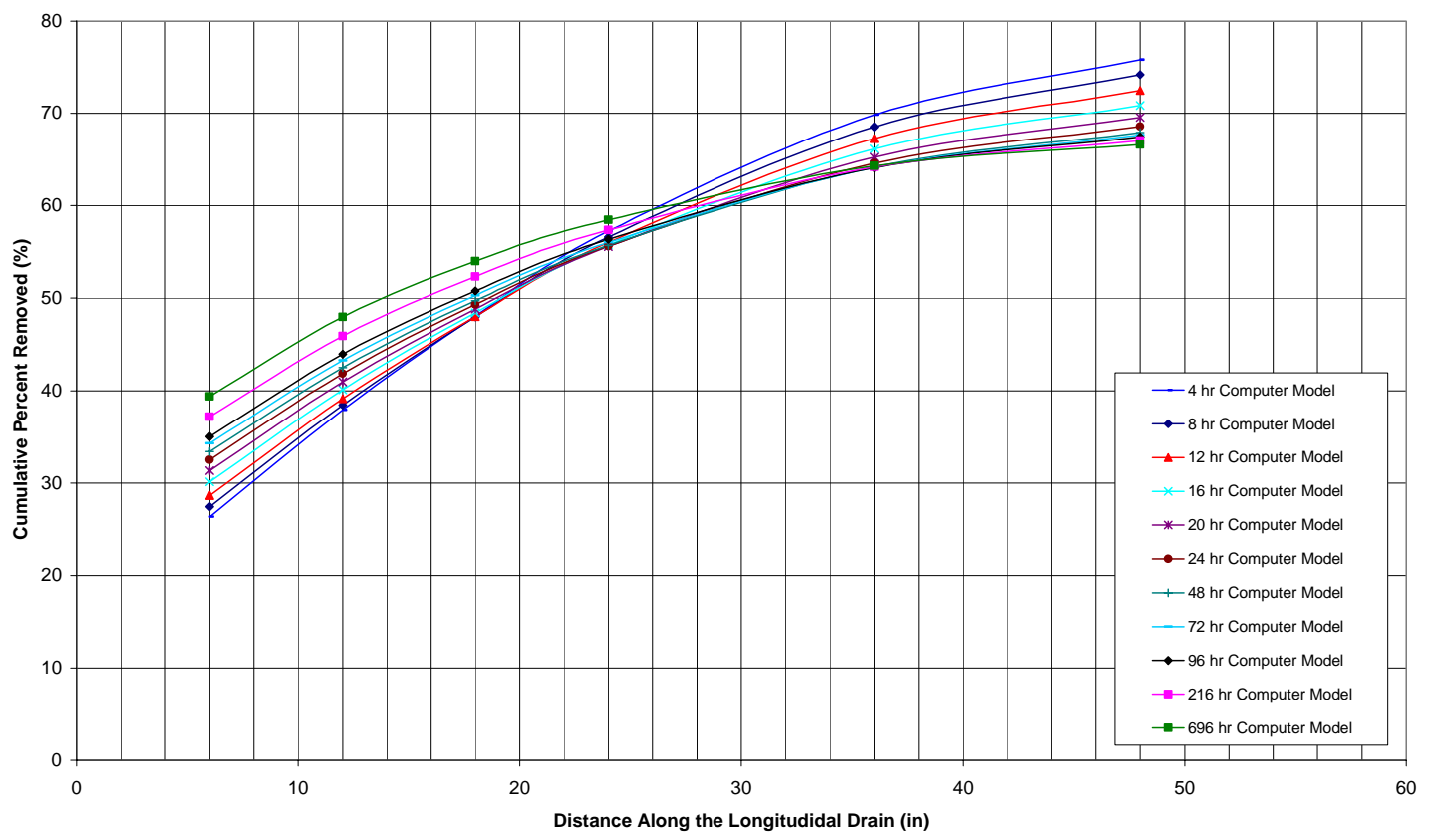

Figure A7.41: Cumulative Percent Removal for case A-48-48-10

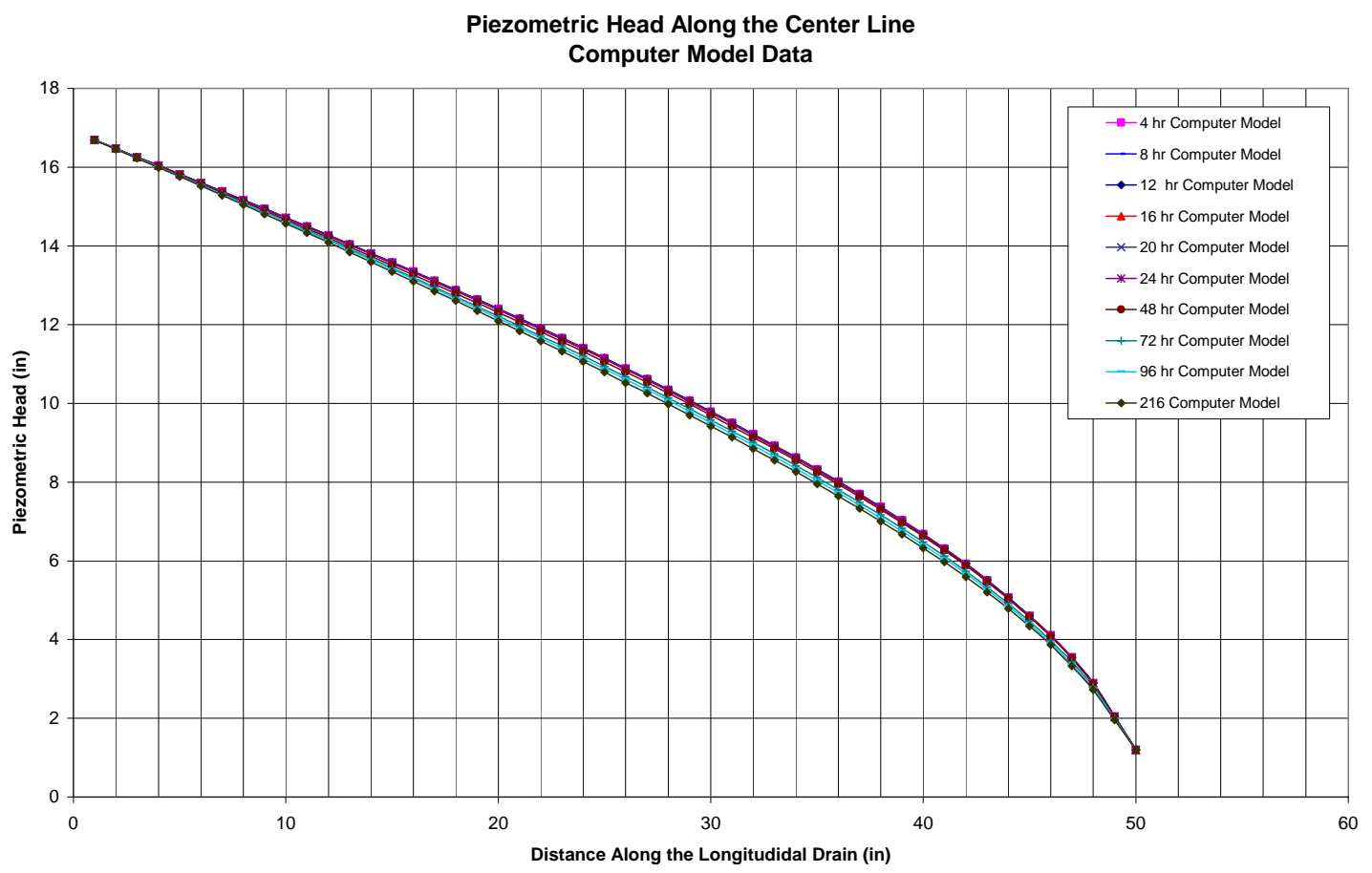

Figure A7.42: Piezometric head along center line for case A-48-48-10 


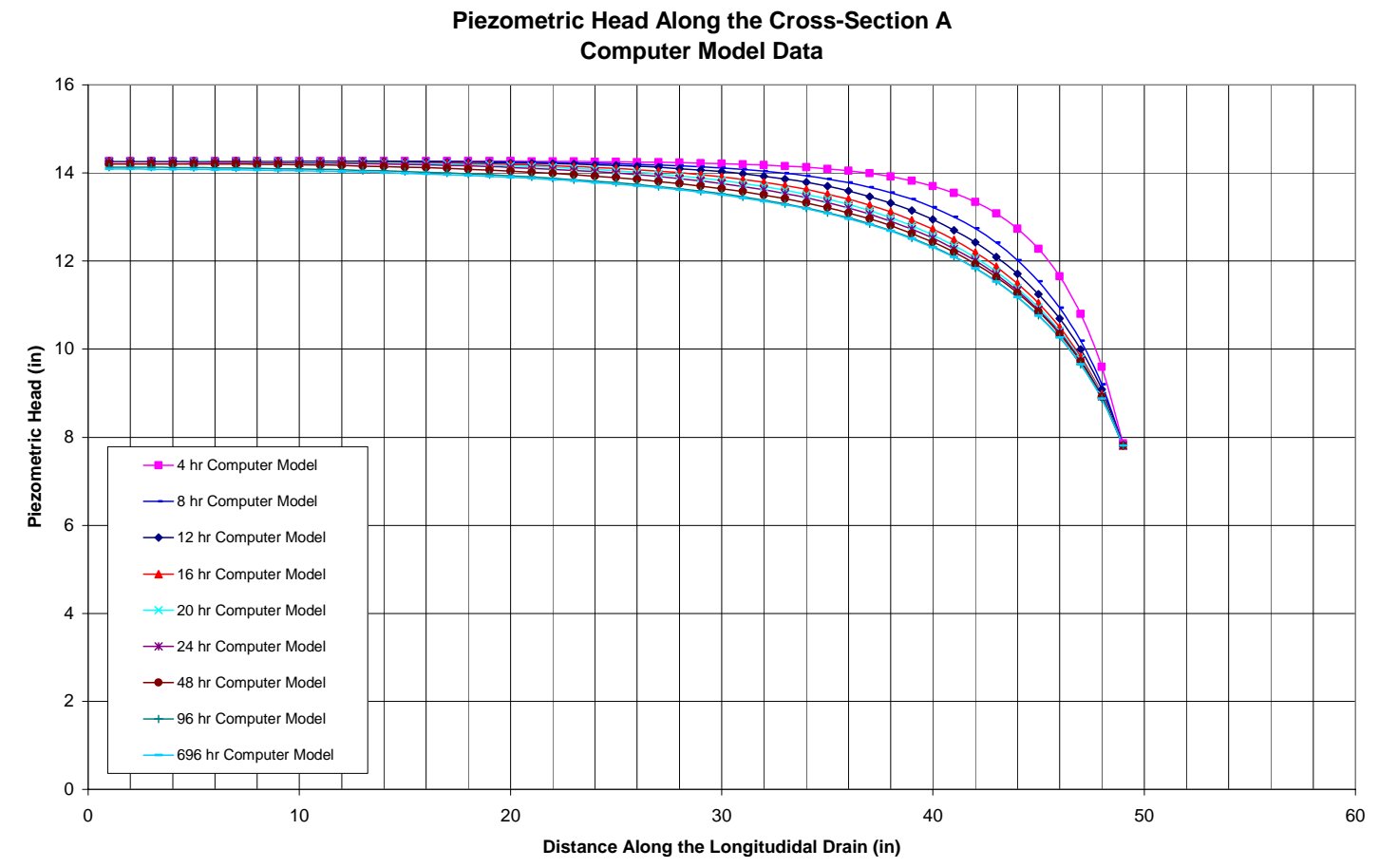

Figure A7.43: Piezometric head along cross-Section X for case A-48-48-10

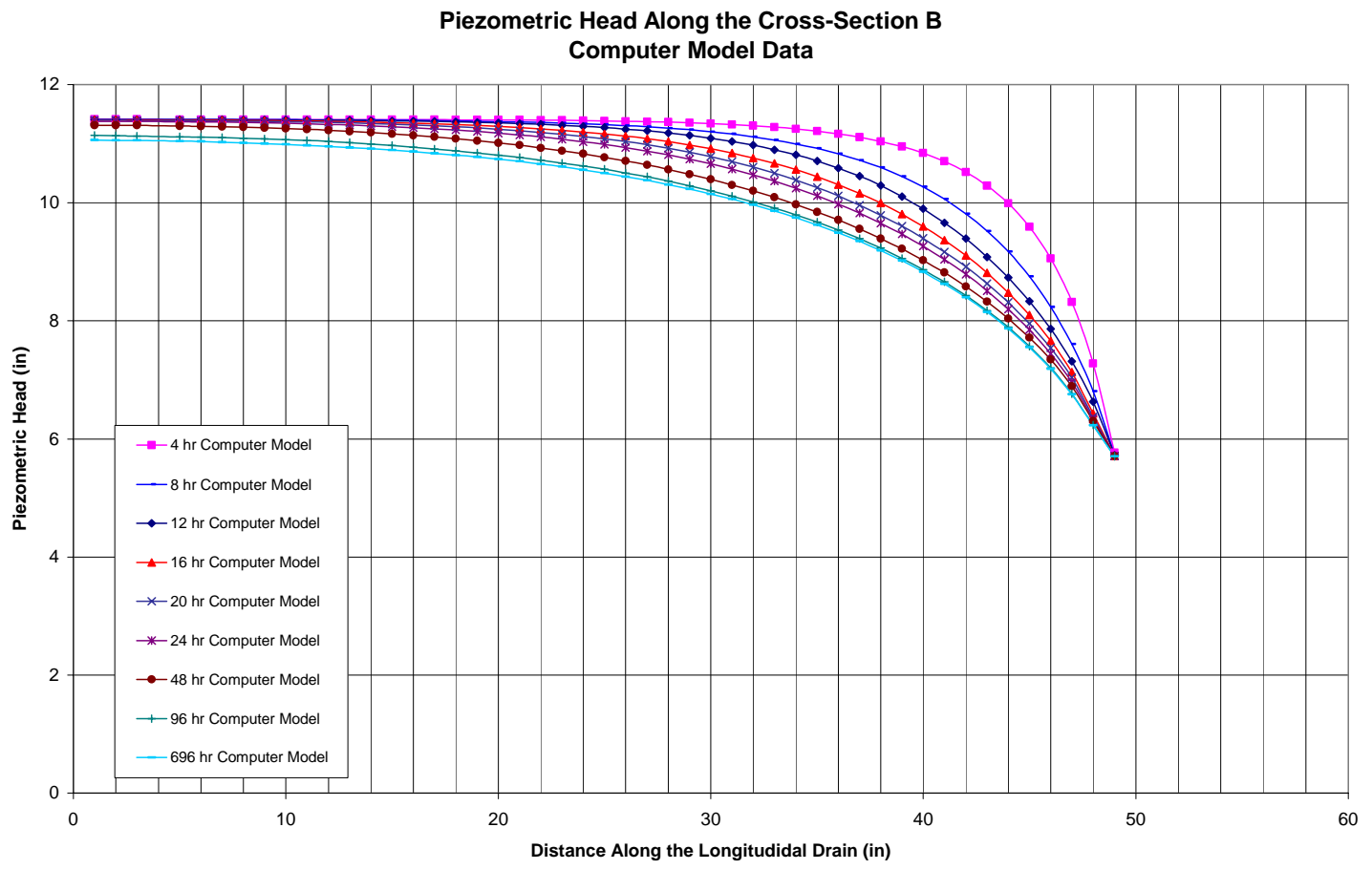

Figure A7.44: Piezometric head along cross-Section Y for case A-48-48-10 
Cumulative Percent Removed Along the Longitudinal Drain

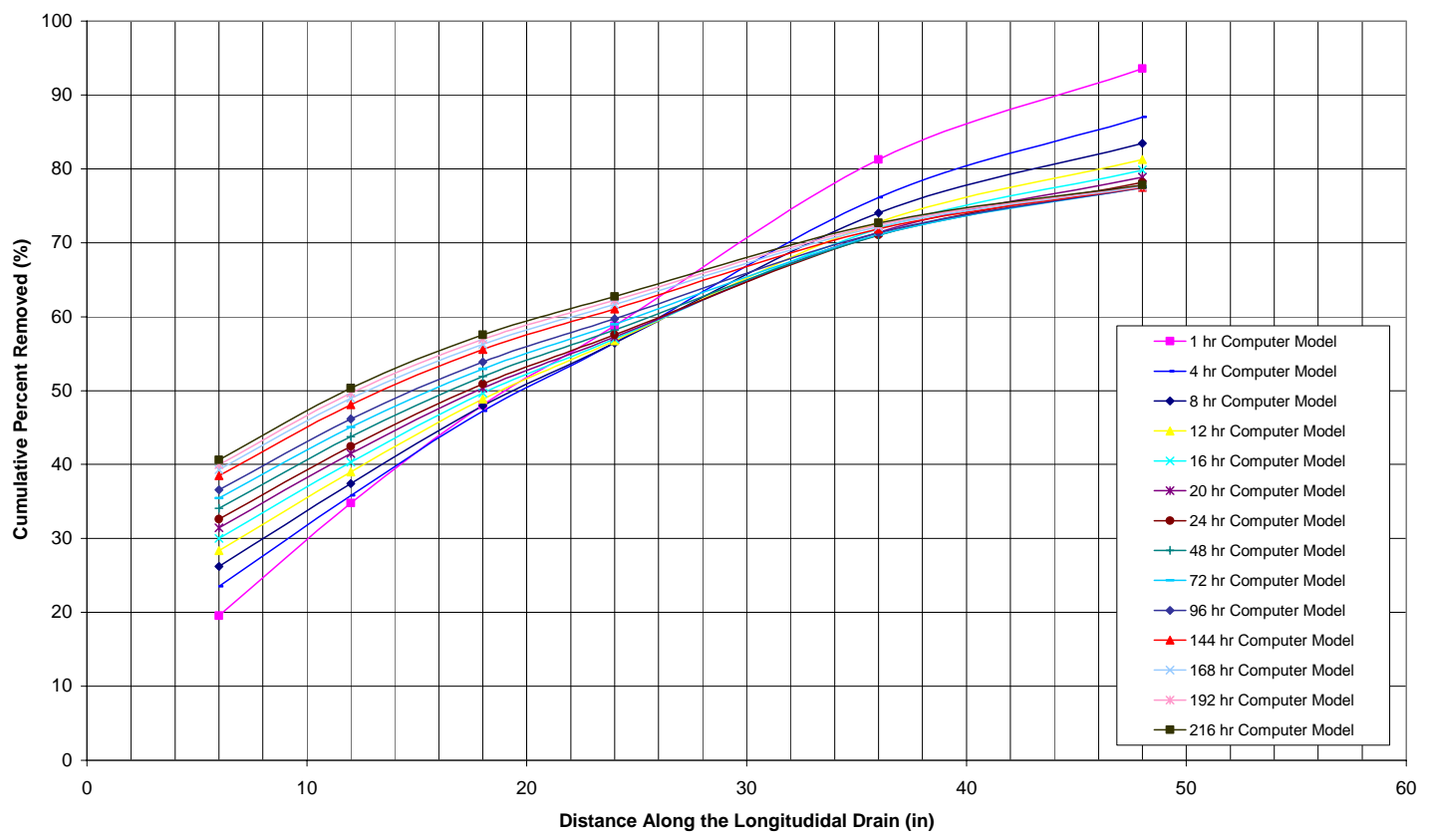

Figure A7.45: Cumulative Percent Removal for case A-48-96-10

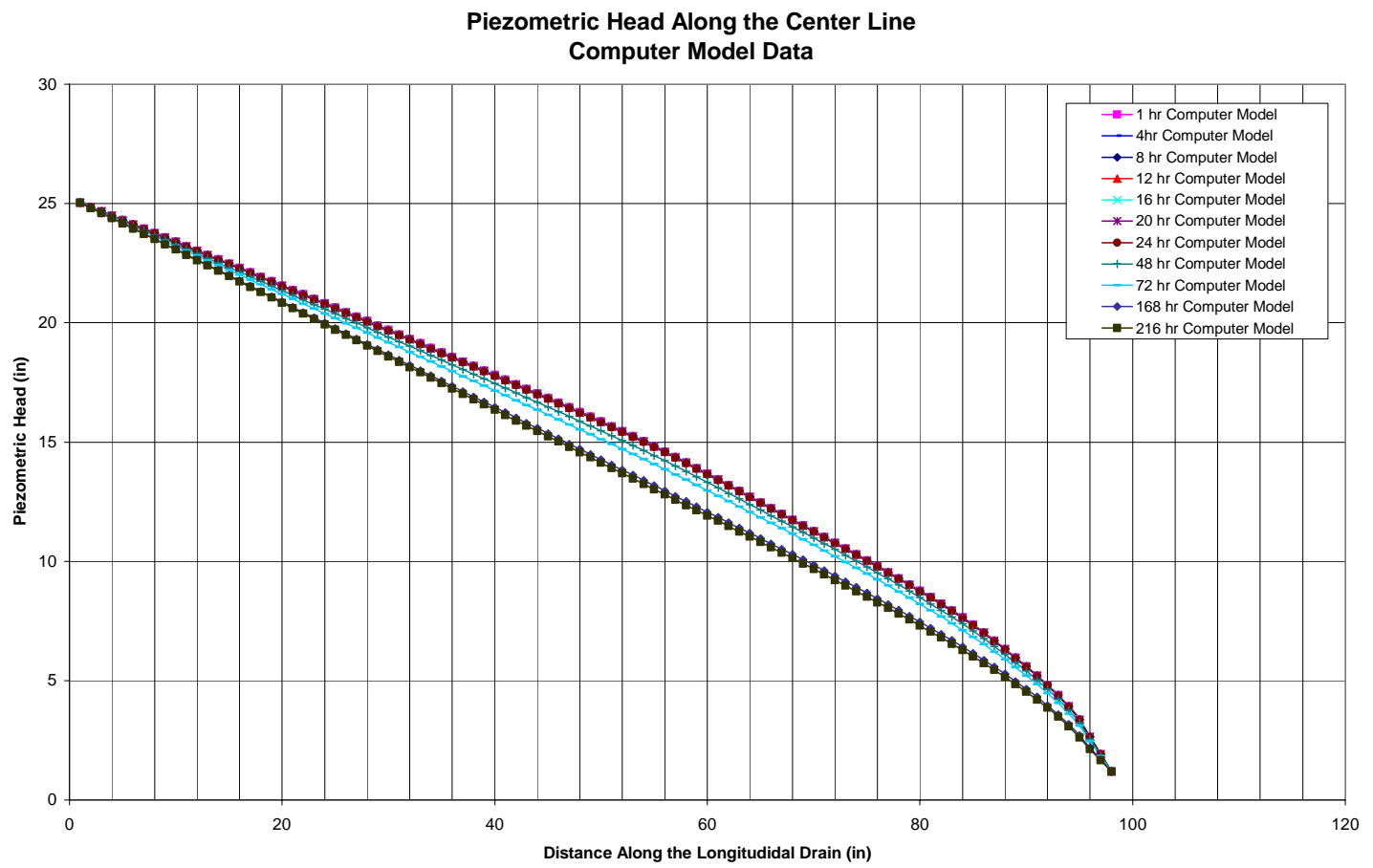

Figure A7.46: Piezometric head along center line for case A-48-96-10 


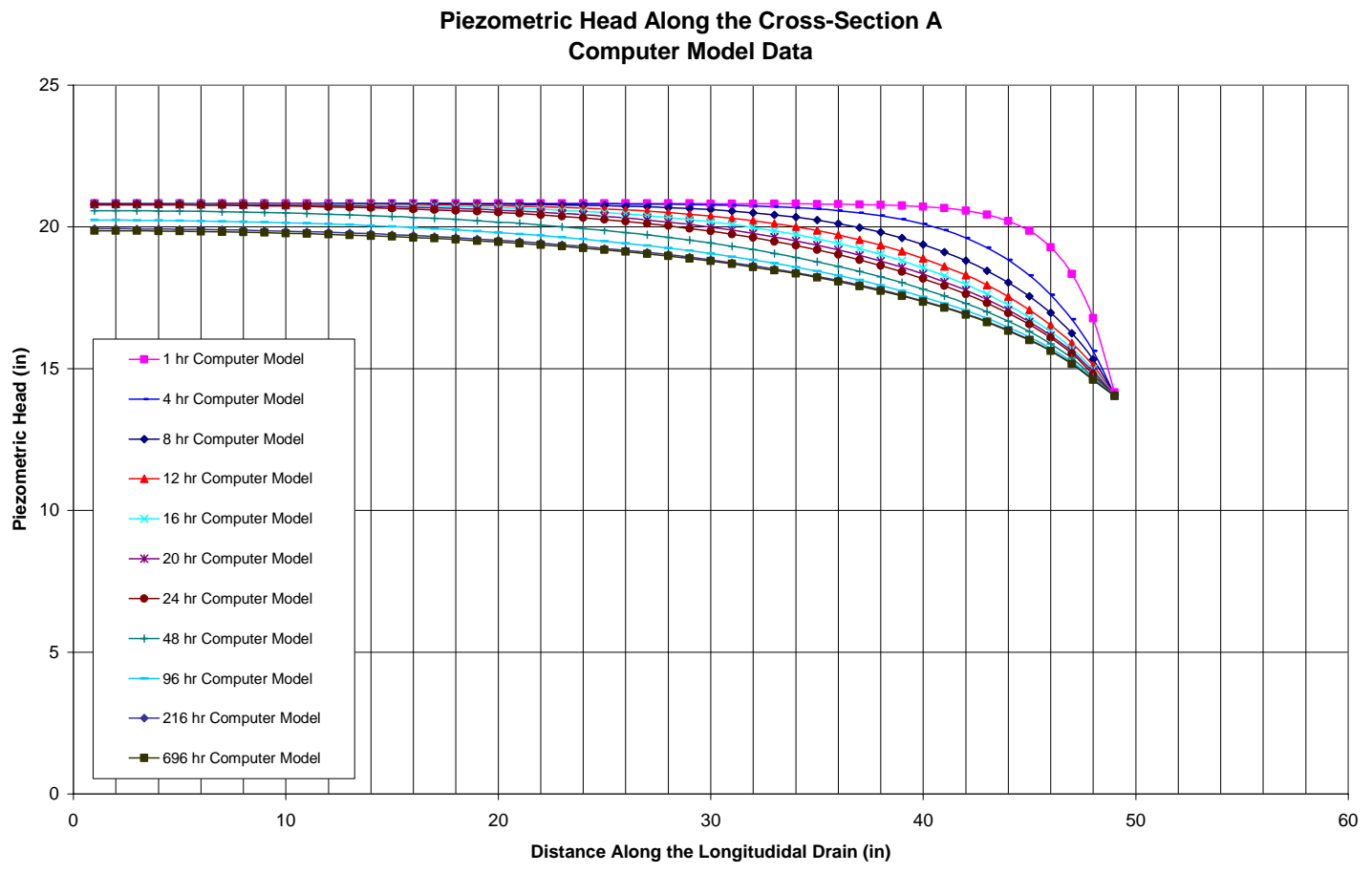

Figure A7.47: Piezometric head along cross-Section X for case A-48-96-10

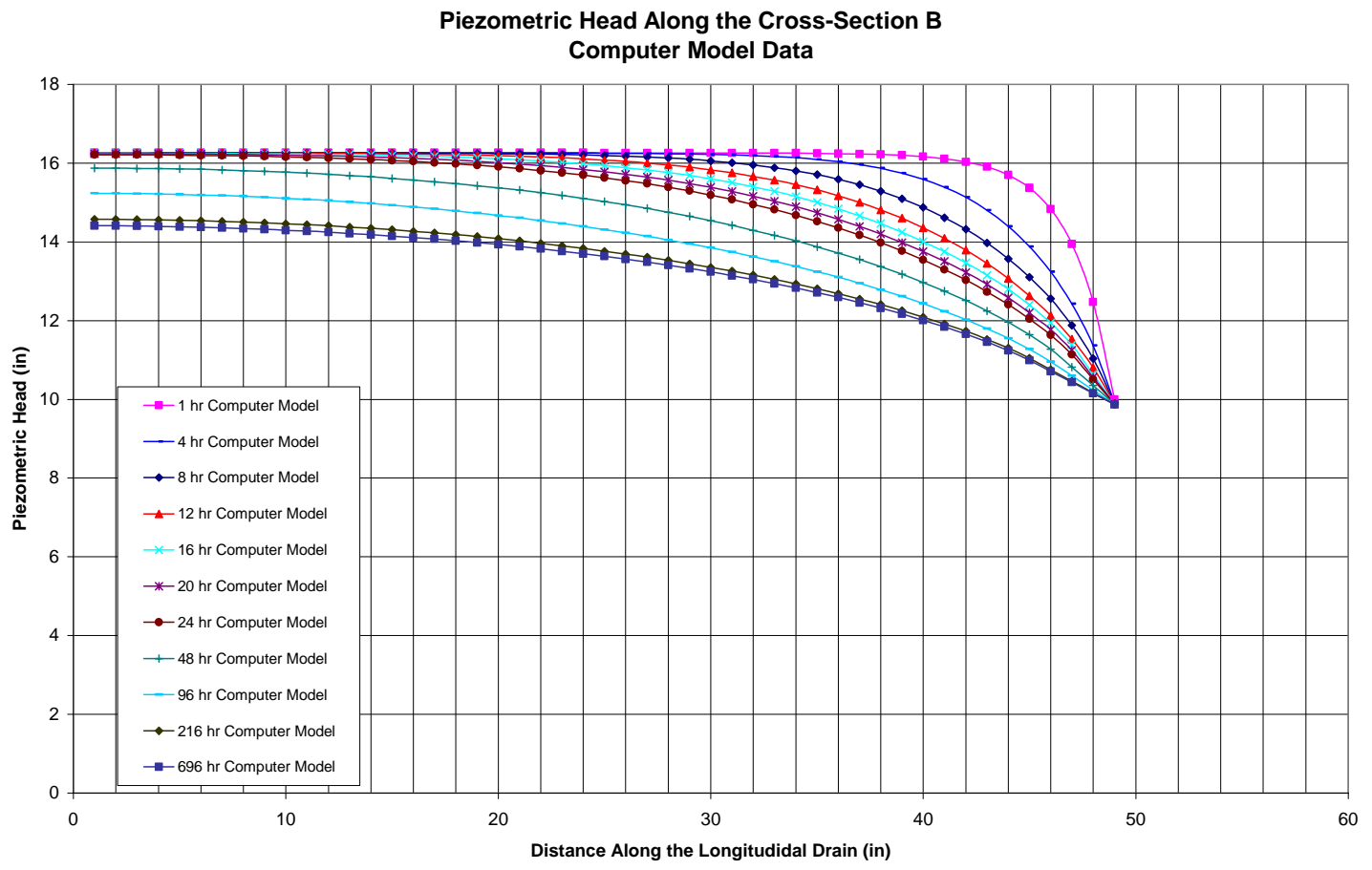

Figure A7.48: Piezometric head along cross-Section Y for case A-48-96-10 
Cumulative Percent Removed Along the Longitudinal Drain

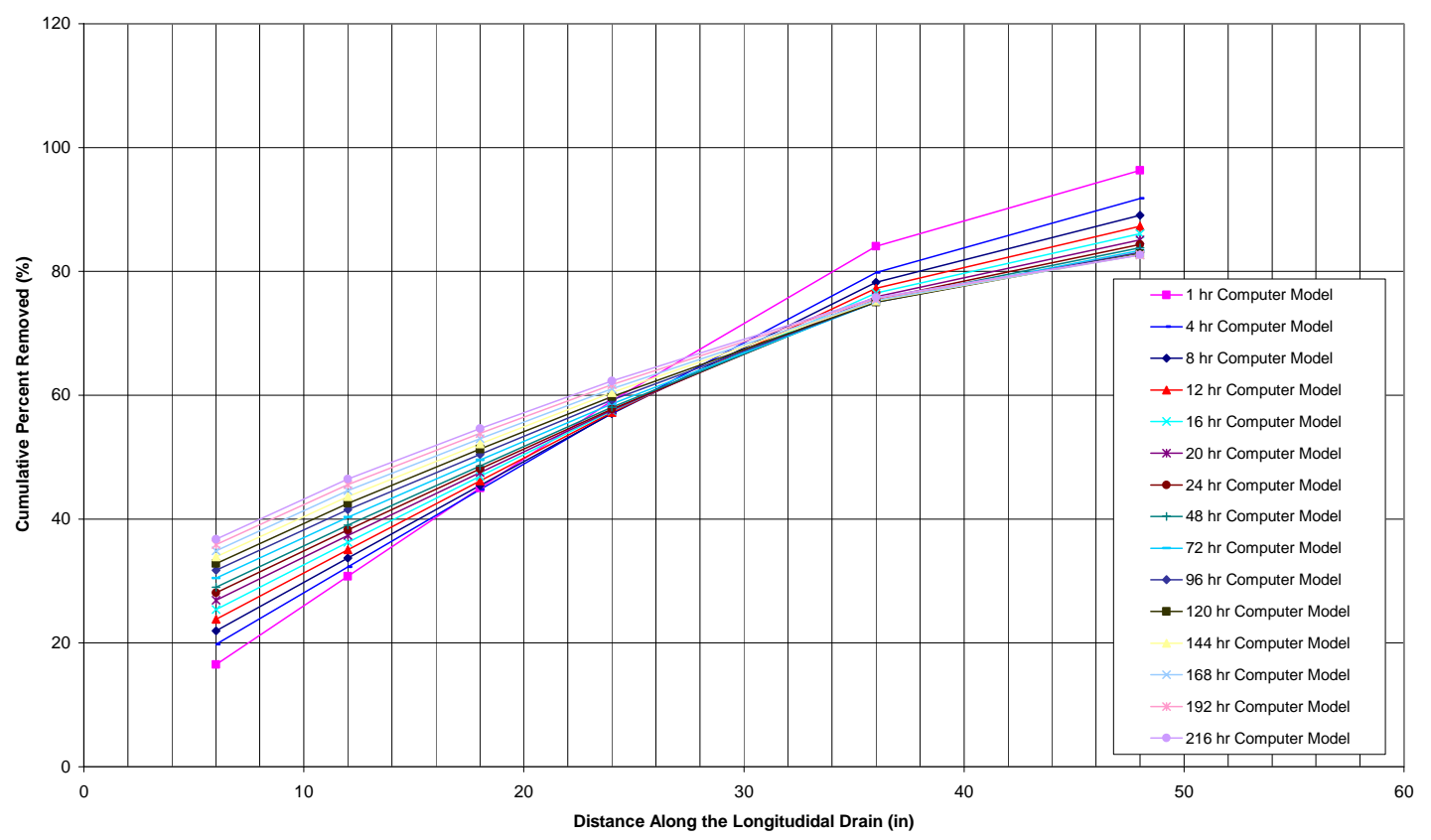

Figure A7.49: Cumulative Percent Removal for case A-48-144-10

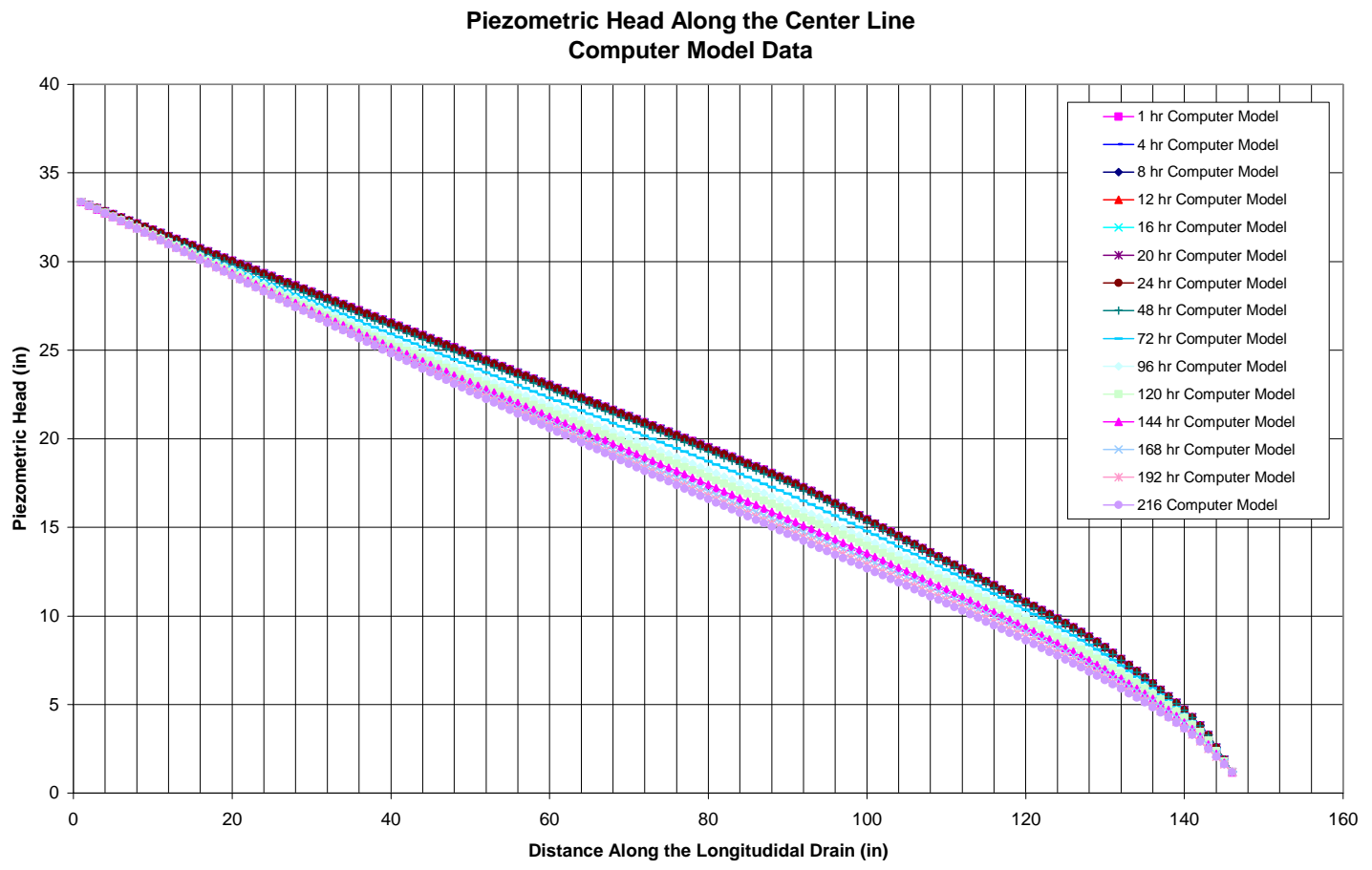

Figure A7.50: Piezometric head along center line for case A-48-144-10 


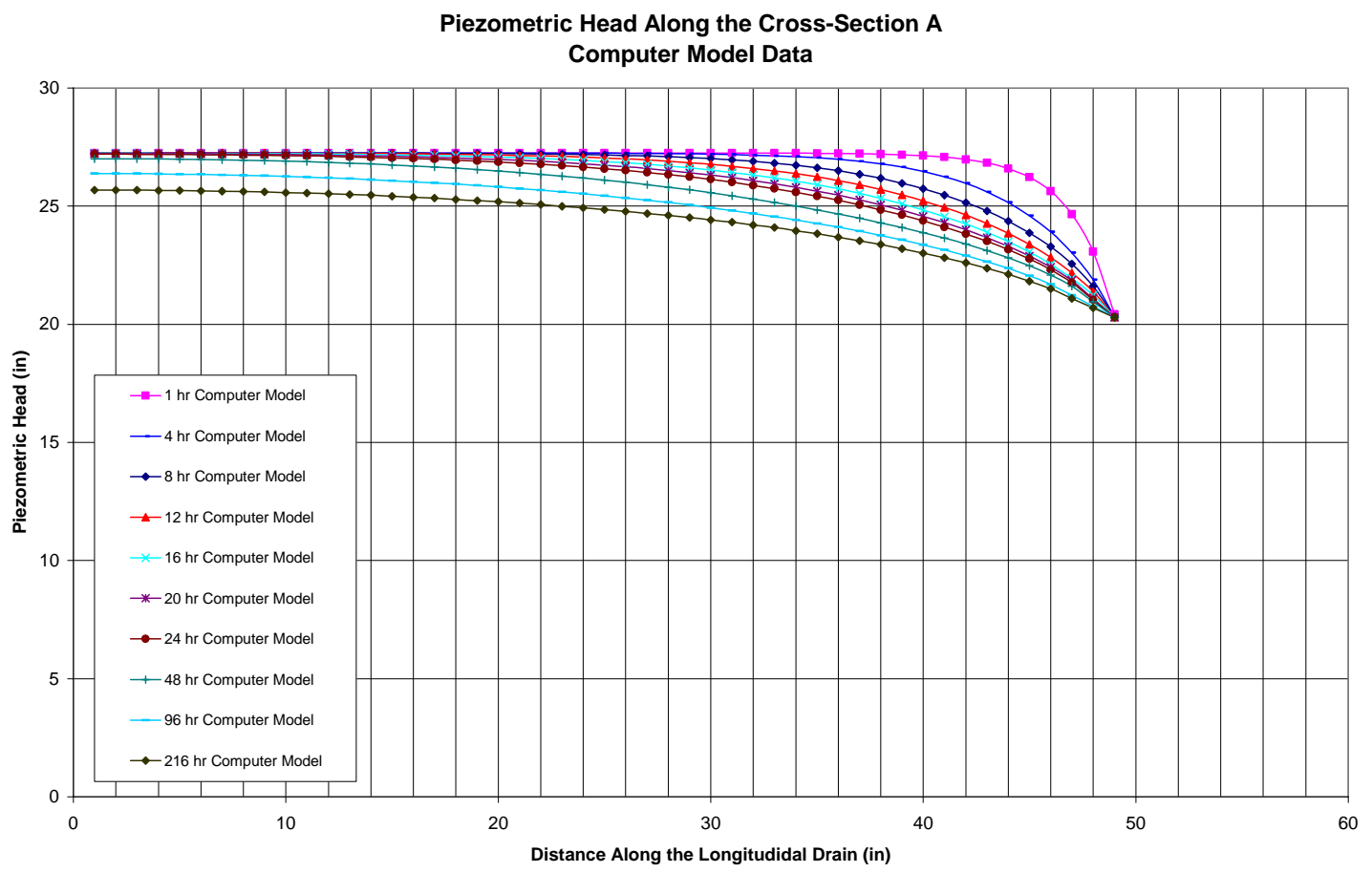

Figure A7.51: Piezometric head along cross-Section X for case A-48-144-10

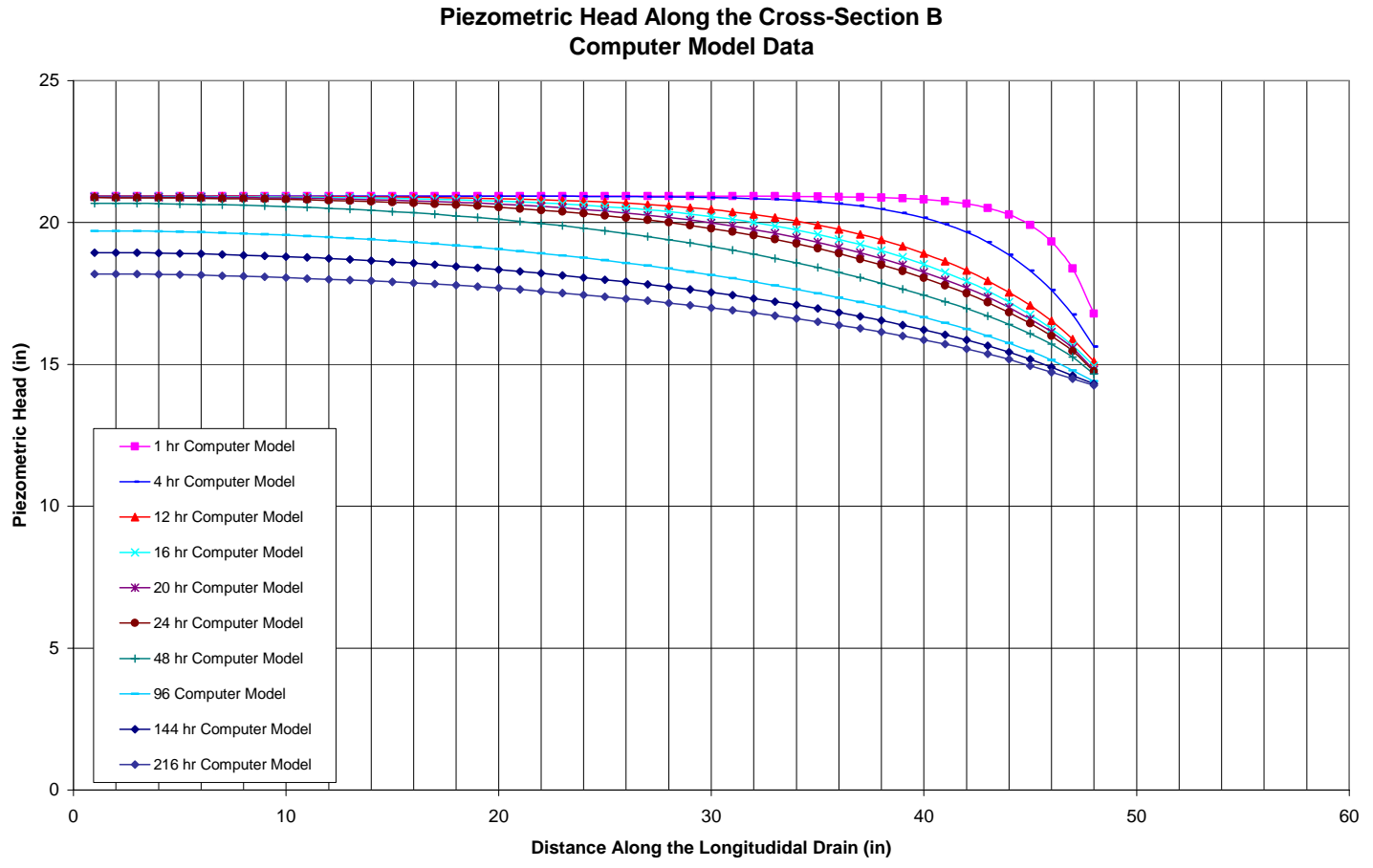

Figure A7.52: Piezometric head along cross-Section Y for case A-48-144-10 
Cumulative Percent Removed Along the Longitudinal Drain

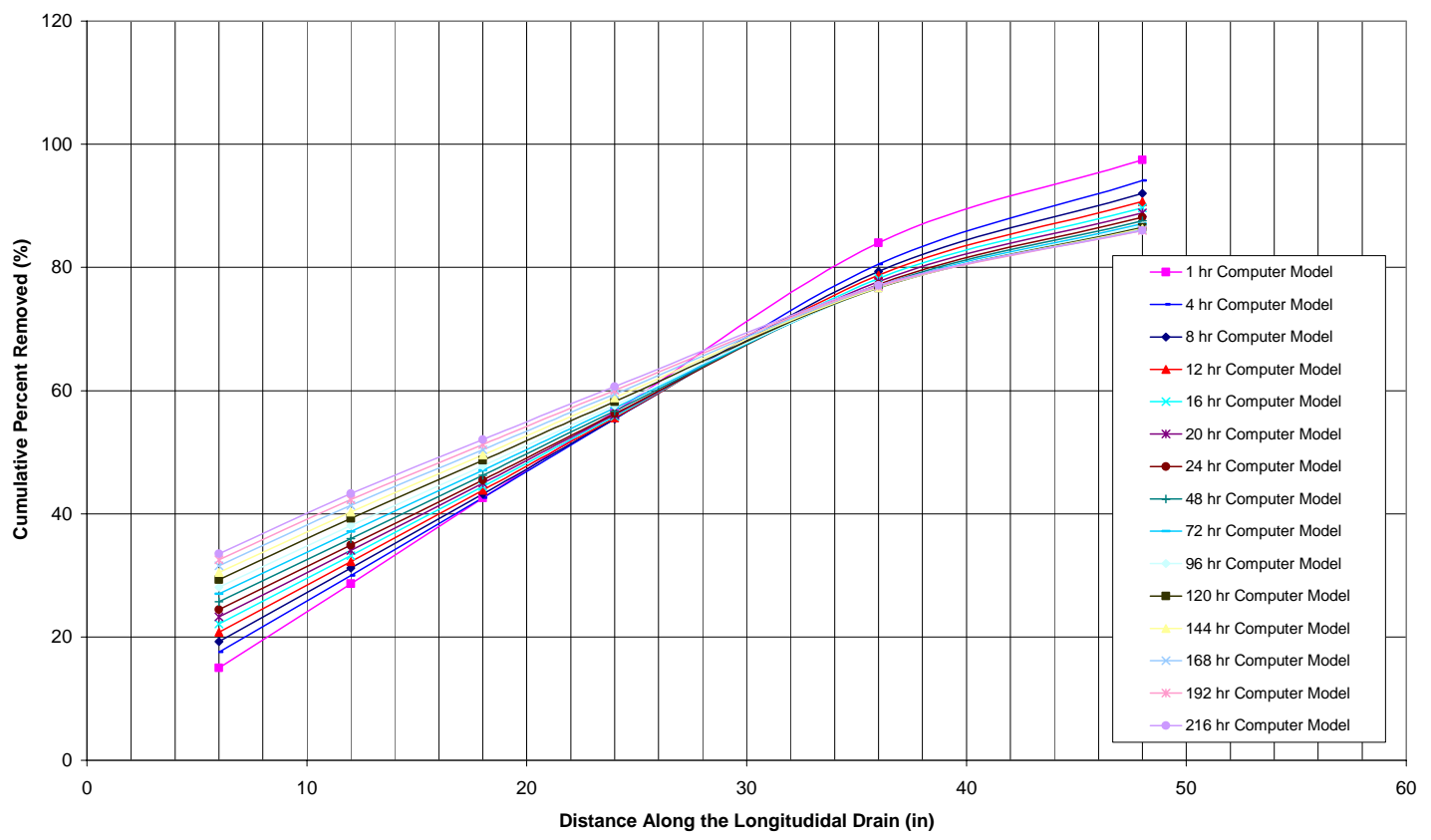

Figure A7.53: Cumulative Percent Removal for case A-48-192-10

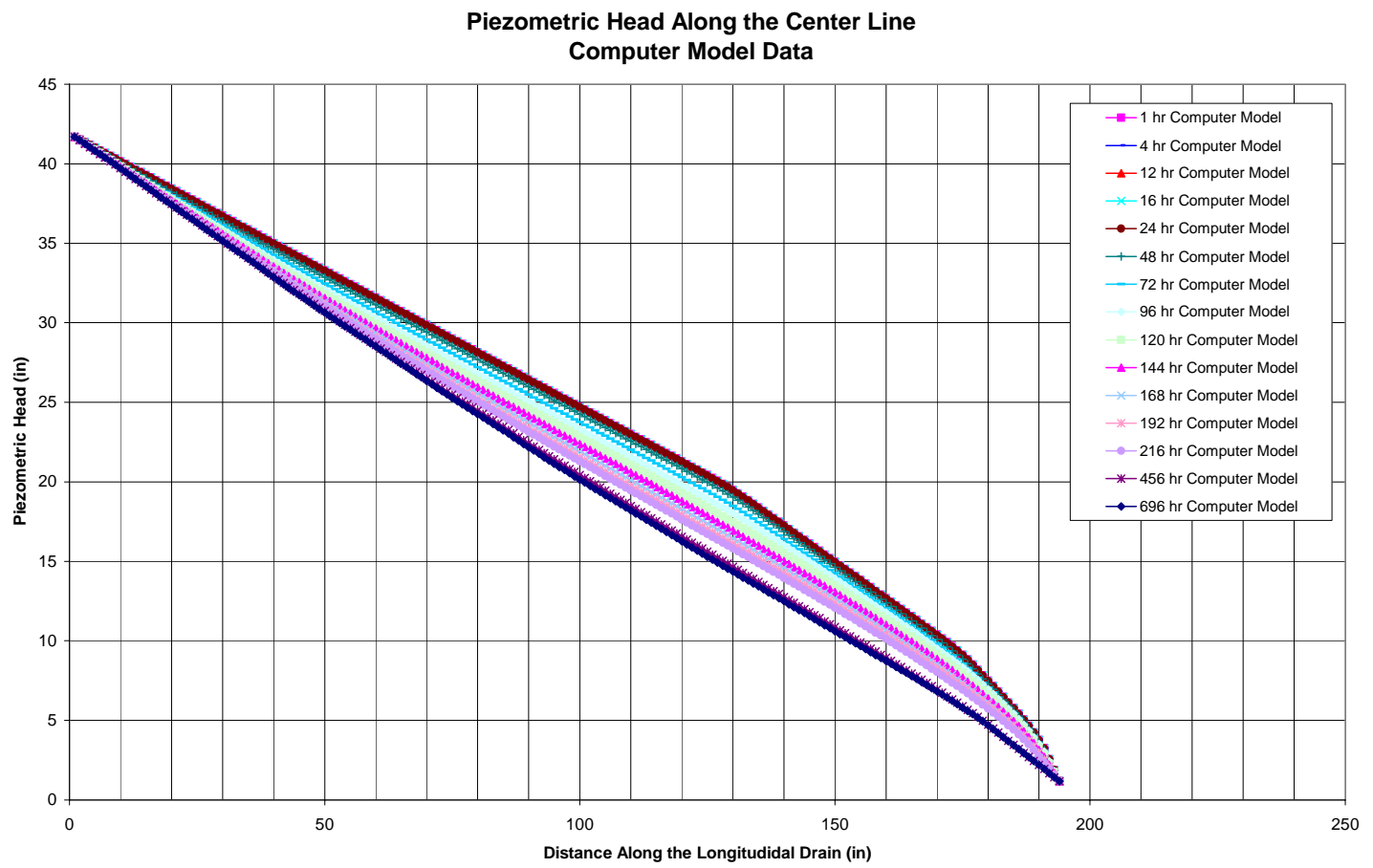

Figure A7.54: Piezometric head along center line for case A-48-192-10 


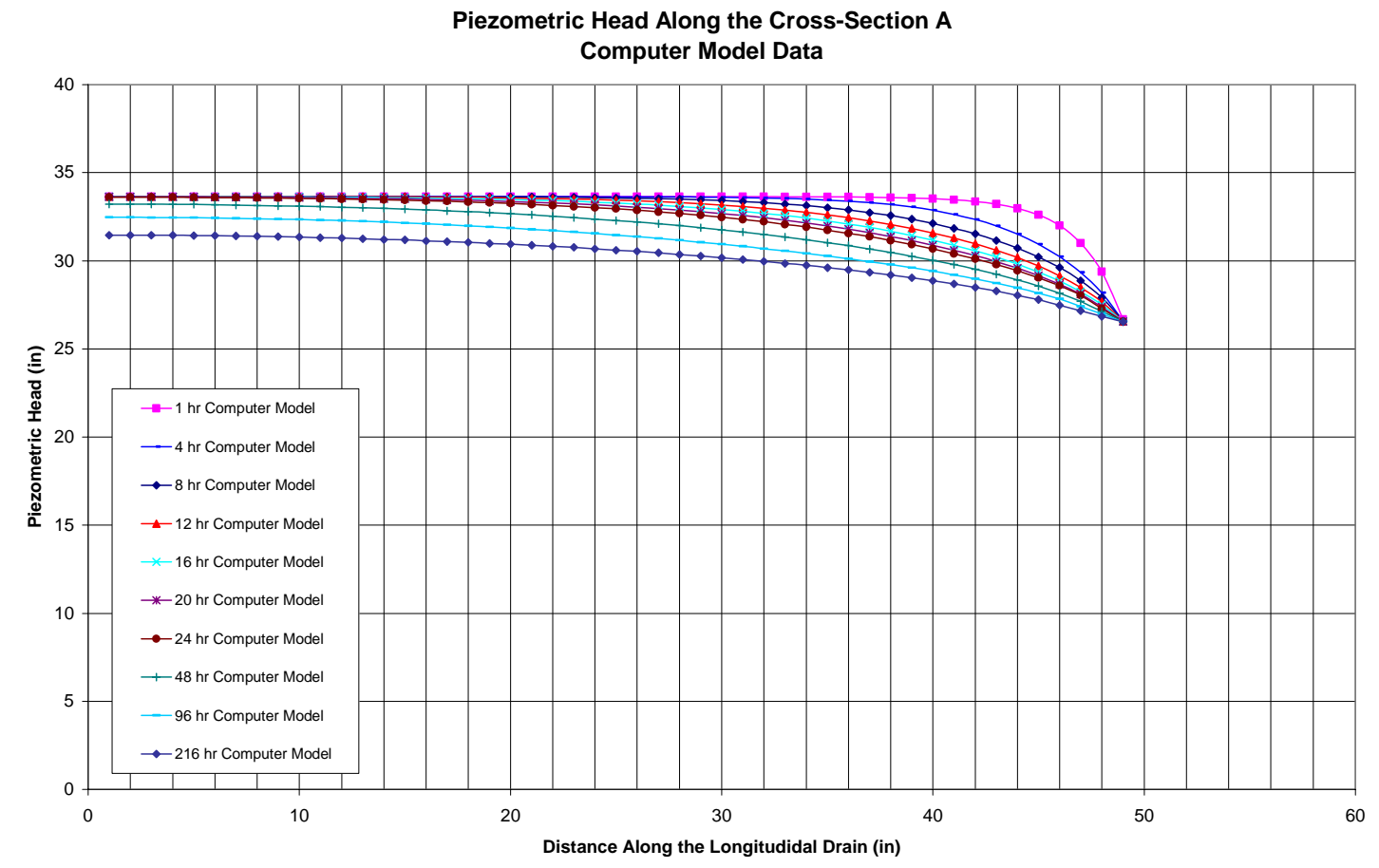

Figure A7.55: Piezometric head along cross-Section X for case A-48-192-10

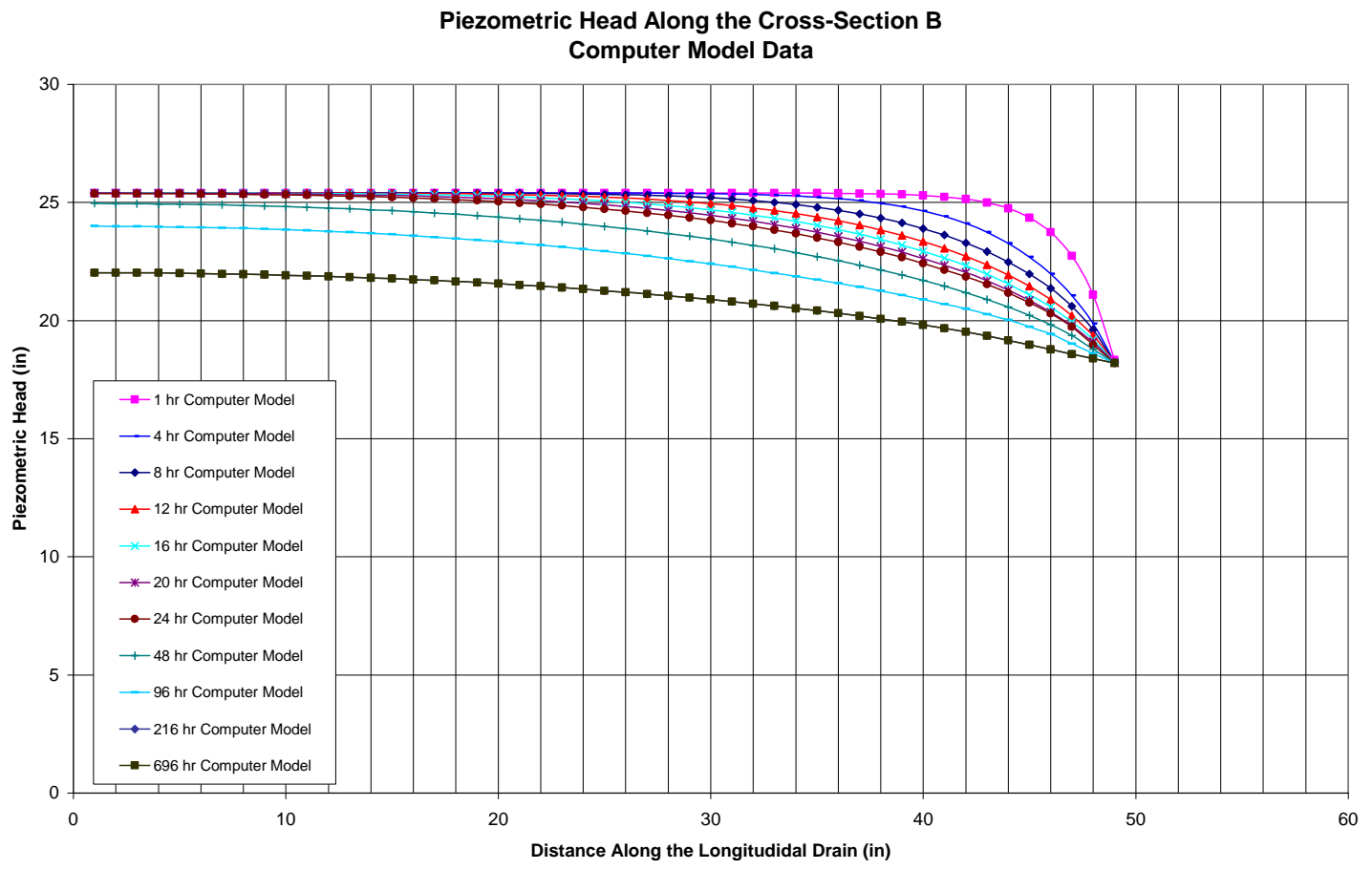

Figure A7.56: Piezometric head along cross-Section Y for case A-48-192-10 
Appendix A8: Results for Field Cases for Soils C and E

$$
\begin{aligned}
& W=12 \text { feet } \\
& I=48 \text { feet } \\
& \theta=20^{\circ}
\end{aligned}
$$




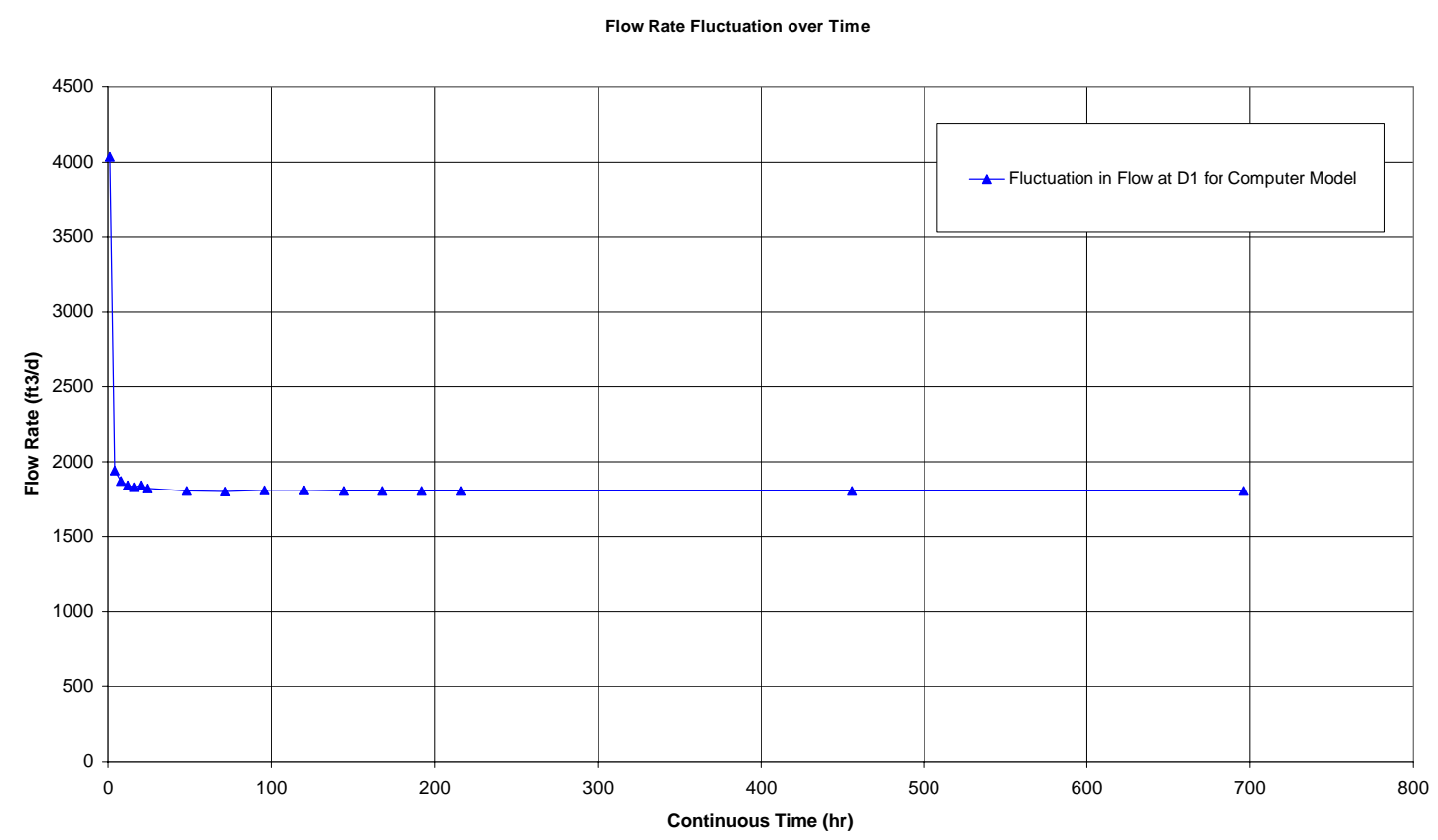

Figure A8.1: Fluctuation of Flow at D1 for Case C-12-48-20.

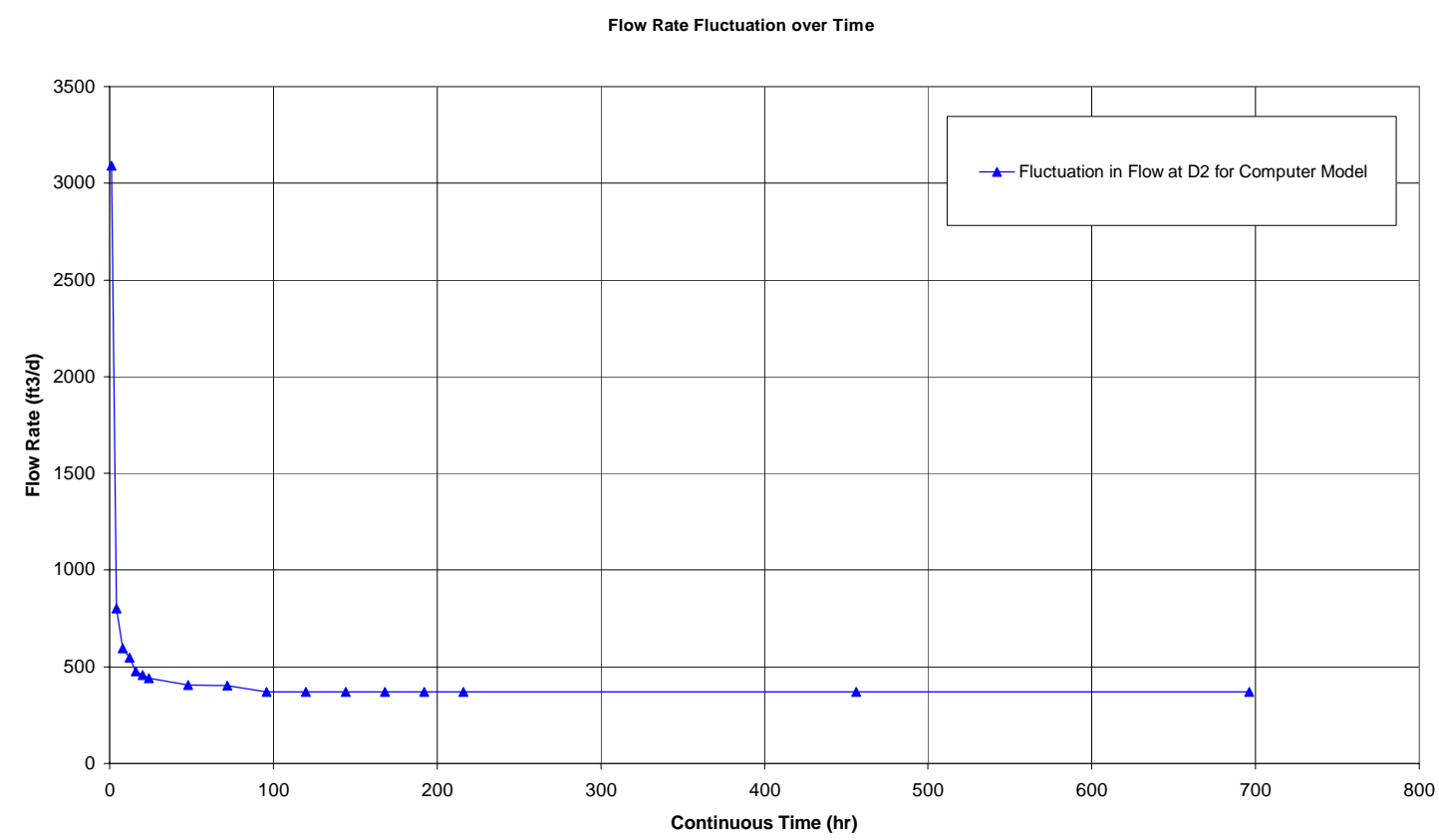

Figure A8.2: Fluctuation of Flow at D2 for Case C-12-48-20 
Flow Rate Fluctuation over Time

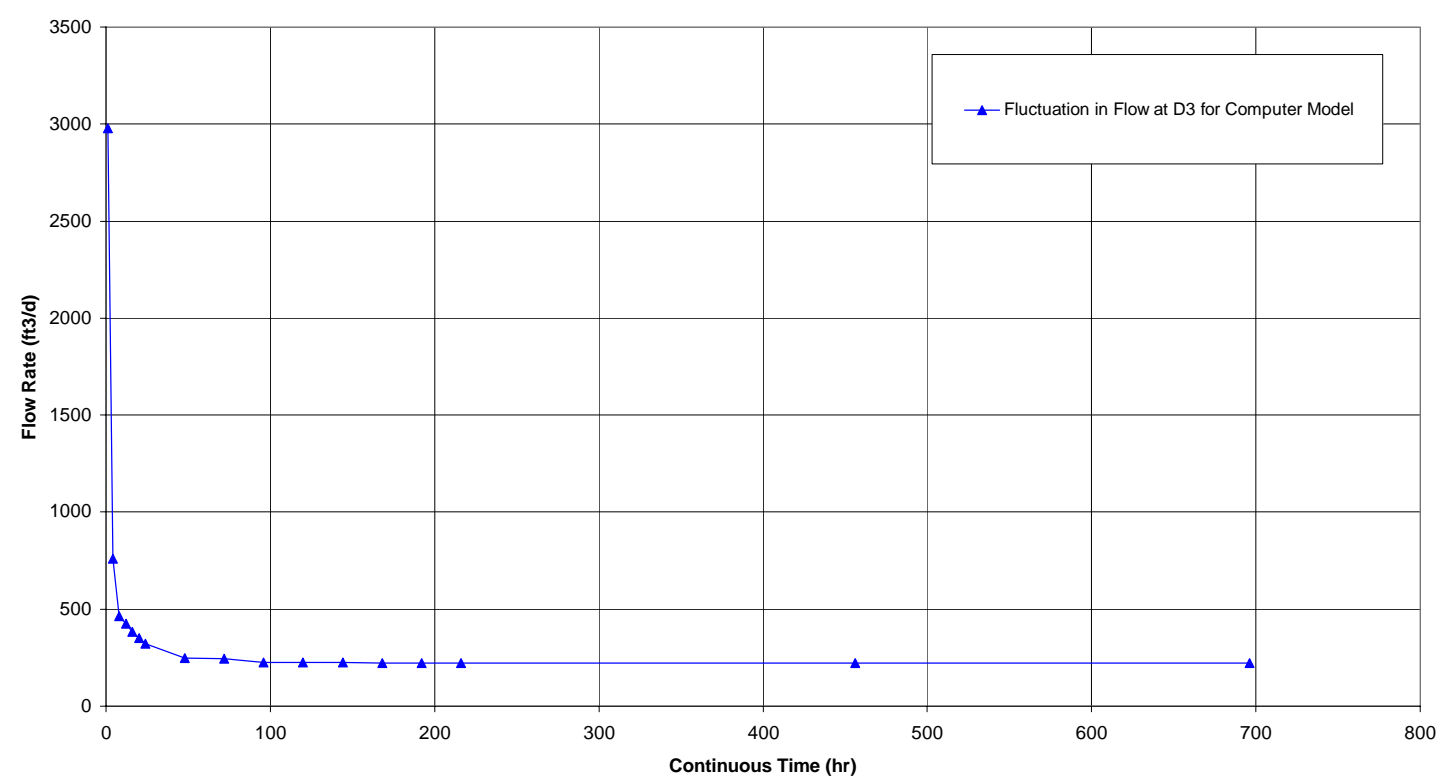

Figure A8.3: Fluctuation of Flow at D3 for Case C-12-48-20

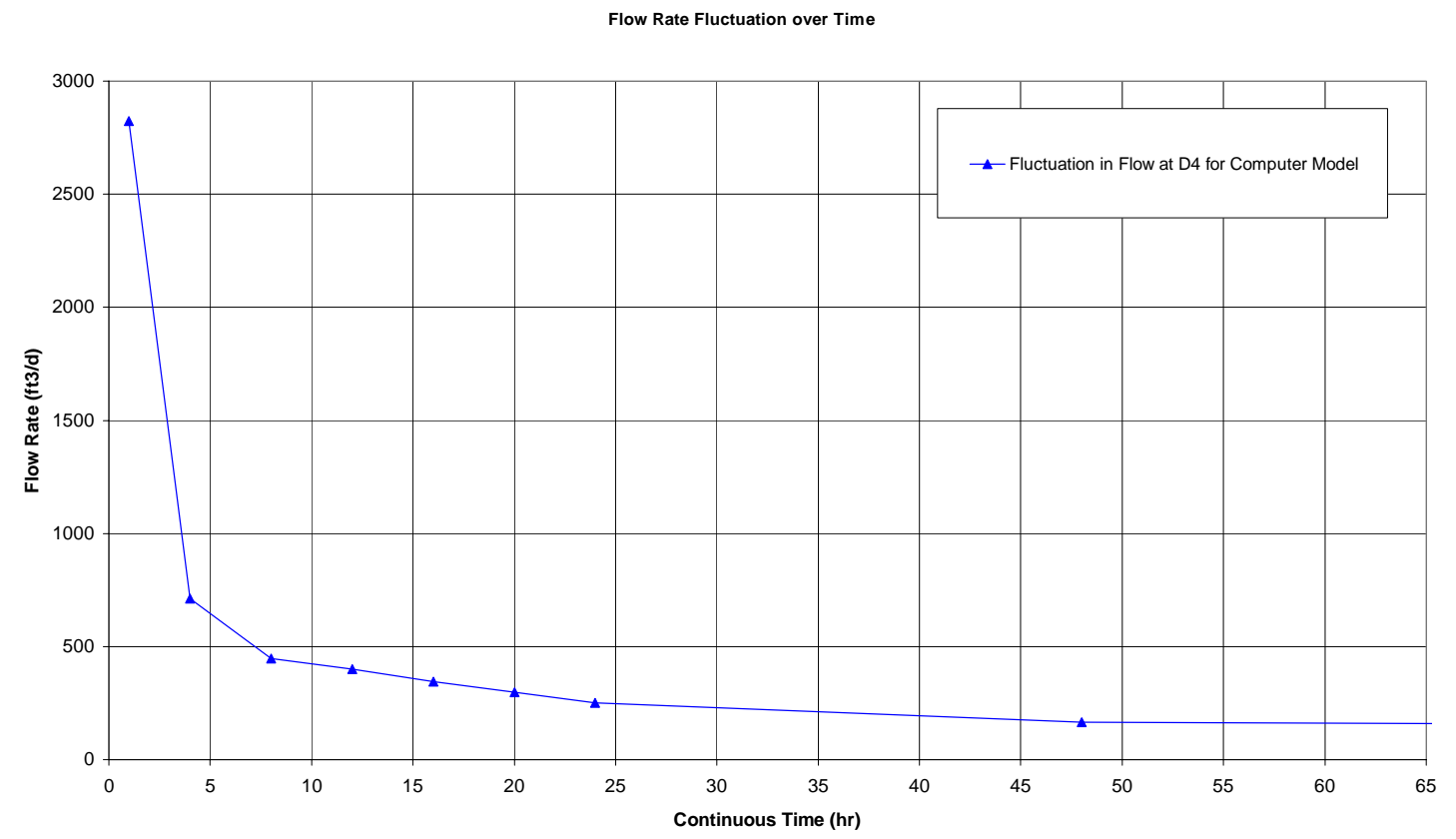

Figure A8.4: Fluctuation of Flow at D4 for Case C-12-48-20 
Flow Rate Fluctuation over Time

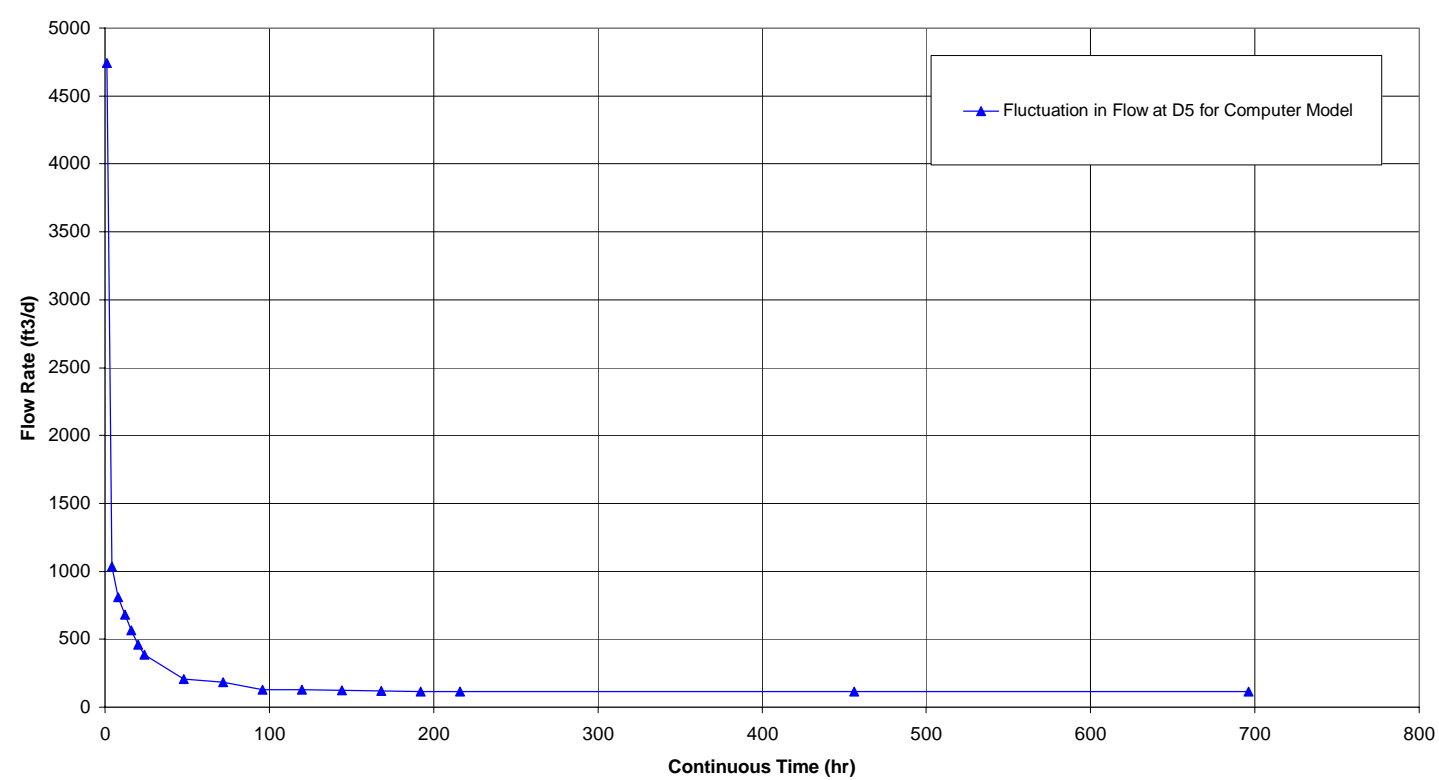

Figure A8.5: Fluctuation of Flow at D5 for Case C-12-48-20

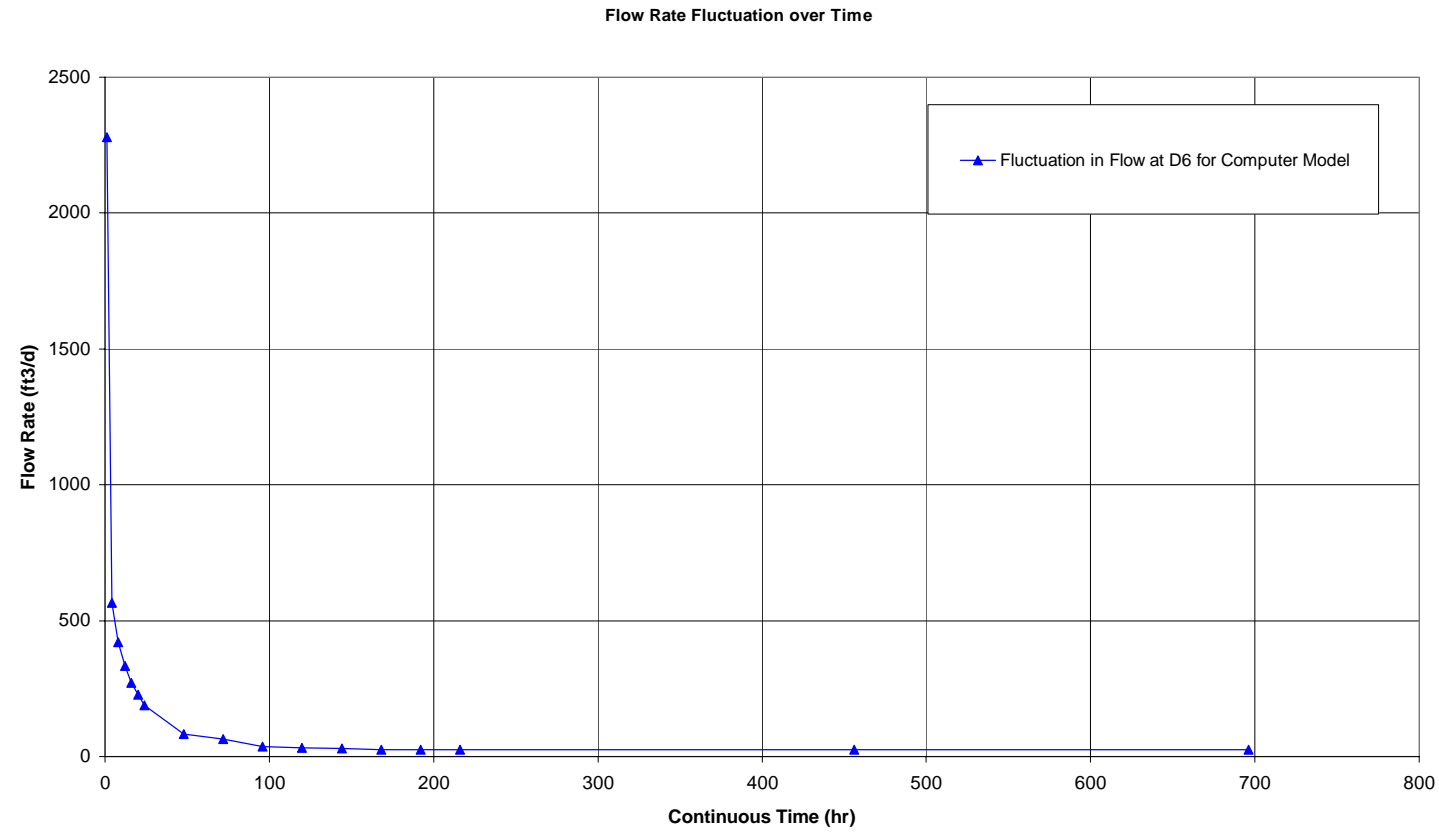

Figure A8.6: Fluctuation of Flow at D6 for Case C-12-48-20 
Flow Rate Fluctuation over Time

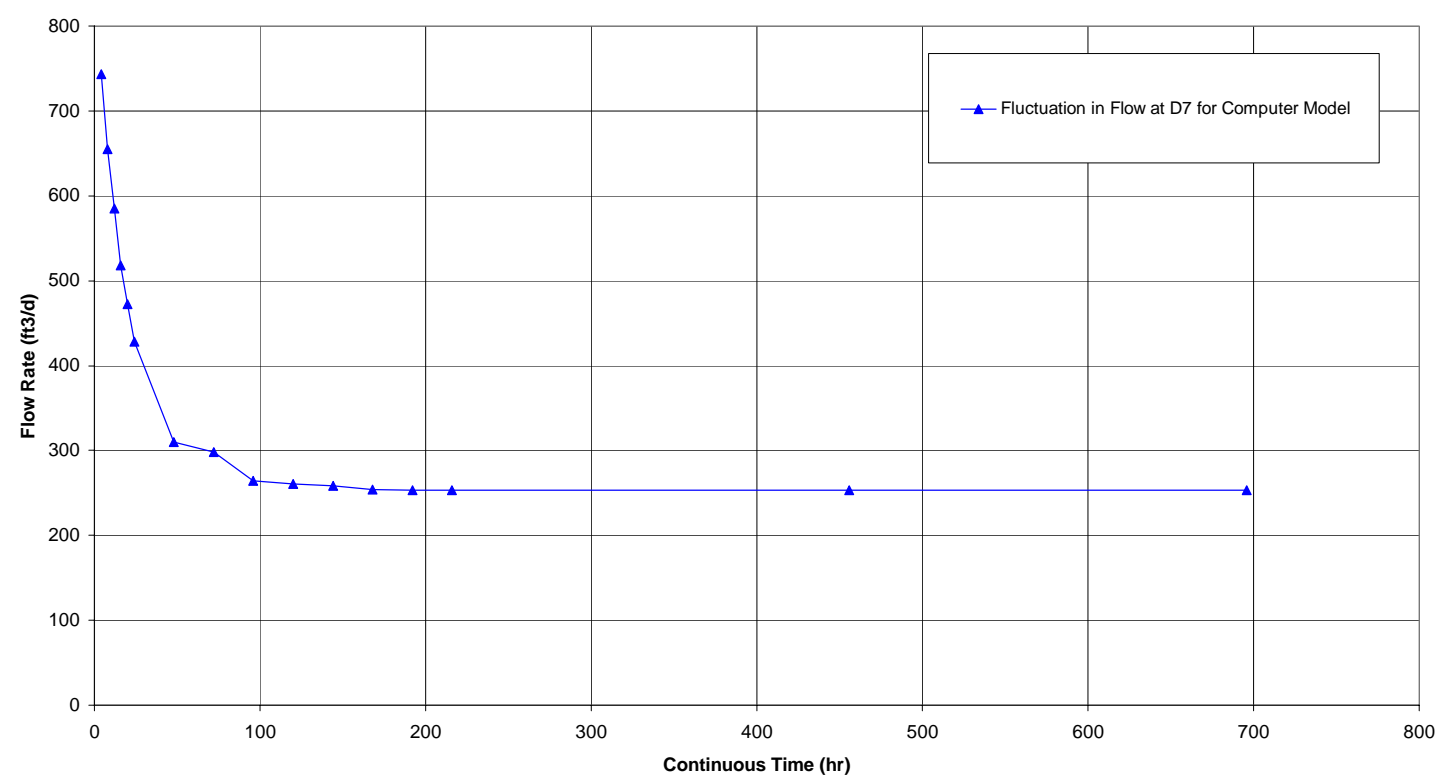

Figure A8.7: Fluctuation of Flow at D7 for Case C-12-48-20

Cumulative Percent Removed Along the Longitudinal Drain

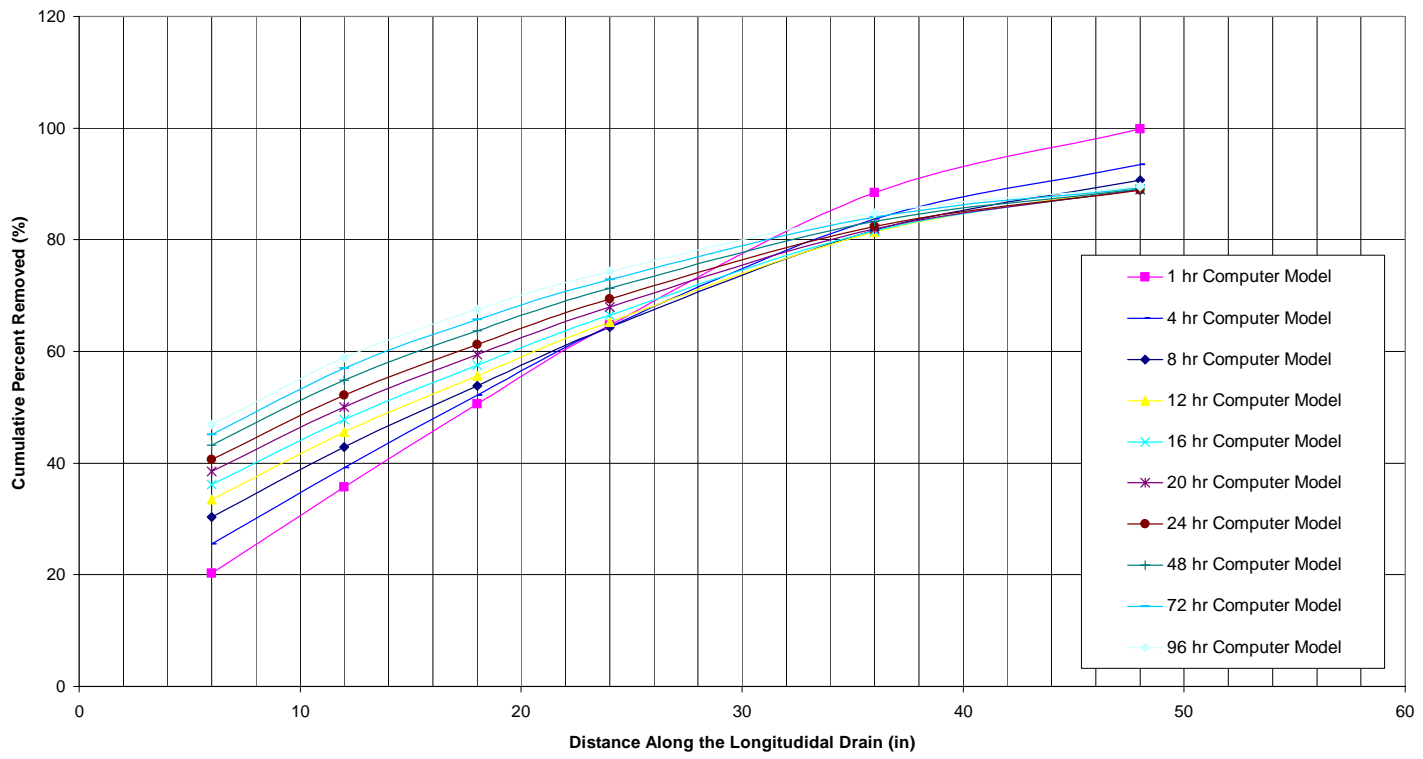

Figure A8.8: Cumulative Percent Removed Along the Drain for Case C12-48-20 


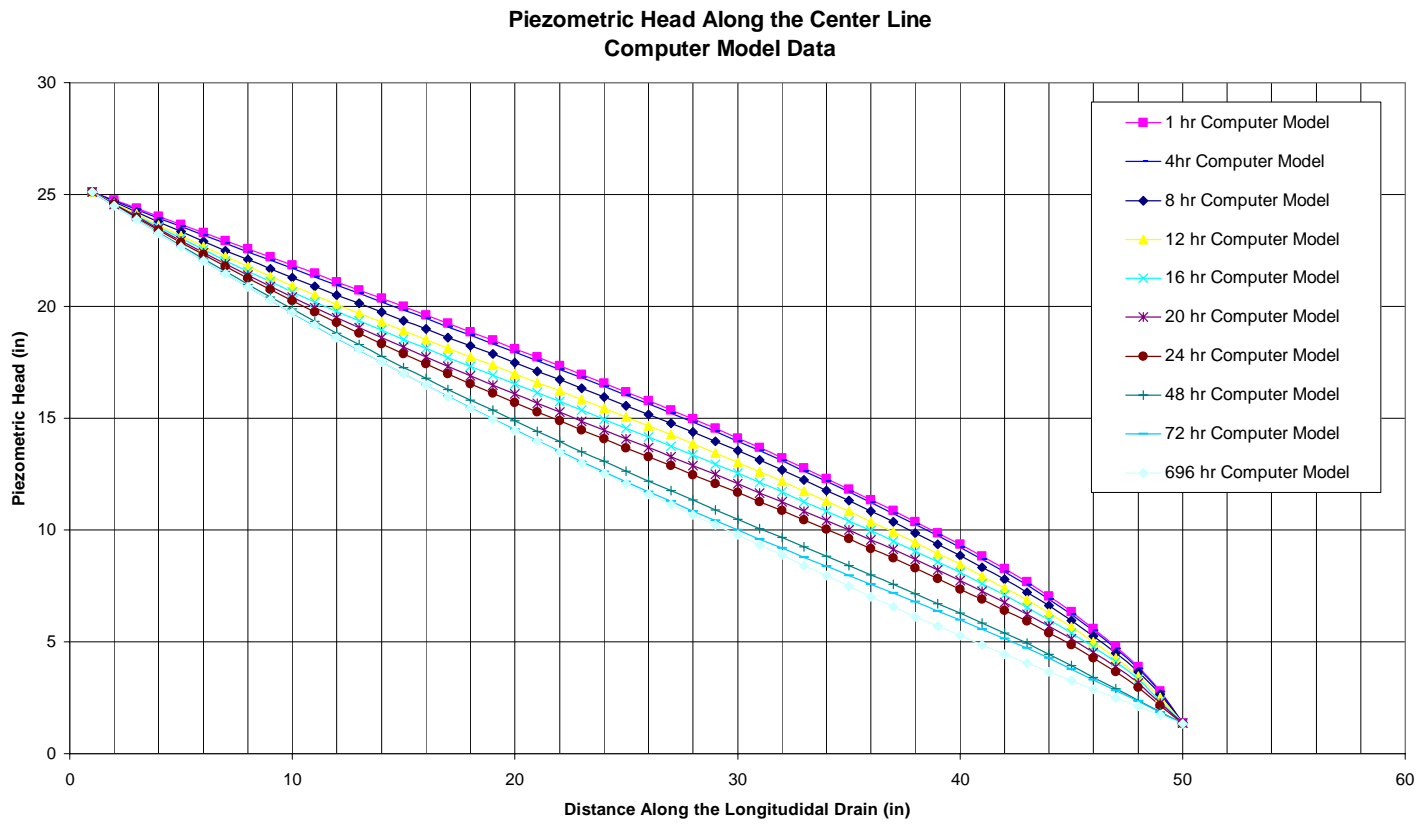

Figure A8.9: Variation of Piezometric Head Along the Center Line for case C-12-48-20

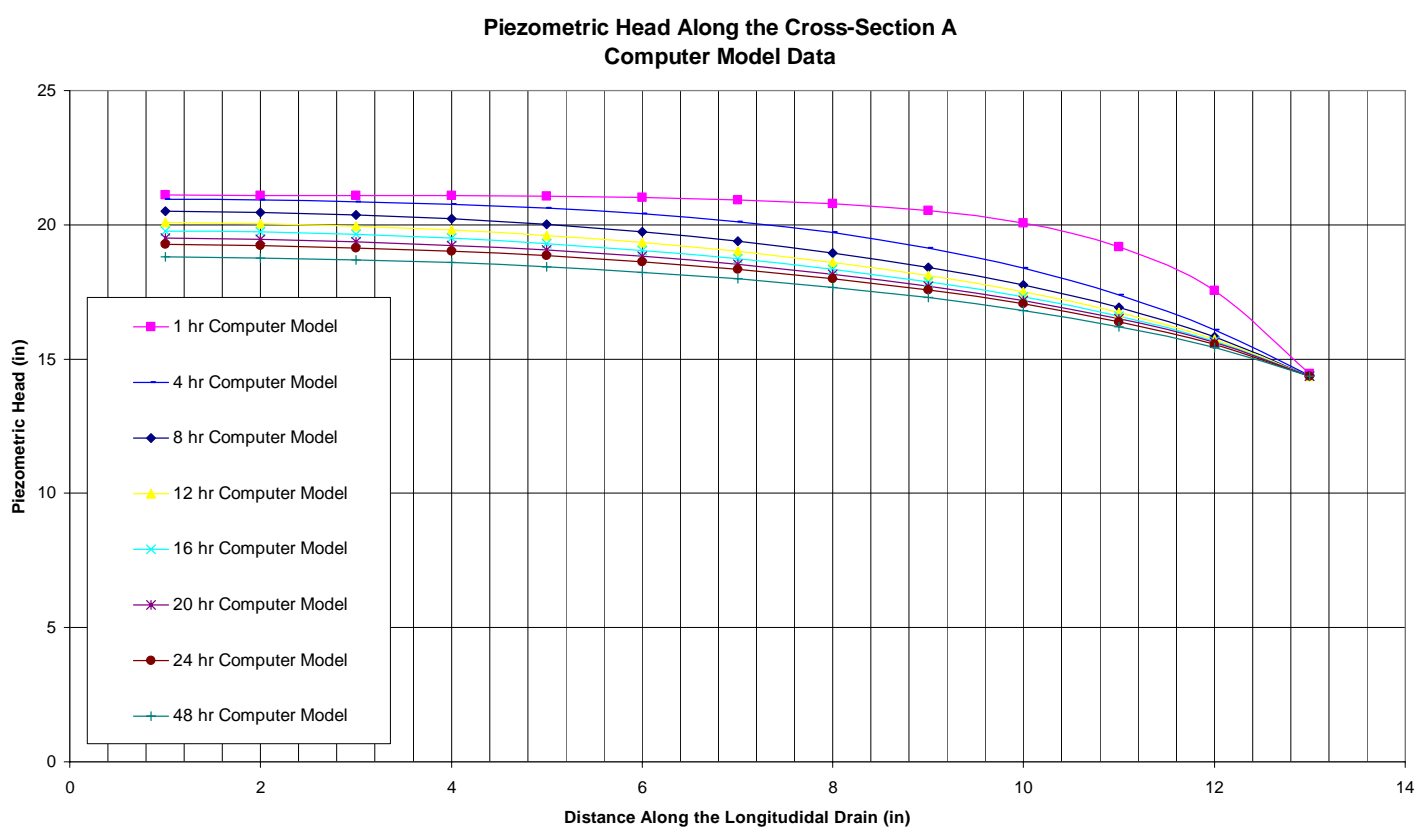

Figure A8.10: Variation of Piezometric Head Along cross-Section A for case C-12-48-20 


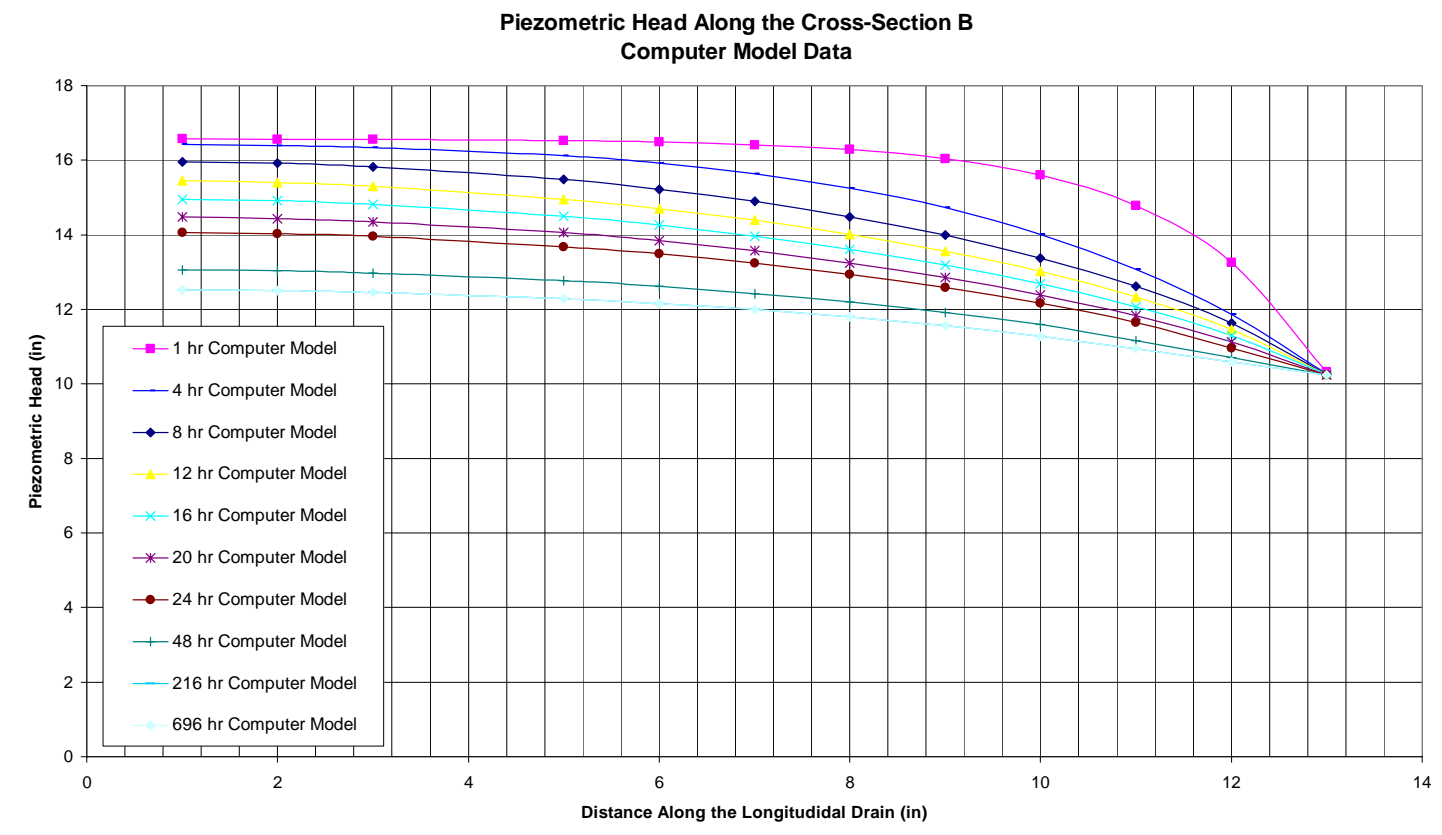

Figure A8.11: Variation of Piezometric Head Along cross-Section B for case C-12-48-20 
Flow Rate Fluctuation over Time

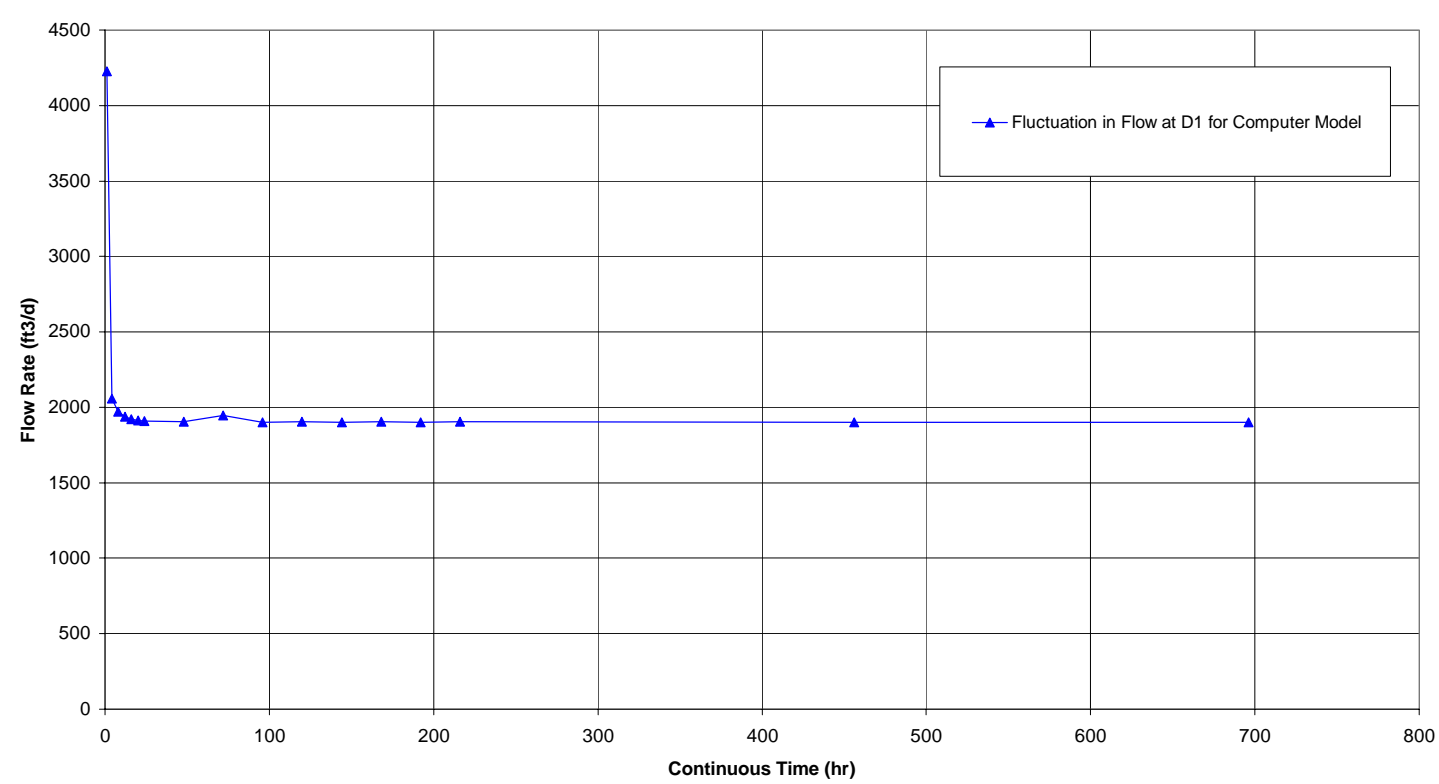

Figure A8.12: Fluctuation of Flow at D1 for Case C-12-48-30

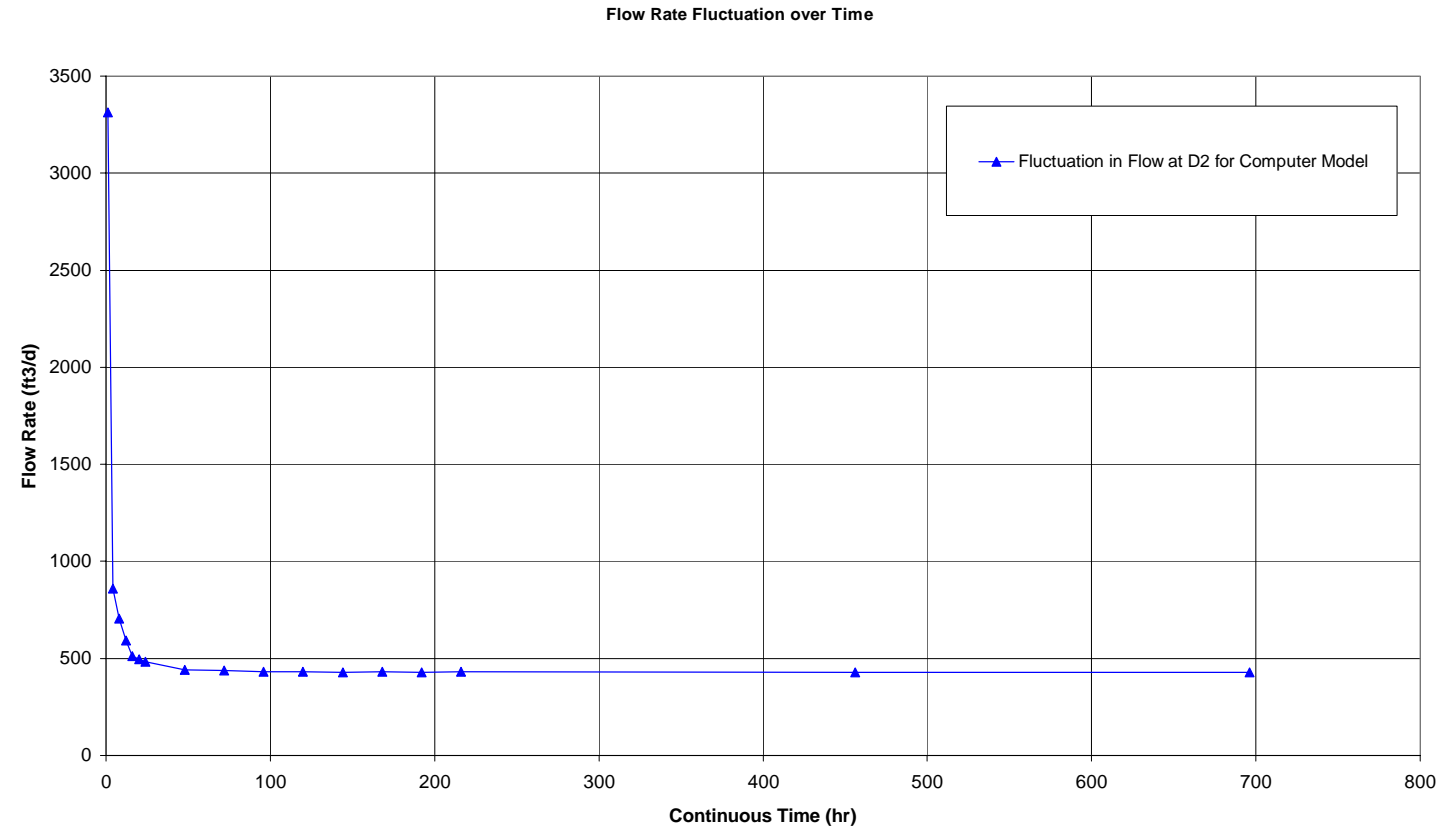

Figure A8.13: Fluctuation of Flow at D2 for Case C-12-48-30 


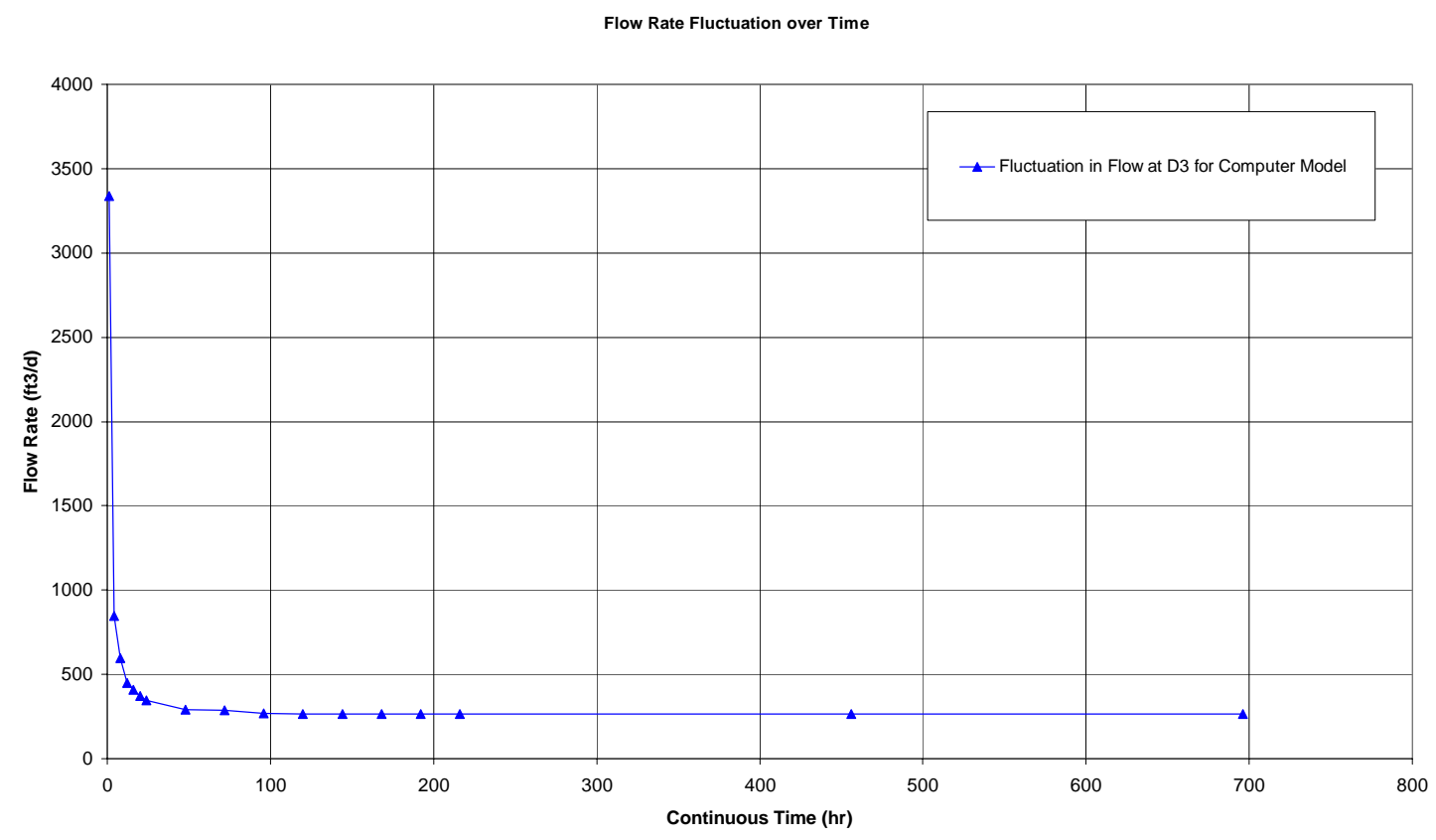

Figure A8.14: Fluctuation of Flow at D3 for Case C-12-48-30

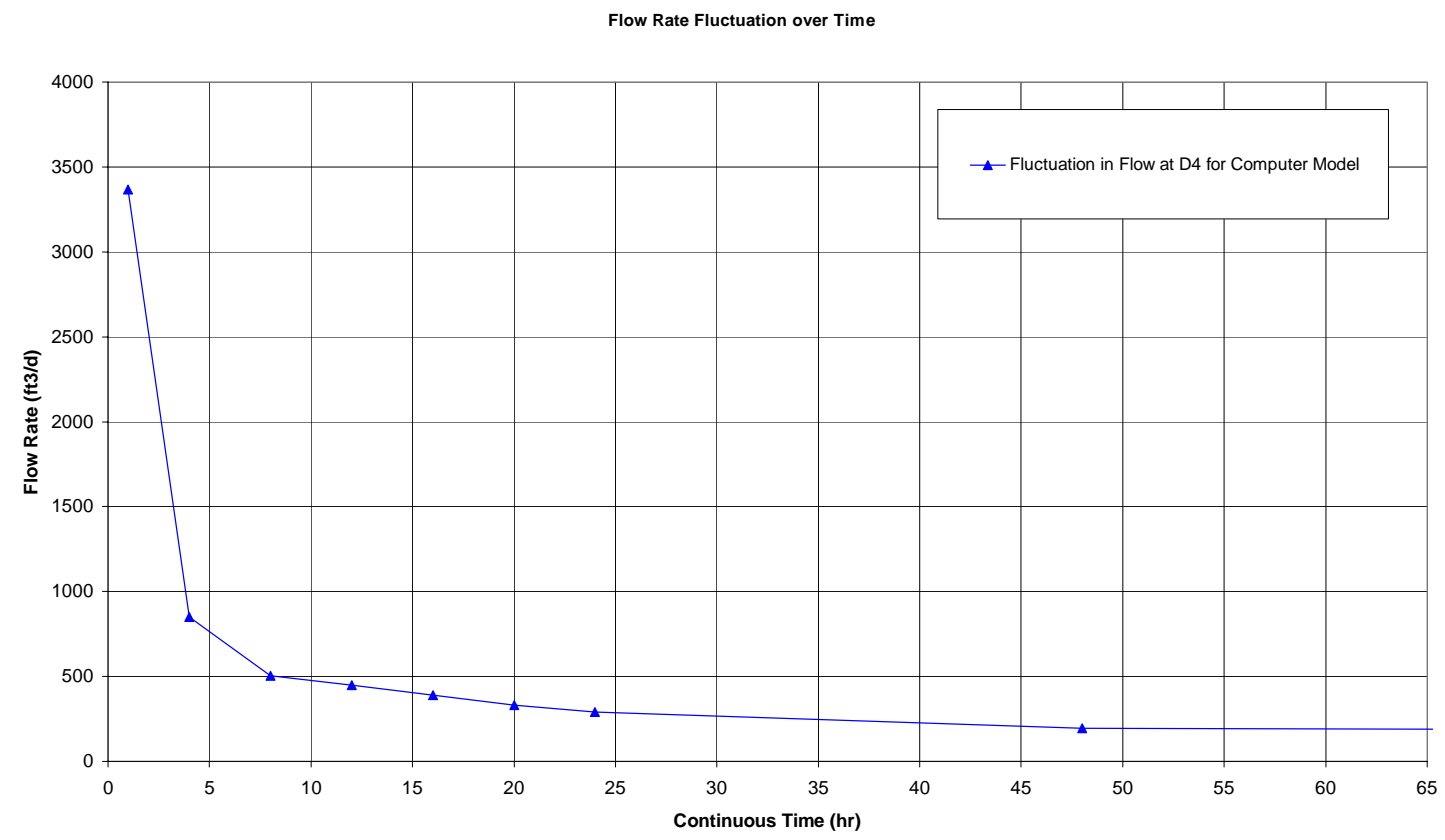

Figure A8.15: Fluctuation of Flow at D4 for Case C-12-48-30 
Flow Rate Fluctuation over Time

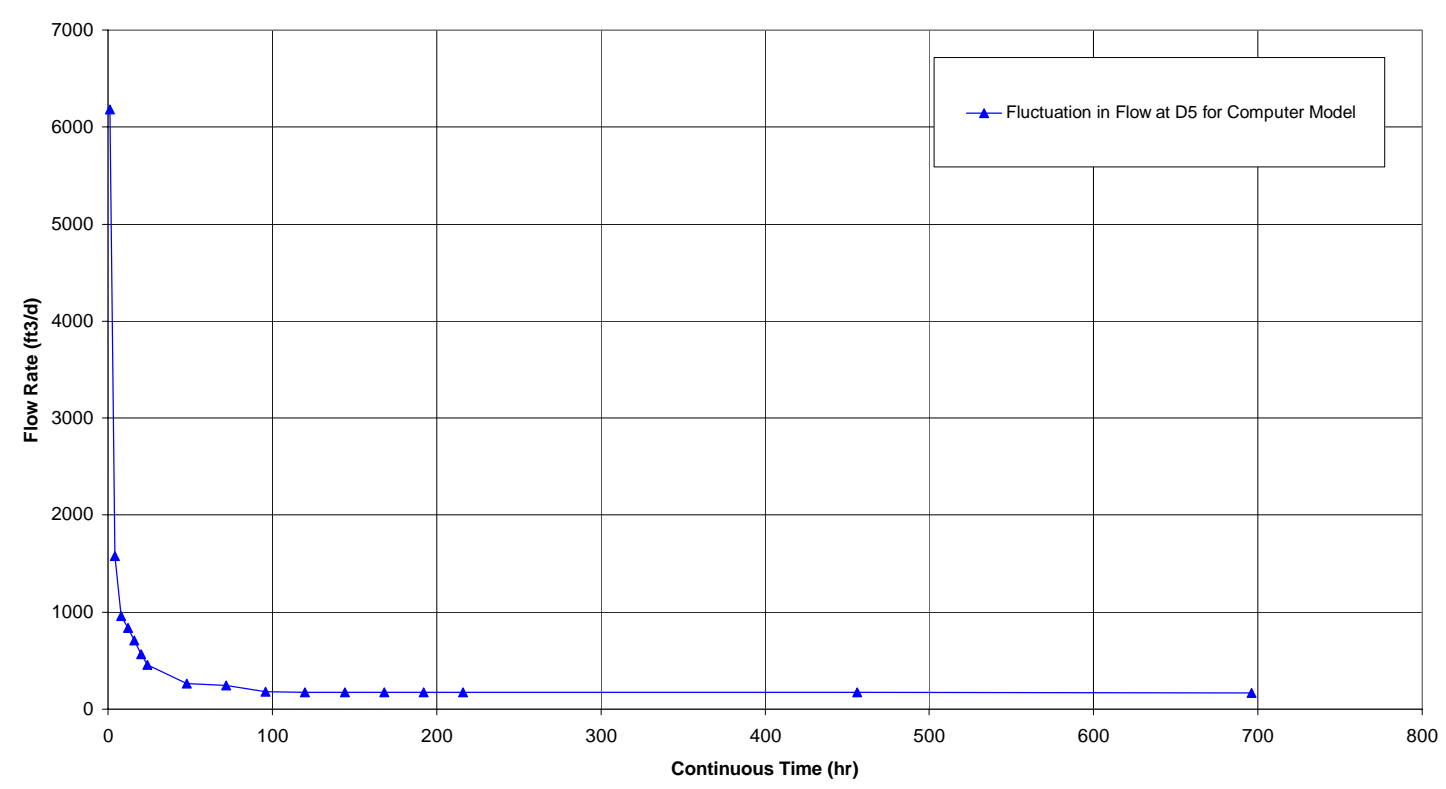

Figure A8.16: Fluctuation of Flow at D5 for Case C-12-48-30

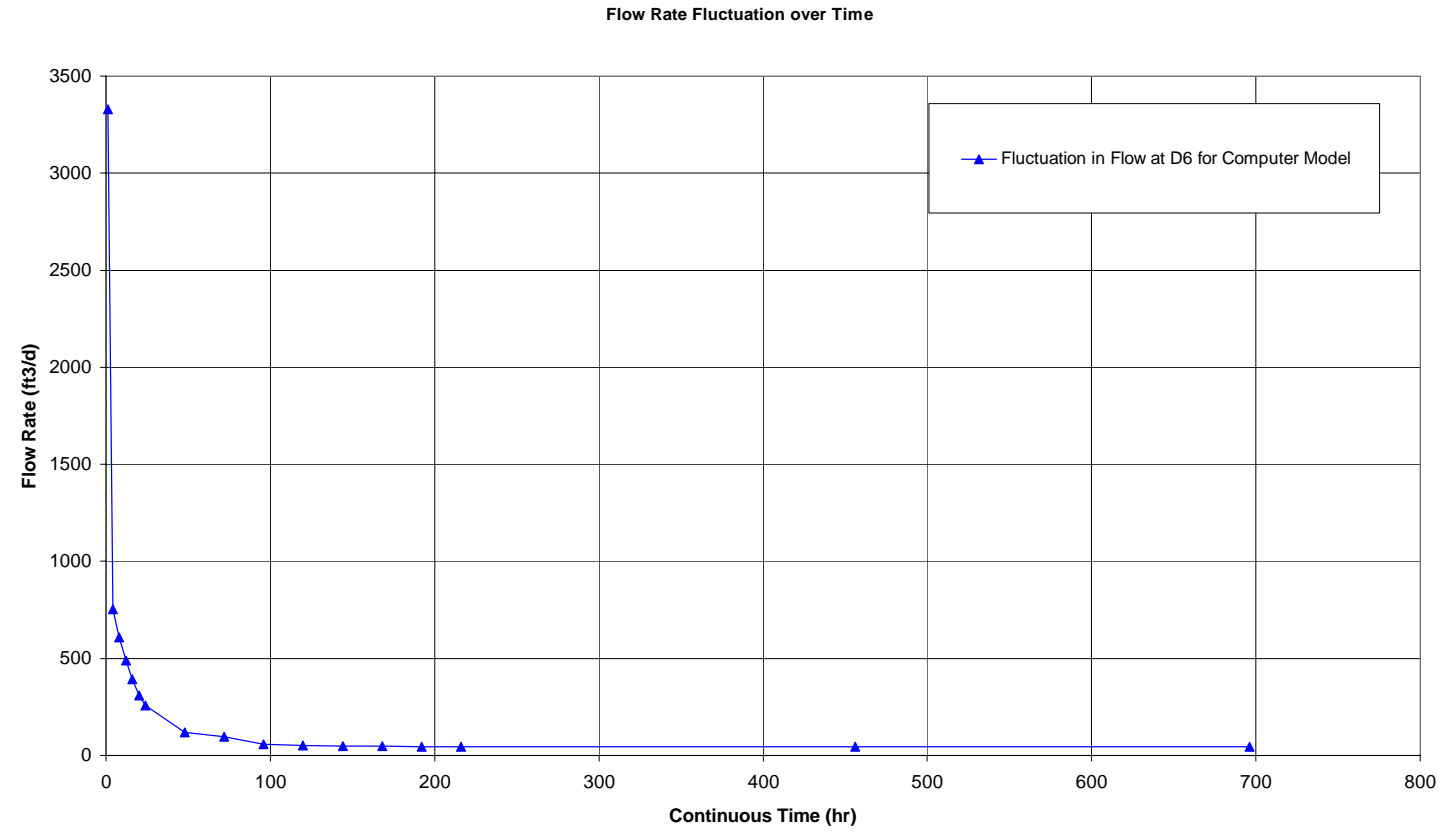

Figure A8.17: Fluctuation of Flow at D6 for Case C-12-48-30 
Flow Rate Fluctuation over Time

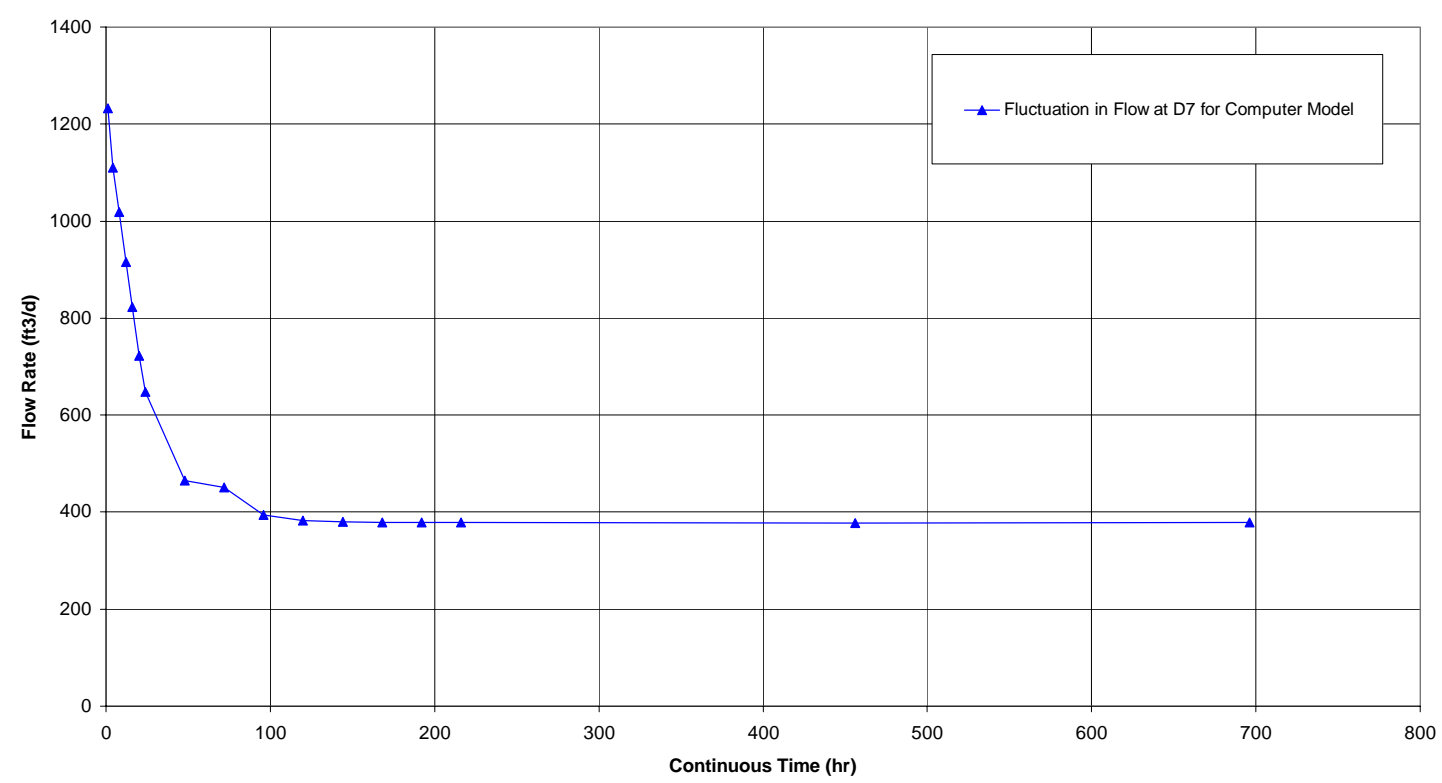

Figure A8.18: Fluctuation of Flow at D7 for Case C-12-48-30

Cumulative Percent Removed Along the Longitudinal Drain

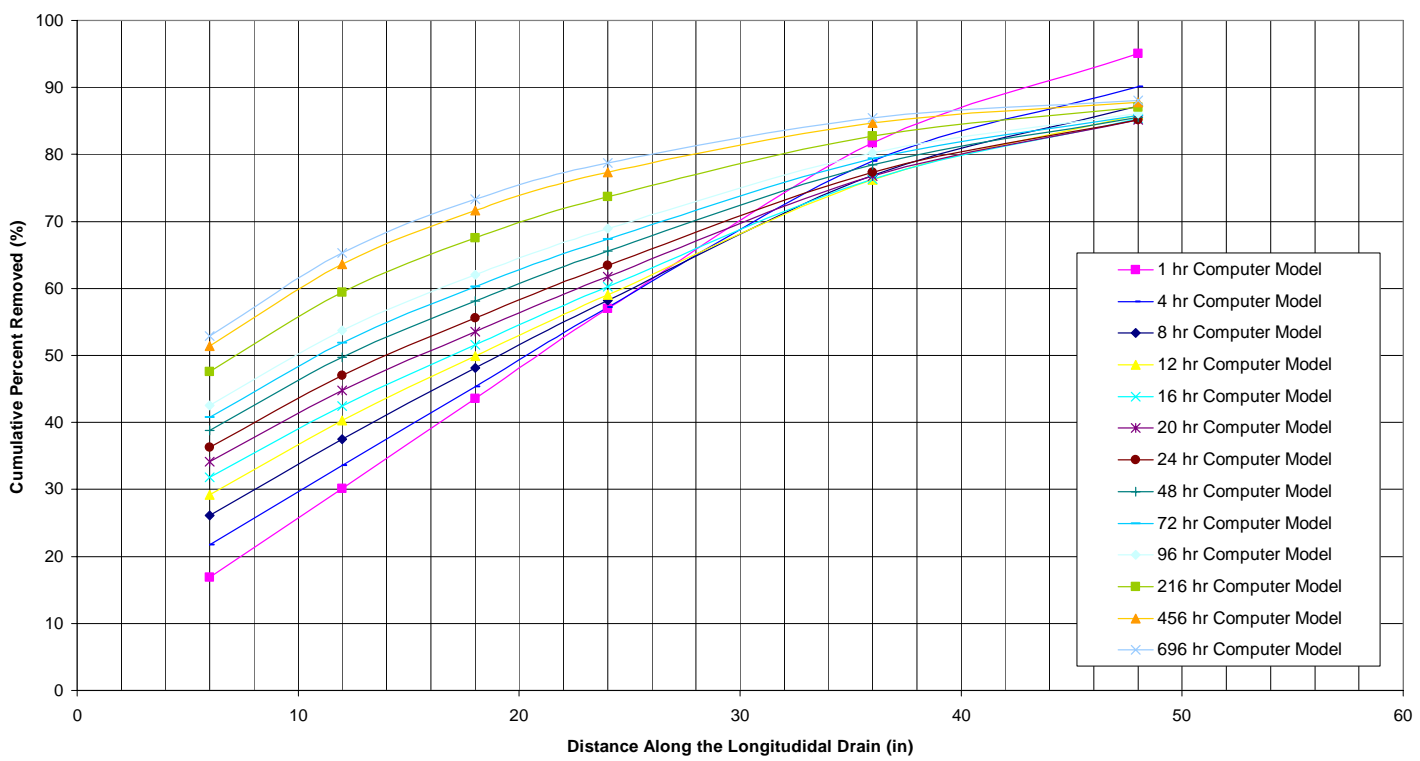

Figure A8.19: Cumulative Percent Removed Along the Drain for Case C12-48-30 


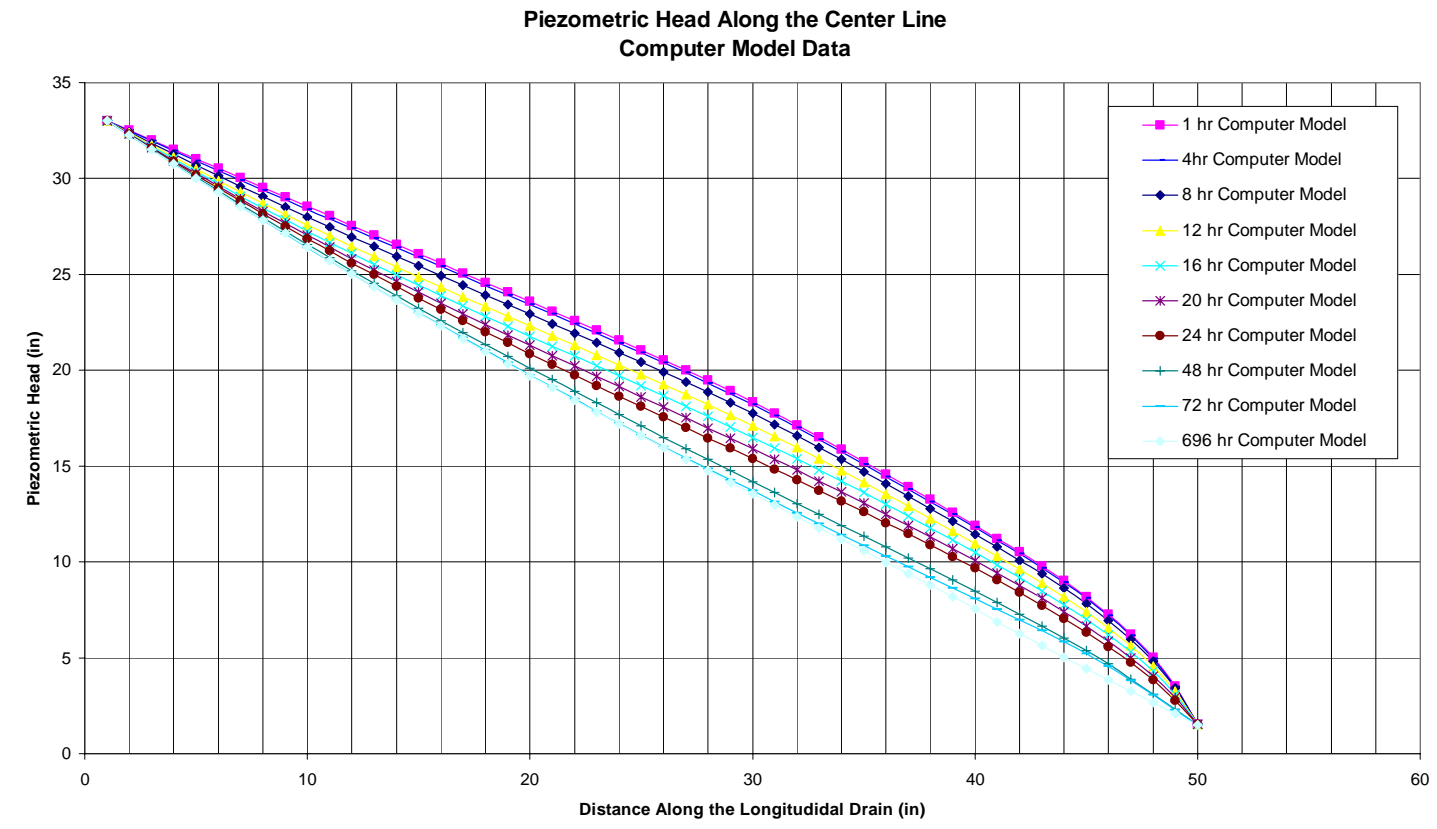

Figure A8.20: Variation of Piezometric Head Along the Center Line for case C-12-48-30

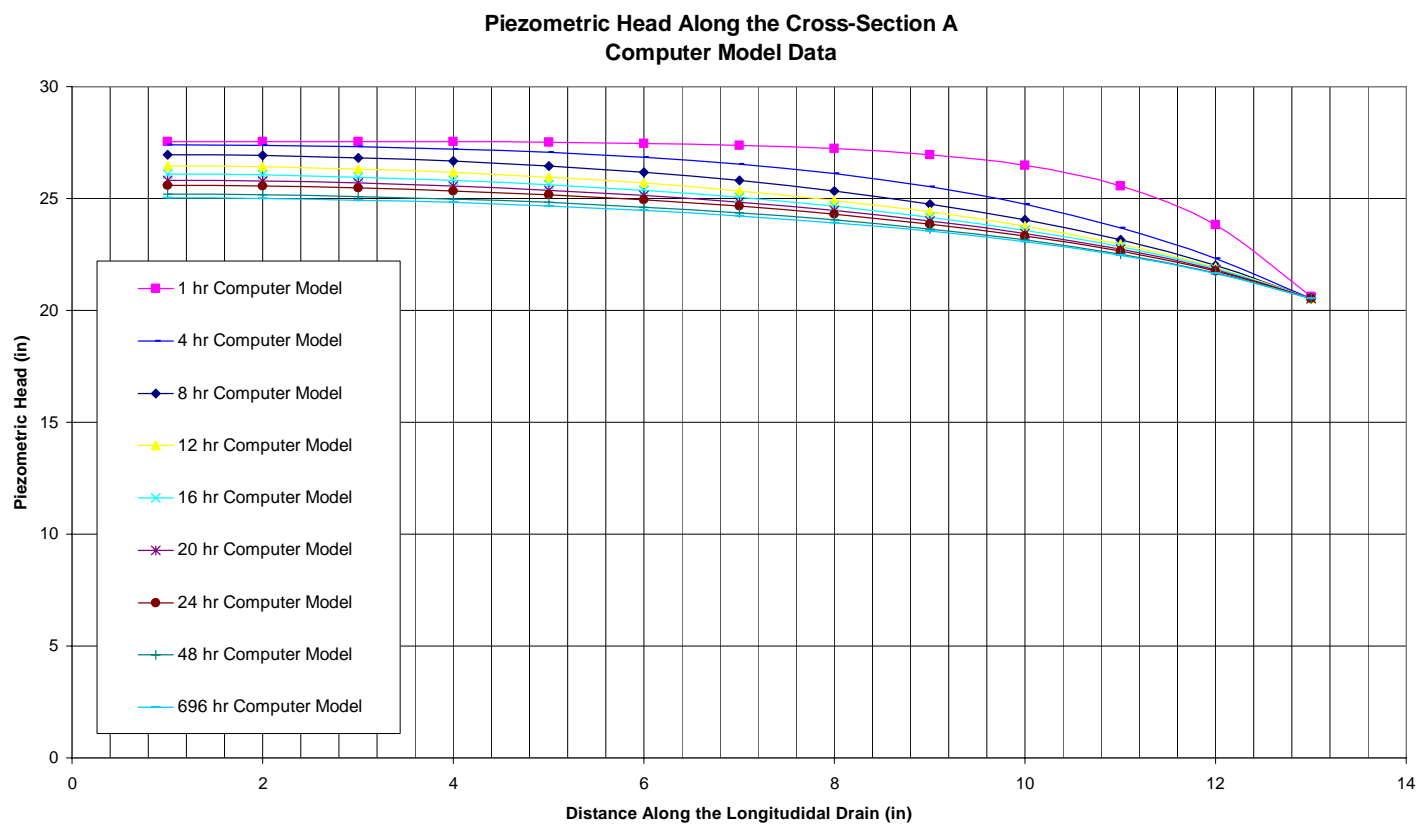

Figure A8.21: Variation of Piezometric Head Along Cross-Section A for case C-12-48-30 


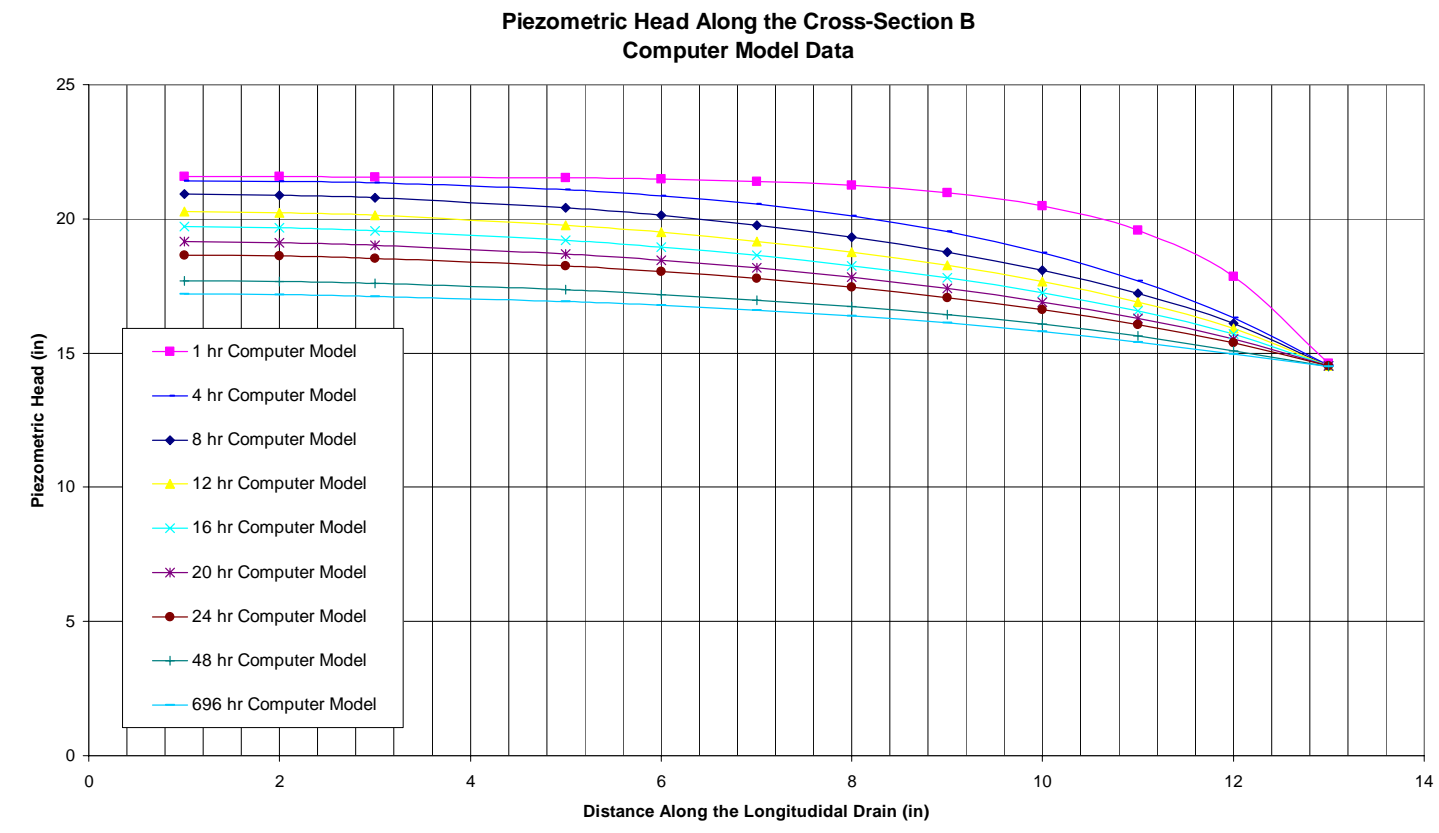

Figure A8.22: Variation of Piezometric Head Along Cross-Section B for case C-12-48-30 
Flow Rate Fluctuation over Time

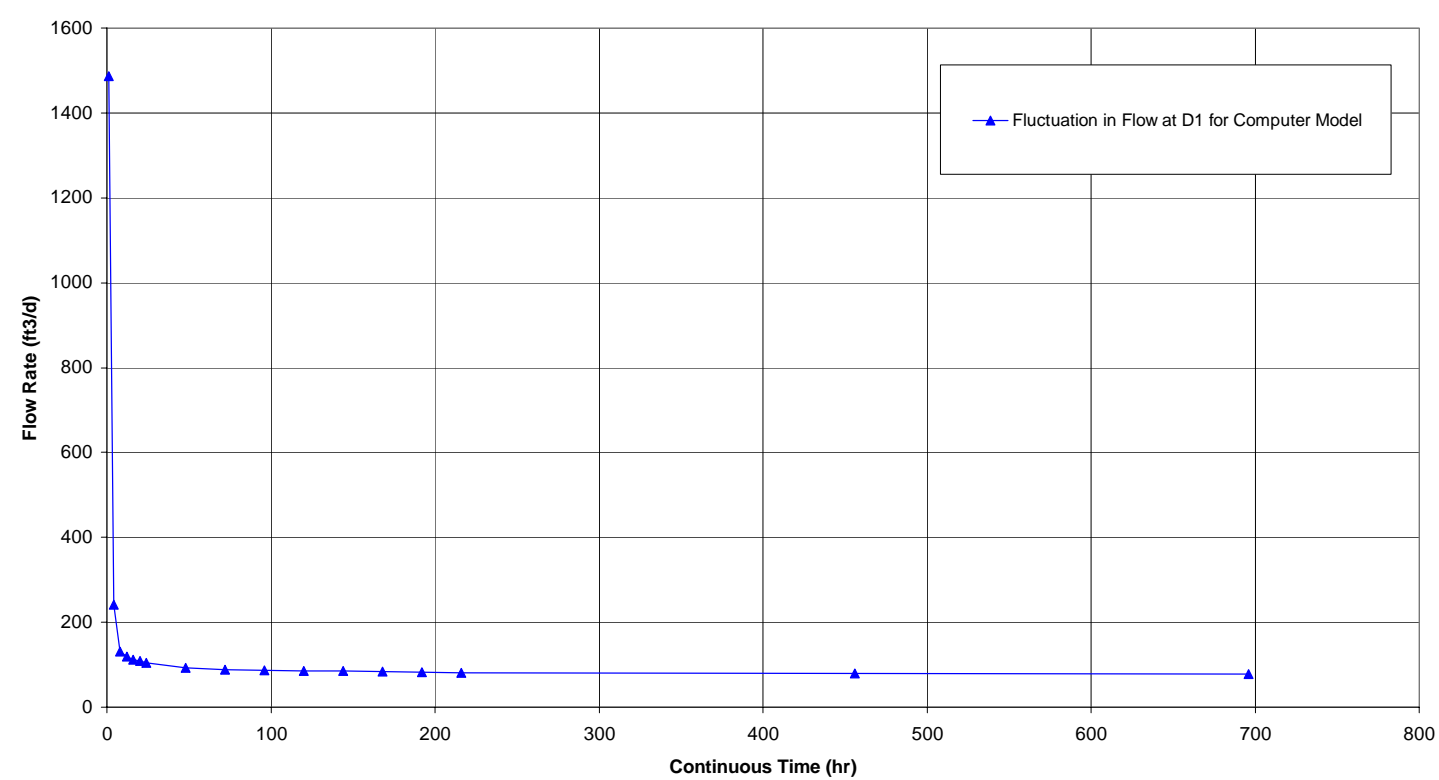

Figure A8.23: Fluctuation of Flow at D1 for Case E-12-48-20

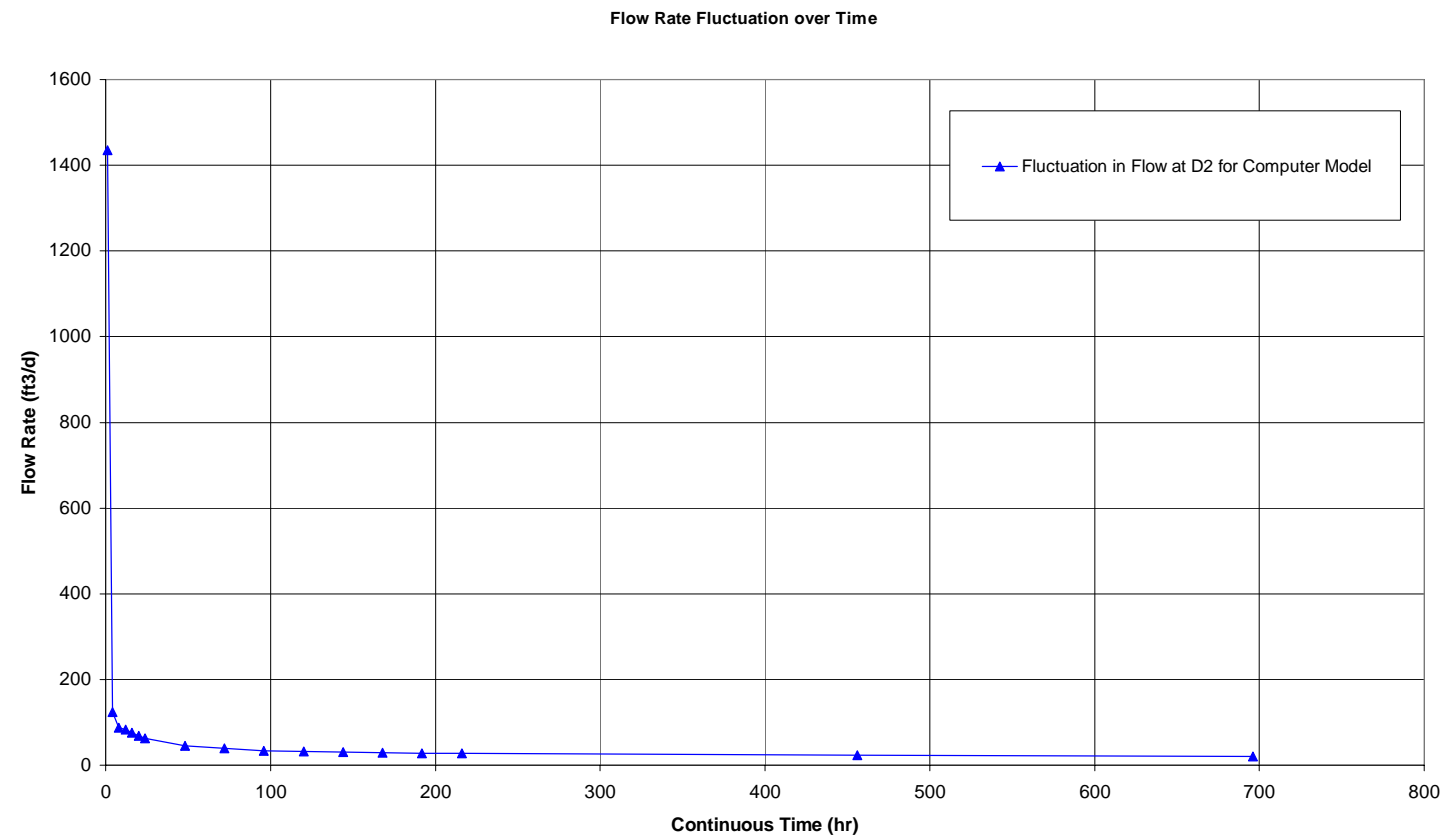

Figure A8.24: Fluctuation of Flow at D2 for Case E-12-48-20 


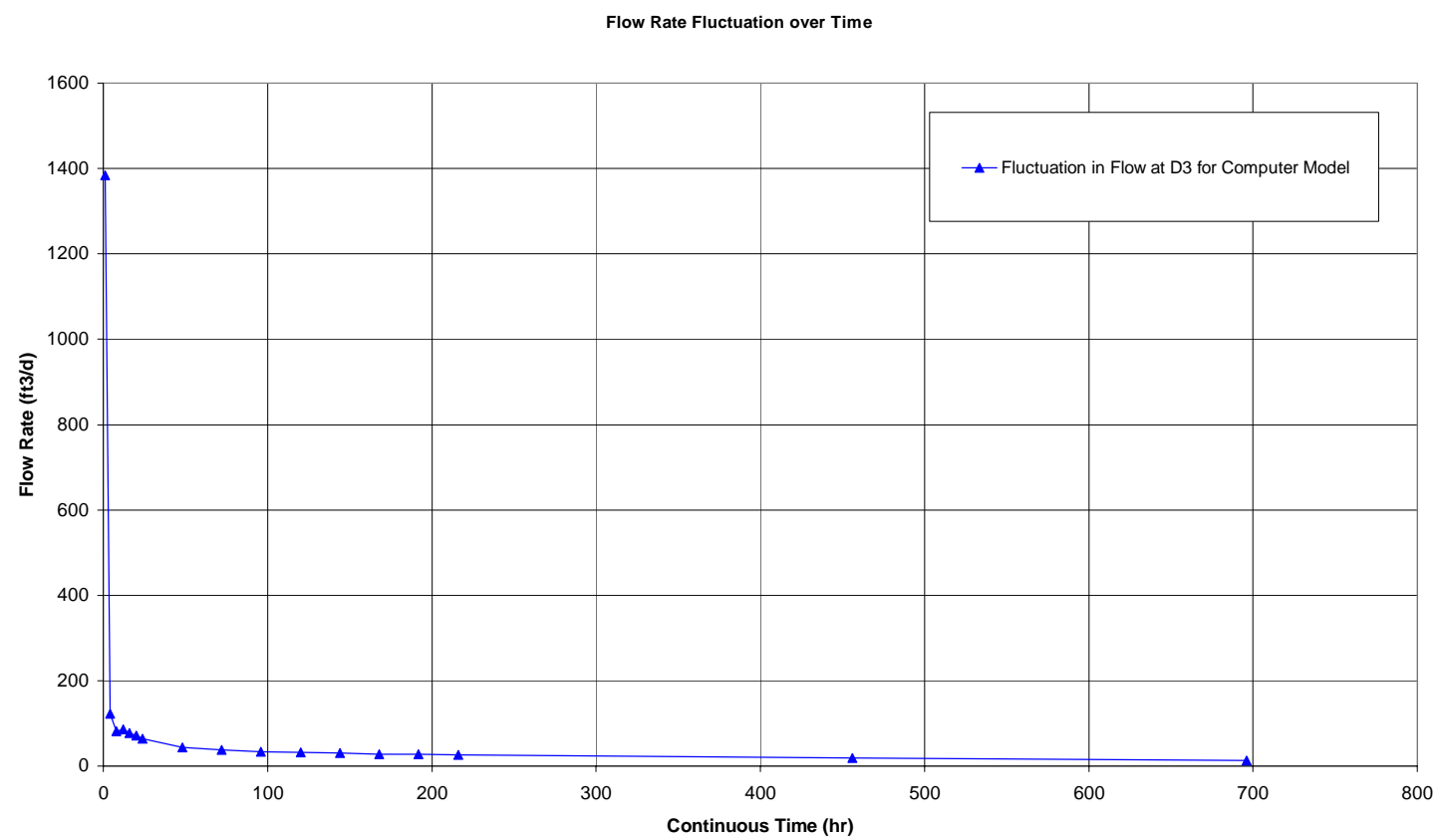

Figure A8.25: Fluctuation of Flow at D3 for Case E-12-48-20

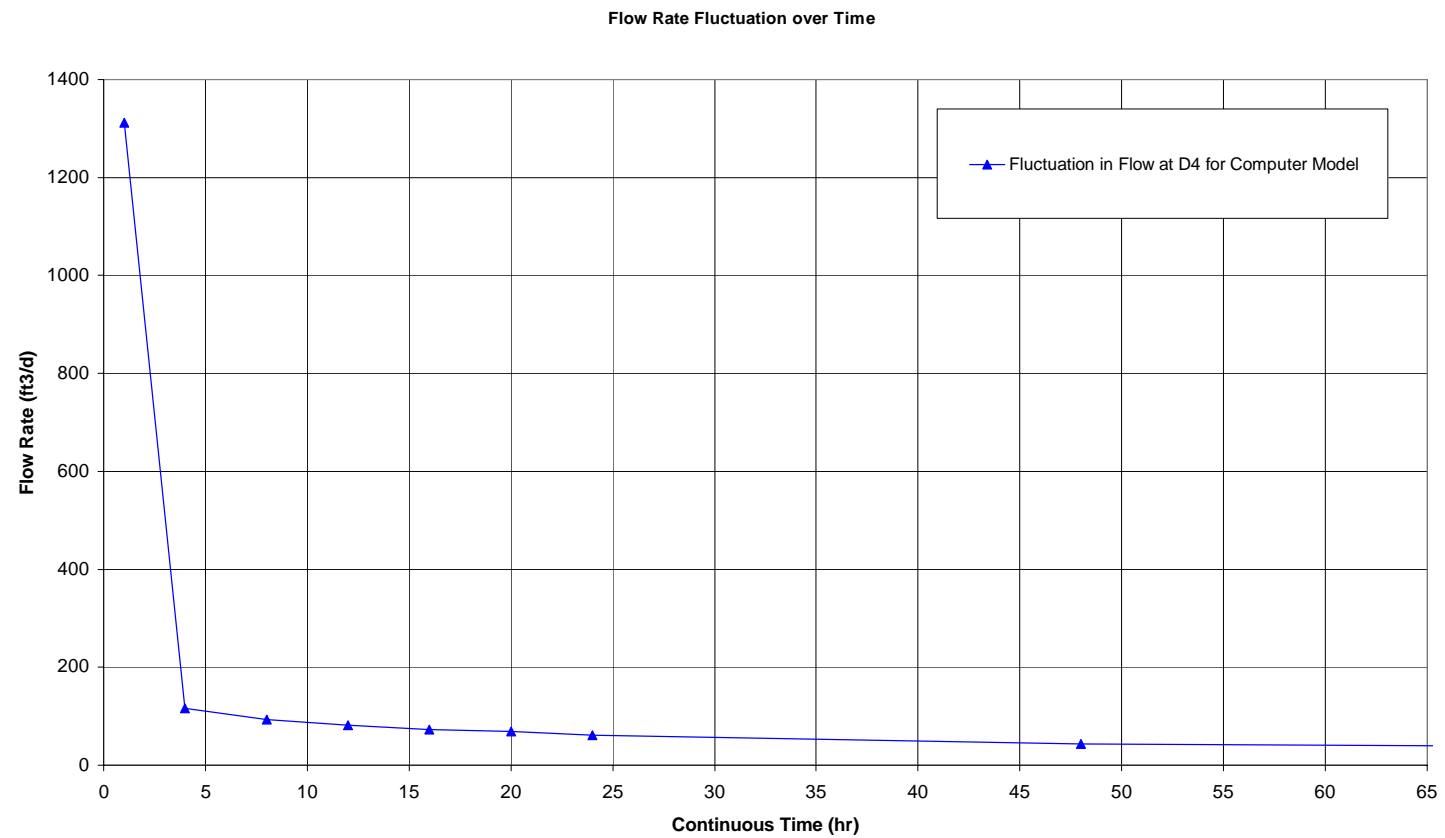

Figure A8.26: Fluctuation of Flow at D4 for Case E-12-48-20 


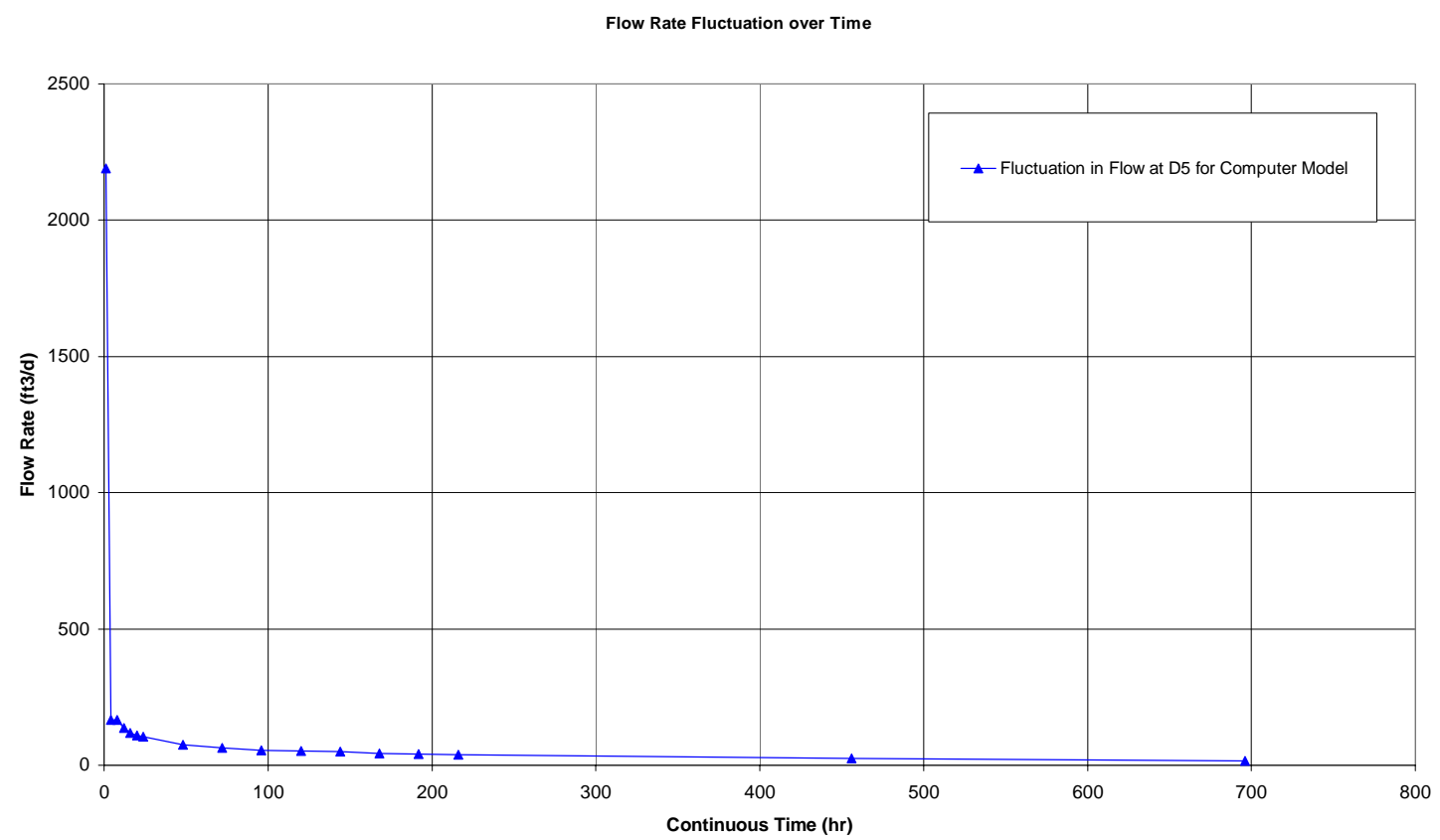

Figure A8.27: Fluctuation of Flow at D5 for Case E-12-48-20

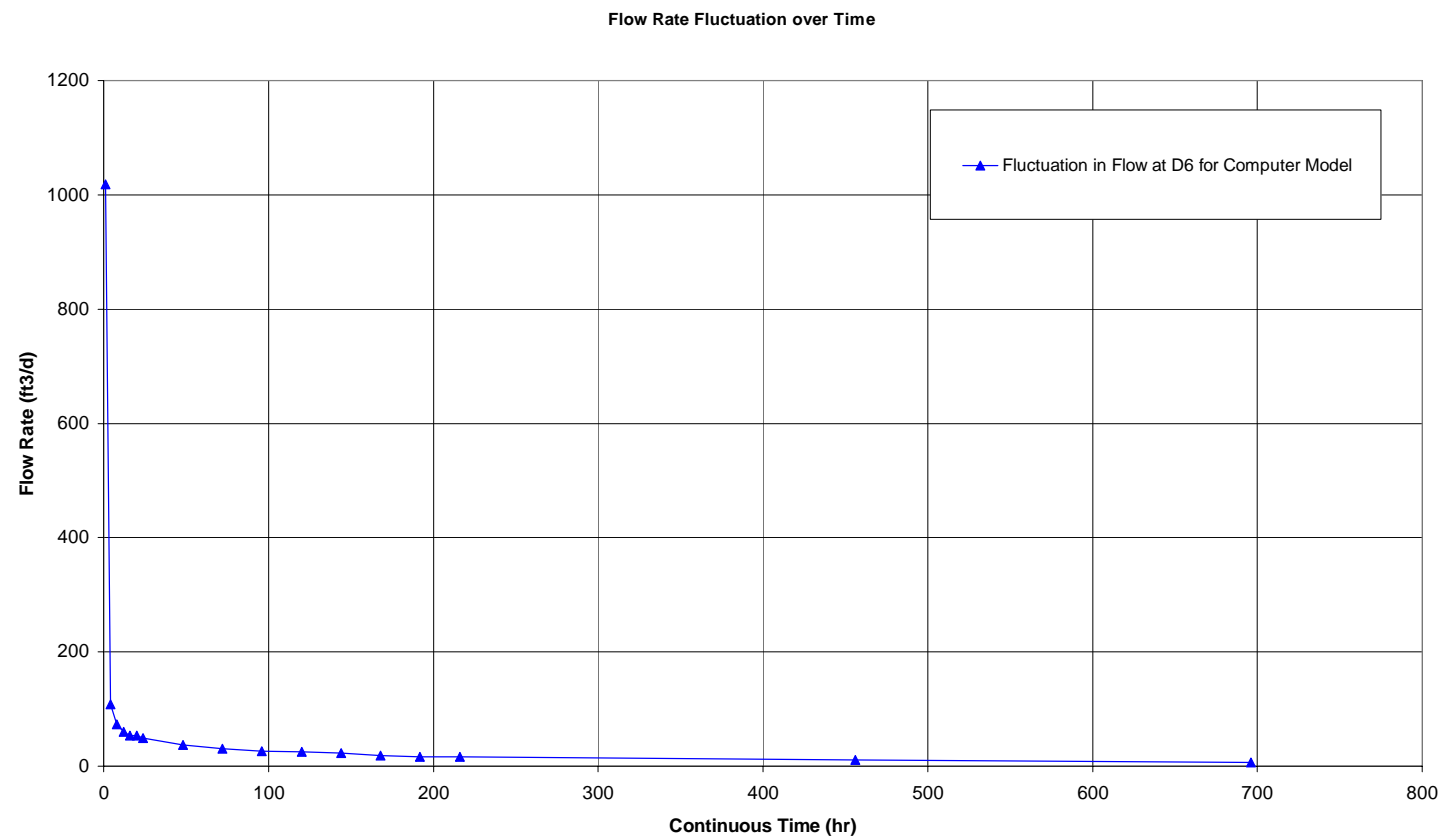

Figure A8.28: Fluctuation of Flow at D6 for Case E-12-48-20 
Flow Rate Fluctuation over Time

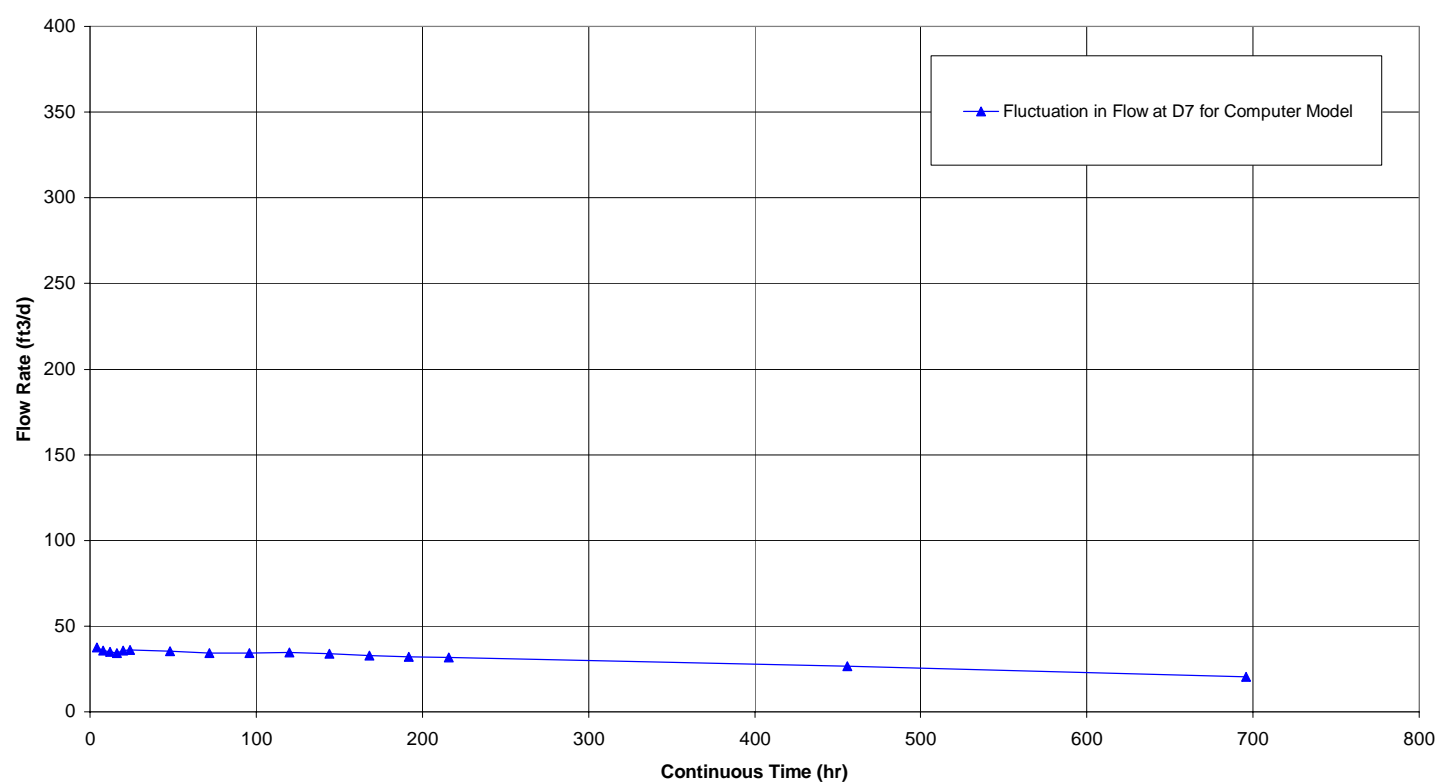

Figure A8.29: Fluctuation of Flow at D7 for Case E-12-48-20

Cumulative Percent Removed Along the Longitudinal Drain

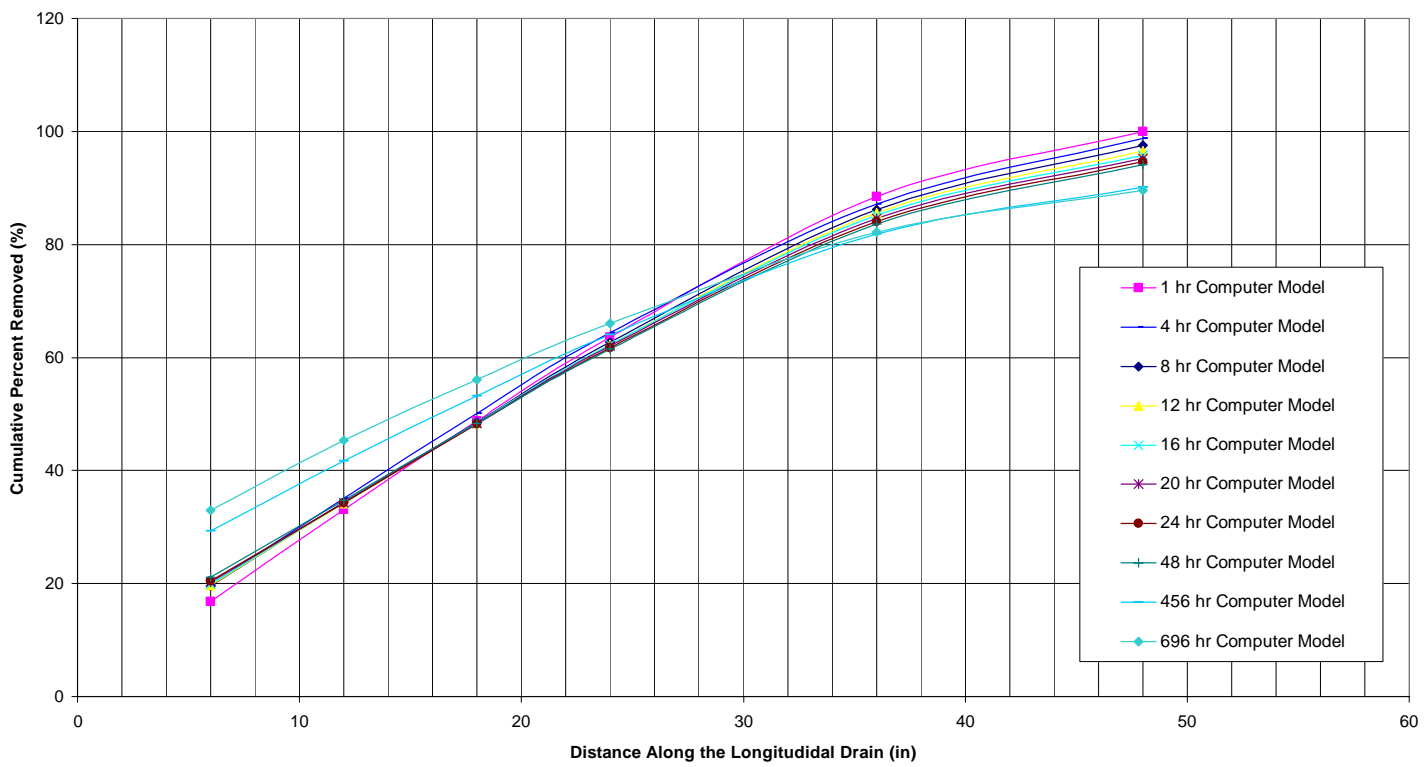

Figure A8.30: Cumulative Percent Removed Along the Drain for Case E-12-48-20 


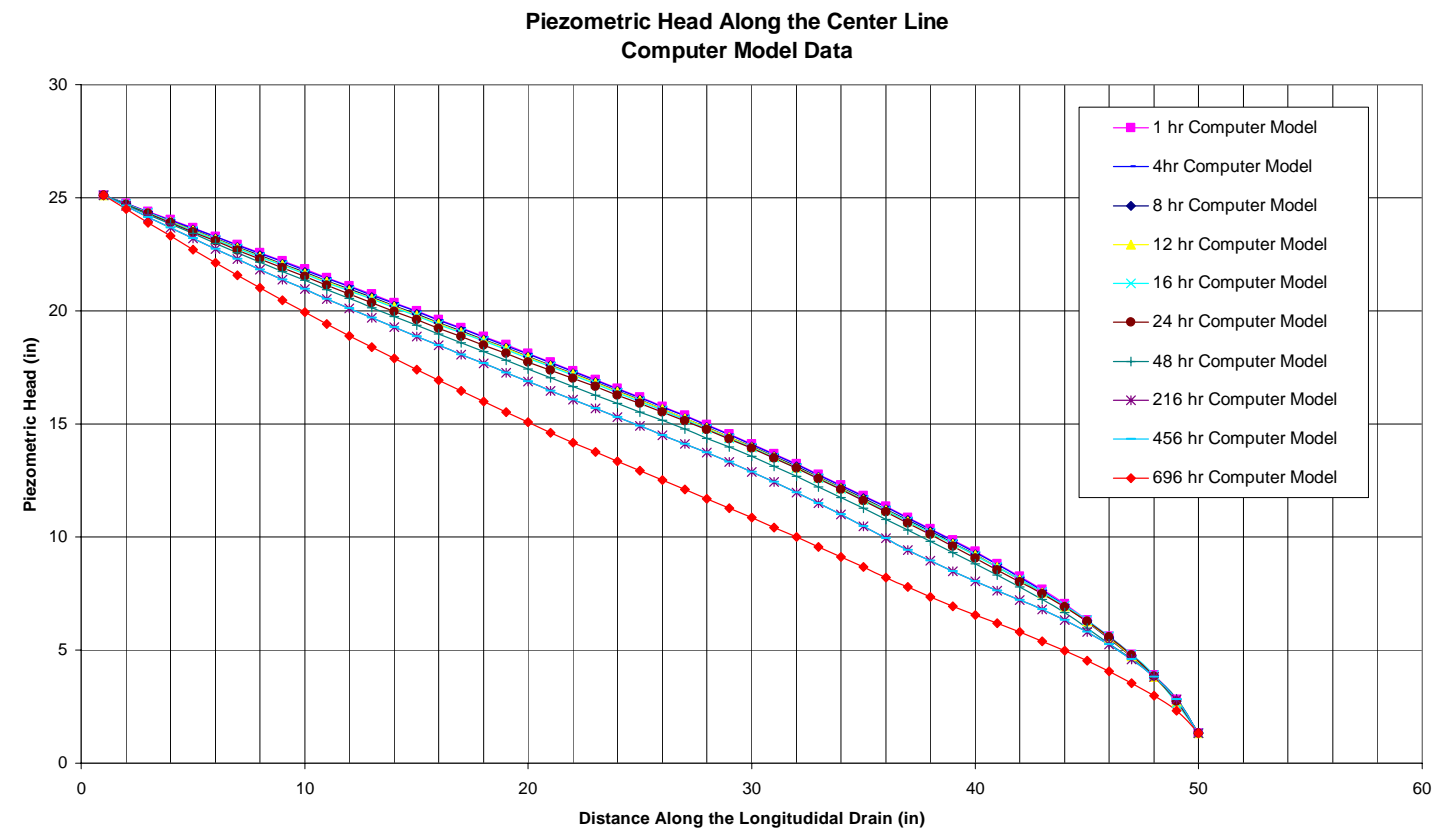

Figure A8.31: Variation of Piezometric Head Along the Center Line for case E-12-48-20

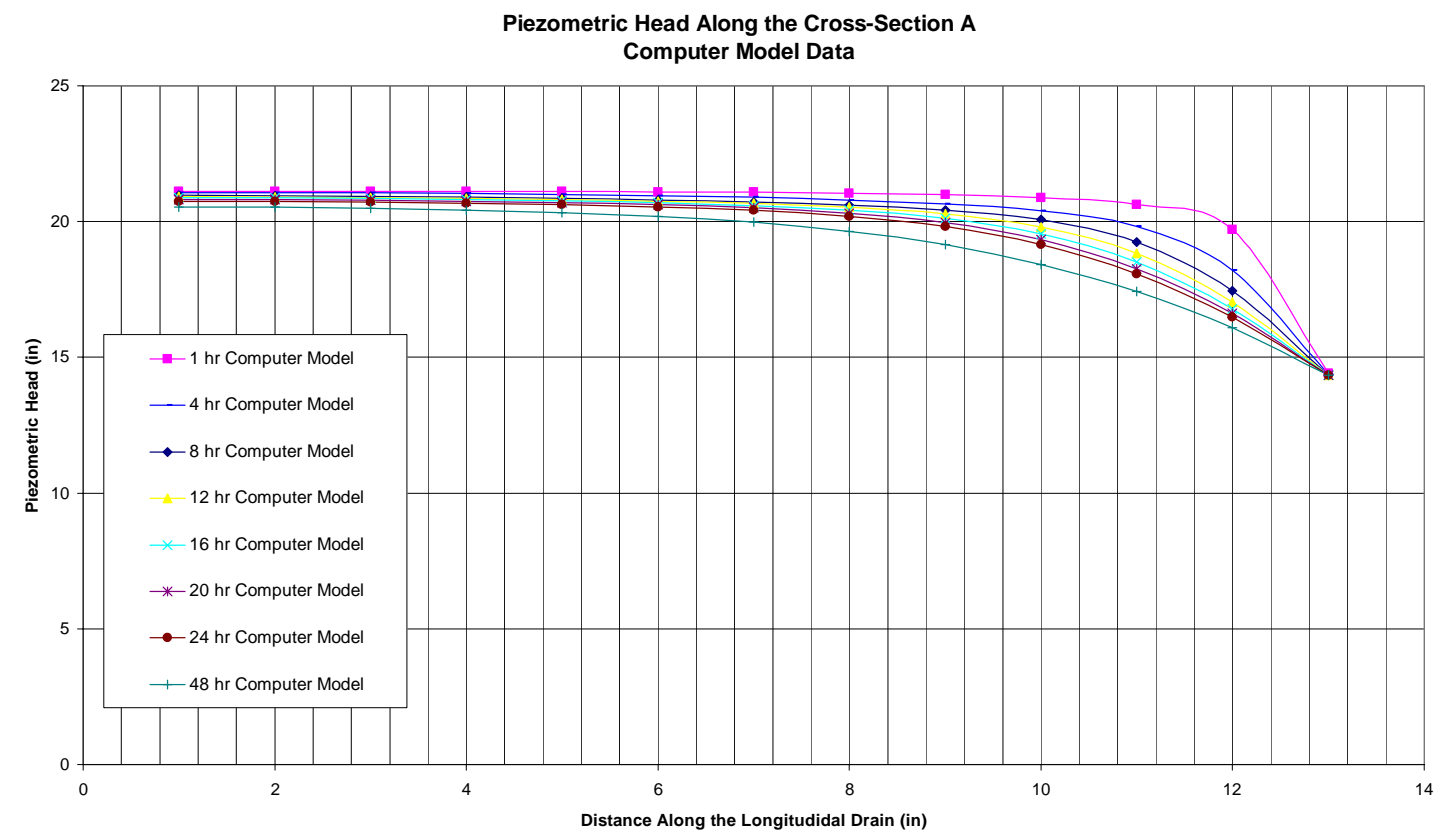

Figure A8.32: Variation of Piezometric Head Along cross-Section A for case E-12-48-20 


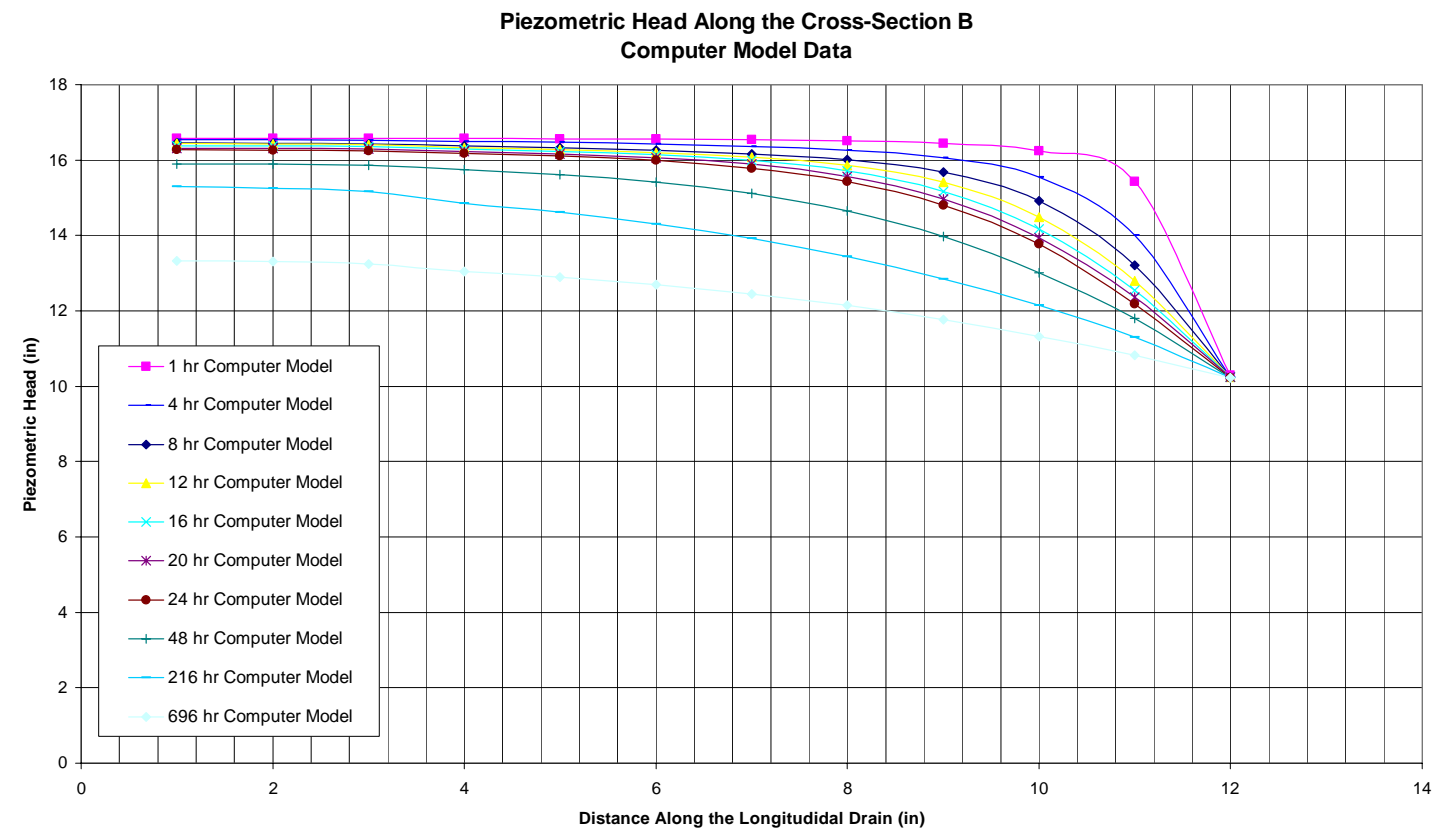

Figure A8.33: Variation of Piezometric Head Along cross-Section B for case E-12-48-20 
Flow Rate Fluctuation over Time

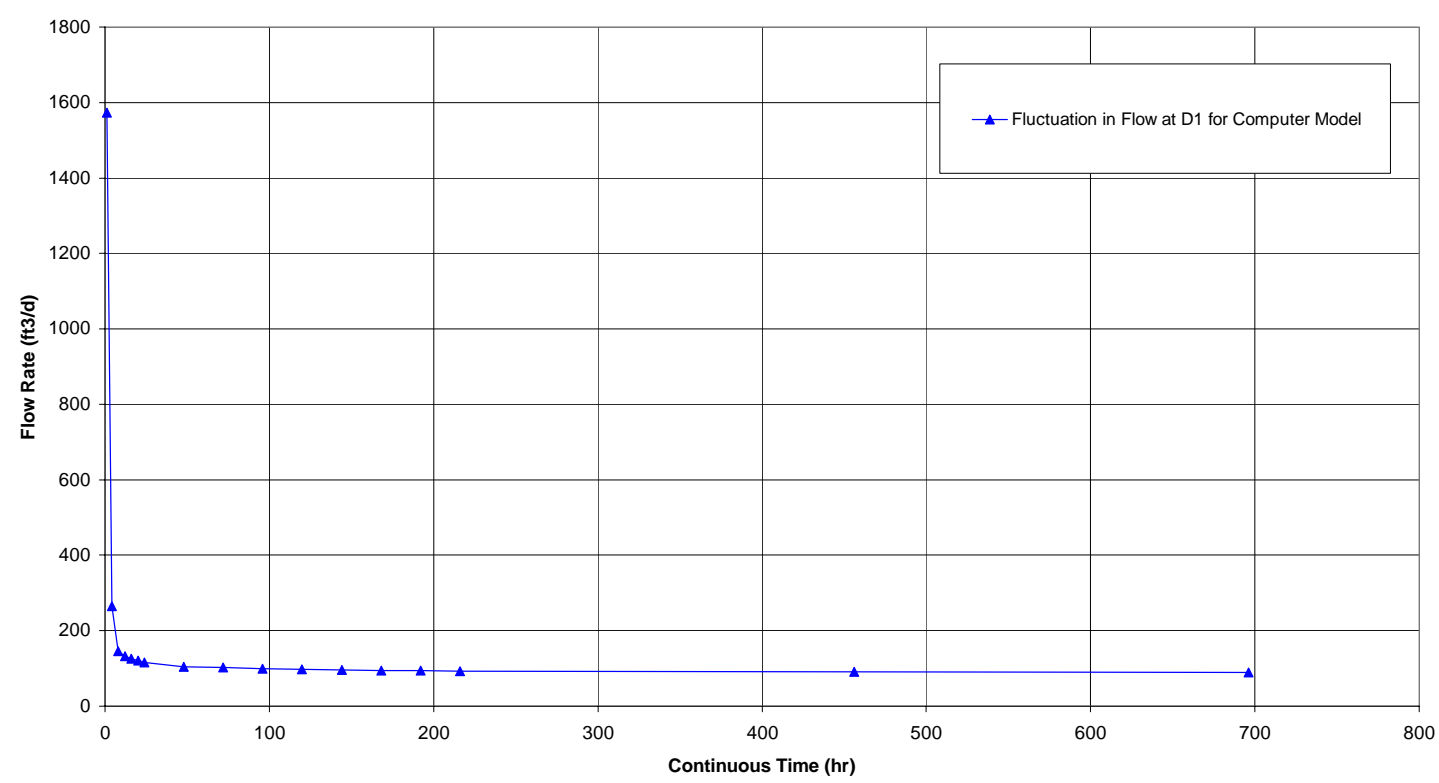

Figure A8.34: Fluctuation of Flow at D1 for Case E-12-48-30

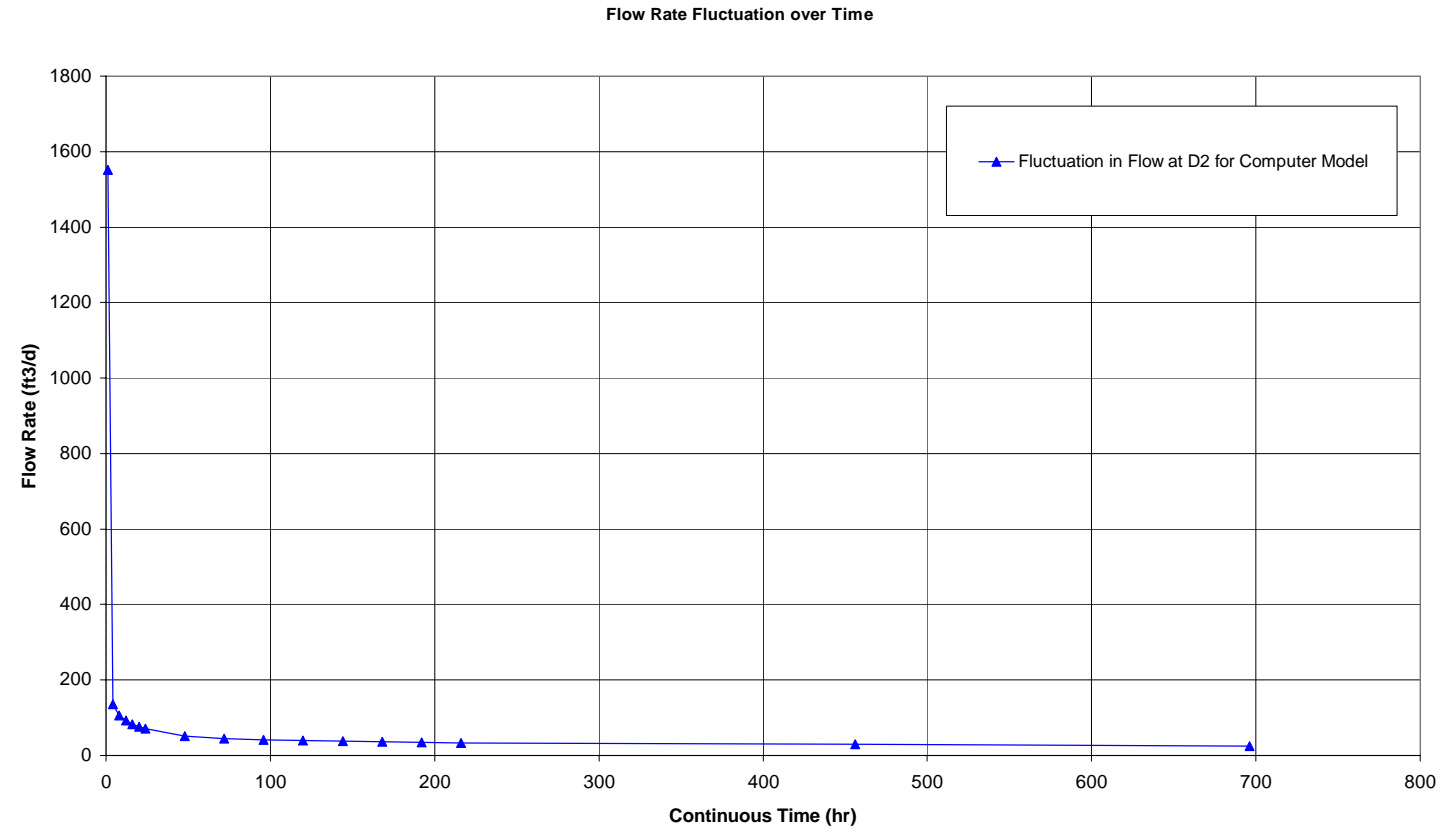

Figure A8.35: Fluctuation of Flow at D2 for Case E-12-48-30 
Flow Rate Fluctuation over Time

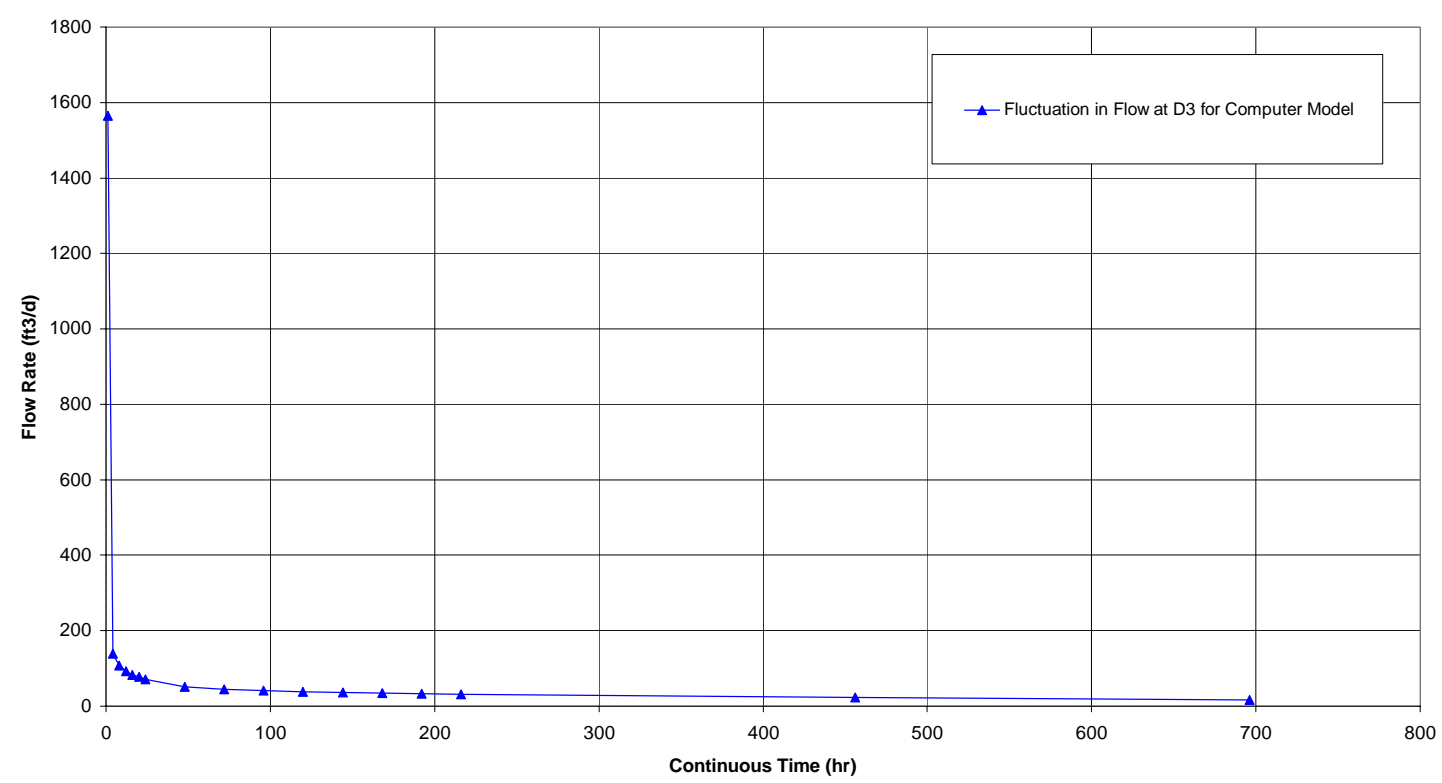

Figure A8.36: Fluctuation of Flow at D3 for Case E-12-48-30

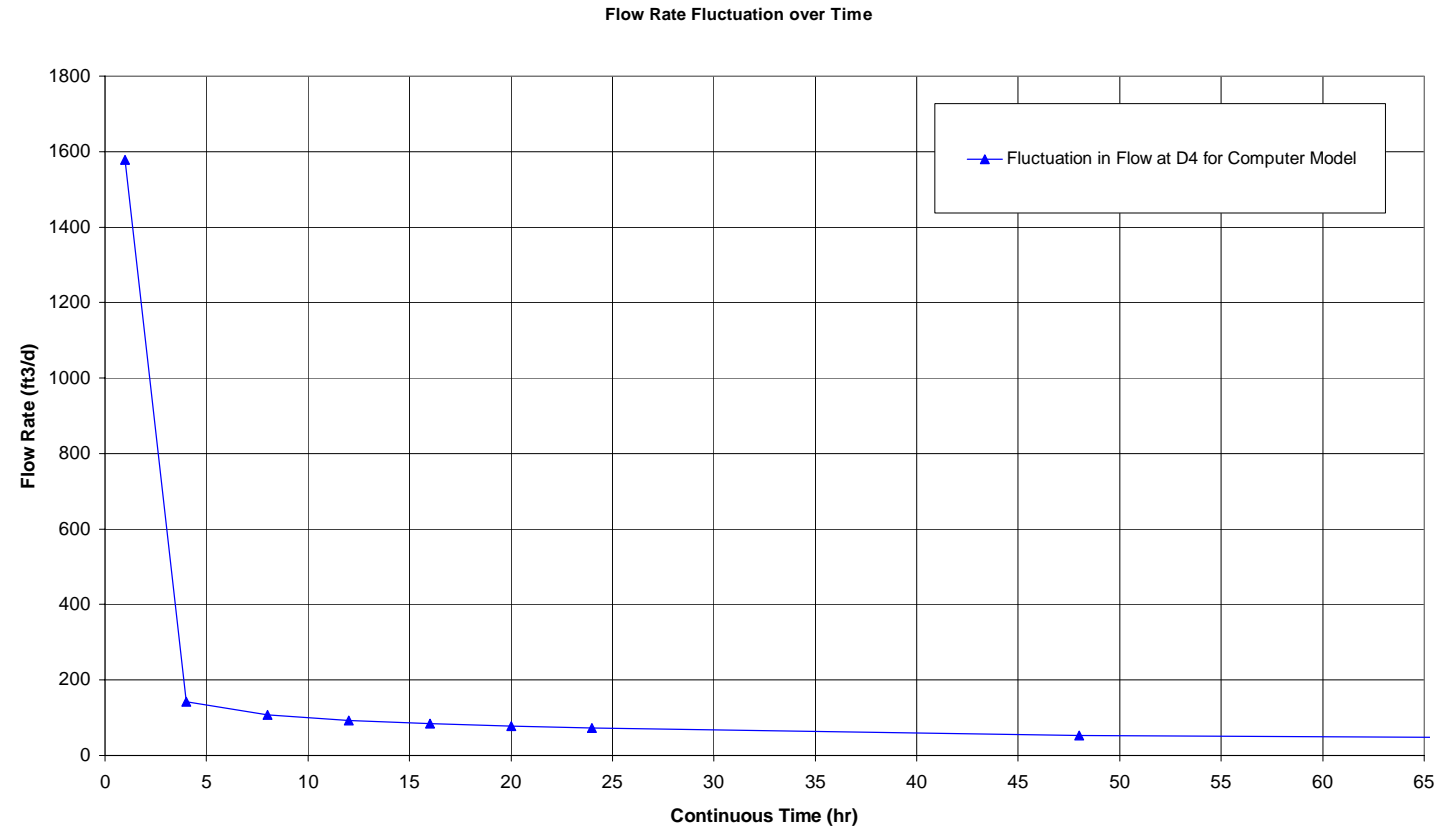

Figure A8.37: Fluctuation of Flow at D4 for Case E-12-48-30 
Flow Rate Fluctuation over Time

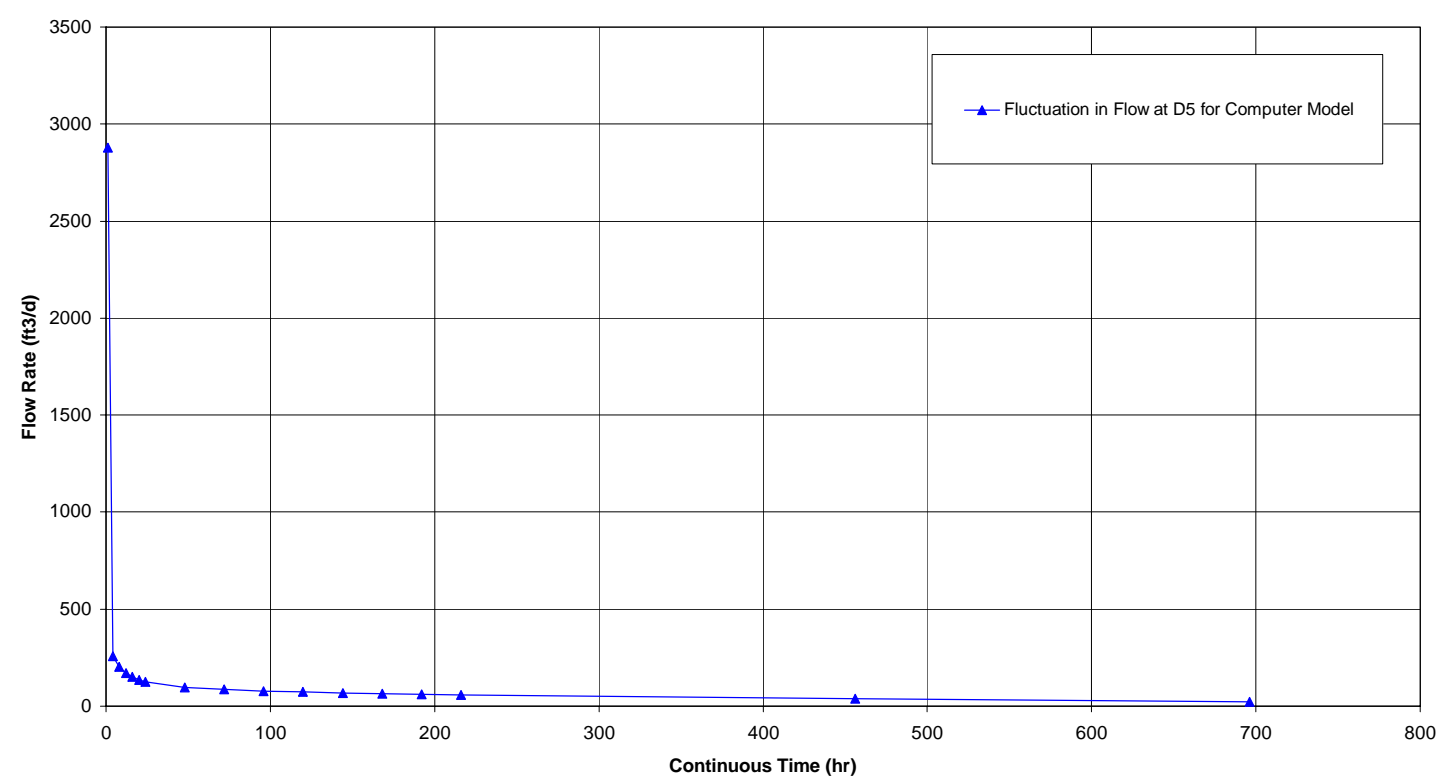

Figure A8.38: Fluctuation of Flow at D5 for Case E-12-48-30

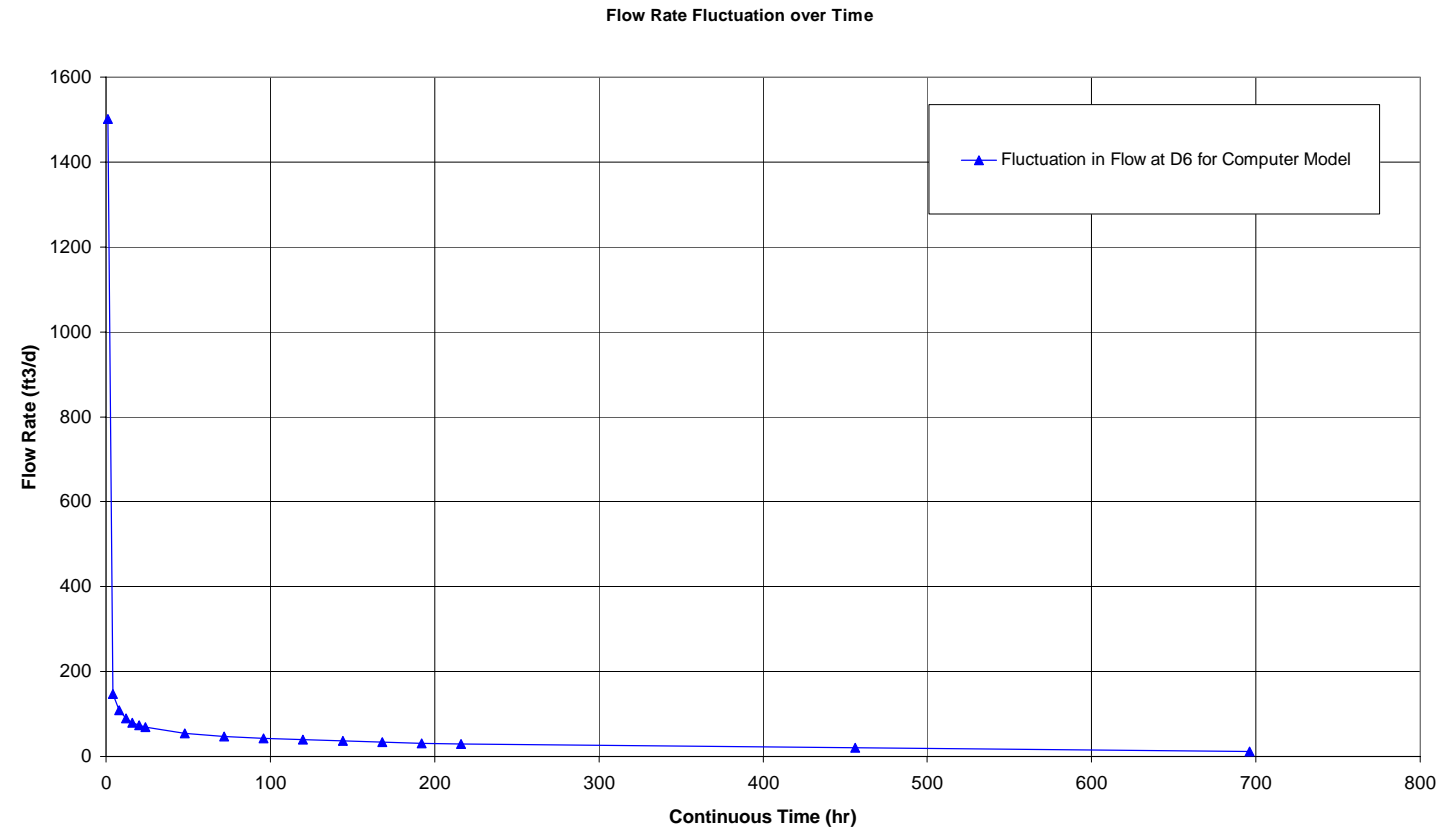

Figure A8.39: Fluctuation of Flow at D6 for Case E-12-48-30 
Flow Rate Fluctuation over Time

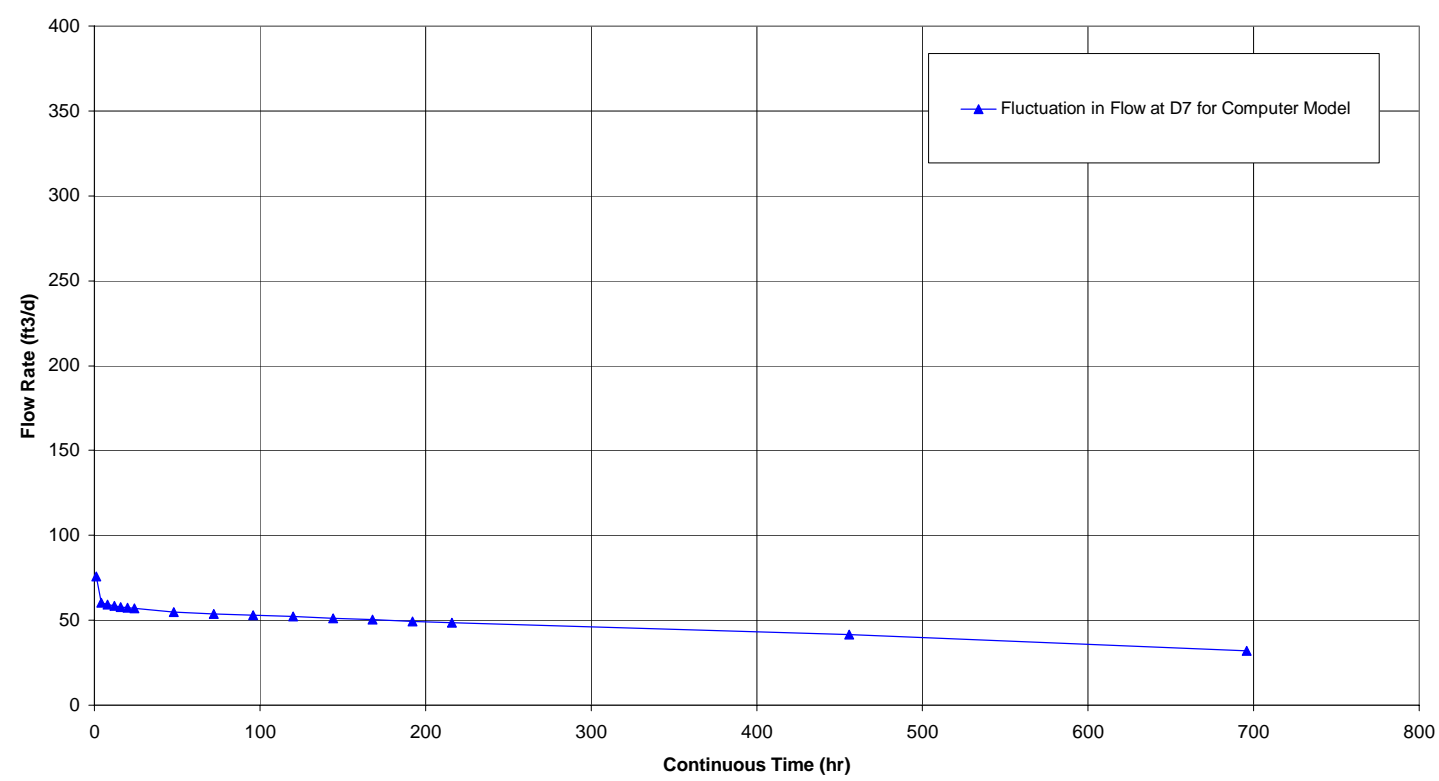

Figure A8.40: Fluctuation of Flow at D7 for Case E-12-48-30

Cumulative Percent Removed Along the Longitudinal Drain

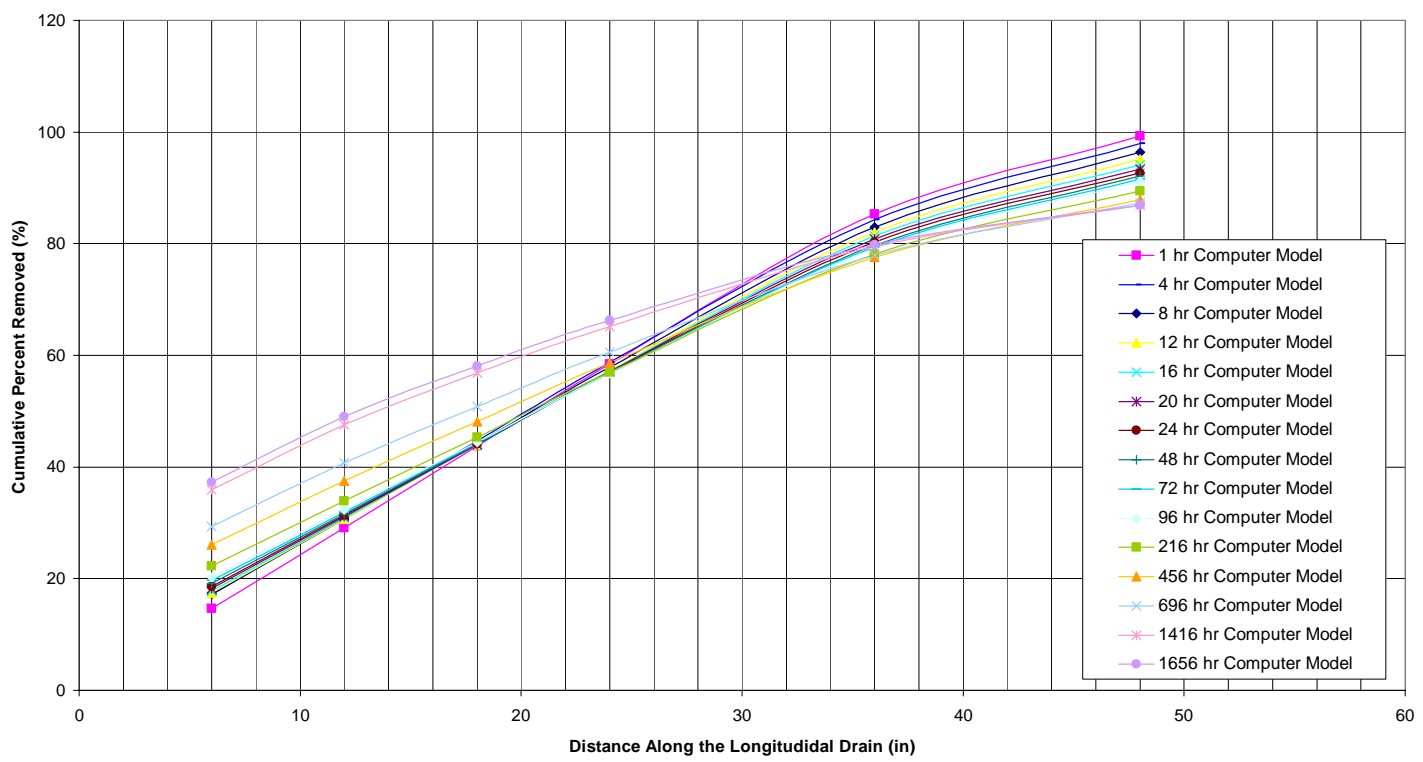

Figure A8.41: Cumulative Percent Removed Along the Drain for Case E-12-48-30 


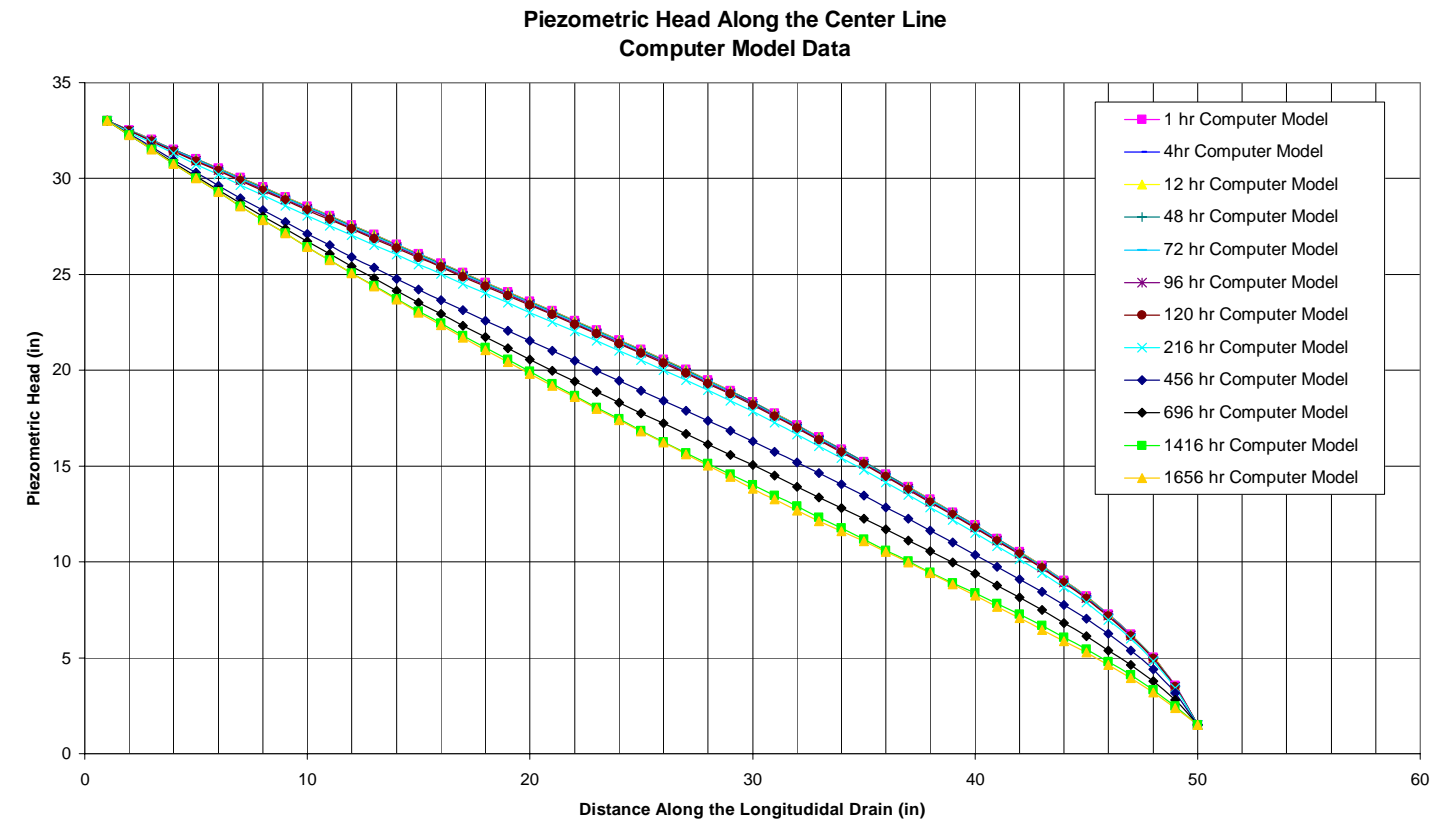

Figure A8.42: Variation of Piezometric Head Along the Center Line for case E-12-48-30

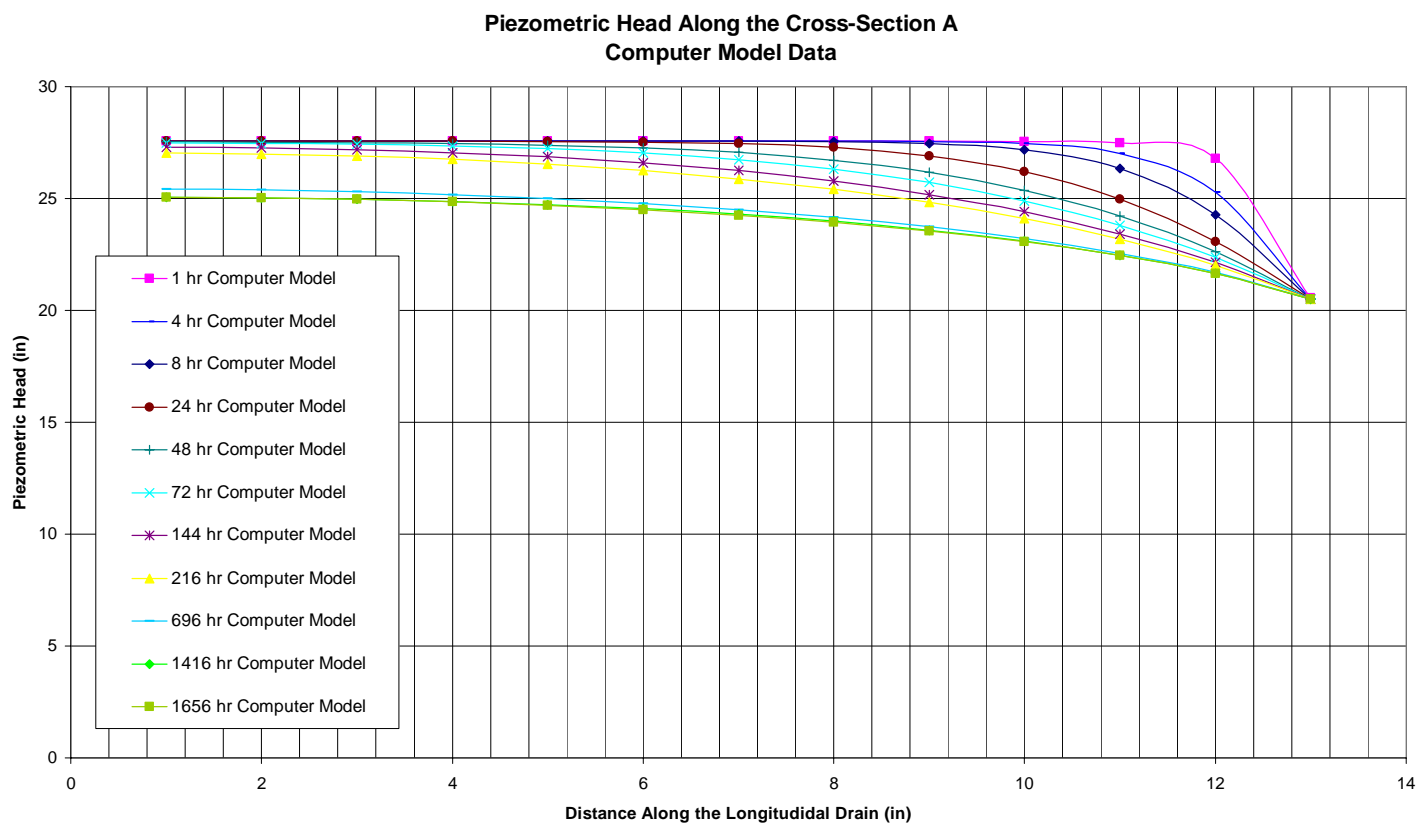

Figure A8.43: Variation of Piezometric Head Along Cross-Section A for case E-12-48-30 


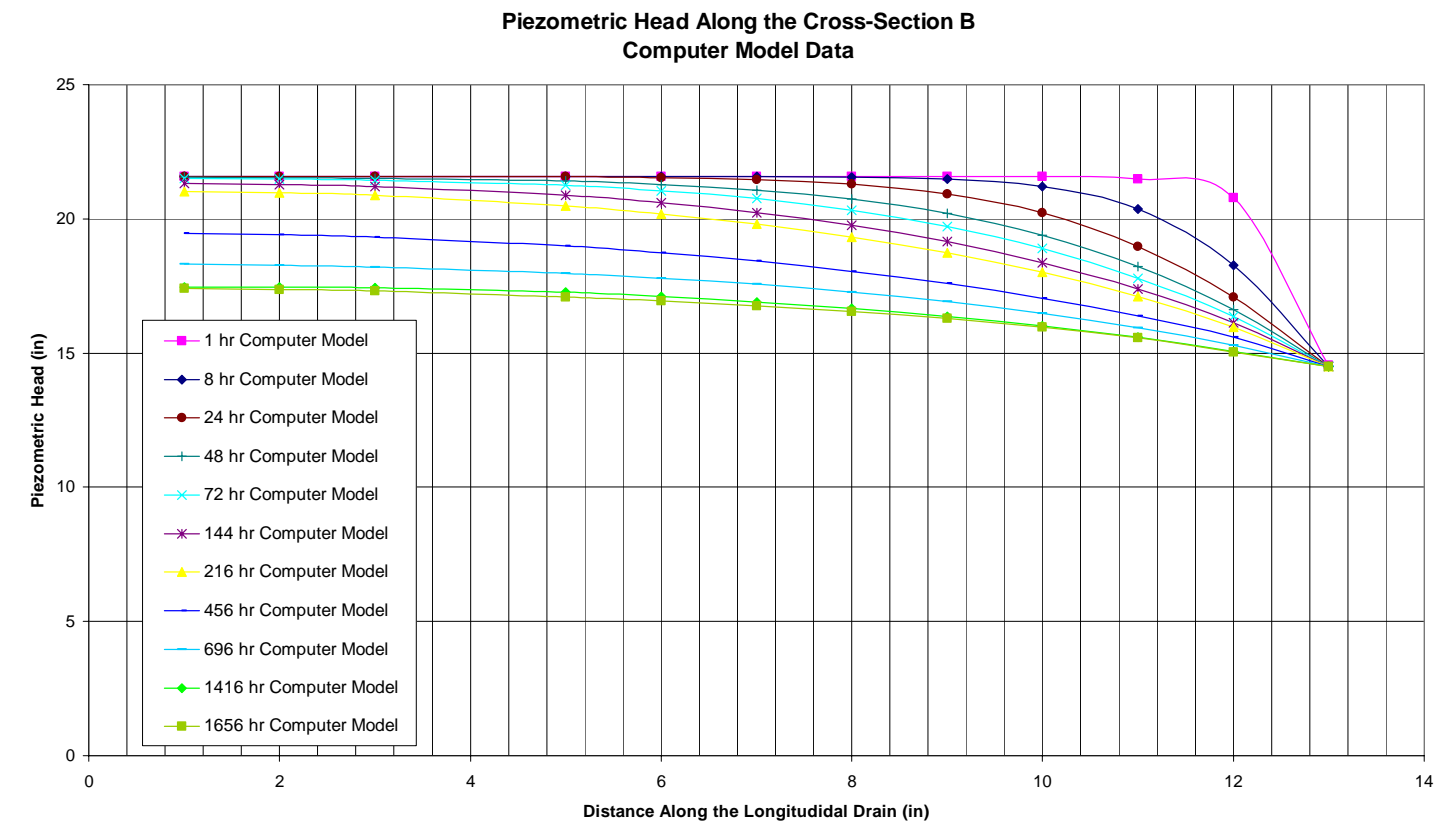

Figure A8.44: Variation of Piezometric Head Along Cross-Section B for case E-12-48-30 
Appendix A9: Grain size distribution and Liquid Limit curves 
The soils used in this investigation have significant amounts of clay. Therefore, a wet sieve analysis was performed for each soil. A significant amount of soil (about $500 \mathrm{~g}$ or about $1 \mathrm{lb})$ was placed on a \#200 sieve $(75 \mu \mathrm{m})$ and carefully washed; making sure that the water-clay mix was collected. Once the presence of clay was no longer visible both samples were placed in an oven for at least $10 \mathrm{hrs}$ at a temperature of $110^{\circ} \mathrm{C}$. When both samples were completely dried, their masses were compared to the original mass to check for loss of material. The coarse sample was the placed inside the sieve stack and shaken for 5 to 10 minutes. The sieves used in this investigation were: \#10, \#20, \#40, \#60, \#80, \#100 and \#200 (2 mm, $0.84 \mathrm{~mm}, 0.42 \mathrm{~mm}, 0.25 \mathrm{~mm}, 0.21 \mathrm{~mm}, 0.149 \mathrm{~mm}$, and 0.075 $\mathrm{mm})$. The sieves were weighted and the percent passing was calculated. Figure A9.1 shows the grain size distribution for all the soil types used in this investigation. Appendix A9 shows distribution curves for each soil.

Grain Size Distribution Curve For Soils Types A, B, C, D and D

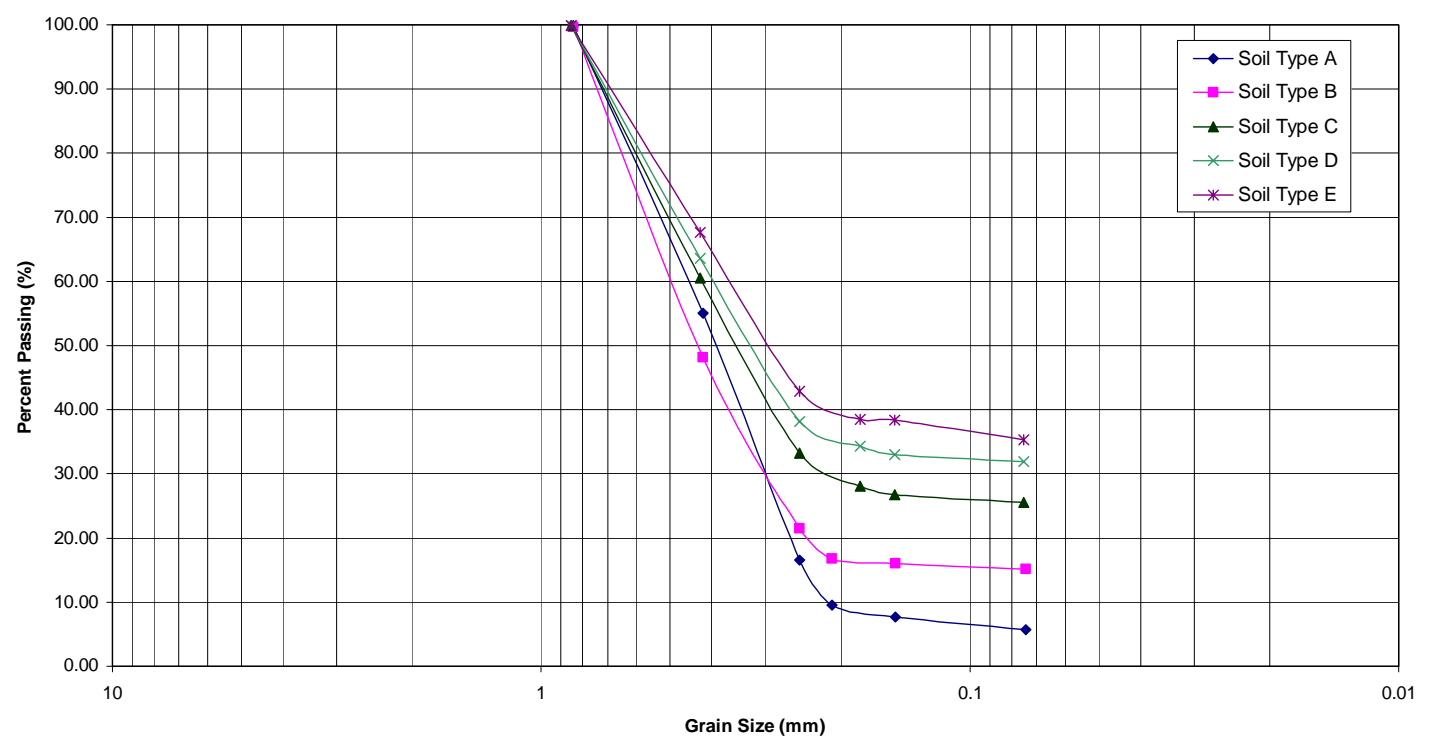

Figure A9.1: Grain Size Distribution curves for All Soil Types 
Atterberg limits for all soil types used in this study were determined as shown in Table A9.1. For the determination of liquid limit (LL), approximately an amount of $100 \mathrm{~g}$ of the soil passing sieve \#40 was used. Water was added to make a cream-like paste which then was placed in the liquid limit device. For the determination of plastic limit, an amount of $50 \mathrm{~g}$ of the soil passing \#40 was used. Water was added until the paste became very thick. The paste was rolled into small threads until they begin to crumble. Samples were taken from the crumpling sections and the plastic limit was calculated. Table A9.1 shows the Atterberg limits for the soils used in this research. Appendix A9 also shows individual liquid limit curves for each soil used.

Table A9.1: Atterberg Limits for soils used in the study

\begin{tabular}{|c|c|c|c|c|c|}
\hline Soil Type & A & B & C & D & E \\
\hline $\begin{array}{c}\text { Liquid } \\
\text { Limit }\end{array}$ & 34 & 38 & 38 & 42 & 42 \\
\hline $\begin{array}{c}\text { Plastic } \\
\text { Limit }\end{array}$ & 27.73 & 30.44 & 32.66 & 33.14 & 33.39 \\
\hline PI & 6.27 & 7.56 & 5.34 & 8.86 & 8.61 \\
\hline
\end{tabular}




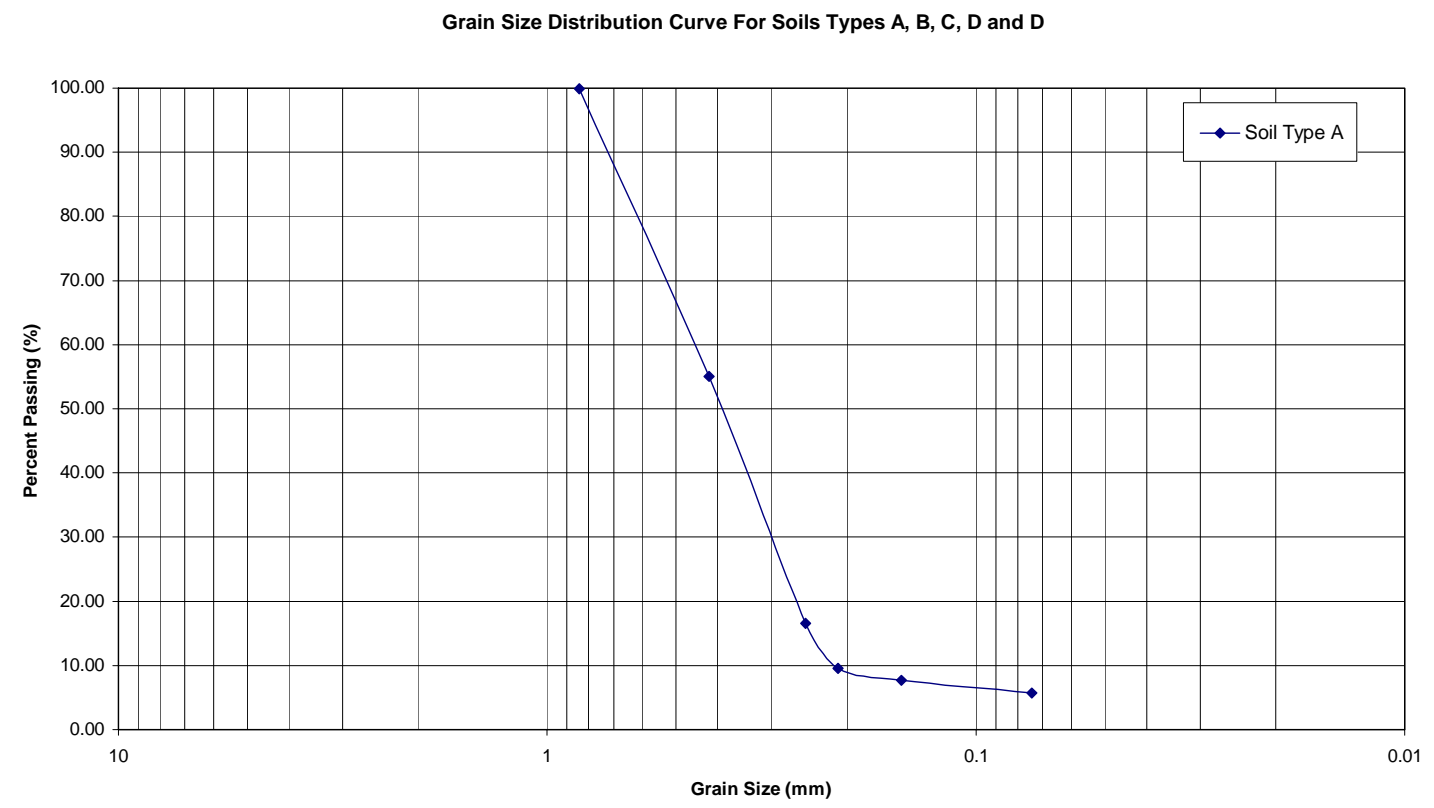

Figure A9.2: Grain Size Distribution curve for Soil Type A

Liquid Limit

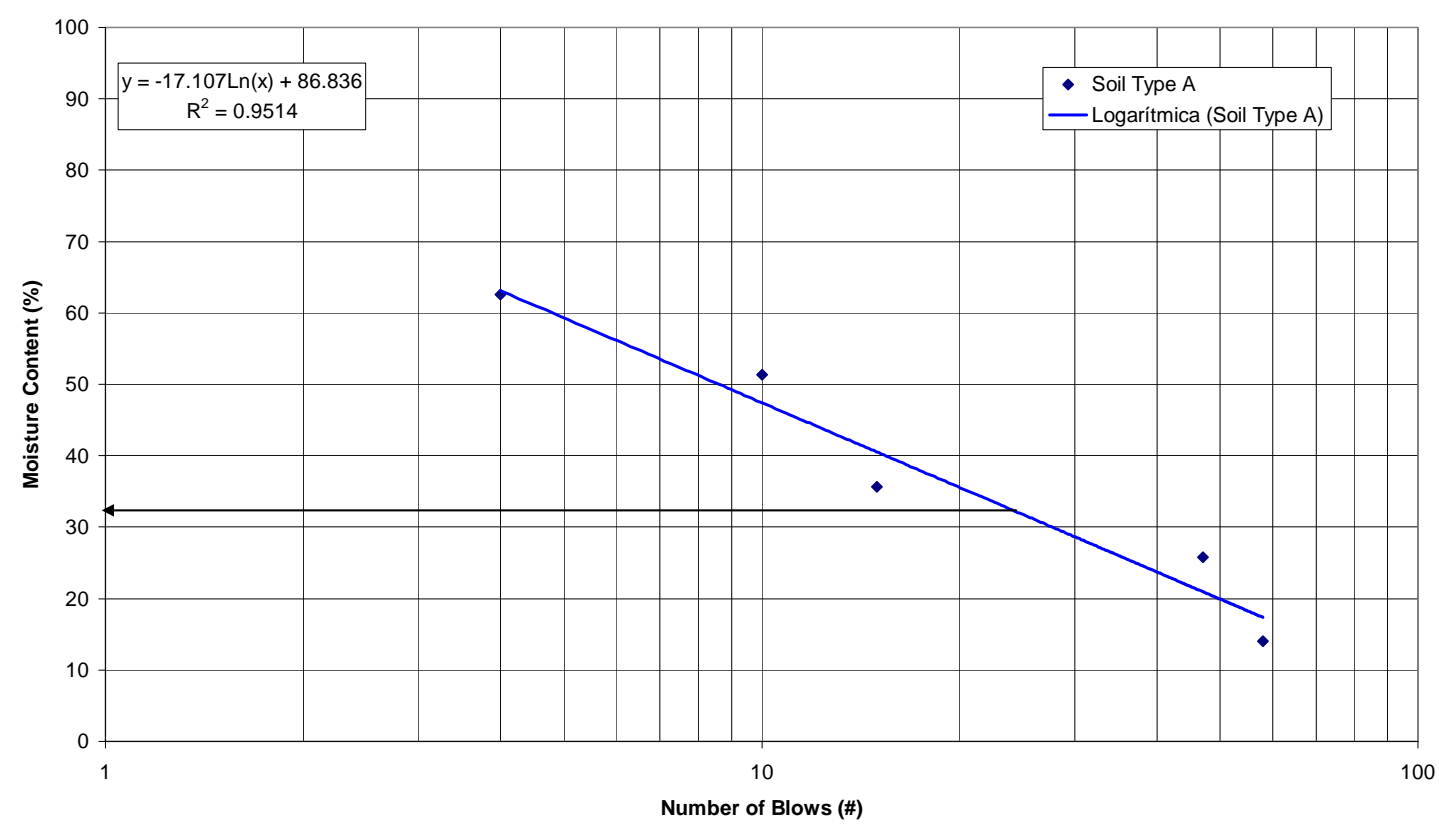

Figure A9.3: Liquid Limit for Soil Type A 


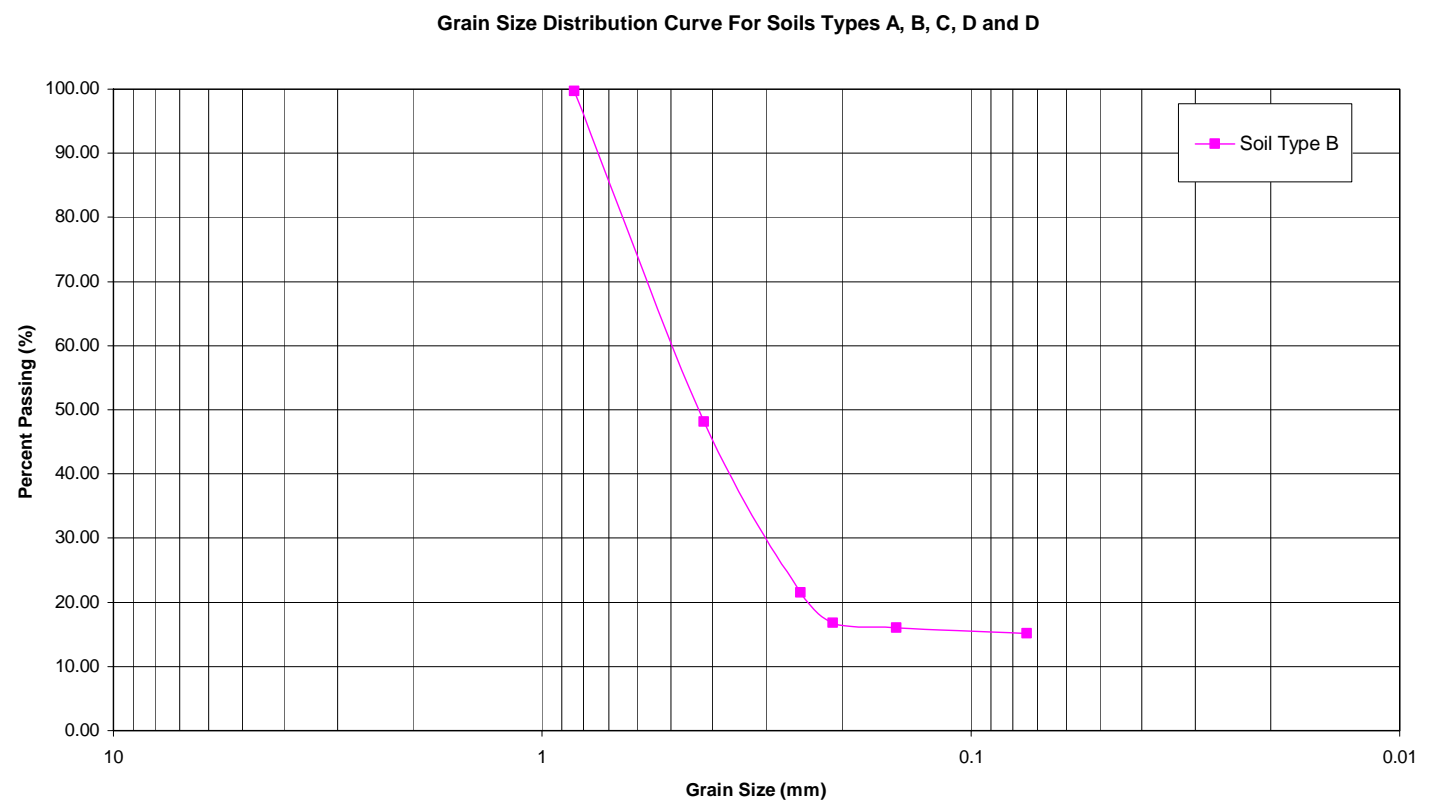

Figure A9.4: Grain Size Distribution curve for Soil Type B

Liquid Limit

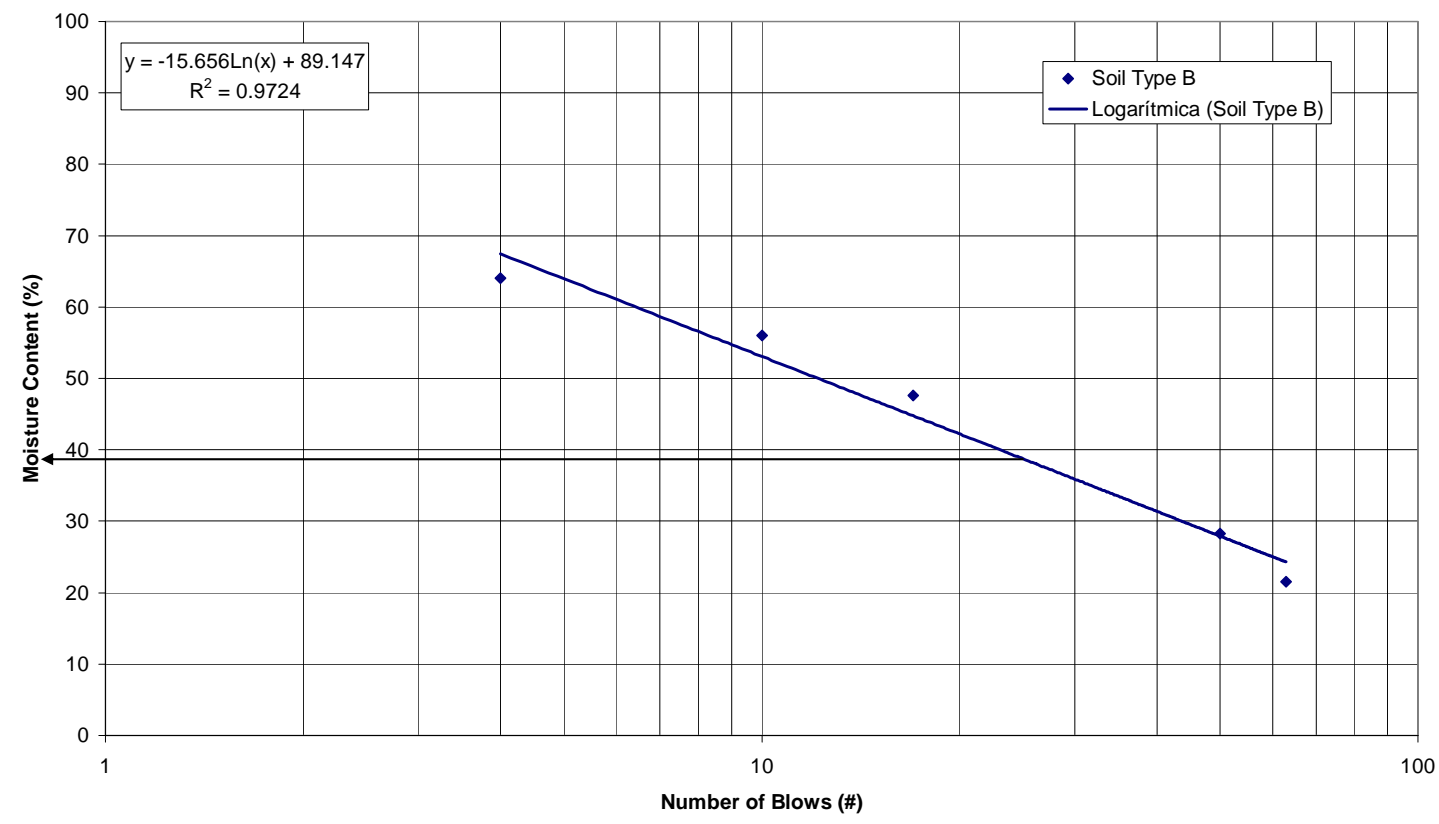

Figure A9.5: Liquid Limit for Soil Type B 


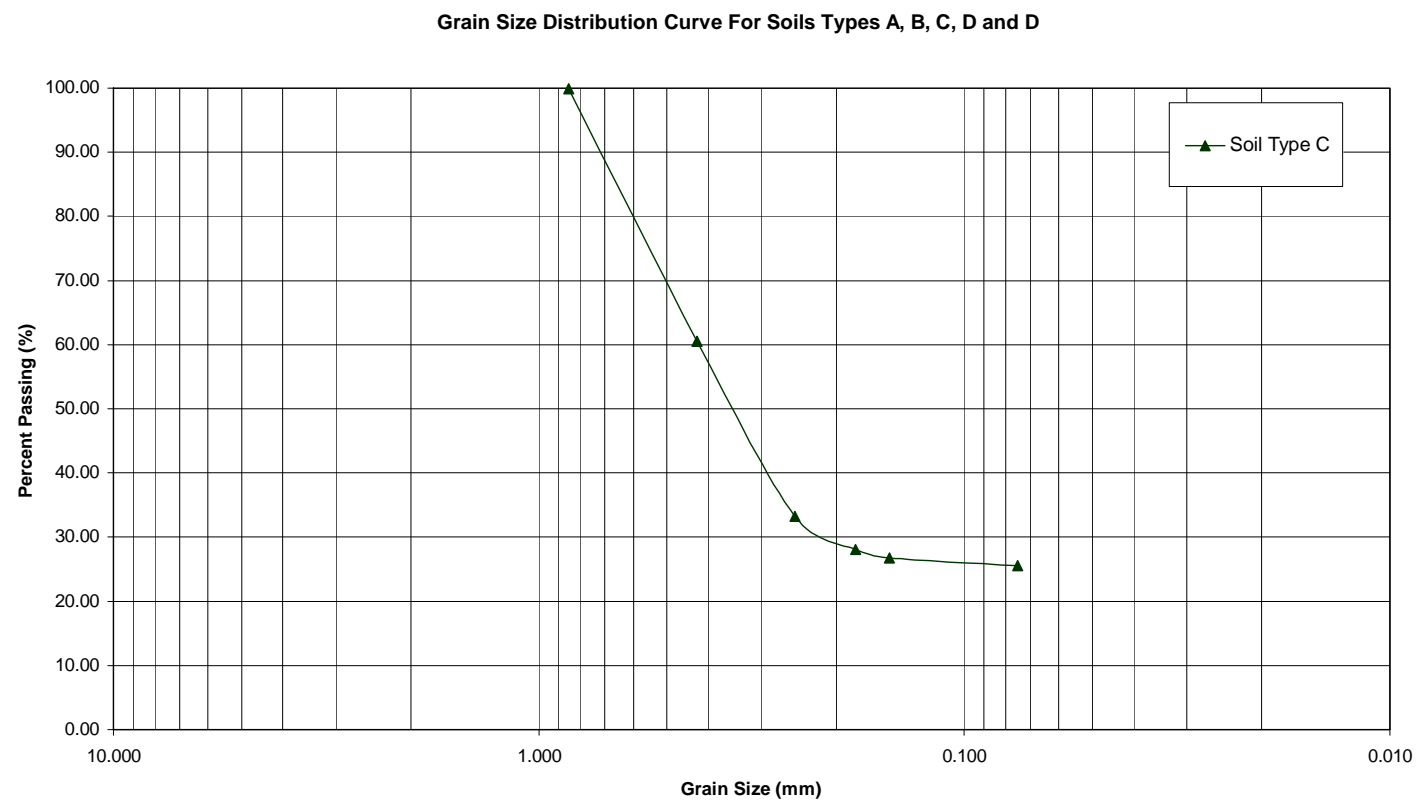

Figure A9.6: Grain Size Distribution curve for Soil Type C

Liquid Limit

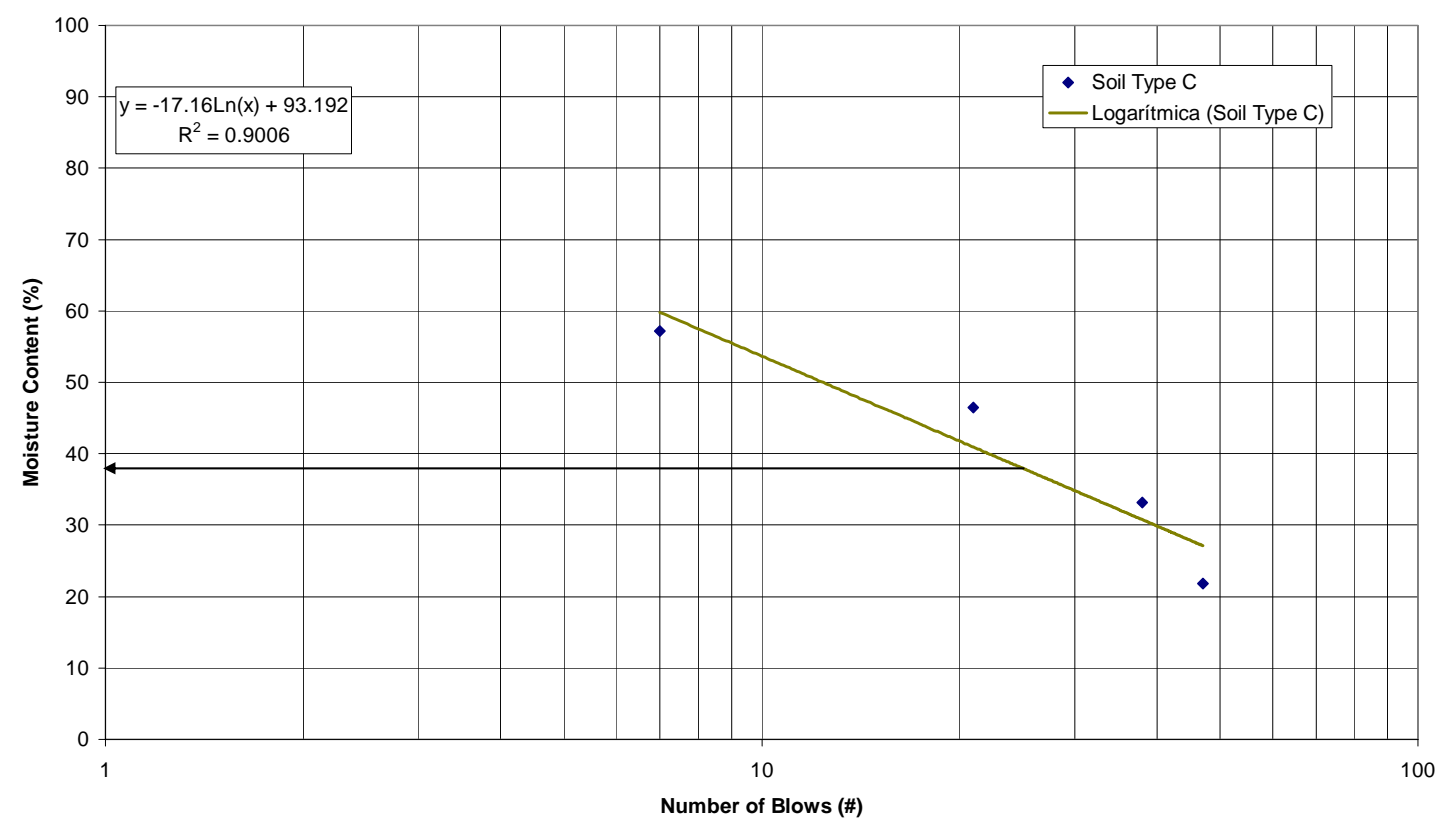

Figure A9.7: Liquid Limit for Soil Type C 
Grain Size Distribution Curve For Soils Types A, B, C, D and D

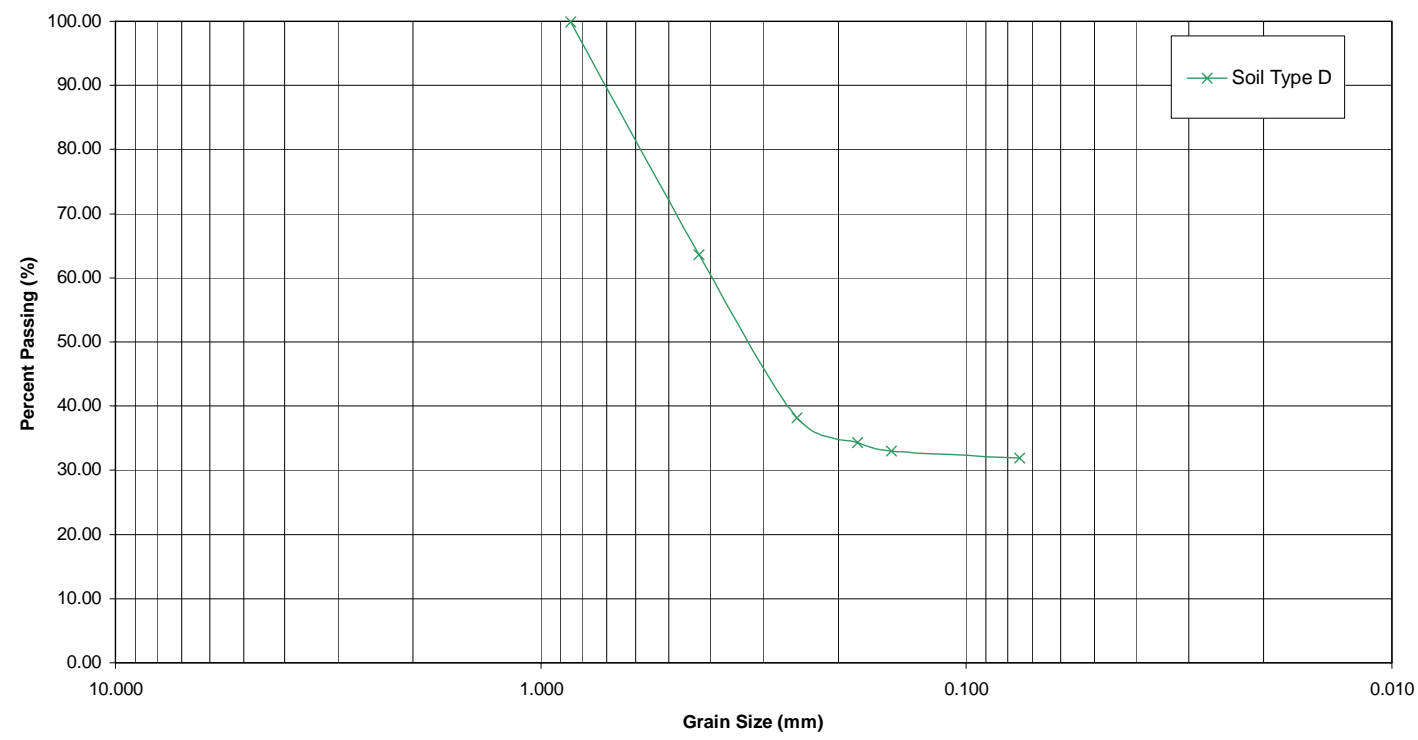

Figure A9.8: Grain Size Distribution curve for Soil Type D

Liquid Limit

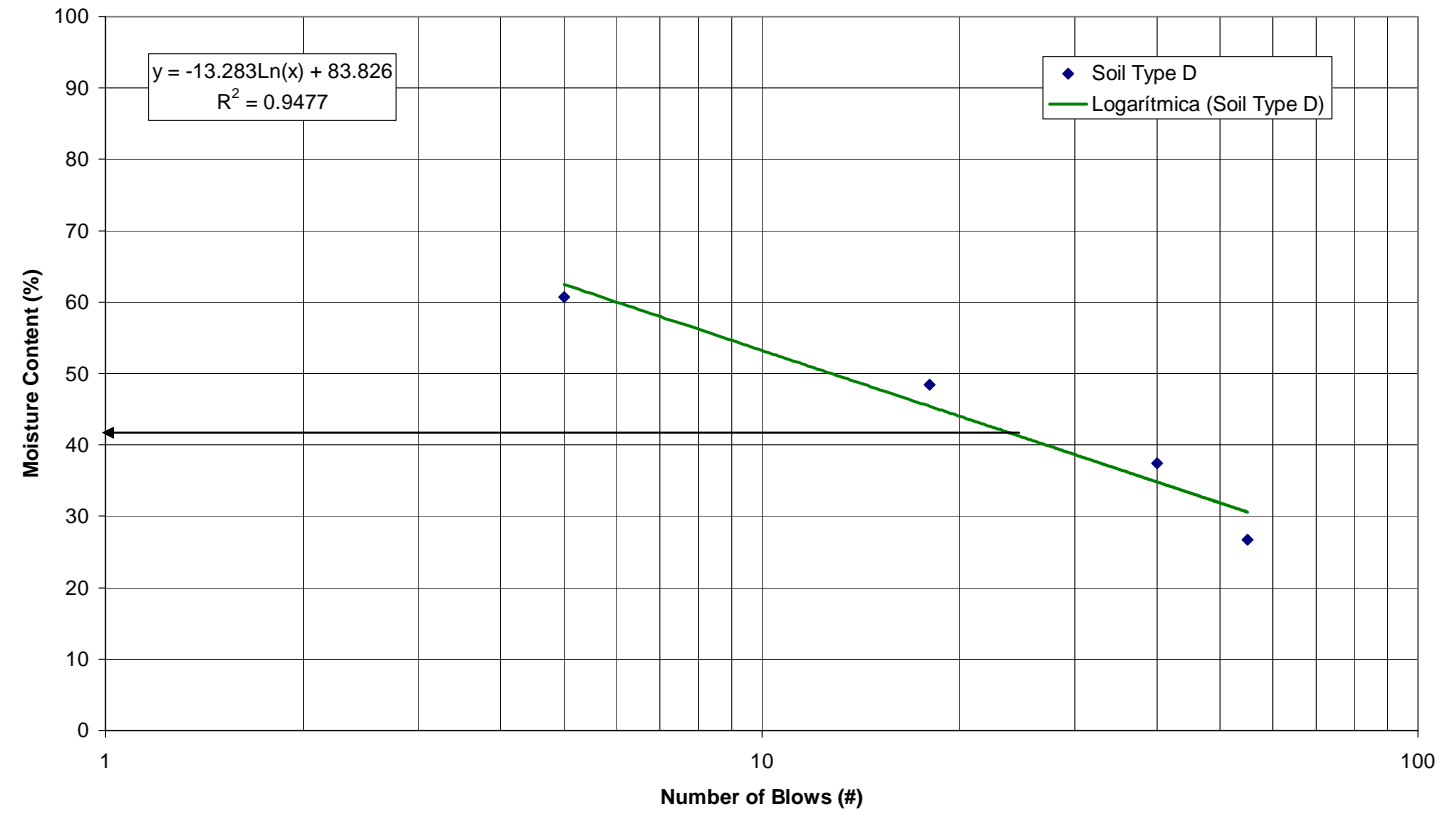

Figure A9.9: Liquid Limit for Soil Type D 
Grain Size Distribution Curve For Soils Types A, B, C, D and D

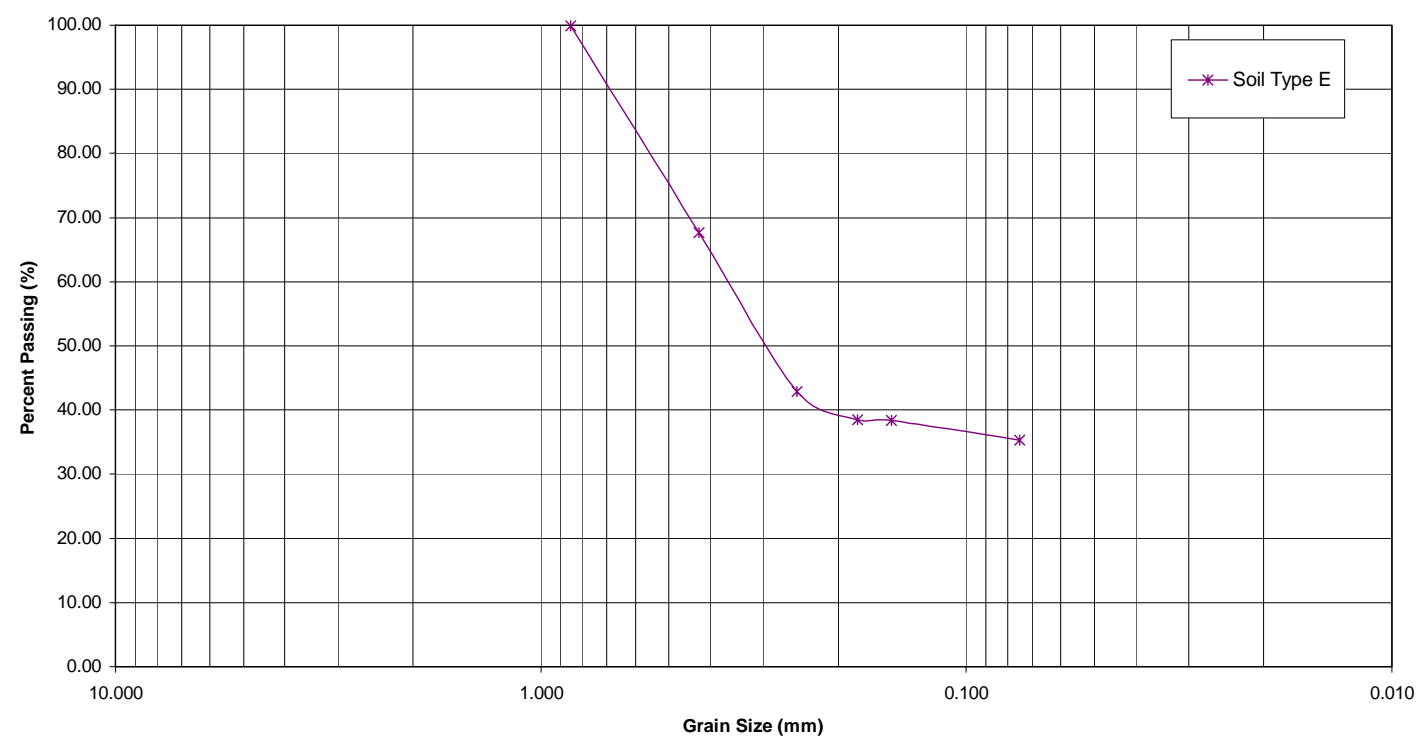

Figure A9.10: Grain Size Distribution curve for Soil Type E

Liquid Limit

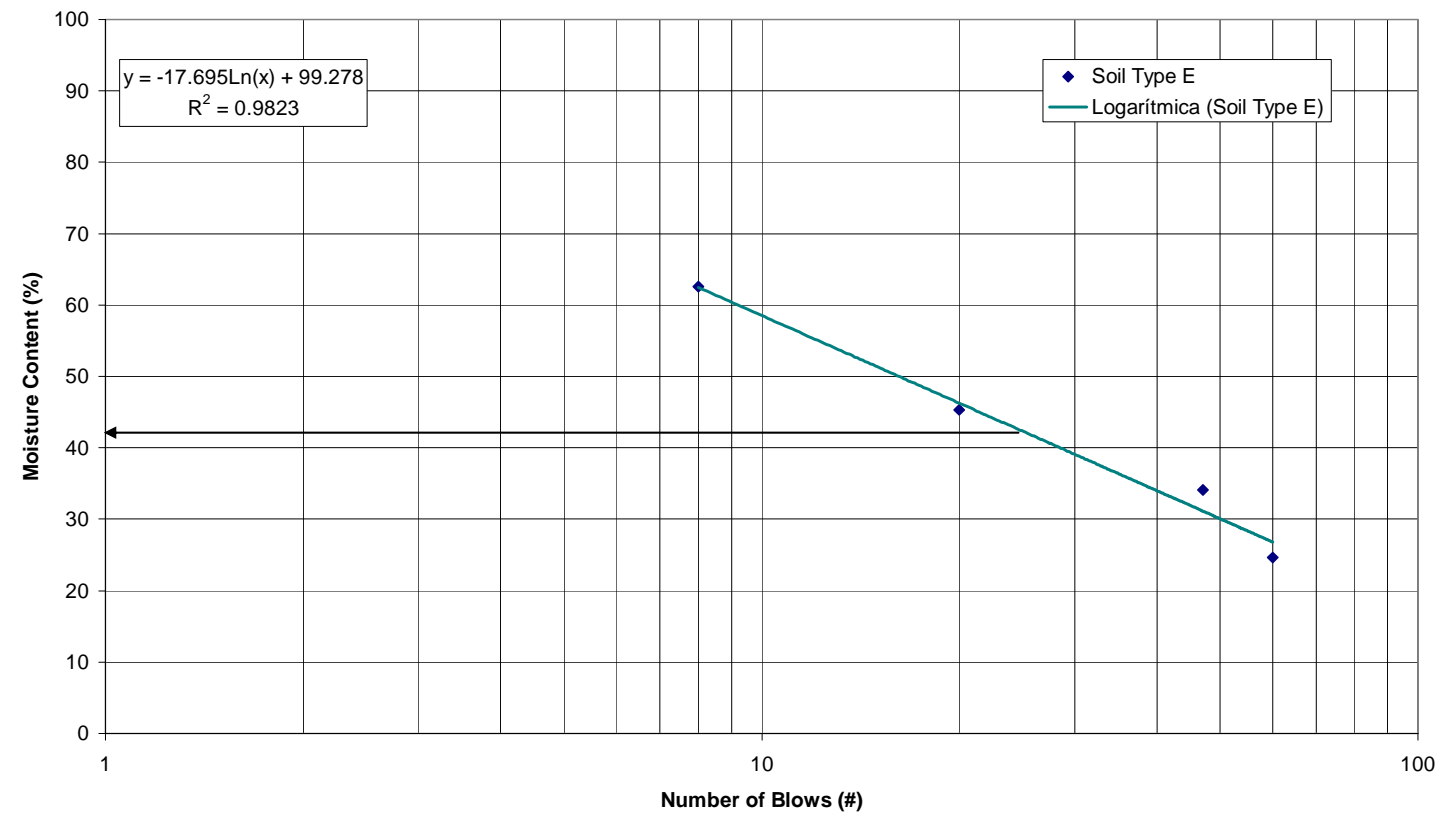

Figure A9.11: Liquid Limit for Soil Type E 
Liquid Limit

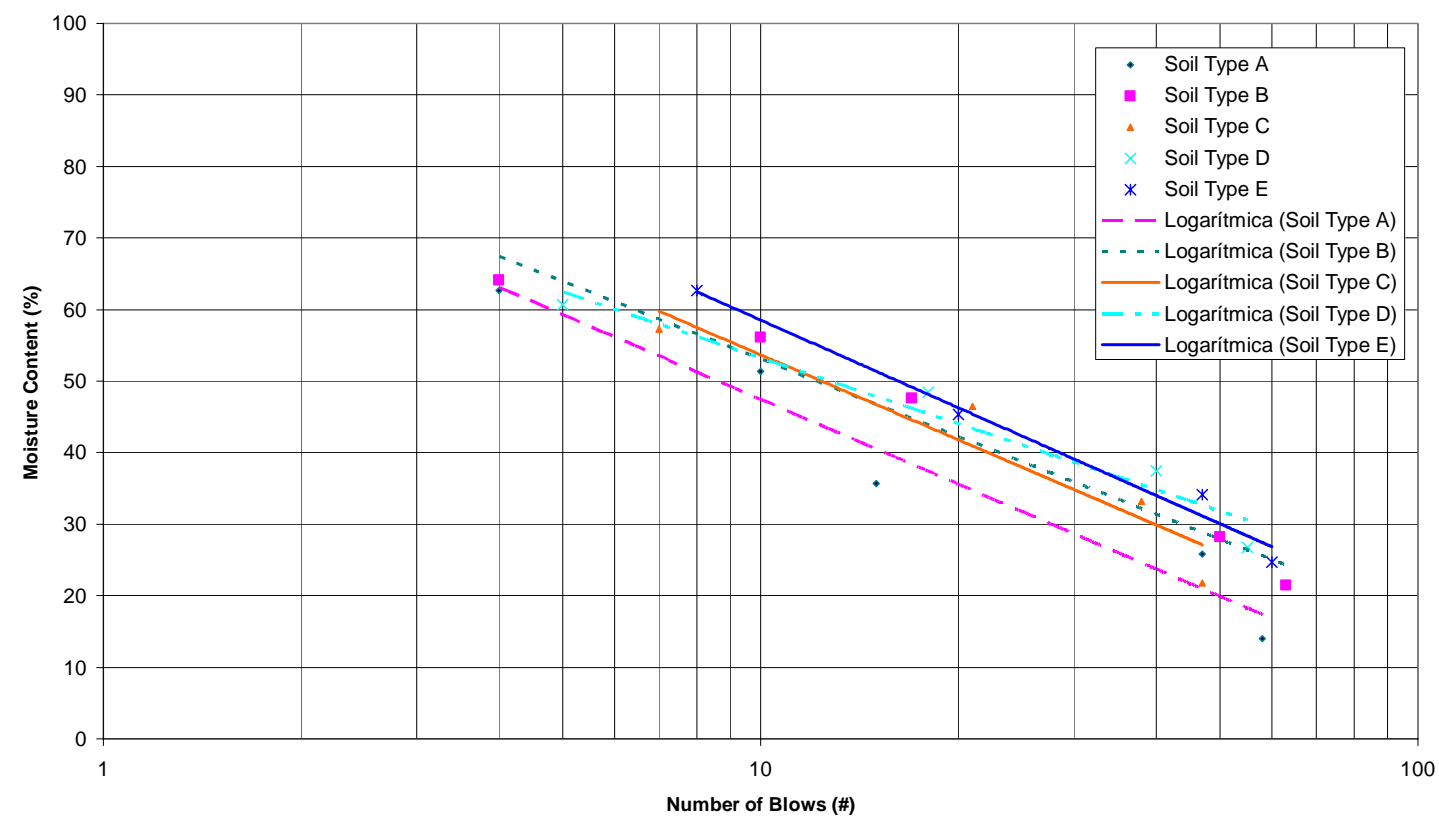

Figure A9.12: Liquid Limit for All Soil Types 